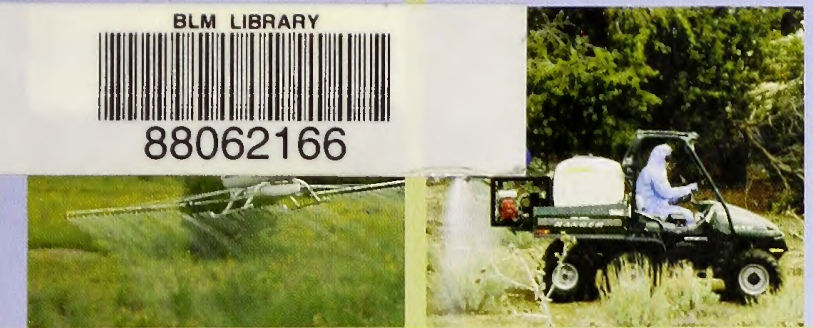

June 2007
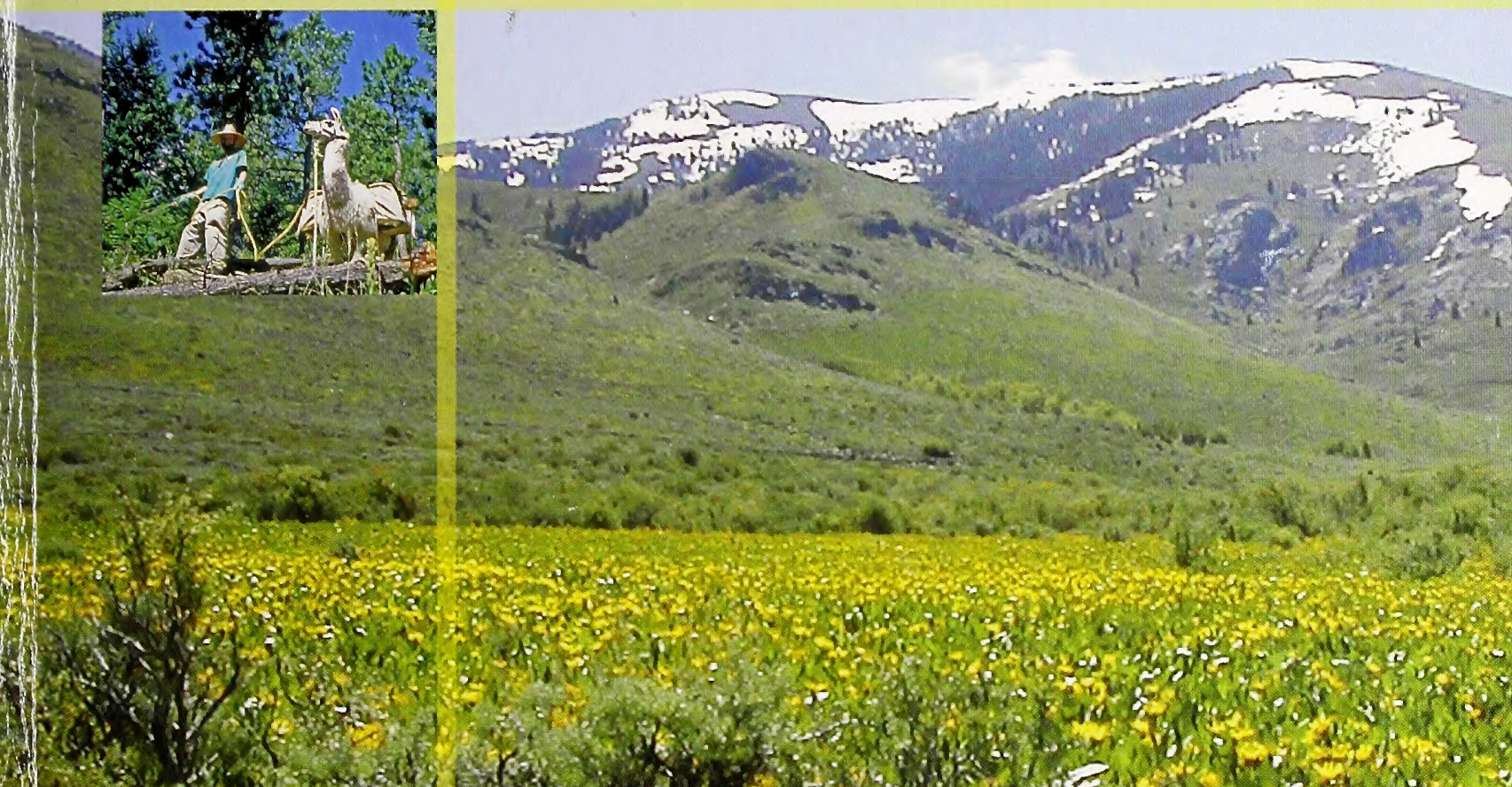

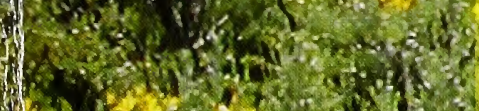
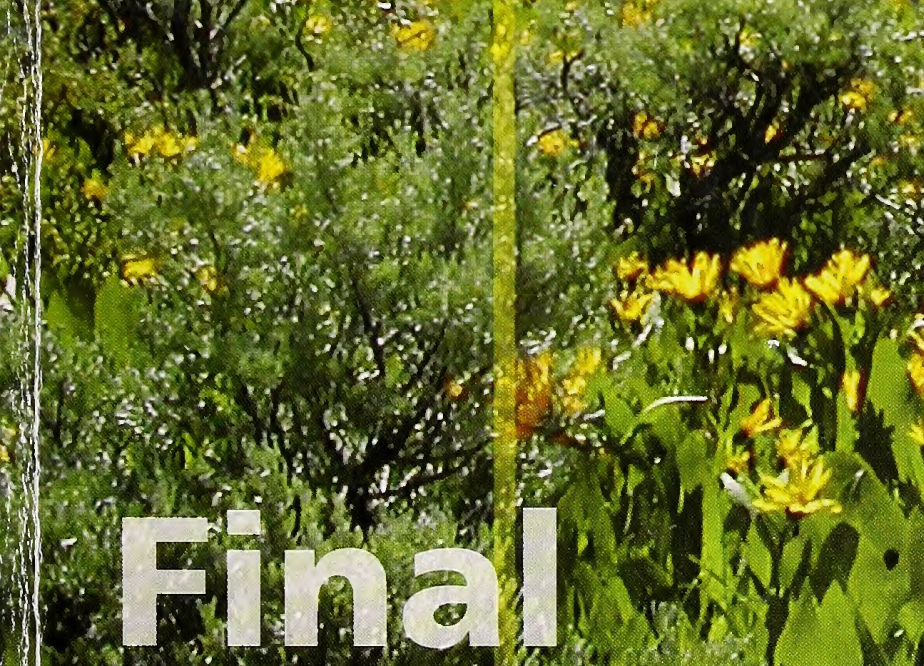

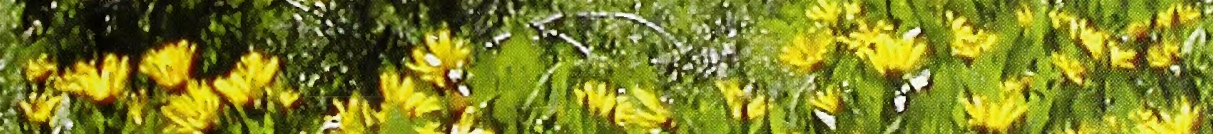

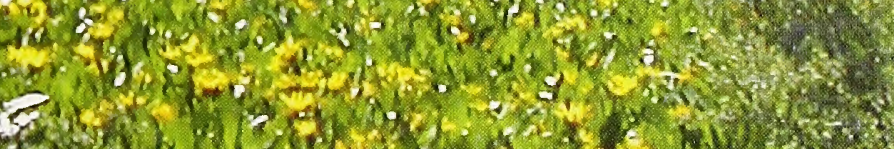

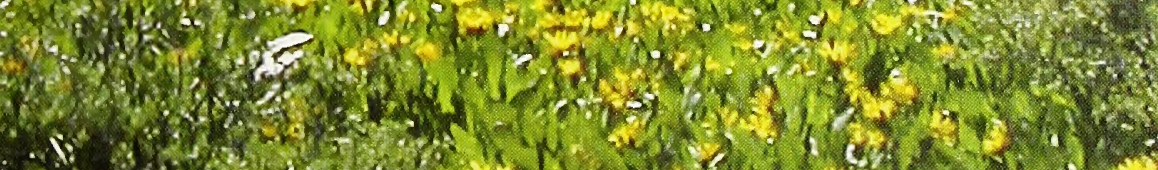

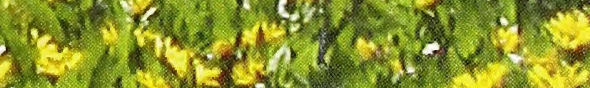

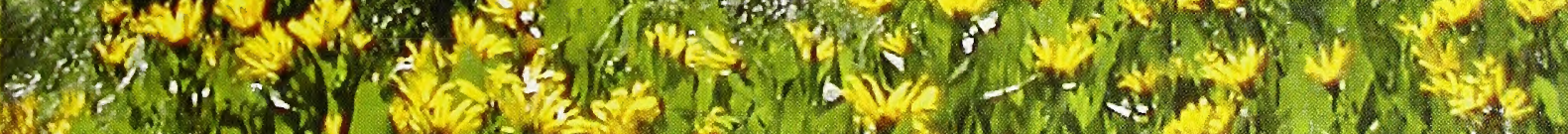
(x)

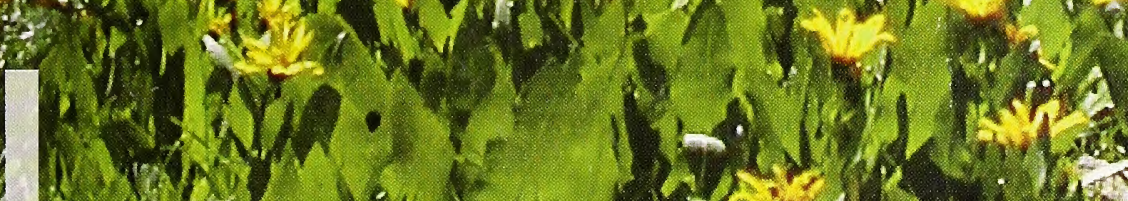

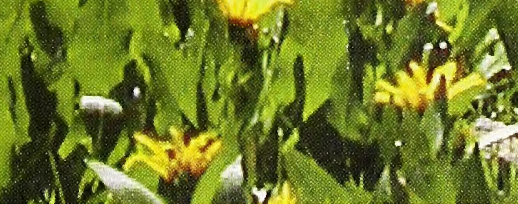
m. 30.4

\title{
Vegetation Treatments
}

\section{Using Herbicides}

\section{on Bureau of Land Management Lands}

in 17 Western States

Programmatic Environmental Impact Statement

Volume 1: Abstract, Executive Summary, and Chapters 1 through 8

U.S. Department of the Interior

Bureau of Land Management

FES 07-21 

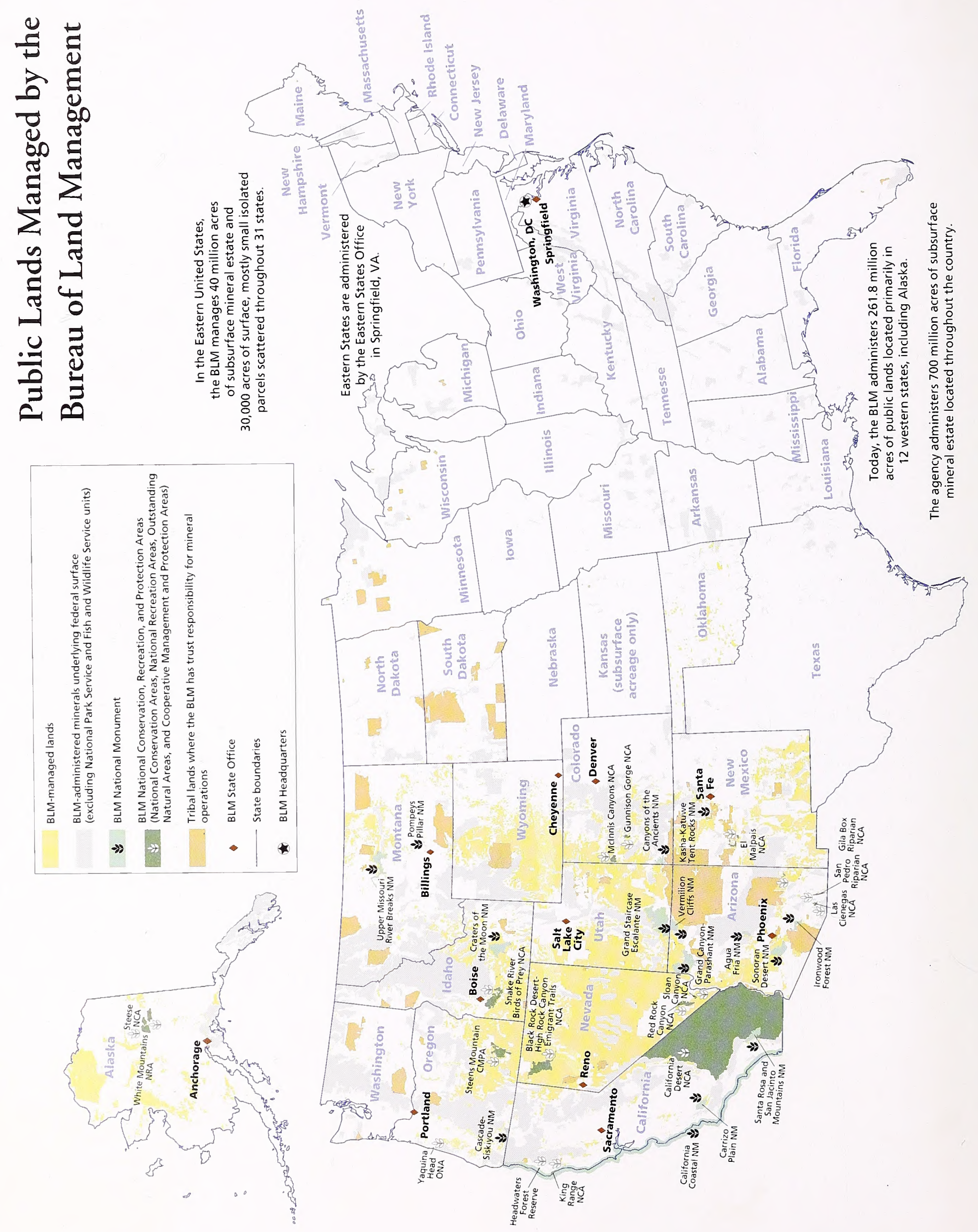


\title{
United States Department of the Interior
}

\author{
BUREAU OF LAND MANAGEMENT \\ Washington, D.C. 20240 \\ http://www.blm.gov
}

Dear Reader:

Enclosed for your review is the Final Vegetation Treatments Using Herbicides on Bureau of Land Management Lands in 17 Western States Programmatic EIS (PEIS) and the Vegetation Treatments on Bureau of Land Management Lands in 17 Western States Programmatic Environmental Report (PER). Together these documents assess, on a National level, the BLM's use of herbicides and describe the environmental effects of using non-herbicide treatment methods, including fire and mechanical, manual, and biological controls.

The Draft PEIS was released for public comment on November 10,2005 for a 60-day public comment period. On January 9, 2006, the comment period was extended for an additional 30 days until February 10 , 2006. Over 3,000 comments have been addressed in the Final PEIS and PER as comment responses and/or changes to the analysis based on the comments received through the public review. Additional information and analysis is included in the FEIS addressing comments related to degradates, use of POEA and R-11 surfactants, and risks associated with endocrine disrupting chemicals. In addition, the FEIS contains subsistence analysis required under Section 801(a) of the Alaska National Interest Lands Conservation Act (ANILCA).

The Final Programmatic EIS assesses five alternative approaches to the use of herbicides to treat vegetation on public lands, details the expected impacts and benefits from the BLM's use of herbicides, and provides analysis to determine which herbicide active ingredients will be approved for use on public lands administered by the BLM in the western United States, including Alaska.

This Final PEIS is available for public review for 30 days. Written comments on the Final PEIS will be accepted until July 30,2007. Upon evaluation of any comments received, a Record of Decision will be issued or a supplemental analysis undertaken to address any significant information not previously considered within the scope of analysis contained in the Final PEIS. Please send written comments to:

\author{
Bureau of Land Management \\ Nevada State Office \\ Attn: Brian C. Amme, EIS Project Manager \\ 1340 Financial Blvd. \\ P.O. Box 12000 \\ Reno, NV 89520-0006
}

Sincerely,

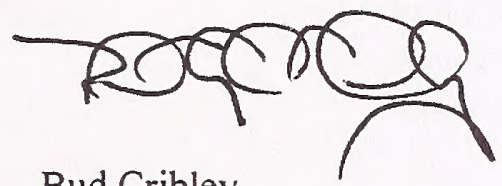

Bud Cribley

Acting Assistant Director,

Renewable Resources and Planning 
FINAL

\title{
PROGRAMMATIC ENVIRONMENTAL IMPACT STATEMENT VEGETATION TREATMENTS USING HERBICIDES ON BUREAU OF LAND MANAGEMENT LANDS IN 17 WESTERN STATES
}

( ) DRAFT

LEAD AGENCY:

PROJECT LOCATION:

COMMENTS ON THIS FINAL PROGRAMMATIC EIS SHOULD BE DIRECTED TO:

\author{
( X ) FINAL \\ U.S. Department of the Interior \\ Bureau of Land Management \\ Washington Office, Washington, D.C.
}

Alaska, Arizona, California, Colorado, Idaho, Montana, Nebraska, Nevada, New Mexico, North Dakota, Oklahoma, Oregon, Texas, South Dakota, Utah, Washington, and Wyoming

Mr. Brian Amme

PEIS Project Manager

Nevada State Office

1340 Financial Boulevard

P.O. Box 12000

Reno, Nevada 89520-0006

Fax: (775) 861-6712

\author{
DATE FINAL PROGRAMMATIC EIS FILED WITH \\ THE U.S. ENVIRONMENTAL PROTECTION \\ AGENCY:
}

DATE BY WHICH COMMENTS MUST BE POSTMARKED TO THE BLM:
June 29, 2007

July 30,2007

\begin{abstract}
This Final Programmatic Environmental Impact Statement (PEIS) analyzes the potential direct, indirect, and cumulative impacts associated with the Bureau of Land Management's use of herbicides on the human and natural environment. An accompanying Final Programmatic Environmental Report (PER) discloses the potential impacts to vegetation and the environment from utilization of non-herbicide treatment techniques, including, but not limited to, fire, mechanical, manual, and biological control methods. Together, herbicide and non-herbicide treatments make up the integrated pest management program that the BLM would apply to approximately 6 million acres annually of public lands in 17 western U.S. states, including Alaska. Alternatives analyzed in the PEIS include the No Action Alternative, or continuation of present management, as outlined in four previous EISs dating from 1986 to 1992. In addition, four action alternatives were evaluated: 1) the Preferred Alternative, which includes herbicide treatments on about 932,000 acres annually and adoption of four new herbicides for use on public lands; 2) a no herbicide use alternative; 3) a no aerial spraying alternative; and 4) an alternative that would limit herbicide use to non-acetolactate synthase-inhibiting active ingredients.
\end{abstract}

RESPONSIBLE OFFICIAL FOR PEIS:
Bud Cribley

Acting Assistant Director

Bureau of Land Management 

EXECUTIVE SUMMARY 



\section{EXECUTIVE SUMMARY}

\section{Proposed Action and Purpose and Need}

The Bureau of Land Management (BLM), an agency of the U.S. Department of the Interior (USDI), administers vegetation on nearly 261 million acres (public lands) in 17 states in the western U.S., including Alaska. Management and control of vegetation on public lands for resource and habitat enhancement is an important function of this agency, including management to reduce the risk of wildfires to people and their property.

The BLM is proposing to treat vegetation on approximately 932,000 acres annually in 17 western states in the U.S., including Alaska, using 14 currently-approved and four new herbicide active ingredients. At present, the BLM treats about 300,000 acres annually using 20 approved herbicides. The proposed action would reduce the risk of catastrophic wildfires by reducing hazardous fuels, restoring firedamaged lands, and improving ecosystem health by 1) controlling weeds and invasive species; and 2) manipulating vegetation to benefit fish and wildlife habitat, improve riparian and wetlands areas, and improve water quality in priority watersheds.

In recent years, the severity and intensity of wildfires in the West has increased dramatically from levels in the 1970s and 1980s, to a million or more acres annually. Changes in the vegetation on public lands have resulted in increases in hazardous flammable fuels.

Much of the increase in hazardous fuels can be attributed to fire exclusion policies over the past 100 years. Contributors to the change include intermittentand long-term drought over the past 40 years and an increase in the spread of noxious weeds species and invasive vegetation.

Invasive vegetation and noxious weeds are the dominant vegetation on an estimated 35 million acres of public lands. The estimated rate of weed spread on western public lands in 1996 was 2,300 acres per day. Invasive vegetation and noxious weeds degrade or reduce soil productivity, water quality and quantity, native plant communities, wildlife habitat, wilderness values, recreational opportunities, and livestock forage, and are detrimental to the agriculture and commerce of the U.S. and to public health. Weed infestations can become permanent if left untreated.

In response to the threats of wildfire and invasive vegetation and noxious weeds, the President and Congress have directed the USDI and BLM, through implementation of the National Fire Plan, and the Healthy Forests Restoration Act of 2003, to take more aggressive actions to reduce catastrophic wildfire risk on public lands. The actions would be taken to protect life and property, and to manage vegetation in a manner that provides for long-term economic sustainability of local communities, improved habitat and vegetation conditions for fish and wildlife, and other public land uses.

The BLM last assessed its use of vegetation treatment methods during the late 1980s and early 1990s, by preparing Environmental Impact Statements (EISs) and Record of Decisions (RODs) that covered vegetation treatment activities in 14 western states in the continental U.S. These EISs evaluated the environmental impacts associated with vegetation control and modification from the use of herbicides, in addition to other treatment methods-manual, mechanical, and biological control methods, and use of fire - on approximately 500,000 acres of public lands a year in the western U.S. The EISs also evaluated the human health and non-target species risks of using 20 herbicide active ingredients on these public lands.

This Vegetation Treatments Using Herbicides on Bureau of Land Management Lands in 17 Western States Programmatic EIS (PEIS) has two primary objectives:

- Determine which herbicide active ingredients are available for use on public lands in the western U.S., including Alaska, to improve the agency's ability to control hazardous fuels and unwanted vegetation. In addition to the herbicides currently approved for use, additional active ingredients are being considered for use by the BLM in order to address emerging weed problems associated with public lands, such as downy brome (cheatgrass) and invasive aquatic species. 
- In consultation with the U.S. Environmental Protection Agency (USEPA), U.S. Fish and Wildlife Service, and National Oceanic and Atmospheric Administration National Marine Fisheries Service, develop a state-of-thescience human health and ecological risk assessment (ERA) methodology. This methodology would serve as the initial standard for assessing human health and ecological risk for herbicides that may become available for use in the future.

The BLM has also prepared a Vegetation Treatments on Bureau of Land Management Lands in 17 Western States Programmatic Environmental Report (PER) describing the environmental impacts of using nonherbicide vegetation treatment methods on public lands. Limiting analysis in the PEIS to the use of herbicides, while analyzing other treatment methods in the PER, was done because the primary issue of controversy identified through scoping, and which required National Environmental Policy Act (NEPA) review, was the BLM's continuing and proposed increase in the use of herbicides in vegetation treatment programs needed to implement the National Fire Plan and related initiatives. The use of herbicides has been affirmed as a central issue for analysis in all past EISs considered in this document. The use of the other non-herbicide techniques in an integrated pest management approach has also been affirmed in all previous EIS Records of Decision, and the BLM is not proposing to make any decisions relative to the use of non-herbicide vegetation treatment methods.

\section{Alternative Proposals}

Five program alternatives were developed for and evaluated in this PEIS, including the Preferred Alternative and the No Action Alternative. Alternative actions were developed that 1) allow the BLM to continue its current use of 20 active ingredients in 14 western states, as authorized by earlier EIS RODs; 2) allow for the use of 14 active ingredients currently used by the BLM and four new active ingredients; 3) prohibit the use of herbicides; 4) prohibit the aerial application of herbicides; or 5) prohibit the use of sulfonylurea and other acetolactate synthase-inhibiting active ingredients. These program alternatives address many of the concerns raised during scoping, in particular the public's desire to see alternatives that place less emphasis on the use of herbicides, while still meeting the program's purpose and need. Alternatives were also developed to ensure that the BLM complied with federal, tribal, state, and local regulations.

\section{Alternative A - Continue Present Herbicide Use (No Action Alternative)}

Under this alternative, the BLM would be able to continue to use 20 active ingredients approved for use in 14 western states under the earlier EIS RODs for each state. The BLM would also continue activities conducted under burned area emergency stabilization and rehabilitation and hazardous fuel reduction that are evaluated by NEPA compliance documents prepared by local BLM field offices. Under this alternative, an estimated 305,000 acres would be treated annually using herbicides.

\section{Alternative B - Expand Herbicide Use and Allow for Use of New Herbicides in 17 Western States (Preferred Alternative)}

This alternative represents the treatment of vegetation using herbicides in 17 western states, including Alaska, Nebraska, and Texas, states that were not included in the earlier EIS assessments. Under the Preferred Alternative, approximately 932,000 acres would be treated annually using herbicides, based on the herbicide use projections developed by BLM field offices. Based on these projections, the majority of treatments would occur in Nevada, Idaho, Oregon, and Wyoming.

Under the Preferred Alternative, the BLM would be able to use, in the western U.S., including Alaska, 14 active ingredients that were approved for use in the earlier RODs and for which an analysis of risks to humans and non-target plants and animals was conducted for this PEIS or by the U.S. Department of Agriculture Forest Service (Forest Service). These active ingredients are 2,4-D, bromacil, chlorsulfuron, clopyralid, dicamba, diuron, glyphosate, hexazinone, imazapyr, metsulfuron methyl, picloram, sulfometuron methyl, tebuthiuron, and triclopyr. The remaining six active ingredients currently approved for use by the BLM-2,4-DP, asulam, atrazine, fosamine, mefluidide, and simazine - have not been used by the BLM for several years, or their use has been limited to a very small number of acres. Although the risks to humans from the use of these chemicals are not significant based on evaluations done for the earlier EISs and a review of the literature for this PEIS, the 
risks to non-target plants and animals, especially species of concern, have not been adequately evaluated. Under this alternative, their use would be discontinued. Should these chemicals be needed by the BLM in the future, the BLM would consult ERAs, if available, or conduct their own ERAs, to assess the risks to non-target and sensitive species. This analysis would be supported by the appropriate NEPA documentation and interagency consultation before these chemicals would be approved for use or applied on the ground.

The BLM would approve four additional active ingredients for use in all 17 states included in this PEIS: imazapic, diquat, diflufenzopyr (in formulation with dicamba), and fluridone. In addition, the BLM would approve diflufenzopyr for use in the future as a stand-alone active ingredient if it becomes registered for herbicidal use. These active ingredients and formulations could only be applied for uses, and at application rates, specified on the label directions.

Under the Preferred Alternative, the BLM proposes to use new active ingredients that are developed in the future if: 1) they are registered by the USEPA for use on one or more land types (e.g., rangeland, aquatic) managed by the BLM; 2) the BLM determines that the benefits of use on public lands outweigh the risks to human health and the environment; and 3) they meet evaluation criteria to ensure that the decision to use the active ingredient is supported by scientific evaluation through human health and ecological risk assessments and NEPA documentation.

\section{Alternative C - No Use of Herbicides}

Under Alternative C, the BLM would not treat vegetation using herbicides and would not use new chemicals that are developed in the future. The BLM would continue to treat vegetation using fire, and mechanical, manual, and biological control methods. A PER has been prepared that accompanies this PEIS and discusses these treatment methods, proposed treatment levels during the next 10 to 15 years, and likely impacts to natural and social resources on public lands from these treatment methods.

\section{Alternative D - No Aerial Applications}

This alternative is similar to the Preferred Alternative in that it represents the treatment of vegetation using herbicides in 17 western states, including Alaska, Nebraska, and Texas, and use of the same active ingredients as allowed under the Preferred Alternative. Under Alternative D, however, only ground-based techniques would be used to apply herbicides and no aerial applications of herbicides would be allowed, which would reduce the risk of spray drift impacting non-target areas. Based on information obtained from field offices, an estimated $55 \%$ of herbicide treatments would occur using ground-based methods during the next 10 years. Thus, the BLM would treat approximately 530,000 acres annually using herbicides under this alternative. In comparison, during 1997 to 2005 , approximately $66 \%$ of herbicide treatments were conducted aerially and $34 \%$ using ground-based methods.

Similar to the Preferred Alternative, the BLM would use new active ingredients developed in the future if they followed protocols for use of new active ingredients identified under the Preferred Alternative.

\section{Alternative E - No Use of Acetolactate Synthase-inhibiting Herbicides}

This alternative was developed based on an alternative proposal for vegetation management on public lands submitted by the American Lands Alliance, an alliance of several environmental and conservation groups.

Under Alternative E, the BLM would not use sulfonylurea and other acetolactate synthase-inhibiting active ingredients approved in the earlier RODs, which are chlorsulfuron, imazapyr, metsulfuron methyl, and sulfometuron methyl. During 1999 to 2000, these active ingredients comprised approximately $28 \%$ of the active ingredients used by the BLM. Since 2001, however, these active ingredients have comprised approximately $8 \%$ of the active ingredients used by the BLM. The BLM would be able to use 10 active ingredients in the 17 western states that were approved for use in the earlier RODs and for which an analysis of risks to humans and non-target plants and animals was conducted for this PEIS. These active ingredients are: 2,4-D, bromacil, clopyralid, dicamba, diuron, glyphosate, hexazinone, picloram, tebuthiuron, and triclopyr. The six other active ingredients currently approved for use by the BLM-2,4-DP, atrazine, asulam, fosamine, mefluidide, and simazine-would not be used unless guidelines given for the Preferred Alternative were met.

The BLM would be allowed to use three additional active ingredients in all 17 states: diquat, diflufenzopyr (if it becomes registered for herbicidal use), and 
fluridone. In addition, the BLM would be able to use a formulation of diflufenzopyr and dicamba. These active ingredients and formulations could only be applied for uses, and at application rates, specified on the label directions. Under Alternative E, the BLM would use new active ingredients developed in the future if they followed protocols for use of new active ingredients identified under the Preferred Alternative and did not contain sulfonylurea and imidazolinone chemistry and other acetolactate synthase-inhibiting compounds.

Under this alternative, the BLM would treat approximately 466,000 acres annually using herbicides. Spot herbicide treatments would be favored over broadcast treatments. Herbicides use would be discouraged in areas populated by amphibians. To protect Native American and Alaska Native resources, the BLM would establish herbicide-free zones around culturally significant plant and wildlife resources. This alternative would place greater emphasis on passive restoration than the other alternatives.

\section{Summary of Impacts}

The direct and indirect effects of herbicide treatment alternatives on natural and socioeconomic resources are evaluated in this PEIS. The cumulative effects that result from the incremental impact of treatment actions when added to the effects of other past, present, and reasonably foreseeable future actions are also evaluated for herbicide and non-herbicide treatments. Standard operating procedures would be used to reduce impacts, and mitigation measures have been proposed to reduce significant adverse impacts to more reasonable levels.

\section{Direct and Indirect Impacts}

In general, potential direct and indirect adverse impacts and benefits would be greatest under the Preferred Alternative and least under Alternative C. Fewer acres would be treated, or treatments would not be conducted aerially, under the other herbicide treatment alternatives, so risks and benefits would be intermediate between the Preferred Alternative and Alternative C.

Impacts from herbicide treatments on local and regional air quality would be minor for all alternatives. Pollutant emissions would be greater under Alternative D than the Preferred Alternative, even though $40 \%$ fewer acres would be treated under Alternative D, because of the large number of acres treated using ground-based application methods under Alternative D. None of the treatments would result in emissions that exceed Prevention of Significant Deterioration thresholds or National Ambient Air Quality Standards.

None of the herbicides commonly used by the BLM appear to result in adverse impacts to soil. Treatments would benefit soil by restoring natural fire regimes and slowing the spread of weeds, which should reduce soil erosion and improve soil productivity. New herbicides proposed for use have little adverse impact on soil.

Several herbicides used, or proposed for use by the BLM, are known groundwater contaminants. Effects to surface water would be minor, and herbicide concentrations in surface water should not exceed safe levels for human health. Herbicide use would improve watershed function and water quality, since many treatments would be targeted at watersheds where water quality does not meet state or tribal standards. Adverse and beneficial impacts of alternatives would primarily be related to number of acres treated. Water quality would not be impacted by herbicides under Alternative $\mathrm{C}$, but land health would deteriorate more rapidly than under the other herbicide treatment alternatives because herbicides could not be used to control weeds and other vegetation.

Herbicides pose risks to terrestrial and aquatic vegetation. Most aquatic herbicides, and several terrestrial herbicides, are non-selective and could adversely impact non-target vegetation. Accidental spills and herbicide drift from treatment areas could be particularly damaging to non-target vegetation, including croplands and other vegetation found on privately-owned lands near treatment areas. Herbicides would help to control aquatic vegetation that chokes waterways and impacts wetland function and values. Upland and riparian area treatments could control weeds and other vegetation to reduce soil erosion and reduce the risk of catastrophic fire. Risks to upland, wetland, and riparian vegetation from proposed herbicides would be similar to, or less than, risks from currently-available herbicides. Adverse impacts from herbicides to terrestrial and aquatic vegetation would be least under Alternative $C$, while benefits would be greatest under the Preferred Alternative. Buffer zones would be used to reduce the risks to vegetation from herbicide treatments under all alternatives proposing herbicide use.

Many of the herbicides currently available for use by the BLM pose risks to fish and wildlife. Accidental 
spills and direct spraying of aquatic organisms could kill or harm animals, or affect the health and behavior of animals. Fish and wildlife could also forage on vegetation that has been treated, or prey on other animals that have been exposed to herbicides, and be harmed. All of the herbicides pose some risk to nontarget terrestrial and aquatic vegetation, and damage to these plants could adversely impact habitats used by fish and wildlife. Acetolactate synthase-inhibiting herbicides are highly potent and can damage plants at low application rates, but do not appear to create unnecessary risks to aquatic organisms or wildlife. Of the new herbicides proposed for use, diquat poses a low to high risk to aquatic organisms and wildlife, depending on application rate and receptor scenario; fluridone, imazapic, and Overdrive ${ }^{\circledR}$ (a formulation of dicamba and diflufenzopyr) pose little or no risk to aquatic organisms and wildlife. The risk for adverse health effects to individual organisms would typically be greater for threatened, endangered, and other special status species than for secure species, depending on the herbicide and the exposure pathway. Furthermore, the risk for associated population-and species-level effects would be much greater for many TES species, given their low numbers and fragmented habitats. Buffers would be used between treatment areas and aquatic habitats to reduce risks to aquatic organisms. Buffers would also be used between treatment areas and habitats of special status species.

Livestock and wild horses and burros could be impacted by herbicides from an accidental spill, direct spray, herbicide drift, or by consuming herbicidetreated vegetation. Effects to animals could include death, damage to vital organs, decrease in growth, decrease in reproductive output and condition of offspring, and increased susceptibility to predation. However, most herbicides currently available for use by the BLM pose little or no risk to these animals. Of the new herbicides proposed for use, only diquat is fairly toxic to livestock and wild horses and burros. However, it would be used by the BLM as an aquatic herbicide, and frequent exposure to these animals would be unlikely. Risks from exposure to herbicides for livestock would be further reduced by restrictions placed on livestock use of treated areas as directed on herbicide labels.

While herbicide treatments could affect cultural or paleontological resources near or on the surface, they would be more likely to affect traditional cultural practices of gathering plants and the health of Native peoples. Cultural and paleontological resources could be impacted by equipment, and to a lesser extent, by the chemicals in herbicides. A risk assessment was conducted to assess the risks to Native peoples from harvesting plants that could be treated with herbicides, or from direct exposure to herbicide spray. Native peoples would face risks when picking berries in areas treated with diquat. They could also face risks when consuming fish contaminated with 2,4-D, hexazinone, or picloram. Native peoples would face risk from diquat or fluridone if these chemicals were accidentally spilled or used at maximum application rates.

Herbicide treatments could affect visual, wilderness, and recreation resources. Treatments would remove and discolor vegetation, making it less visually appealing. Over the long term, landscapes should be more appealing as native vegetation was restored. Treatments in wilderness and other special areas would detract from the "naturalness" of the area. Although use of mechanical equipment would be strongly discouraged in these areas, its use would create noise and reduce the wilderness experience. Recreationists could be exposed to herbicides, experience less visually-appealing landscapes, or find fish and game less plentiful as a result of treatments. In addition, recreational areas could be closed for short periods of time after application to ensure treatment success and protect the health of visitors.

Social effects would be minor at the scale addressed in the PEIS. There would be benefits to communities that supply workers, materials, or services in support of treatment activities. Some businesses, such as recreation-based businesses and ranching operations, could be adversely affected if treatments closed areas used for recreation or by domestic livestock. There are potential environmental justice concerns because a large number of Native peoples and other minority groups live in the West and work in industries (e.g., forest products, herbicide applicator) or conduct activities (e.g., gathering of plants for traditional uses, recreation) that could potentially expose these groups to treated areas.

A human health risk assessment was conducted to assess risks to humans from the use of herbicides. At typical application rates, workers would not be at risk from use of herbicides except when using diquat, 2,4D, 2,4-DP, atrazine, bromacil, diuron, fosamine, hexazinone, mefluidide, simazine, or tebuthiuron. At maximum application rates, there are also risks associated with the use of chlorsulfuron, fluridone, and triclopyr. Public receptors would be at less risk. The 
BLM would not use 2,4-DP, atrazine, fosamine, mefluidide, or simazine under the action alternatives. Except for diquat, new herbicides proposed for use pose few or no risks to workers or the public. To reduce risks from diquat, treatments would occur away from high residential and subsistence use areas.

\section{Cumulative Impacts}

Treatments would contribute only minor amounts of pollutants to the air. Fire use would increase particulate matter in the air, but the amount of pollutants generated by fire use, and their effects on human health, should be less than those from wildfire, resulting in fewer pollutants accumulating than would occur without treatments. Treatments would lead to cumulative loss of soil from removal of vegetation and erosion, but improvement in vegetative quality should slow soil loss on public lands. Erosion has led to poor water quality on portions of public lands. Treatments that slow erosion would also benefit water quality and slow the cumulative loss of water quality. Over half of the wetlands in the U.S. have been lost since settlement by Europeans. Treatments would improve wetland and riparian area functions and values and slow erosion, which contributes to wetland degradation on public lands. With improvement in these areas, habitat for fish and other aquatic organisms would also improve. However, many anadromous fish spend part or most of their lives off of public lands, and thus would potentially have to cope with poorer quality habitat while off of public land.

Fire exclusion and the spread of weeds have degraded vegetation function and quality on public land and have led to a cumulative loss of vegetative productivity. Treatments would restore ecosystem processes and slow this loss. Improvement in vegetation characteristics would benefit wildlife. Some species that have adapted to degraded ecosystems could lose habitat as native vegetation was restored, but most species would benefit. Factors that have led to the loss of native vegetation and ecosystem health have adversely impacted rangelands used by domestic livestock and wild horses and burros. Treatments should improve rangelands for these animals, and ensure that public lands can support viable populations of wild horses and burros and a healthy ranching industry.
Treatments could add to the cumulative loss of paleontological and cultural resources, but risks would be low. Treatments could impact plants used by Native peoples for traditional lifeway uses, and the health of Native peoples. However, the BLM would use herbicides that are generally safe for use around people, and would conduct pre-treatment surveys to identify areas of cultural concern before conducting treatments to reduce the cumulative loss of these values.

Treatments would result in some short-term and temporary loss of visual, recreational, and wilderness and other special area values due to vegetation being killed or discolored. In some cases, areas might be closed to visitors during and after treatments; however, these impacts would be short-term and any values affected would be restored within two growing seasons in most cases.

Treatments would benefit local communities by providing jobs and income, and by reducing the risk of catastrophic wildfire that could harm people and destroy property. These gains would be minor in the context of the western economy, but would still be a cumulative benefit for many rural communities.

Treatments could harm the health of workers and the public. Most herbicides, however, would pose few risks to workers, and even fewer risks to the public, when applied at the typical application rate. New herbicides proposed for use pose few or no risks, except for diquat. If treatments restored natural fire regimes, reduced the risk of catastrophic fire, and slowed the spread of weeds, human health would benefit.

Treatments could result in short-term loss of some resources, including soil, vegetation, wildlife, and livestock forage opportunities. Over the long term, loss of resource values would be slowed, and in some cases, would be reversed. Short-term losses in resource functions would be compensated for by long-term gains in ecosystem health. 


\section{TABLE OF CONTENTS AND LISTS OF TABLES, FIGURES, AND MAPS}





\section{TABLE OF CONTENTS}

\section{VOLUME 1}

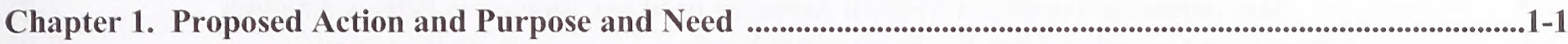

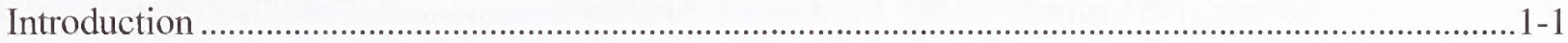

Organization of the Vegetation Treatments Assessments .........................................................1-2

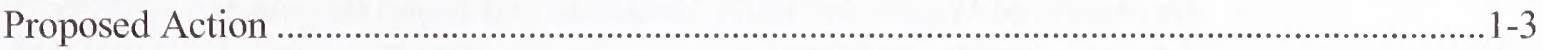

Purpose and Need for the Proposed Action....................................................................................

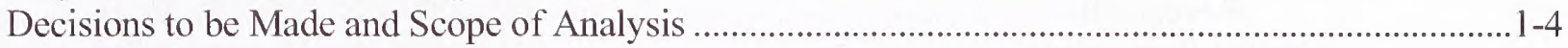

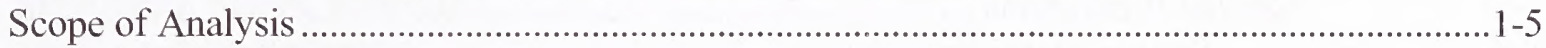

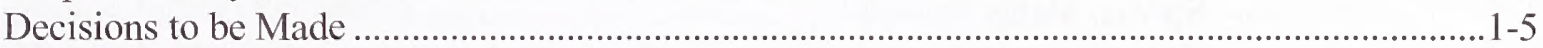

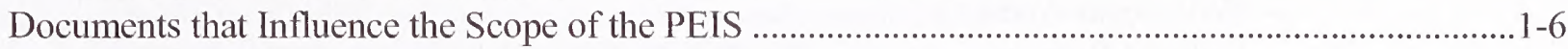

Relationship to Statutes, Regulations, and Policies .........................................................................

Federal Laws, Regulations, and Policies that Influence Vegetation Treatments........................1-6

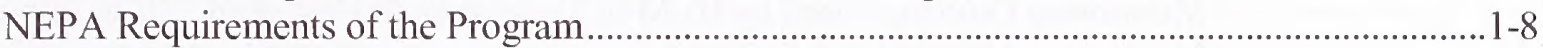

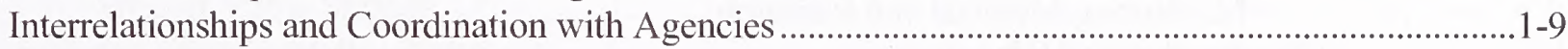

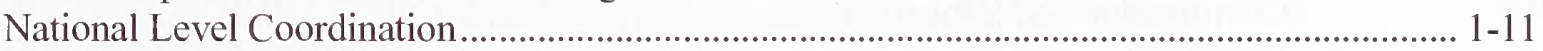

State and County Level Coordination.................................................................................... 1-11

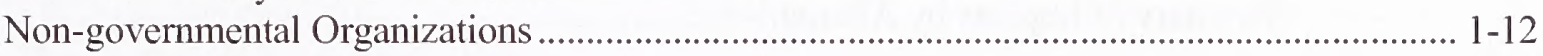

Cooperative Weed Management Areas …............................................................................. 1-12

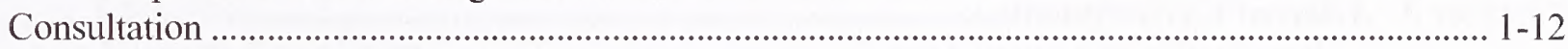

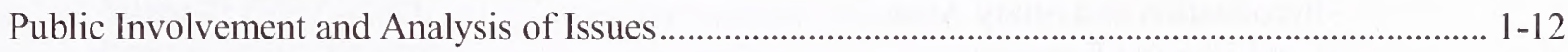

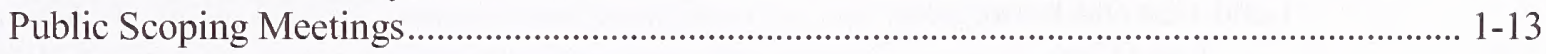

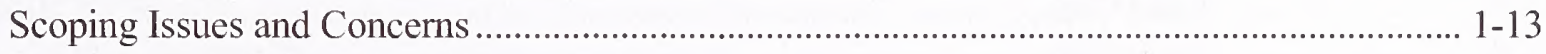

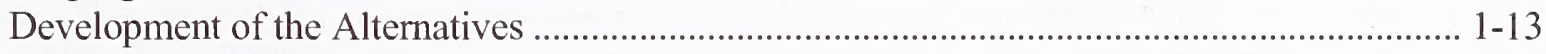

Issues Not Addressed in the Draft PEIS ............................................................................. 1-13

Public Review and Comment on the Draft Programmatic EIS, ER, and BA ........................... 1-14

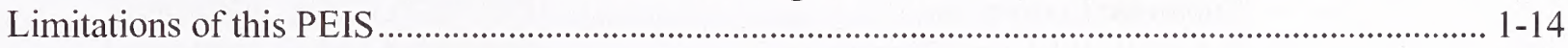

Preview of the Remainder of the PEIS ........................................................................................ 1-15

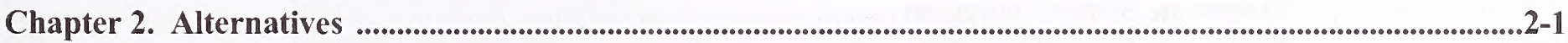

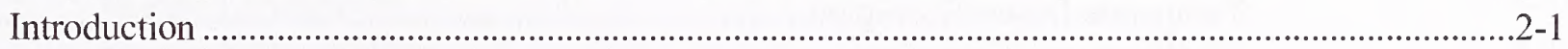

BLM Programs Responsible for Herbicide Treatments................................................................2-1

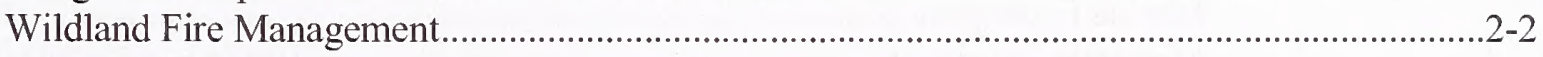

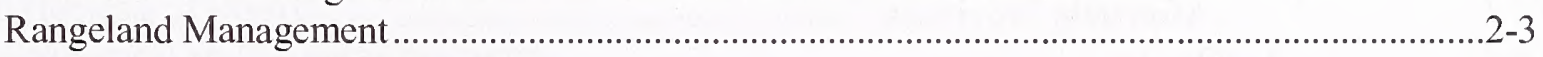

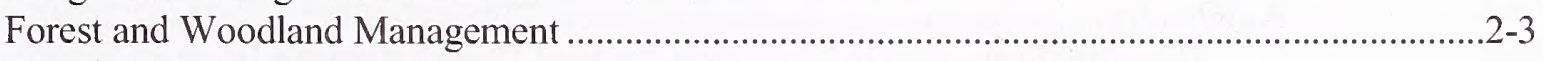

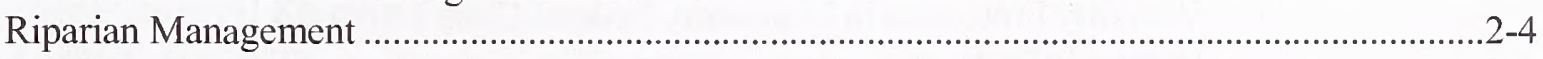

Wildlife, Fisheries, and Threatened and Endangered Species Management ................................2-4

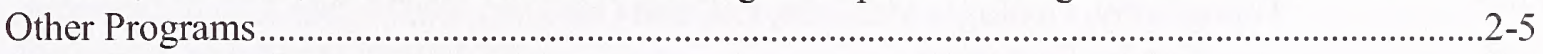

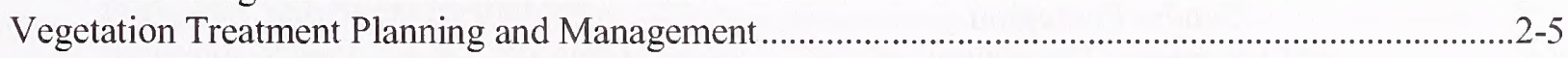

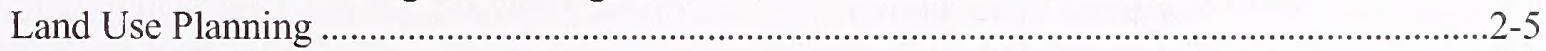

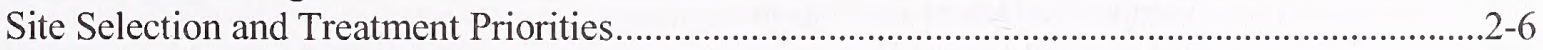

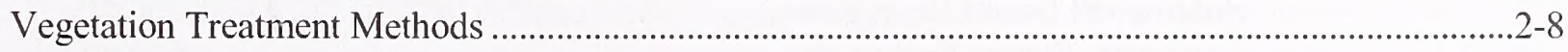

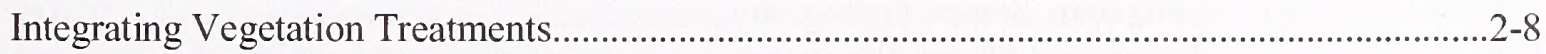

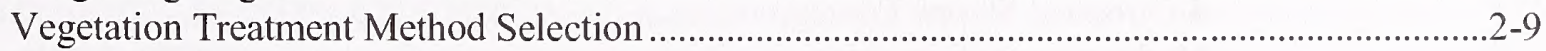

Herbicide Active Ingredients Evaluated under the Proposed Alternatives .......................................2-9

Herbicide Modes of Action and Treatment Methods.................................................................. 2-13

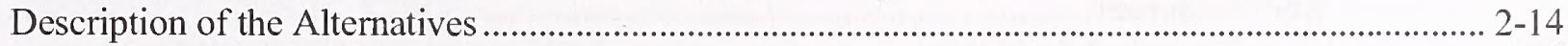

Alternative A - Continue Present Herbicide Use (No Action Alternative).............................. 2-14

Alternative B - Expand Herbicide Use and Allow for Use of New Herbicides in 17 Western

States (Preferred Alternative) ........................................................................................... 2-17 
Alternative C - No Use of Herbicides

Alternative D - No Aerial Application of Herbicides

Alternative E - No Use of Sulfonylurea and other Acetolactate Synthase-inhibiting Active Ingredients.

Determination of Treatment Acreages..

Non-herbicide Treatment Method Acreages used in Cumulative Effects Analysis .................. 2-21

Alternatives Considered but Not Further Analyzed ........................................................................ 2-22

Herbicide Treatment Standard Operating Procedures and Guidelines .......................................... 2-22

Prevention of Weeds and Early Detection and Rapid Response............................................ 2-23

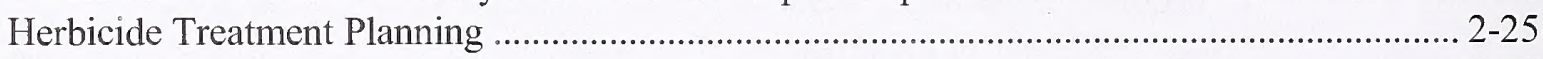

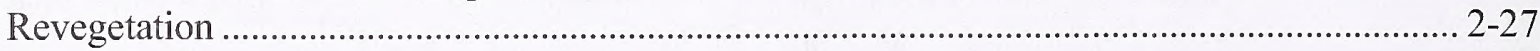

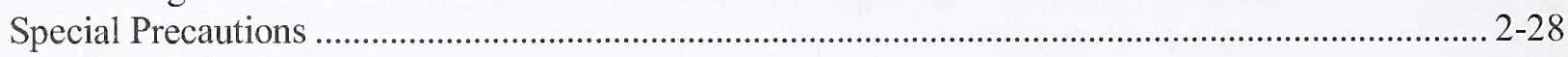

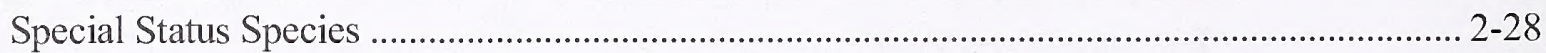

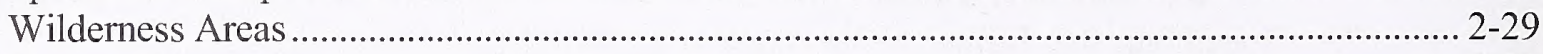

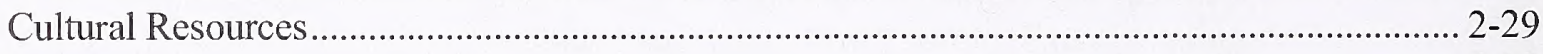

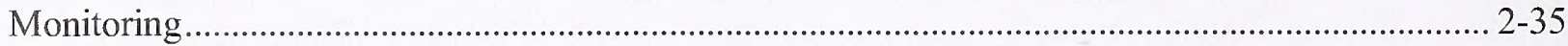

Monitoring Guidance used by BLM in Vegetation Management............................................. 2-37

Monitoring Methods and Research ....................................................................................... 2-38

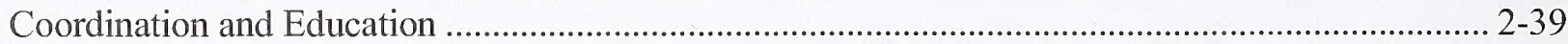

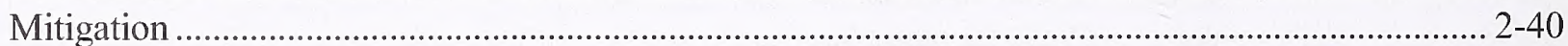

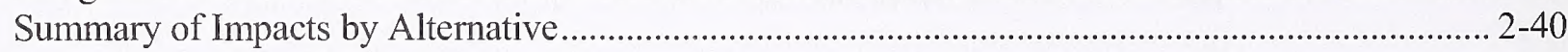

Chapter 3. Affected Environments ............................................................................................... 3-1

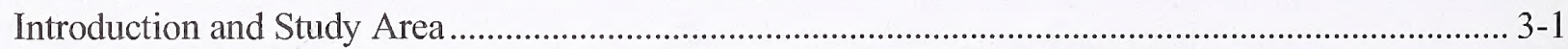

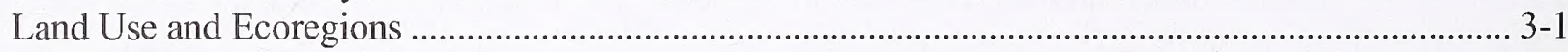

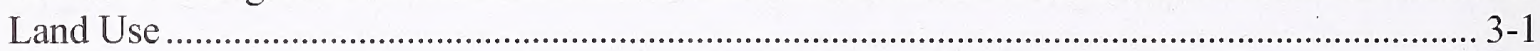

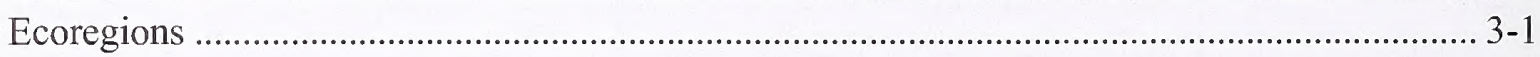

Climate

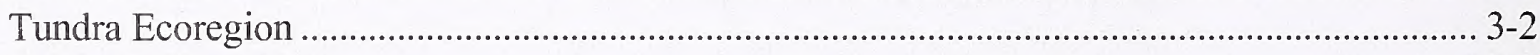

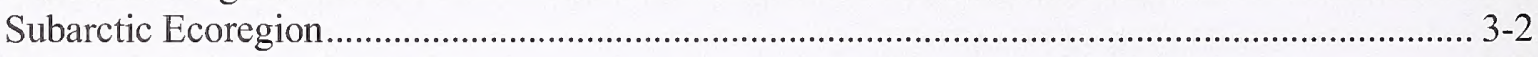

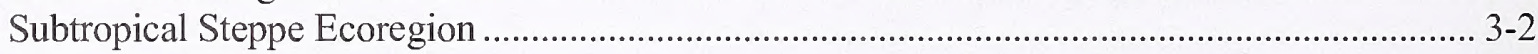

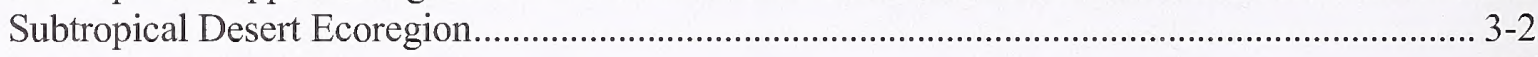

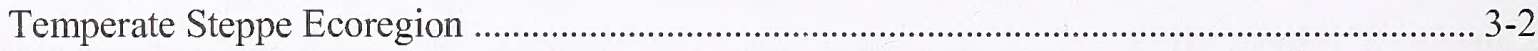

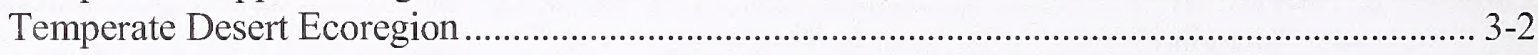

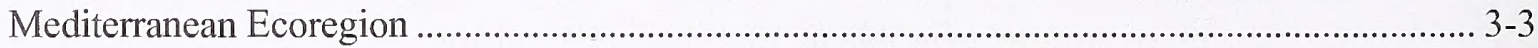

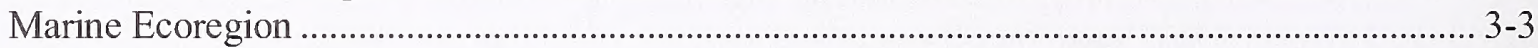

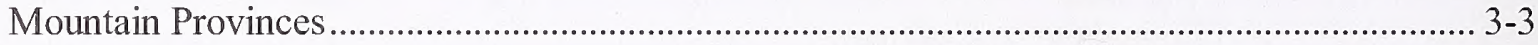

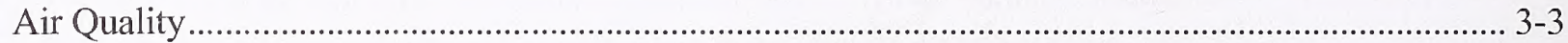

Visibility Protection in Mandatory Federal Class I Areas....................................................... 3-4

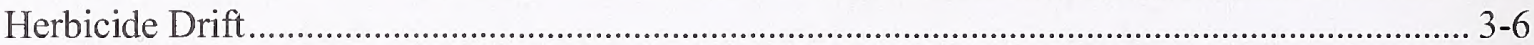

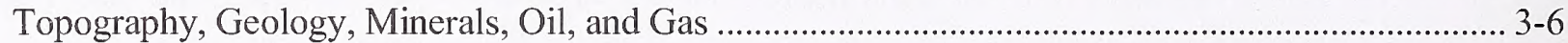

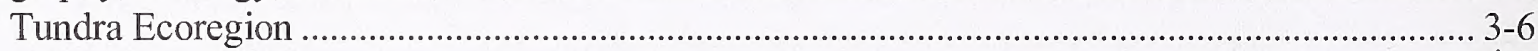

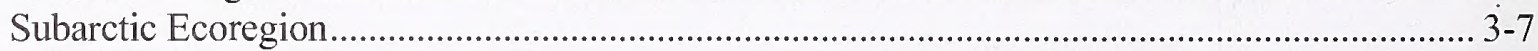

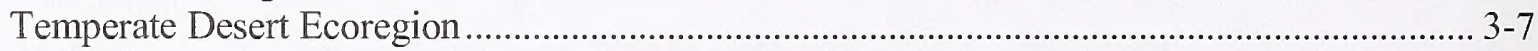

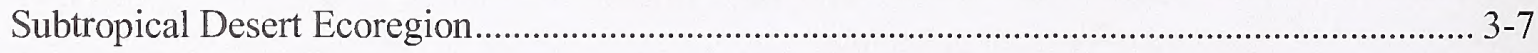

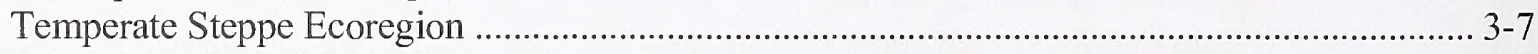

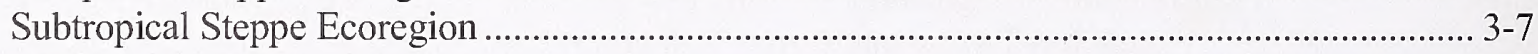

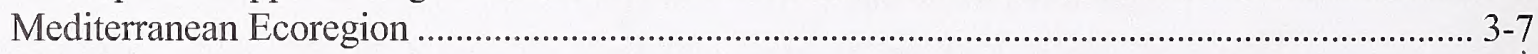

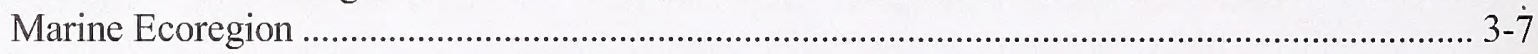

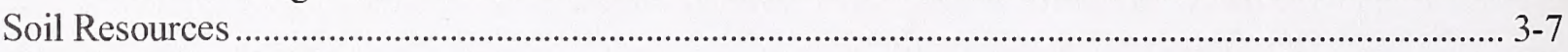

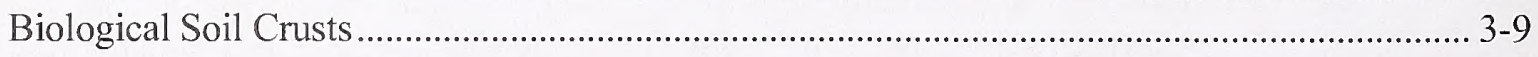

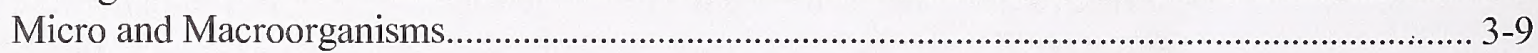

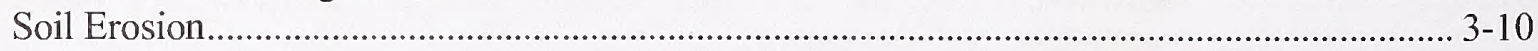


Soil Compaction .

$3-10$

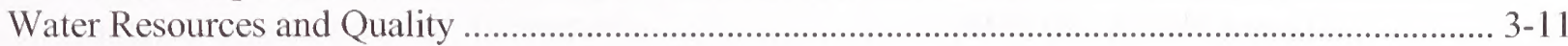

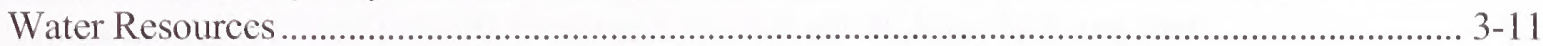

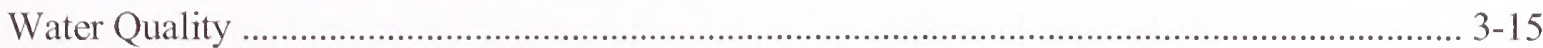

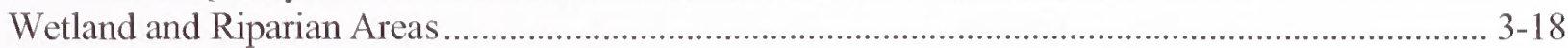

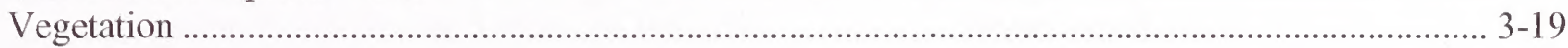

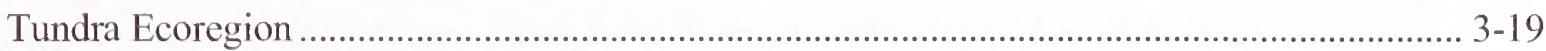

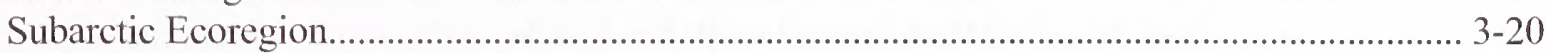

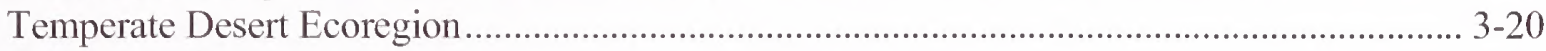

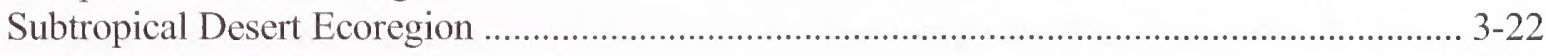

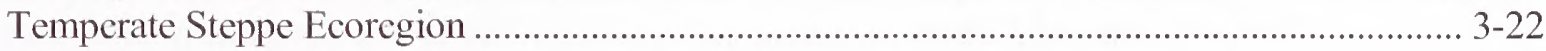

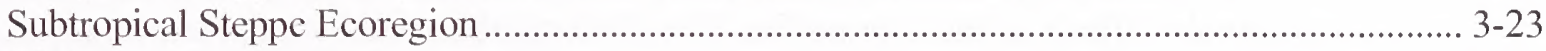

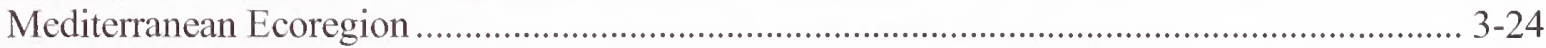

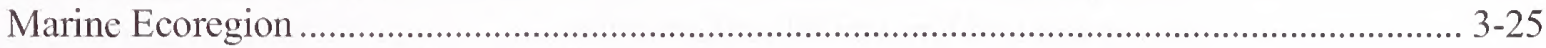

Noxious Weeds and other Invasive Vegetation........................................................................ 3-25

Vegetation Condition and Fire Regimes.............................................................................. 3-27

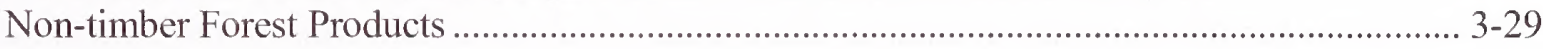

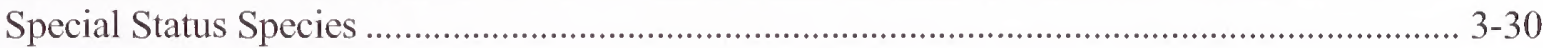

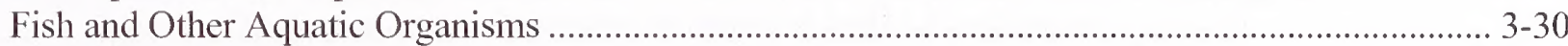

Alaska and the Pacific Northwest ...................................................................................... 3-30

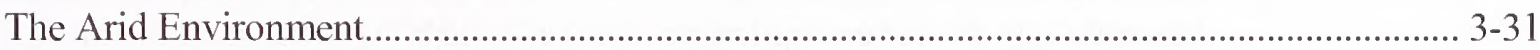

The Upper Colorado River Basin................................................................................. 3-33

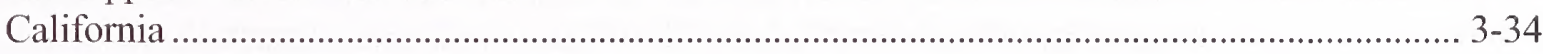

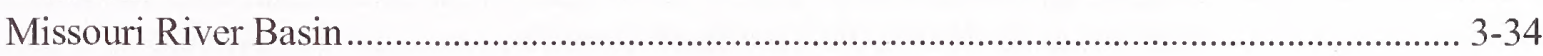

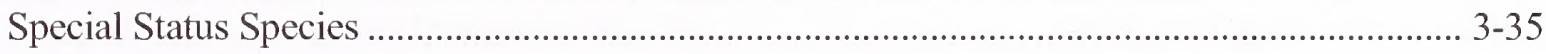

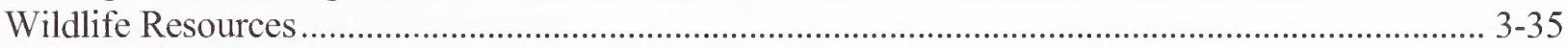

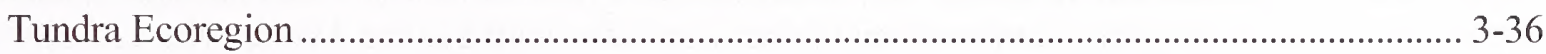

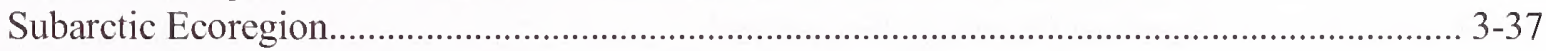

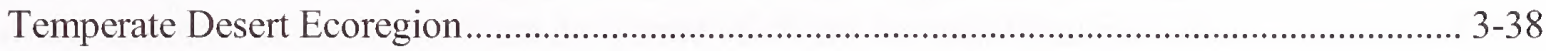

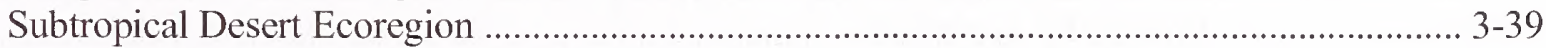

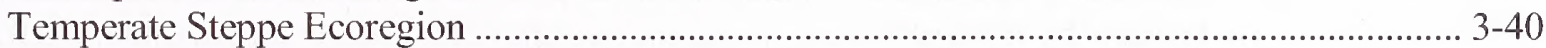

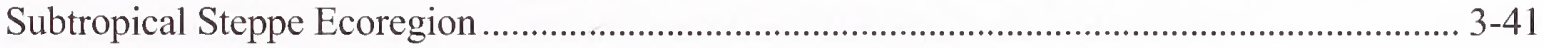

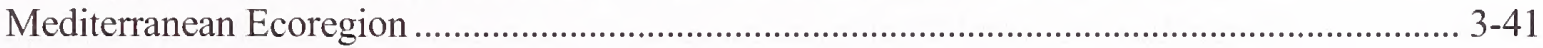

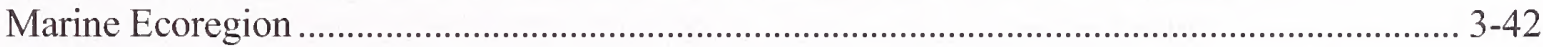

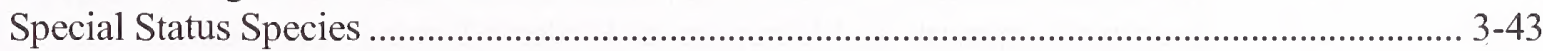

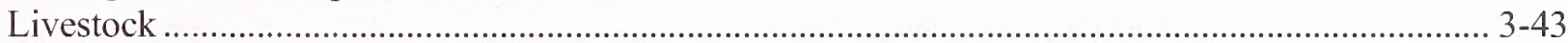

Wild Horses and Burros........................................................................................................... 3-44

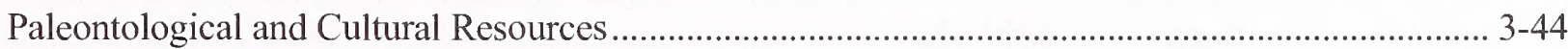

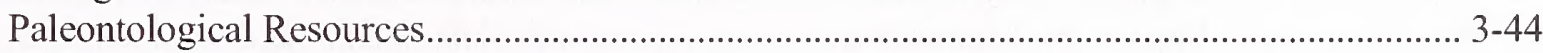

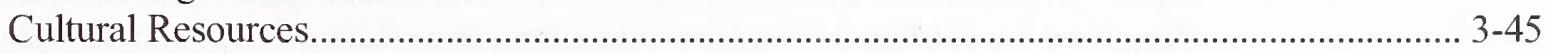

American Indian and Alaska Native Cultural Resources ................................................. 3-45

European Settlement Resources ............................................................................................ 3-54

Important Plant Uses and Species Used by American Indians and Alaska Natives................. 3-54

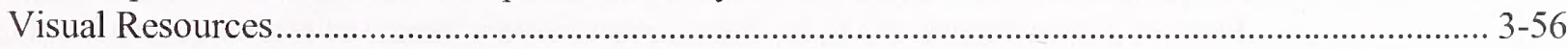

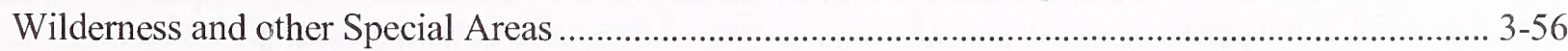

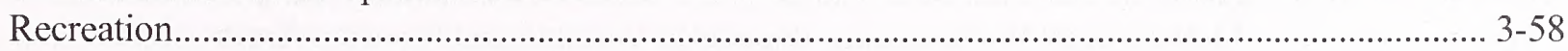

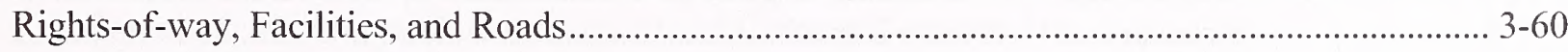

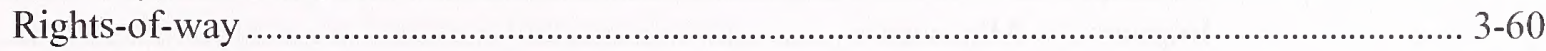

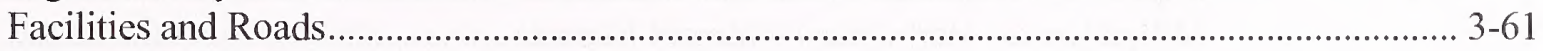

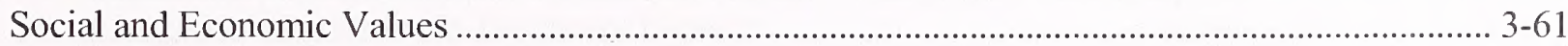

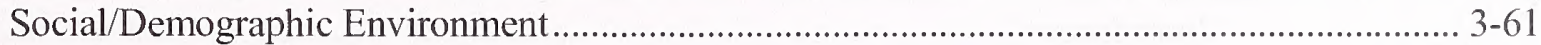

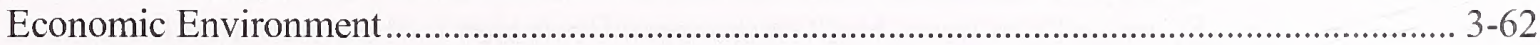

Revenues Generated by BLM Lands ........................................................................................ 3-62 


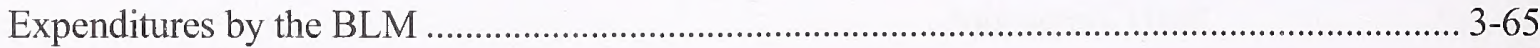

Human Health and Safety ............................................................................................................ 3-69

Background Health Risks....................................................................................................... 3-69

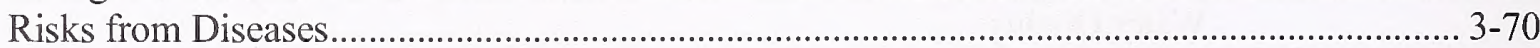

Risks from Injuries ........................................................................................................ 3-70

Risks from Cancer .......................................................................................................... $3-71$

Risk from Using Herbicides on Public Lands .......................................................................... 3-72

Risk from Wildfire Control on Public Lands....................................................................... 3-72

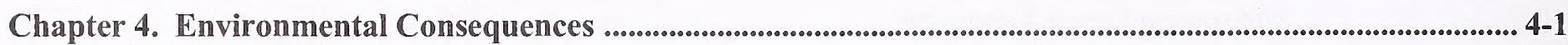

Introduction and Effects ........................................................................................................... 4-1

How the Effects of the Alternatives Were Estimated ........................................................................ 4-1

Assumptions for Analysis .................................................................................................. 4-1

Incomplete and Unavailable Information ............................................................................... 4-3

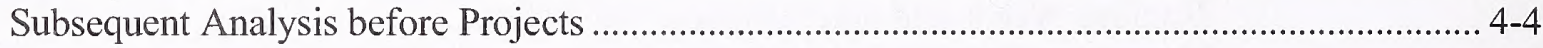

Program Goals by Ecoregion .................................................................................................. 4-4

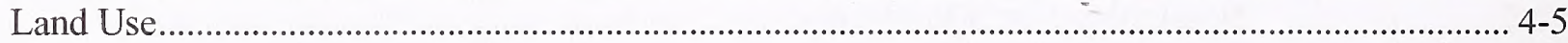

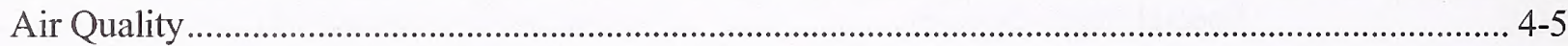

Scoping Comments and Other Issues Evaluated in the Assessment............................................. 4-5

Emission Sources.............................................................................................................. 4-6

Methodology for Assessing Impacts to Air Quality …………………........................................ 4-6

Standard Operating Procedures ................................................................................................. 4-8

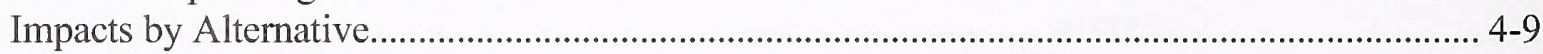

Mitigation for Herbicide Treatment Impacts .......................................................................... 4-13

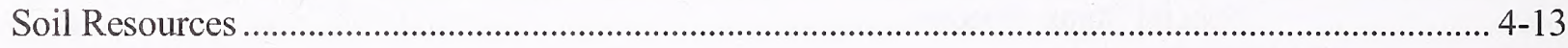

Introduction ........................................................................................................... 4-13

Scoping Comments and Other Issues Evaluated in the Assessment.......................................... 4-13

Standard Operating Procedures ................................................................................................. 4-13

Factors that Influence the Fate, Transport, and Persistence of Herbicides in Soil..................... 4-14

Impacts by Treatment …………………………………………………………………... 4-15

Impacts by Alternative..................................................................................................... 4-21

Mitigation for Herbicide Treatment Impacts ........................................................................... 4-24

Water Resources and Quality...................................................................................................... 4-24

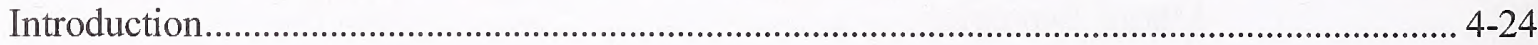

Scoping Comments and Other Issues Evaluated in the Assessment.......................................... 4-24

Standard Operating Procedures ................................................................................................ 4-24

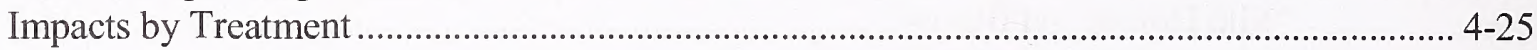

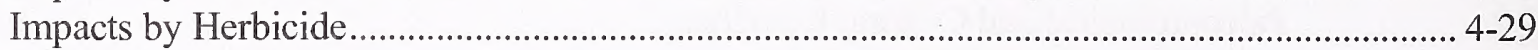

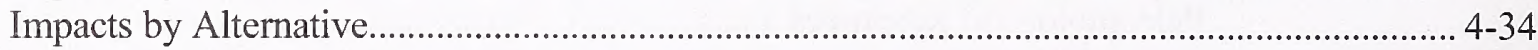

Mitigation for Herbicide Treatment Impacts ......................................................................... 4-36

Wetland and Riparian Areas .................................................................................................... 4-36

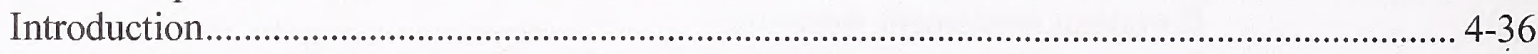

Scoping Comments and Other Issues Evaluated in the Assessment......................................... 4-37

Factors that Influence the Fate, Transport, and Persistence of Herbicides in Wetland and Riparian

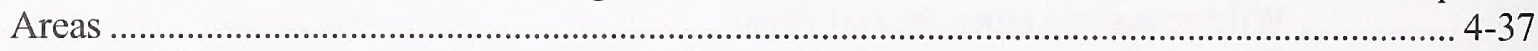

Methodology for Assessing Impacts to Wetland and Riparian Areas ........................................ 4-37

Summary of Herbicide Impacts............................................................................................ 4-37

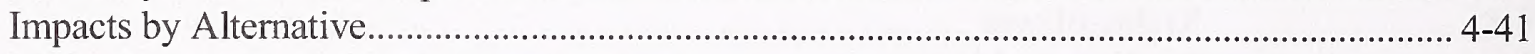

Mitigation for Herbicide Treatment Impacts ........................................................................ 4-44

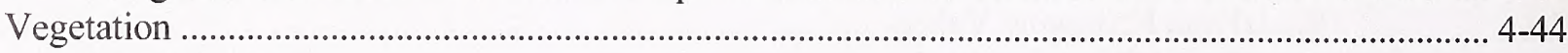

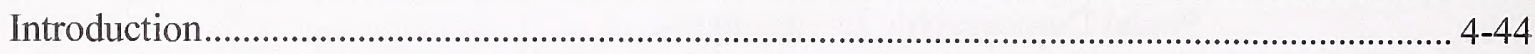

Scoping Comments and Other Issues Evaluated in the Assessment........................................... 4-44

Standard Operating Procedures................................................................................................ 4-44 
Impacts Assessment Methodology .....

Impacts Common to All Treatments

Summary of Herbicide Impacts Evaluated in ERAs ............................................................... 4-63

Other Herbicides Previously Approved for Use on Public Lands .......................................... 4-64

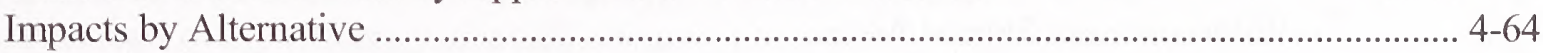

Mitigation for Herbicide Treatment Impacts ......................................................................... 4-71

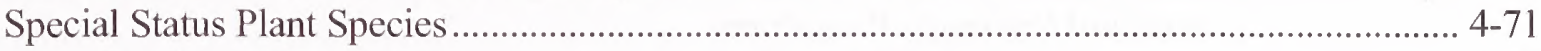

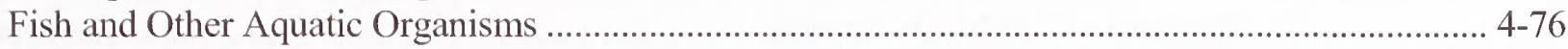

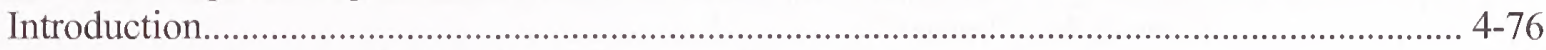

Scoping Comments and Other Issues Evaluated in the Assessment....................................... 4-77

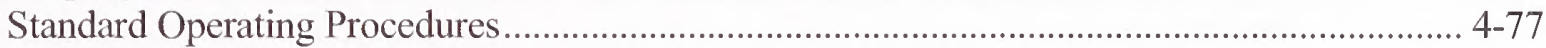

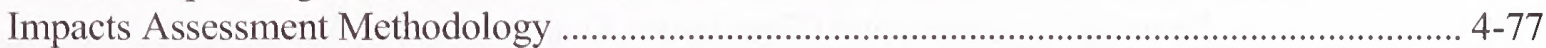

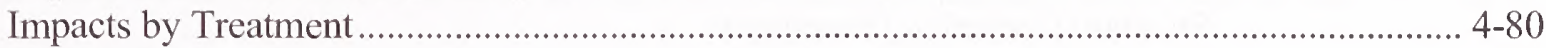

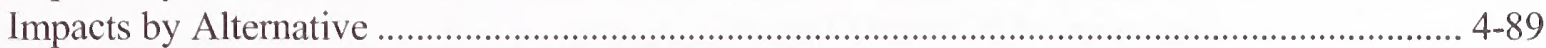

Mitigation for Herbicide Treatment Impacts .................................................................... 4-92

Special Status Fish and Other Aquatic Organisms ..................................................................... 4-92

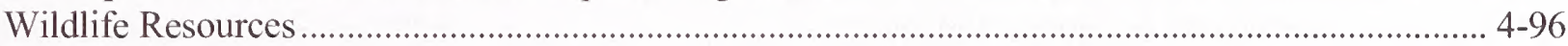

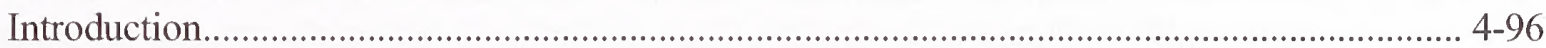

Scoping Comments and Other Issues Evaluated in the Assessment....................................... 4-98

Standard Operating Procedures ................................................................................................ 4-98

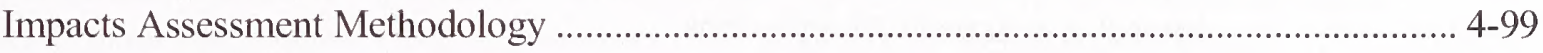

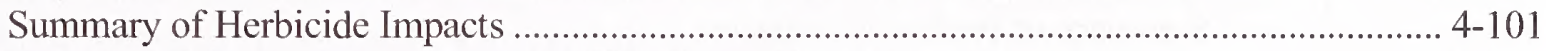

Impacts of Herbicide Treatments on Wildlife and Habitat by Ecoregion................................ 4-109

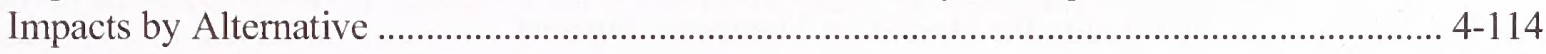

Mitigation for Herbicide Treatment Impacts .................................................................... 4-118

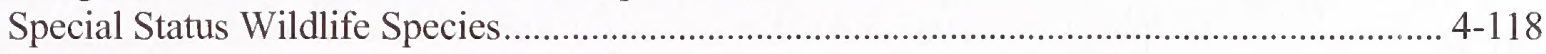

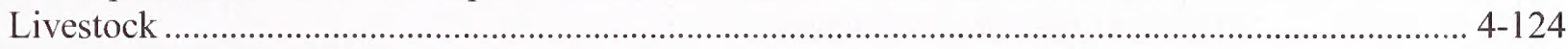

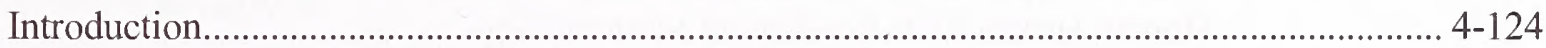

Scoping Comments and Other Issues Evaluated in the Assessment...................................... 4-124

Standard Operating Procedures............................................................................................ 4-124

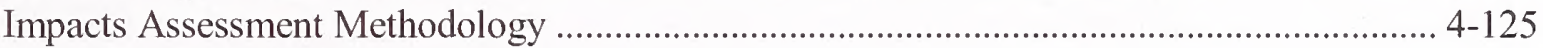

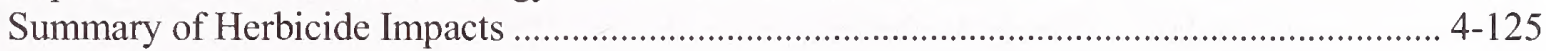

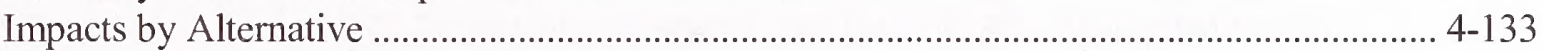

Mitigation for Herbicide Treatment Impacts .................................................................. 4-136

Wild Horses and Burros ............................................................................................................... 4-136

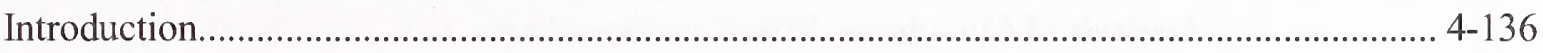

Scoping Comments and Other Issues Evaluated in the Assessment..................................... 4-137

Standard Operating Procedures.......................................................................................... 4-137

Impacts Assessment Methodology …................................................................................ 4-137

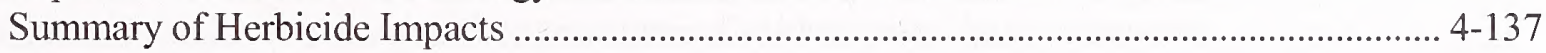

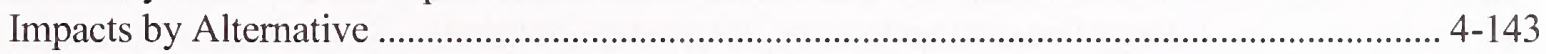

Mitigation for Herbicide Treatment Impacts .............................................................. 4-146

Paleontological and Cultural Resources .................................................................................. 4-146

Scoping Comments and Other Issues Evaluated in the Assessment...................................... 4-147

Standard Operating Procedures for Addressing BLM Actions on Paleontological, Cultural, and

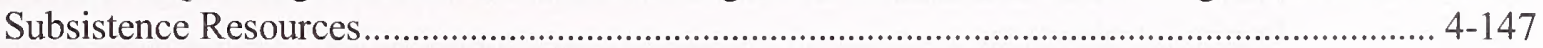

Herbicide Impacts on Paleontological and Cultural Resources ........................................... 4-148

Herbicide Impacts on Native American Health ....................................................................... 4-149

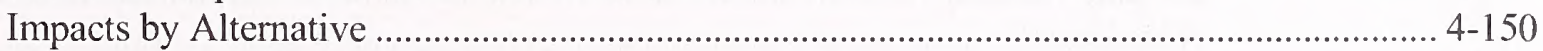

Mitigation for Herbicide Treatment Impacts ...................................................................... 4-152

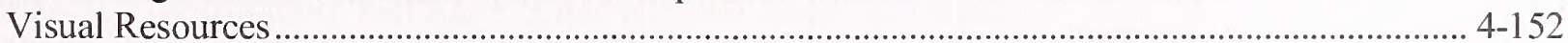

Scoping Comments and Other Issues Evaluated in the Assessment..................................... 4-153

Standard Operating Procedures ..................................................................................... 4-153 
BLM Assessment of Visual Resource Values ........................................................................ 4-153

Summary of Herbicide Impacts..................................................................................... 4-154

Impacts by Alternative..................................................................................................... 4-154

Mitigation for Herbicide Treatment Impacts .......................................................................... 4-155

Wilderness and Special Areas............................................................................................... 4-155

Scoping Comments and Other Issues Addressed in the Assessment ...................................... 4-156

Standard Operating Procedures ......................................................................................... 4-156

Summary of Herbicide Impacts............................................................................................ 4-156

Impacts by Alternative....................................................................................................... 4-157

Mitigation for Herbicide Treatment Impacts ........................................................................ 4-159

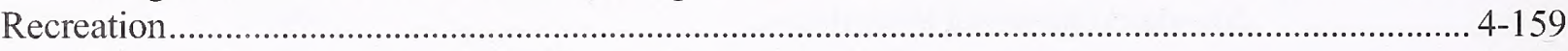

Scoping Comments and Other Issues Evaluated in the Assessment ......................................... 4-159

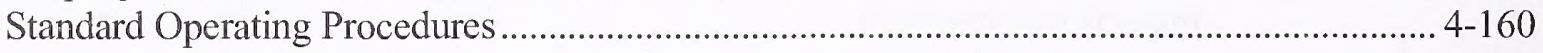

Summary of Herbicide Impacts................................................................................................ 4-160

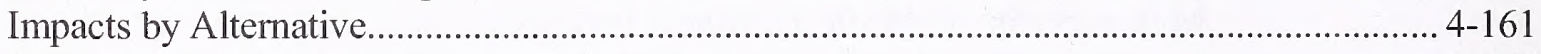

Mitigation for Herbicide Treatment Impacts .......................................................................... 4-163

Social and Economic Values .................................................................................................... 4-163

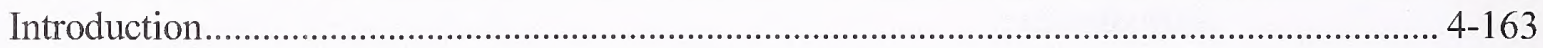

Scoping Comments and Other Issues Evaluated in the Assessment ......................................... 4-164

Standard Operating Procedures .......................................................................................... 4-164

Impact Assessment Assumptions ........................................................................................ 4-165

Summary of Herbicide Impacts............................................................................................... 4-165

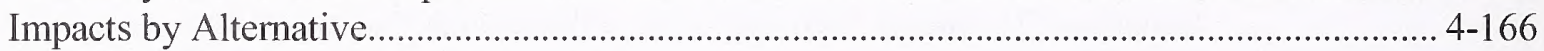

Mitigation for Herbicide Treatment Impacts .................................................................... 4-174

Human Health and Safety ..................................................................................................... 4-174

Scoping Comments and Other Issues Evaluated in the Assessment ......................................... 4-175

Standard Operating Procedures ............................................................................................ 4-175

Human Health Risk Assessment Methodology ........................................................................ 4-175

Uncertainty in the Risk Assessment Process ........................................................................... 4-181

Impacts by Alternative................................................................................................... 4-195

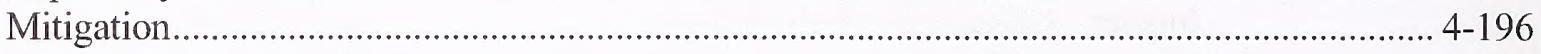

Cumulative Effects Analysis......................................................................................................... 4-197

Structure of the Cumulative Effects Analysis.......................................................................... 4-197

Resource Protection Measures Considered in the Cumulative Effects Analysis..................... 4-201

Other Information Considered in Cumulative Effects Analysis .............................................. 4-202

Analysis of Cumulative Effects by Resources........................................................................... 4-202

Unavoidable Adverse Effects ................................................................................................. 4-243

Relationship between the Local Short-term Uses and Maintenance and Enhancement of

Long-term Productivity .................................................................................................. 4-246

Irreversible and Irretrievable Commitment of Resources ……………………………………... 4-251

Energy Requirements and Conservation Potential ................................................................... 4-253

Natural or Depletable Resource Requirements and Conservation .............................................. 4-253

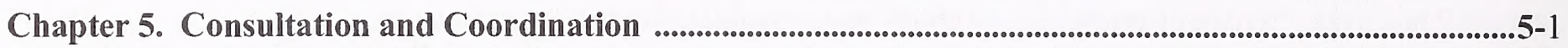

Preview of this Section............................................................................................................... $5-1$

Public Involvement …………………………………………………………………………… 5-1

Federal Register Notices and Newspaper Advertisements.......................................................... 5-1

Scoping Meetings ………………………………………………………………….... $5-1$

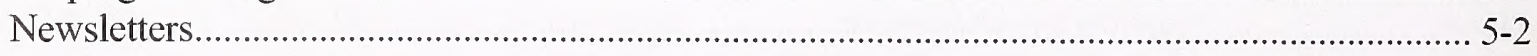

Public Review and Comment on the Draft Programmatic EIS and ER, and Biological

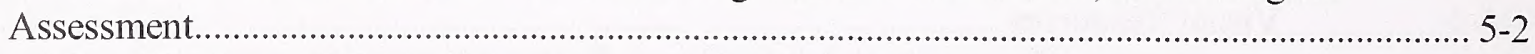

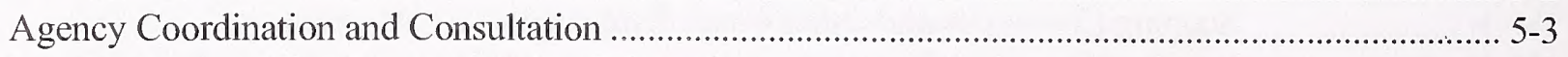

Endangered Species Act Section 7 Consultation ....................................................................... 5-3 
Risk Asscssment Coordination $.5-3$

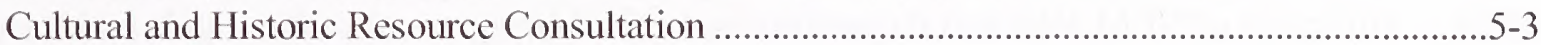

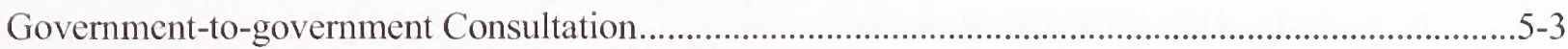

Development of the Final Preferred Alternative ….........................................................................5-4

List of Preparers of the Programmatic EIS...................................................................................

Chapter 6. References

Chapter 7. Glossary

Chapter 8. Index

\section{List of Tables}

1-1 Key Issues (and Number of Comments) Identified During Scoping and Location Where Issues

Are Addressed in the PEIS and PER

2-1 Herbicide Active Ingredients Proposed, Evaluated, and Included in Current Environmental Impact Statements of the Bureau of Land Management.

2-2 States in which Herbicides are Approved for Use on Public Lands Based upon Current Environmental Impact Statements, Court Injunctions, and Changes in Registration Status Average Number of Acres Treated Annually for Each BLM State Jurisdiction during 19972005

Historic Use of Herbicides by the BLM and Projected Future Use of Herbicides by the BLM under Each Alternative.

2-10 Summary and Comparison of Effects on Resources by Alternative.

3-1 Acres of Public Lands in 17 Western States and Percent of Lands in the the State Administered by the BLM.

3-2 National Ambient Air Quality Impact Significance Criteria

3-3 Counties within the Treatment Area that are Designated Nonattainment or Maintenance Areas for Various Pollutants...

3-14 Estimated Recreation Use of Public Lands during Fiscal Year $2005 .$. 
3-19 Estimated Benefits to Local Economies by Recreation on Public Lands during Fiscal Year 2005 ......3-66

3-20 Summary of BLM Jobs and Expenditures for the Management of the Lands and Resources

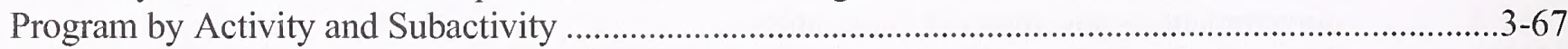

3-21 BLM Wildland Fire Suppression Expenditures Fiscal Year 1998 through Fiscal Year 2005 ...............3-68

3-22 BLM Action Fires Larger than 10,000 Acres during 1999 to 2005 ................................................68

3-23 Herbicide Uses and Costs for Vegetation Treatments on Public Lands during 2005 ..........................3-69

3-24 BLM Payments to States and Local Governments during Fiscal Year 2005 .....................................3-71

3-25 Mortality Rates (per 100,000 Population) and Causes of Death by State 2002-2003.........................3-72

4-1 Estimated Acres Treated Annually using Herbicides for Each State under Each Treatment

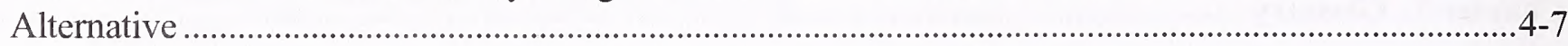

4-2 Annual Emissions Summary for Herbicide Treatments under Alternative A .......................................4-8

4-3 Annual Emissions Summary for Herbicide Treatments under Alternative B ....................................4-9

4-4 Annual Emissions Summary for Herbicide Treatments under Alternative D ....................................4-10

4-5 Annual Emissions Summary for Herbicide Treatments under Alternative E .....................................4-11

4-6 Example NAAQS Compliance Analysis for Chemical Treatment ................................................4-12

4-7 Estimated Soil Half-life and Adsorption Affinity for Active Ingredients .........................................4-15

4-8 Factors Associated with Herbicide Movement to Groundwater.......................................................4-27

4-9 Herbicide Physical Properties and Off-site Movement Potential ......................................................4-28

4-10 Anaerobic Half-life and Relative Mobility in Soil for Herbicides Analyzed in this PEIS ...................4-39

4-11 Risk Categories Used to Describe Typical Herbicide Effects to Vegetation According to Exposure Scenario and Ecological Receptor Group

4-12 Buffer Distances to Minimize Risk to Vegetation from Off-site Drift of BLM-evaluated

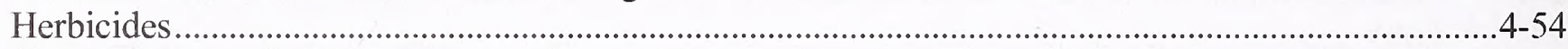

4-13 Risk Categories Used to Describe Effects of Forest Service-evaluated Herbicides According to Exposure Scenario and Ecological Receptor Group ............................................................................4-57

4-14 Buffer Distances to Minimize Risk to Vegetation from Off-site Drift of Forest Serviceevaluated Herbicides

4-15 Percentage of Acres Projected to be Treated Using Herbicides in Each Ecoregion for Each

Vegetation Subclass under the No Action Alternative...

4-16 Percentage of Acres Projected to be Treated Using Herbicides in Each Ecoregion for Each

Vegetation Subclass under the Preferred Alternative

4-17 Risk Categories Used to Describe BLM-evaluated Herbicide Effects on Non Special Status Fish and Aquatic Invertebrates According to Exposure Scenario .

4-18 Risk Categories Used to Describe Forest Service-evaluated Herbicide Effects on Fish and Aquatic Invertebrates According to Exposure Scenario.

4-19 Buffer Distances to Minimize Risk to Non Special Status Fish and Aquatic Invertebrates from Off-site Drift of BLM-evaluated Herbicides from Broadcast and Aerial Treatments

4-20 Risk Categories Used to Describe BLM-evaluated Herbicide Effects on Special Status Fish and Aquatic Invertebrates According to Exposure Scenario

4-21 Buffer Distances to Minimize Risk to Special Status Fish and Aquatic Organisms from Off-site Drift of BLM Herbicides from Broadcast and Aerial Treatments....

4-22 Risk Categories Used to Describe BLM-evaluated Herbicide Effects on Non Special Status Wildlife According to Exposure Scenario...

4-23 Risk Categories Used to Describe Forest Service-evaluated Herbicide Effects on Wildlife According to Exposure Scenario

4-24 Risk Categories Used to Describe BLM-evaluated Herbicide Effects on Special Status Wildlife According to Exposure Scenario.

4-25 Risk Categories Used to Describe BLM-evaluated Herbicide Effects on Livestock and Wild Horses and Burros According to Exposure Scenario.

4-26 Risk Categories Used to Describe Forest Service-evaluated Herbicide Effects on Livestock and Wild Horses and Burros According to Exposure Scenario. 
4-27 BLM-evaluated Herbicide Risk Categories by Aggregate Risk Index for Occupational Receptors 4-185

4-28 BLM-evaluated Herbicide Risk Categories by Aggregate Risk Index for Public Receptors 4-186 Receptors

4-30 Forest Service-evaluated Herbicide Risk Categories by Hazard Quotient for Public Exposures....... 4-188

4-31 Scenarios Resulting in High Risk to Occupational Receptors from Herbicides Evaluated in the 1988-1991 BLM EISs

4-32 Scenarios Resulting in High Risk to Public Receptors from Herbicides Evaluated in the 19881991 BLM EISs

4-33 Herbicide Use in the Western United States for Agricultural Lands and BLM-administered Lands

5-1 List of Preparers of the Programmatic EIS/ER/BA. 5-5

\section{List of Figures}

1-1 Relationship of the PEIS to BLM Field Offices $1-10$

1-2 How this Programmatic EIS is Organized $1-17$

2-2 National Early Warning and Rapid Reponse System for Invasive Plants

3-1 Relationship between Area Occupied by Invasive Species and Time

\section{List of Maps \\ (Located at the end of the chapter)}

1-1 Public Lands Administered by the Bureau of Land Management 


\section{VOLUME 2}

Appendix A. Common and Scientific Names of Plants and Animals Given in This Programmatic

EIS.

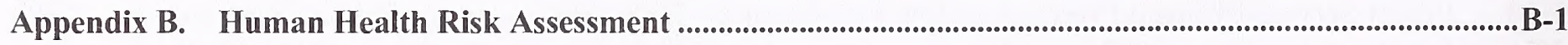

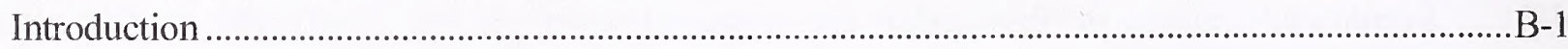

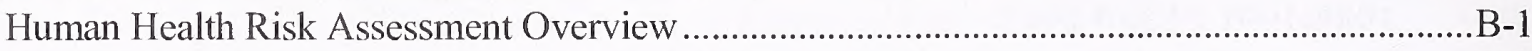

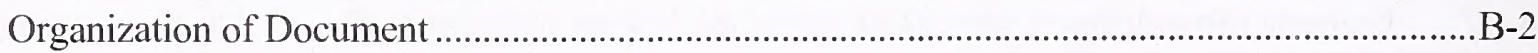

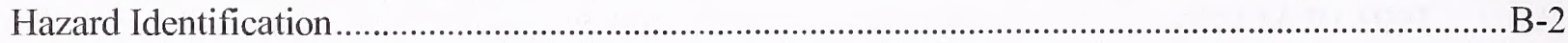

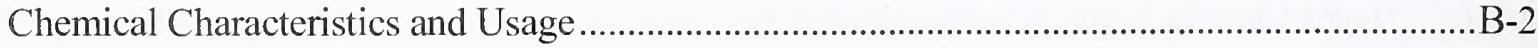

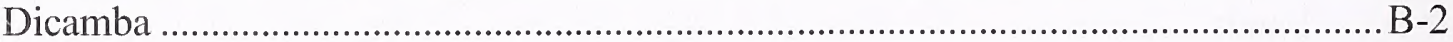

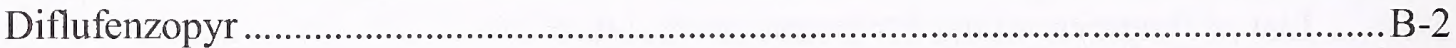

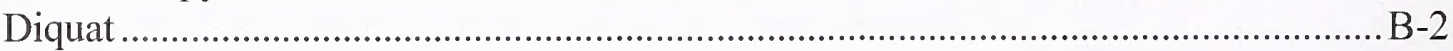

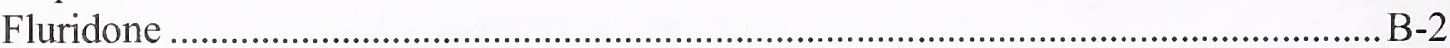

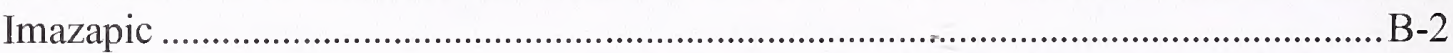

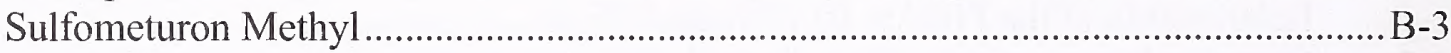

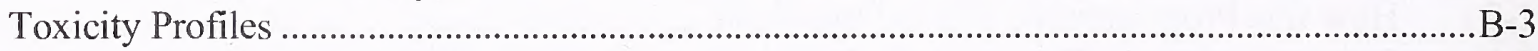

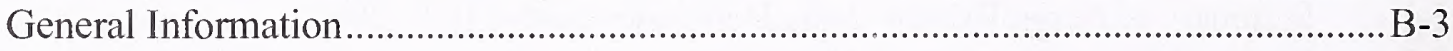

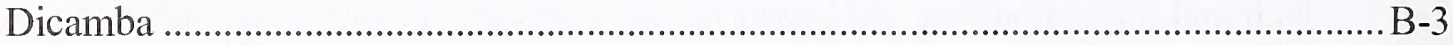

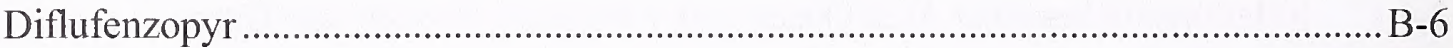

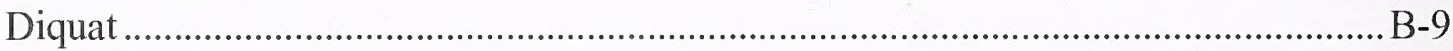

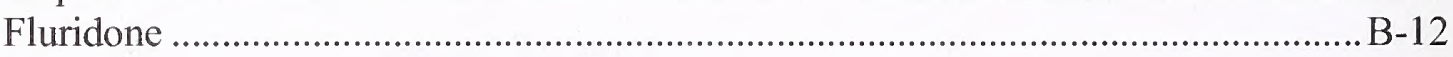

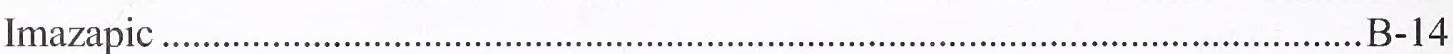

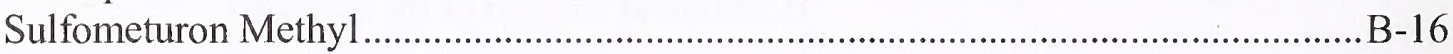

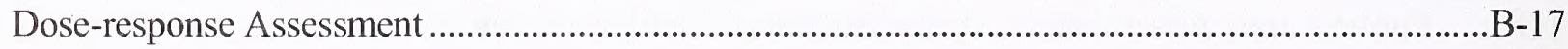

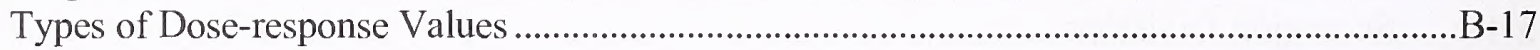

Dietary Assessment................................................................................................... 17

Non-dietary (Occupational or Residential) Assessment ........................................... B-18

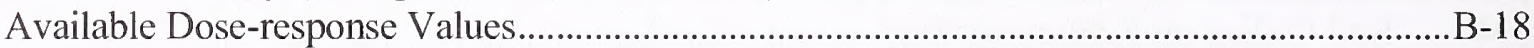

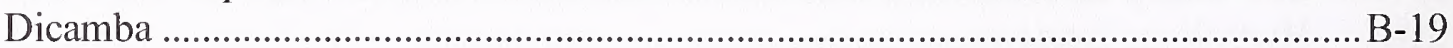

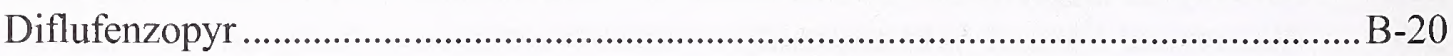

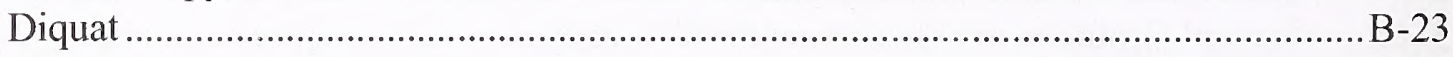

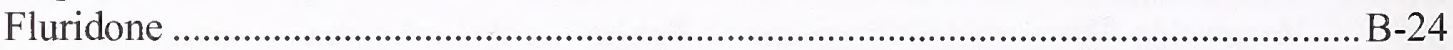

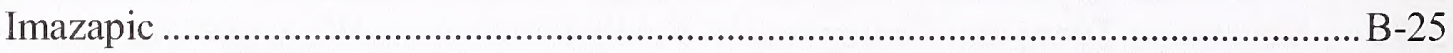

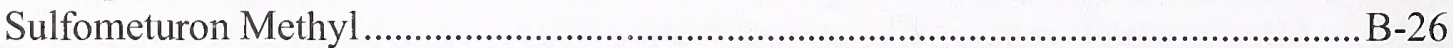

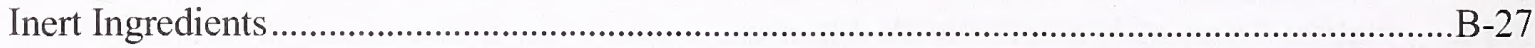

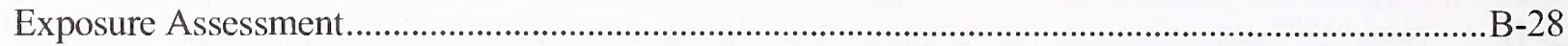

Overview of the BLM Vegetation Treatment Program.............................................................

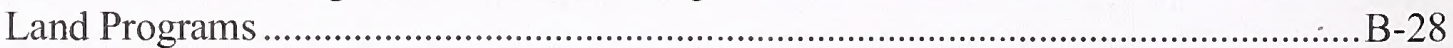

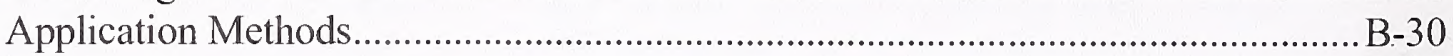

Herbicide Use Parameters .......................................................................................................

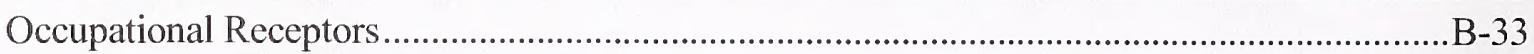

Routine Use Exposure Scenarios........................................................................ B-33

Accidental Exposure Scenarios ............................................................................ B-34

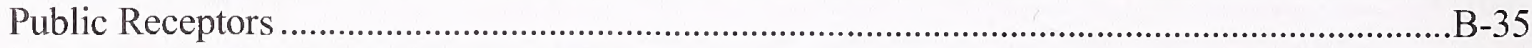

Routine Use Exposure Scenarios.......................................................................... B-35

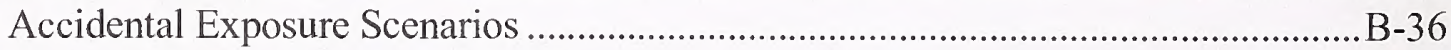

Exposure Parameters for Public Receptors ................................................................ B-37

Calculation of Exposure Point Concentrations .........................................................................

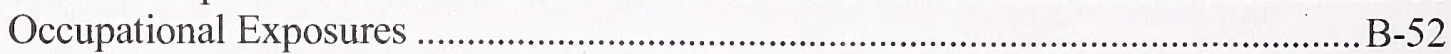




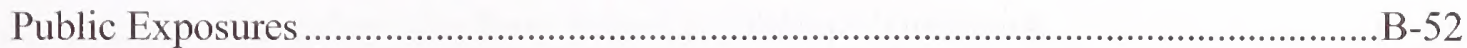

Chemical-specific Parameters .........................................................................................

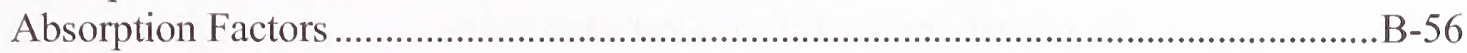

Skin Permeability Constants …………………………………………………... B-56

Fish Bioconcentration Factors ...........................................................................

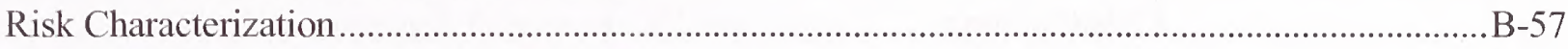

Approach for Risk Characterization .................................................................................

Food (\%PAD) Assessment ……………………………................................

Non-food (MOE) Assessment ……………………………………………............

Aggregate Risk Index .........................................................................................

Equations for Quantifying Potential Exposure and Risk.......................................................... B-58

Estimating Potential Occupational Exposures …………………………………........

Inhalation of Herbicide ………………………………......................................

Estimating Potential Exposure for Public Receptors ………………………………....B-61

Dermal Contact with Herbicide ............................................................................ B-61

Results of Risk Characterization ........................................................................................ B-67

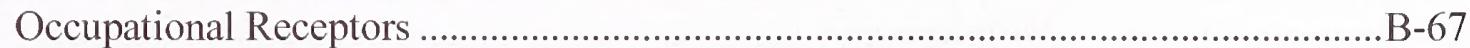

Public Receptors...................................................................................................

Evaluation of Currently-available Herbicide Active Ingredients................................................ B-80

Evaluation of Dose-response Values Used in Previous EISs ......................................B-81

Evaluation of Receptors and Exposure Pathways Used in the Earlier Human

Health Risk Assessments ...................................................................................... B-82

Summary of Currently-available Herbicide Active Ingredient Evaluation .................B-82

Uncertainty Analysis ....................................................................................................

Hazard Identification.............................................................................................8-82

Dose-response Assessment ..................................................................................

Exposure Assessment........................................................................................... B-83

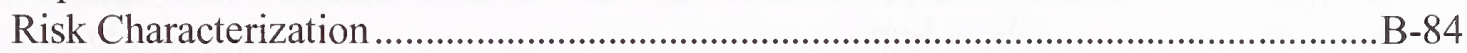

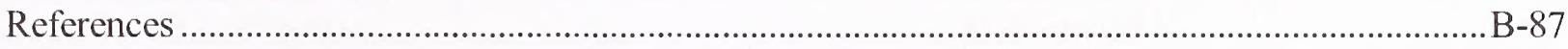

Appendix C. Ecological Risk Assessment ...........................................................................................................................1

Structure and Methodology of the Ecological Risk Assessment............................................................ -1

Problem Formulation...........................................................................................................

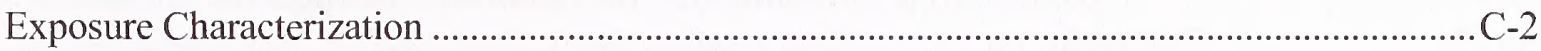

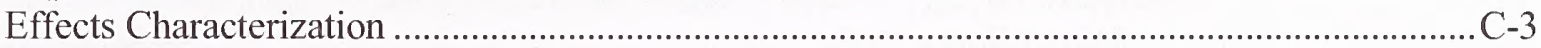

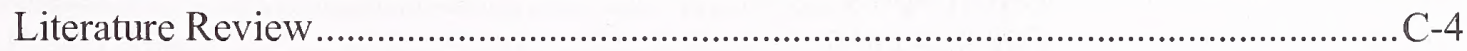

Toxicity Reference Value Development ........................................................................ -4

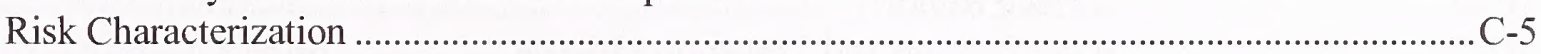

Rare, Threatened, and Endangered Species ……………………………………….... -6

Uncertainty Analysis .......................................................................................................

Application Methods and Herbicide Usage.................................................................................... -8

Aerial Application ...........................................................................................................

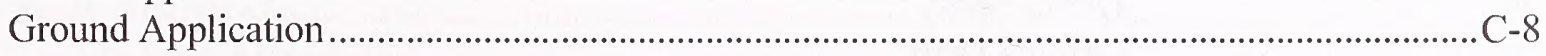

Aquatic Application............................................................................................................

Non-target Species Exposure Characterization .........................................................................

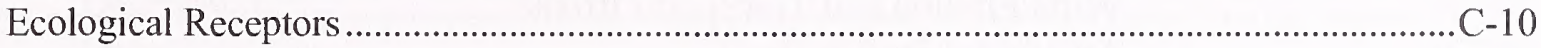

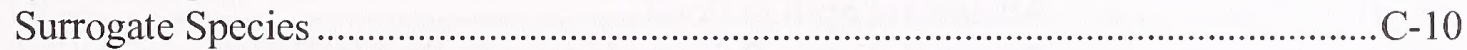

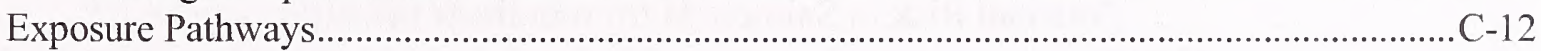

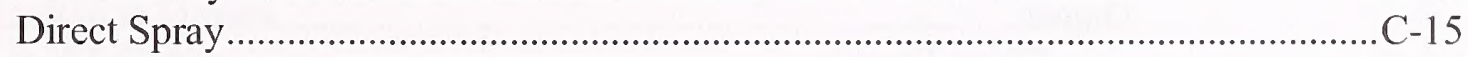

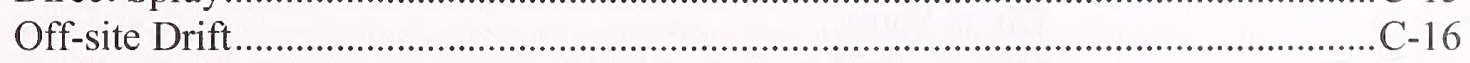

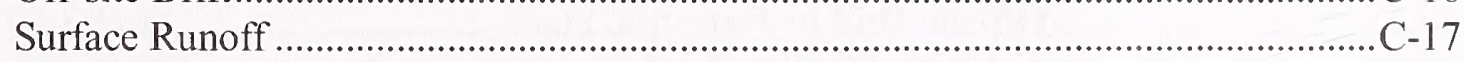

Wind Erosion and Off-site Transport of Terrestrial Herbicide...................................... - 20 


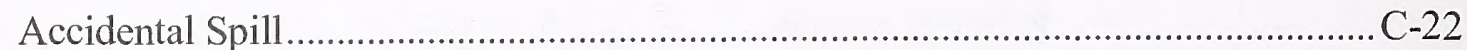

Non-target Species Effects Characterization...............................................................................

Terrestrial Species Effects Characterization ............................................................................... -23

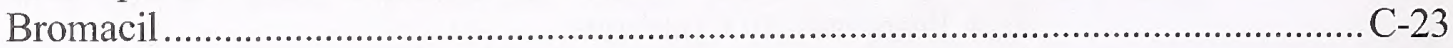

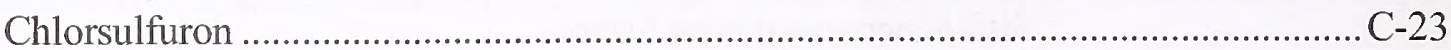

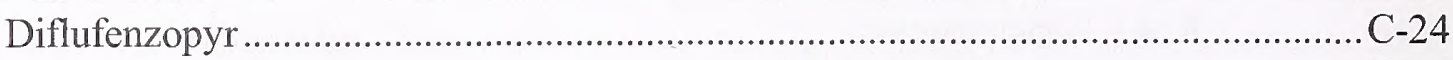

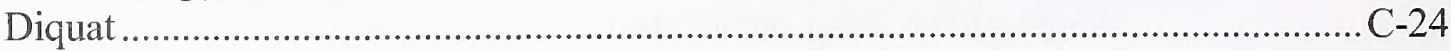

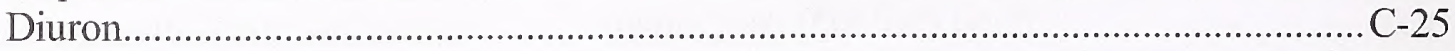

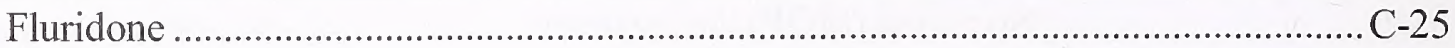

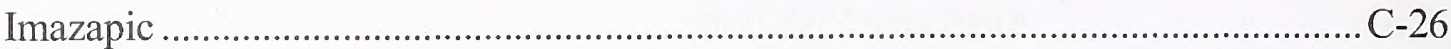

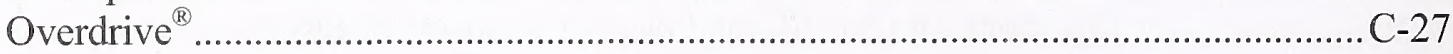

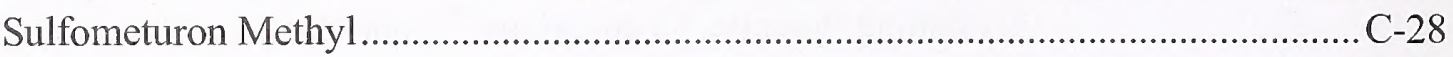

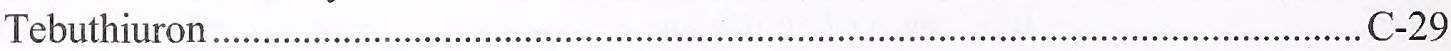

Aquatic Species Effects Characterization ................................................................................

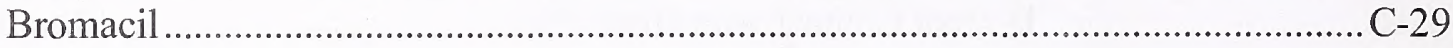

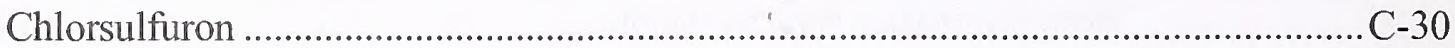

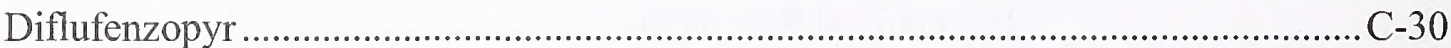

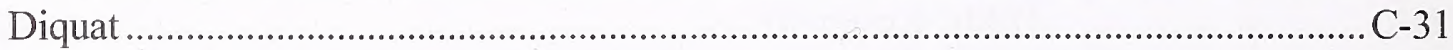

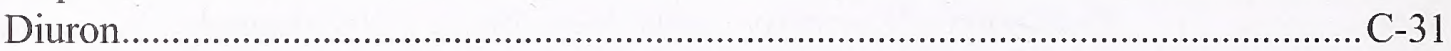

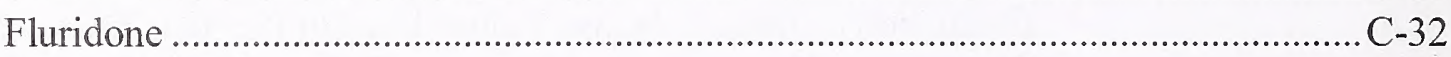

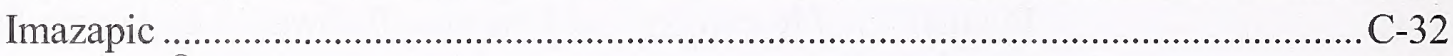

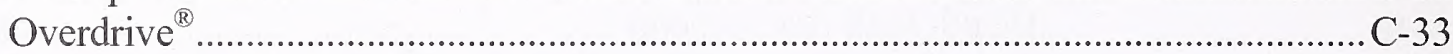

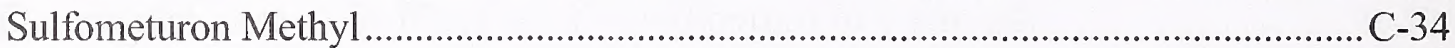

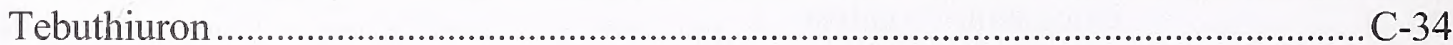

Rare, Threatened, and Endangered Species Characterization ...................................................-35

Non-target Species Risk Characterization ...................................................................................

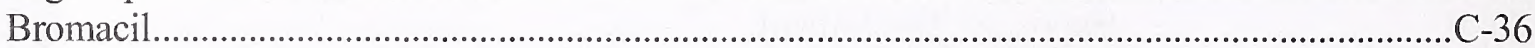

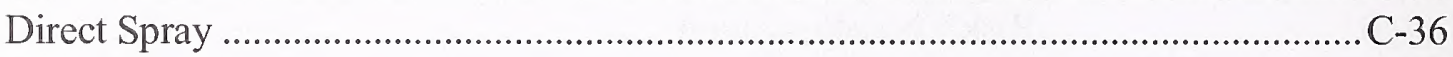

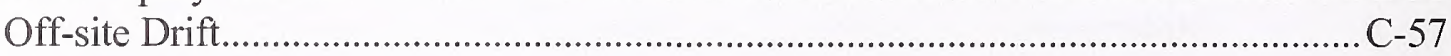

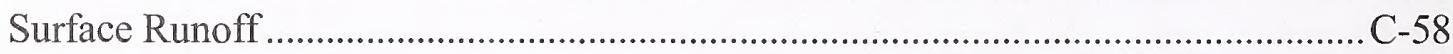

Wind Erosion and Transport Off-site ....................................................................... -58

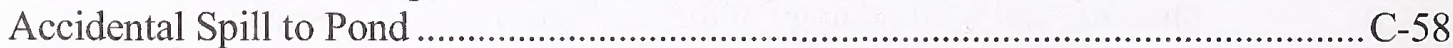

Potential Risk to Salmonids from Indirect Effects..................................................... -59

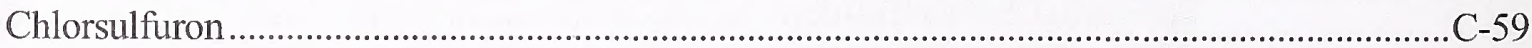

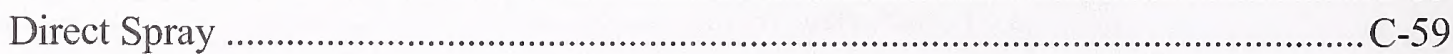

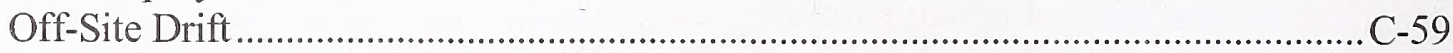

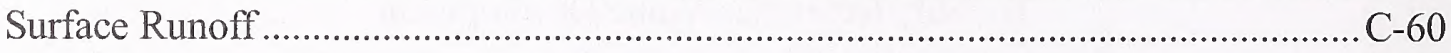

Wind Erosion and Transport Off-site ..................................................................... C-60

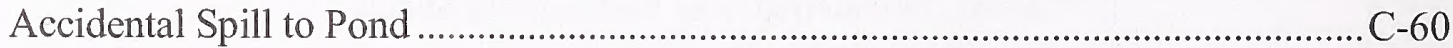

Potential Risk to Salmonids from Indirect Effects..................................................6-61

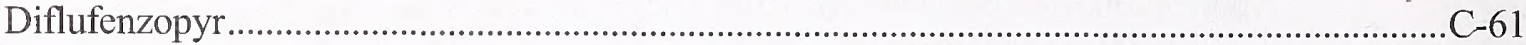

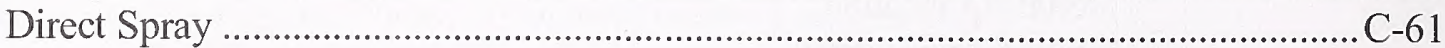

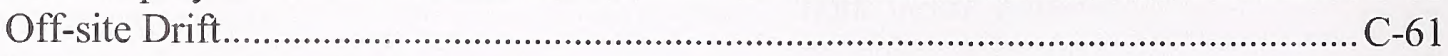

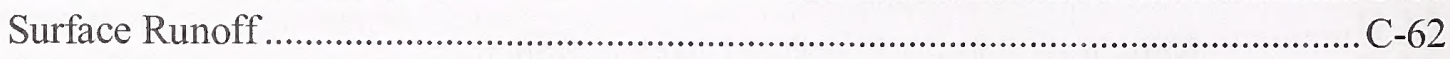

Wind Erosion and Transport Off-site .................................................................... -62

Accidental Spill to Pond .......................................................................................... C-62

Potential Risk to Salmonids from Indirect Effects................................................... C-62

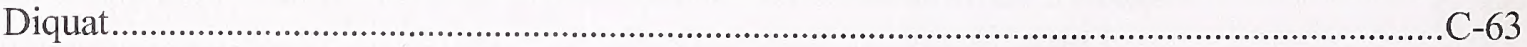

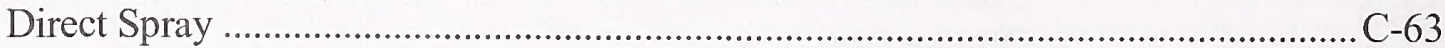

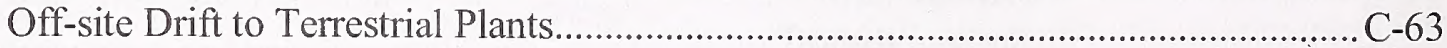

Accidental Spill to Pond ......................................................................................... C-64 
Potential Risk to Salmonids from Indirect Effects ....................................................64

Diuron

Direct Spray

C-64

Off-site Drift.

Surface Runoff

Wind Erosion and Transport Off-site

Accidental Spill to Pond

Potential Risk to Salmonids from Indirect Effects

Fluridone

Direct Spray

Off-site Drift to Non-target Terrestrial Plants ...........................................................6-68

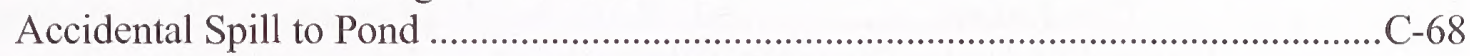

Potential Risk to Salmonids from Indirect Effects................................................6-68 Imazapic

Direct Spray

Off-site Drift

Surface Runoff

Wind Erosion and Transport Off-site ................................................................. -70

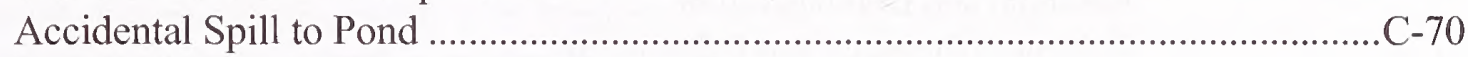

Potential Risk to Salmonids from Indirect Effects .................................................C-70 Overdrive ${ }^{\circledR}$......

Direct Spray

Off-site Drift.

Surface Runoff

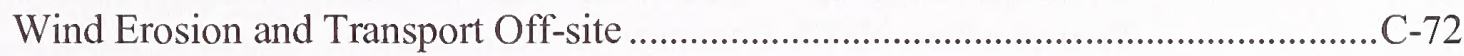

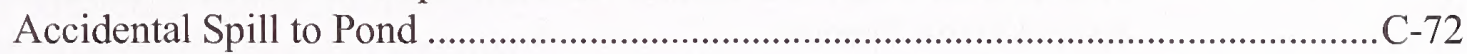

Potential Risk to Salmonids from Indirect Effects ..................................................

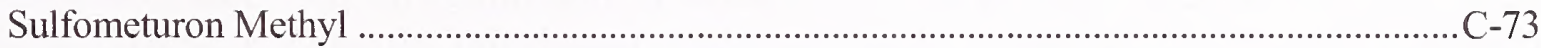

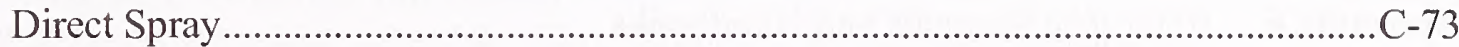

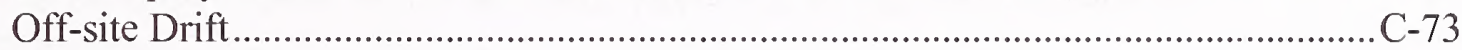

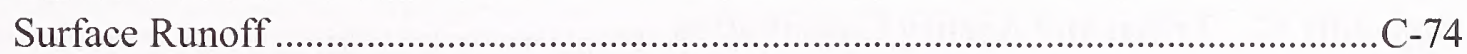

Wind Erosion and Transport Off-site ..................................................................

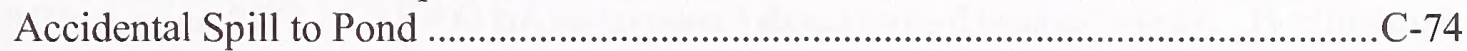

Potential Risk to Salmonids from Indirect Effects....................................................

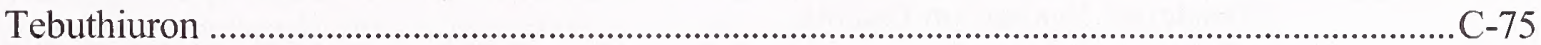

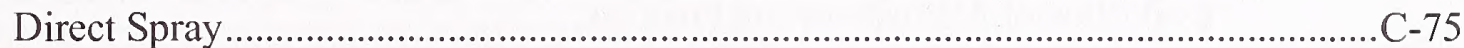

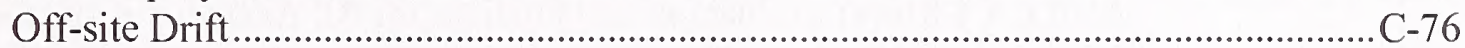

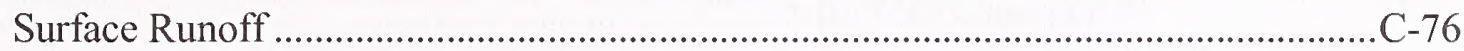

Wind Erosion and Transport Off-site ..............................................................

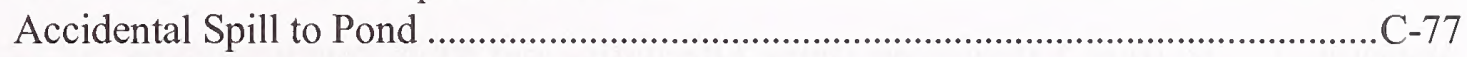

Potential Risk to Salmonids from Indirect Effects..............................................

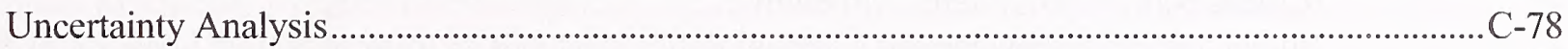

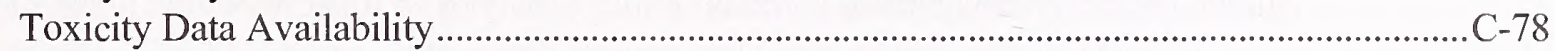

Degradates, Inert Ingredients, Adjuvants, and Tank Mixtures................................................

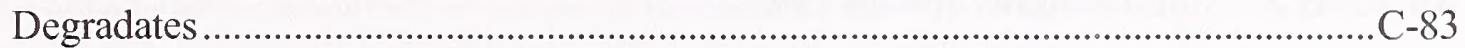

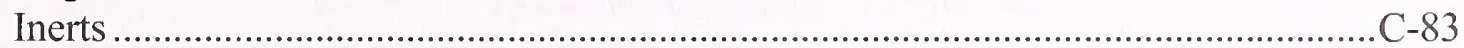

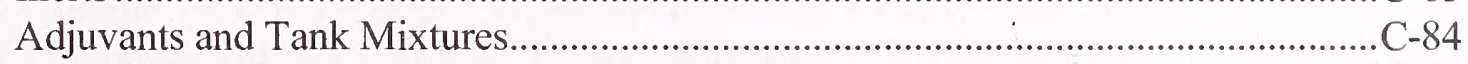

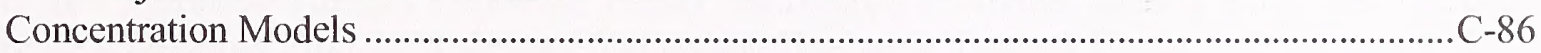

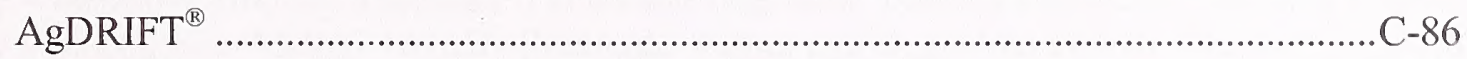

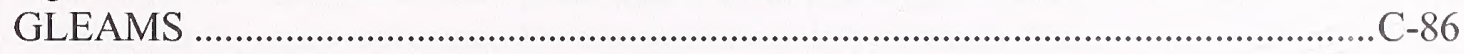

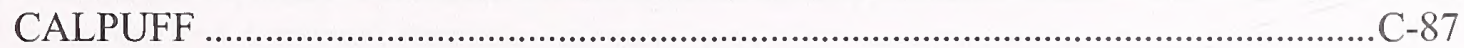




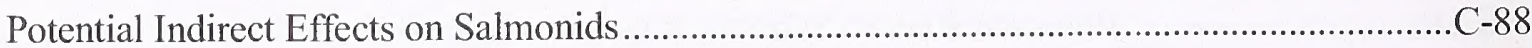

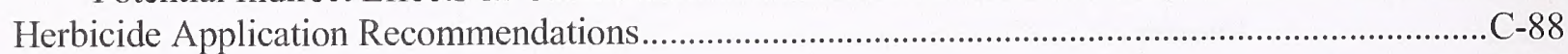

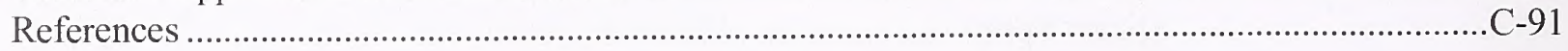

Appendix D. Evaluation of Risks from Degradates, Polyoxyethyleneamine (POEA) and R-11, and

Endocrine Disrupting Chemicalls .................................................................................... D-1

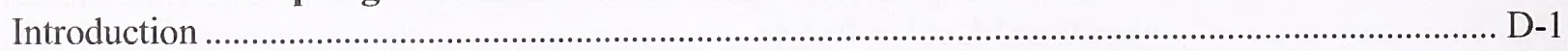

Potential Ecological Impacts of the Surfactant Polyoxyethyleneamine (POEA) and R-11 .............. D-1

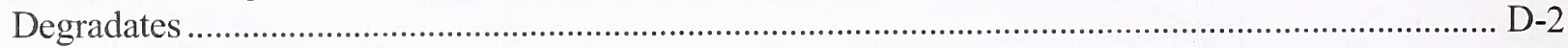

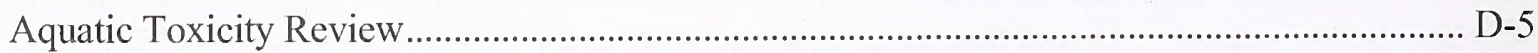

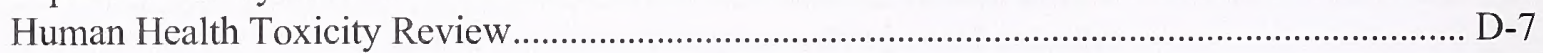

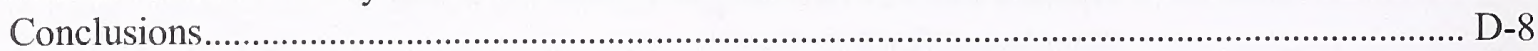

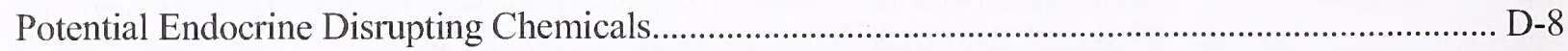

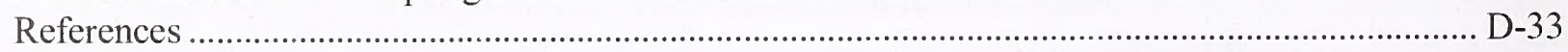

Appendix E. Protocol for Identifying, Evaluating, and Using New Herbicides ..................................................E-1

Identification and Approval of New Chemical Products and Technologies ......................................E-1

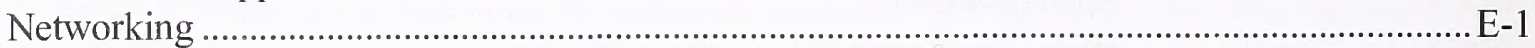

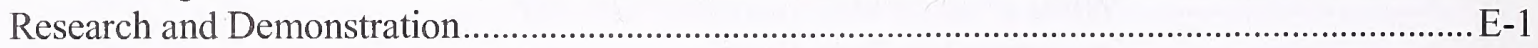

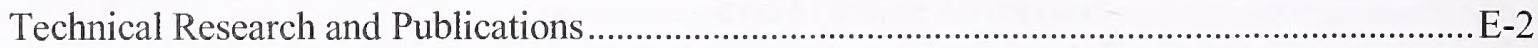

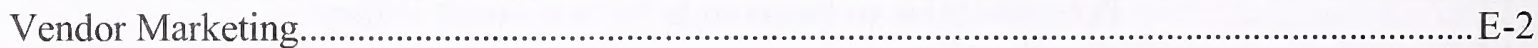

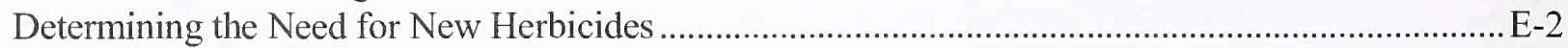

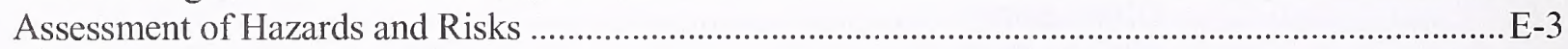

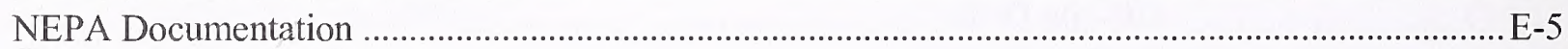

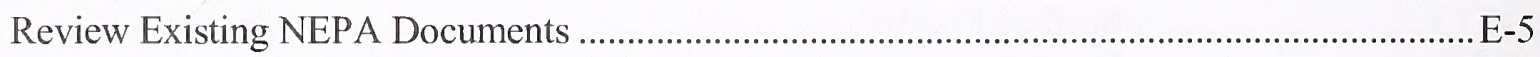

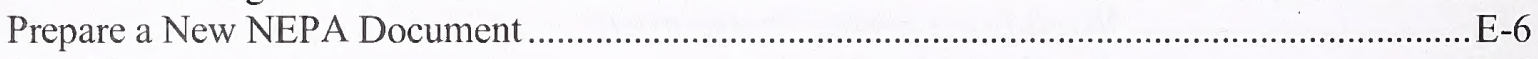

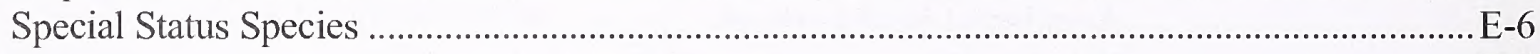

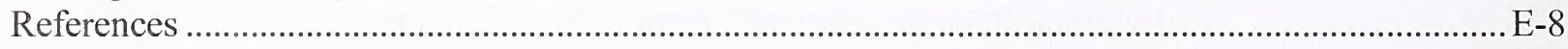

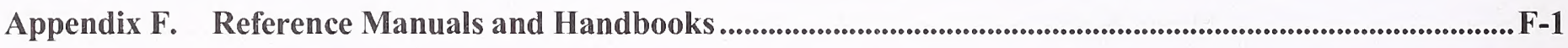

Appendix G. Tribal and Agency Consultation ....................................................................................... G-1

Appendix H. Alaska National Interest Lands Conservation Act (ANILCA) §810 Analysis of Subsistence Impacts....... H-1

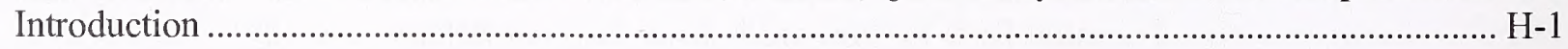

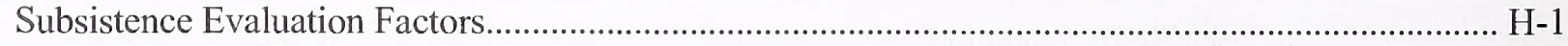

Evaluation of Alternatives and Findings .................................................................................... H-2

ANILCA $\S 810$ (a) Evaluations and Findings for All Alternatives and the Cumulative Case.... H-2

Environmental Justice...........................................................................................................

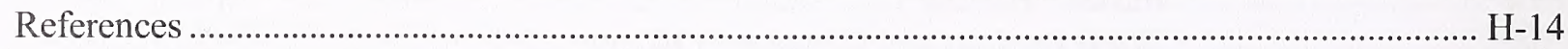

Appendix I. Restore Native Ecosystems Alternative and BLM Policy Analysis............................................... I-1

Restore Native Ecosystems Alternative ........................................................................................... I-1

Bureau of Land Management National Policy Analysis of Restore Native Ecosystems Proposal .... I-23

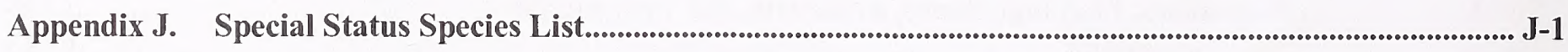




\section{List of Tables}

B-1 Acute Toxicity Categories and Definitions

B-2 Toxicity Categories for Short-term Tests

B-7 Summary of Herbicide Use - Fluridone.

B-10 Summary of Herbicide Risk Categories by Aggregate Risk Index .............................................. B-71

B-11 Occupational Scenarios with Aggregate Risk Indices Below One .....................................................

B-12 Routine Exposure Public Scenarios/Receptors with Aggregate Risk Indices Below One ...................B-77

B-13 Accidental Exposure Public Scenarios with Aggregate Risk Indices Below One ...............................B-78

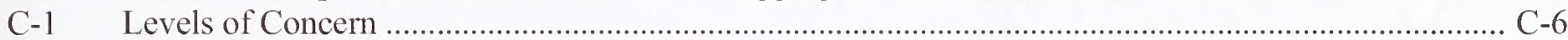

C-2 Herbicide Application Methods and Usage Statistics ..............................................................

C-3 Surrogate Species Used in Quantitative ERA Evaluations ................................................................. 11

C-4 Vertebrate Surrogate Species Evaluated by Life History ................................................................

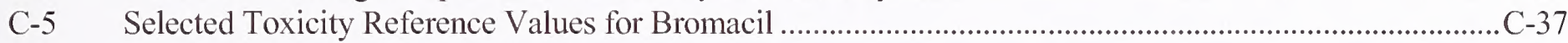

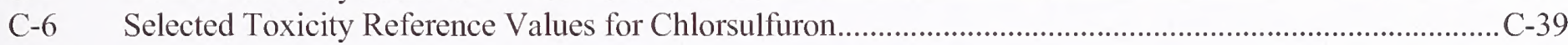

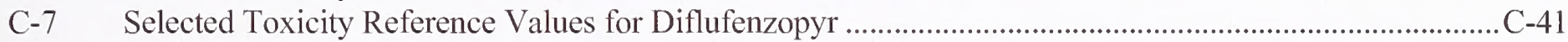

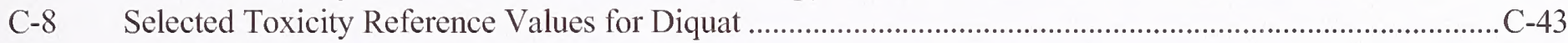

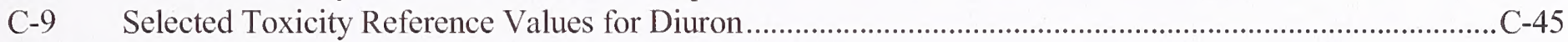

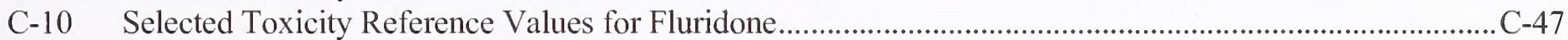

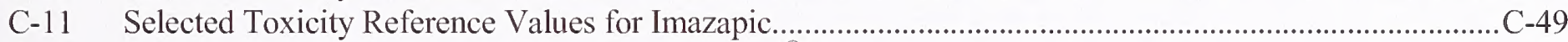

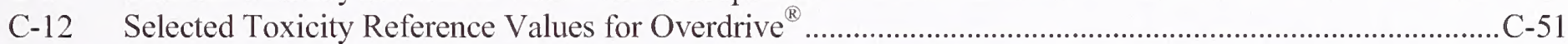

C-13 Selected Toxicity Reference Values for Sulfometuron Methyl …......................................................... -53

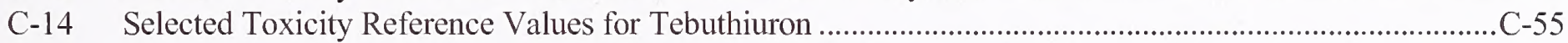

C-15 Risk Levels Used to Describe Typical Herbicide Effects According to Exposure Scenario and

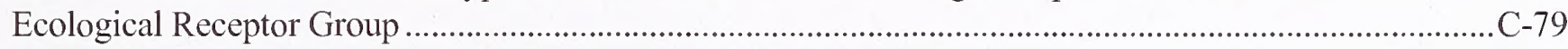

C-16 Buffer Distances (feet) to Minimize Risk from Off-site Drift of Herbicides .............................................89

D-1 Selected Toxicity Values for Polyoxyetheyleneamine .....................................................................

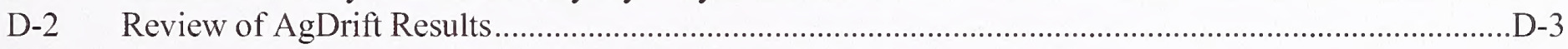

D-3 Polyoxyethyleneamine (POEA) Risk Quotients (RQs) for Aquatic Exposure .....................................D-4

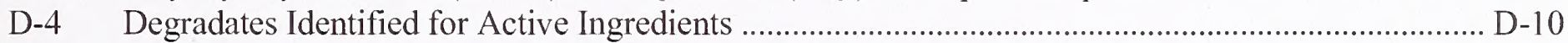

D-5 Listings of Endocrine Disrupting Potential of BLM Herbicides ................................................... D-30

I-1 Bureau of Land Management Policy Analysis of Restore Native Ecosystems Proposal...................... I-24

\section{List of Figures}

C-1 Conceptual Model for Terrestrial Herbicides.

C-2 Conceptual Model for Aquatic Herbicides.

D-1a Aquatic Toxicity - 2,4-D Toxicity Reference Values and Degradate Toxicity Data.............................D-21

D-1b Aquatic Toxicity - 2,4-D Toxicity Reference Values and Degradate Toxicity Data.............................D-22

D-2 Aquatic Toxicity - Diquat Toxicity Reference Values and Degradate Toxicity Data ................................D-23

D-3a Aquatic Toxicity - Diuron Toxicity Reference Values and Degradate Toxicity Data.................................D-24

D-3b Aquatic Toxicity - Diuron Toxicity Reference Values and Degradate Toxicity Data...............................D-25

D-4 Aquatic Toxicity - Fluridone Toxicity Reference Values and Degradate Toxicity Data ...........................D-26

D-5 Aquatic Toxicity - Imazapyr Toxicity Reference Values and Degradate Toxicity Data.............................D-27

D-6 Aquatic Toxicity - Metsulfuron Methyl Toxicity Reference Values and Degradate Toxicity Data ............D-28

D-7 Aquatic Toxicity - Triclopyr Toxicity Reference Values and Degradate Toxicity Data..............................D-29

E-1 New Herbicide Evaluation and Approval Process ........................................................ 


\section{VOLUME 3}

Response to Comments

III-1 
CHAPTER 1

INTRODUCTION 



\section{TABLE OF CONTENTS}

Introduction......

Organization of the Vegetation Treatments Assessments.

Page

Proposed Action..

$.1-1$

$1-2$

$1-3$

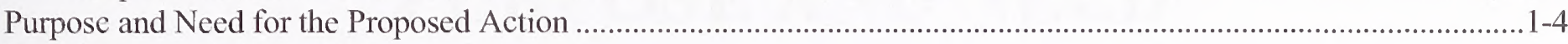

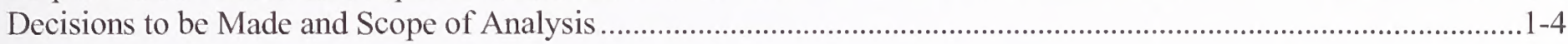

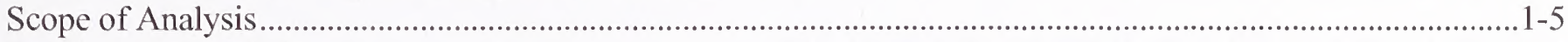

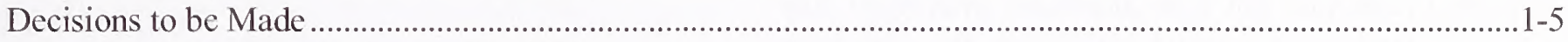

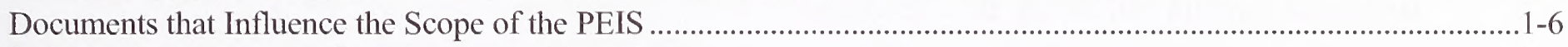

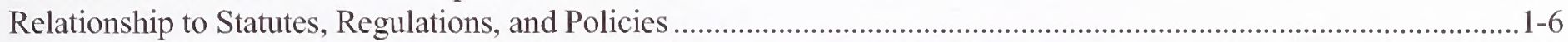

Federal Laws, Regulations, and Policies that Influence Vegetation Treatments ...............................................1-6

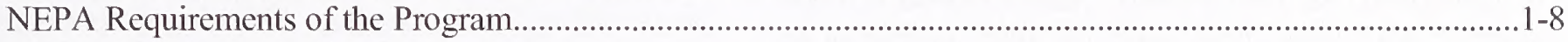

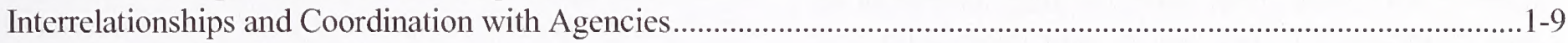

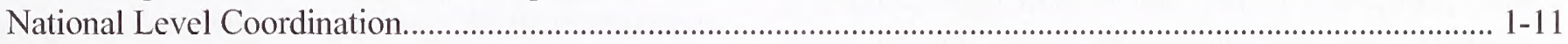

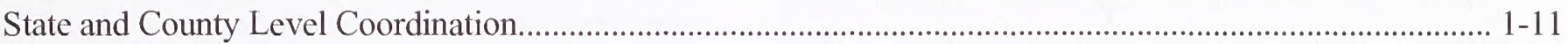

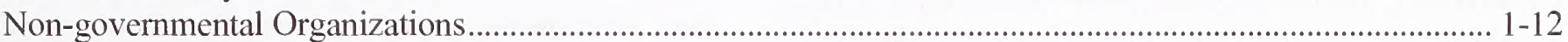

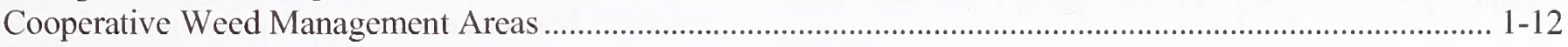

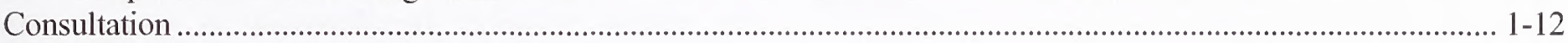

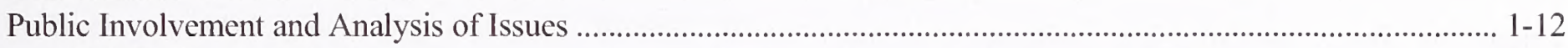

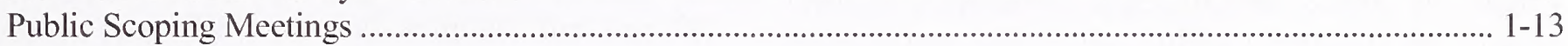

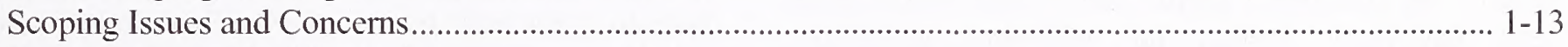

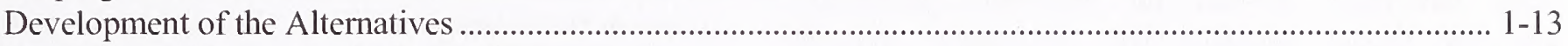

Issues Not Addressed in the Draft PEIS .............................................................................................. 1-13

Public Review and Comment on the Draft Programmatic EIS, ER, and BA.................................................. 1-14

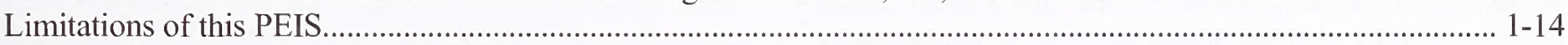

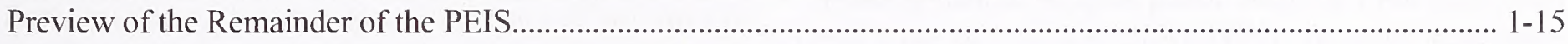

\section{List of Tables}

1-1 Key Issues (and Number of Comments) Identified During Scoping and Location Where Issues Are Addressed in the PEIS and PER

\section{List of Figures}

1-1 Relationship of the PEIS to BLM Field Offices.

1-2 How this Programmatic EIS is Organized....

\section{List of Maps}

1-1 Public Lands Administered by the Bureau of Land Management. 



\section{CHAPTER 1}

\section{PROPOSED ACTION AND PURPOSE AND NEED}

\section{Introduction}

The Bureau of Land Management (BLM), an agency of the U.S. Department of the Interior (USDI), administers vegetation on nearly 261 million acres (public lands; treatment area) in 17 states in the western U.S., including Alaska (Map 1-1). These lands encompass approximately 1 out of every 5 acres from the Rocky Mountains to the Pacific Ocean. Management and control of vegetation for resource and habitat enhancement is accomplished using a variety of treatment methods, including, but not limited to: herbicides, prescribed fire and wildland fire use for resource benefit (collectively termed "fire use"), manual and mechanical methods, and biological controls such as insects, pathogens, fish, and domestic grazing animals.

In recent years, the severity and intensity of wildfires in the West has increased dramatically from levels in the 1970s and 1980s. Although the recent increase in wildfires is directly related to drought conditions throughout the western U.S., it is also influenced by changes in the vegetation on public lands that have occurred during the past 50 years and have resulted in increases in hazardous flammable fuels. Hazardous fuels include living and dead and decaying vegetation that form a special threat of ignition and resistance to control. As the population has increased in the western U.S., the loss of life and property has also increased as more people live in close proximity to public lands in areas now referred to as the wildland urban interface (WUI).

Much of the change in vegetation and increase in hazardous fuels on public lands can be attributed to fire exclusion policies over the past 100 years. Contributors to this change include natural influences, such as intermittent and long-term drought over the past 40 years. They also include anthropogenic influences, such as alteration of vegetation and habitat at the local and landscape levels through authorized uses on public lands (e.g., livestock grazing and timber management), full fire suppression policies to protect infrastructure and vegetative resources, and the increased spread of noxious weed species and invasive vegetation.

Some noxious weeds and other invasive vegetation, such as downy brome ${ }^{1}$ (also known as cheatgrass), act as hazardous fuels in upland landscapes. Downy brome is a self-perpetuating winter annual that spreads easily across upland landscapes altered by fire, through a prolific seed source. Wind and soil erosion transport the seed over wide areas and into previously undisturbed habitats.

Invasive vegetation and noxious weeds are highly competitive and can often out-compete native vegetation, especially on recently disturbed sites. Invasive vegetation and noxious weeds are the dominant vegetation on an estimated 35 million acres of public lands (USDI BLM 2000a). The estimated rate of weed spread on western public lands in 1996 was 2,300 acres per day (USDI BLM 1996). Invasive vegetation and noxious weeds degrade or reduce soil productivity, water quality and quantity, native plant communities, wildlife habitat, wilderness values, recreational opportunities, and livestock forage, and are detrimental to the agriculture and commerce of the U.S. and to public health (National Academy of Sciences 1968, USDI BLM 2000b). Weed infestations can become permanent if left untreated.

In response to the threats of wildfire and invasive vegetation and noxious weeds, the President and Congress have directed the USDI and BLM, through implementation of the National Fire Plan (USDI and U.S. Department of Agriculture [USDA] Forest Service 2001a), and the Healthy Forests Restoration Act of 2003, to take more aggressive actions to reduce catastrophic wildfire risk on public lands. The actions would be taken to protect life and property, and to manage vegetation in a manner that provides for longterm economic sustainability of local communities,

${ }^{1}$ Common and scientific names of plants and animals given in this PEIS are provided in Appendix A. 
improved habitat and vegetation conditions for fish and wildlife, and other public land uses.

As a result of these actions, the amount of hazardous fuels reduction and other vegetation management work conducted by the BLM are expected to increase from current levels to about 6 million acres annually; about 932,000 acres, or $16 \%$ of acres treated, would involve the use of herbicides. The BLM last assessed its use of vegetation treatment methods during the late 1980s and early 1990s, by preparing Environmental Impact Statements (EISs) and Record of Decisions (RODs) that covered vegetation treatment activities in 14 western states in the continental U.S. (all states shown on Map 1-1, except Alaska, Nebraska, and Texas; USDI BLM 1985; 1987a, b; 1988a, b; 1989; 1991a, b; 1992a). The previous EISs primarily focused on vegetation control of competing and unwanted vegetation for resource enhancement (forestry and rangelands), noxious and invasive weed control related to surface use activities (oil and gas, rights-of-way [ROW]), and reduction of hazardous fuels to protect resources at risk from wildfire damage. These EISs evaluated the environmental impacts associated with vegetation control and modification on approximately 500,000 acres of public lands a year in the western U.S. The EISs also evaluated the human health and non-target species risks of using 22 herbicide active ingredients on these public lands.

The impacts of the proposed increased level of vegetation treatments related to the use of herbicides are likely to be greater in magnitude than the impacts assessed in earlier vegetation treatment assessments prepared by the BLM for the western states. In addition, the BLM has identified several new herbicides that it would like to use that are more effective in treating certain types of vegetation than currently approved herbicides. Thus, the BLM has determined that the potential for increased use of herbicides, and approval for use of additional herbicides on public lands, requires further assessment under the National Environmental Policy Act (NEPA).

\section{Organization of the Vegetation Treatments Assessments}

The BLM's assessment of vegetation treatment activities on public lands consists of two interrelated parts this Vegetation Treatments Using Herbicides on Bureau of Land Management Lands in 17 Western States Programmatic EIS (PEIS) addressing the BLM's use of herbicides, and a Vegetation Treatments on Bureau of Land Management Lands in 17 Western

\section{Terminology}

Active ingredient (a.i.) is the chemical or biological component that kills or controls the target pest.

Fire use a term not used in federal fire policy. It is used in the context of the PEIS/PER to refer to prescribed fire or wildland fire use to meet resource objectives.

Hazardous fuels include living and dead and decaying vegetation that form a special threat of ignition and resistance to control.

Herbicide is a chemical pesticide used to treat vegetation.

Invasive plants are plants that are not part of (if exotic), or are a minor component of (if native), the original plant community or communities that have the potential to become a dominant or co-dominant species on the site if their future establishment and growth are not actively controlled by management interventions, or are classified as exotic or noxious plants under state or federal law. Species that become dominant for only one to several years (e.g., short-term response to drought or wildfire) are not invasive plants.

Native species historically occurred or currently occur in a particular ecosystem and were not introduced.

Noxious weeds are designated by federal or state law as generally possessing one or more of the following characteristics: aggressive and difficult to manage; parasitic; a carrier or host of serious insects or disease; or non-native, new, or not common to the U.S.

Prescribed fires are any fire ignited by management actions to meet specific objectives. A written, approved prescribed fire plan must exist, and NEPA requirements (where applicable) must be met, prior to ignition.

Undesirable plants are species classified as undesirable, noxious, harmful, exotic, injurious, or poisonous under state or federal law, but not including species listed as endangered by the Endangered Species Act (ESA), or species indigenous to the planning area.

Weeds are plants that interfere with management objectives for a given area at a given point in time.

Wildfires are unplanned, unwanted wildland fires including unauthorized human-caused fires, escaped wildland fire use events, escaped prescribed fire projects, and all other wildland fires where the objective is to put the fire out.

Wildland fires are any non-structure fires that occur in the wildland. Three distinct types of wildland fire have been defined and include wildfire, wildland fire use, and prescribed fire.

Wildland fire use fires are the application of the appropriate management response to naturally-ignited wildland fires to accomplish specific resource management objectives in predefined designated areas outlined in Fire Management Plans.

Wildland urban interface (WUI) is an area where structures and other human development intermingle with undeveloped wildlands or vegetative fuels. 
States Programmatic Environmental Report (PER; USDI BLM 2007a) describing the environmental effects of using non-herbicide vegetation treatment methods on public lands. This organization was selected because the primary issue of controversy identified through scoping, and which required NEPA revicw, was the BLM's continuing and proposed increase in the use of herbicides in vegetation treatment programs needed to implement the National Fire Plan and related initiatives. The use of herbicides has been affirmed as a central issue for analysis in all past EISs considered in this document.

The use of the other non-herbicide techniques in an integrated pest management approach has also been affirmed in all previous EIS Records of Decision, and the BLM is not proposing to make any decisions relative to the use of non-herbicide vegetation treatment methods.

Although more acres are proposed for treatment under all methods than were identified in previous EISs, the BLM has determined that additional analysis of treating these acres under non-herbicide methods in the PEIS is unnecessary. Congress and the Administration made the decision for federal agencies to treat more acres to reduce the threat of catastrophic fire. The PEIS and PER broadly estimate the acres that could be potentially treated under each method for analysis purposes in the PEIS. The acre totals used in this programmatic analysis are not site-specific as to locations or method(s) used. As identified below in Chapter 2, current land use plans guide the level of treatment activity necessary to meet broad goals and objectives for vegetation. It is anticipated that acres identified for treatments in land use plans and step down activity level plans would be modified in the future as they are revised or amended to reflect the increase in activity mandated by Congress, and that those plans will provide the necessary NEPA analysis to support increased acres of treatment.

Treatment of vegetation is not a static disturbance that accumulates over time. Vegetation treatments are dynamic and typically show results within the first two growing seasons. Once vegetation objectives are met, the projects are maintained over time, resulting in viable and resilient vegetation communities over the long term. As more acres are treated, more acres of vegetation meet management objectives as outlined in local land use plans. Projects implemented over the last ten to twenty years typically have met their objectives and become part of the baseline for analysis of new projects. Because of this dynamic continuum of treatment, revegetation, monitoring, and maintenance, the BLM does not anticipate there would be any different or significant impacts identified beyond what has been analyzed in previous EISs.

This PEIS analyzes the effects of herbicide use on humans, plants, and animals and other environmental and social resources associated with public lands. This analysis will provide the basis for a programmatic Endangered Species Act (ESA) Section 7 consultation with the U.S. Fish and Wildlife Service (USFWS) and National Oceanic and Atmospheric Administration National Marine Fisheries Service (NMFS) on herbicide use, and the potential impacts of herbicide use on plant and animal species of concern.

The PER discloses the general impacts on the environment of using non-herbicide treatment methods, including fire use, and mechanical, manual and biological control methods, to treat hazardous fuels, invasive species, and other unwanted or competing vegetation. The PEIS provides an updated analysis of impacts (direct, indirect, and cumulative) to public land environmental and socioeconomic resources from proposed vegetation treatment activities utilizing herbicides. The PER is linked to the PEIS in the cumulative impact analysis of the PEIS, where all methods of treatment, including the use of herbicides, are assessed.

\section{Proposed Action}

To maintain and improve the effectiveness of its vegetation management practices, the BLM proposes to:

- Determine which herbicide active ingredients are available for use on public lands in the western U.S., including Alaska, to improve the agency's ability to control hazardous fuels and unwanted vegetation. In addition to the herbicides currently approved for use, additional active ingredients are being considered for use by the BLM in order to address emerging weed problems associated with public lands, such as downy brome and invasive aquatic species; and

- In consultation with the U.S. Environmental Protection Agency (USEPA), USFWS, and NMFS, develop a state-of-the-science risk assessment methodology. This methodology will serve as the initial standard for assessing human health and ecological risk for herbicides that may become available for use in the future. 
Actions related to the use of herbicides are addressed in this PEIS. Actions related to the use of other treatment methods are addressed in the PER.

In order to ensure that the agency fulfills its responsibility for protection of the public, Native American and Alaska Native subsistence practices, public land workers, and federally-listed species, species proposed for listing, and BLM sensitive species (collectively referred to as "special status" species), a risk assessment was conducted (see appendices B and C). The assessment consisted of a comprehensive literature search, and in some cases new toxicological analyses, for 1) active ingredients currently in use to determine if there are any new human health and ecological health risks that have been identified since the chemicals were last assessed (1988-1992); and 2) active ingredients proposed for use by the BLM. This risk assessment was used in the assessment of the human health and environmental effects of the various alternatives. An appendix was prepared in response to public comments on the risk assessments prepared for the draft PEIS (Appendix D). Specifically, this appendix addresses three concerns raised by the public about the human health and ecological risk assessments:

- Some surfactants may be more toxic to aquatic receptors than the active ingredient in the formulation. Using polyoxytheyleneamine (POEA) as an example, what are the potential impacts of POEA in different formulations of herbicides containing glyphosate?

- The risk assessments only address the potential impacts of the active ingredients, what about the toxicity of degradates?

- The risk assessments did not identify endocrine disruption as a toxic endpoint. Are any of the herbicides considered to be endocrine disrupting chemicals?

In addition, the BLM developed a risk assessment methodology to be used for analyses of herbicides proposed for use in the future (Appendix E). This methodology is based upon the methodology used for the risk assessments for this PEIS.

\section{Purpose and Need for the Proposed Action}

The purposes of the proposed action are to provide BLM personnel with the herbicides available for vegetation treatment on public lands and to describe the conditions and limitations that apply to their use. The need for the proposed action is to reduce the risk of catastrophic wildfires by reducing hazardous fuels, restoring fire-damaged lands, and improving ecosystem health by 1) controlling weeds and invasive species, and 2) manipulating vegetation to benefit fish and wildlife habitat, improve riparian and wetlands areas, and improve water quality in priority watersheds.

Additional benefits accruing from implementation of the proposed action directly relate to restoration of fish and wildlife habitat and improvement of forest and ecological condition, which would meet BLM and USDI objectives set forth in the Healthy Forests Restoration Act of 2003 and BLM Handbook H-4180-1 (Rangeland Health Standards) to improve the health of the nation's forests and rangelands.

\section{Decisions to be Made and Scope of Analysis}

This PEIS analyzes the effects of using herbicides for treating vegetation on public lands in the western U.S., including Alaska. These lands include Oregon and California Land Grant lands, Coos Bay Wagon Road lands, and lands administered by the BLM through its National Landscape Conservation System (NLCS), such as Wilderness Study Areas (WSAs), designated Wilderness Areas, National Monuments, National Conservation Areas, National Recreation Areas, and areas of critical environmental concern.

Decisions expected to be made through this PEIS process include:

- Which USEPA-registered herbicides will be available for use by the BLM and under what circumstances?

- Which vegetation management practices could be used with applications of herbicides and under what circumstances?

This PEIS makes broad assumptions on the numbers of acres to be treated annually by herbicides by each state or in aggregate on a national scale to assist with the impacts analysis. Because of the broad nature of this PEIS and the uncertainty associated with timing and location of treatments on a national scale, specific levels of acres to be treated by any method are appropriately assessed at the regional, state, or local level. For meaningful NEPA analysis, the BLM assesses the 
overall acres to be treated by each resource program in its land use plan (LUP) EISs (see description of BLM resource programs in Chapter 2), thus these decisions would be made at a later time and at a more site-specific level.

\section{Scope of Analysis}

The focus of this PEIS is to provide an analysis of the expected increased use of herbicides related to implementing mandates to reduce hazardous fuels and manage and control vegetation affecting other resources. This PEIS does not, however, evaluate vegetation treatment activities involving herbicides that are not directly related to the need to reduce hazardous fuels, or to modify the vegetation community to improve rangeland and/or forestland health.

Thus, this PEIS does not evaluate vegetation management that is primarily focused on commercial timber or other forest product enhancement or use activities that are not related to improving forest or rangeland health or work authorized under the Healthy Forests Restoration Act of 2003.

This PEIS will not evaluate policies and programs associated with land use activities authorized by the BLM, such as livestock use, off-highway vehicle (OHV) use, and timber harvesting, and will not make land use allocations nor amend approved land use plans (Federal Register 2002). Human-related activities and natural processes have inherent risks and threats to the health of the land, which can lead to the decline of plant communities and ecosystems. Although this PEIS refers to activities consistent with the authorities under the Federal Land Policy and Management Act (FLPMA) and other statutes that may contribute, in some cases, to land and resource degradation (e.g., livestock grazing, $\mathrm{OHV}$ use, recreation), its focus is on proactive vegetation treatments to maintain and restore ecological conditions. The focus of the PEIS is not to restrict, limit, or eliminate FLPMA-authorized activities as a means to restore land health. These types of management actions are defined and considered under land use planning regulations (43 Code of Federal Regulations [CFR] $1610)$ and are outside the scope of this PEIS.

Commercial timber activities conducted with the primary purpose of providing a sustained yield of timber volume to commercial industries are not included in this PEIS or the associated PER. Rather, they represent a manner of vegetation harvest (i.e., the species [product] is removed and replanted for future harvest). Commercial timber allocations and sustainable harvest were previously analyzed in BLM LUP EISs for the field offices with timber programs.

Although this PEIS addresses herbicide use in relation to vegetation treatments, it does not address vegetation treatments exclusively designed to increase forage production or the effects of livestock grazing on vegetation. The effects on vegetation that result from livestock forage use on public lands were analyzed in previous EISs, both programmatically at the national level (USDI BLM and USDA Forest Service 1994) and at the local land use planning level, in either LUP EISs or as individual EISs or Environmental Assessments (EAs) at the field office level, as well as at the allotment-specific level.

This PEIS does not address abandoned mine land reclamation, or energy production. Abandoned mine land reclamation is a form of site stabilization and remediation that does not necessarily involve vegetation treatment activities, although in some cases vegetation treatments may be associated with site stabilization. The scope of analysis for the overall use of herbicides, and other methods of control outlined in the PER associated with this PEIS, would sufficiently cover their use in these types of activities.

This PEIS will not analyze fire suppression operations, as they do not constitute vegetation treatment actions. This PEIS will address soil stabilization only where specifically related to the vegetation treatment activities. Soil stabilization effects are related to post-fire emergency stabilization (activities undertaken within 1 year of the fire control date) and rehabilitation (treatments applied up to 3 years after the fire control date).

This PEIS addresses the use of chemical herbicides in general. Herbicides are also commonly used to control vegetation by those authorized to use public lands for ROW, lease holdings, oil and gas facilities, and other mineral developments. In many cases, the control of vegetation is stipulated in the ROW, lease, or authorizing permit. These permits and authorizations are issued in conjunction with a site-specific NEPA compliance document (EA or EIS), which assess the impacts of the control method, and identifies mitigation to reduce development impacts on the environment.

\section{Decisions to be Made}

At least 30 days after the USEPA publishes the Notice of Availability (NOA) of the final PEIS, the BLM 
decision-maker will evaluate public comment on the draft and final PEIS and prepare a ROD. The decision may be to select one of the alternatives in its entirety, or to combine features from several alternatives that fall within the range of alternatives analyzed in the PEIS. The ROD will address significant impacts, alternatives, environmental preferences, and relevant economic and technical considerations.

\section{Documents that Influence the Scope of the PEIS}

Much of the scope of this PEIS is based on several EISs that were prepared from 1985 through 1992 to evaluate the use of herbicides for vegetation treatment activities on public lands. These EISs include: Northwest Area Noxious Weed Control Program EIS (USDI BLM 1985), Supplement to the Northwest Area Noxious Weed Control Program (USDI BLM 1987b), California Vegetation Management Final EIS (USDI BLM 1988a), Final EIS Vegetation Treatment on BLM Lands in Thirteen Western States (USDI BLM 1991a), and Final Record of Decision Western Oregon ProgramManagement of Competing Vegetation (USDI BLM 1992a).

These documents identify vegetation treatment activities involving the use of herbicides in 14 western states and evaluate the risks of using 22 herbicide active ingredients. Where appropriate, information in these documents that is relevant to analysis of the current proposal is cited and ineorporated by reference.

Other documents and policies that influence the scope of this PEIS include: 1) National Fire Plan (USDI and USDA 2001a); 2) Healthy Forests Initiative of 2002 and Healthy Forests Restoration Act of 2003 (Public Law 108-148); 3 ) Chapter 3 (Interagency Burned Area Emergency Stabilization and Rehabilitation) in BLM Manual 620 (Wildland Fire Management; USDI 2004); 4) A Collaborative Approach for Reducing Wildland Fire Risks to Communities and the Environment 10Year Comprehensive Strategy Implementation Plan (USDI and USDA 2006a); 5) Protecting People and Sustaining Resources in Fire Adapted Ecosystems: A Cohesive Strategy (USDA and USDI 2006b); 6) Draft Interagency Burned Area Emergency Response Guidebook (USDA and USDI 2006c); 7) Interagency Burned Area Rehabilitation Guidebook (USDA and USDI 2006d); and 8) Draft Burned Area Emergency Stabilization and Rehabilitation Handbook (H-1742-1; USDI BLM 2006a). These documents provide policy and guidance for hazardous fuels reduction and land restoration activities to reduce the risk of wildfires and restore fire-adapted ecosystems, and to rehabilitate and restore lands damaged by wildfires. The Meeting the Invasive Species Challenge Management Plan (National Invasive Species Council 2001) and Partners Against Weeds - An Action Plan for the BLM (USDI BLM 1996) identify appropriate actions to control weeds on public lands.

Numerous other BLM manuals and handbooks were also consulted when developing the PEIS. These are listed in Appendix F.

\section{Relationship to Statutes, Regulations, and Policies}

\section{Federal Laws, Regulations, and Policies that Influence Vegetation Treatments}

Several federal laws, regulations, and policies guide BLM management activities on public lands. The Federal Land Policy and Management Act of 1976 (FLPMA) directs the BLM to manage public lands "in a manner that will protect the quality of scientific, scenic, historic, ecological, environmental, air and atmospheric, water resources and archeological values" and to develop resource management plans (RMPs) consistent with those of state and local governments to the extent that BLM programs also comply with federal laws and regulations. The Taylor Grazing Act of 1934 introduced federal protection and management of public lands by regulating grazing on public lands. The Oregon and California Grant Lands Act of 1937 provides for the management of the revested Oregon and California and reconveyed Coos Bay Wagon Road grant lands for permanent forest production under the principle of sustained yield and for leasing of lands for grazing.

Several acts provide for management and control of invasive vegetation. Two weed control acts; the Carlson-Foley Act of 1968 and the Plant Protection Act of 2000 (Public Law 106-224; includes management of undesirable plants on federal lands) authorize the BLM to manage noxious weeds and to coordinate with other federal and state agencies in activities to eradicate, suppress, control, prevent, or retard the spread of any noxious weeds on federal lands. The Federal Noxious Weed Act of 1974 established and funded an undesirable plant management program, implemented cooperative agreements with state agencies, and established integrated management 
systems to control undesirable plant species. The Noxious Weed Control Act of 2004 established a program to provide assistance through states to eligible weed management entities to control or eradicate harmful, nonnative weeds on public and private lands. The Public Rangelands Improvement Act of 1978 requires the BLM to manage, maintain, and improve the condition of the public rangelands so that they become as productive as feasible.

The BLM must comply with numerous federal laws that govern activities on public lands. The Clean Air Act, as revised in 1990, would primarily govern prescribed fire smoke emissions, and requires the USEPA and states to carry out programs to assure attainment of the National Ambient Air Quality Standards (NAAQS). The Safe Drinking Water Act is designed to protect the quality of public drinking water and its sources. The Wilderness Act of 1974 provides management directions to protect wilderness values and guides activities and permitted uses within these areas.

The Clean Water Act regulates discharges into waters of the United States, including wetlands. As authorized by the Clean Water Act, the National Pollutant Discharge Elimination System (NPDES) permit program controls water pollution by regulating point sources that discharge pollutants into waters of the United States. Based on a recent ruling by the USEPA (2006), an NPDES permit is not required for applications of herbicides directly to water in order to control aquatic vegetation, or for application of herbicides that are present over or near water, where a portion of the herbicide will unavoidably be deposited to the water in order to target the pest vegetation. The ruling does not apply to terrestrial herbicide applications that drift over and into waters of the U.S.; issues related to these applications are under review by the USEPA.

USEPA regulates pesticides under two major federal statutes. The Federal Insecticide, Fungicide and Rodenticide Act (FIFRA) establishes procedures for the registration, classification, and regulation of all pesticides. Before any pesticide may be sold legally, the USEPA must register it. The USEPA may classify a pesticide for general use if it determines that the pesticide is not likely to cause unreasonable adverse effects to applicators, or the environment, or for restricted use if the pesticide must be applied by a certified applicator and in accordance with other restrictions. All the herbicides evaluated in this PEIS, except diflufenzopyr as a stand-alone active ingredient, are registered with the USEPA. Diflufenzopyr is approved as a formulation with dicamba and is labeled as Distinct, but could not bc used as a stand-alone active ingredient by the BLM until it is registered with the USEPA. All applicators that apply them on public lands (i.e., certified applicators or those directly supervised by a certified applicator) must comply with the application rates, uses, and handling instructions on the herbicide label, and where more restrictive, the rates, uses, and handling instructions developed by the BLM. Under the Federal Food, Drug, and Cosmetic Act, the USEPA establishes tolerances (maximum legally permissible levels) for pesticide residues in food.

The Food Quality Protection Act of 1996 changed the way the USEPA sets residue limits (tolerances) for pesticides on foods under the Federal Food, Drug, and Cosmetic Act, and the way the USEPA reviews and approves pesticides under FIFRA. Specifically, the Act mandated a single, health-based standard for all pesticides in all foods; provided special protections for infants and children; expedited approval of safer pesticides; created incentives for the development and maintenance of effective crop protection tools for American farmers; and required periodic reevaluation of pesticide registrations and tolerances to ensure that the scientific data supporting pesticide registrations will remain up to date in the future.

The Resource Conservation and Recovery Act (RCRA) regulates the disposal of toxic wastes, including the disposal of unused herbicides, and provides authority for toxic waste cleanup actions when there is a known operator. The Comprehensive Environmental Response, Compensation and Liability Act (CERCLA) regulates how to clean up spills of hazardous materials and when to notify agencies in case of spills.

Several laws pertain to the protection of plants and animals and their habitats. The Migratory Bird Conservation Act of 1929, as amended, makes it unlawful to directly, or indirectly, harm migratory birds. If the USFWS determines that migratory birds could be harmed by BLM vegetation treatment actions, the two agencies would develop a site-specific assessment and mitigation to prevent harm to these birds. The Endangered Species Act (ESA) of 1973 provides for conserving endangered and threatened species of plants and animals. The ESA also requires that federal agencies consult with the USFWS and NMFS to ensure that any actions that they authorize, fund, or carry out are not likely to jeopardize the continued survival of a listed species or result in the adverse modification or destruction of its critical habitat. The Wild FreeRoaming Horse and Burro Act of 1971, as amended by the Public Rangelands Improvement Act of 1978 
provides for the management, protection, and control of wild horses and burros on public lands and authorizes the "adoption" of wild horses and burros by private individuals. The Fish and Wildlife Conservation Act of 1980 encourages federal agencies to conserve and promote the conservation of non-game fish and wildlife species and their habitats. The Sikes Act of 1974 authorizes the USDI to plan, develop, maintain, and coordinate programs with state agencies for the conservation and rehabilitation of wildlife, fish, and game on public lands.

Laws and acts that pertain to the protection of historic and cultural resources and the rights of Native American tribes and Alaska Native groups include the Historic Sites Act of 1935, which provides for the preservation of historic American sites, buildings, objects, and antiquities of national significance. The National Historic Preservation Act (NHPA) of 1966 requires federal agencies to take into account the potential affects of their actions on properties that are listed or are eligible for listing on the National Register of Historic Places (NRHP), and to consult with State Historic Preservation Officers (SHPOs), Indian tribes, and local governments regarding the effects of federal actions on historic properties. The Archeological Resources Protection Act of 1979 prohibits the excavation, removal, damage, or other alteration or defacement of archaeological resources on federal or Indian lands without a permit. The American Indian Religious Freedom Act of 1978 requires federal land managers to include consultation with traditional Native American or Alaska Native religious leaders in their management plans. The Native American Graves Protection and Repatriation Act of 1990 recognizes the property rights of Native Americans and Alaska Natives in certain cultural items, including Native American and Alaska Native human remains and sacred objects. Section 810 of the Alaska National Interest Lands Conservation Act (ANILCA) addresses the effects of proposed activities on Alaska Native subsistence uses.

This PEIS follows the guidelines in several Executive orders (EOs). Executive Order 11990, Protection of Wetlands, ensures that federal agencies minimize the destruction, loss, or degradation of wetlands, and enhance and preserve the natural and beneficial values of wetlands, when carrying out actions on federal lands. Executive Order 12898, Environmental Justice, requires that federal agencies address the environmental justice of their actions on minority populations and on low-income populations. Executive Order 13045, Protection of Children from Environmental Health
Risks and Safety Risks, ensures that federal agencies identify and assess the environmental health and safety risks that may disproportionately affect children. Executive Order 13084, Consultation and Coordination with Indian Tribal Governments directs federal agencies to respect tribal self-government and sovereignty, tribal rights, and tribal responsibilities whenever they formulate policies "significantly or uniquely affect Indian tribal governments." Executive Order 13112, Invasive Species, directs federal agencies to prevent the introduction of invasive species and provide for their control, and to minimize the economic, ecological, and human health impacts that invasive species cause. Executive Order 13186, Responsibilities of Federal Agencies to Protect Migratory Birds, requires that federal agencies that have, or are likely to have, a measurable negative effect on migratory bird populations develop a Memorandum of Understanding (MOU) with the USFWS that shall promote the conservation of migratory bird populations.

\section{NEPA Requirements of the Program}

Federal agencies are required to prepare an EIS under NEPA when the proposed action is likely to have a significant impact on the quality of the human environment (42 U.S.C. [United States Code] 4321 et seq.; USDI BLM 1988c). An EIS is intended to provide decision-makers and the public with a complete and objective evaluation of significant environmental impacts, beneficial and adverse, resulting from the proposed action and all reasonable alternatives.

The intent of this PEIS is to comply with NEPA by assessing the program impacts of using herbicides to treat vegetation on public lands administered by the BLM. Additional guidance for NEPA compliance and for assessing impacts is provided in the Council on Environmental Quality (CEQ) Regulations for Implementing the Procedural Provisions of NEPA (40 Code of Federal Regulations [CFR] Parts 1500-1508), and the BLM National Environmental Policy. Act Handbook H-1790-1 (USDI BLM 1988b).

To the extent practicable, existing environmental analyses were used in analyzing impacts associated with the proposed action and alternatives, including information contained in documents listed in a previous section, Documents that Influence the Scope of the PEIS.

This PEIS provides a broad, comprehensive background source of information on which any necessary 
subsequent environmental analyses can be tiered. In general, the NEPA process may be done at multiple scales depending on the scope of the proposal, as shown in Figure 1-1. The broadest level, which this PEIS represents, is a national-level programmatic study. This level of study contains broad regional descriptions of resources, provides a broad environmental impact analysis, including cumulative impacts, focuses on general policies, and provides Bureau-wide decisions on herbicide use and other available tools for vegetation management. Additionally, it provides an umbrella ESA Section 7 consultation for the broad range of activities described in the PEIS.

The next scale of analysis represents a regional level of analysis, and may be prepared for regional or statewide programs. A regional level of analysis would typically focus on methods to be used, options, regional or statewide issues, and provide an ESA Section 7 consultation focused on regional issues. Examples of these types of analyses are found in such documents as the Interior Columbia Basin Ecosystem Management Plan (USDA Forest Service and USDI BLM 1997), and the Northwest Area Noxious Weed Control Program EIS (USDI BLM 1985).

Below the regional scale of analysis, there is the option to prepare a field office level of analysis. This analysis may be prepared for district or field office-wide programs. The analysis is tiered to either or both of the two higher scales of analysis and focuses on impacts of methods and options for a single program, such as a field office invasive and noxious weed program or prescribed fire and wildland fire use program. Local LUPs, such as RMPs and Management Framework Plans (MFPs), guide analysis at this level. Collectively, these LUPs outline the specific resource goals and objectives and use allocations for a specific geographic area. The uses and allocations allowed by the LUP are analyzed in an EIS associated with the development of the LUP. Land use plans are developed to include the proposed action and alternatives that identify specific management strategies to meet particular national, regional, and local goals and objectives. This scale provides ESA Section 7 consultation focused on local issues and species of concern that occur within the field office's administrative jurisdiction.

The local scale provides project level analysis and is prepared for site-specific proposals. The analysis may be tiered to any or all of the above scales of analysis. The analysis focuses on site-specific impacts of implementing a single management proposal as identified through local planning. Examples include, but are not limited to, weed control, prescribed fire, hazardous fuel reduction, and WUI projects. Section 7 consultation under the ESA focuses on the implementing actions.

Tiering allows local offices to prepare more specific environmental documents without duplicating relevant portions of this PEIS. Analyses done by local BLM offices will be prepared in accordance with NEPA guidance and will include public involvement as regulated by the CEQ, as well as follow USDI and BLM manual and handbook guidance and pertinent instruction memoranda.

\section{Interrelationships and Coordination with Agencies}

In its role as manager of nearly 261 million acres in the western U.S., including Alaska, the BLM has developed numerous relationships at the federal, tribal, state, and local levels, as well as with conservation and environmental groups with an interest in resource management, and members of the public that use public lands or are affected by activities on public lands.

As noted previously, several federal agencies administer laws that govern activities on public lands. Federal agencies, including the Department of Defense, the Department of Energy, the National Park Service, the USFWS, the Bureau of Reclamation, the Bureau of Indian Affairs, and the USDA Forest Service, administer lands adjacent to or in close proximity to public lands administered by the BLM, and have vegetation management issues that are similar to the BLM's. Other agencies, such as the Agricultural Research Service, the Animal, Plant, Health Inspection Service, the Natural Resource Conservation Service, and the U.S. Geological Survey Biological Services, play vital roles in coordination with national, tribal, state, county and private interests through their oversight and coordination responsibilities. These agencies and the BLM regularly coordinate on vegetation management and control efforts to benefit all federally-administered lands. Other local coordination includes the sharing of equipment, training, and financial resources, and developing vegetation management plans that cross administrative boundaries. 

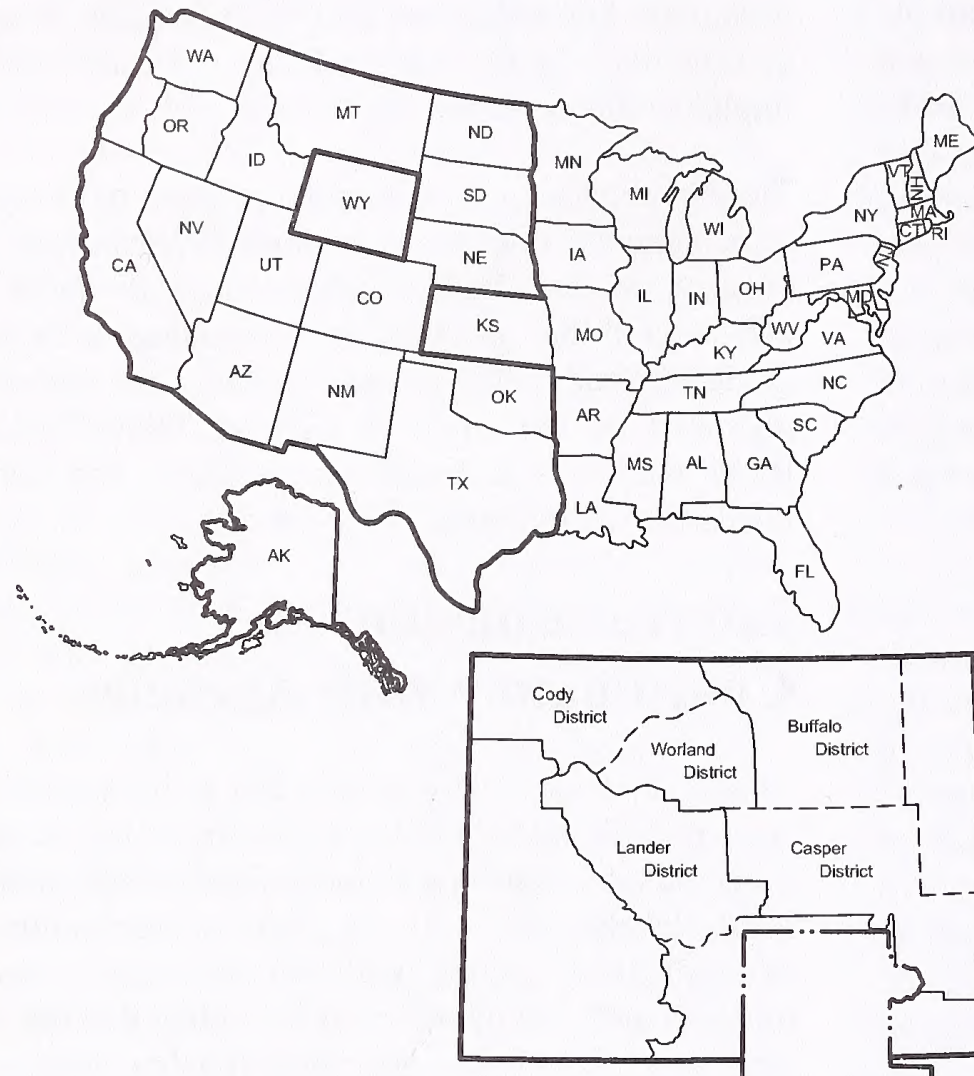

Level 3

Rock Springs District and Resource Areas

District or Resource Area Level of Analysis

Analysis is tiered to either or both above levels. Focuses on impacts of methods and options for specific multi-management proposals, (may become Level 4).

\section{Level 1}

Vegetation Treatments EIS Study Area Regional Level of Analysis:

EIS with broad, regional description of

resources and broad environmental impact analysis. Focuses on general policies.

\section{Level 2}

State of Wyoming

BLM Administrative Offices

Statewide Level of Analysis

Analysis is tiered to level 1 and is prepared

for statewide programs. Focuses on the

impact of methods, options, and individual state issues.

\section{Level 4}

Big Sagebrush Burn Area

Project Level of Analysis

Analysis is tiered to any or all above levels.

Focuses on site-specific impacts of implementing a single management proposal.

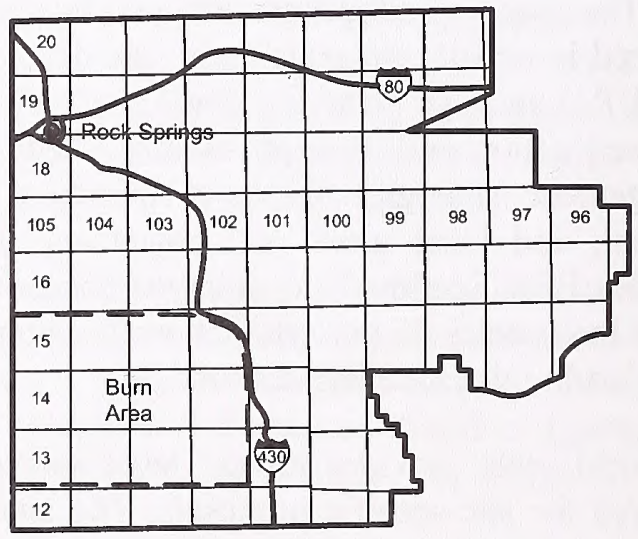

Figure 1-1 


\section{National Level Coordination}

Invasive species management is coordinated by several groups at the national level. The National Invasive Species Council was formed among several federal agencies per Executive Order 13112 to develop strategies to control invasive species on federal lands. Comprised of 16 federal agencies with direct invasive plant management responsibilities, the Federal Interagency Committec for the Management of Noxious and Exotic Weeds serves to coordinate invasive plant management activities in federal lands across the United States and its territories. A related committee is the Federal Interagency Committee on Invasive Terrestrial Animals and Pathogens, which consists of ten federal departments and agencies responsible for managing non-vegetative invasive species in terrestrial ecosystems. The BLM also coordinates with the Aquatic Nuisance Species Task Force, which is cochaired by the USFWS and NMFS, and is responsible for coordinating efforts by the federal government and the private sector in controlling aquatic nuisance species. The BLM also produces national level strategies for invasive species prevention and management (e.g., Partners Against Weeds: An Action Plan for the Bureau of Land Management [USDI BLM 1996], and Pulling Together: National Strategy for Invasive Plant Management [USDI BLM 1998]).

Fire and fuels management coordination involves both federal and state entities. The Wildland Fire Leadership Council is a cooperative, interagency organization dedicated to achieving consistent implementation of the goals, actions, and policies in the National Fire Plan and the Federal Wildland Fire Management Policy. The National Fire and Aviation Executive Board was established to resolve wildland fire management issues on an interagency level by improving coordination and integration of federal fire and aviation programs.

The National Interagency Fuels Coordination Group, chartered under the National Fire and Aviation Executive Board, was established shortly after the National Fire Plan in October of 2001 under the direction and guidance of the Department of the Interior's Bureau of Indian Affairs, BLM, USFWS, National Park Service, and USDA Forest Service. The primary purpose of the group is to provide leadership and coordination in uniting the Departments' resources and fire management programs under a common purpose for reducing risks to communities while improving and maintaining ecosystem health. The Group provides assistance and guidance in the development and implementation of an effective interagency fuels management program, which includes addressing risks from severe fires in WUI communities and restoring healthy ecological systems in other wildland areas.

The National Wildfire Coordinating Group provides coordination among the following agencies and their programs: USDA Forest Service; USDI BLM, National Park Service, Bureau of Indian Affairs, and USFWS; and the National Association of State Foresters. The BLM is also one of six federal agencies that provide scientific support for the management of fuels and wildland fires in the Joint Fire Science Program.

\section{State and County Level Coordination}

The BLM is required to coordinate with state and local agencies under several acts, including: the Clean Air Act, the Sikes Act, FLPMA, and Section 106 of the NHPA. The BLM coordinates closely with state resource management agencies on issues involving the management of public lands, the protection of fish and wildlife populations, including federal- and state-listed threatened and endangered species, invasive and noxious weeds, fuels and wildland fire management, and herbicide application. Herbicide applications are also coordinated with state and local water quality agencies to ensure treatment applications are in compliance with applicable water quality standards, and do not result in unacceptable surface or ground water contamination.

Local and state agencies work closely with the BLM to manage weeds on local, state, and federal lands, and are often responsible for weed treatments on public lands. The BLM participates in exotic plant pest councils, state vegetation and noxious weed management committees, state invasive species councils, county weed districts and weed management associations found throughout the west.

The Healthy Forests Restoration Act (HFRA) directs the USDA Forest Service and USDI BLM to develop an annual program of work for federal land that gives priority to authorized hazardous fuel reduction projects that provide for protecting at risk communities or watersheds. The recommendations made by Community Wildfire Protection Plans (described under Coordination in Chapter 2) are taken into account by the agencies in accordance with HFRA, which gives priority in allocating funding to communities that have adopted these plans, or that have taken measures to encourage 
willing property owners to reduce fire risk on private property (USDA Forest Service and USDI BLM 2004). All prescribed burning is coordinated with state and local air quality agencies to ensure that local air quality is not significantly impacted by BLM activities.

\section{Non-governmental Organizations}

The BLM coordinates at the national and local levels with several resource advisory groups and nongovernmental organizations, including: BLM Resource Advisory Councils, the Western Governors' Association, the National Association of Counties, the Western Area Power Administration, the National Cattlemen's Association, the National Wool Growers Association, the Society of American Foresters, and the American Forest and Paper Association. The BLM also solicits input from national and local conservation and environmental groups with an interest in land management activities on public lands, such as The Nature Conservancy. These groups provide information on strategies for weed prevention, effective weed treatment methods, use of domestic animals to control weeds, landscape level planning, vegetation monitoring, techniques to restore land health, and methods to ensure that prescribed burning does not impact the safe operation of power transmission lines.

\section{Cooperative Weed Management Areas}

Cooperative Weed Management Areas (CWMAs) are composed of local, private, and federal interests. CWMAs typically center on a particular watershed or similar geographic area in order to pool resources and management strategies in the prevention and control of weed populations. Much of the BLM's on-the-ground invasive species prevention and management is done directly or indirectly through CWMAs. The BLM participates in numerous CWMAs throughout the west, several of which are showcase examples of interagency and private cooperation in restoring land health.

\section{Consultation}

As part of this PEIS, the BLM consulted with the USFWS and NMFS as required under Section 7 of the ESA (see Chapter 5 and Appendix G). The BLM prepared a formal initiation package that included: 1) a description of the program, listed threatened and endangered species, species proposed for listing, and critical habitats that may be affected by the program; and 2) a Biological Assessment for Vegetation Treatments on Bureau of Land Management Lands in
17 Western States (BA; USDI BLM 2007b). The BA evaluated the likely impacts to listed species, species proposed for listing, and critical habitats from the proposed use of herbicides and other treatment methods in its vegetation treatment program and identified management practices to minimize impacts to these species and habitats.

The BLM initiated consultation with Native American tribes and Alaska Native groups to identify their cultural values, religious beliefs, traditional practices, and legal rights that could be affected by BLM actions. This included sending out letters to all tribes and groups that could be directly affected by vegetation treatment activities, and requesting information on how the proposed activities could impact Native American and Alaska Native interests, including the use of vegetation and wildlife for subsistence, religious, and ceremonial purposes (see Appendix G).

The BLM conducted an Alaska National Interest Lands Conservation Act (ANILCA) $\S 810$ Analysis of Subsistence. During this process, the BLM invited public participation and collaborated with Alaska Natives to identify and protect culturally significant plants used for food, baskets, fiber, medicine, and ceremonial purposes. The findings required by ANILCA $\S 810$ are given in Appendix $H$.

The BLM also consulted with SHPOs as part of Section 106 consultation under the NHPA to determine how proposed vegetation treatment actions could impact cultural resources. Formal consultations with SHPOs and Indian tribes also may be required during implementation of projects at the local level (see Appendix G).

\section{Public Involvement and Analysis of Issues}

The purpose of scoping is to focus the analysis in an EIS on the significant issues and reasonable alternatives in order to eliminate extraneous discussion and to reduce the length of an EIS (USDI BLM 1988b). Scoping is an ongoing process that involves the public in developing an EIS.

The BLM published a Federal Register (FR) Notice of Intent (NOI) on October 11, 2001, notifying the public that the BLM had formed a team to prepare a PEIS on the treatment of vegetation on public lands in the western U.S., including Alaska. The NOI also stated that comments on the proposal would be accepted from October 12 through November 11, 2001. 
A seeond Federal Register Notice of Intent was published on January 2, 2002, notifying the public of the loeation of publie scoping meetings, and extending the publie eomment period until Mareh 29, 2002.

A third Federal Register Notiee of Intent was published on January 22, 2002, notifying the publie of ehanges to the meeting sehedule.

All affeeted states issued publie notiees of the seoping period, whieh were plaeed in newspapers in or near locations where publie meetings were held. In addition, information on the location of scoping meetings was provided by eleetronie mail in early Deeember 2001, and again in early January 2002, to all members of the publie that had plaeed their names on the eleetronie mailing list for the projeet before the date of the announeements.

\section{Public Scoping Meetings}

Eighteen publie meetings were held in 12 western states, ineluding Alaska, and one meeting was held in Washington, D.C. The seoping meetings were eonducted in an open-house style. Informational displays were provided at the meeting, and handouts deseribing the projeet, the NEPA proeess, and issues and alternatives were given to the publie. A formal presentation provided the publie with additional information on program goals and objeetives. This presentation was followed by a question and answer session.

The BLM reeeived 1,034 requests to be plaeed on the projeet mailing list from individuals, organizations, and government ageneies, and 381 written eomment letters or faesimiles on the proposal. In addition, the publie provided eomments on the projeet at the publie seoping meetings; over 2,800 eatalogued individual comments (written and oral) were given during publie seoping. In many cases, multiple respondents submitted the same eomment. A Scoping Comment Summary Report for the Vegetation Treatments Programmatic EIS (ENSR 2002) was prepared that summarized the issues and alternatives identified during seoping. This doeument was made available to the publie in July 2002.

\section{Scoping Issues and Concerns}

A wide range of issues was identified during seoping. Issues aeeounting for over $80 \%$ of the comments eonsidered in the PEIS and PER are listed in Table 1-1.
The primary issue of eontroversy identified through seoping, and whieh required NEPA review, was the BLM's eontinuing and proposed inerease in the use of herbicides in vegetation treatment programs needed to implement the National Fire Plan and related initiatives. The use of herbieides has been affirmed as a central issue for analysis in all past EISs eonsidered in this doeument.

After seoping, the BLM determined that a NEPA review was not required to assess the impaets of other treatment activities on environmental and soeial resourees on publie lands at the national programmatie level. The use of these teehniques has been affirmed in all previous EISs, and the BLM has authority under existing statutes to utilize these methods of treatment as neeessary. Program- and projeet-specifie NEPA analysis of the use of these teehniques, and under what eireumstanees, will oeeur at the land use planning and projeet level.

\section{Development of the Alternatives}

The publie eomments influeneed the development of several vegetation management alternatives. As noted in Table 1-1, numerous respondents suggested that the BLM reduee or eliminate the use of herbieides, avoid aerial applieations of herbieides, or avoid the use of sulfonylurea and other aeetolaetate synthase (ALS)inhibiting aetive ingredients. Based on these eomments and NEPA-review requirements, alternatives addressing the use of herbieides are evaluated in the PEIS. The effeets of other non-herbieide vegetation treatments are deseribed in the PER.

\section{Issues Not Addressed in the Draft PEIS}

Approximately $16 \%$ of eomments reeeived were not addressed in the PEIS or PER beeause they were beyond the seope of the doeument or did not meet the basie purpose and need of the projeet. The following are examples of eomments not addressed in the PEIS or PER:

- Address the impaets of livestoek grazing on aquifer reeharge and wildlife habitat

- Amend the Mining Aet of 1872

- Have seoping meetings in eaeh distriet and extend the seoping period

- Classify wild horses as big game for sportsmen

- Inerease penalties for violators of OHV rules 
- The BLM is unconstitutional

\section{Public Review and Comment on the Draft Programmatic EIS, ER, and BA}

The Notice of Availability (NOA) of the Draft Vegetation Treatments using Herbicides on Bureau of Land Management Lands in 17 Western States Programmatic Environmental Impact Statement was published in the Federal Register on November 10, 2005. The public comment period was originally scheduled from November 10, 2005, through January 9 , 2006; however, a notice extending the public comment period through February 10, 2006, was published in the Federal Register on January 20, 2006. Public notices announcing the comment period were placed in newspapers with circulation in or near locations where public meetings were held. The BLM issued a press release on November 10,2006 , notifying the public that the Draft PEIS, PER, and BA were available for public review, and listing the schedule for public comment hearings. Information on the Draft PEIS, PER, and BA were also posted on the interactive website. The public was able to access the website to download a copy of the Draft PEIS, PER, and BA.

Public hearings were held in Portland, Oregon on November 28, Sacramento, California on November 29, Salt Lake City, Utah on November 30, Albuquerque, New Mexico on December 1, Grand Junction, Colorado on December 5, Boise, Idaho on December 6, Billings, Montana on December 7, Cheyenne, Wyoming on December 8, and Las Vegas, Nevada, and Washington D.C. on December 13, 2006. These hearings allowed the BLM to provide an overview of the alternatives and to take public comments and subsistence testimony. Nearly 3,000 comments were received on the Draft PEIS, PER, and BA. Comments included letters, electronic mail, facsimiles, and comments provided at the public hearings in Boise and Sacramento (no public testimony was given at the other public hearings). A summary of the comments received and issues identified and specific comments and responses are presented in Volume III of this final PEIS. All comments are reproduced on the CD located in the back pocket of Volume I of the PEIS.

\section{Limitations of this PEIS}

This PEIS is a programmatic document that addresses the broad impacts associated with the proposed action and alternatives to the proposed action. Environmental impacts are assessed at a general level because of the broad land area analyzed in the PEIS. Site-specific impacts would be assessed in NEPA documents prepared by local BLM offices and tiered to this document.

The analyses of impacts of the use herbicides in this PEIS are based on the best and most recent information available. As is always the case when developing management direction for a wide range of resources, not all information that might be desired was available. The CEQ Regulations provide direction on how to proceed with the preparation of an EIS when information is incomplete or unavailable:

"If the information relevant to reasonably foreseeable significant adverse impacts cannot be obtained because the overall costs of obtaining it are exorbitant or the means to obtain it are not known, the agency shall include within the environmental impact statement: 1) a statement that such information is incomplete or unavailable; 2) a statement of the relevance of the incomplete or unavailable information to evaluating reasonably foreseeable significant adverse impacts on the human environment; 3) a summary of existing credible scientific evidence which is relevant to evaluating the reasonably foreseeable significant adverse impacts on the human environment; and 4) the agency's evaluation of such impacts based upon theoretical approaches or research methods generally accepted in the scientific community. For the purposes of this section, "reasonably foreseeable" includes "impacts which have catastrophic consequences, even if their probability of occurrence is low, provided that the analysis of the impacts is supported by credible scientific evidence, is not based on pure conjecture, and is within the rule of reason" (40 CFR 1502.22 b).

For this PEIS, the primary effect of unavailable information is the inability to quantify certain impacts. Where quantification was not possible, impacts have been described in qualitative terms. A summary of existing credible scientific evidence that is relevant to evaluating the reasonably foreseeable adverse impacts on the human and socioeconomic environment and support the BLM's evaluation of such impacts have been included in chapters 3 and 4, in the appendices that accompany this PEIS, and in supporting documents that were prepared for this PEIS that have been included on the accompanying $\mathrm{CD}$ or are available on the BLM website at http://www.blm.gov. A copy of the PER and its supporting documents are also available at this website. 
If changes in the proposed vegetation treatment activities and levels occur in the future, they would be reviewed to determine whether additional environmental documentation was needed, including an EA or EIS. This PEIS would serve as a source document that would be used to support any additional documentation that may be required. Any new or additional actions would also be evaluated for compliance with federal, state, and local laws and regulations prior to implementation, and the public would be informed of any major actions that may be considered for implementation by the BLM as part of the NEPA compliance process.

\section{Preview of the Remainder of the PEIS}

The format of this PEIS follows guidance provided by the CEQ and BLM National Environmental Policy Act Handbook H-1790-1 (USDI BLM 1988b). Because this PEIS contains a broad range of information, Figure 1-2 shows the types of information found in the PEIS, and where it is located. 
TABLE 1-1

Key Issues (and Number of Comments) Identified During Scoping and Location Where Issues Are Addressed in the PEIS and PER

\author{
Issue
}

Where Addressed in PEIS and (PER)

\title{
Program Purpose and Need
}

Focus on long-term ecosystem sustainability and biological diversity; clearly define restoration objectives (39)

Need to address all invasive plants, not just weeds (34)

$1-1,1-3,2-1,2-5,2-$

22, Ch. 4. (Chs. 1, 2)

1-1, 2-3, 2-22 (Chs. 2,

4)

Evaluate land use impacts, such as grazing and fire suppression, on the decline of ecosystem health (377)

1-1, 1-5, Ch. 4 (Chs.1,

2, 4)

Focus on addressing the causes rather than treating the symptoms (102)

$2-5,2-15,2-23$ (Ch.

2)

Address how PEIS will impact Resource Management Plans and other local planning (23)

Work closely with agencies, conservation groups, and private landowners on vegetation management (93)

$1,-5,1-8($ Ch. 1)

1-9, 1-11, 2-25, 2-39,

Ch. 5 (Ch. 1)

\section{Proposed Action}

Ensure that adequate funds are available to treat enough land and monitor treatment success (45)

Consider all treatment methods (11)

Naturally-occurring fires should be allowed to burn and restored to public lands (38)

Use newer, less toxic herbicides where feasible, and limit use or avoid use of herbicides (75)

Describe how herbicides were chosen and evaluated in the PEIS (33)

Describe where acres will be treated and method of accounting for acres that receive multiple treatments (28)

\section{Other Potential Alternatives}

Reduce or eliminate the use of herbicides; apply from the ground rather than from the air (206)

Fuels reduction should only occur in WUI or where there is a threat of significant wildfire (39)

Treat more acres; treat fewer acres (8)

Develop a no-grazing alternative; develop a no-logging alternative; develop a no-OHV alternative (12)

Develop restrictions on motorized vehicle use on public lands (72)

Develop an alternative based on an ecosystem management approach (2)

\section{Restoration Goals and Best Management Practices}

Identify restoration objectives and focus on preventative measures to eliminate the causes of land degradation (103)

Restoration efforts should focus on restoring natural disturbance regimes and ecosystem processes (11)

Improve management of public lands for multiple use and maximum public benefit (22)

Use native plants and certified native seed, where practical, for revegetation (59)

Restrict grazing on lands that are being rehabilitated or that have not been impacted by livestock (10)

Monitor success of treatments and establish performance measures to determine treatment success (42)

Include public education as part of the vegetation treatment program (39)

\section{Environmental Consequences}

Address the impacts on air quality from prescribed burning (18)

Address the impacts of herbicides on water quality (39)

Assess the role of fire in contributing to weed growth (44)

Evaluate the effects of herbicide treatments on non-target species (28)

Address the role of grazing in controlling weeds and other invasive vegetation and hazardous fuels (27)

Vegetation treatments should focus on restoring habitat and natural ecological processes (25)

Address the impacts of treatments on species of concern (55)

Describe how treatments will occur in wilderness areas (26)

Address the impacts of prescribed fire on powerline operations and safety (12)

Evaluate the impacts to subsistence crops used by Native Americans and Alaska Natives (10)

Address the risks to humans and fish and wildlife from use of herbicides and smoke from prescribed fire (54)

Address how will vegetation treatments will affect the local economy (40)

\begin{tabular}{|l|}
\hline 2-22, Ch. 4 (Ch. 2) \\
\hline 2-22, Ch. 4 (Ch 4) \\
\hline 2-1 (Ch. 2) \\
\hline 2-22, 2-27 (Ch. 2) \\
\hline 2-23, 2-32 (Ch. 2) \\
\hline 2-35 (Ch. 2) \\
\hline 2-39 (Ch. 2) \\
\hline
\end{tabular}

$2-22$

2-8, 2-14 (Ch. 2)

$1-1$, (Chs. 2, 3, 4)

2-9, Ch. 4, App. B, C

2-9, Ch. 4, App. B, C

2-21 (Ch. 1)

$2-19$
$1-1,2-22$ (Ch. 2)
$2-22$
$1-5$
$1-5$
$2-20$

$2-20$

(Ch. 4)

4-24

(Chs. 1, 2, 3, 4)

4-44

(Ch. 4)

1-1, 1-3, 2-1, 2-5, 2-8,

Ch. 4 (Chs. 1, 2, 4 )

4-71, 4-92, 4-124 (Ch.

4)

2-16,2-29, 4-155

(Chs. 2, 4)

(Ch. 4)

4-149 (Ch. 4)

4-101, 4-174 (Ch. 4)

4-163 (Ch. 4) 


\section{VOLUME 1}

Chapter 1 Proposed Action and Purpose and Need

Summarizes the proposed action, purpose and need, and decisions to be made in this PEIS.

Chapter 2 Alternatives

Describes and compares the proposed management alternatives.

\section{Chapter 3 Affected Environment}

Presents existing natural and sociocconomic resources on public lands in the western U.S.

\section{Chapter 4 Environmental Consequences}

Evaluates the impacts of the alternatives on public land resources in the western U.S. and describes mitigation proposed for program-related impacts to resources.

\section{Chapter 5 Consultation and Coordination}

Describes the scoping and public hearing processes, agencies contacted, and government-togovernment consultation, and lists the preparers of the PEIS.

\section{Chapter 6 References}

Lists the documents and other sources used to prepare the PEIS.

\section{Chapter 7 Glossary}

Provides definitions for important terms used in the PEIS.

\section{Chapter 8 Index}

Lists where significant issues, resource descriptions, NEPA terms, and agencies and groups discussed in the PEIS are located.

Acronyms, Abbreviations, and Symbols (fold-out at end of Volume 1)

Lists the acronyms, abbreviations, and symbols used in the PEIS.

\section{VOLUME 2}

\section{Appendixes}

A. Common and Scientific Names of Plants and Animals Given in the PEIS

B. Human Health Risk Assessment

C. Ecological Risk Assessment

D. Evaluation of Risks from Degradates, Polyoxythylene-amine (POEA), and Endocrine Disrupting Chemicals

E. Protocol for Identifying, Evaluating, and Using New Herbicides

F. BLM Reference Manuals and Handbooks

G. Consultation Agreements

H. ANILCA Section 810 Analysis of Subsistence Impacts

I. American Lands Alliance Alternative and BLM Analysis of Alternative

J. Special Status Species List

\section{VOLUME 3}

\section{Comments and Responses}

Provides a summary of the comments received on the Draft PEIS, PER, and BA

\section{Related Reports \\ (on the CD located in the back pocket of the PEIS)}

1. Biological Assessment

2. Human Health Risk Assessment Final Report

3. Ecological Risk Assessments for Each Herbicide Evaluated by the BLM

4. Ecological Risk Assessment Protocol

5. Comment Letters. Facsimiles. and Electronic Mail on Draft PEIS. PER. and BA

Figure 1-2

How This Programmatic EIS is Organized. 



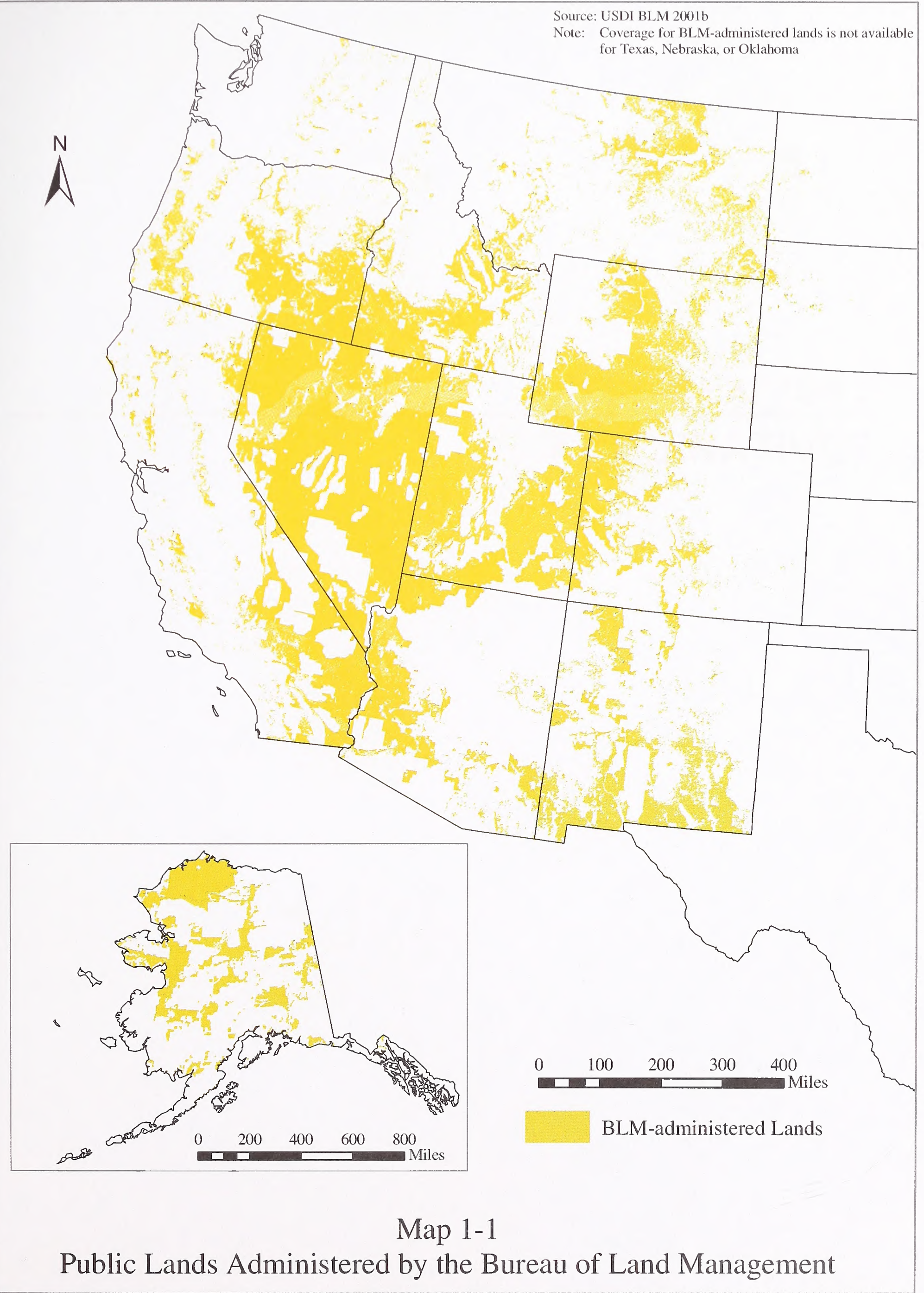



CHAPTER 2 ALTERNATIVES 



\section{TABLE OF CONTENTS}

Introduction

Page

BLM Programs Responsible for Herbicide Treatments

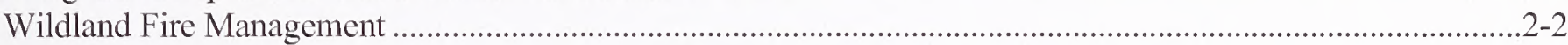

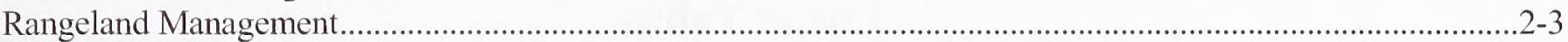

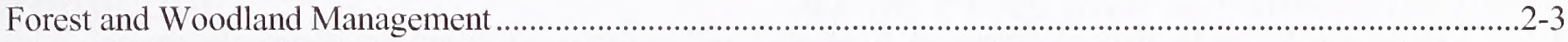

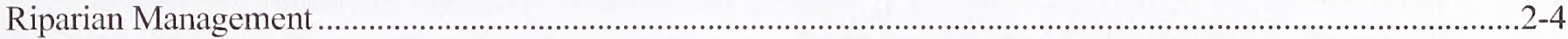

Wildlife, Fisheries, and Threatened and Endangered Species Management......................................................2-4

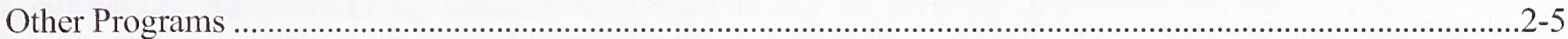

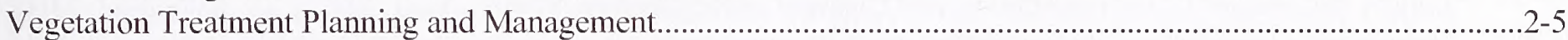

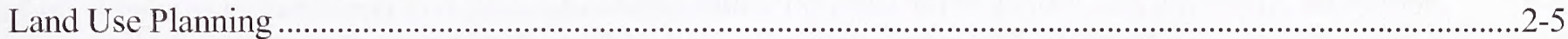

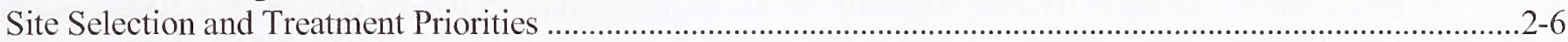

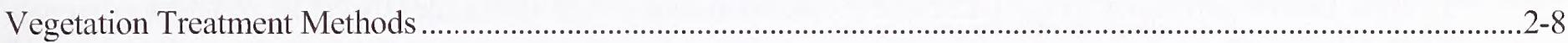

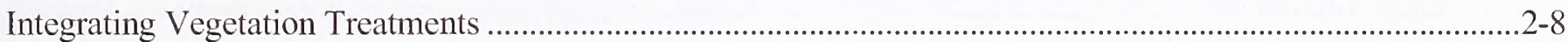

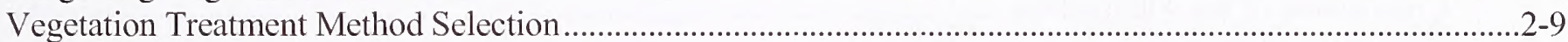

Herbicide Active Ingredients Evaluated under the Proposed Alternatives .............................................................2-9

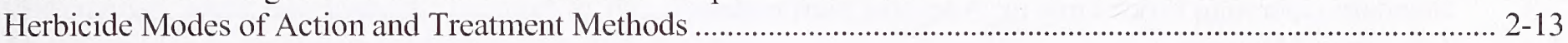

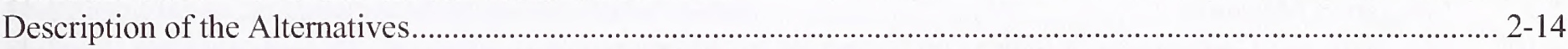

Alternative A - Continue Present Herbicide Use (No Action Alternative).................................................... 2-14

Alternative B - Expand Herbicide Use and Allow for Use of New Herbicides in 17 Western States

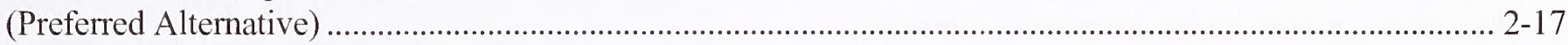

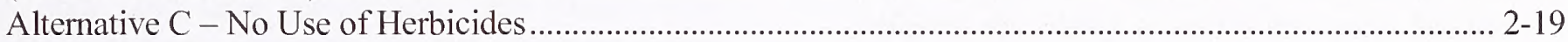

Alternative D - No Aerial Application of Herbicides................................................................................... 2-19

Alternative E - No Use of Sulfonylurea and other Acetolactate Synthase-inhibiting Active Ingredients ......... 2-20

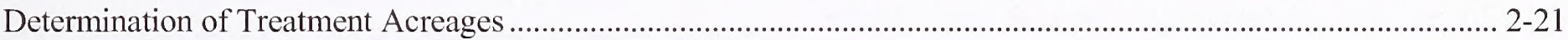

Non-herbicide Treatment Method Acreages used in Cumulative Effects Analysis........................................ 2-21

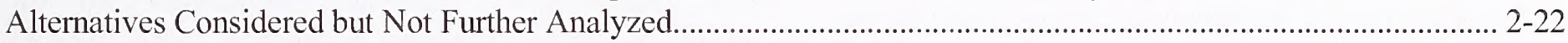

Herbicide Treatment Standard Operating Procedures and Guidelines............................................................ 2-22

Prevention of Weeds and Early Detection and Rapid Response ............................................................ 2-23

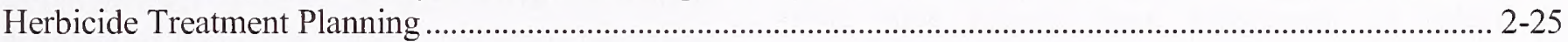

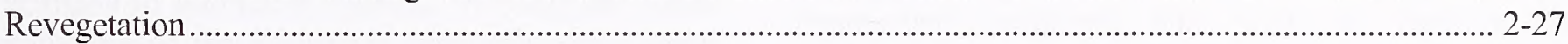

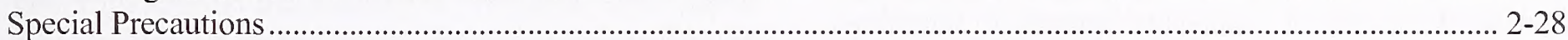

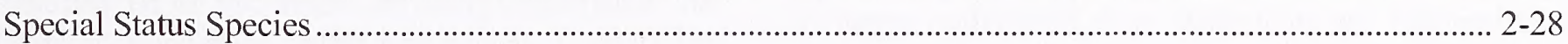

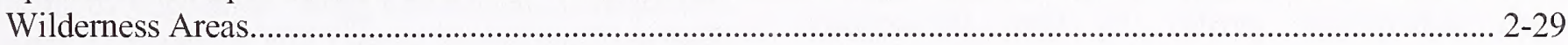

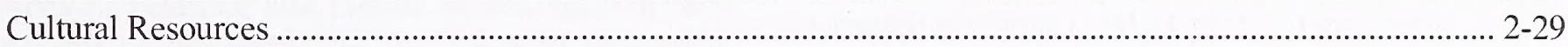

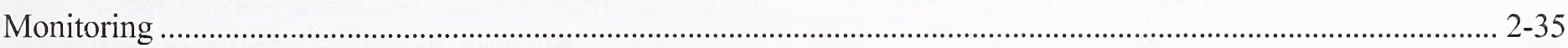

Monitoring Guidance used by BLM in Vegetation Management ........................................................... 2-37

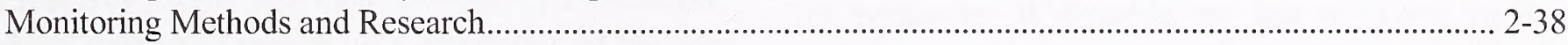

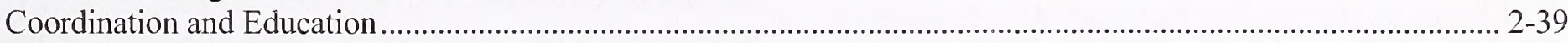

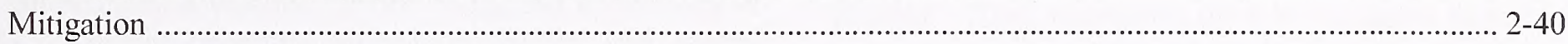

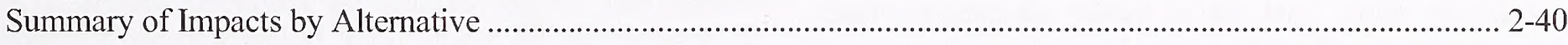




\section{List of Figures}

2-1 Summary of Acres Treated Using Herbicides during 1997-2005.

2-2 National Early Warning and Rapid Reponse System for Invasive Plants

\section{List of Tables}

2-1 Herbicide Active Ingredients Proposed, Evaluated, and included in Current Environmental Impact Statements of the Bureau of Land Management.

2-2 States in which Herbicides are Approved for Use on Public Lands Based upon Current Environmental Impact Statements, Court Injunctions, and Changes in Registration Status .............................................. 2-12

2-3 Herbicides Approved and Proposed for Use on Public Lands .................................................................. 2-15

2-4 Average Number of Acres Treated Annually for Each BLM State Jurisdiction during 1997-2005..... $2-17$

2-5 Historic Use of Herbicides by the BLM and Projected Future Use of Herbicides by the BLM under Each Alternative 


\section{CHAPTER 2}

\section{ALTERNATIVES}

\section{Introduction}

This chapter discusses the preferred and alternative actions that have been developed to treat vegetation using herbicides on public lands in the western U.S., including Alaska. The preferred and alternative actions are those that could be taken to feasibly attain, or approximate the BLM's objectives for vegetation management, as expressed in its programs, policies, and land use plans.

Alternatives were developed to respond to the various significant issues and alternative proposals raised during scoping, yet still meet the project's purpose and need described in Chapter 1. Alternatives were also developed to ensure BLM compliance with federal, tribal, state, and local regulations. This chapter also includes mitigation measures for the proposed action and alternatives.

As described in the Scoping Comment Summary Report for the Vegetation Treatments Programmatic EIS (ENSR 2002), alternative proposals generated during scoping primarily focused on the types of herbicides that would be used by the BLM, methods of application, and amounts of herbicides applied. To help the reader better understand the alternative proposals, this chapter 1) identifies BLM programs primarily responsible for treatment of vegetation using herbicides; 2) describes the types of planning and project implementation that must occur before herbicides can be used on public lands; and 3) lists the herbicides evaluated in the PEIS, their mode of action, and their methods of application. These sections are followed by a description of the five alternatives developed for this PEIS, and a summary of 1) standard operating procedures (SOPs) and special precautions that would apply under all alternatives, 2) additional protective (mitigation) measures developed during preparation of the PEIS, and 3) environmental and socioeconomic impacts that would result from implementation of the alternatives.

\section{BLM Programs Responsible for Herbicide Treatments}

In order to be effective, vegetation management by the BLM must involve all programs that rely on healthy plant species and communities to meet their objectives. The BLM's overarching goal for vegetation management is as follows:

Through an interdisciplinary collaborative
process, plan and implement a set of actions
that improve biological diversity and
ecosystem function and which promote and
maintain native plant communities that are
resilient to disturbance and invasive species.
Healthy functioning plant communities will
enhance the ability to attain economic benefits
on public lands (USDI BLM 2006b).

If this goal is met, eventually the number of acres needing treatment should be reduced as a result of overall improvement in conditions. To achieve this goal, the BLM must 1) understand and plan for the condition and use of public lands, 2) focus on restoring sites that will most benefit from treatments, 3) select the appropriate treatments and SOPs to improve the likelihood of restoration success, 4) monitor treatments to better understand what treatments are successful or unsuccessful, and 5) convey information about treatment activities to BLM staff and the public.

Concurrently, public lands must be administered under the principles of multiple use and sustained yield in accordance with the intent of Congress as stated in the FLPMA. Thus, vegetation must be managed to protect and enhance the health of the land while providing a source of food, timber, and fiber for domestic needs (USDI BLM 2000c). Land-disturbing activities must be conducted in a manner that minimizes ecosystem fragmentation and degradation, and lands should be rehabilitated when necessary to safeguard the long-term diversity and integrity of the land.

Vegetation treatments using herbicides are primarily conducted by the Wildland Fire Management, Rangeland Management, Public Domain Forest 
Management, Riparian Management, and Wildlife and Fisheries Management programs. Each program, as described below, has its own objectives for vegetation management, but still must meet the broad goal identified above. Types of herbicide treatments conducted by these programs include hazardous fuels reduction, weed control, fish and wildlife habitat improvement, habitat improvement for threatened and endangered species, and restoration of riparian habitats.

\section{Wildland Fire Management}

Efforts to reduce the risk of wildfire are primarily the responsibility of the Wildland Fire Management program. During fiscal year (FY) 2005, the Wildland Fire Management program conducted hazardous fuel treatments on about 542,000 acres in the WUI and nearly 727,000 acres in non-WUI areas. The program conducted Emergency Stabilization and Burned Area Rehabilitation activities on nearly 880,000 acres. Together, the USDI and Forest Service conducted over 3 million acres of hazardous fuels treatments and treated nearly 2.4 million acres in the WUI during FY 2005 (USDI BLM 2006c, d). Between 2001 and 2006, federal land management agencies invested more than $60 \%$ of fuels treatment dollars in the WUI, enabling collaborative treatment of some 8.5 million acres near communities (USDI BLM 2006c).

Prior to 1998, the BLM managed hazardous fuels on approximately 57,000 acres annually. Historically, approximately $70 \%$ of acres were managed to restore fire-adapted ecosystems, while the remaining 30\% were managed to reduce wildfire risks to communities.

Under current direction, the number of acres treated annually by the BLM to reduce wildland fire risk would increase significantly, to about 3.5 million acres in the western U.S., including Alaska, and most treatments would occur in the WUI. Although all treatment methods would be used, prescribed fire and mechanical treatments would account for most fuels reduction in the continental U.S., and wildland fires for resource use would account for most fuels reduction in Alaska.

The Wildland Fire Management program is guided by the policies expressed in the following national policy documents: 1) National Fire Plan (USDI and USDA 2001a); 2) Healthy Forests Initiative of 2002 and Healthy Forests Restoration Act of 2003 (Public Law 108-148); 3) Chapter 3 (Interagency Burned Area Emergency Stabilization and Rehabilitation) in BLM Manual 620 (Wildland Fire Management; USDI BLM 2004b); 4) A Collaborative Approach for Reducing Wildland Fire Risks to Communities and the Environment 10-Year Comprehensive Strategy Implementation Plan (USDI and USDA 2006a); 5) Protecting People and Sustaining Resources in Fire Adapted Ecosystems: A Cohesive Strategy (USDI and USDA 2006b); 6) Draft Interagency Burned Area Emergency Response Guidebook (USDI and USDA 2006c); 7) Interagency Burned Area Rehabilitation Guidebook (USDI and USDA 2006d); and 8) Draft Burned Area Emergency Stabilization and Rehabilitation Handbook (H-1742-1; USDI BLM 2006a).

\section{Wildland Urbam Interface (WUI)}

The WUI has generally been defined by the National Wildfire Coordinating Group (NWCG) as "the line, area or zone, where structures and other human development meet or intermingle with undeveloped wildland or vegetative fuel." A more specific definition is provided in the Healthy Forests Restoration Act of 2003:

1. An area within or adjacent to an at-risk community that is identified in recommendations to the Secretary of the Interior or Agriculture in a community wildfire protection plan (CWPP); or

2. In the case of an area for which a CWPP is not in effect:

(a) an area extending $1 / 2$ mile from the boundary of an at-risk community;

(b) an area within 1 1/2 miles from the boundary of an at-risk community, including any land that has a sustained steep slope that creates the potential for wildfire behavior endangering the at-risk community; has a geographic feature that aids in creating an effective fire break such as a road or ridge top; or is in Fire Regime Condition Class 3, as documented by the Secretary of the Interior in the project-specific environmental analysis; and

(c) an area that is adjacent to an evacuation route for an at-risk community that the Secretary determines, in cooperation with the at-risk community, requires hazardous fuel reduction to provide safer evacuation from the at-risk community.

The variation in the WUI definition allows local issues to drive the definition, but makes national mapping of WUI difficult. 


\section{Rangeland Management}

Approximately 165 million acres of public lands are upland rangeland, of which approximately 160 million acres are open to livestock grazing (USDI BLM 2006c). The Rangeland Management program in Alaska is responsible for reindeer grazing on approximately 5 million acres in western Alaska. The Rangeland Management program is responsible for upland health management, assessment, and restoration; rangeland improvement planning and implementation; allotment planning and administration; and resource monitoring. Management of rangeland ecosystems is conducted on a landscape basis through land use plans.

Vegetation treatment activities conducted by this program are designed to promote compliance with the state and regional rangeland health standards, but specific benefits of these projects often include livestock forage improvement, wildlife habitat improvement, suppression of plants that are toxic to wildlife and livestock, removal of plants that compete with more desirable vegetation, improvement of watershed conditions on rangelands, and restoration of native plant communities.

Vegetation treatments on public lands also include activities to control invasive species such as noxious weeds. The BLM uses an integrated pest management approach, more specifically integrated vegetation management. The goal of integrated vegetation management is to control invasive and unwanted vegetation, to prevent the spread of noxious weeds, to eradicate early-detected noxious weed species in areas where certain weeds have not yet become established, and to control weeds where they have become established. Vegetation control methods include physical and biological controls, and use of herbicides. The policy, direction, and requirements for planning and implementing integrated weed management are given in BLM Manual 9015, Integrated Weed Management (USDI BLM 1992b).

A total of 205,256 acres were treated to prevent the spread of noxious weeds and invasive plants in fiscal year (FY) 2005, and an estimated 317,959 acres were treated in FY 2004 by the Invasive and Noxious Weed program (USDI BLM 2006c). In addition, 3.9 million acres were inventoried for weeds during FY 2005.

Currently, the funding and labor resources available to combat weeds dictate a containment strategy. Actions will continue to be targeted at preventing the spread of weeds into the most vulnerable areas (USDI BLM 2000b).

\section{Forest and Woodland Management}

Approximately 26 percent (69 million acres) of the lands managed by BLM consist of forestlands and woodlands (USDI BLM 2006e). Of these lands, 57 million acres are classified as woodlands and 12 million acres are classified as forestlands. Two and one-half million acres are managed under the Oregon and California (O\&C) Grant Lands program, while the remaining 66.6 million acres are managed under the Public Domain Forest Management program.

Woodlands are defined as land with $5 \%$ or more cover of low-stature tree species not typically used in commercial wood products, including land that formerly had such tree cover and will be naturally or artificially regenerated. Forestland is defined as land that has $10 \%$ or more cover of tall-stature tree species typically used in commercial wood products, including land that formerly had such tree cover and will be naturally or artificially regenerated.

Approximately 36.5 million acres of forestlands and woodlands are managed by the BLM in Alaska. These consist primarily of black spruce (14.7 million acres) and white spruce (17.2 million acres) woodlands. The remaining 4.6 million acres consist of many different forest types, including paper birch, aspen, balsam poplar, mountain hemlock and Sitka spruce.

Approximately 16 million of the 32 million acres of BLM forestlands and woodlands found in the remaining 16 western states consist of pinyon/juniper woodlands, where a mix of pinyon pine and juniper tree species predominates. Approximately 2.7 million acres are comprised of the Douglas-fir forest type, 1.9 million acres are the western juniper forest type, 1.1 million acres are the ponderosa pine forest type, and 0.3 million acres each are the lodgepole pine and aspen forest types. The remaining 10 million acres consist of a wide variety of forest and woodland types.

The Public Domain Forest Management and O\&C Grant Lands programs are responsible for timber and non-timber special forest product sales, reforestation efforts, fish and wildlife habitat improvement, and forest vegetation composition and structure improvements intended to increase diversity and productivity of forest landscapes, as well as their resiliency in response to disease, insects, and wildfire. 
The FLPMA and BLM Manual 5000-1, Forest Management Public Domain (USDI BLM 1991c), direct the policy of the Public Domain Forest Management program, including requirements for planning and implementing forestry and woodland management projects.

Management of the O\&C Grant Lands program is authorized under The Oregon and California Grant Lands Act of 1937 (43 U.S.C. 1181). The FLPMA applies to all public lands, including the O\&C grant lands by definition $(\S 103(\mathrm{e}))$. However, $\$ 701(\mathrm{~b})$ of FLPMA (43 USC 170) provides that if any provision of FLPMA is in conflict with or inconsistent with the Oregon and California Grant Lands Act and Coos Bay Wagon Road Act, insofar as they relate to management of timber resources and disposition of revenue from lands and resources, the latter Acts will prevail.

Treatments that are addressed in this document include: 1) reducing plant competition to enhance the growth of desired tree species and structures, 2) managing forest stands to provide habitat for wildlife and prevent epidemic insect or disease outbreaks, and 3) managing vegetation that could serve as fuel for wildfires. In 2006, the program implemented forest restoration treatments on 31,948 acres and forest management treatments on 28,644 acres (USDI BLM 2006c). Sales of timber, wood products, and non-timber special forest products totaled nearly $\$ 36.1$ million during FY 2005 (USDI BLM 2006d).

\section{Riparian Management}

The BLM manages over 23 million acres of riparian and wetland areas, comprising about $9 \%$ of public lands, and providing habitat for roughly $80 \%$ of the fish and wildlife species on public lands. The Riparian Management program's responsibilities include watershed, riparian, and wetland inventories, assessments, maintenance, restoration, and reconstruction. During 2005, the program assessed the condition of over 4,300 miles of streams, implemented enhancement projects on approximately 310 acres of wetlands and 542 miles of streams, and monitored over 8,200 acres of lakes and wetlands and 2,380 miles of streams (USDI BLM 2006c).

\section{Wildlife, Fisheries, and Threatened and Endangered Species Management}

The BLM manages nearly 261 million acres in the 17 western states, including some of the nation's most ecologically diverse wildlife habitat-more habitat than any other federal or state agency. BLM-administered land is important to big game, waterfowl, shorebirds, songbirds, raptors, and hundreds of species of non-game mammals, reptiles, and amphibians.

The BLM's Wildlife Management program provides support for land use planning and development of conservation plans for at-risk species, such as the mountain plover, greater and Gunnison sage-grouse, lesser prairie chickens, white-tailed, black-tailed and Gunnison's prairie dogs, and their habitats. BLM biologists work with partners in big game habitat restoration, including reestablishment of bighorn sheep into historically occupied habitats, restoration of mule deer winter ranges, and enhancement of summer ranges for elk. BLM biologists continue to monitor habitat conditions and populations of numerous species, including prairie dogs, amphibians, sage-grouse, burrowing and spotted owls, muskox, caribou, and moose populations. One of the Wildlife Management program's highest priorities is development and implementation of conservation plans for the greater and Gunnison's sage-grouse. The BLM manages over 30 million acres of sage-grouse habitat in an 11-state region.

The BLM Fisheries program oversees management that directly affects over 155,000 miles of fish-bearing streams and 4 million acres of lakes and reservoirs. Water bodies on BLM-administered lands are diverse, ranging from isolated desert springs harboring populations of rare and unique fishes, to large interior Columbia River tributaries supporting salmon and resident fishes of exceptional regional and national value. These waters also support subsistence fisheries that sustain Native American cultural heritages, as well as fisheries providing recreational opportunities for the growing human population of the western United States.

The BLM's Threatened and Endangered Species Management program is responsible for the management and recovery of federally-listed species, including plants, wildlife, and fish on public lands. In addition, the program is responsible for the management of sensitive plant species on public lands.

The Wildlife Management, Fisheries Management, and Threatened and Endangered Species Management programs support the Great Basin Restoration and the Conservation of Prairie Grasslands initiatives. In 2000, the BLM implemented the Great Basin Restoration Initiative, a regional restoration strategy to restore and 
enhance nearly 70 million acres of sagebrush habitat in Nevada, Utah, Oregon, and Idaho, and California. The focus of this effort is to prevent much of the land burned in wildfires from being overwhelmed by annual grasses and noxious weeds. The same year, the BLM also began the Conservation of Prairie Grasslands initiative to protect and maintain important grasslands on approximately 15 million acres of short- and mixedgrass prairie in a 7 -state area that extends from Canada to Mexico. Both efforts focus on managing healthy landscapes and protecting and restoring habitats to benefit wildlife. The Wildlife Management and Fisheries Management programs are also responsible for managing subsistence uses on public lands in Alaska.

FLPMA and several manuals (BLM Manual 6500 Wildlife and Fisheries Management; BLM Manual 6720 - Aquatic Resource Management; BLM Manual 6780 - Habitat Conservation Management Planning; and BLM Manual 6840 - Special Status Species Management) outline the policy, direction, and requirements for planning and implementing management and treatments for fish, wildlife, and special status species and their habitat.

\section{Other Programs}

Several other programs within the BLM also treat vegetation using herbicides, although to a lesser extent than the programs listed above (USDI BLM 2004a). These include the Cultural Resources, Recreation, Wilderness, Energy and Minerals, Transportation, and Realty and Ownership Management programs. Herbicides are used to manage vegetation on recreation and wilderness areas and on lands disturbed by energy and mineral development. The Realty and Ownership Management program issues ROW. Herbicides are often preferred for use on ROW over other treatment methods or in conjunction with other treatments because they are often most effective at controlling or removing vegetation before, or shortly after, it emerges. Other facilities requiring vegetation management include campgrounds, visitor centers, and other recreational facilities; administrative buildings; communications facilities; and roads. At these sites, vegetation management focuses on controlling vegetation that can pose a safety or fire hazard, or is not aesthetically pleasing The BLM uses premergence and postemergence herbicides to control emerging vegetation.

\section{Vegetation Treatment Planning and Management}

The BLM's Strategic Plan (USDI BLM 2000a); $A$ Collaborative Approach for Reducing Wildland Fire Risks to Communities and the Environment 10-Year Comprehensive Strategy Implementation Plan (USDI and USDA 2002); Partners Against Weeds: An Action Plan for the Bureau of Land Management (USDI BLM 1996), and Pulling Together: National Strategy for Invasive Plant Management (USDI BLM 1998) identify broad objectives for management of vegetation on public land, while treatment activities at the local level are guided by the goals, standards, and objectives of land use plans developed for each BLM field office.

Although vegetation management actually occurs at the local level, policies established at the national level help direct local efforts. Examples of national policy direction designed to improve vegetation management efforts include development of rangeland health standards and development of assessments and evaluations for land, water, air, and vegetative health (USDI BLM 2002a). These assessments provide information that is used to ascertain achievement of land health standards and to identify causes for not meeting standards. These assessments are used to help identify restoration activities and establish restoration priorities.

\section{Land Use Planning}

Land use planning decisions are the basis for every onthe-ground action the BLM undertakes. Land use plans, usually in the form of RMPs, ensure that public lands are managed in accordance with the intent of Congress, as stated in FLPMA (43 USC 1701 et seq.), under the principles of multiple use and sustained yield. As required by FLPMA and BLM policy, "public lands must be managed in a manner that protects the quality of scientific, scenic, historical, ecological, environmental, air and atmospheric, water resource, and archaeological values; that, where appropriate, will preserve and protect certain public lands in their natural condition; that will provide food and habitat for fish, and wildlife and domestic animals; that will provide for outdoor recreation and human occupancy and use; and that recognizes the Nation's need for domestic sources of minerals, food, timber, and fiber from the public lands by encouraging collaboration and public participation throughout the planning process." 
Land use plans guide land use and vegetation management decisions within the geographic area they cover, and provide specific goals, standards, objectives, and expected outcomes that apply to vegetation treatment projects and activities. These plans identify important local resources to be protected, identify historic, current, and future desired conditions for vegetation, and describe land use activities and levels that are appropriate to maintain healthy vegetation. Wise planning also considers the importance of other natural resources, such as water and soil, when developing vegetation restoration strategies. In addition, BLM land use plans identify transportation facilities, utility corridors, and other infrastructure development on public lands that is likely to receive some form of vegetation treatment.

To assist with vegetation management planning, key resource elements, such as plant community types, aquatic habitats, sensitive areas, and invasive species concentration areas, are inventoried and mapped regionally and district-wide. Inventories and maps allow field managers to identify areas of high ecological integrity; to ensure that there is suitable habitat for wide-ranging species; to identify areas where land uses may be incompatible with long-term ecosystem health; and to identify areas that could benefit from improved management. Inventories and mapping are also done at the local level to help managers better understand how proposed projects fit in with vegetative conditions on a larger scale, such as within ecoregions or watersheds. The BLM also cooperates with other agencies, organizations, and landowners in regional planning efforts, including establishment of Cooperative Weed Management Areas.

\section{Site Selection and Treatment Priorities}

Upon approval of a land use plan, subsequent implementation decisions are often put into effect by developing implementation plans. Implementation plans, also referred to as "activity plans," tend to focus on multiple resources, and include vegetation treatment activities within a BLM field office jurisdiction. Implementation plans are made with the appropriate level of NEPA analysis; implementation decisions are usually made by BLM field managers. Implementation decisions identify site-specific vegetation management practices to achieve desired outcomes laid out in the land use plans. Some examples of practices include fuels treatments and integrated vegetation management techniques for weed infestations.

\section{General Site Selection and Treatment Priorities}

Several factors influence where treatments will occur and treatment priorities:

- Statutory mandates, including the FLPMA, ESA, HFRA, and Taylor Grazing Act.

- Program guidance including such initiatives as the Healthy Forests Initiative and the Great Basin Restoration Initiative.

- Goals of the Strategic and Annual Performance Plans.

- Existing risks to resources.

- Likelihood of success in restoring natural biotic communities.

- Cost-effectiveness of actions.

National priorities have been established for various BLM vegetation management programs. These priorities were developed for use in conjunction with state and local office priorities for meeting restoration goals, and address site-specific conditions and/or issues as laid out in the land use plan. For example, the following treatment priorities have been established to promote integrated efforts across BLM resource programs that manage vegetation:

- WUI community protection treatments that are designed to reduce the risk of wildfire to the community and/or its infrastructure developed collaboratively with the community.

- Treatments to restore or maintain healthy, diverse, resilient, and productive native plant communities.

- Special status species habitat improvement projects designed to improve or protect special status fish, wildlife, and plant habitat.

- Treatments that will be planned, implemented, and/or monitored using funding from multiple sources, both internal and external.

- Landscape treatments $(>1,000$ acres for mechanical and $>4,500$ acres for prescribed fires), coordinated across field office boundaries, to improve treatment effectiveness.

- Contracted treatments that support economic opportunities for rural communities and/or high potential to use stewardship contracting authorities. 
- Treatments that have a high potential for woody biomass utilization.

\section{Weed Treatment Site Selection and Treatment Priorities}

For noxious weeds and invasive plants, vegetation treatment priorities identified in the EIS Vegetation Treatment on BLM Lands in Thirteen Western States (USDI BLM 1991a) are still applicable. They are:

- Take actions to prevent or minimize the need for vegetation controls, where feasible.

- Use effective nonchemical methods of vegetation control, where feasible.

- Use herbicides only after considering the effectiveness of all potential methods.

Development of a weed management strategy is set up at the local level and aligned with the land use planning objectives.

Actions to prevent or minimize the need for vegetation control can include protecting intact systems; maintaining conditions that have led to healthy lands (e.g., allowing natural fires to burn); reducing the impact of ongoing activities (e.g., improving grazing management practices); and applying mitigation measures to new projects to minimize soil and vegetation disturbance and avoid introductions of invasive species.

If treatment is required, efforts are focused on activities that restore natural ecosystem processes, and on ventures that are likely to succeed and provide the greatest benefits with the least expenditure of capital. Also beneficial to treatment success is site-specific analysis that includes 1 ) a determination of site potential under current circumstances, 2) an evaluation of land health based on land assessment studies, 3) an assessment of causes of land degradation, 4) an assessment of the likely effectiveness of treatment methods, and 5) an evaluation of the success of restoration efforts on similar types of land.

Several management objectives are considered when determining appropriate treatment of an infestation.

- Containment to prevent weed spread from moving beyond the current infestation perimeter;
- Control to reduce the extent and density of a target weed;

- Eradication to completely eliminate the weed species including reproductive propagulcs (this is usually only possible with small infestations); and

- Restoration of native plant communities and habitats using native species that are adapted to the project site to compete with invasives.

Several variables are considered when determining what, when, and how weed populations should be treated. These include, but are not limited to:

- The species - is it an aggressive non-native species that could be on a state noxious weed list or an adjacent state's noxious weed list, or that could be a species known for altering plant communities or ecological processes on a regional basis? If a species is native to a project area, how does current management influence the increase of the species beyond acceptable levels?

- Location - is the infestation found in a special management area, in a formerly uninfested area, or upslope/upstream from current treatments (i.e., could the species reinfest treated areas)? Does the infestation pressure or negatively impact special status plants or their habitats?

- Extent - is the infestation at a size where eradication is possible, in an area where other infestations are numerous, or of a size that may not be able to be eradicated, but can be contained or controlled to some extent? Is the extent of the infestation so large that one treatment would cover all of the known locations of an endemic species or its required resources?

The following suggests a decision process for prioritizing weed treatments in order to focus efforts towards success. It provides broad guidance to be adapted to the local level based on species, size, and extent of infestations. Priorities are then matched with the management objectives listed above.

1. Highest Priority: New aggressive infestations in an uninfested area or small infestations in areas of special 
concern (e.g., wilderness, research natural areas). Management objective: Eradicate.

2. Higher Priority: Areas of high traffic or sources of infestation and larger infestations in areas of special concern. Management objective: Control.

3. High Priority: Existing large infestations or roadside infestations where spread can be checked or slowed. Management objective: Contain.

The overriding goal is to prioritize treatment methods based on their effectiveness and likelihood to have minimal impacts on the environment, and to restore desirable vegetation on lands where necessary (i.e., where desired vegetation cannot reestablish naturally).

\section{Vegetation Treatment Methods}

Although this PEIS focuses on BLM vegetation treatments using herbicides, such treatments are only a small part of a larger effort proposed by the BLM to treat vegetation on approximately 6 million acres each year. In addition to herbicides, the BLM uses fire and manual, mechanical, and biological control treatment methods. The use of these non-herbicide methods is discussed in more detail in the PER. As with herbicides, treatments using other methods can occur anywhere on public lands, although actual treatment methods, acres treated, and treatment locations are determined at the local field level and by Congressional direction and funding. Currently, the BLM is treating about 2 million acres annually using all methods.

Herbicides are chemicals that kill or injure plants. Herbicides can be categorized as selective or nonselective. Selective herbicides kill only a specific type of plant, such as broad-leaved plants, while nonselective herbicides kill all types of plants. The use of herbicides and modes of action are discussed in more detail below.

Fire use includes prescribed fire and wildland fire use for resource benefits. Prescribed fire is the intentional application of fire to wildland fuels under specified conditions of fuels, weather, and other variables. The intent is for the fire to stay within a predetermined area to achieve site-specific resource management objectives. Wildland fire use for resource benefit is a fire ignited by lightening but allowed to burn within specified conditions of fuels, weather, and topography, to achieve specific objectives
Mechanical treatment involves the use of vehicles such as wheeled tractors, crawler-type tractors, or specially designed vehicles with attached implements designed to cut, uproot, or chop existing vegetation. Mechanical methods that may be used by the BLM include chaining, root plowing, tilling and drill seeding, mowing, roller chopping and cutting, blading, grubbing, and feller-bunching.

Manual treatment involves the use of hand tools and hand-operated power tools to cut, clear, or prune herbaceous and woody species. Treatments include cutting undesired plants above the ground level; pulling, grubbing, or digging out root systems of undesired plants to prevent sprouting and regrowth; cutting at the ground level or removing competing plants around desired species; or placing mulch around desired vegetation to limit competitive growth (USDI BLM 1991a).

Biological control involves the intentional use of domestic animals, insects, nematodes, mites, or pathogens (agents such as bacteria or fungus that can cause diseases in plants) that weaken or destroy vegetation (USDI BLM 1991a, Bonneville Power Administration [BPA] 2000). Biological control is used to reduce the targeted weed population to an acceptable level by stressing target plants and reducing competition with the desired plant species.

\section{Integrating Vegetation Treatments}

The BLM treats vegetation using fire, mechanical and manual methods, biological treatments, and herbicides. In an integrated vegetation management program, each management option is considered, recognizing that no one management option is a stand-alone option and that each has its own strengths and weakness. Utilizing the strengths of each allows for a more effective and environmentally sound program. When the BLM plans vegetation control management projects, all control methods should be available for use, allowing the BLM to select the one method, or the combination of methods, that optimizes vegetation control with respect to environmental concerns, effectiveness, and cost of control.

No individual method will control undesirable vegetation in a single treatment; diligence and persistence will be required over a number of years to subdue vegetation such as weeds. The success of different treatment methods depends on the type of vegetation being controlled. It is important to think of 
these treatment methods as they relate to specific characteristics of weeds and other vegetation.

\section{Vegetation Treatment Method Selection}

Vegetation treatment methods are selected based on several parameters, which may include the following:

- Management program/objective for the site.

- Historic and current conditions.

- Opportunities to prevent future problems.

- Opportunities to conserve native and desirable vegetation.

- Effectiveness and cost of the treatment methods.

- Success of past restoration treatments or treatments conducted under similar conditions or recommendations by local experts.

- Characteristics of the target plant species, including size, distribution, density, life cycle, and life stage in which the plant is most susceptible to treatment.

- Non-target plant species that could be impacted by the treatment.

- Land use of the target area.

- Proximity to communities.

- Slope, accessibility, and soil characteristics of the treatment area.

- Weather conditions at the time of treatment, particularly wind speed and direction, precipitation prior to or likely to occur during or after application, and season.

- Proximity of the treatment area to sensitive areas, such as wetlands, streams, or habitat for plant or animal species of concern.

- Potential impacts to humans and fish and wildlife, including non-game species.

- Need for subsequent revegetation and/or restoration.

These parameters are considered before a treatment method is selected (USDI BLM 1991a). For most vegetation treatment projects, pretreatment surveys are conducted before selecting one or more treatment methods. These surveys involve the consideration of all feasible treatments, including their potential effectiveness based on previous experience, and best available science, impacts, and costs. Before vegetation treatment or ground disturbance occurs, the BLM consults specialists or databases for information on sensitive areas within the project area. The site may have to be surveyed for listed or proposed federal threatened or endangered species and for evidence of cultural or historic sites. In some cases, areas may receive one or more treatments in combination, such as prescribed burning followed by an herbicide application, and some areas may be treated using one or more treatment methods over several years.

\section{Herbicide Active Ingredients Evaluated under the Proposed Alternatives}

In previous EISs, a total of 25 herbicide active ingredients were reviewed, 22 were evaluated, and 20 were approved for use in one or more states (Tables 2-1 and 2-2). The decision to approve these herbicides for use on public lands was based on a detailed analysis of the risks to human health and non-target species from the use of these chemicals.

Since the majority of these assessments were completed in the late 1980 s, a comprehensive literature review was conducted as part of this PEIS to determine whether there was any significant new information relevant to environmental concerns regarding the continued use of these herbicides (McMullin and Thomas 2000). Local BLM field offices were also consulted for information from field applications suggesting that any of these chemicals should be re-analyzed. If so, a new risk assessment for that active ingredient was completed as part of this PEIS in order to assess whether the BLM should continue its use.

Based on the literature review and information from the field, sulfometuron methyl (Oust ${ }^{\mathbb{B}}$ ) was found to potentially have significant impacts on non-target vegetation when carried on soil to untreated areas, effects that were not evaluated earlier. Thus, the toxicity and environmental fate of sulfometuron methyl were analyzed in this PEIS. It was determined that the remaining 19 herbicides did not require further analysis for human health risks. However, the BLM determined that the level of analysis contained in the non-target species assessments for fish and wildlife for the 


\section{Herbicide Terminology}

Active ingredient (a.i.) is the chemical or biological component that kills or controls the target pest.

Adjuvant(s) are chemicals that are added to the pesticide formulation to enhance the toxicity of the active ingredient or to make the active ingredient easier to handle.

Formulation is the commercial mixture of both active and inactive ingredients.

Herbicide is a chemical pesticide used to treat vegetation.

Herbicide resistance occurs when naturally occurring heritable characteristics allow individual weeds to survive and reproduce, producing a population, over time, in which the majority of the plants of the weed species have the resistant characteristics.

Other ingredient(s) are those ingredients that are added to the commercial product (formulation), but are not herbicidally active. In the past, these were referred to as inert ingredients.

previous EISs was inadequate to characterize the risks to species of concern, including anadromous fish.

Since the mid-1990s, the Forest Service conducted ecological risk assessments (ERAs) for nine herbicide active ingredients also used by the BLM: 2,4-D, clopyralid, dicamba, glyphosate, hexazinone, imazapyr, metsulfuron methyl, picloram, and triclopyr. In addition, the Forest Service prepared interactive spreadsheets that allowed the BLM to determine exposure concentrations for plants and animals under different application rates and exposure scenarios for these herbicides. The ERAs and spreadsheets are available on the Internet at the Forest Service Pesticide Management and Coordination websitc at http://www.fs.fed.us/foresthealth/pesticide/risk.shtml.

Information contained in the ERAs was used by the BLM to characterize risks to non-target species from the specific chemicals and is incorporated by reference into this PEIS.

The Forest Service did not conduct ERAs for bromacil, chlorsulfuron, diuron, and tebuthiuron. Thus, the BLM conducted new ERAs for these herbicides as part of this PEIS.

The remaining six active ingredients currently approved for use by the BLM-2,4-DP, asulam, atrazine, fosamine, mefluidide, and simazine-have not been used, or their use has been limited to a very small number of acres, by the BLM for several years, primarily due to the availability of other, more effective approved active ingredients.

The BLM proposes to use four new herbicide active ingredients that are registered and available for use-diflufenzopyr (as a formulation with dicamba), diquat, fluridone, and imazapic. All four of the herbicides have been deemed effective in controlling vegetation, have minimal effects on the environment and human health if used properly, and are registered (except diflufenzopyr as a stand-alone active ingredient) with the USEPA. Diflufenzopyr is approved as a formulation with dicamba and is labeled as Distinct ${ }^{\circledR}$ and Overdrive ${ }^{\circledR}$, but cannot be used as a stand-alone active ingredient by the BLM until it is registered with the USEPA.

The new active ingredients were selected based on: 1) input from BLM field offices on types of vegetation needing control; 2) studies indicating that these active ingredients would be more effective in controlling noxious weeds and other unwanted vegetation targeted for control than active ingredients currently used by the BLM; 3) USEPA approval for use on rangelands, forestlands, and/or aquatic environments (see http://cfpub.epa.gov/oppref/rereg/status.cfm?show=rere $\mathrm{g}$ for information on herbicide registration and fact sheets on all registered products); 4) responses from herbicide manufacturers to a request from the BLM in October 2001 for a list of herbicides not currently approved for use on public lands that may be appropriate to control vegetation; 5) the ability of the herbicide formulations to be applied on a variety of plant species needing control; 6) the level of risk of the herbicidal formulations to human health and the environment; and 7) the funds available to the BLM to conduct human health and ecological risk assessments of the proposed herbicides.

Diflufenzopyr, which is used in combination with dicamba for weed control, inhibits the transport of auxin in the plant. The result is an abnormal accumulation of auxin or auxin-like compounds in the growing points of susceptible plants and an imbalance in growth hormones in the plant. The combination of diflufenzopyr and dicamba is registered for use in all 17 western states except Alaska and California.

Diquat is a post-emergence, nonselective herbicide that can be applied directly to vegetation or to ponds, lakes, or drainage ditches for the management of aquatic weed species. Diquat is a cell membrane disrupter, whose 


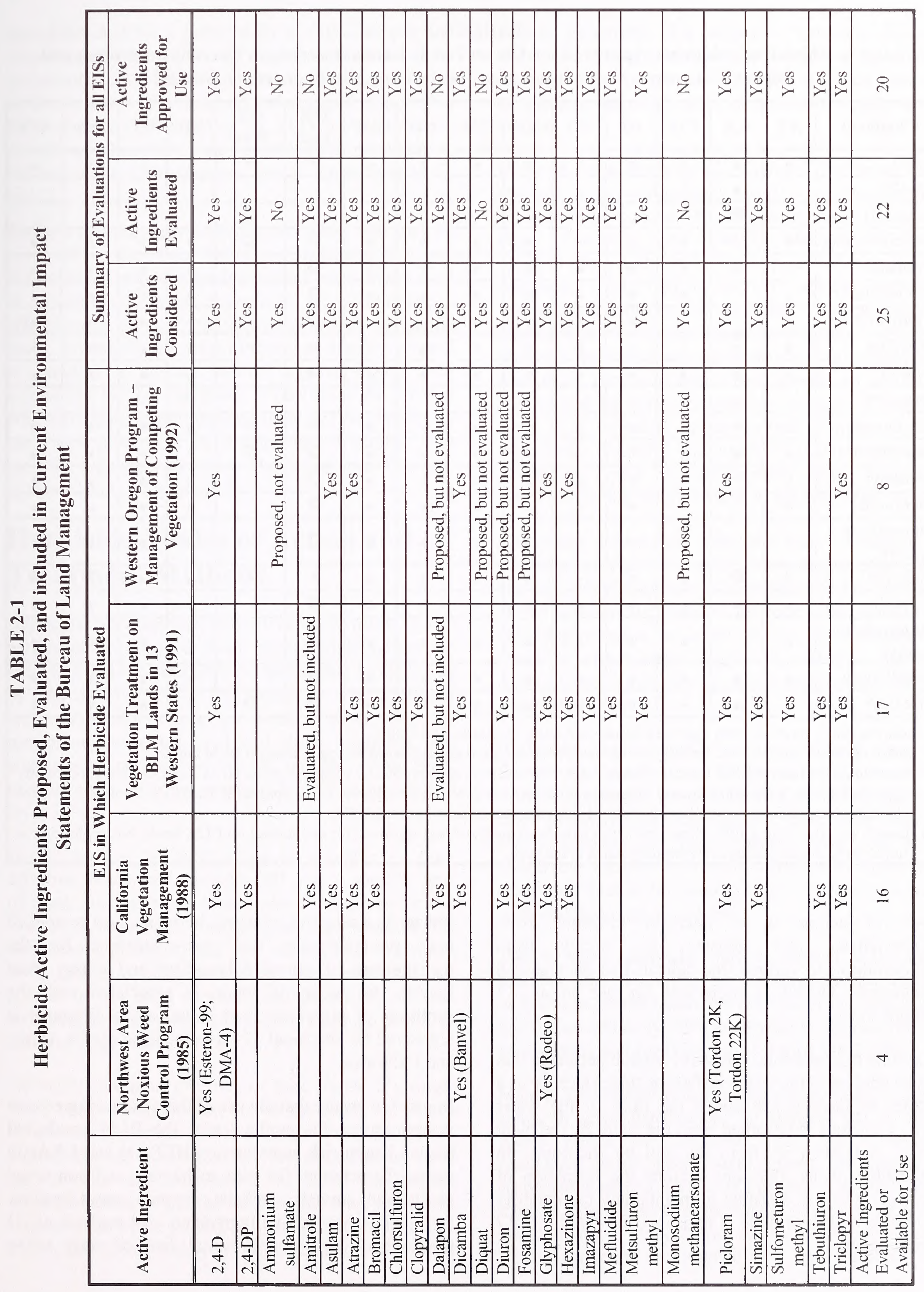


TABLE 2-2

States in which Herbicides are Approved for Use on Public Lands Based upon Current Environmental Impact Statements, Court Injunctions, and Changes in Registration Status ${ }^{1}$

\begin{tabular}{|c|c|c|c|c|c|c|c|c|c|c|c|c|c|c|c|}
\hline Chemical & $\mathbf{A Z}$ & CA & $\mathrm{CO}$ & ID & MT & NV & NM & ND & OK & $\begin{array}{l}\text { OR } \\
\text { East }\end{array}$ & $\begin{array}{c}\text { OR } \\
\text { West }\end{array}$ & SD & UT & WA & WY \\
\hline 2,4-D & 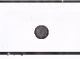 & - & $\circ$ & $\bullet$ & - & - & $\bullet$ & - & - & - & $\bullet$ & $\bullet$ & $\bullet$ & - & - \\
\hline 2,4-DP & & - & & & & & & & & & & & & & \\
\hline Asulam & & O & & & & & & & & & 0 & & & & \\
\hline Atrazine & - & - & - & - & $\bullet$ & - & $\bullet$ & - & - & 0 & 0 & $\bullet$ & $\bullet$ & 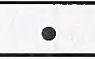 & - \\
\hline Bromacil & - & - & - & - & - & - & - & - & - & 0 & & - & - & $\bullet$ & - \\
\hline Chlorsulfuron & - & & - & - & - & - & - & - & - & 0 & & $\bullet$ & - & $\bullet$ & - \\
\hline Clopyralid & - & & - & - & $\bullet$ & - & - & $\bullet$ & 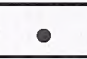 & 0 & & $\bullet$ & $\bullet$ & $\bullet$ & - \\
\hline Dicamba & - & - & - & $\bullet$ & - & - & - & $\bullet$ & - & - & - & - & - & $\bullet$ & - \\
\hline Diuron & 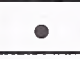 & $\bullet$ & - & $\bullet$ & $\bullet$ & $\bullet$ & $\bullet$ & $\bullet$ & $\bullet$ & 0 & & $\bullet$ & - & $\bullet$ & - \\
\hline Fosamine & & - & & & & & & & & & & & & & \\
\hline Glyphosate & - & $\bullet$ & - & $\bullet$ & - & - & - & - & - & $\bullet$ & $\bullet$ & - & - & $\bullet$ & $\cdot$ \\
\hline Hexazinone & - & - & $\bullet$ & - & - & - & - & - & $\bullet$ & 0 & 0 & - & - & - & - \\
\hline Imazapyr & - & & $\bullet$ & - & - & - & 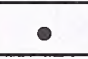 & - & 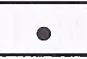 & 0 & & - & - & - & - \\
\hline Mefluidide & - & & $\bullet$ & - & - & - & - & - & - & 0 & & - & $\bullet$ & $\bullet$ & - \\
\hline $\begin{array}{l}\text { Metsulfuron } \\
\text { methyl }\end{array}$ & - & & - & - & $\bullet$ & - & - & - & - & 0 & & - & - & - & $\bullet$ \\
\hline Picloram & - & 0 & - & - & - & 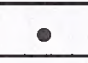 & 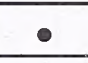 & - & $\bullet$ & - & $\bullet$ & - & $\bullet$ & 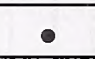 & - \\
\hline Simazine & $\bullet$ & $\bullet$ & - & - & - & - & - & $\bullet$ & $\bullet$ & 0 & & - & $\bullet$ & $\bullet$ & $\bullet$ \\
\hline $\begin{array}{l}\text { Sulfometuron } \\
\text { methyl }\end{array}$ & - & & - & - & $\bullet$ & $\bullet$ & - & - & - & 0 & & - & $\bullet$ & - & - \\
\hline Tebuthiuron & - & - & $\bullet$ & - & - & - & - & - & $\circ$ & 0 & & 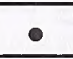 & 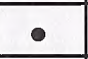 & - & - \\
\hline Triclopyr & $\bullet$ & - & - & $\bullet$ & - & - & - & - & - & 0 & 0 & - & - & - & 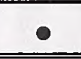 \\
\hline \multicolumn{16}{|c|}{$\begin{array}{l}{ }^{1} \text { These chemicals have not been approved for use in Alaska, Nebraska, and Texas. } \\
\text { - Based upon the current EISs, these herbicides have been analyzed and approved for application on BLM lands. } \\
\text { - Based upon the current EISs, these herbicides have been analyzed and approved for application on BLM lands, but are not currently } \\
\text { approved for use in Oregon per court injunction (Southern Oregon Citizens Against Toxic Sprays (SOCATS) v. Watt, No. 79-1098 } \\
\text { (District Court of Oregon. October 20,1982), 13 Environmental Law Report 20, 176. } \\
\text { Based upon the current EISs, these herbicides have been analyzed and approved for application on BLM lands, but application is } \\
\text { not allowed due to change in registration status in the state. }\end{array}$} \\
\hline
\end{tabular}

mode of action is to intercept electrons from photosynthesis and transfer the energy from photosynthesis to various free radicals that damage cell membranes. Diquat is registered for use in all 17 western states.

Fluridone is a systemic, selective, aquatic herbicide that can be applied to the water surface or subsurface, or as a bottom application just above the floor of the water body. Fluridone is absorbed from the water by the plant shoots and taken up from the soil by the roots. In susceptible plants, fluridone inhibits the formation of carotene, which is essential in maintaining the integrity of chlorophyll. Fluridone is registered for use in all 17 western states.
Imazapic, a selective, systemic herbicide, can be applied both pre-emergence and post-emergence for the management of selective broadleaf and grassy plant species. Its mode of action is associated with the synthesis of branch-chained amino acids. Imazapic is registered for use in all 17 western states except Alaska and California.

In order to ensure that the use of these active ingredients is appropriate for public lands, the BLM conducted human health risk assessments (HHRAs) and ERAs te assess the potential for risks to humans and non-target plants and animals, including special status species, from using these active ingredients. An analysis of: 1) the toxicity and environmental fate of each active 
ingredient, and for a formulation of diflufenzopyr and dicamba (Overdrive $\left.{ }^{\circledR}\right)$; 2) risks associated with surfactants found in herbicide formulations and herbicide active ingredient degradates; and 3) potential for herbicides considered in the PEIS to be endocrine disrupting chemicals, are provided in Chapter 4, Environmental Consequences, and in appendixes B, C, and $\mathrm{D}$.

For new and currently available herbicides that may be proposed for use in the future, the BLM would follow the following steps for conducting risk assessments used in this PEIS: 1) assess a product's or a technology's effectiveness for use on target vegetation on public lands; 2) identify the level of data and analysis needed to conduct a human health and ecological risk assessment for that chemical; 3) determine the level of NEPA documentation required to support a decision to use a new product or technology; and 4) consult with the ESA regulatory agencies. These steps are discussed in more detail in Appendix E.

\section{Herbicide Modes of Action and Treatment Methods}

Herbicides are chemicals that kill or injure plants. Some herbicides are derived from plants, while others are manufactured synthetically. Herbicides can be classified by their mode of action, and include growth regulators, amino acid inhibitors, grass meristem destroyers, cell membrane destroyers, root and shoot inhibitors, and amino acid derivatives, which interfere with plant metabolism in a variety of ways (Table 2-3; Bussan and Dyer 1999).

Herbicides can be categorized as selective or nonselective. Selective herbicides kill only a specific type of plant, such as broad-leaved plants. Many herbicides used for vegetation management are selective for broadleaved plants, so that they can be used to manage such species while maintaining the desirable grass species in rangeland communities. Glyphosate is nonselective, so it must be used carefully around desirable and non-target plants (Rees et al. 1996).

Herbicides are most effective on pure stands of a single weed where desirable and non-target plants are scarce or absent (Colorado Natural Areas Program 2000). Herbicides are also effective for rhizomatous weed species that are unpalatable to livestock, require repeated cutting or pulling for control, or are located in remote areas where pulling and cutting are not feasible. Herbicides often work well in combination with other control treatments. For example, tamarisk, Russian olive, and Siberian elm can be controlled by cutting stems close to the ground in the fall and then spraying or painting the stems with an herbicide registered for that use.

Herbicide treatments would follow BLM procedures outlined in BLM Handbook H-9011-1 (Chemical Pest Control), and manuals 1112 (Safety), 9011 (Chemical Pest Control), and 9015 (Integrated Weed Management), and would meet or exceed states' label standards (USDI BLM 1991a). Several herbicide application methods are available. The application method chosen depends upon the treatment objective (removal or reduction); accessibility, topography, and size of the treatment area; characteristics of the target species and the desired vegetation; location of sensitive areas and potential environmental impacts in the immediate vicinity; anticipated costs; equipment limitations; and meteorological and vegetative conditions of the treatment area at the time of treatment.

Herbicide application schedules are designed to minimize potential impacts to non-target plants and animals, while remaining consistent with the objective of the vegetation treatment program. The application rates depend upon the target species, the presence and condition of non-target vegetation, soil type, depth to the water table, presence of other water sources, and the label requirements.

Herbicides can be applied aerially with helicopters or fixed-wing aircraft, or on the ground with vehicles or manual application devices. Operation of helicopters is more expensive than operation of fixed-wing aircraft, but helicopters are more maneuverable and more effective in areas with irregular terrain. Helicopters also are more effective for treating target vegetation in areas with multiple vegetation types.

Two or more herbicides may be applied at the same time in a tank mix, when tank mixtures are speeified on at least one of the labels for the chemicals used in the mix. Approximately $25 \%$ of herbicide applications on public lands involved tank mixes during 2002-2005.

Manual applications of herbicides are used only in small areas, in areas inaccessible by vehicle, and in areas where weeds are scattered. They are sometimes considered when special status plants are known or suspected in all or a portion of a project area. Herbicides may be applied with a backpack applicator or spray bottle, wick (wiped on), or wand (sprayed on). Herbicides can be applied to trees around the 
circumference of the trunk on the intact bark (basal bark), to cuts in the trunk or stem (frill, or "hack and squirt"), to cut stems and stumps (cut stump), or injected into the inner bark (Tu et al. 2001).

Herbicides can be used selectively to control specific types of vegetation, or non-selectively to clear all vegetation on a particular area. Herbicides can be applied over large areas and/or in remote locations using aircraft, or applied using spot applications in smaller, easily accessible locations.

There are several drawbacks and limitations to herbicide use. Herbicides can damage or kill non-target plants. Herbicides can be toxic or cause health problems in humans, other animals, and other plants. Herbicides must be applied by someone with the appropriate certification identified in state laws and BLM policy (Colorado Natural Areas Program 2000).

Herbicides would be applied according to the current label directions. The BLM would comply with changes in label directions that may occur in the future, and would comply with state registration requirements. Thus, if current state requirements do not allow the application of an herbicide approved for use in the PEIS, the BLM would not apply that herbicide in the state where it is not approved for use.

Weed populations may develop a resistance to a particular herbicide over time. Herbicide resistance is the inherited ability of a plant to survive an herbicide application to which the wild-type was susceptible. Resistant plants occur naturally within a population and differ slightly in genetic makeup, but remain reproductively compatible with the wild-type. Herbicide resistant plants are present in a population in extremely small numbers. The repeated use of one herbicide allows these few plants to survive and reproduce. The number of resistant plants then increases in the population until the herbicide no longer effectively controls the weed. Herbicide resistance is not the natural tolerance that some species have to an herbicide. The appearance of herbicide-resistant weeds is strongly linked to repeated use of the same herbicide or herbicides with the same site of action in a monoculture cropping system or in non-crop areas.

There are several things that can be done, and are being done by the BLM, to minimize the potential development of resistant weed species, including, but not limited to the following:
- Rotate herbicides - by understanding the different modes of action of each herbicide proposed for use on public lands, select the appropriate one to minimize resistance;

- Understand the potential effects of long-term residual herbicides on the selection for resistant weeds, and correctly apply these herbicides with the understanding that they can lead to weed resistance if used yearly for several consecutive years;

- Use mechanical and biological management options to eliminate weed escapes that may represent the resistant population; and

- Keep accurate records of herbicide application.

\section{Description of the Alternatives}

Five program alternatives were developed for and evaluated in this PEIS, including the Preferred Alternative and the No Action Alternative. Alternative actions are those that could be taken to feasibly attain, or approximate the BLM's objectives for herbicide use, as expressed in its programs, policies, and land use plans.

Alternatives were developed that 1) allow the BLM to continue its current use of 20 active ingredients in 14 western states, as authorized by earlier EIS RODs; 2) allow for the use of 14 active ingredients currently used by the BLM and four new active ingredients; 3 ) prohibit the use of herbicides; 4) prohibit the aerial application of herbicides; or 5) prohibit the use of sulfonylurea and other acetolactate synthase-inhibiting active ingredients. These program alternatives address many of the concerns raised during scoping, in particular the public's desire to see alternatives that place less emphasis on the use of herbicides, while still meeting the program's purpose and need. Alternatives were also developed to ensure that the BLM complied with federal, tribal, state, and local regulations.

\section{Alternative A - Continue Present Herbicide Use (No Action Alternative)}

Under this alternative, the BLM would be able to continue to use 20 active ingredients approved for use in western states under the earlier EIS RODs for each state (Table 2-1; USDI BLM 1987a, 1988b, 1991b, 1992a). The BLM would also continue its activities conducted under Emergency Stabilization and Burned Area Rehabilitation and hazardous fuel reduction that are 


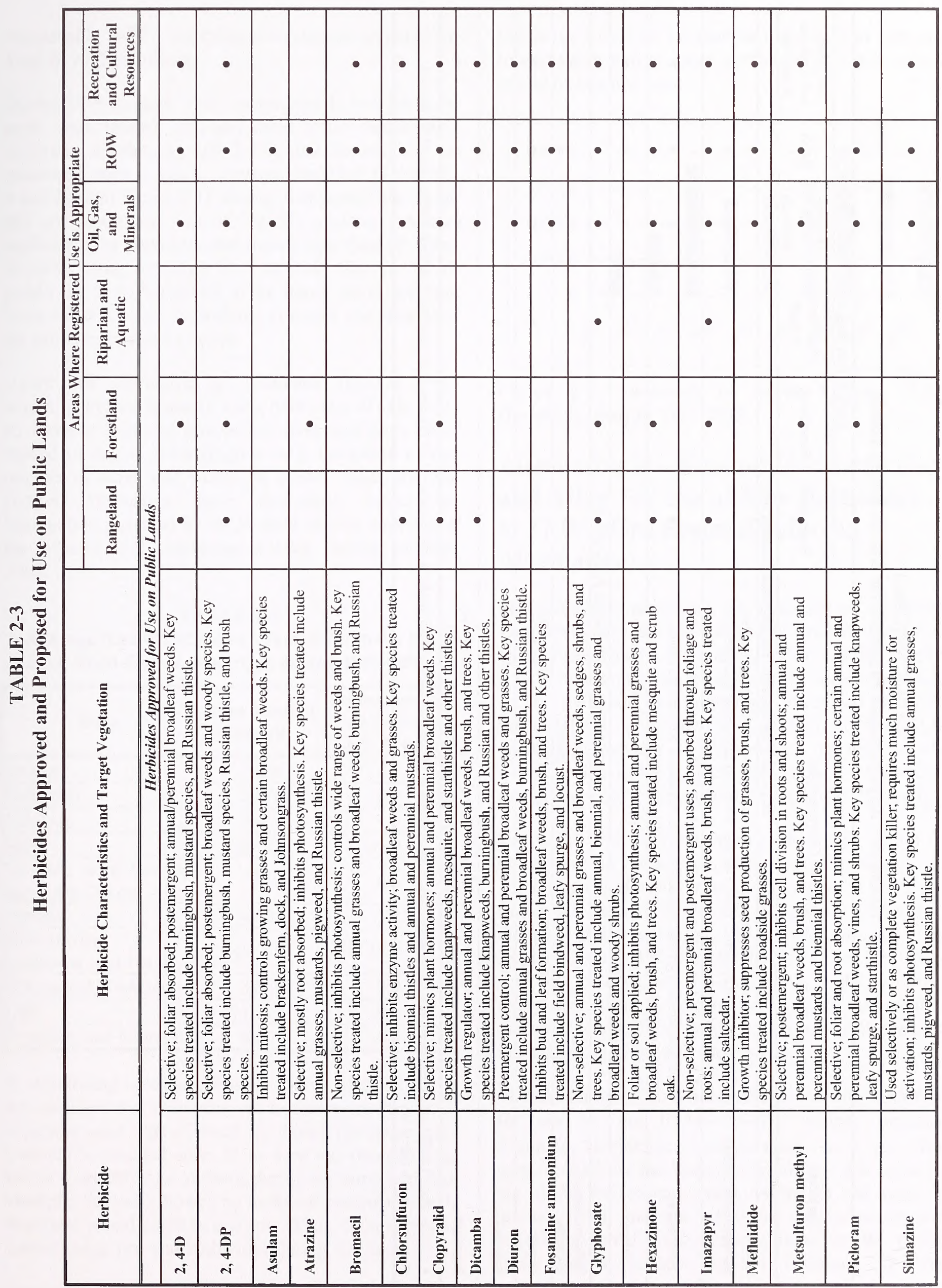




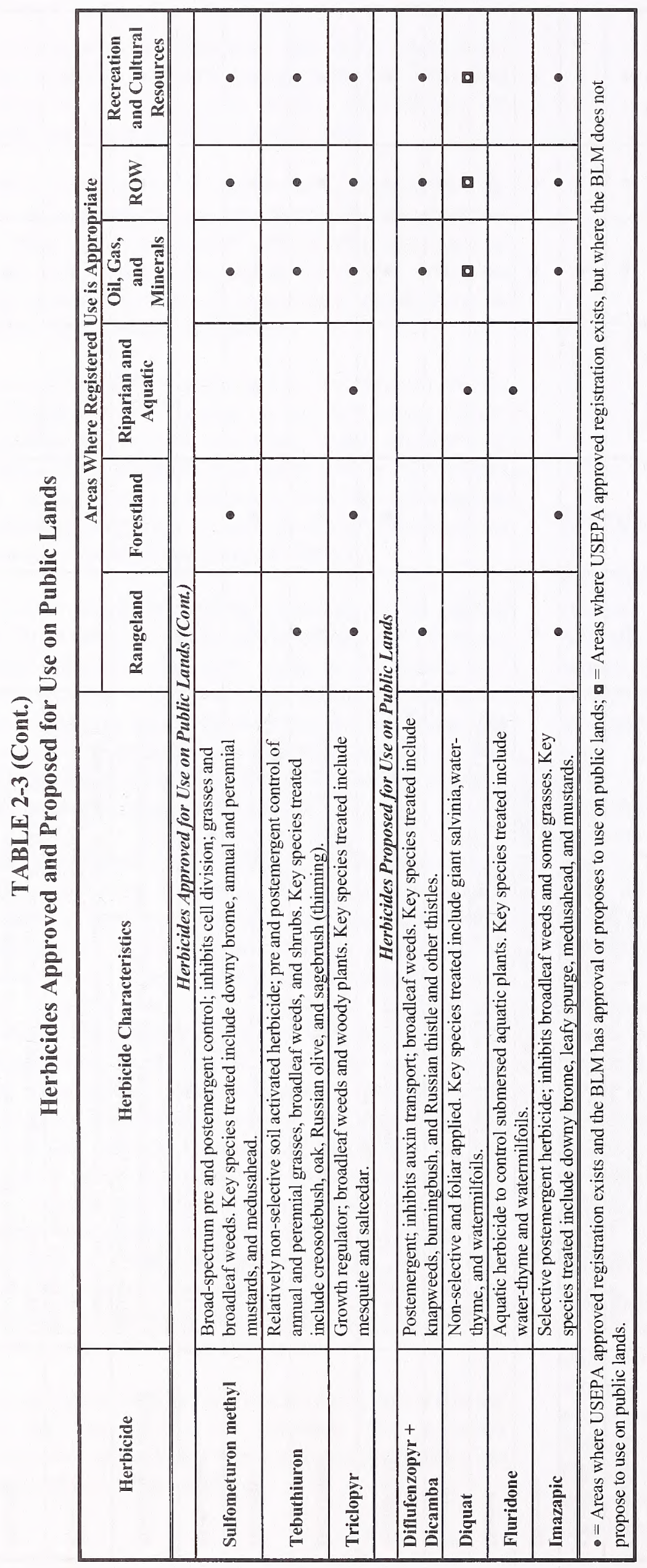


evaluated by NEPA compliance documents prepared by local BLM field offices.

During 1999 through 2005, approximately two-thirds of acres were treated with just three active ingredients: picloram, tebuthiuron, and 2,4-D, and the majority of treatments were in Idaho, Montana, and Utah (Tables 24 and 2-5 and Figure 2-1). During that period, the BLM did not report any use of 2,4-DP, asulam, atrazine, mefluidide, or simazine, and treated less than 50 acres annually using fosamine. It is unlikely that the BLM would use these herbicides in the future since there are more suitable active ingredients available and approved for use to meet current needs.

Under this alternative, an estimated 305,000 acres would be treated annually using herbicides (Table 2-6), an increase over the number of acres that have been treated in recent years (Figure 2-1). Estimates of the number of acres that would be treated under the No Action Alternative were developed based on information provided by BLM field offices throughout the western U.S., including Alaska, during summer 2002.

TABLE 2-4

Average Number of Acres Treated Annually for Each BLM State Jurisdiction during 1997-2005.

\begin{tabular}{|l|c|c|}
\hline \multicolumn{1}{|c|}{ State } & $\begin{array}{c}\text { Acres Treated } \\
\text { Annually }\end{array}$ & $\begin{array}{c}\text { Percentage of } \\
\text { all Public } \\
\text { Lands Treated }\end{array}$ \\
\hline \hline Arizona & 7,664 & 6.3 \\
\hline California & 2,676 & 2.2 \\
\hline Colorado & 5,480 & 4.0 \\
\hline Idaho & 30,572 & 25.0 \\
\hline $\begin{array}{l}\text { Montana, North Dakota, } \\
\text { and South Dakota }\end{array}$ & 7,739 & 6.3 \\
\hline Nevada & 4,820 & 3.9 \\
\hline $\begin{array}{l}\text { New Mexico, } \\
\text { Oklahoma, and Texas }\end{array}$ & 42,570 & 34.8 \\
\hline Oregon and Washington & 3,543 & 2.9 \\
\hline Utah & 11,175 & 9.1 \\
\hline Wyoming and Nebraska & 6,667 & 5.5 \\
\hline
\end{tabular}

In developing acreage estimates for all alternatives, it was assumed that if an acre was treated more than once using the same type of treatment during the same year, it would be counted once. If the acre was treated using two or more different methods during the same year (for example, fire use followed by herbicide treatment), each treatment would count as one acre. Thus, if an acre was treated using fire and herbicides during the same year, two acres would be counted as treated. If an acre was treated using two or more herbicides in a tank mix, it would be counted once.

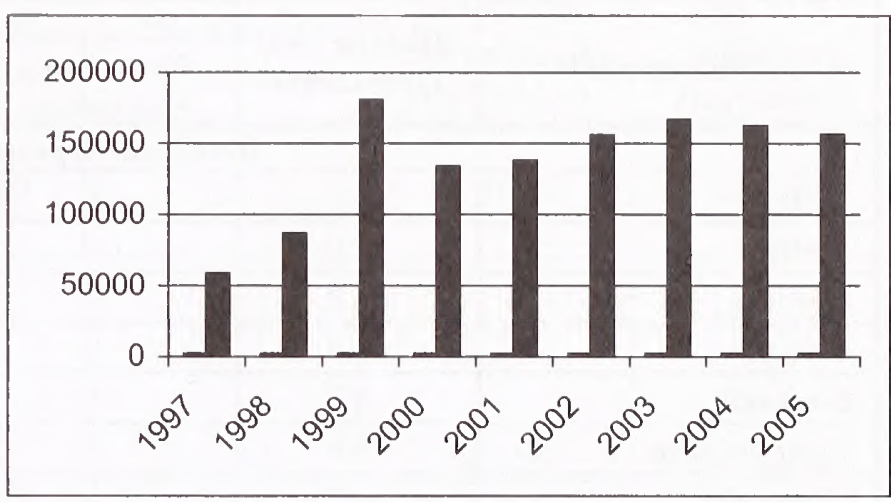

Figure 2-1. Summary of Acres Treated Using Herbicides during 1997-2005.

\section{Alternative B - Expand Herbicide Use and Allow for Use of New Herbicides in 17 Western States (Preferred Alternative)}

This alternative represents the treatment of vegetation using herbicides in 17 western states (including Alaska). Under the Preferred Alternative, approximately 932,000 acres would be treated annually using herbicides, based on the herbicide use projections developed by BLM field offices and funding projections for BLM vegetation treatment activities during the next decade. Based on field office projects, the majority of treatments would occur in Nevada, Idaho, Oregon, and Wyoming.

Under the Preferred Alternative, the BLM would be able to use, in the western U.S., including Alaska, the 14 active ingredients that were approved for use in the earlier RODs and for which an analysis of risks to humans and non-target plants and animals was conducted for this PEIS or by the Forest Service. These active ingredients are: 2,4-D, bromacil, chlorsulfuron, clopyralid, dicamba, diuron, glyphosate, hexazinone, imazapyr, metsulfuron methyl, picloram, sulfometuron methyl, tebuthiuron, and triclopyr.

The remaining six active ingredients currently approved for use by the BLM-2,4-DP, asulam, atrazine, fosamine, mefluidide, and simazine have not been used, or their use has been limited to very few acres, by the BLM for several years. Although the risks to humans from the use of these chemicals are not significant based on evaluations done for the earlier EISs and a review of the literature for this 
TABLE 2-5

Historic Use of Herbicides by the BLM and Projected Future Use of Herbicides by the BLM under Each Alternative (as a percentage of all acres treated using herbicides)

\begin{tabular}{|c|c|c|c|c|c|c|}
\hline \multirow[b]{2}{*}{ Active Ingredient } & \multirow[b]{2}{*}{$\begin{array}{l}\text { Historic Use } \\
\text { (1999-2005) }\end{array}$} & \multicolumn{5}{|c|}{ Projected Use Under Each Alternative } \\
\hline & & $\begin{array}{l}\text { No Action } \\
\text { Alternative }\end{array}$ & $\begin{array}{c}\text { Preferred } \\
\text { Alternative }\end{array}$ & Alternative $\mathrm{C}$ & Alternative D & Alternative E \\
\hline \multicolumn{7}{|c|}{ Herbicides Approved for Use on Public Lands } \\
\hline 2,4-D & 16.9 & 18 & 18 & 0 & 33 & 20 \\
\hline 2,4-DP & 0 & 0 & 0 & 0 & 0 & 0 \\
\hline Asullam & 0 & 0 & 0 & 0 & 0 & 0 \\
\hline Atrazine & 0 & 0 & 0 & 0 & 0 & 0 \\
\hline Bromacil & 0.7 & $<1$ & $<1$ & 0 & $<1$ & $<1$ \\
\hline Chlorsulfuron & 0.9 & 1 & 1 & 0 & 1 & 0 \\
\hline Clopyralid & 4.2 & 8 & 7 & 0 & 5 & 9 \\
\hline Dicamba & 3.2 & 2 & $<1$ & 0 & $<1$ & $<1$ \\
\hline Diuron & 1.1 & $<1$ & $<1$ & 0 & 1 & $<1$ \\
\hline Fosamine ammonium & 0.01 & 0 & 0 & 0 & 0 & 0 \\
\hline Glyphosate & 8.6 & 16 & 10 & 0 & 11 & 19 \\
\hline Hexazinone & 0.4 & $<1$ & $<1$ & 0 & $<1$ & $<1$ \\
\hline Imazapyr & 1.1 & 2 & 2 & 0 & 2 & 0 \\
\hline Mefluidide & 0 & 0 & 0 & 0 & 0 & 0 \\
\hline Metsulfuron methyl & 5.5 & 5 & 5 & 0 & 9 & 0 \\
\hline Picloram & 16.4 & 16 & 15 & 0 & 26 & 16 \\
\hline Simazine & 0 & 0 & 0 & 0 & 0 & 0 \\
\hline Sulfometuron methyl & 7.2 & $<1$ & $<1$ & 0 & 2 & 0 \\
\hline Tebuthiuron & 30.7 & 25 & 25 & 0 & $<1$ & 25 \\
\hline Triclopyr & 3.1 & 5 & 5 & 0 & 4 & 7 \\
\hline \multicolumn{7}{|c|}{ Herbicides Proposed for Use on Public Lands } \\
\hline $\begin{array}{l}\text { Diflufenzopyr + } \\
\text { Dicamba }\end{array}$ & 0 & 0 & 2 & 0 & 5 & 2 \\
\hline Diquat & 0 & 0 & $<1$ & 0 & 1 & $<1$ \\
\hline Fluridone & 0 & 0 & $<1$ & 0 & 1 & $<1$ \\
\hline Imazapic & 0 & 0 & 8 & 0 & 5 & 0 \\
\hline
\end{tabular}

PEIS, the risks to non-target plants and animals, especially species of concern, have not been adequately evaluated. Should these chemicals be needed by the BLM in the future, the BLM would consult ERAs for these active ingredients prepared by the Forest Service or other agencies, if available, or conduct their own ERAs, to assess the risks to non-target species. This analysis would be supported by the appropriate NEPA documentation and interagency consultation before these chemicals would be approved for use or applied on the ground.

The BLM would be allowed to use four additional active ingredients in all 17 states included in this PEIS: imazapic, diquat, diflufenzopyr (in formulation with dicamba), and fluridone. In addition, the BLM would be able to use diflufenzopyr in the future as a stand-alone active ingredient if it becomes registered for herbicidal use. These active ingredients and formulations could only be applied for uses, and at application rates, specified on the label directions. Under the Preferred Alternative, the BLM would also be able to use new active ingredients that are developed in the future if: 1) they are registered by the USEPA for use on one or more land types (e.g., rangeland, aquatic, etc.) managed by the BLM;2) the BLM determines that the benefits of use on public lands outweigh the risks to human health and the environment; and 3) they meet evaluation criteria to ensure that the decision to use the active ingredient is supported by scientific evaluation and NEPA documentation. These evaluation criteria are discussed in more detail in Appendix E. 
TABLE 2-6

Comparison of the Alternatives

\begin{tabular}{|c|c|c|c|c|c|}
\hline Analysis Element & $\begin{array}{l}\text { Alternative } \\
\text { A } \\
\text { (No Action) }\end{array}$ & $\begin{array}{c}\text { Alternative B } \\
\text { (Preferred } \\
\text { Alternative) }\end{array}$ & $\begin{array}{l}\text { Alternative C } \\
\text { (No Use of } \\
\text { Herbicides) }\end{array}$ & $\begin{array}{l}\text { Alternative D } \\
\text { (No Aerial } \\
\text { Spraying of } \\
\text { Herbicides) } \\
\end{array}$ & $\begin{array}{l}\text { Alternative E } \\
\text { (No ALS- } \\
\text { inhibiting } \\
\text { Herbicides) }\end{array}$ \\
\hline $\begin{array}{l}\text { Approximate Number of Acres } \\
\text { Treated Annually Using } \\
\text { Herbicides: }\end{array}$ & 305,000 & 932,000 & 0 & 530,000 & $466,000^{1}$ \\
\hline $\begin{array}{l}\text { Treatment Planning: } \\
\text { Focus of vegetation treatments } \\
\text { Cost of treatment used as a } \\
\text { selection criteria } \\
\text { Width of WUI }\end{array}$ & $\begin{array}{l}\text { Active } \\
\text { No } \\
\text { Variable }\end{array}$ & $\begin{array}{l}\text { Active } \\
\text { No } \\
\text { Variable }\end{array}$ & $\begin{array}{l}\text { Active } \\
\text { No } \\
\text { Variable }\end{array}$ & $\begin{array}{l}\text { Active } \\
\text { No } \\
\text { Variable }\end{array}$ & $\begin{array}{l}\text { Passive } \\
\text { Yes } \\
500 \text { meters }\end{array}$ \\
\hline $\begin{array}{l}\text { Use of Treatments: } \\
\text { Restrictions on acres treated }\end{array}$ & Yes & No & Yes & No & Yes \\
\hline $\begin{array}{l}\text { using herbicides } \\
\text { Restrictions on types of } \\
\text { herbicides used }\end{array}$ & $\mathrm{Yes}^{3}$ & No & No & No & $\mathrm{Yes}^{3}$ \\
\hline $\begin{array}{l}\text { Restrictions on use of herbicides } \\
\text { in amphibian habitats }{ }^{4}\end{array}$ & Yes & Yes & Yes & Yes & $\mathrm{Yes}^{5}$ \\
\hline $\begin{array}{l}\text { Restrictions on use of herbicides } \\
\text { in areas with culturally } \\
\text { significant plant and wildlife } \\
\text { resources }\end{array}$ & No & No & No & No & Yes \\
\hline \multicolumn{6}{|c|}{ 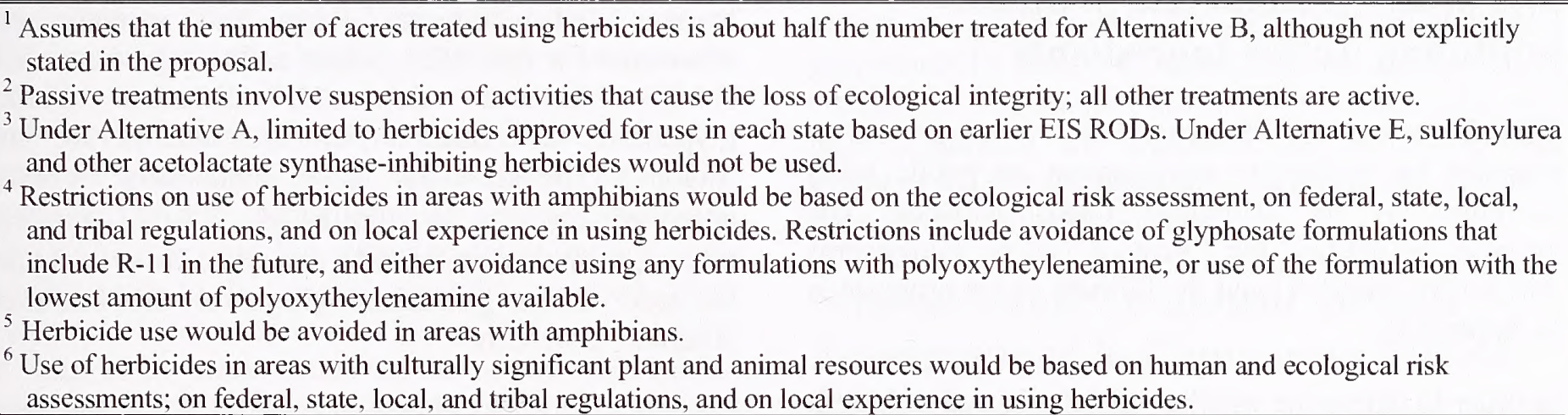 } \\
\hline
\end{tabular}

\section{Alternative C - No Use of Herbicides}

Under Alternative C, the BLM would not be able to treat vegetation using herbicides and would not be able to use new chemicals that are developed in the future. The BLM would be able to treat vegetation using fire, and mechanical, manual, and biological control methods. A PER has been prepared that accompanies this PEIS and discusses these treatment methods, proposed treatment levels during the next 10 to 15 years, and likely impacts to natural and social resources on public lands from these treatment methods (USDI BLM 2007a).

\section{Alternative D - No Aerial Application of Herbicides}

This alternative is similar to the Preferred Alternative in that it represents the treatment of vegetation using herbicides in 17 western states, including Alaska, and use of the same active ingredients as allowed under the Preferred Alternative. Under Alternative D, however, only ground-based techniques would be used to apply herbicides (no aerial applications of herbicides would be allowed) to would reduce the risk of spray drift impacting non-target areas. Based on information obtained from field offices, an estimated $55 \%$ of herbicide treatments would involve use of ground-based methods during the next 10 years. Thus, the BLM 
would treat approximately 530,000 acres annually using herbicides under this alternative. In comparison, during 1997 to 2005 , approximately $66 \% \quad(80,467$ acres annually) of herbicide treatments were conducted aerially and 34\% (41,829 acres annually) using groundbased methods. Most aerial treatments occurred in New Mexico ( $47 \%$ of acres treated in western U.S.), Idaho $(30 \%)$, and Arizona (8\%), while states with the most acres treated using ground-based methods were Utah ( $20 \%$ of acres treated in western U.S.), Idaho $(16 \%)$, and Wyoming (12\%).

Similar to the Preferred Alternative, the BLM would be able to use new active ingredients that are developed in the future if: 1) they are registered by the USEPA for use on one or more land types (e.g., rangeland, aquatic) managed by the BLM; 2) the BLM determines that the benefits of use on BLM lands outweigh the risks to human health and the environment; and 3) they meet evaluation criteria to ensure that the decision to use the active ingredient is supported by scientific evaluation and NEPA documentation.

\section{Alternative $\mathbf{E}$ - No Use of Sulfonylurea and other Acetolactate Synthase- imhibiting Active Ingredients}

This alternative was developed based on an alternative proposal for vegetation management on public lands submitted by the American Lands Alliance. The proposal is entitled the "Restore Native Ecosystems Alternative" (RNEA) and the full text of the proposal is in Appendix I.

In order to determine whether this alternative had merit for analysis relative to the proposed action, or should be dismissed from detailed analysis, a comprehensive policy review of the proposal was conducted by the BLM's National Science and Technology Center during 2002.

The BLM's policy review of the RNEA is provided in Appendix I of the Final PEIS. The policy analysis comprises identification of the individual goals and actions outlined in the RNEA proposal. For each goal or action, a determination has been made whether it is included in current BLM policy (yes/no) and a citation for the policy is provided. Under policy analysis, a brief summary outlining the policy is provided. Under the alternative comparison, the alternatives that apply to the policy are identified. In most cases, the policy is "common to all alternatives." The last column outlines the programmatic net effect or impact of the policy if the analysis is different from that presented in the Final PEIS, or outside the scope of analysis.

Based on this analysis, certain components of the proposal that were relevant and applicable to herbicide use under the proposed action were carried forward into the alternative analyzed in the PEIS. The remaining content of the proposal was determined to be either already covered under existing BLM policy, and therefore already a component of the Preferred Alternative (Alternative B), or outside the scope of analysis of this PEIS.

Under Alternative E, the BLM would not use sulfonylurea and other acetolactate synthase-inhibiting active ingredients approved in the earlier RODs, which are chlorsulfuron, imazapyr, metsulfuron methyl, and sulfometuron methyl. During 1999 to 2000 , these active ingredients comprised approximately $28 \%$ of the active ingredients used by the BLM. Since 2001, however, these active ingredients have comprised approximately $8 \%$ of the active ingredients used by the BLM. The BLM would be able to use, in the 17 western states, 10 active ingredients that were approved for use in the earlier RODs and for which an analysis of their risks to humans and non-target plants and animals was conducted for this PEIS. These active ingredients are: 2,4-D, bromacil, clopyralid, dicamba, diuron, glyphosate, hexazinone, picloram, tebuthiuron, and triclopyr. The six other active ingredients currently approved for use by the BLM-2,4-DP, atrazine, asulam, fosamine, mefluidide, and simazine - would not be used unless guidelines given for the Preferred Alternative were met.

In addition, the BLM would be allowed to use three additional active ingredients in all 17 states: diquat, diflufenzopyr (if it becomes registered for herbicidal use), and fluridone. The BLM would also be able to use a formulation of diflufenzopyr and dicamba. These active ingredients and formulations could only be applied for uses, and at application rates, specified on the label directions.

Under Alternative E, the BLM would be able to use new active ingredients that are developed in the future if they follow protocols for use of new active ingredients identified under the Preferred Alternative and do not contain sulfonylurea and imidazolinone chemistry and other acetolactate synthase-inhibiting compounds.

Under this alternative, the BLM would treat approximately 466,000 acres annually using herbicides (Table 2-6). Spot herbicide treatments would be favored 
over broadcast treatments. Herbicide use would be discouraged in areas populated by amphibians. To protect Native American and Alaska Native resources, the BLM would establish herbicide-free zones around culturally significant plant and wildlife resources.

This alternative would place greater emphasis on passive restoration, by prohibiting or restricting activities such as livestock grazing, OHV use, logging, or oil and gas development in areas where these activities have promoted a less desirable vegetation community, or increased erosion. Chapter 1, Scope of Analysis, clearly states the PEIS does not evaluate these programs. Since these activities are allowed under FLPMA, restrictions on these activities would only be considered to the extent they are consistent with BLM vegetation and land use management practices and policies (e.g. excluding grazing animals from recently seeded areas) and as determined by the authorized office under the appropriate controlling regulations.

\section{Determination of Treatment Acreages}

As discussed earlier, the BLM has been mandated under a variety of statutes and policy initiatives to increase the number of acres of vegetation treated annually to address the issues of catastrophic fire and invasive species spread and their relationships to habitat improvement and maintenance of healthy landscapes. The BLM estimates that approximately 6 million acres would need to be treated annually to meet these mandates. Acres to be treated by the BLM and assessed in this PEIS were estimated based on information provided by BLM field offices throughout the western U.S., including Alaska. Each field office was asked to estimate and summarize proposed vegetation treatment projects likely to occur during the next 10 years. For each project, the field office provided an estimate of the number of acres proposed for treatment, the general vegetation type(s) proposed for treatment, and the vegetation treatment method(s) proposed to be used. In many cases, multiple treatment methods were identified for a particular type of project. Treatments could occur on the same acres several times during 1 year, or over several years. Based on these surveys, field offices identified that approximately 4.6 million acres of treatments would be needed annually.

The BLM also reviewed Fire Regime Condition Classes (FRCCs) and concluded that an additional 1.4 million acres of treatments, beyond the estimates provided by the field offices, would be required annually. These classes were created to represent qualitative measures describing the degree of departure from historical fire regimes. This departure may have resulted from activities such as fire exclusion, timber harvesting, livestock grazing, introduction and establishment of exotic plant species, introduced insects or disease, and/or other management activities, which have altered key ecosystem components such as species composition, structural stage, stand age, canopy closure, and fuel loadings. These treatments would be focused on those areas of vegetation having a high departure from the historical condition and where the risk of losing key ecosystem components to fire or other causes is high (FRCC 3). The intent of these treatments would be to transition FRCC 3 lands to areas where fire regimes are moderately altered from their historical conditions (FRCC 2), or are within their historical range of vegetation variability (FRCC 1).

As a result of these surveys and reviews, an estimated 6 million acres would need to be treated annually. Approximately 3.5 million acres would be treated primarily for hazardous fuels reduction and to control wildfires in the WUI, approximately 1 million acres would be treated to control unwanted vegetation to restore ecosystem health, and about 1.5 million acres a year would be subject to burned area rehabilitation and emergency stabilization efforts. Acres associated with these treatments are dependent on the severity and extent of the fire season in any given year and may vary considerably from this average.

\section{Non-herbicide Treatment Method Acreages used in Cumulative Effects Analysis}

The alternatives describe differing levels of herbicide use, ranging from approximately 932,000 acres annually under Alternative $\mathrm{B}$ to 0 acres annually under Alternative C. However, non-herbicide treatments (manual and mechanical methods, biological control, and use of fire) would also occur under all alternatives. Although non-herbicide treatments were not evaluated in the analysis of direct and indirect effects of herbicide treatments (but were evaluated in the PER), as discussed in Chapter 1 of this PEIS under Decisions to be Made and Scope of Analysis, they are considered in the Cumulative Effects Analysis in Chapter 4 of this PEIS.

Under Alternative A, approximately 645,000 acres would be treated using fire, 582,000 acres would be treated using mechanical methods, 114,000 acres would 
be treated using manual methods, and 253,000 acres would be treated using biological control.

Under Alternative B, approximately 2,107,000 acres would be treated using fire, 2,232,000 acres would be treated using mechanical methods, 271,000 acres would be treated using manual methods, and 454,000 acres would be treated using biological control.

Under alternatives C, D, and E, approximately $1,055,000$ acres would be treated using fire, $1,986,000$ acres would be treated using mechanical methods, 396,000 acres would be treated using manual methods, and 597,000 acres would be treated using biological control.

\section{Alternatives Considered but Not Further Analyzed}

Several other alternatives were identified during public scoping and reviewed by the interdisciplinary team (ENSR 2002). In most cases, these alternatives would not fulfill the purpose and need for the project, are inconsistent with BLM or other federal, state, or local policies or regulations, or are not practical based on likely funding for vegetation treatments. The alternatives that were considered but not further analyzed are:

- Treat up to 25 million acres annually. This alternative was excluded from analysis because the BLM felt it was highly unlikely that the agency would have sufficient funding during the next 10 to 15 years to treat up to 25 million acres annually.

- Treat fewer acres than are currently treated. Under this alternative, fewer acres would be treated annually than would occur under the No Action Alternative (Alternative A). Given that current treatment levels have been insufficient to control unwanted vegetation and reduce the risk of wildfire to life and property on public lands, this alternative would not meet the project purpose and need.

- Do not treat competing and unwanted vegetation. Under this alternative, the BLM would continue burned area rehabilitation and emergency stabilization activities, hazardous fuels reduction activities that did not involve the treatment of vegetation, and passive vegetation management, but would not actively treat competing and unwanted vegetation. This alternative was eliminated because it would not control the spread of unwanted vegetation, which could adversely impact land health on public lands and increase the risk of loss of life and property due to fires.

- Treat only acres needed to protect human health and safety. Under this alternative, the BLM would only treat those acres needed to protect human health and safety. Nearly all of these acres would be associated with hazardous fuels reduction near homes and other developments in the WUI. This alternative was eliminated because it would not maintain or improve land health on most public lands.

- Do not conduct hazardous fuels treatments. Like the preceding alternative, this alternative was excluded because it does not restore the health of fire-adapted ecosystems. The buildup of hazardous fuels that have led to catastrophic wildfires and significant impacts to air quality, water resources, human health, and other resources.

- Revegetate with native vegetation. Under this alternative, only native vegetation would be used to restore fire-impacted and other degraded publie lands. This alternative was eliminated because it has been incorporated into the proposed action to the extent practical.

- Exclude logging, grazing, OHV use, and energy/mineral development on public lands. This alternative was eliminated because FLPMA requires that the BLM manage public lands for multiple uses including those listed. Field offices, however, can limit these activities, consistent with land use plans where doing so benefits vegetation management and land health and complies with the FLPMA.

The rest of this chapter includes actions that would be common to all alternatives.

\section{Herbicide Treatment Standard Operating Procedures and Guidelines}

This section identifies standard operating procedures (SOPs) that would be followed by the BLM under all alternatives to ensure that risks to human health and the environment from herbicide treatment actions would be kept to a minimum. Standard operating procedures are 
the management controls and performance standards required for vegetation management treatments. Thesc practices are intended to protect and enhance natural resources that could be affected by future vegetation treatments.

\section{Prevention of Weeds and Early Detection and Rapid Response}

Once weed populations become established, infestations can increase and expand in size. Weeds colonize highly disturbed ground and invade plant communities that have been degraded, but are also capable of invading intact communities. Therefore, prevention, early detection, and rapid response are the most cost-effective methods of weed control. Prevention, early detection, and rapid response strategies that reduce the need for vegetative treatments for noxious weeds should lead to a reduction in the number of acres treated using herbicides in the future by reducing or preventing weed establishment.

As stated in the BLM's Partners Against Weeds - An Action Plan for the BLM (USDI BLM 1996), prevention and public education are the highest priority weed management activities. Priorities are as follows:

- Priority 1: Take actions to prevent or minimize the need for vegetation control when and where feasible, considering the management objectives of the site.

- Priority 2: Use effective nonchemical methods of vegetation control when and where feasible.

- Priority 3: Use herbicides after considering the effectiveness of all potential methods or in combination with other methods or controls.

Prevention is best accomplished by ensuring the seeds and vegetatively reproductive plant parts of new weed species are not introduced into new areas.

The BLM is required to develop a noxious weed risk assessment when it is determined that an action may introduce or spread noxious weeds or when known habitat exists (USDI BLM 1992b). If the risk is moderate or high, the BLM may modify the project to reduce the likelihood of weeds infesting the site, and to identify control measures to be implemented if weeds do infest the site.

To prevent the spread of weeds, the BLM takes actions to minimize the amount of existing non-target vegetation that is disturbed or destroyed during project or vegetation treatment actions (Table 2-7). During project planning, the following steps are taken:

- Incorporate measures to prevent introduction or spread of weeds into project layout, design, alternative evaluation, and project decisions.

- During environmental analysis for projects and maintenance programs, assess weed risks, analyze potential treatment of high-risk sites for weed establishment and spread, and identify prevention practices.

- Determine prevention and maintenance nceds, to include the use of herbicides if needcd, at the onset of project planning.

- Avoid or remove sources of weed seed and propagules to prevent new weed infestations and the spread of existing weeds.

During project development, weed infestations are prioritized for treatment in project operating areas and along access routes. Weeds present on or near the site are identified, a risk assessment is completed, and weeds are controlled as necessary. Project staging areas are weed free, and travel through weed infested areas is avoided or minimized. Examples of prevention actions to be followed during project activities include cleaning all equipment and clothing before entering the project site; avoiding soil disturbance and the creation of other soil conditions that promote weed germination and establishment; and using weed-free seed, hay, mulch, gravel, soil, and mineral materials on public lands where there is a state or county program in place.

Conditions that enhance invasive species abundance should be addressed when developing mitigation and prevention plans for activities on public lands. These conditions include excessive disturbance associated with road maintenance, poor grazing management, and high levels of recreational use. If livestock grazing is managed to maintain the vigor of native perennial plants, particularly grasses, the chance of weeds invading rangeland is much less. By carefully managing recreational use and educating the public on the potential impacts of recreational activities on vegetation, the amount of damage to native vegetation and soil can be minimized at high use areas, such as campgrounds and OHV trails. Early detection in recreation areas is focused on roads and trails, where much of the weed spread occurs.

The BLM participates in the National Early Warning and Rapid Response System for Invasive Plants (Figure 
TABLE 2-7

Prevention Measures

\begin{tabular}{|c|c|}
\hline BLM Activity & Prevention Measure \\
\hline Project Planning & $\begin{array}{l}\text { - Incorporate prevention measures into project layout and design, alternative evaluation, and } \\
\text { project decisions to prevent the introduction or spread of weeds. } \\
\text { Determine prevention and maintenance needs, including the use of herbicides, at the onset of } \\
\text { project planning. } \\
\text { Before ground-disturbing activities begin, inventory weed infestations and prioritize areas for } \\
\text { treatment in project operating areas and along access routes. } \\
\text { Remove sources of weed seed and propagules to prevent the spread of existing weeds and new } \\
\text { - Peed infestations. } \\
\text { - Pre-treat high-risk sites for weed establishment and spread before implementing projects. } \\
\text { roads, boat launches, and public land kiosks. } \\
\text { Coordinate project activities with nearby herbicide applications to maximize the cost- } \\
\text { effectiveness of weed treatments. }\end{array}$ \\
\hline $\begin{array}{l}\text { Project } \\
\text { Development }\end{array}$ & $\begin{array}{l}\text { - Minimize soil disturbance to the extent practical, consistent with project objectives. } \\
\text { - } \\
\text { Tovoid creating soil conditions that promote weed germination and establishment. } \\
\text { activity areas and keep soil disturbance to a minimum, consistent with project objectives. } \\
\text { - Locate and use weed-free project staging areas. Avoid or minimize all types of travel through } \\
\text { weed-infested areas, or restrict travel to periods when the spread of seeds or propagules is least } \\
\text { likely. } \\
\text { - Prevent the introduction and spread of weeds caused by moving weed-infested sand, gravel, } \\
\text { borrow, and fill material. } \\
\text { Inspect material sources on site, and ensure that they are weed-free before use and transport. } \\
\text { Treat weed-infested sources to eradicate weed seed and plant parts, and strip and stockpile } \\
\text { contaminated material before any use of pit material. } \\
\text { - Survey the area where material from treated weed-infested sources is used for at least } 3 \text { years } \\
\text { after project completion to ensure that any weeds transported to the site are promptly detected } \\
\text { and controlled. } \\
\text { Prevent weed establishment by not driving through weed-infested areas. } \\
\text { - Inspect and document weed establishment at access roads, cleaning sites, and all disturbed } \\
\text { areas; control infestations to prevent spread within the project area. } \\
\text { Avoid acquiring water for dust abatement where access to the water is through weed-infested } \\
\text { sites. } \\
\text { - Identify sites where equipment can be cleaned. Clean equipment before entering public lands. } \\
\text { Clean all equipment before leaving the project site if operating in areas infested with weeds. } \\
\text { Inspect and treat weeds that establish at equipment cleaning sites. } \\
\text { Ensure that rental equipment is free of weed seed. } \\
\text { Inspect, remove, and properly dispose of weed seed and plant parts found on workers' clothing } \\
\text { and equipment. Proper disposal entails bagging the seeds and plant parts and incinerating them. }\end{array}$ \\
\hline Revegetation & $\begin{array}{l}\text { Include weed prevention measures, including project inspection and documentation, in } \\
\text { operation and reclamation plans. } \\
\text { Retain bonds until reclamation requirements, including weed treatments, are completed, based } \\
\text { on inspection and documentation. } \\
\text { To prevent conditions favoring weed establishment, re-establish vegetation on bare ground } \\
\text { caused by project disturbance as soon as possible using either natural recovery or artificial } \\
\text { techniques. } \\
\text { - Maintain stockpiled, uninfested material in a weed-free condition. }\end{array}$ \\
\hline
\end{tabular}


TABLE 2-7 (Cont.)

Prevention Measures

\begin{tabular}{|l|l|l|}
\hline \multicolumn{1}{|c|}{ BLM Activity } & \multicolumn{1}{c|}{ Prevention Measure } \\
\hline $\begin{array}{l}\text { Revegetation } \\
\text { (Cont.) }\end{array}$ & $\begin{array}{l}\text { Revegetate disturbed soil (except travel ways on surfaced projects) in a manner that optimizes } \\
\text { plant establishment for each specific project site. For each project, define what constitutes } \\
\text { disturbed soil and objectives for plant cover revegetation. Revegetation may include topsoil } \\
\text { replacement, planting, seeding, fertilization, liming, and weed-free mulching, as necessary. } \\
\text { - Where practical, stockpile weed-seed-free topsoil and replace it on disturbed areas (e.g., road } \\
\text { embankments or landings). } \\
\text { Inspect seed and straw mulch to be used for site rehabilitation (for wattles, straw bales, dams, } \\
\text { etc.) and certify that they are free of weed seed and propagules. } \\
\text { Inspect and document all limited term ground-disturbing operations in noxious weed infested } \\
\text { areas for at least 3 growing seasons following completion of the project. } \\
\text { Use native material where appropriate and feasible. Use certified weed-free or weed-seed-free } \\
\text { hay or straw where certified materials are required and/or are reasonably available. } \\
\text { Provide briefings that identify operational practices to reduce weed spread (for example, } \\
\text { avoiding known weed infestation areas when locating fire lines). } \\
\text { Evaluate options, including closure, to regulate the flow of traffic on sites where desired } \\
\text { vegetation needs to be established. Sites could include road and trail ROW, and other areas of } \\
\text { disturbed soils. }\end{array}$ \\
\hline
\end{tabular}

2-2). The goal of this System to minimize the establishment and spread of new invasive species through a coordinated framework of public and private processes by:

- Early detection and reporting of suspected new plant species to appropriate officials;

- Identification and vouchering of submitted specimens by designated specialists;

- Verification of suspected new state, regional, and national plant records;

- Archival of new records in designated regional and plant databases;

- Rapid assessment of confirmed new records; and

- Rapid response to verified new infestations that are determined to be invasive.

\section{Herbicide Treatment Planning}

BLM Manual 9011 (Chemical Pest Control) outlines the policies, and BLM Handbook H-9011-1 (Chemical Pest Control; USDI BLM 1988d) outlines the procedures, for use of herbicides on public lands. As part of policy, the BLM is required to thoroughly evaluate the need for chemical treatments and their potential for impact on the environment. The BLM is required to use only USEPA-registered herbicides that have been properly evaluated under NEPA, and to carefully follow label directions and additional BLM requirements.

An operational plan is developed and updated for each herbicide project. The plan includes information on project specifications, key personnel responsibilities, and communication, safety, spill response, and emergency procedures. For application of herbicides not approved for aquatic use, the plan should also specify minimum buffer widths between treatment areas and water bodies. Recommended widths are provided in BLM Handbook H-9011-1 (Chemical Pest Control), but actual buffers are site and herbicide active ingredient specific, and are determined based on a scientific analysis of environmental factors, such as climate, topography, vegetation, and weather; timing and method of application; and herbicide risks to humans and non-target species. Recommended buffer widths for each herbicide active ingredient under different application scenarios are listed later in this chapter under Mitigation. Table 2-8 summarizes important SOPs that should be used when applying herbicides to help protect resources of concern on public lands. 


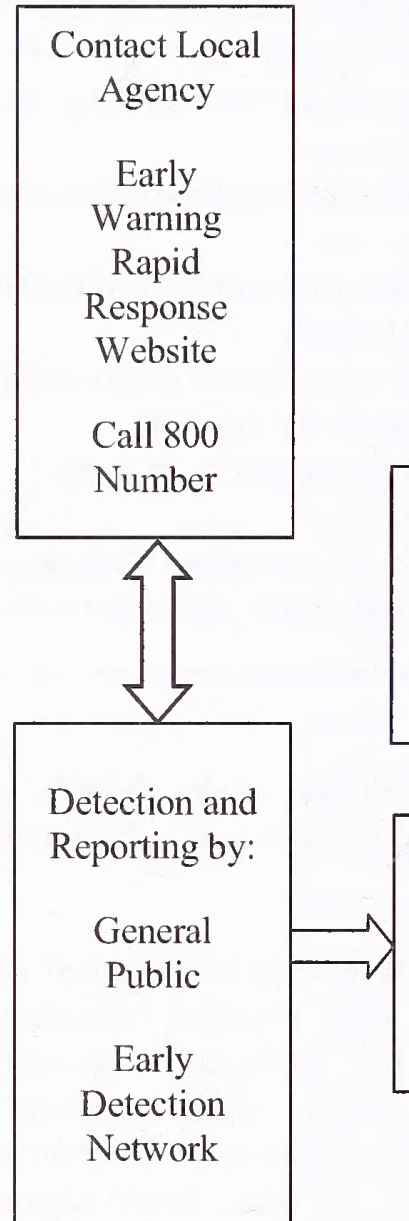

Suspected New National

Records
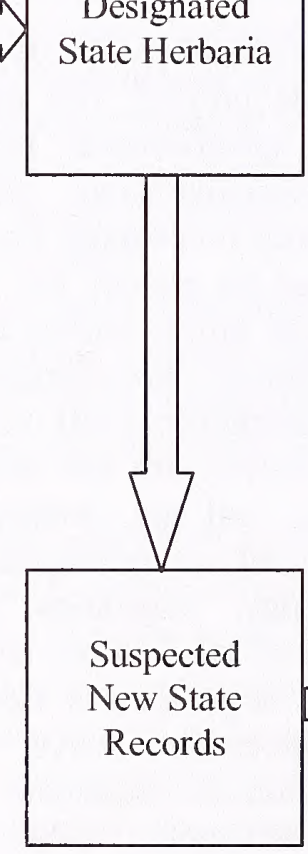

Animal and

Plant Health

Inspection

Service

(APHIS)

National

Agricultural

Pest

Information

System

(NAPIS)

Database

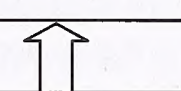

APHIS

New Pest

Advisory

Group

(Regulatory

Assessment)

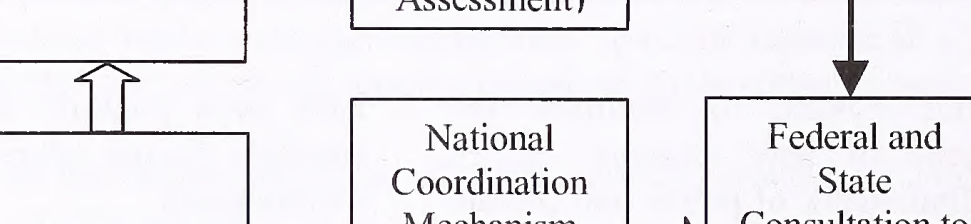

(Ecological

(Ecological

Assessment)

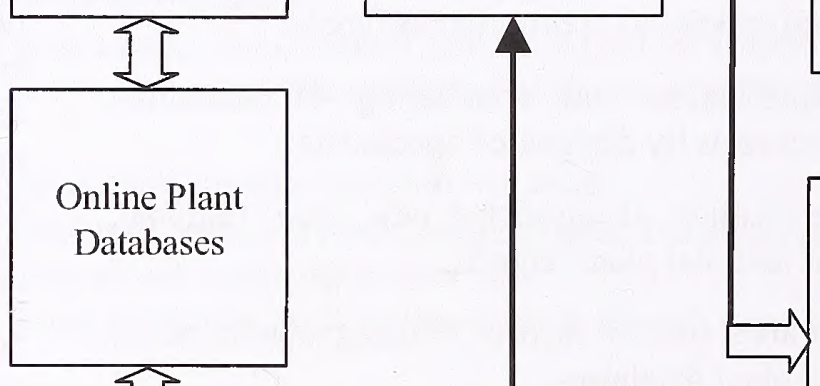

Infestation on

Private Land

Action by:

Owner

County

State

Federal

Infestation on

Public Lands

Action by:

Impacted

Agency

State Weed

Team

Assessment

Public and

Private Lands

Action:

Form a Weed

Management

Area

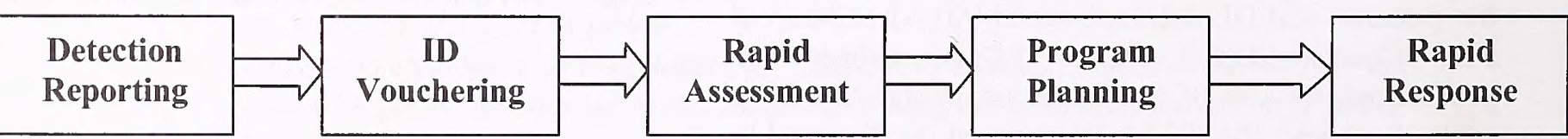

Figure 2-2. National Early Warning and Rapid Response System for Invasive Plants. 


\section{Revegetation}

Disturbed areas may be reseeded or planted with desirable vegetation when the native plant community cannot recover and occupy the site sufficiently.

Determining the need for revegetation is an integral part of developing a vegetation treatment. The most important component of the process is determining whether active (seeding/planting) or passive (natural recovery) revegetation is appropriate.

USDI policy states, "Natural recovery by native plant species is preferable to planting or seeding, either of natives or non-natives. However, planting or seeding should be used only if necessary to prevent unacceptable erosion or resist competition from nonnative invasive species" $(620$ Departmental Memorandum 3 2004). This policy is reiterated in the USDI Burned Area Emergency Stabilization and Rehabilitation Manual, the BLM Burned Area Emergency Stabilization and Rehabilitation Manual (BLM H-1742-1; USDI BLM 2006a), and the Interagency Burned Area Rehabilitation Guidebook (USDI and USDA 2006d).

In addition to these handbooks and policy, use of native and non-native seed in revegetation and restoration is guided by BLM Manual 1745 (Introduction, Transplant, Augmentation and Reestablishment of Fish, Wildlife and Plants). This manual states that native species shall be used, unless it is determined through the NEPA process that: 1) suitable native species are not available; 2) the natural biological diversity of the proposed management area will not be diminished; 3 ) exotic and naturalized species can be confined within the proposed management area; 4) analysis of ecological site inventory information indicates that a site will not support reestablishment of a species that historically was part of the natural environment; or 5) resource management objectives cannot be met with native species.

When natural recovery is not feasible, revegetation can be used to stabilize and restore vegetation on disturbed sites and to eliminate or reduce the conditions that favor invasive species. Reseeding or replanting may be required when there is insufficient vegetation or seed stores to naturally revegetate the site.

To ensure revegetation success, there must be adequate soil for root development and moisture storage, which provides moisture to support the new plants. Chances for revegetation success are improved by selecting seed with high purity and percentage germination; selecting native species or cultivars adapted to the area; planting at proper depth, seeding rate, and time of the ycar for the region; choosing the appropriate planting method; and, where feasible, rcmoving competing vegetation. Planting mixtures are adapted for the treatment arca and site uses. A combination of forbs, perennial grasses, and shrubs is typically used on rangeland sites, while shrubs and trees might be favored for riparian and forestland sites. A mixture of several native plant species and types or functional groups enhances the value of the site for fish and wildlife and improves the health and aesthetic character of the site. Mixtures can better take advantage of variable soil, terrain, and climatic conditions, and thus are more likely to withstand insect infestations and survive adverse climatic conditions.

The USDI BLM Native Seed program, which is in its sixth year, was developed in response to Congressional direction to supply native plant material for emergency stabilization and longer-term rehabilitation and restoration efforts. The focus of the program is to increase the number of native plant species for which seed is available and the total amount of native seed available for these efforts. To date, the program has focused on native plant material needs of emergency stabilization and burned area rehabilitation in the Great Basin, but is expanding to focus on areas such as western Oregon, the Colorado Plateau, and most recently the Mojave Desert. The Wildland Fire Management Program funds and manages the effort (USDI BLM 2006c).

The National Seed Warehouse is a storage facility for the native seed supply. Through a Memorandum of Understanding with the BLM Idaho State Director, each state (Idaho, Oregon, Nevada, Utah and Colorado) can reserve an annual seed supply for purchase based on a reasonable projection of annual acreage to be stabilized or rehabilitated over a 5 -year period.

The Great Basin Restoration Initiative (GBRI) grew out of concern for the health of the Great Basin after the wildfires of 1999. The goal of GBRI is to implement treatments and strategies to maintain functioning ecosystems and to proactively restore degraded ones at strategic locations. Native plants are emphasized in restoration projects where their use is practical and the potential for success is satisfactory. Monitoring is recommended to measure treatment success. To increase the availability of native plants, especially native forbs, the GBRI has established a collaborative native plant project, the Great Basin Native Plant Selection and Increase Project, to increase native plant 
availability and the technology to successfully establish these plants. This project is supported by funding from the BLM's Native Plant Initiative.

The BLM will follow the following SOPs when revegetating sites:

- Cultivate previously disturbed sites to reduce the amount of weed seeds in the soil seedbank.

- Revegetate sites once work is completed or soon after a disturbance.

- When available, use native seed of known origin as labeled by state seed certification programs.

- Use seed of non-native cultivars and species only when locally adapted native seed is not available or when it is unlikely to establish quickly enough to prevent soil erosion or weed establishment.

- Use seed that is free of noxious and invasive weeds, as determined and documented by a seed inspection test by a certified seed laboratory.

- Limit nitrogen fertilizer applications that favor annual grass growth over forb growth in newly seeded areas, especially where downy brome and other invasive annuals are establishing.

- Use clean equipment, free of plants and plant parts, on revegetation projects to prevent the inadvertent introduction of weeds into the site.

- Where important pollinator resources exist, include native nectar and pollen producing plants in the seed mixes used in restoration and reclamation projects. Include non-forage plant species in seed mixes for their pollinator/host relationships as foraging, nesting, or shelter species. Choose native plant species over manipulated cultivars, especially of forbs and shrubs, since natives tend to have more valuable pollen and nectar resources than cultivars. Ensure that bloom times for the flowers of the species chosen match the activity times for the pollinators. Maintain sufficient litter on the soil surfaces of native plant communities for ground-nesting bees.

- Where feasible, avoid grazing by domestic and wild animals on treatment sites until vegetation is well established. Where total rest from grazing is not feasible, efforts should be made to modify the amount and/or season of grazing to promote vegetation recovery within the treatment area. Reductions in numbers, permanent or temporary fencing, changes in grazing rotation, and identification of alternative forage sources are examples of methods that could be used to remove, reduce or modify grazing impacts during vegetation recovery.

\section{Special Precautions}

\section{Special Status Species}

Federal policies and procedures for protecting federallylisted threatened and endangered plant and animal species, and species proposed for listing, were established by the Endangered Species Act of 1973 and regulations issued pursuant to the Act. The purposes of the Act are to provide mechanisms for the conservation of threatened and endangered species and their habitats. Under the Act, the Secretary of the Interior is required to determine which species are threatened or endangered and to issue recovery plans for those species.

Section 7 of the Act specifically requires all federal agencies to use their authorities in furtherance of the Act to carry out programs for the conservation of listed species, and to ensure that no agency action is likely to jeopardize the continued existence of a listed species or adversely modify critical habitat. Policy and guidance (BLM Manual 6840; Special Status Species) also stipulates that species proposed for listing must be managed at the same level of protection as listed species.

The BLM state directors may designate special status in cooperation with their respective state. These special status species must receive, at a minimum, the same level of protection as federal candidate species. The BLM will also carry out management for the conservation of state-listed species, and state laws protecting these species will apply to all BLM programs and actions to the extent that they are consistent with FLPMA and other federal laws.

The BLM consulted with the USFWS and NMFS during development of the PEIS as required under Section 7 of the Endangered Species Act. As part of this process, the BLM prepared a formal consultation package that included a description of the program; species listed as threatened or endangered, species 
proposed for listing, and critical habitats that could be affected by the program; and a BA that evaluated the likely impacts to listed species, species proposed for listing, and critical habitats from the proposed vegetation treatment program. Over 300 species were evaluated in the BA. The BA also provides broad guidance at a programmatic level for actions that would be taken by the BLM to avoid adversely impacting species or critical habitat (USDI BLM 2007b).

Before any vegetation treatment or ground disturbance occurs, BLM policy requires a survey of the project site for species listed or proposed for listing, or special status species. This is done by a qualified biologist and/or botanist who consults the state and local databases and visits the site at the appropriate season. If a proposed project may affect a proposed or listed species or its critical habitat, the BLM consults with the USFWS and/or NMFS. A project with a "may affect, likely to adversely affect" determination requires formal consultation and receives a Biological Opinion from the USFWS and/or NMFS. A project with a "may affect, not likely to adversely affect" determination requires informal consultation and receives a concurrence letter from USFWS and/or NMFS, unless that action is implemented under the authorities of the alternative consultation agreement pursuant to counterpart regulations established for National Fire Plan projects.

\section{Wilderness Areas}

Wilderness areas, which are designated by Congress, are defined by the Wilderness Act of 1964 as places "where the earth and its community of life are untrammeled by man, where man himself is a visitor who does not remain." The BLM manages 175 Wilderness Areas encompassing over 7.2 million acres (USDI BLM 2006d).

Activities allowed in wilderness areas are identified in wilderness management plans prepared by the BLM. The BLM does not ordinarily treat vegetation in wilderness areas, but will control invasive and noxious weeds when they threaten lands outside wilderness area or are spreading within the wilderness and can be controlled without serious adverse impacts to wilderness values.

Management of vegetation in a wilderness area is directed toward retaining the natural character of the environment. Tree and shrub removal is usually not allowed, except for fire, insect, or disease control. Reforestation is generally prohibited except to repair damage caused by humans in areas where natural reforestation is unlikely. Only native species and primitive methods, such as hand planting, are allowed for reforestation.

Tools and equipment may be used for vegetation management when they are the minimum amount necessary for the protection of the wilderness resource. Motorized tools may only be used in special or emergency cases involving the health and safety of wilderness visitors, or the protection of wilderness values.

Habitat manipulation using mechanical or chemical means may be allowed to protect threatened and endangered species and to correct unnatural conditions, such as weed infestations, resulting from human influence.

The BLM also manages a total of 610 Wilderness Study Areas (WSAs) encompassing nearly 14.3 million acres. These are areas that have been determined to have wilderness characteristics worthy of consideration for wilderness designation. The BLM's primary goals in WSAs are to manage them so as to not impair their wilderness values and to maintain their suitability for preservation as wilderness until Congress makes a determination on their future.

In WSAs, the BLM must foster a natural distribution of native species of plants and animals by ensuring that ecosystems and processes continue to function naturally.

\section{Cultural Resources}

The effects of BLM actions on cultural resources are addressed through compliance with the National Historic Preservation Act, as implemented through a national Programmatic Agreement (Programmatic Agreement among the Bureau of Land Management, the Advisory Council on Historic Preservation, and the National Conference of State Historic Preservation Officers Regarding the Manner in Which BLM Will Meet Its Responsibilities Under the National Historic Preservation Act) and state-specific protocol agreements with SHPOs. The BLM's responsibilities under these authorities are addressed as early in the vegetation management project planning process as possible. 
TABLE 2-8

Standard Operating Procedures for Applying Herbicides

\begin{tabular}{|c|c|}
\hline Resource Element & Standard Operating Procedure \\
\hline Guidance Documents & $\begin{array}{l}\text { BLM Handbook H-9011-1 (Chemical Pest Control); and manuals } 1112 \text { (Safety), } 9011 \text { (Chemical } \\
\text { Pest Control), } 9012 \text { (Expenditure of Rangeland Insect Pest Control Funds), } 9015 \text { (Integrated Weed } \\
\text { Management), and } 9220 \text { (Integrated Pest Management) }\end{array}$ \\
\hline General & 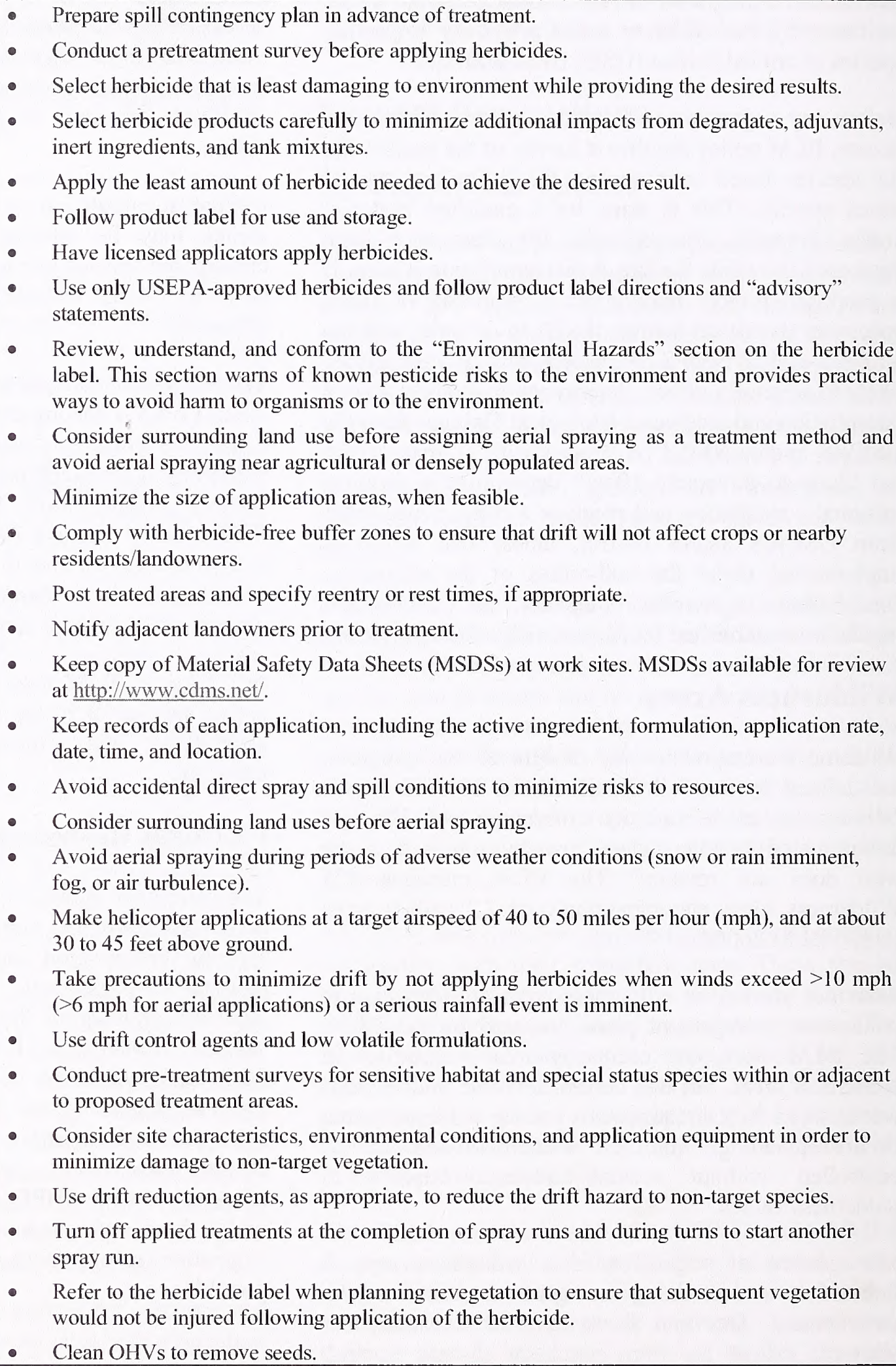 \\
\hline
\end{tabular}


TABLE 2-8 (Cont.)

Standard Operating Procedures for Applying Pesticides

\begin{tabular}{|c|c|}
\hline Resource Element & Standard Operating Procedure \\
\hline $\begin{array}{l}\text { Air Quality } \\
\text { See Manual } 7000 \text { (Soil, Water, } \\
\text { and Air Management) }\end{array}$ & $\begin{array}{l}\text { - Consider the effeets of wind, humidity, temperature inversions, and heavy rainfall on herbieide } \\
\text { effectiveness and risks. } \\
\text { - Apply herbieides in favorable weather eonditions to minimize drift. For example, do not treat } \\
\text { when winds exeed } 10 \mathrm{mph} \text { ( } 6 \text { mph for aerial applieations) or rainfall is imminent. } \\
\text { - Use drift reduetion agents, as appropriate, to reduee the drift hazard. } \\
\text { - Seleet proper application equipment (e.g., spray equipment that produees } 200 \text { - to } 800 \text {-mieron } \\
\text { diameter droplets [spray droplets of } 100 \text { mierons and less are most prone to drifi]). } \\
\text { - Select proper application methods (e.g., set maximum spray heights, use appropriate buffer } \\
\text { distances between spray sites and non-target resources). }\end{array}$ \\
\hline $\begin{array}{l}\text { Soil } \\
\text { See Manual } 7000 \text { (Soil, Water, } \\
\text { and Air Management) }\end{array}$ & $\begin{array}{l}\text { Minimize treatments in areas where herbieide runoff is likely, sueh as steep slopes when heavy } \\
\text { rainfall is expeeted. } \\
\text { Minimize use of herbieides that have high soil mobility, particularly in areas where soil } \\
\text { properties increase the potential for mobility. } \\
\text { Do not apply granular herbieides on slopes of more than } 15 \% \text { where there is the possibility of } \\
\text { runoff earrying the granules into non-target areas. }\end{array}$ \\
\hline $\begin{array}{l}\text { Water Resourees } \\
\text { See Manual } 7000 \text { (Soil, Water, } \\
\text { and Air Management) }\end{array}$ & $\begin{array}{l}\text { - Consider elimate, soil type, slope, and vegetation type when developing herbieide treatment } \\
\text { programs. } \\
\text { - Select herbieide produets to minimize impaets to water. This is espeeially important for } \\
\text { applieation seenarios that involve risk from aetive ingredients in a partieular herbieide, as } \\
\text { predieted by risk assessments. } \\
\text { - Use local historical weather data to choose the month of treatment. Considering the phenology } \\
\text { of the target speeies, sehedule treatments based on the eondition of the water body and existing } \\
\text { water quality eonditions. } \\
\text { Plan to treat between weather fronts (calms) and at appropriate time of day to avoid high winds } \\
\text { that increase water movements, and to avoid potential stormwater runoff and water turbidity. } \\
\text { Review hydrogeologie maps of proposed treatment areas . Note depths to groundwater and } \\
\text { areas of shallow groundwater and areas of surfaee water and groundwater interaetion. } \\
\text { Minimize treating areas with high risk for groundwater eontamination.. } \\
\text { Conduet mixing and loading operations in an area where an accidental spill would not } \\
\text { contaminate an aquatic body. } \\
\text { Do not rinse spray tanks in or near water bodies. Do not broadcast pellets where there is danger } \\
\text { of eontaminating water supplies. } \\
\text { Maintain buffers between treatment areas and water bodies. Buffer widths should be developed } \\
\text { based on herbieide- and site-specifie criteria to minimize impaets to water bodies. } \\
\text { Minimize the potential effeets to surfaee water quality and quantity by stabilizing terrestrial } \\
\text { areas as quiekly as possible following treatment. }\end{array}$ \\
\hline Wetlands and Riparian Areas & $\begin{array}{l}\text { Use a seleetive herbieide and a wick or baekpack sprayer. } \\
\text { Use appropriate herbieide-free buffer zones for herbieides not labeled for aquatie use based on } \\
\text { risk assessment guidanee, with minimum widths of } 100 \text { feet for aerial, } 25 \text { feet for vehicle, and } \\
10 \text { feet for hand spray applications. }\end{array}$ \\
\hline $\begin{array}{l}\text { Vegetation } \\
\text { See Handbook H-4410-1 } \\
\text { (National Range Handbook), } \\
\text { and manuals } 5000 \text { (Forest } \\
\text { Management) and } 9015 \\
\text { (Integrated Weed } \\
\text { Management) }\end{array}$ & $\begin{array}{l}\text { - Refer to the herbieide label when planning revegetation to ensure that subsequent vegetation } \\
\text { would not be injured following applieation of the herbieide. } \\
\text { - Use native or sterile speeies for revegetation and restoration projeets to eompete with invasive } \\
\text { speeies until desired vegetation establishes } \\
\text { - Use weed-free feed for horses and paek animals. Use weed-free straw and muleh for } \\
\text { revegetation and other aetivities. } \\
\text { - Identify and implement any temporary domestie livestoek grazing and/or supplemental feeding } \\
\text { restrietions needed to enhanee desirable vegetation reeovery following treatment. Consider } \\
\text { adjustments in the existing grazing permit, needed to maintain desirable vegetation on the } \\
\text { treatment site. }\end{array}$ \\
\hline
\end{tabular}


TABLE 2-8 (Cont.)

Standard Operating Procedures for Applying Pesticides

\begin{tabular}{|c|c|}
\hline Resource Element & Standard Operating Procedure \\
\hline Pollinators & $\begin{array}{l}\text { - Complete vegetation treatments seasonally before pollinator foraging plants bloom. } \\
\text { Time vegetation treatments to take place when foraging pollinators are least active both } \\
\text { seasonally and daily. } \\
\text { Design vegetation treatment projects so that nectar and pollen sources for important pollinators } \\
\text { and resources are treated in patches rather than in one single treatment. } \\
\text { Minimize herbicide application rates. Use typical rather than maximum rates where there are } \\
\text { important pollinator resources. } \\
\text { Maintain herbicide free buffer zones around patches of important pollinator nectar and pollen } \\
\text { sources. } \\
\text { Maintain herbicide free buffer zones around patches of important pollinator nesting habitat and } \\
\text { hibernacula. } \\
\text { Make special note of pollinators that have single host plant species, and minimize herbicide } \\
\text { spraying on those plants (if invasive species) and in their habitats. }\end{array}$ \\
\hline $\begin{array}{l}\text { Fish and Other Aquatic } \\
\text { Organisms } \\
\text { See manuals } 6500 \text { (Wildlife } \\
\text { and Fisheries Management) } \\
\text { and } 6780 \text { (Habitat } \\
\text { Management Plans) }\end{array}$ & $\begin{array}{l}\text { - Use appropriate buffer zones based on label and risk assessment guidance. } \\
\text { Minimize treatments near fish-bearing water bodies during periods when fish are in life stages } \\
\text { most sensitive to the herbicide(s) used, and use spot rather than broadcast or aerial treatments. } \\
\text { Use appropriate application equipment/method near water bodies if the potential for off-site } \\
\text { drift exists. } \\
\text { For treatment of aquatic vegetation, 1) treat only that portion of the aquatic system necessary to } \\
\text { achieve acceptable vegetation management; } 2 \text { ) use the appropriate application method to } \\
\text { minimize the potential for injury to desirable vegetation and aquatic organisms; and 3) follow } \\
\text { water use restrictions presented on the herbicide label. }\end{array}$ \\
\hline $\begin{array}{l}\text { Wildlife } \\
\text { See manuals } 6500 \text { (Wildlife } \\
\text { and Fisheries Management) } \\
\text { and } 6780 \text { (Habitat } \\
\text { Management Plans) }\end{array}$ & $\begin{array}{l}\text { Use herbicides of low toxicity to wildlife, where feasible. } \\
\text { Use spot applications or low-boom broadcast operations where possible to limit the probability } \\
\text { of contaminating non-target food and water sources, especially non-target vegetation over areas } \\
\text { larger than the treatment area. } \\
\text { Use timing restrictions (e.g., do not treat during critical wildlife breeding or staging periods) to } \\
\text { minimize impacts to wildlife. } \\
\text { Avoid using glyphosate formulations that include R-11 in the future, and either avoid using any } \\
\text { formulations with POEA, or seek to use the formulation with the lowest amount of POEA } \\
\text { available, to reduce risks to amphibians. }\end{array}$ \\
\hline $\begin{array}{l}\text { Threatened, Endangered, and } \\
\text { Sensitive Species } \\
\text { See Manual } 6840 \text { (Special } \\
\text { Status Species) }\end{array}$ & $\begin{array}{l}\text { Survey for special status species before treating an area. Consider effects to special status } \\
\text { species when designing herbicide treatment programs. } \\
\text { Use a selective herbicide and a wick or backpack sprayer to minimize risks to special status } \\
\text { plants. } \\
\text { Avoid treating vegetation during time-sensitive periods (e.g., nesting and migration, sensitive } \\
\text { life stages) for special status species in area to be treated. }\end{array}$ \\
\hline $\begin{array}{l}\text { Livestock } \\
\text { See Handbook H-4120-1 } \\
\text { (Grazing Management) }\end{array}$ & $\begin{array}{l}\text { Whenever possible and whenever needed, schedule treatments when livestock are not present } \\
\text { in the treatment area. Design treatments to take advantage of normal livestock grazing rest } \\
\text { periods, when possible. } \\
\text { As directed by the herbicide label, remove livestock from treatment sites prior to herbicide } \\
\text { application, where applicable. } \\
\text { - Use herbicides of low toxicity to livestock, where feasible. } \\
\text { Take into account the different types of application equipment and methods, where possible, to } \\
\text { reduce the probability of contamination of non-target food and water sources. } \\
\text { Avoid use of diquat in riparian pasture while pasture is being used by livestock. } \\
\text { - Notify permittees of the project to improve coordination and avoid potential conflicts and } \\
\text { safety concerns during implementation of the treatment. } \\
\text { - Notify permittees of livestock grazing, feeding, or slaughter restrictions, if necessary. } \\
\text { - Provide alternative forage sites for livestock, if possible. }\end{array}$ \\
\hline
\end{tabular}


TABLE 2-8 (Cont.)

Standard Operating Procedures for Applying Pesticides

\begin{tabular}{|c|c|}
\hline Resource Element & Standard Operating Procedure \\
\hline Wild Horses and Burros & $\begin{array}{l}\text { - Minimize using herbicides in areas grazed by wild horses and burros. } \\
\text { - Use herbicides of low toxicity to wild horses and burros, where feasible. } \\
\text { in accordance with label directions for livestock. } \\
\text { - Take into account the different types of application equipment and methods, where possible, to } \\
\text { reduce the probability of contaminating non-target food and water sources. }\end{array}$ \\
\hline $\begin{array}{l}\text { Cultural Resources and } \\
\text { Paleontological Resources } \\
\text { See handbooks H-8120-1 } \\
\text { (Guidelines for Conducting } \\
\text { Tribal Consultation) and H- } \\
8270-1 \text { (General Procedural } \\
\text { Guidance for Paleontological } \\
\text { Resource Management), and } \\
\text { manuals } 8100 \text { (The } \\
\text { Foundations for } \\
\text { ManagingCultural Resources), } \\
8120 \text { (Tribal Consultation } \\
\text { Under Cultural Resource } \\
\text { Authorities), and } 8270 \\
\text { (Paleontological Resource } \\
\text { Management), } \\
\text { See also: Programmatic } \\
\text { Agreement among the Bureau } \\
\text { of Land Management, the } \\
\text { Advisory Council on Historic } \\
\text { Preservation, and the National } \\
\text { Conference of State Historic } \\
\text { Preservation Officers } \\
\text { Regarding the Manner in } \\
\text { Which BLM Will Meet Its } \\
\text { Responsibilities Under the } \\
\text { National Historic Preservation } \\
\text { Act. }\end{array}$ & $\begin{array}{l}\text { - Follow standard procedures for compliance with Section } 106 \text { of the National Historic } \\
\text { Preservation Act as implemented through the Programmatic Agreement among the Bureau of } \\
\text { Land Management, the Advisory Council on Historic Preservation, and the National } \\
\text { Conference of State Historic Preservation Officers Regarding the Manner in Which BLM Will } \\
\text { Meet Its Responsibilities Under the National Historic Preservation Act and state protocols or } \\
\text { 36 CFR Part 800, including necessary consultations with State Historic Preservation Officers } \\
\text { and interested tribes. } \\
\text { - Follow BLM Handbook H-8270-1 (General Procedural Guidance for Paleontological } \\
\text { Resource Management) to determine known Condition I and Condition } 2 \text { paleontological areas, } \\
\text { or collect information through inventory to establish Condition } 1 \text { and Condition } 2 \text { areas, } \\
\text { determine resource types at risk from the proposed treatment, and develop appropriate } \\
\text { measures to minimize or mitigate adverse impacts. } \\
\text { - Consult with tribes to locate any areas of vegetation that are of significance to the tribe and that } \\
\text { might be affected by herbicide treatments. } \\
\text { Work with tribes to minimize impacts to these resources. } \\
\text { - Follow guidance under Human Health and Safety in areas that may be visited by Native } \\
\text { peoples after treatments. }\end{array}$ \\
\hline $\begin{array}{l}\text { Visual Resources } \\
\text { See handbooks H-8410-1 } \\
\text { (Visual Resource Inventory) } \\
\text { and H-8431-1 (Visual } \\
\text { Resource Contrast Rating), } \\
\text { and manual } 8400 \text { (Visual } \\
\text { Resource Management) }\end{array}$ & $\begin{array}{l}\text { Minimize the use of broadcast foliar applications in sensitive watersheds to avoid creating large } \\
\text { areas of browned vegetation. } \\
\text { Consider the surrounding land use before assigning aerial spraying as an application method. } \\
\text { Minimize off-site drift and mobility of herbicides (e.g., do not treat when winds exceed } 10 \\
\text { mph; minimize treatment in areas where herbicide runoff is likely; establish appropriate buffer } \\
\text { widths between treatment areas and residences) to contain visual changes to the intended } \\
\text { treatment area. } \\
\text { If the area is a Class I or II visual resource, ensure that the change to the characteristic } \\
\text { landscape is low and does not attract attention (Class I), or if seen, does not attract the attention } \\
\text { of the casual viewer (Class II). } \\
\text { Lessen visual impacts by: 1) designing projects to blend in with topographic forms; 2) leaving } \\
\text { some low-growing trees or planting some low-growing tree seedlings adjacent to the treatment } \\
\text { area to screen short-term effects; and 3) revegetating the site following treatment. } \\
\text { When restoring treated areas, design activities to repeat the form, line, color, and texture of the } \\
\text { natural landscape character conditions to meet established Visual Resource Management } \\
\text { (VRM) objectives. }\end{array}$ \\
\hline
\end{tabular}


TABLE 2-8 (Cont.)

Standard Operating Procedures for Applying Pesticides

\begin{tabular}{|c|c|}
\hline Element & Standard Operating Procedure \\
\hline $\begin{array}{l}\text { Wilderness and Other Special } \\
\text { Areas } \\
\text { See handbooks H-8550-1 } \\
\text { (Management of Wilderness } \\
\text { Study Areas (WSAs)), and H- } \\
8560-1 \text { (Management of } \\
\text { Designated Wilderness Study } \\
\text { Areas), and Manual } 8351 \\
\text { (Wild and Scenic Rivers) }\end{array}$ & $\begin{array}{l}\text { Encourage backcountry pack and saddle stock users to feed their livestock only weed-free feed } \\
\text { for several days before entering a wilderness area. } \\
\text { Encourage stock users to tie and/or hold stock in such a way as to minimize soil disturbance } \\
\text { and loss of native vegetation. } \\
\text { - Revegetate disturbed sites with native species if there is no reasonable expectation of natural } \\
\text { regeneration. } \\
\text { Provide educational materials at trailheads and other wilderness entry points to educate the } \\
\text { public on the need to prevent the spread of weeds. } \\
\text { Use the "minimum tool" to treat noxious and invasive vegetation, relying primarily on use of } \\
\text { ground-based tools, including backpack pumps, hand sprayers, and pumps mounted on pack } \\
\text { and saddle stock. } \\
\text { - Use chemicals only when they are the minimum method necessary to control weeds that are } \\
\text { spreading within the wilderness or threaten lands outside the wilderness. } \\
\text { Give preference to herbicides that have the least impact on non-target species and the } \\
\text { wilderness environment. } \\
\text { Implement herbicide treatments during periods of low human use, where feasible. } \\
\text { Address, wilderness and special areas in management plans. } \\
\text { Maintain adequate buffers for Wild and Scenic Rivers ( } 1 / 4 \text { mile on either side of river, } 1 / 2 \text { mile in } \\
\text { Alaska). }\end{array}$ \\
\hline $\begin{array}{l}\text { Recreation } \\
\text { See Handbook H-1601-1 } \\
\text { (Land Use Planning } \\
\text { Handbook, Appendix C) }\end{array}$ & $\begin{array}{l}\text { - Schedule treatments to avoid peak recreational use times, while taking into account the } \\
\text { optimum management period for the targeted species. } \\
\text { - Notify the public of treatment methods, hazards, times, and nearby alternative recreation areas. } \\
\text { - } \quad \text { Adhere to entry restrictions identified on the herbicide label for public and worker access. } \\
\text { - } \quad \text { Use herbicides during periods of low human use, where feasible. }\end{array}$ \\
\hline Social and Economic Values & $\begin{array}{l}\text { - Consider surrounding land use before selecting aerial spraying as a method, and avoid aerial } \\
\text { spraying near agricultural or densely-populated areas. } \\
\text { - Post treated areas and specify reentry or rest times, if appropriate. } \\
\text { Notify grazing permittees of livestock feeding restrictions in treated areas, if necessary, as } \\
\text { per label instructions. } \\
\text { - Notify the public of the project to improve coordination and avoid potential conflicts and } \\
\text { safety concerns during implementation of the treatment. } \\
\text { - Control public access until potential treatment hazards no longer exist, per label instructions. } \\
\text { - Observe restricted entry intervals specified by the herbicide label. } \\
\text { - Notify local emergency personnel of proposed treatments. } \\
\text { Use spot applications or low-boom broadcast applications where possible to limit the } \\
\text { probability of contaminating non-target food and water sources, especially vegetation over } \\
\text { areas larger than the treatment area. } \\
\text { Consult with Native American tribes and Alaska Native groups to locate any areas of } \\
\text { vegetation that are of significance to the tribe and that might be affected by herbicide } \\
\text { treatments. } \\
\text { To the degree possible within the law, hire local contractors and workers to assist with } \\
\text { herbicide application projects and purchase materials and supplies, including chemicals, for } \\
\text { herbicide treatment projects through local suppliers. } \\
\text { To minimize fears based on lack of information, provide public educational information on } \\
\text { the need for vegetation treatments and the use of herbicides in an Integrated Pest } \\
\text { Management program for projects proposing local use of herbicides. }\end{array}$ \\
\hline
\end{tabular}


TABLE 2-8 (Cont.)

Standard Operating Procedures for Applying Pesticides

\begin{tabular}{|c|c|}
\hline Resource Element & Standard Operating Procedure \\
\hline Rights-of-way & $\begin{array}{l}\text { - Coordinate vegetation management activities where joint or multiple use of a ROW exists. } \\
\text { - Notify other public land users within or adjacent to the ROW proposed for treatment. } \\
\text { - Use only herbicides that are approved for use in ROW areas. }\end{array}$ \\
\hline Human Health and Safety & $\begin{array}{l}\text { - Establish a buffer between treatment areas and human residences based on guidance given in } \\
\text { the HHRA, with a minimum buffer of } 1 / 4 \text { mile for aerial applications and } 100 \text { feet for ground } \\
\text { applications, unless a written waiver is granted. } \\
\text { - Use protective equipment as directed by the herbicide label. } \\
\text { - Post treated areas with appropriate signs at common public access areas. } \\
\text { - } \quad \text { Observe restricted entry intervals specified by the herbicide label. } \\
\text { - } \text { exposide public notification in newspapers or other media where the potential exists for public } \\
\text { - Have a copy of MSDSs at work site. } \\
\text { - } \quad \text { Cotify local emergency personnel of proposed treatments. } \\
\text { - Secure containers during transport. } \\
\text { - Follow label directions for use and storage. } \\
\text { - Dispose of unwanted herbicides promptly and correctly. }\end{array}$ \\
\hline
\end{tabular}

The BLM meets its responsibilities for consultation and government-to-government relationships with Native American tribes by consulting with appropriate tribal representatives prior to taking actions that affect tribal interests. The BLM's tribal consultation policies are detailed in BLM Manual 8120 (Tribal Consultation Under Cultural Resource Authorities) and Handbook H8120-1 (Guidelines for Conducting Tribal Consultation). The BLM consulted with Native American tribes and Alaska Native groups during development of this PEIS. Information gathered on important tribal resources and potential impacts to these resources from herbicide treatments is presented in the analysis of impacts.

When conducting vegetation treatments, field office personnel consult with relevant parties (including tribes, native groups, and SHPOs), assess the potential of the proposed treatment to affect cultural and subsistence resources, and devise inventory and protection strategies suitable to the types of resources present and the potential impacts to them.

Herbicide treatments, for example, are unlikely to affect buried cultural resources, but might have a negative effect on traditional cultural properties comprised of plant foods or materials significant to local tribes and native groups. These treatments require inventory and protection strategies that reflect the different potential of each treatment to affect various types of cultural resources.

Impacts to significant cultural resources are avoided through project redesign or are mitigated through data recovery, recordation, monitoring, or other appropriate measures. When cultural resources are discovered during vegetation treatment, appropriate actions are taken to protect these resources.

\section{Monitoring}

Monitoring ensures that vegetation management is an adaptive process that continually builds upon past successes and learns from past mistakes. The regulations of 43 CFR 1610.4-9 require that land use plans establish intervals and standards for monitoring and evaluating of land management actions. During preparation of implementation plans, treatment objectives, standards, and guidelines are stated in measurable terms, where feasible, so that treatment outcomes can be measured, evaluated, and used to guide future treatment actions. This approach ensures that vegetation treatment processes are effective, adaptive, and based on prior experience.

The diversity of plant communities on BLM lands calls for a diversity of monitoring approaches. Monitoring strategies may vary in time and space depending oni the 
species. Sampling designs and techniques vary depending on the type of vegetation. Guidance on monitoring methodologies can be found in such BLM documents as Measuring and Monitoring Plant Populations (BLM Technical Reference 1730-1), which was developed in cooperation with The Nature Conservancy. Other guidance documents include Sampling Vegetation Attributes (Interagency Technical Reference 4400-4), developed in cooperation with the Forest Service, the Natural Resource Conservation Service, and the Cooperative Extension Service; and the Ecological Site Inventory (BLM Inventory and Monitoring Technical Reference 1734-7). These documents, as well as numerous other guidance documents for specific plant communities, can be found on the National Science and Technology Center website (http://www.blm.gov/nstc). These documents, plus any regionally specific documents developed to meet management objectives allow for the flexibility needed to monitor the variety of vegetation on public lands.

Two types of monitoring of vegetation treatments may be pursued by the BLM. One type is implementation monitoring which answers the question, "Did we do what we said we would do?" The second type is effectiveness monitoring, which answers the question, "Were treatment and restoration projects effective?" Implementation monitoring is usually done at the land use planning level or through annual work plan accomplishment reporting. Effectiveness monitoring is usually done at the local project implementation level.

Invasive plant implementation monitoring for nonherbicide treatments is accomplished through site revisits performed during the growing season of the target species to determine if treatments were implemented correctly and the best time for follow-up treatments.

For herbicide use, implementation monitoring is accomplished through the use of Pesticide Use Proposals (PUPs) and Pesticide Application Records. Both documents are required by the BLM in order to track pesticide use annually. The PUP requires reporting of the pesticide proposed for use and the maximum application rate. It also requires reporting of the number and timing of applications. Targeted species and nontargeted species at the treatment site are described, as well as the other site characteristics. A description of sensitive resources and mitigation measures to protect these resources is also required. Most importantly, the integrated weed management approach to be taken (i.e., the combination of treatments to be used) is required. The NEPA document that analyzes the effects of the treatment must also be referenced. PUPs must be signed by a certified weed applicator, the field office manager, state coordinator, and deputy state director before the treatment can go forward. The Pesticide Application Record, which must be completed within 24 hours after completion of the application, documents the actual rate of application and that all the above factors have been taken into account. Pesticide Application Records are used to develop annual state summaries of herbicide use for BLM.

PUPs and Pesticide Application Records can also be used for more site-specific implementation monitoring. For example, the Application Record can be used to track whether the application was made at the correct time, if mitigation for sensitive wildlife concerns is included in the PUP.

Monitoring of invasive plant treatment effectiveness can range from site visits to compare the targeted population size against pre-treatment inventory data, to comparing pre-treatment and post-treatment photo points, to more elaborate transect work, depending on the species and site-specific variables. The goals of monitoring should be to answer questions such as the following:

- What changes in the distribution, amount, and proportion of invasive plant infestations have resulted due to treatments?

- Has infestation size been reduced at the project level or larger scale (such as a watershed)?

- Which treatment methods, separate or in combination, are most successful for a particular species? (USDA Forest Service 2005).

Monitoring data can have far-reaching applications in fire management because it provides the scientific basis for planning and implementing future burn treatments. Measuring post-fire ecosystem response allows the BLM to understand the consequences of fire on important ecosystem components and to share this knowledge in a scientifically based language. Monitoring is the critical feedback loop that allows fire management to constantly improve prescriptions and fire plans based on the new knowledge gained from field measurements. FIREMON is an interagency monitoring program that is used for monitoring fuels treatment effectiveness. When a fuels treatment project involves an invasive species (such as tamarisk or Russian olive), monitoring can be done using a program such as FIREMON. 
Another monitoring protocol frequently used to inventory and monitor forest vegetation is called the Forest Vegetation Information System or FORVIS. FORVIS is a system for storage, retrieval, and analysis of data about forestlands. These data describe existing vegetation, classify sites relative to current condition, can be used in forest growth and structure and wildlife habitat models, describe landscapes, aid in developing forest restoration treatments, and provide a record of treatment and disturbance events.

BLM monitoring activities also include the BLM Legacy program, which is an outgrowth of the need to provide current BLM field managers and specialists with an opportunity to learn about past land management practices and land treatments, and to evaluate the results of those practices 25 or more years later (USDI BLM 2002c). The Legacy program is intended to bring together current land managers and specialists with retired and active employees who performed the land treatments in the past. The underlying philosophy of the program is that if BLM land managers do not learn from the past, they cannot know which treatments are effective and which are not.

The Healthy Forests Restoration Act of 2003 instructs the BLM to establish a collaborative multiparty monitoring, evaluation, and accountability process when significant interest is expressed in such an approach. The process is used to assess the positive and negative ecological and social effects of projects carried out under Healthy Forests Restoration Act authority. Multiparty monitoring can be an effective way to build trust and collaboration with local communities and diverse stakeholders, including interested citizens and tribes.

The results of monitoring should be made available to interested parties. A website with links to geospatial and other data sets will ensure that inventory data, and treatment methods and results, are shared easily. The BLM has a website, http://www.blm.gov, with links to BLM programs, such as the weed program, and other data sources, including geospatial data. Most state offices are tied into state data clearinghouses that contain useful information gathered by federal, state, and local agencies.

\section{Monitoring Guidance used by BLM in Vegetation Management}

The BLM has prepared numerous guidance and strategy documents to aid field personnel in developing and implementing monitoring plans and strategies. These include the following:

- BLM National Monitoring Strategy (2006). The BLM is currently developing a national strategy to manage the collection, storage, and use of data describing the interrelationship of resource conditions, resource uses, and the BLM's own activities. The goals of the strategy are to: 1) enhance the efficiency and effectiveness of the BLM's assessment, inventory, and monitoring efforts; 2) establish and use a limited number of resource indicators that are common to most or all BLM field offices, and that are comparable or identical to measures used by other government agencies and non-governmental organizations; and 3) standardize data collection, evaluation, and reporting in a way that improves the quality of the BLM's land use planning and other management decisions, and enhances the BLM's ability to manage for multiple uses.

- BLM Land Use Planning Handbook H-16011 (2005). Establishes requirements for periodic implementation and effectiveness monitoring for land use planning decisions.

- Monitoring Manual for Grasslands, Shrubland, and Savanna Ecosystems Vols. I and II. USDA Agricultural Research Service (2005). Provides quantitative methods to address indicators of rangeland health.

- BLM Technical Reference 1730-2 Biological Soil Crusts (2001). Provides technical guidance on how to develop and implement effective monitoring plans for biological soil crusts.

- BLM Handbook H-4180-1 Rangeland Health Standards (2001). Provides technical guidance on evaluating rangeland health, developing plans to improve rangeland health, and monitoring the progress of rangeland health plans.

- BLM Technical Reference 1730-1 Measuring and Monitoring Plant Populations (1998). Provides technical guidance on how to develop and implement effective monitoring plans for vegetation and use monitoring in adaptive management. 
- BLM Technical Reference 1734-4 Sampling Vegetative Attributes (1996). Provides the basis for consistent, uniform, and standard vegetation attribute sampling that is economical, repeatable, statistically reliable, and technically adequate.

- Manual Section 9011 Chemical Pest Control (1992). Establishes requirements for monitoring pesticide applications.

- Manual Section 9014 Use of Biological Control Agents of Pests on Public Lands (1990). Establishes requirements to monitor success or failure in survival, control, and spread of biological agents.

- Guidelines for Coordinated Management of Noxious Weeds (1990). Provides guidance on establishing monitoring plans for noxious weeds and their control.

- BLM Handbook H-4400-1 Range Monitoring and Evaluation (1989). Provides technical guidance on how to measure vegetation uses such as livestock grazing, wild horse and burro use, and wildlife browsing and foraging.

- BLM Handbook H-9011-1 Chemical Pest Control (1988). Provides technical guidance on post-treatment evaluations for pesticide applications to occur within 2 years of treatment.

- NEPA Handbook H-1790-1 Chapter VI Monitoring (1988). All actions and mitigation measures, including monitoring and enforcement programs, adopted in a decision document are legally enforceable commitments. The purposes of monitoring in a NEPA context are to 1) ensure compliance with decisions, 2) measure effectiveness of decisions, and 3) evaluate validity of decisions.

- Manual Section 1734 Monitoring and Inventory Coordination (1983). Provides the BLM with technical guidance on how to develop and implement effective monitoring plans for vegetation.

Numerous other technical references for inventory, monitoring, and assessment are found at: http://www.blm.gov/nstc/library/techref.htm. In addition, state-specific handbooks to guide monitoring based on the national level guidance (e.g., Nevada Monitoring Handbook, Oregon Monitoring Handbook).

\section{Monitoring Methods and Research}

Fuels treatment and noxious weed control projects must begin with an understanding of which techniques and monitoring methods are most effective, as determined through careful research and follow-up monitoring. The BLM has been supporting research at universities and Forest Service research stations through the Joint Fire Science program and projects such as the Great Basin Restoration Initiative. The Joint Fire Science program has supported research on such topics as fire effects, effects from fuels treatments, and the use of fire as a tool in controlling invasive plants (http://jfsp.nifc.gov/). Under the Great Basin Restoration Initiative, ongoing projects involving weed control, restoration, and fire treatments help provide a link between science and management to ensure that ecologically-based restoration is implemented. These projects are summarized

http://www.fire.blm.gov/gbri/technology.html.

Dissemination of research and monitoring results and information occurs in a variety of ways, including formal conferences and workshops of fire management professionals, the National Science and Technology Center, publications such as Resource Notes, and BLM state websites. Snapshots, an online publication found at http://www.fire.blm.gov/snapshots.htm, highlights BLM projects that support the National Fire Plan. Examples of successful projects and community collaborations that have been discussed in Snapshots include creation and monitoring of fuels breaks, habitat improvement through prescribed burning, fuels reduction and associated monitoring, and the progress of a downy brome taskforce. Examples of project successes include the following:

- In Wyoming, a multi-agency prescribed burn was completed in 2005 to reduce hazardous fuels and improve the health and vigor of native plant communities. Monitoring methods include permanent vegetation transects and photo points to provide post-burn results and an elk collaring study to show which treatment areas are being used by elk. The information obtained during this study will be shared with the public, and the site will be used by school classes. 
- In Wyoming, a tamarisk reduction project was started in the Bighorn Basin in 2000 to restore native cottonwood galleries. The project involves various combinations of treatments, as well as plantings of native species following the treatments.

- In Washington, the BLM has been treating reed canarygrass since 2003, using a combination of prescribed burning, herbicides, and mowing, followed by seedbed preparation and reseeding with native seed mixtures. This project is a partnership with the Natural Resource Conservation Service, Washington State Department of Fish and Wildlife, and the U.S. Fish and Wildlife Service.

BLM offices maintain monitoring reports to document that fuels treatments meet set objectives. Monitoring plans typically include plots and photo points, at which pre- and post-treatment data are collected. This type of monitoring has successfully provided data that has allowed the BLM to confirm that project goals have been met.

\section{Coordination and Education}

As demonstrated at public scoping meetings for the PEIS, the public is deeply interested in BLM vegetation treatment activities, especially individuals that live in close proximity to public lands, have commercial operations dependant on vegetation on or adjacent to public lands, or use public lands for recreation. The BLM strives to keep the public informed about its vegetation treatment activities through regular coordination and communication. The BLM also encourages the public to participate in the environmental review process during the development and analysis of local vegetation management programs.

Several laws and Executive Orders set forth public involvement requirements, including involving the public in the environmental analysis, land use planning, and implementation decision-making processes to address local, regional, and national interests (USDI BLM 2000f).

The BLM is ultimately responsible for land use plan decisions, including decisions about vegetation management, on public lands. The BLM has found, however, that collaborative relationships with stakeholders, including individuals, communities, and governments, improves communication, provides a greater understanding of different perspectives, and helps to find solutions to issues and problems. Input from the public and government agencies has been critical during development of this PEIS and the PER.

The NEPA process ensures that the public is allowed input into vegetation management actions on public lands. For treatment projects requiring an EA or EIS, the BLM must notify the public of the proposed project and give the public the opportunity to comment on the site-specific analysis done for the project. Treatment actions may be modified in response to comments posed by the public. The public may also be invited to observe treatment activities and participate in project monitoring.

Public lands are often commingled with private lands, or lands under the jurisdiction of tribal, state, or local governments or other federal agencies. Multijurisdictional planning assists land use planning efforts when there is a mix of land ownership and government authorities, and there are opportunities to develop complementary decisions across jurisdictional boundaries.

Examples of these planning efforts include development of weed treatment programs involving the BLM and nearby private landowners, or coordination with parties who hold land use authorizations including ROW, leases, permits, or easements. Many BLM weed coordinators hold classes for public land users to make them aware of the problem and to solicit their help in reporting new weed infestations.

Because vegetation treatments have a direct effect on the productivity and use of grazing allotments, coordination and consultation with the grazing permittee(s), and any other interested parties affected by a vegetation treatment, would be necessary.

It is critical that the BLM notify potentially affected parties of treatment activities that occur on public lands. This can be done through a letter, phone call, meeting, newsletter, newspaper article, or other medium to ensure that potentially affected parties can comment on the proposed action and take any steps needed to protect life and property from proposed actions.

Prior to herbicide treatments, the BLM posts entry points onto public lands where the herbicide application will take place. Information provided in the posting will includes herbicide product applied; active ingredients; USEPA registration number; application date; period of time which must elapse before a person without 
protective clothing may enter a treatment site; and other warnings or information required to ensure the safety of the public.

The BLM enjoys wide participation in various national, state, and local prevention and education efforts pertaining to noxious and invasive species and hazardous fuels management. The BLM participates in state FireWise programs, state Fire Safe Councils, the National Wildfire Coordinating Group Wildland Fire Education Working Team, and the National Wildland Fire Prevention and Education Team. Local education efforts such as Project: FIRE bring BLM natural resource professionals into schools to educate students about fire prevention and safety. Noxious weed and invasive species education programs span the K-12 grades and are led by many local BLM field office ecologists and natural resource professionals. The BLM also participates in Project Learning Tree. Project Learning Tree, one of the most widely-used environmental education programs in, the country, provides education curricula for fire and invasive species education.

\section{Mitigation}

Table 2-9 identifies the measures the BLM proposes to mitigate adverse environmental impacts identified in Chapter 4 (Environmental Consequences). As defined by CEQ regulation 1508.20 , mitigation includes: 1) avoiding the impact altogether by not taking a certain action or parts of an action; 2) minimizing impacts by limiting the degree or magnitude of the action and its implementation; 3) rectifying the impact by repairing, rehabilitating, or restoring the affected environment; 4) reducing or eliminating the impact over time by preservation and maintenance operations during the life of the action; and 5) compensating for the impact by replacing or providing substitute resources or environments.
Numerous mitigation measures were developed from information provided in ERAs and during development of this PEIS. The measures listed below would apply to plants, animals, and other resources at the programmatic level in all 17 western states. However, local BLM field offices could use interactive spreadsheets and other information contained in the ERAs to develop more site-specific mitigation and management plans based on local conditions (e.g., soil type, rainfall, vegetation type, herbicide treatment method, and herbicide application rate). It is possible that mitigation measures would be less restrictive than those listed below if local site conditions were evaluated using the ERAs when developing project-level mitigation plans. In addition, the BLM may be able to use timing restrictions or similar practices to reduce the level of risk to an acceptable level. For example, it may be necessary to apply diuron at the typical herbicide application rate to ensure protection of a migratory bird species. However, it may be acceptable to use the maximum application rate during periods of the year when the bird has migrated from the treatment area. Local field managers would consult the ERAs and review species life history requirements before making these decisions to ensure that birds and other resources are adequately protected.

\section{Summary of Impacts by Alternative}

Table 2-10 summarizes the likely effects of vegetation treatments using herbicides for each alternative. Information contained in this table is discussed in more detail in Chapter 4 (Environmental Consequences). 
TABLE 2-9

Mitigation Measures

\begin{tabular}{|c|c|}
\hline Resource & Mitigation Measures \\
\hline Air Quality & None proposed. \\
\hline Soil Resources & None proposed. \\
\hline Water Resources and Quality & $\begin{array}{l}\text { - Establish appropriate (herbicide specific) buffer zones to downstream water bodies, habitats, } \\
\text { and species/populations of interest (see Appendix C, Table C-16). }\end{array}$ \\
\hline Wetland and Riparian Areas & - See mitigation for Water Resources and Quality and Vegetation. \\
\hline Vegetation & $\begin{array}{l}\text { - Minimize the use of terrestrial herbicides (especially bromacil, diuron, and sulfometuron } \\
\text { methyl) in watersheds with downgradient ponds and streams if potential impacts to aquatic } \\
\text { plants are of concern. } \\
\text { Establish appropriate (herbicide specific) buffer zones around downstream water bodies, } \\
\text { habitats, and species/populations of interest. Consult the ERAs for more specific information } \\
\text { on appropriate buffer distances under different soil, moisture, vegetation, and application } \\
\text { scenarios. } \\
\text { To protect special status plant species, implement all conservation measures for plants } \\
\text { presented in the Vegetation Treatments on Bureau of Land Management Lands in } 17 \text { Western } \\
\text { States Programmatic Biological Assessment. }\end{array}$ \\
\hline $\begin{array}{l}\text { Fish and Other Aquatic } \\
\text { Organisms }\end{array}$ & $\begin{array}{l}\text { - Limit the use of diquat in water bodies that have native fish and aquatic resources. } \\
\text { - Limit the use of terrestrial herbicides in watersheds with characteristics suitable for potential } \\
\text { surface runoff, that have fish-bearing streams, during periods when fish are in life stages most } \\
\text { sensitive to the herbicide(s) used. } \\
\text { - To protect special status fish and other aquatic organisms, implement all conservation measures } \\
\text { for aquatic animals presented in the Vegetation Treatments on Bureau of Land Management } \\
\text { Lands in } 17 \text { Western States Programmatic Biological Assessment. } \\
\text { - Establish appropriate herbicide-specific buffer zones for water bodies, habitats, or fish or other } \\
\text { aquatic species of interest (see Appendix C, Table C-16, and recommendations in individual } \\
\text { ERAs). } \\
\text { Avoid using the adjuvant R-11 }{ }^{\circledR} \text { in aquatic environments, and either avoid using glyphosate } \\
\text { formulations containing POEA, or seek to use formulations with the least amount of POEA, to } \\
\text { reduce risks to aquatic organisms. }\end{array}$ \\
\hline Wildlife & $\begin{array}{l}\text { - To minimize risks to terrestrial wildlife, do not exceed the typical application rate for } \\
\text { applications of dicamba, diuron, glyphosate, hexazinone, tebuthiuron, or triclopyr, where } \\
\text { feasible. } \\
\text { - Minimize the size of application areas, where practical, when applying 2,4-D, bromacil, diuron, } \\
\text { and Overdrive }{ }^{\circledR} \text { to limit impacts to wildlife, particularly through contamination of food items. } \\
\text { - Where practical, limit glyphosate and hexazinone to spot applications in rangeland and wildlife } \\
\text { habitat areas to avoid contamination of wildlife food items. } \\
\text { Avoid using the adjuvant R-11 } 1^{\circledR} \text { in aquatic environments, and either avoid using glyphosate } \\
\text { formulations containing POEA, or seek to use formulations with the least amount of POEA, to } \\
\text { reduce risks to amphibians. } \\
\text { Do not apply bromacil or diuron in rangelands, and use appropriate buffer zones (see } \\
\text { Vegetation section in Chapter 4) to limit contamination of off-site vegetation, which may serve } \\
\text { as forage for wildlife. } \\
\text { Do not aerially apply diquat directly to wetlands or riparian areas. } \\
\text { To protect special status wildlife species, implement all conservation measures for terrestrial } \\
\text { animals presented in the Vegetation Treatments on Bureau of Land Management Lands in } 17 \\
\text { Western States Programmatic Biological Assessment. Apply these measures to special status } \\
\text { species (refer to conservation measures for a similar size and type of species, of the same } \\
\text { trophic guild). }\end{array}$ \\
\hline
\end{tabular}


TABLE 2-9

Mitigation Measures (Cont.)

\begin{tabular}{|c|c|c|}
\hline Resource & Mitigation Measures \\
\hline \hline & $\bullet \quad$ Minimize potential risks to livestock by applying diuron, \\
\hline
\end{tabular}

- Minimize potential risks to livestock by applying diuron, glyphosate, hexazinone, tebuthiuron, and triclopyr at the typical application rate, where feasible.

- Do not apply 2,4-D, bromacil, dicamba, diuron, Overdrive ${ }^{\circledR}$, picloram, or triclopyr across large application areas, where feasible, to limit impacts to livestock, particularly through the contamination of food items.

Livestock

- Where feasible, limit glyphosate and hexazinone to spot applications in rangeland.

- Do not aerially apply diquat directly to wetlands or riparian areas used by livestock.

- Do not apply bromacil or diuron in rangelands, and use appropriate buffer zones (see Vegetation section in Chapter 4) to limit contamination of off-site rangeland vegetation.

- Minimize potential risks to wild horses and burros by applying diuron, glyphosate, hexazinone, tebuthiuron, and triclopyr at the typical application rate, where feasible.

- Consider the size of the application area when making applications of 2,4-D, bromacil, dicamba, diuron, Overdrive ${ }^{\mathbb{Q}}$, picloram, and triclopyr in order to reduce potential impacts to livestock.

- Apply herbicide label grazing restrictions for livestock to herbicide treatment areas that support populations of wild horses and burros.

Wild Horses and Burros

- Where feasible, limit glyphosate and hexazinone to spot applications in rangeland.

- Do not apply bromacil or diuron in grazing lands within herd management areas, and use appropriate buffer zones (see Vegetation section in Chapter 4) to limit contamination of vegetation in off-site foraging areas.

- Do not apply 2,4-D, bromacil, or diuron in herd management areas during the peak foaling season (March through June, and especially in May and June), and do not exceed the typical application rate of Overdrive ${ }^{\circledR}$ or hexazinone in HMAs during the peak foaling season.

- Do not exceed the typical application rate when applying 2,4-D, bromacil, diquat, diuron, fluridone, hexazinone, tebuthiuron, and triclopyr in known traditional use areas.

Paleontological and Cultural

Resources

- Avoid applying bromacil or tebuthiuron aerially in known traditional use areas.

- Limit diquat applications to areas away from high residential and traditional use areas to reduce risks to Native Americans and Alaska Natives.

\begin{tabular}{l}
\hline Visual Resources \\
\hline Wilderness and Other Special \\
Areas
\end{tabular}

None proposed.

Mitigation measures that may apply to wilderness and other special area resources are associated with human and ecological health and recreation. Please refer to the Vegetation, Fish and Other Aquatic Resources, Wildlife Resources, Recreation, and Human Health and Safety sections of Chapter 4.

\begin{tabular}{l|l} 
Recreation & $\begin{array}{l}\text { Mitigation measures that may apply to recreational resources are } \\
\text { ecological health. Please refer to the Vegetation, Fish and Other } \\
\text { Resources, and Human Health and Safety sections of Chapter } 4 .\end{array}$ \\
\hline
\end{tabular}

Mitigation measures that may apply to recreational resources are associated with human and

\begin{tabular}{|l|l}
\hline Social and Economic Values & None proposed. \\
\hline
\end{tabular}

- Use the typical application rate, where feasible, when applying 2,4-D, 2,4-DP, atrazine, bromacil, diquat, diuron, fluridone, fosamine, hexazinone, tebuthiuron, and triclopyr to reduce risk to occupational and public receptors.

- Avoid applying atrazine, bromacil, diuron, or simazine aerially.

- Limit application of chlorsulfuron via ground broadcast applications at the maximum application rate.

Human Health and Safety

- Limit diquat application to ATV, truck spraying, and boat applications to reduce risks to occupational receptors; limit diquat applications to areas away from high residential and subsistence use to reduce risks to public receptors.

- Evaluate diuron applications on a site-by-site basis to avoid risks to humans. There appear to be few scenarios where diuron can be applied without risk to occupational receptors.

- Do not apply hexazinone with an over-the-shoulder broadcast applicator. 


\begin{tabular}{|c|c|c|c|c|}
\hline \multirow{5}{*}{ 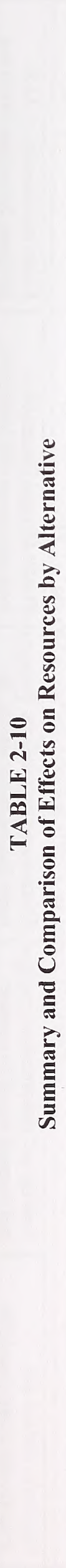 } & \multirow[b]{5}{*}{ 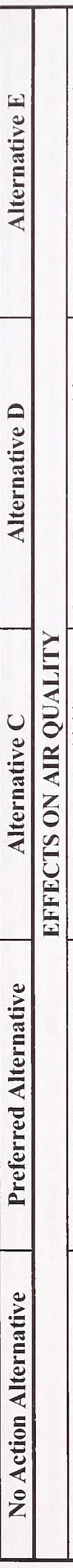 } & 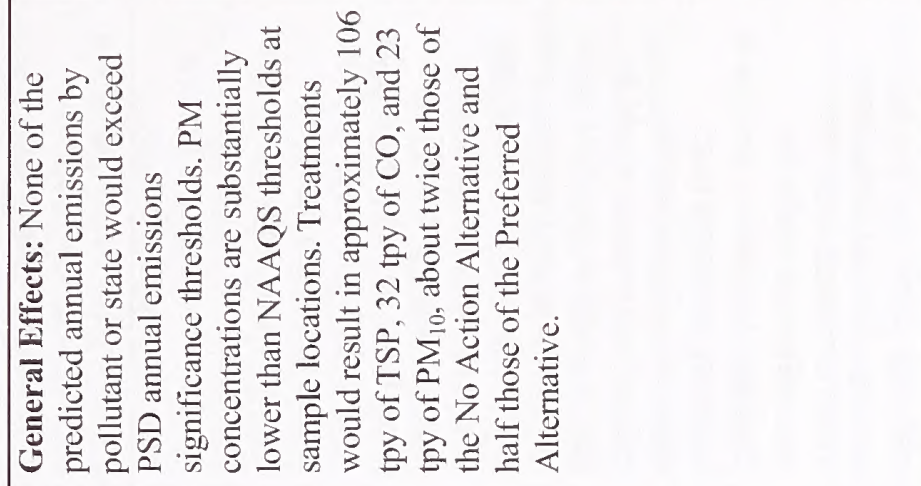 & \multirow{5}{*}{ 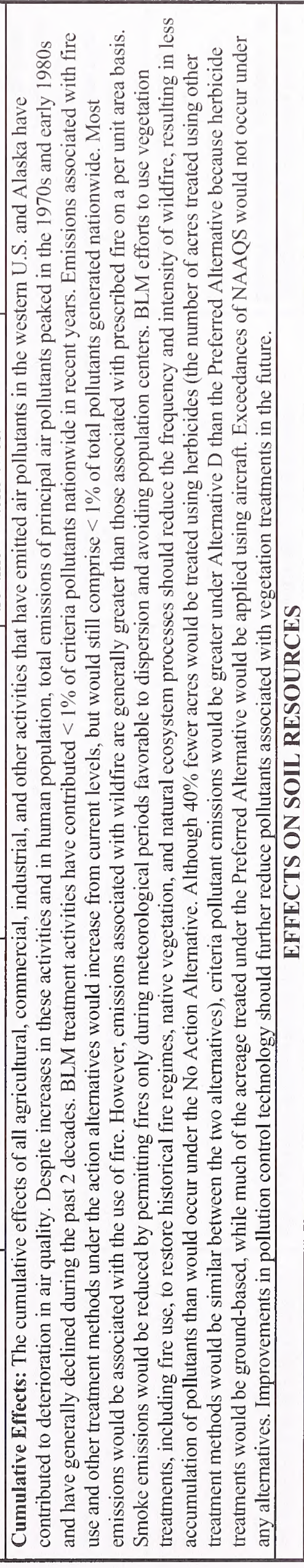 } & \\
\hline & & 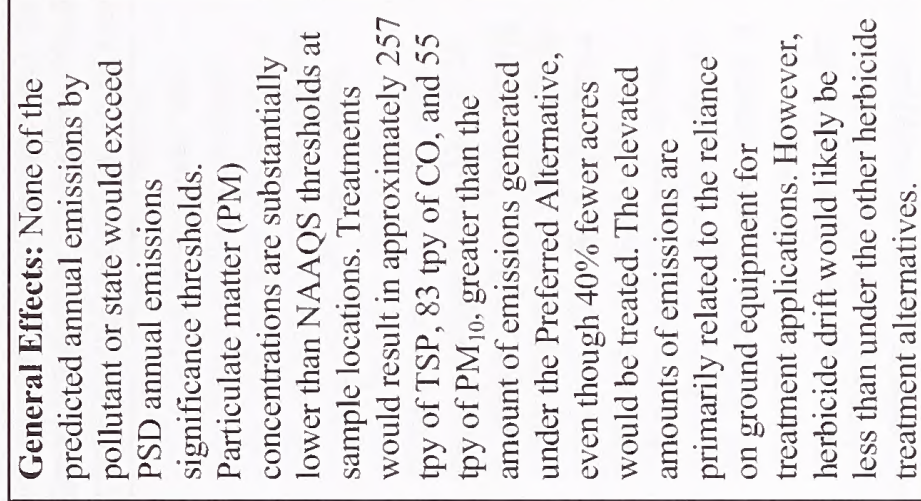 & & \\
\hline & & 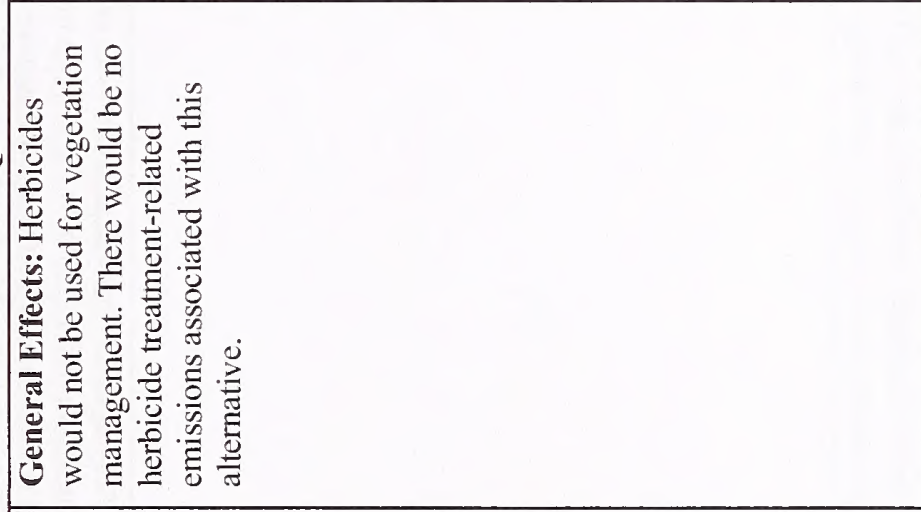 & & \\
\hline & & 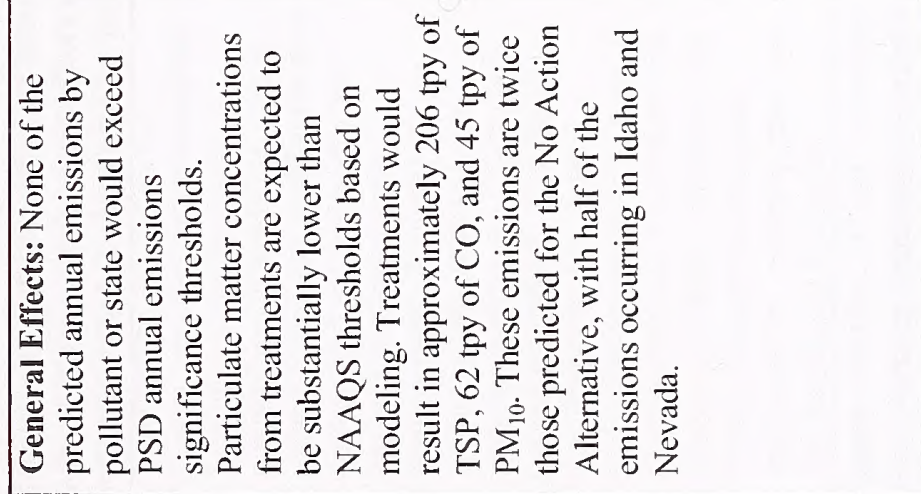 & & \\
\hline & & 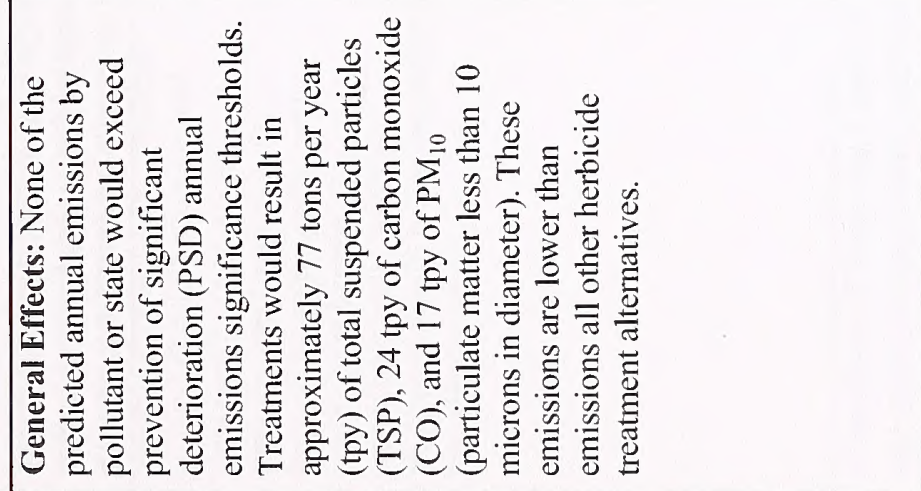 & & \\
\hline
\end{tabular}




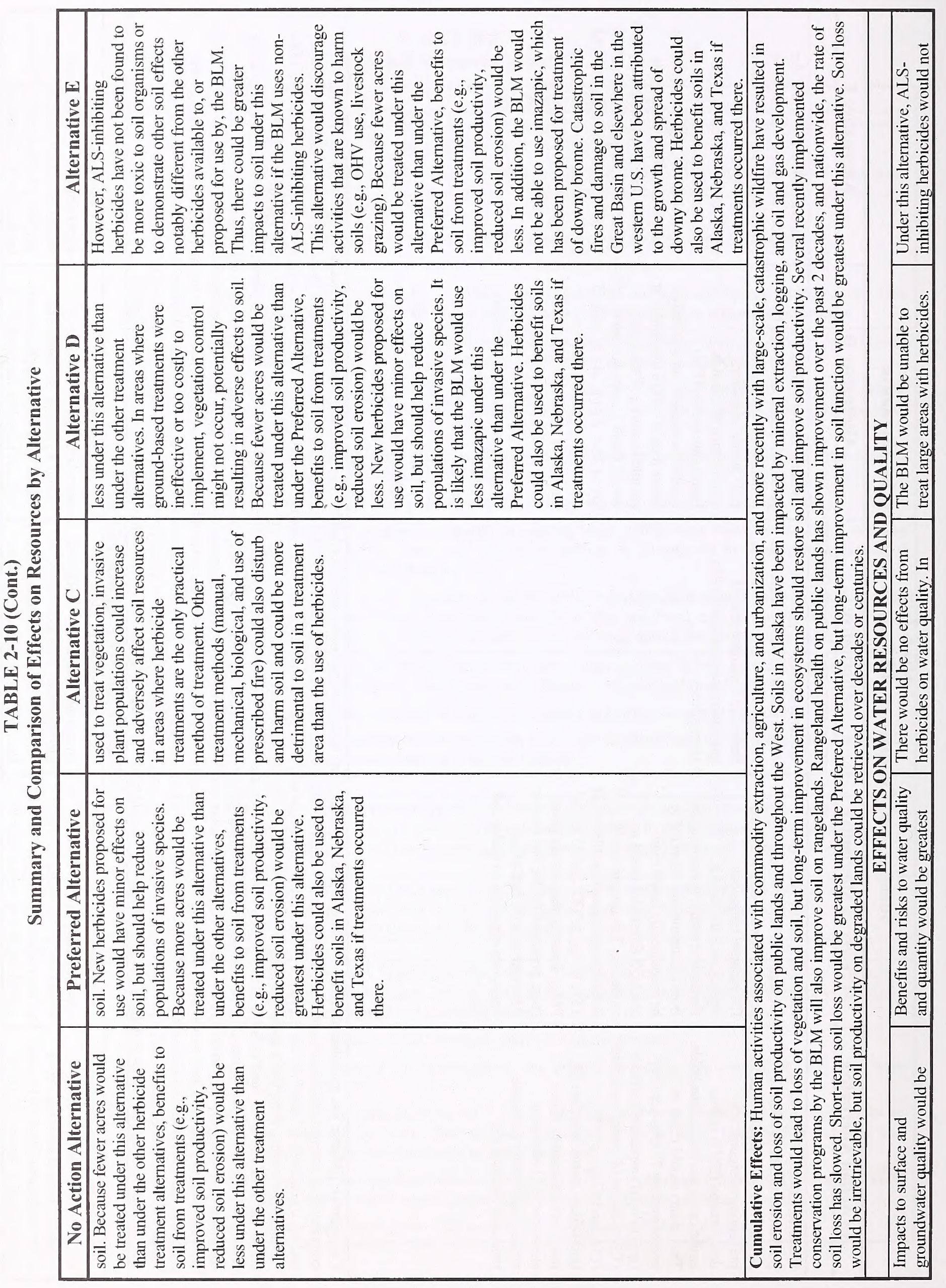




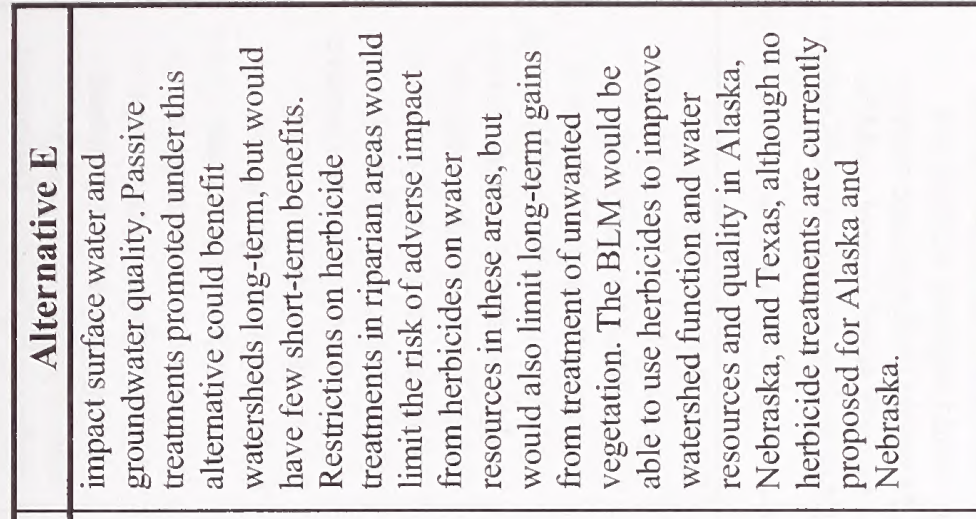

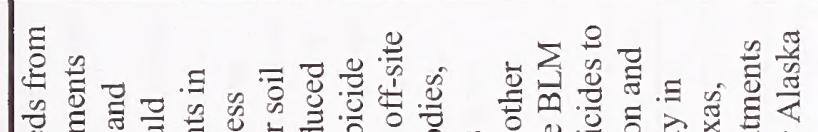

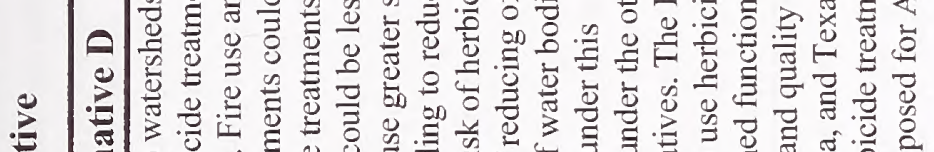

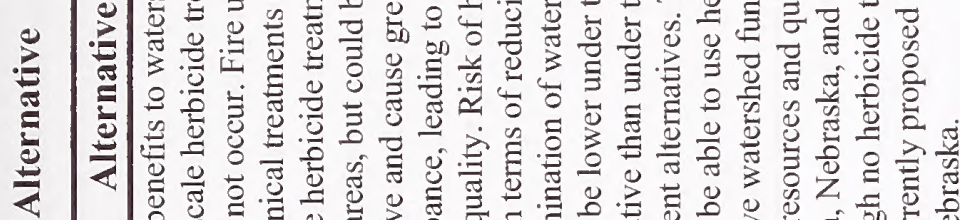

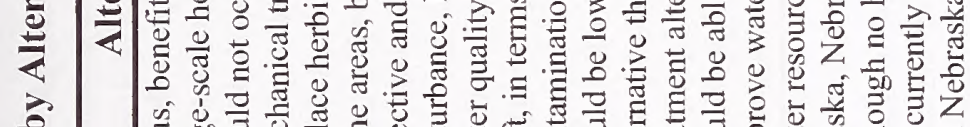

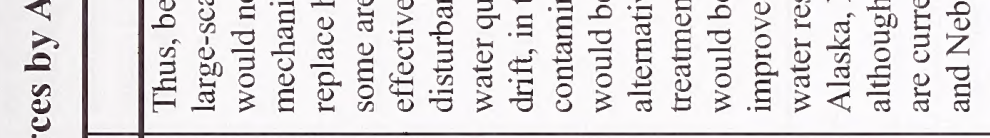

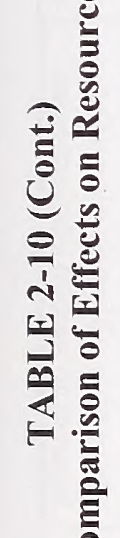

| $\stackrel{0}{\stackrel{0}{0}}$

苞苛导

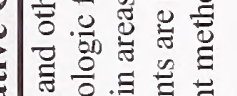

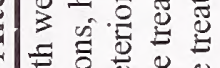

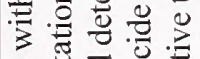

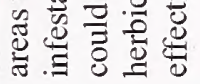

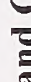

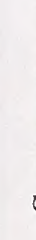

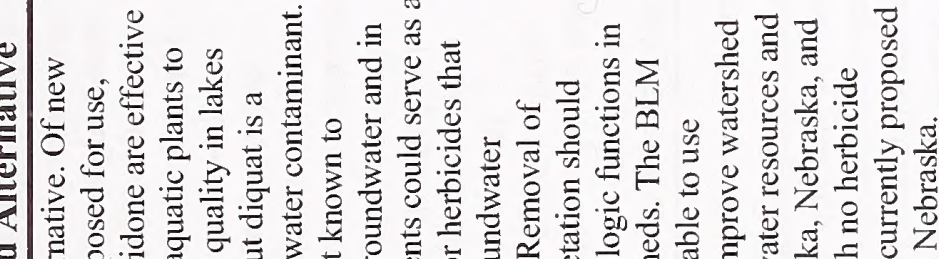

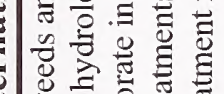

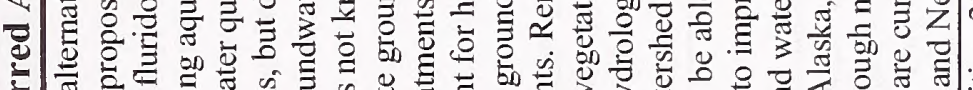

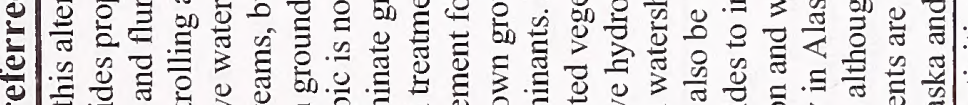

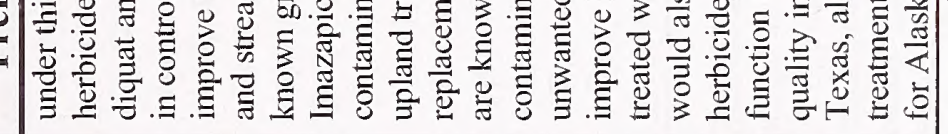

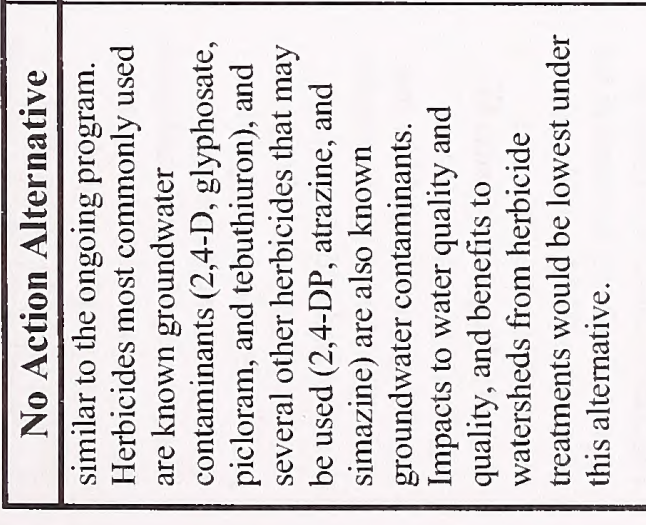

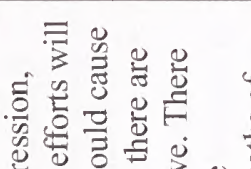

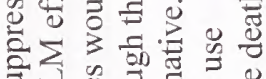

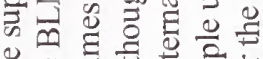

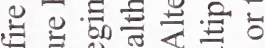

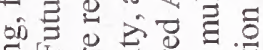

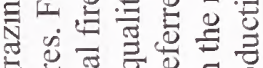

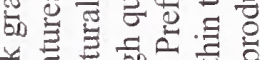

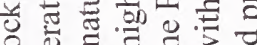

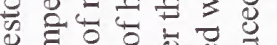

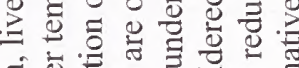

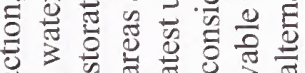

过造.

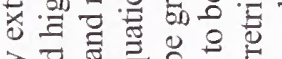

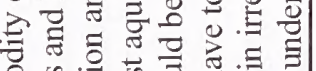

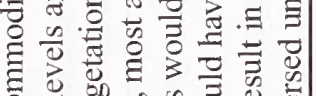

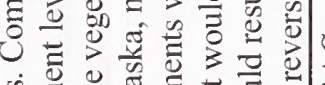

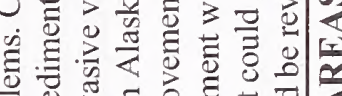

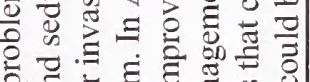

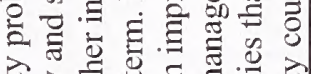

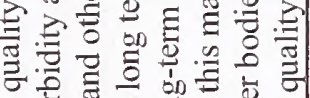

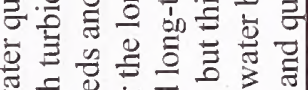

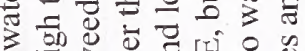

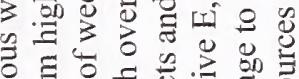

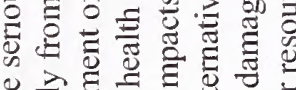

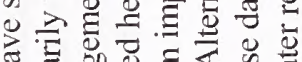

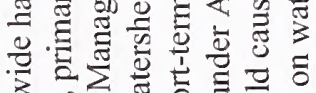

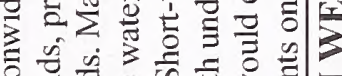

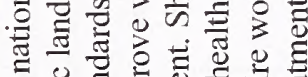

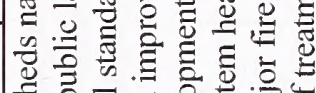

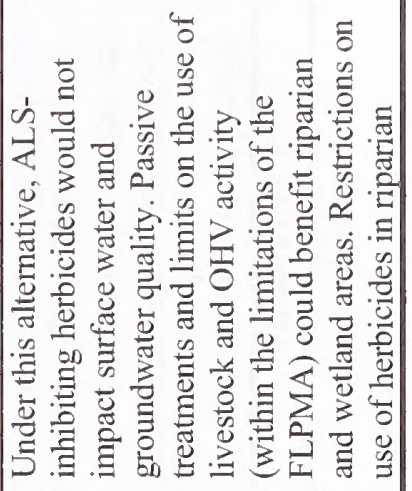

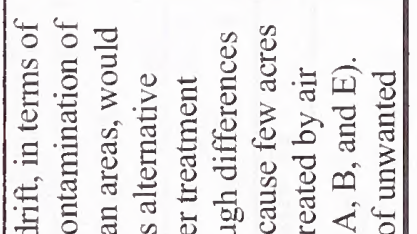

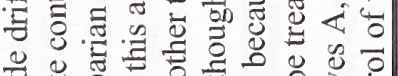

눈

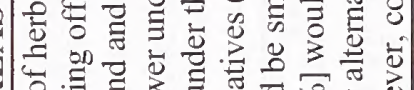

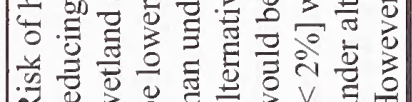

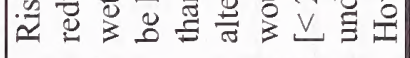

$\overrightarrow{0}$

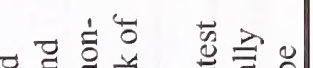

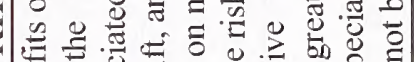

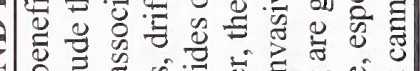

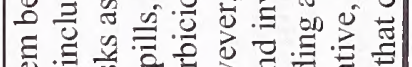

焉

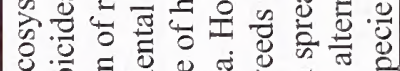

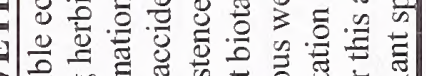

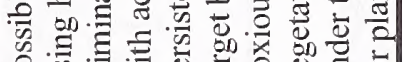

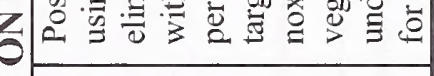

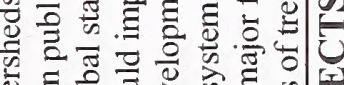

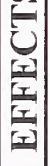

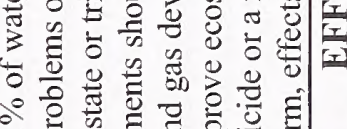

i 胥芯芯

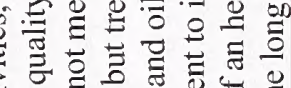

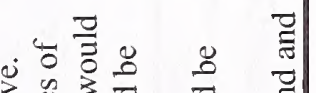

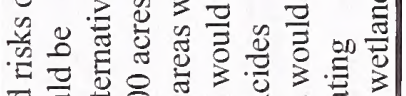

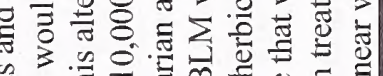

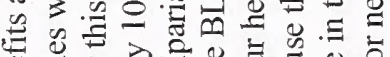

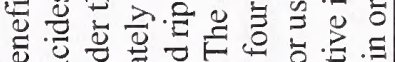

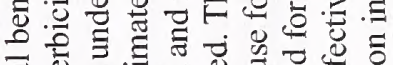

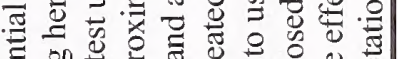

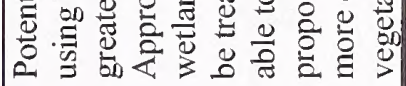

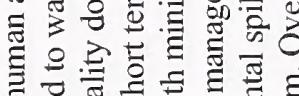

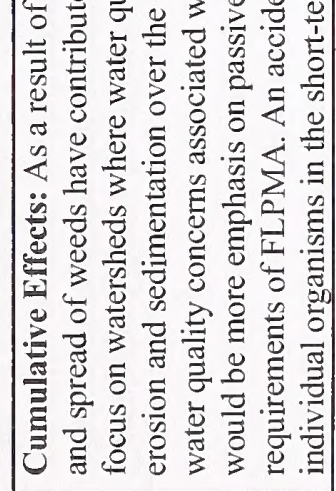

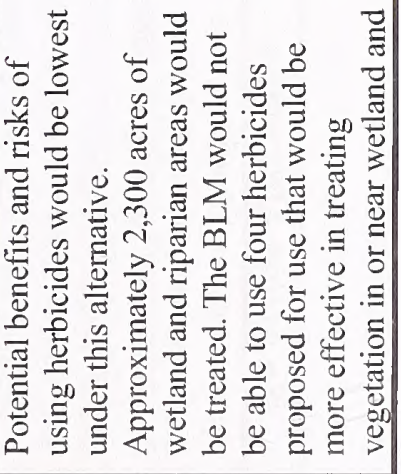




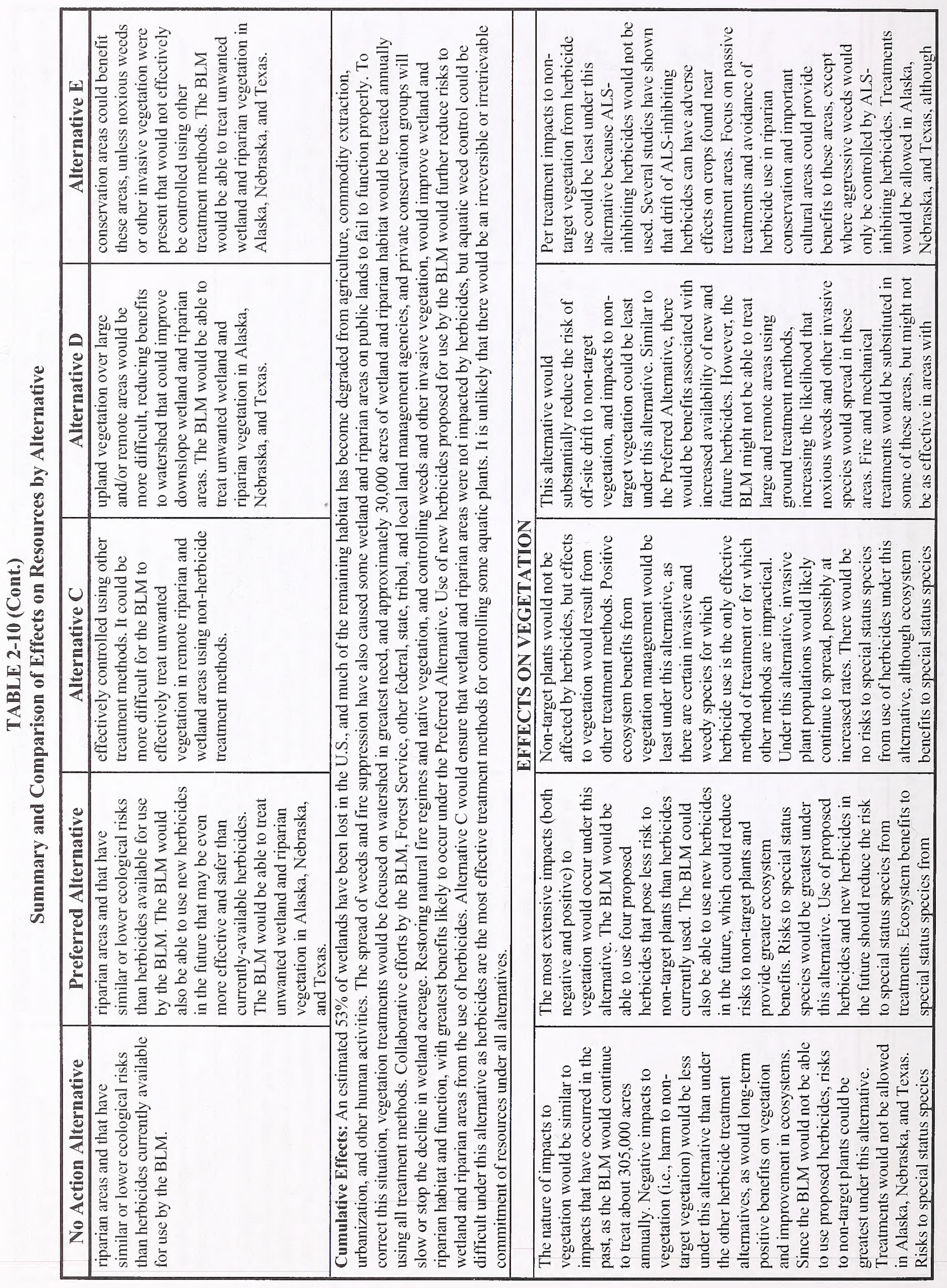




\begin{tabular}{|c|c|c|c|c|c|}
\hline \multirow{5}{*}{ 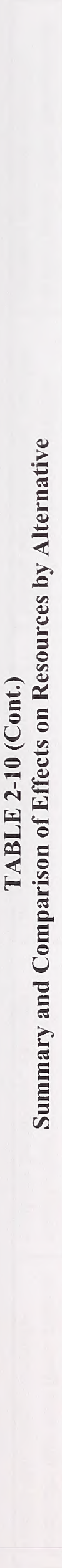 } & & 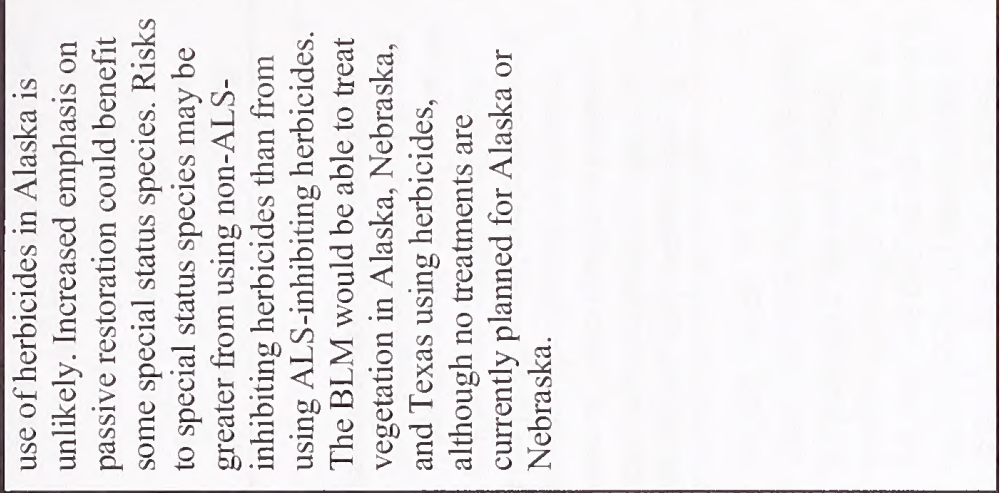 & \multirow{5}{*}{\multicolumn{2}{|c|}{ 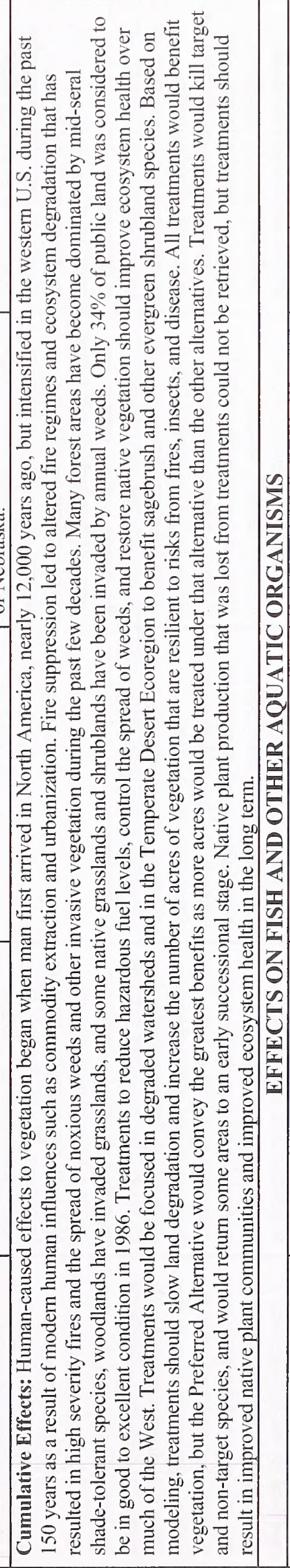 }} & \multirow{2}{*}{ 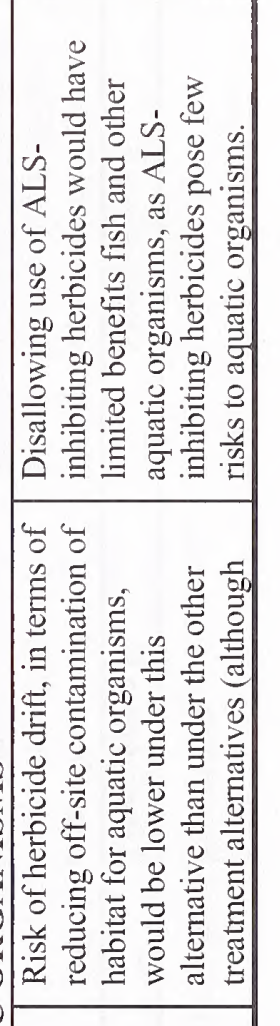 } \\
\hline & & 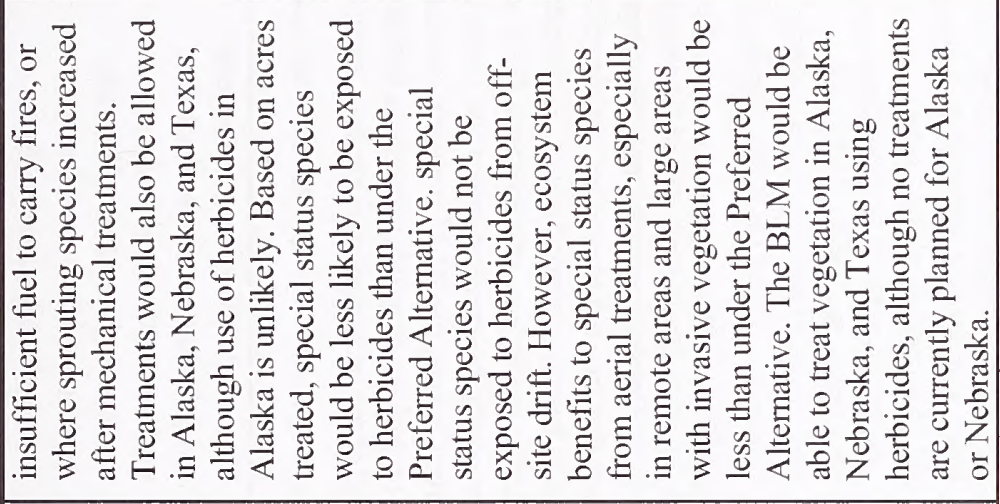 & & & \\
\hline & & 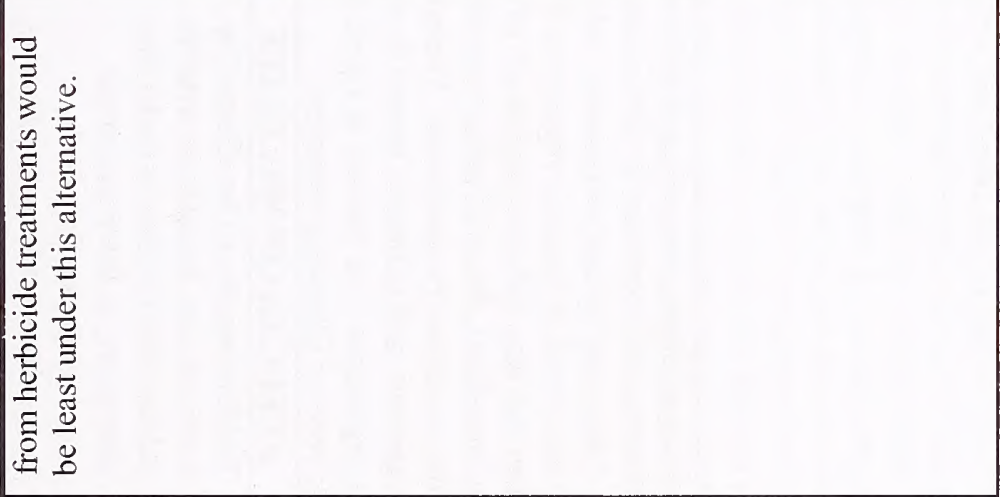 & & & 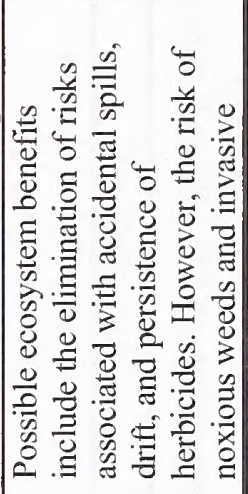 \\
\hline & & 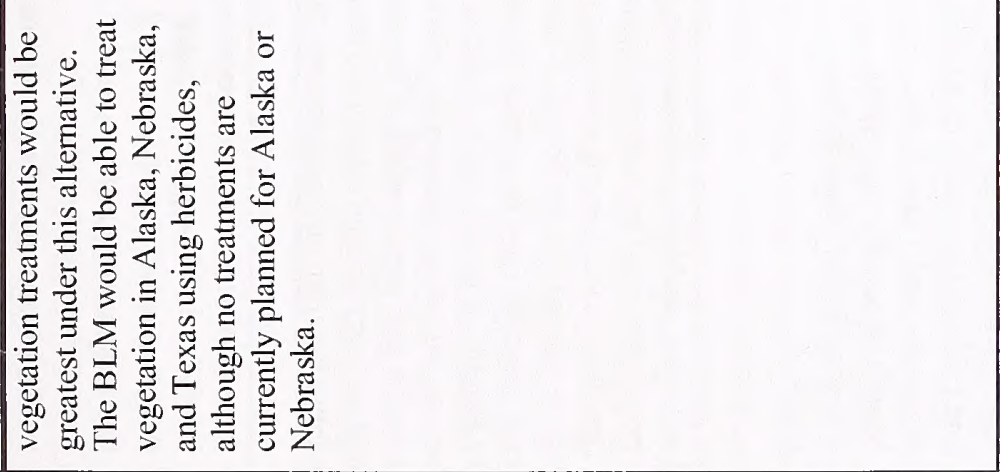 & & & 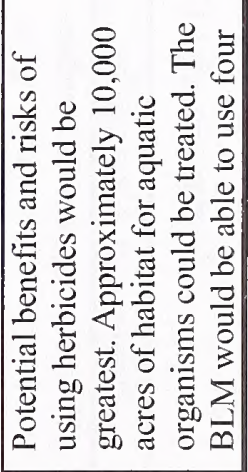 \\
\hline & 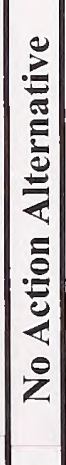 & 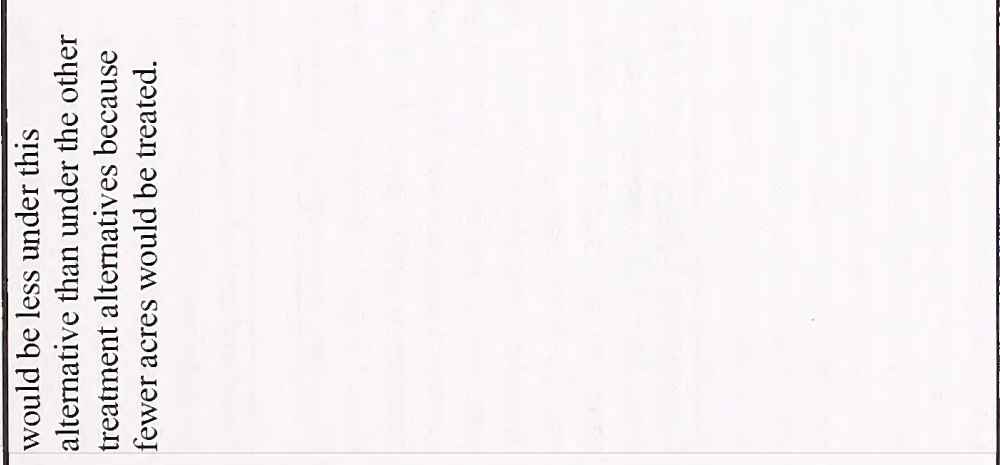 & & & 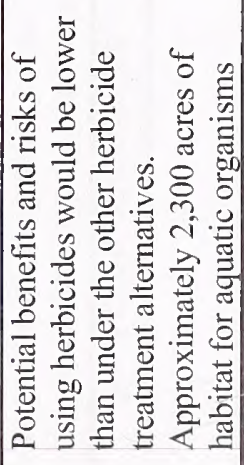 \\
\hline
\end{tabular}




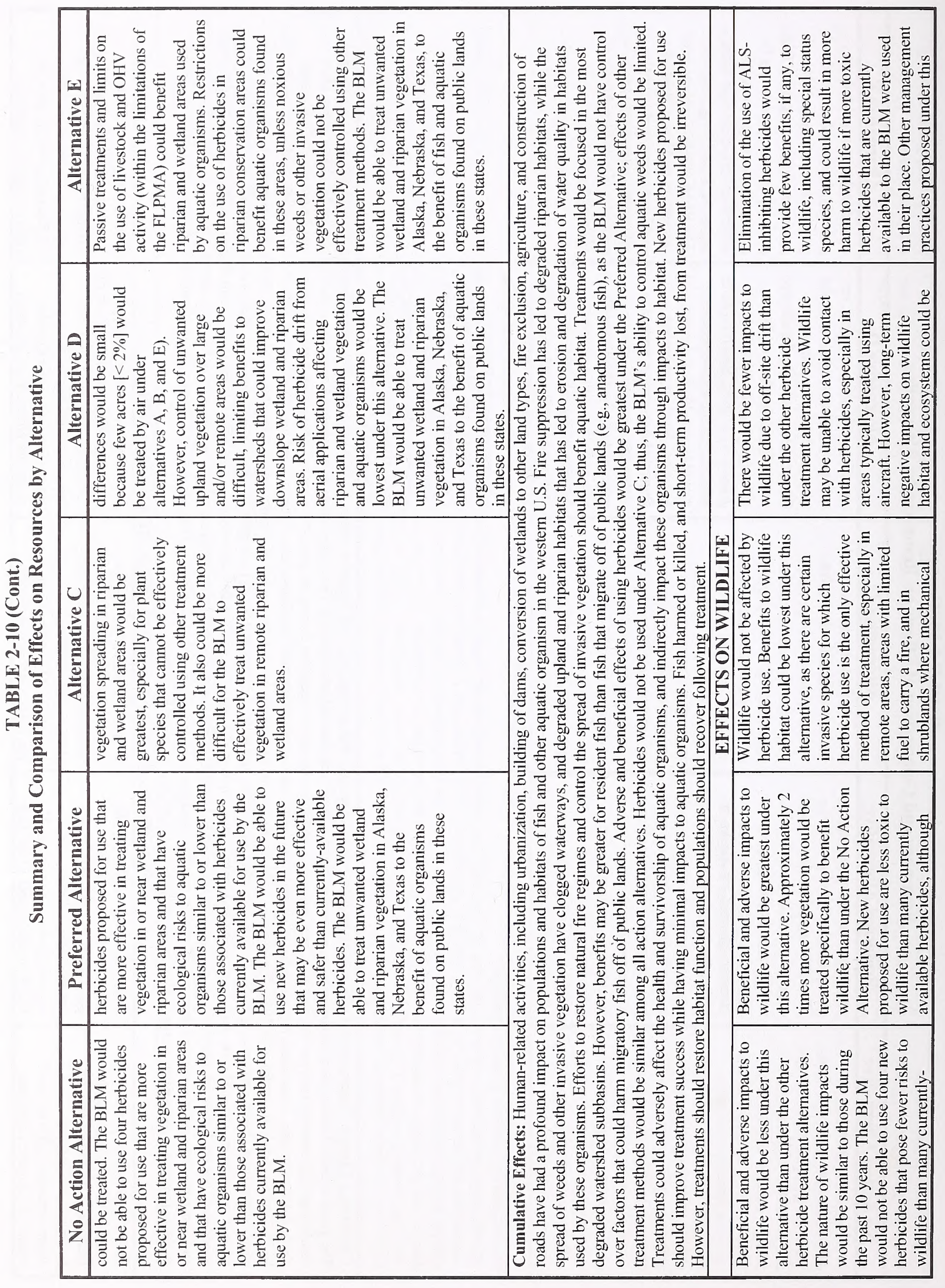




\begin{tabular}{|c|c|c|c|c|}
\hline \multirow{5}{*}{ 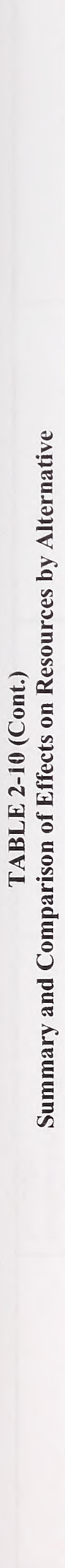 } & & 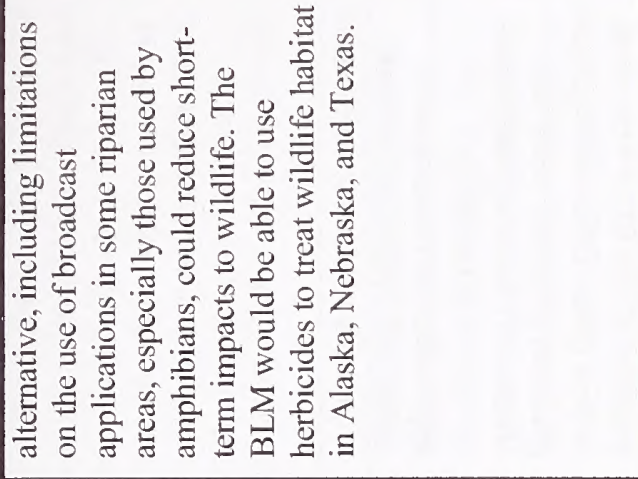 & \multirow{5}{*}{ 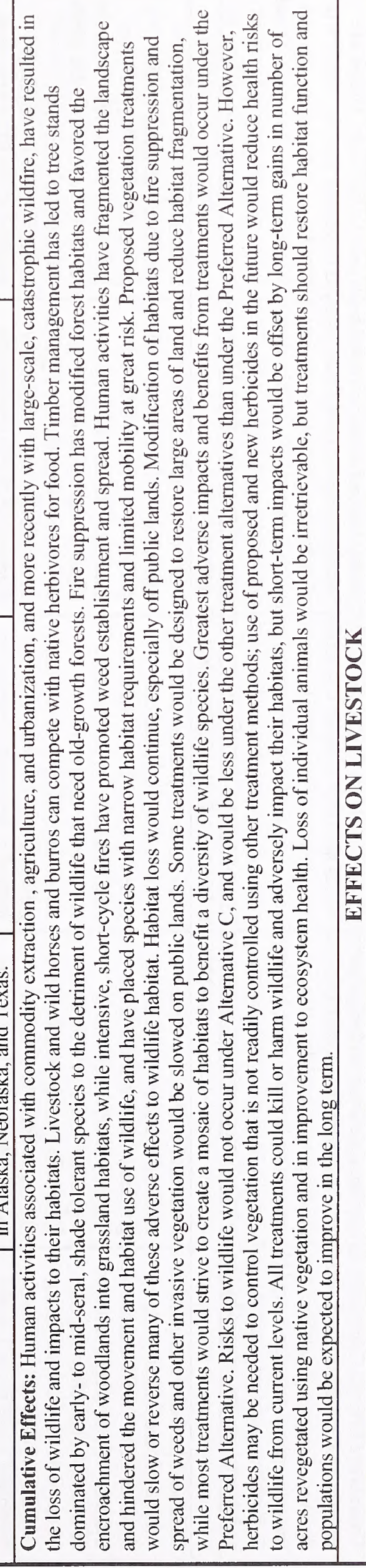 } & \multirow{2}{*}{ 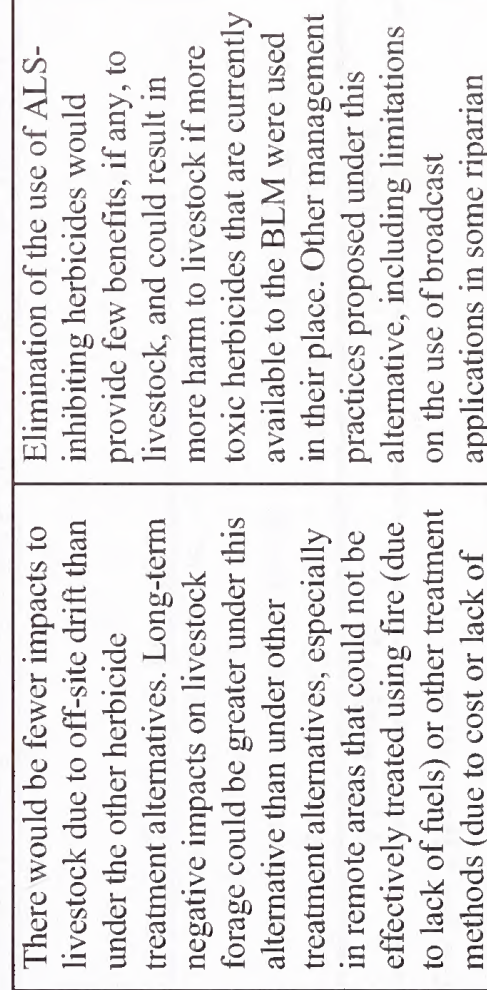 } \\
\hline & & 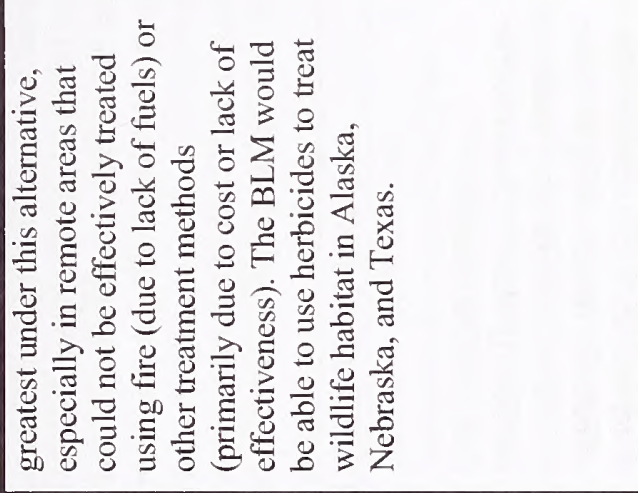 & & \\
\hline & & 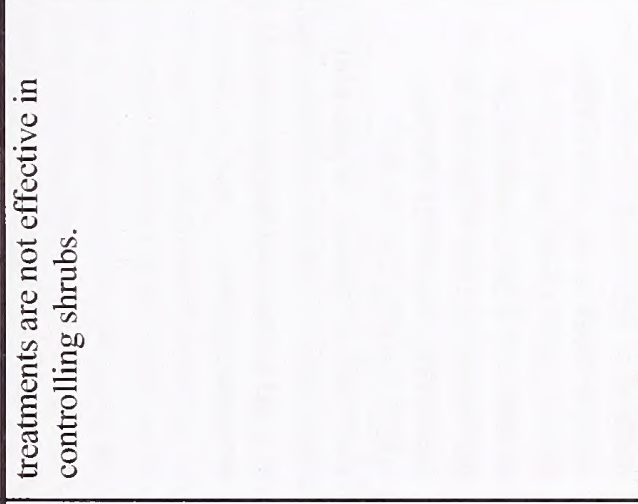 & & 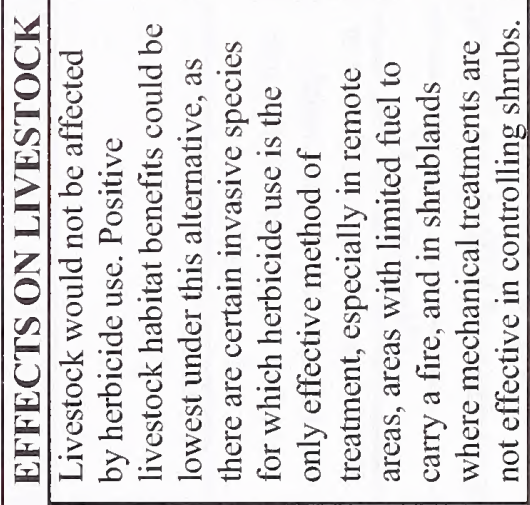 \\
\hline & 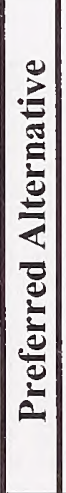 & 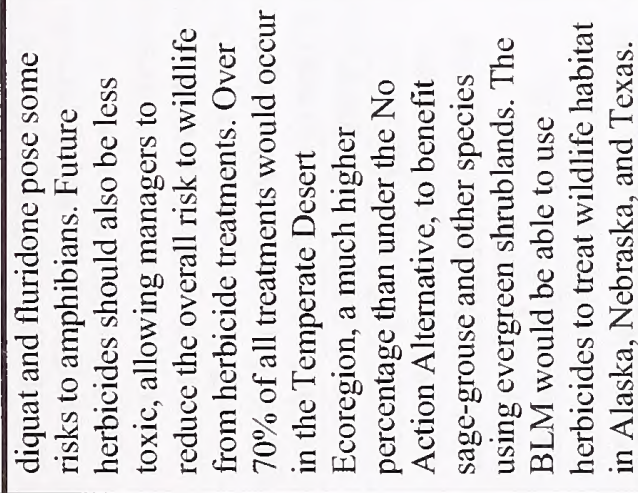 & & 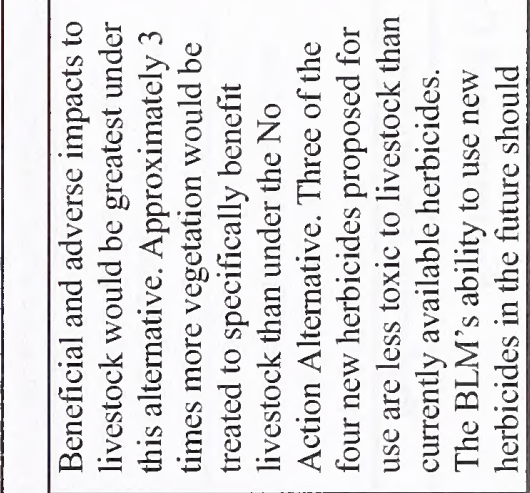 \\
\hline & & 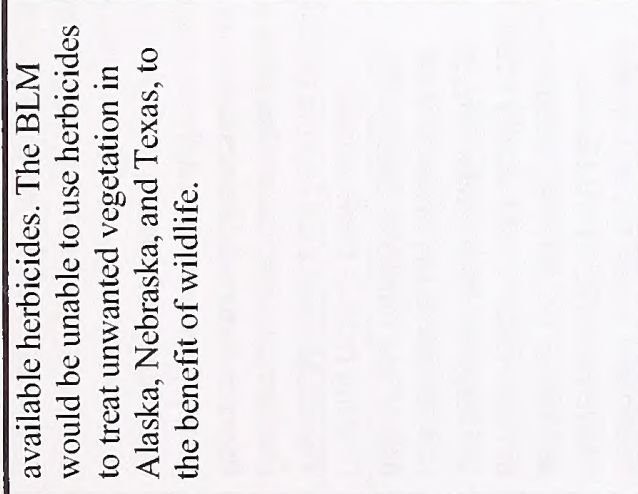 & & 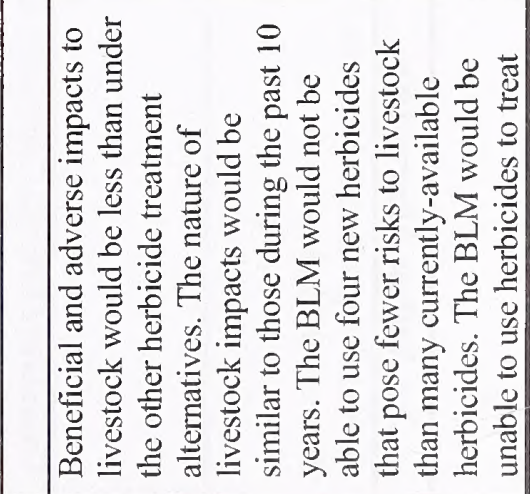 \\
\hline
\end{tabular}




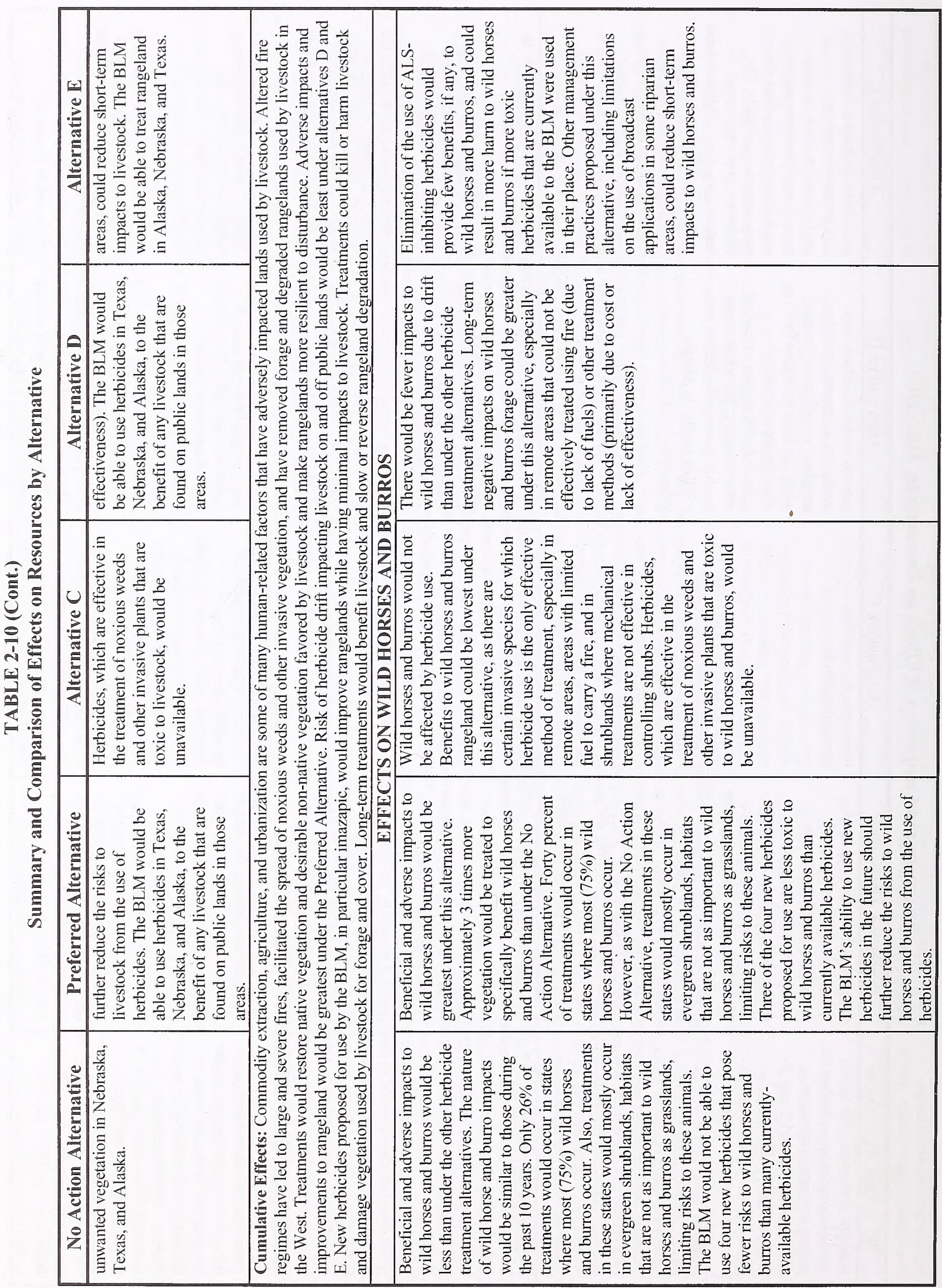




\begin{tabular}{|c|c|c|c|}
\hline \multirow{5}{*}{ 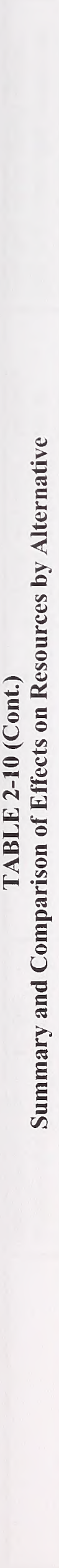 } & \multirow{5}{*}{\multicolumn{2}{|c|}{ 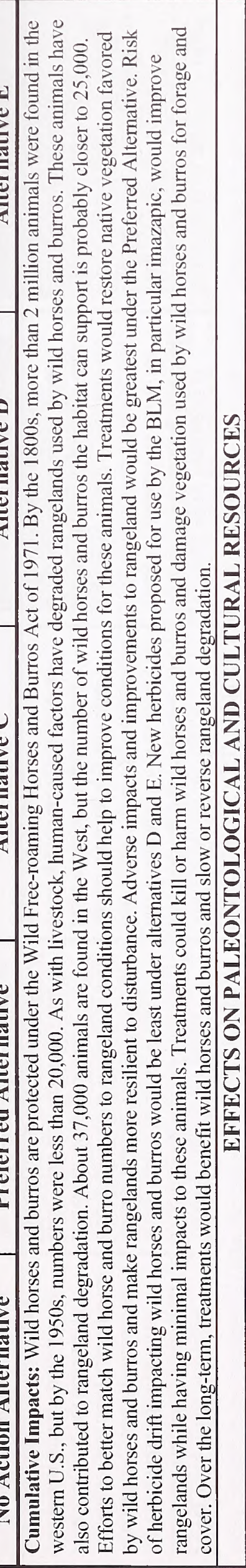 }} & 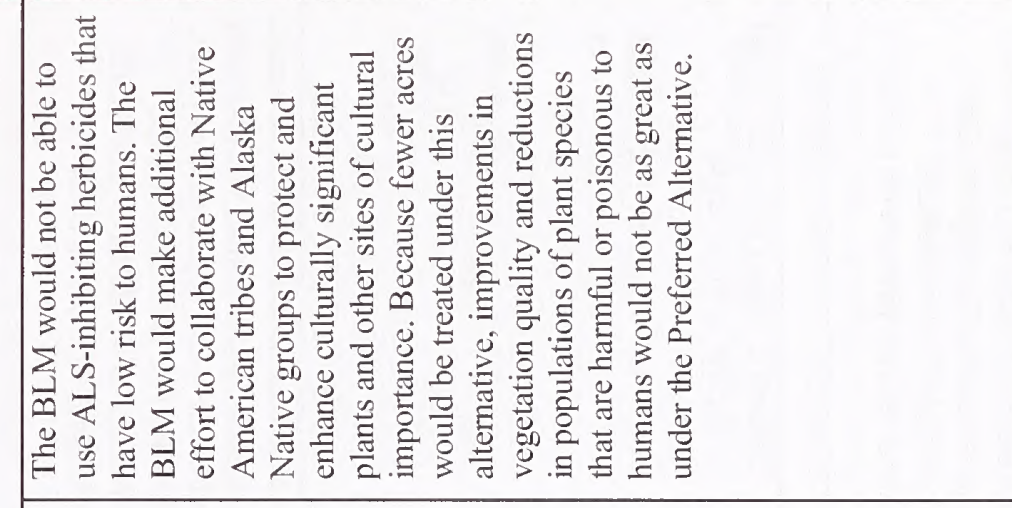 \\
\hline & & & 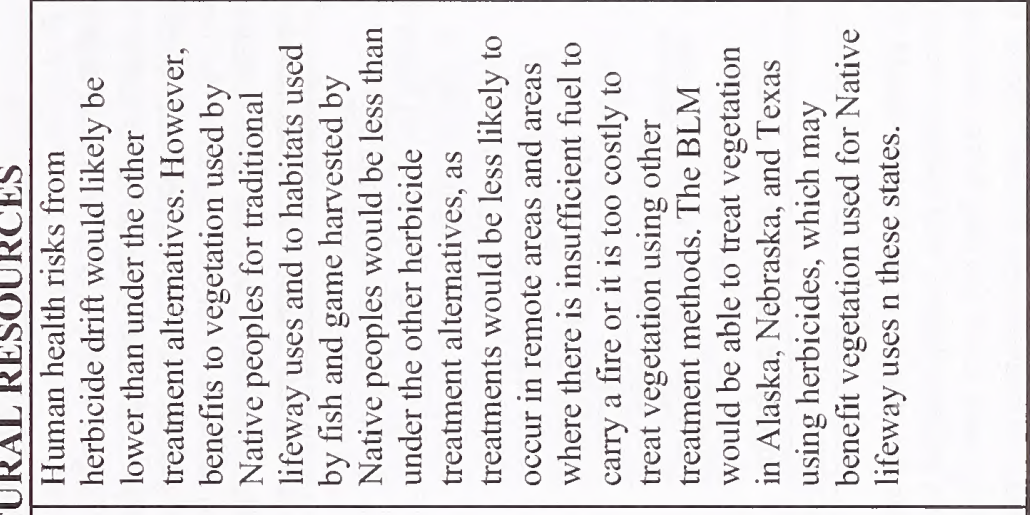 \\
\hline & & & 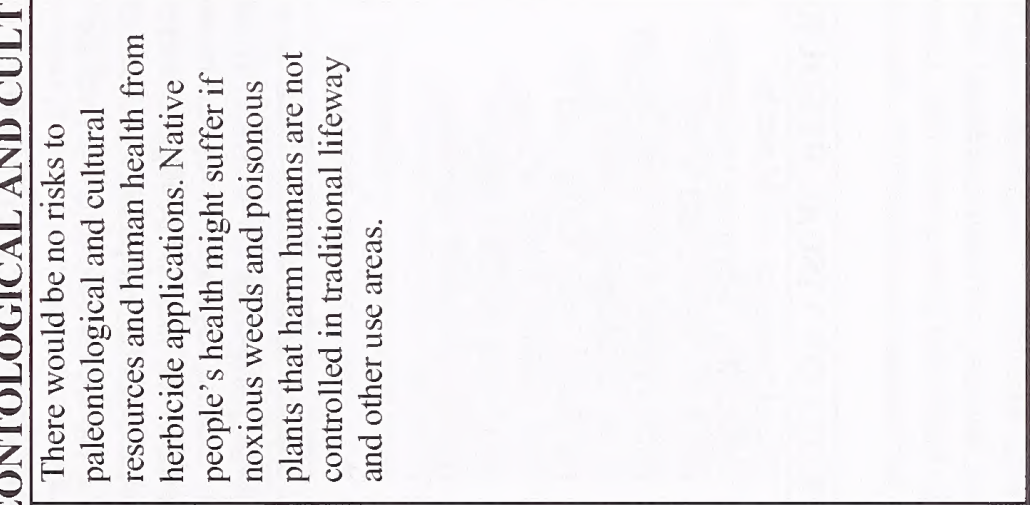 \\
\hline & & & 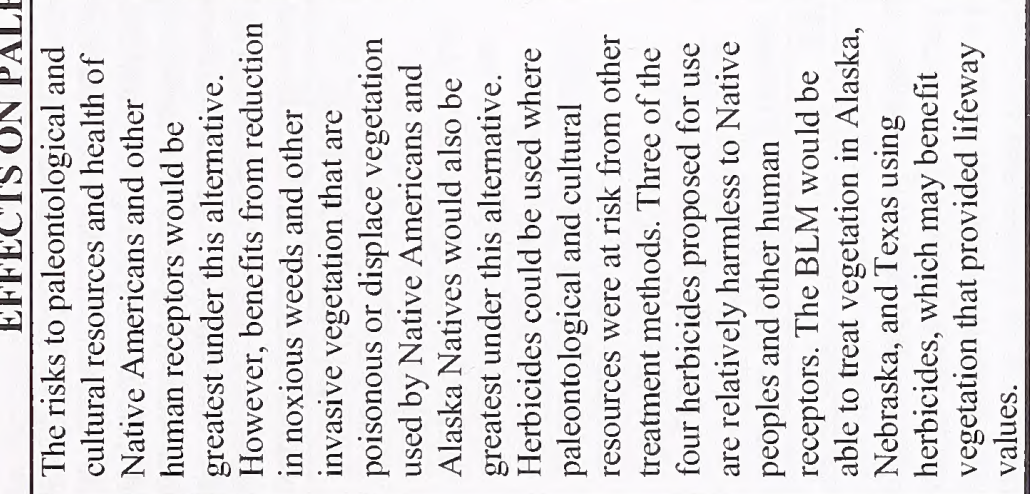 \\
\hline & & & 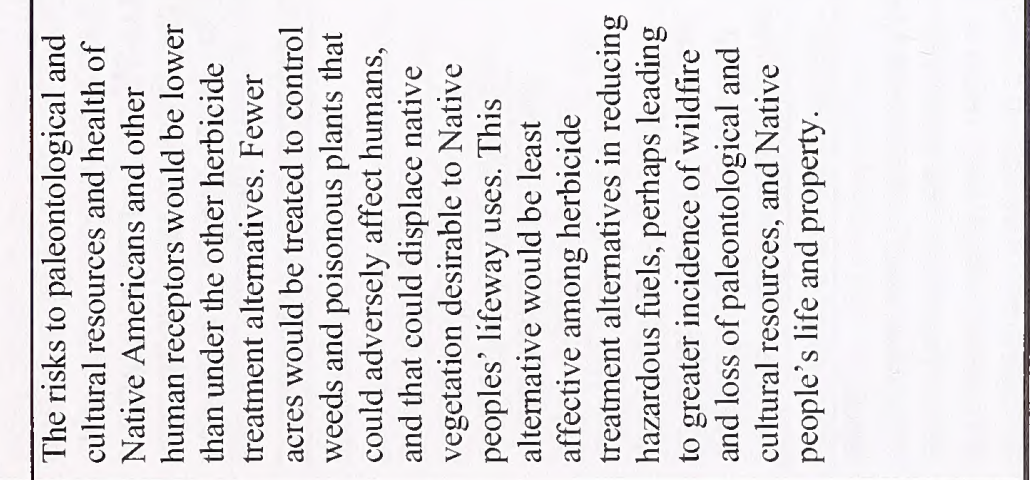 \\
\hline
\end{tabular}




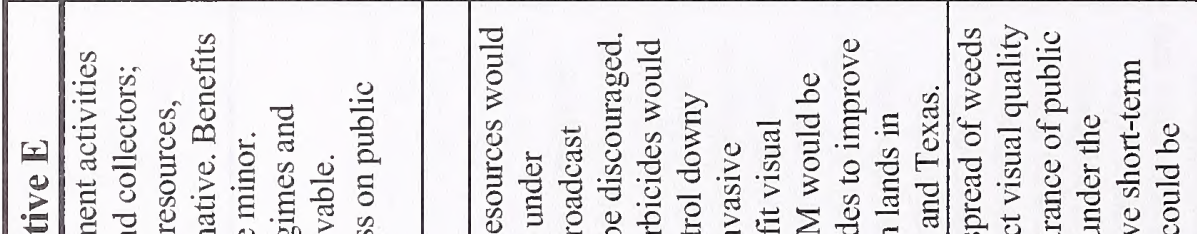

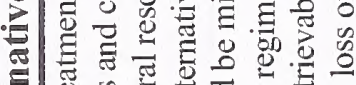

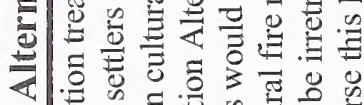

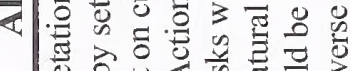

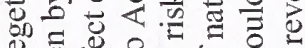

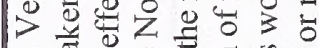

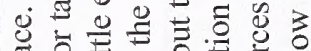

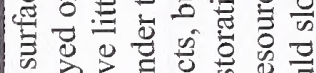

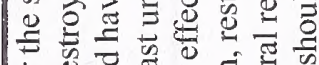

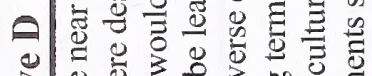

总

Е

承

충

管

量

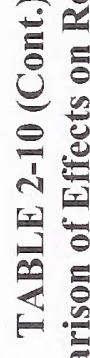

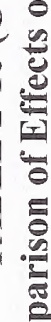

हैं

ह

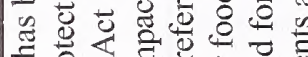

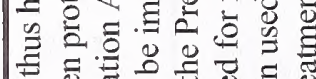

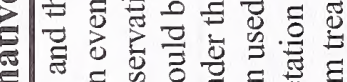

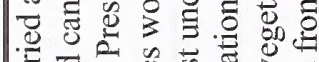

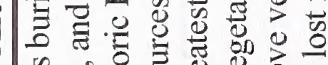

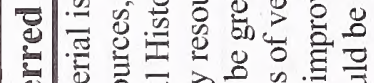

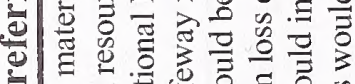

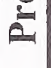

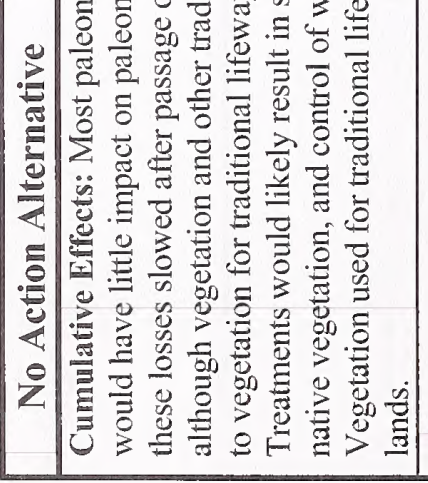

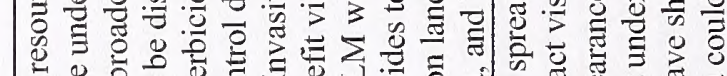

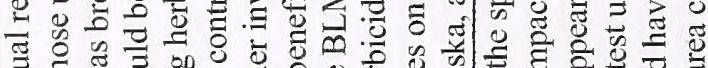

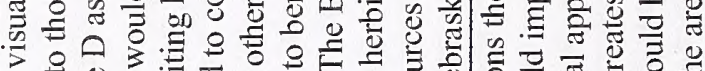

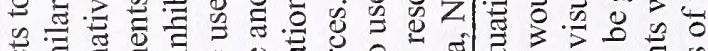

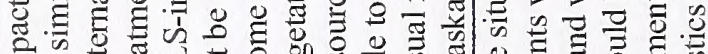

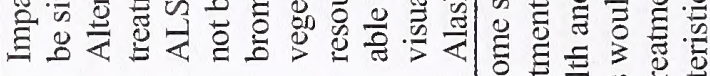
矛

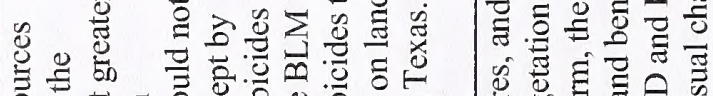

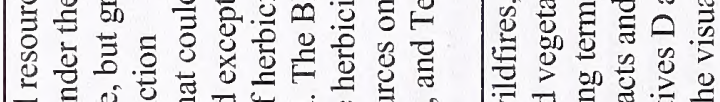

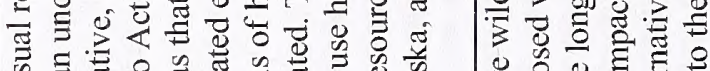

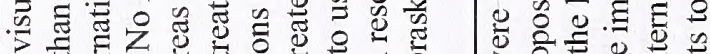

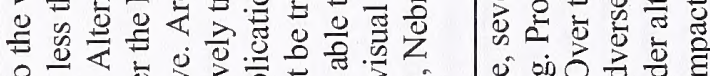

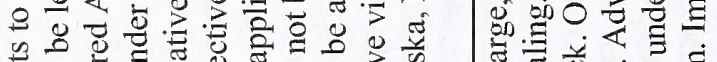

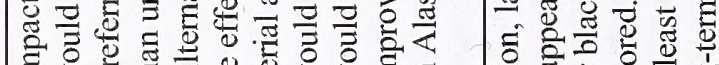

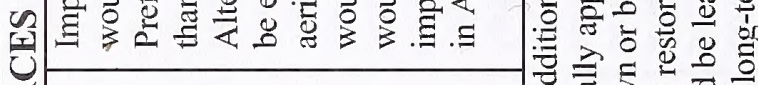
更

官

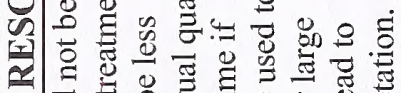

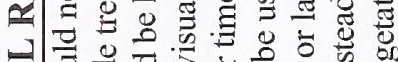

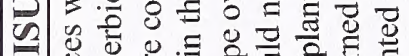

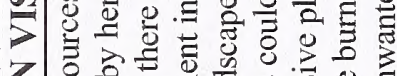

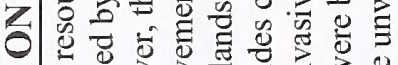

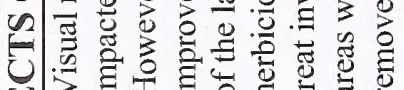

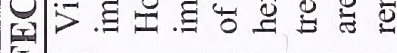

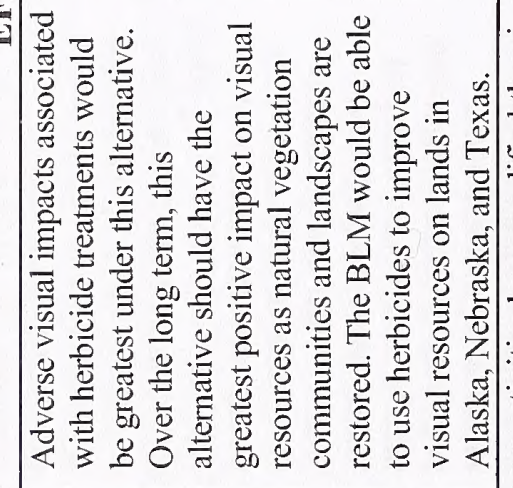

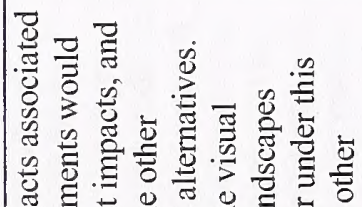

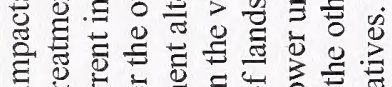

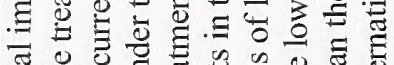

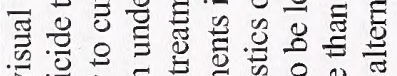

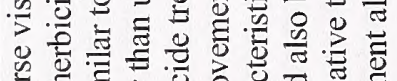

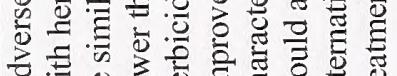

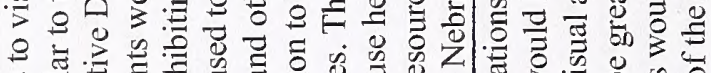

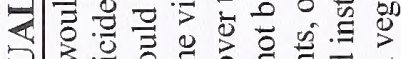

空

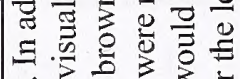

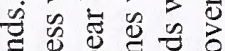

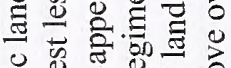

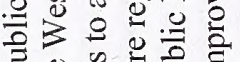

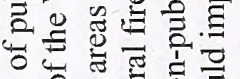

为 0 品

政 过 ฐँच o

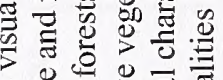

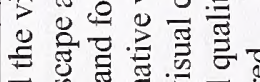

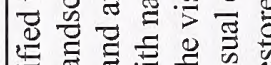

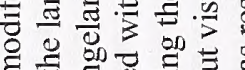

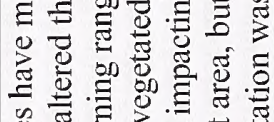
员

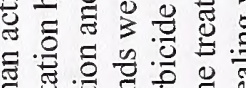

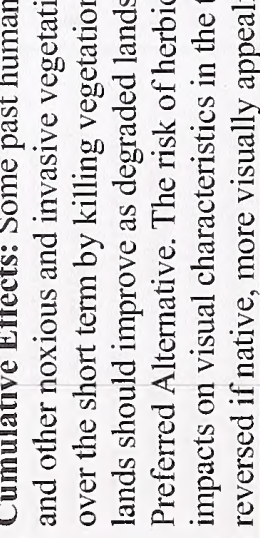

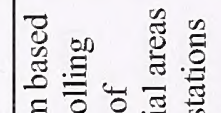

峞

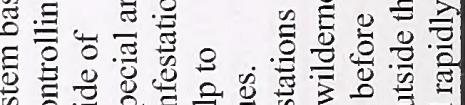

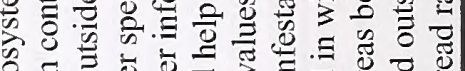
过

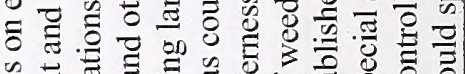

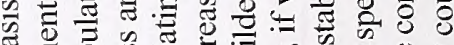

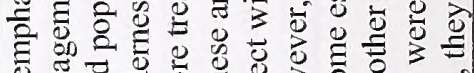

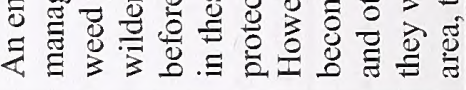

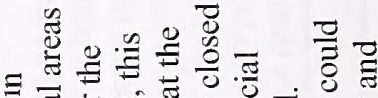

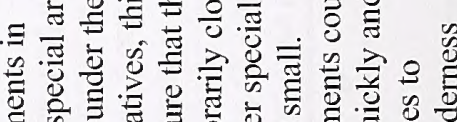
ङ

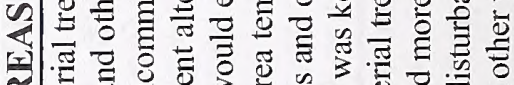

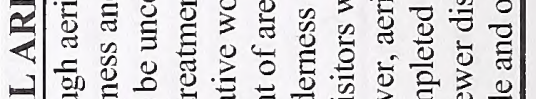

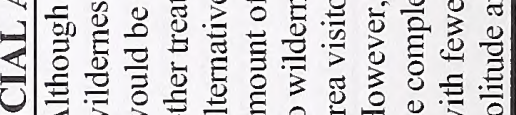

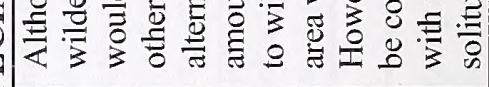

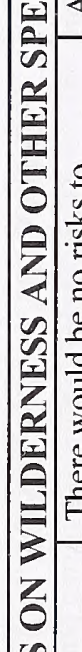

$89 \frac{\overline{7}}{7}$

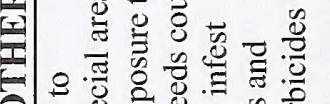

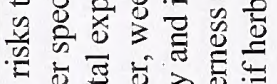

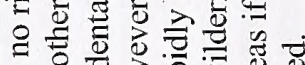

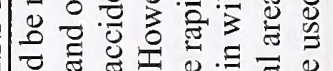
क

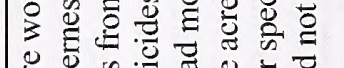

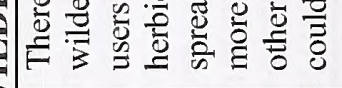

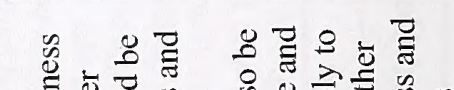

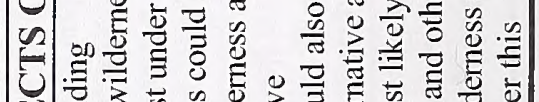

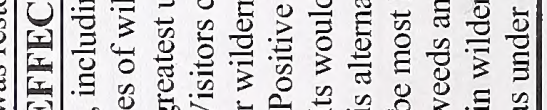

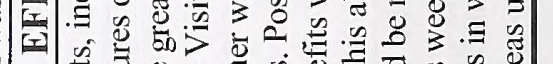

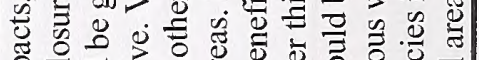

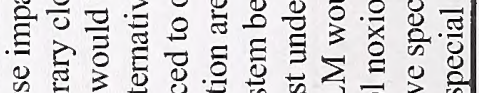

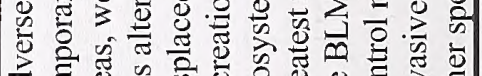

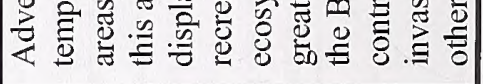

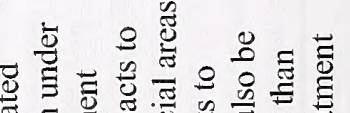

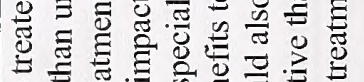

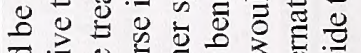

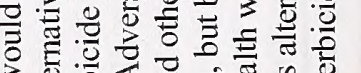

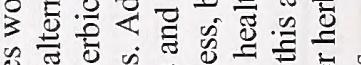

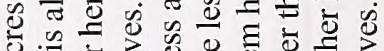

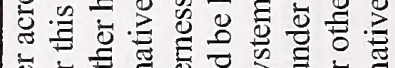
可言部 


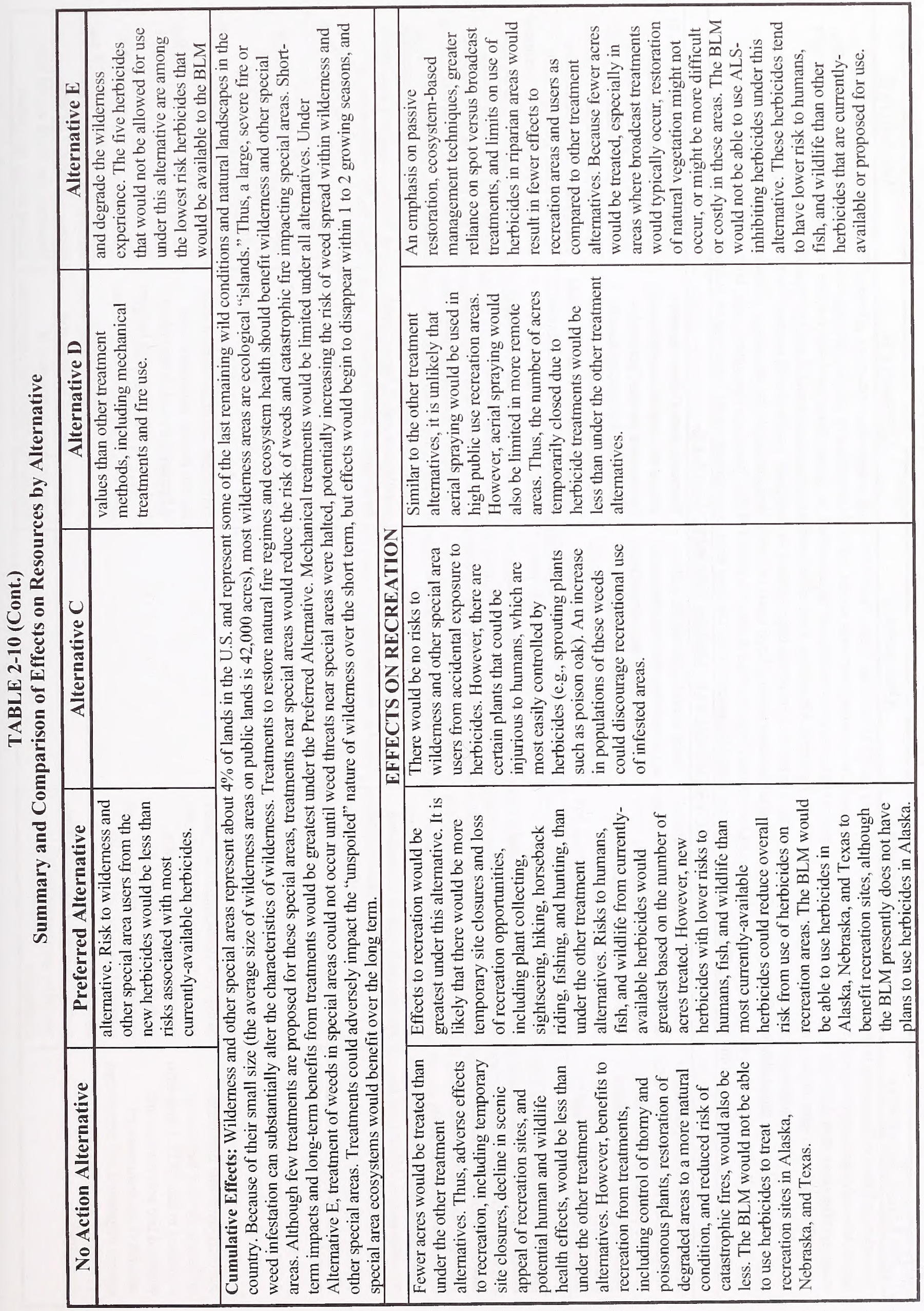




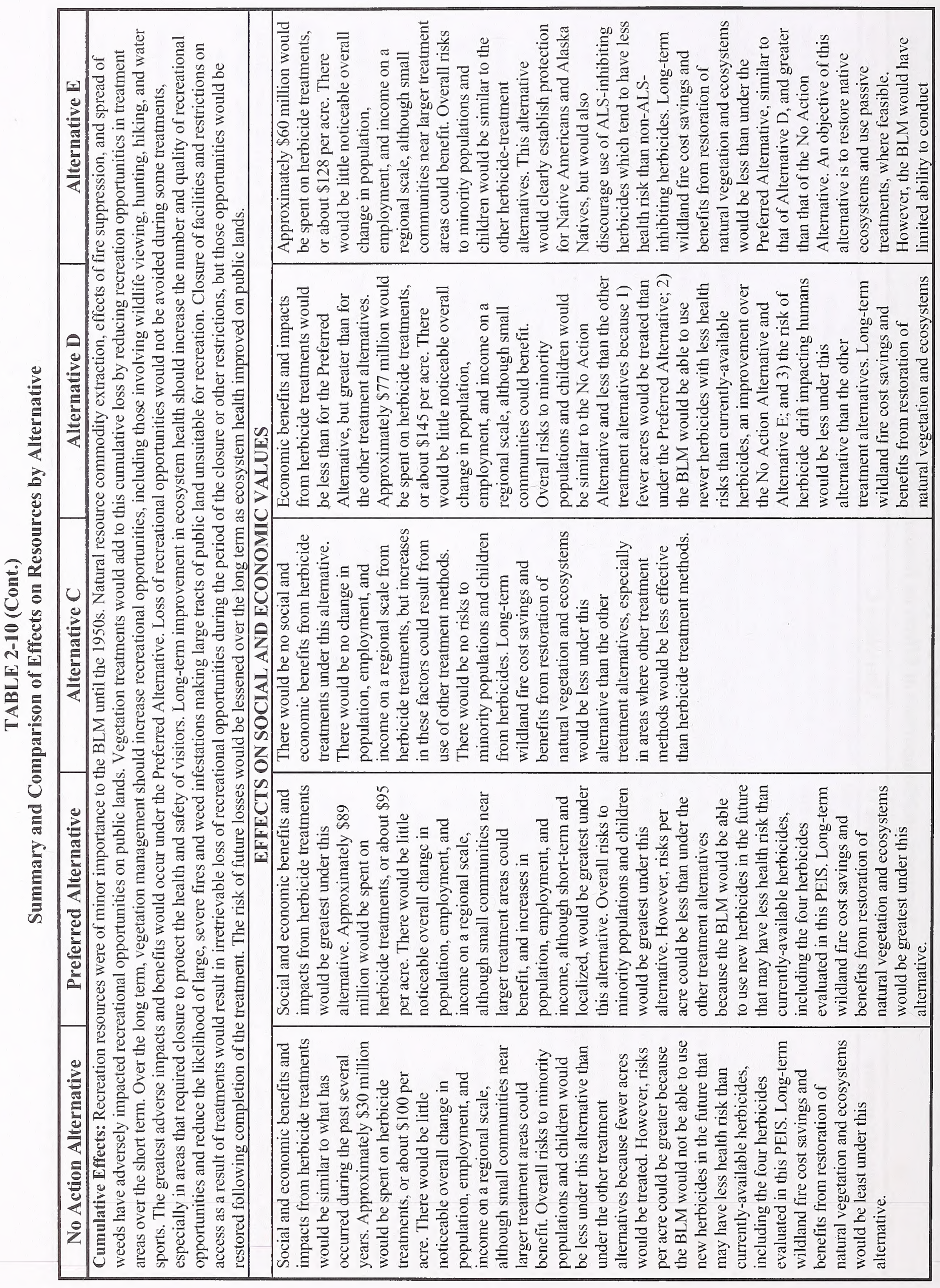




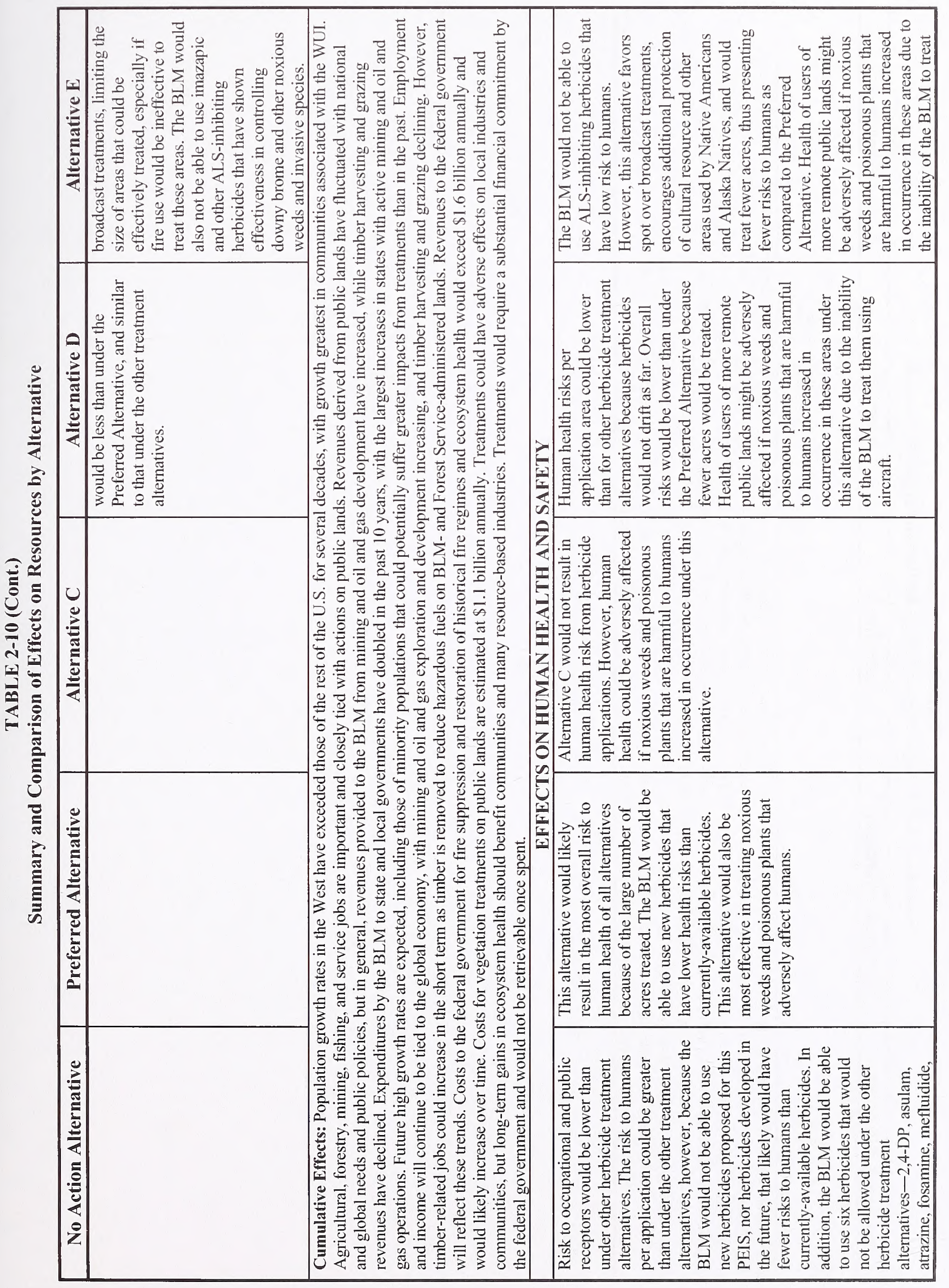




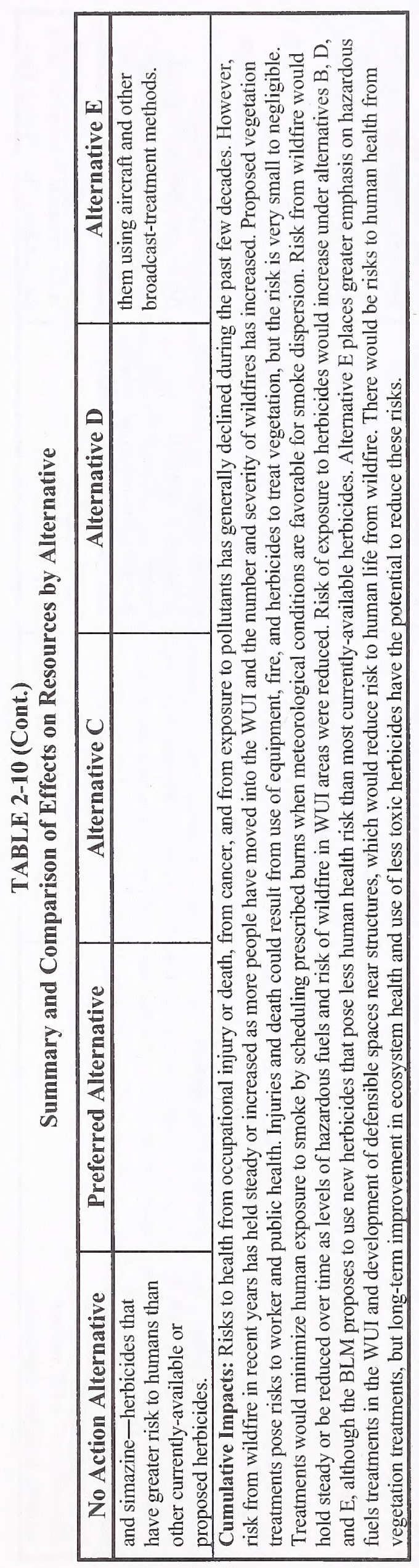


CHAPTER 3 AFFECTED ENVIRONMENT 



\section{TABLE OF CONTENTS}

Introduction and Study Area

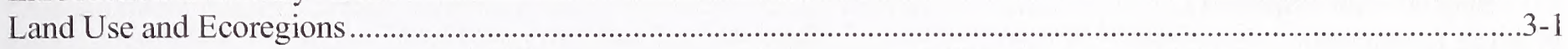

Land Use

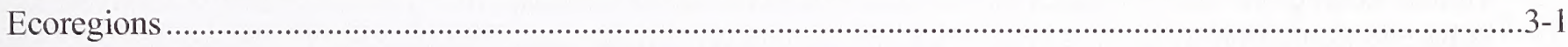

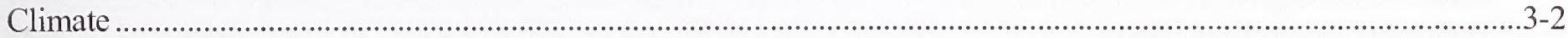

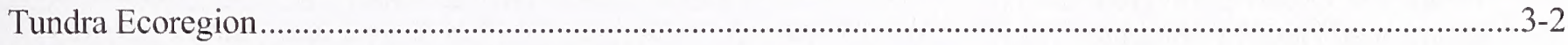

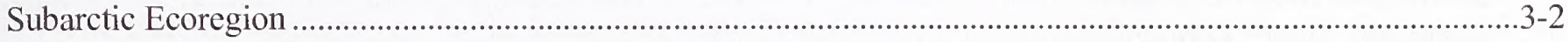

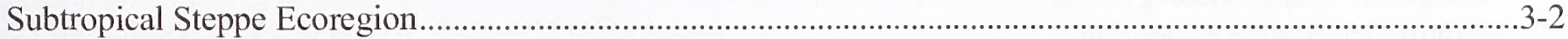

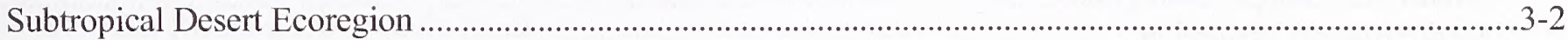

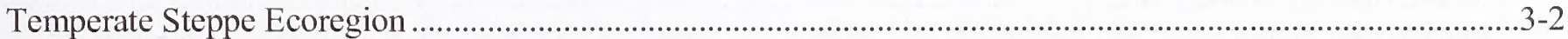

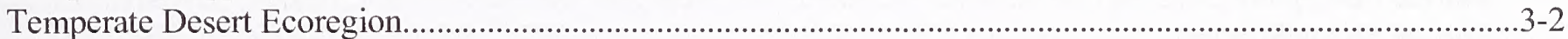

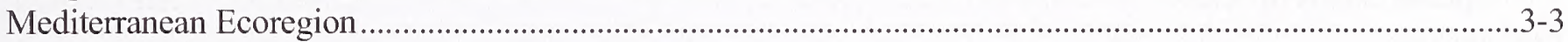

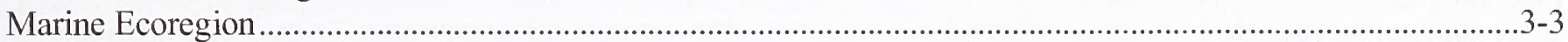

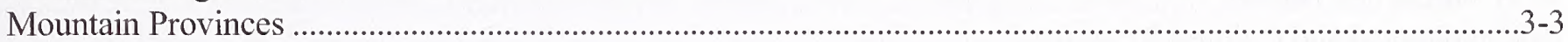

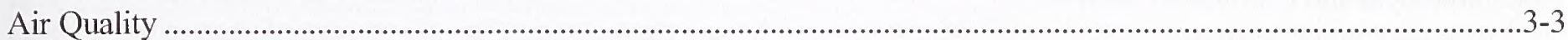

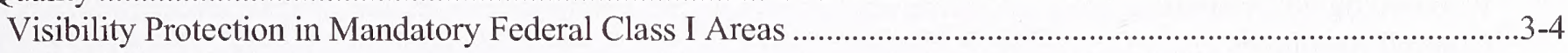

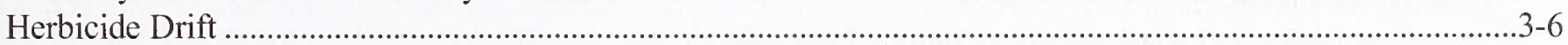

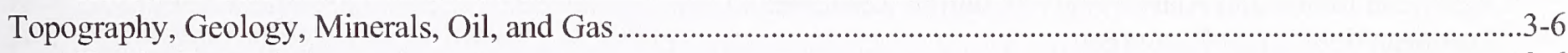

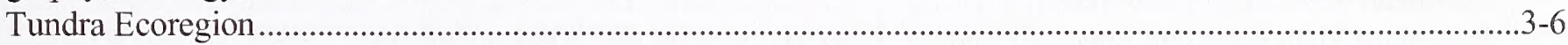

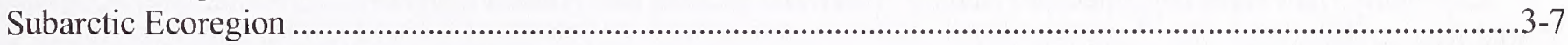

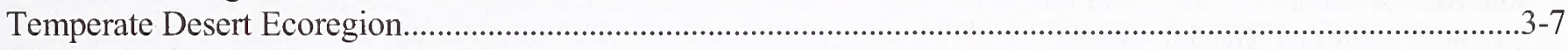

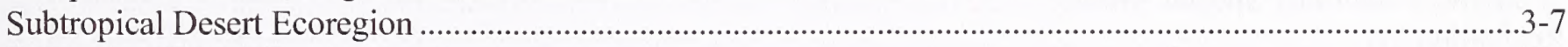

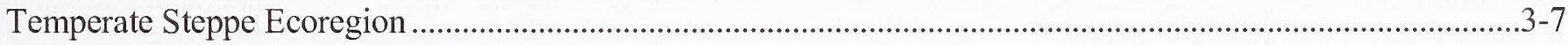

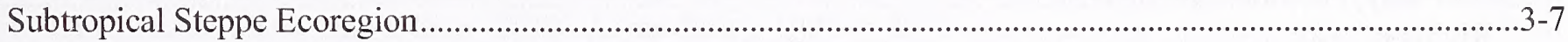

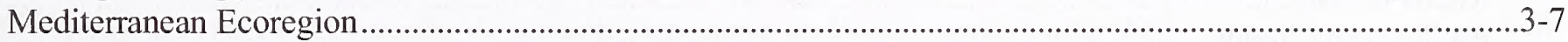

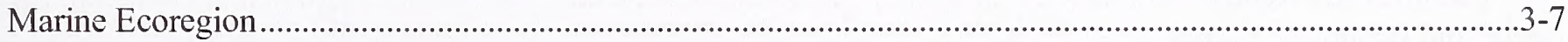

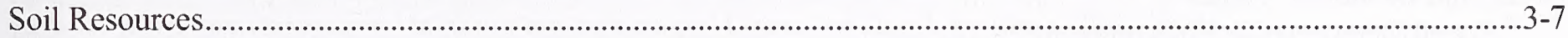

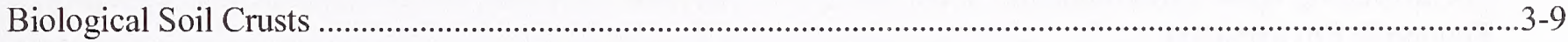

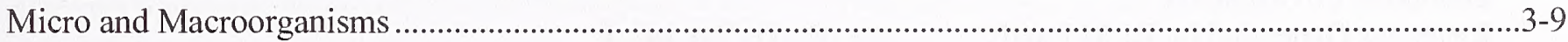

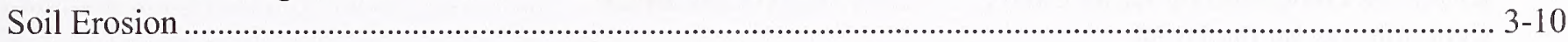

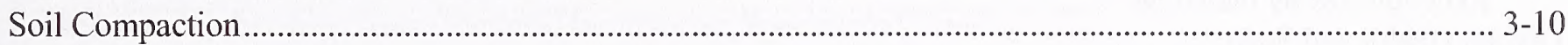

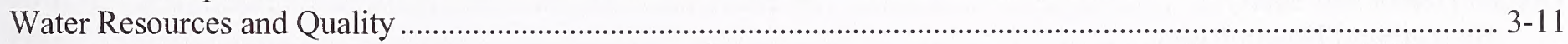

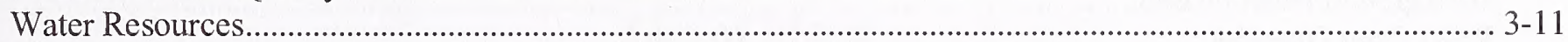

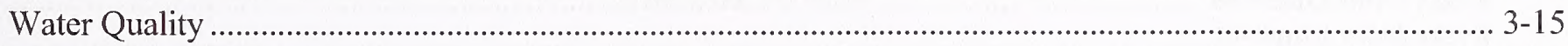

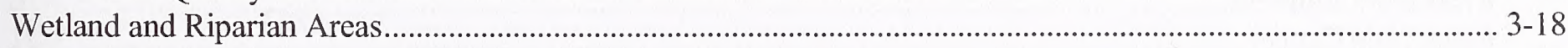

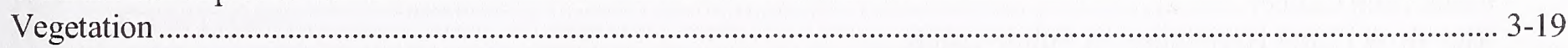

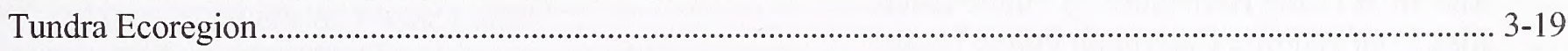

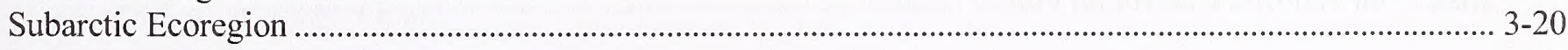

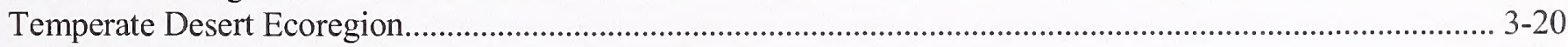

Subtropical Desert Ecoregion ................................................................................................................. 3-22

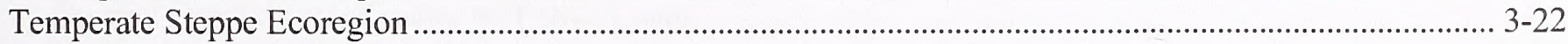

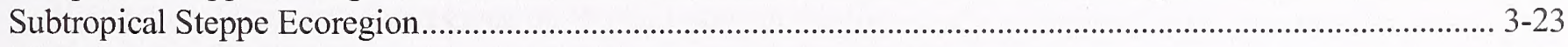

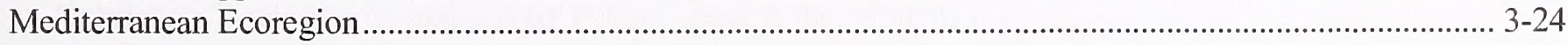

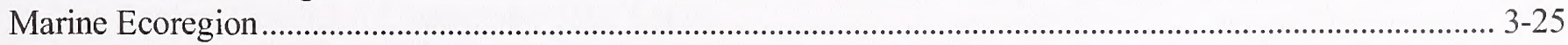

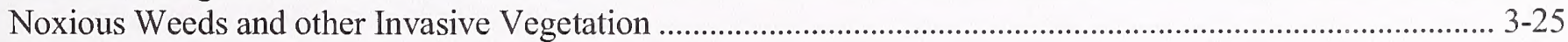

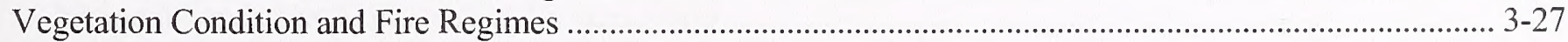

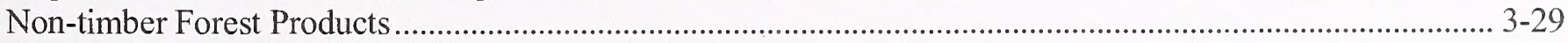

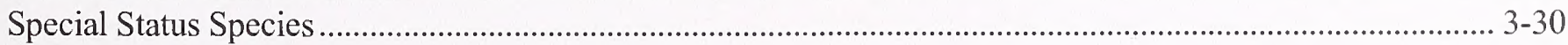

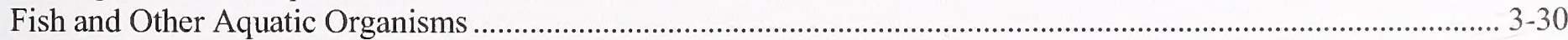

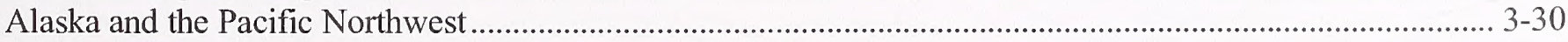




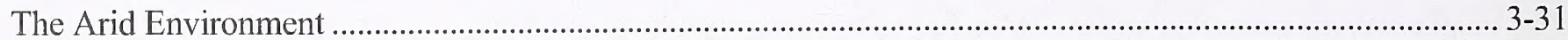

The Upper Colorado River Basin ...................................................................................................... 3-33

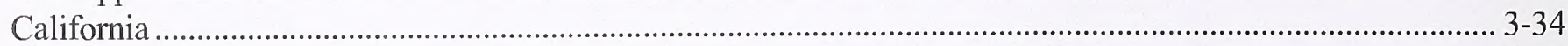

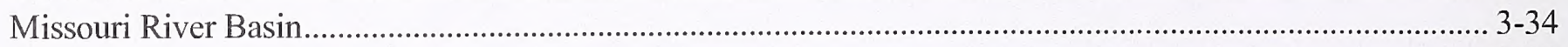

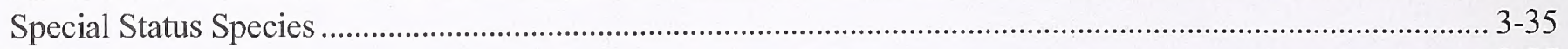

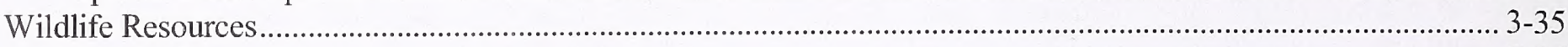

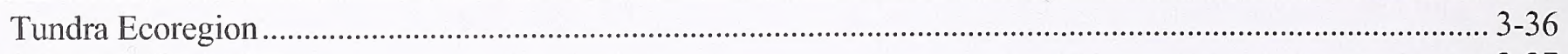

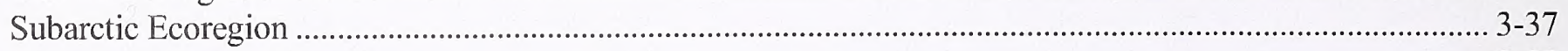

Temperate Desert Ecoregion............................................................................................................... 3-38

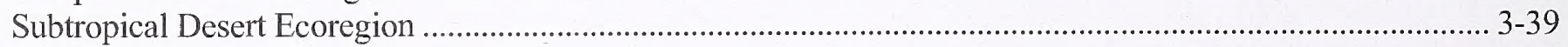

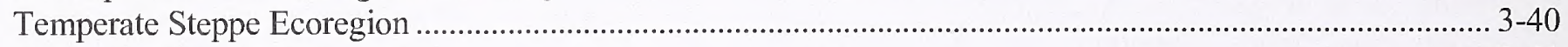

Subtropical Steppe Ecoregion................................................................................................................. 3-4

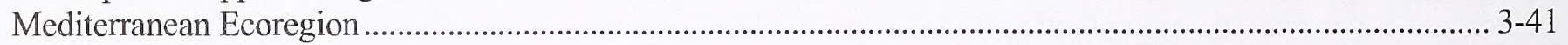

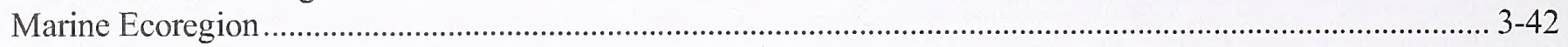

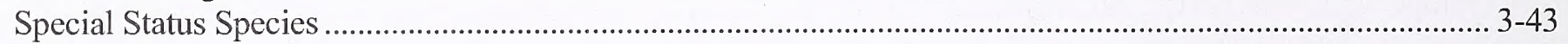

Livestock

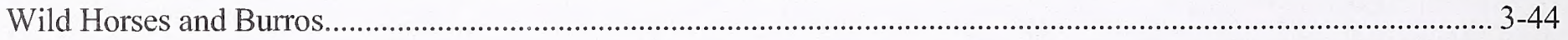

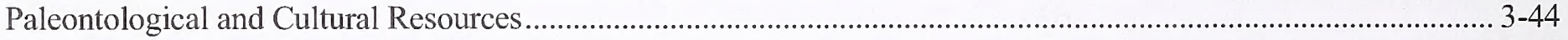

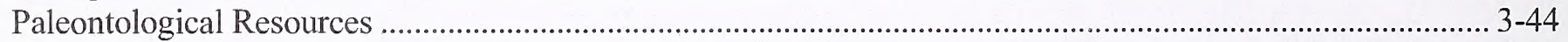

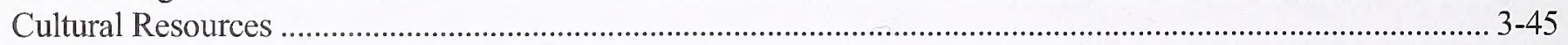

American Indian and Alaska Native Cultural Resources.......................................................................... 3-45

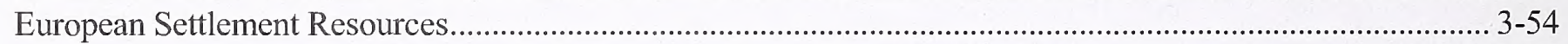

Important Plant Uses and Species Used by American Indians and Alaska Natives ........................................ 3-54

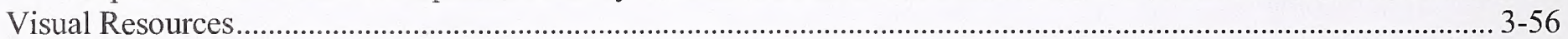

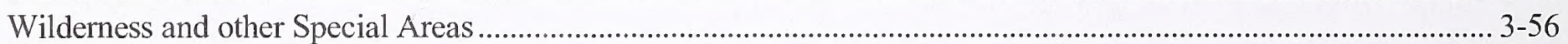

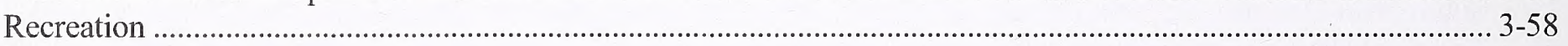

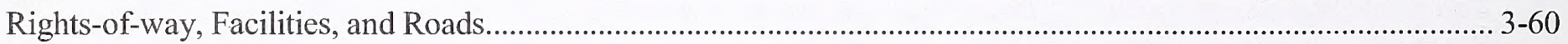

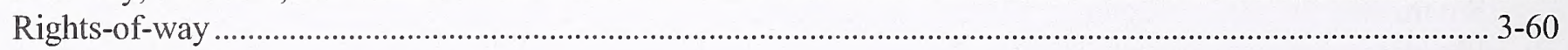

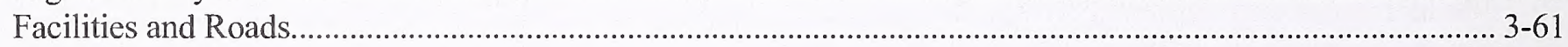

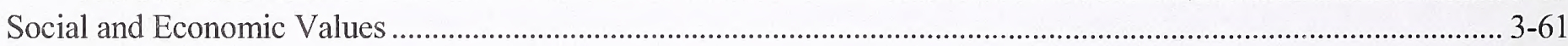

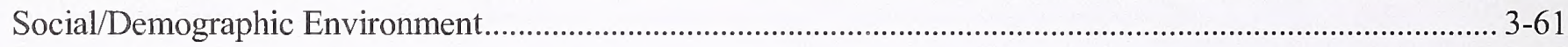

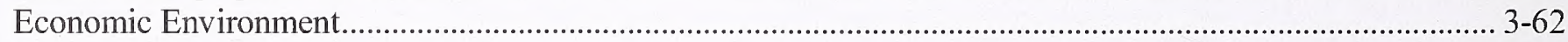

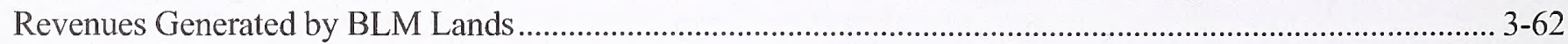

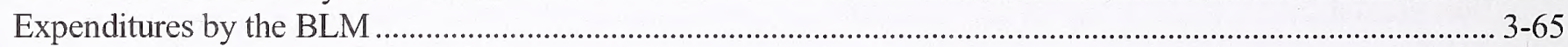

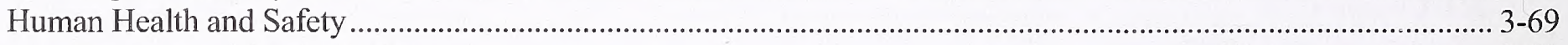

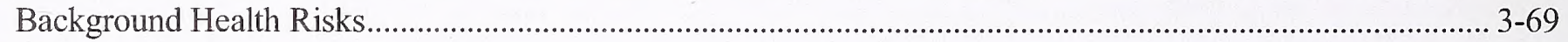

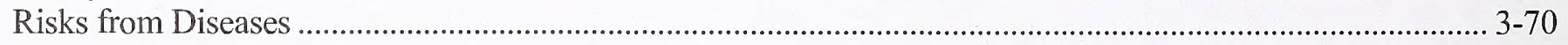

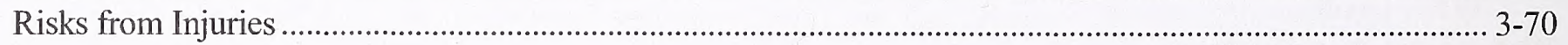

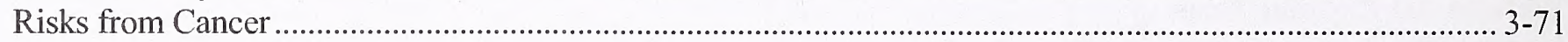

Risk from Using Herbicides on Public Lands ............................................................................................. 3-72

Risk from Wildfire Control on Public Lands ................................................................................................. 3-72 


\section{List of Tables}

3-1 Acres of Public Lands in 17 Western States and Percent of Lands in the the State Administered by the BLM.

National Ambient Air Quality Impact Significance Criteria..

Counties within the Treatment Area that are Designated Nonattainment or Maintenance Areas for

Various Pollutants

Vegetation Classification System

3-21

Estimated Acres of Weed Infestations on Public Lands in 2000 ............................................................ 3-28

Grazing Permits and Leases in Force and Active Animal Unit Months during Fiscal Year 2005 .............. 3-44

Wild Horses and Burros on Public Lands in Fiscal Year 2005 ............................................................. 3-45

Interpreted Paleontological Sites on Public Lands .............................................................................. 3-46

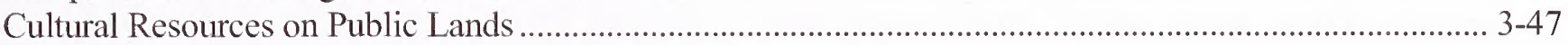

Culture Areas, Prehistoric Occupation Periods, and Selected Common Site Types .................................... 3-48

European Settlement Resource Types ……...................................................................................... 3-55

Visual Resource Management Classes and Objectives and Appropriate Management Activities .............. 3-58

National Landscape Conservation System and Other Special Designation Areas on Public Lands as

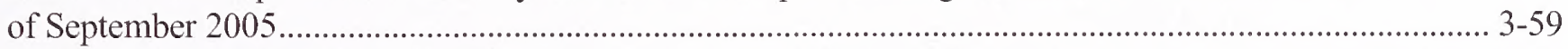

3-14 Estimated Recreation Use of Public Lands during Fiscal Year 2005 .................................................. 3-60

3-16 Percent Unemployment for Western U.S. and Alaska .................................................................. 3-64

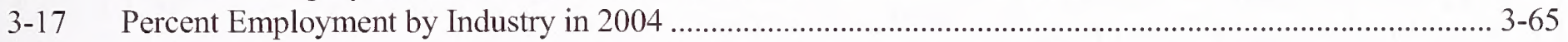

3-18 Revenues Generated from Public Lands by Source for Fiscal Year 2005 ............................................. 3-66

3-19 Estimated Benefits to Local Economies by Recreation on Public Lands during Fiscal Year 2005 ............. 3-66

3-20 Summary of BLM Jobs and Expenditures for the Management of the Lands and Resources Program by Activity and Subactivity ............................................................................................................... 3-67

3-21 BLM Wildland Fire Suppression Expenditures Fiscal Year 1998 through Fiscal Year 2005 .................... 3-68

3-22 BLM Action Fires Larger than 10,000 Acres during 1999 to 2005 ...................................................... 3-68

3-23 Herbicide Uses and Costs for Vegetation Treatments on Public Lands during 2005 ............................... 3-69

3-24 BLM Payments to States and Local Governments during Fiscal Year 2005 ........................................... 3-71

3-25 Mortality Rates (per 100,000 Population) and Causes of Death by State 2002-2003 _................................ 3-72

\section{List of Figures}

3-1 Relationship between Area Occupied by Invasive Species and Time.

\section{List of Maps}

Ecoregion Divisions

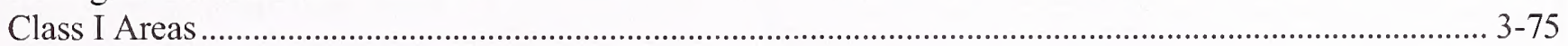

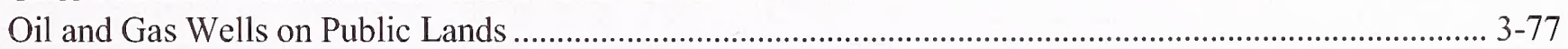

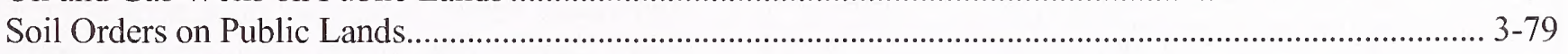

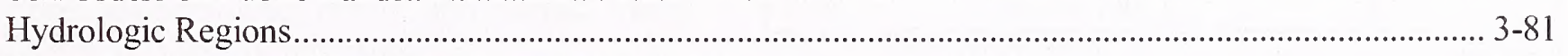

Wastershed Surface Water Quality on Public Lands ......................................................................... 3-83

General Groundwater Quality on Public Lands................................................................................. 3-85

Vegetation Types and Ecoregions on Public Lands in Alaska................................................................ 3-87

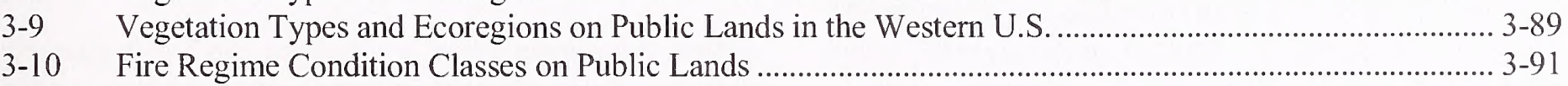

3-11 Native Areas of Western North America......................................................................................... 3-93

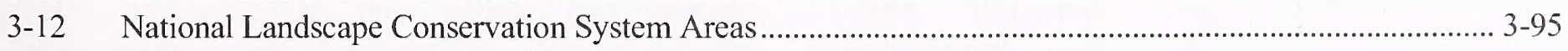




\section{CHAPTER 3}

\section{AFFECTED ENVIRONMENT}

\section{Introduction and Study Area}

This chapter describes the natural and socioeconomic environment of public lands in the western U.S., including Alaska, which would be affected by the alternatives under consideration. It focuses on resources that were identified in Chapter 1, and is useful in understanding the environmental, cultural, and social consequences of the proposed program and alternatives.

\section{Land Use and Ecoregions}

\section{Land Use}

The BLM manages nearly 261 million acres in the western U.S. and Alaska. Public lands represent from less than $0.1 \%$ of the total land area in some states to over $67 \%$ of lands in Nevada (Table 3-1).

Approximately 164 million acres of public lands are upland rangeland, of which approximately 161 million acres are open to livestock grazing. Other public uses on rangeland include recreation, and oil, gas, and mineral development.

Another 55 million acres are forestland and woodland. Forestlands and woodlands are a source of timber and other forest products, and are used for livestock grazing, recreational, and cultural purposes.

Wetland and riparian areas total about 23 million acres and are primarily used for recreation and grazing. The remaining 19 million acres consist of barren mountains, mountaintops, glaciers, sand dunes, and playas. These areas are primarily used for recreation.

\section{Ecoregions}

Because this PEIS addresses a broad geographic region with a diverse range of biophysical characteristics, it is useful to subdivide this region into smaller, homogeneous areas for analysis. Where possible, information on resources has been organized by ecoregions rather than by state boundaries. Ecoregions are geographic areas that are delineated and defined by similar climatic conditions, geomorphology, and soils (Bailey 1997, 2002). Since these factors are relatively constant over time and strongly influence the ecology of vegetative communities, ecoregions may have similar potentials and responses to disturbance (Clarke and Bryce 1997; Jensen et al. 1997). Ecoregions, therefore, provide a useful framework for organizing, interpreting, and predicting changes to vegetation following management treatments.

TABLE 3-1

Acres of Public Lands in 17 Western States and Percent of the State Administered by the BLM

\begin{tabular}{|l|r|c|}
\hline \multicolumn{1}{|c|}{ State } & $\begin{array}{c}\text { Acres of } \\
\text { BLM Land }\end{array}$ & $\begin{array}{c}\text { Percent of State Lands } \\
\text { Administered by the BLM }\end{array}$ \\
\hline \hline Alaska & $85,468,616$ & 23.5 \\
\hline Arizona & $12,218,180$ & 16.8 \\
\hline California & $15,230,638$ & 15.1 \\
\hline Colorado & $8,363,916$ & 12.6 \\
\hline Idaho & $12,001,817$ & 22.5 \\
\hline Montana & $7,963,511$ & 8.5 \\
\hline Nebraska & 6,354 & $<0.1$ \\
\hline Nevada & $47,824,624$ & 67.6 \\
\hline New Mexico & $13,371,737$ & 17.2 \\
\hline North Dakota & 58,837 & 0.1 \\
\hline Oklahoma & 2,136 & $<0.1$ \\
\hline Oregon & $16,135,761$ & 26.0 \\
\hline South Dakota & 274,437 & 0.6 \\
\hline Texas & 11,833 & $<0.1$ \\
\hline Utah & $22,858,179$ & 42.1 \\
\hline Washington & 408,580 & 0.9 \\
\hline Wyoming & $18,366,584$ & 29.3 \\
\hline Total & $260,565,740$ & 23.5 \\
\hline \hline Source: USDI BLM $(2006 \mathrm{c}, \mathrm{d})$. & Acreages are approximate and \\
subject to change in response to land transfers.
\end{tabular}

The public lands addressed in this PEIS lie within eight major physiographic regions, or ecoregion divisions: Tundra, Subarctic, Subtropical Steppe, Subtropical Desert, Temperate Steppe, Temperate Desert, Mediterranean, and Marine, including Mountain Provinces (Map 3-1). 


\section{Climate}

Climate is the statistical distribution of atmospheric conditions, as determined by the weather patterns that result from long-term fluctuations in global atmospheric and hydrologic cycles. Climatic patterns describe the annual distribution of energy and moisture, thus affecting the amount and seasonal distribution of temperature, precipitation, and winds. These factors influence the composition and distribution of rangeland vegetation, as well as the formation and erosion of rangeland soils, and hydrological conditions. These factors also influence the distribution of wind-borne air pollutants, such as smoke from wildfires and prescribed fires.

The western U.S. experiences several broad climatic groups: polar, boreal, temperate, Mediterranean highland, and dry. Polar and boreal climates dominate in Alaska, while a humid temperate climate is characteristic of the coastal areas of Washington, Oregon, and northern California. The southern California coast has a Mediterranean climate, while mountainous areas have a highland climate. The rest of the western states east of the Cascade, Sierra Nevada, and Rocky mountains are characterized by a dry climate. On a regional scale, temperature and precipitation vary with latitude, elevation, distance from the oceans, and the position of mountain ranges with respect to prevailing winds. The eight ecoregions found in the treatment area are based on the seasonality of precipitation, and on the degree of dryness or cold, and depend largely on latitude and continental position.

\section{Tundra Ecoregion}

The climate of the westernmost and northernmost portion of Alaska (including the Alaska Peninsula and Aleutian Islands), is typified by cold Arctic air masses. The tundra climate has a very short, cool summer and a long, severe winter, with the warmest average monthly temperature between $50{ }^{\circ} \mathrm{F}$ and $32{ }^{\circ} \mathrm{F}$ (freezing). Between 55 and 188 days per year typically have a daily mean temperature above freezing. Annual precipitation is often less than 8 inches, but the climate is humid because of the low potential evaporation.

\section{Subarctic Ecoregion}

The moist, boreal climate type demonstrates a large seasonal temperature range. Winters dominate, with cool, short summers. Because average monthly temperatures are below freezing for up to 7 consecutive months, soil moisture freezes solidly to depths up to 14 feet. Only a single month has an average temperature above $50^{\circ} \mathrm{F}$. The limited precipitation (10 to 20 inches annually) falls mainly during the short summer months, although thunderstorms are uncommon.

\section{Subtropical Steppe Ecoregion}

The western subtropical steppe borders deserts on both the north and south, with the temperate steppe to the north and east. This ecoregion division has a hot semiarid climate where potential evaporation exceeds precipitation, and where all months have average temperatures above freezing. Bright sunny days with cool clear nights are typical. Precipitation ranges from 10 to 20 inches per year, with a summertime peak due to thunderstorm activity.

\section{Subtropical Desert Ecoregion}

South and west of the Arizona-New Mexico Mountains is the subtropical desert climate. This region is not only very dry, but also has extreme maximum summer temperatures. In addition, both daytime solar and nocturnal radiation are high, leading to extreme daily temperature variations. Annual precipitation is less than 8 inches.

\section{Temperate Steppe Ecoregion}

Temperate steppes are areas with a semiarid continental climatic regime, where evaporation usually exceeds precipitation. Seven or fewer months have an average temperature above $50^{\circ} \mathrm{F}$. Winters are cold and dry, and summers are warm to hot, with at least 1 month's average temperature below freezing.

\section{Temperate Desert Ecoregion}

Temperate deserts are generally dry with wide temperature differences between summer and winter. In the intermountain region between the Pacific coast and Rocky Mountains, the temperate desert has a very pronounced drought season and a short humid season. Most precipitation falls in winter, despite a small peak in late spring. Eight or more months have an average temperature above $50^{\circ} \mathrm{F}$. Winter is relatively short, but with at least 1 month's average temperature below freezing. 


\section{Mediterranean Ecoregion}

Most of California west of the Sierra Nevada Mountains and Mojave Desert is typified by alternate wet winters and dry summers, within a strong transition zone between the dry desert and the wet coast. Mild temperatures dominate, with the coldest average monthly temperature between $65^{\circ} \mathrm{F}$ and $27^{\circ} \mathrm{F}$. Most precipitation occurs in winter, with the wettest month receiving nearly 3 times the precipitation of the driest summer month.

\section{Marine Ecoregion}

The temperate oceanic climate extends from southeast Alaska down the Pacific Coast to southwestern Oregon. This climate receives abundant rainfall from maritime air masses, with average temperatures moderated by the ocean. Although the warmest average monthly temperature is above $72{ }^{\circ} \mathrm{F}$ for at least 4 months, the average temperature is above $50^{\circ} \mathrm{F}$; the coldest month averages just above $32^{\circ} \mathrm{F}$. Annual precipitation is high (40 to 80 inches per year), but significantly lower in summer. The relatively low temperatures reduce evaporation, producing a very damp, humid climate with substantial cloud cover. Mild winters and cool summers are typical.

\section{Mountain Provinces}

The mountainous portions of all eight ecoregion divisions exhibit a highland climate, where site-specific conditions vary greatly, depending on altitude and exposure. Windward slopes typically have greater precipitation (and leeward slopes less precipitation) than the ecoregion division as a whole. Southern exposures also tend to be warmer than slopes with northern exposures. Finally, the occurrence of mountain winds (up slope during the day, down slope at night) and diurnal temperature inversions is greatest near mountains.

\section{Air Quality}

Because air pollution can directly pose health risks and cause significant welfare impacts to humans, improvement of air quality in the U.S. is an important regulatory goal. The Clean Air Act (originally passed in 1955 and amended several times since), establishes a mandate to reduce emissions of specific pollutants via uniform federal standards. Under the Act, the USEPA is responsible for setting standards and approving state implementation plans (SIPs) to ensure that local agencies comply with the Act.

The standards set by the USEPA include primary and secondary NAAQS for six pollutants, referred to as criteria pollutants, to protect public health and welfare. The criteria pollutants are sulfur dioxide $\left(\mathrm{SO}_{2}\right)$, nitrogen dioxide $\left(\mathrm{NO}_{2}\right)$, carbon monoxide $(\mathrm{CO})$, ozone $\left(\mathrm{O}_{3}\right)$, lead $(\mathrm{Pb})$, and particulate matter $(\mathrm{PM})$.

Particulate matter (PM) is a generic term for a broad class of chemically and physically diverse substances that exist as discrete particles over a wide range of sizes. For regulatory purposes, PM is sub-classified by the particle's aerodynamic diameter. $\mathrm{PM}_{10}$ includes all PM with an aerodynamic diameter of 10 microns or less and is referred to as inhalable PM. $\mathrm{PM}_{2.5}$ includes all PM with an aerodynamic diameter of 2.5 microns or less, called fine PM, and is by definition a subset of $\mathrm{PM}_{10}$. Studies have shown more serious health effects associated with $\mathrm{PM}_{2.5}$; therefore, the USEPA promulgated more stringent standards for this class of PM.

The NAAQS are listed in Table 3-2. The primary NAAQS protect the health of sensitive individuals, and the secondary NAAQS protect the general welfare of the public. Different averaging periods are established for the criteria pollutants based on their potential health and welfare effects. The NAAQS are enforced by states, which in some cases have adopted additional or more stringent standards.

All areas of the nation have been classified based on their status with regard to attaining the NAAQS. An area is designated by the USEPA as being in attainment for a criteria pollutant if ambient concentrations of that pollutant are below the NAAQS, or being in nonattainment if criteria pollutant concentrations violate the NAAQS. Once nonattainment areas comply with the NAAQS, they are designated as maintenance areas. Areas that are classified as nonattainment must implement a plan to reduce ambient concentrations below the NAAQS. Areas where insufficient data are available to determine attainment status are designated as unclassified, and are treated as attainment areas for regulatory purposes.

The Clean Air Act also provides for the prevention of significant deterioration (PSD) of air quality, especially in areas of the country where the air quality is much better than standards. In Class I areas, only a 
TABLE 3-2

National Ambient Air Quality Impact Significance Criteria $\left(\mu \mathrm{g} / \mathrm{m}^{3}\right)$

\begin{tabular}{|c|c|c|c|c|c|}
\hline \multirow{2}{*}{ Pollutant } & \multirow{2}{*}{ Averaging Period ${ }^{1}$} & \multicolumn{2}{|c|}{ NAAQS } & \multicolumn{2}{|c|}{ PSD Imcrements $^{2}$} \\
\hline & & Primary & Secondary & Class I & Class III \\
\hline $\mathrm{NO}_{2}$ & Annual & 100 & 100 & 2.5 & 25 \\
\hline \multirow{2}{*}{$\mathrm{CO}$} & 1-hour & 40,000 & NA & NA & NA \\
\hline & 8-hour & 10,000 & $\mathrm{NA}$ & $\mathrm{NA}$ & $\mathrm{NA}$ \\
\hline \multirow{2}{*}{$\mathrm{PM}_{10}$} & 24-hour & 150 & 150 & 8 & 30 \\
\hline & Annual & NA & $\mathrm{NA}$ & 4 & 17 \\
\hline \multirow{2}{*}{$\mathrm{PM}_{2.5}$} & 24-hour & 35 & 35 & NA & NA \\
\hline & Annual & 15 & 15 & NA & NA \\
\hline \multirow{3}{*}{$\mathrm{SO}_{2}$} & 3-hour & NA & 1,300 & 25 & 512 \\
\hline & 24-hour & 365 & NA & 5 & 91 \\
\hline & Annual & 80 & NA & 2 & 20 \\
\hline Lead & Quarter & 1.5 & 1.5 & NA & NA \\
\hline \multirow{2}{*}{$\mathrm{O}_{3}$} & 1 -hour ${ }^{3}$ & 235 & 235 & NA & NA \\
\hline & 8 -hour ${ }^{3}$ & 157 & 157 & NA & NA \\
\hline \multicolumn{6}{|c|}{$\begin{array}{l}{ }^{1} \text { Annual standards are never to be exceeded. Short-term standards (those other than annual or quarterly) are not to be exceeded more } \\
\text { than once per year, except for } \mathrm{O}_{3} \text {, } \mathrm{PM}_{10} \text {, and } \mathrm{PM}_{2.5} \text { standards. For } \mathrm{O}_{3} \text {, the expected number of days with ozone levels above the } \\
\text { standard is not to be exceeded more than once per calendar year. For } \mathrm{PM}_{10} \text {, the standard is attained when the } 99^{\text {th }} \text { percentile } \\
\text { concentration for the year is less than the standard. For } \mathrm{PM}_{2.5} \text {, the standard is attained when the } 98^{\text {th }} \text { percentile concentration for the } \\
\text { year is less than the standard. } \\
{ }^{2} \text { Prevention of significant deterioration (PSD) increments are the maximum amounts of pollutants allowed above a specified baseline } \\
\text { concentration. Class I areas are predominantly large national parks and wilderness areas as of August } 7,1977 \text {. } \\
{ }^{3} \text { The } 1 \text {-hour NAAQS will no longer apply to an area } 1 \text { year after the effective date of the designation of that area for the } 8 \text {-hour ozone } \\
\text { NAAQS. The effective designation date for most areas is June } 15,2004 \text {. } \\
\text { NA = Not applicable. }\end{array}$} \\
\hline
\end{tabular}

very small amount or increment of air quality deterioration is permissible. Class I areas include specified national parks, wilderness areas, and certain Indian reservations (Map 3-2). Mandatory Class I areas, which include large national parks and wilderness areas that were in existence on August 7, 1977, are a subset of Class I areas that may not be redesignated, and are subject to visibility protection regulations. All areas that have not been designated Class I are considered Class II areas. The PSD permit provisions of the Clean Air Act only apply to stationary sources of air pollution and do not include prescribed fire, which is defined as a temporary source. Some states, however, have regulations to restrict intrusions of smoke from prescribed burning that might adversely impact visibility within mandatory federal Class I and other smoke-sensitive areas.

Detailed knowledge of the existing air quality for the area covered by this PEIS is limited to available monitoring sites for criteria pollutants. In the undeveloped regions of public lands, ambient pollutant levels are expected to be low, and probably negligible in remote areas. In general, locations experiencing high ambient pollutant levels in the treatment area are areas with commercial and industrial land use (areas with mills, power plants, etc.), and local population centers (areas with automobile exhaust, residential heating, etc.).

Table 3-3 lists counties with public lands that are designated as nonattainment or maintenance areas for each criteria pollutant. $\mathrm{PM}_{10}, \mathrm{O}_{3}$, and $\mathrm{NO}_{2}$ concentrations are expected to be higher near industrial areas and cities where there are significant combustion sources and vehicles. High $\mathrm{SO}_{2}$ concentrations occur primarily near coal-fired power plants, smelters, and refineries.

\section{Visibility Protection in Mandatory Federal Class I Areas}

Under the Clean Air Act, Congress created the Grand Canyon Visibility and Transport Commission (GCVTC). The GCVTC was comprised of eight western states, six tribal agencies, and four federal land management agencies, and was charged with assessing the current scientific information on 
TABLE 3-3

Counties within the Treatment Area that are Designated Nonattainment or Maintenance Areas for Various Pollutants

\begin{tabular}{|c|c|c|c|}
\hline Pollutant & State & Nonattainment & Maintenance \\
\hline \multirow{11}{*}{$\mathrm{PM}_{10}$} & Arizona & $\begin{array}{l}\text { Cochise*, Gila*, Maricopa*, Pima*, Pinal*, } \\
\text { Santa Cruz*, Yuma* }\end{array}$ & Gila*, Mohave* \\
\hline & California & $\begin{array}{l}\text { Fresno*, Imperial*, Inyo*, Kern*, Kings*, } \\
\text { Madera*, Mono*, Riverside*, San Bernardino, } \\
\text { Stanislaus*, Tulare* }\end{array}$ & Kern*, Mono* \\
\hline & Colorado & Prowers* & $\begin{array}{l}\text { Adams*, Arapahoe*, Archuleta*, Boulder*, } \\
\text { Broomfield, Denver, Douglas, Freemont*, Jefferson, } \\
\text { Pitkin*, Routt*, San Miguel* }\end{array}$ \\
\hline & Idaho & Bannock*, Bonner, Power*, Shoshone* & Ada* \\
\hline & Montana & Missoula*, Rosebud*, Silver Bow* & None \\
\hline & Nevada & Clark*, Washoe* & None \\
\hline & New Mexico & Dona Ana* & None \\
\hline & Oregon & Jackson*, Lake*, Lane* & Josephine*, Klamath* \\
\hline & Utah & Salt Lake, Utah & None \\
\hline & Washington & Yakima* & None \\
\hline & Wyoming & Sheridan* & None \\
\hline \multirow{5}{*}{$\mathrm{SO}_{2}$} & Arizona & Cochise*, Gila*, Pinal* & Greenlee*, Pima* \\
\hline & Montana & Lewis and Clark*, Yellowstone* & None \\
\hline & Nevada & None & White Pine* \\
\hline & New Mexico & None & Grant* \\
\hline & Utah & Salt Lake*, Tooele* & None \\
\hline $\mathrm{NO}_{2}$ & None & None & None \\
\hline \multirow{11}{*}{$\mathrm{CO}$} & Alaska & None & Fairbanks North Star* \\
\hline & Arizona & Maricopa* & Pima* \\
\hline & California & Los Angeles*, Riverside*, San Bernardino* & $\begin{array}{l}\text { Butte*, El Dorado*, Fresno*, Kern*, Napa*, } \\
\text { Placer*, San Diego*, Solano*, Sonoma*, } \\
\text { Stanislaus*, Yolo* }\end{array}$ \\
\hline & Colorado & None & Boulder*, El Paso*, Jefferson*, Larimer*, Teller* \\
\hline & Idaho & None & Ada* \\
\hline & Montana & Missoula* & Cascade*, Yellowstone* \\
\hline & Nevada & None & Carson City*, Douglas*, Washoe* \\
\hline & New Mexico & None & Bernalillo \\
\hline & Oregon & Marion*, Polk* & $\begin{array}{l}\text { Clackamas*, Jackson*, Josephine*, Klamath*, } \\
\text { Lane*, Washington* }\end{array}$ \\
\hline & Utah & Utah* & Salt Lake \\
\hline & Washington & Spokane* & Yakima* \\
\hline \multirow{7}{*}{ Ozone } & Arizona & Maricopa* & None \\
\hline & California & $\begin{array}{l}\text { Butte, El Dorado*, Fresno*, Imperial, Kern*, } \\
\text { Kings, Napa*, Placer*, Riverside*, San } \\
\text { Bernardino*, San Diego*, Solano*, Sonoma*, } \\
\text { Stanislaus, Tulare, Yolo }\end{array}$ & Kern*, Monterey, San Benito, San Diego \\
\hline & Colorado & None & Boulder*, Jefferson \\
\hline & Nevada & Washoe & Clark*, King*, Pierce*, Snohomish*, Yakima* \\
\hline & New Mexico & Dona Ana* & None \\
\hline & Oregon & Marion*, Polk* & Clackamas*, Washington* \\
\hline & Utah & None & Salt Lake \\
\hline Lead & Montana & Lewis and Clark* & None \\
\hline \multicolumn{4}{|c|}{$\begin{array}{l}\text { * Only a portion of the county is in nonattainment or maintenance for the pollutant. } \\
\text { Notes: States that are not listed for a particular pollutant do not have counties within the treatment area that are also within } \\
\text { nonattainment or maintenance areas for that pollutant. } \\
\text { Source: USEPA Green Book available at http://www.epa.gov/oar/oagps/greenbk/. }\end{array}$} \\
\hline
\end{tabular}


visibility impacts and making recommendations for addressing regional haze in the western U.S (GCVTC 1996). The GCVTC signed and submitted more than 70 recommendations to the USEPA indicating that visibility impairment was caused by a wide variety of sources and pollutants, and that a comprehensive strategy was needed to remedy regional haze (Grand Canyon Visibility Transport Commission 1996). Based on the findings and recommendations from the GCVTC, the USEPA established regional haze regulations, and encouraged states to coordinate their implementation efforts through regional planning organizations.

The Western Regional Air Partnership (WRAP) was established in 1997 as a successor to the GCVTC. The WRAP is a voluntary organization comprised of 13 western governors (Alaska, Arizona, California, Colorado, Idaho, Montana, North Dakota, New Mexico, Oregon, South Dakota, Utah, Washington, and Wyoming), 11 tribal leaders, and 2 federal departments (USDA and USDI).

In the 1990 amendments to the Clean Air Act, the U.S. Congress directed the USEPA to develop regional haze regulations to achieve the national visibility goal of "the prevention of any future, and the remedying of any existing impairment of visibility in mandatory Class I federal areas, which impairment results from manmade air pollution."

The USEPA promulgated the Regional Haze Rule in 1999 to improve visibility in 156 mandatory federal Class I national parks and wilderness areas where visibility is an important value (USEPA 1999a). Improvement in visibility must be made every 10 years for the $20 \%$ most impaired (haziest) days, and there must be no degradation for the $20 \%$ best (clearest) days, until the national visibility goal is reached in 2064 . State implementation plans and tribal implementation plans (TIPs) outline how reasonable progress towards this goal will be achieved and demonstrated. Section 308 of the Regional Haze Rule provides nationally applicable provisions of the rule in the development of SIPs and TIPs, which address regional haze.

\section{Herbicide Drift}

Aerial and ground application of herbicides may transport herbicides through drift, allowing airborne herbicides to move beyond the intended target. The primary factors that influence drift are droplet size, wind speed, humidity, formulation of the herbicide, height of emission, equipment and application techniques, and the size of the area treated with the herbicide. The factor that has the greatest influence on downwind movement is droplet size. Procedures that can be employed to reduce drift include: 1) using a lower spray nozzle height, 2) using the lower end of the pressure range, 3) increasing the spray nozzle size, 4) using drift-reducing nozzles, 5) using drift control additives, and 6) using sprayer shields (Hofman and Solseng 2001). Additionally, several university extension service agencies provide assistance regarding SOPs to minimize herbicide spray drift (Dexter 1993, Hofman and Solseng 2001).

\section{Topography, Geology, Minerals, Oil, and Gas}

The diversity in the landscape of the treatment areas reflects differences in geologic processes and the effects of climate, which have been shaping the land over a long period of time.

In 2005 , on-shore public lands produced about $40 \%$ of the nation's coal, about $11 \%$ of its natural gas, and about $5 \%$ of its oil (USDI BLM 2006c). In FY 2005, the BLM administered over 54,000 oil and gas leases, of which approximately 21,000 leases were producing. BLM geothermal resources produced over 34 megawatt-hours of electric power. Information pertaining to mineral, oil, and gas resources, presented below, was gathered from the Mineral Resources Program, a section of the U.S. Geological Survey (USGS).

\section{Tundra Ecoregion}

The Tundra Ecoregion is rich in minerals, oil, and gas. Metallic minerals including silver, lead, and zinc are found throughout the North Slope region of Alaska. To the south, along the western coast of Alaska, are significant concentrations of gold. The Northern Alaska physiographic province accounts for almost half of the oil and more than half of the undiscovered conventional gas assessed on onshore federal lands. Oil and coal resources extracted in Alaska are predominantly from the Tundra Ecoregion (i.e., North Slope). As of 2005, Alaska accounted for $17 \%$ of the crude oil discovered in the U.S. (Energy Information Administration 2006). 


\section{Subarctic Ecoregion}

Gold is the most dominant mineral extracted in this ecoregion. Other mineral operations include copper mining, and production of aggregate (c.g., construction sand, gravel, and crushed stone). There are limited discoveries of coal, gas, and oil resources in the central portion of Alaska.

\section{Temperate Desert Ecoregion}

Raw, non-fuel minerals extracted throughout this ecoregion include aggregate, gypsum, limestone, trona, shale, and stone. Metallic minerals, predominantly silver and gold, are extracted in the southern portions of this ecoregion. There is very little oil and gas found in this ecoregion. However, coalfields located in the Temperate Steppe Ecoregion extend into this ecoregion, and are found throughout southwest Wyoming and central and southwest Utah.

\section{Subtropical Desert Ecoregion}

Minerals predominantly extracted from the western portion of this ecoregion are construction aggregate including construction sand, gravel, and crushed stone. Metallic minerals (e.g., gold, silver, and copper) dominate the central and eastern portion of this region. Gypsum is prominent in southern Nevada. Limited oil and gas reserves are located in southern Arizona and southwest New Mexico. No coalfields are found in this ecoregion.

\section{Temperate Steppe Ecoregion}

Construction aggregate (including crushed stone and common clay) is the dominant mineral extracted throughout the southern and central sections of this ecoregion. While industrial minerals within this region are predominantly extracted for construction purposes, Wyoming contains the world's largest source of trona. Trona is the principal ore from which soda ash is produced. Metallic minerals and precious stones (i.e., gems) are extracted throughout the northern and northeastern portions of the ecoregion.

There are significant deposits of coal concentrated throughout the Colorado Plateau extending into the Rocky Mountains and Great Plains. Significant oil reserves are located throughout the region (Map 3-3). The Powder River Basin and the Wyoming Thrust Belt provinces of the Rocky Mountains and Northern Great Plains regions have the second largest concentrations (behind Alaska) of undiscovered conventional oil and gas, respectively, assessed on federal lands (Gautier et al. 1998; U.S. Departments of Interior, Agriculture, and Energy 2003).

\section{Subtropical Steppe Ecoregion}

Construction aggregate and metallic minerals dominate the nonfuel minerals extracted in this ecoregion. In addition, potash accounts for a significant portion of minerals mined in New Mexico. The Carlsbad Potash District (in New Mexico) is the largest potashproducing area in the U.S. (Energy Information Administration 2001). There are extensive coalfields throughout northern Arizona and New Mexico. These fields extend up into the Colorado Plateau. No oil or natural gas reserves have been located in this ecoregion.

\section{Mediterranean Ecoregion}

Industrial minerals such as aggregate, limestone, and shale dominate mineral extraction throughout this ecoregion. There is no coal mining within this ecoregion, although oil and natural gas extraction is predominant in the San Joaquin, Ventura/Santa Barbara, Los Angeles, and Santa Maria regions.

\section{Marine Ecoregion}

Metallic minerals such as gold, silver, aluminum, lead, and zinc are mined in southeast Alaska and in Washington. In western Oregon, aggregate is the most dominant mineral extracted. There are no significant oil, natural gas, or coal resources within this region.

\section{Soil Resources}

Soils in the treatment area are diverse and range from the arid, saline soils of the southwest, to the clayey glaciated soils of Montana, to the cold, wet permafrost soils of Alaska. Soils are the result of complex interactions between parent material (geology), climate, topography, organisms, and time (Brady and Weil 1999). Soils are classified by the degree of development into distinct layers or horizons and their prevailing physical and chemical properties (Fanning and Fanning 1989). Similar soil types are grouped together into soil orders based on defining characteristics, such as organic matter and clay content, amount of mineral weathering, water and temperature regimes, or other characteristics that give soil unique properties, such as the presence of volcanic ash or pcrmafrost (Jenny 1980). 
Eleven soil orders are represented on public lands in the western U.S. and Alaska (Map 3-4). Because soils develop under local conditions of climate, parent material, and vegetation, each ecoregion may contain several or all of the soil orders as a result of various combinations of local soil forming factors. Soils are organized here by soil order rather than by ecoregion.

Aridisols are found on over $40 \%$ of public lands (105 million acres). They occur across wide parts of the western U.S. in Nevada, Arizona, New Mexico, central Wyoming, southern Idaho, and southern California. These soils are characterized by an extreme water deficiency. They are light colored soils, are low in organic matter, and may have subsurface accumulations of soluble materials, such as calcium carbonate, silica, gypsum, soluble salts, and exchangeable sodium. Vegetation on these soils includes scattered desert shrubs and short bunchgrasses, which are important resourc̄es for livestock. Aridisols are generally not very productive without irrigation, and may be prone to salinity buildup. Surface mineral deposits often form physical crusts that impede water infiltration.

Gelisols occur on over $27 \%$ of public lands ( 71 million acres), almost exclusively in the tundra regions of Alaska. They are underlain by permanently frozen ground (permafrost). Some gelisols in wet environments have developed large accumulations of organic matter, particularly in areas of bogs and wetlands. Soil forming processes take place very slowly above the permafrost in the active layer that thaws seasonally. These soils support tundra vegetation of lichens, grasses, and low shrubs that grow during the brief summers. Plant productivity is low and limited by the extremely short growing season of the northern latitudes, low levels of solar radiation, and poor water drainage. Bare rock is also common in Alaska, comprising nearly 8 million acres.

Mollisols occur on about $15 \%$ of public lands ( 40 million acres). They are found in much of North and South Dakota and northern Montana, as well as in eastern Oregon, Washington, and Idaho where they have developed from basalt and loess parent materials. These soils typically support grasslands and are mineral soils with thick, dark-colored surface horizons rich in organic matter from the dense root systems of prairie grasses. They are one of the most productive soils on public lands, and their high organic matter content helps reduce the risk of groundwater contamination by herbicides. Mollisols extend from upland areas to the prairie grasslands, where they are most abundant. Mollisols support a variety of plant communities, including grasslands, chaparral-mountain shrub, and forests. Since they have developed primarily under grassland vegetation, mollisols have been used extensively for livestock grazing.

Entisols occur on about $9 \%$ of public lands (23 million acres). Entisols occur extensively in eastern Montana, western Colorado, South Dakota, Wyoming, Utah, and central California. They are young, weakly developed mineral soils that lack significant profile development (soil horizons) and are often found in lower elevation, arid and semiarid environments supporting desert shrub and sagebrush communities. Entisols can include recent alluvium, sands, soils on steep slopes, and shallow soils. Soil productivity ranges from very low in soils forming in shifting sand or on steep rocky slopes to very high in certain soils formed in recent alluvium. Productivity is often limited by shallow soil depth, low water holding capacity, or inadequate available moisture, but these soils do support rangeland vegetation and may support trees in areas of higher precipitation.

Alfisols occur on less than $2 \%$ of public lands (4 million acres). They can be found throughout the mountains of western Montana and Wyoming and in central Colorado and California. They are characterized by subsurface clay accumulations and nutrient-enriched subsoil. Alfisols commonly have a mixed vegetative cover and are productive for most crops, including commercial timber.

Inceptisols also occur on less than $2 \%$ of public lands (4 million acres). Inceptisols are found in northern Idaho and parts of Washington, Oregon, and Montana, as well as southwest Alaska. They are generally young mineral soils, but have had more time to develop profile characteristics than Entisols. They principally occur in very cool to warm, humid and subhumid regions and in most physiographic conditions, and often support coniferous and deciduous forests as well as rangeland vegetation. They may form in resistant rock or thin volcanic ash on steep mountain slopes or depressions, on top of mountain peaks, or next to rivers. Productivity is varied and may be high where moisture is adequate.

The other soil orders represent less than $1 \%$ of public lands each ( 1 million acres or less), and therefore, will not be discussed in detail. Andisols are soils that have formed on volcanic ash deposits. They have high amounts of volcanic glass and organic matter, giving them a light, fluffy texture. Histosols are organic soils that typically form in lowland areas with poor water drainage. While not extensive, Histisols are often 
associated with riparian or wetland resources and can be very important locally.

Spodosols are highly leached, acid soils that typically form on sandy soils under cold, humid conditions at high elevations. Ultisols are strongly acid mineral soils associated with advanced soil weathering and are low in nutrients. Vertisols have large amounts of expanding clay that causes them to have high shrinking and swelling characteristics.

The concept of soil quality encompasses a soil's capacity to function and to sustain plant and animal productivity, air and water quality, and human health (Soil Quality Institute 2001). It is a function of each soil's inherited properties (texture, type of minerals, depth) as well as more dynamic properties that can change with management (porosity, infiltration, effective ground cover, and aggregate stability). The ability of a soil to filter, buffer, degrade, immobilize, and detoxify herbicides is a function of the soil quality.

Management activities can result in changes in certain soil properties such as soil porosity, organic matter, biological activity, and susceptibility to erosion. These changes in turn affect the fate of herbicides in soils. For example, disturbances that result in increased susceptibility to erosion will affect the off-site movement of certain herbicides that are designed to bind to soil particles. Herbicides can alter soil organism diversity and composition. Compaction or surface disturbance may affect soil activated herbicides from reaching the root zone of target plants.

\section{Biological Soil Crusts}

Biological soil crusts (also known as cryptogamic, microbiotic, cryptobiotic, or microphytic crusts) are commonly found in semiarid and arid environments. They provide important functions, such as improving soil stability and reducing erosion, fixing atmospheric nitrogen and contributing nutrients to plants, and assisting with plant growth (Belnap and Gardner 1993, Evans and Ehleringer 1993, Eldridge and Greene 1994, Belnap and Giliette 1998, Harper and Belnap 2001). Crusts are composed of a highly specialized nonvascular plant community consisting of cyanobacteria, green and brown algae, mosses, and lichens, as well as liverworts, fungi, and bacteria (Belnap and Phillips 2001). Biological soil crusts occupy open spaces between the sparse vegetation of the Great Basin, Colorado Plateau, Sonoran Desert, and the inner Columbia Basin, and also occur in agricultural areas and native prairies, and in Alaska.

Biological soil crusts can reach up to several inches in thickness and vary in terms of color, surface topography, and surficial coverage. Crusts generally cover all soil spaces not occupied by vascular plants, which may be $70 \%$ or more in arid regions (Belnap 1994). They are well adapted to severe growing conditions, but are influenced by disturbances such as compression from domestic livestock grazing, tourist activities (hiking, biking, and OHVs), mechanical treatment and agricultural practices (extensive tillage and planting), application of herbicides, and military activities (Peterjohn and Schlesinger 1990, Belnap 1995, USGS 2004). Disturbance of biological crusts results in decreased soil organism diversity, nutrients, stability, and organic matter. Trampling may reduce the number of crust organisms found on the surface and increase runoff and the rate of soil loss without apparent damage to vegetation (Eldridge 1996). Burial of crusts by sediments kills non-mobile photosynthetic components (mosses, lichens, and green algae) of the crust (Campbell 1979). Fires can cause severe damage to biological crusts, but recovery is possible, depending on fire size and intensity. Shrub presence (particularly sagebrush) may increase fire intensity, thereby decreasing the likelihood of early vegetative or crust recovery after a burn (USGS 2003).

\section{Micro and Macroorganisms}

Microorganisms help to break down and convert organic remains into forms that can be used by plants. Microorganisms, such as mycorrhizal fungi, nitrogenfixing organisms, and certain types of bacteria assist plant growth, suppress plant pathogens, and build soil structure. One of the main benefits of mycorrhizal fungi is the improved uptake of nutrients (predominantly phosphorous) and water by plants (Allen 1991). Soil microorganisms are also important in the breakdown of certain types of herbicides.

Macroorganisms, such as insects, earthworms, and small burrowing mammals, mix the soil and allow organic matter on the surface to become incorporated into the soil. These organisms are part of a food chain that is essential to the cycling of nutrients within the soil. Soil microorganisms are also important in the breakdown of certain types of pesticides. 


\section{Soil Erosion}

Soil erosion is a concern throughout the western U.S. and Alaska, particularly in semiarid rangelands. The quantity of soil lost by water or wind erosion is influenced by climate, topography, soil properties, vegetative cover, and land use. While erosion occurs under natural conditions, rates of soil loss may be accelerated if human activities are not carefully managed.

Tundra lands in Alaska are susceptible to erosion if the thick vegetative mat overlying permafrost is disturbed or removed. Trails quickly turn into widely braided ruts, especially in wetlands and at streambank crossings. The resulting gully erosion can rapidly erode substantial quantities of previously frozen soils. Erosion from aufeis (thick ice that builds ups as a result of repeated overflow) and anchor ice is also a concern due to spring breakup flood events leaving disturbed streamchannels. These events cause previously stable riparian areas to form a long-lasting sequence of extensively braided channels, especially in glacial soils.

Rangelands are affected by all four types of water erosion-sheet, rill, gully, and streambank. Sheet erosion is relatively uniform erosion from the entire soil surface and is therefore often difficult to observe, while rill erosion is initiated when water concentrates in small channels as it runs off the soil. Sheet and rill erosion are capable of reducing the productivity of rangeland soils, but often go unnoticed. Gully and streambank erosion is far more visible, and may account for up to $75 \%$ of erosion in desert ecosystems (Hein 2002). Changes in water flow patterns in arid areas resulting from thunderstorms and fire events can cause an increase in the size and frequency of runoff events and sediment yield to local water sources (Water Science and Technology Board and Board on Environmental Studies and Toxicology 2002).

It is possible to control rates of soil erosion by managing vegetation, plant residues, and soil disturbance. Vegetative cover is the most significant factor in controlling erosion because it intercepts precipitation, reduces rainfall impact, restricts overland flow, and improves infiltration. Biological soil crusts are particularly important for protecting the soil and controlling erosion in desert regions, but are easily disturbed by grazing and human activities.

With a decrease in vegetative cover, the potential risk of herbicides entering surface water and groundwater can increase (Purdue Pesticide Program 2001). Herbicides can be transported by surface water runoff, potentially increasing the risk of direct injury to nontarget species, harming aquatic organisms in streams and ponds, and leading to groundwater contamination (University of Missouri Extension 1997).

Differences in chemical solubility, adsorptive characteristics, volatility, and degradability, plus soil properties that affect water movement, biological activity, and chemical retention, affect the amount of a herbicide that may leach to groundwater. The speed at which leaching of chemicals through soil occurs is dependent on the soil characteristics. Soil texture (sand, silt, and clay) affects the movement of water and herbicides through soil. The coarser the soil, the faster the movement of percolating water and the lower the opportunity for adsorption of dissolved chemicals. Soils with more clay and organic matter tend to hold water and dissolved chemicals longer. These soils also have far more surface area onto which herbicides can be adsorbed (LaPrade 1992).

Wind erosion is most common in arid and semiarid regions where lack of soil moisture greatly reduces the adhesive capability of soil (Brady and Weil 2002). In addition to moisture content, soil particle size (texture), mechanical stability of aggregates and clods, and presence of vegetation also affect the ability of wind to move soil. While wind erosion on rangelands is difficult to quantify, the presence of natural vegetation on most rangelands is generally sufficient to keep wind erosion from becoming a serious problem. Most wind erosion problems result from bare, exposed soils with weak or degraded soil structure, such as along trails or on sand dunes or disturbed surfaces. Herbicides can be potentially transported by blowing soils after application. Herbicides bound to soil particles may be moved offsite by wind erosion events.

\section{Soil Compaction}

Soil compaction occurs when moist or wet soil aggregates are pressed together and the pore space between them is reduced. Compaction changes soil structure, reduces the size and continuity of pores, and increases soil density. Wheel traffic, large animals, vehicles, and people can cause soil compaction. Generally, soils made up of particles of about the same size compact less than soil with a variety of particle sizes. Numerous rock fragments can create bridges that reduce compaction. Plant litter and roots, and soil organic matter, structure, moisture, and texture all affect 
a soil's ability to resist compaction. In areas of rangeland where compaction exists, compacted soil extends generally less than 6 inches below the soil surface, although it can be as deep as 2 feet under heavily used tracks and roads (USDA Natural Resource Conservation Service 1996). Compaction becomes a problem when the increased soil density limits water infiltration, increases runoff and erosion, or limits plant growth or nutrient cycling (Soil Quality Institute 2001).

\section{Water Resources and Quality}

\section{Water Resources}

Water resources in the western U.S. and Alaska are important for fish and wildlife habitat and a variety of human needs, such as domestic consumption, industrial activities, crop irrigation, livestock watering, and recreation. Numerous legal and policy requirements have been established to manage water resources for these multiple needs, including the Clean Water Act, the Colorado River Basin Salinity Control Act, and EO 11988 (Floodplain Management).

Water resources are classified as surface water or groundwater. Surface water resources include rivers, streams, lakes, ponds, reservoirs, and wetlands. Major river systems (e.g., Colorado, Columbia, Snake, Missouri, Arkansas, Rio Grande, and Yukon rivers) and their tributaries are important sources of water in the western U.S and Alaska.

The quantity and quality of surface water resources are affected by precipitation, topography, soil type, vegetation, agricultural practices, urbanization, and general land use practices, especially for large tracts of public land. The alteration of vegetative cover from land use practices can have significant impacts on water infiltration, soil erosion, and stream sedimentation.

The largest quantities of useable freshwater occur as groundwater, which provides drinking water for more than $97 \%$ of the rural population without access to public-water supplies, and between 30 and $40 \%$ of the water used for agriculture (Alley et al. 1999). Groundwater is obtained primarily from wells that tap into aquifers. Aquifers are layers of permeable rocks that are recharged with freshwater from precipitation that percolates through the unsaturated zone to the water table, typically in upland, mountainous areas. Recharge rates generally range from a tiny fraction to about one-half of the average annual precipitation. Streams are commonly a significant source of recharge to groundwater downstream from mountain fronts and steep hillslopes in arid and semiarid areas.

As shown on Map 3-5, nine hydrologic regions have been identified in the treatment area: Alaska, Pacific Northwest, California, Upper Colorado, Lower Colorado, Rio Grande, Missouri, Great Basin, and Arkansas-White-Red (Seaber et al. 1987). Most public lands occur in arid to semiarid environments in the Great Basin and Colorado drainage basins.

\section{Alaska Hydrologic Region}

The BLM administers approximately 143,000 miles of riparian habitat and nearly 12.6 million acres of wetlands in Alaska (USDI BLM 2006d). This hydrologic region occupies the entire state of Alaska, and is characterized by an abundance of water resources. Major river systems, such as the Yukon, drain the mountain ranges, and extensive wetlands dot the low-lying plains and coastal regions.

The Yukon and Kuskokwim river drainages are two of the dominant drainages in Alaska. The Yukon River drains an area of more than 330,000 square miles $\left(\mathrm{mi}^{2}\right)$, making it the fourth largest drainage basin in North America. Its mainstem, the Yukon River, originates in northwestern Canada and extends through central Alaska, discharging into the Bering Sea (Brabets et al. 2000). Major tributaries of the Yukon River include the Tanana, Nenana, and Chena rivers.

The Kuskokwim River is the second largest drainage in Alaska. The glacially turbid mainstem is approximately 900 miles long, originating from the interior headwaters of the Kuskokwim Mountains and the shadows of the Alaska Range. The Kuskokwim River flows in a southwest direction to the Bering Sea.

Hydrologic processes are strongly affected by the presence of permafrost, which may thaw seasonally or be continuous throughout the year, particularly in the North Slope. In central Alaska, permafrost is discontinuous, and an active layer at the surface that thaws during the summer months can supply groundwater for domestic use. The valleys of major rivers have alluvial aquifers with an active layer in the summer months that also supply good quality groundwater. During the winter, permafrost generally extends to the surface, impeding water infiltration and groundwater recharge. 


\section{Pacific Northwest Hydrologic Region}

The Pacific Northwest Hydrologic Region includes the wet coastal areas of Oregon and Washington, as well as the semiarid Columbia Plateau in eastern Washington, Oregon, and southern Idaho. The region is drained by the Columbia, Willamette, and Snake River systems, which are important sources of hydroelectric power and irrigation for agriculture.

The coastal areas of Oregon and Washington are influenced by medium to high rainfall levels due to the interaction between marine weather systems and the mountainous nature of the region. Mountains within this area are generally rugged with steep canyons. Tributary streams are short and have steep gradients, creating rapid surface water runoff with relatively shortterm water storage, limiting recharge.

The Columbia River Basin drains approximately $259,000 \mathrm{mi}^{2}$. The basin extends roughly from the crest of the Coast Ranges of Oregon and Washington, east through Idaho, to the Continental Divide in the Rocky Mountains of Montana and Wyoming; and from the headwaters of the Columbia River in Canada to the high desert of northern Nevada and northwestern Utah. Its mainstem, the Columbia River, originates in two lakes that lie between the Continental Divide and the Selkirk Mountain Range in British Columbia. After flowing a circuitous path for approximately 1,200 miles, it joins the Pacific Ocean near Astoria, Oregon.

The Columbia River has 10 major tributaries-the Kootenay, Okanagan, Wenatchee, Spokane, Yakima, Snake, Deschutes, Willamette, Cowlitz, and Lewis rivers.

The Pacific Northwest Hydrologic Region includes a network of coastal streams and rivers. Many are raindriven systems that are hydrologically flashy and influenced primarily by rain storms during the winter. Streams west of the Cascade Range typically discharge directly into the Pacific Ocean.

The southernmost portion of this hydrologic region extends down to the northern portion of the Great Basin. This area is geologically very new and contains extensive areas of lava and other volcanic rock. The rock substrata are very permeable; therefore, streams tend to lose much of their flow through percolation. Only large rivers that lie below the water table contain substantial flows year-round. In most years, abundant precipitation along the western side of the Cascade Range produces abundant surface water flow in streams flowing off the Cascade Range to the Pacific Ocean. Aridity progressively increases and precipitation decreases east of the Cascade Range because of rainshadow effects caused by the mountains.

Timing of precipitation east of the Cascade Range coincides with periods of relatively high solar radiation; thus, precipitation is rapidly evaporated, limiting the amount of surface water available to streams in this portion of the region (Spence et al. 1996). Generally, streams that flow year-round east of the Cascade Range are fed by snowmelt from higher elevations or by groundwater discharge from aquifers recharged during periods of abundant precipitation.

Groundwater is an important resource in this hydrologic region for domestic consumption and irrigation, particularly when surface water supplies are insufficient. It is generally contained in shallow alluvial aquifers along major streams and their valleys.

\section{Califormia Hydrologic Region}

This hydrologic region includes nearly the entire state of California, as well as parts of southern Oregon. The region is characterized by a Mediterranean climate with winter precipitation, and a prolonged summer period with little precipitation.

The California region is drained by rivers such as the Sacramento and San Joaquin. Surface water flow in streams is derived mainly from snowmelt in the mountainous areas during the spring months. During the remainder of the year, many streams have no flow or intermittent flow that follows major storms.

Groundwater in the mountainous areas is relatively deep, and is contained in sedimentary units that continue under the intermountain basins and form a deep reservoir that is seldom tapped because of its depth. Shallow groundwater can be found in sands and gravels that fill the basins between the mountain ranges. This groundwater is fed by infiltration of surface water from streams that flow off the mountain ranges. Groundwater in southeastern California is the main source of water for domestic consumption and agricultural irrigation.

\section{Upper Colorado Hydrologic Region}

This hydrologic region includes the Colorado Plateau, which encompasses parts of southern Wyoming, western Colorado, eastern Utah, and northern Arizona and New Mexico. The upper reaches of the Colorado 
River and its tributaries drain this region. Precipitation varies greatly with elevation, and occurs as winter snows and heavy fall rainstorms.

Perennial surface water flow occurs in major rivers (e.g., the Green River and Colorado River). Major streams are fed by snowmelt in the mountainous areas. Dams serve as flood control, domestic supply, and power generation for the major urban centers, as well as provide surface water for irrigation. Intermittent flow occurs in tributaries to the major rivers, and ephemeral flow occurs in small canyons. Surface water runoff or groundwater baseflow are the major processes that deliver precipitation and snowmelt to streams. In Colorado, the annual hydrograph for most streams is dominated by snowmelt in the mountains; however, there is also a rain component, which varies by region. For instance, in the southwest portion of Colorado, summer monsoonal flow produces ample rain. The larger rivers in Colorado are perennial, but the smaller rivers and streams are either intermittent or ephemeral.

Groundwater is found in most of the sedimentary rocks of the Colorado Plateau, and is the major source of water for domestic and municipal use. Major aquifer systems are not present; groundwater is localized and can be abundant in some areas and absent in others. Farming and ranching are usually limited to stream valleys, where irrigation water comes mostly from surface water. Groundwater baseflow is the major source of water for perennial flows in the late summer and early fall. Seeps and springs are an historic source of water for Native American tribes and a current source of water for smaller ranches.

\section{Lower Colorado Hydrologic Region}

This hydrologic region is comprised of the lower reaches of the Colorado River in the desert southwest of Arizona, New Mexico, and southern Nevada. In this region, public lands are mainly restricted to the arid valleys, while many of the upland areas are administered by the Forest Service. The climate is arid, and precipitation is limited to the winter months and periods of heavy storms. Most precipitation during summer evaporates before it can infiltrate into the desert sands.

Surface water flow in the arid basins of the southwest is ephemeral to non-existent most of the year. Spring snowmelt and periods of heavy rain during the winter result in surface water flow in the mountainous areas and along the mountain fronts in the intervening basins. During the rest of the year, surface water flow is absent except after major storms, where flash floods are common along the mountain fronts. Only major rivers draining the Colorado Plateau or the Mogollon Rim, such as the Gila and Bill Williams rivers, have perennial flow.

Groundwater is found in the alluvium of the basins and in the bedrock of the mountainous areas (i.e., deep reservoirs to depths of many thousands of feet). Groundwater is recharged by precipitation in the mountains and infiltration of stream flow along the base of the mountains. The shallow groundwater reservoirs are used extensively for irrigation and domestic consumption. Irrigation demand and mine dewatering have substantially lowered the water levels in the shallow groundwater reservoirs of the Arizona basins. However, groundwater levels in the basins of southern New Mexico have not been substantially affected by irrigation. Many of the basins have shallow groundwater surfacing in playa lakes.

\section{Rio Grande Hydrologic Region}

This region occupies central New Mexico and western Texas. The Rio Grande and Pecos rivers are major surface water resources that derive their water from the mountainous regions of southern Colorado and flow through New Mexico to the Gulf of Mexico. Surface water flow is present year-round in the Rio Grande and is caused by spring snowmelt and summer monsoon thunderstorms. Agricultural diversions account for approximately $90 \%$ of surface water use and may result in practically no flow during the summer months (Levings et al. 1998).

The Rio Grande aquifer system covers a 70,000- $\mathrm{mi}^{2}$ area of southern Colorado, central New Mexico, and western Texas. It consists of a network of hydrologically interconnected aquifers in basin-fill deposits located along the valleys of the Rio Grande and nearby rivers. These aquifers are generally composed of unconsolidated sediment deposits present in intermountain basins. Groundwater recharge primarily originates as precipitation in the mountainous areas that surround the basins, while most of the precipitation that falls in the valleys is lost to evaporation and transpiration. Potential evaporation may exceed 100 inches per year, while precipitation is frequently less than 8 inches per year (Levings et al. 1998).

Most groundwater withdrawal occurs as discharge from pumping wells, of which about $90 \%$ is used for irrigation of commercial crops. Most cities and 
communities in the area, such as Albuquerque, Las Cruces, and Santa Fe, New Mexico, rely on groundwater for municipal use. Groundwater withdrawals in closed basins have caused long-term water level declines, while withdrawals from wells located near the Rio Grande, or its perennial tributaries, generally do not cause long-term water level declines in the aquifer.

\section{Missouri Hydrologic Region}

This hydrologic region covers the largest geographic area of the nine regions, including much of Montana, Wyoming, northeastern Colorado, North Dakota, South Dakota, and Nebraska. This region represents the eastern front of the Rocky Mountains stretching to the Great Plains, most of which is drained by the Missouri and Platte rivers and their tributaries.

Surface water resources are dominated by the major rivers and their tributaries. Precipitation is generally sparse in the summer and fall months, and surface water flow is generally dependent on snowmelt in the mountainous areas. Rivers flow mainly from late spring to early fall and can be dry in some parts of the region during the winter months. Surface water is directly connected to groundwater through shallow alluvial aquifers that are found along all the major rivers and their tributaries. Groundwater baseflow supplies stream and river flow in the late summer and fall. Surface water is the main source of municipal and irrigation water in the Rocky Mountain region, and irrigation return flow is a major component of surface water flow.

Groundwater in Wyoming and western Montana is found both in the igneous rocks of the uplifts and the basins, although groundwater in the uplifts is generally not used. Groundwater is used extensively for irrigation, much of it becoming irrigation return water that flows into major streams and their tributaries. In addition to irrigation, groundwater is also used for municipal and domestic water supplies. Major aquifers in the Great Plains are the Ogallala Aquifer of eastern Wyoming, Nebraska, and Kansas, and the Dakota Aquifer of North and South Dakota. These aquifers are overdrawn and the water table has been declining for decades. Recharge comes only from stream infiltration and spring snowmelt.

\section{Great Basin Hydrologic Region}

The Great Basin of Nevada and Utah is an arid region located in the rainshadow of the Sierra Nevada Mountains. The Great Basin is characterized by northerly trending mountain ranges and intermountain valleys with closed drainage. Precipitation generally falls as rain and snowfall in the mountains. Streams flowing down from the mountains carry water to the basins, which infiltrates into the alluvial sediments and provides the only substantial recharge to groundwater in the basins. Surface water flow in the basins is derived almost entirely from the mountain streams.

Apart from major rivers (e.g., the Humbolt and Truckee rivers), surface water flow in the basins of Utah and Nevada is intermittent along the mountain fronts and ephemeral in the basins themselves. Surface water flow in the mountainous areas is limited mainly to late spring snowmelt in the higher areas of the ranges. Agricultural diversions of major streams exiting the mountains are common, and major rivers are used extensively for irrigation. Surface water flow in northern Nevada has been affected by groundwater pumping from mining areas into the rivers. The Humboldt River, from Battle Mountain to Winnemucca, Nevada, is dominated by mine discharge.

Groundwater is found in the alluvium of the basins and in the deeper rocks that underlie the alluvial basins. Shallow groundwater in the alluvium of the basins is the main source of water for domestic consumption, irrigation, and power plant cooling. Some areas of the Great Basin, particularly in northern Nevada, have geothermal reservoirs that underlie the shallow groundwater reservoirs. These geothermal waters have been tapped, often inadvertently, by open pit mining and dewatering of areas used for gold mining. The Great Basin contains many of the largest groundwater reservoirs in the United States. These reservoirs are largely untapped at present, but major urban areas like Las Vegas are actively pursuing their development.

\section{Arkansas-White-Red Hydrologic Region}

This hydrologic region occupies the drainage of the Arkansas, Canadian, and Red River basins above the points of the highest backwater effect of the Mississippi River. It includes all of Oklahoma and parts of Colorado, New Mexico, Texas, Kansas, Missouri, and Louisiana. Only a relatively small proportion of public lands are found in this region, primarily concentrated near the headwaters of the Arkansas River in central Colorado and near the headwaters of the Canadian River in northeastern New Mexico.

Surface waters generally originate from precipitation falling in the eastern Rocky Mountains. Precipitation is relatively sparse in the summer and fall months, and 
surface water flow is typically dependent on snowmelt in the mountainous areas. Surface water resources are used extensively for agricultural irrigation.

Groundwater resources, which are extensive in this region, consist primarily of the Ogallala Aquifer and alluvial aquifers associated with the river valleys. The Ogallala Aquifer underlies much of this region, and water withdrawals are used almost exclusively for irrigation (Robson and Banta 1995).

\section{Water Quality}

Water quality is defined in relation to its specified and/or beneficial uses, such as human consumption, irrigation, fisheries, livestock, industry, or recreation. The quality of surface water is determined by interactions with soil, transported solids (organics and sediments), rocks, groundwater, and the atmosphere. The Clean Water Act established the basic structure for regulating discharges of pollutants into the waters of the U.S., and is responsible for setting water quality standards for all contaminants in surface waters. Section 313 of the Clean Water Act requires all federal agencies to comply with state water quality standards "...to the same extent as any nongovernmental entity." Thus, the BLM has a responsibility to fulfill its obligations under the Clean Water Act and Safe Drinking Water Act, to maintain waters that meet or surpass designated beneficial uses, to restore impaired water resources in support of their designated beneficial uses, and to provide water for public consumption and use (USEPA 2003d).

Section 303(d) of the Clean Water Act requires that water bodies violating state water quality standards and failing to protect beneficial uses be identified and placed on a 303(d) list (USEPA 2003d). The delisting of 303 (d) listed streams is a priority of the BLM.

Nonpoint source pollution, the largest source of water quality problems, comes from diffuse or scattered sources rather than from an outlet, such as a pipe that constitutes a point source. Sediment is a nonpoint source of pollution that results from activities such as livestock grazing and timber harvest. Erosion and delivery of eroded soil to streams is the primary nonpoint source pollution problem of concern to the BLM (USDI BLM 1980).

The most important factors affecting water quality are sediments, microbes, pesticides, nutrients, metals, and radionuclides (Nash 1993). Sedimentation and nutrient loading affect surface waters, while agricultural runoff and industrial wastes can also leach into groundwater. Surface water quality is also affected by solar loading and shade producing vegetation that affect water temperature, flow, total suspended solids (TSS), total dissolved solids (TDS), turbidity, changes in dissolved oxygen, salinity, and acidity.

The susceptibility of aquifers to groundwater contamination relates to geology, depth to groundwater, infiltration rates, and solubility of contaminants. Deep aquifers are often too deep to be affected by surface alteration or shallow waste disposal. However, shallow aquifers may be directly affected by surface alternation and by waste and wastewater disposal. Shallow, unconfined aquifers with rapid recharge rates are generally the most vulnerable to contamination because of the rapid infiltration of groundwater from the surface to the water table.

Water quality data for the surface and groundwater resources of the western states are available from the USGS National Water Information System (NWIS) database (USGS 2002b), the USGS National Water Quality Assessment (NAWQA) Program (USGS 2002c), the USEPA's Index of Watershed Indicators (USEPA 1999b), the USEPA's National Water Quality Inventory (USEPA 2000a), the USGS Groundwater Atlas of the United States (USGS 2000), and from state water quality databases. These sources have been used to develop a general assessment of water quality in the hydrologic regions of the western states (including Alaska), where the BLM has substantial land management responsibility. Data from the USEPA's Index of Watershed Indicators characterizes the condition and vulnerability of each of the 2,262 subbasins in the U.S. (Map 3-6). Information on general groundwater quality (based on concentration of TDS) was compiled from the USEPA's National Water Quality Inventory (USEPA 2000a; Map 3-7).

\section{Alaska Hydrologic Region}

Surface and groundwater resources in Alaska are of relatively good quality. The lack of industrial and agricultural development reduces the risk of contamination of water resources. Human activities, such as mining, oil drilling, and waste disposal in small villages contribute to localized surface and groundwater pollution. Oil drilling adds petrochemicals to both surface water and groundwater, and waste disposal adds nitrates and colliform bacteria. Public lands have localized surface water and groundwater contamination from oil drilling. 


\section{Pacific Northwest Hydrologic Region}

Surface water quality has been degraded in the agricultural areas of eastern Washington and Oregon and in southern Idaho by contamination resulting from agricultural and grazing practices. Elevated levels of nitrates, phosphates, and other nutrients are found in these waters. In Montana, agricultural practices in the Bitterroot Valley have added nutrients to surface water. Fish farming has also contributed to elevated nutrient levels in these streams and rivers of Washington. Irrigation return waters in the Snake River Basin are contributing nutrients and pesticides to surface waters (Clark et al. 1998). Herbicide use results in elevated levels of these chemicals in surface waters during the growing season; however, these levels typically decline after the growing season.

Groundwater is generally of good quality for most uses across the Pacific Northwest. Rivers and streams with lower water quality are primarily the result of thermal modifications, pathogens, habitat alteration, and concentrated agricultural activities in areas such as the Willamette Valley and the Columbia Plateau (Wentz et al. 1998; Williamson et al. 1998; USEPA 2000a). Elevated levels of nitrates and pesticides have been detected in the groundwater in the Snake River Basin and the Columbia Plateau.

\section{California Hydrologic Region}

Surface water resources in California show elevated concentrations of TDS from high salinity, particularly in the southern portion of the region. Groundwater and surface water diversions are used for agricultural irrigation in California. Because of the arid nature of the climate, much of this irrigation water evaporates, leading to irrigation return waters that flow back into streams with elevated levels of salt, nutrients, and pesticides. In the agricultural areas of the Central Valley of California (San Joaquin and Sacramento River basins), nutrient loadings to streams and accumulation of pesticides in aquatic organisms and streambed sediments are a problem (Dubrovsky et al. 1998; Domagalski et al. 2000). Nitrate concentrations in streams generally meet USEPA drinking water standards, but at levels that can pose a problem for aquatic life.

Groundwater in southern California has naturally high concentrations of TDS from the presence of evaporite beds in the sedimentary rocks that underlie the desert areas. In agricultural areas, extensive fertilizer use, combined with heavy irrigation to overcome the high evaporation rates, have resulted in elevated concentrations of nitrates in shallow groundwater reservoirs. Pesticides are present in shallow groundwater reservoirs, but at concentrations generally below USEPA drinking water standards. In agricultural areas, groundwater is used for irrigation, leading to substantial declines in shallow groundwater tables and contamination of groundwater resources by agricultural practices. In the desert areas administered by the BLM, groundwater is generally not affected by pesticides. The low recharge rate for groundwater in these areas means that any application of herbicides is unlikely to enter and affect groundwater resources.

\section{Upper Colorado Hydrologic Region}

In this hydrologic region, surface waters generally flow out of the southern Rocky Mountains and work their way to major rivers. Water quality in the southern Rocky Mountains is generally good, except in historic mining areas. As the surface waters pass through the Colorado Plateau country, quality declines due to agricultural practices, evaporation, a change in the nature of the bedrock, and urban wastewater disposal practices (Spahr et al. 2000). Concentrations of nutrients and pesticides increase as the waters pass through this area. Groundwater quality in this region appears to be influenced mainly by the nature of the bedrock. In areas of sedimentary rock, concentrations of TDS, along with radon, uranium, and metals, can be high. Mesozoic rocks in this region may host uranium, selenium, evaporite, and copper deposits. In areas of the Colorado Plateau administered by the BLM, grazing and mining are the main activities, often leading to local groundwater contamination from metals, especially the uranium-rich areas of the Colorado Plateau.

\section{Lower Colorado Hydrologic Region}

High surface water temperatures in this hydrologic region affect water quality. Total dissolved solids concentrations can be elevated, especially along major rivers with extensive agriculture in their river valleys, such as the Salt and Gila rivers of Arizona. Agricultural land use practices and mining have been the major contributors to surface water degradation in this region. Public lands in this region are used mainly for grazing and mining, resulting in localized impacts to surface waters. These impacts include increases in turbidity, sedimentation, salinity, and possible chemical contamination. High erosion rates can be expected wherever there is a large percentage of exposed soil, a very common result of grazing by domestic animals in this region (Bogan et al. 2003). 
Groundwater quality in this region is dependent on the rocks that host the groundwater reservoir. Shallow groundwater reservoirs are mainly in alluvium or Late Tertiary sedimentary beds dominated by lakebeds and evaporites, causing saline groundwater with elevated concentrations of TDS. In mining districts, concentrations of metals are elevated in the groundwater, and in areas of extensive grazing, shallow alluvial groundwater may have elevated concentrations of nitrates and bacteria. Deep groundwater reservoirs are usually contained in carbonate rocks, leading to groundwater of good quality and low concentrations of TDS.

\section{Rio Grande Hydrologic Region}

Elevated levels of TDS associated with agriculture in the Rio Grande River valley can pose a problem for surface water quality. Agricultural practices along the Rio Grande River have also contributed nutrients and pesticides to surface waters (Levings et al. 1998). The upper reaches of the Rio Grande River in Colorado and the tributaries to the Rio Grande River in southern Colorado have shown elevated metal concentrations, primarily due to the Creede, Colorado, mining district.

Most of the groundwater resources utilized in the Rio Grande River basin are used for irrigation and livestock watering, although drinking water is also an important use. Nitrate concentrations may exceed USEPA standards, particularly in agricultural areas such as the San Luis and Rincon valleys. Pesticides have been detected in the groundwater in both agricultural and urban areas, but generally do not exceed USEPA standards. Volatile organic compounds (VOCs) may be present in shallow groundwater in urban areas such as Albuquerque and Santa Fe (Levings et al. 1998).

\section{Missouri Hydrologic Region}

In the high Rocky Mountains of this hydrologic region, surface water has low concentrations of dissolved solids and meets all aquatic and drinking water standards, except in areas of historic mining. As surface water leaves the mountains and enters the plains and valleys surrounding the mountainous area, the water quality changes. In Colorado, agricultural land use practices and urban wastewater disposal degrade the water quality by adding nutrients and pesticides (Dennehy et al. 1998). In Wyoming, dewatering from mining and petroleum extraction has resulted in localized increases in concentrations of dissolved solids and metals in surface waters. Grazing activities in the Great Plains affect surface water quality by contributing sediments and nutrients. Bacterial contamination of surface water by domestic livestock is considered a significant nonpoint source of water pollution (Bohn and Buckhouse 1985, George 1996). Areas of extensive agriculture often have elevated nutrients and pesticides in the surface water. Agricultural practices have contributed nutrients and pesticides to surface waters in basins along major rivers in this region.

Groundwater in this region is generally of good quality and low in TDS, except in areas of historic and presentday mining, where there are elevated concentrations of sulfate and metals in the groundwater. In areas of the Rocky Mountains administered by the BLM, mining is the principal source of groundwater contamination. A secondary source of contamination is the geology of the bedrock, where rocks rich in uranium and radon contribute to groundwater. This is particularly evident in Wyoming and in the South Platte River basin of Colorado (Dennehy et al. 1998). Shallow alluvial groundwater in agricultural areas has elevated concentrations of nutrients and pesticides. Shallow groundwater along the Colorado Front Range and in large urban areas of the Rocky Mountains shows local evidence of contamination by wastewater, petroleum by-products, and nutrients and/or pesticides used on lawns and golf courses. In the Great Plains, groundwater has nitrate concentrations that often exceed the USEPA limit of 10 parts per million (ppm) and also has elevated concentrations of pesticides.

\section{Great Basin Hydrologic Region}

Water quality in the rivers and streams of this hydrologic region has been affected by agricultural land use along the major rivers, urban waste disposal practices, the chemical composition of rocks in the river basins, and past mining activity. Public lands in the Great Basin generally exclude urban and agricultural areas, but include most of the areas of past mining. Agricultural practices have contributed nutrients and pesticides to surface waters in basins along major rivers. Urban areas, such as Reno, Las Vegas, and Salt Lake City, have added nutrients and synthetic organic compounds to surface waters as well. Past mining activity has added metals to surface waters in localized areas throughout the Great Basin. The chemical makeup of near-surface rocks has contributed arsenic, uranium, and radon to surface waters (Bevans et al. 1998).

Groundwater quality in the Great Basin is determined mainly by the chemistry of the rocks that host the groundwater reservoir. Groundwater in reservoirs made of carbonate rocks and sandstones has relatively low 
concentrations of TDS and is of good quality. Groundwater in the central parts of basins with playa lakes, and in areas with evaporite beds, generally has elevated concentrations of salts and TDS. Groundwater in mining areas often has high localized concentrations of mercury, arsenic, and other metals. In areas of extensive agriculture, shallow alluvial aquifers are often contaminated with nitrates and pesticides.

\section{Arkansas-White-Red Hydrologic Region}

Surface water quality is typically moderate in this hydrologic region, and poor in areas with extensive agricultural or livestock production. The upper reaches of the Arkansas River, where most public lands are located, rely primarily on spring snowmelt for recharge and are generally of better water quality than other portions of the region.

Groundwater quality is relatively good in this region. The TDS concentration of water in the aquifers in eastern Colorado and eastern New Mexico is generally less than 500 milligrams per liter $(\mathrm{mg} / \mathrm{L})$, but may exceed $1,000 \mathrm{mg} / \mathrm{L}$ in small areas of Colorado. Concentrations less than $250 \mathrm{mg} / \mathrm{L}$ are found in northeastern Colorado and are the result of relatively high recharge rates in areas of sandy soil that contains few soluble minerals (Robson and Banta 1995).

\section{Wetland and Riparian Areas}

Wetlands are generally defined as areas inundated or saturated by surface water or groundwater at a frequency and duration sufficient to support vegetation that is typically adapted for life in saturated soil. Wetlands include bogs, marshes, shallows, muskegs, wet meadows, estuaries, and riparian areas. According to the 1987 Corps of Engineers Wetland Delineation Manual, an area must exhibit evidence of at least one positive wetland indicator from each of the following parameters to be defined as a wetland (Environmental Laboratory 1987):

- Soills - The substrate is predominately undrained hydric soil, or the soils posses characteristics that are associated with reducing soil conditions;

- Hydrology - The area is inundated either permanently or periodically at a mean water depth of less than 6.6 feet or the soil is saturated to the surface at some time during the growing season of the prevalent vegetation; and

- Vegetation - The land supports predominately hydrophytes. Hydrophytes are macrophytic plants with the ability to grow in water or on a substrate that is at least periodically deficient in oxygen as a result of excessive water content and depleted soil oxygen levels.

The BLM administers approximately 12.8 million acres of wetlands. Of these, approximately 12.6 million acres are found in Alaska (USDI BLM 2006d).

Riparian and wetland areas comprise approximately $9 \%$ of public lands (USDI BLM 2006c). The benefits of these vital areas, however, far exceed their relatively small acreage. The functions of wetland and riparian areas include water purification, stream shading, flood attenuation, shoreline stabilization, groundwater recharge, and habitat for aquatic, semiaquatic, and terrestrial plants and animals (USEPA 2001b).

The BLM has surveyed $89 \%$ of the wetland acreage in the lower 48 states. Only a small fraction of the wetlands in Alaska have been surveyed due to their pristine nature and lack of immediate development pressure. Sixty-seven percent of wetlands in the lower 48 states evaluated were judged to be functioning properly (USDI BLM 2006d). Ninety-eight percent of Alaska wetlands are assumed to be functioning properly. The remaining Alaska wetlands have been placed in the "Unknown" category because some questions have been raised about development impacts.

The BLM defines properly functioning wetlands as those that: 1) support adequate vegetation, landform, or debris to dissipate energies associated with wind action, wave action, and overland flow from adjacent sites, thereby reducing erosion and improving water quality; 2) filter sediment and aid floodplain development; 3) improve floodwater retention and groundwater recharge; 4) develop root masses that stabilize islands and shoreline features against cutting action; 5) restrict water percolation; 6) develop diverse ponding characteristics to provide the habitat and the water depth, duration, and temperature necessary for fish production, waterbird breeding, and other uses; and 7) support greater biodiversity (Prichard et al. 2003). This assessment does not take into consideration the habitat value of the wetland to fish and wildlife.

About $20 \%$ of wetlands are considered to be functional, but at risk, and $2 \%$ are non-functional, in terms of their 
ability to dissipate energy associated with high-flow events (USDI BLM 2006d). Public lands with poorly functioning wetlands tend to be located in the southwestern U.S.

Riparian areas, according to the BLM, are green zones along flowing-water features such as rivers, streams, and creeks (Gebhardt et al. 1990). These areas exclude streams where water flows for only brief periods during storm runoff events (ephemeral streams). The BLM administers approximately 143,000 miles of riparian habitat in the treatment area. Of this, approximately 107,565 miles are found in Alaska (USDI BLM 2006d).

It is estimated by the BLM that $46 \%$ of surveyed riparian areas in the lower 48 states and $100 \%$ of riparian areas in Alaska are properly functioning in terms of having adequate vegetation, landform, or large woody debris present to dissipate stream energy associated with high waterflows (USDI BLM 2006c). Eight percent of riparian areas in the lower 48 states are considered non-functional, and $38 \%$ are functioning but at risk (USDI BLM 2006c). Poorest functioning riparian areas are found in the southwest and Montana, while most riparian areas in Alaska, Colorado, and Utah function properly.

\section{Vegetation}

The composition and distribution of plant communities in the western U.S. have been influenced by many factors, including climate, drought, insects, diseases, wind, domestic livestock grazing, cultivation, browsing by wildlife, and fire (Gruell 1983). Other activities that have a direct and/or indirect effect on plant communities include logging, minerals extraction and reclamation activities, recreational activities, and ROW development including road construction and maintenance. In addition, competition with non-native invasive plant species has resulted in the loss of native plant communities in portions of the western states.

Before European settlement, naturally occurring fire was an important influence on the landscape of the West, and plant communities are adapted to the occasional intense fires that burned over the landscape (Gruell 1983). The exclusion of fire following European settlement has caused significant changes in plant species composition in the western U.S., especially in areas adapted to fire (Swetnam 1990). Where fire-adapted communities previously limited the expansion of juniper, sagebrush, and other less firetolerant species, exclusion of fire has resulted in invasion of these species into the surrounding ecosystems (Gruell 1983). The circumstance has also contributed to accumulation of hazardous fuels.

Vegetation within the treatment area has been classified into 14 subclasses that are consistent with the National Vegetation Classification Standard (Federal Geographic Data Committee 1997; Table 3-4). The subclasses differentiate vegetation on the basis of growth form (tree, shrub, or herb), life history strategy (evergreen or deciduous, annual or perennial), and percent of canopy closure (forest or woodland) or hydrologic influences. The following sections discuss important vegetation subclasses for each ecoregion.

\section{Tundra Ecoregion}

Located at high latitudes in northern and western Alaska, plant communities in the Tundra Ecoregion are adapted to withstand an extremely short growing season, continuous permafrost, and limited rooting depths. Slow-growing dwarf shrubs, grasses and sedges, and cryptogams (lichens) are the dominant vegetation types in this region. Approximately 39 million acres of public lands occur within this ecoregion.

Perennial graminoid communities are found on over 13 million acres (Map 3-8). Along Alaska's coastal regions to the north, west, and southwest, cottongrass-tussock communities are the most widespread plant systems. Cottongrass occurs as the dominant species in extensive patches in flat, poorly drained areas, and is associated with other sedges, dwarf shrubs, lichens, mosses, dwarf birch, Labrador tea, and cinquefoil. Similar plant communities are also found at low elevations in the mountainous North Slope and Alaska Peninsula regions.

Deciduous shrublands (both dwarf and non-dwarf) are found in many of the same areas as perennial graminoid communities, as well as higher elevation alpine areas. Deciduous dwarf-shrubland occurs on over 10 million acres and is characterized by shrubs that are less than 2 feet tall, a reduced stature that is attributable to extremely harsh growing conditions. Characteristic plant species include dwarf birch, willow, blueberry, and Labrador tea and other shrubs. A variety of forbs and graminoids are found in the understory, and lichen species may be an important component. At high elevations in mountainous areas, dwarf Arctic birch, crowberry, and dwarf blueberry are also common. 
Deciduous shrubland species occur on over 6 million acres and are generally the same as those found in deciduous dwarf-shrublands, but are taller because of slightly better growing conditions. Willow, dwarf birch, alder, huckleberry, Labrador tea, and heath species are common. These communities may be successional to forest or woodland, or may be the climax vegetation where frozen and poorly drained permafrost soils limit tree growth. Stunted black spruce and other tree species are occasionally scattered throughout shrub communities.

In areas underlain by permafrost, nearly 3 million acres of sedge-dominated wet meadows, bogs, and wetlands are scattered among the shrublands. Along major rivers and streams, riparian communities composed of alder, willows, and stunted stands of spruce and birch can be found. In shrublands, pure stands of stunted alder shrubs are found in wet drainages, at the head of streams, along river terraces, or on slopes. Some evergreen spruce woodlands, spruce hardwood forests composed of white spruce, paper birch, and alder, and black spruce forests also occur, in low amounts, in the Tundra Ecoregion.

\section{Subarctic Ecoregion}

Located within the central continental region of Alaska, the Subarctic Ecoregion primarily consists of evergreen forests and open lichen woodlands collectively known as the boreal forest, or taiga. The climate in this region is characterized by low precipitation (10 to 20 inches average annual precipitation), extreme ranges of temperature, low humidity, and high evaporation rates. However, as it is a diverse area, large portions of this region are semiarid as well. Approximately 43 million acres of public lands occur in this ecoregion.

Over 20 million acres of evergreen woodlands and mixed evergreen-deciduous woodlands can be found throughout this region. Within the lowland areas of interior central Alaska, evergreen woodlands are often composed of pure stands of black spruce, with an understory of willow, dwarf birch, crowberry, blueberry, lichens, and mosses. Within the mountainous regions of central and south-central Alaska, woodlands are also common, typically supporting a number of boreal tree species: white spruce, black spruce, tamarack, balsam poplar, paper birch, and aspen.

Deciduous shrubland occurs on 10 million acres, predominantly at higher elevations in the mountainous areas of this region. These shrublands are composed of a wide variety of low growing shrubs, herbs, grasses, and sedges, rooted in mosses and lichens. Mountain avens, low growing willows, dwarf birch, Labrador tea, blueberry, green alder, moss campion, and blackish oxytrope are all common species. Along riparian areas, deciduous tree species are prevalent. Paper birch, aspen, and balsam poplar are all found in these deciduous forest riparian communities. Extensive sphagnum bogs occur in old river terraces, ponds, and sloughs. These scattered wetlands are composed of sphagnum and other mosses, sedges, bog rosemary, Labrador tea, rose, birches, willow, bog cranberry, soapberry, and blueberry. About 2 million acres of forested communities also occur in the Subarctic Ecoregion. Mixed evergreen-deciduous forests, supporting many of the same species as woodlands, can be found in mountainous areas between elevations of about 1,000 and 3,000 feet (timberline). Spruce-hardwood forests, eonsisting of white spruce, birch, aspen, and poplar, with an undergrowth of mosses and berries, are common.

\section{Temperate Desert Ecoregion}

The Temperate Desert Ecoregion is composed of arid lands in the rain shadow of the Pacific mountain ranges, including the Great Basin, Columbia Plateau, and Wyoming Basin. Plant communities, which are adapted to pronounced summer drought and cold winters, are composed primarily of xerophytic semidesert shrubs. Approximately 105 million acres of public lands occur in this ecoregion.

Evergreen shrublands in the form of sagebrush communities occur on nearly 74 million acres (Map 3$9)$. These shrublands typically consist of fairly dense to open vegetation, with shrubs that are 2 to 6 feet high and an understory of perennial and annual grasses and forbs (Cronquist et al. 1972). On the drier sites, shrub density is generally high, while on more mesic sites individuals are more robust and widely spaced, with greater coverage of herbaceous species.

In the plains and tablelands of the Columbia River and Snake River plateaus and the Wyoming Basin, representative shrubs in sagebrush communities include big sagebrush, black sagebrush, low sagebrush, Mormon tea, and bitterbrush (Cronquist et al. 1972). Important perennial grasses include bluebunch and western wheatgrass, Sandberg bluegrass, Idaho fescue, and basin wildrye. Medusahead and downy brome are introduced annual grasses that have become abundant in these communities where the native herbaceous 
TABLE 3-4

Vegetation Classification System

\begin{tabular}{|c|c|c|}
\hline Order & Class & Subclass \\
\hline \multirow{6}{*}{ Tree Dominated } & \multirow{3}{*}{ Closed Tree Canopy } & 1. Evergreen Forest \\
\hline & & 2. Deciduous Forest \\
\hline & & 3. Mixed Evergreen-Deciduous Forest \\
\hline & \multirow{3}{*}{ Open Tree Canopy } & 4. Evergreen Woodland \\
\hline & & 5. Deciduous Woodland \\
\hline & & 6. Mixed Evergreen-Deciduous Woodland \\
\hline \multirow{4}{*}{ Shrub Dominated } & \multirow{2}{*}{ Shrubland } & 7. Evergreen Shrubland \\
\hline & & 8. Deciduous Shrubland \\
\hline & \multirow{2}{*}{ Dwarf-Shrubland } & 9. Evergreen Dwarf-Shrubland \\
\hline & & 10. Deciduous Dwarf-Shrubland \\
\hline \multirow{3}{*}{ Herb Dominated } & \multirow{4}{*}{ Herbaceous Vegetation } & 11. Perennial Graminoid \\
\hline & & 12. Annual Graminoid or Forb \\
\hline & & 13. Perennial Forb \\
\hline & & 14. Riparian/Wetland \\
\hline
\end{tabular}

understory has been depleted, particularly in lower precipitation zones. They have an adaptive advantage over seedlings of most existing grass species in their ability to take advantage of limited moisture early, short lifespans, and prolific seed production. Where repeated fire or grazing have removed the native vegetation, these invasives, as well as invasive forbs, will dominate the site, taking advantage of what moisture exists and outcompeting the native vegetation. They then dry out and become fuel, burning very intensely and carrying fire into previously unburned areas, thus repeating and expanding the cycle.

In the Great Basin and northern Colorado Plateau, common shrubs in salt desert shrub communities are shadscale, fourwing saltbush, spiny hopsage, and greasewood. These communities occur from valley bottoms to mid-elevations in areas with shallow water tables and accumulated salts. Understory vegetation is generally sparse, with a large amount of bare soil or desert pavement exposed (MacMahon 1988). Species such as saltgrass, Indian ricegrass, squirreltail, fescues, and James' galleta may be found in this understory layer. Fires are generally absent due to the sparse fuels, and efforts to reestablish native plant communities are complicated by the dry conditions.

In the mountainous regions, sagebrush communities can be found scattered throughout the forested areas, and sagebrush communities dominate the foothills adjacent to the forested habitat. These higher elevation sagebrush communities are dominated by big sagebrush and other shrubs including antelope bitterbrush, mountain mahogany, and snowberry. The herbaceous component of these plant communities often contains Idaho fescue, bluebunch wheatgrass, various needlegrass and bluegrass species, and a variety of forbs.

Pinyon-juniper (evergreen) woodlands occur on nearly 14 million acres. These communities can be found in small areas in central Oregon, and at elevation zones above sagebrush communities throughout the rest of the ecoregion. Young pinyon-juniper trees are easily killed by fire, which historically limited their expansion into sagebrush communities (West and Van Pelt 1987). Stands of pinyon-juniper have established in many locations, and form dense canopies that cause the loss of understory plants. These closed-canopy pinyon-juniper stands generally do not have enough understory shrubs to carry a surface fire, and do not burn until conditions are met to carry a crown fire.

Deciduous shrublands typically occur at similar elevations as sagebrush, on arid, saline soils on nearly 3 million acres. Dropping leaves during times of drought enable plants such as greasewood, hopsage, catclaw acacia, and European smoketree to survive the harsh conditions. Many of these species are fairly tolerant of alkaline and saline conditions, and occur as lesser members of sagebrush and pinyon-juniper communities.

Other vegetation classes include the perennial bunchgrass grasslands of Oregon, Washington, and Idaho (6 million acres), and the evergreen forests that 
occur at elevations above woodlands (over 1 million acres). Dominant tree species in these forests include ponderosa pine and Douglas-fir. In a few areas, mountains are high enough to support subalpine fir and Engelmann spruce.

\section{Subtropical Desert Ecoregion}

The Subtropical Desert Ecoregion occupies southeast California, southern Nevada, Arizona, New Mexico, and western Texas, and includes the Chihuahuan, Sonoran, and Mojave deserts. Vegetation is adapted to dry conditions, and includes numerous xerophytic plants, such as small, hard-leaved or spiny shrubs, cacti, or hard grasses, which are widely spaced and provide little ground cover. Large portions of these hot deserts have no visible plants and are made of shifting sand dunes or nearly sterile salt flats. Approximately 29 million acres of public lands occur in this ecoregion.

Although major fires were not historically common in this region due to the wide spacing between plants and sparse fuels, the invasion of fire-prone species (e.g., red brome, downy brome, and buffelgrass) has shortened the fire interval in some areas, resulting in significant changes in plant communities.

Evergreen shrub communities are prevalent in desert habitats on over 23 million acres of public lands. On the plains of the Sonoran Desert, shrublands of creosote bush and saltbush species cover extensive areas in nearly pure stands. Individual shrubs are typically widely spaced, with large amounts of bare ground in between.

Large plants, such as the treelike saguaro cactus, prickly pear cactus, ocotillo, ereosote bush, and smoke tree often form communities with a near-woodland appearance. They are commonly associated with blue paloverde, bursage, mesquite, desert ironwood, crown of thorns, jojoba, acacia, and many species of cactus, yucca, and agave.

In the Mojave Desert, Joshua tree shrublands are widespread. Other common shrubs in this region include creosotebush, bursage, thornbush, shadscale, all scale, spiny hopsage, and greasewood. The Mojave Desert is especially rich in annual plants, which are abundant during the rainy season in winter and spring (Brown 1982).

Shrublands occurring adjacent to shallow playa lakes and desert washes, and in other moist habitats, have a unique species composition. Greasewood and catclaw acacia, which occur as scattered individuals in many plant communities throughout the ecoregion, often form pure stands in desert washes. Mesquite is another shrub species that may be found growing along washes and watercourses. Shrubs associated with alkaline soils near playas include mesquites, whitethorn acacia, blue paloverde, ironwood, desert willow, and canyon ragweed.

Evergreen shrublands in the Chihuahuan Desert include such species as mesquite, American tarwort, acacia, and creosotebush. Shrubs have recently increased in density in the Chihuahuan Desert, which is thought to have historically existed as open grassland or grassland scattered with shrubs (Buffington and Herbel 1965). Evergreen shrublands grade into grasslands, with the relative abundance of each plant community determined by such factors as fire, grazing, climate change, and seed dissemination (Holechek et al. 1995).

Perennial grasslands occur on nearly 4 million acres in the high plains of southeast Arizona (in the Chihuahuan Desert), where they are best developed on deep, welldrained soils on level sites (Brown 1982). Black grama and tobosagrass grasses are characteristic, along with sideoats grama and hairy grama, bush muhly, vine and curly mesquite, pappusgrass, tanglehead, and threeawn. Shrubs and succulents characteristic of this grassland include yucca, bear grass, agaves, sumac, ocotillo, acacias, mimosas, and cacti.

Deciduous and evergreen woodlands occur in select areas on over 1 million acres, predominantly on higher elevation slopes (pinyon-juniper woodlands) and in eastern New Mexico (oak and mesquite woodlands).

\section{Temperate Steppe Ecoregion}

The Temperate Steppe Ecoregion, which is typified by a semiarid continental climate, includes the Rocky Mountains and the Great Plains. Vegetation communities adapted to this climate include steppe, or shortgrass prairie, and semidesert, as well as the evergreen and deciduous forests and woodlands of the Rocky Mountains. Approximately 19 million acres of public lands occur in this ecoregion.

Perennial grassland communities are widespread in this ecoregion (over 4 million acres), which includes the prairie grasslands of the Great Plains, the Palouse grasslands of Oregon, Washington, and Idaho, and the mountain grasslands of the Rocky Mountains. 
Prairie grasslands, which occur on the broad, flat belt of land that slopes eastward from the foothills of the Rocky Mountains, vary in height in response to precipitation. Dominant grasses in the shortgrass communities are buffalograss and blue grama, which occur with other herbs, as well as some woody species, including mesquite, sagebrush, and yucca.

Mixed grass communities include both warm-season (e.g., blue grama) and cool season species, such as needlegrasses, wheatgrasses, and fescues grass species. Shrubs, including juniper, sagebrush, rabbitbrush, and forbs are also important components of mixed grass communities (Brown 1982).

The Palouse grasslands, or northwest bunchgrass prairies, are dominated by bluebunch wheatgrass, Idaho fescue, Sandberg bluegrass, and rough fescue. Many of the introduced species are Mediterranean annuals that are well adapted to grazing and the predominantly winter precipitation regime.

Perennial mountain grasslands are scattered throughout areas at elevations from 3,000 to over 9,000 feet in the Rocky Mountains, particularly in western Montana. These grasslands are part of the vegetation mosaic created by the highly complex environment of the Rocky Mountains. Important grasses in these communities include bromes, bluegrasses, oatgrasses, sedges, wheatgrasses, fescues, needlegrasses, hairgrasses, reedgrasses, bentgrasses, and junegrass. Forb components vary with site, latitude, and management. Shrubs include several species of sagebrush, rabbitbrush, snakeweed, shrubby cinquefoil, rose, horsebrush, and prickly pear cactus (Mueggler and Stewart 1980).

Evergreen forests occur on over 2 million acres in the mountain regions, with species composition that varies by altitude. Subalpine forests are composed of Engelmann spruce, subalpine fir, and mountain hemlock. Below this zone, Douglas-fir, western white pine, grand fir, western larch, lodgepole pine, and ponderosa pine are common. Lodgepole pine or ponderosa pine forests may occur at the lowest elevations, and often grade into grasslands or evergreen shrubland. Fire is an important component of all of these forests, with the highest natural frequency on the lowest elevation sites. Lodgepole pine is specifically adapted to regenerate after fire.

Deciduous forests may occur along streams and rivers in the eastern portion of this ecoregion. Eastern species such as ash, hackberry, elm, birch, and bur oak may be found. Deciduous forests composed of quaking aspen are prevalent throughout the Rocky Mountains up into Alaska (DeByle and Winokur 1985). Aspen may form extensive pure stands or exist as a minor component of other forest types.

The most common type of shrubland in this ecoregion is sagebrush steppe. Sagebrush-dominated communities occur on the plains and lower mountain slopes on nearly 8 million acres. Chaparral shrublands and pinyonjuniper woodlands ( 2 million acres) are also found in some of the lower elevation arcas on warm, dry sites.

\section{Subtropical Steppe Ecoregion}

The Subtropical Steppe Ecoregion, located in northern Arizona, New Mexico, and Texas, is composed of plateaus and high plains. Because of its altitude, the climate is semiarid, rather than arid. This region is composed primarily of grassland vegetation, with locally found shrubs and woodlands. Pinyon-juniper woodlands are common on the Colorado Plateau. To the east, in New Mexico and Texas, grasslands grade into savanna woodlands or semideserts composed of xerophytic shrubs and trees. Approximately 13 million acres of public lands occur in this ecoregion.

The perennial graminoid communities in this region are composed of xerophytic grasses, with shrubs and low trees growing singly or in clumps, and occupy over 4 million acres. Common grass species include blue and hairy grama, buffalograss, threeawn species, sideoats grama, bluestem, and bristly wolfstail. Shrubs and trees, such as mesquite, oaks, and junipers, often grow in open stands among the grasses. The perennial grasslands grade into evergreen woodlands, with the respective coverage of each vegetation class dependent on the amount and type of disturbance to which a particular area is subjected.

Evergreen woodlands of drought-tolerant juniper and pinyon pines consist of a relatively open canopy on dry sites at mid-elevations on nearly 4 million acres. Plant composition in pinyon-juniper woodlands exhibits wide geographic variation. In the Colorado Plateau and the central and southern Rockies, doubleleaf pinyon replaces singleleaf pinyon and is associated with Rocky Mountain juniper, Utah juniper, and oneseed juniper (Cronquist et al. 1972). In the dry mountains of southern New Mexico and Arizona, alligator juniper, Emory oak, gray oak, and Mexican pinyon dominate (Brown 1982). The understory layer of shrubs, grasses, and forbs in these communities is composed of representatives from 
adjacent sites above and below the woodland zone. Important understory species include big sagebrush, western and bluebunch wheatgrass, blue grama, cliffrose, bitterbrush, Indian ricegrass, mountain mahogany, rubber rabbitbrush, and Mormon tea (Garrison et al. 1977).

It is estimated that small surface fires historically occurred every 10 to 30 years (Leopold 1924), and large stand-replacing fires occurred every 100 to 300 years (Miller and Rose 1999). Fires easily kill young trees and frequent fires maintain the sagebrush-grassland communities (West and Van Pelt 1987). Drought and competition from grasses probably helped slow the invasion of juniper into adjacent shrublands, particularly at lower elevations. Many pinyon-juniper sites may have historically cycled between grass-shrub and pinyon-juniper communities, with fire as the chief driving force (West and Van Pelt 1987).

At higher elevations (up to 7,000 feet), chaparral is a common type of evergreen shrubland on over 4 million acres, with pinyon-juniper and oak-juniper woodlands also occurring. Plant communities consist of dense to moderately open stands of evergreen and sclerophyllous shrubs of relatively uniform height. Most chaparral shrubs are deep-rooted, sprout readily from the root crown, and regenerate quickly after burning (Brown 1982). Shrub live oak is common, and associated with mountain mahogany, yellowleaf silktassel, sumac, hollyleaf buckthorn, pointleaf and Pringle manzanita, desert ceonothus, and other oak species. Grass species may include sideoats grama and hairy grama, cane bluestem, plains lovegrass, threeawn, and bristly wolfstail. Forbs are not particularly abundant, except during a brief period after burns (Brown 1982).

Evergreen forests occur at the highest elevations in this region. Over 7,000 feet, forests of ponderosa pine, Douglas-fir, lodgepole pine, limber pine, and aspen may be found. Engelmann spruce, corkbark fir, limber pine, and bristlecone pine occur in subalpine forests.

\section{Mediterranean Ecoregion}

The Mediterranean Ecoregion occupies most of California (excluding deserts in the southeastern portion of the state) and a portion of southern Oregon. This region supports a distinctive assemblage of hard-leaved evergreen trees and shrubs, commonly known as chaparral, which are adapted to withstand severe summer droughts and frequent fires. Coniferous forests and oak woodlands are also characteristic of the region.
Approximately 6 million acres of public lands occur in this ecoregion.

Evergreen shrubland occurs on over 2 million acres. Along coastal areas a type of chaparral known as maritime chaparral is common. Inland evergreen shrublands are found in the low hills of mountainous regions, often forming a mosaic pattern with deciduous (oak) woodlands, grasslands, or evergreen forests. Important chaparral species include manzanita, wedgeleaf ceanothus, hollyleaf buckthorn, poison oak, chamise, Christmasberry, mountain mahogany, California scrub oak, blue oak, and interior live oak (Holechek et al. 1995). Chaparral shrubs are adapted to recurrent fire, and the ecosystem depends on periodic fires for its persistence. Herbaceous vegetation is generally lacking in chaparral communities, except after fire.

Nearly 1 million acres of deciduous woodlands and evergreen woodlands also occur in foothills throughout California, typically on sites that are more mesic than those occupied by chaparral. Deciduous oak woodlands include stands of Oregon white oak, California black oak, blue oak, valley oak, and various other oaks. On cooler, moister sites in the Coast Ranges, oak woodlands merge with mixed hardwood forests in which tanoak, California laurel, and Pacific madrone are common. Evergreen live oaks are common associates, and conifer species such as Coulter pine, digger pine, Douglas-fir, and grand fir may also be present. Understory vegetation varies by location and may include poison oak, snowberry, serviceberry, blackberry, wild oats, bromes, bluegrass, ryegrass, and needlegrass.

Evergreen woodland communities composed of live oaks occur in moist, frost-free areas such as the coastal hills from San Francisco into southern California, where adequate moisture and mild temperatures allow them to carry out photosynthesis through the winter. Evergreen oak woodlands are composed of species such as canyon live oak, interior live oak, coast live oak, and Engelmann oak. Oak woodlands may exist as open, park-like savannas, occupying a transition zone between grasslands and denser woodlands. Shrubs are generally absent because they cannot compete with trees for moisture on drier sites. Evergreen woodlands also include some endemic tree species such as Monterey cypress, Torrey pine, Monterey pine, and Bishop pine.

In the mountains of California and southern Oregon, evergreen forests are the dominant vegetation type, occupying nearly 2 million acres of public lands. These 
forests are a diverse assemblage of many conifer species, and are adapted to a long, warm growing season, relatively mild winters, and periods of summer drought. Tree species include ponderosa pine, Douglasfir, white fir, sugar pine, incense cedar, Jeffrey pine, California red fir, and giant sequoia (Szaro 1995). At elevations between 6,500 and 9,500 feet, subalpine forests composed of mountain hemlock, California red fir, lodgepole pine, western white pine, and whitebark pine occur.

Evergreen forests also occur along coastal northwestern California as redwood-dominated communities. Other common tree species forests include Douglas-fir, western hemlock, and western red cedar. The understories are dominated by Pacific rhododendron, western azalea, salal, California huckleberry, western swordfern, and redwood sorrel. Pine-cypress forests also occur along the coast, while mixed forests of tanoak, coast live oak, madrone, and Douglas-fir occur further inland.

For the most part, annual and perennial graminoid communities are located in the valleys and plains of the Mediterranean Ecoregion. While it is generally believed that the Central Valley, the largest grassland expanse in California, was historically dominated by perennial grassland communities, other plant communities (e.g., oak woodlands, chaparral, annual grasslands, and desert scrub) may have also been present (Blumler 1992, Hamilton 1997). Large portions of the native vegetation have been replaced by annual grasses, however, as a result of introduced species, fires, and overgrazing by livestock of early Spanish settlers (Sims 1988). Annual grasses include introduced species such as wild oat, slender oat, soft chess, ripgut brome, red brome, and wild barley. Common forbs include redstem filaree, broadstem filaree, turkey mullein, true clovers, and burclover. Perennial grasses, which are found in moist, lightly grazed or relict areas, include Idaho fescue and purple needlegrass (Garrison et al. 1977). With the development of irrigation, the California grassland ecosystem has become intensively utilized for agriculture.

\section{Marine Ecoregion}

The Marine Ecoregion Division occupies the Cascade and Coast Ranges of western Washington and Oregon, and the Coast Mountains of southeastern Alaska, along the Pacific Coast. The mild, rainy climate produces conditions that are hospitable for dense forest communities, which are characteristic of this region.
Approximately 4 million acres of public lands occur in this ecoregion.

In the Cascade and Coast Ranges, complex, multistoried evergreen forests occupy over 1 million acres, with species composition varying by altitude and climate. At lower elevations, Douglas-fir, western red cedar, western hemlock, grand fir, silver fir, Sitka spruce, and Alaska cedar are the dominant tree species. Subalpine forests composed of mountain hemlock, subalpine fir, whitebark pine, and Alaska cedar extend to timberline, which varies from 7,700 to 10,000 feet. In the drier climates of the eastern Cascade Range, forests dominated by ponderosa pine are common. Evergreen forests are often associated with understory plants such as vine maple, huckleberry, elderberry, salal, Oregon grape, twinflower, and western swordfern (Franklin 1988).

The area between the Cascade and Coast ranges is also characterized by dense evergreen forests. Much of the land in this intermountain region once existed as Douglas-fir, western redcedar, and western hemlock forests, but has since been developed for agricultural and urban uses.

Evergreen forests are also the predominant vegetation type found in the Coast Mountains of southeastern Alaska. Forests in this region are restricted to low elevation, coastal rainforests dominated by Sitka spruce and western hemlock. Associated species include Alaska cedar and mountain hemlock.

Along the major river channels, deciduous riparian forests composed of broadleaf trees such as black cottonwood, red alder, willow, and birch are common. In poorly drained areas, wetlands characterized by sphagnum moss, sedges, and willows occur.

Vegetation types with minor coverage in the Marine Ecoregion include Oregon white oak woodlands, which occur as scattered stands at low elevations, and prairics (perennial graminoid communities), which now occur only as remnant patches in the Willamette Valley and Puget Sound lowlands. Both of these community types are being lost as a result of succession by evergreen forests and development.

\section{Noxious Weeds and other Invasive Vegetation}

Invasive plants are undesirable plants that infest land or deplete water resources, and may cause physical and 
economic damage or have other adverse effects on humans. Invasive plants are increasingly recognized as a major threat to ecosystems. Many invasive taxa have transformed both the structure and function of ecosystems by changing nutrient cycling or disturbance regimes (D'Antonio et al. 1999; Rejmanek et al. 2005). The spread of invasive plants threatens the structure and function of many ecosystems worldwide (Higgens et al. 1996; Drake et al. 1989). Certain invasive plant species have the ability to spread over large areas or acutely threaten an ecosystem over its continental range (Hobbs and Humphries 1995). There are estimated to be over 2,000 species of non-native plants in the U.S. (U.S. Congress Office of Technology and Assessment 1993), over 1,000 of which are invasive (Rejmanek et al. 2005). Approximately $10 \%$ of invasive species have profound effects on biodiversity, and clearly demand a major allocation of resources for containment, control, and/or eradication.

Noxious weeds are invasive plants that are designated and regulated by state and federal laws, such as the Federal Noxious Weed Act, because they are detrimental to agriculture, commerce, and/or public health. Noxious weeds are generally non-native invasive plants that have been either accidentally or intentionally introduced.

\section{The Extent of the Problem}

It is estimated that invasive plants already infest well over 100 million acres in the U.S., and they continue to spread at an estimated rate of 3 million acres annually (USDI BLM 1998). Weed infestations are capable of destroying wildlife habitat; reducing opportunities for hunting, fishing, camping and other recreational activities; displacing many threatened and endangered species; reducing plant and animal diversity because of weed monocultures; and costing millions of dollars in treatments and loss of productivity to land owners.

Besides ecological changes, invasive plants can cause impacts to public safety. While the spread of downy brome has increased the frequency and severity of fires, to the detriment of native plants and animals, as well as property and human safety, other species have caused unforeseen disasters as well. In 1936, for example, the town of Bandon, Oregon, was destroyed and 11 citizens killed by a fire propagated by gorse, a highly flammable plant introduced 70 years earlier (Simberloff 1996). This species is still being battled along the Oregon and California coasts.

\section{Traits of Invasive Plants}

Invasive plants and noxious weeds have biological traits that enable them to colonize new areas and successfully compete with native species. While not all invasive species share many of these traits, most species have one or more that allow them to compete successfully. These traits may include deep tap root systems and very little surface foliage (allowing the plants to grow later in the summer than most native rangeland plants); earlier growth and reproduction than most natives; long-lived seeds in a viable seedbank; adaptations for spreading long and short distances; production of many seeds from one plant; long lifespan; ability to delay flowering; ability to reproduce vegetatively; tolerance for a wide range of physical conditions; rapid growth; self pollination; ability to compete intensively for nutrients; and production of toxic compounds that negatively affect neighboring plants (adapted from USDA Forest Service 2005).

Some plant communities and ecosystems are more susceptible to plant invasion than others. Very few invaders are successful in successionally advanced plant communities. Open and disturbed communities are more invaded, while undisturbed forests are less invaded (Rejmanek et al. 2005).

\section{Mechanisms of Invasion}

Invasive plants have been introduced into the U.S. through a variety of pathways. Some non-native species were intentionally introduced for beneficial reasons and later became invasive. Purple loosestrife, which was originally introduced in ballast water dumped from ships coming from Europe, is still sold as an ornamental plant in garden centers in many states. Dalmatian toadflax is another introduced ornamental that can still be found in garden seed mixes. Saltcedar was introduced for erosion control, as was European beachgrass along the West Coast. Many other invasive plants have been introduced unintentionally via air, water, rail, or road transportation pathways. Common methods of introduction include contaminated seed, feed grain, hay, straw, and mulch; movement of contaminated equipment across uncontaminated lands; animal fur and fleece; spreading of gravel, roadfill, and topsoil contaminated with noxious weed seed; and plants and seeds sold through nurseries as ornamentals (USDI BLM 1996).

Once introduced, invasive plants are spread primarily by vehicles, humans, wild horses, livestock, wind, water, and wildlife. Initially, invasive weeds may 
become established in disturbed sites such as trailheads, along roads and trails, firebreaks, landing pads, oil and gas development sites, wildlife and/or livestock concentration areas, and campgrounds, but may also invade relatively undisturbed sites.

The plant invasion process occurs in three phases: introduction, establishment, and spread. Once an introduction occurs, a delay or lag phase often takes place while an invasive plant becomes established. The length of this initial phase varies, but it can last for up to 100 years (Hobbs and Humphries 1995). This phase is followed by a period of rapid growth that continues until the invasive species reaches the bounds of its new range (Figure 3-1; Mack et al. 2000).

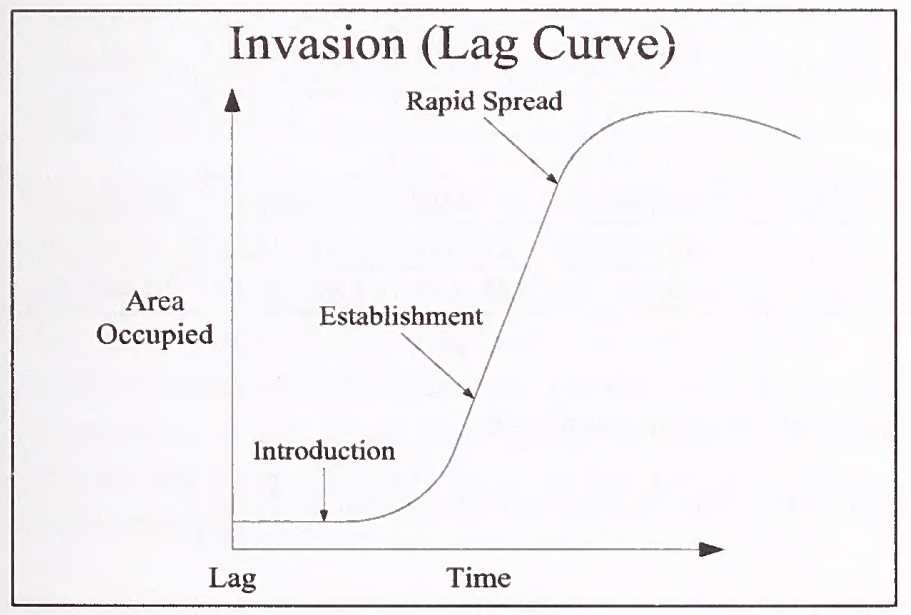

Figure 3-1. Relationship between Area Occupied by Invasive Species and Time.

Understanding this process is critical for making timely and appropriate decisions for managing invasive plants. Preventing the spread of species during the lag phase should be a priority for managers. The establishment phase, while enough residual desired vegetation remains, should be another crucial time for controlling infestations (USDA Forest Service 2005).

Sleeper weeds, a relatively new concept, are invasive plant species with populations that are known to have increased significantly more than 50 years after becoming naturalized (Groves 2006). Common reed, for example, has been identified as a sleeper weed in Quebec, Canada. While the species has been present in Quebec since 1916, it did not spread on a large scale until the 1960 's, most likely after the development of the highway network (Lelong et al 2007). Controlling newly introduced populations of non-native species should help to alleviate the development of sleeper weeds
Maintaining cover of native plant specics on public lands may be critical to halting the spread of noxious weeds. In a 45-ycar study of a sagebrush steppe landscape in Idaho, areas with the highest cover of native species exhibited the greatest resistance to invasion by downy brome (Anderson and Inouye 2001).

\section{BLM Infestations}

In 2006, the BLM estimated that nearly 45 million acres of public lands were infested with weeds (Table 3-5). The estimated rate of weed spread on western public lands in 1996 was 2,300 acres per day (USDI BLM 1996). A recent estimate of weed spread on all western federal lands is $10 \%$ to $15 \%$ annually (Asher and Dewey 2005). The states with the largest weed infestations on public lands are Utah, Nevada, Arizona, and Oregon (Table 3-5). The most dominant invasive plants consist of grasses in the Bromus genus, which represent nearly $70 \%$ of the total infested area. A single species, downy brome, occupies an estimated 10 million acres alone. Another grass, red brome, has invaded portions of the Southwest. Other important weed species that occupy over 100,000 acres include halogeton, common Mediterranean grass, medusahead, houndstongue, leafy spurge, Canada thistle, saltcedar, spotted knapweed, rush skeletonweed, Russian knapweed, diffuse knapweed, yellow star-thistle, and hoary cress.

The BLM treated approximately 50,000 to 320,000 acres of noxious weeds during 1997 through 2006. Treatments included a combination of chemical, mechanical, manual, biological, and cultural controls, and herbicides have been used to create firebreaks in shrublands as well as improve forage for livestock and wildlife. Each year, over half of the treatment acres were in Montana, and over 35,000 treatment acres were in Idaho. In 2005, the BLM inventoried nearly 6.4 million acres for weeds, and evaluated weed treatments on over 278,000 acres of treatment lands (USDI BLM 2006c).

\section{Vegetation Condition and Fire Regimes}

In support of national-level fire planning and ecological assessment, the Fire Regime Condition Class (FRCC) concept was devised. The BLM uses the FRCC concept to describe ecological departure. It is a measure that helps to describe common issues on public lands, such as altered disturbance regimes, invasive species, or highly altered plant communities. Generally, FRCC is 
TABLE 3-5

Estimated Acres of Weed Infestations on Public Lands in 2000

\begin{tabular}{|c|c|c|c|c|c|c|c|c|}
\hline State & $\begin{array}{l}\text { Bromus } \\
\text { species }^{1}\end{array}$ & Halogeton & $\begin{array}{c}\text { Mediter- } \\
\text { ranean } \\
\text { grass }^{2}\end{array}$ & $\begin{array}{c}\text { Medusa } \\
\text { head }\end{array}$ & $\begin{array}{c}\text { Centaurea } \\
\text { spp. }{ }^{3}\end{array}$ & $\begin{array}{l}\text { Hounds- } \\
\text { tongue }\end{array}$ & Other & Total \\
\hline Alaska $^{4}$ & -- & -- & -- & -- & -- & -- & 992 & 992 \\
\hline Arizona & $5,007,000$ & 5,000 & $3,190,600$ & 0 & 150 & 0 & 86,000 & $8,288,637$ \\
\hline California & 517,000 & 4,000 & 243,000 & 261,000 & 35,000 & 0 & 69,000 & $1,129,000$ \\
\hline Colorado & $1,952,000$ & 372,000 & 0 & 0 & 23,000 & 408,000 & 329,000 & $3,084,000$ \\
\hline Idaho & $2,814,000$ & $--^{4}$ & 0 & 15,000 & 214,000 & 500 & 376,000 & $3,419,500$ \\
\hline Montana & 933,018 & 300 & 0 & 0 & 157,726 & 9,580 & 180,929 & $1,281,553$ \\
\hline Nebraska $^{4}$ & -- & -- & -- & -- & -- & -- & -- & - \\
\hline North Dakota & 0 & 0 & 0 & 0 & 0 & 0 & 2,196 & 2,196 \\
\hline New Mexico & 30 & 21 & 0 & 0 & 7,000 & 0 & 41,000 & 48,051 \\
\hline Nevada & $6,564,244^{5}$ & $1,050,000$ & $1,500,000$ & 5,000 & 18,100 & 50 & 120,000 & $9,257,394$ \\
\hline Oklahoma $^{4}$ & -- & -- & -- & -- & -- & -- & -- & - \\
\hline $\begin{array}{l}\text { Oregon and } \\
\text { Washington }\end{array}$ & $5,139,000$ & 151,000 & 0 & 676,000 & 48,000 & 113 & 393,000 & $6,407,113$ \\
\hline South Dakota & 208 & 0 & 0 & 0 & 3 & 66 & 2,111 & 2,388 \\
\hline Texas $^{4}$ & -- & -- & -- & -- & -- & -- & -- & \\
\hline Utah & $6,948,000$ & $3,063,000$ & 94,000 & 25 & 51,000 & 604 & 130,000 & $10,286,629$ \\
\hline Wyoming & $1,395,000$ & 1,500 & 0 & 0 & 47,000 & 27,000 & 188,000 & $1,658,500$ \\
\hline Total & $31,269,500$ & $4,646,821$ & $5,027,600$ & 957,025 & 600,979 & 445,913 & $1,918,228$ & $44,865,953$ \\
\hline \multicolumn{9}{|c|}{$\begin{array}{l}{ }^{1} \text { Includes downy, rigput, Japanese, and red bromes. } \\
{ }^{2} \text { This refers to Schismus barbatus. } \\
{ }^{3} \text { Includes spotted, Russian, diffuse, squarrose, and Tyrol knapweeds and yellow and malta starthistles. } \\
{ }^{4} \text { No data were reported for this state. } \\
{ }^{5} \text { Acres calculated through GIS based on } 10 \% \text { cover estimate derived from remote sensing data sources. Acreage includes } \\
\text { undifferentiated Bromus and other invasive annual grass species. } \\
\text { Source: Peterson (2006). }\end{array}$} \\
\hline
\end{tabular}

one piece of information used to describe the health of public lands.

The first national FRCC assessment was completed in the late 1990s and published in Development of Coarsescale Spatial Data for Wildland Fire and Fuel Management (Coarse Scale; Schmidt et al. 2002). This analysis was used in the Draft PEIS. This assessment excluded public lands in Alaska (86 million acres), as well as 25.5 million acres of agricultural, barren, and urban/developed lands in the lower 48 states. Three condition classes were established to represent qualitative measures describing the degree of departure from historical fire regimes. Departure from historical fire regimes may result from activities, such as fire exclusion, timber harvesting, livestock grazing, introduction and establishment of exotic plant species, introduced insects or disease, and/or other management activities, that alter key ecosystem components such as species composition, structural stage, stand age, canopy closure, and fuel loadings.
While the intent of the Coarse Scale analysis was regional and national characterization, USDI agencies found the analysis to be of limited utility, especially for public lands in the western U.S. The condition classes in the Coarse Scale analysis were assigned based on successional stages for potential natural vegetation groups. Public lands were poorly represented in this effort for two reasons. First, some vegetation types, such as annual grasses or woodlands, could not be discerned in the vegetation classification used (Kuchler's Potential Natural Vegetation Groups; Kuchler 1964). Second, condition class assignments relied heavily on forest canopy cover thresholds, which have limited applicability to the majority of public lands.

Because of these shortfalls, a second national FRCC analysis was conducted as part of the Rapid Assessment Phase of the Landscape Fire and Resource Management Planning Tools Project (LANDFIRE). The Rapid Assessment Phase is intended as an interim product while further refinement of LANDFIRE continues. 
LANDFIRE is a 5-year, multi-partner project producing consistent and comprehensive maps and data describing vegetation, wildland fuel, and fire regimes across the United States. It is a shared project between the wildland fire management programs of the USDA and USDI.

Intended to better represent USDI-administered lands, the Rapid Assessment Phase mapped FRCC based on potential natural vegetation groups (historic vegetation), S-class (current seral stages), and historic fire regimes of the coterminous United States. Despite some localized inaccuracies, the Rapid Assessment Phase layer is the most accurate FRCC summary map for lands managed by the BLM, to date. Like the first national FRCC assessment, the second national FRCC assessment also excluded lands in Alaska as well as agricultural, barren, and urban/undeveloped lands in the lower 48 states.

The Rapid Assessment Phase is primarily intended for use at the national, regional, or state level, but not the local level. As a result, the Rapid Assessment Phase, like the Coarse Scale Analysis, is not intended to portray district or field office site conditions. FRCC can be assessed at the local level using a variety of tools (besides the national map), such as the FRCC software or GIS mapping tools.

For this Final PEIS, departures from historical fire regimes are based on the Rapid Assessment Phase analysis, and have been grouped into three classes, as shown on Map 3-10. Condition Class 1 lands (27.2 million acres of public lands; acres are approximate as federal agencies are updating and refining acreage estimates) are characterized by fire regimes that are within their historical range of vegetation variability characteristics, fuel composition, and fire frequency, severity, and pattern. Fire behavior, effects, and other associated disturbances are comparable to those that took place prior to management practices that do not mimic the normal fire regime. The structure and composition of vegetation and fuels are similar to the historical regime, and the risk of losing key ecosystem components to fire is low. These areas can generally be maintained within the historical fire regime with treatments such as prescribed fire. Wildland fire use for resource benefit may also be used to maintain these areas.

Condition Class 2 lands ( 79.5 million acres) have fire regimes that have been moderately altered from their historical conditions. They experience either an increased or decreased fire frequency of one or more return intervals, resulting in changes to fire size, intensity, and severity, and/or landscape patterns. Vegetation composition and structure and fuels have been moderately altered from their historical range, and have a moderate risk of losing key ecosystem components due to fire or other causes. These lands may need moderate levels of restoration treatments, such as prescribed fire and hand or mechanical treatments, to be restored to the historical fire regime.

Condition Class 3 lands (54.7 million acres) have fire regimes that have a high departure from the historical condition, and the associated risk of losing key ecosystem components to fire or other causes is high. Vegetation composition, structure, and diversity, as well as fuels, have been significantly altered from their historical range. Due to these alterations, Condition Class 3 areas are especially susceptible to severe and intense wildland fires. These areas often require high levels of restoration treatments, such as hand or mechanical treatments, before prescribed fire can be used to restore the historical fire regime (Schmidt et al. 2002). Almost 41\% (21.2 million acres) of the Class 3 lands occur in the Temperate Desert Ecoregion. 15.5 million acres occur in the Subtropical Desert Ecoregion, 8.2 million acres occur in the Temperate Steppe Ecoregion, and 5.4 million acres occur in the Subtropical Steppe Ecoregion. An additional 1.5 million acres of Class 3 lands occur in evergreen forests of the Mediterranean Ecoregion.

A comparison by acreage shows that the acreage of FRCC Condition Class 3 lands increased substantially between the Coarse Scale and Rapid Assessment Phase analysis. The Rapid Assessment Phase analysis further supports the need for treatment of large numbers of acres in the West to improve condition class.

Further information and methods can be found at the FRCC website and in the Interagency FRCC Guidebook (www.frcc.gov).

\section{Non-timber Forest Products}

Non-timber forest products include all plant materials other than timber that are extracted from forests for human use (National Network of Forest Practitioners 2005). They consist of medicinal plants (e.g., ginseng, goldenseal), wild foods (e.g., mushrooms, berries, roots, syrups), decoratives and floral greens (e.g., salal, ferns, boughs), flavors and fragrances (e.g., sassafras, balsam fir), fibers (e.g., cedar bark, sweet grass, lichens), wild native seeds and transplants for restoration and nursery 
stock, plant dyes, arts and crafts materials, and resins and saps. These forest products are harvested for a variety of reasons, including subsistence, cultural, spiritual, commercial, recreational, and educational purposes.

Native American tribes and Alaska Natives traditionally used forest products for tools, food, construction materials, medicine, and religious ceremonies. Forest products used included bark for housing, branches and stems for utensils and tools, and wood for containers (Chamberlain et al. 1998). Much of the knowledge gained from Native American tribes and Alaska Native groups has influenced the development of the U.S. herbal medicinal industry. A discussion of Native American and Alaska Native plant uses is provided in the Cultural Resources section of this chapter, and in Appendix D of the PER.

During FY 2005, approximately $\$ 194,000$ worth of non-timber forest products was sold by the BLM. The actual value of non-timber forest products harvested on public lands is substantially greater (USDI BLM $2006 \mathrm{c}$ ). Over $40 \%$ of non-timber forest product sales on public lands were in western Oregon, and about $13 \%$ were in Nevada. Other important states for non-timber forest product sales are Colorado and Utah.

\section{Special Status Species}

There are over 150 plant species occurring on or near public lands in the treatment area that are federallylisted as threatened or endangered, or proposed for listing. The number may change over time depending on future evaluations of each species' status. BLM policy states that BLM actions must not adversely impact special status species, which include species that are listed under the ESA, given some form of special designation to denote rarity by the state, or are listed as sensitive by the BLM. Special status species, other than those already listed under the ESA, are in potential danger of becoming listed under the ESA. Special status plant species are distributed throughout the western U.S., including Alaska. A list of these species can be found in Appendix J.

For this PEIS, the BLM has consulted with the USFWS and NMFS since 2001 on listed species and species proposed for listing, and their critical habitats, that could be affected by the proposed treatments. As part of the consultation process, the BLM prepared a Vegetation Treatments on Bureau of Land Management Lands in 17 Western States Programmatic Biological
Assessment, which provides a description of the distribution, life history, and current threats for each species (USDI BLM 2007a). Information contained in the BA will be used as a guideline by BLM field offices when developing local projects.

\section{Fish and Other Aquatic Organisms}

The BLM administers lands directly affecting almost 155,000 miles of fish-bearing streams and 4 million acres of reservoirs and natural lakes (USDI BLM $2006 \mathrm{~d}$ ). These habitats range from isolated desert springs of the Southwest to large interior rivers and their numerous tributaries.

For this section, the eight geographic regions that were used to describe water resources in the treatment area are used to describe associated aquatic organisms and their habitats (Map 3-5). Key fish species have been identified for each region. These species are ecologically representative of the region(s), use major habitat types within the region, and strongly influence the aquatic community structure. As a result of species distributions and ecological similarities between regions, some key species may occur in more than one geographic region.

\section{Alaska and the Pacific Northwest}

The most significant group of native fishes found in Alaska and the Pacific Northwest, in terms of their ecological, cultural, and commercial importance, is the salmonid family. All members of this group, which include salmon, trout, char, and whitefish, require relatively pristine, cold freshwater habitats during part or all of their life cycles, and as such, depend greatly on the conditions of the surrounding forests and rangelands to ensure their survival (Meehan 1991).

Most salmonids use large stream and river systems with direct ocean access. In Alaska, significant streams within public lands include the Colville River and Yukon River systems. The most significant system in Pacific Northwest is the Columbia River Basin. With its headwaters in British Columbia, the Columbia River extends over 1,200 miles to the Pacific Ocean.

Salmonid productivity within a freshwater system is dependent on the underlying stream productivity and the period of use by salmonids during their life cycle. Five general factors determine the suitability of aquatic 
habitat for salmonids: flow regime, water quality, habitat structure, food (energy) source, and biotic interactions. All salmonids require suitable habitat for spawning, incubation, and rearing. Generally, adult salmon require spawning gravel (less than 2 inches in diameter) and overhead streambank or vegetative cover from predation, while eggs and newly hatched salmon (alevins) require stable gravel and cool (less than $57^{\circ} \mathrm{F}$ ) and highly oxygenated water (Meehan 1991). Bull trout, which tend to spend most, if not all of their life in inland waters, require water less than $42^{\circ} \mathrm{F}$ for spawning and rearing of newly hatched young. Because salmonids prefer cold water, temperatures above $77^{\circ} \mathrm{F}$ are lethal to most species in this family (Meehan and Bjornn 1991).

Migrant salmonids pass through several distinct habitats while traveling to and from feeding or breeding habitats, utilizing the full extent of the watershed. The importance of each habitat type differs by species. Chinook salmon, for example, spawn in the mainstem of a river. Upon emerging from the gravel, individuals either start their migration to the sea within their first year (ocean-type) or mature within rivers for 2 to 3 years before migrating to sea (stream-type). In contrast, resident trout populations, such as rainbow, bull, and cutthroat trout, may spend their life (5 to 6 years) in various freshwater systems, including small streams or lakes, and do not migrate to the sea (Meehan and Bjornn 1991).

Various fish species have been introduced into aquatic systems throughout Alaska and the Pacific Northwest. Most of the non-native species have been introduced to promote sportfishing opportunities. Some have escaped from fish farms. Introduced salmonids (such as brook, brown, lake, and hatchery-raised rainbow trout), centrarchids (such as bass and sunfish), and percids (such as walleye) now support many, if not most, of the non-native sport fishing opportunities within these regions (Mills 1994).

A variety of aquatic invertebrates occur in Northwest and Alaskan streams. These species can be quite susceptible to instream activity (e.g., removal of large woody debris), or disturbances in riparian zones. The diversity of aquatic insects is naturally low in glacierfed streams. Streams flowing through conifer forest, however, support a diverse aquatic invertebrate fauna, including many mayflies, stoneflies, and caddisflies (Whittier et al. 1988). The diversity of freshwater mollusks is also usually highest in montane, spring-fed streams and pools (Forest Ecosystem Management Assessment Team 1993).

\section{The Arid Environment}

In arid regions, hydrologic inputs that drive aquatic systems come in pulses of short duration. Although rain may trigger biological processes, such as reproduction, after long dry periods, a severe rainfall that creates flash flooding can exert considerable pressure on fish species and community structure (Naiman 1981). The natural hydrology of southwestern desert rivers and streams is highly variable and episodic (Rinne and Stefferud 1997). Natural flow regimes have been considered optimum for sustaining native fish populations (Poff et al. 1997). Although many streams of the U.S. deserts have been highly modified, reducing the impacts of flash floods on fish communities, these sudden rain inputs may still be detrimental. Carrying heavy silt, flash floods may remove or destroy habitat features such as shoreline vegetation, leaving fish species susceptible to rising water temperatures (Naiman 1981).

Because there is limited hydrological connection among water bodies within the desert, fish distribution is also limited. Some streams continually flow through the humid desert regions, terminating in closed lakes or dissipating in the sand, while other streams originate from subterranean sources, emerging as springs. Springs occur throughout the desert ecosystem, ranging from quiet pools or trickles to active aquifers. Many larger springs emit warm water, with temperatures above the mean annual air temperature, and range from fresh to highly mineralized, carrying large amounts of dissolved materials or extremely low dissolved oxygen levels (Naiman 1981). Although each spring or pool is species-poor, most aquatic inhabitants of each pool are short-lived (1-2 years) and native to only a single locality (Naiman 1981, Page and Burr 1991).

Aquatic species have been introduced into this ecosystem, either on purpose or accidentally, changing the ecological balance to favor many of the non-native species. Invasive fish reduce numbers of native species through competition, hybridization, predation, and the spread of pathogens to which they have developed resistance in their home waters, but to which native species have not (Rinne 1995, 2003). Overall, nonnative fish species now outnumber natives in number of species, population density, and often biomass at many localities (Platania and Bestgen 1988; Griffith and Tiersch 1989; Douglas et al. 1994).

Large reservoirs and diversions have been constructed on various rivers and streams, at least partially to deliver irrigation water for agricultural purposes. Additionally, 
domestic livestock grazing has impacted some rangelands, and historical grazing pressures in riparian areas have reduced the function of some aquatic habitats.

\section{Lower Colorado River and the Rio Grande}

These regions cover portions of Nevada, Arizona, New Mexico, and Texas. Grasses and shrubs cover large expanses of the southwest region. This vegetation helps to reduce runoff and erosion during the rainy season. During the dry seasons, dormant vegetation and vegetative litter serve a similar function and are critical for the overall health of these rangeland systems. Livestock grazing in the region has reduced the quality of plant communities, resulting in increased runoff into streams during heavy rainfall, and localized lowering of water tables (Naiman 1981, Rinne and Minckley 1991). These impacts, combined with upper basin modifications, including dams, have impacted fish habitat throughout the lower Colorado and Rio Grande rivers.

The Colorado River, which was once a warm, silted, swift river, is now a cold, clear series of artificial impoundments. These impoundments are a significant threat to desert waterways, and in some instances can end a stream's existence, as has occurred in the lower reaches of the Salt and Gila rivers in Arizona (Cole 1981). The Glen Canyon Dam on the Colorado River, upstream of Lee's Ferry, eliminated the seasonal variation in the river's discharge, ionic composition, temperature, and sediment load in the gorge of the Grand Canyon. The impoundment has altered both the flow of the river and the river's potential for fish habitat downstream. As a consequence, most native fish populations in the Colorado River Basin have declined substantially throughout much of the species' ranges.

The Family Cyprinidae is the most dominant native fish group within the lower basin region, followed by the Family Catostomidae. The Cyprinidae family is composed mainly of minnow species, including the threatened Colorado pikeminnow and bonytail chub, while the Catostomidae family includes the threatened razorback sucker (Starnes 1995). Impoundments have had the greatest impacts on these fish communities (Minckley and Deacon 1991).

Bonytail chubs were historically common, migrating throughout the mainstem of the Colorado River and many of its tributaries, including the Green, Gunnison, Yampa, and Gila rivers, before the construction of large dams (Kaeding et al. 1986). Although bonytails continue to be found in low numbers in several manmade lakes, including Lake Mohave, the temperature and physical and chemical composition of these lakes is very different from those in which the fish evolved (Minckley 1973, Minckley and Deacon 1991).

The headwaters of the Rio Grande River originate in the Rocky Mountains of southwestern Colorado and the river meanders approximately 1,900 miles across Colorado, New Mexico, and Texas before terminating at the Gulf of Mexico (Water in the West 2002). Public lands within the Rio Grande region are limited to the upper and middle reaches of this drainage. Most precipitation in the basin falls as snow near its headwaters or as rain near its mouth, while little water is contributed to the system along the middle reaches of this river, particularly within the Chihuahuan Desert.

Historically, riparian woodlands in the Rio Grande River Valley were a mosaic of various-aged stands dominated by cottonwood and willow (Cassell 1998). However, conversion of much of this land to residential and agricultural uses has modified this floodplain area, significantly reducing the quantity and quality of wetland and riparian habitat (Cassell 1998; Levings et al. 1998). These changes, combined with instream modifications, have reduced fish habitat considerably throughout the region.

Prior to the construction of dams like the Cochiti Dam, the Rio Grande River had characteristics similar to the Colorado River, and was considered a swift, warm, muddy river (Scurlock 1998). The settling effects of dam reservoirs have resulted in slower, clearer, colder water. This modification of water quality has had a debilitating effect on the range of the Rio Grande silvery minnow, a species that once extended from Española, New Mexico, in the Rio Grande River Valley to the Gulf of Mexico; and in the Pescos River from Santa Rosa, New Mexico, to the confluence with the Rio Grande River in south Texas (Federal Register 1994). Currently, it is found only in a 170-mile reach of the middle Rio Grande River in New Mexico. Much of its decline may be attributed to modification of stream habitat by impoundments, water diversion for agriculture, and stream channelization.

Many non-native fish species have adapted well to the instream modifications to the Lower Colorado and Rio Grande rivers (Maddux et al. 1993; Douglas et al. 1994). Usually more aggressive than native fish and able to outcompete them for resources, these non-native species include walleye, bass (large and smallmouth), 
and rainbow, brook, and brown trout (Douglas et al. 1994).

\section{Great Basin}

The Great Basin covers an arid expanse of approximately $190,000 \mathrm{mi}^{2}$ and is bordered by the Sierra Nevada Range on the west, the Rocky Mountains on the east, the Columbia Plateau on the north, and the Mojave and Sonoran deserts on the south. The Great Basin is the area of internal drainage between the Rocky Mountains and the Sierra Nevada Range. Streams in this area never reach the ocean, but are instead confined, draining to the base of the basin, and typically resulting in terminal lakes, such as Mono Lake and the Great Salt Lake, marshes, or sinks that are warm and saline (Moyle 1976).

Many Great Basin fish are adapted to extreme conditions. Trout are predominantly found in lakes and streams at higher elevations within the basin (Behnke 1992). Bonneville cutthroat trout have persisted in the isolated, cool mountain streams of the eastern Great Basin, while Lahontan cutthroat trout populations occupy small, isolated habitats throughout the basin. These trout species are unusually tolerant of both high temperatures $\left(>80{ }^{\circ} \mathrm{F}\right)$ and large daily fluctuations in temperature (up to $68^{\circ} \mathrm{F}$ ). They are also quite tolerant of high alkalinity $(>3,000 \mathrm{mg} / \mathrm{L})$ and dissolved solids (>10,000 mg/L; Behnke 1992).

Water diversions, subsistence harvest, and stocking with non-native fish (particularly rainbow trout) have caused the extirpation of the Bonneville cutthroat trout from most of its range. Although Lahontan cutthroat trout were once common in desert lakes, including Pyramid, Walker, Summit, and Independence lakes, and large rivers, such as the Humboldt, Truckee, and Walker rivers, they have declined in numbers overall, disappearing in many areas (Hudson et al. 2000).

The decline of Lahontan cutthroat trout abundance is a result of habitat loss, interbreeding with introduced rainbow trout, and competition with other species of trout; these factors continue to be the primary threats to the species (Coffin and Cowan 1995, Dunham 1998).

Minnows and pupfish are the dominant fish species at lower elevations and are found in thermal artesian springs and streams (Cole 1981, Feldmeth 1981). Various native and non-native minnows (e.g., dace, chubs, shiners), are common throughout streams and lakes of the basin. Pupfish, however, are very site- specific and live, by choice, at the extreme upper limit of their zone of thermal tolerance (Feldmeth 1981).

Pupfish are able to survive extreme environmental conditions, tolerating water temperatures as high as 115 ${ }^{\circ} \mathrm{F}$, salinity as high as 142 parts per thousand (ppt; ocean water is typically $33 \mathrm{ppt}$ ), and oxygen concentrations as low as $0.13 \mathrm{mg} / \mathrm{L}$ (Page and Burr 1991). Because of the high water temperatures, pupfish have developed behavioral traits to regulate body temperature. They have been observed migrating to shallow pools in the morning and remaining there throughout the day, returning to deep water at night. While some pupfish populations are isolated in extremely variable environments (i.e., rapidly fluctuating water levels and temperature gradients), others are isolated in stable springs with constant temperatures (Biological Resource Research Center 2001, NatureServe Explorer 2001).

The most significant problem facing desert fish are the limited water supply. Desert fishes have a tenuous hold on survival under natural conditions, occurring only in the few permanent springs, rivers, and lakes, and their existence has been placed in doubt by human activities (Deacon and Williams 1991). Pumping groundwater for agriculture has threatened several pupfish populations, including the Devil's Hole pupfish (Deacon and Williams 1991).

Aquatic invertebrates are probably diverse within the Great Basin region, though relatively little is known about them (Hershler and Pratt 1990). Streams flowing within mountainous forest region support diverse aquatic invertebrate fauna including mayflies, stoneflies, and caddisflies. Small springs contain diverse molluscan fauna (Hershler and Sada 1987). Spring biotic communities are usually less diverse than stream communities, and springs are often habitat for endemic species because they are predictable, benign habitats that have served as refugia during dry periods.

\section{The Upper Colorado River Basin}

The Colorado River is the primary river of the southwestern U.S., draining approximately $242,000 \mathrm{mi}^{2}$ from portions of Wyoming, Colorado, Utah, New Mexico, Arizona, Nevada, and California. The headwaters of the Colorado River are located in Rocky Mountain National Park in Colorado, from which the river flows southwest, toward the Gulf of California.

The Colorado River Basin is divided into two basins, the Lower and Upper basins, with a dividing line near Lee's Ferry, Arizona. Three distinct aquatic zones have 
been identified in the Upper Colorado Basin (Joseph et al. 1977). The upper (headwater) zone is characterized by cold and clear water, a high gradient, and a rocky or gravel substrate. Resident salmonid populations are predominant in this zone. An intermediate zone occurs as the stream flows out of the upper zone. Within the intermediate zone, water discharge rates and temperature increase, and water is turbid during spring runoff and after heavy rainfall. The substrate is generally rocky with occasional expanses of sand. The lower (large-river) zone has warm water, meandering sections, and a low gradient in flat terrain. Minnows and suckers are the dominant fish communities of the intermediate and lower zones.

The construction of reservoirs, such as Fontenelle and Flaming Gorge, has had profound effects on water flow and quality throughout the upper basin region; lower summer water temperatures have resulted, and spawning of native fish has virtually ceased (Carlson and Carlson 1982, Wullschleger 2000). The humpback chub, for example, prefers deep, fast-moving, turbid waters often associated with canyon-bound segments of the rivers (Valdez and Clemmer 1982). Historically, this species occurred in great numbers throughout the Colorado River system from the Green River in Wyoming to the Gulf of California in Mexico. Today, due to lower water temperature and migration routes blocked by dams, this species can only be found in limited deep, canyon-bound portions of the Colorado River (Douglas and Marsh 1996).

Native salmonids in the upper zone of the Upper Colorado River Basin are disappearing with the introduction of rainbow, brook, and cutthroat trout for sport fishing (Miller et al. 1982). The habitat immediately downstream of constructed reservoirs favors these non-native salmonids (Platania 2003). In addition, non-native species effectively outcompete native species for available resources, and interbreed with native species (Joseph et al. 1977; Rinne and Minckley 1991). Populations of native species within lakes are also declining as a result of competition with and predation by, introduced non-native species, such as carp, northern pike, and red shiner (Rinne and Minckley 1991).

\section{California}

California has two distinct fish habitat regions: northern and southern California. The northern region extends from the Oregon border south to Sacramento (the most southern reaches of salmon distribution in North
America). This region includes rain-fed coastal streams, snow-fed streams of western Sierra Nevada, and the Central and San Joaquin valleys. Habitat characteristics are very similar to those observed in the western Pacific Northwest, with a dominance of evergreen forests throughout the area. Streams in the coastal region usually have steep drainages and are characterized by extreme seasonal flow, flooding in the winter and becoming intermittent in summer (Moyle 1976). Water flow in snow-fed streams is more constant than in coastal streams, a condition to which native fish are adapted.

Fish habitats within southern California are located predominantly within the arid southeast region of the state, and include numerous rivers and lakes. Native fish communities, such as those comprised of pupfish and minnows in the lower elevations and cutthroat trout in the mountainous regions, and their aquatic habitats, exhibit characteristics similar to those seen in the Lower Colorado and Great Basin regions.

\section{Missouri River Basin}

The Missouri River Basin encompasses 529,350 $\mathrm{mi}^{2}$ and flows for over 2,340 miles, from its headwaters at the confluence of the Gallatin, Madison, and Jefferson rivers in the Rocky Mountains at Three Forks, Montana, to its confluence with the Mississippi River at St. Louis, Missouri.

The Missouri River historically carried a heavy silt load, collected from tributaries in the northern part of its drainage. Its wide and diverging channel created shifting sandy islands, spits, and pools, resulting in fish species suited to its turbid and dynamic conditions. Many of the fish species within the upper reaches of the Missouri River are considered benthic fishes, such as sturgeon and minnows (Duffy et al. 1996; Scarnecchia et al. 2002).

Public lands in Montana occur predominantly in the northeastern portion of the state. The surrounding habitat, referred to as the Milk River Basin, has relatively high densities of depressional wetlands dominated by shortgrass prairies. The upper reaches of the Missouri River and its major tributaries maintain the healthiest fish populations in the basin (White and Bramblett 1993). However, dams built along the mainstem of the Missouri River, such as the Fort Peck Dam in Montana, have limited fish migration patterns and water flow, as well as the movement of silt downstream, resulting in declining fish numbers and 
reduced quality spawning and rearing habitat (Hesse et al. 1989). This combination of habitat loss and poor dam management has contributed to the decline of many native mainstem species including paddlefish, sturgeon, and several species of chub.

Native species such as the sicklefin chub, sturgeon chub, and pallid sturgeon prefer silty rivers with a diversity of depths and velocities forming braided channels, sand bars, sand flats, and gravel bars, all of which were historically common along the Missouri River (Gilbraith et al. 1998; Scarnecchia et al. 2002). All three species have been affected by changes in the Missouri River. Although the chub species have managed to effectively reproduce where habitat conditions allow, the pallid sturgeon has been unable to adapt well to the present river conditions, resulting in a significant decline in its abundance (Duffy et al. 1996). The endangered pallid sturgeon, a bottom feeder, may become extinct, as changes in water flows continue to affect food sources, spawning habitat, and the timing of reproduction (USFWS 1990).

Introduced species, such as rainbow trout, have been stocked throughout Montana. Rainbow trout have adapted well to the wide range of habitats available within the basin. The species has successfully integrated into this aquatic system, and has caused a severe reduction in the range of native cutthroat trout through hybridization and competition (Walleyes Unlimited 2002). Other introduced species that have adapted well to the modifications of the Missouri River drainage in Montana include smallmouth bass, walleye, and white crappie.

The Missouri River drainage includes all of Wyoming east of the Continental Divide, and represents $74 \%$ of the state's surface area. Typically, streams along the southern boundary of Wyoming originate from the mountainous region of northern Colorado and are characterized by high gradients, cobble and boulder substrates, and riparian areas dominated by conifers and willows. This area of Wyoming drains into the North Platte River drainage, comprising $24 \%$ of the surface area of Wyoming. Native and introduced salmonids such as rainbow, brook, and cutthroat trout dominate fish communities within this region.

As streams flow onto the arid, desert plains, they are characterized by low gradients, meandering or braided channels, and silt, sand, and gravel substrates, with riparian areas dominated by cottonwoods, willows, shrubs, and grasses. Central and northern Wyoming are considered high cold desert. Native and non-native minnows and suckers dominatc fish communities.

\section{Special Status Species}

There are over 100 aquatic animal species occurring on or near public lands that are federally listed as threatened or endangered, or are proposed for future listing. Included in the total number are 59 species/subspecies of fish, 13 species of mollusk, and 6 aquatic arthropods. A complete list of these special status species may be found in Appendix J. Please note that this list is dynamic, and will likely change throughout the time period considered by this PEIS.

Special status aquatic animal species are found on public lands throughout the United States. A number of listed salmon populations are found in rivers of the Pacific Coast states. In arid habitats, many special status fish species are found in the rare and fragile desert wetlands and springs, as well as in the major rivers such as the Colorado and the Rio Grande. In the deserts of the Great Basin and Colorado Plateau, terminal lakes, marshes, and sinks provide important habitats for special status fish species that are adapted to their warm, saline conditions.

Special status mollusks occur predominantly in the Snake River of Idaho, and in thermal habitats and small springs and wetlands in New Mexico, Arizona, and Utah. Aquatic arthropods of special concern occur predominantly in the vernal pools of California.

\section{Wildlife Resources}

Public lands sustain an abundance and diversity of wildlife and wildlife habitat. Public lands provide a permanent or seasonal home for more than 3,000 species of amphibians, reptiles, birds, and mammals.

Wildlife populations are found in areas where their basic needs-food, shelter, water, reproduction, and movement-are met. The area in which the needs of a particular population are met is its habitat. Many animals have special behaviors and physical traits that allow them to successfully compete with other animals in only one or a few habitats; many threatened and endangered species fall into this category. Other animals, such as mule deer, coyote, and American robin are less specialized and can use a wider range of habitats. 
Several features make some habitats better for wildlife than others. In turn, the more of these features that are present, the greater the diversity of wildlife species that is likely to be present. These features include:

- $\quad$ Structure - shape, height, density, and diversity of the vegetation and other general features of the terrain.

- Vertical layers - layers of vegetation (e.g., herbaceous, shrub, and forest canopy).

- Horizontal zones - vegetation and other habitat features that vary across an area.

- Complexity - an integration of vertical layers and horizontal zones.

- Edge - the area where two types of vegetative communities meet, such as a forest and shrub community.

- Special features - unique habitat features needed for survival or reproduction, including snags (dead trees), water, and rock outcrops.

Of the 164 million acres of rangeland administered by the BLM within the western states, $52 \%$ have been inventoried for habitat quality. Of those acres, $42 \%$ are rated as excellent or good, $42 \%$ are rated as fair, and $16 \%$ are rated as poor based on the departure of vegetation composition from a reference condition (USDI BLM 2006d). The BLM also administers 55 million acres of forestlands and woodlands. Of these acres, $16 \%$ have been rated as healthy and providing good habitat for wildlife, while $25 \%$ are in need of restoration, including mechanical thinning, fuels reduction, and prescribed fire. The condition of the remaining acres is unknown (USDI BLM 2004a).

An important activity of the BLM is to manage vegetation to improve wildlife habitat. Plants, which are an important component of habitat, provide food and cover. Food is a source of nutrients and energy, while cover reduces the loss of energy by providing shelter from extremes in wind and temperature, and also affords protection from predators. The following section describes the important characteristics of wildlife and habitat in the eight ecoregions that comprise the treatment area, focusing primarily on the vegetative characteristics of habitat and how wildlife use this vegetation.

\section{Tundra Ecoregion}

Because of the short growing seasons and low summer temperatures, vegetation in tundra areas exhibits simple structure, few layers, limited complexity, low primary productivity, low decomposition rates, low stress tolerance, and high susceptibility to physical disturbance. Thus, on an annual basis, the tundra supports fewer wildlife species and numbers than other ecoregions, although it does support large populations of some wildlife, such as shorebirds and waterfowl, during summer.

Wildlife species in tundra habitats fall into three categories: 1) resident species that remain active yearround, 2) resident species hibernating in winter, and 3) migratory species present for only a portion of the year (Lent 1986). Resident species that remain active yearround include the willow ptarmigan, common raven, snowy owl, Arctic fox, brown lemming, muskox, and caribou. Hibernating species include the Arctic ground squirrel, and hoary marmot. The great majority of the 97 or so bird species using the tundra are migratory (Pitelka 1979).

Except for the wood frog, there are no amphibians or reptiles in the Tundra Ecoregion. Because they are coldblooded animals, the climate is too cold for these groups. Wood frogs are unique in that they partially freeze in winter; up to one-third of the water in a wood frog's body may turn to ice for a period of several weeks (USGS 2004).

The tundra has low species diversity; tundra insect fauna, for example, is only $1 \%$ to $5 \%$ as rich in species as the insect fauna found at temperate latitudes (Bolen 1998). Wildlife populations are also constrained by the low plant productivity, and can fluctuate greatly in response to annual changes in plant productivity. Animal population peaks can markedly alter vegetation and other habitat features in some instances, leading to sharp declines in population numbers. The brown lemming is the classic example of a cyclic species, with extreme fluctuations in numbers. Lemmings clip and consume large amounts of dormant vegetation under the snow during winter. During periods with large populations of lemming, lemmings remove much of the vegetation during winter, resulting in limited food during summer, and also limited protective cover against predators. As lemming populations decline due to starvation and predation, species that prey upon lemmings, such as the snowy owl and Arctic fox, also show marked population declines. 
The widespread occurrence of shallow lakes and wetlands during the summer creates ideal conditions for insects, especially mosquitoes. Mosquitoes have adapted to the harsh winter by overwintering in an egg stage that is resistant to drying, hatching as larvae when warmer weather and moisture returns in the spring. Plant-eating insects are rare in the Tundra Ecoregion, likely due to the low growth rate of the vegetation. Nearly all insects prey on animals, biting the animal or burrowing into its skin or flesh.

Insect fauna provides an important prey base for migratory shorebirds and waterfowl. To cope with the short summer and limited food supplies, migratory birds tend to nest almost immediately upon arriving on the breeding grounds, and young hatch when insects and vegetation are most abundant. Waterfowl, other small birds, and small mammals are preyed upon by Arctic fox, snowy owl, gyrfalcons, peregrine falcons, and rough-legged hawks (World Wildlife Fund 2002).

Even resident populations of the tundra can be quite mobile in their search for suitable food and cover. Arctic foxes may travel hundreds of miles in search of new denning areas, while caribou may go years without using certain winter ranges. Ptarmigan congregate by the thousands in favorable winter valleys in winter, but disperse widely during the summer.

Suitable habitat for denning or burrowing species may be limited in areas with continuous or near-continuous permafrost. Burrowing species must select areas where the permafrost is not near the surface. The presence of deep snowdrifts is important for denning wolverines, polar bears, and brown bears. Talus slopes and cut banks are important habitat features used by denning Arctic foxes. Raptors tend to nest along river and coastal bluffs because of the generally flat, treeless character of the Arctic tundra.

\section{Subarctic Ecoregion}

The Subarctic Ecoregion, or boreal forest, is the largest ecoregion in North America. The vegetation is similar in structure and dominated by relatively few species of conifers, including white and black spruce, and tamarack, and some birch and aspen. Boreal forests are structurally more complex than tundra, and thus support a greater diversity of wildlife species. These forests provide habitat for large mammals, such as grizzly bear, black bear, wolf, moose, caribou, and wolverine; small mammals, such as red fox, American beaver, American marten, and weasels; birds, such as spruce and ruffed grouse, owls, and raven; and the amphibian, wood frog.

Many species have unique adaptations to survive in subarctic forests. Herbivores typically graze on herbaceous and shrubby vegetation during the summer, but shift to a high fiber diet of conifer needles and woody shrub browse during winter.

White-winged crossbills are an example of a species that have adapted to the abundant cone seeds in boreal forests. These birds move in large flocks when cone supplies are abundant, but are nomadic when cone supplies are limited. White-winged crossbills also breed opportunistically, when cone supplies are most abundant.

Bog vegetation occurs widely throughout the Subarctic Ecoregion. Bogs are characterized by a spongy underfoot of peat that provides a rooting layer for most vegetation, and is often overlain by sphagnum moss. In Interior Alaska, bogs are often underlain by permafrost. Bogs tend to have limited structural complexity, as trees and shrubs are often sparse in bogs. Thus, fewer wildlife species are found in bogs than upland forests. The high water table of bogs also discourages burrowing species.

Fires, which are normal, recurring events in boreal forest ecosystems, help maintain ecosystem productivity and biodiversity (Rowe et al. 1974; Adams et al. 2000). Large area fires are common due to the uniformity of the vegetation and presence of a continuous layer of surface fuels, the moss and lichen layer. Fires can also destroy the rich growth of lichens found in the northern portions of the boreal forest. These lichens are an important food source for barren-ground caribou, comprising $60 \%$ to $80 \%$ of the winter diet of caribou (Boertje and Garner 1998, Bolen 1998). Fire may be necessary to maintain lichen ranges in the long term, because in old stands, competition from sphagnum moss, shade from trees, or the old age of lichens may limit lichen productivity (Andreev 1954, Viereck 1973, Zoltai 1974, Maikawa and Kershaw 1976).

After a fire of adequate severity, birch, aspen, and willow can revegetate the area, either sprouting from surviving roots or establishing from seed where adjacent seed sources exist. Willow, in particular, is the mainstay of the moose's winter diet, and moose populations thrive in such burned areas. However, because lichens are slow growing, it can take decades before the biomass of lichens for winter caribou grazing reaches its preburn levels (Joly et al. 2002). Schaefer and Pruitt (1991) observed that burned areas did not provide 
suitable winter habitat for caribou, but that fires could enhance the quality and abundance of summer forage.

\section{Temperate Desert Ecoregion}

Vegetation structure in the Temperate Desert Ecoregion tends to reflect the area's precipitation pattern and temperature regimes (Jones 1986). Sagebrush is codominant with perennial bunchgrasses in the wetter, northern part of the ecoregion, but sagebrush dominates in the southern, drier portion (Paige and Ritter 1999). Trees are mostly limited to the pinyon-juniper woodlands found at higher elevations, and along watercourses.

Northern, cooler desert regions, such as the Great Basin Desert, support far fewer wildlife species than southern, warmer deserts found in the Subtropical Desert Ecoregion (Bender 1982, Brown 1982). The shorter growing season of the northern deserts results in lower plant productivity and a lower diversity and abundance of animal prey. Thermal regimes in northern deserts also limit the activity of wildlife, especially coldblooded animals such as amphibians and reptiles, to short periods each year.

The Great Basin Desert, which is the largest desert in North America, is dominated by two structurally and floristically simple plant communities - sagebrush and saltbush. Because most precipitation in the region falls during the winter when plants are dormant, there is insufficient moisture during the growing season for the development of plant structure and diversity needed to support an abundance of wildlife species. This desert supports large populations of pronghorn antelope, and also provides critical habitat for sage-grouse species that use sagebrush for food and cover.

Desert habitats have some of the most unusual wildlife in the treatment area. Desert animals are adapted to survive under extreme environmental conditions, including low, erratic rainfall, and highly variable temperatures. Many small desert mammals require no free water, but survive on their own metabolic water and through water conservation measures, such as being active only at night and excreting uric acid rather than urea. Spadefoot toads have a special appendage on their hind foot that allows them to burrow into the soil to avoid daytime heat, and breeding activities are timed to occur during periods with summer thunderstorms.

Special features, such as water and rock outcrops, are critical habitat components in desert environments. Permanent and temporary water sources are scarce in this ecoregion, but their importance cannot be overstated. Riparian areas are especially important in the desert. For example, of the 148 species of breeding birds in the Great Basin Desert, 131 are dependent upon riparian areas for all or part of their life requisites.

Talus slopes, cliffs, and rock outcrops provide nesting and feeding habitat, thermal and escape cover, and resting sites for wildlife. Common reptiles that use these features include the common garter snake, western rattlesnake, and sagebrush lizard. Rodents and other small mammals use rock features to hide from predators, and to avoid temperature extremes. Bats use caves and rock outcrops as roost and nursery sites. Deep, rugged cliffs are used by desert bighorn sheep for lambing, escape, and thermal cover. Raptors, including golden eagles and several species of hawks use cliffs and rock outcrops as nest and perch sites. The canyon walls of the Snake River provide nesting habitat for one of the highest densities of predatory birds in the world (USDA Forest Service and USDI BLM 1997).

Soil characteristics determine the number of subsurface sites available to wildlife in the desert. Lack of vegetative structure in deserts is often offset by subsurface space created by deep and diverse soils. Subsurface sites provide shelter from daytime heat, protection from predators, and sources of food for predator, such as snakes.

Wildlife habitat in this ecoregion has undergone great change during the past century, usually to the detriment of native species. For example, cool-season bunchgrasses once dominated large areas of the Columbia Plateau. Much of the grassland community has since been lost with the conversion of lands to agricultural and urban uses. Changes in fire regimes and grazing by domestic livestock have modified significant portions of the remaining grassland habitat. Species associated with native perennial bunchgrass communities, including the Columbian sharp-tailed grouse, kit fox, and Idaho ground squirrel, have declined in numbers more than other species' groups in the region. These species rely on grassland vegetation for plant and insect forage, nesting and brood-rearing habitat, and hiding cover.

Much of the sagebrush habitat in the Temperate Desert Ecoregion has been lost or modified during the past several decades, resulting in habitat fragmentation. This loss is a result of conversion to agricultural and urban uses, grazing, altered fire regimes, and the encroachment of downy brome, other weeds, and woody species such as juniper and Douglas-fir (USDA 
Forest Service and USDI BLM 1997). The best sagebrush habitat occurs where there is a mix of multiage sagebrush with associated perennial bunchgrasses and forbs, interspersed with open wet meadows or riparian areas. These are key habitat components for sage-grouse and other wildlife. During winter, sagegrouse feed almost exclusively on the leaves of sagebrush (Patterson 1952; Wallestad et al. 1975).

\section{Subtropical Desert Ecoregion}

The Subtropical Desert Ecoregion is composed of the Mohave, Sonoran, and Chihuahuan deserts. In contrast to the cooler deserts of the Temperate Desert Ecoregion, the hotter deserts of the Subtropical Desert Ecoregion tend to have a more diverse flora and fauna. The northern limits of many species common in Mexico are found in this ecoregion, such as brown-crested flycatcher, vermilion flycatcher, black-tailed gnatcatcher, hooded skunk, pocketed free-tail bat, coatimundi, and jaguar. The Sonoran Desert is the most floristically diverse of the three deserts, and as a result, has the greatest diversity of wildlife. The desert tortoise, which is federally listed as a threatened species (in the Mojave Desert only), is found in this ecoregion. Longlived and once common, desert tortoises have suffered population declines due to adverse impacts associated with human activities (USFWS 1994a).

The ecoregion is characterized by widely dispersed desert plants that provide little ground cover for wildlife. Canopy cover rarely exceeds $50 \%$, and there is usually extensive bare ground between plants. In the Mojave and Sonoran deserts, several species of cacti, ocotillo, yucca, and other woody species provide areas of near-woodland habitat that support a greater diversity of wildlife than other areas with less plant structure.

Like species in the Temperate Desert, wildlife in the Subtropical Desert have evolved numerous means to deal with water scarcity and other rigors of the hot desert. Presence of standing water in winter and new herbaceous growth in spring provide water and forage for most wildlife (Laudenslayer and Boggs 1988). During summer and fall, some species, such as the desert kangaroo rat and other rodents, derive water from the seeds in their diet. Saguaro, as well as most other species of cactus, has spines for protection from many grazing animals. However, collared peccaries and many desert rodents can avoid or digest cactus spines and obtain water from the plants' succulent tissues.
Black-throated sparrows secrete highly-concentrated urine and dry feces, and thus need little drinking water. In contrast, most other desert-living bird species show few adaptations for coping with water scarcity and simply fly to water sources to meet their needs. Reptiles and small mammals are active mostly at night and retreat to cool burrows, or seek shelter under vegetation or in rock outcrops to avoid the midday sun and reduce water loss. The yucca night lizard, for example, is restricted to desert regions with downed litter of yucca and agave plants (Jones 1986).

Salt balance is an important physiological function in desert animals. Chuckwallas, desert lizards, eat the fleshy tissue of cacti, and are able to excrete salt from their nostrils by sneezing, without losing much water. Many other lizard species also have salt glands for excreting salt.

The structure of live vegetation is probably the most important habitat feature in these deserts. Shrubs and tall cacti are used by lizards for feeding and breeding, and lizards climb onto creosote bushes during the day to avoid hot ground temperatures. Vertical structure provides nesting, feeding, and breeding niches for birds. Cacti provide roosting and breeding habitats for bats that small shrubs do not provide. Horizontal vegetation structure is also important, as some species of birds prefer either open or closed habitats, and many species of lizards require more open areas for foraging, but closed habitat the rest of the time to avoid the heat and predators (Pianka 1966, Rottenberry and Wiens 1980).

The extensive root systems of certain desert plants, such as creosotebush, provide access to subsurface openings for toads, salamanders, lizards, snakes, and small mammals. Creosotebush areas found in the Chihuahuan and Sonoran deserts have little vegetative structure, but have a rich diversity of wildlife because of favorable soils that allow access to subsurface space.

Desert wildlife have evolved characteristics that are adaptive to the attributes of certain plant species. Desert iguanas feed heavily on creosotebush buds, especially during the spring, and their distribution is closely related to the distribution of creosotebush (Norris 1953). Several birds rely on the saguaro and other cacti for roosting and nesting, including elf owl, cactus wren, and gilded flicker. Cavity-nesting birds often select vegetation with spines, perhaps to discourage nest predation by small mammals and reptiles. The Gila woodpecker and gilded flicker both excavate nest cavities in saguaro cacti, but due to differences in bill structure, the gilded flicker must excavate its cavity near 
the top of the cactus, while the Gila woodpecker can excavate cavities near the base of the trunk.

\section{Temperate Steppe Ecoregion}

The Temperate Steppe Ecoregion is comprised of prairie grasslands, evergreen and deciduous forests, and sagebrush and chaparral shrublands. Prairie grasslands occur in an environment with irregularities in weather patterns, including wet and dry spells, which occur often enough to impose severe stresses on wildlife. In a drought year, for example, reduced moisture and higher temperatures can greatly affect the abundance and quality of vegetation used for food and cover, often leading to substantial population declines in some species, especially birds.

The characteristics and habitats of grassland animals differ from those of animals that inhabit shrublands and forests. Many grassland species live in burrows, including burrowing owls, prairie dogs, ground squirrels, pocket gophers, black-footed ferrets, and American badgers. Burrows provide a place to hide from predators, a more stable microclimate during hot summers and cold winters, and shelter from grassland fires (Brown 1982).

If an animal cannot hide in a burrow, it must be a fast runner to avoid predation. The swift fox can travel at 25 miles per hour ( $\mathrm{mph}$ ), while the pronghorn can run at 70 $\mathrm{mph}$. Even quail and grouse often run instead of flying to escape predation, staying close to the ground and using the vegetation as cover.

Grassland animals tend to occur in large social groups. For example, millions of American bison occurred on the Great Plains in presettlement days and millions of prairie dogs have been found in a single prairie dog town. Wildlife species living in grasslands tend to be more social than their forestland counterparts. Prairie dogs live in large, highly organized social units, while their eastern woodland counterpart, the woodchuck, rarely interacts with its own species. Flocking species are also more prevalent in grasslands than in forestlands. Socialization enables the members of a flock to more readily detect predators, but also to convey other information, such as mating status, which is difficult to ascertain in open grassland where sound is muffled and perches are few. Raptors are also more common in grasslands than other habitats, as open spaces favor animals with good vision and provide an abundance of prey items.
Compared with other habitats, grasslands tend to have low bird species diversity and abundance (Wiens and Dyer 1975). Although grasslands are highly productive, they are structurally simple and less complex than other habitat types, and thus provide birds with few niches to exploit. Bird species tend to differentiate themselves based on the cover and height of the grassland vegetation, with the horned lark and burrowing owl selecting areas with low, scattered vegetation, and the savanna sparrow and bobolink selecting high, dense herbaceous cover.

Grasslands found in the proposed treatment area include the Great Plains, shortgrass prairie, intermountain grasslands, and the Palouse grasslands. The mixed prairie of the Great Plains constitutes the eastern range for many grassland animals, including the prairie dog, pronghorn, swift fox, and desert cottontail. It was also the home of the American bison. The shortgrass prairie to the west of the Great Plains, and east of the Rocky Mountains, is where true grassland animals are found. Many of the species found here cannot survive in the tallgrass and mixed prairies because they are less able to see and flee from predators.

Wildlife found in the intermountain grasslands associated with the Rocky Mountains are similar to those found in grasslands to the east, except species that need a year-round supply of green grass do not occur. Deer, elk, and pronghorn survive in the intermountain grasslands by foraging upon shrubs and other woody vegetation during winter. Ground squirrel diversity is especially high in the intermountain grasslands, with 19 of the 22 species of ground squirrels in North America found in this region. Much of the Palouse grasslands have been converted to agriculture or lost to shrubland encroachment, greatly reducing their value to sharptailed grouse and other wildlife that were once common.

Evergreen and deciduous forests are found at higher elevations and along streams and other aquatic areas. The plant species composition of coniferous forest stands, and the types of wildlife that use them, varies with altitude. Aspen is an important component of many deciduous forests. Aspen typically is found in moist areas and becomes established after fire or other disturbance has cleared a suitable area. American beaver use aspen limbs and foliage for food and to build dams and lodges. Snowshoe hare feed on aspen twigs and bark during winter, and aspen buds are important in the winter diet of ruffed grouse. American badger, ground squirrels, and other burrowing animals provide bare ground needed by aspen seeds to germinate. 


\section{Subtropical Steppe Ecoregion}

The Subtropical Steppe Ecoregion is composed primarily of grassland vegetation, with local occurrences of shrubs and woodlands. Grassland wildlife species found in the Temperate Steppe Ecoregion are also found here, such as pronghorn, mule deer, white-tailed deer, coyote, American badger, and black-tailed jackrabbit. The northern limit of distribution of several mammals, including the Mexican ground squirrel and gray fox, occurs in the grasslands of this ecoregion (Bailey 1997).

Woodlands formed of pinyon and several species of juniper (pinyon-juniper woodlands) are found on about 4 million acres, and are also found in other ecoregions. The canopy of these woodlands is generally open, and the trees are far apart. Open stands of pinyon-juniper with abundant vegetation below the trees provide the best wildlife habitat. These woodlands generally do not have the structure and complexity to support a large diversity of wildlife as compared to other forest types, although a study in Utah showed that avian species diversity in pinyon-juniper woodlands is similar to species diversity in other woodland and forest types (Paulin et al. 1999).

Reptiles are not common in pinyon-juniper woodlands. Birds feed on pinyon and juniper seeds and berries, find nesting cavities within juniper trunks, and use the stringy and fibrous juniper bark for nesting material. The pinyon jay, plain titmouse, and bushtit are obligate to these woodlands, and 144 different species of birds have been observed in pinyon-juniper woodlands in New Mexico (Short and McCulloch 1977). Avian species diversity is usually greater in pinyon-juniper woodlands than in adjacent grasslands (Sieg 1991).

Abert's squirrel, pinyon mouse, wood rat, gray fox, and other small mammals eat berries, seeds, and the inner twigs from pinyon-junipers. Mule deer, white-tailed deer, elk, pronghorn, and desert bighorn sheep may occur throughout the year in pinyon-juniper woodlands. Leaves and berries of pinyon pine and juniper trees are eaten by large mammals.

Most food habit studies have shown that the value of pinyon-juniper woodlands to wildlife is usually related to the quantity and composition of the vegetation growing in association with pinyon-juniper. As pinyonjuniper stands mature, the trend is toward increased tree density and finally, dense canopy cover. The dense canopy cover shades out plants found below pinyon- junipers, reducing the variety of plant types that can provide food and cover for wildlife. Small mammals, deer, and elk use of pinyon-juniper woodlands declines as tree canopies become more dense, although some species, like pinyon mice and pinyon jays, may favor denser stands (Short and McCulloch 1977, Willis and Miller 1999).

\section{Mediterranean Ecoregion}

The vegetation of the Mediterranean Ecoregion is dominated by grassland, shrubland, and forestland habitats. Many shrub (chaparral) and forest/woodland plant species have thick, hard, evergreen leaves. The number of wildlife species using shrub habitats is limited by the lack of trees in shrublands. However, wildlife species diversity can also be limited in evergreen woodlands due to the paucity of shrubs in these communities, as shrubs are often unable to compete with trees for the limited moisture.

Because of their tough, leathery texture, the leaves of vegetation in chaparral communities are resistant to wilting, and thus provide cover for wildlife even during the frequent droughts typical of the region. Wildlife found in chaparral tend to be species that nest on the ground or in shrubs, such as ground- and shrub-nesting birds and rodents, or that prey upon ground- and shrubdwelling species, including coyote, striped skunk, and bobcat.

Although this ecoregion supports a diverse vertebrate fauna, including numerous species of reptiles and rodents, only a limited number of species are closely tied to the chaparral. These include the mountain quail, California thrasher, wrentit, brush rabbit, California mouse, and dusky-footed woodrat.

Mountain quail favor slopes covered with chaparral. They feed on acorn mast, fruits, and seeds in the fall, leafy foods during winter, and bulbs in the spring and summer. Thrashers and wrentits find good food and cover in the chaparral, and are more often seen than heard in the dense vegetation. The brush rabbit does not use burrows regularly like most other species of rabbits, perhaps because of the dense chaparral cover. Woodrats construct stick dens that are also used by the California mouse. Since homes are constructed of sticks, woodrats are vulnerable to fires in chaparral communities.

Chaparral communities are adapted to fire, and wildlife respond by retreating to burrows, hiding in rock crevices, or escaping from the area. After a fire, seedcating birds, such as mourning doves, move into the 
area to feed on seeds exposed by fire. Mule deer seek out the temporary community of herbaceous plants that develop during the first year or two after the fire. Many of these plants produce bright flowers that attract nectarfeeding insects and birds.

Deciduous and evergreen woodlands provide vegetation structure and complexity that benefits a variety of wildlife species. The habitat often occurs in a mosaiclike pattern of conifer stands intermixed with deciduous tree stands. The shrub and herbaceous strata are often poorly developed in these woodlands. Mature woodlands are important to cavity nesting birds, and oak mast crops are an important food source for birds and mammals, such as scrub and Steller's jays, acorn woodpecker, wild turkey, mountain quail, California ground squirrel, western gray squirrel, black bear, and mule deer (Anderson 1988). Amphibians that reside in the forest detritus layers include Mount Lyell salamander, ensatina, and relictual slender salamander (McDonald 1988).

Oak woodlands serve as important wildlife habitat, supporting over 300 vertebrate species, many of which are special status species such as the California spotted owl and willow flycatcher (Thomas 1997). Oak trees provide nesting sites for both canopy- and cavitynesting birds, and the acorns they produce are an autumn food source relied upon by many bird and mammal species (Almeda County Agriculture Advisory Committee 2005).

Annual and perennial grasslands are found in central and coastal California. Annual grassland habitats consist largely of non-native annuals that have displaced native perennials (Kie 1988). Habitat structure and wildlife abundance are dependent on a mix of plant species at a site. Sites with western brackenfern exhibit a taller, more diverse structure than sites with shorter grasses. Many wildlife species use grassland habitats, but some require special habitat features, such as cliffs, caves, ponds, or shrubby areas for breeding, resting, and escape cover.

\section{Marine Ecoregion}

The Marine Ecoregion is dominated by evergreen and, to a lesser extent, deciduous forests located along the Pacific Coast. These forests are managed by the BLM primarily for timber production and wildlife habitat.

Temperate forests are among the most productive habitats in the world (Whittaker 1975). The energy available to wildlife from temperate forests vegetation, along with their structure and complexity, provide habitat for a diversity of wildlife. Temperate forests are also routinely subject to disturbances that increase variability in the environment and create edge habitat. In turn, the succession of vegetation types that follow a disturbance provide habitats for a succession of wildlife species.

In general, deciduous trees support more wildlife than evergreen trees (Glenn-Lewin 1977). Conifer forage is less palatable than deciduous forage, which means that there are fewer animals that can consume the foliage, and in turn, be consumed by predators. Conifer foliage is also relatively unpalatable to decomposing organisms, such as fungi and bacteria, so the decomposition of coniferous matter is often a slow process (Hunter 1990). Deciduous trees generally have more structural complexity than conifers, providing more places for animals to feed and seek shelter.

Conifers do possess characteristics that are critical to the survival of many wildlife species. Spruce grouse are dependent on conifer foliage to survive the winter. Conifer stands also provide crucial winter cover to elk, deer, and other wildlife by blocking wind and keeping snow from reaching the ground, covering browse, and restricting animal movements. However, the foliage that captures snowfall also intercepts light in the spring, reducing the amount of light that can reach the forest floor, warm the soil, and stimulate the growth of herbaceous vegetation and shrubs used by these wildlife.

Since this ecoregion is characterized by abundant rainfall, there is an abundance of moisture on the forest floor, as well as in ponds and streams, to support a diversity of amphibians. All frogs and toads in this region lay their eggs in water. Most salamanders lay their eggs in or near water, while others lay their eggs on land under logs (Ensatina), in rock outcrops (western red-backed salamander), or both (clouded salamander). Many of these amphibians spend a portion or most of their lives out of water, living under moist logs, dead wood, or forest litter, or in burrows or root or rock crevasses.

Few reptiles are found in this ecoregion. The alligator lizard is the only widely distributed species found in forested habitats, and the painted turtle and western pond turtle are the only turtles common in the area. The most common snake is the northwestern garter snake.

Birds have adapted to exploit the different layers of vegetation in the forest. Ruffed grouse, winter wren, 
American robin, spotted towhee, and dark-eyed junco are often found near the forest floor or in shrubs. Woodpeckers and brown creepers are seen moving up and down the trunks of trees in search of insects. Nuthatches and chickadees exploit the cone seeds, while warblers and kinglets glean insects from the upper deciduous forest canopy.

Like birds, mammals exploit the vegetation types and strata found in the forest. Shrews, mice, and moles are fossorial or live near the forest floor. Rabbits and hares reside near the ground and seek shelter in dense herbaceous or shrub vegetation. Wide-roaming species that live near the ground include black-tailed deer, elk, black bear, mountain lion, and bobcat. Deer and elk tend to remain in dense forest stands during the day to seek shelter, but move to more open shrublands and grasslands at night to feed, and thus favor forest habitat interspersed with shrubland/grassland habitats. Bears favor large stands of contiguous forest, but also use shrublands with abundant berries and other forage.

Several special habitat features have been identified in forests that are important to wildlife. Snags, which are dead or dying trees, are critical to many species of wildlife. Cavities in snags provide shelter and nesting sites for woodpeckers, owls, and other cavity-using wildlife, while dead and dying bark often harbors large numbers of insect prey for birds. Edges are places where different plant communities or successional stages meet, such as between a forest clearing and dense forest stand. A large number of species are found at edges, and some species reach their maximum population densities there (Hunter 1990). For some species of birds, however, nest predation is higher for individuals nesting near edges than for those nesting in the forest interior.

A number of species rely on old-growth forests for most or all of their life requisites. Old-growth forests in the Marine Ecoregion generally consist of conifer trees with a diameter of more than 3 feet at the base of the tree, and that are more than 200 years old (Bolen 1998). These forests also contain a multilayered canopy and numerous snags and logs. Vaux's swifts depend on large, hollow snags for nesting and roosting habitat. Marbled murrelets use the stout branches of old-growth trees for nest platforms. Northern spotted owl nest in tree cavities and feed on northern flying squirrels. Banana slugs, Pacific giant salamander, Olympic salamander, and Oregon slender salamander are other species that prefer the rotting logs and moist soil conditions found in old-growth habitats.

\section{Special Status Species}

There are over 75 terrestrial animal spccies occurring on or near public lands in the treatment arca that are federally listed as threatened or endangered, or proposed for listing. Included in the total number are 10 species of arthropod, 7 species of amphibian, 5 species of reptile, 20 species of bird, and 27 species of mammal. A complete list of special status animal species may be found in Appendix J. Please note that this list is dynamic, and will likely change throughout the time period considered by this PEIS.

Special status animal species are found on public lands throughout the U.S. Special status arthropods are largely butterflies that occur mostly in open habitats. Special status amphibians occur in wetland habitats throughout the West, and special status reptiles occur in warm habitats of California and the southwest. Special status birds and mammals use a wide range of habitats found on public lands throughout the western U.S.

\section{Livestock}

Approximately 161 million acres of public lands are open to livestock grazing, with use levels established by the Secretary of the Interior and administered through the issuance of grazing permits/leases. The majority of the grazing permits issued by the BLM involve grazing by cattle, with fewer and smaller grazing permits for other kinds of livestock (primarily sheep and horses).

The BLM administers grazing lands under 43 CFR Part 4100 and BLM Handbooks 4100 to 4180 , and conducts grazing management practices through BLM Manual Handbook H-4120-1 (Grazing Management; USDI BLM 1984a). Management of livestock grazing is authorized and enforced through both permits and leases, and is commonly carried out through the development and implementation of allotment management plans (AMPs) and/or terms and conditions of the grazing permit or lease. The grazing permit establishes the allotment(s) to be used, the total amount of use, the number and kind of livestock, and the season of use. The grazing permit may also contain terms and conditions as appropriate to achieve management and resource condition objectives. Allotment management plans further outline how livestock grazing is managed to meet multiple-use, sustained-yield, and other needs and objectives, as determined through land use plans.

Geographically specific rangeland health standards and guidelines are identified for each state to help direct the 
grazing program for those states. Each year the BLM conducts reviews of land within its jurisdiction to determine the level of compliance with rangeland health standards. At a minimum, grazing is managed to ensure that 1) watersheds are in or making significant progress towards properly functioning physical condition; 2) ecological processes including the hydrologic cycle, nutrient cycle, and energy flow are maintained; 3 ) water quality complies with state water quality standards; and 4) significant progress is being made toward restoring or maintaining habitats for all special status species, including federally-listed threatened or endangered species. Reviews of rangeland health standards are often conducted when grazing permits or leases expire, particularly when those permits or leases are within high priority watersheds.

Public lands provide an important source of forage for many ranches and help to support the agricultural component of many communities scattered throughout the west. As of October 2005, the total number of grazing permits/leases in force was 17,940 , with a total of 12.7 million Animal Use Months (AUMs) authorized (Table 3-6; USDI BLM 2006d). Grazing authorizations produced approximately $\$ 14.5$ million in annual revenues in FY 2005 (USDI BLM 2006c).

\section{Wild Horses and Burros}

The BLM, in conjunction with the Forest Service, manages wild horses and burros on BLM- and Forest Service-administered lands through the Wild FreeRoaming Horse and Burro Act of 1971. In FY 2005, wild horse and burro populations on public lands totaled over 31,760 animals, with nearly half of these animals living in Nevada (Table 3-7). Another 25,000 animals are held in holding pens. The population of wild horses and burros is approximately 4,000 animals above the Appropriate Management Level (AML) of 27,500. The AML is an estimate of the number of wild horses and burros that public lands can support while maintaining a thriving natural ecological balance (USDI BLM 2006c, d).

Animals are managed within 201 Wild Horse and Burro HMAs (USDI BLM 2006c). Wild horse herds grow at an average rate of $20 \%$ annually. Management is accomplished by carefully controlling horse and burro populations so that their numbers do not exceed the carrying capacity of the land. This is done primarily by gathering animals periodically so that numbers are near the AML. Fertility control is being used in some herd management areas (HMAs) as a means to reduce the population growth rate. It has shown to be effective thus far and will likely be used on a larger scale in future years.

When horse and burro populations begin to exceed the AML, excess animals are gathered and offered to the public through periodic adoption. In FY 2005, 5,700 wild horses and burros were adopted in the U.S. Thirtytwo percent of these were adopted in the eastern U.S. Nearly 209,000 animals have been adopted since 1971 (USDI BLM 2006d). In 2001, the BLM implemented a program to further reduce the wild horse and burro population to approximately 27,500 animals. Public lands inhabited by wild horses or burros are closed to grazing under permit or lease by domestic horses and burros. The Wild Free-Roaming Horse and Burro Act mandates that wild horses and burros can only be managed in areas where they were found in 1971. Those that stray onto non-designated public and/or private lands are removed.

TABLE 3-6

Grazing Permits and Leases in Force and Active Animal Unit Months during Fiscal Year 2005

\begin{tabular}{|l|c|c|}
\hline \multicolumn{1}{|c|}{ State } & $\begin{array}{c}\text { Leases and } \\
\text { Permits }\end{array}$ & Active AUMs \\
\hline Arizona & 757 & 660,511 \\
\hline California & 573 & 421,843 \\
\hline Colorado & 1,588 & 662,920 \\
\hline Idaho & 1,889 & $1,351,806$ \\
\hline $\begin{array}{l}\text { Montana, } \\
\text { North Dakota, and South } \\
\text { Dakota }\end{array}$ & 4,289 & $1,366,331$ \\
\hline Nevada & 644 & $2,130,112$ \\
\hline $\begin{array}{l}\text { New Mexico, } \\
\text { Oklahoma, and Texas }\end{array}$ & 2,290 & $1,861,369$ \\
\hline Oregon and Washington & 1,579 & $1,058,756$ \\
\hline Utah & 1,525 & $1,237,117$ \\
\hline Wyoming and Nebraska & 2,806 & $1,950,312$ \\
\hline Total & 17,940 & $12,701,077$ \\
\hline \hline Source: BLM Public Land Statistics (USDI BLM 2006d). \\
\hline
\end{tabular}

\section{Paleontological and Cultural Resources}

\section{Paleontological Resources}

The BLM is responsible for managing the public lands and their various resources so that they are utilized in a manner that will best meet the present and future needs of this Nation. The western U.S. has a fossil record that 
TABLE 3-7

Wild Horses and Burros on Public Lands in Fiscal Year 2005

\begin{tabular}{|l|r|r|r|r|r|r|}
\hline \multirow{2}{*}{ State } & \multicolumn{3}{|c|}{ Wild Horses } & \multicolumn{3}{c|}{ Wild Burros } \\
\cline { 2 - 7 } & $\begin{array}{c}\text { Free- } \\
\text { Roaming } \\
\text { Population }\end{array}$ & Adopted & Removed & $\begin{array}{c}\text { Free- } \\
\text { Roaming } \\
\text { Population }\end{array}$ & Adlopted & Removed \\
\hline \hline Arizona & 230 & 218 & 1 & 1,542 & 91 & 53 \\
\hline California & 3,079 & 705 & 992 & 1,228 & 231 & 252 \\
\hline Colorado & 800 & 292 & 357 & 0 & 17 & 0 \\
\hline Idaho & 704 & 110 & 360 & 0 & 0 & 0 \\
\hline $\begin{array}{l}\text { Montana, North Dakota, and South } \\
\text { Dakota }\end{array}$ & 142 & 4 & 0 & 0 & 0 & 0 \\
\hline Nevada & 13,251 & 54 & 5,805 & 1,464 & 0 & 68 \\
\hline New Mexico, Oklahoma, and Texas & 82 & 916 & 23 & 0 & 69 & 0 \\
\hline Oregon and Washington & 2,670 & 313 & 891 & 15 & 6 & 0 \\
\hline Utah & 2,420 & 173 & 248 & 142 & 20 & 0 \\
\hline Wyoming and Nebraska & 3,991 & 420 & 1,973 & 0 & 1 & 0 \\
\hline Total & 27,369 & 3,205 & 10,650 & 4,391 & 435 & 373 \\
\hline \hline
\end{tabular}

includes almost all of the geologic periods from the Cambrian (500+ million years ago) to the Holocene (Recent; the last 10,000 years), and nearly every imaginable ancient environment. Many fossil deposits are of national and international importance, and many thousands of different kinds of fossils were originally made known to the scientific world from specimens first found in the West.

The BLM manages fossils as a natural heritage resource on the lands it administers under the general guidance of the FLPMA and NEPA. Fossils are managed to promote their use in research, education, and recreation, and paleontological localities are an important consideration in developing land use management decisions. More than 200 properties, totaling more than 5 million acres, are managed either wholly or in part for paleontological values or contain paleontological values that may require special management strategies in the future. Significant paleontological resources can also be found on other public lands estimated to total over 20 million acres. Because of the increasing interest and activity related to fossils over the past 3 decades, it is estimated that there are more than 50,000 fossil sites documented on public lands. Table 3-8 lists the localities that include many of these sites.

\section{Cultural Resources}

Cultural resources include archaeological, historic, or architectural sites, structures, or places with important public or scientific uses, and may include definite locations (sites or places) of traditional cultural or religious importance to specific social or cultural groups. Cultural resources are concrete, material places and things that the BLM locates, classifies, and ranks. The BLM manages cultural resources according to their relative importance, to protect significant cultural resources from inadvertent loss, destruction, or impairment, and to encourage and accommodate the appropriate uses of these resources through planning and public participation.

The cultural heritage for public lands administered by the BLM in 17 western states extends back 11,000 to 13,000 years before the present (BP). As one moves forward in time, the number and variety of sites increases mainly as a result of the increase in Native populations and, after $1500 \mathrm{AD}$ or so, European and Euroamerican immigration.

Table 3-9 summarizes the number of acres of public lands inventoried for cultural resources, the number of properties found on public lands, and the number of properties listed in the NRHP.

\section{American Indian and Alaska Native Cultural Resources}

This review uses the culture area approach as defined in the Handbook of North American Indians (Sturtevant 1978-2001). See Map 3-11 for the location of these 
TABLE 3-8

Interpreted Paleontological Sites on Public Lands

\begin{tabular}{|c|c|}
\hline State & Interpreted Locations \\
\hline Colorado & $\begin{array}{l}\text { - } \quad \text { Dinosaur Diamond Byway } \\
\text { - } \quad \text { Kremmld Park Fossil Area } \\
\text { - Rabbit Valley Traceoul Through Time } \\
\text { - } \quad \text { Fruita Paleontology Area }\end{array}$ \\
\hline Idaho & - Malm Gulch Area of Critical Environmental Concern (ACEC) \\
\hline Utah & $\begin{array}{ll}\text { - } & \text { Cleveland Lloyd Dinosaur Quarry } \\
\text { - } \quad \text { Copper Ridge Sauropod Dinosaur Tracks } \\
\text { - Mill Canyon Dinosaur Trail } \\
\text { - Warner Valley Dinosaur Track Site }\end{array}$ \\
\hline Wyoming & $\begin{array}{ll} & \text { Red Gulch Track Site ACEC } \\
\text { - } & \text { Big Cedar Ridge Fossil Plant Area ACEC } \\
\text { - } & \text { Dry Creek Petrified Tree Environmental Education Area }\end{array}$ \\
\hline
\end{tabular}

areas. These regions represent areas within which specific cultural groups shared certain cultural characteristics and histories. Each culture area section provides a brief review of the archaeology and ethnography of that area. Table 3-10, summarizing examples of major types of archaeological sites likely to be in each culture area, follows this section.

\section{Arctic and Subarctic (Alaska)}

Archaeological research suggests that the earliest human migrants crossed into the New World via the Bering Land Bridge, likely following large herbivorous Pleistocene animals, such as mastodon, woolly mammoth, horse, and American bison. In this culture area, typical artifacts from the period 13,000 to 9,000 Before Present (BP) include lanceolate projectile points, bifacial knives and scrapers, and retouched flake tools (Ames and Maschner 1999, Dixon 1999). Cultural resource sites from this time period include open campsites, habitations or campsites located in caves or rockshelters, and sites where game animals were killed and/or processed.

As the post-glacial climate in Alaska warmed, prehistoric cultures became more established. Early aboriginal groups, with a subsistence strategy similar to that of the Paleoindians, used tool assemblages dominated by microblades, small wedge-shaped cores, and burins.

Cultures from 9,000 to 6,000 BP often are referred to as the Microblade Tradition (Dumond 1987). In addition to open campsites and sites with skin-covered tents, semi- subterranean houses are documented for this period (Anderson 1984). By 6,000 BP, the Northern Archaic Tradition had arisen in the boreal forests of the interior, represented by small, seasonal campsites and tool assemblages composed of lanceolate and side-notched projectile points and scrapers (Dumond 1987). Technological advances during the period 6,000 to 250 BP led to the development of several distinct cultures. Tool kits of the widespread Arctic Small Tool Tradition included small stone endblades and sideblades inserted into the shafts of arrows or spears (Dumond 1987). Populations of Arctic Small Tool Tradition people developed highly specialized maritime technologies (kayaks, umiaks, dogsleds, toggling harpoons, bow and arrows, and ground slate tools). Habitations, in the form of semisubterranean houses, often were clustered in villages (McCartney 1984, Dumond 1987).

At present, the Alaska Natives and Indians are the dominant native groups of Alaska. In general, the Inuit (Eskimo and Aleut) inhabit the coastal areas and adjacent tundra, while Indians (Athabaskan or Tlingit) inhabit the interior forests and southeast Alaska, though both groups have tremendous intra-cultural diversity and overlapping resource exploitation areas. Terrestrial and marine mammals and fish are the primary source of food for both groups; plants being of lesser importance, given the short growing season.

Kelp and berries are the principal plant foods, with mushroom, wild parsnip, wild rhubarb, and lupine roots also gathered. Dune grass is used to weave baskets and mats (Kehoe 1992). Alaskan Indians have focused their subsistence activities on marine whales and seals, 
TABLE 3-9

Cultural Resources on Public Lands

\begin{tabular}{|l|c|c|c|c|}
\hline \multicolumn{1}{|c|}{ State } & $\begin{array}{c}\text { Number of } \\
\text { Acres } \\
\text { (in millions) }\end{array}$ & $\begin{array}{c}\text { Number of } \\
\text { Acres } \\
\text { Surveyed }\end{array}$ & $\begin{array}{c}\text { Percent of } \\
\text { Acres } \\
\text { Surveyed }\end{array}$ & $\begin{array}{c}\text { Number of } \\
\text { Properties } \\
\text { Recorded }\end{array}$ \\
\hline \hline Alaska & 85.5 & 109,872 & 0.1 & 3,205 \\
\hline Arizona & 12.2 & 822,100 & 6.7 & 11,858 \\
\hline California & 15.2 & $1,813,118$ & 11.9 & 28,454 \\
\hline Colorado & 8.4 & $1,493,770$ & 17.9 & 39,232 \\
\hline Idaho & 12.0 & $2,020,017$ & 16.8 & 14,604 \\
\hline Montana, North Dakota, and South Dakota & 8.3 & $1,340,862$ & 16.2 & 10,224 \\
\hline Nevada & 47.8 & $2,183,973$ & 4.6 & 44,851 \\
\hline New Mexico, Oklahoma, and Texas & 13.4 & $1,441,183$ & 10.8 & 34,931 \\
\hline Oregon and Washington & 16.5 & $1,585,580$ & 9.6 & 12,623 \\
\hline Utah & 22.9 & $1,801,321$ & 7.9 & 38,526 \\
\hline Wyoming and Nebraska & 18.4 & $2,590,769$ & 14.1 & 40,157 \\
\hline Total & 260.6 & $17,202,565$ & 6.6 & 278,665 \\
\hline Source: BLM Public Land Statistics (USDI BLM 2006f). & & \\
\hline
\end{tabular}

seasonal fish runs, and inland caribou herds and a variety of other land mammals.

Edible plant resources of the interior include a wide variety of berries, fern roots, lily bulbs, mushrooms, wild onions, wild rhubarb, rose hips, and various roots (Kehoe 1992). Birch bark continues to be used for the manufacture of many utilitarian objects, including baskets, shelters, cooking pots, and canoes. The wood of birch, spruce, and willow has been used for bows, arrows, snowshoe frames, wooden tools, and house and canoe frames. Ropes and fishing nets have been made from willow bast, nettle fibers, and spruce roots. Additional uses of spruce roots include containers, basketry, sewing thread, and twine (McClellan and Deniston 1981).

\section{Northwest Coast}

Archaeological evidence for occupation of this culture area dates back to about $11,000 \mathrm{BP}$, though faunal remains from the Olympic Peninsula suggest human presence earlier than 12,000 BP (Lyman 1991). Early peoples' subsistence systems focused on maritime resources, and typical artifacts consist of large chipped stone projectile points, microblades, compound harpoons, and grinding stones (Ames and Maschner 1999). Due to the damp climate and acidic soils in this region, faunal remains and tools made from perishable items dating to this period are rarely preserved. In addition, the changing sea levels over the last 10,000 years have inundated many of the older occupation or processing sites.

By about 5,000 BP, sea levels rose and stabilized, and distinctive cultural patterns emerged. Bone and ground stone tools were prevalent from Southeast Alaska to Puget Sound, as were large settlements and specialized maritime subsistence strategies. There is evidence of sedentism (pithouses and shell middens in western Washington) from 3,500 $\mathrm{BP}$, and it appears that by 3,000 BP, trade networks with Plateau cultures were well established (Nelson 1990). Petroglyph sites begin during this period (Boreson 1998, Ames and Maschner 1999).

By 1,000 BP, most Northwest Coast groups occupied village sites on a year-round basis. Many village sites were located for defensive purposes and included fortifications, suggesting the presence of warfare, social complexity, and competition for resources (Ames and Maschner 1999). Typical artifacts include composite woodworking tools, netsinkers, bone and antler tools, and copper and iron tools. Archaeological sites in the Northwest Coast region are generally difficult to locate because of dense vegetation and poor preservation (Nelson 1990).

A handful of "wet sitcs" occurring in the Pacific Northwest have been systematically studied, with 
TABLE 3-10

Culture Areas, Prehistoric Occupation Periods, and Selected Common Site Types

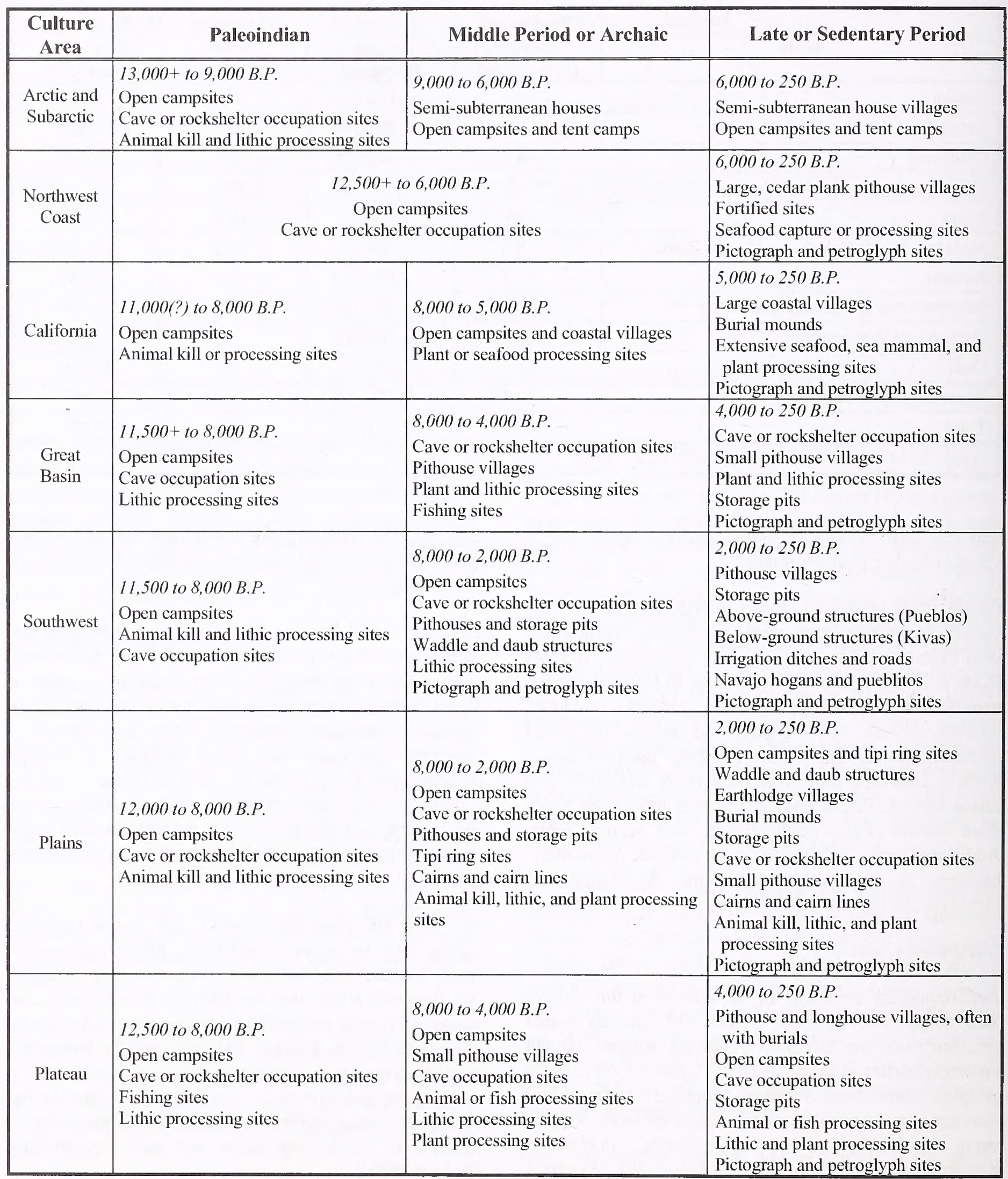


excellent preservation of organic components, such as acorns, wood, and basketry items, from prehistoric sites on the Olympic Peninsula of Washington, including Ozette, the Hoko River, and Mud Bay, and also the "Sunken Village" on the Willamette River in Oregon (Croes 2007).

Food resources currently used by native Northwest groups include salmon, halibut, cod, candlefish (an important source of dietary oil), clams, whales, elk, deer, mountain sheep, and bear. Plant food sources, which are numerous in this culture area, include edible ferns and lilies, the tuber of the wapato, over 40 fruits and berries, edible nuts, leaves, and shoots, and certain types of algae, seaweed and kelp. Many groups used controlled burning to maintain prairies, and berry, root, and nut-producing areas along the coast from California to British Columbia (Suttles 1990, Ames and Maschner 1999).

Forest resources are used extensively, particularly western red cedar and Alaska cedar, for canoes, for plank house construction, and for specialized ritual purposes such as totem poles and masks. Sitka spruce has often been used for houses and canoes, and western hemlock and Douglas-fir saplings have been used to construct fish weirs. Red alder, Rocky Mountain maple, and Alaska cedar have been used for spoons, bowls, masks, and dishes; and western yew has been used for bows, wedges, clubs, and digging sticks. Plant materials used to make rope and cordage include the limbs of western red cedar, the stipes of bull kelp, the roots of cedar and spruce, and the fibers of stinging nettle and Indianhemp. Materials used in basketry include cedar roots, cattail, tule, beargrass, and various sedges and grasses. The inner bark of western red cedar and Alaska cedar is used for baskets, mats, skirts, capes, towels, and diapers. There are numerous medicinal plants in the Northwest region, including devil's club, kinnikinnick, hogfennel, and tobacco (Suttles 1990).

\section{Southwest}

Between 11,500 and 8,000 BP, human groups practiced a highly mobile hunting and gathering subsistence strategy. In general, the oldest archaeological sites in this culture area are located near now extinct springs, large and small Pleistocene lakes (playas), or major drainages, and consist of open camps, animal kill sites, animal processing sites, or caves.

Archaeological sites dating from 8,000 to $2,000 \mathrm{BP}$ are either open campsites located near water sources, containing chipped and ground stone tools, or are in rockshelters or caves, where well-preserved twined sandals, wood artifacts, and basketry are often recovered (Kehoe 1992). Horticulture was introduced into the southwest as early as 4,500 BP, although domestic crops did not substantially contribute to the diet until later (Woodbury and Zubrow 1979). Typical artifacts of the period include stemmed projectile points used with atlatls, basketry, scrapers, grinding slabs, and cobble tools. Remains of surface structures, made of posts and brush or other material, are documented beginning midway through the period in the West (Irwin-Williams 1979). The first pit house sites and storage pits are documented late in this period (Woodbury and Zubrow 1979). Petroglyphs and pictographs are first produced during this time period (Schaafsma 1980).

Researchers have subdivided the Southwest, starting from about 2,000 BP, into the Anasazi, Mogollon, Hohokam, and Hakataya geographical-cultural areas. The Anasazi occupied variable topography during the generally cooler and moister climates; the Mogollon inhabited well-watered, forested and mountainous regions; the Hohokam were located in low, dry deserts; and the Hakataya occupied the hot desert regions bordering the lower Colorado River (Woodbury 1979). Parts of the region were intensively occupied and socially and economically linked to the civilizations of the Mexican Classic Period, when sedentary cultures began to emerge (Irwin-Williams 1979).

Maize was cultivated in earnest by about 2,200 BP, and was soon followed by beans, squash, cotton, and other crops (Irwin-Williams 1979; Woodbury and Zubrow 1979). By $1,700 \mathrm{BP}$, some inhabitants of the region had developed sophisticated irrigation, pottery, storage pits, and pit house villages. Eventually, small to large permanent towns of multi-story, aboveground structures (pueblos) were developed. Sites dating to this period may include features such as irrigation canals, wells, storage pits, and roads. Typical artifacts consist of pottery (used for the storage of crops), basketry, and small corner-notched projectile points indicating the adoption of the bow and arrow by 1,500 BP (Woodbury and Zubrow 1979).

The Pueblo Indians are best known for their agricultural development of corn, beans, and squash. In addition, wild plants (e.g., amaranth, chenopods, wild onion, wild celery, sage, grass seeds, juniper berries, pine nuts, acorns, walnuts, agave, prickly pear, and tree cholla) were eaten (Bodine 1979, Plog 1979). Other plants are used for clothing, shelter, and medicine. Baskets are made from yucca fibers, cotton is used for weaving, 
blankets are made from small palms, yucca roots are used for hair washing, and gourds are used as containers (Bodine 1979, Kennard 1979, Plog 1979, Schroeder 1979).

The Yuman groups (Colorado River Tribes) living along the Colorado and Middle Gila rivers have traditionally cultivated corn, squash, pumpkins, melons, beans, and cotton (Maxwell 1978). Important animal foods include small game and fish, and important plant resources include prickly pear, saguaro, mesquite, and numerous nuts and berries (Maxwell 1978, Jorgensen 1980). Yuman groups living on or near the Colorado Plateau practiced agriculture in the canyons in summer, then hunted deer, antelope, bighorn sheep, and rabbits in the fall. They also gathered pinyon nuts, juniper berries, various cacti, and other plants for both subsistence and domestic purposes (Khera and Mariella 1983, McGuire 1983, Schwartz 1983).

Southern Athapaskan or Apachean-speaking tribes occupied mueh of eastern Arizona, portions of New Mexico around the Pueblos, southeastern Colorado, western Oklahoma, and parts of western and southern Texas beginning about 700 BP. Following contact with the indigenous Pueblo peoples, the Navajo readily adopted maize, bean, and squash agriculture. The Western Apache, Jicarilla, and Lipan cultivated crops less intensively, and the remaining groups did not adopt any agricultural practices. With arrival of the Spanish, the Navajo readily adopted the raising of horses, sheep, goats, and cattle, and cultivated orchards and other introduced crops (Basso 1983, Opler 1983, Tiller 1983, Witherspoon 1983).

Traditional plants gathered by the Apacheans include agave crowns, saguaro cactus fruit, yucca, prickly pear, mesquite beans, acorns, pinyon nuts, numerous berries, grass seeds, wild root crops, and various greens or young plants. Yucca has been used to make shampoo, and the sap of Spanish bayonet and other plants has been used to make dyes. Common basketry plants include sourberry, willow, martinia, and bata mota. At least 29 species of plants have been used for medicinal purposes. Various large and small game animals were hunted for food and hides.

\section{Great Basin}

Two of the oldest archaeological sites in this culture area are the Tule Springs campsite $(11,000 \mathrm{BP})$ and Danger Cave (9,000 BP; Aikens 1983). Typical artifacts of the period from 11,000 to $8,000 \mathrm{BP}$ include lanceolate-shaped and long-stemmed projectile points, occasional fluted points, specialized scrapers, chipped stone crescents, and drills (Warren and Crabtree 1986). This period also includes the earliest evidence of basket making (Adovasio 1986). Inhabitants of the region likely were highly mobile hunter-gatherers with a generalized big game hunting and collecting economy.

The warm and dry climatic conditions during 8,000 to 7,000 BP limited human subsistence activities. Sites dating to this period are rare, and include caves (Aikens 1983) and rockshelters in drier areas, or pithouse villages located in valley bottoms near permanent streams and springs (Elston 1986). During this period, generalized hunting and collecting remained the major subsistence practices, although seed collecting and processing activities gained importance, as indicated by bedrock mortars and milling stones. Root collecting and fishing also gained importance during this period (Mehringer 1986). Typical artifacts include projectile points used with atlatls, basketry, twined sandals, and various wooden implements (Aikens and Madsen 1986).

By about 4,000 BP, subsistence systems were broadbased and resource-rich areas were heavily exploited seasonally. The shift in styles of projectile points over time indicates the adoption of the bow and arrow. While caves continued to be occupied (Aikens 1983), many locations along major rivers contained small pithouse villages with associated storage facilities (Butler 1986). Horticulture was introduced in the eastern Great Basin and Owens Valley by Southwest cultures around 1,500 BP. Outside of these areas, hunting and gathering remained the primary form of subsistence. An expanded reliance on pinyon nut gathering, as evidenced by mortars and pestles, also occurred during this period (Aikens and Madsen 1986, Elston 1986). Petroglyphs were common by $3,000 \mathrm{BP}$ and pictographs by 1,000 BP (Schaafsma 1986).

Prior to the acquisition of the horse in the late 1700s, Shoshone and Northern Paiute in the High Desert region and western Wyoming fished for salmon in the spring and dug camas roots in the summer. These groups traveled to the mountains of southeastern Idaho and northern Utah to hunt deer and elk in the fall. After the development of equestrian culture, ranges and territories extended into present-day Wyoming and Montana, in seasonal pursuit of buffalo.

In the high desert, the single-leaf pinyon nut was an important staple, along with plant resources such as chenopod, blazingstar, grass seeds, mesquite, salvia, various cacti, and gourds (Egan 1917; Steward 1939, 
1997; Thomas et al. 1986). The Westcrn Shoshone wore hats made from twined sage bark or willow and clothing made from bark, grass, or fur. A large number of plants have also been used for basketry in this region (Adovasio 1986; Fowler 1986; Thomas et al. 1986). The Eastern Shoshone pursued game more extensively, while fish were a substantial part of the Northern Paiute diet (Liljeblad and Fowler 1986, Murphy and Murphy 1986, Shimkin 1986).

The aboriginal groups of the low desert, such as the Ute, Southern Paiute, Kawaiisu, Owens Valley Paiute, and Panamint, exhibited seasonal migration by traveling into the deserts and valleys in the winter and mountains in the summer. With the introduction of horses, these groups ranged onto the Plains, and adopted a Plains pattern, such as buffalo hunting and use of long-pole tepees (Conetah 1982, Janestki 1991, Kehoe 1992).

Plants utilized within the low desert region included berries, roots of sego lily and bulrush, some cacti, pinyon, and mesquite beans. Low desert tribes also hunted large and small animals (Kelly 1964, 1976; Kroeber 1976; Kelly and Fowler 1986). Plant materials used to make cordage included sagebrush bark, juniper bark, dogbane, yucca, and nettle. Tule reeds had multiple uses, in such items as balsa rafts, mats, and blankets (Callaway et al. 1986). Present day Moapa Paiutes still use desert fan palms for making baskets, food, and shelter (Moapa Memories 2002). Jimson weed, tobacco, nettle, and red ants are some of the traditional medicines used by Native groups in this region (Zigmond 1986).

\section{Plateau}

Because of the arid climate during the period from 12,500 to $8,000 \mathrm{BP}$, resources in this culture area were concentrated along the margins of rivers and major tributaries. Archaeological sites dating to this period include caves, rock shelters, and open camps. The low frequency of early sites is generally attributed to the low population densities of the highly mobile huntergatherers who occupied the Plateau. Stemmed and unstemmed lanceolate projectile points, microblades, cobble tools, scrapers, gravers, and bifaces are common artifacts associated with the period. Although groups engaged in fishing, intensive utilization of riverine resources did not occur until later, when climatic conditions stabilized (Ames et al. 1998; Ames and Maschner 1999).

A gradual increase in moisture from 8,000 to $4,000 \mathrm{BP}$ helped expand the range of sagebrush steppe and stimulate the productivity of root crops across the region. Human groups continued to practicc highly mobile subsistence strategies with an increasing reliance on salmon (Chatters and Pokotylo 1998). Other than the addition of large side-notched points, and a decrease in the overall size of projectile points, evidence of atlat use, the tool kit is similar to that of the preceding period. The appearance of individual or small numbers of pit houses along major drainages signified the rise of semisedentary settlement strategies, and hopper mortars and milling stones provide evidence for the increased importance of roots and other plant resources in the diet. Other site types include large open sites lacking evidence of habitations, caves, short-term camps, resource extraction sites, and resource processing sites, generally located farther from the major drainages (Ames et al. 1998).

A cooling climate around 4,000 BP helped to stabilize salmon productivity by restricting the seasonality of the salmon migrations (Butler and Schalk 1986). In response, inhabitants of the Plateau intensified their use of salmon, storing it for year-round consumption, and structuring their subsistence strategies to coincide with seasonal salmon migrations. Semi-permanent villages of various-sized pit houses, and longhouses appearing about 1,500 BP, were located mainly along rivers and major tributaries and occupied during the winter months. Some of the habitations were eventually used for human burials. Camps positioned at strategic resource locales in the uplands and mountains were used on a seasonal basis. Cave sites produce wellpreserved wood and fiber artifacts. The adoption of the bow and arrow; specialized fishing technologies including nets, harpoons, and barbed bone points; and the continued presence of grinding and pounding tools are evidence of increasingly complicated subsistence strategies (Ames et al. 1998). Petroglyphs and pictographs, dating as early as 3,500 $\mathrm{BP}$, are most common near the larger settlements on major rivers (Boreson 1998).

The hallmark of northern and southern Plateau cultures is still salmon fishing. For many Plateau groups, plant resources also constitute a large portion of the diet. Significant plant resources utilized by these groups include root crops of camas, bitter root, lomatium, balsamroot, and yellowbells, and various berries. These plant resources have not only provided food, but have also been used for such functions as shelter, clothing, basketry, and medicine. Some Plateau groups traditionally burned habitats to enhance the production 
of usable plant material, including berries (Chatters 1998, Ross 1998).

In the southern Plateau, traditional dwellings were semisubterranean and constructed from wood and large mats made of tule bulrushes or cattail reeds, sewn together with Indianhemp (Schuster 1998). The main firewoods of the region are Douglas-fir and ponderosa pine, with alder wood preferred for cooking or smoking salmon. Douglas-fir saplings have been used for fish net poles, greasewood twigs for sewing needles, Indianhemp for fishing nets and other weaving purposes, and cattail leaves for weaving bags. Rosewood has been used in cradleboards, and has been hung in homes to repel ghosts. Medicinal and religious plants include mullein, willow bark, and tobacco (Hunn 1990, Hunn and French 1998).

In the northern Plateau, tule reeds and cedar bark were used for covering structures, and tule was also used for matting and bedding, and to shroud corpses. Sources of baskets and bags included birch bark, cedar bark, cedar and spruce roots, and Indianhemp (for cordage). Underground storage casks were made from cottonwood bark, canoes were made from white pine bark, snowshoe frames were made from maple boughs, and mats used to dry salmon were made from willow shoots. Sources of dye included huckleberries and the inner bark of Oregon grape, and sunflower root was used to make shampoo (Kennedy and Bouchard 1998, Miller 1998).

\section{California}

The Lake Mojave sites, dating to over $10,000 \mathrm{BP}$, represent some of the oldest archaeological materials in this culture area. These sites include evidence of big game hunting and gradual expansion into the use of plant resources. Open camp and processing sites suggest that there were few early occupants of the region who maintained a highly mobile subsistence strategy. Artifacts include large, fluted projectile points, lanceolate-shaped points, shouldered points, chipped stone crescents, scrapers, knives, and choppers (Wallace 1978).

Between 8,000 and 7,000 BP, an arid environment caused lakes and marshes to dry, forcing people to adapt to new environments (Moratto 1984). Based on the presence of milling stones, a shift from big game hunting to plant and seed collecting occurred between 8,000 and 5,000 BP. Artifact assemblages are surprisingly homogeneous, consisting mostly of heavy, deep-basined milling and hand stones, with occasional projectile points that were likely used with atlatls (Wallace 1978).

About 5,000 BP, transition began toward a more diversified subsistence economy that included the exploitation of marine and terrestrial resources. Inland sites show evidence of intensive plant processing indicated by the presence of mortars and pestles. Archaeological and climatic evidence from the last 2,000 years indicates that subsistence and settlement patterns in California remained quite stable. Coastal groups relied on marine resources; northern groups relied on riverine resources, especially salmon; central and southern groups relied on lake and marsh resources; and groups throughout the state relied on deer and acorns. The presence of bedrock mortars in the Sierra Nevada foothills indicates continuous use of the same areas. There is also evidence that widespread burning of forests was conducted to stimulate plant growth and provide forage for deer, a universal food source (Driver and Massey 1957, Lewis 1973, Bendix 2002). The earliest petroglyphs appear to correlate with similar ones from the Great Basin dating 3,000 BP, while very elaborate, perhaps ceremonial, pictographs are thought to be no more than 1,000 years old (Clelow 1978).

Coastal groups have long exploited coastal marine and inland oak forest resources, where they collect acorns and hunt large and small game. A variety of plants provide building materials, basketry materials, clothing, and medicine. The redwood tree was used to construct permanent dwellings and large canoes, as well as clothing made from its bark. Juniper and tule were also used to make shelters. Tule reeds are used in basketry (in addition to numerous other plants), boats, clothing, and matting. Materials used to make dyes include green oak galls, burned pepperwood berries, tan oak bark, and alder bark. Medicinal plants include tobacco, angelica, and pepperwood leaf (Loeb 1926, Maxwell 1978).

In the valleys between the Sierra Nevada and coastal ranges, riparian corridors and foothills rich in oak groves provide acorns, a staple diet of many California tribes. Migrating salmon are an important food source, as are berries, bulbs, tubers, and roots. Native groups of the Central Valley and Sierra region hunted waterfowl using snares, nets, arrows, and decoys. Tule growing in wetlands has been an important component of baskets, matting, dwellings, and watercraft. Plants used for cordage and rope include milkweed, Indianhemp, dogbane, and inner willow bark. Medicinal plants include tobacco and horehound (Levy 1978, Wallace 1978). 
In the desert region of southeast California, important tribal resources included fish, shellfish, deer, rabbit, rodents, and insects. Additional dietary staples, still used, include wild grass, mescal beans, pinyon seeds and nuts, and mesquite beans, which are ground into flour and made into cakes (Barrows 1900, Kelly 1964, Kroeber 1976).

In the desert region, dwellings were constructed from a wide variety of plants, including juniper, manzanita, greasewood, mountain oak, and mesquite, with tule, carrizo, ferns, bark, or reeds often used for thatching. Plants used for basketry include tule, sumac, squawbrush, and a variety of rushes and grasses. Yucca has been used for cordage. A number of plants were used for clothing and sandals, including the inner bark of willow and cottonwood trees, mescal and yucca fibers, and mesquite bark. Creosote bush and milkweed wcre used as adhesives, and yucca root has been used to make soap. Among the wide variety of medicinal plants are tobacco, jimson weed, wormwood, creosote, and sumac (Bean and Saubel 1972).

\section{Plains}

Human occupation of this culture area dates to at least 11,500 BP. Highly mobile hunters occupied sites on a short-term basis or repeatedly over varying lengths of time. These sites, which were frequently located near water sources, often include finely manufactured fluted, stemmed, or lanceolate points in association with skeletons of extinct game species.

American bison hunting has played a significant role in the subsistence economy of Plains groups throughout prehistory. Additional utilized fauna included elk, mountain sheep, deer, antelope, bear, and various small mammals, as well as fish, freshwater mussels, reptiles, and amphibians. Archaeological evidence indicates that roots, bulbs, berries, fruits, and seeds were collected and often processed using a variety of grinding stones (Frison 2001, Vehik 2001).

Typical artifacts of the period from 8,000 to $2,000 \mathrm{BP}$ include medium-sized lanceolate to large, side-notched projectile points, corner-notched dart points, hide scrapers, milling or grinding stones, coiled basketry, and pottery. Although open campsites (often with fire pits), cave or rockshelter sites, and American bison kill and processing sites are the most common sites, burials, as well as sites containing housepits and/or food cache pits are also documented throughout this period. In addition, the use of teepees, based on the presence of stone circles at cultural resources sites, is evident (Frison 2001, Vehik 2001).

Petroglyphs and pictographs (rock art) date from this period (2,000 to $250 \mathrm{BP})$, occurring on rock outcrops in the northern and northwestern Plains and southeastern Colorado (Frison 2001, Gunnerson 2001). With the appearance of the bow and arrow in the northwestern Plains about 1,900 BP, hunting became more efficient. The use of teepees by the more nomadic western and northwestern Plains dwellers became very common throughout the period, to the point where some multiple stone circle sites are labeled villages (Frison 2001). By $1,500 \mathrm{BP}$, farming of maize, beans, squash, and sunflowers was established in the eastern Plains and spread to sedentary groups living in earth lodge villages along the Missouri River (Maxwell 1978; Kehoe 1992; Wedel 1961, 1983; Wedel and Frison 2001; Wood and Irwin 2001).

At the time of European contact, plants used for subsistence by Plains groups included prairic turnip, groundnut, ground bean, sunflower, Jerusalem artichoke, serviceberries, mesquite beans, cacti, camas, and grass seeds. Maize, beans, and squash were also cultivated (Maxwell 1978, Wedel 1983, Wedel and Frison 2001). Following the introduction of horses by the Spanish in the $16^{\text {th }}$ century, subsistence patterns of many Plains groups shifted from sedentary, part-time farming and hunting to mounted hunting heavily focused on the migratory herds of American bison. During the $1700 \mathrm{~s}$, pressure from the Europeans generated movements of woodland groups, such as the Sioux, onto the Plains. By the late 1700 s, the dependence on plants for subsistence by these groups waned (Maxwell 1978).

Plains groups have used plants for a variety of purposes, in addition to subsistence. Tobacco has been used in religious ceremonies. Cottonwood and willow were used to provide fuel and building materials, and willow has been used for boat frames. Oak, elm, and huckleberry are also high quality building materials, and poles made from pine have been used for teepee frames. Willow, box elder bark, and nettles have been used to make baskets, which are often colored with a black dye derived from walnuts. Medicinal plants of the Plains include mescal beans and sweetgrass. Bowls were made from box elder, and bows from cedar, ash, and hickory. Sage was used to help whiten hides (Brown and Irwin 2001, Voget 2001, Wedel and Frison 2001, Wood and Irwin 2001). 


\section{European Settlement Resources}

Euro-American contacts with the western U.S and Alaska generally began with exploration or trading, with missionary activities soon following in some of the areas. The earliest exploration occurred in the Southwest and in California in the 1500s, with settlements by the military, missionaries, and colonists in the 1600s in the Southwest, and in the later 1700s in California. In the late 1700s, Spanish, Russian, British, and American exploration and trade extended up and down the West Coast of North America. By the late 1700 s and early 1800s, explorers such as Lewis and Clark and fur traders traversed the interior of what is now the western U.S. Table 3-11 shows the types of European settlement resources typically present in the cultural areas.

The discovery and the promise of precious metals first inspired conquest of Native People through treaty and force, then created the market for the development of agriculture, timber, and fisheries, and finally motivated the construction of a transportation system sufficient to transport people and goods. Although furs and precious metals drew the first adventurers, a more permanent settlement of the West in the late $19^{\text {th }}$ and early $20^{\text {th }}$ centuries was related to agriculture. In most of the arid regions of the West agriculture primarily consisted of ranching. During this time, the Homestead Act and other similar programs transferred most of the irrigable land to private ownership, and the adjacent public land was used for grazing livestock by the ranchers who had either homesteaded or purchased those private lands. Beginning about the turn of the $20^{\text {th }}$ century, the federal government reserved tracts of land in the West for management by agencies such as the Forest Service and National Park Service, and, after its formation in the middle of the century, by the BLM. These lands remain in the public domain.

The history of the rural western U.S. encompasses several broad themes and periods including exploration, discovery of the region's mineral wealth, conflict, and settlement, and includes the growth of communities dependent upon resource extraction-farming, ranching, logging, fishing, and mining. These communities were in turn linked to local, regional, and national markets through a complex and evolving system of trails, military roads, wagon roads, rail lines, and navigable river corridors, a trend that continues into the modern period. By the mid- $20^{\text {th }}$ century, with the region secured and transportation assured, recreation and tourism increasingly comprised the economic base of western communities, and military training use escalated in response to the training needs of the modern military.

Public lands in the West contain cultural resources representing all major periods and events in the broad sweep of western history. The most common rural manifestations of these dominant themes include transportation resources such as ferry sites, railroads, trails, and roads; military sites (training grounds and battlefields); and mining resources related to exploration (prospect pits), extraction (adits, hydraulic cuts, and quarries), and processing (smelters and mills). Other resources include homesteading, ranching and farming resources (human and animal shelter and irrigation development); fishery resources (boats, fish traps, and weirs); and logging resources (stumpage, sawmills, and human and animal shelter). Evidence of community development includes rural schools, stores, churches, and community centers. Recreation and leisure sites include cabins, resorts, and trail systems.

\section{Important Plant Uses and Species Used by American Indians and Alaska Natives}

Although universally important, plant use by Native American and Alaska Native groups is extremely varied, both by region and by group. Subsistence use of such plant products as roots and tubers, stalks, leaves, berries, and nuts is essential to native people. Vegetation also provides habitat for important wildlife species.

Most Native American and Alaska Native groups constructed a variety of residential shelters and other buildings such as ceremonial lodges and sweat houses using a combination of materials, usually employing a locally derived hardwood as part of the structural frame. The frames were then covered with other readily available materials, such as planks, mats, brush, and other materials. Wood has been burned to cook food, warm dwellings, and facilitate toolmaking. Trees have been fashioned into various types of watercraft and terrestrial hauling devices. Various woods have been carved or used to produce utilitarian implements like bowls and spoons, and also ceremonial items, such as pipes and totems, and many other items of material culture.

The use of plants for medicinal purposes is widespread, as is the use of tobacco. Plants such as tobacco, sweet grass, cedar, and sage, have seen important religious 
TABLE 3-11

European Settlement Resource Types

\begin{tabular}{|c|c|c|}
\hline Site Type & Examples & Culture Region \\
\hline \multicolumn{3}{|c|}{ Transportation } \\
\hline River navigation & Fords, cable ferries, and shipwrecks & All \\
\hline $\begin{array}{l}\text { Overland navigation (both } \\
\text { railroad and non-railroad) }\end{array}$ & $\begin{array}{l}\text { Trails, wagon roads, truck trails (public and private), engineered features } \\
\text { (bridges, trestles, ballast, track, and ties), and construction camps }\end{array}$ & All \\
\hline \multicolumn{3}{|c|}{ Exploration and Overland Migration } \\
\hline $\begin{array}{l}\text { Trails (most often at } \\
\text { topographic restrictions, } \\
\text { such as canyons) }\end{array}$ & Trail ruts (rock) and trail ruts (earth) & All \\
\hline $\begin{array}{l}\text { Geological landmarks with } \\
\text { cultural and historical value }\end{array}$ & Rock promontories, springs, passes, and meadows & All \\
\hline Inscriptions & Petroglyphs (chiseled inscriptions), pictographs, and carvings on trees & All \\
\hline Missions & Schools, churches, agricultural plots, orchards, and housing & All \\
\hline \multicolumn{3}{|c|}{ Military } \\
\hline Battlefields (Indian wars) & Not applicable & All except Alaska \\
\hline Training grounds & World War I, World War II, Korean War, and Cold War eras & $\begin{array}{l}\text { Great Basin, Plateau, } \\
\text { and Desert Southwest }\end{array}$ \\
\hline Transportation routes & Trails and wagon roads & All \\
\hline \multicolumn{3}{|c|}{ Agriculture } \\
\hline Ranching and farming & $\begin{array}{l}\text { Home ranch facilities (including foundations), outlying buildings and } \\
\text { structures, cultural landscape elements (including fences, stock ponds and } \\
\text { trails, dams, and river fords), irrigation structures, and archaeological sites }\end{array}$ & All \\
\hline \multicolumn{3}{|c|}{ Commerce/Urban Development } \\
\hline Urban settlement & Civic, commercial, and domestic & All \\
\hline \multicolumn{3}{|c|}{ Mining } \\
\hline $\begin{array}{l}\text { Resources associated with } \\
\text { extraction }\end{array}$ & $\begin{array}{l}\text { Resources associated with prospecting (locating ore) and development } \\
\text { (accessing and removing ore), resources associated with placer mining } \\
\text { (sluicing), and lode mining (adits, waste rock, and interior tramways) }\end{array}$ & All \\
\hline $\begin{array}{l}\text { Resources associated with } \\
\text { beneficiation and refining }\end{array}$ & $\begin{array}{l}\text { Mills (various types), smelters, tailing piles, tailing ponds, power plants, } \\
\text { and refineries }\end{array}$ & All \\
\hline Support facilities & Bunkhouses, mess halls, livestock shelters, and trash dumps & All \\
\hline Transportation systems & Trails, two-track roads, truck trails, rail lines, and construction debris & All \\
\hline \multicolumn{3}{|c|}{ Logging } \\
\hline Extraction & Stumps, skid lines, and sky-line cables & All \\
\hline Processing & Lumber mills and power plants & All \\
\hline Support facilities & Shingle camps, logging camps, and livestock facilities & All \\
\hline Transportation & Roads, donkey engines, big wheels, rail lines, and flumes & All \\
\hline \multicolumn{3}{|c|}{ Fisheries } \\
\hline $\begin{array}{l}\text { Extraction (except } \\
\text { processing-related and } \\
\text { support facilities) }\end{array}$ & Weirs, fish traps, natural features (falls, eddies), and boats & All \\
\hline \multicolumn{3}{|c|}{ BLM Administration and Development } \\
\hline Administrative facilities & $\begin{array}{l}\text { Buildings (administrative, maintenance, and warehouse) and livestock } \\
\text { facilities }\end{array}$ & All \\
\hline Interpretation & Museums and interpretive signs & All \\
\hline Recreation (pre-1934) & $\begin{array}{l}\text { Camp sites, developed natural features, summer homes, interpretive signs, } \\
\text { roads, and trails }\end{array}$ & All \\
\hline Recreation (post-1934) & Campground, developed water source, and roads and trails & All \\
\hline
\end{tabular}


and other ceremonial uses. The use of grasses and other plant resources for basket, box, and tool making also can be observed in the cultures of numerous Native American and Alaska Native groups. Plant products also have been used to make textiles, cordage, and matting, as well as to tan hides. The use of plant dyes, paints, and soaps is widespread.

\section{Visual Resources}

The public lands administered by the BLM contain many outstanding scenic landscapes. Visual resources in these landscapes consist of land, water, vegetation, wildlife, and other natural or man-made features visible on public lands. Vast areas of grassland, shrubland, canyonland, and mountain ranges on public lands provide scenic views to recreationists, visitors, adjacent landowners, and those just passing through. Roads, rivers, and trails on public lands pass through a variety of characteristic landscapes where natural attractions can be seen and where cultural modifications exist. Activities occurring on these lands, such as recreation, mining, timber harvesting, grazing, or road development, for example, have the potential to disturb the surface of the landscape and impact scenic values.

Public lands have a variety of visual (scenic) values which warrant different levels of management. The BLM uses a system called VRM (visual resource management; Manual 8400) to systematically identify and evaluate these values to determine the appropriate level of scenery management (USDI BLM 1984b). The VRM process involves 1) identifying scenic values, 2) establishing management objectives for those values through the land use planning process, and 3) then designing and evaluating proposed activities to analyze effects and develop mitigations to meet the established VRM objectives.

The BLM Visual Resource Inventory Handbook (Handbook 8410-1; USDI BLM 1986a) sets forth the procedures for inventorying scenic values and establishing VRM objectives, referred to as Management Classes. A visual resource inventory is informational in nature and does not set forth management direction. A visual resource inventory is based on an analysis of three primary criteria influencing visual values: 1) inherent scenic quality, 2) public sensitivity to landscape change, and 3) distance zones from primary travel ways or special areas. These three criteria are ranked for all acres of public land and a final VRM inventory rating is identified.
These ratings are then used during the land use planning process and considered along with other resource objectives to determine final VRM objectives, or classes. BLM policy requires that every acre of BLM land be inventoried and assigned a VRM class ranging from Class I to Class IV. After VRM classes have been established, Bureau policy requires all management aetivities to be designed to meet the assigned classes. Class IV allows for the most visual change to the existing landscape, while Class I allows the least (Table $3-12)$.

The Visual Contrast Rating Handbook (Handbook 8431-1; USDI BLM 1986c) is used to provide an objective and consistent method for describing landscape character, evaluating visual effects of activities, and developing mitigation to meet VRM objectives. The contrast rating process involves describing the landscape in the context of the basic environmental design elements and features that comprise it. The elements of form, line, color, and texture are used when describing and evaluating landscapes. Activities or modifications in a landscape that repeat these elements are thought to be in harmony with their surroundings. Modifications that do not harmonize are said to be in contrast with their surroundings. Visual resource design techniques and best management practices (BMPs) are then used in project development to minimize contrast in order to meet the VRM Class objectives established in the LUP.

\section{Wildermess and other Special}

\section{Areas}

The BLM manages certain lands under its jurisdiction that possess unique and important historical, anthropological, ecological, biological, geological, and paleontological features. These features include undisturbed wilderness tracts, critical habitat, natural environments, open spaces, scenic landscapes, historic locations, cultural landmarks, and paleontologically rich regions. Special management is administered with the intent to preserve, protect, and evaluate these significant components of our national heritage. Most special areas are either designated by an Act of Congress or by Presidential Proclamation, or are created under BLM administrative procedures.

The National Landscape Conservation System is the primary management framework for these specially designated lands. The NLCS was created in June 2000 by the BLM to bring into a single system some of the 
agency's premier areas. Of the nearly 261 million acres administered by the BLM, nearly 43 million acres on 867 BLM units are managed under the NLCS program (Map 3-12 and Table 3-13). The NLCS designations include National Monuments, National Conservation Areas, Designated Wilderness and WSAs, National Scenic and Historic Trails, and Wild, Scenic, and Recreational Rivers (USDI BLM 2006d).

Fourteen of the 15 BLM-administered National Monuments are areas designated by the President, under the authority of the Antiquities Act of 1906, for the protection of objects of scientific and historical interest that are located on federal lands. Congress has also created a BLM National Monument on which to conserve, protect, enhance and manage public lands. National Conservation Areas, Cooperative Management and Protections Areas, Outstanding Natural Areas, National Recreation Areas, and Forest Reserves are designated by Congress to conserve, protect, enhance, and manage public land areas for the benefit and enjoyment of present and future generations. These 13 areas, totaling 14 million acres, feature exceptional natural, recreational, cultural, wildlife, aquatic, archeological, paleontological, historical, educational, and scientific resources. Additionally, the White Mountains National Recreation Area in Alaska is approximately 1 million acres and was designated by the Alaska National Interest Lands Conservation Act of 1980. The White Mountains National Recreation Area is managed for multiple uses with an emphasis on recreational uses (USDI BLM 2006c).

National Wilderness Areas, designated by Congress, are defined by the Wilderness Act of 1964 as places "where the earth and its community of life are untrammeled by man, where man himself is a visitor who does not remain." Designation is aimed at ensuring that these lands are preserved and protected in their natural condition. Wilderness Areas, which are generally 5,000 acres or more in size, offer outstanding opportunities for solitude or a primitive and unconfined type of recreation; such areas may also contain ecological, geological, or other features that have scientific, scenic, or historical value. The BLM manages 175 Wilderness Areas encompassing nearly 7.2 million acres (USDI BLM 2006d).

Wilderness Study Areas have been designated by the BLM as having wilderness characteristics, thus making them worthy of consideration by Congress for wilderness designation. Currently, the BLM manages 610 WSAs encompassing 14.3 million acres. While Congress considers whether to designate a WSA as permanent wilderness, the BLM manages the area to prevent impairment of its suitability for wilderness designation.

National Wild and Scenic Rivers (WSRs) are rivers (or river sections) designated by Congress or the Secretary of the Interior, under the authority of the Wild and Scenic Rivers Act (WSRA) of 1968, to protect remarkable scenic, recreational, geologic, fish and wildlife, historic, cultural, or other similar values and to preserve the river in its free-flowing condition. The law recognizes three classes of rivers - wild, scenic, and recreational. Wild rivers are free of impoundments and generally inaccessible except by trail, with watersheds or shorelines essentially primitive and water unpolluted. Scenic rivers are free of impoundments with shorelines or watersheds largely undeveloped, but accessible in places by roads. Recreational rivers are readily accessible by road or railroad, may have some development along their shoreline, and/or may have undergone some impoundment or diversion in the past. The BLM manages all or portions of 38 rivers totaling 2,052 miles as part of the National WSR System (USDI BLM 2006d).

Congress, under the National Trails System Act of 1968, designates areas as National Scenic and Historic Trails. National Scenic Trails offer maximum outdoor recreation potential and provide enjoyment of the various qualities (scenic, historical, natural, and cultural) of the areas through which these trails pass. National Historic Trails are extended trails that follow as closely as possible, on federal land, the original trails or routes of travel with national historical significance. Designation identifies and protects historic routes and their historic remnants and artifacts for public use and enjoyment. A designated trail must meet certain criteria, including having a significant potential for public recreational use or interest based on historical interpretation and appreciation.

The NLCS differs from the National Park System and the National Wildlife Refuge System in several ways. Visitor facilities are often located in adjacent communities, providing local economic opportunities and minimizing new development in the special areas. Traditional land uses, such as livestock grazing, are often permitted in these areas, and the local communities and interested public are encouraged to participate in the planning and management of them. Other special areas managed by the BLM outside of the NLCS framework include Areas of Critical Environmental Concern (ACEC), Research Natural Areas, National Natural Landmarks, National 
TABLE 3-12

Visual Resource Management (VRM) Classes and Objectives and Appropriate Management Activities

\begin{tabular}{|c|l|c|l|}
\hline $\begin{array}{c}\text { VRM } \\
\text { CLASS }\end{array}$ & \multicolumn{1}{|c|}{ Visual Resource Objective } & $\begin{array}{c}\text { Change Allowed } \\
\text { (Relative Level) }\end{array}$ & \multicolumn{1}{c|}{$\begin{array}{c}\text { Relationship to the Casual } \\
\text { Observer }\end{array}$} \\
\hline Class I & $\begin{array}{l}\text { Preserve the existing character of the } \\
\text { landscape. Manage for natural ecological } \\
\text { changes. }\end{array}$ & Very Low & $\begin{array}{l}\text { Activities should not be visible and } \\
\text { must not attract attention. }\end{array}$ \\
\hline Class II & $\begin{array}{l}\text { Retain the existing character of the } \\
\text { landscape. }\end{array}$ & Low & $\begin{array}{l}\text { Activities may be visible, but should } \\
\text { not attract attention. }\end{array}$ \\
\hline Class III & $\begin{array}{l}\text { Partially retain the existing character of the } \\
\text { landscape. }\end{array}$ & Moderate & $\begin{array}{l}\text { Activities may attract attention but } \\
\text { should not dominate the view. }\end{array}$ \\
\hline Class IV & $\begin{array}{l}\text { Provide for management activities which } \\
\text { require major modification of the existing } \\
\text { character of the landscape. }\end{array}$ & High & $\begin{array}{l}\text { Activities may attract attention, may } \\
\text { dominate the view, but are still } \\
\text { mitigated. }\end{array}$ \\
\hline
\end{tabular}

Recreation Trails, and a variety of other area designations.

The -BLM uses the ACEC designation to highlight public land areas where special management attention is necessary to protect and prevent irreparable damage to important historical, cultural, and scenic values; fish or wildlife resources; or other natural systems or processes. The ACEC designation may also be used to protect human life and safety from natural hazards. The BLM identifies, evaluates, and designates ACECs through its resource management planning process. Allowable management practices and uses, mitigation, and use limitations, if any, are described in the planning document.

Under current guidelines, ACEC procedures also are used to designate Research Natural Areas, Outstanding Natural Areas, and other natural areas requiring special management attention. The National Natural Landmarks Program recognizes and encourages the conservation of outstanding examples of natural history. National Natural Landmarks are designated by the Secretary of the Interior and are the best examples of biological and geological features in both public and private ownership within the U.S. The Recreational Trails Program provides funds to the states to develop and maintain recreational trails and trail-related facilities for both non-motorized and motorized recreational trail uses.

Among these groups, 903 areas comprising nearly 13 million acres are designated as ACECs; 45 areas comprising over 417,000 acres are designated as National Natural Landmarks; and 164 areas comprising over 323,000 acres are designated as Research Natural Areas. An additional 30 million acres fall under various other designations, such as the Lake Todatonten Special Management Area, the Santa Rosa Mountains National
Scenic Area, Herd Management Areas, and Globally Important Bird Areas. In addition, there are over 2,950 miles of vehicle routes and trails designated as National Backcountry Byways and National Recreation Trails (USDI BLM 2006c, d).

The BLM also cooperates with the National Park Service in implementing the National Natural Landmark Program as it applies to public lands. The National Park Service, through the National Natural Landmark Program, designates significant examples of the Nation's ecological and geological heritage.

\section{Recreation}

Public lands provide visitors with a wide range of recreational opportunities, including hunting, fishing, camping, hiking, dog mushing, cross-country skiing, boating, hang gliding, OHV driving, mountain biking, birding, viewing scenery, and visiting natural and cultural heritage sites. In addition to the recreational opportunities afforded the public by wilderness and other special areas discussed earlier, the BLM administers 205,498 miles of fishable streams, 2.2 million acres of lakes and reservoirs, 6,600 miles of floatable rivers, over 500 boating access points, 300 Watchable Wildlife sites, 55 National Back Country Byways, 5,500 miles of National Scenic, Historic, and Recreational Trails, and thousands of miles of multiple use trails used by motorcyclists, hikers, equestrians, and mountain bikers (USDI BLM 2006c).

The BLM's long-term goal is to provide opportunities to the public for environmentally responsible recreation. Over 4,000 communities with a combined population of 23 million people are located within 25 miles of public lands, and approximately $40 \%$ of public lands are 


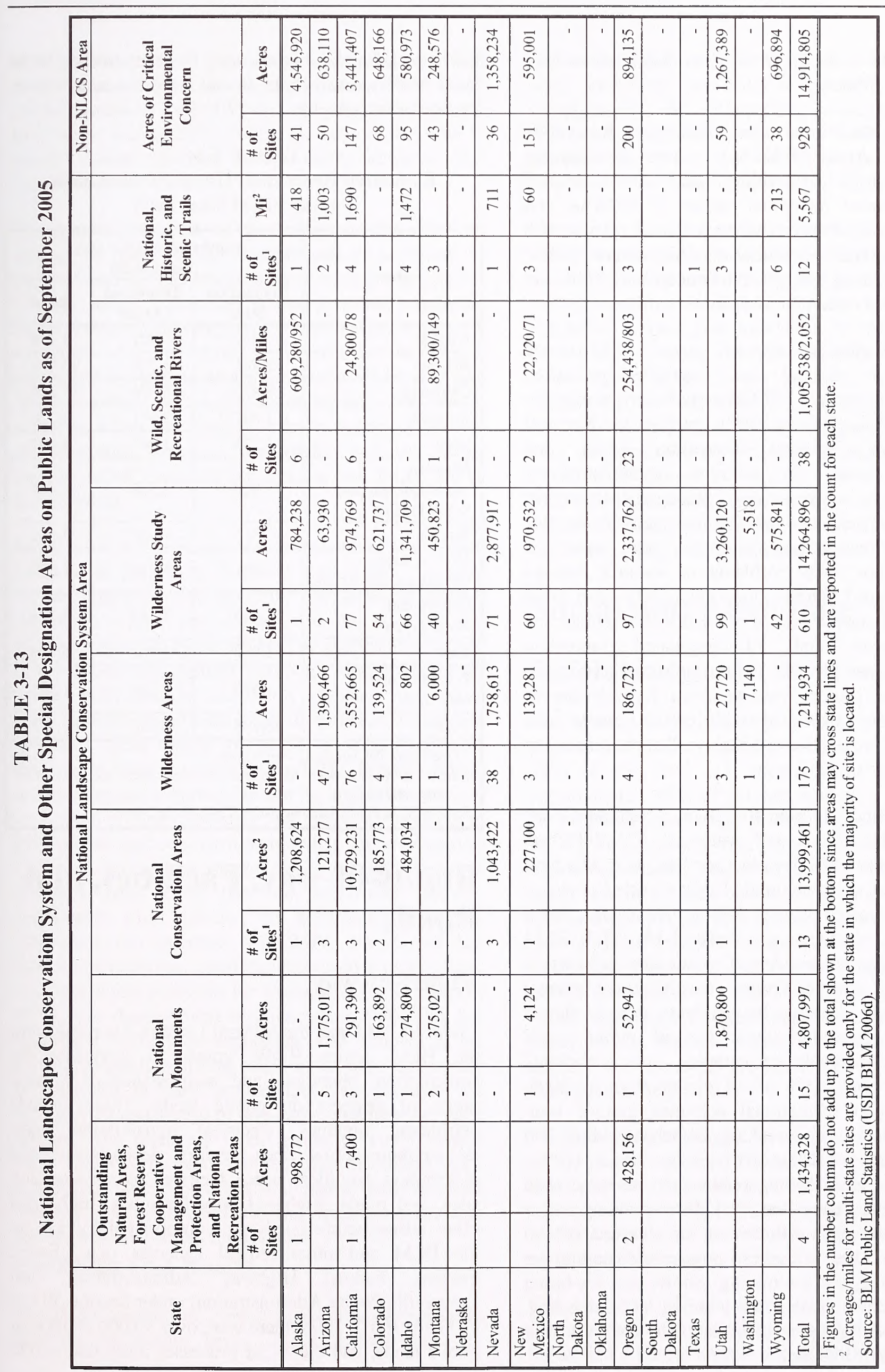


located within a day's drive of a major urban area (USDI BLM 2006c).

Most BLM lands are managed as Extensive Recreation Management Areas (ERMAs), where management consists primarily of providing basic information and access. Dispersed recreation occurs in ERMAs, and visitors have the freedom of recreational choice with minimal regulatory constraints. Significant public recreation issues or management concerns are limited in these areas, and nominal management suffices.

Special Recreation Management Areas (SRMAs) are places where special or intensive recreation management is needed. SRMAs include congressionally recognized areas, such as WSRs, parts of the National Trail System, National Recreation Areas, and Wilderness Areas. In addition, administratively recognized areas where issues or management concerns may require special or intensive management are also designated. Areas where visitor use may cause user conflicts, visitor safety problems, or resource damage are also included. These more intensively used areas require direct supervision of recreational activities and of commercial and BLM-regulated recreation operations. Most SRMAs require selective vegetation treatments to protect visitors from hazards and/or adverse effects associated with certain plants, and replanting of vegetation in highly disturbed areas to improve appearance.

BLM field offices reported 56 million recreational visits to BLM public lands and waters in FY 2005, an increase of nearly $4 \%$ from the previous year. The total amount of time spent on public lands, reported as visitor days, was estimated at 66.2 million visitor days, down $5 \%$ from the previous year (Table 3-14; USDI BLM $2006 \mathrm{~d})$. The greatest number of visitor days occurred in Arizona and California. Overall, developed recreational sites were used about as frequently as non-developed dispersed areas. Recreational use of public lands consists predominately of camping and picnicking, which represented $43 \%$ of all visitor days in 2005 . Other important recreational activities include nonmotorized travel, such as hiking, horseback riding, and mountain biking $(10 \%)$; off-highway travel $(10 \%)$; hunting (8\%); and viewing public land resources and interpretation and education (6\%). The remaining visitor days were associated with driving for pleasure, special events, sports and activities, power and non-power boating, fishing, and swimming. Snow- and ice-based activities, such as cross-country skiing, snowmobiling, and snowshoeing, represented less than $1 \%$ of visitor days (USDI BLM 2006c).
Commercial revenues generated by recreation on BLM lands are discussed in the Social and Economic Values section of this chapter.

TABLE 3-14

Estimated Recreation Use of Public Lands during Fiscal Year 2005

\begin{tabular}{|l|c|c|c|}
\hline \multirow{2}{*}{ State } & \multicolumn{3}{c|}{$\begin{array}{c}\text { Number of Visitor Days } \\
\text { (thousands) }\end{array}$} \\
\cline { 2 - 4 } & $\begin{array}{c}\text { Recreation } \\
\text { Sites }\end{array}$ & $\begin{array}{c}\text { Dispersed } \\
\text { Areas }\end{array}$ & Total $^{2}$ \\
\hline \hline Alaska & 297 & 921 & 1,218 \\
\hline Arizona & 7,541 & 1,776 & 13,958 \\
\hline California & 8,426 & 8,776 & 17,246 \\
\hline Colorado & 1,637 & 3,021 & 4,776 \\
\hline Idaho & 1,234 & 2,847 & 4,102 \\
\hline $\begin{array}{l}\text { Montana, } \\
\text { North Dakota, and } \\
\text { South Dakota }\end{array}$ & 920 & 2,528 & 3,448 \\
\hline Nevada & 915 & 4,644 & 5,560 \\
\hline $\begin{array}{l}\text { New Mexico, } \\
\text { Oklahoma, and Texas }\end{array}$ & 581 & 1,416 & 1,997 \\
\hline $\begin{array}{l}\text { Oregon and } \\
\text { Washington }\end{array}$ & 2,015 & 3,712 & 5,727 \\
\hline Utah & 1,912 & 3,883 & 6,226 \\
\hline $\begin{array}{l}\text { Wyoming and } \\
\text { Nebraska }\end{array}$ & 630 & 1,258 & 1,890 \\
\hline Total & 26,108 & 34,782 & 66,178 \\
\hline \hline $\begin{array}{l}\text { 1 One visitor day equals 12 visitor hours. } \\
\text { Includes visitor days } \\
\text { partnership sites. } \\
\text { Source: BLM Public Land Statistics (USDI BLM } 2006 \mathrm{~d} \text { ). }\end{array}$ \\
\hline
\end{tabular}

\section{Rights-of-way, Facilities, and Roads}

\section{Rights-of-way}

Under FLPMA and the Mineral Leasing Act provisions, the BLM issues ROW grants to authorize the construction, operation, and maintenance of a wide range of projects on public lands. These include petroleum pipelines, electrical transmission lines, telecommunications lines, energy development and distribution facilities, water facilities, communication sites, and roads. Rights-of way for roads, trails, and other infrastructure needs are appropriated for use by the BLM and other federal agencies (e.g., Forest Service, Federal Highway Administration, and Bonneville Power Administration) under Section 507 of FLPMA. In FY 2005, there were over 90,000 ROWs on public lands, and the BLM processes more than 4,000 
new applications each year. Energy-related applications comprise about $60 \%$ of new applications (USDI BLM 2006c). Demand for ROWs on public lands is expected to increase substantially during the next decade due to energy needs, changes in the utility industry, and increased urbanization.

The length and width of an ROW (and the resulting acreage of public lands) is dependant on a variety of physical and operational factors, including topography, geology, safety, type of use or uses proposed within the ROW, current technology, and access needs. Rights-ofway may also be subject to controls or limitations prescribed by law or identified within BLM land use plans. The BLM encourages the utilization of ROWs in common, where practical, in order to minimize adverse environmental impacts. The BLM land use plans identify ROW corridors for existing and future ROW development.

Rights-of-way are issued for short-term use of public lands or in perpetuity. Right-of-way grants generally include provisions that authorize the holder to manage vegetation within and adjacent to the ROW using methods approved by the BLM. The scope and intensity of vegetation management treatments within ROWs are operationally specific and highly variable. Inspections are conducted at periodic intervals to assess vegetation treatment needs within the ROW. Several techniques are used to manage vegetation in ROW. Preeemergence or postemergence herbicides can be applied to prevent or control young emerging and existing vegetation. Mechanical methods, such as mowing, are also used to eliminate undesirable vegetation. In certain situations, livestock have been used to selectively remove undesirable plant species, in a targeted approach. Vegetation can interfere with ROW site access and facility maintenance, interfere with electric power flow, and pose safety problems for workers and other users of ROW. The development and maintenance of ROW has significant impacts on vegetation. The removal of the existing vegetation during construction activities results in increases in bare ground that can facilitate the introduction and spread of non-native and invasive plant species. The relatively open nature of ROW makes them attractive to many recreationists, including $\mathrm{OHV}$ enthusiasts, horseback riders, and hikers. However these activities can also facilitate the spread of invasive species that are present on ROW.

\section{Facilities and Roads}

The BLM operates or oversees operation on numerous facilities on public lands. These include oil, gas, geothermal, and mineral exploration and production sites, including over 21,000 production sites; 510 campgrounds, 87 interpretive centers, and other recreational facilities; over 4,300 buildings and 713 administrative sites; over 76,000 miles of roads; and communication facilities (USDI BLM 2006c).

Construction and operations disturbance can often introduce noxious weeds and other invasive vegetation to facility sites and roads. In general, vegetation management at facilities focuses on controlling vegetation that can pose a safety or fire hazard, or is not aesthetically pleasing. In such situations the vegetation is managed using several methods, which can be integrated into an effective management process. Residual herbicides, applied to vegetation before or after emergence, offer extended management in areas where bare ground is required for safety purposes. Mechanical methods, such as mowing, and manual control by hand pulling have been used to manage vegetation along roads, as well as in sensitive areas.

\section{Social and Economic Values}

\section{Social/Demographic Environment}

The western U.S., including Alaska, is more sparsely populated than the rest of the U.S., containing about $32 \%$ of the total U.S. population, but comprising approximately $65 \%$ of the total land area. In 2000 , over 89 million people lived in this region, with over 50 million in California and Texas, alone (Table 3-15). Population density is relatively low, averaging about 40 people per $\mathrm{mi}^{2}$, which is half of the national average of nearly 80 people per $\mathrm{mi}^{2}$. Density ranges from about 1 person per $\mathrm{mi}^{2}$ in Alaska to over 217 persons per $\mathrm{mi}^{2}$ in California. Based on 2000 census data, population growth between 1990 and 2000 averaged over 16\%, which was slightly higher than the national average. Many of the western states, however, exceeded the national average, with growth rates of $20 \%$ or higher during this time period.

Within regions of the western states, mobility patterns of the population were evident. Population declined in rural areas and increased in urban areas. Growth of the western states during this time occurred predominantly in WUI areas, due to expansion of urban population areas into previously rural areas.

The western U.S. contains a large percentage of the nation's minority populations, including over $60 \%$ of the nation's Hispanics and American Indians, and over 
$50 \%$ of the nation's Asian/Pacific Islanders. In particular, Arizona, California, New Mexico, and Texas contain large Hispanic populations, which comprise from 25 to over $40 \%$ of the total population in each of these states. Over $15 \%$ of Alaska's population is comprised of American Indians.

The age distribution of the population of the western U.S. is similar to the nationwide distribution. Approximately $27 \%$ of the population is under 18 years of age, while about $11 \%$ is over 65 . Alaska and Utah are slight exceptions, with a higher percentage of people under 18 (over 30\%) and a lower percentage of people over 65 ( $5 \%$ and $8 \%$, respectively).

\section{Economic Environment}

\section{Employment}

Between 1990 and 2000, employment growth in the western U.S. averaged $21 \%$, which slightly exceeded the national average of about $18 \%$. Nevada and Arizona had the most employment growth overall $(60 \%$ and $42 \%$, respectively) while California and Alaska had below-average employment growth of less than $15 \%$. Most employment growth during this time occurred in the management, professional, and related occupations $(26 \%)$ and in the service sector $(15 \%)$, while negligible growth occurred in the manufacturing sector.

In December 2006, the nationwide unemployment rate was $4.5 \%$ (Table 3-16). Unemployment rates in the western U.S. exceeded the national average, with the greatest unemployment in Alaska (6.7\%), Oregon $(5.4 \%)$, and Washington $(5.0 \%)$. The unemployment rate was lowest in Utah $(2.6 \%)$ and Montana $(2.9 \%$; U.S. Department of Labor Bureau of Labor Statistics 2007). Unemployment rates were generally higher for African Americans and Hispanics than other races.

Over $23 \%$ of the nation's employment opportunities, amounting to over 40 million jobs, are located in the western U.S. (Table 3-17). Employment in the trade and services industries accounts for over half of the total jobs. Industries related to natural resources, such as agriculture and mining, are important sources of employment and represent nearly one third of the nation's agricultural services, forestry, and fishing jobs. Employment in the government and military sector is higher in Alaska than in other states, accounting for $27 \%$ of total jobs versus about $17 \%$ overall in the western U.S.

\section{Income}

In 2000, the per capita income in the western U.S. was $\$ 20,215$, which was similar to the national average of $\$ 21,690$. Per capita income was greatest in Colorado, Washington, Alaska, and California, and lowest in Montana, Idaho, and Utah. In 1999, approximately $12 \%$ of the population of the western U.S. lived below the poverty level, which was consistent with the national average. The highest poverty rates occurred in Montana, California, and Arizona, while the lowest rates occurred in Alaska, Colorado, and Utah (U.S. Department of Commerce Bureau of the Census 2004).

In 1999, the highest mean annual income in the western U.S. was paid to individuals employed by the federal government $(\$ 63,048)$, followed by the mining $(\$ 57,458)$, transportation and public utilities $(\$ 50,397)$, and manufacturing $(\$ 50,201)$ sectors. The lowest average income was realized by those working in the agricultural services, forestry, and fishing $(\$ 18,845)$ and retail trade $(\$ 20,332)$ industries (U.S. Department of Commerce Bureau of the Census 2004).

\section{Revenues Generated by BLM Lands}

The BLM allows land use for authorized private commercial activities such as energy and mineral commodity extraction, timber harvesting, livestock grazing, recreation, and the development of ROW on public land. Income generated by public land is used to assist state and local governments, support the General Fund of the U.S. Treasury, and offset charges for program operations where certain fees collected can be retained by the BLM. During FY 2005, the BLM collected nearly $\$ 1.6$ billion from a variety of land uses in the western U.S. (Table 3-18).

Operating revenues from mineral leases and permits totaled \$178.3 million in FY 2005 (USDI BLM 2006c). These receipts include rental collections from oil and gas ROW, revenues from developed lands within the Naval Oil Shale Reserve in Colorado, lease rentals and bonus bids from the National Petroleum Reserve in Alaska, and fees related to mining claims, holding fees, and non-operating revenues.

Woodland products are an important commodity and source of revenue generated on public lands. These products include timber; other wood products, such as fuelwood, posts, and poles; and non-wood forest products, such as Christmas trees, cactus, seed, yucca, pinyon nuts, mushrooms, and yew bark. During FY 1997 to 2005, an average of approximately \$35 million was generated annually from woodland products 


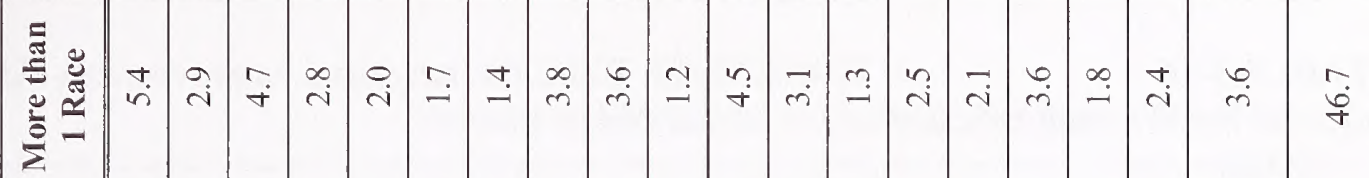

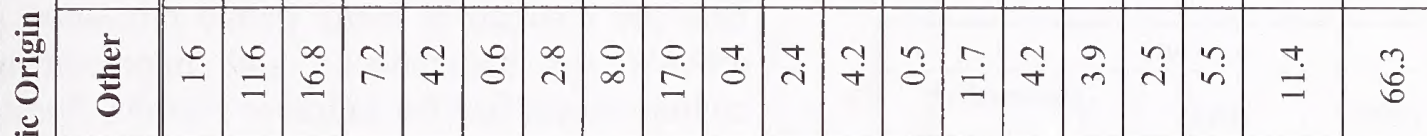

峞

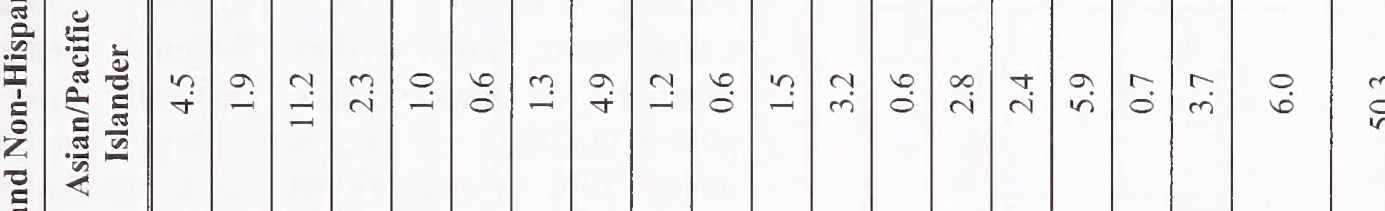

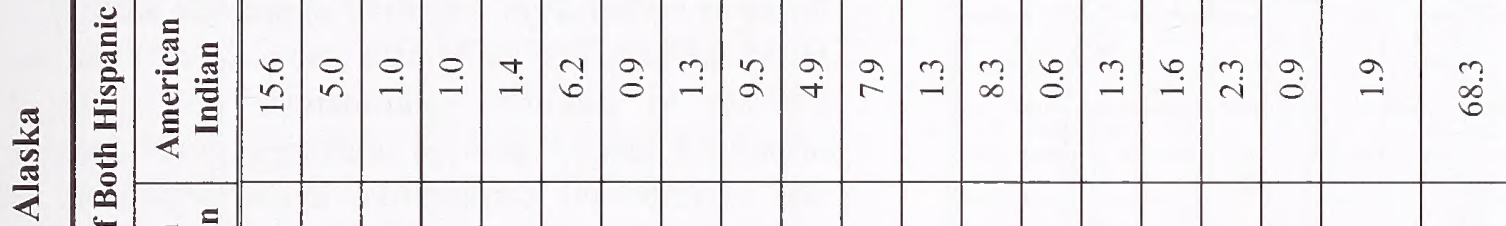

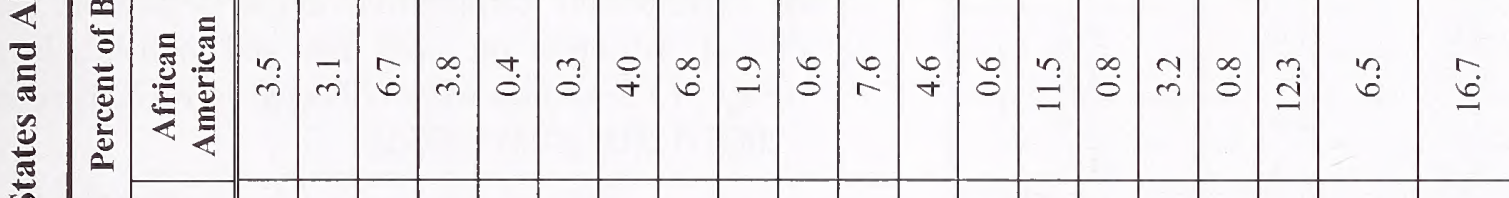

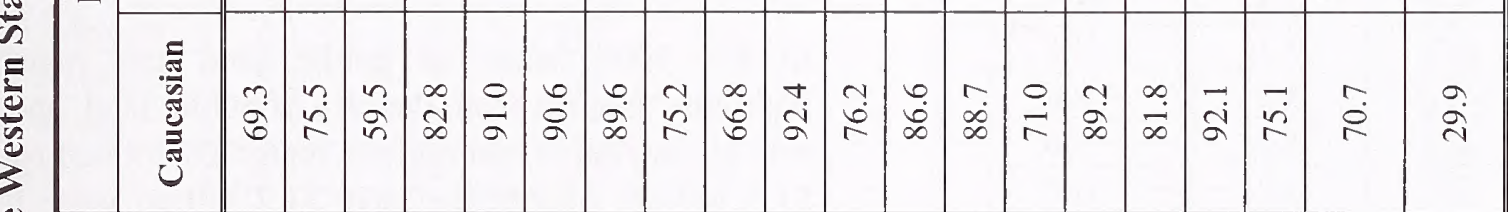

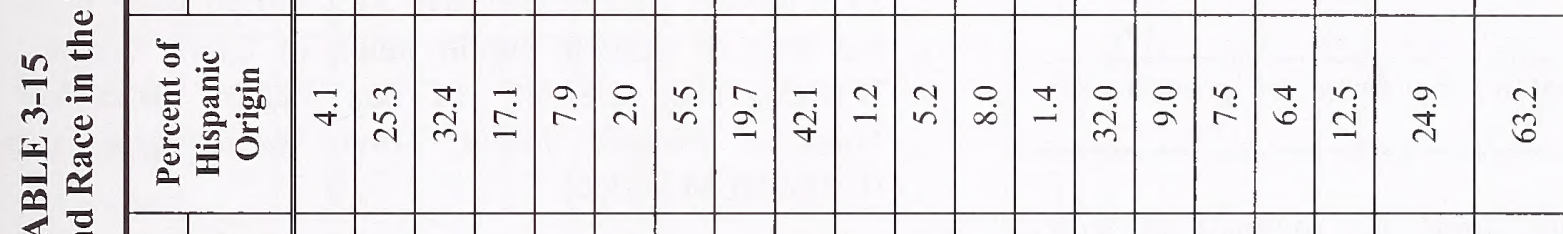

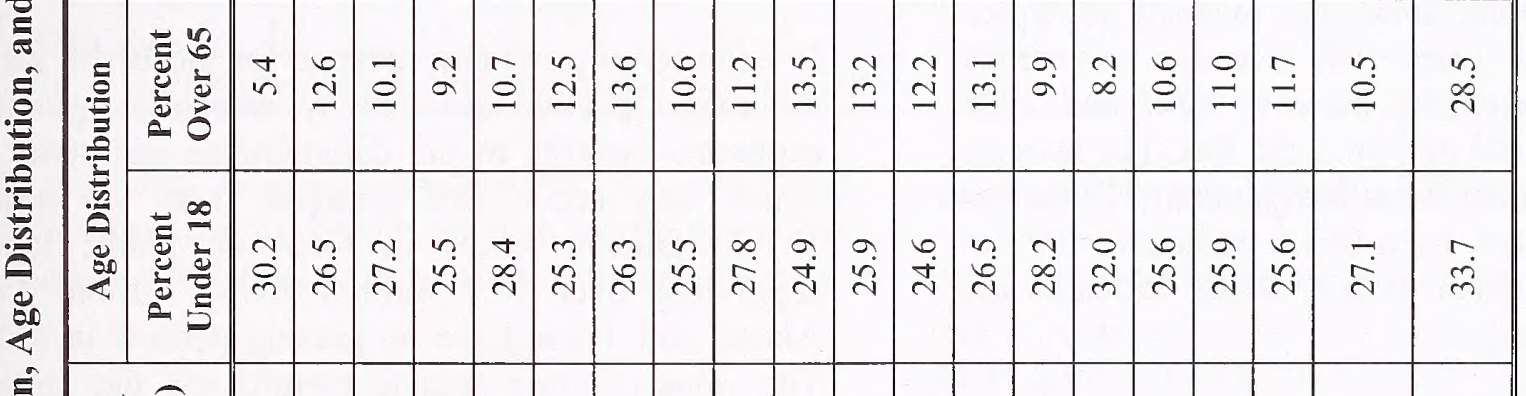

을

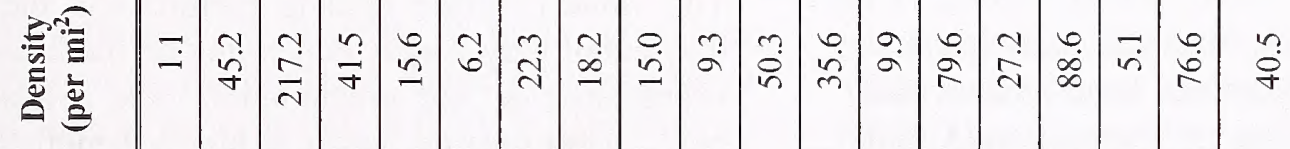

\begin{tabular}{|c|c|c|c|c|c|c|c|c|c|c|c|c|c|c|c|c|c|c|c|c|}
\hline 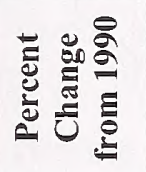 & 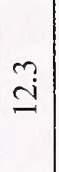 & $\begin{array}{l}0 \\
\infty \\
\dot{i}\end{array}$ & $\overrightarrow{\mathrm{c}}$ & $\stackrel{+}{\vec{r}}$ & $\tilde{\tilde{I}}$ & $\stackrel{+}{=}$ & 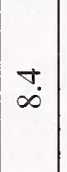 & ळे & $\tilde{b}$ & $\because$ & $\ddot{a}$ & ڤે & $\stackrel{\infty}{\sim}$ & $\begin{array}{l}\infty \\
\grave{i}\end{array}$ & $\stackrel{\grave{\lambda}}{\grave{\lambda}}$ & 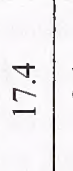 & $\vec{\infty}$ & $\begin{array}{l}0 \\
= \\
=\end{array}$ & $\stackrel{n}{n}$ & ' \\
\hline 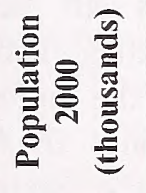 & $\tilde{\sigma}$ & $\begin{array}{l}\vec{m} \\
\vec{n}\end{array}$ & \begin{tabular}{|l}
$\hat{E}$ \\
$\infty$ \\
$\tilde{m}$ \\
$\tilde{m}$
\end{tabular} & $\begin{array}{l}\overrightarrow{0} \\
\tilde{\sigma}^{2}\end{array}$ & בे & ฉ̊ & $\vec{\nabla}$ & $\stackrel{\infty}{\stackrel{2}{二}}$ & $\underset{\infty}{\stackrel{\infty}{-}}$ & I & $\begin{array}{c}8 \\
8 \\
0 \\
m \\
m\end{array}$ & $\begin{array}{l}\vec{\gamma} \\
\text { r }\end{array}$ & $n$ & $\begin{array}{l}\sqrt{1} \\
\infty \\
0 \\
\tilde{1}\end{array}$ & $\begin{array}{l}\tilde{n} \\
\hat{i}\end{array}$ & $\begin{array}{l}\mathbb{D} \\
\infty \\
n^{\circ}\end{array}$ & 孛 & 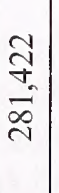 & 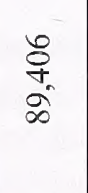 & $\frac{\infty}{\dot{m}}$ \\
\hline 营 & $\begin{array}{l}\frac{\pi}{g} \\
\frac{\pi}{2}\end{array}$ & $\begin{array}{l}\frac{g}{3} \\
\frac{\pi}{2} \\
\frac{\pi}{2}\end{array}$ & 䄊 & $\frac{8}{\frac{\pi}{0}}$ & 苞 & 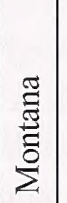 & 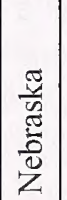 & $\begin{array}{l}\frac{\pi}{0} \\
\frac{\pi}{0} \\
z\end{array}$ & 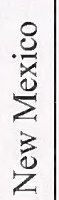 & 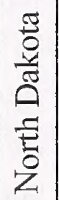 & 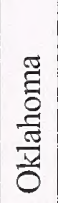 & $\begin{array}{l}\tilde{\Xi} \\
0 \\
0 \\
0 \\
0\end{array}$ & 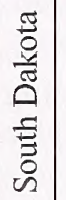 & & 氶 & 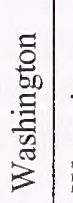 & 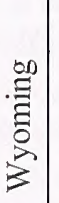 & 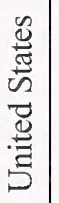 & 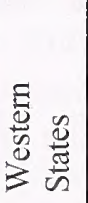 & 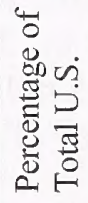 \\
\hline
\end{tabular}


TABLE 3-16

Percent Unemployment for Western U.S. and Alaska

\begin{tabular}{|l|c|c|c|}
\hline \multirow{2}{*}{ State } & \multicolumn{3}{|c|}{ Year } \\
\cline { 2 - 4 } & $\mathbf{1 9 9 0}$ & $\mathbf{2 0 0 0}$ & $\begin{array}{c}\text { December } \\
\mathbf{2 0 0 5}\end{array}$ \\
\hline Alaska & $\mathbf{7 . 0}$ & 6.6 & 6.7 \\
\hline Arizona & 5.5 & 3.9 & 4.1 \\
\hline California & 5.8 & 4.9 & 4.8 \\
\hline Colorado & 5.0 & 2.7 & 4.0 \\
\hline Idaho & 5.9 & 4.9 & 3.2 \\
\hline Montana & 6.0 & 4.9 & 2.9 \\
\hline Nebraska & 2.2 & 3.0 & 3.1 \\
\hline Nevada & 4.9 & 4.1 & 4.4 \\
\hline New Mexico & 6.5 & 4.9 & 3.8 \\
\hline North Dakota & 4.0 & 3.0 & 3.2 \\
\hline Oklahoma & 5.7 & 3.1 & 3.8 \\
\hline Oregon & 5.6 & 4.9 & 5.4 \\
\hline South Dakota & 3.9 & 2.3 & 3.2 \\
\hline Texas & 6.3 & 4.2 & 4.5 \\
\hline Utah & 4.3 & 3.2 & 2.6 \\
\hline Washington & 4.9 & 5.2 & 5.0 \\
\hline Wyoming & 5.5 & 3.9 & 3.0 \\
\hline United States & 5.6 & 4.0 & 4.5 \\
\hline \hline $\begin{array}{l}\text { Source: U.S. Department of Labor Bureau of Labor Statistics } \\
\text { (2007). }\end{array}$ \\
\hline
\end{tabular}

harvested from public lands, the majority of which came from timber sales. The average volume of timber harvested annually between 1997 and 2005 was approximately 30 million cubic feet. The revenue generated from timber sales has generally decreased over the past 8 years, from $\$ 83.6$ million in 1997 to $\$ 36.1$ million in 2005 (USDI BLM Public Land Statistics 1997-2006).

Ninety percent of income from the sale of timber and other vegetative materials is derived from Oregon and California and Coos Bay (Oregon) Wagon Road Grant Lands. Timber harvest levels on these lands are guided by the direction of the Northwest Forest Plan. Timber sales on other public lands include sales from salvage timber and forest health projects.

Grazing fees are derived using a formula established in the Public Rangelands Improvement Act of 1978, which is based on several index factors, including private land lease rates, beef cattle prices, and the cost of production. In 2006 , the fee was $\$ 1.56$ per AUM, down from $\$ 1.79$ in 2005 (USDI BLM 2006c). Approximately $\$ 14.5$ million was collected in grazing receipts in 2005. Half of the grazing fees are used by the BLM for rangeland improvements (USDI BLM 2006d).

Fees are charged at many public recreation sites to provide for maintenance and improvement, and include access fees for Entrance Permits, Special Area Permits, Daily Use Permits, Commercial, Competitive, and Group Permits, Leases, and Passports. At other locations, generally those without public facilities, no fees are charged. In FY 2005, nearly $79 \%$ of recreational use on public lands, in terms of visitor days, occurred in non-fee areas (USDI BLM 2006d). The BLM also issues special recreation permits to qualified commercial companies and organized groups such as outfitters, guides, vendors, and commercial competitive event organizers who conduct activities on both fee and non-fee lands. Nearly $\$ 13.3$ million were collected in recreation fees in 2005 (USDI BLM 2006d).

In FY 2005, sales of public land and material, including receipts from the sale of public land, and the sale of vegetative and mineral materials, totaled nearly $\$ 1.5$ billion, of which nearly $\$ 1.2$ billion were from the sale of certain public lands in Clark County, Nevada, near the city of Las Vegas, under the Southern Nevada Public Land Management Act (USDI BLM 2006c).

In addition to providing revenue for the BLM, all of the major public land activity categories generate economic benefits to the communities and states in which they occur. For example, there are nearly 18,000 grazing leases in force on public lands, supporting over 12.7 million AUMs (Table 3-6). Alaska and Texas have no grazing permits in force. The value of these grazing permits and the acreage they entail vary widely depending on the location, soil characteristics, and precipitation. The availability of public land grazing leases is highly beneficial, if not crucial, to some ranching operations, however, and consequently is very important to many rural communities throughout the West.

Similarly, mineral development is an economic mainstay of many western communities. Table 3-17 illustrates the relative importance to the employment base of mineral extraction, particularly in Arizona, Wyoming and Nevada. Each of these states, plus Alaska, has a much higher percentage of employment in mining/natural resource industry than the average for the West as a whole. This industry sector includes oil and gas, coal, aggregates, and hard rock minerals such as gold and copper. Alaska's oil industry not 
TABLE 3-17

Percent Employment by Industry in 2004

\begin{tabular}{|c|c|c|c|c|c|c|c|c|c|c|c|}
\hline State & 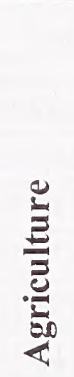 & 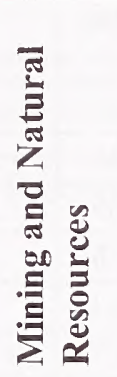 & 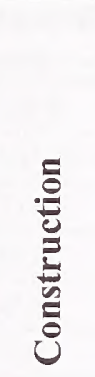 & 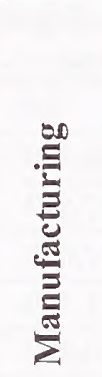 & 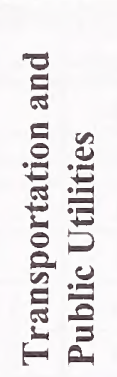 & 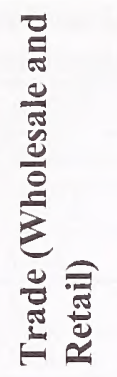 & 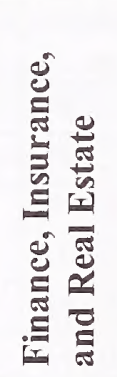 & : & 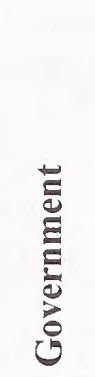 & 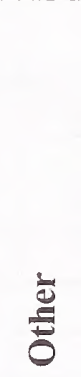 & 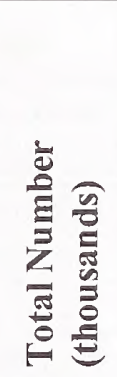 \\
\hline Alaska & 0.3 & 3.5 & 6.5 & 3.5 & 20.6 & 13.8 & 4.8 & 7.7 & 27.4 & 3.6 & 301 \\
\hline Arizona & 2.7 & 8.6 & 8.4 & 7.2 & 19.0 & 15.8 & 6.8 & 14.0 & 17.6 & 3.7 & 2,379 \\
\hline California & 3.1 & 0.2 & 5.8 & 10.5 & 18.9 & 15.5 & 0.6 & 15.1 & 16.4 & 3.4 & 14,633 \\
\hline Colorado & 2.0 & 0.7 & 7.0 & 7.0 & 18.7 & 15.3 & 7.1 & 13.9 & 16.7 & 4.0 & 2,186 \\
\hline Idaho & 6.5 & 0.8 & 7.3 & 10.3 & 19.8 & 16.5 & 4.6 & 12.9 & 19.7 & 3.1 & 600 \\
\hline Montana & 6.5 & 1.7 & 6.5 & 4.6 & 20.8 & 17.0 & 5.2 & 8.4 & 21.4 & 4.0 & 410 \\
\hline Nebraska & 6.9 & 0.1 & 5.3 & 11.0 & 21.6 & 16.1 & 6.9 & 10.3 & 17.8 & 3.8 & 917 \\
\hline Nevada & 1.4 & 7.8 & 10.2 & 4.0 & 17.0 & 14.1 & 5.4 & 8.1 & 14.0 & 3.0 & 1,165 \\
\hline New Mexico & 2.5 & 1.9 & 6.4 & 4.6 & 17.3 & 14.4 & 4.4 & 11.4 & 25.3 & 3.6 & 799 \\
\hline North Dakota & 8.8 & 1.1 & 5.4 & 7.0 & 21.3 & 17.4 & 5.6 & 7.1 & 23.0 & 4.6 & 341 \\
\hline Oklahoma & 3.3 & 2.2 & 4.3 & 9.7 & 18.8 & 15.2 & 5.7 & 10.8 & 20.5 & 5.0 & 1,472 \\
\hline Oregon & 4.3 & 0.6 & 5.3 & 12.6 & 19.9 & 16.4 & 6.1 & 11.1 & 17.0 & 3.6 & 1,624 \\
\hline South Dakota & 9.2 & 0.2 & 5.4 & 9.9 & 20.3 & 17.2 & 7.2 & 6.2 & 19.7 & 4.2 & 385 \\
\hline Texas & 2.9 & 1.6 & 5.9 & 9.3 & 20.6 & 16.4 & 6.2 & 11.3 & 17.7 & 3.8 & 9,519 \\
\hline Utah & 2.4 & 0.7 & 6.8 & 10.3 & 19.8 & 15.7 & 5.8 & 12.6 & 18.0 & 2.9 & 1,119 \\
\hline Washington & 2.9 & 0.3 & 6.3 & 9.6 & 19.2 & 15.8 & 5.8 & 11.2 & 19.3 & 3.7 & 2,752 \\
\hline Wyoming & 5.5 & 8.1 & 8.2 & 3.8 & 19.1 & 14.4 & 4.1 & 6.0 & 25.4 & 3.7 & 259 \\
\hline Western U.S. & 3.2 & 0.8 & 5.8 & 9.3 & 19.5 & 15.8 & 6.1 & 12.8 & 17.6 & 3.6 & 40,861 \\
\hline
\end{tabular}

only supports ongoing employment, it contributes toward minimizing taxes for all state residents and has provided a substantial cash rebate to residents over the years.

The BLM estimated the benefits to local economies from recreation on public lands. These estimates serve as one example of the economic activity that depends on the public land base. Recreational activity provides revenue for local economies through expenditures associated with activities such as hunting, fishing, and wildlife viewing (Table 3-19). In FY 2005, an estimated $\$ 3$ billion was injected into local economies through these recreation-associated expenditures (USDI BLM $2006 \mathrm{c}$, d). These activities produce indirect financial benefits to community businesses providing food, lodging, equipment sales, transportation, and other services. State fish and wildlife management agencies also benefit from spending associated with these activities from sources such as state tax revenue and state administered fishing and hunting license programs.

\section{Expenditures by the BLM}

The budget for the BLM was $\$ 1.78$ billion in FY 2006, and is projected to be $\$ 1.8$ billion in FY 2007 (USDI BLM 2006c). In FY 2006, \$848 million was allocated to management of lands and resources (Table 3-20). These expenditures included integrated management of public land, renewable and cultural resources, fish and wildlife, threatened and endangered species, recreation, and energy and minerals.

\section{Willdand Fire Management}

While the amount budgeted for wildland fire management may be relatively consistent from year to year, the cost of fighting fires has varied substantially. The USDI allocated $\$ 800$ million to wildland fire management for FY 2006 for all USDI fire efforts (USDI BLM 2006c).

Table 3-21 shows the BLM's fire suppression expenditures for recent years. The variability often 
TABLE 3-18

Revenues Generated from Public Lands by Source for Fiscal Year 2005

\begin{tabular}{|c|c|c|c|c|c|c|c|}
\hline State & $\begin{array}{c}\text { Mineral } \\
\text { Leases } \\
\end{array}$ & $\begin{array}{c}\text { Timber } \\
\text { Sales }\end{array}$ & $\begin{array}{c}\text { Land and } \\
\text { Material Sales }\end{array}$ & $\begin{array}{c}\text { Grazing } \\
\text { Fees } \\
\end{array}$ & $\begin{array}{c}\text { Recreation } \\
\text { Fees } \\
\end{array}$ & Other ${ }^{1}$ & Total \\
\hline Alaska & $\$ 64,139,369$ & $\$ 17,490$ & $\$ 202,736$ & $\$ 0$ & $\$ 260,115$ & $\$ 801,390$ & $\$ 65,421,100$ \\
\hline California & 220,665 & $1,605,477$ & $1,388,651$ & 267,679 & $3,347,666$ & $2,815,390$ & $9,645,528$ \\
\hline Colorado & $15,499,973$ & 38,502 & 640,191 & 617,622 & 424,138 & 667,176 & $17,887,602$ \\
\hline Nebraska & 0 & 0 & 0 & 1,510 & 0 & 0 & 1,510 \\
\hline Nevada & 130,948 & 6,441 & $1,240,628,540$ & $2,101,628$ & $2,140,736$ & $4,838,503$ & $1,249,846,796$ \\
\hline New Mexico & 957,739 & 14 & $3,739,748$ & $2,174,496$ & 396,957 & 721,915 & $7,990,869$ \\
\hline North Dakota & 2,172 & 0 & 1,573 & 18,731 & 0 & 2,460 & 24,936 \\
\hline Texas & 634 & 0 & 0 & 0 & 0 & 0 & 634 \\
\hline Utah & 129,034 & 25 & 586,121 & $1,136,093$ & $2,155,660$ & 656,863 & $4,663,796$ \\
\hline Washington & 84 & 10,455 & 28,165 & 51,906 & 0 & 18,028 & 108,638 \\
\hline Wyoming & 851,335 & 23,070 & $1,622,279$ & $2,285,227$ & 218,650 & $1,026,460$ & $6,027,021$ \\
\hline Other & $93,700,388^{3}$ & 0 & 0 & 0 & 0 & 0 & $93,700,388$ \\
\hline Total & $178,302,334$ & $26,413,785$ & $1,252,024,986$ & $14,539,876$ & $13,029,595$ & $115,754,381$ & $1,498,906,604$ \\
\hline \multicolumn{8}{|c|}{$\begin{array}{l}{ }^{1} \text { Includes fees and commissions, ROW rents, rent of land, and other sources. } \\
{ }^{2} \text { Includes Land Utilization Project land purchased by the federal government under Title III of the Bankhead-Jones Farm Tenant Act and subsequently } \\
\text { transferred to the USDI. } \\
{ }^{3} \text { Includes mining claim and holding fees and non-operating revenue. }\end{array}$} \\
\hline
\end{tabular}

TABLE 3-19

Estimated Benefits to Local Economies by Recreation on Public Lands in Fiscal Year 2005

\begin{tabular}{|l|c|c|c|c|}
\hline \multicolumn{1}{|c|}{ State $^{1}$} & $\begin{array}{c}\text { Fishing } \\
\text { Expenditures }\end{array}$ & $\begin{array}{c}\text { Hunting } \\
\text { Expenditures }\end{array}$ & $\begin{array}{c}\text { Wildlife Viewing } \\
\text { Expenditures }\end{array}$ & Total \\
\hline Alaska & $\$ 116,425,359$ & $\$ 22,158,084$ & $\$ 80,372,999$ & $\$ 218,956,442$ \\
\hline Arizona & $17,251,493$ & $45,326,644$ & $154,080,147$ & $216,658,284$ \\
\hline California & $54,815,364$ & $82,363,747$ & $411,761,577$ & $548,940,688$ \\
\hline Colorado & $74,107,778$ & $154,416,602$ & $98,545,120$ & $327,069,500$ \\
\hline Idaho & $44,282,994$ & $72,746,698$ & $66,800,278$ & $183,829,970$ \\
\hline Montana & $13,377,194$ & $23,635,550$ & $33,670,436$ & $70,683,180$ \\
\hline Nevada & $43,973,306$ & $101,344,319$ & $193,650,554$ & $338,968,179$ \\
\hline New Mexico & $21,802,203$ & $27,218,884$ & $106,404,864$ & $155,425,951$ \\
\hline Oregon & $60,958,338$ & $140,939,262$ & $219,081,863$ & $420,979,463$ \\
\hline Utah & $46,208,009$ & $92,412,855$ & $245,410,668$ & $384,031,532$ \\
\hline Washington & $1,876,536$ & $2,044,106$ & $5,274,085$ & $9,194,727$ \\
\hline Wyoming & $10,459,904$ & $39,947,204$ & $85,394,947$ & $135,802,055$ \\
\hline Total & $505,538,478$ & $804,553,955$ & $1,700,447,538$ & $3,010,539,971$ \\
\hline \hline $\begin{array}{l}\text { IEstimates include only states with more than 75,000 acres of public lands. No estimates were made for Nebraska, North Dakota, Oklahoma, South } \\
\text { Dakota, and Texas. } \\
\text { Source: BLM Public Lands Statistics (USDI BLM 2006d). }\end{array}$ \\
\hline
\end{tabular}


TABLE 3-20

Summary of BLM Jobs and Expenditures for the Management of the Lands and Resources Program by Activity and Subactivity (dollars in thousands)

\begin{tabular}{|c|c|c|c|c|}
\hline \multirow{2}{*}{ Activity/Subactivity } & \multicolumn{2}{|c|}{2005 (Actual) } & \multicolumn{2}{|c|}{2006 (Enacted) } \\
\hline & $\mathrm{FTE}^{1}$ & Amount & FTE $^{1}$ & Amount \\
\hline Management of Lands and Resources & 6,287 & $\$ 836,826$ & 6,138 & $\$ 847,632$ \\
\hline Land Resources & 1,493 & 188,014 & 1,456 & 187,613 \\
\hline Soil, Water, Air & 246 & 34,738 & 240 & 33,838 \\
\hline Range Management & 6,880 & 69,183 & 658 & 69,870 \\
\hline Forest Management & 72 & 8,895 & 75 & 10,404 \\
\hline Riparian Management & 195 & 21,228 & 190 & 22,124 \\
\hline Cultural Resources & 130 & 14,925 & 127 & 15,015 \\
\hline Wild Horse and Burros & 170 & 39,045 & 166 & 36,362 \\
\hline Wildlife and Fisheries & 298 & 36,947 & 302 & 40,480 \\
\hline Wildlife Management & 197 & 25,063 & 202 & 28,166 \\
\hline Fisheries Management & 101 & 11,884 & 100 & 12,314 \\
\hline Threatened and Endangered Species & 176 & 21,144 & 171 & 21,254 \\
\hline Recreation & 553 & 60,589 & 548 & 65,131 \\
\hline Wilderness Management & 145 & 16,431 & 141 & 16,559 \\
\hline Recreation Resource Management & 408 & 44,158 & 407 & 48,752 \\
\hline Resource Protection & 536 & 81,501 & 527 & 84,358 \\
\hline Energy and Minerals & 1,009 & 106,631 & 993 & 108,157 \\
\hline Realty and Ownership & 731 & 92,624 & 710 & 88,978 \\
\hline Transportation Facilities and Maintenance & 426 & 77,813 & 395 & 76,646 \\
\hline Workforce Organization and Support & 626 & 142,161 & 611 & 144,446 \\
\hline Alaska Minerals & 15 & 3,944 & 11 & 2,263 \\
\hline Other $^{2}$ & 663 & 25,458 & 639 & 27,306 \\
\hline \multicolumn{5}{|c|}{$\begin{array}{l}{ }^{1} \text { Full Time Equivalent. } \\
{ }^{2} \text { Includes Communications Sites Management, Mining Law Administration, Land Resources Information Systems, Challenge Cost } \\
\text { Share, and Reimbursable programs. } \\
\text { Source: USDI BLM (2006c). }\end{array}$} \\
\hline
\end{tabular}

results from changing weather, but terrain, vegetation, and proximity to populated areas all contribute to the cost of fighting a fire.

The cost of fire suppression also depends on the number and size of fires. Approximately $95 \%$ of wildland fires are controlled in the initial attack, when they are relatively small and not yet seriously out of control. Table 3-22 illustrates the acreage lost to large fires (greater than 10,000 acres) in recent years. Notably, there were relatively few large fires in 2001 and 2003, which likely contributed to reduced suppression expenditures in those years. 2004 was an anomaly in that costs remained relatively low despite an extremely large acreage lost to fire. The most likely reason is that nearly all of the large fires that year were in Alaska, and several were sufficiently remote, or in such rugged terrain, that they were allowed to burn without a major effort to control them.

\section{Hazardous Fuels Reduction}

Reducing the hazardous fuels available to sustain a wildland fire can be costly. The USDI treated 542,568 acres in the WUI during 2005 at an average cost of \$244 per acre. Treatment can cost up to $\$ 5,000$ per acre for labor-intensive, small, mechanical treatments in forested WUI areas. During the same year, the USDI treated 726,835 acres in non-WUI areas at a cost of about $\$ 104$ per acre (USDI BLM 2006c).

\section{Weed Management}

Herbicides and other vegetation management methods are employed to control invasive plant species, which have caused a variety of problems on public lands. The Vegetation section of this chapter addresses several major types of weed infestations on public lands. As Duncan and Clark (2005) noted, "The economic impact of most (weed) species is poorly documented. This is generally due to the lack of quantitative information on 
ecosystem impacts and the challenge of assessing nonmarket cost such as those to society and the environment (e.g., changes in fire frequency, wildlife habitat, aesthetics, loss of biodiversity)."

TABLE 3-21

BLM Wildland Fire Suppression Expenditures Fiscal Year 1998 through Fiscal Year 2005

\begin{tabular}{|c|c|c|}
\hline Fiscal Year & Expenditure & $\begin{array}{c}\text { Percent Change } \\
\text { from Prior Year }\end{array}$ \\
\hline 1998 & $\$ 63,470,000$ & NA \\
\hline 1999 & $85,724,000$ & 35.1 \\
\hline 2000 & $228,394,000$ & 166.4 \\
\hline 2001 & $192,115,000$ & -15.9 \\
\hline 2002 & $204,666,000$ & 6.5 \\
\hline 2003 & $151,994,000$ & -25.8 \\
\hline 2004 & $158,626,000$ & 4.4 \\
\hline 2005 & $218,445,000$ & 39.7 \\
\hline \hline $\begin{array}{l}\text { NA = Not applicable } \\
\text { Source: USDI BLM (2006c). }\end{array}$ \\
\hline
\end{tabular}

Expenditures for herbicides used on BLM land are a relatively small part of the agency's budget, accounting for only a little more than $\$ 2.7$ million in FY 2005 (Table 3-23). Table 3-23 includes only the cost of the chemicals; labor and equipment costs for herbicide application are in addition to the costs shown. The BLM estimated it spent $\$ 9.6$ million to treat approximately 205,000 acres ( $\$ 47$ per acre) to treat weeds during FY 2005; These costs included herbicide, labor, and equipment costs. The cost of herbicides can vary dramatically, depending on the type selected and the method of application. Costs can also vary significantly by geographic region, vendor, type of chemical (generic versus branded), and size and terrain of the application target area. The Forest Service estimated the average cost per acre at $\$ 100$ for ground applications and $\$ 25$ for aerial applications (USDA Forest Service 2005). The BLM's range of estimated application costs is even broader. For ground applications, BLM's estimates range from $\$ 50$ to $\$ 300$ per acre for backpack or ATV applications and $\$ 25$ to $\$ 75$ per acre for boom sprayer applications. Aerial applications are estimated at $\$ 6$ to $\$ 40$ per acre for fixed-wing aircraft and $\$ 25$ to $\$ 200$ per acre for helicopter applications.

It is estimated that downy brome infests over 56 million acres in the 17 western states and that the infestation is growing at 14\% per year (Duncan and Clark 2005). As indicated in Table 3-5, more than 90 million acres of public lands are infested with downy brome and other brome species. Downy brome can increase the frequency and intensity of wildfire and destroy the structure of the native plant communities, particularly sagebrush habitats. Because of its widespread dominance, downy brome has become the most important forage grass in the western U.S. However, it is highly unreliable as a forage base for both cattle and wildlife because it can exhibit "tenfold differences (300$3,500 \mathrm{lbs} /$ acre) from year to year" in productivity, depending on precipitation.

Once a treatment is accomplished, it is then costly to rehabilitate the land. Cost per acre to stabilize and rehabilitate disturbed land is estimated at \$17. During 1991, however, it cost $\$ 100,000$ to rehabilitate the 1,700 acres burned in the Snake River Birds of Prey Area, Idaho, or almost $\$ 59$ per acre. During 2004, it cost the BLM $\$ 1,640$ per acre to restore 12,000 acres of forestland and woodlands. The unit cost ranged from $\$ 295$ per acre in New Mexico to $\$ 2,730$ per acre in Oregon (USDI BLM 2005a).

TABLE 3-22

\section{BLM Action Fires Larger Than 10,000 Acres ${ }^{1}$ during 1999 to 2005}

\begin{tabular}{|c|c|c|c|}
\hline $\begin{array}{c}\text { Callendar } \\
\text { Year }\end{array}$ & $\begin{array}{l}\text { Number } \\
\text { of Fires }\end{array}$ & $\begin{array}{c}\text { Average } \\
\text { Size } \\
\text { (Acres) } \\
\end{array}$ & $\begin{array}{c}\text { Total } \\
\text { Acreage }\end{array}$ \\
\hline 1999 & 64 & 44,990 & $2,879,351$ \\
\hline 2000 & 66 & 34,851 & $2,300,187$ \\
\hline 2001 & 28 & 40,524 & $1,134,662$ \\
\hline 2002 & 46 & 55,484 & $2,552,265$ \\
\hline 2003 & 23 & 55,940 & $1,286,612$ \\
\hline 2004 & 51 & 122,805 & $6,263,059$ \\
\hline 2005 & 98 & 68,277 & $6,691,137$ \\
\hline Total & 376 & 61,455 & $23,107,273$ \\
\hline
\end{tabular}

\section{Payments to State and Local Governments}

Where the federal government maintains public land, it makes payments to state and local governments for a variety of purposes. Receipts from coal leases and bonus payments, for example, are shared. Payments in lieu of taxes help address the loss of potential local tax income that could have been generated from those public lands if they were in private ownership. Payments in lieu of taxes, as well as other forms of transfer payments, are generally set by law and provided according to a formula. Payments in lieu of taxes, for example, are computed based on the number of acres of public lands within each county and multiplied by a dollar amount per acre. Over \$2 billion in payments 
TABLE 3-23

Herbicide Uses and Costs for Vegetation Treatments on Public Lands during 2005

\begin{tabular}{|c|c|c|c|c|}
\hline Herbicide & $\begin{array}{c}\text { Type of } \\
\text { Application }\end{array}$ & Acres Treated ${ }^{1}$ & $\begin{array}{c}\text { Total Herbicide } \\
\text { Expenditure }^{2}\end{array}$ & $\begin{array}{l}\text { Cost per Acre for } \\
\text { Herbicide }\end{array}$ \\
\hline $2,4-\mathrm{D}$ & $\begin{array}{l}\text { Aerial } \\
\text { Ground }\end{array}$ & $\begin{array}{r}1,689 \\
40,133\end{array}$ & $\begin{array}{r}\$ 5,474 \\
186,515\end{array}$ & $\begin{array}{r}\$ 3.24 \\
4.65\end{array}$ \\
\hline Bromacil & $\begin{array}{l}\text { Aerial } \\
\text { Ground }\end{array}$ & $\begin{array}{r}0 \\
2,999 \\
\end{array}$ & $\begin{array}{r}0 \\
379,763 \\
\end{array}$ & $\begin{array}{r}\text { NA } \\
126.63 \\
\end{array}$ \\
\hline Chlorsulfuron & $\begin{array}{l}\text { Aerial } \\
\text { Ground }\end{array}$ & $\begin{array}{r}374 \\
2,667\end{array}$ & $\begin{array}{l}35,572 \\
51,836\end{array}$ & $\begin{array}{l}95.11 \\
19.44 \\
\end{array}$ \\
\hline Clopyralid & $\begin{array}{l}\text { Aerial } \\
\text { Ground }\end{array}$ & $\begin{array}{l}5,168 \\
6,277 \\
\end{array}$ & $\begin{array}{l}169,510 \\
268,032 \\
\end{array}$ & $\begin{array}{l}32.80 \\
42.70\end{array}$ \\
\hline Dicamba & $\begin{array}{l}\text { Aerial } \\
\text { Ground }\end{array}$ & $\begin{array}{r}48 \\
7,664\end{array}$ & $\begin{array}{r}945 \\
150,245\end{array}$ & $\begin{array}{l}19.69 \\
19.60\end{array}$ \\
\hline Diuron & $\begin{array}{l}\text { Aerial } \\
\text { Ground }\end{array}$ & $\begin{array}{r}0 \\
4,427 \\
\end{array}$ & $\begin{array}{r}0 \\
72,340 \\
\end{array}$ & $\begin{array}{r}\mathrm{NA} \\
16.34 \\
\end{array}$ \\
\hline Fosamine & $\begin{array}{l}\text { Aerial } \\
\text { Ground }\end{array}$ & $\begin{array}{l}0 \\
0 \\
\end{array}$ & $\begin{array}{l}0 \\
0\end{array}$ & $\begin{array}{l}\text { NA } \\
\text { NA }\end{array}$ \\
\hline Glyphosate & $\begin{array}{l}\text { Aerial } \\
\text { Ground }\end{array}$ & $\begin{array}{r}11,032 \\
8,309\end{array}$ & $\begin{array}{l}25,648 \\
56,487\end{array}$ & $\begin{array}{l}2.32 \\
6.80\end{array}$ \\
\hline Hexazinone & $\begin{array}{l}\text { Aerial } \\
\text { Ground }\end{array}$ & $\begin{array}{r}0 \\
4,952 \\
\end{array}$ & $\begin{array}{r}0 \\
3,138 \\
\end{array}$ & $\begin{array}{l}\text { NA } \\
0.63 \\
\end{array}$ \\
\hline Imazapic & $\begin{array}{l}\text { Aerial } \\
\text { Ground }\end{array}$ & $\begin{array}{r}0 \\
45\end{array}$ & $\begin{array}{r}0 \\
1,309\end{array}$ & $\begin{array}{r}\text { NA } \\
29.10\end{array}$ \\
\hline Imazapyr & $\begin{array}{l}\text { Aerial } \\
\text { Ground }\end{array}$ & $\begin{array}{l}1,203 \\
1,788\end{array}$ & $\begin{array}{l}151,340 \\
105,619 \\
\end{array}$ & $\begin{array}{r}125.80 \\
59.07 \\
\end{array}$ \\
\hline Metsulfuron methyl & $\begin{array}{l}\text { Aerial } \\
\text { Ground }\end{array}$ & $\begin{array}{r}663 \\
14,129 \\
\end{array}$ & $\begin{array}{r}5,529 \\
178,208 \\
\end{array}$ & $\begin{array}{r}8.34 \\
12.61 \\
\end{array}$ \\
\hline Picloram & $\begin{array}{l}\text { Aerial } \\
\text { Ground }\end{array}$ & $\begin{array}{r}4,158 \\
28,385 \\
\end{array}$ & $\begin{array}{r}67,497 \\
629,897 \\
\end{array}$ & $\begin{array}{l}16.23 \\
22.19 \\
\end{array}$ \\
\hline Sulfometuron methyl & $\begin{array}{l}\text { Aerial } \\
\text { Ground }\end{array}$ & $\begin{array}{r}0 \\
304 \\
\end{array}$ & $\begin{array}{r}0 \\
7,741 \\
\end{array}$ & $\begin{array}{r}\mathrm{NA} \\
25.46 \\
\end{array}$ \\
\hline Tebuthiuron & $\begin{array}{l}\text { Aerial } \\
\text { Ground }\end{array}$ & $\begin{array}{r}40,755 \\
0\end{array}$ & $\begin{array}{r}47,427 \\
0\end{array}$ & $\begin{array}{l}1.16 \\
\text { NA }\end{array}$ \\
\hline Triclopyr & $\begin{array}{l}\text { Aerial } \\
\text { Ground }\end{array}$ & $\begin{array}{l}4,000 \\
3,170 \\
\end{array}$ & $\begin{array}{l}23,750 \\
85,966\end{array}$ & $\begin{array}{r}5.94 \\
27.12 \\
\end{array}$ \\
\hline \multicolumn{5}{|c|}{$\begin{array}{l}{ }^{1} \text { Acres treated do not take into account whether the aerial application was by helicopter or airplane, nor do they distinguish between } \\
\text { ground application methods. Costs would vary depending on the application method. } \\
{ }^{2} \text { Total herbicide expenditure and cost per acre do not include costs for labor, equipment, and application, and represent an average cost } \\
\text { for use throughout the BLM. } \\
\text { NA = Not available or not applicable. }\end{array}$} \\
\hline
\end{tabular}

have been made since 1976. Table 3-24 shows the BLM payments to states and local governments for FY 2004.

\section{Human Health and Safety}

\section{Background Health Risks}

This section discusses background information on human health risks of injuries, and cancer and other diseases for people living in the states in which the
BLM is planning to implement vegetation treatments. People living in these states are exposed to a variety of risks common to the U.S. as a whole, including automobile accidents and other injuries; contaminants in the air, water, soil, and food; and various diseases. Risks to workers may differ from those facing the general public, depending on the nature of a person's work. Some of these risks may be quantified, but a lack of data allows for only a qualitative description of certain risks. Where data are only available for the U.S. as a whole, it is assumed that these data apply to 
the treatment states. Information for this section was obtained from the Centers for Disease Control and Prevention (CDC), the National Center for Injury Prevention and Control (NCIPC), the National Center for Health Statistics (NCHS), the National Institute for Occupational Safety and Health (NIOSH), and the Bureau of Labor Statistics.

\section{Risks from Diseases}

\section{Disease Incidence}

Despite the difficulties in establishing correlations between work conditions and disease, certain illnesses have been linked to occupational hazards. For example, asbestosis and lung cancer among insulation and shipyard workers has been linked to their exposure to asbestos (NIOSH 2002). Pneumoconiosis among coal miners has been correlated with the inhalation of coal dust. Occupational exposures to some metals, dusts, and trace elements, as well as CO, carbon disulfide, halogenated hydrocarbons, nitroglycerin, and nitrates, can result in increased incidence of cardiovascular disease. Neurotoxic disorders can arise from exposure to a wide range of chemicals, including some pesticides. Dermatological conditions like contact dermatitis, infection, trauma, cancer, vitiligo, uticaria, and chloracne have a high occurrence in the agricultural, forestry, and fishing industries.

\section{Disease Mortality}

Mortality rates for states in the BLM treatment area are listed in Table 3-25. The five most common causes of death in the U.S., as well as in the treatment states, are heart disease, cancer, stroke, respiratory disease, and accidents (Minino et al. 2002). Counties in the western U.S. that have the highest mortality rates are located in central Nevada, north and southcentral California, and western Montana. Mortality rates are generally lowest in counties in western Utah, central Idaho, and northwest Wyoming (NCHS 2007). Mortality rates for males are nearly one and a half times those as for females, and mortality rates for African Americans are nearly one and a half times those of Caucasians (NCHS 2007).

\section{Risks from Injuries}

\section{Injury Incidence}

In 2005, more than 29.3 million nonfatal injuries were reported in the United States, 4.4 million of which were transportation related (CDC 2007a). Injuries accounted for $26 \%$ of emergency department visits during 2004 (NCHS 2007).

The rate of hospitalizations for injury is significantly higher among elderly persons than among all other age groups (CDC 2005). The NIOSH estimates that approximately 10 million traumatic work-related injuries occur annually. Some chronic injuries may be directly linked to the nature of the work performed. For example, vibration syndrome affects a large proportion of workers using chippers, grinders, chainsaws, jackhammers, or other handheld power tools, causing blanching and reduced sensitivity in the fingers. The Bureau of Labor Statistics reported that in 1995, an estimated $62 \%$ of all work-related illness cases were due to musculoskeletal disorders associated with repeated trauma, such as that associated with the use of power tools (NIOSH 1997). Noise-induced hearing loss may also affect production workers who are exposed to noise levels of 80 decibels or more on a daily basis.

Acute trauma at work remains a leading cause of death and disability among U.S. workers. During the period from 1980 through 1995, at least 93,338 workers in the U.S. died as a result of trauma suffered on the job, with an average of about 16 deaths per day (NIOSH 2001). The Census of Fatal Occupational Injuries Summary by the BLS (U.S. Department of Labor Bureau of Labor Statistics 2004) identified 5,559 workplace deaths from acute traumatic injury in 2003. Occupational fatalities resulted from a number of causes, including motor vehicle accidents, machines, falls, homicide, electrocution, and being struck by falling objects (NIOSH 2002).

The occupational fatality rate in 2005 was approximately 4.0 fatalities per 100,000 employed. Fatality rates were highest for the agriculture, forestry, fishing, and hunting; mining; transportation; and construction industries. The fatality rate for the agriculture, forestry, fishing, and hunting sector was the highest, at 32.5 fatal industries per 100,000 workers. The mining sector had the second highest rate, at 25.6 fatalities per 100,000 employed. In the transportation and construction industries the rates were 17.6 and 11.0 fatalities per 100,000 employed, respectively. The largest number of fatal work injuries resulted from construction-related incidents, which accounting for $21 \%$ of workplace fatalities in 2003 (U.S. Department of Labor Bureau of Labor Statistics 2004). 
TABLE 3-24

BLM Payments to States and Local Govermments during Fiscal Year 2005

\begin{tabular}{|c|c|c|c|c|c|c|c|c|}
\hline \multirow[b]{2}{*}{ State } & \multirow{2}{*}{$\begin{array}{c}\text { Payments } \\
\text { in Lieu of } \\
\text { Taxes }\end{array}$} & \multirow{2}{*}{$\begin{array}{c}\text { Mineral } \\
\text { Leasing } \\
\text { Act }\end{array}$} & \multicolumn{3}{|c|}{ Taylor Grazing $\mathrm{Act}^{2}$} & \multirow{2}{*}{$\begin{array}{c}\text { Proceeds } \\
\text { of Sales }\end{array}$} & \multirow[b]{2}{*}{ Other } & \multirow{2}{*}{$\begin{array}{c}\text { Total } \\
\text { Payments }\end{array}$} \\
\hline & & & $\begin{array}{c}\text { Section } \\
3 \\
\end{array}$ & $\begin{array}{c}\text { Section } \\
15 \\
\end{array}$ & Other & & & \\
\hline Alaska & $\$ 15,785,027$ & $\$ 29,559$ & $\$ 0$ & $\$ 0$ & $\$ 0$ & $\$ 5,412$ & $\$ 31,594,5953^{3}$ & $\$ 47,414,593$ \\
\hline Arizona & $19,233,774$ & 45,743 & 43,124 & 79,669 & 0 & 107,081 & 0 & $19,509,331$ \\
\hline California & $19,002,175$ & 122,757 & 14,012 & 55,755 & 0 & 45,359 & 0 & $19,240,058$ \\
\hline Colorado & $16,839,759$ & 129,557 & 53,520 & 30,062 & 43,068 & 29,640 & 0 & $17,125,606$ \\
\hline Montana & $17,188,322$ & 18,056 & 128,785 & 95,678 & 0 & 20,175 & $649,745^{4}$ & $18,100,761$ \\
\hline Nebraska & 676,604 & 0 & 0 & 664 & 0 & 0 & 0 & 677,268 \\
\hline Nevada & $13,732,723$ & 65,445 & 233,458 & 705 & 0 & 824,000 & $204,497,479^{5}$ & $219,353,810$ \\
\hline New Mexico & $22,386,899$ & 475,204 & 170,502 & 135,900 & 14 & 88,389 & $8,269^{4}$ & $23,265,177$ \\
\hline North Dakota & 950,280 & 1,086 & 0 & 7,921 & 0 & 67 & 0 & 959,354 \\
\hline Utah & $19,622,224$ & 55,319 & 104,868 & 0 & 0 & 15,337 & 0 & $19,797,748$ \\
\hline Washington & $6,322,087$ & 42 & 0 & 22,367 & 0 & 5,378 & 0 & $6,349,874$ \\
\hline Wyoming & $14,810,769$ & 413,269 & 145,697 & 327,446 & 6,924 & 78,040 & 0 & $15,782,145$ \\
\hline Western States & $195,612,593$ & $1,379,995$ & $1,193,49$ & 869,973 & 50,006 & $1,286,190$ & $350,100,934$ & $550,493,183$ \\
\hline All States & $226,356,675$ & $1,379,995$ & $1,193,49$ & 869,973 & 50,006 & $1,286,458$ & $350,100,934$ & $581,237,533$ \\
\hline \multicolumn{9}{|c|}{$\begin{array}{l}{ }^{1} \text { Payments in lieu of taxes are made by the USDI, Office of the Secretary, for tax-exempt federal lands administered by the BLM, National Park Service, } \\
\text { USFWS, and Forest Service, as well as for federal water projects and some military installations. } \\
\text { Including payments for FY } 2004 \text { that were processed in FY } 2005 \text {. } \\
{ }^{3} \text { National Petroleum Reserve - Alaska lands. } \\
{ }^{4} \text { Land utilization lands under the Bankhead-Jones Farm Tenant Act (7 U.S.C. 1012). } \\
{ }^{5} \text { Land utilization sales under the Southern Nevada Public Land Management Act resulted in direct payments at the time of sale totaling } \$ 193,566,000 \text {. } \\
\text { Calendar year payments to Clark County and the State of Nevada under the Santini-Burton Act totaled } \$ 3,784,080 \text {. } \\
{ }^{6} \text { Oklahoma royalties. } \\
\text { Source: USDI BLM }(2006 \mathrm{c}) \text {. }\end{array}$} \\
\hline
\end{tabular}

\section{Injury Mortality}

Over 167,000 Americans died from injuries nationwide in 2004. About $26 \%$ of these resulted from motor vehicle accidents, while other accidental deaths occurred from unintentional falls, drowning, and poisoning (CDC 2007a). Injury is the leading cause of death and disability among children and young adults.

\section{Risks from Cancer}

\section{Cancer Incidence}

Nationwide, the chance of developing some form of cancer during one's lifetime is estimated to be about one in four (Calabrese and Dorsey 1984). There are many causes of cancer development, including occupational exposure to carcinogens, environmental contaminants, and substances in food. In the U.S., one-third of all cancers are attributed to tobacco smoking. Work- related cancers are estimated to account for $4 \%$ to $20 \%$ of all malignancies. It is difficult to quantify the information because of the long time intervals between exposure and diagnosis, personal behavior patterns, job changes, and exposure to other carcinogens. The NIOSH has reported that approximately 20,000 cancer deaths and 40,000 new cases of cancer each year in the U.S. are attributable to occupational hazards. Millions of U.S. workers are exposed to substances that have tested as carcinogens in animal studies (NIOSH 2002).

Cancer Mortality. Based on the data shown in Table 325 , cancer accounted for between 13 and $33 \%$ of all deaths in the treatment states in 2002-2003. Nationwide, cancer account for approximately $23 \%$ of all fatalities (NCHS 2007). Cancer mortality rates are generally highest in counties in western and southern Nevada and northern California and lowest in counties in Utah, central Colorado, and northern New Mexico (Devesa et 
TABLE 3-25

Mortality Rates (per 100,000 Population) and Causes of Death by State 2002-2003

\begin{tabular}{|c|c|c|c|c|c|}
\hline \multirow[b]{3}{*}{ State } & \multicolumn{5}{|c|}{ Cause of Death } \\
\hline & \multirow[b]{2}{*}{ All } & \multicolumn{2}{|c|}{ Diseases } & \multirow[b]{2}{*}{ Cancer } & \multirow[b]{2}{*}{ Accidents } \\
\hline & & $\begin{array}{l}\text { Cerebrovascular and } \\
\text { Cardiovascular Disease }\end{array}$ & $\begin{array}{c}\text { Chronic Respiratory } \\
\text { Disease }\end{array}$ & & \\
\hline Alaska & $812.5^{1}$ & 235.7 & 47.4 & 186.9 & 58.2 \\
\hline Arizona & 788.0 & 248.1 & 46.8 & 171.9 & 48.1 \\
\hline California & 762.3 & 283.8 & 43.1 & 175.9 & 28.2 \\
\hline Colorado & 784.5 & 231.4 & 53.0 & 169.5 & 42.0 \\
\hline Idaho & 800.4 & 264.3 & 48.3 & 175.6 & 45.4 \\
\hline Montana & 841.3 & 249.4 & 58.4 & 190.3 & 53.3 \\
\hline Nebraska & 799.9 & 262.4 & 47.4 & 183.2 & 38.0 \\
\hline Nevada & 920.1 & 303.9 & 64.5 & 203.1 & 40.5 \\
\hline New Mexico & 820.1 & 240.4 & 49.3 & 169.7 & 61.9 \\
\hline North Dakota & 765.2 & 260.8 & 40.0 & 180.7 & 36.3 \\
\hline Oklahoma & 967.9 & 367.4 & 55.2 & 202.5 & 47.4 \\
\hline Oregon & 823.7 & 256.9 & 48.9 & 195.8 & 37.6 \\
\hline South Dakota & 782.1 & 264.1 & 42.4 & 186.7 & 46.9 \\
\hline Texas & 863.6 & 307.5 & 44.6 & 187.8 & 39.9 \\
\hline Utah & 778.2 & 239.7 & 35.3 & 143.1 & 34.1 \\
\hline Washington & 785.3 & 258.9 & 47.4 & 190.9 & 36.0 \\
\hline Wyoming & 852.9 & 258.8 & 60.7 & 185.0 & 56.0 \\
\hline United States & 842.7 & 295.5 & 43.4 & 193.0 & 36.6 \\
\hline
\end{tabular}

al. 1999), and differ depending on race and sex. Generally, males have higher rates of cancer mortality than females, and African Americans have higher rates than Caucasians.

\section{Risk from Using Herbicides on Public Lands}

Based on the BLM's injury breakout report (USDI BLM 2005b), only one minor injury from use of herbicides was recorded during FY 2005.

\section{Risk from Wildfire Control on Public Lands}

During FY 2005, 24,683 fires totaling 6,691,137 acres were suppressed on public lands. Over three out of every four fires were caused by lightning, while the remainder were caused by humans. Approximately 56\% of fires occurred on forestlands, the remainder on rangelands and other land types (USDI BLM 2006d).
Wildfires cause the loss of life and property. According to the National Interagency Fire Center (2005), 12 people died from wildland fire-related accidents in 2005. From 1999 to 2005, the leading cause of firefighter deaths nationally, which include federal, state, and local firefighters and volunteers, as well as private individuals who were involved in direct support of wildland fire operations are: vehicle accidents $(23.8 \%)$, heart attacks $(22.7 \%)$, aircraft accidents $(22.3 \%)$, and burnovers/entrapments $(20.2 \%)$.

During FYs 2002 to 2005, 49 USDI personnel were injured conducting fire operations. During 2005, wildland fires resulted in the loss of 240 primary residences and 750 total structures on lands near BLMor Forest Service-administered lands (USDI BLM 2006c). 


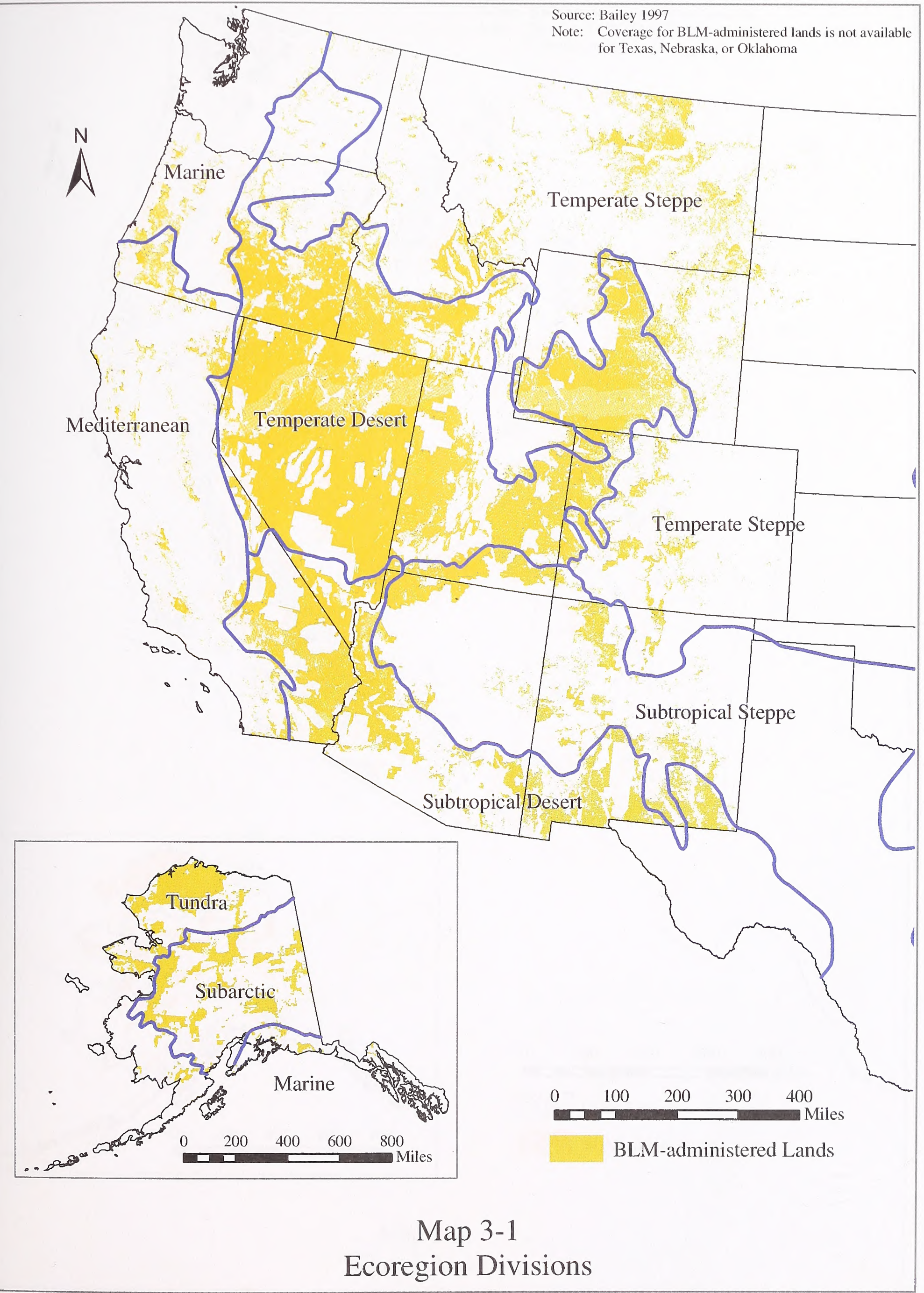







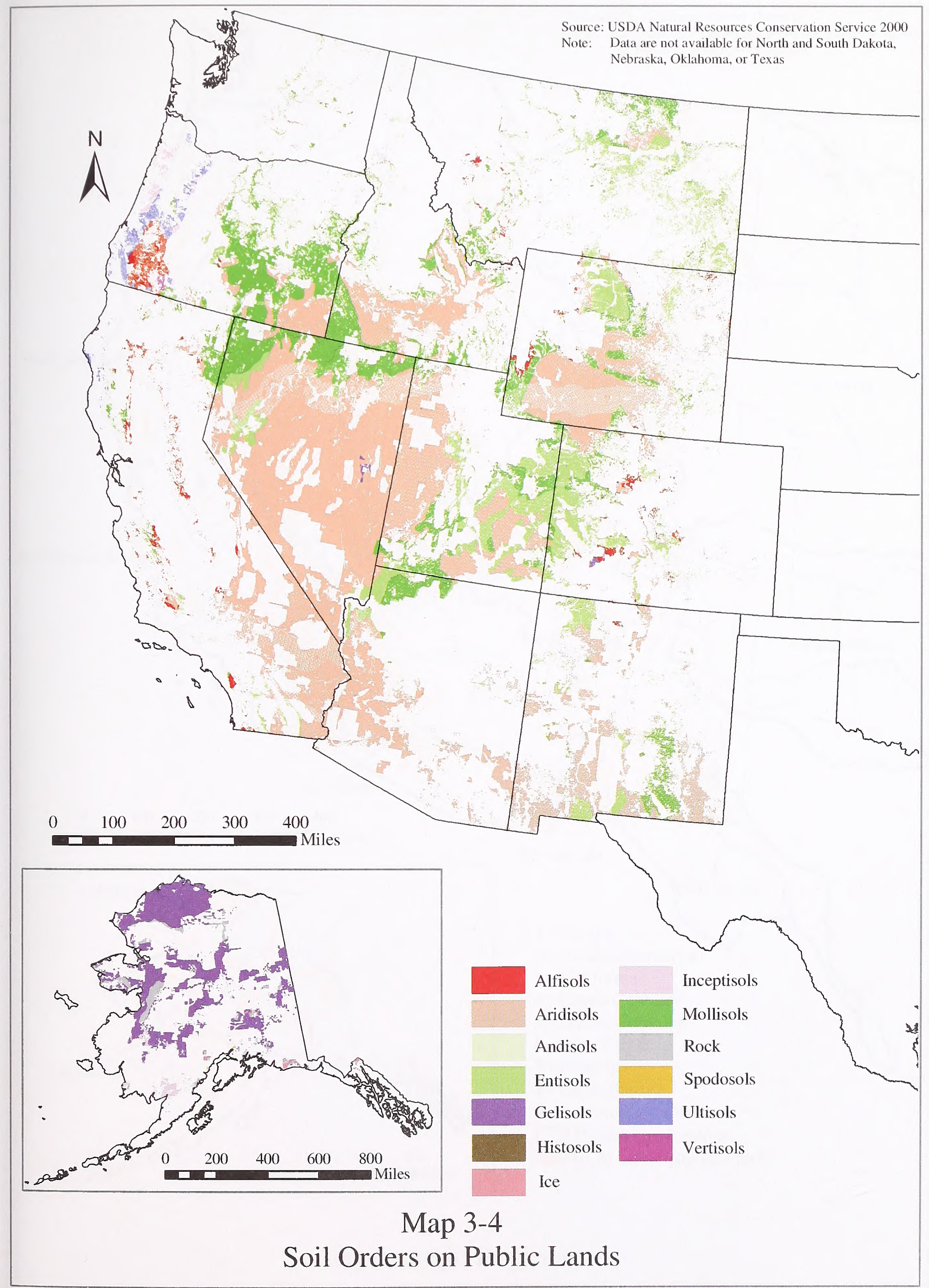





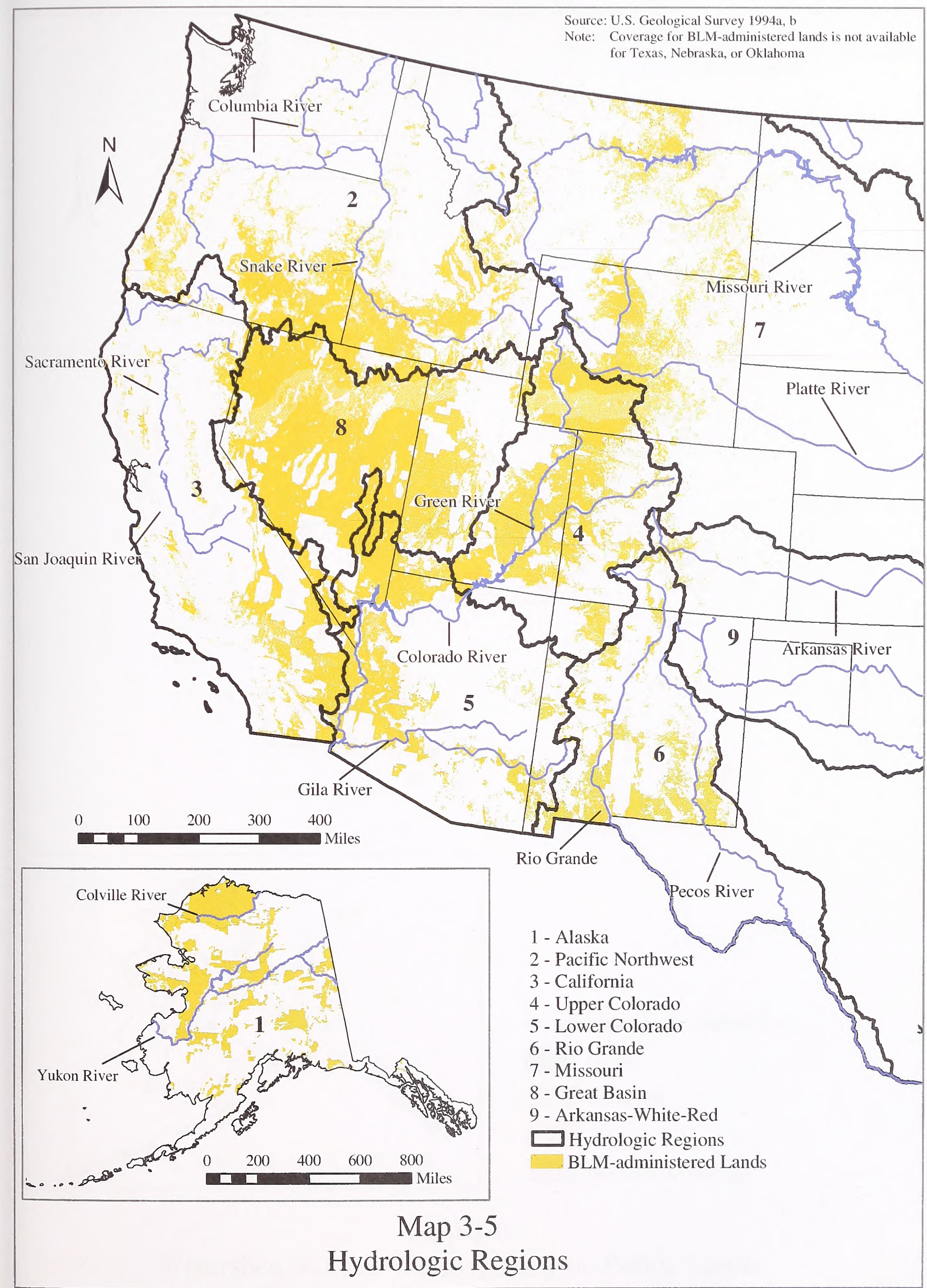





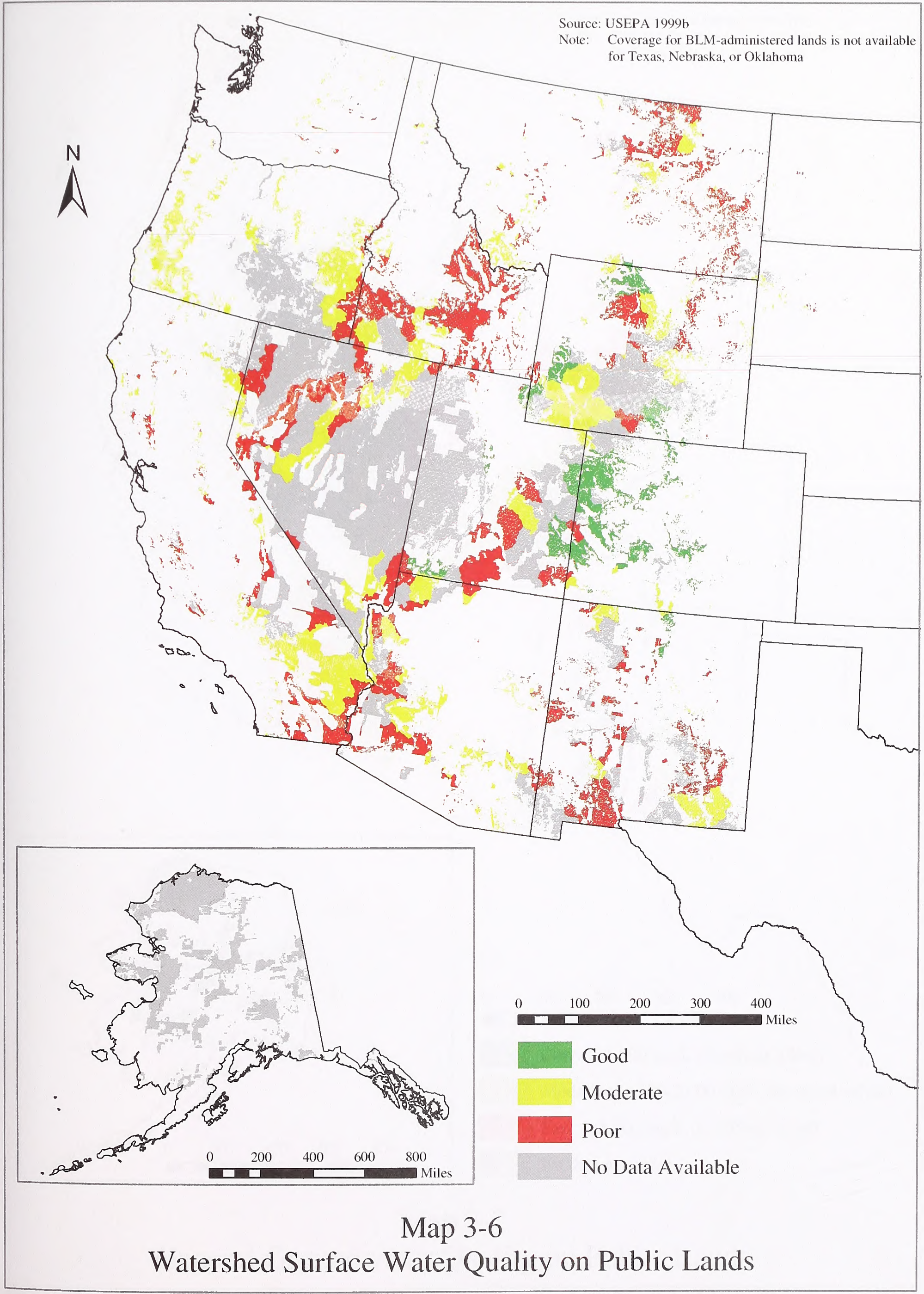





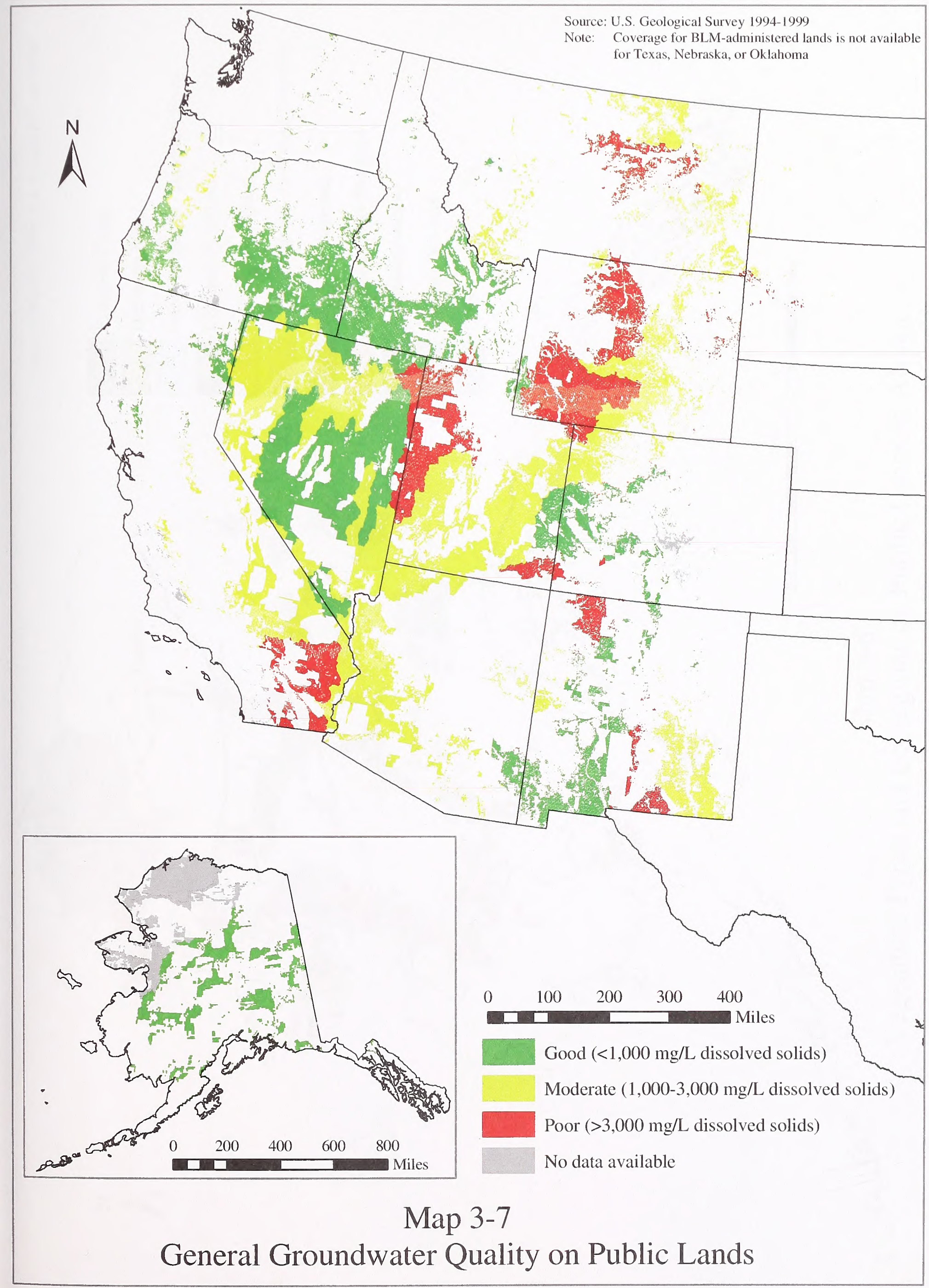





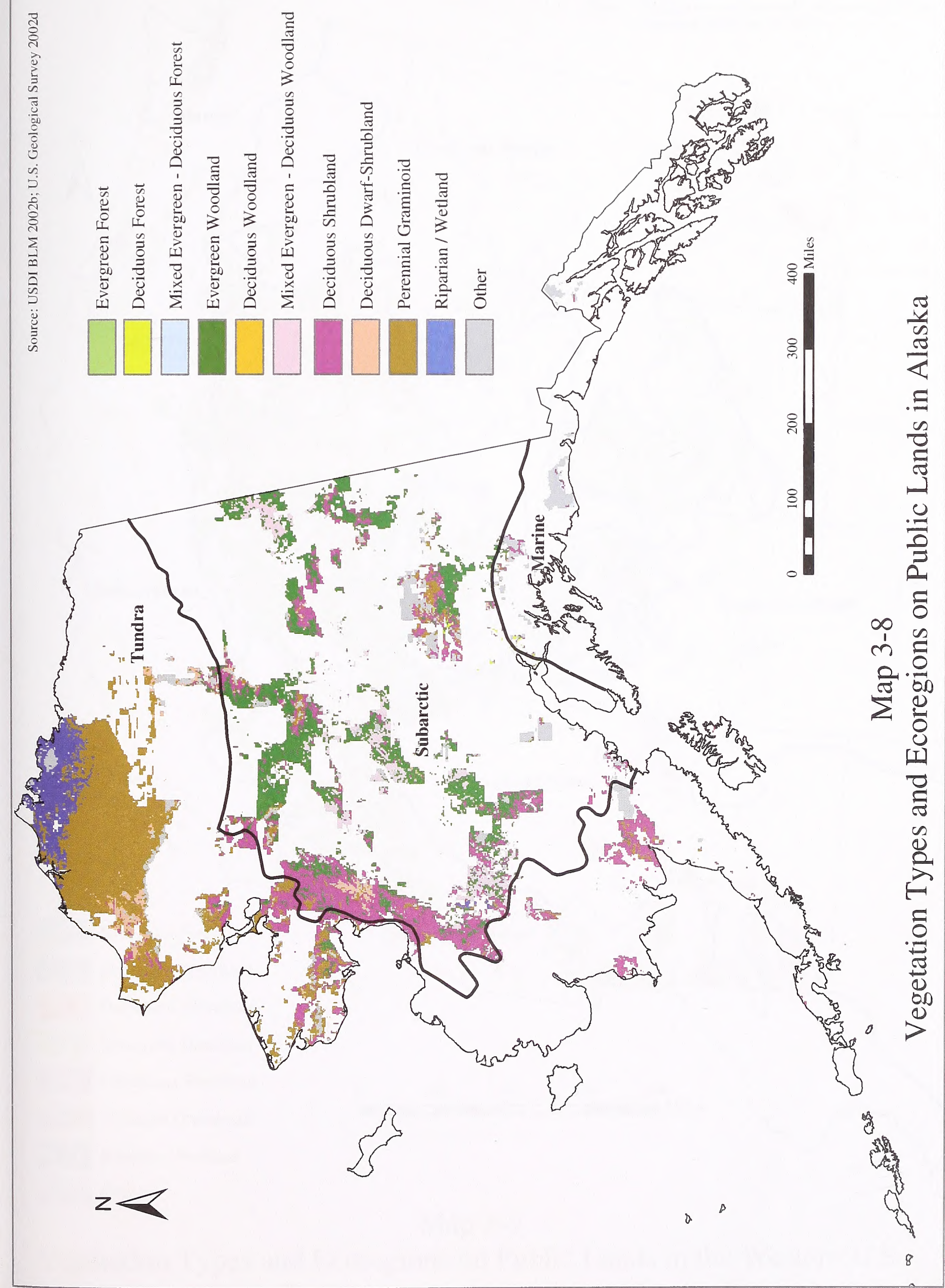





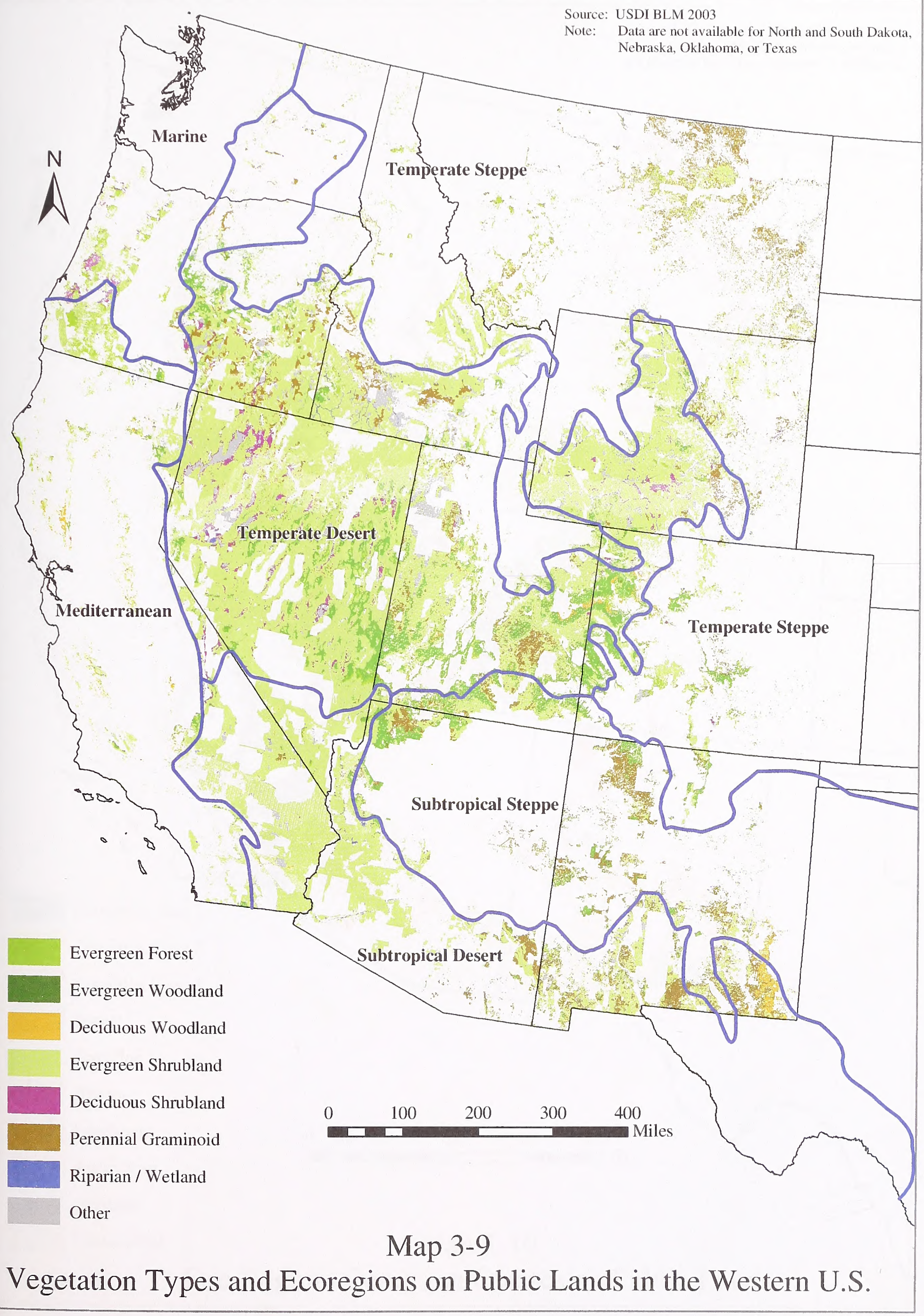





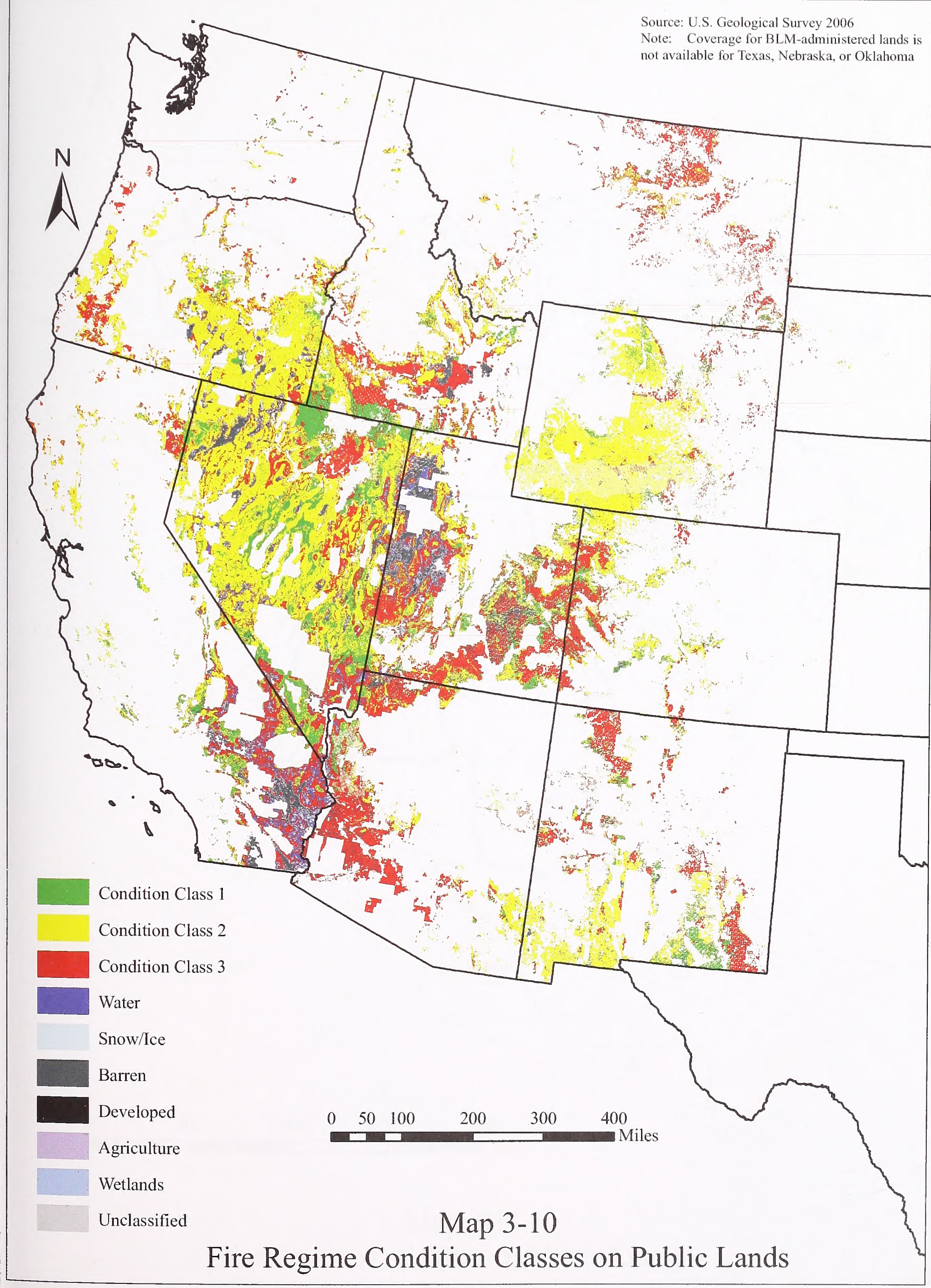





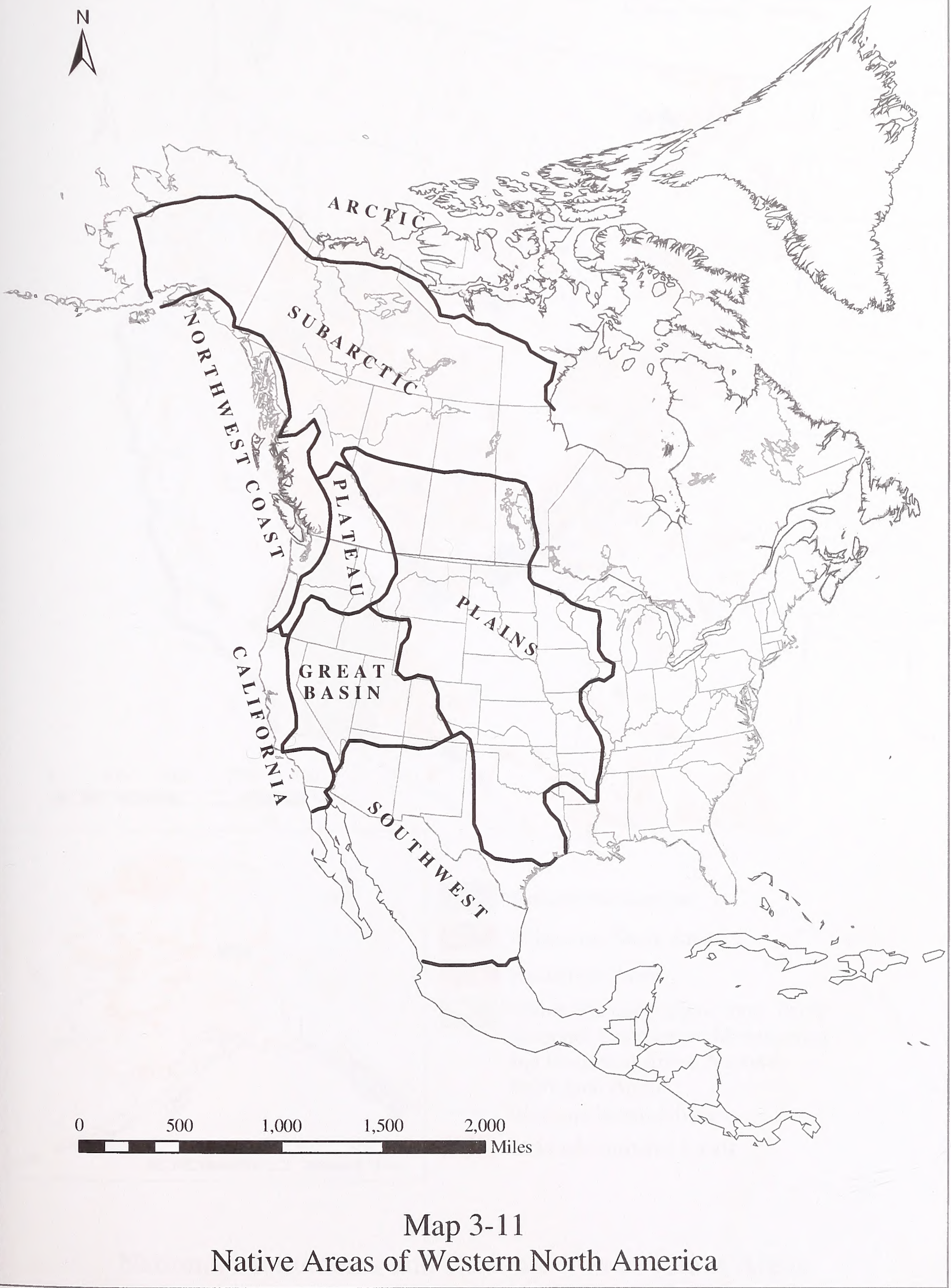




CHAPTER 4 ENVIRONMENTAL CONSEQUENCES 



\section{TABLE OF CONTENTS}

Introduction and Effects

Page

How the Effects of the Alternatives Were Estimated ....... 4-1

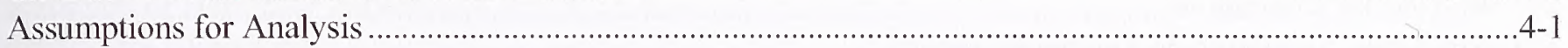

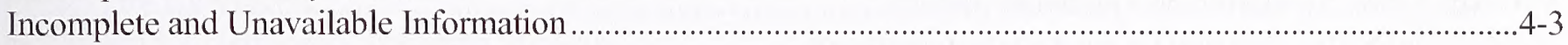

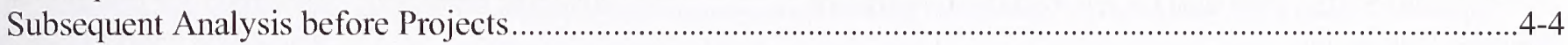

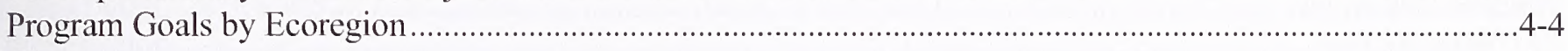

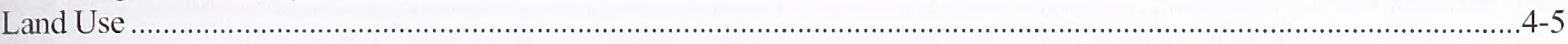

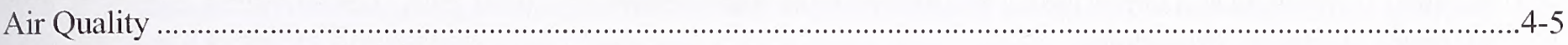

Scoping Comments and Other Issues Evaluated in the Assessment .....................................................4-5

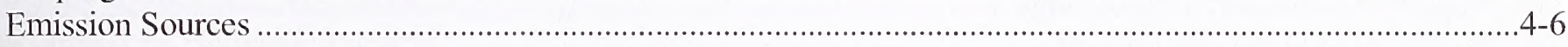

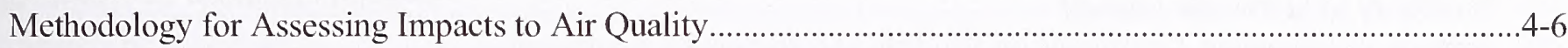

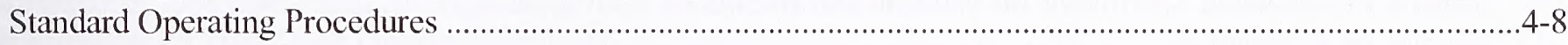

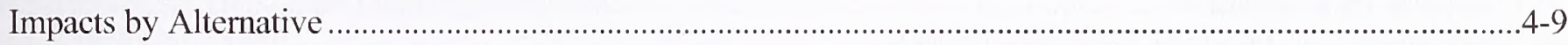

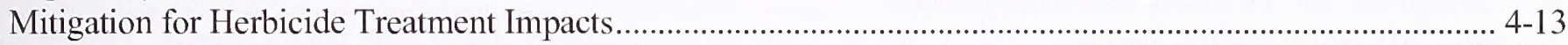

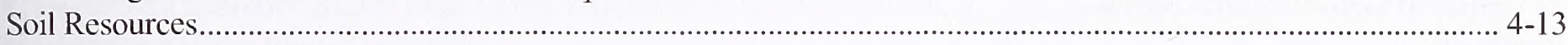

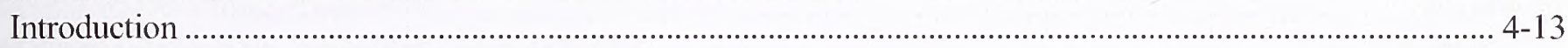

Scoping Comments and Other Issues Evaluated in the Assessment ........................................................... 4-13

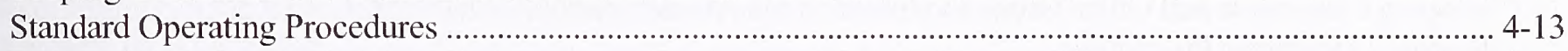

Factors that Influence the Fate, Transport, and Persistence of Herbicides in Soil ............................................ 4-14

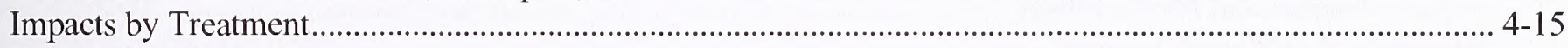

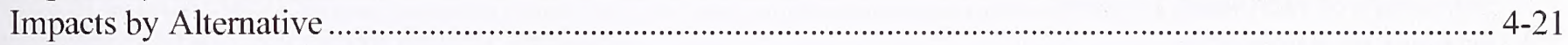

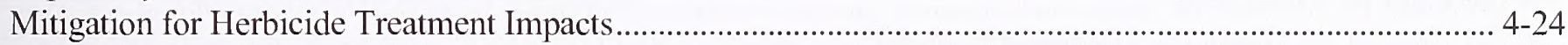

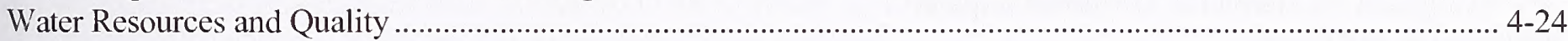

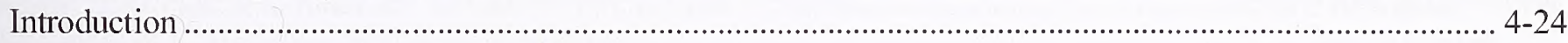

Scoping Comments and Other Issues Evaluated in the Assessment ............................................................. 4-24

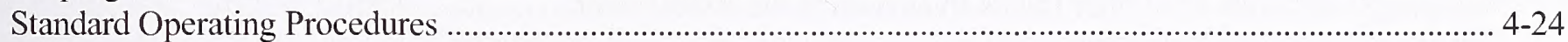

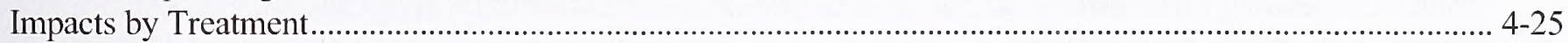

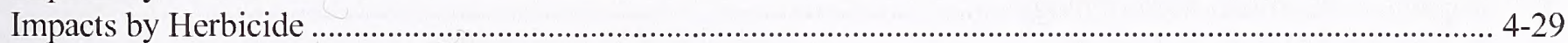

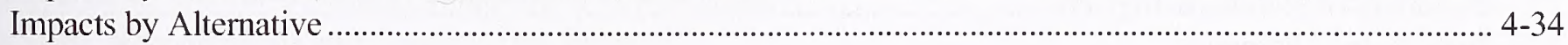

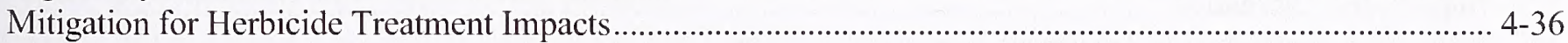

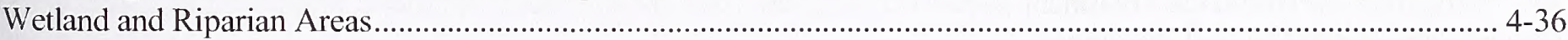

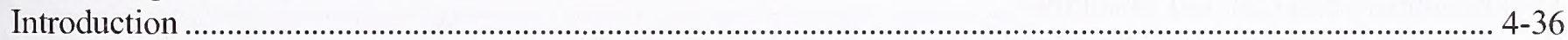

Scoping Comments and Other Issues Evaluated in the Assessment ........................................................ 4-37

Factors that Influence the Fate, Transport, and Persistence of Herbicides in Wetland and Riparian Areas ...... 4-37

Methodology for Assessing Impacts to Wetland and Riparian Areas ......................................................... 4-37

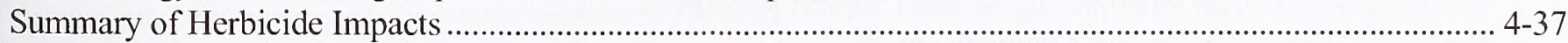

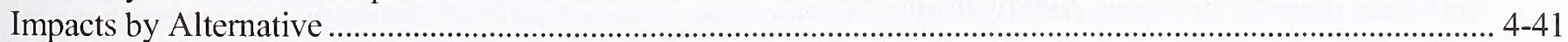

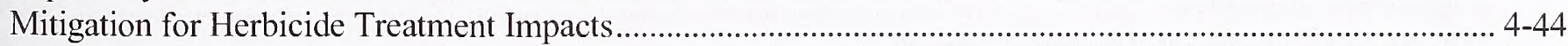

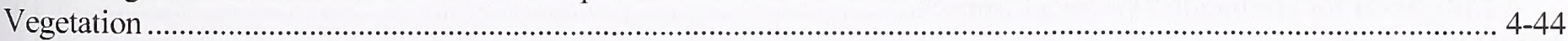

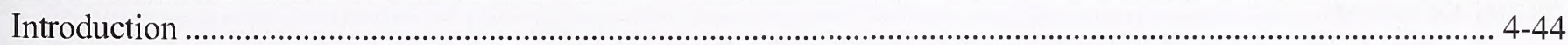

Scoping Comments and Other Issues Evaluated in the Assessment …....................................................... 4-44

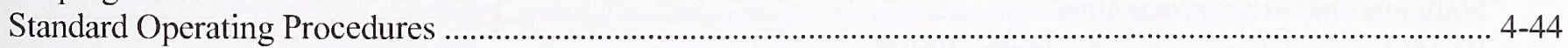

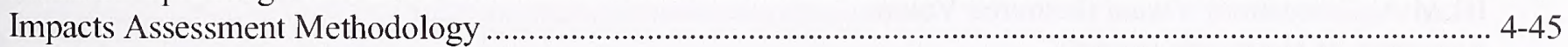

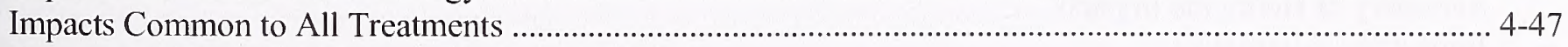

Summary of Herbicide Impacts Evaluated in ERAs............................................................................. 4-63

Other Herbicides Previously Approved for Use on Public Lands ..................................................................... 4-64

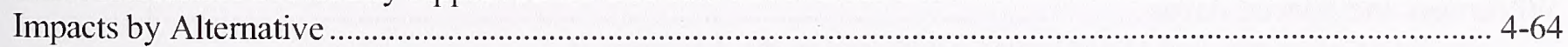

Mitigation for Herbicide Treatment Impacts............................................................................................. 4-71

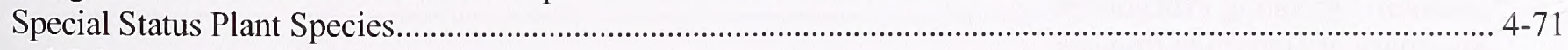

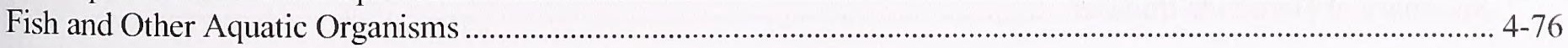




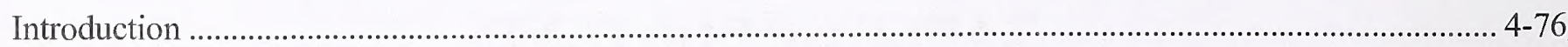

Scoping Comments and Other Issues Evaluated in the Assessment.............................................................. 4-77

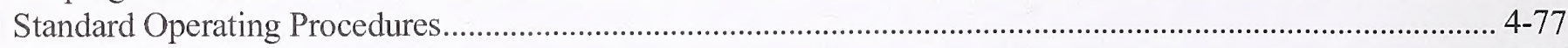

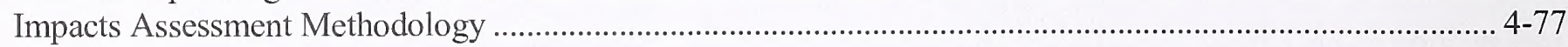

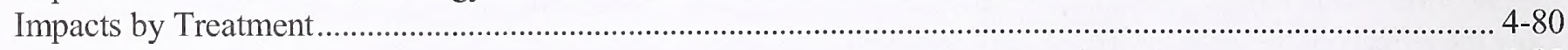

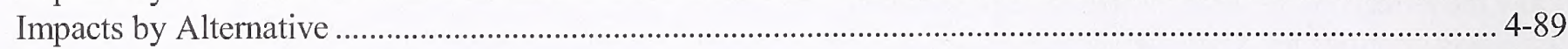

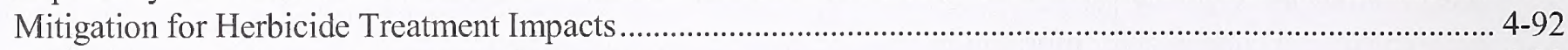

Special Status Fish and Other Aquatic Organisms .................................................................................... 4-92

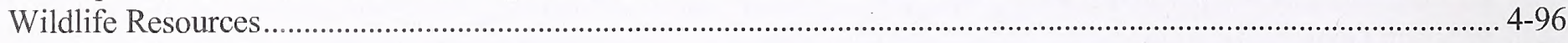

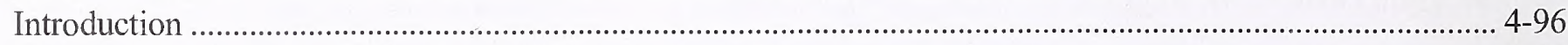

Scoping Comments and Other Issues Evaluated in the Assessment......................................................... 4-98

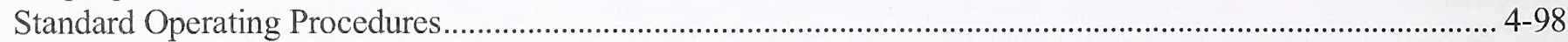

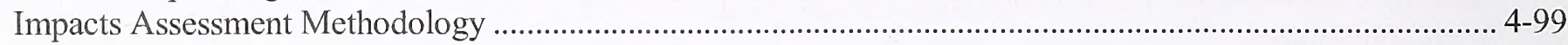

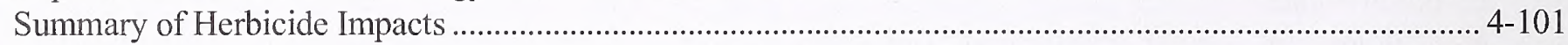

Impacts of Herbicide Treatments on Wildlife and Habitat by Ecoregion ...................................................... 4-109

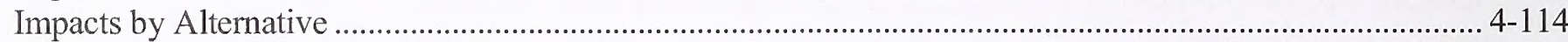

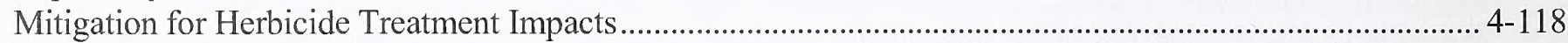

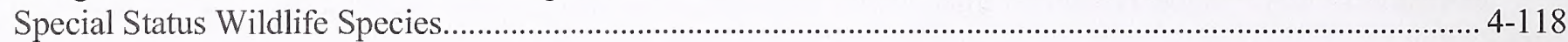

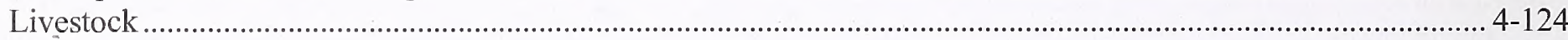

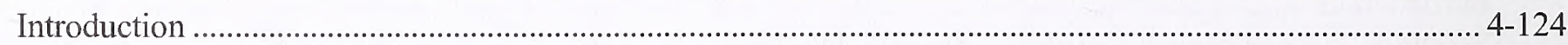

Scoping Comments and Other Issues Evaluated in the Assessment......................................................... 4-124

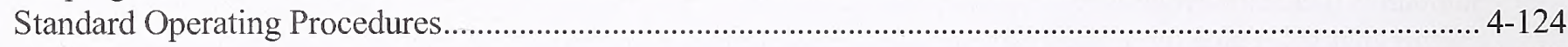

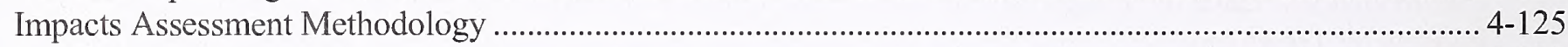

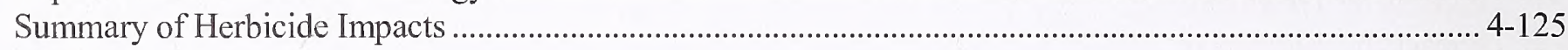

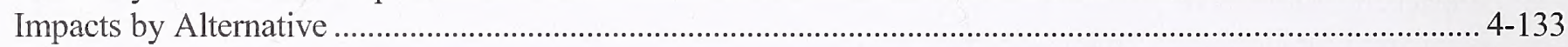

Mitigation for Herbicide Treatment Impacts ........................................................................................ 4-136

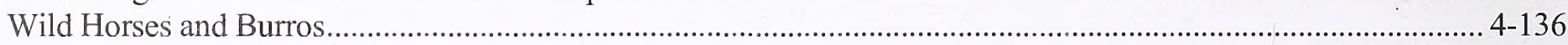

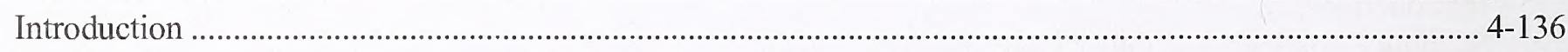

Scoping Comments and Other Issues Evaluated in the Assessment............................................................ 4-137

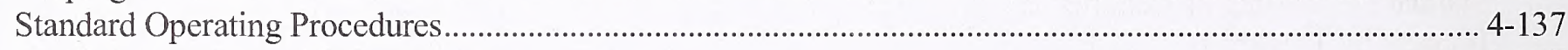

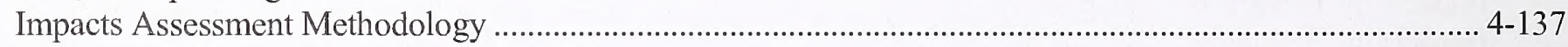

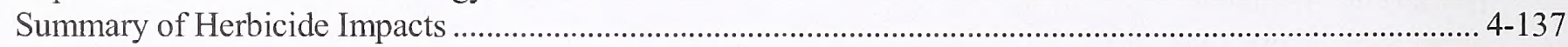

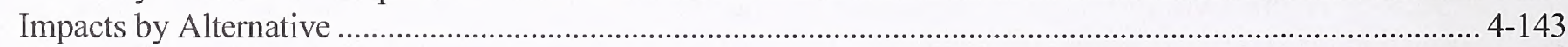

Mitigation for Herbicide Treatment Impacts ........................................................................................ 4-146

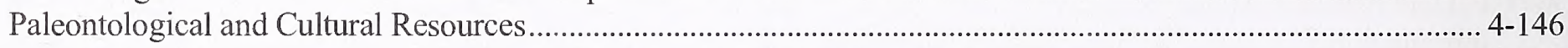

Scoping Comments and Other Issues Evaluated in the Assessment.............................................................. 4-147

Standard Operating Procedures for Addressing BLM Actions on Paleontological, Cultural, and Subsistence

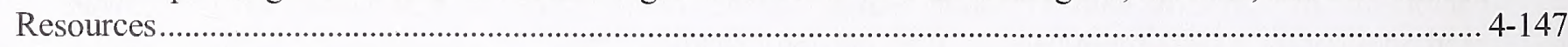

Herbicide Impacts on Paleontological and Cultural Resources ............................................................... 4-148

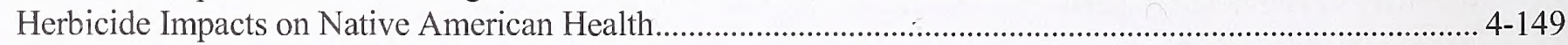

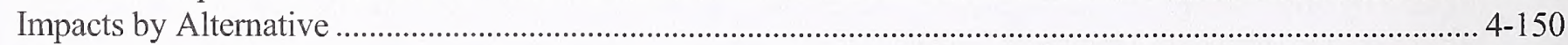

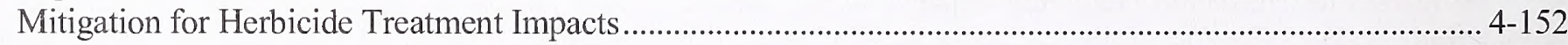

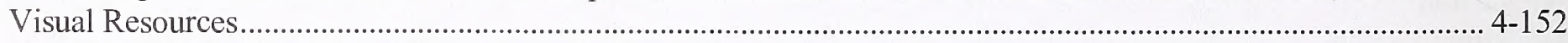

Scoping Comments and Other Issues Evaluated in the Assessment.......................................................... 4-153

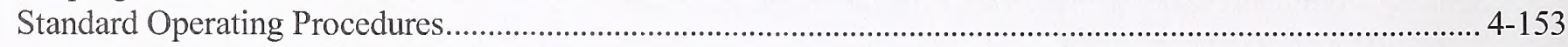

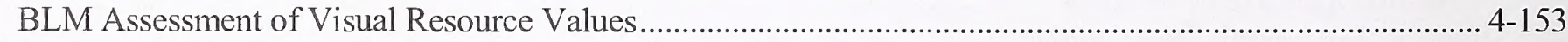

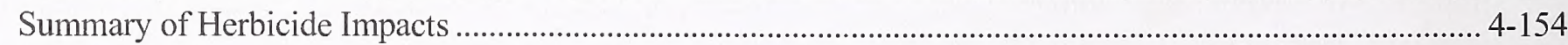

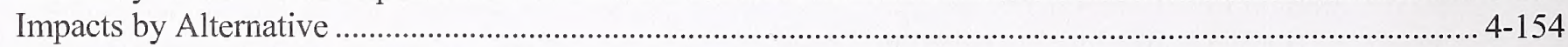

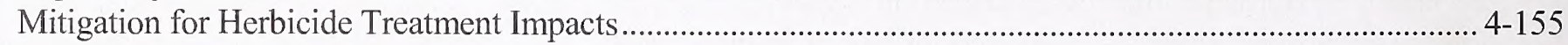

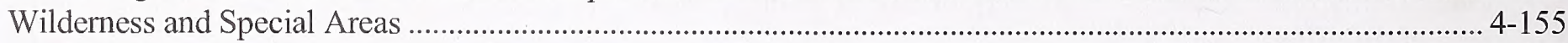

Scoping Comments and Other Issues Addressed in the Assessment........................................................... 4-156

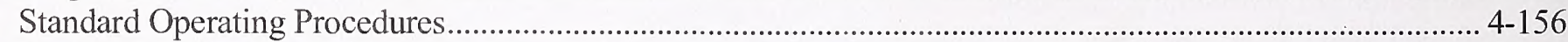

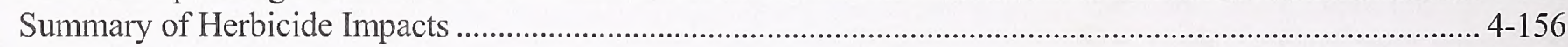




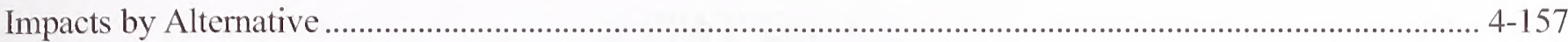

Mitigation for Herbicide Treatment Impacts ............................................................................................. 4-159

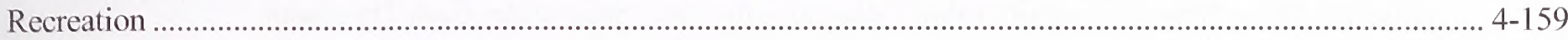

Scoping Comments and Other Issues Evaluated in the Assessment …..................................................... 4-159

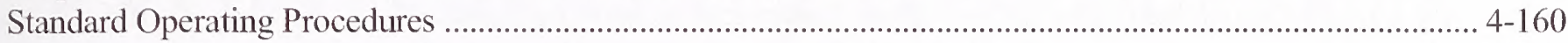

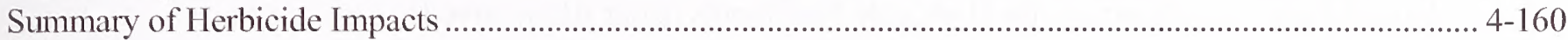

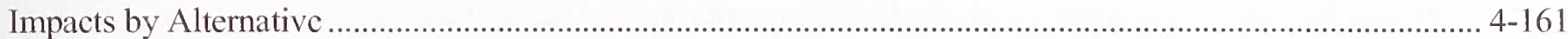

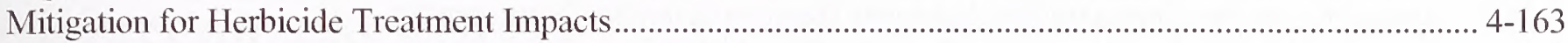

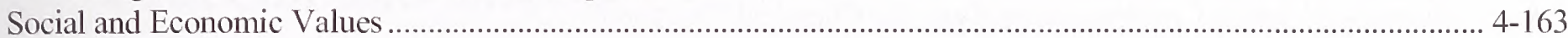

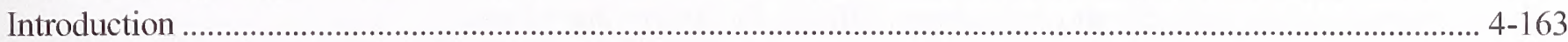

Scoping Comments and Other Issues Evaluated in the Assessment ........................................................ 4-164

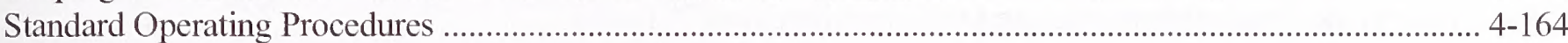

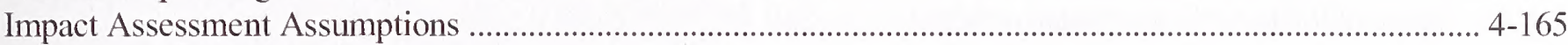

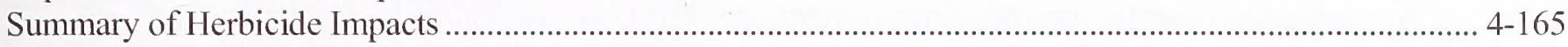

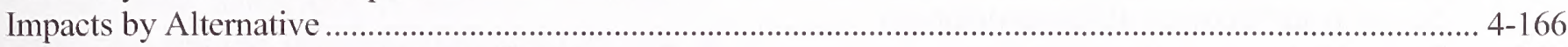

Mitigation for Herbicide Treatment Impacts..................................................................................... 4-174

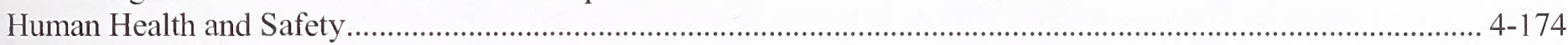

Scoping Comments and Other Issues Evaluated in the Assessment ........................................................ 4-175

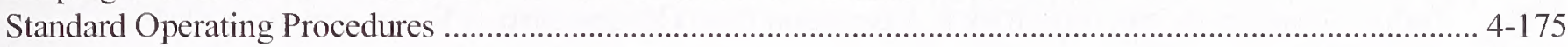

Human Health Risk Assessment Methodology..................................................................................... 4-175

Uncertainty in the Risk Assessment Process .............................................................................................. 481

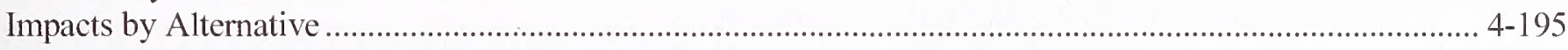

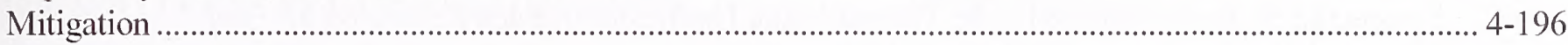

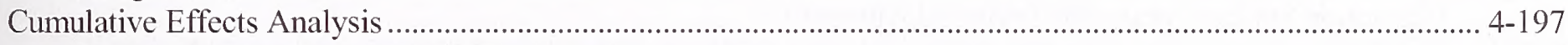

Structure of the Cumulative Effects Analysis .............................................................................................. 4-197

Resource Protection Measures Considered in the Cumulative Effects Analysis .......................................... 4-201

Other Information Considered in Cumulative Effects Analysis .................................................................... 4-202

Analysis of Cumulative Effects by Resources ............................................................................................. 4-202

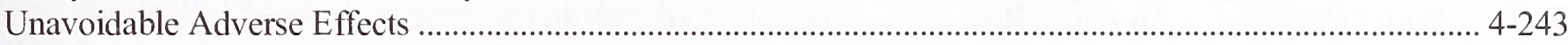

Relationship between the Local Short-term Uses and Maintenance and Enhancement of Long-term

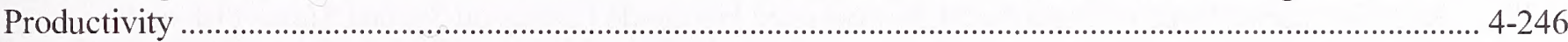

Irreversible and Irretrievable Commitment of Resources ....................................................................... 4-251

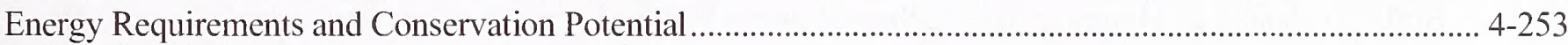

Natural or Depletable Resource Requirements and Conservation............................................................ 4-253 


\section{List of Tables}

4-1 Estimated Acres Treated Annually using Herbicides for Each State under Each Treatment

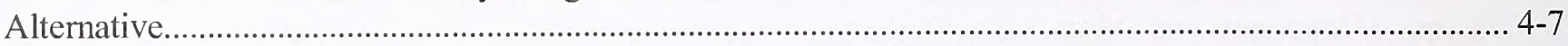

4-2 Annual Emissions Summary for Herbicide Treatments under Alternative A ….................................... 4-8

4-3 Annual Emissions Summary for Herbicide Treatments under Alternative B............................................ 4-9

4-4 Annual Emissions Summary for Herbicide Treatments under Alternative D .......................................... 4-10

4-5 Annual Emissions Summary for Herbicide Treatments under Alternative E........................................... 4-11

4-6 Example NAAQS Compliance Analysis for Chemical Treatment ......................................................... 4-12

4-7 Estimated Soil Half-life and Adsorption Affinity for Active Ingredients.............................................. 4-15

4-8 Factors Associated with Herbicide Movement to Groundwater ................................................................ 4-27

4-9 Herbicide Physical Properties and Off-site Movement Potential................................................................ 4-28

4-10 Anaerobic Half-life and Relative Mobility in Soil for Herbicides Analyzed in this PEIS ......................... 4-39

4-11 Risk Categories Used to Describe Typical Herbicide Effects to Vegetation According to Exposure

Scenario and Ecological Receptor Group ................................................................................................ 4-49

4-12 Buffer Distances to Minimize Risk to Vegetation from Off-site Drift of BLM-evaluated Herbicides ........ 4-54

4-13 Risk Categories Used to Describe Effects of Forest Service-evaluated Herbicides According to Exposure Scenario and Ecological Receptor Group................................................................................... 4-57

4-14 Buffer Distances to Minimize Risk to Vegetation from Off-site Drift of Forest Service-evaluated

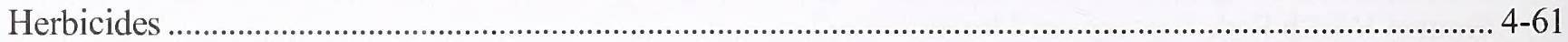

4-15 Percentage of Acres Projected to be Treated Using Herbicides in Each Ecoregion for Each Vegetation Subclass under the No Action Alternative

4-16 Percentage of Acres Projected to be Treated Using Herbicides in Each Ecoregion for Each Vegetation Subclass under the Preferred Alternative...

4-17 Risk Categories Used to Describe BLM-evaluated Herbicide Effects on Non Special Status Fish and Aquatic Invertebrates According to Exposure Scenario.

4-18 Risk Categories Used to Describe Forest Service-evaluated Herbicide Effects on Fish and Aquatic Invertebrates According to Exposure Scenario.

4-19 Buffer Distances to Minimize Risk to Non Special Status Fish and Aquatic Invertebrates from Offsite Drift of BLM-evaluated Herbicides from Broadcast and Aerial Treatments.....

4-20 Risk Categories Used to Describe BLM-evaluated Herbicide Effects on Special Status Fish and Aquatic Invertebrates According to Exposure Scenario.

4-21 Buffer Distances to Minimize Risk to Special Status Fish and Aquatic Organisms from Off-site Drift of BLM Herbicides from Broadcast and Aerial Treatments ........................................................................ 4-98

4-22 Risk Categories Used to Describe BLM-evaluated Herbicide Effects on Non Special Status Wildlife According to Exposure Scenario............................................................................................................... 4-103

4-23 Risk Categories Used to Describe Forest Service-evaluated Herbicide Effects on Wildlife According

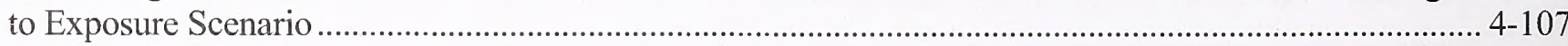

4-24 Risk Categories Used to Describe BLM-evaluated Herbicide Effects on Special Status Wildlife According to Exposure Scenario..

4-25 Risk Categories Used to Describe BLM-evaluated Herbicide Effects on Livestock and Wild Horses and Burros According to Exposure Scenario.

4-26 Risk Categories Used to Describe Forest Service-evaluated Herbicide Effects on Livestock and Wild Horses and Burros According to Exposure Scenario .

4-27 BLM-evaluated Herbicide Risk Categories by Aggregate Risk Index for Occupational Receptors .......... 4-185

4-28 BLM-evaluated Herbicide Risk Categories by Aggregate Risk Index for Public Receptors..................... 4-186

4-29 Forest Service-evaluated Herbicide Risk Categories by Hazard Quotient for Occupational Receptors..... 4-187

4-30 Forest Service-evaluated Herbicide Risk Categories by Hazard Quotient for Public Exposures ............... 4-188

4-31 Scenarios Resulting in High Risk to Occupational Receptors from Herbicides Evaluated in the 1988-

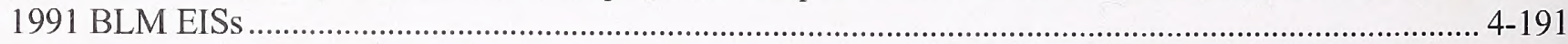

4-32 Scenarios Resulting in High Risk to Public Receptors from Herbicides Evaluated in the 1988-1991

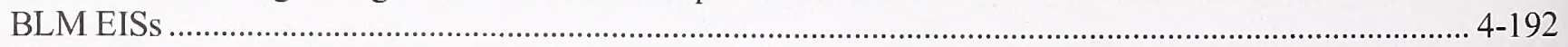

4-33 Herbicide Use in the Western United States for Agricultural Lands and BLM-administered Lands ......... 4-200 


\section{CHAPTER 4}

\section{ENVIRONMENTAL CONSEQUENCES}

\section{Introduction and Effects}

This chapter examines how vegetation treatment activities may affect natural, cultural, and socioeconomic resources on public lands. The focus of the analysis is on alternative proposals for treating public lands using herbicides. A summary of impacts associated with the use of other treatment methods is included in the Vegetation Treatments on Bureau of Land Management Lands in 17 Western States PER (USDI BLM 2007a).

\section{How the Effects of the Alternatives Were Estimated}

Within each resource area, applicable direct and indirect effects are evaluated. Cumulative effects, unavoidable adverse effects, and resource commitments that are lost or cannot be reversed are identified for all treatment activities in the PEIS. These impacts are defined as follows:

- Direct effects - Those effects that are caused by the action and occur at the same time and in the same general location as the action.

- Indirect effects - Those effects that occur at a different time or in a different location than the action to which the effects are related.

- Cumulative effects - Those effects that result from the incremental impact of the action when it is added to other past, present, and reasonably foreseeable future actions. Cumulative effects can result from individually minor but collectively significant actions taking place over a period of time. For this PEIS, potential cumulative effects include those that could occur on other federal and non-federal lands.

- Unavoidable adverse commitments - Those effects that could occur as a result of implementing any of the action alternatives. Some of these effects would be short term, while others would be long term.
- Irreversible commitments - Those commitments that cannot be reversed, except perhaps in the extreme long term. This term applies primarily to the effects of use of nonrenewable resources, such as minerals or cultural resources, or to factors, such as soil productivity, that are renewable only over long periods of time.

- Irretrievable commitments - Those commitments that are lost for a period of time. For example, timber production is lost while an area is mined. The production lost is irretrievable, but the action is not irreversible. If the site is reclaimed, it is possible to resume timber production.

In addition, the PEIS considers the interaction of effects, as follows:

- "Additive" - total loss of sensitive resources from more than one incident.

- "Countervailing" - negative effects are compensated for by beneficial effects.

- "Synergistic" - total effect is greater than the sum of the effects taken independently.

This chapter should be read together with Chapter 2 (Alternatives), which explains the alternative proposals the BLM is considering for treating vegetation using herbicides, and Chapter 3 (Affected Environment), which describes the important resources and their occurrence and status on public lands. The analyses of environmental consequences in this chapter build upon and relate to information presented in these earlier chapters to identify which resources may be impacted and how and where impacts might occur.

\section{Assumptions for Analysis}

This analysis addresses large, regional-scale trends and issues that require integrated management across broad landscapes. It also addresses regional-scale trends and changes in the social and economic needs of people. This analysis does not identify site-specific effects because site-specific information is not essential for 
determining broad-scale management direction. As discussed in Chapter 1, Proposed Action and Purpose and Need, site-specific issues would be addressed through NEPA compliance for resource management activities and other land use plans prepared at the state, district, or field office level.

Vegetation treatments are proposed, designed, and implemented within a natural resource management context that assumes certain conditions exist or are met. They are implemented with consideration for the larger vegetation management context in which they occur. For example, if a target vegetation type is treated and removed, the BLM first considers how the area will be revegetated or stabilized to ensure the long-term viability of the project area. The BLM does not leave bare ground at treatment sites that would allow weeds and invasive species to increase in abundance, which would negate the treatment effort. Treated vegetation is removed from the site if it poses a further risk as hazardous fuel.

Certain assumptions about treatments have been made in this PEIS. The analysis of impacts presented in Chapter 4 assumes that vegetation treatments would be developed and applied in an IPM context, and that the tool(s) identified for the treatment would be the appropriate means to achieve the project objective. The analysis assumes that post-treatment follow-up such as re-seeding and monitoring would occur, as required under most BLM vegetation programs including Emergency Stabilization (ES) and Burned Area Rehabilitation (BAR). The analysis assumes that maintenance of past treatments has occurred, and that the BLM would make an investment in maintaining the condition achieved or objectives of the project, rather than implementing stand-alone, one-time treatments. The analysis also assumes that the BLM would determine the need for the action based on past monitoring, and that additional monitoring would occur after the project to ascertain its effectiveness in achieving the resource objective.

The analysis of impacts assumes that SOPs would be followed by the BLM under all alternatives to ensure that risks to human health and the environment from herbicide treatment actions would be kept to a minimum (see Table 2-8). Examples of SOPs that pertain to all resource areas include the following:

- Prepare a spill contingency plan in advance of treatment.

- Conduct a pre-treatment survey.
- Identify the most appropriate treatment method. If chemicals are the appropriate treatment, then select the chemical that is least damaging to the environment while providing the desired results.

- Review, understand, and conform to the "Environmental Hazards" section on the herbicide label. This section warns of known pesticide risks to the environment and provides practical ways to avoid harm to organisms or the environment.

- Consider surrounding land uses before selecting aerial spraying as a treatment method.

- Notify adjacent landowners prior to treatment.

- Apply the least amount of herbicide needed to achieve the desired results.

- Follow the product label for use and storage.

- Have licensed applicators apply herbicides.

- Use only USEPA-approved herbicides, and follow product label directions and "advisory" statements.

- Keep a copy of Material Safety Data Sheets (MSDSs) at work sites.

- Keep records of each application.

- Avoid accidental direct spray and spill conditions to minimize risks to resources.

- Avoid aerial spraying during periods of adverse weather conditions.

- Make helicopter applications at a target airspeed of 40 to $50 \mathrm{mph}$, and at about 30 to 45 feet above ground.

Additional SOPs specific to individual resources have been provided in the impacts analysis section for each resource, as well as in Table 2-8.

The analysis assumes that the BLM would comply with federal, state, tribal, and local regulations that govern activities on public lands. In addition, mitigation measures have been identified for most resource areas that could apply to one or more alternatives to further reduce impacts associated with herbicide treatments. 


\section{Incomplete and Unavailable Information}

According to the Council on Environmental Quality regulations for implementing the procedural provisions of NEPA (40 CFR 1502.22), if the information is essential to a reasoned choice among alternatives and the cost of gathering it is not excessive, it must be included or addressed in the PEIS.

Knowledge is, and always will be, incomplete regarding many aspects of terrestrial and aquatic species, forestland, rangelands, the economy, and society. However, central ecological, economic, and social relationships are well established, and a substantial amount of credible information about ecosystems in the project area is known. The alternatives were evaluated using the best available information.

As noted in Chapter 1, the primary issue of controversy identified through scoping, and which required NEPA review, was the BLM's continuing use of herbicides and proposed increase in herbicide use in vegetation treatment programs needed to implement the National Fire Plan and related initiatives. The use of herbicides has been affirmed as a central issue for analysis in all past EISs considered in this document.

To address issues related to the use of herbicides, the BLM prepared human health and ecological risk assessments for 10 herbicides/formulations currentlyavailable to the BLM (bromacil, chlorsulfuron, diuron, sulfometuron methyl, and tebuthiuron), or proposed for future use (diflufenzopyr, diquat, fluridone, imazapic, and Overdrive ${ }^{\circledR}$ [diflufenzopyr in a formulation with dicamba]). The BLM also consulted risk assessments prepared by the Forest Service for nine other herbicides used by the BLM (2,4-D, clopyralid, dicamba, glyphosate, hexazinone, imazapyr, metsulfuron methyl, picloram, and triclopyr). For the remaining six herbicides (2,4-DP, asulam, atrazine, fosamine, mefluidide, and simazine), the BLM consulted earlier EISs prepared by the BLM, and the literature developed since 1991, to evaluate risks. These six herbicides would not be used by the BLM under the Preferred Alternative and Alternatives D and E, but could be used if the No Action Alternative was selected.

Risk assessments were developed in cooperation with the USEPA, USFWS, and NMFS, and are considered state-of-the-science. As such, they address many of the risks that would be faced by humans, plants, and animals, including special status species, from the use of the herbicides, and supercede risk assessments prepared by the BLM for the previous vegetation treatment EISs.

To assess risks to other resources from the use of herbicides, the BLM consulted information in the risk assessments and supporting documentation (see appendixes B, C, and D and supporting Human Health and Ecological Risk Assessment reports); state, federal, and local databases, Geographic Information System (GIS) themes, and contract reports; subject experts within and outside of the BLM; and the current literature.

A programmatic analysis over a 17 -state area generally summarizes information that may be available at finer scales (e.g. at the regional and local level), but is too decentralized and dispersed to be presented effectively. For example, although information pertaining to monitoring land use plan management activities over the last 20 or more years may be available at local BLM offices, it would take many years to summarize the conclusions contained in this vast amount of information for this PEIS, and the cost would be exorbitant. The BLM is currently undertaking a National Monitoring Initiative with an objective of bringing together a wide range of monitoring data into a central clearinghouse. This project has only recently become feasible due to the advancements of GIS and internet technology. The National Monitoring Initiative has been funded in the last 2 fiscal years, and is expected to take many years to complete.

The specific locations of all past treatment projects are not available for discussion in this PEIS. To date, the BLM has not developed a central clearinghouse of GIS data identifying the locations of all past projects that have occurred on public lands. These data are available in local field office GIS databases, maps, or project files. Locations of future projects are also unknown, as they will be determined later in time and are not necessarily identified at this time; for this PEIS analysis, these locations have been estimated. Local site-specific land use plans and activity plans will identify the priorities of each field office. The appropriate mix of treatments and their location is addressed at the Resource Management Planning (RMP) level.

This PEIS identifies human health and ecological risks associated with USEPA-registered herbicide active ingredients, as well as inerts and degradates for which information is available and not constrained by confidential business information (CBI) restrictions. Preparing a risk assessment for every conceivable combination of herbicide, tank mix, surfactant, 
adjuvant, and other possible mixture is not feasible, as the BLM cannot prepare hundreds of risk assessments, and the cost would be exorbitant. To the degree a toxic substance is known to pose a significant human or ecological risk, the BLM has undertaken the necessary analysis to assess its impacts through risk assessments.

One resource area for which information is incomplete or unavailable is social and economic values. Although supply and labor costs related to vegetation treatments are likely to be available at the local or county level, they are not quantifiable over a 17-state area. The social and economic costs of invasive and noxious weeds are only now being understood and quantified by economists and vegetation scientists at local and regional scales. At the national scale, however, quantification of these costs is not possible beyond identifying basic trends, given the variety of economic, social and environmental factors involved in estimating these effects. As identified below, this PEIS assumes that locally available data would be consulted when proposing and assessing impacts under NEPA for sitespecific projects at the local level.

While additional information may add precision to estimates or better specify relationships, new or additional information is unlikely to significantly change the understanding of the relationships that form the basis of the effects analysis presented in this chapter.

\section{Subsequent Analysis before Projects}

Before site-specific actions are implemented and an irreversible commitment of resources made, information essential to those fine-scale decisions will be obtained by the local land managers. Localized data and information will be used to supplement or refine regional-level data and identify methods and procedures best suited to local conditions in order to achieve the objectives in this PEIS. Further analysis may be necessary to deal with site-specific conditions and processes. For example, mitigation measures identified in the following sections would be appropriate for protecting resources under the wide range of conditions that must be considered at the programmatic level of analysis. However, by considering more site-specific parameters, such as soil and vegetation type and amount of rainfall, the BLM may be able to use less restrictive mitigation measures and still ensure adequate protection of the resource; the possibility that more restrictive measures would be necessary could also occur. This subsequent analysis will be used to bridge the gap between broad-scale direction and site-specific decisions. This "step-down" analysis is described in Chapter 1 and shown in Figure 1-1.

\section{Program Goals by Ecoregion}

The goals of chemical vegetation treatments, by ecoregion where treatments are planned, are discussed below.

\section{Temperate Desert Ecoregion}

Over $70 \%$ of herbicide treatments would occur on BLM land in the Temperate Desert Ecoregion. Most of these treatments would be used to meet vegetation and integrated weed management (IWM) objectives (33\% of treatments), reduce hazardous fuels $(25 \%)$, conduct ES and BAR activities (19\%), and improve rangeland health $(12 \%)$. Improvements of wildlife habitat and watershed health are objectives of lesser importance $(6 \%$ and $5 \%$ of treatments, respectively) in this ecoregion.

\section{Temperate Steppe Ecoregion}

In the Temperate Steppe Ecoregion, most herbicide treatments would be conducted to meet IVM and/or IWM objectives ( $62 \%$ of treatments). Other important objectives include hazardous fuels reduction $(25 \%)$ and improvement of rangeland health $(11 \%)$.

\section{Subtropical Steppe Ecoregion}

On BLM lands in the Subtropical Steppe Ecoregion, herbicide treatments would be used to improve habitat (38\% of treatments), improve rangeland health $(21 \%)$, reduce hazardous fuels $(17 \%)$, and meet IVM and/or IWM objectives (11\%).

\section{Mediterramean Ecoregion}

In the Mediterranean Ecoregion, chemical treatments would be conducted primarily to improve forest health (35\% of treatments), and to meet maintenance-related $(28 \%)$ and IVM and/or IWM $(20 \%)$ objectives. Improvement of rangeland health $(9 \%)$ and recreation areas $(6 \%)$ would also be important objectives.

\section{Marine Ecoregion}

On BLM lands in the Marine Ecoregion, the majority of herbicide treatments would be conducted to meet IVM and/or IWM (69\%) and maintenance-related (22\%) objectives. Some less important treatment objectives include maintaining ROW (3\%), improving forest 
health (3\%), and improving habitat for native vegetation $(3 \%)$.

\section{Land Use}

As discussed in Chapter 1, several federal laws, regulations, and policies guide BLM management activities on public lands. These include the FLPMA of 1976, which directs the BLM to manage public lands "in a manner that will protect the quality of scientific, scenic, historic, ecological, environmental, air and atmospheric, water resources and archeological values" and to develop resource management plans consistent with those of state and local governments to the extent that BLM programs also comply with federal laws and regulations. The Taylor Grazing Act of 1934 provides federal protection and management of public lands by regulating grazing on public lands. The Oregon and California Grant Lands Act of 1937 provides for the management of the revested Oregon and California and reconveyed Coos Bay Wagon Road grant lands for permanent forest production under the principle of sustained yield and for leasing of lands for grazing.

Management actions on public lands are guided by LUPs. Land use plan decisions establish goals and objectives for resource management, the measures needed to achieve these goals and objectives, and parameters for using public lands (USDI BLM 2000g). As discussed in Chapter 1, land use planning occurs at several levels. Planning at multiple levels allows the BLM to tailor decisions to specific needs and circumstances. The broadest level, which this PEIS represents, is a national-level programmatic study. This level of study contains broad regional descriptions of resources, provides a broad environmental impact analysis, including cumulative impacts, focuses on general policies, and provides Bureau-wide decisions on herbicide use and other available tools for vegetation management. Additionally, it provides an umbrella ESA Section 7 consultation for the broad range of activities described in the PEIS.

At the national level, this PEIS and the PER identify broad management goals and evaluate resource issues of national interest. This PEIS assumes that vegetation treatments could occur on up to approximately 6 million acres annually, that treatments would focus on areas with high levels of hazardous fuels and unwanted vegetation, that land uses would comply with the intent of Congress as stated in the FLPMA (43 U.S.C. $1701 \mathrm{et}$ seq.), and that future land uses would be similar to those that currently occur on public lands. Based on these evaluations, modifications to existing land uses could occur at lower levels, primarily the field office level, based on recommendations in the PEIS and PER.

\section{Air Quality}

Air quality is the measure of the atmospheric concentration of defined pollutants in a specific area. Air quality is affected by pollutant emission sources, as well as the movement of pollutants in the air via wind and other weather patterns. Air quality standards have been designated in the U.S. to prevent significant human health and welfare impacts caused by pollutants in the air. The Clean Air Act, as amended in 1990, establishes a mandate to reduce emissions of specific pollutants via uniform federal standards. As the agency responsible for implementing the Act, the USEPA established the NAAQS for six pollutants to protect public health and welfare. These criteria pollutants are $\mathrm{SO}_{2}, \mathrm{NO}_{2}, \mathrm{CO}, \mathrm{O}_{3}$, lead, $\mathrm{PM}_{10}$, and $\mathrm{PM}_{2.5}$. In addition, PSD regulations, implemented as part of the New Source Review program, guide permitting officials in limiting potential air quality impacts above legally defined baseline levels (USEPA 2004). In essence, established facilities with new major pollutant sources that were previously in attainment of the NAAQS (or were unclassifiable with respect to these standards) are still considered to have acceptable emissions levels if the potential cumulative impacts do not exceed these guideline PSD significance levels. Prevention of Significant Deterioration levels are used in this analysis as criteria to indicate whether the herbicide use alternatives would significantly affect air quality.

The majority of the area covered by this PEIS meets existing air quality standards; however, there are many counties (or portions of counties) where air pollutants exceed maximum levels of one or more of the NAAQS (see Table 3-3). In addition, the Clean Air Act stipulates that the air quality of most areas should not significantly deteriorate. Therefore, this PEIS considers the contribution of proposed herbicide treatment alternatives to levels of the abovementioned criteria pollutants.

\section{Scoping Comments and Other Issues Evaluated in the Assessment}

In line with scoping comments, this section assesses the effects of herbicide treatments on air pollutants and consequent effects on visibility and NAAQS. Most scoping comments were related to the impacts of smoke 
from prescribed burning treatments on air quality. Specifically, comments called for an evaluation of the cumulative effects of smoke and an evaluation of the human health effects of smoke, particularly on asthmatics and in non-attainment zones (areas with levels of one or more criteria pollutants greater than the NAAQS). The impacts of prescribed burning on air quality are discussed in the PER (USDI BLM 2007b).

\section{Emission Sources}

The potential impacts of herbicide use on air quality originate primarily from ground vehicle (truck, allterrain vehicle $[\mathrm{ATV}]$, and boat) and aircraft (plane and helicopter) emissions, as well as fugitive dust (dust created by vehicle travel on unpaved roads) resulting from herbicide transport and application. In addition, spray drift (movement of herbicide in the air to unintended locations) and volatilization (the evaporation of liquid to gas) of applied herbicides temporarily results in herbicide particles in the air, which can be inhaled and deposited on skin or plant surfaces and affect humans, wildlife, and non-target plants. Herbicide particles can be transported away from the target location, depending on weather conditions and the herbicide application method. Spray drift and other offsite herbicide transport processes (e.g., wind blown dust) are discussed briefly in this section and more specifically in the sections pertaining to risks to humans, wildlife, non-target plants, and other resources.

\section{Methodology for Assessing Impacts to Air Quality}

\section{Vehicle Use Emissions}

This analysis includes annual emissions for the proposed alternatives and treatments by state for the following compounds: $\mathrm{CO}$, total suspended particles (TSP), $\mathrm{PM}_{10}, \mathrm{PM}_{2.5}, \mathrm{NO}_{2}$, and VOCs. Lead and $\mathrm{SO}_{2}$ emissions should not occur, or occur in trace amounts, as a result of herbicide treatments involving vehicles and aircraft.

Exhaust emission factors were determined using vehicle data provided by the USDI BLM and the USEPA's Compilation of Air Pollutant Emission Factors (USEPA 1995a). Emission factors for fugitive dust from roads (assumed to be unpaved) were determined from trip mileage and soil properties provided by the BLM and the USEPA's Compilation of Air Pollutant Emission Factors (USEPA 2003a). All other emissions that would be associated with herbicide treatments would be negligible, and are therefore not included in the annual emissions computations for each treatment alternative.

The potential annual emissions that would result from herbicide treatment within each state were based on an estimate of the annual acreage that would be treated by each of the five herbicide treatment methods (helicopter, fixed-wing plane, truck, ATV, and backpack) for each state for each alternative action (Table 4-1). To calculate the annual number of events for each treatment method by state, the estimated annual number of acres treated was divided by the total acreage per single treatment event. The annual air pollutant emissions from herbicide treatments for each state were then predicted based on emissions per treatment event.

\section{Exhaust Emissions from Transportation Vehicles}

To predict the annual vehicle emissions from each treatment method, the exhaust emissions for a single event were multiplied by the annual number of events per state for each method. The amount of pollutant emissions due to exhaust from transportation vehicles was calculated using the procedures (e.g., regarding trip mileage, vehicle type) described in the Annual Emissions Inventory for BLM Vegetation Treatment Alternatives (ENSR 2005a).

\section{Particulate Emissions from Unpaved Roads}

To predict the particulate emissions from travel on unpaved roads, the emissions for a single event were multiplied by the annual number of events per state for each treatment method. The amount of pollutant emissions due to exhaust from unpaved roads and vehicles was calculated using the procedures described in ENSR (2005a).

\section{Total Anmual Chemical Treatment Emissions}

The annual pollutant emissions from vehicle exhaust and fugitive dust were combined for each treatment method. The resulting annual emissions for each method were then summed, yielding the total predicted emission by state and alternative (Tables 4-2 to 4-5). Because the proposed acreage to be treated by state and alternative is subject to change, so are the estimated annual emissions, as they are directly dependent on the number of acres treated. The total estimated emissions were then compared to the PSD emission source modeling threshold significance level. Under the PSD 
TABLE 4-1

Estimated Acres Treated Annually using Herbicides in Each State under Each Treatment Alternative

\begin{tabular}{|l|r|r|r|r|r|}
\hline \multirow{2}{*}{ State } & \multicolumn{5}{|c|}{ Treatment Alternative } \\
\cline { 2 - 6 } & \multicolumn{1}{|c|}{$\mathbf{A}$} & \multicolumn{1}{c|}{ B } & C & D & E \\
\hline Alaska & 0 & 0 & 0 & 0 & 0 \\
\hline Arizona & 9,960 & 36,300 & 0 & 23,595 & 18,150 \\
\hline California & 5,060 & 5,620 & 0 & 3,935 & 2,810 \\
\hline Colorado & 7,770 & 20,960 & 0 & 13,625 & 10,480 \\
\hline Idaho & 57,100 & 258,990 & 0 & 168,345 & 129,480 \\
\hline Montana & 23,190 & 53,160 & 0 & 34,555 & 26,580 \\
\hline Nebraska & 0 & 0 & 0 & 0 & 0 \\
\hline Nevada & 24,970 & 206,560 & 0 & 82,625 & 103,270 \\
\hline New Mexico & 96,620 & 88,600 & 0 & 35,440 & 44,295 \\
\hline North Dakota & 10 & 10 & 0 & 10 & 5 \\
\hline Oklahoma & 0 & 0 & 0 & 0 & 0 \\
\hline Oregon (Total) & 20,960 & 70,280 & 0 & 26,000 & 35,135 \\
\hline Eastern & 8,380 & 28,110 & 0 & 10,400 & 14,055 \\
\hline Western & 12,570 & 42,170 & 0 & 15,600 & 21,080 \\
\hline South Dakota & 1,030 & 1,600 & 0 & 640 & 800 \\
\hline Texas & 0 & 11,830 & 0 & 7,100 & 5,915 \\
\hline Utah & 21,660 & 20,480 & 0 & 15,360 & 10,240 \\
\hline Washington & 1,940 & 4,640 & 0 & 3,015 & 2,320 \\
\hline Wyoming & 35,130 & 152,820 & 0 & 114,615 & 76,400 \\
\hline Total & 305,400 & 931,850 & 0 & 528,860 & 465,880 \\
\hline
\end{tabular}

program, if potential emissions for a given source and pollutant are less than the designated PSD level of 250 tons per year, it is assumed that these emissions are unlikely to significantly impact air quality. This is a conservative assumption, given that PSD levels are designed to apply to a single facility or a group of facilities, whereas the total predicted pollutant emissions presented here would be spread throughout an entire state or region.

\section{CALPUFF Modeling}

The USEPA's guideline California Puff (CALPUFF) "lite" air pollutant dispersion model (referenced in Appendix W of 40 CFR Part 51) was used to provide an example of potential PM (TSP, $\mathrm{PM}_{10}$, and $\mathrm{PM}_{2.5}$ ) impacts resulting from assumed herbicide application methods. Since most criteria pollutant emissions were very low, only example PM impacts were modeled. The total fugitive dust particulate emissions per truck spraying event (10 acres sprayed over 8 hours) were used to estimate maximum daily emission rates in the CALPUFF modeling analysis. Because vehicles traveling on unpaved roads emit the most PM (dust), and the truek spray scenario includes the most travel on dirt roads, this scenario was conservatively used to model the maximum potential impacts. Activities related to airplane and helicopter aerial spraying, ATV spraying, and backpack spraying would cause substantially fewer PM emissions than truck spraying, and therefore are not included in the example modeling. Chemical treatment example modeling was conducted for five representative locations: Tucson International Airport (Arizona), Glasgow International Airport (Montana), Winnemucca Weather Service Office Airport (Nevada), Medford/Jackson County Airport (Oregon), and Lander/Hunt Field (Wyoming).

Total PM emissions were calculated for each treatment "event," and then divided by the number of days per event in order to determine daily TSP, $\mathrm{PM}_{10}$, and $\mathrm{PM}_{2.5}$ emissions. The daily emissions were modeled using CALPUFF "lite" based on a full year of meteorological conditions to predict the maximum air quality impacts likely to occur. The maximum potential impact period was defined as those consecutive days (excluding months when treatment activity is unlikely) during which the highest short-term impacts were predicted to occur. Once the period of maximum potential impact was established, CALPUFF "lite" was re-run, with daily emissions occurring only during that period, to determine both short-term and annual impacts (assuming one herbicide treatment event in each location per year). Because only one event was modeled per year, the results are provided as an example of the 
TABLE 4-2

Annual Emissions Summary for Herbicide Treatments under Alternative A

\begin{tabular}{|c|c|c|c|c|c|c|}
\hline \multirow{2}{*}{ State } & \multicolumn{6}{|c|}{ Pollutant (tons per year) } \\
\hline & $\mathrm{CO}$ & $\mathrm{NO}_{\mathrm{X}}$ & TSP & $\mathbf{P M}_{10}$ & $\mathbf{P M}_{2.5}$ & VOCs \\
\hline Alaska & 0.00 & 0.00 & 0.00 & 0.00 & 0.00 & 0.00 \\
\hline Arizona & 0.93 & 0.11 & 4.02 & 0.85 & 0.12 & 0.07 \\
\hline California & 0.49 & 0.06 & 2.14 & 0.45 & 0.06 & 0.03 \\
\hline Colorado & 0.76 & 0.09 & 1.81 & 0.40 & 0.05 & 0.07 \\
\hline Idaho & 5.34 & 0.64 & 13.30 & 2.91 & 0.37 & 0.38 \\
\hline Montana & 2.17 & 0.26 & 5.05 & 1.13 & 0.14 & 0.15 \\
\hline Nebraska & 0.00 & 0.00 & 0.00 & 0.00 & 0.00 & 0.00 \\
\hline Nevada & 1.31 & 0.15 & 5.76 & 1.23 & 0.17 & 0.09 \\
\hline New Mexico & 5.29 & 0.59 & 19.33 & 4.33 & 0.59 & 0.44 \\
\hline North Dakota & 0.00 & 0.00 & 0.00 & 0.00 & 0.00 & 0.00 \\
\hline Oklahoma & 0.00 & 0.00 & 0.00 & 0.00 & 0.00 & 0.00 \\
\hline Oregon (Total) & 1.97 & 0.22 & 10.37 & 2.47 & 0.35 & 0.14 \\
\hline Eastern & 0.81 & 0.10 & 2.55 & 0.56 & 0.07 & 0.06 \\
\hline Western & 1.15 & 0.13 & 7.82 & 1.91 & 0.27 & 0.08 \\
\hline South Dakota & 0.05 & 0.01 & 0.13 & 0.03 & 0.01 & 0.00 \\
\hline Texas & 0.00 & 0.00 & 0.00 & 0.00 & 0.00 & 0.00 \\
\hline Utah & 2.57 & 0.30 & 9.05 & 1.99 & 0.27 & 0.22 \\
\hline Washington & 0.18 & 0.02 & 0.42 & 0.09 & 0.01 & 0.01 \\
\hline Wyoming & 2.57 & 0.30 & 6.02 & 1.31 & 0.17 & 0.22 \\
\hline Total & 23.63 & 2.75 & 77.40 & 17.19 & 2.31 & 1.82 \\
\hline
\end{tabular}

maximum emission concentrations resulting from a single annual herbicide treatment event.

\section{Comparison to Air Quality Standards}

The short-term air quality impacts, as predicted using CALPUFF "lite," were compared to the applicable NAAQS as a threshold of significance (Table 4-6). Potential direct air quality impacts for TSP, $\mathrm{PM}_{10}$, and $\mathrm{PM}_{2.5}$ predicted using CALPUFF "lite" were added to a representative rural background concentration, and then compared to the NAAQS to determine if the example treatment method scenarios would be likely to exceed any NAAQS due to a single herbicide spraying event. No such exceedances of the applicable threshold values were predicted.

\section{Spray Drift and Volatilization}

Spray drift from various herbicide application methods was assessed using the model AgDRIFT ${ }^{\circledR}$ Version 2.0.05 (SDTF 2002), a product of a Cooperative Research and Development Agreement between the USEPA's Office of Research and Development and the Spray Drift Task Force (SDTF, a coalition of pesticide registrants). Maximum herbicide concentrations by particle size were predicted at increasing distances from the point of application 24 hours after treatment. These concentrations were modeled for the five representative locations described above, and averaged to present the potential effects of spray drift. Toxic risks to humans, wildlife, and non-target plants and other resources potentially affected by drift are presented in the relevant sections of this chapter.

\section{Standard Operating Procedures}

The BLM has developed several management practices to minimize the potential adverse effects of herbicide use on air quality. These management practices are based on direction provided in BLM air quality, chemical pest control, and weed management manuals (e.g., manuals 7000 and 9011) and handbooks (e.g., H9011-1; USDI BLM 1988d). Most of this guidance is related to the effects of spray drift or other forms of wind transport of herbicides. For example, guidance on spray particle size, wind velocity and direction, height of spray boom, herbicide formulation, and drift control spray systems is presented with respect to effects on spray drift and non-target species. The following SOPs have been developed to guide herbicide applications to minimize the effects on air quality: 
TABLE 4-3

Annual Emissions Summary for Herbicide Treatments under Alternative B

\begin{tabular}{|l|c|c|c|c|c|c|}
\hline \multirow{2}{*}{ State } & \multicolumn{7}{|c|}{ Pollutant (tons per year) } \\
\cline { 2 - 7 } & $\mathbf{C O}$ & NO $_{\mathbf{X}}$ & TSP & PM $_{\mathbf{1 0}}$ & PM $_{\mathbf{2 . 5}}$ & VOCs \\
\hline \hline Alaska & 0.00 & 0.00 & 0.00 & 0.00 & 0.00 & 0.00 \\
\hline Arizona & 3.40 & 0.41 & 14.66 & 3.09 & 0.42 & 0.24 \\
\hline California & 0.54 & 0.06 & 2.37 & 0.50 & 0.07 & 0.04 \\
\hline Colorado & 2.06 & 0.24 & 4.88 & 1.07 & 0.14 & 0.18 \\
\hline Idaho & 24.22 & 2.92 & 60.35 & 13.18 & 1.67 & 1.71 \\
\hline Montana & 4.97 & 0.60 & 11.58 & 2.58 & 0.32 & 0.35 \\
\hline Nebraska & 0.00 & 0.00 & 0.00 & 0.00 & 0.00 & 0.00 \\
\hline Nevada & 10.81 & 1.26 & 47.63 & 10.18 & 1.39 & 0.75 \\
\hline New Mexico & 4.85 & 0.54 & 17.73 & 3.97 & 0.54 & 0.40 \\
\hline North Dakota & 0.00 & 0.00 & 0.00 & 0.00 & 0.00 & 0.00 \\
\hline Oklahoma & 0.00 & 0.00 & 0.00 & 0.00 & 0.00 & 0.00 \\
\hline Oregon (Total) & 5.00 & 0.57 & 28.77 & 6.97 & 0.99 & 0.34 \\
\hline Eastern & 1.31 & 0.15 & 2.55 & 0.56 & 0.07 & 0.09 \\
\hline \multicolumn{1}{|c|}{ Western } & 3.87 & 0.43 & 26.22 & 6.40 & 0.91 & 0.26 \\
\hline South Dakota & 0.08 & 0.01 & 0.20 & 0.05 & 0.01 & 0.01 \\
\hline Texas & 1.07 & 0.13 & 2.46 & 0.55 & 0.07 & 0.08 \\
\hline Utah & 2.42 & 0.28 & 8.56 & 1.88 & 0.25 & 0.21 \\
\hline Washington & 0.43 & 0.05 & 1.01 & 0.23 & 0.03 & 0.03 \\
\hline Wyoming & 2.42 & 0.28 & 5.69 & 1.24 & 0.16 & 0.21 \\
\hline Total & 62.27 & 7.35 & 205.89 & 45.49 & 6.06 & 4.55 \\
\hline
\end{tabular}

- Consider the effects of wind, humidity, temperature inversions, and heavy rainfall on herbicide effectiveness and risks.

- Apply herbicides in favorable weather conditions to minimize drift. For example, do not treat when winds exceed $10 \mathrm{mph}(6 \mathrm{mph}$ for aerial applications) or rainfall is imminent.

- Use drift reduction agents, as appropriate, to reduce the drift hazard.

- Select proper application equipment (e.g., spray equipment that produces 200 - to 800 micron diameter droplets [spray droplets of 100 microns and less are most prone to drift]).

- Select proper application methods (e.g., set maximum spray heights, use appropriate buffer distances between spray sites and non-target resources).

The analysis of potential air quality impacts assumes that guidance provided in BLM manuals, handbooks, and SOPs would be followed during herbicide treatment activities.

\section{Impacts by Alternative}

\section{Impacts Common to All Alternatives}

The potential impacts from herbicide applications on local and regional air quality would be minor for each treatment alternative. None of the predicted annual emissions by pollutant, state, or herbicide treatment alternative (A, B, D, and E) would exceed PSD annual emission significance thresholds. Furthermore, the total emissions from all the states, for each pollutant under each alternative, would be less than $25 \%$ of the PSD threshold (250 tons per year) for a single facility. Comparing the total emissions produced by all the states to the PSD threshold is especially conservative because the PSD threshold is designed to apply to one facility or a group of facilities and not entire states. For each treatment alternative, potential emissions would be highest in states with the greatest number of acres treated under each alternative. In addition, all PM concentrations resulting from a single example herbicide spraying event, as modeled using CALPUFF "lite," would be substantially lower than NAAQS thresholds at the five representative locations, and predicted concentrations would be at least four orders of magnitude smaller than assumed background 
TABLE 4-4

Annual Emissions Summary for Herbicide Treatments under Alternative D

\begin{tabular}{|l|c|c|c|c|c|c|}
\hline \multirow{2}{*}{ State } & \multicolumn{7}{|c|}{ Pollutant (tons) } \\
\cline { 2 - 7 } & CO & NO $_{\mathbf{X}}$ & TSP & PM $_{\mathbf{1 0}}$ & PM $_{\mathbf{2 . 5}}$ & VOCs \\
\hline \hline Alaska & 0.00 & 0.00 & 0.00 & 0.00 & 0.00 & 0.00 \\
\hline Arizona & 1.75 & 0.14 & 14.45 & 3.05 & 0.42 & 0.10 \\
\hline California & 0.56 & 0.07 & 2.41 & 0.51 & 0.07 & 0.04 \\
\hline Colorado & 2.49 & 0.24 & 5.74 & 1.21 & 0.15 & 0.18 \\
\hline Idaho & 25.63 & 3.63 & 63.68 & 13.86 & 1.76 & 1.95 \\
\hline Montana & 5.15 & 0.61 & 11.88 & 2.63 & 0.33 & 0.36 \\
\hline Nebraska & 0.00 & 0.00 & 0.00 & 0.00 & 0.00 & 0.00 \\
\hline Nevada & 13.46 & 2.16 & 57.73 & 12.08 & 1.64 & 1.09 \\
\hline New Mexico & 6.37 & 1.05 & 21.26 & 4.70 & 0.63 & 0.78 \\
\hline North Dakota & 0.00 & 0.00 & 0.003 & 0.00 & 0.00 & 0.00 \\
\hline Oklahoma & 0.00 & 0.00 & 0.00 & 0.00 & 0.00 & 0.00 \\
\hline Oregon (Total) & 3.89 & 0.40 & 20.55 & 4.81 & 0.67 & 0.26 \\
\hline Eastern & 1.39 & 0.15 & 4.26 & 0.93 & 0.12 & 0.09 \\
\hline Western & 2.50 & 0.25 & 16.29 & 3.88 & 0.55 & 0.16 \\
\hline South Dakota & 0.10 & 0.01 & 0.23 & 0.05 & 0.01 & 0.01 \\
\hline Texas & 1.11 & 0.13 & 2.54 & 0.56 & 0.07 & 0.78 \\
\hline Utah & 2.63 & 0.29 & 9.17 & 1.98 & 0.27 & 0.22 \\
\hline Washington & 0.50 & 0.05 & 1.13 & 0.25 & 0.03 & 0.03 \\
\hline Wyoming & 19.84 & 2.07 & 46.05 & 9.80 & 1.23 & 1.55 \\
\hline Total & 83.48 & 108.50 & 256.82 & 55.49 & 7.28 & 7.35 \\
\hline
\end{tabular}

concentrations (Table 4-6). Concentrations would vary by alternative based on the number of treatment events.

Under the proposed alternatives, atmospheric concentrations of herbicides (predicted by particle size) resulting from spray drift from aerial, ground vehicle, and hand application would be temporary in nature (most predominant at the time and location of treatment) and, as predicted by modeling, would not significantly impact air quality. Maximum average herbicide concentrations from all five example modeling locations, 24 hours after treatment, were modeled at various distances from the point of application. Herbicide concentrations in the air tend to increase up to 1.5 kilometers $(\mathrm{km})$ from the point of application (concentrations may double between 0.6 and $1.5 \mathrm{~km}$ from the application site), but then decrease slowly at greater distances.

Chemical volatilization is temporary in nature, and none of the herbicides proposed for use are likely to result in substantial volatilization from soils. Chemical vapor pressure (the pressure exerted by a vapor in equilibrium with its solid or liquid phase) largely affects the potential for volatilization of applied herbicides. Based on their vapor pressures, bromacil, diflufenzopyr
(Lyman et al. 1990; National Library of Medicine 2002), diquat (National Library of Medicine 2003), diuron (Lyman et al. 1990; Mackay et al. 1997), sulfometuron methyl (Lyman et al. 1990; National Library of Medicine 2003), and tebuthiuron (Tomlin 1994) are not expected to volatilize from dry or wet soil surfaces. Vapor pressure values are not available for imazapic; however, imazapic does not volatilize when applied in the field (American Cyanamid Company 2000 cited in $\mathrm{Tu}$ et al. 2001), and volatilization of imazapic from terrestrial systems is insignificant. Fluridone might volatilize slowly from wet soil surfaces, but volatilization from dry soils would not be expected (Lyman et al. 1990; Mackay et al. 1997; National Library of Medicine 2002). In addition, dicamba may volatilize from soil surfaces, but such an occurrence is not considered likely unless dicamba has been exposed at the soil surface under hot and dry conditions for several weeks (USDI BLM 1988d). Therefore, application of the evaluated herbicides would not impact air quality through volatilization. 
TABLE 4-5

Annual Emissions Summary for Herbicide Treatments under Alternative $\mathbb{E}$

\begin{tabular}{|l|c|c|c|c|c|c|}
\hline \multirow{2}{*}{ State } & \multicolumn{7}{|c|}{ Pollutant (tons) } \\
\cline { 2 - 7 } & $\mathbf{C O}$ & $\mathbf{N O}_{\mathbf{X}}$ & $\mathbf{T S P}$ & $\mathbf{P M}_{\mathbf{1 0}}$ & $\mathbf{P M}_{\mathbf{2 . 5}}$ & VOCs \\
\hline \hline Alaska & 0.00 & 0.00 & 0.00 & 0.00 & 0.00 & 0.00 \\
\hline Arizona & 1.70 & 0.20 & 7.33 & 1.54 & 0.21 & 0.12 \\
\hline California & 0.27 & 0.03 & 1.18 & 0.25 & 0.03 & 0.02 \\
\hline Colorado & 1.03 & 0.12 & 2.44 & 0.53 & 0.07 & 0.09 \\
\hline ldaho & 12.12 & 1.46 & 30.17 & 6.59 & 0.84 & 0.86 \\
\hline Montana & 2.49 & 0.30 & 5.79 & 1.29 & 0.16 & 0.18 \\
\hline Nebraska & 0.00 & 0.00 & 0.00 & 0.00 & 0.00 & 0.00 \\
\hline Nevada & 5.41 & 0.63 & 23.81 & 5.09 & 0.70 & 0.38 \\
\hline New Mexico & 2.43 & 0.27 & 8.86 & 1.98 & 0.27 & 0.20 \\
\hline North Dakota & 0.00 & 0.00 & 0.00 & 0.00 & 0.00 & 0.00 \\
\hline Oklahoma & 0.00 & 0.00 & 0.00 & 0.00 & 0.00 & 0.00 \\
\hline Oregon (Total) & 3.32 & 0.38 & 17.48 & 4.17 & 0.58 & 0.23 \\
\hline Eastern & 1.39 & 0.16 & 4.36 & 0.97 & 0.13 & 0.10 \\
\hline Western & 1.94 & 0.21 & 13.11 & 3.20 & 0.46 & 0.13 \\
\hline South Dakota & 0.04 & 0.00 & 0.10 & 0.02 & 0.00 & 0.00 \\
\hline Texas & 0.53 & 0.07 & 1.23 & 0.27 & 0.03 & 0.04 \\
\hline Utah & 1.21 & 0.14 & 4.28 & 0.94 & 0.13 & 0.10 \\
\hline Washington & 0.22 & 0.03 & 0.51 & 0.11 & 0.01 & 0.02 \\
\hline Wyoming & 1.21 & 0.14 & 2.85 & 0.62 & 0.08 & 0.10 \\
\hline Total & 31.98 & 3.77 & 106.03 & 23.40 & 3.11 & 2.34 \\
\hline
\end{tabular}

Alternative A - Continue Present Herbicide Use (No Action Alternative)

Under the No Action Alternative, following the current vegetation management program, approximately 305,000 acres would be treated with herbicides each year (Table 4-1). This is the lowest treatment acreage of all alternatives, and it would correspond to emissions of approximately 77 tpy of TSP, 24 tpy of CO, and 17 tpy of $\mathrm{PM}_{10}$, with emissions of all other pollutants totaling less than 3 tpy (Table 4-2). These emissions are lower than those associated with each of the other alternatives. In general, emissions would be greatest in states where more acres are treated (e.g., Idaho, New Mexico, Utah, and Wyoming).

\section{Alternative B - Expand Herbicide Use and Allow for Use of New Herbicides in 17 Western States (Preferred Alternative)}

Under the Preferred Alternative, an estimated 932,000 acres would be treated using herbicides annually. As this is the alternative with the greatest number of acres treated, it would also result in the greatest pollutant emissions (206 tpy TSP, 62 tpy CO, and 45 tpy $\mathrm{PM}_{10}$; Table 4-3)--over 2 times the expected emissions under the No Action Alternative. These emissions would dominate in states with the greatest number of acres treated. Over half of the proposed herbicide treatment acreage under the preferred alternative would occur in Idaho and Nevada. Therefore, over half the predicted annual emissions would occur in these two states.

\section{Alternative C - No Use of Herbicides}

Under Alternative $\mathrm{C}$, herbicides would not be used for vegetation management. Because there would be no associated emissions, herbicide treatments would not impact air quality. However, as under all of the alternatives, other treatment methods (fire use and mechanical, manual, and biological control methods) would emit pollutants, as discussed in the PER.

\section{Alternative D - No Aerial Applications}

Under Alternative D, about 529,000 acres would be treated annually using ground application methods alone. Although about $40 \%$ fewer acres would be treated under this alternative than under the Preferred Alternative, Alternative D would generate the most pollutant emissions (Table 4-4). Alternative D would result in approximately 257 tpy TSP, 83 tpy of CO emissions, and 55 tpy of $\mathrm{PM}_{10}$ emissions, which is more than $20 \%$ more pollutant emissions than under the 
TABLE 4-6

Example NAAQS Compliance Analysis for Chemical Treatment

\begin{tabular}{|c|c|c|c|c|c|c|}
\hline Location & Pollutant & $\begin{array}{l}\text { Averaging } \\
\text { Period }\end{array}$ & $\begin{array}{l}\text { CALPUFF } \\
\text { Concentration } \\
\left(\mu \mathrm{g} / \mathrm{m}^{3}\right)\end{array}$ & $\begin{array}{c}\text { Background } \\
\text { Concentration } \\
\left(\mu \mathrm{g} / \mathrm{m}^{3}\right)\end{array}$ & $\begin{array}{c}\text { Total } \\
\text { Concentration } \\
\left(\mu \mathrm{g} / \mathrm{m}^{3}\right)\end{array}$ & $\begin{array}{l}\text { NAAQS } \\
\text { Standard } \\
\left(\mu \mathrm{g} / \mathrm{m}^{3}\right)\end{array}$ \\
\hline \multirow{6}{*}{$\begin{array}{l}\text { Tucson, } \\
\text { Arizona }\end{array}$} & \multirow{2}{*}{ TSP } & 24-hour & $2.79 \mathrm{E}-04$ & 40 & 40 & $\overline{\mathrm{NA}}$ \\
\hline & & Annual & $7.65 \mathrm{E}-07$ & 11 & 11 & NA \\
\hline & \multirow{2}{*}{$\mathrm{PM}_{10}$} & 24-hour & $5.47 \mathrm{E}-04$ & 30 & 30 & 150 \\
\hline & & Annual & $1.50 \mathrm{E}-06$ & 8 & 8 & 50 \\
\hline & \multirow{2}{*}{$\mathrm{PM}_{2.5}$} & 24-hour & $7.21 \mathrm{E}-05$ & 30 & 30 & 35 \\
\hline & & Annual & $1.97 \mathrm{E}-07$ & 8 & 8 & 15 \\
\hline \multirow{6}{*}{$\begin{array}{l}\text { Glasgow, } \\
\text { Montana }\end{array}$} & \multirow{2}{*}{ TSP } & 24-hour & $1.06 \mathrm{E}-04$ & 40 & 40 & NA \\
\hline & & Annual & $2.90 \mathrm{E}-07$ & 11 & 11 & NA \\
\hline & \multirow{2}{*}{$\mathrm{PM}_{10}$} & 24-hour & $2.36 \mathrm{E}-04$ & 30 & 30 & 150 \\
\hline & & Annual & $6.48 \mathrm{E}-07$ & 8 & 8 & 50 \\
\hline & \multirow{2}{*}{$\mathrm{PM}_{2.5}$} & 24-hour & $2.82 \mathrm{E}-05$ & 30 & 30 & 35 \\
\hline & & Annual & $7.74 \mathrm{E}-08$ & 8 & 8 & 15 \\
\hline \multirow{6}{*}{$\begin{array}{l}\text { Winnemucca, } \\
\text { Nevada }\end{array}$} & \multirow{2}{*}{ TSP } & 24-hour & $1.36 \mathrm{E}-04$ & 40 & 40 & $\mathrm{NA}$ \\
\hline & & Annual & $3.72 \mathrm{E}-07$ & 11 & 11 & NA \\
\hline & \multirow{2}{*}{$\mathrm{PM}_{10}$} & 24-hour & $2.72 \mathrm{E}-04$ & 30 & 30 & 150 \\
\hline & & Annual & $7.44 \mathrm{E}-07$ & 8 & 8 & 50 \\
\hline & \multirow{2}{*}{$\mathrm{PM}_{2.5}$} & 24-hour & $3.60 \mathrm{E}-05$ & 30 & 30 & 35 \\
\hline & & Annual & $9.85 \mathrm{E}-08$ & 8 & 8 & 15 \\
\hline \multirow{6}{*}{$\begin{array}{c}\text { Medford, } \\
\text { Oregon }\end{array}$} & \multirow{2}{*}{ TSP } & 24-hour & $3.75 \mathrm{E}-03$ & 40 & 40 & NA \\
\hline & & Annual & $1.04 \mathrm{E}-05$ & 11 & 11 & NA \\
\hline & \multirow{2}{*}{$\mathrm{PM}_{10}$} & 24-hour & $8.20 \mathrm{E}-03$ & 30 & 30 & 150 \\
\hline & & Annual & $2.28 \mathrm{E}-05$ & 8 & 8 & 50 \\
\hline & \multirow{2}{*}{$\mathrm{PM}_{2.5}$} & 24-hour & $1.14 \mathrm{E}-03$ & 30 & 30 & 35 \\
\hline & & Annual & $3.19 \mathrm{E}-06$ & 8 & 8 & 15 \\
\hline \multirow{6}{*}{$\begin{array}{l}\text { Lander, } \\
\text { Wyoming }\end{array}$} & \multirow{2}{*}{ TSP } & 24-hour & $6.08 \mathrm{E}-05$ & 40 & 40 & NA \\
\hline & & Annual & $1.67 \mathrm{E}-07$ & 11 & 11 & NA \\
\hline & \multirow{2}{*}{$\mathrm{PM}_{10}$} & 24-hour & $1.37 \mathrm{E}-04$ & 30 & 30 & 150 \\
\hline & & Annual & $3.75 \mathrm{E}-07$ & 8 & 8 & 50 \\
\hline & \multirow{2}{*}{$\mathrm{PM}_{2.5}$} & 24-hour & $1.72 \mathrm{E}-05$ & 30 & 30 & 35 \\
\hline & & Annual & $4.70 \mathrm{E}-08$ & 8 & 8 & 15 \\
\hline \multicolumn{7}{|c|}{$\begin{array}{l}{ }^{1} \mathrm{PM}_{10} \text { Data from Table } 6.1 \text { of the Montana Modeling Guideline for Air Quality Permits (November 2002; Montana Department of Environmental } \\
\text { Quality [2002]). TSP concentrations calculated by multiplying } \mathrm{PM}_{10} \text { data by 1.33. } \mathrm{PM}_{10} \text { concentrations are also conservatively used as background } \\
\text { concentrations for } \mathrm{PM}_{2.5} \text {. } \\
{ }^{2} \text { None of the states analyzed have ambient air quality standards for TSP. } \\
\mathrm{NA}=\text { Not applicable. }\end{array}$} \\
\hline
\end{tabular}

Preferred Alternative. Compared to the Preferred Alternative, there would be greater engine emissions from ground vehicle use (in the absence of aerial spraying) and greater fugitive dust emissions from use of these vehicles on dirt roads. None of the states analyzed have ambient air quality standards for TSP, and all other emissions for this alternative (and for each state) would be below the PSD emission significance threshold of 250 tpy. However, because the potential for spray drift is usually highest in aerial applications, drift per acre of application would likely be lower for
Alternative D than for alternatives A, B, and E (spray drift is also largely dependent on weather conditions such as wind speed, temperature, and precipitation). See the Vegetation, Fish and Other Aquatic Resources, Wildlife Resources, and Human Health and Safety sections for the potential toxic effects of spray drift on humans, non-target plants, and animals. 


\section{Alternative E - No Use of Acetolactate Synthase- inhibiting Herbicides}

Under Alternative E, approximately 466,000 acres would be treated annually using herbicides. Particulate emissions under Alternative E (106 tpy TSP, 32 tpy CO, and 23 tpy $\mathrm{PM}_{10}$; Table 4-5) would be about twice those under the current vegetation management program (No Action Alternative). Half of the acreage treated would be in Idaho and Nevada, which would experience slightly more than half $(53 \%)$ of the emissions under Alternative E.

\section{Mitigation for Herbicide Treatment Impacts}

No mitigation measures are proposed for air quality.

\section{Soil Resources}

\section{Introduction}

Soil refers to the loose material composed of weathered rock and other minerals and partly decayed organic matter that covers large parts of land surfaces. Soil provides habitats for a great variety of organisms, functions as an essential component of terrestrial ecosystems, and is the essential medium for plant growth (Wild 1993). Healthy soil is fundamental to high functioning ecosystems, contains a diverse, thriving community of organisms, and. functions to protect downgradient ecosystems by functioning as a physical and biological filter of chemicals in the environment.

Noxious weeds and other invasive vegetation can impact soil function and reduce soil biodiversity. The amount of moisture in the soil can be altered if infiltration is reduced and runoff is increased on sites dominated by weeds (Lacey et al. 1989). Many noxious and invasive weeds have relatively sparse canopies, which allow for greater evaporation from the exposed soil than dense vegetative cover. Sites infested with weeds often have more extreme soil temperatures that can alter soil moisture regimes. Noxious and invasive weeds may alter soil nutrient availability for native species, alter soil constituents (e.g., soil fungi and bacteria), and slow the rate of natural plant succession (Olson 1999). Some weeds also produce toxins or allelopathic compounds that can suppress the growth and germination of other plants (Kelsye and Bedunah 1989).
Herbicide applications inevitably result in contact with soils, either intentionally for systemic treatments, or unintentionally as spills, overspray, spray drift, or windblown dust. In addition to direct application, transmission to soil may occur when an herbicide is transported through the plant from sprayed aboveground portions to roots, where it may be released into soil. Also, some herbicides remain active in plant tissue and can be released into the soil during plant decay and result in residual herbicide activity.

\section{Scoping Comments and Other Issues Evaluated in the Assessment}

Commentors on the draft PEIS encouraged the BLM to focus vegetation management within the structure of achieving long-term ecosystem sustainability and maintaining biological diversity. In a general sense, soil health is a keystone factor for maintaining ecosystem sustainability. Concerns were voiced for evaluating groundwater protection, as certain soil characteristics play a role in attenuating the risk of groundwater contamination.

There was considerable concern that the PEIS should address herbicide fate and transport, such as runoff, overspray, drift, and drift of wind-eroded soil. One respondent recommended measuring organochlorine residues in soil. Other respondents felt that disturbances to biological soil crusts should be eliminated, that sites where the crust species are locally extinct must be reinoculated, and that signs should be placed alongside trails to educate hikers about biological soil crusts.

\section{Standard Operating Procedures}

The BLM would implement several SOPs to reduce impacts to soil:

- Minimize treatments in areas where herbicide runoff is likely, such as steep slopes when heavy rainfall is expected.

- Minimize use of herbicides that have high soil mobility, particularly in areas where soil properties increase the potential for mobility.

- Do not apply granular herbicides on slopes of more than $15 \%$ where there is the possibility of runoff carrying the granules into non-target areas. 


\section{Factors that Influence the Fate, Transport, and Persistence of Herbicides in Soil}

The fate and transport of herbicides in soil is a function of their interaction with the soil environment, and is generally considered a complex process (Bovey 2001). Chemical, physical, and biological soil processes influence herbicide availability, phytotoxicity, and fate and transport (Anderson 1982). Herbicides dissipate from soils by transport with water or wind, through chemical or biological degradation processes, or by immobilization through adsorption onto soil surfaces.

\section{Chemical Processes}

\section{Adsorption}

Adsorption to soil surfaces is probably the most influential factor on the fate and transport of herbicides in soils (Chiou and Kile 2000). Adsorption in soils is the process whereby ions and molecules are bonded to the surface of soil colloids due to the electrical attraction between themselves and the colloidal particles. All soilapplied herbicides are adsorbed to some extent. Adsorption occurs onto clay particles and onto both the solid and dissolved forms of organic matter. Adsorption affects herbicide mobility and availability to plants and other organisms, which in turn influences herbicide fate.

The organic carbon-water partitioning coefficient $\left(\mathrm{K}_{\mathrm{oc}}\right)$, measures the affinity of a chemical to adsorb to soil organic carbon (a component of soil organic matter) relative to water (Table 4-7). For a given chemical, the greater the $\mathrm{K}_{\mathrm{oc}}$ value, the less soluble the chemical is in water and the higher affinity the chemical has for soil organic carbon. For most chemicals, a higher affinity for soil organic carbon (greater $\mathrm{K}_{\mathrm{oc}}$ ) results in less mobility in soil. When herbicide active ingredients are very water-soluble (low $\mathrm{K}_{\mathrm{oc}}$ values), the risk of leaching through soils and transport to surface water and groundwater increases.

\section{Photochemical Decomposition and Chemical Reactions with Soil Constituents}

Photodegradation and chemical reactions are common chemical degradation pathways in the environment. Herbicides may degrade in the presence of sunlight, converting to degradation products in a relatively short time. Chemical reactions, including hydrolysis, occur when chemical transformations replace or remove portions of the herbicide active ingredient's chemical structure, rendering it inactive.

\section{Physical Processes}

\section{Leaching}

Leaching through soils is dependent on herbicide use patterns as well as soil texture, total organic carbon in soil, chemical half-life, amount and time of rainfall, and depth to water table. Fine-grained soils inhibit herbicide leaching because of either low vertical permeability through the soil or high soil surface area, both of which enhance adsorption to the solid phase. Coarse-grained soils with low total organic carbon do not adsorb herbicides as readily, and leaching is more likely.

\section{Volatility}

Volatilization is the process by which a substance passes from a solid or liquid state to a gaseous state. The volatilization of herbicides applied to soils is of concern when poor weed control occurs due to loss of the herbicides from the soil, or when injury to non-target species occurs due to drip of the vapors of the herbicides. None of the herbicides proposed for use are likely to result in substantial volatilization from soils.

Herbicide movement in soil depends on herbicide concentration, as well as on the physical status of soil, especially soil moisture content, organic matter content, and temperature.

Generally, herbicides may be moved from the application area with water runoff, or be leached through soil by rainwater infiltration and potentially reach the groundwater. Herbicide transport in runoff is usually greatest in areas with poorly infiltrating soils, flooding, and steep slopes. Poorly infiltrating soil includes compacted soil, soil with a non-biological surface crust, and fine textured soil, such as clay and clay loam.

\section{Transport with Water or Wind}

Herbicide transport includes movement with water or wind.

Wind can transport herbicides that have adsorbed to particles. The potential for wind blown transport depends on the weather and condition of the soil. Fine sand or silty textured soils, low soil stability, soil disturbance, and dryness all increase the risk for wind erosion of herbicide-containing particles. 
TABLE 4-7

Estimated Soil Half-life and Adsorption Affinity for Active Ingredients

\begin{tabular}{|l|c|c|}
\hline \multicolumn{1}{|c|}{ Herbicide } & $\begin{array}{l}\text { Soil Half- } \\
\text { life (days) }\end{array}$ & Soil Adsorption (K ${ }_{\text {oc }}$ ) \\
\hline \hline 2,4-D & 10 & $\begin{array}{l}20 \mathrm{~m} / \mathrm{g} \text { (acid/salt), } \\
100 \mathrm{~mL} / \mathrm{g}(\text { ester) }\end{array}$ \\
\hline 2,4-DP & 10 & $1,000 \mathrm{~mL} / \mathrm{g}$ \\
\hline Asulam & 7 & $40 \mathrm{~mL} / \mathrm{g}$ \\
\hline Atrazine & 60 & $100 \mathrm{~mL} / \mathrm{g}$ \\
\hline Bromacil & 40 & $32 \mathrm{~mL} / \mathrm{g}$ \\
\hline Chlorsulfuron & 40 & $40 \mathrm{~mL} / \mathrm{g}$ \\
\hline Clopyralid & $60 \mathrm{~mL} / \mathrm{g}$, ranges to \\
\hline $\begin{array}{l}\text { Dicamba, sodium salt, } \\
\text { or dimethylamine salt }\end{array}$ & 14 & $2 \mathrm{~mL} / \mathrm{g}$ \\
\hline $\begin{array}{l}\text { Diflufenzopyr, sodium } \\
\text { salt }\end{array}$ & 2 to 14 & $18 \mathrm{to} 156 \mathrm{~mL} / \mathrm{g}$ \\
\hline Diquat & 1,000 & $1,000,000 \mathrm{~mL} / \mathrm{g}$ \\
\hline Diuron & 90 & $480 \mathrm{~mL} / \mathrm{g}$ \\
\hline Fluridone & 21 & $1,000 \mathrm{~mL} / \mathrm{g}$ \\
\hline Fosamine & 8 & $150 \mathrm{~mL} / \mathrm{g}$ \\
\hline Glyphosate & 47 & $24,000 \mathrm{~mL} / \mathrm{g}$ \\
\hline Hexazinone & 90 & $54 \mathrm{~mL} / \mathrm{g}$ \\
\hline Imazapic & 120 to 140 & $206 \mathrm{~mL} / \mathrm{g}$ \\
\hline Imazapyr & 25 to 141 & $1,000 \mathrm{~mL} / \mathrm{g}$ \\
\hline Mefluidide & 4 & $200 \mathrm{~mL} / \mathrm{g}$ \\
\hline Metsulfuron methyl & 30 & $35 \mathrm{~mL} / \mathrm{g}$ \\
\hline Picloram & 90 & $16 \mathrm{mg} / \mathrm{L}$ \\
\hline Simazine & 60 & $130 \mathrm{~mL} / \mathrm{g}$ \\
\hline Sulfometuron methyl & 20 & $78 \mathrm{~mL} / \mathrm{g}$ \\
\hline Tebuthiuron & 360 & $80 \mathrm{~mL} / \mathrm{g}$ \\
\hline Triclopyr & 46 & $20 \mathrm{~mL} / \mathrm{g}(\mathrm{salt})$, \\
\hline Source: Vogue et al. (1994). & & $780 \mathrm{~mL} / \mathrm{g}($ ester) \\
\hline
\end{tabular}

\section{Biological Processes}

For best results, herbicides must remain in soils in an active and available form until their purpose is accomplished. Herbicidal activity is desirable, however, only until the herbicides have achieved their intended effect; longer persistence may pose a hazard to subsequent land use (Anderson 1982).

The length of time that an herbicide remains active in soils is called soil persistence or soil residual life. The half-life is the time it takes for half of the mass of an herbicide to disappear. The half-life can vary widely in soil, with some times as short as a matter of days and others taking years (Table 4-7). Chemical characteristics of the herbicide, as well as soil characteristics, especially moisture, temperature, organic matter, and the type and activity of soil organisms influence herbicide half-lives.
Soil microorganisms can sometimes degrade herbicide active ingredients. Moderate temperatures, organic material, and adequate moisture result in biologically active soils with large populations of soil microorganisms usually including capabilities for biodegradation. In contrast, soils that are very dry or wet, very cold or hot, or have low organic matter generally have less biological activity and smaller populations of active soil microorganisms.

\section{Impacts by Treatment}

The following section discusses impacts to soil from herbicides currently used by the BLM and from herbicides proposed for use. This assessment of impacts assumes that SOPs (see Table 2-8) would be followed. SOPs are designed to reduce potential unintended impacts to soil. These procedures include using the lowest effective application rate; testing smaller areas for unintended consequences prior to treating larger areas; evaluating soil characteristics to determine the likelihood of herbicide transport by runoff, infiltration, or wind; limiting herbicide use on fine-textured and sandy soils, especially where soil can be transported onto adjacent areas potentially harming non-target vegetation; and carefully evaluating the use of herbicides on hot, dry, cold, wet, sodic (containing high levels of sodium), and saline (containing high levels of salts) soils.

Herbicides may indirectly affect soil through plant removal resulting in changes in physical and biological soil parameters. As vegetation is removed, there is less plant material to intercept rainfall and less to contribute organic material to the soil. Loss of plant material and soil organic matter can increase the risk of soil susceptibility to wind and water erosion. The risk for increased erosion would be temporary, lasting only until vegetation was reestablished. If herbicide treatments lead to revegetation with native plants, soil stability may be improved relative to sites dominated by invasive plants.

There are few studies addressing herbicide effects on biological soil crusts. Therefore, caution should be used when applying these chemicals to soils supporting biological soil crusts (Belnap et al. 2001) or to areas where management goals include crust recovery.

Youtie et al. (1999) studied the effects of two glyphosate herbicide formulations (Roundup ${ }^{\circledR}$ and Accord $($ ) on moss-dominated biological soil crusts in a native bunchgrass community invaded by non-native 
grasses. Effects were measured by the change between pre- and post-treatment cover. The results showed that herbicide treatments did not have short-term impacts on bryophyte (moss and liverwort) cover or species diversity. In addition, biological crust cover was reduced where annual grass leaf litter accumulated, and herbicide treatment reduced litter buildup, suggesting that herbicide treatment slowed the loss of crust cover from annual grass invasion. The authors cautioned that removal of annual grasses requires repeated applications of herbicides and that long-term effects were not known.

Gadkari (1988 cited in Belnap et al. 2001) observed that a photosynthesis-inhibiting herbicide (simazine) had a significant impact on Nostoc (an algal community constituent) growth and nitrogen fixation. Some herbicides appear to inhibit growth and reproduction of green algae when biological crust species are tested under lab conditions (Belnap et al. 2001). Both positive and negative effects have becn observed, depending on the compound and the species (Metting 1990). Peterson et al. (1994 cited in SERA 2004e) observed significant inhibition in growth of three species of cyanobacteria in laboratory exposures using metsulfuron methyl at a concentration of 0.003 milligrams active ingredient per liter (mg a.i./L). Of the several common constituents of the crust community, the cyanobacteria, which generally are embedded in the soil, may be the most resilient. In contrast, because lichen and moss constituents generally lay above the soil surface, they may be more susceptible to herbicide damage (Belnap 2005).

\section{Impacts of BLM-evaluated Herbicides}

\section{Bromacil}

Bromacil can be used as a pre-emergent herbicide, and residual soil activity is necessary for this herbicide to be effective. Bromacil is persistent and highly mobile in soil, with a half-life of 124 to 155 days (see ENSR $2005 \mathrm{~b}$ ). There is limited research on the toxicity of bromacil to most soil organisms. It biodegrades in anaerobic soil, but biodegradation is slow in aerobic soil, with an estimated biodegradation half-life of 275 to 350 days, suggesting possible toxicity to some soil organisms. One soil bacterial isolate that can biodegrade bromacil has been identified (Chaudhry and Cortez 1988).

\section{Chlorsulfuron}

Chlorsulfuron rapidly degrades in acidic soil by chemical hydrolysis, but remains relatively stable in neutral soil (see ENSR 2005c). The products of chemical hydrolysis are then biodegraded in soil (Sarmah and Sabadie 2002). Chlorsulfuron soil biodegradation rates are negatively correlated with $\mathrm{pH}$ and positively correlated with temperature, soil moisture content, organic matter content, and microbial biomass (James et al. 1999).

Chlorsulfuron reportedly remains active in soils for more than 1 year after application, especially at low temperatures and high $\mathrm{pH}$ (James et al. 1999). In a laboratory study in sandy soil, only $4 \%$ of added chlorsulfuron was transformed 126 days after application, and high residual concentrations were found in the lower soil profile (Andersen et al. 2001). Sarmah et al. (1999) observed that the rate of chlorsulfuron degradation in alkaline subsoils was slow. They concluded that under conditions conducive to leaching in alkaline systems, prolonged persistence of chlorsulfuron in the soil profile is possible. It is likely that in some soils dissipation rates could be slower than the reported average, including arid soils with high $\mathrm{pH}$ and low organic matter.

Chlorsulfuron appears to be only mildly toxic to terrestrial microorganisms, and effects are generally transient (SERA 2004a) even though bacteria have an enzyme that is functionally equivalent to the herbicide target enzyme in plants. Biodegradation of chlorsulfuron does occur in some soil systems. For example a bacterial strain (Pseudomonas fluorescens strain B2) isolated from soil was able to degrade $32 \%$ of added chlorsulfuron within 2 weeks (Zanardini et al. 2002). Rovesti and Desco (1990 cited in SERA 2004a) studied two soil nematode species in soil exposed to 312 to $10,000 \mathrm{ppm}$ chlorsulfuron for 72 hours, and no effect was observed on reproduction, viability, or movement.

\section{Diurom}

Diuron is highly persistent and has low to moderate mobility in soil (see ENSR 2005f). Despite its reported low to moderate soil mobility, diuron is frequently detected in groundwater (Spurlock et al. 2000). Sorption studies of diuron have shown that the proportion of organic matter in soil directly influences the amount of adsorbed diuron. Biodegradation is the major source of diuron attenuation, occurring under both aerobic and anaerobic conditions. 
In one study, biodegradation in soil increased with increasing temperature and decreasing initial concentration, while $\mathrm{pH}$ had little effect on the degradation rates (ENSR 2005f). Biodegradation does not occur at freezing temperatures. 3,4-dichloraniline (3,4-DCA) is one breakdown product of diuron. 3,4DCA is also persistent in soil and reportedly exhibits a higher toxicity to some receptors (Tixier et al. 2002; Skogerboe 2003; Giacomazzi and Cochet 2004). In soil, 3,4-DCA can exceed $5.0 \mu \mathrm{g} /$ kilograms $(\mathrm{kg})$ at typical application rates (Giacomazzi and Cochet 2004). Waterfleas are negatively affected by fairly low concentrations $(1.0 \mu \mathrm{g} / \mathrm{L})$ of $3,4-\mathrm{DCA}$ in water, but it is unknown if effects to crustaceans occur in soil. Widehem et al. (2002) identified a common soil bacteria capable of transforming diuron to 3,4-DCA. In addition, 3,4-DCA was degraded by four fungal species (Tixier et al. 2002).

Diuron had adverse effects on bacterial community structure and on bacterial activity at a concentration of $25 \mathrm{mg} / \mathrm{L}$ (Giacomazzi and Cochet 2004). One study showed by molecular techniques that bacterial diversity seemed to decrease in soil treated by diuron or other phenylurea herbicides.

\section{Dicamba}

Dicamba is not adsorbed by most soils and is highly mobile. Dicamba is moderately persistent in soil. Biodegradation is its primary fate, with slower rates at lower temperatures and in dry soil. It is likely to be rapidly degraded in soils with high microbial populations, but dissipates more slowly in hardwood forest soils (Voos and Groffman 1997a, b). The slower dissipation in hardwood forest soils is probably attributable to adsorption of dicamba in acidic and highly organic soil horizons. One study reported that dicamba dissipated from grassland soils in Texas in 4 weeks when applied at $0.25 \mathrm{lb} / \mathrm{ac}$, and in 9 to 16 weeks when applied at $0.5 \mathrm{lb}$ a.i./ac (Bovey 2001). However, when dicamba granules were applied at rates of 1.5 or $1.86 \mathrm{lbs}$ a.i./ac to sand in semiarid grassland, dicamba residues were detected up to 48 inches deep 53 weeks after application. The primary breakdown product of dicamba is 3,6-dichlorosalicylic acid, which adsorbs to soils strongly. Very little information is available on the toxicity of this breakdown product (USDA Forest Service 1999).

According to one study, dicamba caused a transient decrease in nitrification after incubation in sandy loam soil at an application rate of $10 \mathrm{mg} / \mathrm{kg}$, but this decrease was not substantial and was not observed after 3 weeks of incubation ( $\mathrm{Tu}$ 1994). In the same study, dicamba did not affect ammonia formation or sulfur oxidation. Martens and Bremner (1993) showed that dicamba did not affect urea hydrolysis or nitrification in four soil types at an application rate of $1 \mathrm{mg} / \mathrm{kg}$. Dicamba did decrease urea hydrolysis by $6 \%$ in one of the four soil types, and inhibited nitrification in two of the soils at 7 and 14 days, but not at 21 days, after application at a rate of $50 \mathrm{mg}$ a.i. $/ \mathrm{kg}$ soil. After herbicide applications for 24 years, there were no detectable residues of dicamba in soil at two long-term tillage sites or one long-term manured site, probably due to biodegradation and mobility (Miller et al. 1995).

\section{Diffufenzopyr}

Biodegradation, photodegradation, and hydrolysis are the primary mechanisms that remove diflufenzopyr from soil. $\mathrm{K}_{\mathrm{oc}}$ values range from 18 to $156 \mathrm{ml} / \mathrm{g}$. Soil biodegradation and photodegradation half-lives are 14 days or less (USEPA 1999c). Diflufenzopyr appears to be soluble enough that transport in surface runoff is possible, especially in neutral to alkaline soils (see ENSR 2005d).

\section{Diquat}

Diquat readily adsorbs to soil surfaces, effectively immobilizing the chemical. The amount of diquat adsorbed depends on the type and amount of clay particles present, with soils high in clay adsorbing larger amounts than sandy soils. Sodic and saline soils adsorb reduced amounts (Kookana and Aylmore 1993). Diquat is resistant to anaerobic and aerobic biodegradation, possibly in part because it adsorbs so well to soil particles. There is some evidence that the more loosely bound fraction of diquat may be subject to slow biodegradation (Howard 1991). The half-life of diquat is 3 years or longer (see ENSR 2005e).

\section{Fluridone}

Fluridone applications target unwanted aquatic vegetation, especially submerged vegetation. Fluridone adsorption to soil increases with clay content, organic matter content, cation exchange capacity, surface area, and decreasing pH (Weber et al. 1986 and Reinert 1989 cited in ENSR 2005g). The half-life of fluridone ranges from 44 to 365 days when it is applied on sandy loam, sandy clay loam, and peaty loam soils $\left(10^{\circ} \mathrm{C}\right.$ and $18^{\circ}$ to $24{ }^{\circ} \mathrm{C}$; Howard 1991). Longer half-lives tend to be associated with dry soils (Malik and Drennan 1990 cited in ENSR 2005g). Fluridone can volatilize slowly from 
wet soil surfaces, but volatilization from dry soils would not be expected (ENSR 2005g).

The toxicity of fluridone to earthworms has been measured. No mortality was seen in direct exposures up to $103 \mathrm{mg} / \mathrm{L}$ (103 ppm; Eli Lilly and Company 2003); this concentration is approximately 1,000 times greater than the expected soil concentration in a typical use application.

\section{Imazapic}

Imazapic is moderately persistent in soils and has not been found to move laterally with surface water. Imazapic has a half-life of 120 days in soil due to photolysis and a half life of 31 to 233 days in soil due to microbial degradation (American Cyanamid Company 2000 cited in Tu et al. 2001). Most imazapic is lost through biodegradation. Sorption to soil increases with decreasing $\mathrm{pH}$ and increasing organic matter and clay content. Little is known concerning the effects of imazapic on soil organisms or processes (see ENSR 2005h).

In the risk assessment for imazapic (SERA 2004c), Groundwater Loading Effects of Agricultural Management Systems (GLEAMS) modeling estimated the proportion of applied imazapic lost by runoff for clay, loam, and sand at rainfall rates ranging from 5 to 250 inches per year. Runoff would be negligible in relatively arid environments, as well as areas with sandy or loam soils. In clay soils, which have the highest runoff potential, off-site loss could reach up to $3.5 \%$ of the applied amount in regions with very high rainfall rates. The model showed that as rainfall rate increases, maximum soil concentrations are reduced because of imazapic losses from soil through percolation or runoff. Modeling also showed that longer-term concentrations in soil vary substantially with rainfall rates, ranging from about 1 to $2 \mathrm{mg}$ a.i. $/ \mathrm{kg}$ soil in very arid soils to about $0.01 \mathrm{mg}$ a.i. $/ \mathrm{kg}$ soil in regions with high rainfall.

\section{Sulfometurom Methyl}

Sulfometuron methyl is hydrolyzed in acidic soil, but is stable in neutral soil. Hydrolysis and biodegradation appear to be important degradation pathways in soil (Sarmah and Sabadie 2002). The degradation rate for sulfometuron methyl was found to increase with increasing soil temperature and moisture content, and the half-life ranged from 2 to 5 weeks. Sulfometuron methyl moves readily through conductive, coarsetextured soils such as sand and sandy loams (ENSR 2005j).
Effects of sulfometuron methyl to soil organisms are not well studied. A study on the response of ectomycorrhizal symbiotic formation to sulfometuron methyl applications showed that the herbicide did not result in a reduction of the symbiont on tree seedlings (Busse et al. 2004).

\section{Tebuthiuron}

In soil, tebuthiuron is resistant to abiotic degradation and biodegradation. Its field half-life ranges from 2 weeks to over 33 months (see ENSR 2005k). It has a low adsorption affinity to soil, with some adsorption occurring as organic matter and clay content increase. It is mobile in soil and has been detected in groundwater (USEPA 1994a).

The amount of tebuthiuron recovered from application sites in northcentral Arizona declined from $55 \%$ of that applied after 1 year to $5 \%$ after 8 years, but then increased during the remaining 3 years of the study. The increase may have been due to release of the soiladsorbed fraction. No metabolites were found, suggesting little or no degradation in soil (National Library of Medicine 2002). Montgomery (1997) reported that $38 \%$ of tebuthiuron applied to rangeland at a rate of $0.84 \mathrm{~kg} / \mathrm{ha}$ tebuthiuron remained after 21 months.

In an evaluation of brush control and reseeding in a post oak forest using tebuthiuron applied at a rate of 2.2 $\mathrm{kg} /$ hectare (ha), Gay et al. (1997) determined that total soil nitrogen was unchanged after treatment regardless of the reseeding method, possibly indicating few changes to nitrogen cycling from treatment methods. After a tebuthiuron application at the rate of $1.01 \mathrm{~kg} / \mathrm{ha}$ in pellet form to sagebrush semi-desert in Utah, soft brome had both reduced persistent mycorrhizal root infection and reduced mycorrhizal spore density in its rhizosphere (Allen and West 1993). The herbicide did not appear to affect germination of mycorrhizal spores collected 6 months after herbicide application. Mostafa and Helling (2003) isolated three tebuthiuron-degrading bacteria from soil. Shelton et al. (1996) demonstrated that a Streptomyces strain degraded tebuthiuron in vitro.

\section{Impacts of Forest Service-evaluated Herbicides}

\section{2,4-D}

It is generally accepted that 2,4-D is rapidly inactivated in moist soil (Bovey 2001). However, its fate is largely dependent on pH (Aly and Faust 1964 cited in Tu et al. 2001). In alkaline soil, 2,4-D is rapidly converted to a 
form that is susceptible to photodegradation and biodegradation, and that does not readily adsorb to soil particles. In acidic soil, 2,4-D resists degradation (Johnson et al. 1995 cited in Tu et al. 2001).

The half-life of 2,4-D averages 10 days in moist soils, but can be longer in cold or dry soils, or where the microbial community is not present to facilitate degradation (Tu et al. 2001). Warm and moist soil conditions that enhance microbial populations facilitate 2,4-D degradation (Foster and McKercher 1973 cited in Tu et al. 2001). In addition, 2,4-D has been shown to dissipate more rapidly in soils previously treated with $2,4-\mathrm{D}$, presumably because of an increase in 2,4-D degrading bacteria after the first application (Oh and Tuovinen 1991, Smith and Aubin 1994, and Shaw and Burns 1998 cited in Tu et al. 2001).

Studies have generally shown that at typical application rates, no effect from 2,4-D can be detected on soil macroorganisms (Eijsackers and Van Der Drift 1976). Furthermore, most studies of the effects of 2,4-D on microorganisms concluded that the quantity of 2,4-D reaching the soil from typical applications would probably not have a serious negative effect on most soil microorganisms (Bovey 2001).

\section{Clopyralid}

Clopyralid is unstable in soil, and its field dissipation half-life ranges from 10 to 161 days (SERA 2004b). Clopyralid does not appear to bind tightly to soil and will leach under favorable conditions; however, the potential for leaching or runoff is attenuated by the apparently rapid biodegradation of clopyralid in soil. Clopyralid can be persistent in plants, and can result in soil activity when plants containing clopyralid die and biodegrade, releasing clopyralid to the soil where it can again be taken up by plants.

Hassan et al. (1994 cited in SERA 2004b) summarized the effects of clopyralid on potential biocontrol agents. Exposures to clopyralid resulted in less than $30 \%$ mortality to 14 out of 17 insects and predatory mites in contact bioassays. Higher mortality rates ( $25 \%$ to $50 \%$ ) were observed with clopyralid exposures to three insects: a beetle species, a pirate bug, and a green lacewing. A laboratory study on spiders reported an acute (96-hour) lethality of less than 10\% following a direct application of clopyralid (as Lontrel EC, an emulsifiable concentrate of clopyralid) at the recommended application rate (Pekar 2002).
At concentrations of 1 or $10 \mathrm{mg}$ a.i. $/ \mathrm{kg}$ soil, clopyralid had no effect on nitrification, nitrogen fixation, or degradation of carbonaceous material (Hassan et al. 1994 cited in SERA 2004b). Applications of Lontrel EC at $0.26 \mathrm{lb} / \mathrm{ac}$ had no substantial effect on spore germination in a fungal bioherbicide for round-leaved mallow (Grant et al. 1990 cited in SERA 2004b).

\section{Glyphosate}

Glyphosate is a polar compound that is inactivated by soil adsorption. Adsorption is controlled by soil $\mathrm{pH}$ to a large degree (Gimsing et al. 2004). Glyphosate is watersoluble, but it has a high affinity to bind to soil particles (SERA 2003a). Adsorption of glyphosate increases with increasing clay content and cation exchange capacity, and decreasing soil $\mathrm{pH}$ and phosphorous content (Sprankle et al. 1975, Hance 1976, Nomura and Hilton 1977, and Rueppel et al. 1977 cited in Tu et al. 2001).

Glyphosate is biodegraded by soil organisms, and many species of soil microorganisms can use glyphosate as a carbon source (SERA 2003a). Glyphosate exposure results in the inhibition of respiration and nucleic acid synthesis in plants and in microorganisms. There is little information, however, to suggest that glyphosate is harmful to soil microorganisms under field conditions; some studies suggest glyphosate may benefit some soil microorganisms.

In a study of the direct and indirect effects of long-term glyphosate applications in ponderosa pine plantations in California, Busse et al. (2004) determined that both direct and indirect soil microbial characteristics in the top 4 inches of soil were generally unchanged after 9 to 13 years of continuous vegetation control by glyphosate. Single or repeated applications of glyphosate at the recommended field concentration had little effect on microbial communities.

\section{Hexazimone}

Hexazinone has a relatively low affinity for soil particles and dissolves in soil water. Biodegradation is an importation fate, and the half-life in soil averages about 90 days, although hexazinone has been reported in the soil at low concentrations for up to 3 years after application. Soil organic matter content does not affect adsorption.

One field study designed to detect effects on non-target species suggests that hexazinone may have an effect on the behavior of soil mites. At an application rate of 0.9 $\mathrm{lb} / \mathrm{ac}$, soil mites tended to migrate deeper into the soil 
than mites from untreated plots. However, it is not known whether this behavior is related to toxicity, avoidance, or some other unidentified factor (Badejo and Adejuyigbe 1994). When testing pure strains of ectomycorrhizal fungi in a laboratory assessment, Diaz et al. (2003) determined that hexazinone had little or no adverse effect on fungi, and even stimulated the growth of one strain.

Hexazinone did not adversely affect the nitrogen cycle or soil respiration in acidic plant soils when applied at the recommended application rate (Vienneau et al. 2004). Busse et al. (2004) found that hexazinone did not alter soil respiration and the capability of mycorrhizal fungi to infect conifer seedling roots, even at concentrations detrimental to seedling growth.

\section{Imazapyr}

Imazapyr is water soluble, potentially mobile, and has a long half-life (SERA 2004d). Imazapyr does not readily bind to mineral soils, but is likely to bind relatively strongly to organic soil. In a study of the fate of imazapyr applied to a railroad ROW, most imazapyr was found in the upper 12 inches of the soil and exhibited a half-life in the range of 67 to 144 days (Borjesson et al. 2004).

Imazapyr may persist in soil for a prolonged period in relatively arid regions, and does not bind tightly to alkaline soils with low organic matter. Thus, the potential for longer-term effects on soil organisms and downgradient systems exists (SERA 2004d). Imazapyr can "leak" from treated plants into the soil, where it remains active and can be taken up by non-target plants (Tu et al. 2001).

Effects on soil microorganisms appear to be highly species specific, with variations in sensitivity among species of up to a factor of 100 (SERA 2004d). Imazapyr can affect some sensitive microorganisms and potentially shift soil microbial community composition toward imazapyr tolerant species. Imazapyr can inhibit rates of cellulose decomposition and carboxymethyl cellulase activity in peat soil with $59 \%$ organic carbon (Ismail and Wong 1994 cited in SERA 2004d).

\section{Metsulfurom Methyl}

The principal modes of degradation of metsulfuron methyl are hydrolysis and microbial degradation, with the latter being the only major pathway in alkaline soils (Sarmah et al. 1998). Degradation rates are affected by soil temperature, moisture content, and soil $\mathrm{pH}$. Half- lives in acidic or neutral soils vary from 5 to 190 days (Sarmah and Sabadie 2002, SERA 2004e). In acidic soils, adsorption of metsulfuron methyl is influenced by soil temperature, clay content, and organic matter content. In alkaline soils, adsorption is very low and leaching potential is high. This is likely to result in increased persistence in alkaline subsoils that often lack organic matter and biological activity (Sarmah et al. 1998).

An application of metsulfuron methyl at a rate of $5 \mathrm{mg}$ a.i./kg soil decreased levels of amylase, urease, and protease activity in loamy sand and clay loam soil (Ismail et al. 1998). At surface application rates of 0.04 to $0.067 \mathrm{lb} / \mathrm{ac}$, decreases in soil bacteria were apparent for 3 days but reversed completely after 9 days. Biodegradation of metsulfuron methyl increased as soil moisture increased from $20 \%$ to $80 \%$ of field capacity, and half-life increased when temperature was raised from $20^{\circ}$ to $30^{\circ} \mathrm{C}$ (Ismail and Azlizan 2002). Peterson et al. (1994 cited in SERA 2004e) observed significant inhibition in growth of three species of cyanobacteria using metsulfuron methyl at a concentration of 0.003 mg a.i./L.

\section{Picloram}

Photolysis and biodegradation are primary mechanisms of dissipation of picloram (USDA Forest Service 2000a). Picloram adsorbs to clay particles and organic matter, but if the soil contains little clay or organic matter, picloram is easily moved by water. Picloram has been reported to remain active in soil at levels toxic to plants for more than 1 year at typical application rates (SERA 2003b). The half-life of picloram in soil is reported to vary from 1 month under favorable environmental conditions to more than 4 years in arid regions (USDA Forest Service 2000a). Picloram can be persistent in plants. When plant parts containing picloram degrade, they may release it into the soil, where it can then be taken up by other plants.

The persistence of picloram in soil is dependant on soil moisture and temperature. Picloram dissipates most slowly when soils are alkaline, fine textured, and low in organic matter. Picloram degrades more rapidly under anaerobic than aerobic conditions and at lower application rates (USDA Forest Service 2000a).

Higher soil concentrations of picloram result in longer persistence of the compound. With high application rates, picloram may inhibit microbial activity (Krzyszowska et al. 1994). There does not appear to be a defined threshold for picloram toxicity to soil 
microorganisms (SERA 2003b). Concentrations of picloram in the soil as low as $0.025 \mathrm{mg}$ a.i. $/ \mathrm{kg}$ soil appear to result in an increase in the persistence of picloram, which may be attributable to negative effects on microbial populations.

\section{Triclopyr}

There are two formulations of triclopyr - a triethyamine salt (TEA) and a butoxyethyl ester (BEE). Both formulations degrade to triclopyr acid in soil. Degradation occurs primarily through microbial metabolism, but photolysis and hydrolysis can be important. The average half-life of triclopyr acid in soil is 30 days ( $T u$ et al. 2001). Triclopyr can be persistent in plants. When plants containing triclopyr die and biodegrade, they may release triclopyr to the soil, where it can then be taken up by other plants.

Microbial metabolism accounts for a significant percentage of triclopyr degradation in soils (SERA $2003 \mathrm{c})$. In general, warm moist soils with a high organic content will support the highest rates of herbicide metabolism (Newton et al. 1990 cited in Tu et al. 2001). Johnson et al. (1995) found that microbial degradation of triclopyr was significantly higher in moist versus dry soils, and at $30^{\circ} \mathrm{C}$ versus $15^{\circ} \mathrm{C}$. They also found that sunlight plays a role in the rate of microbial metabolism of triclopyr, as microbial metabolism slowed when soil was deprived of light.

Triclopyr inhibited growth of four types of ectomycorrhizal fungi associated with conifer roots at concentrations of 1,000 ppm and higher (Estok et al. 1989). Some evidence of inhibition of fungal growth was detected in bioassays with as little as $100 \mathrm{ppm}$ triclopyr. Typical usage in forest plantations, however, results in triclopyr residues of only 4 to $18 \mathrm{ppm}$ on the forest floor.

\section{Impacts of Other Herbicides Currently Available for Use}

Asulam, atrazine, fosamine, mefluidide, simazine and 2,4-DP (also known as dichlorprop) have been previously approved for use on public lands in many western states (see Table 2-2), and risk assessments for these herbicides were provided in earlier BLM vegetation treatment EISs. The use of these herbicides by the BLM has been quite limited, with only fosamine used in the last 7 years. Table $2-3$ provides information on areas where use of these herbicides is appropriate.
Atrazine, simazine, and 2,4-DP are persistent in soil, do not adsorb well, and are generally considered mobile. Persistence in soil is extended under dry and/or cold conditions. Asulam does not adsorb well; however, it is readily biodegraded and its metabolites will adsorb to the soil (Vogue et al. 1994; Information Ventures, Inc. 1995a, b, c; Mahler et al. 1998).

Mefluidide is not strongly adsorbed to the soil and has a half-life from 1 to 2 weeks. It does not cause adverse effects in soil microorganisms (Information Ventures, Inc. 1995d). Because fosamine is rapidly metabolized by soil microbes, it does not persist in soils; reported half-lives range from 1 to 6 weeks (Han 1979 cited in Tu et al. 2001).

\section{Impacts by Alternative}

The BLM proposes use of herbicides to treat vegetation to improve ecosystem function and health, including soil health. However, herbicide treatments can also affect soil fertility and function, and can kill or harm soil organisms. The benefits and risks to soil under each alternative are discussed in the following sections.

\section{Alternative A - Continue Present Herbicide Use (No Action Alternative)}

Under the No Action Alternative, the BLM would continue current vegetation treatment programs in 14 western states and would treat an estimated 305,000 acres per year using both ground-based and aerial methods. Public lands in Alaska, Texas, and Nebraska are not included under this alternative.

Under this alternative, the BLM would be able to use the 20 herbicides previously approved in earlier EISs. However, based on the recent pattern of BLM herbicide use, it is likely that approximately three quarters of the area treated would involve the use of only four herbicides: 2,4-D, glyphosate, picloram, and tebuthiuron (Table 2-5). It is also likely that asulam, 2,4-DP, atrazine, mefluidide, and simazine would not be used at all because they have not been used in the last 7 years, and fosamine would likely be used on less than 50 acres annually.

Of the herbicides most often used by the BLM, chlorsulfuron, picloram, and tebuthiuron are persistent in soil for a year or more, while glyphosate and 2,4-D are relatively non-persistent in soil. None of these herbicides appears to result in severe adverse impacts to soil. Of these, glyphosate has been shown to have little or no impact on biological crust cover after 1 year, 
while impacts from the other commonly-used herbicides are less well known. 2,4-D, glyphosate, picloram, tebuthiuron, and other herbicides used by the BLM could benefit soil by removing invasive species and other unwanted vegetation and allowing restoration of native vegetation.

Fewer acres would be treated under this alternative than under the other alternatives. Negative effects to soils associated with invasive species could be greater because fewer acres with invasive species would be treated. Generally, invasive plants can increase the potential for wind or water erosion by altering fire frequency or producing chemicals that directly affect soil quality or organisms. These negative effects include increased sediment deposition and erosion, and alterations in soil nutrient cycling (Bossard et al. 2000). For example, millions of acres of grassland in the Great Basin have been taken over by downy brome. A study that compared soil organisms in native grasslands after invasion by soft brome found that the soft brome caused negative changes in most levels of the soil food web (Belnap and Phillips 2001). Soft brome invasion also appears to change soil physical characteristics and alter the cycling of carbon and nitrogen (Norton et al. 2004).

In areas with saltcedar invasions, salt accumulates in the soil as salt-accumulated leaves decompose. Scotch broom and gorse can increase the nitrogen content in soil, potentially giving an advantage to non-native species that thrive in a nitrogen-rich soil (Bossard et al. 2000). Studies in Montana have shown that sedimentation and erosion rates were $50 \%$ to $200 \%$ greater on sampling plots dominated by spotted knapweed than on plots dominated by native bunchgrasses (Lacey et al. 1989). In a few instances, invasive plants can positively affect soil through enrichment of certain nutrients and by providing erosion control.

Under this alternative, the BLM would not be able to use herbicides to eliminate unwanted vegetation on BLM lands in Texas (11,833 acres), Nebraska (6,354 acres) and Alaska (85.5 million acres). Invasive species are common on Texas and Nebraska public lands. In Alaska, there are only small, scattered outbreaks of invasive species, and the focus of invasive species treatments is to control these outbreaks before they become much larger. There is concern in Alaska regarding the use of herbicides in sensitive environments, including on tundra and in boreal forests, but herbicide use may be appropriate where impacts to soil and other resources would be negligible, and where other treatment methods may not provide adequate vegetation control (Hebert 2001).

\section{Alternative B - Expand Herbicide Use and Allow for Use of New Herbicides in 17 Western States (Preferred Alternative)}

Under the Preferred Alternative, the BLM would be able to use four new herbicides in addition to 14 previously-approved herbicides to treat approximately 932,000 acres annually across 17 western states.

As discussed under the No Action Alternative, the use of herbicides would have both beneficial and adverse effects to soil. The area treated under this alternative would be approximately 3 times greater than under the No Action Alternative. Thus, effects would be approximately 3 times greater. By treating a larger area than under the No Action Alternative, the BLM would have a greater likelihood of reducing the number of acres covered by weeds and other invasive vegetation and restoring ecosystem function, to the benefit of soil resources.

Based on BLM patterns of use, 2,4-D, glyphosate, picloram, and tebuthiuron would comprise about $70 \%$ of the currently-used herbicides that would be used under this alternative. The risks and benefits of using these herbicides are discussed under the No Action Alternative. Approximately $10 \%$ of all treatment acres would be treated with the new herbicides, and of these, most would be treated using imazapic. Imazapic would be used to control downy brome, hoary cress, perennial pepperweed, and several other invasive species that are known to alter soil characteristics, alter wildfire intensity and frequency, and increase soil erosion. Potential effects to soil and soil organisms from the new herbicides appear to be minor.

In addition to using the four new herbicides, the BLM would be able to use herbicides in Alaska, Nebraska, and Texas. Although little to no herbicide usage is planned for Alaska under this alternative, being able to use herbicides in Nebraska and Texas would allow for a more comprehensive weed management program that should reduce the negative effects of invasive species on soil in those states.

If new herbicides are developed in the future that provide control of unwanted vegetation superior to that of currently-used or proposed herbicides and with fewer risks to soil and other resources, the BLM would be able to use these herbicides to the benefit of soil resources 
upon completion of appropriate risk assessments and associated NEPA analysis.

\section{Alternative C - No Use of Herbicides}

Under Alternative C, no herbicides would be used in the BLM vegetation management program in 17 western states. Some areas would not be treated by any method, while other areas would be treated by mechanical, manual, biological, or fire methods.

Without the use of herbicides, it is likely that invasive plants would continue to rapidly spread, resulting in dramatic and potentially irreversible effects on soil quality through changes in organic matter content, diversity and abundance of soil organisms, and nutrient and water availability. As discussed above, weeds and other undesirable vegetation can outcompete native vegetation and lead to widespread incidence of fire and other conditions that can result in increased rates of soil erosion and loss of soil productivity. Other treatment methods, including use of fire, machinery, and livestock can remove vegetation, but also disturb soil, leading to soil erosion and loss of soil quality (see PER). In many situations, herbicides are the only, or the most effective method for controlling invasive vegetation. For example, mechanical and manual methods are not appropriate for large-scale treatments (hundreds to thousands of acres), and for treatments in remote areas that would require construction of roads and other soil disturbing activities to allow access by mechanical equipment. The effects of non-herbicide treatments on soil are discussed in the PER.

\section{Alternative D - No Aerial Applications}

Under Alternative D, the BLM would be able to use 14 previously-approved and four newly-approved herbicides in 17 states, but would not be able to apply herbicides from aircraft. Relative to other alternatives, there would be a reduced risk of inadvertent applications from off-site drift. Subsequently, there could be less risk to non-target soils.

Ground-based treatments could be used to in place of aerial treatments in some locations. However, in other areas ground-based treatments would be ineffective or too costly to implement, including remote areas, areas with difficult terrain, and large expanses of woodland and forest. Other locations where ground-based treatments would be ineffective include areas with extensive coverage of invasive species (such as downy brome in the Great Basin). Ground-based herbicide applications in these areas might not be comprehensive enough to adequately control invasive species, and reinvasion would require additional treatments in the same area, requiring more herbicide to be used (USDI BLM 1991a).

Non-herbicide methods of vegetation control may be substituted in areas unsuitable for ground-based herbicide treatment. For example, where there is sufficient fuel to carry a fire, prescribed fire could be used to control large areas of invasive vegetation. Currently, vegetation management best practices use herbicide applications following fire to avoid reinvasion and promote native vegetation. In many areas, this would be impractical without the option of aerial application. Also, mechanical and/or biological treatments could be used instead, but the amount of area that could be treated by these methods would be substantially less, and these treatments would disturb more soil than aerial herbicide treatments (see PER).

\section{Alternative $\mathbb{E}$ - No Use of Acetolactate Synthase- inhibiting Herbicides}

Under this alternative, the BLM would not be able to use ALS-inhibiting herbicides. This group of herbicides has been shown to damage off-site native and crop species, and several weed species can develop resistance to these herbicides, making them less effective. Under this alternative, four currentlyapproved herbicides (metsulfuron methyl, sulfometuron methyl, chlorsulfuron, and imazapyr) and one proposed herbieide (imazapic) would not be used. The number of acres treated under this alternative would be approximately one-half the acreage that would be treated under the Preferred Alternative. In addition, aerial herbicide treatments and herbicide treatments in wetland, riparian, wilderness, and cultural resource areas would be discouraged, while more passive treatment methods would be promoted.

The impacts associated with reducing the area treated are discussed under Alternative $\mathrm{C}$, and impacts associated with restrictions on aerial application are discussed under Alternative D. Impacts to soils associated with the use of herbicides in wetland and riparian areas are discussed in the Wetland and Riparian section of this chapter. Use of herbicides in areas with cultural resources is discussed in the Cultural Resources section.

This alternative would limit activities that are known to impact soils and lead to invasive species establishment, such as OHV use, minerals extraction, forestry, and livestock grazing. However, OHV use and livestock 
grazing could only be restricted to levels consistent with adopted BLM LUPs. Restrictions on grazing and $\mathrm{OHV}$ use would benefit soils, but in areas with extensive infestations of weeds and other invasive vegetation, the full benefits of restricting grazing, OHV use, and other ground-disturbing activities might not be fully realized until invasive species were controlled and sites were restored with native vegetation.

An extensive knowledge of ALS-inhibiting chemical behavior in soil appears to be lacking, including toxicity of residues, remnants of degradation products, presence and release of bound residues, and potential for groundwater pollution (Sarmah and Sabadie 2002). At this time, ALS-inhibiting herbicides have not been found to be more or less toxic to soil organisms or to demonstrate other soil effects that are notably different from those associated with the other herbicides.

Under this alternative, the BLM would not be able to use imazapic, which is proposed for extensive control of downy brome. This could reduce the number of acres of downy brome treated in the Great Basin and elsewhere, and could increase adverse effects to soil in comparison to the No Action Alternative.

\section{Mitigation for Herbicide Treatment Impacts}

No mitigation measures are proposed for soil resources.

\section{Water Resources and Quality}

\section{Introduction}

The proposed herbicide treatments have the potential to affect water resources on or near public lands by altering water flows, surface water and groundwater quantity and quality, and rates of groundwater recharge. Surface water provides an important source of drinking water, provides habitat for fish and wildlife, and is used for recreation. Groundwater, and especially potable groundwater, provides drinking water for more than $97 \%$ of the rural population without access to public water supplies, and provides $30 \%$ to $40 \%$ of the water used for agriculture (Alley et al. 1999).

Studies have shown some groundwater supplies to be contaminated with herbicides and other contaminants (total dissolved solids, metals, etc). Generally, shallow groundwater aquifers are at greater risk for contamination than deeper sources. Water quality data for the surface water and groundwater resources of the western states are available from several data sources, as discussed in Chapter 3 under Water Resources and Quality. These sources were used to develop a general assessment of water quality in the hydrologic regions of the western states, including Alaska, where the BLM has substantial land management responsibility. Data from the USEPA's Index of Watershed Indicators characterizes the condition and vulnerability of each of the 2,262 subbasins in the U.S. (Map 3-6). Information on general groundwater quality (based on concentration of TDS) was compiled from the USEPA's National Water Quality Inventory (USEPA 2000a; Map 3-7). Based on these assessments, watershed and groundwater water quality is poor to moderate over many areas in the West, primarily in areas associated with agricultural activities. Thus, actions that further deteriorate water quality or watershed health need to be carefully evaluated before being implemented on public lands.

\section{Scoping Comments and Other Issues Evaluated in the Assessment}

During scoping, commentors encouraged the BLM to evaluate the effects of herbicides on watersheds and watershed sustainability; water supply (yield); and infiltration, runoff, and other hydrologic processes; and to address protection of surface water and groundwater quality and quantity, including conservation and pollution. A number of commentors pointed out the potential impacts associated with herbicide runoff, overspray, and drift. Commentors suggested that the effects of herbicide metabolites in water should be addressed. Specific concerns regarding the impacts of herbicides on water quality degradation and the accumulation of herbicides in surface water and groundwater were raised. Commentors also expressed concern about the effects of invasive species (saltcedar in particular) on water quality and quantity, and on riparian habitats.

\section{Standard Operating Procedures}

The following discussion addresses potential impacts from herbicides currently available for use by the BLM and from herbicides proposed for use. This assessment of impacts assumes that SOPs (Table 2-8) designed to reduce potential unintended impacts to water are used. The following SOPs are recommended to reduce potential unintended impacts to water quality and quantity from the application of herbicides: 
- Consider climate, soil type, slope, and vegetation type when developing herbicide treatment programs.

- Note depths to groundwater and identify areas of shallow groundwater and areas of surface water and groundwater interaction.

- Review hydrogeologic maps of proposed treatment areas or conduct site reconnaissance to identify areas of shallow groundwater.

- Select herbicide products to minimize impacts to water. This is especially important for application scenarios that involve risk from active ingredients in a particular herbicide, as predicted by risk assessments.

- Use local historical weather data to choose the month of treatment. Based on the phenology of the target species, schedule treatments based on the condition of the water body and existing water quality conditions.

- Plan to treat between weather fronts (calms) and at the appropriate time of day to avoid high winds that increase water movements, and to avoid potential stormwater runoff and water turbidity.

- When possible, plan to treat shallow areas, which are easier to control.

- Conduct mixing and loading operations in an area where an accidental spill would not contaminate an aquatic body.

- Do not rinse spray tanks in or near water bodies.

- Do not broadcast pellets where there is danger of contaminating water supplies.

- Minimize treating areas with high risk for groundwater contamination.

- Maintain buffers between treatment areas and water bodies. Buffer widths should be developed based on herbicide- and site-specific criteria to minimize impacts to water bodies.

- Minimize the potential effects to surface water quality and quantity by stabilizing terrestrial areas as quickly as possible following treatment.

\section{Impacts by Treatment}

\section{Aquatic Vegetation Control Using Herbicides}

\section{Water Quality}

The BLM currently uses four herbicides in riparian and aquatic habitats-2,4-D, glyphosate, imazapyr, and triclopyr - and is proposing to use diquat and fluridone in these areas as well. The remaining herbicides available to the BLM, or proposed for use, are registered for use on terrestrial sites.

Herbicides applied to streams, ponds, and lakes for aquatic vegetation control could impact surface water quality if applied at concentrations that exceed label requirements. Based on the HHRA (see the Human Health and Safety section in this chapter and Appendix $\mathrm{B})$, there would be low risk to drinking water in areas treated with diquat, fluridone, glyphosate, or imazapyr, even if these herbicides were accidentally spilled in streams, ponds, or lakes used by humans. However, risk to drinking water associated with 2,4-D or triclopyr applications would be moderate to high.

Aquatic plant control can cause a high rate of plant decomposition and may cause rapid oxygen loss from water that can seriously degrade water quality. The magnitude of this effect depends on water temperature, lake or pond stratification, and the amount and rate of plant decomposition. The effects can persist from a few weeks to an entire growing season, but are generally not permanent.

The proliferation of invasive and unwanted aquatic vegetation in surface waters can affect water quality, resulting in water quality degradation. Blooms of weedy vegetation can result in reduced drinking water quality, potentially limit recreation opportunities, and lead to depletion of oxygen in water, which can degrade fish and wildlife habitat. Infestations can block channels or culverts, causing flooding. Use of aquatic herbicides to remove weedy and invasive aquatic vegetation could reverse such infestations and greatly improve water quality and enhance fish and wildlife habitat and recreational opportunities.

Water quality degradation could result from removal of riparian vegetation and reduction in shade. With the loss of shade, the resulting increase in surface-water temperature fluctuations could drive water temperature beyond tolerable limits for temperature sensitive fish and other aquatic species. 


\section{Water Quantity}

Applications of herbicides to aquatic systems would not directly modify water quantity. However, indirect impaets to water quantity could occur if treatments involving the removal of unwanted aquatic vegetation were to reduce plant uptake of water, thereby increasing the amount of available water.

\section{Terrestrial Vegetation Control Using Herbicides}

\section{Water Quality}

The four primary means of off-site movement of herbicides are runoff, drift, misapplication/spills, and leaching. Surface water could be affected by any of these means, while groundwater potentially would be affected only by leaching. Site conditions and application technique are other factors that can influence the effects of an herbicide on water quality.

Runoff and Leaching. There are three physical properties that, when combined with climate, geology, and topography, determine the runoff and leaching potential of an herbicide: 1) persistence, which is the time a chemical stays active; 2) soil adsorption, which is the tendency of a chemical to bind to soil particles; and 3) solubility, which is the tendency of a chemical to dissolve in water (BPA 2000).

Herbicides must be relatively persistent in order to have either leach or runoff potential (non-persistent herbicides do not stay active long enough to create a risk). If an herbicide has a high soil adsorption, it is more likely to run off with soil movement. Soils high in organic content or clay tend to be the most adsorptive, while sandy soils low in organic content are typically the least adsorptive (USDI BLM 1991a). If an herbicide has low soil adsorption, it is likely to leach down through the soil. If an herbicide is highly soluble in water, it is likely to leach; with low solubility, it is likely to run off. Tables 4-8 and 4-9 list the factors associated with herbicide movement to groundwater, and physical properties and off-site movement potential (leaching and runoff) for each currently available and proposed herbicide.

Even if an herbicide has runoff or leaching potential, the likelihood of it reaching a water body also depends on site characteristics. For example, if a persistent herbicide with a high potential for leaching to groundwater was used at a site with low annual precipitation, and the depth to groundwater was over 100 feet, the overall potential for that herbicide to reach groundwater before degrading would be quite low. Conversely, the same herbicide, applied at a site with high annual rainfall, coarse underlying soils, and groundwater depths less than 100 feet would have a higher relative potential of reaching groundwater. Herbicides that are highly water soluble, relatively persistent, and not readily adsorbed by soil particles have the greatest potential for movement into the groundwater. Sandy soils low in organic content are the most susceptible to groundwater contamination (USDI BLM 1991a).

Drift. Herbicide drift can degrade surface water quality. Herbicides can reach water through drift, the airborne movement of herbicides beyond the treatment area. Three factors contribute to drift: 1) application technique; 2) weather conditions; and 3) applicator error. Aerial and broadcast applications are most likely to reach water through drift, because the herbicide is sprayed from a helicopter/plane or through a boom and must settle through the air to reach the treatment area. Spot and localized applications are less likely to result in drift because these applications are targeted to specific plants, and less herbicide is applied. Wind speed and air temperature, and their effect on herbicide evaporation, affect the potential for drift. During application when winds are over $5 \mathrm{mph}$ and temperatures are warm, the potential for drift is greater (BPA 2000). Peak concentrations from aerial spraying of fine droplets with 50- to 70-foot buffer zones commonly range from 0.130 to 0.148 ppm (USDA 1988). Well-vegetated buffers can intercept herbicides and reduce the potential for herbicides to reach surface water. The BLM typically uses nozzles that produce large droplets, and requires 100-foot or wider buffers, to minimize the risk of herbicides drifting into surface waters (USDI BLM 1991a). Still, buffer widths up to 1,500 feet may be required for some herbicides to protect sensitive aquatic species from exposure to aerial drift (Appendix C).

The potential for spray drift to impact perennial and intermittent streams would be low because minimum 10-foot (ground-hand application), 25-foot (groundvehicle), or 100-foot (aerial) buffers would be provided between treatment areas and water bodies (Note: The BLM would use information in the ERAs to develop more precise buffer distances based on soil, precipitation, vegetation, and treatment characteristics; see Appendix C). Herbicides applied near water bodies would have to move through the buffers, and would likely be mixed and diluted. The potential for spray drift to impact ephemeral streams would be 
TABLE 4-8

Factors Associated with Herbicide Movement to Groundwater

\begin{tabular}{|c|c|}
\hline Category & Properties Increasing Likelihood of Groundwater Detection \\
\hline Herbicide properties & $\begin{array}{l}\text { Greater mobility (lower adsorption) } \\
\text { Greater pesticide persistence (lower reactivity) }\end{array}$ \\
\hline Agricultural management practices & $\begin{array}{l}\text { Higher pesticide use } \\
\text { Increasing proximity to pesticide application areas } \\
\text { Reductions in depth or frequency of tillage }\end{array}$ \\
\hline Well characteristics & $\begin{array}{l}\text { Decreasing well depth } \\
\text { Dug or driven (versus drilled) wells } \\
\text { Poorer integrity of surficial or annular well seals }\end{array}$ \\
\hline Hydrogeologic and edaphic factors & $\begin{array}{l}\text { Unconsolidated aquifer materials (versus bedrock) } \\
\text { Decreasing depth of upper surface of aquifer } \\
\text { Decreasing thickness or absence of confining layers } \\
\text { Higher hydraulic conductivity } \\
\text { Higher soil permeability } \\
\text { Increased recharge (from precipitation or irrigation) } \\
\text { Younger groundwater age }\end{array}$ \\
\hline
\end{tabular}

greatest because there are no proposed buffers for these streams. Herbicides applied near ephemeral streams are often liberated during storm surges (USDI BLM 1991a; Appendix C).

Misapplications and Spills. Herbicides registered for use in terrestrial habitats may affect surface water and groundwater as a result of unintentional spills or movement of herbicides from the upland sites into aquatic systems. Pollution results from herbicide concentrations that are elevated enough to impair water quality and the beneficial use of that water (USDI BLM 1991a). The potential for upland herbicide applications to reach water is affected by the herbicide's physical properties, the application method and rate, and site conditions (BPA 2000).

Most experts agree that misapplications and spills are the leading cause of impacts on non-target resources. Misapplications and spills are caused by failure to follow label instructions and restrictions, and by applicator carelessness. The impacts of spills depend on the persistence and mobility of the spill, as well as how quickly and thoroughly the spill is cleaned up.

Site Conditions. Site conditions that determine the potential for an herbicide to intercept water include proximity of the treatment area to water and buffer width. The type of water body determines the potential for contamination, should an herbicide reach the water body. Small, still water bodies, such as ponds and small wetlands, are the most likely to be affected; these water bodies move small volumes of water and have a limited ability to disperse or dilute contaminants. By contrast, large fast-moving rivers would be least likely to be affected because the volume and turbulence of the water would help dilute the herbicide quickly (BPA 2000).

Rainfall is another factor affecting the potential for herbicides to contaminate water bodies after treatment. Herbicides, particularly granular formulations, are likely to be washed from treatment areas toward water bodies.

The vegetation, ground cover, or soil type between a treatment area and a water body can influence whether herbicides will reach water. Thick vegetation might block drift or absorb an herbicide moving through water or ground before it reaches a water body. In comparison, where little to no vegetation is present, the herbicide would encounter less resistance when washing toward the water body.

Additional effects to water quality that could occur from herbicide treatments include increased nutrient loads to surface water and groundwater. Soluble nutrients can enter surface water or groundwater. Nutrients adsorbed to particles may be moved to water bodies by wind and water erosion. Nutrient enrichment of aquatic systems can lead to algal blooms and eutrophication (mineral and organic nutrient loading and subsequent proliferation of plant 
TABLE 4-9

Herbicide Physical Properties and Off-site Movement Potential

\begin{tabular}{|c|c|c|c|c|c|}
\hline \multirow[b]{2}{*}{ Herbicide } & \multicolumn{3}{|c|}{ Physical Properties } & \multicolumn{2}{|c|}{ Off-site Movement Potential } \\
\hline & Persistence & Solubility (mg/l) & $\begin{array}{l}\text { Adsorption } \\
\text { (Koc) }\end{array}$ & $\begin{array}{c}\text { Groundwater } \\
\text { Leaching }\end{array}$ & $\begin{array}{c}\text { Surface Water } \\
\text { Runoff } \\
\end{array}$ \\
\hline \multicolumn{6}{|c|}{ Aquatic Use Herbicides } \\
\hline $2,4-\mathrm{D}$ & Moderate & $3.39 \times 10^{4}$ & 19-109 & Moderate & Low \\
\hline $2,4-\mathrm{DP}$ & Low & 50 & 1,000 & Low & Moderate \\
\hline Diquat & High & 700,000 & 690 & Low & High \\
\hline Fluridone & Low & 10 & 1,000 & Low & High \\
\hline Glyphosate & Moderate & 900,000 & 24,000 & Low & High \\
\hline Imazapyr & Moderate & $>11,000$ & 100 & High & Low \\
\hline Triclopyr TEA & Moderate & $2,100,000$ & 20 & High & Low \\
\hline Triclopyr BEE & Moderate & 23 & 780 & Low & High \\
\hline \multicolumn{6}{|c|}{ Terrestrial Use Herbicides } \\
\hline Asulam & Low & 7 & 55,000 & Moderate & Low \\
\hline Atrazine & Moderate & 33 & 100 & High & Moderate \\
\hline Bromacil & Moderate & 700 & 32 & High & Moderate \\
\hline Chilorsulfuron & Moderate & 7,000 & 400 & High & Low \\
\hline Clopyralid & Moderate & 300,000 & 6 & High & Low \\
\hline Dicamba & Moderate & 400,000 & 3 & High & Low \\
\hline Diflufenzopyr & Low & 5,850 & $18-156$ & High & Moderate \\
\hline Diuron & Moderate & 42 & 480 & Moderate & High \\
\hline Fosamine ammonium & Low & Completely soluble & 79 & Low & Low \\
\hline Hexazinone & High & 33,000 & 40 & High & Moderate \\
\hline Imazapic & High & 2,200 & 206 & Low & Low \\
\hline Mefluidide & Low & 180 & 200 & Low & Moderate \\
\hline Metsulfuron methyl & Moderate & 9,500 & 35 & High & Moderate \\
\hline Picloram & Moderate & 200,000 & 16 & High & Low \\
\hline Simazine & Moderate & 6 & 130 & High & Moderate \\
\hline Sulfometuron methyl & Low & 70 & 78 & Moderate & Moderate \\
\hline Tebuthiuron & High & 2,500 & 80 & High & Low \\
\hline
\end{tabular}

life), resulting in decreased dissolved oxygen contents. The extent and duration of effects would be dependent on the geographic location, and on the extent of vegetation removal, as well as on revegetation management practices. The removal of large amounts of vegetation along streams could lead to higher water temperatures, to the detriment of fish and other aquatic organisms.

In contrast to the negative effects to water that could result from herbicide treatments, herbicide use can benefit water quality if vegetation removal reduces the risk of fire and post-fire sedimentation. Treatment of upland areas could reduce hazardous fuels and contribute to long-term benefits to surface water quality by reducing the risk of high-intensity wildfires. In addition, the use of herbicides to control invasive species in terrestrial and aquatic systems could provide long-term benefits to water quality with the return of more stable soils, attenuated nutrient cycling, and a return to normal fire cycles.

Application Technique. Application technique can also have an impact on leaching and runoff potential. Applications over large areas (broadcast and aerial techniques) are more likely to result in deposition of herbicides in soils than spot or localized treatments, thus increasing the potential for runoff and leaching.

From a watershed perspective, the concentration and amount of the herbicide applied can influence the risk of water contamination. The ratio of treated to untreated surface area in any given watershed is usually sufficiently low to permit rapid dilution. This ratio is 
much lower than that for the concentrated areas or blocks of land typically targeted by the BLM for rangeland and forestry treatments. For example, aerial application of herbicides along a 100 -foot wide ROW would result in about $2 \%$ to $3 \%$ of a 640 -acre area (section) being treated. By contrast, treatment areas of $10 \%$ to $25 \%$ per section can occur in forestry practice, and areas greater than $75 \%$ per section are common in rangeland applications. Risk of direct application to streams along ROW would increase if the linear flight path of the applicator crossed several streams. No single factor can be used to anticipate the effect of herbicides on stream systems. By following label instructions and restrictions, and establishing buffers, applicators can reduce the potential for herbicides to reach water bodies.

\section{Water Quantity}

The use of herbicides to remove vegetation could affect water quantity by altering both the magnitude of base flows and the frequency and magnitude of peak flows. For some treatment areas, the removal of vegetation, especially in large quantities, could improve groundwater recharge by limiting the amount of water lost through sublimation or plant evapotranspiration. In this case, base flows, which are dependent on the quantity of groundwater discharge, would increase. These changes could be very minor or short-lived if the vegetation did not evapotranspirate or sublimate large proportions of precipitation, or if areas were revegetated quickly (Satterlund and Adams 1992).

Under some circumstances, vegetation removal could result in the reduction of groundwater discharge and base flow as a function of reduced infiltration rates. Reduced infiltration rates result in more surface runoff reaching streams and lakes immediately after a rain event, thus increasing the velocity, frequency, and magnitude of peak stream flows. These changes in water quantity could alter the physical characteristics of stream channels and affect the speed of water movement. Any changes would last until the site was revegetated.

\section{Impacts by Herbicide}

\section{Aquatic Vegetation Control}

\section{2,4-D}

The salt formulation of 2,4-D is registered for use in aquatic systems. 2,4-D is a known groundwater contaminant; the USEPA has set a maximum concentration of $0.07 \mathrm{mg} / \mathrm{L}$ as a permissible level for this herbicide in potable water.

Concentrations of up to $61 \mathrm{mg} / \mathrm{L} 2,4-\mathrm{D}$ have been reported immediately following direct application to water. Based on label directions, treated water should not be used for irrigation if the water could be consumed by humans. Concentrations as low as 0.22 $\mathrm{mg} / \mathrm{L}$ can damage sensitive plants (Que Hee and Sutherland 1981 cited in Tu et al. 2001).

There are conflicting conclusions regarding biodegradation of 2,4-D in aquatic systems (Que Hee and Sutherland 1981 and Wang et al. 1994 cited in Tu et al. 2001). Biodegradation can take place in bottom sediments if the appropriate microbial population is present and the $\mathrm{pH}$ level is sufficiently high, but it is not likely to occur in the water column. Under acidic conditions, when microbial activity is inhibited (Sandmann et al. 1988 cited in Tu et al. 2001), biodegradation may not occur. Differences in reported half-lives of 2,4-D may arise from differences in the microbial populations in treatment areas and the influence of plants on soil biological and chemical properties (Boucard et al. 2005).

2,4-D changes form and function with changes in $\mathrm{pH}$ (Que Hee and Sutherland 1981 cited in Tu et al. 2001). In alkaline waters, 2,4-D takes a negatively-charged form that is water-soluble and remains in the water column. In water of a lower $\mathrm{pH}, 2,4-\mathrm{D}$ remains in a neutral molecular form, increasing its potential for adsorption to organic particles in water and increasing its persistence. 2,4-D is predicted to adsorb to suspended particles in muddy waters with a fine silt load (Que Hee and Sutherland 1981 cited in Tu et al. 2001), but little adsorption has been observed in the field (Halter 1980 cited in Tu et al. 2001).

In terrestrial applications, most formulations of 2,4-D do not bind tightly with soils, and therefore have a moderate potential to leach into the soil column and to move off site in surface or subsurface water flows (Johnson et al. 1995 cited in Tu et al. 2001). In a study on groundwater expressed as spring flow, 2,4-D was detected in $7 \%$ of the samples (Wood and Anthony 1997).

\section{Diquat}

Diquat would be applied to remove emergent, floating, or submerged aquatic vegetation. In aquatic systems, diquat (ionic) adsorbs to sediment, suspended solids, and aquatic vegetation, and becomes immobilized 
(Simsiman and Chesters 1976). Thus, diquat is ineffective in turbid waters. Loss of diquat from aquatic systems, both through photolysis and biodegradation, is possible, but only when the herbicide is not adsorbed to solid surfaces. When adsorbed, the herbicide is protected from biodegradation and photolysis (Howard 1991). Aquatic half-lives of 1 to 2 days have been reported for diquat, as a result of sorption onto particulates and sediments (National Library of Medicine 2002). Diquat is a known groundwater contaminant, and the USEPA has set a maximum concentration level of $20 \mu \mathrm{g} / \mathrm{L}$ for potable water. It has a moderate potential to leach into the groundwater and a high potential to be transported in surface water runoff.

\section{Fluridome}

Fluridone would be applied to ponds, lakes, canals, and reservoirs, but has limited use in flowing water because it works through contact maintained over several weeks. Water quality is not degraded when fluridone is used at a concentration of less than $20 \mathrm{ppb}$, and it is generally considered safe to use in areas where swimming or fishing occur (Washington Department of Ecology 2002). Whole-lake treatments using fluridone are possible because the herbicide does not cause a rapid plant kill, which could result in oxygen-depleted water and reduced water quality.

Photodegradation in aquatic systems is an important loss pathway for fluridone (British Crop Protection Council and The Royal Society of Chemistry 1994). Fluridone is stable to hydrolysis, volatilizes slowly from water, and adsorbs to suspended solids and sediments (USEPA 1986; Lyman et al. 1990; Tomlin 1994; Mackay et al. 1997; ENSR 2005g). Desorption from sediments followed by photolysis is reported to be a loss pathway (ENSR 2005g). Biodegradation can also remove fluridone from aquatic systems. Aquatic dissipation half-lives from 4 days to 9 months (anaerobic sediments) have been reported. Fluridone has low potential to leach to groundwater and is not known to contaminate groundwater. It does have high potential to be transported in stormwater runoff.

\section{Glyphosate}

Glyphosate, which is registered for aquatic use, would be applied to wetland and emergent aquatic vegetation. Glyphosate dissipates rapidly from surface water through adsorption to organic substances and inorganic clays and by biodegradation (Folmar et al. 1979; Feng et al. 1990; Zaranyika and Nydandoro 1993; Paveglio 1996 cited in Tu et al. 2001). It does not photodegrade, and in water has an estimated half-life of 12 days to 10 weeks. It is generally considered immobile because of its adsorption characteristics; however, it is a known groundwater contaminant. The USEPA has set a maximum concentration limit of $0.7 \mathrm{mg} / \mathrm{L}$ as a permissible level for glyphosate in potable water.

Strong adsorption to particles slows microbial degradation, allowing glyphosate to persist in aquatic environments. Glyphosate can be inactivated by adsorption if mixed with muddy water (Tu et al. 2001). Residues adsorbed to suspended particles are precipitated into bottom sediments where they can persist until biodegraded or be released into water (Goldsborough and Brown 1993 and Extension Toxicology Network 1996a cited in Tu et al. 2001).

Glyphosate is unlikely to enter waters through surface runoff or subsurface flow because it binds strongly to soils, except when the soil itself is washed away by runoff; even then, it remains bound to soil particles and generally unavailable (Rueppel et al. 1977 and Malik et al. 1989 cited in Tu et al. 2001). More recent studies found solution-phase glyphosate in $36 \%$ of 154 stream samples, while its degradation product, aminomethylphosphonic acid, was detected in $69 \%$ of the samples. The highest measured concentration of glyphosate was $8.7 \mu \mathrm{g} / \mathrm{L}$, well below the USEPA's maximum concentration limit of $700 \mu \mathrm{g} / \mathrm{L}$.

Glyphosate may stimulate algal growth at low concentration; Austin et al. (1991) have suggested that this could contribute to eutrophication of waterways. An increase in periphyton concentrations in artificial streams has been reported by Austin et al. (1991), and Wong (2000) reported an increase in chlorophyll-a synthesis by a green microalgae (Scenedesmus quadricauda) at a concentration of $0.02 \mathrm{mg} / \mathrm{L}$ (cited in SERA 2003a).

\section{Imazapyr}

Imazapyr is registered for use in aquatic systems, including brackish and coastal waters, to control emergent, floating, and/or riparian and wetland plants. Imazapyr is water soluble and potentially mobile (SERA 2004d). Imazapyr is rapidly degraded by sunlight in aquatic solutions, with a half-life of approximately 2 days that decreases with increasing $\mathrm{pH}$ (Mallipudi et al. 1991 and Mangels 1991 cited in Tu et al. 2001). Imazapyr does not appear to degrade in anaerobic systems, such as wetland soil or lake or pond sentiments, and will bind strongly to peat (American Cyanamid 1986 cited in Tu et al. 2001). 
In their literature revicw of imazapyr, Tu et al. (2001) found no reports of imazapyr contamination in water despite its potential for mobility. It is not known to be a groundwater contaminant. Battaglin et al. (2000) stated that little is known about its occurrence, fate, or transport in surface water or groundwater. In one study, imazapyr (from terrestrial applications) was detected in $4 \%$ of the 133 samples taken from streams, but was not detected in reservoirs or groundwater.

\section{Triclopyr}

The two formulations of triclopyr, a triethyamine salt and a BEE, behave very differently in water. Both formulations are used to control woody riparian vegetation. However, only the triethylamine salt formulation of triclopyr (known as Garlon $3 \mathrm{~A}^{\circledR}$, now marketed as Renovate $3^{\circledR}$ ), is registered for use for selective control of submersed aquatic plants. Both formulations readily degrade to the acid form, which is the active form in plants.

The triethyamine salt formulation of triclopyr is soluble in water and photodegrades in several hours with adequate sunlight. Field studies have shown that triclopyr (salt formulation) and its metabolites dissipate from water, with half-lives ranging from 0.5 to 10 days and sediment dissipation half-lives ranging from 3 to 13 days (Petty et al. 2003). Johnson et al. (1995) found triclopyr acid in water had a half-life due to photolysis of 1 to 12 hours (cited in Tu et al. 2001). The rate of degradation in water is generally dependent on water temperature, $\mathrm{pH}$, and sediment content.

No adverse effects on water quality were observed following triclopyr triethyamine salt applications in two studies of whole-pond applications in closed systems (no water exchange; Petty et al. 2001). Results of these studies were comparable with those of triclopyr dissipation studies conducted in reservoirs, lakes, and river systems, and indicated that the degradation and dissipation of triclopyr and its metabolites are similar in representative systems throughout the U.S. (Petty et al. 2001).

The BEE formulation (terrestrial use only, not registered for aquatic application) is not water-soluble and can partition into organic materials and be transported to sediments, where it is persistent. Alternatively, bound ester forms can degrade through hydrolysis or photolysis to triclopyr acid (Smith 1976 cited in Tu et al. 2001), which will diffuse into the water column and continue to degrade ( $\mathrm{Tu}$ et al. 2001). The fate and effects of triclopyr BEE were investigated in a first-order forest stream (Thompson et al. 1995). Measurements of triclopyr in stream samples indicated that the ester form was rapidly converted to the acid, and that partition to organic materials occurred as chemical pulses moved downstream.

\section{Assessment of Impacts of Herbicides Used for Terrestrial Vegetation Control}

\section{Bromacil}

Bromacil is mobile in soil and can reach groundwater and surface water. It can be persistent in most aquatic environments because it is stable to hydrolysis, and photodegradation occurs rapidly only under alkaline conditions (ENSR 2005b). Bromacil is a known groundwater contaminant, and the USEPA standard for drinking water is $90 \mu \mathrm{g} / \mathrm{L}$. The environmental hazards section of current product labels includes a groundwater advisory warning users not to apply bromacil in areas with permeable soils in order to protect water quality. Biodegradation is a major loss mechanism in aerobic and anaerobic aquatic systems. Bromacil is not expected to partition to suspended particles or sediments in aquatic systems, but will remain dissolved in the water column and has a high potential to leach into the groundwater.

\section{Chlorsulfuron}

Chlorsulfuron is persistent and mobile in some soils. In aquatic environments, the environmental fate of chlorsulfuron is related to $\mathrm{pH}$ and temperature. Hydrolysis rates are fastest in acidic waters and slower in more alkaline systems (Sarmah and Sabadie 2002). As hydrolysis rates drop, biodegradation becomes the mechanism affecting the breakdown of chlorsulfuron. Photodegradation is not an important loss mechanism in natural systems, although photodegradation has been observed under laboratory conditions. Aquatic dissipation half-lives from 24 days to more than 365 days have been reported (ENSR 2005c), with a shorter time reported for flooded soil (47 to 86 days) than anaerobic aquatic systems (109 to 263 days; SERA 2004a). Chlorsulfuron is not known to be a groundwater contaminant, but has a high potential to leach into the groundwater. Chlorsulfuron has low potential to be transported in surface water; in a large study of surface water, chlorsulfuron was detected in only $1 \%$ of the 133 samples taken from Midwest streams (Battaglin et al. 2000). 


\section{Clopyralid}

Clopyralid does not appear to bind tightly to soil and will leach under favorable conditions (SERA 2004b). However, leaehing and subsequent contamination of groundwater appear to be minimal, which is consistent with a short-term monitoring study of clopyralid in surface water after an aerial application (Rice et al. 1997a cited in SERA 2004b). Clopyralid is not known to be a common groundwater contaminant, and no major off-site movement has been documented. Clopyralid does not bind with suspended particles in water; biodegradation in aquatic sediments is the main pathway for dissipation. The average half-life of clopyralid in water has been measured at 9 and 22 days (Dow AgroSciences 1998).

\section{Dicamba}

Because dicamba is mobile in soil, terrestrial application of this herbicide can result in groundwater and surface water contamination under conditions that favor such activities. Biodegradation is the major mechanism for dicamba degradation in water. Although photodegradation occurs, it is not the major loss process. Hydrolysis and sediment adsorption are not significant loss mechanisms (Howard 1991). Dicamba is a known groundwater contaminant, and has a high potential to leach into groundwater. The USEPA has set health advisory concentration levels for dicamba (e.g. $300 \mu \mathrm{g} / \mathrm{L}$ for 1-day exposures), but has not set maximum concentration limits for potable water. Dicamba is registered for use on ditch banks, but should not be applied directly to water.

Following herbicide applications for 1 to 24 years, there were no detectable residues of dicamba in groundwater at two long-term tillage sites and one long-term manured site in Alberta (Miller et al. 1995). However, a regional study of pesticides in shallow groundwater in Delaware, Maryland, and Virginia detected dicamba in groundwater at low concentrations, generally less than 3 $\mu \mathrm{g} / \mathrm{L}$ (Koterba et al. 1993).

\section{Diflufenzopyr}

Diflufenzopyr appears to be soluble, with transportation from surface runoff following application, particularly when diflufenzopyr is applied on soils with neutral to alkaline $\mathrm{pH}$. However, based upon proposed uses, fate characteristics, and model predictions, the USEPA does not include diflufenzopyr among constituents that occur in significant quantities in drinking water (USEPA 1999c). Diflufenzopyr is not a known groundwater contaminant.

Biodegradation, photolysis, and hydrolysis are important mechanisms in removing diflufenzopyr from aquatic systems. Its half-life is less than 1 month, with hydrolysis and photolysis rates higher in acidic environments. The aquatic dissipation half-life for diflufenzopyr is 25 to 26 days in aerobic and 20 days in anaerobic conditions. Diflufenzopyr's expected half-life in small ponds is estimated at 24 days. These factors suggest that diflufenzopyr would be removed from an aquatic environment relatively rapidly if contamination occurred (USEPA 1999c).

\section{Diurom}

Diuron is a known surface water and groundwater contaminant. The USGS National Ambient Water Quality Assessment Program analyzed pesticide occurrence and concentrations for major aquifers and shallow groundwater in agricultural areas and found diuron in $71 \%$ of 2,608 samples. The maximum concentration of diuron was $0.34 \mathrm{ppb}$. The USEPA recently (February 2005) placed diuron on the drinking water contaminant candidate list. Diuron is currently labeled for use on ditch banks, but should not be applied directly to water.

In aquatic systems, biodegradation and photodegradation appear to be the primary loss mechanisms for diuron. An aquatic biodegradation halflife of 33 days has been reported for aerobic systems. Aquatic dissipation half-lives have been reported ranging from 3 to 10 days in anaerobic pond sediment to 177 days in a drainage ditch. Diuron is stable to hydrolysis and is unlikely to volatilize from aquatic systems (USEPA 2001a). Diuron is expected to adsorb to suspended solids and sediments (National Library of Medicine 2002).

The principal product of biodegradation is 3,4dichloraniline (3,4-DCA), which also persists and exhibits higher toxicity than diuron (Tixier et al. 2002; Giacomazzi and Cochet 2004). In areas where diuron is used for crop production, monitoring has shown high concentrations of 3,4-DCA in small streams. 3,4-DCA was detected year-round in surface water (333 detections, 13 non-detections), with a range from 0.05 $\mathrm{ppb}$ (detection limit) to $26 \mathrm{ppb}$; the majority of the sample detections were less than 1 ppb (USEPA 2001a). At a poorly drained field site along an intermittent stream in Oregon, diuron and its transformation product, DCPMU (3-(3,4-dichlorophenyl)-1-methyl-urea), were 
detected in the stream at a maximum concentration of $28 \mu \mathrm{g} / \mathrm{L}$, and were detected in shallow groundwater immediately adjacent to a tributary stream at 2 to 13 $\mu \mathrm{g} / \mathrm{L}$. Movement through soil transported the herbicide and its metabolite to the stream, while surface runoff removed less than $1 \%$ of the applied herbicide (Field et al. 2003).

\section{Hexazinone}

Hexazinone and its degradates persist, are highly mobile, and are readily washed into surface waters. Hexazinone has been identified as a groundwater contaminant in Hawaii, Minnesota, Georgia, Arkansas, Florida, Maine, and North Carolina. The USEPA Office of Water has issued a lifetime health advisory, which sets a maximum concentration level of $0.21 \mathrm{mg} / \mathrm{L}$ for hexazinone in drinking water. In addition, the USEPA requires a groundwater advisory on all product labels stating that hexazinone must not be used on permeable soils. In areas where irrigation water is contaminated with hexazinone or where groundwater discharges to surface water, hexazinone residues in water could pose a threat to plants. Hexazinone is labeled for use on ditch banks, but should not be applied directly to water.

In surface water, hexazinone resists photodegradation (Neary et al. 1983 cited in Tu et al. 1991). Hexazinone does not bind strongly to particulates or sediments. The main method of degradation is by microorganisms in soils. The average half-life of hexazinone in soils and water is 90 days (Tu et al. 2001). Hexazinone has been detected in streams near terrestrial application sites up to 30 days after treatment, and reported in runoff up to 6 months post-treatment in a forestry dissipation study (Neary and Michael 1996; Michael et al. 1999). Mayack et al. (1982) and Neary et al. (1984, 1993 cited in Tu et al. 2001) concluded that hexazinone was diluted in the mainstream flow to very low concentrations in forested watersheds.

\section{Imazapic}

In aquatic systems, imazapic rapidly photodegrades, with a half-life of 1 to 2 days (Tu et al. 2001). Since aerobic biodegradation occurs in soils, aerobic biodegradation is likely important in aquatic systems. Aquatic dissipation half-lives have been reported from 30 days (water column) to 6.7 years in anaerobic sediments (SERA 2004c). Little is known about the occurrence, fate, or transport of imazapic in surface water or groundwater (Battaglin et al. 2000). However, according to the herbicide label for Plateau ${ }^{\circledR}$, in which
Imazapic is the active ingredient, it is believed to be a groundwater contaminant (BASF 2004).

\section{Metsulfuron Methyl}

Metsulfuron methyl is stable to hydrolysis at neutral and alkaline pHs and has a half-life of 3 weeks in acidic systems (Extension Toxicology Network 1996b). The persistence of metsulfuron methyl (initial concentration $10 \mu \mathrm{g} / \mathrm{L}$ ) was investigated using in situ enclosures in a woodland/boreal forest lake, and the half-life was estimated at approximately 29 days (Thompson et al. 1992). Adsorption to sediments and suspended solids is not expected to be an important fate (USDA 1995). Little is known about the occurrence, fate, or transport of metsulfuron methyl in surface water or groundwater (Battaglin et al. 2000). Metsulfuron methyl is not known to be a groundwater contaminant, although it has a high potential to leach into the groundwater.

\section{Picloram}

Picloram can move off site through surface or subsurface runoff, and has been detected in the groundwater of 11 states (Howard 1991 cited in EXTOXNET 1996c). The USEPA's maximum concentration level for picloram in potable water is 0.5 $\mathrm{mg} / \mathrm{L}$. Picloram does not bind strongly with soil particles and is not degraded rapidly in the environment (Tu et al. 2001). Concentrations in runoff have been reported to be great enough to damage crops, and could cause damage to certain submerged aquatic plants (Forsyth et al. 1997 cited in Tu et al. 2001). Therefore, picloram should not be applied near waters used for irrigation or adjacent to areas with aquatic species of concern.

Picloram may degrade through photolysis, especially in non-turbid and moving water. Woodburn et al. (1989) found that the half-life of picloram in water was 2 to 3 days (cited in $\mathrm{Tu}$ et al. 2001). Maximum picloram runoff generally occurs following the first significant rainfall, after which runoff concentrations drop to levels that persist up to 2 years post-application (Scifres et al. 1971; Johnsen 1980; Mayeux et al. 1984; and Michael et al. 1989 cited in Tu et al. 2001).

\section{Sulfometuron Methyl}

Sulfometuron methyl degrades quickly by hydrolysis in acidic water, but is stable in neutral water. Biodegradation and photolysis are major loss pathways in aquatic systems, where hydrolysis rates generally are slow. Aquatic dissipation half-lives are estimated at 1 to 
3 days to 2 months in aerobic systems, and several months in anaerobic sediments (Extension Toxieology Network 1996d). Little is known about its occurrence, fate, or transport in surface water or groundwater in the U.S. (Battaglin et al. 2000). Sulfometuron methyl is not known to be a groundwater contaminant. In one surface water study, sulfometuron was detected in $2 \%$ of 133 samples taken from streams.

\section{Tebuthiurom}

Tebuthiuron persists in the environment, perhaps because of its low sorption affinity to soil. Tebuthiuron can be used on ditch banks, but should not be applied directly to water. In one study of 71 streams, tebuthiuron was detected in $16 \%$ of 134 stream samples taken, with concentrations up to $0.076 \mu \mathrm{g} / \mathrm{l}$, but was not detected in groundwater (Battaglin et al. 2001). In water, tebuthiuron is resistant to hydrolysis and photolysis, although some photodegradation has been reported at a pH of 9 (National Library of Medicine 2002). Tebuthiuron is expected to slowly biodegrade in aquatic systems. Aquatic dissipation half-lives are estimated to be longer than 1 month under aerobic conditions, and longer than 12 months under anaerobic conditions (USEPA 1994a).

\section{Other Herbicides Previously Approved for Use on BLM Lands}

Asulam, atrazine, fosamine, mefluidide, simazine, and 2,4-DP (also known as dichlorprop) are currently approved for use on public lands. However, the historical use of these herbicides by the BLM has been quite limited, with only fosamine used in the last 7 years. 2,4-DP is registered to control aquatic weeds in ditches and for upland purposes, is mobile in soils, and has been detected in surface water and groundwater (National Library of Medicine 2002). Both atrazine and simazine persist in rainwater, groundwater, and surface water. Mefluidide and fosamine are not commonly known to contaminate groundwater or surface water. Fosamine adsorbs to soil and biodegrades, making it less likely to be mobilized. However, upon reaching water it is generally stable until it partitions into sediments (Tu et al. 2001).

\section{Impacts by Alternative}

The BLM would focus treatment efforts on watersheds that provide opportunities for watershed improvement and protection (USDI BLM 2000a). In addition, the BLM would strive to increase the number of properly functioning wetland/riparian areas and uplands to benefit water quality.

Much of this work would be directed at hazardous fuels and weed reduction to improve watershed function and water quality and reduce the risk of catastrophic fires. When fire clears the vegetation, the soils that were anchored by root systems become vulnerable to wind and water erosion. When soils are carried into lakes and streams, water quality diminishes as a function of increased sedimentation and turbidity (USDI BLM 2000d). Work would also be directed at controlling invasive vegetation, such as pinyon and juniper that have overtaken many native shrub and grassland communities. These trees diminish water that native species are reliant upon and can cause increased soil erosion (USDI BLM 1999).

Watersheds dominated by annual grasses such as downy brome offer far less protection from wildland fire and erosion than those dominated by native grasses. The reduced cover provided by annuals allows more rainfall to strike the soil surface, loosening soil particles and forming a seal over the pores at the soil surface. As the pores seal, infiltration decreases, which leads to increased runoff and loss of soil moisture. Eventually, soils are transported to streams and other aquatic bodies, increasing sedimentation and reducing water quality.

\section{Alternative A - Continue Present Herbicide Use (No Action Alternative)}

Under the No Action Alternative, the BLM would treat an estimated 305,000 acres per year using the current vegetation treatment programs in 14 western states. This alternative is a continuation of the current vegetation management program using both ground-based and aerial treatment methods. Public lands in Alaska, Nebraska, and Texas have not been part of the herbicide program historically, and would not be included under this alternative.

Impacts to surface water and groundwater quality and quantity would be similar to impacts from the ongoing program. Under the No Action Alternative, it is unlikely that 2,4-DP, asulam, atrazine, mefluidide, and simazine would be used, and fosamine might only be used on a limited basis ( $<100$ acres annually). Of these herbicides, atrazine, simazine, and 2,4-DP are known groundwater contaminants.

Based on historic use, 2,4-D, glyphosate, picloram, and tebuthiuron would constitute approximately $70 \%$ of herbicide use. All of these herbicides are known 
groundwater contaminants, although only glyphosate has high surface water runoff potential. In addition, of the other herbicides proposed for use, diquat, diuron, bromacil, dicamba and hexazinone are also known to be groundwater contaminants. For most terrestrial applications, herbicide concentrations are diluted as they move from the treated site to downgradient locations (Michael 2000). Out of 236 studies of pesticide contamination of surface waters in drainage basins throughout the U.S., none reported pesticide concentrations exceeding USEPA safe levels for human health, except where chemicals were applied directly to or spilled into the stream channel (Larson et al. 1997).

Under the No Action Alternative, Overdrive ${ }^{\circledR}$, diquat, fluridone, and imazapic would not be available for use. Both diquat and fluridone are considered effective against the invasive plant Eurasian watermilfoil, as well as other problematic aquatic plants (Washington Department of Ecology 2002, Skogerboe 2003). Triclopyr would be the only herbicide under this alternative available to treat submersed vegetation. Prohibiting the use of two proposed herbicides available for treatment of aquatic plants would potentially allow for continued negative effects on water quality associated with some forms of weeds and invasive aquatic vegetation, potentially resulting in degraded fish and wildlife habitat and limited recreation opportunities.

Fewer acres would be treated under this alternative than under the other alternatives. Therefore, impacts on water quality and quantity from herbicides would be more limited. However, continued impacts to water quality and quantity from invasive plant species over the untreated areas could potentially occur.

\section{Alternative B - Expand Herbicide Use and Allow For Use of New Herbicides in 17 Western States (Preferred Alternative)}

Under the Preferred Alternative, an estimated 932,000 acres per year would be treated across 17 western states. Out of all the alternatives, this is the largest acreage proposed for treatment. Therefore, benefits and risks to surface water and groundwater would be greater than under the other alternatives. It is estimated that several thousand acres of public lands are being newly infested by noxious invasive weeds each day. The result is damage to watersheds and subsequent deterioration in water quality and quantity. Until more acres are treated, it will be impossible for the BLM to bring the spread of invasive plants down to a reasonable level by locating and treating new infestations, and reducing the size of existing infestations.
Under the Preferred Alternative, herbicide use in Alaska, Ncbraska, and Texas would be allowed, although little or no herbicide treatment is planned for Alaska. Use in Nebraska and Texas would allow for a more comprehensive weed management program that would help reduce the negative effects of invasive species in those two states.

This alternative would prohibit the use of 2,4-DP, asulam, atrazine, fosamine, mefluidide, and simazine, but would allow four new herbicides (Overdrive ${ }^{\circledR}$, diquat, fluridone, and imazapic) to be used, in addition to approved herbicides. Approximately $10 \%$ of treatment acres would be treated using these new herbicides. Diquat and fluridone could be directly applied in aquatic systems to control unwanted submersed aquatic vegetation. Approval of diquat and fluridone would provide new capabilities for controlling invasive aquatic plants and could provide benefits to water quality if invasive aquatic plants were eliminated. Fluridone, in particular, has been effective at controlling Eurasian watermilfoil without resulting in impacts to drinking water quality or recreation (Washington Department of Ecology 2002).

Both dicamba and diquat are known groundwater contaminants. However, increased protection of groundwater could be possible if imazapic (not known to contaminate groundwater) was used for treating terrestrial species in place of one of these known groundwater contaminants. Diflufenzopyr is not known to contaminate groundwater, but has a high potential to leach to groundwater. Except for fluridone, which has a high potential for surface water runoff, the proposed herbicides have low potential to flow to aquatic bodies in stormwater runoff.

\section{Alternative C - No Use of Herbicides}

No herbicides would be used in the BLM vegetation management program under Alternative C. Some areas would not be treated, while other areas would be treated by mechanical, manual, or biological methods, or fire. Without treatment, land degradation would accelerate, leading to poorer water quality. As discussed in the PER, other treatments also impact water quality and quantity, with fire and mechanical treatments having the greatest effects. However, the risks of impacts to surface water and groundwater quality would be low under this alternative.

The only alternatives to herbicide treatment of submersed vegetation are mechanical or manual removal; water drawdown on controlled reservoirs, 
lakes, and ponds; and flooding with salt or brackish water. These treatments generally are not as effective as chemical treatments at controlling many invasive aquatic plants (Aquatic Ecosystem Restoration Foundation 2004, USDI BLM 2007a). Without effective treatment, some invasive aquatic plants would go largely uncontrolled, potentially resulting in degraded water quality and reduced quantity.

\section{Alternative D - No Aerial Applications}

Under Alternative D, herbicide treatment with four newly-approved herbicides and the previously-approved herbicides would be allowed in 17 states. These herbicides would be applied by ground application methods. The estimated area treated would be approximately 529,000 acres per year. Ground-based herbicide treatments could be used to replace aerial treatments in some locations, and non-herbicide treatment methods could be substituted in some areas unsuitable for ground-based herbicide treatment.

Aerial application has the advantage of treating large areas or areas of difficult terrain. However aerial application is more likely to result in misapplications or drift, and thus negatively impact water quantity and quality. The extent of the impact would depend on the weather, the size and location of the treatment area, the use of buffers, and the kind and concentration of herbicide used.

\section{Alternative $\mathbb{E}$ - No Use of Acetolactate Synthase- inhibiting Herbicides}

Under Alternative E, the BLM would not be able to use ALS-inhibiting herbicides (chlorsulfuron, imazapyr, imazapic, metsulfuron methyl, and sulfometuron methyl). Approximately 466,000 acres would be treated under this alternative. Aerial and broadcast treatments and treatments in wetland, riparian, wilderness, and cultural resource areas would be discouraged, while more passive treatment methods would be promoted. Of the six herbicides registered for aquatic use, imazapyr is ALS-inhibiting and would not be allowed. Of the four newly proposed herbicides, imazapic is ALS-inhibiting and would not be allowed.

Impacts associated with size of treatment area are discussed under Alternative $\mathrm{C}$; impacts associated with aerial applications are discussed under Alternative D. Because of the smaller treatment acreage, the negative effects of weedy and invasive species on water quality and quantity could be greater than under the other alternatives. The risks to water quality and quantity from use of herbicides would be lower than under the Preferred Alternative. Fewer treatments in wetland and riparian areas could correspond to greater impacts to surface water quality if wetland areas containing substantial infestations of invasive species were to remain untreated.

Currently, little is known about the occurrence, fate, or transport of ALS-inhibiting herbicides in surface water or groundwater in the U.S. (Battaglin et al. 2000, 2001). An extensive study of Midwestern streams, reservoirs, and groundwater in 1998 found relatively low concentrations of sulfonylurea and imidazolinone herbicides in $83 \%$ of 133 samples from streams, in 6 of 8 reservoir samples, and 5 of 25 groundwater samples. These results indicate that some ALS-inhibiting herbicides are mobile and may reach surface water and groundwater. Therefore, contamination of water resources by ALS-inhibiting herbicides would potentially be less than under the other alternatives.

\section{Mitigation for Herbicide Treatment Impacts}

The following mitigation measure should be considered to reduce, minimize, or mitigate impacts to water resources from the use of herbicides:

- Establish appropriate (herbicide specific) buffer zones to downstream water bodies, habitats, and species/populations of interest (see Appendix C, Table C-16).

\section{Wetland and Riparian Areas}

\section{Introduction}

The BLM manages over 23 million acres classified as riparian or wetland. Wetland and riparian areas in the western U.S. and Alaska are influenced by human activity, natural disturbance, and local physical and biological conditions. Invasive plant species degrade wetland and riparian area function and present a challenge to vegetation management. An estimated 59,000 acres of wetland habitat and 16,500 stream miles on BLM lands lack characteristics necessary for "high" functioning wetland and riparian habitats (USDI BLM 2006d). Invasive plant species are one cause of degradation of wetland function.

The proposed herbicide treatments could cause longterm alterations to vegetation, hydrology, or soils to the extent that a specific area no longer functions properly 
or is fragmented, the biodiversity of high quality areas is reduced, or special status wildlife or plants are harmed or displaced. Treatments would be beneficial, as they contribute to removal or control of invasive species and replacement with native species.

\section{Scoping Comments and Other Issues Evaluated in the Assessment}

During scoping, concerns pertaining to treatment of wetland and riparian areas included protection of unique areas and areas of high biological importance; management of invasive species (e.g., saltcedar) that provide habitat for species that use aquatic and riparian areas; and the need to maintain species diversity and sensitive areas like vernal pools. One proposed treatment alternative included a suggestion to defer treatments in wetland and riparian areas where longterm control of invasive species is unlikely.

\section{Factors that Influence the Fate, Transport, and Persistence of Herbicides in Wetland and Riparian Areas}

If applied directly to wetlands and riparian areas, herbicides dissipate by transport through water or wind, through chemical or biological degradation, or through adsorption and immobilization in soils. When herbicides are applied to well-drained areas, adjacent wetlands and riparian areas can play a critical role in filtering herbicides from runoff, through physical trapping and through chemical and biological processes. These affect herbicide availability, phytotoxicity, and fate and transport (Anderson 1982).

Saturated wetland soils have chemical and biological characteristics that are different from well-drained upland soils, including oxidation-reduction status, $\mathrm{pH}$, and high organic content. For example, oxygen depletion of saturated soils facilitates oxidationreduction, reductive chemical processes, and anaerobic microbial processes. Soil $\mathrm{pH}$ can be closer to neutral in wetland soils than in well-drained soils, or wetland soils may be more acidic than well-drained areas if peat is present. The characteristics of wetland soils affect their capacity to adsorb, transport, and transform herbicides. The extent of the effects on herbicide fate is dependent on the duration of saturation, soil temperature, the kind and amount of organic matter, and the nature and content of reactive chemicals present in the soil. For example, some chemical processes that degrade herbicides only occur to measurable degrees when soils are anaerobic or lack free oxygen.

The rate of breakdown in anaerobic systems can be estimated by the measured anaerobic half-life (Table 410). Generally, anaerobic degradation processes are much slower than the degradation processes in welldrained soils where oxygen is present.

\section{Methodology for Assessing Impacts to Wetland and Riparian Areas}

The BLM reviewed the literature and findings from ERAs to assess the impacts to aquatic plant species from the use of herbicides (ENSR 2005b-k, SERA 2005a). The ERA methods and results for aquatic and terrestrial vegetation are summarized in the Vegetation section of this chapter. Methods used by the BLM are presented in detail in the Vegetation Treatments Programmatic EIS Ecological Risk Assessment Protocol (ENSR 2004) and in Appendix C; methods used by the Forest Service are available at http://www.fs.fed.us/r6/invasiveplant-cis/.

Herbicide use poses potential risks to aquatic and riparian plant species. However, appropriate implementation of SOPs should minimize these risks (see Table 2-8). These SOPs include the following:

- Survey for special status aquatic and riparian plant species before treating an area.

- Use drift reduction agents to reduce the risk of drift hazard.

- Use a selective herbicide and a wick or backpack sprayer.

- Use an appropriate herbicide-free buffer zone for herbicides not labeled for aquatic use. This information is discussed in the ERA guidance provided in the Vegetation section of this chapter.

\section{Summary of Herbicide Impacts}

\section{Impacts from Herbicides Applied to Wetlands and Riparian Areas}

Use of herbicides to control aquatic and riparian vegetation can improve habitat quality for fish and wildlife, improve hydrologic function, and reduce soil erosion. Non-native species, such as purple loosestrife, form extensive monotypic stands that displace native vegetation used by wetland animal species for food and 
cover (Bossard et al. 2000). Purple loosestrife can also alter the hydrology and soil conditions of wetland pastures and impact recreational activities. Water-thyme is an aquatic species that forms large mats that fill the water column and can severely restrict water flow, leading to a decrease in habitat for fish and wildlife and water quality. Eurasian milfoil is an aquatic species that has spread widely over the western U.S. and has been found to alter the physical and chemical characteristics of lakes and streams. Much of the BLM's vegetation control effort in wetland and riparian areas would focus on these species.

Most aquatic herbicides are non-selective and could cause adverse impacts to non-target wetland and riparian species diversity, competitive interactions, species dominance, and vegetation distribution (Kleijn and Snoeijing 1997). Herbicide applications could reduce plant cover, leading to increased sedimentation, increased nutrient loading, alterations in native vegetation, and changes to temperature and hydrologic conditions.

An increase in soil erosion and surface water runoff could result from vegetation reduction, which could lead to streambank erosion and sedimentation in wetlands and riparian areas (Ott 2000). The amount and likelihood of streambank erosion and sedimentation would be directly proportional to the size of the treatment area (i.e., larger treatment areas would lead to increased risk of streambank erosion and sedimentation). Additionally, sedimentation could result in a reduction in the acres of wetland and riparian habitat.

The following six chemicals are approved for use in aquatic systems by the USEPA, including wetlands and riparian areas. Two of these chemicals (diquat and fluridone) are newly proposed for use on public lands.

\section{$2,4-1 D$}

2,4-D salt formulations are approved for use in riparian and aquatic systems. The principal hazard of 2,4-D exposure to non-target plants is from unintended direct deposition or spray drift (SERA 1998), 2,4-D salt formulations can be used in spot treatments and applied according to the labeled rate without substantially affecting native aquatic vegetation and without significantly changing species diversity (USDA Forest Service 2005, Washington Department of Ecology 2004). 2,4-D has been shown to be effective for treating Eurasian watermilfoil. 2,4-D ester formulations are toxic to fish and aquatic invertebrates and should not be used near aquatic systems. Kuhlmann et al. (1995) found no biodegradation of 2,4-D under anaerobic (sulfate reducing) conditions in a laboratory experiment of sediments and groundwater. In aerobic riparian soils that have a high content of organic material, an active microbial community, high $\mathrm{pH}$ values, and high temperatures, toxic effects are limited because of rapid degradation of 2,4-D. 2,4-D may inhibit shoot and/or root growth of macrophytes in aquatic systems (Roshon et al. 1999).

\section{Diquat}

Diquat, a contact herbicide approved for floating, submerged, and aquatic vegetation, would be used in ponds, lakes, canals, and reservoirs. Diquat persists in the environment, but is quickly adsorbed to soils and sediments, immobilizing it and rendering it unlikely to contaminate leachate or runoff. Target wetland species that could be controlled by diquat include Eurasian watermilfoil, water-thyme, water hyacinth, and giant salvinia. Diquat kills on contact, but it does not kill plant roots, and therefore it is often used for singleseason control of submerged aquatic plants and not for plant eradication (Washington Department of Ecology 2004).

As a non-selective aquatic herbicide, diquat should not be applied in wetlands where there is the potential for killing or harming aquatic plants of concern. Large areas should not be treated with diquat in a single application without some procedure to remove treated vegetation, as studies have shown that rapid rates of plant decomposition following treatment may deoxygenate water, potentially resulting in negative effects to fish and other aquatic organisms.

\section{Fluridone}

Fluridone is a slow-acting, broad-spectrum aquatic herbicide that can be used at low concentrations on both submerged and emergent aquatic plants. Fluridone photodegrades, volatilizes slowly from water, and adsorbs to suspended solids and sediments (National Library of Medicine 2002).

Fluridone would be used to treat ponds, lakes, canals, and reservoirs, but not flowing waters where contact time cannot be maintained. It is a non-selective herbicide at higher application rates, but is most frequently applied at lower application rates, where it selectively affects submerged aquatic plants while only minimally affecting emergent vegetation. Where the entire water body is infested with a non-invasive 
species, such as Eurasian watermilfoil, a whole water body treatment of fluridone can be used. Fluridone is not suitable for spot treatments (sites less than 5 acres within a larger water body), as it is difficult to maintain enough contact time between the plant and the fluridone to kill the plant (Washington Department of Ecology 2004)

\section{Glyphosate}

Glyphosate is approved for fresh and brackish water, including estuaries, and wetland and emergent aquatic vegetation. Glyphosate may be used in riparian and aquatic habitats along shorelines for species such as purple loosestrife, reed canarygrass, giant reed, and cattail, and for floating aquatic species such as waterlily. Disking, with a follow-up application of glyphosate the following year, has been used effectively in Washington State to control reed canarygrass (Paveglio and Kilbride 2000) Glyphosate is also used to control grasses, herbaceous plants, and some broadleaf trees and shrubs in riparian areas. Glyphosate dissipates rapidly from surface water by adsorption and biodegradation and may move into surface water with eroded soil particles.

Freshwater aquatic macrophytes and algae are reported to be sensitive to glyphosate at concentrations as low as $20 \mathrm{mg} / \mathrm{l}$; however, stimulation in growth of some green algae has also been reported at low concentrations ( 0.02 mg/l; SERA 2003a).

\section{Imazapyr}

Imazapyr is approved for use in wetlands and riparian areas, including brackish and coastal waters. It is used to control emergent and floating plants. Imazapyr has been shown to be effective in the management of saltcedar, which has invaded many riparian zones throughout the western U.S.. Imazapyr is used to treat emergent wetland plants such as cordgrass, reed canarygrass, and phragmites, and floating plants such as waterlily. Imazapyr use may result in effects to nontarget aquatic vegetation, and high concentrations of imazapyr in surface water may adversely affect some aquatic macrophytes (SERA 2004d).

Residual soil contamination with imazapyr could be prolonged in some areas, possibly resulting in substantial inhibition of plant growth (SERA 2004d). Imazapyr is not likely to degrade in anaerobic soils or sediments, and has been shown to strongly bind to peat (American Cyanamid 1986, SERA 2004d).
TABLE 4-10

Anaerobic Half-life in Soil for Herbicides Analyzed in this PEIS

\begin{tabular}{|l|c|}
\hline \multicolumn{1}{|c|}{ Herbicide } & $\begin{array}{c}\text { Anaerobic Soill Half-life } \\
\text { (days) }\end{array}$ \\
\hline 2,4-D & 333 \\
\hline 2,4-DP & $>200$ \\
\hline Asulam & $>14$ \\
\hline Atrazine & $15-77$ \\
\hline Bromacil & 144 to 198 \\
\hline Chlorsulfuron & $>1,000$ \\
\hline Clopyralid & Not determined \\
\hline Dicamba & 20 \\
\hline Diflufenzopyr & $>1,000$ \\
\hline Diquat & 5 to 100 \\
\hline Diuron & 4 to 270 \\
\hline Fluridone & 4 \\
\hline Fosamine ammonium & 12 to 70 \\
\hline Glyphosate & Stable \\
\hline Hexazinone & $>1,000$ \\
\hline Imazapic & $>500$ \\
\hline Imazapyr & No information found \\
\hline Mefluidide & 338 \\
\hline Metsulfuron methyl & 88 \\
\hline Overdrive & $>500$ \\
\hline Picloram & 71 \\
\hline Simazine & 60 \\
\hline Sulfometuron methyl & Not determined \\
\hline Tebuthiuron & $<1$ \\
\hline Triclopyr & \\
\hline \hline $\left.\begin{array}{l}\text { Sources: Krueger et al. 1991; USEPA 1992, 1994a, b, 1995c, } \\
\text { 1996, 1999a, 2001b, 2003d; Krzyszowska et al. 1994; Tomlin } \\
\text { 1994; Kuhlmann et al. 1995; SERA 1997, 2003a, 2003b, 2004c, } \\
\text { 2004d, 2004e; Harrison et al. 1998; Strek 1998a, b; Suzuki et al. } \\
\text { 2001. }\end{array}\right)$ \\
\hline
\end{tabular}

\section{Triclopyr}

Triclopyr controls a variety of weed species and can be effective as a spot treatment for Eurasian watermilfoil because it is relatively selective for this species at low application rates. In addition, it is effective in riparian areas as a treatment for purple loosestrife, as it does not damage native grasses and sedges (Washington Department of Ecology 2004).

Commercial formulations of triclopyr may contain the triethylamine salt (TEA) or the BEE formulations, both of which degrade to an acid form. Both formulations are used to selectively treat unwanted riparian woody vegetation; however, only the TEA formulation is approved for selective control of submersed aquatic vegetation (SERA 2003c). Triclopyr BEE is projected 
to be somewhat more hazardous when used where runoff to open water may occur.

\section{Impacts from Herbicides Applied to Uplands}

Non-target wetland and riparian areas could be exposed to herbicides through a variety of routes, including accidental spills or direct spray, local spray drift from adjacent target areas, surface water runoff, and soil erosion (Karthikeyan et al. 2003). Risks to wetland and riparian non-target species would depend on a number of factors, including the amount, selectivity, and persistence of the herbicide used; the application method used; the timing of the application; and the plant species present. Risks to wetlands and riparian areas from surface runoff would be influenced by precipitation rates, soil types, and proximity to the application area. Some herbicides (e.g., sulfometuron methyl) that adsorb onto soil particles could be carried off site, increasing their risk of affecting vegetation in wetlands and riparian areas.

Unintentional applications can have severe negative impacts on wetland and riparian systems. In particular, accidental spills near wetland and riparian areas could be particularly damaging to wetland and riparian vegetation. Spray drift can also degrade water quality in wetland and riparian areas and could damage non-target vegetation.

\section{Bromacil}

Bromacil is not selective, and accidental exposure could injure riparian shade trees and other desirable non-target wetland and riparian vegetation. Bromacil is mobile and has the ability to persist in wetland environments.

\section{Chlorsulfurom}

Chlorsulfuron is effective at low concentrations and is prone to leaching. Hydrolysis rates are the fastest in acidic waters and are slower as the $\mathrm{pH}$ rises (Sarmah and Sabadie 2002). When hydrolysis rates drop, biodegradation becomes the primary loss mechanism. Strek (1998a, b) studied the dissipation of chlorsulfuron in an anaerobic sediment/water system; biodegradation progressed much more slowly than in aerobic soil systems, with a half-life greater than 365 days.

\section{Clopyralid}

Clopyralid typically leaches and is generally rapidly degraded in soil, except in arid soils with low microbial populations where it remains stable and could potentially reach wetlands and riparian areas. Clopyralid is relatively non-toxic to aquatic plants. Overall, effects to non-target wetland and riparian vegetation from normal application of clopyralid are likely to be limited to sensitive plant species in or very near the treatment area, and could be avoided by maintaining an adequate buffer between the treatment area and wetland and riparian areas (SERA 2004b). Clopyralid is not likely to affect aquatic plants via off-site drift or surface runoff pathways; however, the higher concentrations associated with accidental spills could result in temporary growth inhibition of aquatic plants.

\section{Dicamba}

Direct spray and accidental spill scenarios of dicamba pose a moderate to high risk to both terrestrial and aquatic plants. In water, biodegradation is the major mechanism for dicamba degradation. Dicamba is mobile in soils and is therefore likely to reach surface water and groundwater. A study on the fate of dicamba in a riparian wetland showed that dicamba was demethylated to 3,6-dichlorosalicylic acid under both aerobic and anaerobic conditions. The rates of dicamba degradation were generally more rapid in the surface than in the subsurface soil microcosms. The study indicated that some riparian wetland soils possess limited potential to degrade dicamba (Pavel et al. 1999).

\section{Diffufenzopyr}

Diflufenzopyr is an active ingredient in the herbicide formulation Overdrive ${ }^{\circledR}$, along with dicamba. Diflufenzopyr is not approved for the treatment of aquatic plants, but poses a low risk to riparian species and aquatic plants via off-site drift.

\section{Diuron}

Under accidental direct spray and spill scenarios for diuron, there is generally a high risk to aquatic plants. Off-site drift typically poses low to moderate risk to aquatic plants, provided the ERA-recommended 900foot buffer is used (ENSR 2005f).

\section{Hexazinome}

Aquatic plants are at moderate to high risk from acute and chronic exposure to hexazinone at both the typical and maximum application rates. Aquatic algal species are also sensitive to hexazinone exposure. Furthermore, it is likely that aquatic macrophytes are sensitive, based on the effects of hexazinone on algae and terrestrial plants (SERA 1997). 


\section{Imazapic}

The risk to aquatic plants from accidental spills of imazapic is moderate to high at the maximum application rate and low to moderate at the typical application rate (there is no acute risk to aquatic plants in standing water at the typical application rate). Aquatic plants are generally not at risk from off-site drift of imazapic, except when applied aerially at the maximum application rate with a buffer of 100 feet or less. Imazapic rapidly degrades through photodegradation in aquatic systems (SERA 2004c).

\section{Metsulfuron Methyl}

Aquatic macrophytes face low risk from acute exposure to metsulfuron methyl at upper exposure limits (SERA 2004e). Metsulfuron methyl is stable to hydrolysis at neutral and alkaline pHs. Larsen and Aamand (2001) evaluated biodegradation of metsulfuron methyl (25 $\mu \mathrm{g} / \mathrm{L})$ under anaerobic and aerobic conditions in sandy sediments; the herbicide did not biodegrade under any of these conditions.

\section{Picloram}

The toxicity of picloram to aquatic plants varies substantially among different species. There is low risk to sensitive aquatic macrophytes from acute exposure to picloram at the maximum application rate. Because picloram does not bind strongly to soil particles and is not rapidly degraded in the environment, it has a high potential for being transported to wetland and riparian areas.

\section{Sulfometuron Methyl}

Aquatic plants are at high risk from accidental direct spray and spill of sulfometuron methyl, but are unlikely to be at risk from off-site drift, provided a minimum 900 -foot buffer is maintained, as recommended in the ERA for this herbicide (ENSR 2005j). Aquatic plants in standing water are typically at low to moderate risk for adverse effects from surface runoff scenarios. Sulfometuron methyl should not be applied during high winds, as drift could cause extensive damage to vegetation at a substantial distance from the application site.

\section{Tebuthiuron}

Aquatic plants are at high risk for adverse effects under tebuthiuron spill scenarios, and potentially at high risk for adverse effects from direct spray scenarios. Aquatic plants are not at risk for adverse effects under scenarios involving off-site drift of tebuthiuron; however, surface runoff typically poses a risk to submerged aquatic plants for herbicide treatments at the maximum application rate, and at the typical application rate in sandy soils. Tebuthiuron is resistant to hydrolysis and photolysis in aquatic systems; however, some photodegradation has been reported at alkaline conditions $(\mathrm{pH}=9)$, and tebuthiuron is expected to biodegrade slowly in aquatic systems.

\section{Impacts of Other Herbicides Currently Available for Use}

Asulam, atrazine, fosamine, mefluidide, simazine and 2,4-DP (also known as dichlorprop) are currently approved for use on public lands in many western states (see Table 2-2). These herbicides have not been used, or have only been used infrequently (fosamine), during the past 7 years. They are not registered for use in riparian or aquatic areas. Atrazine, simazine, and 2,4-DP are persistent and considered mobile in well-drained soils, and could reach wetlands and riparian areas. Persistence is extended under dry and/or cold conditions. Mefluidide is not strongly adsorbed to soil but has a half-life of 1 to 2 weeks. Fosamine is rapidly metabolized by soil microbes and does not persist (Han 1979 cited in Tu et al. 2001).

\section{Impacts by Alternative}

\section{Alternative A - Continue Present Herbicide Use (No Action Alternative)}

Under the No Action Alternative, the BLM would continue its ongoing vegetation treatment programs in 14 western states, and would be able to use 20 herbicides that were previously approved under earlier RODs. Herbicide use under the No Action Alternative would impact target and non-target vegetation over an estimated 305,000 acres annually, including approximately 2,300 acres of riparian and aquatic habitat. Herbicides used to control aquatic and riparian vegetation under this alternative could include 2,4-D, glyphosate, and imazapyr, which are registered for aquatic uses; and dicamba, tebuthiuron, and triclopyr in riparian areas where contact with water can be avoided.

The nature of impacts would be similar to those that have occurred in the past 10 years. Negative impacts to wetland and riparian vegetation would be lower than under the other herbicide treatment alternatives $(B, D$, and $E$ ) because far fewer acres would be treated. In addition, adverse impacts to wetland and riparian 
vegetation in areas receiving treatments could be greater than at present if newer, more effective herbicides could not be used.

Of the 20 herbicides previously approved, it is unlikely that 2,4-DP, asulam, atrazine, fosamine, mefluidide, or simazine would be used. It is likely that 2,4-D and glyphosate (aquatic uses), and picloram and tebuthiuron (upland uses), would be used most frequently under this alternative. Glyphosate and 2,4-D have been demonstrated to provide benefits through the control of invasive riparian and wetland plant species.

Diflufenzopyr+dicamba (as Overdrive ${ }^{\circledR}$ ), diquat, fluridone, and imazapic would not be available for use under this alternative. Risks to wetland and riparian areas from use of these herbicides are similar to or lower than risks associated with currently-approved herbicides. Use of other herbicides in place of these four herbicides could pose a greater risk to wetland and riparian plants under accidental spill and drift scenarios than under alternatives B, D, and E. In addition, fluridone is specifically indicated for aquatic use, whereas none of the other currently-approved herbicides are strictly aquatic herbicides. Under the other herbicide treatment alternatives, aquatic vegetation would be treated with diquat and fluridone, both of which are effective in the control of Eurasian watermilfoil, waterthyme, water hyacinth, and giant salvinia. The other herbicides registered for aquatic use-glyphosate and triclopyr - are not as effective in controlling these species.

Under the No Action Alternative, the BLM would not be ablc to use new chemicals that may become available in the future and that may be more effective and safer to use in wetland and riparian areas than herbicides currently available to the BLM. Public lands in Alaska, Nebraska, and Texas have not been part of the herbicide program historically, and would not be included under this alternative.

\section{Alternative $\mathbb{B}$ - Expand Herbicide Use and Allow for Use of New Herbicides in 17 Western States (Preferred Alternative)}

Under Alternative $B$, the Preferred Alternative, herbicide treatments would occur on approximately 932,000 acres annually across 17 western states, of which about 10,000 acres would consist of aquatic and riparian habitat. The BLM would only be allowed to use 14 currently-approved herbicides (six fewer than under the No Action Alternative), but would be able to use the four new herbicides evaluated in this PEIS. In addition, the BLM would be able to treat vegetation using herbicides in Alaska, Ncbraska, and Texas. Although it is anticipated that few or no herbicide treatments would occur in Alaska, the BLM would retain the option to use herbicides in Alaska should the need arise and the benefits of using herbicides outweigh the risks of other treatment methods.

This alternative could result in the most extensive impacts to wetlands and riparian areas (both negative and positive) because it proposes the greatest total treatment acreage (more than four times the acreage proposed under the No Action Alternative).

The BLM's ability to use four new chemicals (fluridone and diquat for aquatic applications, and imazapic and Overdrive ${ }^{\circledR}$ for terrestrial applications), would provide new capabilities for controlling problematic invasive species and would potentially result in benefits to wetland and riparian areas if invasive species were controlled or eliminated. Fluridone, in particular, has been effective at controlling Eurasian watermilfoil (Washington Department of Ecology 2002). Based on recent use patterns, 2,4-D, glyphosate, picloram, and tebuthiuron would continue to comprise the majority of herbicide use under this alternative. The benefits and risks of these herbicides are discussed under the No Action Alternative.

Overdrive ${ }^{\circledR}$ and imazapic would primarily be used on rangelands, but their use could still provide greater benefits to riparian and wetland areas, relative to the No Action Alternative. Overdrive ${ }^{(B}$ would be used to treat thistles and knapweeds, while imazapic could be used to control downy brome. These invasive plant species degrade riparian habitats and can lead to shortened fire cycles, followed by soil erosion and sedimentation.

The ability to use herbicides as they become registered with the USEPA would allow BLM managers more options in choosing herbicides to match treatment goals and application conditions, and options to use herbicides that pose less risk to wetlands and riparian areas than currently-used or proposed herbicides.

The BLM does not propose to use herbicides in Alaska (where the majority of the wetland and riparian areas on BLM lands are found). However, the BLM would retain the option to use herbicides in Alaska should the need arise and the benefits of using herbicides outweigh the risks of other treatment methods. 


\section{Alternative C - No Use of Herbicides}

Herbicides would not be used to manage vegetation under Alternative C. Primary effects to riparian and wetland vegetation would stem from other vegetation treatment methods including fire, manual, mechanical, and biological control (see PER; USDI BLM 2007a). The possible ecosystem benefits of not using herbicides would be the elimination of risks to non-target biota associated with accidental spills, drift, and persistence of herbicides.

Without herbicide treatments, it is likely than some invasive plants would continue to spread rapidly, resulting in dramatic and potentially irreversible effects on wetland and riparian areas. As discussed previously, invasive species outcompete native vegetation and lead to widespread incidence of fire and other conditions that can result in loss of ecosystem function in wetlands and riparian areas.

Positive ecosystem benefits as a result of vegetation management could be reduced under this alternative, as there are certain invasive species for which herbicide use is the only effective method of treatment or the only practical method, based on cost, time, accessibility, or public concerns. For example, rough terrain that cannot be accessed for ground-based treatments could potentially be treated using herbicides applied by aircraft. Other treatment methods, such as mechanical, fire, and biological, can result in soil disturbance and sedimentation of aquatic bodies, and may not adequately treat the pest plant.

In addition, it is often difficult to eradicate some species (such as aquatic species and those that resprout from rhizomes) by means other than herbicide application. These species include Eurasian watermilfoil and waterthyme, which form dense mats of aquatic vegetation that crowd out native plants and degrade fish habitat (Bossard et al. 2000). Chemical treatments (including the use of 2,4-D, diquat, and fluridone) are more effective at controlling these species than other treatments, such as mechanical harvesters that tend to fragment and spread the weed.

\section{Alternative D - No Aerial Applications}

Alternative D is similar to the Preferred Alternative in that it would allow for use of the same herbicides in the same areas, and would have similar benefits associated with increased availability of new and future herbicides. However, this alternative would not allow the use of aerial application methods, thereby reducing the total treatment acreage to 530,000 acres. Howcver, there would be little difference between the alternatives as far as treatments in wetlands and riparian areas and associated impacts. Nearly all $(98 \%)$ of the acreage proposed for treatment in wetland and riparian habitats under the Preferred Alternative would be treated using ground-based methods, and therefore could also be treated under Alternative D. However, the potential for impacts to wetlands and riparian areas from off-site drift from upland treatment areas would be substantially less under Alternative $D$ than under the Preferred Alternative. Drift is a major route of unintended damage to non-target vegetation, with aerial application being the primary cause of off-site drift.

Under this alternative, invasive plant populations in remote wetland and riparian areas would likely continue to spread. Ground-based herbicide treatments could be used in some locations, but likely would not be used in areas that are too remote, have difficult terrain, or cover large expanses. Areas with coverage of invasive species may not be comprehensively treated using ground-based methods, and subsequent reinvasion could require frequent re-treatment in the same area. Non-herbicide vegetation control may be substituted in areas unsuitable for ground-based herbicide treatment. For example, prescribed fire can be used to control some unwanted vegetation types. However, many invasive riparian and wetland plant species are able to resprout after fire. Biological treatments have been shown to be effective in some riparian and wetland areas for some species; however, the number of invasive species with known biological eontrol agents and the effectiveness of these agents are limited.

\section{Alternative $\mathbf{E}$ - No Use of Acetolactate Synthase- inhibiting Herbicides}

Approximately 466,000 acres would be treated under Alternative $\mathrm{E}$, which is slightly less than the acreage that would be treated under Alternative $\mathrm{D}$, and less than half of the acreage that would be treated under the Preferred Alternative. Under this alternative, ALSinhibiting herbicides would not be allowed, including imazapic, imazapyr, chlorsulfuron, metsulfuron methyl, and sulfometuron methyl. Of these, only imazapyr is registered for use in wetland and riparian areas. ALSinhibiting herbicides are potent and have the benefit of very low application rates; however, their potency leads to residual herbicidal activity. This group of herbicides has been shown to damage off-site native and crop species, and several weed species can develop resistance to these herbicides, making them less effective. 
Under this alternative, herbicide treatments would be discouraged, broadcast spraying would be prohibited, and passive treatment methods would be promoted in wetland and riparian areas. Imazapyr has been shown to be effective against saltcedar, a particularly pernieious riparian area invader that has few effective treatments. The inability to use imazapyr to control species such as saltcedar could potentially correspond to greater adverse effects to wetland and riparian areas form these invasive species than under the other alternatives, in which imazapyr use is allowed.

Alternative E proposes management that may benefit wetland and riparian areas, such as limiting the effects of minerals extraction, forestry practices, livestock grazing and $\mathrm{OHV}$ use. However, these restrictions would be applied only to the extent that they are consistent with adopted BLM LUPs.

\section{Mitigation for Herbicide Treatment Impacts}

See mitigation measures for Water Resources and Quality and Vegetation sections.

\section{Vegetation}

\section{Introduction}

The present-day composition and distribution of plant communities in the western U.S. are influenced by many factors, including physical factors (e.g., climate, drought, wind, geology, topography, elevation, latitude, slope, exposure) and natural disturbance and humanmanagement patterns (e.g., insects, disease, fire, cultivation, domestic livestock grazing, wildlife browsing; Gruell 1983). In addition, exotic plant species have caused a decline in extent of some native plant communities in each of the western states. The rapid expansion of invasive plant species across public lands continues to be a primary cause of ecosystem degradation, and control of these species is one of the greatest challenges in ecosystem management. The recent increase in wildfires has been influenced by changes in vegetation on public lands over the past 100 years, which have resulted in increases in hazardous flammable fuels

\section{Scoping Comments and Other Issues Evaluated in the Assessment}

The largest number of comments submitted was related to vegetation. Numerous scoping comments were centered around a desire for the BLM to focus on longterm ecosystem sustainability and biological diversity. Numerous comments suggested that the PEIS address all invasive plants, not just weeds. One respondent proposed focusing on minimizing the spread of existing weed infestations, while others wanted to ensure that weed control measures do not result in more ecological discurbances than the weeds themselves. A large number of comments recommended evaluating the impact of herbicides on other plant and animal species within the areas considered for treatment. Several comments called for the PEIS to address the impacts of new-generation, high-potency pesticides on non-target plants. There was some concern about weeds becoming herbicide resistant, and about how the BLM would prevent the death of beneficial native plants from herbicides. To improve sage-grouse habitat, one respondent recommended that instead of burning sagebrush, the BLM should treat strips of vegetation with herbicides, allow cattle to break the vegetation down, and then plant the area with grass.

\section{Standard Operating Procedures}

There are risks to non-target plants associated with herbicide use. However, these risks can be minimized by following certain SOPs, which can be implemented at the local level according to specific conditions. The following general procedures are designed by the BLM to reduce potential unintended impacts to vegetation from herbicide treatments:

- Conduct pre-treatment surveys for sensitive habitat and special status species within or adjacent to proposed treatment areas.

- Consider site characteristics, environmental conditions, and application equipment in order to minimize damage to non-target vegetation.

- Use drift reduction agents, as appropriate, to reduce the drift hazard to non-target species.

- Turn off aerially applied treatments at the completion of spray runs and during turns to start another spray run.

- Refer to the herbicide label when planning revegetation to ensure that subsequent 
vegetation will not be injured following application of the herbicide.

- Clean OHVs to remove seeds.

- Use native or sterile species for revegetation and restoration projects.

- Use weed-free feed for horses and pack animals.

- Use weed-free straw and mulch for revegetation and other activities.

These procedures would help minimize impacts to plants and ecosystems on public lands to the extent practical. As a result, long-term benefits to native plant communities from the control of invasive species would likely outweigh any short-term negative impacts to native plants associated with herbicide use.

\section{Impacts Assessment Methodology}

The BLM reviewed the literature and findings from ERAs conducted by the BLM and Forest Service, and from earlier BLM vegetation treatment EISs, to assess the impacts to target and non-target vegetation from the use of herbicides (ENSR 2005b-k; SERA 2005a). The methods presented here are a brief overview of the ERA process to determine the risks to non-target species associated with herbicide use. The ERA methods are presented in detail in Appendix C. In addition, the BLM reviewed information provided by local field offices in 2002 for development of this PEIS. This information included the location, treatment method, application method, vegetation class, and size of the treatment (in acres) for treatments proposed during the next 10 to 15 years.

\section{BLM Methodology}

\section{Problem Formulation}

Both terrestrial and aquatic non-target plants, including surrogates for special status species, were evaluated to determine assessment endpoints and associated measures of effect. The essential biological requirements (i.e., survival, growth, and reproduction) of each of these groups of organisms are the attributes to be protected from herbicide exposure. Assessment endpoints, for the most part, reflect direct effects of an herbicide on these organisms, but indirect effects were also considered.

Measures of effect are measurable changes in an attribute of an assessment endpoint (or its surrogate, as discussed below) in response to a stressor to which it is exposed (USEPA 1998a). For the screening-level ERA, the measures of effect associated with the assessment endpoints generally consisted of acute and chronic toxicity data (from pesticide registration documents and from the available scientific literature) for the most appropriate surrogate species. Assessment endpoints for non-target vegetation include acute mortality and adverse direct effects on growth, reproduction, or other ecologically important sublethal processes.

\section{Exposure Characterization}

In order to assess the potential ecological impacts of these herbicide uses, the following exposure scenarios were considered that address herbicide exposure and acute and chronic (short- and long-term) impacts that may occur under a variety of conditions:

- Direct spray of the receptor or water body;

- Off-site drift of spray to terrestrial areas and water bodies;

- Surface runoff from the application area to offsite soils or water bodies;

- Wind erosion resulting in deposition of contaminated dust; and

- Accidental spills to water bodies.

The AgDRIFT ${ }^{\circledR}$ computer model was used to estimate off-site herbicide transport due to spray drift. The GLEAMS computer model was used to estimate off-site transport of herbicide in surface runoff and root zone groundwater transport. The CALPUFF computer model was used to predict the transport and deposition of herbicides sorbed (i.e., reversibly or temporarily attached) to wind-blown dust. Each model simulation was conservatively approached with the intent of predicting the maximum potential herbicide concentration that could result from the given exposure scenario.

\section{Effects Characterization}

In the majority of cases, toxicological data do not exist for the specific plant receptors of concern. Consequently, toxicological data for surrogate species, obtained from a literature review, were evaluated and used to establish quantitative benchmarks (i.e., toxicity reference values [TRVs]) for the ecological receptors of concern. Data from scientific studies were used to compile statistical endpoints into a matrix for each chemical and receptor. Data were further subdivided 
into acute adverse effect levels, chronic adverse effect levels, and no observed adverse effect levels (NOAELs). For each chemical, receptor, and route of exposure, the lowest reported acute statistical endpoint was selected as the acute TRV. Chronic TRVs, based on longer exposure periods and associated endpoints such as growth and reproduction, were developed, when possible, to provide supplementary data to the risk assessment. Before the chronic NOAEL TRV was determined, a chronic lowest observed adverse effect level (LOAEL) was identified, which was the lowest herbicide level that was found to cause significant adverse effects in a chronic study. Once a LOAEL was selected, the chronic NOAEL TRV was established as the highest NOAEL value that was less than both the LOAEL and the acute TRV. Once developed, TRVs were compared with predicted environmental concentrations of the herbicide to determine the likelihood of adverse effects to ecological receptors.

\section{Risk Characterization}

In order to address potential risks to plant receptors, risk quotients (RQs) were calculated by dividing the estimated exposure concentration (EEC) for each of the previously described scenarios by the appropriate herbicide-specific TRV. To facilitate the translation of RQs into readily applicable estimates of risk, the calculated RQs were compared to Levels of Concern (LOCs) used by the USEPA in screening the potential risk of herbicides. Distinct USEPA LOCs are currently defined for the following risk presumption categories:

- Acute high risk - The potential for acute risk is high;

- Acute restricted use - The potential for acute risk is high, but may be mitigated;

- Acute endangered species - Special status species may be adversely affected; and

- Chronic risk - The potential for chronic risk is high.

The ecological risk implications of various exposure estimates can be readily determined by noting which RQs exceed the corresponding LOCs.

The risks of tank mixes on plant receptors were determined using the assumption that the products in tank mixes act in an additive manner. The predicted RQs for two active ingredients were summed for each individual exposure scenario to see if additional RQs exceeded the corresponding LOCs. However, there is some uncertainty in this evaluation because herbicides in tank mixes may not interact in an additive manner; this may overestimate risk if the interaction is antagonistic, or it may underestimate risk if the interaction is synergistic. In addition, other products may also be included in tank mixes and may contribute to the potential risk.

\section{Uncertainty Analysis}

For any ERA, a thorough description of uncertainties is a key component of risk determination that serves to identify possible weaknesses in the analysis and to elucidate what impact such weaknesses might have on the final risk conclusions. In this analysis, listed uncertainties were followed by a logical discussion of what bias, if any, the uncertainty may introduce into the risk conclusions. This bias was represented in qualitative terms that best describe whether the uncertainty might: 1) underestimate risk, 2) overestimate risk, 3 ) be neutral with regard to the risk estimates, or 4) be unable to be determined without additional study.

\section{Forest Service Methodollogy}

The Forest Service risk assessment methodology was similar to that used by the BLM (see SERA 2001 a for a complete description of the methodology). The steps involved in the Forest Service risk assessments include hazard identification, exposure assessment, dose response assessment, and risk characterization.

Hazard identification involved the review of existing data with a focus on the dose-response and doseseverity relationships to determine the effect levels (e.g., NOAEL, LOAEL) and assessment endpoints (e.g., acute toxicity, subchronic or chronic systemic toxic effects, reproductive and teratogenic effects) that are most relevant for the herbicide risk assessments.

In the exposure assessment phase, the Forest Service developed four general and accidental/incidental exposure scenarios (i.e., direct spray, spray drift, runoff, and wind erosion) for groups of non-target vegetation according to the application method and the chemical and toxicological properties of the given herbicide. The Forest Service scenario of contaminated irrigation water-a direct application scenario-was not evaluated by the BLM because their vegetation treatment program does not typically involve irrigation of vegetation. 
Dose response assessment described the degree or severity of risk as a function of dose. A dose was derived - usually from a series of experimental dosesthat was associated with a negligible, or at least a defined, level of risk. These dose levels are generally referred to as reference values, or more specifically as "reference doses" (RfDs). To derive the reference value, the experimental threshold was divided by uncertainty factors used to account for discrepancies between experimental exposure conditions and the conditions of the receptor might experience during Forest Service exposure. Often, reference values are standard across government agencies.

The risk characterization process then compared the exposure assessment to the dose response assessment to determine an LOC for a specific exposure scenario. Hazard Quotients (HQs) were developed through this process. Hazard Quotients are analogous to the RQs developed in the BLM risk assessments-they are calculated as the projected level of exposure (i.e., EEC) divided by an index of an acceptable level of exposure or otherwise defined level of exposure (e.g., a NOAEL divided by an uncertainty factor). In addition, the herbicides were all compared based on their selectivity, potency, persistence in the environment, and ability to move off site.

As with the BLM risk assessments, information on effects to native species was incomplete (the USEPA conducts studies predominantly on agricultural crops, rather than native species), so impacts were extrapolated from the risk assessment or herbicide labels. Using herbicide labels to identify close relatives of native or desirable species does help to reduce uncertainty. However, Boutin et al. (2004) concluded that it was likely that the suite of species currently used in most risk assessments were not representative of the habitats found adjacent to agricultural treatment areas, and might cause an unacceptable bias and underestimated risk.

\section{Impacts Common to All Treatments}

The effectiveness of herbicide treatments in managing target plants and the extent of disturbance to native plant communities varies by the extent and method of treatment (e.g., aerial vs. ground) and chemical used (e.g., selective vs. non-selective), as well as by local plant types and physical features (e.g., soil type, slope) and weather conditions (e.g., wind speed) at the time of application. Treatments would likely affect plant species composition of an area and might affect plant species diversity. Species composition and species diversity are equally important contributors to ecosystem function (USDA Forest Service 2005). Because certain herbicides may target certain types of plants (e.g., broadleaf species), an herbicide treatment program for a given ecosystem and area should include multiple types of herbicides. For example, if picloram or clopyralid are the only herbicides used in a highly invaded area, weedy annual grasses, such as medusahead, downy brome, and barbed goatgrass may begin to dominate. The following sections detail the possible effects of herbicide treatments on both target and non-target plants.

\section{Non-target Plants}

Herbicides could come into contact with and impact non-target plants through drift, runoff, wind transport, or accidental spills and direct spraying. Potential impacts include mortality, reduced productivity, and abnormal growth. Risk to off-site plants from spray drift is greater under scenarios with smaller buffer zones and application from greater heights (i.e., aerial application or ground application with a high boom). Risk to offsite plants from surface runoff is influenced by precipitation rate, soil type, and application area. Plant receptors would be at risk under most accidental exposure scenarios (i.e., direct spray or spill). Persistent herbicides (e.g., bromacil) adsorbed to soil particles could also be carried off-site by wind or water, affecting plants in other areas. Risk assessments predicted no risk to plant receptors from wind transport of herbicide particles under all of the evaluated scenarios. (However, an incident of extensive damage to crop species has been reported as a result of drift of sulfometuron methyl over a large area [see ENSR 2005j]). Application rate is a major factor in determining risk, with higher application associated with greater risk to plants under various exposure scenarios.

\section{Target Plants}

Herbicides offer an effective and often resourceefficient means of treating and managing unwanted vegetation. Mechanical and manual methods are often more time and labor intensive than herbicide application, and cause soil disturbance, which can provide the appropriate conditions for invasive weeds to resprout from roots and rhizomes or grow from dormant seeds. In addition, herbicide use may be seen as less dangerous than treatment with prescribed fire in dry areas that have high fire risk. The use of herbicides would benefit plant communitics with weed infestations by decreasing the growth, sced production, and 
competitiveness of target plants, thereby releasing native species from competitive pressures (e.g., water, nutrient, and space availability) and aiding in the reestablishment of native species. The degree of benefit to native communities would depend on the toxicity of the herbicide to the target species and its effects on nontarget species, as well as the success of the treatments over both the short and long term.

Use of preemergence and postemergence soil residual herbicides is common in ROWs, near oil and gas and other facilities, and along roads where vegetation must be eliminated for safety, to reduce fire hazards, and for aesthetic purposes. Other treatment methods, such as manual methods and use of fire, are often not as effective at eliminating vegetation and may not be as safe to use as herbicides.

Some treatments are very successful at removing weeds over the short term, but are not successful at promoting the establishment of native species in their place. In such cases, seeding of native plant species would be beneficial. Weeds may resprout or reseed quickly, outcompeting native species, and in some cases increasing in vigor as a result of treatments. The success of treatments would depend on numerous factors, and could require the use of a combination of methods to combat undesirable species. In addition, repeated use of a particular herbicide on a particular site could cause target weeds to develop a certain level of resistance to that herbicide over time, reducing the effectiveness of long-term treatments.

Invasive plant treatment effectiveness monitoring would be conducted at treated sites and would range from site re-visits to compare the targeted population size against pre-treatment inventory data, to comparing pretreatment and post-treatment photo points, to more elaborate transect work depending on the species and site specific variables. The goals of such monitoring would be to: 1) identify what changes in distribution, amount, and proportion of invasive plant infestations have resulted due to treatments; 2) determine if infestation size been reduced at the project level or at a larger scale such as a watershed; and 3) determine which treatment methods, separate or in combination, are most successful for a given species (USDA Forest Service 2005).

In addition to herbicide treatments, the BLM would use other forms of vegetation treatment on public lands. A PER has been developed to accompany this PEIS that discusses these treatment methods, along with their likely impacts to natural resources over the next 10 years. In many cases, the treatments would return all or a portion of the treated area to an early successional stage, killing off disturbance-intolerant species (e.g., sagebrush) and freeing up resources such as light and nutrients for early successional species (e.g., annual grasses and forbs). In areas where fire suppression has historically occurred, vegetation treatments would be expected to benefit native plant communities by mimicking a natural disturbance component that has been missing from these eommunities, altering them over time. In areas that have been highly degraded, merely restoring disturbance to the ecosystem may in some cases adversely affect native plant communities by encouraging the spread of weeds or the persistence of an altered vegetation structure and species composition. These effects would vary depending on the treatment used, the type of vegetation on the treatment site, the amount of degradation on the site, and numerous other factors.

\section{Impacts of BLM-Evaluated Herbicides}

\section{Bromacil}

Bromacil is a non-selective, "broad-spectrum," systemic herbicide, which is most effective against annual and perennial weeds, brush, woody plants, and vines. Bromacil kills target plants by blocking electron transport and the transfer of light energy, thereby disrupting photosynthesis. Because of its non-selective nature, bromacil may be highly effective in areas where a variety of invasive species dominate and where very few non-target plants exist. Bromacil is best used in areas where bare ground is desired (e.g., around fences and structures); it has high residual activity, so it would be effective for an extended period of time.

Because of its non-selective qualities, bromacil poses a high risk to non-target species in the immediate vicinity of the treatment area. The risk assessment for bromacil shows that it poses a high risk to non-target terrestrial and aquatic plants in accidental direct spray and spill scenarios (Table 4-11). Off-site drift of bromacil generally poses a moderate risk to non-target terrestrial plants, with somewhat lower risk as buffer zones get larger and application heights get smaller, and with high risk to special status terrestrial plants under scenarios involving the maximum application rate at lower buffer distances and higher application heights. Most off-site drift scenarios pose low or no risk to aquatic plants. At buffer distances of 900 feet, aquatic plants are not at risk from off-site drift of bromacil. Bromacil does not pose a risk to typical non-target terrestrial plants under surface runoff scenarios, but does pose a low risk to special 


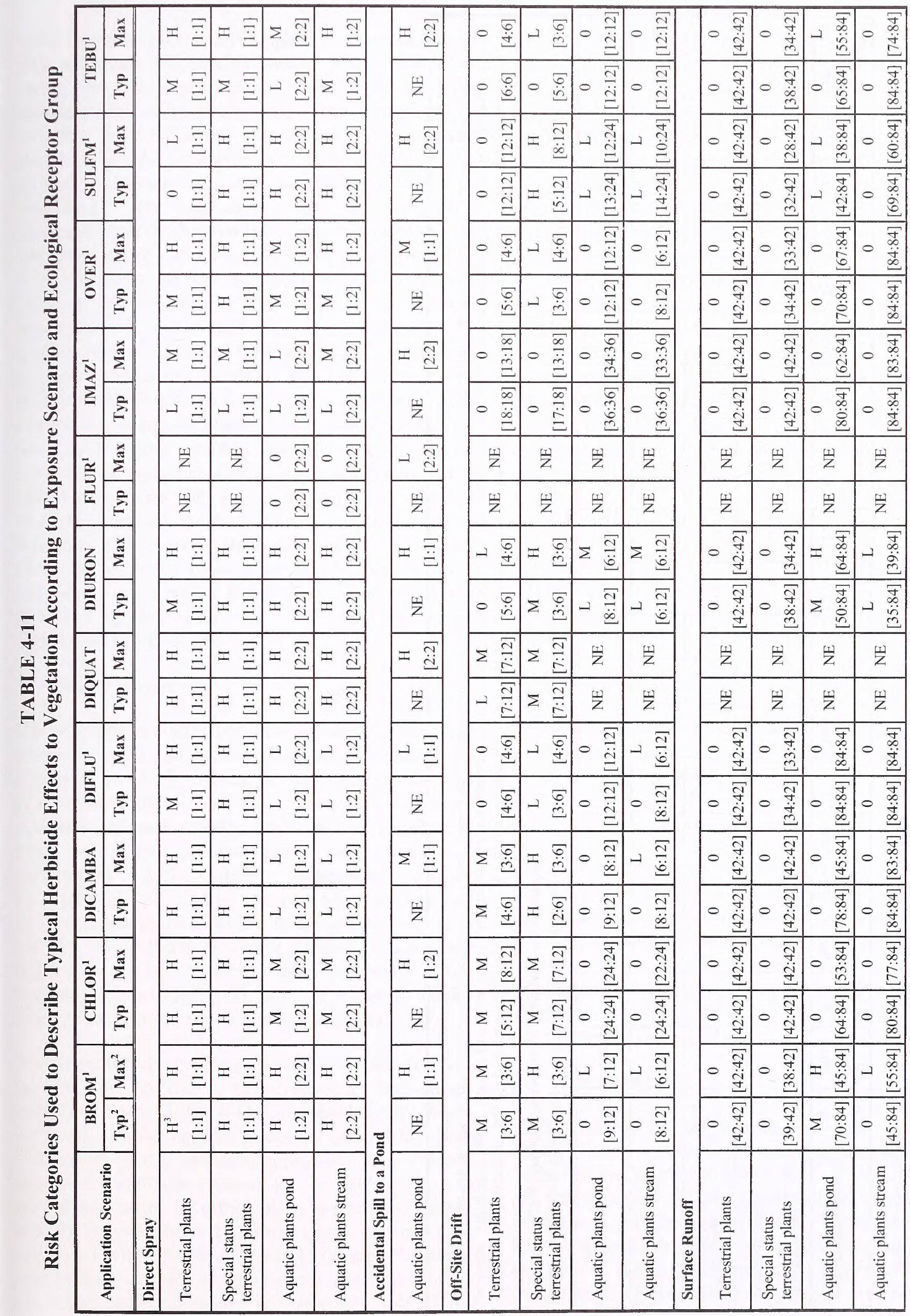




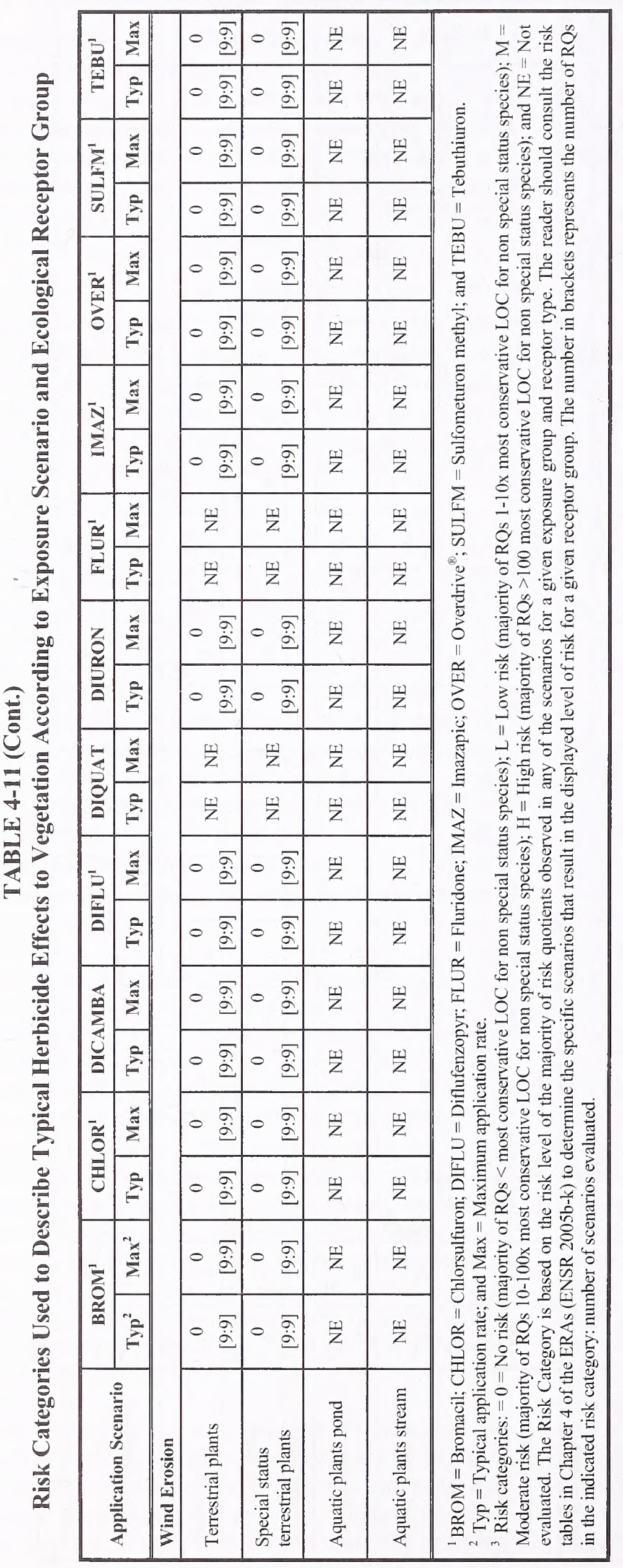


status terrestrial plants when applied in watersheds with clay soils and precipitation levels greater than 100 inches per year (in/yr). Aquatic plants are at risk from surface runoff of bromacil; under most surface runoff scenarios there would be a moderate risk to aquatic plants in ponds associated with applications at the typical application rate, and moderate to high risk associated with applications at the maximum application rate (higher risk with increased precipitation and sand or clay soils). Aquatic plants in streams are at no to low risk under most surface runoff scenarios, with moderate risk when bromacil is applied at the maximum application rate and in sand soils or in loam soils with greater application areas (100 and 1,000 acres) and increased precipitation (200 to $250 \mathrm{in} / \mathrm{yr}$ ). For applications of bromacil at the typical application rate, chronic risk to aquatic plants in the stream from surface runoff of bromacil would be much less than acute risk (chronic risk would be low in larger application areas and in watersheds with sand soils and more than 100 in/yr precipitation). Because bromacil is a non-selective herbicide and poses a significant risk to non-target plants, it would be most appropriately used in areas exclusively composed of invasive species at substantial distances (greater than 900 feet) from non-target populations (Table 4-12).

\section{Chlorsulfuron}

Chlorsulfuron is a selective herbicide used on perennial broadleaf weeds and grasses. Chlorsulfuron inhibits the synthesis of ALS, which is the catalyst for the production of amino acids that are required for protein synthesis and cell growth. Chlorsulfuron is effective both pre- and post-emergence, inhibiting seed germination and killing established plants. Chlorsulfuron is highly active, with only small concentrations required to kill target plants. Due to its activity, chlorsulfuron is highly effective in managing aggressive invasive species such as hoary cress, perennial pepperweed, and selected biennial thistles (bull, musk, and Scotch), and yellow starthistle.

Accidental direct spray or spill of chlorsulfuron poses a moderate to high risk to terrestrial plants and aquatic plants in streams (Table 4-11). Accidents mostly pose a moderate risk to aquatic plants in ponds (but high chronic risk at the maximum application rate). Off-site drift of chlorsulfuron presents low to moderate risk to typical non-target terrestrial plant species and higher risk to special status terrestrial plant species. Risk associated with off-site drift would be high for aerial applications and ground applications with high booms and small buffer distances. In more than half of the modeled scenarios, no risk to aquatic plants from offsite drift of chlorsulfuron was predicted. Risk to aquatic plants was never predicted when chlorsulfuron was applied either aerially or on the ground with 900 -foot buffers (Table 4-12). However, there would be a low risk to aquatic plants with smaller buffer distances. Terrestrial plants are not at risk from surface runoff of chlorsulfuron; however, aquatic plants are at low risk at higher precipitation levels and in watersheds with loam soils, particularly at the maximum application rate (aquatic plants in streams are not at chronic risk under any scenario). Because of its activity, chlorsulfuron should be applied at the lowest possible dose and with buffer distances of at least 900 feet from non-target plant populations, particularly if the non-target plants are perennial and broadleaved or grasses. This herbicide may be best used at low rates and spot applications on highly aggressive species and in areas where target plants are the dominant species.

\section{Dicamba}

Overdrive ${ }^{\circledR}$ is a formulation of dicamba and diflufenzopyr. An analysis of risks to vegetation for dicamba was conducted during preparation of the Overdrive ${ }^{\mathbb{R}}$ ERA.

Risk assessments predicted high risk to non-target terrestrial plants and low to moderate risk to aquatic plants under accidental direct spray and spill scenarios (Table 4-11). Off-site drift of dicamba poses moderate to high risk to terrestrial plants with buffers of less than 1,000 feet for typical species, and buffers of less than 1,050 feet for special status species.

Aquatic plants in streams are at low risk under scenarios involving off-site drift of dicamba when it is applied at the maximum rate. Surface runoff does not pose a risk to special status terrestrial plants. Dicamba could be effective in suppression or control of weeds when applied at least 1,000 feet from non-target plant populations of interest or 1,050 feet from special status plant species (Table 4-12).

\section{Diflufenzopyr}

Diflufenzopyr, an active ingredient in the herbicide formulation Overdrive ${ }^{\circledR}$ (along with dicamba), is a selective, systematic herbicide active ingredient used for the management of annual broadleaf weeds postemergence, and the management and/or suppression of many perennial broadleaf weeds and annual grasses. Accidental direct spray and spill scenarios pose a moderate to high risk to non-target terrestrial plants and 
a low chronic risk to aquatic plants (Table 4-11). Offsite drift of diflufenzopyr poses low risk to terrestrial plants with buffers of less than 100 feet for typical species and less than 900 feet for special status species. Aquatic plants are not at risk under off-site drift or surface runoff scenarios. However, surface runoff poses low to moderate risk to special status terrestrial plants in watersheds with clay and loam soils and $25 \mathrm{in} / \mathrm{yr}$ of precipitation or more. Diflufenzopyr could be effective in suppression or management of several broadleaf weeds in native perennial grasslands when applied at least 100 feet from non-target plant populations of interest or 900 feet from special status plant species (Table 4-12). Its use should be avoided in areas containing special status plants that have clay and/or loam soil types and moderate to high levels of precipitation.

\section{Diquat}

Diquat is a non-selective, contact herbicide for weed management in non-cropland and aquatic areas. The BLM proposes to use diquat only in aquatic areas. Diquat is a cell membrane disrupter that is activated by exposure to sunlight to form oxygen compounds that damage eell membranes. As a non-selective aquatic herbicide, diquat is best used to control aggressive invasive plant species in water bodies where few native plant species exist. Appropriate target species include Eurasian watermilfoil, water-thyme, water hyacinth, and giant salvinia. Diquat does kill plant parts on contact, but it does not kill the roots of the plant, and therefore is often used for single-season control of submersed aquatic plants (Washington Department of Ecology 2004).

Accidental spray and spill of diquat poses moderate to high risk to terrestrial plants at the typical application rate and high risk at the maximum application rate (Table 4-11). Accidental sprays or spills of diquat pose a high risk to aquatic plants. Off-site drift of diquat to terrestrial areas poses a low risk to terrestrial plants, which is associated with aerial applications and ground applications at short buffer distances. Non special status terrestrial plants are not at risk if diquat is applied aerially or from the ground with buffers greater than 1,200 feet (Table 4-12). As a non-selective aquatic herbicide, diquat should not be applied in water bodies where there are aquatic plants of concern. Riparian species within 900 feet of the water body should also be considered, as they may be at risk from off-site drift of diquat; this risk would be lessened if diquat were applied via a ground application method. Diquat should not be used if special status riparian plants are present.

\section{Diuron}

Diuron is a non-selective, broad-spectrum herbicide, effective both pre- and post-emergence. Diuron disrupts photosynthesis by blocking electron transport and the transfer of light energy, thereby resulting in plant death. Because of its non-selective nature, diuron may be highly effective in areas where a variety of invasive species dominate and where very few non-target plants exist. Diuron is best used in areas where bare ground is desired (e.g., around fences and structures).

Risk assessments generally predicted high risk to terrestrial and aquatic plants under accidental direct spray and spill scenarios (risk to typical terrestrial plant species is moderate at the typical application rate; Table 4-11). Off-site drift of diuron presents a risk to special status terrestrial plants under all modeled scenarios, with higher risk at the maximum application rate and at shorter buffer distances. Typical terrestrial plant species are also at risk under scenarios of off-site drift when diuron is applied at the maximum application rate and with buffer distances less than 900 feet, and when applied at the typical application rate with a high boom and a buffer less than 100 feet. Off-site drift of diuron poses low to moderate risk to aquatic plants under most application scenarios. In some cases application with a 900-foot buffer does not pose a risk to aquatic plants, depending on the application rate, the application height, and the type of water body (Table 4-12). In a few cases (clay soils with more than 50 in/yr precipitation and loam soils with $250 \mathrm{in} / \mathrm{yr}$ ), surface runoff of diuron poses a low risk to special status terrestrial plants. Surface runoff poses a moderate to high risk to aquatic plants in ponds under the majority of scenarios. Aquatic plants in the stream are at low risk from surface runoff under most scenarios. Diuron is most safely applied with spot applications at the typical application rate, especially in the vicinity of water bodies with aquatic plants of interest or near special status plants.

\section{Fluridone}

Fluridone is a slow-acting, broad-spectrum, systemic aquatic herbicide that can be used selectively at low concentrations. Fluridone kills target plants by causing the breakdown of chlorophyll, thereby preventing plants from synthesizing food. Because of this mode of action, fluridone must remain in contact with the target aquatic species for an extended period of time, depending on the species, for effective control. Fluridone is one of two new herbicides proposed for use by the BLM that can effectively target harmful and invasive underwater 
aquatic plants; in particular, it would be used to manage water-thyme and Eurasian watermilfoil. Often these aquatic invasives are great disrupters of aquatic ecosystem function. Fluridone may be most effectively used when smaller water bodies are heavily or completely infested with these invasive plants-i.e., in situations where complete eradication is possible in order to prevent the spread of remaining plants. However, at low concentrations, some native aquatic plants, especially pondweeds, may escape harm (Washington Department of Ecology 2004).

Risk to terrestrial plants from fluridone application could not be evaluated because of a lack of toxicity testing. Aquatic plants are at low risk under scenarios involving an accidental spill of fluridone mixed for the maximum application rate (Table 4-11). Because the risks associated with off-site drift of fluridone to terrestrial plants are unknown, care should be taken in the application of fluridone, even though it appears to be safe to non-target aquatic plants if used as registered. Off-site deposition rates of fluridone suggest that small percentages $(0-24 \%)$ of the chemical would drift off site, potentially affecting terrestrial plants. Drift would be lowest $(0-2 \%)$ when fluridone is applied on the water surface with buffer distances of 100 feet or more. The low toxicity of fluridone to aquatic plants suggests that it may not be effective against certain aquatic species. Rates and application methods must be adjusted according to target species identity to achieve management goals, while maintaining care to minimize off-site drift, particularly if non-target plants of interest are within 100 feet of the application site (Table 4-12).

\section{Imazapic}

Imazapic, an ALS-inhibitor, is a selective, systemic herbicide used on annual and perennial broadleaf weeds and grasses. Like other ALS-inhibitors, imazapic is quite active, with only small concentrations required to kill target plants. Due to its activity, imazapic may be highly effective, particularly in spot applications, at controlling aggressive invasive species that have not responded to other herbicides or treatment methods. Several short-term studies have shown that preemergent/fall application of imazapic can be effective in controlling invasive species (e.g., leafy spurge) while improving the establishment of native grassland plants (Beran et al. 1999; Markle and Lym 2001; Masters et al. 2001; Kirby et al. 2003). However, despite its selectivity, studies have found that some plants that are supposedly tolerant to imazapic are likely to be injured if they are directly sprayed by the herbicide at the typical application rate (many native bunchgrasses remain tolerant [SERA 2001b]). Imazapic is proposed for BLM use in fuels reduction because of its effectiveness against downy brome, and in forested rangeland management because of its effectiveness against hoary cress and perennial pepperweed. Accidental direct spray and spill scenarios pose a low risk to terrestrial plants for applications at the typical application rate, and a moderate risk for applications at the maximum application rate (Table 4-11). Aquatic plants are at moderate to high risk for adverse effects from accidents for applications at the maximum application rate, and low to moderate risk for applications at the typical application rate. There is no acute risk to aquatic plants in a water body under typical application rate scenarios (ENSR 2005h). When imazapic is applied aerially with buffers of 300 feet or less, off-site drift presents low risk to terrestrial plants. Aquatic plants are generally not at risk from off-site drift of imazapic, except when applied aerially at the maximum application rate with a buffer of 100 feet or less (Table 4-12). Surface runoff of imazapic presents a low risk to aquatic plants in ponds for applications at the maximum application rate in areas with sandy soils and precipitation greater than $25 \mathrm{in} / \mathrm{yr}$. Overall, application of imazapic at the typical application rate, with buffers greater than 300 feet during aerial application, should not pose a risk to non-target plants.

\section{Overdrive $^{\circledR}$}

Overdrive ${ }^{\circledR}$ is an herbicide formulation containing the active ingredients dicamba and diflufenzopyr. It is a selective, systematic herbicide for the management of broadleaved weeds pre- or post-emergence. Diflufenzopyr inhibits the transport of auxin (a hormone that regulates plant growth and development), and dicamba functions as a synthetic auxin. When used together, these chemicals disrupt plant hormone balance and protein synthesis (Retzinger and Mallory-Smith 1997). Because Overdrive ${ }^{\circledR}$ targets dicotyledons (broadleaved plants), it can be used in native grasslands, particularly if invasive broadleaves are more of a problem than invasive annual grasses. This herbicide provides a good option for vegetation and wildlife habitat management in forested rangeland settings. It can be used to control several broadleaf species, including burningbush, pigweed, Russian thistle, biennial thistles (bull, musk, and Scotch), knapweeds (diffuse, Russian, and spotted), and field bindweed.

Risk assessments predicted moderate to high risk to terrestrial and aquatic plants under direct spray and accidental spill scenarios (Table 4-11). Off-site drift of Overdrive $^{\circledR}$ poses a low risk to special status terrestrial 
TABLE 4-12

Buffer Distances to Minimize Risk to Vegetation from Off-site Drift of BLM-evaluated Herbicides

\begin{tabular}{|c|c|c|c|c|c|c|c|c|c|c|c|}
\hline $\begin{array}{c}\text { Application } \\
\text { Scenario }\end{array}$ & $\mathrm{BROM}^{1}$ & CHLR ${ }^{1}$ & $\mathrm{DICM}^{1}$ & DIFLU ${ }^{1}$ & DIQT $^{1}$ & $\mathrm{DIUR}^{1}$ & FLUR $^{1}$ & IMAZ $^{1}$ & OVER $^{1}$ & SULF $^{1}$ & TEBU $^{1}$ \\
\hline \multicolumn{12}{|c|}{ Buffer Distance (feet) from Non-target Aquatic Plants } \\
\hline \multicolumn{12}{|c|}{ Typical Application Rate } \\
\hline Aerial & NA & 0 & NA & NA & NE & NA & NE & 0 & NA & 1,300 & NE \\
\hline Low Boom ${ }^{2}$ & 100 & 0 & 0 & 100 & NE & 900 & NE & 0 & 100 & 900 & 0 \\
\hline \multicolumn{12}{|c|}{ Maximum Application Rate } \\
\hline Aerial & NA & 300 & NA & NA & NE & NA & NE & 300 & NA & 1,500 & NE \\
\hline Low Boom ${ }^{2}$ & 900 & 0 & 0 & 900 & NE & 1,000 & NE & 0 & 900 & 900 & 0 \\
\hline High Boom ${ }^{2}$ & 900 & 0 & 0 & 900 & NE & 1,000 & NE & 0 & 900 & 900 & 0 \\
\hline \multicolumn{12}{|c|}{ Buffer Distance (feet) from Non-target Terrestrial Plants } \\
\hline \multicolumn{12}{|c|}{ Typical Application Rate } \\
\hline \multicolumn{12}{|c|}{ Maximum Application Rate } \\
\hline Aerial & NA & 1,350 & NA & NA & 1,200 & NA & $\mathrm{NE}$ & 900 & NA & 0 & $\mathrm{NE}$ \\
\hline Low Boom ${ }^{2}$ & 1,000 & 1,000 & 1,050 & 100 & 900 & 200 & NE & 0 & 100 & 0 & 50 \\
\hline High Boom ${ }^{2}$ & 1,000 & 1,000 & 1,050 & 100 & 900 & 500 & NE & 0 & 100 & 0 & 50 \\
\hline \multicolumn{12}{|c|}{ Buffer Distance (feet) from Threatened, Endangered, and Sensitive Plants } \\
\hline \multicolumn{12}{|c|}{ Typical Application Rate } \\
\hline Aerial & NA & 1,400 & NA & NA & 1,200 & NA & NE & 0 & NA & 1,500 & NE \\
\hline Low Boom ${ }^{2}$ & 1,200 & 1,000 & 1,050 & 100 & 900 & 1,000 & NE & 0 & 100 & 1,100 & 0 \\
\hline High Boom ${ }^{2}$ & 1,200 & 1,000 & 1,050 & 900 & 900 & 1,000 & NE & 0 & 900 & 1,000 & 50 \\
\hline \multicolumn{12}{|c|}{ Maximum Application Rate } \\
\hline
\end{tabular}

plants at distances greater than 100 feet (Table 4-12). Surface runoff generally does not pose a risk to nontarget plants, except to special status terrestrial species under scenarios in which Overdrive ${ }^{\circledR}$ is applied in watersheds with silt and clay soils and precipitation greater than $25 \mathrm{in} / \mathrm{yr}$, and to aquatic species in watersheds with silt, clay, and sand soils and precipitation greater than $25 \mathrm{in} / \mathrm{yr}$ or in all soil types with precipitation greater than $200 \mathrm{in} / \mathrm{yr}$ (at the maximum application rate). It appears that Overdrive can be safely applied in areas that do not contain special status plants and where non-target plants of interest are not broadleaved (i.e., they are monocotyledons such as grasses and lilies).

\section{Sulfometuron Methyl}

Sulfometuron methyl, an ALS-inhibitor, is a broadspectrum, pre- and post-emergent herbicide used to target broadleaf weeds and annual and perennial grass species. Like chlorsulfuron and imazapic, sulfometuron methyl is highly active, but is less selective than chlorsulfuron. Therefore, sulfometuron methyl should not be used in situations where selectivity is required, but could be useful in areas with multiple highly aggressive invasive species that have not responded to other herbicides or treatment methods. Sulfometuron methyl is effective in the management of downy brome, hoary cress, and perennial pepperweed. As with other highly active herbicides, care should be taken to apply 
sulfometuron methyl using methods and under conditions that limit the potential for spread off site.

For applications of sulfometuron methyl at the maximum application rate, accidental direct spray and spill scenarios pose a high risk to aquatic species and special status terrestrial plant species and a low risk to typical plant species (Table 4-11). Off-site drift of sulfometuron methyl presents a high risk to special status terrestrial plants, but no risk to typical plants species under modeled scenarios. This prediction contradicts past reported incidents of damage to crops resulting from off-site drift covering large distances from the site of application. In addition, other risk evaluations have reported potential damage to nontarget plants even when applied at distances of greater than 900 feet (Table 4-12). Aquatic plants are at low risk under off-site drift scenarios, with some higher levels of risk at shorter buffer distances. Aquatic plants are not at risk under off-site drift scenarios if a minimum 900-foot buffer distance is used. Surface runoff of sulfometuron methyl poses a low to moderate risk to special status terrestrial plants, if applied in watersheds with clay or silt soils or loam soils and 100 in/yr precipitation or greater. Aquatic plants in ponds are at low to moderate risk under most surface runoff scenarios. Aquatic plants in streams are at low to moderate risk in watersheds with sand soils or greater than $50 \mathrm{in} / \mathrm{yr}$ of precipitation. Sulfometuron methyl should not be applied in the vicinity of special status plant species. In addition, this active ingredient should be applied with buffers greater than 900 feet from aquatic areas and non-target terrestrial plants of interest. Furthermore, it has been shown that application in areas with dry soils that have been recently disturbed, and therefore are more susceptible to off-site drift, can be problematic. However, application in watersheds with high probability for surface runoff (sandy soils, high precipitation) could also pose an additional risk to aquatic plants.

\section{Tebuthiuron}

Tebuthiuron is a relatively non-selective herbicide absorbed by plant roots through the soil for use against broadleaved and woody weeds and grasses. Tebuthiuron disrupts photosynthesis by blocking electron transport and the transfer of light energy. Because of its nonselectivity, tebuthiuron should be used in areas dominated by invasive species, particularly woody invasives, such as in rangelands or ROWs invaded by shrubs, trees, and other undesirable species. The strength of this herbicide is its use as a habitat modifier in the BLM sagebrush management program. At low rates of application, tebuthiuron is used to thin sagebrush, creating a more favorable habitat for sagebrush-dependent species.

Accidental direct spray and spill scenarios pose a high risk to terrestrial plants for applications of tebuthiuron at the maximum application rate, and a moderate risk for applications at the typical application rate (Table 4-11). Aquatic plants are at high risk under spill scenarios, aquatic plants in ponds are at low to moderate risk under direct spray scenarios, and aquatic plants in streams are at moderate to high risk under direct spray scenarios. Off-site drift from applications at a distance of less than 900 feet poses a low risk to terrestrial plants under several exposure scenarios, mostly for applications at the maximum application rate and at distances of less than 100 feet (Table 4-12). Aquatic plants are not at risk under off-site drift scenarios; however, surface runoff poses a risk to aquatic plants in ponds under most scenarios when tebuthiuron is applied at the maximum application rate, and under select scenarios when applied at the typical application rate (e.g., most sand soils). Aquatic plants in streams are at risk under a few surface runoff scenarios involving the maximum application rate (e.g., sand soils with precipitation $50 \mathrm{in} / \mathrm{yr}$ and greater, and large application areas). Threatened, endangered, and sensitive terrestrial plants in watersheds with clay and silt soils and precipitation of $50 \mathrm{in} / \mathrm{yr}$ and greater are also at risk under surface runoff scenarios. Most risk to vegetation from registered use of tebuthiuron can be avoided by applying at the typical application rate, using buffers of more than 100 feet, and avoiding application near special status species.

\section{Impacts of Forest Service-evaluated Herbicides}

The following information for eight herbicides proposed for use by the BLM is taken from ERAs prepared by the Forest Service to support assessment of the environmental consequences of using these herbicides in Forest Service vegetation management programs. Because the Forest Service completed these ERAs prior to the completion of this PEIS, the BLM has used these ERAs to assess the potential ecological impacts of vegetation treatments with these herbicides in future management activities. The BLM previously evaluated and approved these eight herbicides in earlier EISs. As part of their risk assessments, the Forest Service developed worksheets, which allowed the BLM to assess risks of the herbicides using BLM maximum application rates and LOCs (rather than the Forest Service rates and LOCs), so that the risk assessment process for the Forest Service-evaluated herbicides 
parallels the BLM process as much as possible. However, risk scenarios modeled for terrestrial plants may be different than those modeled in BLM ERAs, depending on the specificity of available toxicity data. The assessment of impacts below is presented using the Forest Service upper estimates of HQs to maximize the conservatism of the assessment. In addition, it should be noted that HQs developed by the Forest Service (as well as the BLM) are already conservative for many reasons (e.g., use of most sensitive values for exposure and dose/response assessments).

\section{2,4-D}

2,4-D is a plant growth regulator that acts as a synthetic auxin hormone. 2,4-D alters the metabolism and growth characteristics of plants, often causing a proliferation of abnormal growth that interferes with the transport of nutrients throughout the plant. Broad-leaved plants are more -susceptible to the effects of 2,4-D than narrowleaved plants, such as grasses. Plant community diversity studies have shown that 2,4-D can be effectively used in invasive species management without significantly affecting species diversity (USDA Forest Service 2005). This herbicide has limited residual activity and limited effectiveness on perennial species, but it does have some effectiveness in managing biennial thistles (bull, musk, Scotch) in forested rangeland situations, possibly for the enhancement of wildlife species. 2,4-D may also be used in riparian and aquatic areas. It is effective on broadleaved plants, such as Eurasian watermilfoil, and may be used in spot treatments at the labeled rate without substantially affecting native aquatic plants (Washington Department of Ecology 2004).

The principal hazard to non-target plants is unintended direct deposition or spray drift of 2,4-D (SERA 1998). Non-target plants that are accidentally sprayed at normal application rates are likely to be damaged (Table 4-13). Although off-site drift exposure scenarios were not directly modeled, ERAs predicted that drift of 2,4-D following low-flight agricultural application would result in deposition of the herbicide at $5 \%$ of the application rate 100 feet downwind from the application site. Thus, at the maximum BLM application rate for terrestrial scenarios (1.9 lbs a.i./ac), the deposition at 100 feet would be $0.1 \mathrm{lbs}$ a.i./ac, decidedly less than the lowest rate expected to affect sensitive plants $(0.5 \mathrm{lbs}$ a.i./ac). If 2,4-D were to drift off site during aquatic applications at the maximum application rate $(8 \mathrm{lbs}$ a../ac), the deposition at 100 feet would be $0.4 \mathrm{lbs}$ a.i./ac. This is slightly below the minimum application rate used by the Forest Service, suggesting that at a buffer distance of 100 feet, damage to less sensitive plants (e.g., grasses) is unlikely. The effects on sensitive plants (e.g., broadleaves) at this distance are less certain. At a buffer distance of 200 feet, herbicide deposition is predicted to be $2 \%$ of the application rate, resulting in deposition of $0.16 \mathrm{lbs}$ a.i./ac, a concentration that is unlikely to affect non-target plants, when applied at the maximum application rate. Therefore, damage to offsite plants from terrestrial applications of 2,4-D at the maximum application rate plants is unlikely if buffer distances are at least 100 feet. For aquatic applications, a buffer of at least 200 feet should protect off-site plants from damage during applications at the aquatic maximum application rate.

The toxicity of 2,4-D to aquatic plants is low at the typical application rate, but moderate at the maximum application rate. Risks are greater in cases of direct application to water bodies or accidental direct spills. One study suggested that 2,4-D application to water bodies may result in adverse effects on aquatic macrophytes, although the concentrations that inhibited shoot and/or root growth by $25 \%$ and $50 \%$ were below the expected environmental concentrations from typical use (Roshon et al. 1999).

\section{Clopyralid}

Clopyralid is a selective herbicide most effectively used post-emergence for the control of broadleaf weeds. Clopyralid is a plant growth regulator that is rapidly absorbed across leaf surfaces, and acts as a synthetic auxin hormone, causing a proliferation of abnormal growth that interferes with the transport of nutrients, which can then result in substantial damage to the plant, or death. The modeled BLM application rates were 0.35 pounds acid equivalent per acre (lb a.e./ac; typical) and $1 \mathrm{lb}$ a.e./ac (maximum). Clopyralid would be considered for use in forested rangeland areas for the management of several weedy species, including diffuse and spotted knapweed, yellow starthistle, and bull, Canada, Scotch, and musk thistles.

As expected, direct spray of clopyralid poses a high risk to sensitive plant species; direct spray also poses a low risk to tolerant plant species for applications at the maximum application rate (Table 4-13). Off-site drift of clopyralid from low-boom ground applications and aerial applications may cause damage to sensitive plant species at distances of about 500 feet from the application site, when applied at the typical application rate (SERA 1999), and at distances of greater than 900 feet when applied at the maximum application rate 


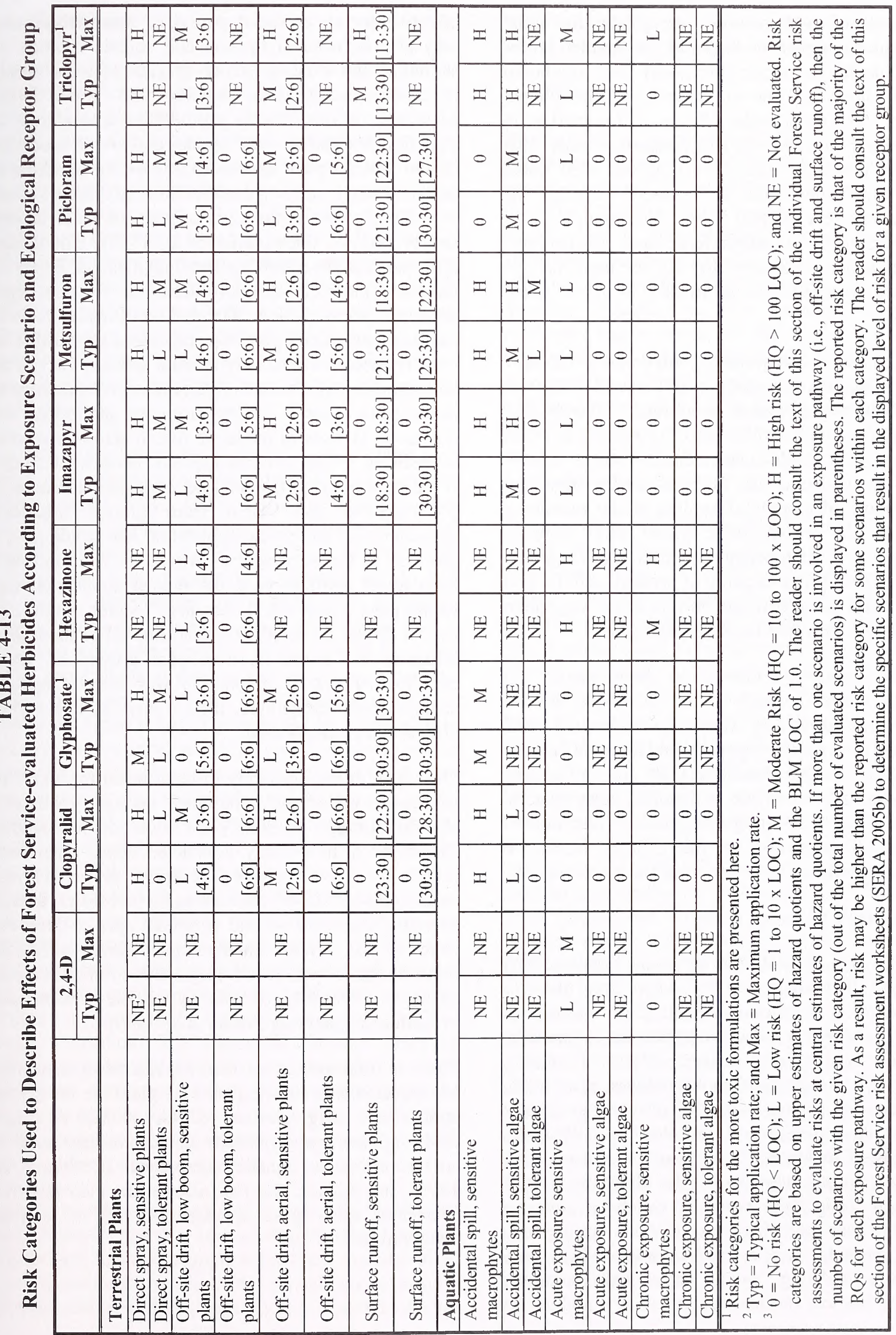


(Table 4-14). Hazard quotients are greater for aerial applications (moderate to high risk at smaller buffer distance and higher application rates) than low-boom ground applications (low to moderate risk). Tolerant species are not at risk under off-site drift scenarios. In addition, the Forest Service risk assessment states that damage to non-target species via off-site drift could probably be minimized or avoided during the application process (SERA 1999). For instance, welldirected ground applications (e.g., spot applications) conducted under conditions that do not favor off-site drift would probably have no impact on off-site plant species.

Clopyralid tends to leach into the soil column with rain, where it is rapidly degraded, except in arid soils with low microbial populations. It is not readily absorbed by roots, suggesting that surface runoff is unlikely to affect off-site vegetation. However, sensitive plant species face-low to moderate risk under scenarios involving surface runoff of clopyralid applied at the maximum application rate in clay soils, which allow minimal infiltration, at most precipitation levels (i.e., greater than $10 \mathrm{in} / \mathrm{yr}$ ). Wind erosion of treated soil in arid climates could cause damages to non-target vegetation within 200 to 900 feet of the application site.

Clopyralid is relatively non-toxic to aquatic plants. It is not likely to affect aquatic plants via off-site drift or surface runoff pathways. However, accidental spills may result in temporary growth inhibition of aquatic plants; spills would present a high risk to aquatic macrophytes and a low risk to sensitive algae species. Overall, effects to non-target vegetation from normal application of clopyralid are likely to be limited to sensitive plant species in or very near the treatment area.

\section{Glyphosate}

Glyphosate is a non-seleetive systemic herbicide that can damage all groups or families of non-target plants to varying degrees. Glyphosate inhibits the production of aromatic amino acids and certain phenolic compounds. This leads to a variety of toxic effects in plants, including the inhibition of photosynthesis, respiration, and nucleic acid synthesis, thereby resulting in cellular disruption, decreased growth, and death at sufficiently high levels of exposure. Because of its non-selective nature, glyphosate may be highly effective in spot applications or in areas where a variety of invasive species dominate and where very few non-target plants exist. Glyphosate is best used in areas where bare ground is desired (e.g., around fences and structures); however, it has low residual activity, so it would not be effective for an extended period of time. Glyphosate may also be used in riparian and aquatic habitats on shoreline and floating-leaved species such as purple loosestrife, giant reed, cattails, and water lilies. Exposure via direct spray would pose a moderate to high risk to sensitive plant species and low to moderate risk to tolerant plant species (Table 4-13). In addition, one field study suggests that drift from glyphosate could affect long-term sustainability of populations of lichens and bryophytes (Newmaster et al. 1999). Unintended drift, particularly following aerial application, is one of the more plausible exposure scenarios for non-target terrestrial plants (SERA 2003a). The estimates for offsite drift encompass plausible exposures attributable to wind erosion. For relatively tolerant species, there is no indication that glyphosate is likely to result in damage at distances as close as 50 feet from the application site (Table 4-14). Low to moderate risk to sensitive species is predicted for ground broadcast and aerial applications at the maximum application rate, at off-site distances of 100 feet or less. Drift from ground broadcast applications at the typical application rate would pose a low risk to sensitive species within 25 feet, and drift from aerial application at the typical application rate would pose a low risk to sensitive species within 300 feet. It should be noted, however, that all of these drift estimates are based on low-boom ground or aerial broadcast sprays. If glyphosate was directly applied using a backpack sprayer, little if any damage due to drift would be anticipated.

Plant species are not likely to be affected by runoff of glyphosate under any conditions; because glyphosate absorbs strongly to soil, plant roots do not readily absorb it. A field study conducted using glyphosate found no effect to plant diversity in an 11-year examination of site-preparation using herbicides, though structural composition and perennial species presence were altered. These changes may have ecological implications if species lost (e.g., native huckleberry or cherry) were heavily fed upon by wildlife or were used in traditional gathering (Miller et al. 1999).

There is little indication from the risk assessment that adverse effects to aquatic plants are plausible for typical applications of glyphosate (SERA 2003a). A single study suggests that glyphosate application may result in adverse effects on aquatic macrophytes (Roshon et al. 1999). In addition, the risk assessment indicates that accidental spills pose a moderate risk to aquatic macrophytes. 


\section{Hexazinone}

Hexazinone is an "s-triazine" herbicide that inhibits photosynthesis and the synthesis of RNA, proteins, and lipids. Although some foliar absorption may occur, the major route of exposure involves hexazinone moving from the soil surface to the root system of plants, where, in most species, it is readily absorbed and translocated throughout the plant. The differential toxicity of hexazinone to plants is based on variations in the ability of different plants to absorb, degrade, and eliminate the herbicide. The BLM modeled application rates of $1 \mathrm{lb}$ a.i./ac (typical rate) and $8 \mathrm{lbs}$ a.i./ac (maximum rate). Hexazinone is effective against woody species (e.g., juniper, mesquite, cottonwood), and therefore is not used in forested rangeland areas. It may be used for fuels reduction.

As with other herbicides, hexazinone may affect nontarget plants through accidental direct spray and off-site drift scenarios (SERA 1997). During aerial applications at the typical application rate and at distances of 100 feet or less from the application site, some damage to sensitive non-target vegetation is plausible due to drift of liquid formulations (low risk). At maximum application rates, sensitive species may be at low to moderate risk under scenarios involving drift following aerial applications at distances of 500 feet or less (no risk is predicted at 900 feet from the application site; Tables 4-13 and 4-14). There would be a low risk to tolerant species under scenarios involving aerial drift at maximum application rates at distances of 50 feet or less (no risk is predicted at 100 feet). Ground applications of granular formulations or spot treatments with liquid applications of hexazinone should be associated with minimal drift; however, there are no studies available in the literature to support this speculation. In addition, soil contamination and consequent transport of hexazinone to off-site nontarget vegetation may occur. Based on the limited doseresponse data available for plants, the levels of exposure detected are likely to be toxic to non-target as well as target vegetation. The magnitude of any observed effects will be determined predominantly by local conditions, particularly soil type and rainfall. In porous and/or sandy soils with low levels of organic matter and under conditions of high rainfall, adverse effects to offsite vegetation are most plausible.

Aquatic plants are at moderate to high risk under acute and chronic exposure scenarios involving both the typical and maximum application rates. Aquatic algal species are also sensitive to hexazinone exposure. Furthermore, it is likely that aquatic macrophytes are sensitive based on the effects of hexazinone on algae and terrestrial plants (SERA 1997; Roshon et al. 1999).

\section{Imazapyr}

Imazapyr is an ALS-inhibiting herbicide used in the control of a variety of grasses, broadleaf weeds, vines, and brush species. Although post-emergence application is more effective than pre-emergence application, toxicity can be induced either through foliar or root absorption. Due to its activity, imazapyr may be highly effective in controlling aggressive invasive species that have not responded to other herbicides or treatment methods. The strength of this herbicide is in the management of saltcedar in riparian zones. In addition, imazapyr can be used to treat emergent plants such as spartina, reed canarygrass, and phragmites, and floatingleaved plants such as water lilies. BLM application rates modeled were $0.45 \mathrm{lb}$ a.i./ac (typical rate) and $1.5 \mathrm{lbs}$ a.i./ac (maximum rate).

Imazapyr is an effective herbicide, and even "tolerant" plants that are directly sprayed with imazapyr at normal application rates are likely to be damaged (SERA 2004d). The risk assessment predicted a high risk to sensitive plant species and a moderate risk to tolerant species under direct broadcast spray scenarios (Table 413). Off-site drift of imazapyr could cause damage to sensitive plant species at distances of less than 900 feet from the application site after both ground broadcast (low boom) or aerial applications at the typical application rate, and possibly at distances greater than 900 feet after applications at the maximum application rate (low to moderate risk for ground applications and low to high risk for aerial applications at both application rates; 900 feet was the maximum distance modeled), depending on site-specific conditions, such as wind speed and foliar interception (Table 4-14). Tolerant species are not likely to be affected by off-site drift of imazapyr, except under drift scenarios following 1) low boom ground application at the maximum application rate at distances of 25 feet or less, or 2) aerial application at the maximum application rate at distances of 100 feet or less. In addition, wind erosion of soil contaminated with imazapyr could lead to adverse effects to sensitive plants, particularly in relatively arid environments and where local soil surface and topographic conditions favor wind erosion. However, the risk assessment estimated daily soil losses from erosion to be $0.001 \%$ to $0.1 \%$ of the application rate, similar to loss predicted from off-site drift at distances greater than 500 feet from the application site (SERA 2004d). 
When applied to areas in which runoff is favored (e.g., clay soils over a wide range of rainfall rates or loam soils at annual rainfall rates of $100 \mathrm{in} / \mathrm{yr}$ or more), damage from runoff appears to be more likely than damage from drift. For applications at the typical application rate, the risk assessment predicted low risk to plants at sites with clay soils and 15 to $20 \mathrm{in} / \mathrm{yr}$ precipitation, and with loam soils and more than 100 in/yr precipitation; moderate risk to plants at sites with clay soils and 25 to $150 \mathrm{in} / \mathrm{yr}$ precipitation; and high risk to plants at sites with clay soils and more than $200 \mathrm{in} / \mathrm{yr}$ precipitation. For applications at the maximum application rate, the risk assessment predicted moderate risk to plants on sites with clay soils and 15 to $25 \mathrm{in} / \mathrm{yr}$ precipitation, and to plants on sites with loam soils and more than $100 \mathrm{in} / \mathrm{yr}$ precipitation; and high risk to plants on sites with clay soils and more than $50 \mathrm{in} / \mathrm{yr}$ precipitation. Residual soil contamination with imazapyr could be prolonged in some areas, possibly resulting in substantial growth inhibition (Rahman et al. 1993 cited in SERA 2004d). In relatively arid areas in which microbial degradation may be the predominant factor in the decline of imazapyr residuals in soil, residual toxicity to sensitive plant species could last for several months to several years (estimated at 10 months to 5.5 years [SERA 2004d]).

Effects to aquatic plants are also plausible. Peak concentrations of imazapyr in surface water could be associated with adverse effects to some aquatic macrophytes (low risk at both application rates). Longer term concentrations of imazapyr, however, are substantially below the level of concern (LOC; SERA 2004d).

Unicellular algae do not appear to be at risk from routine imazapyr application (Roshon et al. 1999, SERA 2004d). Accidental spills of imazapyr pose a high risk to aquatic macrophytes and a moderate to high risk to sensitive algae species.

\section{Metsulfuron Methyl}

Metsulfuron methyl is a selective ALS-inhibiting herbicide used pre- and post-emergence in the control of many annual and perennial weeds and woody plants. Due to its potency, metsulfuron methyl may be highly effective in controlling aggressive invasive species that have not responded to other herbicides or treatment methods. Metsulfuron methyl can be used in forested areas for the management of wildlife habitat and for the control of invasive plant species such as hoary cress, perennial pepperweed, biennial thistles (bull, musk, and Scotch), and yellow starthistle. The BLM application rates modeled were $0.03 \mathrm{lb}$ a.i./ac (typical rate) and 0.15 $\mathrm{lb}$ a.i./ac (maximum rate).

For terrestrial plants, the dominant factor in determining the risk characterization is the potency of metsulfuron methyl relative to the application rate (SERA 2004e). The typical application rate is over 800 times greater than the no observable effects concentration (NOEC) in the vegetative vigor (direct spray) assay of the most sensitive non-target species and approximately 8 times greater than the NOEC for the most tolerant species in the same assay. Exposure via direct spray poses a high risk to sensitive species and a low to moderate risk to tolerant species (Table 4-13). Damage to sensitive nontarget species could be expected in ground broadcast applications at distances of about 900 feet from the application site at the typical application rate in areas in which off-site drift is not reduced by foliar interception (Table 4-14; SERA 2004e). Risks to sensitive nontarget terrestrial plants from off-site drift are slightly higher for aerial applications (low to high risk) than for low-boom ground applications (low to moderate risk). In addition, tolerant plants face low risk from aerial applications with buffers of 25 feet at the typical application rate and 50 feet at the maximum application rate. Directed foliar applications (i.e., via backpack sprayer) may reduce the risk of off-site drift by an unquantifiable amount (SERA 2004e).

Runoff of metsulfuron methyl could be substantial under favorable conditions. In watersheds with clay soils and 15 to $250 \mathrm{in} / \mathrm{yr}$ of precipitation, sensitive terrestrial plants face mostly high risk from exposure via runoff; tolerant plants face low risks at the typical application rate with 50 to $250 \mathrm{in} / \mathrm{yr}$ precipitation, and low to moderate risks at the maximum application rate with 15 to $250 \mathrm{in} / \mathrm{yr}$ precipitation. Plants in watersheds with loam soils face lower risks of damage via runoff of metsulfuron methyl, with risks only predicted for sensitive plants for applications at the typical rate at sites with $100 \mathrm{in} / \mathrm{yr}$ precipitation, or for applications at the maximum application rate at sites with 100 to 250 in/yr precipitation.

In very arid regions, in which runoff might not be substantial, wind erosion could result in damage to offsite plant species, depending on local conditions. Daily soil losses as a result of wind erosion range from $0.001 \%$ to $0.1 \%$ of the application rate- similar to offsite losses associated with drift at a distance of 500 feet or more from the application site (SERA 2004e).

The potential for damage to aquatic plants appears to be substantially less than the potential for damage to 
TABLE 4-14

Buffer Distances to Minimize Risk to Vegetation from Off-site Drift of Forest Service-evaluated Herbicides

\begin{tabular}{|c|c|c|c|c|c|c|c|c|}
\hline $\begin{array}{c}\text { Application } \\
\text { Scenario }\end{array}$ & 2,4-D & Clopyralid & Glyphosate & Hexazinone & Imazapyr & $\begin{array}{l}\text { Metsulfuron } \\
\text { Methyl }\end{array}$ & Picloram & Triclopyr \\
\hline \multicolumn{9}{|c|}{ Buffer Distance (feet) from Sensitive Plants } \\
\hline \multicolumn{9}{|c|}{ Typical Application Rate } \\
\hline Aerial & NE & 900 & 300 & 300 & 900 & 900 & $>900$ & 500 \\
\hline Low Boom & NE & 900 & 50 & NE & 900 & 900 & $>900$ & 300 \\
\hline \multicolumn{9}{|c|}{ Maximum Application Rate } \\
\hline Aerial & $\mathrm{NE}$ & 1,000 & 300 & 900 & $>900$ & $>900$ & $>900$ & $>900$ \\
\hline Low Boom & NE & 1,000 & 300 & $\mathrm{NE}$ & $>900$ & $>900$ & $>900$ & $>900$ \\
\hline \multicolumn{9}{|c|}{ Buffer Distance (feet) from Tolerant Terrestrial Plants } \\
\hline \multicolumn{9}{|c|}{ Typical Application Rate } \\
\hline Aerial & NE & 0 & 25 & NE & 100 & 50 & 25 & $\mathrm{NE}$ \\
\hline Low Boom & $\mathrm{NE}$ & 0 & 25 & 0 & 25 & 25 & 25 & NE \\
\hline \multicolumn{9}{|c|}{ Maximum Application Rate } \\
\hline Aerial & $\mathrm{NE}$ & 25 & 50 & $\mathrm{NE}$ & 300 & 100 & 50 & $\mathrm{NE}$ \\
\hline Low Boom & NE & 25 & 25 & 100 & 50 & 25 & 25 & NE \\
\hline
\end{tabular}

terrestrial plants, except under accidental spill scenarios. The HQs for routine acute and chronic exposure of aquatic algae are all substantially below the LOC; i.e., there is no risk predicted (SERA 2004e). Aquatic macrophytes face low risk from acute exposure to metsulfuron methyl at upper exposure limits. Accidental spills would pose a high risk to aquatic macrophytes, moderate to high risk to sensitive algae species, and low to moderate risk to tolerant algae species.

\section{Picloram}

Picloram is a pyridine herbicide that acts as a plant growth regulator. It mimics naturally occurring plant auxins or hormones in a manner that leads to uncontrolled and abnormal growth that can in turn lead to gross signs of toxicity or death (SERA 2003b). Picloram is more toxic to broadleaf and woody plants than grains or grasses (Extension Toxicology Network 1996c, SERA 2003b). Picloram is reportedly a good choice for vegetation management in habitat modification situations because it can manage undesirable broadleaf species, including woody species, without injury to desirable grasses. It may be particularly effective in maintaining species diversity in grasslands invaded by spotted knapweed, where its persistence in soils allows it to help initially suppress spotted knapweed seedlings (Rice et al. 1997a); repeated application may be required to successfully control knapweed due to its long-term seed viability
(USDA Forest Service 2005). The resistance potential of non-target plants to picloram has not been generally documented; however, it is known that yellow starthistle has developed resistance to picloram, with resistant plants being more tolerant by factors ranging from 3- to 35-fold compared to non-resistant plants (Fuerst et al. 1996 cited in SERA 2003b). The BLM application rates modeled were $0.35 \mathrm{lbs}$ a.e./ac (typical rate) and $1.0 \mathrm{lbs}$ a.e./ac (maximum rate).

Picloram can be considered highly selective to broadleaf plants, but may be toxic to many different plant species if directly sprayed at the typical application rate (SERA 2003b). The risk assessment showed that direct spray of picloram at the typical and maximum application rates poses a high risk to sensitive plant species and a low to moderate risk to tolerant plant species (Table 4-13). Off-site drift of picloram associated with ground and aerial applications may cause damage to sensitive plant species at distances of nearly 1,000 feet from the application site (risk is low to moderate for low-boom ground applications and low to high for aerial applications), depending on wind speed and foliar interception (Table 4-14; SERA 2003b). Tolerant plant species would probably not be impacted by the drift of picloram (low risk is predicted only at the maximum application rate and a distance of 25 feet or less) and might experience relatively little damage unless they were directly sprayed. 
Runoff may present a significant risk to sensitive nontarget terrestrial plant species under conditions in which runoff is favored (mostly high risk is predicted in watersheds with clay soil over a very wide range of rainfall amounts). Low risk is also predicted for sensitive plants in watersheds with loam soils and 100$150 \mathrm{in} / \mathrm{yr}$ precipitation, and for tolerant species in watersheds with clay soils and 150 to $250 \mathrm{in} / \mathrm{yr}$ precipitation, when picloram is applied at the maximum application rate.

Daily soil losses due to wind erosion, expressed as a portion of application rate, could be in the range of 0.00001 to 0.001 . This is substantially less than off-site losses associated with runoff from clay but similar to off-site losses associated with drift in the range of about 200 feet to 900 feet. As with the drift scenarios, wind erosion could lead to adverse effects in sensitive plant species. Wind erosion of soil contaminated with picloram is most plausible in relatively arid environments and where local soil surface and topographic conditions favor this type of event. Furthermore, there is high potential for picloram to leach into groundwater in most soils (USDA Forest Service 2005). In addition, because picloram persists in soil, non-target plant roots can take up picloram, which could impact revegetation efforts.

The toxicity of picloram to aquatic plants varies substantially among different species; however, the only risks predicted by ERAs for routine exposures are a low risk to sensitive aquatic macrophytes from acute exposure to picloram at the maximum application rate, and a moderate risk to sensitive algae species from an accidental spill of picloram.

\section{Triclopyr}

Triclopyr is a selective, systemic herbicide used on broadleaf and woody species. Triclopyr mimics auxin, a plant growth hormone, thus disrupting the normal growth and viability of plants. Commercial formulations include two triclopyr derivatives, triclopyr acid and triclopyr BEE, which were evaluated separately in the Forest Service risk assessment (including separate worksheet calculations). Triclopyr could be used to manage woody riparian and aquatic species of interest, including saltcedar and willow. Triclopyr can be effective as a spot treatment for Eurasian watermilfoil because it is relatively selective for this species at low application rates. In addition, it is effective in riparian areas as a treatment for purple loosestrife because it does not damage native grasses and sedges (Washington Department of Ecology 2004). The BLM application rates modeled in the worksheets were $1.0 \mathrm{lbs}$ a.e./ac (typical rate) and $10.0 \mathrm{lbs}$ a.e./ac (maximum rate).

Because of the relatively low toxicity of triclopyr acid (terrestrial plant $\mathrm{NOEC}=0.333 \mathrm{lb} / \mathrm{ac}$ ) compared to triclopyr BEE (terrestrial plant $\mathrm{NOEC}=0.003 \mathrm{lb} / \mathrm{ac}$ ), the risk characterization for the former is much less severe than the latter (SERA 2003c). Direct spray of both formulations poses a high risk to plants (Table 413). The potential impact of off-site drift associated with broadcast applications varies substantially with the application rate. At the typical application rate, potentially damaging exposure could occur within about 300 feet of the application site. At the maximum application rate, damaging drift could occur at distances of greater than 900 feet from the application site (Table 4-14; SERA 2003c).

At the typical application rate, potentially damaging runoff from triclopyr acid would be anticipated only under relatively high rainfall conditions in watersheds with clay soils (low risk was predicted for sensitive and tolerant species with rainfall of $200 \mathrm{in} / \mathrm{yr}$ or greater). While a lesser amount of triclopyr BEE will run off, low to moderate risk to plants is predicted for applications of this more toxic formulation, starting at relatively modest rainfall rates (i.e., 15 to 25 inches per year) in all modeled soil types (i.e., clay, loam, sand). At the maximum application rate, damage due to runoff after the application of triclopyr acid would be expected at annual rainfall rates as low as 25 inches per year in clay, loam, and sand soils (mostly low risk). For triclopyr $\mathrm{BEE}$, low to high risk is predicted for applications in all but the most arid areas.

Both formulations of triclopyr have been found to decrease the relative long-term abundance and diversity of lichens and bryophytes; normal application rates in aerial spraying were found to reduce abundance by $75 \%$, with colonists and drought tolerant species being less susceptible than later-successional mesophytic forest species (Newmaster et al. 1999). Triclopyr was also found to inhibit growth of four types of ectomychorrhizal fungi associated with conifer roots at concentrations of 1,000 parts per million (Estok et al. 1989 cited in SERA 2003c).

Aquatic stream plants are at low risk from routine acute exposure to triclopyr acid at the maximum application rate. For longer-term exposures, there is no predicted risk to aquatic plants associated with triclopyr TEA applications, even at the maximum application rate. Triclopyr BEE is much more toxic to aquatic plants than triclopyr TEA under laboratory conditions; however, the 
levels of exposure under field conditions would be less, even under acute scenarios because of the rapid hydrolysis of triclopyr BEE to triclopyr acid, as well as the lesser runoff of triclopyr BEE resulting from low water solubility and high affinity for soils (SERA 2003d). Nonetheless, triclopyr BEE is projected to be somewhat more hazardous when used where runoff to open water may occur. Acute exposure poses a low risk to aquatic stream plants under scenarios involving applications at the typical rate, and a moderate risk under scenarios involving applications at the maximum rate. Accidental spill of triclopyr acid poses a low to moderate risk to aquatic macrophytes and algae, whereas accidental spill of triclopyr BEE poses a high risk to aquatic macrophytes and algae.

\section{Impacts of Tank Mixes}

Risk assessment analysis of tank mixes indicates that risks to plants vary by tank mix. Tank mixes of bromacil and sulfometuron methyl, and of imazapic and diflufenzopyr, pose a greater risk to aquatic plants and special status terrestrial plants than bromacil, imazapic, or diflufenzopyr alone (risks to aquatic plants are not greater versus imazapic applied alone). In some cases, plant species may be particularly sensitive to these tank mixes. In addition, application of a tank mix of chlorsulfuron and diuron poses a greater risk to all plant receptors than application of chlorsulfuron alone (but not application of diuron alone). Risks to most receptors are also greater for a tank mix of sulfometuron methyl and bromacil, versus sulfometuron methyl alone.

There is some uncertainty in this evaluation because herbicides in tank mixes may not interact in an additive manner; the evaluation may overestimate risk if the interaction is antagonistic, or it may underestimate risk if the interaction is synergistic. In addition, other products may also be included in tank mixes that contribute to the potential risk. Based on the results of ERAs, precautions (e.g., increased buffers, decreased application rates) should be taken when applying tank mixes to reduce the increased risks to plants associated with these applications.

\section{Summary of Herbicide Impacts Evaluated in ERAs}

The effects of herbicides on target plants depend on their mode of action. Contact herbicides (e.g., diquat) only kill the plant parts that they touch, while translocated herbicides (e.g., dicamba) are transported throughout the plant. Herbicides that provide long-term weed management (e.g., bromacil) affect plants when they are present in the soil, with the degree of damage and non-selectivity often increasing with herbicide concentration (Holecheck et al. 1995). Selective herbicides only affect certain plant species, whcreas non-sclective herbicides affect all or most plant species. The non-selective herbicides evaluated in this PEIS include bromacil, diquat, diuron, fluridone (except at low concentrations), glyphosate, sulfometuron methyl, and tebuthiuron. The other herbicides (2,4-D, chlorsulfuron, clopyralid, diflufenzopyr, hexazinone, imazapic, imazapyr, metsulfuron methyl, Overdrive ${ }^{\circledR}$, picloram, and triclopyr) exhibit some selective qualities and would be most effective when used to target certain plant species. Because of their selective nature, they may be able to be used in areas where non-target vegetation exists in communities with target vegetation. In addition, diquat and fluridone would be used exclusively for the management of aquatic plants; 2,4D, glyphosate, imazapyr, and triclopyr could be used for aquatic as well as terrestrial vegetation management.

The herbicides that create the most short-term risk to non-target plant species, given that application scenarios follow SOPs, are those that are applied in a manner that increases the likelihood for off-site transport (e.g., drift, surface runoff). The risk characterization process of the ERA indicated that risk to typical and special status terrestrial plants is moderate under scenarios involving off-site drift of bromacil and chlorsulfuron and risk to special status terrestrial plants is moderate to high under scenarios involving off-site drift of diquat, diuron, and sulfometuron methyl. Diuron poses a moderate risk to aquatic plants under scenarios involving off-site drift associated with applications at the maximum application rate. None of the herbicides pose risk to non-target plants under wind erosion scenarios.

Impacts to non-target plants would be lessened for herbicides that selectively target the desired species type. However, some changes in species composition could occur in these communities despite lessened impacts to non-target species as a result of altered competitive relationships. The lasting effects of treatments using non-selective herbicides would depend on the species present in the seedbank to reestablish at the site. In many cases, reseeding or replanting treatments would be necessary after an application of a non-selective herbicide to ensure the presence of native species on the site following treatment.

The ALS-inhibiting herbicides evaluated in this PEIS are chlorsulfuron, imazapic, imazapyr, metsulfuron methyl, and sulfometuron methyl. These herbicides are 
applied at low application rates, with only small concentrations necessary to damage plants. The ERAs predicted some risks to non-target plants associated with those herbicides; however, the risks were similar to the risks associated with the other evaluated herbicides. Nevertheless, because of the potency of these herbicides, they may be most appropriate for use when the target plant is the dominant cover species, or when there is a particularly aggressive invasive species that has not successfully controlled by other methods (USDA Forest Service 2005).

\section{Other Herbicides Previously Approved for Use on Public Lands}

Asulam, atrazine, fosamine, mefluidide, simazine, and 2,4-DP (also known as dichlorprop) are currently approved for use on public lands. However, the historical use of these herbicides by the BLM has been quite limited, with only fosamine used in the last 7 years (on less than 50 acres annually). Asulam is used in postemergent control of broadleaf weeds, perennial grasses, and nonflowering plants in forestry and rangeland areas and ROW (Information Ventures, Inc. 1995a). Atrazine provides selective weed control in conifer reforestation, and on ROW, and energy, mineral, cultural, and recreation sites. It is toxic to many plants and should not be used under windy conditions near desirable trees, shrubs, or plants (Information Ventures, Inc. 1995b). Fosamine is used to control brush and herbaceous plants. No acute effects to aquatic plants are expected from normal use of fosamine, but movement of fosamine from the treatment site due to drift or runoff can adversely affect non-target and non-target species (USEPA 1995d). Mefluidide is registered for forestry, rangeland, and ROW. Contact with non-target species may injure or kill susceptible plants (Information Ventures, Inc. 1995c). Simazine is a selective herbicide that is used to control broadleaf and grass weeds in forestry, rangeland, and ROW uses. It is toxic to many plants (Information Ventures, Inc. 1995d). 2,4-DP is registered to control aquatic weeds in ditches and for a variety of upland uses. It is a broadleaf herbicide (Pesticide Management Educator Program 2001).

\section{Impacts by Alternative}

The overall goal of treating vegetation would be to restore natural fire regimes and to reduce or eliminate populations of undesirable vegetation. Treatments aimed at achieving these goals should result in a more desirable successional stage in forest and rangeland habitats, increase plant species diversity, and create a more stratified age structure for wildlife.

Species diversity and vegetative structural components would be enhanced under most treatments, although some treatments could be designed to reduce the size or density of stands of trees or shrubs. Herbicides would provide better control of resprouting vegetation than other treatment methods, particularly when applied before burning. Herbicides would be used on rangelands dominated by annual grasses, such as downy brome and medusahead, followed by revegetation with perennial grasses and forbs. Herbicides would also be used to suppress or thin shrubs in favor of herbaceous vegetation. In some areas, herbicide treatments might reduce the cover of perennial grasses and forbs over the short term, but perennial grass and forbs communities should improve over the long term as shrub stands are thinned to allow more light and nutrients to reach the understory and competition for annual grasses and forbs is reduced.

The following sections detail the expected effects of each of the five alternatives on target and non-target plant communities, and provide comparisons of effects among alternatives. These effects may vary depending on the acreage treated using different application methods and different herbicides, as well as the size of treatment events.

\section{Altermative A - Continue Present Herbicide Use (No Action Altermative)}

Under the No Action Alternative, the BLM would continue current vegetation treatment programs in 14 western states, and would treat an estimated 305,000 acres per year using both ground-based and aerial methods. Public lands in Alaska, Nebraska, and Texas would not be eligible for herbicide treatments under this alternative.

Under this alternative, the BLM would be able to use the 20 herbicides previously approved in earlier EIS RODs. However, based on the recent pattern of BLM herbicide use, it is likely that approximately $75 \%$ of the area treated would involve the use of only four herbicides: 2,4-D, glyphosate, picloram, and tebuthiuron (see Table 2-5).

As the No Action Alternative would be a continuation of current vegetation treatment practices, impacts to vegetation would be similar in nature to those that have occurred in the past. As a result, invasive species would likely continue their rapid expansion across western 
landscapes. Negative impacts to vegetation (i.e., harm to non-target plants) could be lower than under the other herbicide-use alternatives based on the number of acres treated. However, long-term benefits to plant communities (i.e., eradication of unwanted vegetation and resulting improvements in ecosystems) would be much less under this alternative than the other alternatives. Invasive plant populations would likely continue to expand at the current rate or more quickly, increasing damage to native plant communities and inhibiting ecosystem functions.

Because the new herbicides proposed for use by the BLM (diquat, fluridone, imazapic, and Overdrive ${ }^{\mathbb{B}}$ ) would not be used under this alternative, risks to vegetation would be different than under the other alternatives. The risks to terrestrial plants associated with exposure to these four herbicides (especially imazapic) under accidental direct spray, spill, and offsite drift scenarios are lower than those associated with exposure to bromacil and chlorsulfuron, and similar to or lower than the risks associated with exposure to the other pre-approved herbicides. Imazapic has been reported to successfully control the spread of aggressive invasives, including downy brome, Russian knapweed, and perennial pepperweed, and has had positive effects on native prairie restoration (Whitson 2001, Shinn and Thill 2002). In addition, risks to aquatic plants associated with use of the new herbicides are similar to or lower than those associated with use of the preapproved herbicides (e.g., bromacil, diuron), under all application scenarios. Since the BLM would not use the new herbicides under the No Action Alternative, risks to terrestrial plants from accidents and off-site drift during each application event could be greater than under the other herbicide-use alternatives in situations where less harmful new herbicides would otherwise be appropriate. However, risks to special status terrestrial plants from surface runoff would be greatest with the use of diflufenzopyr, suggesting that per treatment risks to these species under surface runoff scenarios might be less under this alternative than under the other herbicide-use alternatives.

Over half the treatments occurring under the No Action Alternative would be in the Temperate Desert Ecoregion, with a third of the treatments targeted to improve sagebrush and other evergreen shrublands, and a third targeted at annual and perennial invasive grasses and forbs (Table 4-15). The focus of most treatments in this ecoregion is to improve habitat for sage-grouse and other wildlife that use sagebrush communities by improving the structural diversity and species composition of sagebrush and rabbitbrush stands, removing invasive species, and promoting production of perennial grasses and forbs desired by sage-grouse and other wildlife (Paige and Ritter 1999). Picloram may be active in the soil for an extended period of time after application and is potentially more damaging to perennial grasses than 2,4-D. Application of picloram to control rabbitbrush and forbs in this ecoregion should decrease production of some desirable shrubs, forbs, and grasses, although grass production should recover as picloram dissipates (USDI BLM 1991a).

Glyphosate could be used to spot treat unwanted annual grasses and forbs. It is effective on downy brome, but is non-selective and can harm desirable plant species if not used carefully. Tebuthiuron is a broad-spectrum herbicide that has a long period of activity in the soil and is effective at thinning sagebrush. However, tebuthiuron may damage grasses and other desirable plants. Application of tebuthiuron at high rates has been shown to decrease perennial grasses and allow annual grasses, as well as rabbitbrush, to increase.

Forty percent of herbicide treatments would occur in the Subtropical Steppe, Temperate Steppe, and Subtropical Desert ecoregions. Within these regions, over half the treatments would be targeted at evergreen shrublands. As in the Temperate Desert Ecoregion, treatments would focus on management of sagebrush/rabbitbrush and control of annual and perennial invasive forbs and grasses.

Over three-quarters of the treatments in the Subtropical Steppe Ecoregion would be focused on sagebrush and other evergreen shrublands, while $12 \%$ of the treatments in this ecoregion would focus on pinyon, juniper and other evergreen woodland species. Picloram and tebuthiuron are the main herbicides used to treat pinyon-juniper woodlands. Both picloram and tebuthiuron may persist in the soil for several years and may injure understory grasses, shrubs, and forbs. Treating individual trees with these herbicides is often a more effective means of controlling trees and less injurious to understory species than broadcast applications. Using picloram on some sites can also result in dominance by annual grasses, such as downy brome or medusahead, if these species become resistant to picloram (USDI BLM 1991a).

Over three-quarters of the treatments in the Temperate Steppe Ecoregion would be focused on annual and perennial grasses and forbs, including downy brome, knapweeds, and thistles. Control of broadleaf plants using selective herbicides, such as 2,4-D, usually 
increases grass production. 2,4-D is also effective in controlling weedy forbs, such as bull, musk, and Scotch thistle. 2,4-D can be tank mixed with other herbicides, such as glyphosate, dicamba, picloram, and triclopyr to enhance the aetivity of these herbicides. Applications of selective herbicides, such as 2,4-D, are expected to increase grasses and decrease broadleaf species. Applications of picloram may damage sensitive grasses as well as broadleaf plants, and can substantially alter the composition of grassland communities (USDI BLM 1991a).

Herbicides such as picloram and tebuthiuron are used to control woody species such as mesquite, creosotebush, and snakeweed in Subtropical Desert habitats. These herbicides usually decrease woody plant growth and increase growth of grasses, although it may take several years before grass and forb production increases in response to reduced competition from shrubs. Picloram is effective in controlling snakeweed, while tebuthiuron is effective in controlling creosotebush and tarbrush. However, tebuthiuron can be injurious to many grasses and forbs, and may promote the development of annual forbs, including Russian thistle. Dicamba has been used to control undesirable herbaceous and woody species and has minimal impact on grasses if applied at normal application rates ( 0.5 to $1 \mathrm{lb}$ a.i./acre; USDI BLM 1991a).

Under this alternative, the BLM would be able to continue to use 2,4-DP, asulam, atrazine, fosamine, mefluidide, and simazine, although it is unlikely that these herbicides would be used. In recent years, the BLM has used other herbicides in their place that are more effective or have fewer environmental and/or human health risks. Bromacil, dicamba, and glyphosate have been substituted for asulam; bromacil, diuron, sulfometuron methyl, and tebuthiuron have replaced atrazine; triclopyr has replaced fosamine; sulfometuron methyl has replaced mefluidide (and imazapic would also replace mefluidide); diuron and hexazinone have replaced simazine; and 2,4-D, dicamba, imazapyr, and triclopyr have replaced 2,4-DP.

\section{Alternative $\mathbb{B}$ - Expand Herbicide Use and Allow for Use of New Herbicides in 17 Western States (Preferred Alternative)}

Alternative B, the Preferred Alternative, would result in the treatment of approximately 932,000 acres across the 17 western BLM states. In addition to the 14 currentlyapproved herbicides, the BLM would be able to use the four others evaluated in this PEIS.
Under this alternative, over $70 \%$ of acres would be treated in the Temperate Desert Ecoregion, a much greater proportion than would be treated under the No Action or other alternatives (Table 4-16). Fifteen percent of treatments would occur in the Temperate Steppe Ecoregion. As under the No Action Alternative, treatments in the Temperate Desert Ecoregion would be targeted primarily toward sagebrush, rabbitbrush, and other evergreen shrubland species, and annual grass and perennial forb weeds, while those in the Temperate Steppe Ecoregion would focus on control of invasive annual and perennial grasses and forbs.

This alternative would result in the most extensive impacts to vegetation (both negative and positive) because it proposes the most acres for treatment ( 3 times the acreage proposed under the No Action Alternative). The use of the four new herbicides and the ability to use future herbicides that become registered with the USEPA would allow BLM managers more options in choosing herbicides to best match treatment goals and application conditions, and might therefore reduce overall risk to vegetation and increase positive ecosystem benefits from treatment. In addition, the ability to use future registered herbicides would allow the BLM to employ the most technologically-advanced herbicides, which would likely reduce risk to non-target plants and increase management benefits. This alternative would also reduce risks and negative impacts associated with other vegetation management methods (e.g., risk of escaped prescribed fires; see the PER). Furthermore, it is useful to have a range of herbicides and herbicide types available for use to combat diverse weed problems, and to minimize the chance that invasive species will become resistant to herbicides that are sprayed in the same location for several years. Weed resistance to herbicides can be minimized by using multiple herbicides with different sites of action in the same application, alternating herbicides with different sites of action each year, or alternating herbicide use with other effective forms of treatment (e.g., prescribed fire, mechanical removal).

Based on BLM patterns of use, 2,4-D, glyphosate, picloram, and tebuthiuron would comprise about $70 \%$ of the herbicides that would be used under this alternative (see Table 2-5). The risks and benefits of using these herbicides are discussed under the No Action Alternative. Approximately $10 \%$ of all treatment acres would be treated with the new herbicides, and of these, over three-fourths of these acres would be treated using imazapic. Imazapic could be used in all areas except riparian and wetland areas. Imazapic would be 
TABLE 4-15

Percentage of Acres Projected to be Treated Using Herbicides in Each Ecoregion for Each Vegetation Subclass under the No Action Alternative

\begin{tabular}{|c|c|c|c|c|c|c|c|c|}
\hline \multirow[b]{2}{*}{ Vegetation Subclass $^{1}$} & \multicolumn{8}{|c|}{ Ecoregion } \\
\hline & 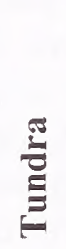 & 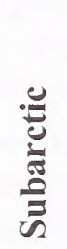 & 苞 & 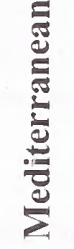 & 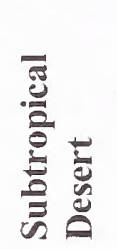 & 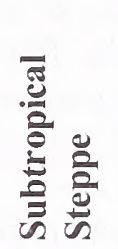 & 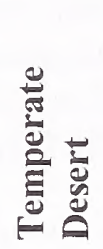 & 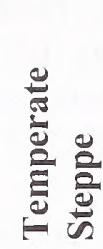 \\
\hline Evergreen forest & 0 & 0 & 86 & 74 & 0 & $<1$ & 3 & 1 \\
\hline Deciduous forest & 0 & 0 & 0 & 0 & 0 & 0 & 3 & 0 \\
\hline Mixed evergreen/deciduous forest & 0 & 0 & 0 & 0 & 0 & 0 & 0 & 0 \\
\hline Evergreen woodland & 0 & 0 & 0 & 1 & 3 & 12 & 5 & 2 \\
\hline Deciduous woodland & 0 & 0 & 0 & $<1$ & 7 & 4 & 0 & 0 \\
\hline $\begin{array}{l}\text { Mixed evergreen/deciduous } \\
\text { woodland }\end{array}$ & 0 & 0 & 0 & 0 & 0 & 0 & 0 & 0 \\
\hline Evergreen shrubland & 0 & 0 & 0 & 6 & 88 & 77 & 30 & 6 \\
\hline Deciduous shrubland & 0 & 0 & 0 & 0 & 0 & 3 & $<1$ & 0 \\
\hline Evergreen dwarf-shrubland & 0 & 0 & 0 & 0 & 0 & 0 & 0 & 0 \\
\hline Deciduous dwarf-shrubland & 0 & 0 & 0 & 0 & 0 & 0 & 0 & 0 \\
\hline Perennial graminoid & 0 & 0 & 14 & $<1$ & 0 & 1 & 9 & 22 \\
\hline Annual graminoid or forb & 0 & 0 & 0 & 16 & 0 & $<1$ & 21 & 3 \\
\hline Perennial forb & 0 & 0 & 0 & 1 & $<1$ & 1 & 14 & 29 \\
\hline Riparian/wetland & 0 & 0 & 0 & 2 & $<1$ & 1 & 1 & 0 \\
\hline More than one subclass & 0 & 0 & 0 & 0 & 2 & 1 & 14 & 38 \\
\hline Total for all ecoregions & 0 & 0 & 1 & 3 & 15 & 17 & 51 & 13 \\
\hline
\end{tabular}

used to control downy brome, hoary cress, perennial pepperweed, and several other invasive species that are known to displace native vegetation and alter wildfire intensity and frequency.

About $2 \%$ of all treatment acres would be treated using Overdrive ${ }^{\circledR}$. Overdrive ${ }^{\circledR}$ would be used on rangelands, ROW, oil, gas, and mineral sites, and cultural and recreation sites. This herbicide is not effective at controlling downy brome, but does have activity on oak species that may be controlled to reduce hazardous fuels. It also provides activity on several annual broadleaf species including burningbush, pigweed, and Russian thistle; several biennial species including bull, musk, and Scotch thistle, teasel, and diffuse knapweed; and several perennial species including spotted and Russian knapweed and field bindweed. The herbicide is also effective in controlling poisonous plants, such as whorled milkweed.

In addition to being able to use four new herbicides under this alternative, the BLM would be able to use herbicides in Alaska, Nebraska, and Texas. Although no herbicide treatments are planned on public lands in Alaska under this alternative, the ability to use herbicides in Nebraska and Texas would allow for more comprehensive weed management programs in these states.

\section{Altermative C - No Use of Herbicides}

Under Alternative C, non-target plants would not be affected by herbicide use. Effects to vegetation would stem from other vegetation treatment methods (see the accompanying PER). In general, the potential negative impacts to non-target plants from manual and mechanical treatment methods are expected to be lower than those from chemical and prescribed fire methods (the impacts from biological methods are less certain). Positive ecosystem benefits as a result of vegetation management may be less than under the Preferred Alternative, as there are certain invasive species for which herbicide use is the only effective method of treatment or for which treatment by other methods is impractical due to cost, time, accessibility, or public concerns (e.g., saltcedar in riparian areas). For example, 
rough terrain may prevent treatment by methods that require ground vehicle and foot access, while aerial treatment with herbicides would be possible in these areas. Vegetation treatments on ROW and oil and gas production facilities would have to be done by manual and mechanical means, or not done at all. Both options may be unfeasible for ROW, while the latter option would compromise the safety of oil and gas production facilities (USDI BLM 1991a).

In addition, it is often difficult to eradicate some species, such as shrubs that resprout from roots, by means other than herbicide application (e.g., rabbitbrush, honey mesquite, Harvard oak, tree cholla). Similarly, pre-emergent herbicides that persist in the soil are the most effective means of controlling invasive plants with seeds that remain viable for long periods of time. Furthermore, where prescribed fire is an appropriate alternative to larger-scale herbicide use (such as in rangelands), neighboring communities may object to the resulting smoke production or risk from escaped fires.

Under this alternative, without the use of herbicides, fewer total acres would be treated annually, and in some areas invasive plant populations would spread at a faster rate, than under the other alternatives, particularly where other treatment methods are not effective or possible (e.g., steep, rocky terrain, and large tracts of rangeland or grassland dominated by invasive, resprouting shrubs or without enough fine fuels to carry prescribed fires). In these areas, degradation of native plant communities would be greater than under the other alternatives.

\section{Alternative D - No Aerial Applications}

Alternative D would allow the use of the same herbicides in the same areas as allowed under the Preferred Alternative, and the benefits associated with availability of new and future herbicides would be the same for both alternatives. However, Alternative D would prohibit aerial herbicide applications. The total treatment acreage would be reduced to approximately 530,000 acres, because some large and remote areas cannot be effectively treated by ground application methods. This alternative would result in substantially fewer impacts to non-target vegetation from off-site drift as compared to alternatives where aerial spraying would be allowed. Drift is a major route of unintended damage to plants, and aerial application is a primary cause of off-site drift. Impacts per treatment would also be much lower under this alternative than under alternatives $\mathrm{A}$ and $\mathrm{B}$, and would be similar to or less than per area impacts under Alternative E.

Under this alternative, it is likely that long-term negative effects on desired plant communities and ecosystems would be greater than any potential shortterm negative effects that would result from aerial applications under other alternatives. In addition, direct and indirect impacts from other vegetation treatment options might increase if these methods were used more extensively to compensate for the reduced number of acres treated by herbicides. These impacts could include greater vegetation damage from the use of ground-based equipment than under the other alternatives.

Prescribed fire and mechanical treatment would be substituted for aerial herbicide treatments as much as possible in large areas proposed for treatment. Fire would not be effective in areas with insufficient fuels to carry fire, while mechanical treatments might not be suitable in areas where sprouting species, such as rabbitbrush, might increase after mechanical treatment. This alternative would preclude treatment of large expanses of downy brome and other invasive annual grasses using imazapic and other herbicides. Fire could also result in substantial damage to sagebrush stands and enhance the development and spread of downy brome and other annual grasses, while mechanical disturbance could also lead to conditions that enhance the spread of weeds and other invasive plants (USDI BLM 1991a).

Nearly all (91\%) aerial treatments are proposed for the Subtropical Steppe and Temperate Desert ecoregions. Of these, two-thirds would occur in evergreen shrublands to remove invasive vegetation, such as downy brome. The remaining treatments would focus primarily on control of undesirable annual and perennial grasses and forbs. Controlling sprouting woody species in areas where an herbaceous community is desired could be difficult because herbicide use would be limited and sprouting might be enhanced by burning and mechanical methods. Under this alternative, more acres in these ecoregions would continue to be dominated by shrubs, and the herbaceous component of plant communities would not be as diverse or productive as in communities where aerial applications of herbicides were used.

About $7 \%$ of aerial treatments would occur in the Temperate Steppe Ecoregion, with most of these treatments used to control perennial forbs such as knapweed, thisties, and leafy spurge. Prescribed fire could be used to treat large acreages, but control of 
TABLE 4-16

Percentage of Acres Projected to be Treated Using Herbicides in Each Ecoregion for Each Vegetation Subclass under the Preferred Altermative

\begin{tabular}{|c|c|c|c|c|c|c|c|c|}
\hline \multirow[b]{2}{*}{ Vegetation Subclass $^{1}$} & \multicolumn{8}{|c|}{ Ecoregion } \\
\hline & E & 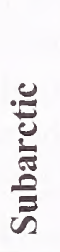 & $\frac{\mathscr{E}}{\sum}$ & 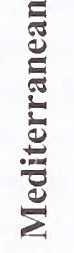 & 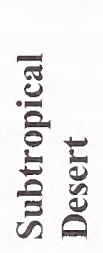 & 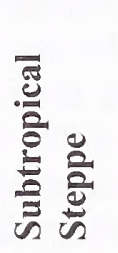 & 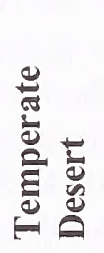 & 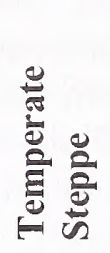 \\
\hline Evergreen forest & 0 & 0 & 79 & 76 & 0 & $<1$ & 1 & 1 \\
\hline Deciduous forest & 0 & 0 & 0 & 0 & 0 & 0 & $<1$ & $<1$ \\
\hline Mixed evergreen/deciduous forest & 0 & 0 & 0 & 0 & 0 & 0 & 0 & $<1$ \\
\hline Evergreen woodland & 0 & 0 & 0 & 6 & 0 & 1 & 2 & $<1$ \\
\hline Deciduous woodland & 0 & 0 & 0 & $<1$ & 5 & 5 & 0 & 0 \\
\hline Mixed evergreen/deciduous woodland & 0 & 0 & 0 & 0 & 0 & 0 & 0 & 0 \\
\hline Evergreen shrubland & 0 & 0 & 0 & 8 & 26 & 42 & 36 & 21 \\
\hline Deciduous shrubland & 0 & 0 & 0 & 0 & 32 & 4 & $<1$ & 0 \\
\hline Evergreen dwarf-shrubland & 0 & 0 & 0 & 0 & 0 & 0 & 0 & 0 \\
\hline Deciduous dwarf-shrubland & 0 & 0 & 0 & 0 & 0 & 0 & 0 & 0 \\
\hline Perennial graminoid & 0 & 0 & 21 & $<1$ & 0 & 33 & 8 & 26 \\
\hline Annual graminoid or forb & 0 & 0 & 0 & 10 & 0 & 8 & 20 & 2 \\
\hline Perennial forb & 0 & 0 & 0 & $<1$ & $<1$ & 1 & 12 & 23 \\
\hline Riparian/wetland & 0 & 0 & 0 & $<1$ & 2 & 4 & 1 & 0 \\
\hline More than one subclass & 0 & 0 & 0 & 0 & 34 & 3 & 21 & 26 \\
\hline Total for all ecoregions & 0 & 0 & $<1$ & 4 & $<1$ & 9 & 71 & 16 \\
\hline
\end{tabular}

noxious weeds and other broadleaf species in this ecoregion would not be as effective as under the Preferred Alternative.

\section{Alternative E - No Use of Acetolactate Synthase- inhibiting Active Ingredients}

Alternative $\mathrm{E}$ was developed based on a proposal for ecosystem-based vegetation management submitted by the American Lands Alliance, an alliance of several environmental and conservation groups (see Appendix I). Approximately 466,000 acres would be treated under Alternative $\mathrm{E}$, which is slightly less than the acreage that would be treated under Alternative D and less than half of the acreage that would be treated under the Preferred Alternative. However, there would still be an increase from the average annual treatment acreage over the past 8 years (and likely to occur under the No Action Alternative). In addition to a relatively low impact to vegetation as a result of the low number of treatment acreage, per treatment impacts under Alternative E would also be lower than under the other herbicide-use alternatives because of the restrictions detailed by this alternative - most notably prohibition of the use of ALS-inhibiting active ingredients.

Sulfonylurea herbicides and other ALS-inhibiting herbicides (e.g., chlorsulfuron, imazapic, imazapyr, metsulfuron methyl, sulfometuron methyl) block the synthesis of amino acids that are required for protein production and cell growth; thereby resulting in plant death. These herbicides are biologically active at small concentrations, which is beneficial to herbicide applicators because a small dose may be used, thereby saving money and possibly resulting in fewer cases of unintended damage to wildlife and the environment (e.g., groundwater contamination [Obrigawitch et al. 1998]). However, because of their high potency, these chemicals may pose excessive dangers to non-target plants. Off-site movement of even small concentrations of these herbicides can result in extensive damage to surrounding plants, and damage to non-target plants may result at concentrations lower than those reportedly required to kill target invasive species (Fletcher et al. 1996), including concentrations that cannot be detected by any standard chemical protocol (Whitcomb 1999). One study reported that drift of chlorsulfuron caused 
$82 \%$ to $100 \%$ reductions in the yield of several crop species when it was applied at 0.008 to 0.004 times the label-suggested application rate (such as might occur with off-site drift) at critical stages of plant development (Fletcher et al. 1996). However, another study reported that risks to non-target plants associated with sulfonylurea herbicides are similar to those associated with other herbicides used at higher application rates (Obrigawitch et al. 1998). In addition, a predominant problem with ALS-inhibiting herbicides is that they can quickly confer resistance to weed populations, particularly since they are often used extensively as the primary weed control method and they have a single mode of action and long residual activity, allowing ample opportunity for the ALS-encoding gene in the target weed to mutate-resulting in a resistant version of ALS (Whitcomb 1999, Tranel and Wright 2002).

Sulfometuron methyl has been implicated in several cases of large-scale damage to non-target species as a result of off-site drift. In Franklin County, Washington, drift of sulfometuron methyl (as the active ingredient in the herbicide Oust ${ }^{\circledR}$ ) caused over a million dollars in damage to more than 700 miles of roadside, including 300,000 young trees in one nursery (Turner 1987). Damage to croplands occurred in Idaho when public lands damaged by wildfire were treated with Oust ${ }^{\circledR}$ and treated soils drifted off-site in wind-blown soil. Responses by agencies to these types of findings varies from warnings about applying these herbicides during critical reproductive periods of non-target plants or during likely drift conditions to suggestions that the use of these herbicides should be severely limited or discontinued, or that the practice of aerial spraying should be abandoned. Because of the risks associated with off-site drift, the labeled use of sulfometuron methyl for burned areas has been rescinded by the USEPA, although the herbicide can still be used on noncrop and forestry sites per label directions.

Under this alternative, the BLM would not be able to use chlorsulfuron, imazapic, imazapyr, metsulfuron methyl, or sulfometuron methyl. However, other herbicides proposed for use by the BLM pose risks that are similar to those associated with these five herbicides; therefore, it is uncertain whether this use restriction would actually reduce risk to non-target plants.

This restriction could ameliorate some of the public concern associated with herbicide use on public lands. However, the potency of these herbicides allows them to be used in very small amounts, which could limit their exposure to off-site species via runoff or drift. In addition, these herbicides may be most effective on particularly aggressive invasive species that have not responded to other herbicides or treatment methods. Control of these aggressive species may not be possible under Alternative E. Furthermore, as mentioned in the No Action Alternative, it is useful to have a range of herbicides and herbicide types available for use to combat diverse weed problems, and to minimize the chance that invasive species will become resistant to herbicides that are sprayed in the same location for several years.

Alternative $\mathrm{E}$ incorporates other management practices that would be likely to have positive impacts on vegetation communities. The suggested use of 500-foot buffers between broadcast herbicide applications and special status plants would reduce risks to sensitive plants from off-site drift and surface runoff. However, herbicide damage from off-site drift has been noted up to a mile from application, and the ERA predicted risks to special status terrestrial plants from application of bromacil and diuron at distances up to 900 feet. Alternative $\mathrm{E}$ would limit the use of broadcast applications, which would reduce the risks to non-target plants associated with off-site drift. Broadcast applications could be used in appropriate situations (i.e., where no other method is practical and non-target plant species and aquatic areas are distant from the application area), however, which would result in some ecosystem benefits from larger scale herbicide applications. Herbicides would not be used in riparian conservation areas, which would protect sensitive aquatic plant species and attendant ecosystem functions in these key areas. However, if these areas were to become degraded by invasive species, it could be more difficult to control and eradicate these species using non-herbicide methods, which would imperil native plants and important riparian ecosystem functions in these and adjoining areas.

While per treatment ecosystem benefits could be greater under Alternative $\mathrm{E}$ than under the other herbicide-use alternatives as a result of this ecosystem-based management approach, overall benefits to vegetation and ecosystems across the 17 western states (that could not be attained using other treatment methods) would be lower under this alternative because of the relatively low treatment acreage and the inability to use certain practices in situations where they are warranted (e.g., use of ALS-inhibitor herbicides on highly aggressive weeds). 


\section{Mitigation for Herbicide Treatment Impacts}

In addition to the SOPs identified earlier in this section and in Table 2-8, the following measures are recommended to reduce impacts to non-target vegetation from the use of herbicides:

- Minimize the use of terrestrial herbicides (especially bromacil, diuron, and sulfometuron methyl) in watersheds with downgradient ponds and streams if potential impacts to aquatic plants are of concern.

- Establish appropriate (herbicide specific) buffer zones around downstream water bodies, habitats, and species/populations of interest (see Tables 4-12 and 4-14). Consult the ERAs for more specific information on appropriate buffer distances under different soil, moisture, vegetation, and application scenarios.

- Limit aerial application of chlorsulfuron, metsulfuron methyl, and sulfometuron methyl to areas with difficult land access, where no other means of application is possible.

\section{Special Status Plant Species}

\section{Introduction}

As discussed in Chapter 3, public lands in the western U.S. support over 1,000 plant species that have been given a special status based on their rarity or sensitivity. Special status plants include approximately 150 species that are federally listed as threatened or endangered, or are proposed for federal listing. The remaining special status species include candidates for federal listing, and other species that warrant special attention and could potentially require federal listing in the future. Many of these species are threatened by competition with nonnative plants and other invasive species. The Vegetation Treatments on Bureau of Land Management Lands in 17 Western States Programmatic Biological Assessment (USDI BLM 2007b) provides a description of the distribution, life history, and current threats for each federally-listed plant species, as well as species proposed for listing. The BA also discusses the risks to threatened and endangered species, and species proposed for listing (collectively referred to as TEP plants) associated with each of the herbicides proposed for use by the BLM under the different alternatives.

\section{Impacts Assessment Methodology}

The BLM reviewcd the literature and findings from ERAs conducted by the BLM and Forest Service to assess the impacts to sensitivc plant species from the use of herbicides (ENSR 2005b-k; SERA 2005a). The ERA methods are summarized earlier in the Vegetation section of this chapter. Methods used by the BLM are presented in detail in the Vegetation Treatments Programmatic EIS Ecological Risk Assessment Protocol (ENSR 2004) and in Appendix C; methods used by the Forest Service can be viewed on the Internet at http://www.fs.fed.us/r6/invasiveplant-eis/.

Although BLM ERAs used the same LOC for all nontarget plant species, separate plant toxicity endpoints were selected to provide extra protection to special status plant species (see Table 4-11). Thus, ERAs for some herbicides predicted higher risks for special status plant species than for "typical" plant species under certain exposure scenarios. Risk assessments completed by the Forest Service also used different toxicity endpoints for sensitive and tolerant plant species. Risks to special status plant species were determined by comparing the HQs for sensitive plant species developed by the Forest Service with the same LOC that was used to determine risks to plants in the BLM ERAs (see Table 4-13).

Herbicide use does pose potential risks to sensitive plant species. However, these risks can be minimized by following certain SOPs, which can be implemented at the local level according to specific conditions (see Table 2-8). These SOPs include:

- Survey for special status plant species before treating an area. Consider effects to special status species when designing herbicide treatment programs.

- Use drift reduction agents to reduce the risk of drift hazard.

- Use a selective herbicide and a wick or backpack sprayer to minimize risks to special plants.

\section{Summary of Herbicide Impacts}

Many special status plant spccies are threatened by the spread of non-native plants. Although a discussion of individual plant species is beyond the scope of this PEIS, the BA provides additional information on which TEP plant species are most at risk from competition with non-native plants. Invasive species are expected to 
continue to spread into habitats occupied by special status species, potentially encroaching on populations and resulting in reductions in population size and vigor, and even extirpation, in some cases. Furthermore, species with very small populations are also at risk of extirpation as a result of fire, even in habitats that are adapted to fire.

Fuels reduction and control of competing vegetation are important components of management programs for special status plant species. However, the sensitivity of these species requires special care during management to ensure that the management actions themselves do not harm or endanger populations. In the case of special status plant species, manual spot applications of herbicides may be the only suitable means of applying herbicides that can adequately ensure the protection of sensitive populations. In the case of special status plant species that are not federally listed or proposed for listing, the impacts associated with herbicide use would be a factor of the herbicide's ability to control nonnative plants that threaten the species' habitat over the long term, and the extent of short-term harm that the herbicide would cause the species. For species with populations that are declining but secure, some mortality or a reduction in population size over the short term could be acceptable, provided the overall habitat for the species was improved, and provided herbicides did not remain in the soil and continue to impact growth and regeneration over the long term. In addition, treatment of weeds in areas that are close to sites that currently support special status species may improve habitat to such a degree that the rarer species are allowed to spread into portions of their original range that are no longer suitable for supporting them.

In some cases, special status plants are present because the site is pristine or relatively undisturbed. Herbicide use would not be required in these places. Similarly, most of the areas where aggressive herbicide treatments would take place (such as oil and gas ROW, heavily grazed rangelands) are unlikely (though not unknown) to support extensive populations of special status species.

All of the herbicides analyzed in ERAs would pose risks to terrestrial special status plant species in a situation where plants were directly sprayed, at either typical or maximum application rates, during a treatment. Herbicides with the greatest likelihood of harming special status plants (i.e., those that pose a high risk when applied at the typical application rate) include bromacil, chlorsulfuron, clopyralid, diflufenzopyr, diquat, imazapyr, metsulfuron methyl, Overdrive ${ }^{\circledR}$, picloram, sulfometuron methyl, and triclopyr. These herbicides would also present the most risk to terrestrial special status plant species as a result of drift from a nearby application site. The herbicide with the lowest risk to terrestrial plants is imazapic, which, according to ERAs, can be broadcast sprayed by ground methods 25 feet from a sensitive plant without risk.

The likelihood of adverse effects to special status terrestrial plants as a result of surface runoff from an upslope treatment site is dependent both on the herbicide used and the site conditions. Certain sites, such as those with clay soils that experience high annual rainfall, are more susceptible to surface runoff of rainwater. The timing of the herbicide application prior to a major rain event and the persistence of the herbicide on the site are also factors. Based on information from the ERAs, herbicides with the greatest likelihood of affecting special status plant species via surface runoff include imazapyr, metsulfuron methyl, picloram, and triclopyr. Of these herbicides, picloram has the longest soil half-life (see Soil Resources section). Herbicides with the least likelihood of impacting special status terrestrial plant species include imazapic, chlorsulfuron, and glyphosate, which pose no risk to sensitive plants via surface runoff, and bromacil, which poses low risks to sensitive plants only under a narrow range of site conditions.

The vast majority of the BLM's special status plant species are terrestrial. However, there are also aquatic plant species (including species in wetland habitats) for which separate risk analyses were completed. Aquatic plants could be harmed by a normal application of an aquatic herbicide, accidental direct spray or spray drift of a terrestrial herbicide from a nearby upland, accidental spill, or surface runoff from an upslope area into the water body where the plant is located. Use of 2,4-D and diquat to control vegetation in aquatic habitats would pose the greatest risks to any special status plant species also in the habitat. Aquatic herbicides that would be safe for use in aquatic habitats where special status plant species occur include fluridone and aquatic formulations of glyphosate. In addition, triclopyr acid could be applied directly to the water column at the standard concentration without harm to sensitive aquatic plants.

The terrestrial herbicides that would pose the greatest risks to special status aquatic plants as a result of accidental direct spray, spray drift, or surface runoff include 2,4-D (assumed), bromacil, diquat, diuron, hexazinone (assumed), and sulfometuron methyl. An accidental spill of most terrestrial herbicides would pose 
quite a high risk to special status plants. Notable exceptions would be picloram, with no risk, and diflufenzopyr with low risks. Based on the results of risk assessments, the safest terrestrial herbicides to use near aquatic habitats would be picloram and diflufenzopyr.

Additional indirect effects to certain special status plant species could occur if populations of pollinators were harmed by herbicide spraying. However, according to risk assessments risks to pollinators would be less than those associated with direct spray of the rare plants themselves. Management efforts to protect rare plants would also help prevent harm to insects in the vicinity. These management efforts include:

- Designating buffer zones around rare plants.

- Managing herbicide drift especially to nearby blooming plants.

- Using typical rather than maximum rates of herbicides in areas with rare plants.

- Choosing herbicide formulations that are not easily carried by social insects to hives, hills, nests and other "homes" in areas with rare plants.

- Choosing herbicides that degrade quickly in the environment when herbicides must be used in rare plant habitat.

- Timing the herbicide applications when pollinators are least active, such as in the evenings or after blooming has occurred for the day in rare plant habitat, and if necessary dividing the rare plant habitat into several treatments rather than one large treatment to keep from treating all blooming species at one time.

Effects to pollinators would be short-term, and population-level effects are not anticipated when these types of management practices are incorporated into project design when rare plants are present.

\section{Alternative A - Continue Present Herbicide Use (No Action Alternative)}

Under this alternative, approximately 305,000 acres of public lands would be treated with herbicides annually. Based solely on acres treated, special status plant species would be less likely to be exposed to herbicides under this alternative than under the other herbicide-use alternatives. Therefore, less harm to special status plants and plant populations from herbicide exposure should occur. For special status plant species, risks for impacts from herbicide exposure should not be substantially different under all the action alternatives, since the BLM would design herbicide treatments to avoid risks to these species (which would include the use of protective spray buffers and other mitigation measures identified in the BA). Nonetheless, the likelihood of an accidental exposure would be lower under the No Action Alternative, since less herbicide would be sprayed on public lands annually.

Because fewer acres would be treated with herbicides than under the other herbicide-use alternatives, less fuels reduction (i.e., through control of downy brome) and control of non-native species using herbicides would occur under the No Action Alternative. Although most fuels reduction is done using other treatment methods, it is expected that the risk of a fire damaging populations of special status species would be higher than under the other alternatives, since there likely would likely be less total fuels reduction on public lands. Furthermore, since existing weed infestations would not be controlled as rigorously with herbicides, it is expected that populations of non-native species would spread at a faster rate than under the other herbicide-use alternatives. In some circumstances, populations of special status plant species that occur in the same habitats as targeted weed species, and that are threatened by their spread, would be more likely to decline as a result of competition with weeds under this alternative than under the other herbicide-use alternatives.

Under this alternative, only those herbicides currently used by the BLM would be used to treat vegetation. Based on herbicide usage in the past decade, the majority of the total acreage would be treated with picloram, tebuthiuron, and 2,4-D. Risks to terrestrial plants associated with picloram are relatively high. Risks associated with tebuthiuron are low to moderate. Risks associated with 2,4-D are unknown, and given the lack of phytotoxicity information for this herbicide, assumed to be high. Risks to aquatic plants associated with picloram are very low. Risks associated with tebuthiuron range from low to high. Risks associated with 2,4-D are low to moderate. Therefore, risks to most special status plants would likely vary from low to high under this alternative, depending on the herbicide used. 


\section{Alternative B - Expand Herbicide Use and Allow for Use of New Herbicides in 17 Westerm States (Preferred Alternative)}

Under this alternative, approximately 932,000 acres of public lands would be treated with herbicides annually. Based solely on acres treated, special status plant species would be more likely to be exposed to herbicides under this alternative than under the other alternatives. Therefore, more harm to special status plants and plant populations from herbicide exposure would likely occur. In the case of special status plant species, the likelihood of an accidental exposure to herbicides would be greater than those under the other alternatives, since more acres would be treated, and more herbicide would be utilized. However, impacts to these species from herbicide exposure should not be substantially different than under the other alternatives, since the BLM would design herbicide treatments to avoid risks to these species (which would include the use of protective spray buffers and other mitigation measures identified in the BA). In addition, areas most in need of treatment, which would also receive the most intensive herbicide treatments, are not likely to support extensive populations of special status plant species.

Because more acres would be treated with herbicides than under the other alternatives, more fuels reduction and control of non-native species using herbicides would occur under the Preferred Alternative. Therefore, populations of special status species would be most likely to benefit from herbicide treatments through habitat improvements under this alternative. It is expected that the extent and rate of spread of weeds would be lowest under this alternative, and that there would be less competition with populations of special status plant species than under the other alternatives.

Under the Preferred Alternative, the BLM would be able to use only 14 of the 20 herbicides that would be available under the No Action Alternative, but would also be able to use four new herbicides, and additional new herbicides that become available for use in the future. The two new terrestrial herbicides, imazapic and diflufenzopyr, have low risks to sensitive terrestrial plants under most conditions. Therefore, risks to special status species could be reduced under this alternative, provided the BLM used these herbicides in place of herbicides with higher risks to sensitive plants, such as picloram and 2,4-D.

Of the two new aquatic herbicides, fluridone poses no risk to sensitive non-target plants during an application, but there are moderate to high risks associated with using diquat. Given that the risks associated with diquat are higher than those associated with aquatic herbicides currently used by the BLM, impacts to aquatic special status plant species would likely be greater under the Preferred Alternative than under the No Action Alternative, especially if diquat was used in place of other less toxic herbicides.

Finally, the greater number of herbicides available for use and the flexibility of additional future options under the Preferred Alternative would potentially allow the BLM to come up with treatment programs that are more effective at reducing weed infestations, safer for sensitive, non-target plants, and less likely to result in reduced effectiveness of herbicides from repeated use than under the No Action alternative.

\section{Alternative C - No Use of Herbicides}

Under this alternative, no public lands would be treated with herbicides. Therefore, special status species on public lands would not be exposed to herbicides unless chemicals were transported onto the land from off-site. The risks to special status plant species for harm due to herbicide exposure would be near zero under this alternative, and therefore much lower than under the other alternatives. However, impacts to these species from herbicide exposure should not be substantially different than under the other alternatives, since measures to protect these species would be implemented under the other alternatives.

Under this alternative, the BLM would be less effective at controlling weed infestation than under the other alternatives. Non-native plant species, including those that compete with, or are a threat to, special status plant species, would spread at a faster rate than under the other alternatives. Although other treatment methods could be substituted for herbicide treatments, it is unlikely that these control measures would be as effective under all circumstances. Furthermore, some treatments must be combined with herbicide treatments to achieve the desired result (e.g., burning or mechanical treatments followed by spraying). These treatments would be used on their own under this alternative, and would not be as effective at controlling weed infestations.

Under this alternative, special status plant species and their habitats would not benefit from manual spot treatments of herbicides, which can be used to control weed infestations in areas that are too sensitive to receive more disturbing or wide-scale treatments. Under this alternative, the BLM would have fewer tools to 
control weeds near populations of special status species, many of which are threatened by non-native species. Overall, less would be done to improve the habitat of these species, making them more at risk for future population declines or extirpations.

\section{Alternative D-No Aerial Applications}

Under this alternative, approximately 530,000 acres would be treated with herbicides annually, fewer than under the Preferred Alternative, but more than under all of the other alternatives. Based solely on acres treated, special status plant species would be less likely to be exposed to herbicides than under the Preferred Alternative, but more likely to be exposed to herbicides than under the other alternatives. Accordingly, the second greatest amount of herbicide-related impacts to special status plant populations would occur under this alternative. In the case of special status plant species, impacts would be similar to those under the other alternatives, since all herbicide treatments would be designed to avoid risks to these species. Risks for accidental exposure could be higher than under alternatives, A, C, and E.

Plant species of concern would not be exposed to herbicides directly from off-site drift associated with an aerial application. Adverse effects to terrestrial and aquatic special status plants could potentially occur by ground applications at distances ranging from 25 to 1,500 feet.

The amount of fuels reduction and control of non-native species, and the related benefits to special status species from habitat improvement would also be second highest under this alternative. Because aerial spraying would not occur under this alternative, the BLM would be unable to treat areas that are inaccessible by ground methods. In these areas, weed infestations would persist and likely spread, potentially impacting nearby populations of special status plant species.

Under this alternative, the herbicides available for use by the BLM would be the same as those discussed for the Preferred Alternative. The benefits associated with flexibility in selecting herbicides, and in using new herbicides that become available in the future, would be the same as those discussed under the Preferred Alternative. In some instances, herbicides with lower risks to special status plant species could be selected instead of herbicides that are currently being used. In addition, the BLM would have more flexibility to come up with treatment programs that are more effective at reducing weed infestations, safer for sensitive, non- target plants, and less likely to result in reduced effectiveness of herbicides from repeated use than under the No Action Alternative.

\section{Alternative $\boldsymbol{E}$ - No Use of Acetolactate Symthase- inhibiting Active Ingredients}

Under this alternative, approximately 466,000 acres would be treated with herbicides annually, more than under the No Action Alternative, but fewer than under the other herbicide-use alternatives. Based solely on acres treated, special status plant species would be less likely to be exposed to herbicides, and therefore would suffer fewer herbicide-related impacts than under the other action alternatives (with the exception of Alternative C). Suggested 500-foot buffers would help to protect these species further from impacts related to herbicide exposure, although for some herbicides this buffer would be insufficient to prevent all impacts to non-target sensitive plants. In the case of special status plant species, impacts would be similar to those under the other alternatives, since all herbicide treatments would be designed to avoid risks to these species. Risks for accidental exposure could be higher than under alternatives $\mathrm{A}$ and $\mathrm{C}$.

The amount of fuels reduction and control of non-native species, and the related benefits to special status species from habitat improvement would also be greater than under alternatives $\mathrm{A}$ and $\mathrm{C}$. Although fewer total acres would be treated than under Alternative $\mathrm{D}$, and broadcast spraying would be minimized, the BLM would be able to conduct aerial spraying to reduce weed infestations in some areas if other means could not be used. Habitat improvements for these species would largely depend on the amount of other treatments (including manual spot applications of herbicide) that would be feasible in these areas.

The increased emphasis on passive restoration under Alternative $\mathrm{E}$ would likely benefit certain populations of special status plant species by helping to prevent the spread of weeds and limiting some forms of disturbance. With this type of management in place, it is possible that fewer herbicide treatments would be necessary in certain areas, minimizing risks to special status plants. In areas where such restrictions would be inconsistent with BLM management practices, they would not be enacted, and no benefit to special status plant species would occur.

Under this alternative, the BLM would not be able to use ALS-inhibiting herbicides (chlorsulfuron, imazapic, imazapyr, metsulfuron methyl, sulfometuron methyl, 
and any other ALS-inhibiting herbicides that are made available in the future). Chlorsulfuron, imazapyr, metsulfuron methyl, and sulfometuron methyl pose high risks to special status terrestrial species under scenarios involving spray drift, and low to high risks under scenarios involving surface runoff. Prohibiting use of these herbicides could benefit special status terrestrial plant species, provided that one or more herbicides with lower risks to non-target plants were used in their stead. Imazapic, however, is the herbicide with the lowest risk to sensitive terrestrial plant species out of all the herbicides analyzed in the ERAs. Therefore, prohibiting its use would eliminate a suitable low risk option for treating weeds and other invasive vegetation such as downy brome, mustards, and thistles, and would require the BLM to use an herbicide with greater risk of harming special status plant species, unless a safer replacement was made available in the future.

The risks of ALS-inhibiting herbicides on special status aquatic plant species range from none to moderate, depending on the application rate and exposure scenario, and are similar to the risks associated with most of the herbicides the BLM would be allowed to use under this alternative. Therefore, potential impacts to aquatic plants from off-site drift and runoff would be much the same under this alternative as under alternatives $B$ and $D$, except that there would potentially be less use of herbicides in riparian areas under Alternative E, limiting the likelihood of exposure.

Since the BLM would be able to use new herbicides that are made available in the future under this alternative, there would be more flexibility for creating effective treatment programs that minimize risks to special status plant species than under alternatives $\mathrm{A}$ and $\mathrm{C}$. Because of the inability to use ALS-inhibiting herbicides, however, this flexibility would be less than that offered under alternatives B and $\mathrm{D}$.

\section{Mitigation for Herbicide Treatment Impacts}

The following mitigation is recommended to reduce the likelihood of impacts to special status plant species from herbicide applications. This mitigation should be implemented in addition to the SOPs designed to protect plants presented in Chapter 2 (Alternatives) and the general mitigation recommended in the Vegetation section.

- To protect special status plant species, implement all conservation measures for plants presented in the Vegetation Treatments on Bureau of Land Management Lands in 17
Western States Programmatic Biological Assessment (USDI BLM 2007b). Apply these measures to sensitive plant species, as well as listed species.

\section{Fish and Other Aquatic Organisms}

\section{Introduction}

The BLM administers lands directly affecting almost 155,000 miles of fish-bearing streams and 4 million acres of reservoirs and natural lakes (USDI BLM 2006c). These habitats range from isolated desert springs of the Southwest to large interior rivers and their numerous tributaries throughout the Pacific Northwest and Alaska. Today, the rapid expansion of invasive species across public lands is one of the primary threats to ecosystem health and one of the greatest challenges in ecosystem management.

The BLM herbicide treatment program is designed to benefit ecosystems by removing and controlling the spread of invasive plant species. In aquatic systems, these plants (e.g., Eurasian watermilfoil, water-thyme) may clog slow-moving water bodies, contaminating water with an overabundance of organic material. This organic material reduces light and dissolved oxygen levels, eliminating habitat and decreasing growth or killing native plants and animals.

Riparian systems may be invaded by non-native species, which can be detrimental to native aquatic species. In riparian areas, non-native plants (e.g., common reed, saltcedar, Japanese knotweed) often support fewer native insects than native plant species, which could affect food availability for insectivorous fish species, such as salmonids. The replacement of native riparian plant species with some invasive species may adversely affect stream morphology (including shading and instream habitat characteristics), bank erosion, and flow levels. Removal of invasive species through herbicide use, when physical and climatic conditions and herbicide formulations allow treatments to be safe for native species and water quality, can help to restore a more complex vegetative and physical structure and natural levels of processes such as sedimentation and erosion. 


\section{Scoping Comments and Other Issues Evaluated in the Assessment}

Numerous scoping comments were centered around a desire for the BLM to focus on long-term ecosystem sustainability and biological diversity. There was some concern about herbicide bioaccumulation in fish. Many reviewers expressed a desire that the BLM use newer, less toxic herbicides and/or limit or avoid herbicide use.

\section{Standard Operating Procedures}

This assessment of impacts assumes that SOPs (listed in Table 2-8) are used to reduce potential unintended impacts to fish and other aquatic organisms. These include the following:

- Develop and update an operational plan for each herbicide project that includes information on project specifications; key personnel responsibilities; communication procedures; safety, spill response, and emergency procedures; and minimum buffer widths for herbicides not approved for aquatic use.

- Use appropriate buffer zones based on label and risk assessment guidance.

- Minimize treatments near fish-bearing water bodies during periods when fish are in life stages most sensitive to the herbicide(s) used, and use spot rather than aerial treatments.

- Use appropriate application equipment and methods near water bodies if the potential for off-site drift exists.

- Where feasible, use spot hand applications within 20 feet of perennial streams and nonperennial streams with flowing water at the time of application.

- Use herbicides that are least toxic to fish, yet still effective.

- For treatment of aquatic vegetation, 1) treat only that portion of the aquatic system necessary to achieve acceptable vegetation management, 2) use the appropriate application method to minimize the potential for injury to desirable vegetation and aquatic organisms, and 3) follow use restrictions on the herbicide label.

\section{Impacts Assessment Methodology}

\section{BLM Risk Assessment Methodology}

A literature review and ERA were conducted to assess the impacts to fish and other aquatic resources from the use of herbicides. The methods presented here are a brief overview of the ERA process to determine the risks of herbicide use to fish and aquatic invertebrates. The ERA methods are presented in detail in the Vegetation Treatments Programmatic EIS Ecological Risk Assessment Protocol (ENSR 2004) and in Appendix $\mathrm{C}$ of this document.

\section{Problem Formulation}

Fish and aquatic species, including special status species, were evaluated to determine assessment endpoints and associated measures of effect. The essential biological requirements (i.e., survival, growth, and reproduction) for each of these groups of organisms are the attributes to be protected from herbicide exposure. Assessment endpoints, for the most part, reflect direct effects of an herbicide on these organisms, but indirect effects were also considered.

Measures of effect are measurable changes in an attribute of an assessment endpoint (or its surrogate, as discussed below) in response to a stressor to which it is exposed (USEPA 1998a). For the screening-level ERA, the measures of effect associated with the assessment endpoints generally consisted of acute and chronic toxicity data (from pesticide registration documents and from the available scientific literature) for the most appropriate surrogate species.

\section{Exposure Characterization}

The BLM uses herbicides in a variety of programs with several different application methods. In order to assess the potential ecological impacts of these herbicide uses, a variety of exposure scenarios were considered. These scenarios were selected based on actual BLM herbicide usage under a variety of conditions. The exposure scenarios considered in the ERAs were organized by potential exposure pathways. In general, the exposure scenarios describe how a particular receptor group may be exposed to the herbicide as a result of a particular exposure pathway. These exposure scenarios were designed to address herbicide exposure and acute and chronic (short- and long-term) impacts that may occur under a variety of conditions (e.g., accidental spills, surface runoff, and off-site drift into water bodies) and are as follows: 
- Direct spray of the receptor or water body

- Off-site drift of spray to terrestrial areas and water bodies

- Surface runoff from the application area to offsite soils or water bodies

- Wind erosion resulting in deposition of contaminated dust into water bodies

- Accidental spills to water bodies

Fish and other aquatic animals are exposed to herbicides in three primary ways: 1) dermally, by direct absorption through the skin from swimming in herbicidecontaminated waters; 2) breathing, by direct uptake of herbicides through the gills or mouth during respiration; and 3) orally, by drinking herbicide-contaminated water or feeding on herbicide-contaminated prey. The type of exposure depends on the nature of the application, and the characteristic of the herbicide and the area treated. The susceptibility of fish and other aquatic organisms to herbicides depends on the herbicide formulation as well as the species exposed to it. Tolerance of fish and other aquatic organisms to herbicides is usually a function of size and metabolism.

A major problem associated with herbicide use is offsite drift to non-target resources. Herbicides drifting off site may eventually reach water bodies and contaminate fish and other aquatic organisms.

The AgDRIFT $\left({ }^{\circledR}\right.$ computer model was used to estimate off-site herbicide transport due to spray drift. The GLEAMS computer model was used to estimate off-site transport of herbicides in surface runoff and root zone groundwater transport. The CALPUFF computer model was used to predict the transport and deposition of herbicides sorbed (i.e., reversibly or temporarily attached) to wind-blown dust. Each model simulation was approached with the intent of predicting the maximum potential herbicide concentration that could result from the given exposure scenario.

Aquatic exposure pathways were evaluated for fish, aquatic invertebrates, and non-target aquatic plants in two types of generic aquatic habitat: 1$)$ a small pond (1/4acre pond $1 \mathrm{~m}$ in depth, resulting in a volume of 1,011,715 liters); and 2) a small stream representative of Pacific Northwest low-order streams that provide habitat for critical life stages of anadromous salmonids.

\section{Effects Characterization}

In the majority of cases, toxicological data do not exist for the specific ecological receptors of concern (i.e., fish and aquatic invertebrate species of interest) considered in the risk assessment. Consequently, toxicological data for surrogate species (e.g., bluegill sunfish for warmwater species and rainbow trout for coldwater species) were evaluated and used to establish quantitative benchmarks for the ecological receptors of concern. These benchmark values are referred to as TRVs. Once developed, TRVs were compared with predicted environmental concentrations to determine the likelihood of adverse effects to ecological receptors.

\section{Risk Characterization}

In order to address potential risks to ecological receptors, RQs were calculated by dividing the EEC for each of the previously described scenarios by the appropriate toxicity endpoint, an herbicide-specific TRV. For fish, the TRV was a species-specific toxicity value derived from the literature.

To facilitate the translation of RQs into readily applicable estimates of risk, the calculated RQs were compared to LOCs used by the USEPA in screening the potential risk of pesticides. These LOCs are used by the USEPA to analyze potential risk to non-target organisms and to assess the need to consider regulatory action. Distinct USEPA LOCs are currently defined for the following risk presumption categories:

- Acute high risk - the potential for acute risk is high.

- Acute restricted use - the potential for acute risk is high, but may be mitigated.

- Acute endangered species - Special status species may be adversely affected.

- Chronic risk - the potential for chronic risk is high.

The ecological risk implications of various exposure estimates can be readily determined by noting which RQs exceed the corresponding LOCs.

\section{Forest Service Methodology}

The Forest Service risk assessment methodology was similar to that used by the BLM (see SERA 2001 a for a complete description of the current methodology). The steps involved in the Forest Service risk assessments 
include hazard identification, exposure assessment, dose response assessment, and risk characterization.

Hazard identification involved review of existing data, with a focus on dose-response and dose-severity relationships to determine the effect levels (e.g., NOAEL, LOAEL) and assessment endpoints (e.g., acute toxicity, subchronic or chronic systemic toxic effects, reproductive and teratogenic effects) that are most relevant for the herbicide risk assessments.

In the exposure assessment phase, the Forest Service developed four general and accidental/incidental exposure scenarios (i.e., direct spray, spray drift, runoff, and wind erosion) according to the application method and the chemical and toxicological properties of the given herbicide. The Forest Service scenario of contaminated irrigation water - a direct application scenario-was not evaluated by the BLM because the BLM does not typically irrigate vegetation. However, the BLM analyzed a scenario for accidental direct spray over streams for all terrestrial and aquatic herbicides. This would be the exposure route (for aquatic animals) most representative of what could occur while treating edges of ditches.

Dose response assessment described the degree or severity of risk as a function of dose. The risk characterization process then compared the exposure assessment to the dose response assessment to determine an LOC for a specific exposure scenario. Hazard quotients were developed through this process. Hazard quotients are analogous to the RQs developed in the BLM risk assessments - they are calculated as the projected level of exposure (i.e., EEC) divided by an index of an acceptable level of exposure or otherwise defined level of exposure (e.g., a NOAEL divided by an uncertainty factor). In addition, the herbicides were all compared based on their selectivity, potency, persistence in the environment, and ability to move off site. The BLM ERAs used BLM herbicide application rates, which may differ from those of the Forest Service.

\section{Adjuvants, Degradates, Inert Ingredients, and Tank Mixes}

\section{Adjuvants}

The BLM reviewed toxicity data for adjuvants, such as surfactants and anti-foam agents, to assess risks to aquatic life. In addition, the GLEAMS model was used to evaluate the risks associated with polyoxyethylenamine (POEA) and R-11, surfactants found in some glyphosate formulations (see Appendix
D) that are more toxic to aquatic organisms than glyphosate itself. These adjuvants are of greatest concern in terms of potential effects to fish and aquatic invertebrates. Using the GLEAMS model, the BLM predicted the portion of an adjuvant that would potentially reach an adjacent water body via surface runoff.

\section{Degradates}

Degradates may be more or less mobile and more or less toxic in the environment than their source herbicides (Battaglin et al. 2003). Differences in environmental behavior (e.g., mobility) and toxicity between parent herbicides and degradates makes prediction of potential impacts challenging. For example, a less toxic, but more mobile, bioaccumulative or persistent degradate may have a greater adverse impact due to residual concentrations in the environment. The BLM conducted a detailed analysis of degradates for herbicides proposed for use under the herbicide treatment program. Several databases, including USEPA's ECOTOX database (http://cfpub.epa.gov/ecotox/), were searched, and relevant aquatic toxicity data for 11 degradates were identified and considered in the analysis.

\section{Inert Ingredients}

Relatively little toxicity information was found on inert ingredients during preparation of the BLM ERAs. A few acute studies on aquatic or terrestrial species were reported. No chronic data, no cumulative effects data, and almost no indirect effects data (food chain species) were found for the inerts in the 10 herbicides.

A number of the inert ingredients found in herbicides are List 4 compounds (Inerts of Minimal Toxicity), which are naturally-occurring earthen materials (e.g., clay materials or simple salts) that would produce no toxicity at applied concentrations. However, some of the inerts, particularly the List 3 compounds and unlisted compounds, may potentially be moderately to highly toxic to aquatic species based on information in Material Safety Data Sheets or published data.

As a tool to evaluate List 3 and unlisted inerts in the ecological risk assessment, the exposure concentration of the generalized inert compound was calculated and compared to toxicity information. As described in more detail in Appendix D of the ERAs, the GLEAMS model was set up to simulate the effects of a generalized inert compound in a base-case watershed (annual precipitation rate of 50 inches per year, application area 
of 10 acres, slope of 0.05 , surface roughness of 0.015 , erodibility of 0.401 tons per acre, vegetation type of weeds) with a sand soil type. The chemical characteristics of the generalized inert compound were set at either extremely high or low values to describe it as either a very mobile or stable compound. The application rate of the inert/adjuvant compound was fixed at $1 \mathrm{lb}$ a.i./acre.

\section{Tank Mives}

The BLM evaluated risks to aquatic organisms from mixing two herbicides together in a tank mix. The BLM assumed that products in a tank mix act in an additive manner. Therefore, to simulate a tank mix of two herbicides, RQs for those two herbicides were combined (see Appendix E of each ERA; diquat, fluridone, and tebuthiuron are not generally tank mixed by the BLM and were not included in the analysis). The application rates within the tank mix are not necessarily the same as those of each individual active ingredient applied alone. The percent of RQs exceeding LOCs for each of the 10 herbicide active ingredients was compared to the percent of RQs exceeding LOCs for tank mixes, to determine whether additional risks to aquatic organisms were predicted for tank mixes.

\section{Impacts by Treatment}

The potential for effects on fish and other aquatic populations as a result of herbicide treatments would vary by the extent and method of treatment and chemical used. Herbicides could enter water bodies and come into contact with fish and aquatic invertebrates through drift, runoff, wind transport, accidental spills, and direct spraying. Potential impacts include mortality, reduced productivity, abnormal growth, and alteration of critical habitat. In general, risk to aquatic invertebrates and fish from spray drift is greater with smaller buffer zones, greater application rates, and greater application heights (i.e., aerial application or ground application with a high boom). Risk to aquatic invertebrates and fish from surface runoff is influenced by precipitation rate, soil type, and application area. There would be a risk to aquatic invertebrates and fish associated with most accidental exposure scenarios (i.e., direct spray or spill into a water body). Persistent herbicides (e.g., sulfometuron methyl) adsorbed to soil particles could also be carried off-site by wind or water, affecting fish and aquatic invertebrates in nearby aquatic areas. However, ERAs predicted no or low (diuron) risk to fish as a result of wind transport of herbicide particles under all evaluated scenarios.
Application rate was a major factor in determining risk, with higher application rates more likely to pose a risk to fish under the various exposure scenarios.

The risk characterization process of the ERA suggested that chlorsulfuron, dicamba, diflufenzopyr, Overdrive ${ }^{\circledR}$, and sulfometuron methyl are very safe to fish and aquatic invertebrates, as there is no risk associated with use of these herbicides under any of the evaluated scenarios, including accidental direct spray or spill. In addition, imazapic does not pose a risk to fish or aquatic invertebrates, except when directly sprayed over a stream at the maximum application rate. There is no risk to fish or aquatic invertebrates associated with off-site drift of bromacil or tebuthiuron. Under surface runoff scenarios, diuron can present a moderate to high risk to fish and aquatic invertebrates if applied at the maximum application rate. The risks to fish and aquatic invertebrates associated with application of aquatic herbicides to ponds and streams is greater for diquat than for fluridone, which when applied at the typical application rate only poses a risk to aquatic invertebrates in streams (aquatic herbicides are not typically applied to streams; therefore, this is an accidental scenario). Tables 4-17 and 4-18 show the level of risk to fish and aquatic invertebrates for the different herbicides and application scenarios.

All of the herbicides pose some risk to non-target terrestrial and aquatic plants; these risks should be considered, as damage to riparian and aquatic plants may affect fish and aquatic invertebrates. The sections on Vegetation and Wetlands in this chapter discuss these risks, as well as herbicide application practices that can be used to reduce risk.

The ALS-inhibiting herbicides evaluated in this PEIS are chlorsulfuron, imazapic, imazapyr, metsulfuron methyl, and sulfometuron methyl (all terrestrial herbicides). These herbicides are considered to be highly potent and are applied at low application rates because only small concentrations are necessary to damage plants. There is low risk to aquatic invertebrates associated with direct spray of imazapic or imazapyr at the maximum application rate. However, this risk is similar to or less than risks associated with the other evaluated herbicides, and could be avoided by applying at the typical application rate. Therefore, the ALSinhibiting herbicides do not appear to pose an unnecessary risk to fish and aquatic invertebrates. In addition, it is possible that because they can be applied at very low rates, there is less risk of off-site transport associated with their use. 


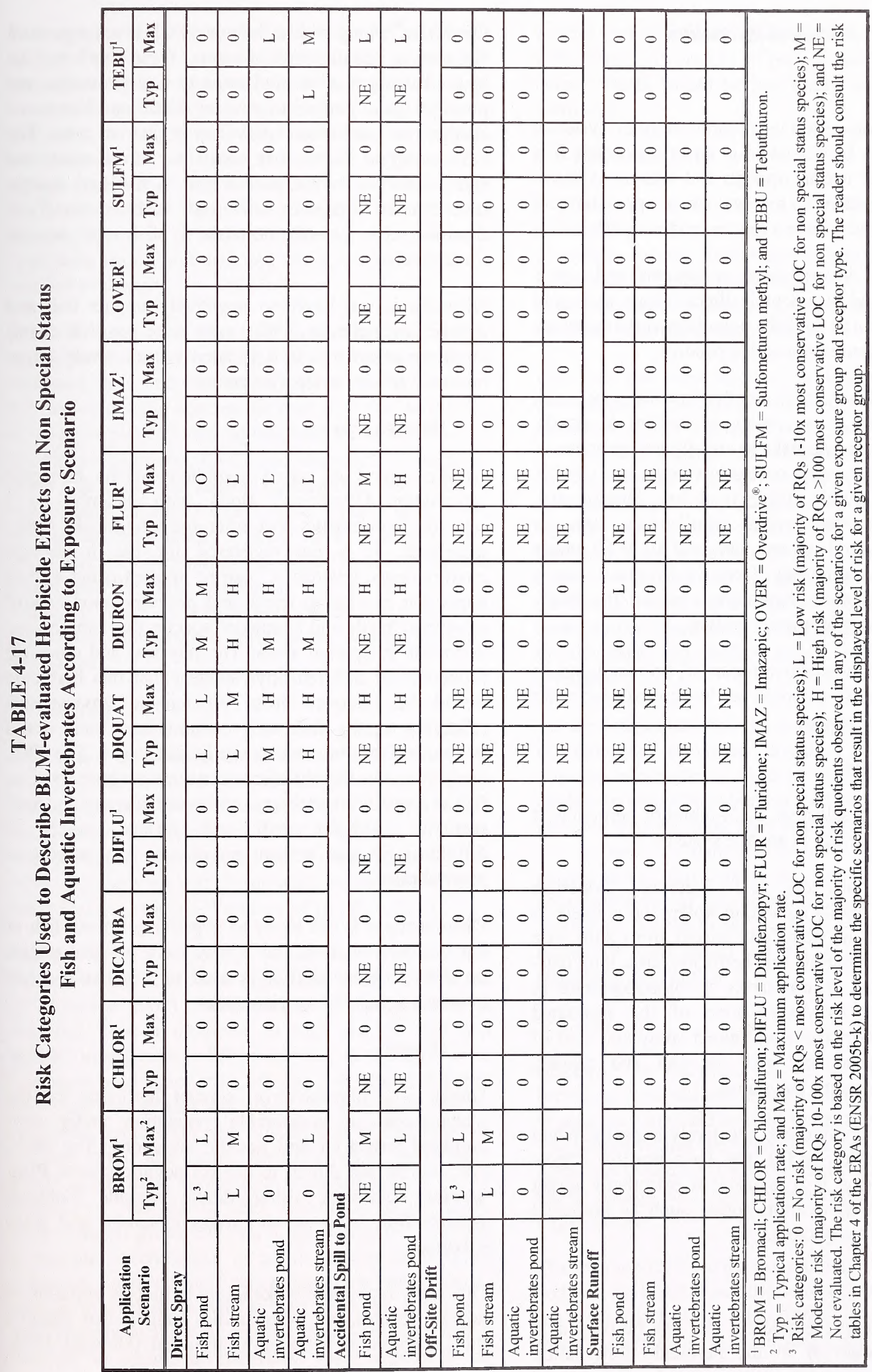




\section{Impacts of BLM-evaluated Herbicides}

\section{Bromacil}

Bromacil is a non-selective, broad-spectrum, systemic herbicide that can be persistent in aquatic systems. It is not registered for use in riparian and aquatic systems. Bromacil does not tend to bioconcentrate appreciably in fish tissue. Bromacil poses a low to moderate risk to

fish and aquatic invertebrates in streams and ponds under typical and accidental direct spray and spill scenarios. Compared to fish, aquatic invertebrates are less sensitive to acute bromacil exposures.

Off-site drift of bromacil generally does not pose a risk to fish or aquatic invertebrates in streams or ponds. Surface runoff poses no risks to aquatic invertebrates or fish in streams, but could pose a low acute and chronic risk to fish in ponds (there is a low chronic risk associated with the typical application rate, in watersheds with sand or loam soils and 10 to 50 inches per year of precipitation). Because bromacil has a higher affinity for water than organic carbon, it is likely to run off from soils into water bodies.

Because of the non-selective nature of bromacil and its likelihood for runoff, it should not be applied near water bodies, especially ponds.

\section{Chlorsulfuron}

Chlorsulfuron is a selective, ALS-inhibitor herbicide. It is not registered for use in aquatic systems.

Chlorsulfuron's physical and chemical properties suggest that it is highly soluble in water, and is likely to remain dissolved in water and runoff from soils into water bodies. In addition, this herbicide has a long halflife in ponds, but is not likely to bioconcentrate in aquatic wildlife. However, none of the evaluated scenarios, including accidental direct spray and spill of chlorsulfuron, pose any risk to fish and aquatic invertebrates in streams and ponds.

Chlorsulfuron is not likely to negatively impact fish and aquatic invertebrates, and it may have positive effects on these organisms if it is used to selectively target nuisance species in riparian zones, such as perennial pepperweed and hoary cress.

\section{Dicamba}

Dicamba is an active ingredient that can be used as a stand-alone product or in the herbicide formulation
Overdrive ${ }^{\circledR}$ along with diflufenzopyr. It is not registered for use in aquatic environments. Overdrive ${ }^{\circledR}$ can be applied using a wick applicator in riparian areas, and provides good control of several thistle and knapweed species that can become prevalent in riparian areas. The ERA analysis shows that accidental direct spray and spill scenarios do not pose a risk to fish and aquatic invertebrates. Off-site drift and surface runoff of dicamba also present no risk to fish and aquatic invertebrates.

Dicamba is not likely to negatively impact fish and aquatic invertebrates, and it may have positive effects on these organisms if it is used to selectively target nuisance species in riparian zones.

\section{Diflufenzopyr}

Diflufenzopyr, an active ingredient in the herbicide formulation Overdrive ${ }^{\circledR}$ along with dicamba, is a selective, systematic post-emergence herbicide active ingredient. It is not registered for use in aquatic environments. Overdrive ${ }^{\mathbb{B}}$ can be applied using a wick applicator in riparian areas, and provides good control of several thistle and knapweed species that can become prevalent in riparian areas. The physical and chemical properties of diflufenzopyr suggest that this herbicide would be removed from an aquatic environment relatively rapidly following contamination and would not appreciably bioconcentrate in fish tissue. The ERA analysis shows that diflufenzopyr does not pose a risk to fish or aquatic invertebrates under direct spray and spill scenarios. Off-site drift and surface runoff of diflufenzopyr also present no risk to fish or aquatic invertebrates.

Diflufenzopyr is not likely to negatively impact fish or aquatic invertebrates, and it may have positive effects on these organisms if it is used to selectively target nuisance species in riparian zones.

\section{Diquat}

Diquat is a non-selective, contact herbicide for the management of undesirable vegetation under noncropland terrestrial and aquatic situations. The BLM proposes to use diquat to control aquatic plants. Plant species controlled using diquat include Eurasian watermilfoil, water-thyme, water hyacinth, and giant salvinia.

One study reported the likelihood of bioconcentration in aquatic species, but other studies suggest that diquat's bioconcentration potential is minimal (Howard 1991; 
Petit et al. 1995; MacKay et al 1997). An accidental spill of diquat would pose a high risk to fish and aquatic invertebrates. Direct spray of diquat to ponds, as would occur with typical aquatic applications, would pose a low risk to fish and moderate risk to aquatic invertebrates. Direct spray to streams, which are not typical application sites, would pose a low risk to fish and predominantly a high risk to aquatic invertebrates. Because diquat is an aquatic herbicide, risk to aquatic organisms via off-site drift and surface runoff scenarios was not evaluated.

Given the short-term risks of diquat to fish and aquatic invertebrates, this herbicide should be used on a restricted basis, and then only in ponds that support very few native aquatic species because they are dominated by invasive plants. Other aquatic herbicides evaluated in this PEIS - fluridone, 2,4-D, and imazapyr-pose much lower risk to fish and aquatic invertebrates and could be used instead of diquat when native aquatic species are present, as appropriate, if they have activity on the target species. Glyphosate is also used to control aquatic plants, but the risks associated with its use may be similar to those associated with diquat, depending on application rate, product formulation, and the receptor of concern.

\section{Diuron}

Diuron is a broad-spectrum herbicide with a relatively short half-life and little to no impact on measured water quality variables (Perschbaucher et al. 2004). It would not be used in riparian or aquatic habitats. Previous studies suggest that diuron tends to remain in the soil rather than moving into groundwater or running off into water bodies (Mueller-Warrant and Griffith 2005).

Diuron has a low to moderate tendency to bioaccumulate in aquatic organisms (National Library of Medicine 2002). Accidental direct spray and spill scenarios pose a moderate to high risk to fish and aquatic invertebrates. When applied at the typical or maximum application rate, off-site drift of diuron poses no to low risk to fish and aquatic invertebrates. At the maximum application rate, off-site drift of diuron poses low risk to fish and aquatic invertebrates in streams and ponds under most application scenarios with a buffer distance of 100 feet or less. According to the ERA, surface runoff poses low risk to fish and no or low risk to aquatic invertebrates in ponds in the majority of scenarios. Surface runoff also poses a low risk to fish in streams in watersheds with at least 25 inches of rain per year (mostly at the maximum application rate), and a low risk to aquatic invertebrates, when applied at the typical and maximum application rates in watersheds with at least 10 inches of precipitation per year. In all cases, effects would be less likely in watersheds with loam soils.

\section{Fluridone}

Fluridone is a slow-acting, broad-spectrum aquatic herbicide that can be used selectively for management of aquatic species, including water-thyme and Eurasian watermilfoil. As fluridone is relatively non-persistent, it is not expected to affect water quality for a substantial period of time (Muir et al. 1980).

Fluridone has little tendency to bioaccumulate in fish (Washington Department of Health 2000). An accidental spill of fluridone poses moderate to high risk to fish and aquatic invertebrates. Direct spray of fluridone over a pond (normal application) at the maximum application rate poses a low risk to fish and aquatic invertebrates. Accidental direct spray of fluridone over a stream (aquatic herbicides are not typically applied to streams) at the maximum application rate poses no or low risk to fish and aquatic invertebrates. Because fluridone is an aquatic herbicide, off-site drift and surface runoff scenarios were not evaluated.

To the extent that typical use of fluridone is successful in removing damaging invasive vegetation with a minimal of residence time in the water body, water quality and wildlife habitat in water bodies would likely improve over the long term with its use. Because there are no risks to fish and aquatic invertebrates from normal use of fluridone at the typical application rate, appropriate use of this herbicide would likely result in an overall benefit to fish and other aquatic organisms. Fluridone poses much lower risk to fish and aquatic organisms than diquat.

\section{Imazapic}

Imazapic, an ALS-inhibitor, is a selective, systemic herbicide. It would not be used for treatment of aquatic vegetation, but could be used in riparian areas where the application could be monitored to ensure that the herbicide would not come in direct contact with water. Leafy spurge and the perennial mustards would be target species.

The average half life for imazapic in a pond is 30 days, and this herbicide has little tendency to bioaccumulate in fish (Barker et al. 1998). According to the manufacturer's label, imazapic has a high runoff 
potential from soils for several months or more after application. Accidental direct spray and spill scenarios generally pose no risk to fish or aquatic invertebrates when imazapic is applied at either the typical or maximum application rate. Risk assessments show fish and aquatic invertebrates are not at risk from off-site drift or surface runoff of imazapic.

When imazapic is used appropriately, it should not impact fish or aquatic invertebrates in streams or ponds. There is only a low chance of risk to stream aquatic invertebrates in the case of accidental direct spray. The use of imazapic may have positive effects on fish and aquatic invertebrates if it is used to selectively target nuisance species in riparian zones.

\section{Overdrive $^{(}$}

Overdrive ${ }^{\circledR}$ is an herbicide formulation containing the active ingredients dicamba and diflufenzopyr. It is a selective, systematic herbicide, with low residence times in water bodies and a low bioconcentration potential (National Library of Medicine 2002). Overdrive ${ }^{\circledR}$ application does not pose a risk to fish or aquatic invertebrates under any application scenario (also see toxicity studies under dicamba and diflufenzopyr).

Overdrive $^{\circledR}$ is not likely to negatively impact fish and aquatic invertebrates, and it may have positive effects on these organisms if it is used to selectively target nuisance plant species in riparian zones, provided herbicide use is seen as an acceptable vegetation treatment method in these sensitive areas.

\section{Sulfometurom Methyl}

Sulfometuron methyl, an ALS-inhibitor, is a broadspectrum, pre- and post-emergent herbicide. It is not approved for use in aquatic systems, but could be used to treat perennial pepperweed, hoary cress, and other weeds associated with riparian systems if the application was made far enough from water to ensure that the active ingredient did not get into the water. Sulfometuron methyl has a relatively low residence time in aquatic systems, and bioaccumulation in aquatic organisms has not been detected (Extension Toxicology Network 1996d).

According to ERAs, there would be no risks to fish or aquatic invertebrates associated with the use of sulfometuron methyl under any of the evaluated scenarios. Therefore, if herbicide treatments are needed in riparian areas, sulfometuron methyl may be able to effectively target nuisance plants without negative impacts to fish and aquatic invertebrates. In addition, use of sulfometuron methyl in riparian zones may have positive effects on fish and aquatic invertebrates if it results in more diverse vegetation structure and native plant communities.

\section{Tebuthiurom}

Tebuthiuron is a relatively non-selective herbicide absorbed by plant roots through the soil. Tebuthiuron has little tendency to bioaccumulate in aquatic organisms (National Library of Medicine 2002), but may have a moderate residence time in water bodies (over 1 year in anaerobic conditions).

Under an accidental spill scenario, tebuthiuron would pose a low risk to fish and aquatic invertebrates in ponds. Accidental direct spray of tebuthiuron over the pond would pose a low chronic risk to aquatic invertebrates, and accidental direct spray over a stream would pose a low to moderate chronic risk to aquatic invertebrates. Fish are not at risk from accidental direct spray. Off-site drift and surface runoff of tebuthiuron does not pose a risk to fish or aquatic invertebrates.

If tebuthiuron is applied at the typical application rate, under normal application scenarios, it is likely to have little or no impact on fish or aquatic invertebrates.

\section{Impacts of Forest Service-evaluated Herbicides}

The following information for eight herbicides used by the BLM is taken from ERAs prepared by the Forest Service to support their assessment of the environmental consequences of using these herbicides in Forest Service vegetation management programs. The BLM previously evaluated and approved these eight herbicides in an earlier EIS-Vegetation Treatment on BLM Lands in Thirteen Western States (USDI BLM 1991a).

\section{$2,4-D$}

2,4-D is an herbicide that has formulations registered for use on aquatic vegetation, including water hyacinth and Eurasian watermilfoil, and as a tank mix partner to control purple loosestrife. The toxicity of 2,4-D to fish and other aquatic organisms is relatively low (Norris et al. 1991). Risk is greater under scenarios of direct application to water bodies or accidental direct spills. The ester formulations of 2,4-D (including the BEEs found in Aqua-Kleen) are approximately 200 to 1,000 times more toxic to fish than the amine formulations, 
when toxicity is measured by acute (24- to 48-hour) $\mathrm{LC}_{50}$ (concentration causing $50 \%$ mortality [median lethal concentration]) values. While these esters are chemically stable, they are short-lived in natural water because of biological degradation. At the typical application rate, 2,4-D poses a low risk to fish and aquatic invertebrates, while at the maximum application rate, 2,4-D poses a moderate risk to fish and aquatic invertebrates under scenarios of accidental direct spray or spill to a stream and pond (Table 4-18). Routine acute and chronic exposure scenarios do not pose a risk to fish.

\section{Clopyralid}

Clopyralid is a selective herbicide most effectively used post-emergence for the control of broadleaf weeds. It is not registered for aquatic vegetation management, but can be used in riparian areas if the application does not impact standing water. Clopyralid is used to treat teasel, common cocklebur, and several species of thistles and knapweeds that could be found in riparian areas. Based on limited acute bioassays, clopyralid appears to be relatively non-toxic to fish and aquatic invertebrates. The risk assessment only predicted risks to aquatic organisms associated with accidental spill scenarios, with low risk to fish and aquatic invertebrates for the typical application rate and low risk to fish and moderate risk to aquatic invertebrates for the maximum application rate.

\section{Glyphosate}

Glyphosate is a non-selective systemic aquatic herbicide. It can be applied as a broadcast, spot, or wipe application, and is effective in controlling purple loosestrife, common reed, cattail, and in some situations, saltcedar. In general, glyphosate is very immobile in soil, being readily adsorbed by soil particles and subject to microbial degradation (Norris et al. 1991). This immobility reduces the potential for glyphosate to enter water bodies during runoff.

Based on bioassays, technical grade glyphosate is classified as non-toxic to practically non-toxic in freshwater fishes (USEPA OPP 1993). Some formulations are more toxic to fish than technical grade glyphosate. At the typical application rate, the less toxic formulation of glyphosate poses little risk to fish or aquatic invertebrates, except under accidental spill scenarios, for which there is a low to moderate risk to fish and a low risk to aquatic invertebrates. At the typical application rate, the more toxic formulation of glyphosate poses a high risk to fish and aquatic invertebrates under accidental spill scenarios, and a low risk under routine acute exposure scenarios (moderate risk to sensitive fish species). At the maximum application rate, the less toxic formulation of glyphosate poses a low risk to fish and aquatic invertebrates under acute exposure scenarios. Accidental spills for the maximum application rate pose moderate to high risk to fish and low risk to aquatic invertebrates. At this same application rate, the more toxic formulation of glyphosate poses a high risk to fish and a low risk to aquatic invertebrates under accidental spill scenarios, and moderate risk to fish and low risk to aquatic invertebrates under acute exposure scenarios. Based on these data, the USEPA classified glyphosate formulation as moderately toxic to practically non-toxic to freshwater fishes (SERA 2003a).

\section{Hexazinone}

According to ERAs, there is no risk to fish or aquatic invertebrates in ponds or streams associated with any exposure scenario for hexazinone (accidental spill scenarios were not modeled).

Bioassays on the active ingredient hexazinone and commercial formulations that include hexazinone indicate that commercial formulations are substantially less toxic than the active ingredient alone, even when exposures are normalized for hexazinone levels (Wan et al. 1988). Some aquatic invertebrates, such as daphnids and glass shrimp, are thought to be slightly more sensitive to hexazinone than fish.

\section{Imazapyr}

Imazapyr is an ALS-inhibiting herbicide used in the control of a variety of grasses, broadleaf weeds, vines, brush species, and aquatic vegetation. It is effective in the control of saltcedar, which dominates many riparian systems in the West. Imazapyr is relatively non-toxic to fish and aquatic invertebrates (SERA 2004d). At the typical and maximum application rates, imazapyr poses no risk to fish or aquatic invertebrates in streams or ponds under acute and chronic exposure scenarios. For the typical application rate, moderate risk is predicted for sensitive fish species for accidental spill scenarios, and for the maximum application rate, high risk to sensitive fish and low risk to tolerant fish and aquatic invertebrates are predicted for accidental spill scenarios.

Aquatic invertebrates have similar sensitivity to imazapyr as fish. Based on two studies using Daphnia magna, no mortality was observed at 24 or 48 hours of exposure of up to $100 \mathrm{mg} / \mathrm{L}$ of imazapyr; with the 
second study showing a NOEC after 48 hours at 180 $\mathrm{mg} / \mathrm{L}$ (SERA 2004d). No adverse effects to fish and other aquatic organisms appear to be likely at either the typical application rate or the maximum application rate for a normal exposure.

\section{Metsulfurom Methyl}

Metsulfuron methyl is a selective ALS-inhibiting herbicide used pre- and post-emergence in the control of many annual and perennial weeds and woody plants. It is not registered for use in aquatic situations, but can be applied in riparian areas if the herbicide does not come into contact with water (SERA 2004e). Overall, metsulfuron methyl appears to have a very low potential to cause any adverse effects in aquatic animals. According to the ERAs, metsulfuron methyl poses almost no risk to fish or aquatic invertebrates in streams and ponds under accidental, acute, and chronic exposure scenarios involving application of typical and maximum rates (although an accidental spill at the maximum application rate poses a low risk to sensitive fish species).

Values from 96-hour $\mathrm{LC}_{50}$ values for acute toxicity in bluegill sunfish and rainbow trout ranged from approximately $150 \mathrm{mg} / \mathrm{L}$ to $1,000 \mathrm{mg} / \mathrm{L}$ for both species (SERA 2004e). In rainbow trout, signs of sublethal toxicity include erratic swimming behavior, lethargy, and color change at concentrations around $100 \mathrm{mg} / \mathrm{L}$, with a NOEC of $10 \mathrm{mg} / \mathrm{L}$ (SERA 2004e). One investigation did not observe any effects on rainbow trout hatching, larval survival, or larval growth over a 90-day exposure period, at a NOEC of up to $4.5 \mathrm{mg} / \mathrm{L}$ (Kreamer 1996 cited in SERA 2004e). The NOEC of 10 $\mathrm{mg} / \mathrm{L}$ for sublethal effects in rainbow trout is approximately 100 times more sensitive than bluegill sunfish that has a NOEC of $1,000 \mathrm{mg} / \mathrm{L}$.

Metsulfuron methyl is relatively non-toxic to aquatic invertebrates. Based on acute bioassays in daphnids, metsulfuron methyl is relatively non-toxic, with an acute median exposure concentration $\left(\mathrm{EC}_{50}\right)$ value for immobility ranging from over $150 \mathrm{mg} / \mathrm{L}$ to $720 \mathrm{mg} / \mathrm{L}$ and acute NOEC values for immobility ranging from over $150 \mathrm{mg} / \mathrm{L}$ to $420 \mathrm{mg} / \mathrm{L}$ (SERA 2004e). Typically, the endpoint for aquatic invertebrates when exposed to high concentrations of metsulfuron methyl is a decrease in growth rate.

\section{Picloram}

Picloram is a pyridine herbicide that acts as a plant growth regulator. It would not be used to control aquatic vegetation.

The acute and chronic toxicity of picloram to aquatic organisms has been assayed in various species of fish and invertebrates. Based on studies, the USEPA classified picloram acid as moderately toxic to freshwater fish (SERA 2003b).

According to the ERAs, when applied at either the typical or the maximum application rate, picloram poses low risk to sensitive fish species under acute exposure scenarios. Under accidental spill scenarios, risks to sensitive fish are high, risks to tolerant fish are low (for both application rates), risks to aquatic invertebrates are low for the typical rate, and risks to aquatic invertebrates are moderate for the maximum rate.

\section{Triclopyr}

Triclopyr is a selective, systemic herbicide used on broadleaf and woody species, including woody species found in riparian and aquatic areas, such as saltcedar, willows, and purple loosestrife. Commercial formulations of triclopyr may contain the acid formulation (TEA) or the BEE formulation; these triclopyr derivatives are evaluated separately in the Forest Service risk assessment. The risk characterizations for aquatic animals differ for triclopyr TEA and triclopyr BEE. When applied at the typical or maximum application rate, triclopyr TEA poses no risk to fish or aquatic invertebrates in streams or ponds under acute and chronic exposure scenarios. Under an accidental spill scenario, there would be low risk to fish and aquatic invertebrates. When applied at the typical rate, triclopyr BEE would pose a moderate risk to fish and a low risk to aquatic invertebrates under acute exposure scenarios, and a high risk to fish and a moderate risk to aquatic invertebrates under a scenario involving an accidental spill into a stream or pond. Triclopyr acid would pose a moderate risk to fish and a high risk to aquatic invertebrates under an accidental spill scenario involving the maximum application rate. Triclopyr BEE would pose a high risk to fish and a moderate risk to aquatic invertebrates under acute exposure scenarios at the maximum rate, and high risk to fish and aquatic invertebrates as a result of an accidental spill into a stream or pond.

Some effects may be anticipated for fish and aquatic invertebrates under certain conditions. While there is a 


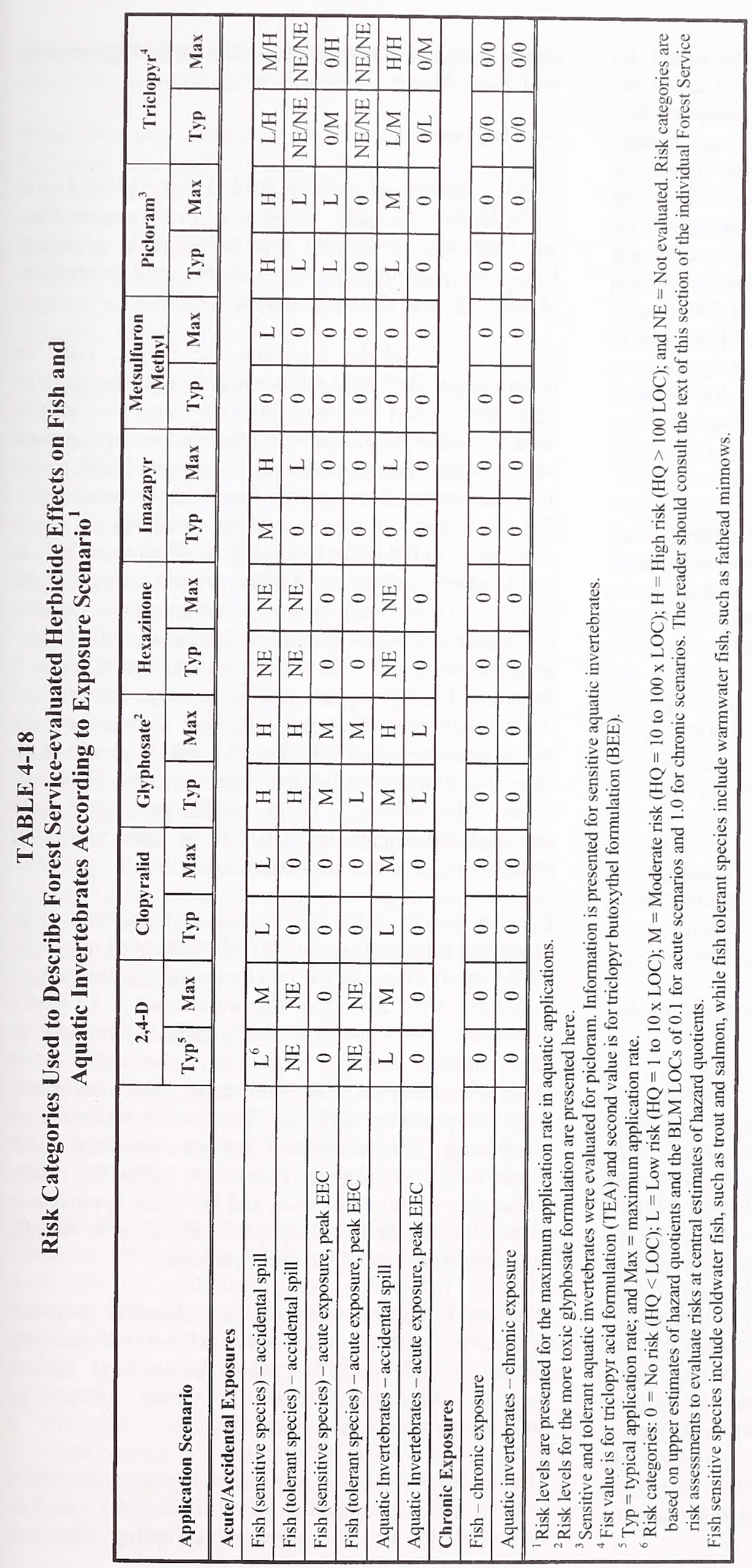


major difference in the potential hazards posed by triclopyr TEA formulations (which are registered for aquatic use; e.g., Garlon $3 \mathrm{~A}^{\circledR}$ ) and triclopyr BEE formulations (which are not registered for aquatic use; e.g., Garlon $4^{\circledR}$ ) to fish, there are no significant differences among species in terms of sensitivity to the various agents. Sublethal effects of Garlon $4^{\circledR}$ on salmonids occur at concentrations between 0.32 and $0.43 \mathrm{mg} / \mathrm{L}$, where fish were lethargic, while behavioral changes to Garlon $3 \mathrm{~A}^{\circledR}$ would occur at $200 \mathrm{mg} / \mathrm{L}$. Subchronic toxicity in fathead minnows (at the embryolarval stages) was observed when the fish were subjected to $140 \mathrm{mg} / \mathrm{L}$ of triclopyr TEA for 28 days (Mayes et al. 1984; Mayes 1990, cited in SERA 2003c). This study found that survival of these minnows was greatly reduced at this toxicity level.

Based on acute lethality, aquatic invertebrates are equally sensitive as fish to the various forms of triclopyr (SERA 2003c). No significant effects have been noted on frog embryos with the application of Garlon $3 \mathrm{~A}^{\circledR}$ and Garlon $4^{\circledR}$. Studies on embryos and tadpoles of three frog species using Garlon $4^{\circledR}$, exposure to $0.6,1.2$, and $4.6 \mathrm{ppm}$ a.e. caused no effect on hatching success, malformations, or subsequent avoidance behavior of embryos, although the two higher concentrations were associated with mortality or immobility in tadpoles (SERA 2003c).

Although triclopyr BEE is more toxic than triclopyr TEA, the risk of triclopyr BEE to aquatic animals is low, as this formulation will rapidly hydrolyze to triclopyr acid, lowering risk to aquatic animals.

\section{Impacts of Other Herbicides Currently Available for Use}

Asulam, atrazine, 2,4-DP, fosamine, mefluidide, and simazine were approved for use in the earlier BLM EISs. Research shows asulam, fosamine, mefluidide, and simazine are practically nontoxic to cold- and warmwater fish (rainbow trout and bluegill sunfish, respectively) while asulam is slightly toxic to aquatic invertebrates (Daphnia magna; Extension Toxicology Network 1993; USEPA 1995b, d; English Nature 2003). Data show that atrazine may cause reductions in phytoplankton, zooplankton, aquatic invertebrate, and fish populations, but in general, is not acutely toxic (USEPA 2003b). 2,4-DP may be toxic to aquatic organisms. The 2,4-DP butoxy ethyl ester (technical) is highly toxic to fish, but practically nontoxic to freshwater invertebrates (Wan et al. 1990). The BLM has not used any of these herbicides, except fosamine (less than 50 acres annually), since 1997.
Impacts of Adjuvants, Degradates, Inert Ingredients, and Tank Mixes

\section{Adjuvants}

Various sources of toxicity data (Muller 1980; Lewis 1991; Dorn et al. 1997; Wong et al. 1997) suggest that, for herbicides with high application rates, adjuvants have the potential to cause acute, and potentially chronic, adverse effects to aquatic species.

Based on GLEAMS modeling for POEA, risks to aquatic organisms were not predicted for the majority of pond and stream scenarios involving exposure to this adjuvant. However, risks were predicted (using the most conservative acute endangered species LOC) for applications at a distance of 0 feet from the water body. This scenario, which essentially assumes a direct application to the water body with no dilution or drift, is highly conservative and highly unlikely under BLM application practices. Risks to special status aquatic organisms in streams and ponds were also predicted for aerial applications of POEA at the maximum rate at a distance of 100 feet from the water body. Therefore, a buffer zone of greater than 100 feet is necessary for aerial applications of POEA at the maximum rate in an area containing special status aquatic species. However, it is unlikely that the BLM would apply glyphosate formulations containing POEA in an area known to contain special status aquatic species.

For non special status species, the only predicted risks to aquatic organisms occurred under scenarios involving POEA applications at the maximum application rate, at a distance of 0 feet from the water body. As stated previously, this scenario is highly unlikely and assumes zero dilution and no drift (i.e., essentially direct application). Furthermore, even under these conditions, risks are predicted only for fish, not invertebrates or amphibians. This assessment indicates that even under conservative conditions (scenarios with the most conservative amount of drift, and herbicide applications at the maximum rate) the potential risks to aquatic receptors from POEA would be minimal.

Because of a lack of physical chemical property information, POEA was not modeled for leaching properties and runoff to water bodies and aquatic receptors. Therefore, there is some uncertainty associated with risk from this exposure.

The adjuvant R-11 is a nonylphenol ethoxylate that is acutely toxic to aquatic life (Stark 2003) and is suspected to be an endocrine-disrupting chemical 
(Bakke 2003). The BLM has decided to suspend the use of R-11 in its herbicide applications.

When selecting adjuvants, BLM land managers must follow all label instructions and abide by any warnings. In general, adjuvants compose a relatively small portion of the volume of herbicide applied. Nonetheless, selection of adjuvants with limited toxicity and low volumes is recommended for applications near aquatic habitats to reduce the potential for the adjuvant to influence the toxicity of the herbicide.

\section{Degradates}

Based on a review of toxicity data for adjuvants, in most cases, predicted risks to aquatic organisms from degradates would likely be less than risks from the active ingredients diquat, diuron, imazapyr, and metsulfuron methyl predicted in ERAs. For some degradates associated with 2,4-D, diuron, fluridone, and triclopyr, selected aquatic species may be more sensitive to the degradate than to the active ingredient. These findings should be considered in the context of herbicide use practices, the concentration of degradate relative to the parent compound, the process of degradate production, and the body of available toxicity data. For instance, in some cases, the increased toxicity of the degradate may be offset by the fact that only a minute amount of the degradate is produced, which would likely disperse rapidly in an active aquatic system. Furthermore, focusing on a single toxicity study may be overly conservative and may not be representative of risks found in the field or in other laboratory studies.

\section{Inert Ingredients}

Based on GLEAMS modeling of a generalized inert compound in a "base case" watershed, concentrations of inert ingredients exceeded concentrations of herbicide active ingredients under all stream and pond scenarios.

In general, greater exposure concentrations of inerts occurred under higher application rates, exceeding 1 $\mathrm{mg} / \mathrm{L}$ for the maximum pond application scenario. These results suggest that inerts associated with the application of herbicides may contribute to acute toxicity to aquatic organisms if they reach the aquatic environment. However, given the lack of specific inert toxicity data, this statement may overestimate their potential toxicity. It is assumed that toxic inerts would not represent a substantial percentage of the herbicide, and that minimal impacts to the environment would result from these inert ingredients.

\section{Tank Mives}

Risk assessment analysis of tank mixes indicates that risks to aquatic organisms vary by tank mix. The risks to fish and aquatic invertebrates associated with applications of tank mixes of bromacil plus sulfometuron methyl, and imazapic plus diflufenzopyr are no greater than those associated with applications of bromacil, imazapic, or diflufenzopyr alone. Risks to aquatic receptors for a tank mix of chlorsulfuron and diuron are greater than those for chlorsulfuron (but not diuron) alone, and risks for a tank mix of sulfometuron methyl and bromacil are greater than for bromacil applied alone.

There is some uncertainty in this evaluation because herbicides in tank mixes may not interact in an additive manner; this may overestimate risk if the interaction is antagonistic, or it may underestimate risk if the interaction is synergistic. In addition, other products may also be included in tank mixes and may contribute to the potential risk.

To reduce the potential for negative impacts to aquatic organisms, BLM land managers must follow all label instructions and abide by any warnings. Labels for both tank mixed products should be thoroughly reviewed, and mixtures with the least potential for negative effects should be selected, particularly when a mixture is applied in a manner that increases the potential for risk to nearby aquatic organisms.

\section{Impacts by Alternative}

Important invasive species that would be treated by the BLM using herbicides include water-thyme and Eurasian watermilfoils, which are found in ponds, lakes, and streams; and perennial pepperweed, saltcedar, knapweed, and thistles, which are found in riparian habitats. These species displace native vegetation and decrease species diversity. Dense concentrations of aquatic plants can lower the concentration of dissolved oxygen in the water and can upset the balance of the fish community by providing too much cover for small fish (Payne and Copes 1986). Invasive riparian plants form monocultures that crowd out more desirable native plant species.

The BLM proposes to treat aquatic and riparian vegetation to improve habitat for fish and aquatic organisms on public lands. However, herbicide treatments can also lead to the harm or even death of fish and aquatic organisms. The following discusses the 
habitat benefits and health risks to fish and aquatic organisms under each alternative.

\section{Alternative A - Continue Present Herbicide Use (No Action Alternative)}

Under the No Action Alternative, the BLM would continue its ongoing vegetation treatment programs in 14 western states, and would be able to use 20 herbicides previously approved under earlier RODs. Herbicide use under the No Action Alternative would impact target and non-target vegetation over an estimated 305,000 acres annually, including approximately 2,250 acres of riparian and aquatic habitat. Herbicides used to manage aquatic and riparian vegetation under this alternative could include select formulations of 2,4-D, glyphosate, and imazapyr, and certain formulations of triclopyr in riparian areas where contact with water could be avoided. The BLM would not be able to use herbicides to treat public lands in Alaska, Nebraska, or Texas under this alternative.

The nature of impacts to fish and aquatic invertebrates (positive and negative) would be similar to those that have occurred in recent years. Negative impacts to fish and aquatic invertebrates associated with herbicide use would be lower than under the other herbicide treatment alternatives (B, D, and E) because far fewer acres would be treated. However, long-term positive impacts to riparian and aquatic vegetation communities and resulting positive impacts on fish and aquatic invertebrates would also be lower under this alternative. These positive long-term impacts to fish and aquatic invertebrates include improvement of riparian and instream habitat, through eradication of aquatic weeds that dominate water systems and the resulting increase in dissolved oxygen content, and the regrowth of native riparian vegetation and increase in shade habitat.

In addition, because the new herbicides proposed in this PEIS (Overdrive ${ }^{\circledR}$, diquat, fluridone, and imazapic) would not be used, risks to fish and aquatic invertebrates would be different under this alternative. Because the BLM would not use the new herbicides, which have low risks to aquatic wildlife, per area risks to fish and aquatic invertebrates from accidental and drift scenarios could be greater than under the other herbicide-use alternatives. Furthermore, fluridone is specifically indicated for aquatic use, whereas none of the other previously-approved herbicides are strictly aquatic herbicides. Diquat and select formulations of 2,4-D would be used in the aquatic vegetation treatment program, both of which have been effective in the control of Eurasian watermilfoil and water-thyme. The other herbicides registered for aquatic use, glyphosate and triclopyr, are not as effective in controlling these species.

Under this alternative, the BLM would be able to continue to use asulam, atrazine, 2,4-DP, fosamine, mefluidide, and simazine on public lands, although these chemicals have not been used, or used sparingly (fosamine) since 1997. These chemicals are not approved for use in riparian and aquatic habitats, except for 2,4-DP, which could be used to treat western brackenfern in riparian habitats. Except for 2,4-DP, these herbicides are practically nontoxic to slightly toxic to freshwater fish.

\section{Alternative B - Expand Herbicide Use and Allow for Use of New Herbicides in 17 Western States (Preferred Alternative)}

The Preferred Alternative would result in the herbicide treatment of approximately 932,000 acres annually across 17 western states, of which about 10,100 acres would consist of aquatic and riparian habitat. The BLM would only be allowed to use 14 previously-approved herbicides, six fewer than under the No Action Alternative, but would also be able to use the four new herbicides evaluated in this PEIS. In addition, the BLM would be able to treat vegetation using herbicides in Alaska, Texas, and Nebraska, although it is anticipated that few or no herbicide treatments would occur in Alaska.

As this alternative proposes to treat the most acres of all the alternatives (more than four times the acreage proposed under the No Action Alternative), it could result in the most extensive impacts to fish and aquatic invertebrates. The potential for acute and chronic toxic effects to fish and other aquatic organisms could be four times greater under this alternative than under the other alternatives, due to the greater acreage that would be considered.

The BLM's ability to use four new chemicals (fluridone and diquat for aquatic applications, and imazapic and Overdrive $^{\circledR}$ for terrestrial applications), could reduce risks to fish and other aquatic organisms. For example, fluridone shows no risks to aquatic organisms at normal application rates and could replace other aquatic herbicides currently used by the BLM on public lands. It appears to be effective in the control of Eurasian watermilfoil and water-thyme, and can be used instead of diquat in states where diquat is not legal for use in aquatic systems, such as California (Bossard et al. 2000). 
Overdrive ${ }^{\circledR}$ and imazapic would primarily be used on rangelands, but could still provide benefits greater than those under the No Action Alternative. Overdrive ${ }^{\circledR}$ would be used to treat thistles and knapweeds, while imazapic could be used to control downy brome. These invasive plant species degrade riparian and rangeland habitats and can lead to shortened fire cycles, followed by soil erosion and sedimentation. Under accidental direct spray and spill and off-site drift scenarios, Overdrive ${ }^{\circledR}$ and imazapic present very low or no risks to fish and aquatic invertebrates, similar to chlorsulfuron, diflufenzopyr, and sulfometuron methyl but lower than the risks associated with other herbicides currently being used. For the surface runoff scenarios that were evaluated, risks to fish and aquatic invertebrates were not predicted for any of the new herbicides, whereas some of the other herbicides do present risk to these organisms under some surface runoff scenarios. Each of the currently available and new herbicides evaluated in this PEIS has different properties (e.g., mode of action), is suggested for different uses, and is most effective/least risky in different scenarios, suggesting that the more herbicides available for use, the easier it is to select one or more that would present the least risk to fish and aquatic invertebrates for specific aquatic applications or terrestrial applications near water bodies.

Under the Preferred Alternative, the BLM would be able to use new herbicides approved in the future under the Preferred Alternative. Use of these herbicides could potentially reduce risks to fish and aquatic organisms associated with herbicide use, particularly if they were less toxic or used in smaller quantities than currently used and proposed herbicides.

\section{Alternative C - No Use of Herbicides}

Under Alternative $\mathrm{C}$, fish and aquatic invertebrates would not be affected by herbicide use; effects would stem from other vegetation treatment methods (see the accompanying PER). Ecosystem benefits resulting from vegetation management could be reduced under this alternative, as there are certain invasive species for which herbicide use is the only effective method of treatment or for which treatment using other methods is impractical due to cost, time, accessibility, or public concerns. For example, rough terrain may not allow treatment by methods requiring terrestrial vehicle and foot access, but these inaccessible areas could potentially be treated using herbicides applied by aircraft. Other treatment methods, such as mechanical methods and fire use, can result in soil disturbance and sedimentation of aquatic bodies, and may not adequately treat the pest plant.
In addition, it is often difficult to eradicate some species, such as aquatic species and those that resprout from rhizomes, by means other than herbicide application. For example, Eurasian watermilfoil and water-thyme form dense mats that crowd out native aquatic plants and degrade fish habitat (Bossard et al. 2000), and in some cases chemical treatments, including the use of 2,4-D, diquat, and fluridone, are more effective than other treatments, such as mechanical harvesters that tend to fragment and spread the weed. This treatment alternative would likely leave many aquatic areas untreated, resulting in continued negative impacts to the aquatic species that are native to these areas.

\section{Alternative D - No Acrial Applications}

Alternative D would allow use of the same herbicides in the same areas as under the Preferred Alternative, and would have similar benefits associated with the increased availability of new and future herbicides. Although this alternative would not allow the use of aerial application methods, thereby reducing the total potential treatment acreage (to 530,000 total acres), there would have little difference between Alternative D and the Preferred Alternative as far as acreage treated in aquatic and riparian habitats. Nearly all $(98 \%)$ of the acres proposed for treatment in aquatic and riparian habitats under the Preferred Alternative would be treated using ground-based methods, and therefore could also be treated under Alternative D. This alternative would substantially reduce the potential for impacts to water bodies as a result of off-site drift from application on upland habitats. Drift is a major route of unintended damage to water bodies and resident fish and aquatic invertebrates, with aerial application the primary cause of off-site drift. Therefore, per area impacts would be much lower under this alternative than under the No Action Alternative and the Preferred Alternative, and would be similar to or less than per area impacts from Alternative E. However, without the use of aerial spraying, large areas of vegetation would remain untreated under Alternative $\mathrm{D}$, which could lead to continued or future degradation of upland habitats to the detriment of nearby streams and other aquatic habitats.

\section{Alternative $\mathbf{E}$ - No Use of Acetolactate Synthase- inhibiting Active Ingredients}

Approximately 466,000 acres would be treated under Alternative $\mathrm{E}$, which is slightly less than the acreage that would be trcated under Alternative D, and less than half of the acreagc that would be treated under the 
Preferred Alternative. In addition, the BLM would not be able to use ALS-inhibiting active ingredients (i.e., chlorsulfuron, imazapic, imazapyr, metsulfuron methyl, and sulfometuron methyl).

Of the herbicides that would be unavailable to the BLM under this alternative, imazapyr is the only one that could be used in riparian and aquatic habitats, where it has been shown to be very effective against saltcedar. Imazapyr poses little risk to fish and aquatic organisms when used at typical application rates. Without imazapyr, the BLM would likely treat larger stands of saltcedar using prescribed fire followed by a foliar application of triclopyr, and smaller stands by cutting the stem and applying triclopyr.

Chlorsulfuron, imazapic, and sulfometuron methyl do not pose risks to fish or aquatic invertebrates. Metsulfuron methyl poses a low risk to aquatic invertebrates in streams under an accidental direct spray scenario involving the maximum application rate (an unlikely scenario). Therefore, disallowing use of these four herbicides would be unlikely to benefit fish and aquatic organisms if they are replaced with herbicides that are more harmful to fish and other aquatic organisms.

Alternative $\mathrm{E}$ incorporates other management practices that would be likely to have positive effects on fish and aquatic invertebrates. In addition, herbicides would not be used in riparian conservation areas, which would protect aquatic species and attendant ecosystem functions in these key habitats.

\section{Mitigation for Herbicide Treatment Impacts}

The following recommended general management practices are designed to reduce potential unintended impacts to non special status fish and aquatic invertebrates from the application of herbicides in the BLM vegetation management program. Mitigation appropriate for special status species is later in this section under Special Status Fish and Other Aquatic Organisms.

- Limit the use of diquat in water bodies that have native fish and aquatic resources.

- Limit the use of terrestrial herbicides (especially diuron) in watersheds with fishbearing streams during periods when fish are in life stages most sensitive to the herbicide(s) use.
- Establish appropriate herbicide-specific buffer zones for water bodies, habitats, and aquatic species of interest (see Table 4-19, Appendix $\mathrm{C}$, Table $\mathrm{C}-16$, and recommendations in individual ERAs).

- Avoid using the adjuvant $\mathrm{R}-11^{\circledR}$ in aquatic environments, and either avoid using glyphosate formulations containing POEA, or seek to use formulations with the least amount of POEA, to reduce risks to aquatic organisms.

- Consider the proximity of application areas to salmonid habitat and the possible effects of herbicides on riparian and aquatic vegetation. Maintain appropriate buffer zones around salmonid-bearing streams (see Appendix C, Table C-16, and recommendations in individual ERAs).

These practices would help minimize impacts to fish, aquatic invertebrates, and aquatic ecosystems on public lands to the extent practical.

\section{Special Status Fish and Other Aquatic Organisms}

\section{Introduction}

As discussed in Chapter 3, public lands in the western U.S. support over 150 species of aquatic animals that have been given a special status based on their rarity or sensitivity. Included are 78 species of fish, 13 mollusks, and 7 species of aquatic arthropods that are federallylisted as threatened or endangered, or are proposed for federal listing. Populations of non-native aquatic species and riparian weeds may alter aquatic habitats, making them less suitable for special status fish and aquatic invertebrates. The Vegetation Treatments on Bureau of Land Management Lands in 17 Western States Programmatic Biological Assessment (USDI BLM $2007 \mathrm{~b}$ ) provides a description of the distribution, life history, and current threats for each federally-listed animal species, as well as species proposed for listing.

\section{Impacts Assessment Methodology}

Beginning in spring 2002, the BLM participated in an Ad Hoc Interagency Team to address the effects of invasive vegetation and noxious weed treatments on humans, plants, and animals. This team consisted of ecologists and toxicologists from the BLM, USEPA, NMFS, and USFWS. 
TABLE 4-19

Buffer Distances to Minimize Risk to Non Special Status Fish and Aquatic Invertebrates from Off-site Drift of BLM-evaluated Herbicides from Broadcast and Aerial Treatments

\begin{tabular}{|c|c|c|c|c|c|c|c|c|c|c|c|}
\hline $\begin{array}{c}\text { Application } \\
\text { Scenario }\end{array}$ & BROM $^{1}$ & CHLR & DICA & DIFLU & DIQT & DIUR & FLUR & IMAZ & OVER & SULF & TEBU \\
\hline \multicolumn{12}{|c|}{ Minimum Buffer Distance (feet) from Fish and Aquatic Invertebrates } \\
\hline Aerial & NA & 0 & NA & NA & NA & NA & NA & 0 & NA & 0 & NA \\
\hline Low boom & 0 & 0 & 0 & 0 & NA & 0 & NA & 0 & 0 & 0 & 0 \\
\hline Aerial & $\mathrm{NA}$ & 0 & $\mathrm{NA}$ & $\mathrm{NA}$ & $\mathrm{NA}$ & $\mathrm{NA}$ & NA & 0 & NA & 0 & NA \\
\hline Low boom & 0 & 0 & 0 & 0 & NA & 100 & NA & 0 & 0 & 0 & 0 \\
\hline High boom & 0 & 0 & 0 & 0 & $\mathrm{NA}$ & 100 & NA & 0 & 0 & 0 & 0 \\
\hline \multicolumn{12}{|c|}{$\begin{array}{l}{ }^{1} \text { BROM }=\text { Bromacil; } \text { CHLR }=\text { Chlorsulfuron; DICA }=\text { Dicamba; DIFLU }=\text { Diflufenzopyr; DIQT }=\text { Diquat; DIUR = Diuron; FLUR = Fluridone; IMAZ = } \\
\text { Imazapic; OVER = Overdrive }{ }^{\circledR} \text { SULFM = Sulfometuron methyl; and TEBU = Tebuthiuron. } \\
\text { NA = Not applicable. } \\
\text { Boom height = The Tier I ground application model allows selection of a low ( } 20 \text { inches }) \text { or a high ( } 50 \text { inches }) \text { boom height. }\end{array}$} \\
\hline
\end{tabular}

In May 2002, the BLM began the process of developing the assessment procedures that would be followed while conducting ERAs. This process involved close coordination with NMFS, the USFWS, and the USEPA; representatives of these agencies participated in weekly telephone calls with the BLM and its contractor who prepared the ERAs. These agencies also provided information they felt was necessary to meet their requirements for consultation under the ESA, and reviewed draft work products prepared by the BLM contractor. In November 2002, the BLM submitted a draft Vegetation Treatments Programmatic EIS Ecological Risk Assessment Protocol to the USEPA, NMFS, and USFWS. Comments from these agencies were used in the development of the final ERA protocol (ENSR 2004). Risk assessments for 10 chemicals were completed in May 2005 (ENSR 2005b-k). Information from the ERAs is included in the BA and in this section, including information on likely risks to special status fish and other aquatic resources, and on SOPs that should be followed to minimize these risks.

The BLM also reviewed the literature and findings from ERAs conducted by the Forest Service to assess the impacts to sensitive fish and aquatic invertebrate species from the use of eight herbicides currently used by the BLM (2,4-D, clopyralid, glyphosate, hexazinone, imazapyr, metsulfuron methyl, picloram, and triclopyr; SERA 2005a). The ERA methods are summarized earlier in this section. Methods used by the BLM are presented in detail in the Vegetation Treatments Programmatic EIS Ecological Risk Assessment Protocol (ENSR 2004) and in Appendix E; methods used by the Forest Service are available at http://www.fs.fed.us/r6/invasiveplant-eis/.

There are potential risks to sensitive fish and aquatic invertebrate species. Although the predicted risks for adverse health effects to individual organisms are the same as those predicted for non special status fish and aquatic invertebrate species, the associated populationand species-level effects would be much greater for many sensitive species because of their limited/fragmented distribution and limited population size. Risks to special status fish and aquatic invertebrate species can be minimized by following certain SOPs, which can be implemented at the local level according to specific conditions (see Table 2-8). These SOPS include the following:

- Survey for special status fish and aquatic invertebrate species before treating an area. Consider effects to special status species when designing herbicide treatment programs.

- Use drift reduction agents to reduce the risk of drift hazard.

- Select herbicide products carefully to minimize additional impacts from degradates, adjuvants, inert ingredients, and tank mixtures.

- Maintain appropriate buffer zones between treatment areas and water bodies with special status fish and aquatic invertebrates.

- Minimize treatments near water bodies during periods when fish and aquatic invertebrates are 
in the life stage most sensitive to the herbicide used.

\section{Summary of Herbicide Effects to Special Status Fish and Aquatic Invertebrates}

The invasion and spread of non-native plant species into aquatic and riparian habitats may affect certain populations of special status fish and aquatic invertebrates. An overview of the ways in which nonnative aquatic and riparian plants may affect aquatic habitats is presented earlier in this section. As discussed in the BA, numerous listed fish and other aquatic species are threatened by the changes in water quality and flow which may result from weed infestations. Salmon, for example, require a high level of dissolved oxygen, which is reduced when aquatic weeds such as Eurasian watermilfoil and water-thyme invade an aquatic system. A decrease in dissolved oxygen associated with the encroachment/excessive growth of vegetation has also been listed as a threat to the Foskett specked dace in south-central Oregon (USFWS 1985) and the unarmored threespine stickleback in southern California (NatureServe Explorer 2001). For species such as these, herbicide treatments to reduce coverage of non-native plant species in aquatic and riparian habitats would likely improve habitat over the long term.

Numerous special status aquatic animals, however, are most threatened by changes in water levels and quality associated with development, upslope land use practices, and groundwater pumping, and the expansion of non-native fish populations. For most of the aquatic animals discussed in the BA, invasions of non-native plant species into riparian and aquatic habitats were not listed as threats to the species' survival. For these animals, health risks and increased inputs of chemicals into the water associated with herbicide spraying could outweigh any habitat improvements resulting from minimized weed infestations. In addition, some herbicide treatments could have short-term adverse effects on special status fish and aquatic invertebrates by killing non-target native vegetation and reducing the overall cover of riparian vegetation that regulates water temperature through shading. It is also likely, however, that the weed infestations (if present) in or near the aquatic habitats that support some of these species do not currently require herbicide treatments under the BLM's vegetation management programs.

A more conservative LOC of 0.05 was used to determine risks to special status fish and aquatic invertebrates. The potential effects of herbicides on special status aquatic animals could be greater than the effects on non special status fish and other aquatic organisms (an LOC of 0.1 was used for non special status species), as shown in Table 4-20 for BLMevaluated herbicides. Aquatic herbicides with the greatest likelihood of impacting special status fish and aquatic invertebrates during a normal application to an aquatic habitat include diquat and the more toxic formulation of glyphosate. Normal aquatic applications of 2,4-D and imazapyr would not pose a risk to special status fish or aquatic invertebrates.

Terrestrial herbicides with the greatest likelihood of impacting special status aquatic animals as a result of a spill, drift, accidental direct spray into an aquatic habitat, or surface runoff are diuron, picloram, and the more toxic formulation of glyphosate. According to ERAs, there would be no risks to fish or aquatic invertebrates associated with chlorsulfuron, dicamba, diflufenzopyr, imazapic, Overdrive ${ }^{\circledR}$, or sulfometuron methyl.

\section{Alternative A - Continue Present Herbicide Use (No Action Alternative)}

Under this alternative, approximately 2,300 acres of aquatic and riparian habitats and 302,700 acres of upland habitats on public lands would be treated with herbicides annually. Considering acreage alone, it is likely that special status fish and aquatic invertebrates would be exposed to herbicides less under this alternative than under the other herbicide-use alternatives. Adverse health risks associated with herbicide exposure should be less extensive, as well. Risks to special status species would also be lower, although mitigation would be required to protect these species and their habitat from harm under all alternatives, which should minimize differences in risk to special status species.

Control of weed infestations in aquatic and riparian areas would be less extensive under the No Action Alternative than under the other herbicide-use alternatives. Therefore, the degree of benefit to special status aquatic animals, particularly species that are currently threatened by infestations of non-native plants, would likely be lower than under the other herbicideuse alternatives. However, short-term adverse impacts to habitats that support special status aquatic animals (such as increased water temperatures) would be lower as well. The degree of benefits versus impacts to these habitats from treatments would largely depend on where the treatments occurred. 
Under this alternative, only those herbicides currently used by the BLM would be used to treat vegetation. 2,4$\mathrm{D}$, glyphosate, imazapyr, and triclopyr acid would be used in aquatic and riparian habitats. Certain herbicides that are not registered for aquatic use (i.e., dicamba and clopyralid) could also be used in riparian areas, provided the herbicide did not contact the water. Of these herbicides, only glyphosate is likely to pose toxicological risks to special status fish and aquatic invertebrates during a normal application, but only if the more toxic formulation is used, or the less toxic formulation is applied at the maximum application rate. Although risks associated with an accidental spill would be greater, continuing use of these herbicides to treat riparian and aquatic vegetation should continue to pose a low risk to special status aquatic animals.

\section{Alternative B - Expand Herbicide Use and Allow for Use of New Herbicides in 17 Western States (Preferred Alternative)}

Under the Preferred Alternative, approximately 10,000 acres of aquatic and riparian habitats and 922,000 acres of upland habitats on public lands would be treated with herbicides annually. Based on acreage, this alternative would entail the greatest amount of herbicide exposure to special status fish and aquatic invertebrates. Although a greater amount of herbicides would be used in aquatic and riparian habitats than under the other alternatives, risks to aquatic animals from their normal use would remain minimal, provided glyphosate was only applied at typical application rates, and only the less toxic formulation was used. However, since more terrestrial herbicides would be used under this alternative as well, risks associated with accidental spill of those herbicides in or near a water body, and accidental direct spray into a water body, would also be greater than under the other alternatives.

The most extensive control of weed infestations in aquatic and riparian areas would occur under this alternative. Therefore, the degree of benefit to special status aquatic animals over the long term through habitat improvements would potentially be greater than under the other alternatives. As under the other alternatives, the degree of benefits versus impacts to these habitats from treatments would largely depend on where the treatments occurred.

Under the Preferred Alternative, the BLM would be able to use 14 of the 20 currently-approved herbicides that are currently available for use under the No Action Alternative, as well as four new herbicides and other new herbicides that become available in the future. One of the two new aquatic herbicides that could be used under this alternative, diquat, would pose low to high risks to fish, and moderate to high risks to aquatic invertebrates during a normal application, depending on the application rate and type of aquatic habitat. Fluridone would pose no to moderate risks to fish and aquatic invertebrates, depending on the application rate and type of aquatic habitat. Use of diquat or fluridone in place of safer aquatic herbicides under the Preferred Alternative would likely increase the incidence of adverse health effects to aquatic organisms per area treated, relative to the No Action Alternative. Dicamba, Overdrive $^{\circledR}$, and imazapic pose no risk to fish or aquatic invertebrates. Therefore, these herbicides would provide the BLM with increased safe options for treating riparian areas under the Preferred Alternative. Herbicides that become available in the future could allow the BLM even more flexibility to develop effective treatment programs in and near aquatic habitats, while minimizing risks to special status aquatic organisms.

\section{Alternative $C-N o$ Use of Herbicides}

Under this alternative, no public lands would be treated with herbicides. Therefore, there would be no impacts to special status aquatic animals as a result of herbicide exposure during vegetation treatments. The BLM would likely be less effective at controlling weed infestations than under the other alternatives, so there would be fewer benefits to special status fish and aquatic invertebrate habitat that is degraded by non-native species. In addition, if other treatment methods were used to control weeds in riparian areas in lieu of herbicides, the disturbance to habitat could be greater. Mechanical methods and containment using domestic animals, for example, can result in greater sedimentation into aquatic habitats and more extensive removal of riparian vegetation, as compared to herbicide treatments, which would affect water quality.

\section{Alternative D - No Aerial Applications}

Under this alternative, approximately 530,000 acres would be treated with herbicides annually, more than under all other altcrnatives except the Preferred Alternative. However, the amount of riparian and aquatic habitat treated would be similar to the amount that would be treated under the Preferred Alternative, since ground-based methods would be used to apply herbicides to $98 \%$ of the treated acreage in these habitats. Therefore, the risks to aquatic animals from exposure to herbicides would potentially be somewhat lower, but not substantially different, than under the 
Preferred Alternative. It is likely that riparian and aquatic habitats that support special status fish and aquatic invertebrates would be exposed to less off-site drift than under the No Action and Preferred alternatives, since aerial spraying would not occur in adjacent upland areas.

The amount of long-term benefit, as well as the shortterm adverse impacts, to riparian and aquatic habitats associated with herbicide applications would be much the same as under the Preferred Alternative. In addition, the herbicides available for use by the BLM would be the same as those discussed for the Preferred Alternative. The risks associated with using diquat and fluridone, and the benefits associated with flexibility in selecting herbicides, and in using new herbicides that become available in the future, would be the same as those discussed under the Preferred Alternative.

\section{Alternative $\mathbb{E}$ - No Use of Acetolactate Synthase- Inhibiting Active Ingredients}

Under this alternative, approximately 466,000 acres would be treated with herbicides annually, more than under the No Action alternative, but fewer than under the other herbicide-use alternatives. In addition, herbicide use in riparian and aquatic habitats would be minimized by prohibiting its use in riparian conservation areas and limiting the use of broadcast applications. These management practices would help minimize the risk that special status fish and aquatic invertebrates would be exposed to herbicides. Risks to special status aquatic animals from herbicide exposure would be lower than under the Preferred Alternative and Alternative $\mathrm{C}$, and in some areas would be lower than under No Action Alternative.

The limited number of acres treated and the additional restrictions on herbicide treatments in and near aquatic habitats would limit some opportunities for using herbicides to make long-term habitat improvements. Accordingly, the associated short-term adverse impacts to habitats that support aquatic animals would be minimized in certain areas as well. The degree of effect to special status fish and aquatic invertebrates would depend on where herbicide applications were allowed to occur, and whether the BLM would use manual treatment methods, or a different type of vegetation treatment, in place of broadcast treatments in habitats that support special status species.

Under this alternative, the BLM would not be able to use chlorsulfuron, imazapic, imazapyr, metsulfuron methyl, sulfometuron methyl, or any other ALS- inhibiting herbicides that are made available in the future. Of these, imazapyr is registered for use in riparian areas, and the other four herbicides can be used in riparian areas, providing no herbicide is allowed to enter adjacent water bodies. None of these herbicides pose toxicity risks to spccial status fish or aquatic invertebrates during a direct spray into an aquatic habitat, even at the maximum application rate. Eliminating the use of ALS-inhibitors would reduce the BLM's choices when developing treatment programs, and could result in greater risks to special status aquatic animals if other more toxic herbicides were used in their place.

\section{Mitigation for Herbicide Treatment Impacts}

The following mitigation is recommended to reduce the likelihood of impacts to special status fish and aquatic invertebrates from herbicide applications. This mitigation should be implemented in addition to the SOPs and mitigation designed to protect aquatic animals presented earlier in this section.

- Implement all conservation measures for aquatic animals presented in the Vegetation Treatments on Bureau of Land Management Lands in 17 Western States Programmatic Biological Assessment (USDI BLM 2007b).

- Establish appropriate herbicide-specific buffer zones for water bodies that are habitats for fish or other aquatic species of interest as shown in Table 4-21.

- At the local level, consider effects to special status fish and other aquatic organisms when designing treatment programs.

These practices would help minimize impacts to fish, aquatic invertebrates, and aquatic ecosystems on public lands to the extent practical.

\section{Wildlife Resources}

\section{Introduction}

The nearly 261 million acres of public lands sustain an abundance and diversity of wildlife resources. Public lands provide a permanent or seasonal home for more than 2,400 species of amphibians, reptiles, birds, and mammals (USDI BLM 2006c). An important activity of the BLM is managing vegetation to improve wildlife habitat-areas where basic needs such as food, 


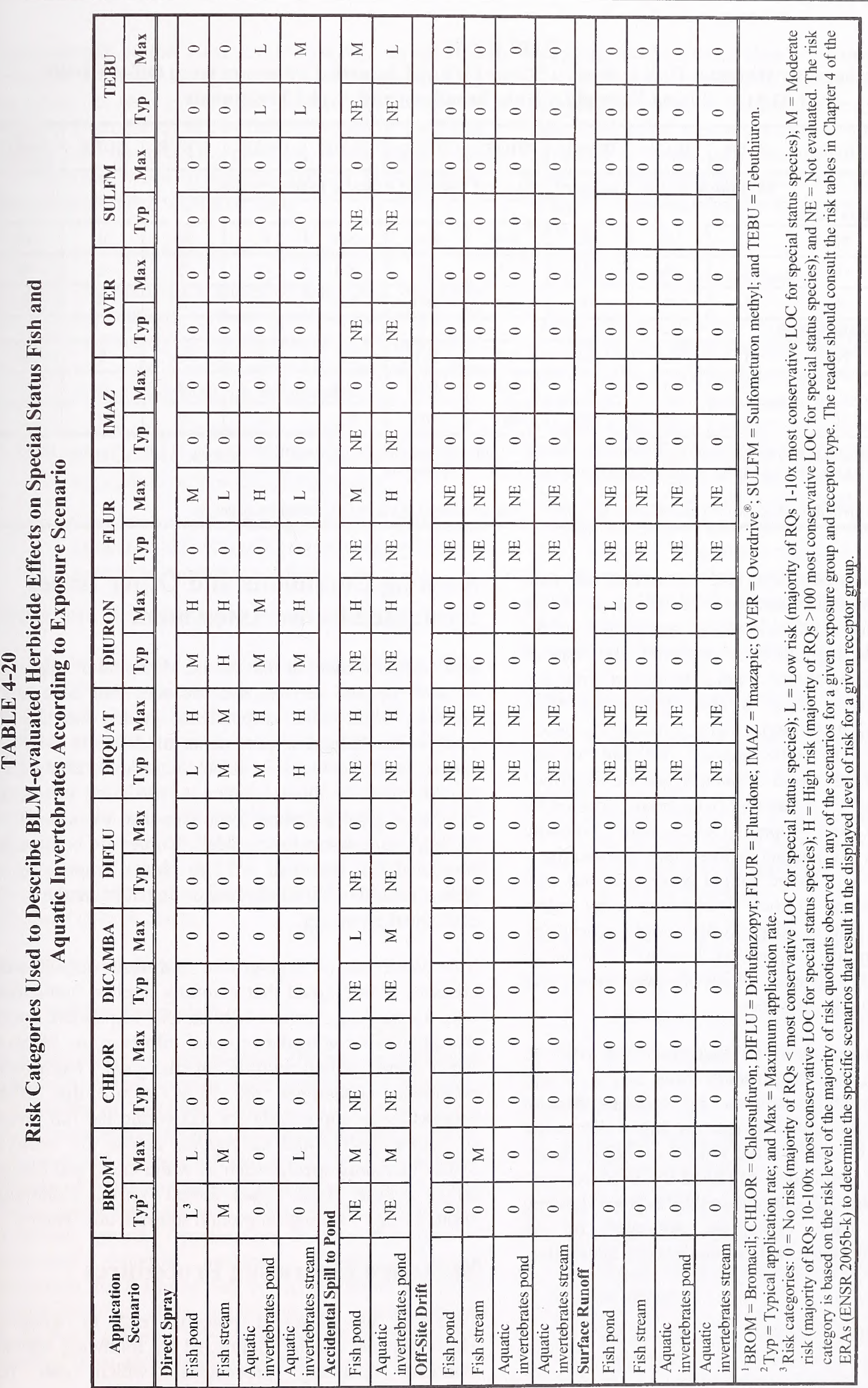


TABLE 4-21

Buffer Distances to Minimize Risk to Special Status Fish and Aquatic Organisms from Off-site Drift of BLM-evaluated Herbicides from Broadcast and Aerial Treatments

\begin{tabular}{|c|c|c|c|c|c|c|c|c|c|c|c|}
\hline $\begin{array}{c}\text { Application } \\
\text { Scenario }\end{array}$ & BROM $^{1}$ & CHLR & DICA & DIFLU & DIQT & DIUR & FLUR & IMAZ & OVER & SULF & TEBU \\
\hline \multicolumn{12}{|c|}{ Minimum Buffer Distance (feet) from Fish and Aquatic Invertebrates } \\
\hline \multicolumn{12}{|c|}{ Typical Application Rate } \\
\hline Aerial & NA & 0 & NA & NA & NA & NA & NA & 0 & NA & 0 & NA \\
\hline Low boom & 0 & 0 & 0 & 0 & NA & 0 & NA & 0 & 0 & 0 & 0 \\
\hline High boom & 0 & 0 & 0 & 0 & NA & 100 & NA & 0 & 0 & 0 & 0 \\
\hline \multicolumn{12}{|c|}{ Maximum Application Rate } \\
\hline Aerial & NA & 0 & NA & NA & NA & NA & NA & 0 & NA & 0 & NA \\
\hline Low boom & 0 & 0 & 0 & 0 & NA & 100 & NA & 0 & 0 & 0 & 0 \\
\hline High boom & 0 & 0 & 0 & 0 & NA & 900 & NA & 0 & 0 & 0 & 0 \\
\hline
\end{tabular}

shelter, water, reproduction, and movement are met. Plants are an important component of habitat, providing food and cover for wildlife. Food is a source of nutrients and energy, while good cover prevents the loss of energy by providing shelter from extremes in wind and temperature. Cover also affords protection from predators. The eight ecoregions encompassed by public land in the western states support different wildlife species and habitats; these characteristics are described further in Chapter 3. Areas that have been impacted by invasive plants may support fewer native wildlife species in areas with intact native plant communities. Invasive plants can change habitat conditions and vital ecosystem functions in such a way that some native species are not able to adapt to the altered ecosystem. These areas may also support an increased number of non-native wildlife species, which compete with native wildlife for available resources.

This section begins with an assessment of risks to general wildlife, including insects, birds, and small and large mammals, and is followed by an assessment of risks to special status wildlife species. Initial discussion in this section focuses on the risks to wildlife health from the use of herbicides, followed by an assessment of the risks and benefits to wildlife from treating vegetation in each ecoregion, followed by an assessment of impacts to wildlife under each alternative.

\section{Scoping Comments and Other Issues Evaluated in the Assessment}

Some respondents felt that the BLM should manage for biodiversity and identify specific sites that have high wildlife value. Other respondents wanted the EIS to address the habitat requirements of different wildlife species and the ways in which vegetation treatments would influence these habitats. Considering treatment effects to ground-nesting birds was also mentioned as an important issue to consider. Numerous comments promoted the idea that wildlife habitat improvement efforts should be directed at restoring habitat and natural ecological processes.

The protection of sage-grouse and their habitat was advised. It was noted that carefully applied herbicides may improve sage-grouse habitat. One respondent noted that aggressive saltcedar removal efforts in the Mojave River have killed wildlife in the past. Numerous comments encouraged the BLM to use this PEIS process as an opportunity for recovering the full range of native species and ecosystems across the western states, including species such as white-tailed and blacktailed prairie dogs, black-footed ferret, Columbia spotted frog, Washington ground squirrel, and wolves.

\section{Standard Operating Procedures}

Herbicide use poses a potential risk to wildlife. However, risk can be minimized by following certain standard operating procedures, which can be 
implemented at the local level according to specific conditions. The following general procedures, which are designed to reduce potential unintended impacts to wildlife from the application of herbicides in the BLM vegetation management program, were taken into consideration when evaluating risks to wildlife from herbicide use (also see Table 2-8):

- Use herbicides of low toxicity to wildlife.

- Use spot applications or low-boom broadcast applications, where possible, to limit the probability of contaminating non-target food and water sources, especially vegetation over areas larger than the treatment area.

- Conduct pre-treatment surveys for sensitive habitat and special status species within or adjacent to proposed treatment areas.

- Use timing restrictions (e.g., do not treat during critical wildlife breeding or staging periods) to minimize impacts to wildlife.

\section{Impacts Assessment Methodology}

The BLM reviewed the literature and findings from Ecological Risk Assessments (ERAs) conducted by the BLM and Forest Service to assess the impacts to wildlife from the use of herbicides (ENSR 2005b-k; USDA Forest Service 2005). The methods presented here provide a brief overview of the ERA process to determine the risks of herbicide applications to wildlife species. The ERA methods are presented in detail in Appendix C and in the Vegetation Treatments Programmatic EIS Ecological Risk Assessment Protocol (ENSR 2004).

\section{BLM Methodology}

\section{Problem Formulation}

Wildlife receptors, representing different categories of terrestrial animal species, were evaluated to determine the effects of herbicide exposure in terms of certain assessment endpoints and associated measures of effect. The essential biological requirements for each of these groups of organisms are the endpoints to be protected from herbicide exposure. These endpoints include mortality, growth, reproduction, or other ecologicallyimportant sublethal processes. These assessment endpoints, for the most part, reflect the direct effects of an herbicide on these organisms, but indirect effects were also considered. Measures of effect are measurable changes in an attribute of an assessment endpoint (or its surrogate, as discussed below) in response to a stressor to which it is exposed (USEPA 1998a). For the screening-level ERA, the quantitative measures of effect associated with the assessment endpoints generally consisted of acute and chronic toxicity data (from pesticide registration documents and from the available scientific literature) for the most appropriate surrogate species.

\section{Exposure Characterization}

The BLM uses herbicides in a variety of programs (e.g., maintenance of rangeland and recreational sites) with several different application methods (e.g., application by aircraft, vehicle, backpack). In order to assess the potential ecological impacts of these herbicide uses to terrestrial wildlife, the following exposure scenarios and receptor types were considered as routes of the most plausible acute and chronic (short- and long-term) impacts that would occur under a variety of conditions. These receptors represent a range of wildlife receptors that could be extrapolated to the typical wildlife species found on public lands. These receptors also represent different feeding guilds (herbivore, omnivore, and carnivore). The exposure scenarios include:

Direct spray of terrestrial wildlife:

- Small mammal - 100\% absorption

- Pollinating insect $-100 \%$ absorption

- Small mammal - $1^{\text {st }}$ order dermal absorption (absorption occurs over 24 hours, taking into consideration the potential for some herbicide to not be absorbed)

Indirect contact with foliage after direct spray:

- Small mammal - 100\% absorption

- Pollinating insect - $100 \%$ absorption

- Small mammal $-1^{\text {st }}$ order dermal absorption

Ingestion of food items contaminated by direct spray:

- Small mammalian herbivore - acute and chronic exposure

- Large mammalian herbivore - acute and chronic exposure

- Small avian insectivore - acute and chronic exposure

- Large avian herbivore - acute and chronic exposure 
- Large mammalian carnivore - acute and chronic exposure

Exposure scenarios involving off-site drift, surface runoff, and wind erosion were not modeled for terrestrial wildlife because the direct spray scenarios were more conservative than scenarios involving wind erosion or runoff. Risk from consumption of food would be much greater if the food item was directly sprayed by an herbicide than if the herbicide drifted or was carried by water onto the food item.

\section{Effects Characterization}

In the majority of cases, toxicological data do not exist for specific wildlife species of concern. Consequently, toxicological data for surrogate wildlife receptors, obtained from a literature review, were evaluated and used to establish quantitative benchmarks (i.e., toxicity reference values for the ecological species of concern). Data from acceptable studies were used to compile statistical endpoints into a matrix for each chemical and for each receptor. Data were further subdivided into acute adverse-effect-levels, chronic adverse-effectlevels, and no-observed-adverse-effect-levels. For each chemical, receptor, and route of exposure, the lowest reported herbicide level resulting in an identified acute statistical endpoint was selected as the acute TRV. Chronic TRVs, based on longer exposure periods and associated endpoints such as growth and reproduction, were developed, when possible, to provide supplementary data to the risk assessment. Before the chronic NOAEL TRV was determined, a chronic lowest-observed-adverse-effect-level was identified, which was the lowest herbicide level that was found to cause significant adverse effects in a chronic study. Once a LOAEL was selected, the chronic NOAEL TRV was established as the highest NOAEL value that was less than both the LOAEL and the acute TRV. Once developed, TRVs were compared with predicted environmental concentrations (estimated exposure concentrations of the herbicide to evaluate the likelihood of adverse effects to ecological receptor).

\section{Risk Characterization}

In order to address potential risks to wildlife receptors from exposure to herbicides, RQs were calculated by dividing the estimated exposure concentration for each of the previously described scenarios by the appropriate herbicide-specific TRV. To facilitate the translation of RQs into readily applicable estimates of risk, the calculated RQs were compared to levels of concern defined by the USEPA for screening the potential risk of pesticides. Distinct USEPA LOCs were used for acute and chronic risks, and for potential increased risks to special status species. The ecological risk implications of various exposure estimates can be readily determined by noting which $R Q s$ exceed the corresponding LOCs.

\section{Forest Service Methodology}

The Forest Service risk assessment methodology was similar to that used by the BLM (see SERA [2001a] for a complete description of the current methodology). The steps involved in the Forest Service risk assessments were classified as hazard identification (analogous to BLM problem formulation), exposure assessment, dose response assessment (analogous to BLM effects characterization), and risk characterization.

Hazard identification involved the review of existing data with a focus on the dose-response and doseseverity relationships to determine the effect levels (e.g., NOAEL, LOAEL) and assessment endpoints (e.g., acute toxicity, subchronic or chronic systemic toxic effects, reproductive effects) that are most relevant for the herbicide risk assessments.

In the exposure assessment phase, the Forest Service developed several general and accidental/incidental exposure scenarios: direct spray, ingestion of contaminated media (via grooming activities, vegetation, prey species, or water), and indirect contact with contaminated vegetation. Actual exposure scenarios and receptors depended on the available herbicide toxicity data. The Forest Service also used an allometric approach to model exposure for different sizes of animals; however, exposure assessments were only as specific as the available toxicity data. For example, if the hazard identification process suggested that large mammals would be more sensitive than small mammals, or birds more sensitive than mammals, then exposure levels were modeled separately. Exposures also varied depending on the application method and the chemical and toxicological properties of the given herbicide.

Dose response assessment described the degree or severity of risk as a function of dose. A dose was derived - usually from a series of experimental dosesthat was associated with a negligible, or at least a defined, level of risk. These dose levels are generally referred to as reference values, or more specifically as "reference doses" (RfDs). To derive the reference value, the experimental threshold was divided by an uncertainty factor used to account for discrepancies 
between expcrimental exposure conditions and the actual conditions the receptor might experience during Forest Service exposure. Often, reference values are standard across government agencies.

The risk characterization process then compared the exposure assessment to the dose response assessment to develop hazard quotients for risk determination. HQs are analogous to the RQs developed in the BLM risk assessments; they are calculated as the projected level of exposure (i.e., EEC) divided by an index of an acceptable level of exposure or otherwise defined level of exposure (e.g., a NOAEL divided by an uncertainty factor). In addition, the herbicides were all compared based on their selectivity, potency, persistence in the environment, and ability to move off site.

\section{Summary of Herbicide Impacts}

While some field studies suggest that appropriate herbicide use is not likely to directly affect wildlife (e.g., Cole et al. 1997, Sullivan et al. 1998), there is the potential for herbicides (used properly or improperly) to harm wildlife individuals, populations, or species (USDA Forest Service 2005). Possible adverse direct effects to individual animals include death, damage to vital organs, change in body weight, decrease in healthy offspring, and increased susceptibility to predation. Adverse indirect effects include reduction in plant species diversity and consequent availability of preferred food, habitat, and breeding areas; decrease in wildlife population densities within the first year following application as a result of limited reproduction; habitat and range disruption (as wildlife may avoid sprayed areas for several years following treatment), resulting in changes to territorial boundaries and breeding and nesting behaviors; and increase in predation of small mammals due to loss of ground cover (USEPA 1998b).

In the absence of prominent direct effects, it can be said that the main risk to wildlife from herbicide use is habitat modification. In forests, for example, herbicide use may result in minor and temporary effects on plant communities and wildlife habitats following single applications to young stands or stands following harvest, including some beneficial effects, but it usually results in a significant drop in forage the season following treatment. However, forage species and wildlife use of treated areas are likely to recover two to several years after treatment (Escholz et al. 1996; McNabb 1997; Miller and Miller 2004).
The extent of direct and indirect impacts to wildlife would vary by the effectiveness of herbicide treatments in controlling target plants and promoting the growth of native vegetation, as well as by the extent and method of treatment (e.g., aerial vs. ground) and chemical used (e.g., toxic vs. non-toxic; selective vs. non-selective), the physical features of the terrain (e.g., soil type, slope), and weather conditions (e.g., wind speed) at the time of application. The impacts of herbicide use on wildlife would depend directly on the sensitivity of each species to the particular herbicides used, the pathway by which the individual animal was exposed to the herbicide, and indirectly on the degree to which a species or individual was positively or negatively affected by changes in habitat. Species that reside in an area year-round and have a small home range (e.g., insects, small mammals, territorial birds), would have a greater chance of being directly adversely impacted if their home range was partially or completely sprayed because they would have greater exposure to herbicides-either via direct contact upon application or indirect contact as a result of touching or ingesting treated vegetation.

In addition, species feeding on animals that have been exposed to high levels of herbicide would be more likely to be impacted, particularly if the herbicide bioaccumulates in their systems. Although these scenarios were not modeled, wildlife could also experience greater impacts in systems where herbicide transport is more likely, such as areas where herbicides are aerially sprayed, dry areas with high winds, or areas where rainfall is high and soils are porous. Wildlife that inhabit subsurface areas (e.g., insects, burrowing mammals) may also be at higher risk if soils are nonporous and herbicides have high soil-residence times. The degree of interception by vegetation, which depends on site and application characteristics, would also affect direct spray impacts. The impacts of herbicide use on wildlife would primarily be site- and application-specific, and as such, site assessments would have to be performed at the field level, using available impact information, to determine an herbicideuse strategy that would minimize impacts to wildlife, particularly in habitat that supports special status species.

The BLM and Forest Service risk assessments suggested several common impacts of herbicides to wildlife. Birds or mammals that eat grass that has been sprayed with herbicides have relatively greater risk for harm than animals that eat other vegetation or seeds, because herbicide residue is higher on grass (Fletcher et 
al. 1994; Pfleeger et al. 1996). This phenomenon is apparent with large mammalian herbivores in the BLM risk assessments. Grass foragers might include deer, elk, rabbits and hares, chukar, quail, and geese (USDA Forest Service 2005). However, harmful doses of herbicide are not likely unless the animal forages exclusively within the treatment area for an entire day. For example, studies of white-tailed deer have reported an average home range of about 400 acres (Fowler 2005), which would be about the size of the typical application area (two-thirds of herbicide treatments would be 400 acres or less), and less than half the size of a large application area of 1,000 acres (20\% of treatments would be 1,000 acres or larger). Scenarios of chronic consumption of contaminated vegetation would also be unlikely if vegetation were to show signs of damage (these signs may not occur immediately after spraying). In addition, insect foragers (e.g., bats, shrews, and numerous bird species) would be at risk from herbicide applications because of the small size of insects and their correspondingly large surface area.

\section{Impacts of BLM-Evaluated Herbicides}

Risks from direct spray and spills, indirect contact with foliage after direct spray, and ingestion of food items contaminated by direct spray are generally low or nonexistent for terrestrial fauna, with a few exceptions, particularly for mammalian herbivores and pollinating insects. Specific risks to wildlife from each individual herbicide are presented below. See the tables and figures in Section 4 of the ERAs for each herbicide for risk information on ecological receptor groups according to herbicide application method. Also, see Table 4-22, and Appendix C, for a summary of the typical degree of risk each of the BLM herbicides poses to different receptor categories under different routes of exposure.

\section{Bromacil}

Direct spray of a pollinating insect poses a low risk for scenarios involving the typical and maximum application rates. This is a conservative scenario that assumes the insect absorbs $100 \%$ of the herbicide with no degradation or limitations to uptake. The ERAs predicted low acute and chronic risks to small mammalian herbivores for scenarios involving ingestion of food sprayed at the maximum application rate. No acute risk, and low chronic risk, was predicted for large mammalian herbivores ingesting vegetation sprayed at the typical application rate, and moderate acute and chronic risks were predicted for similar exposure scenarios involving the maximum application rate.
Therefore, direct spray of bromacil at the maximum application rate poses a risk to pollinating insects and large mammalian herbivores, as well as to small mammalian herbivores and large mammalian carnivores. Chronic risks to large mammalian herbivores are moderate, suggesting that caution is needed when applying this herbicide in forage areas, although it is unlikely that large mammals would obtain food solely within the application area, as assumed by ERAs. Because bromacil is a non-selective herbicide and is registered for non-cropland uses, it is not likely to be used in rangelands or wildlife grazing areas where some vegetative cover is desired; this would limit its exposure to large mammalian herbivores. If typically foraged rangeland plants were protected from off-site transport of bromacil, for example by using appropriate buffer zones (see Vegetation section in this chapter), then large mammalian herbivores would not likely be at risk from off-site drift or surface runoff of bromacil (these scenarios were not modeled). Risks to birds and small mammals under any modeled scenario are unlikely. Use of bromacil in spot applications or over small areas would be unlikely to adversely impact wildlife populations and should have positive effects through beneficial habitat modification.

\section{Chlorsulfuron}

Risk quotients for terrestrial wildlife were all below the most conservative LOC of 0.1 (acute endangered species), indicating that direct spray of chlorsulfuron is not likely to pose a risk to terrestrial animals. Therefore, use of chlorsulfuron would primarily affect wildlife through habitat modification. Its use in forested rangeland and other wildlife habitat areas could benefit wildlife over the long term by controlling invasive plant species and promoting the establishment and growth of native plant species that may provide more suitable wildlife habitat and forage.

\section{Dicamba}

Overdrive $^{\circledR}$ is a formulation of dicamba and diflufenzopyr. An analysis of risks to wildlife was conducted for dicamba during preparation of the Overdrive ${ }^{\circledR}$ ERA. However, an ERA report for dicamba was not done by the BLM as part of this PEIS, although some information on dicamba is included in the Overdrive $^{\circledR}$ ERA. The Forest Service conducted an ERA for dicamba, which the reader is encouraged to review (available at http://www.fs.fed.us/foresthealth/pesticide/risk.shtml). 


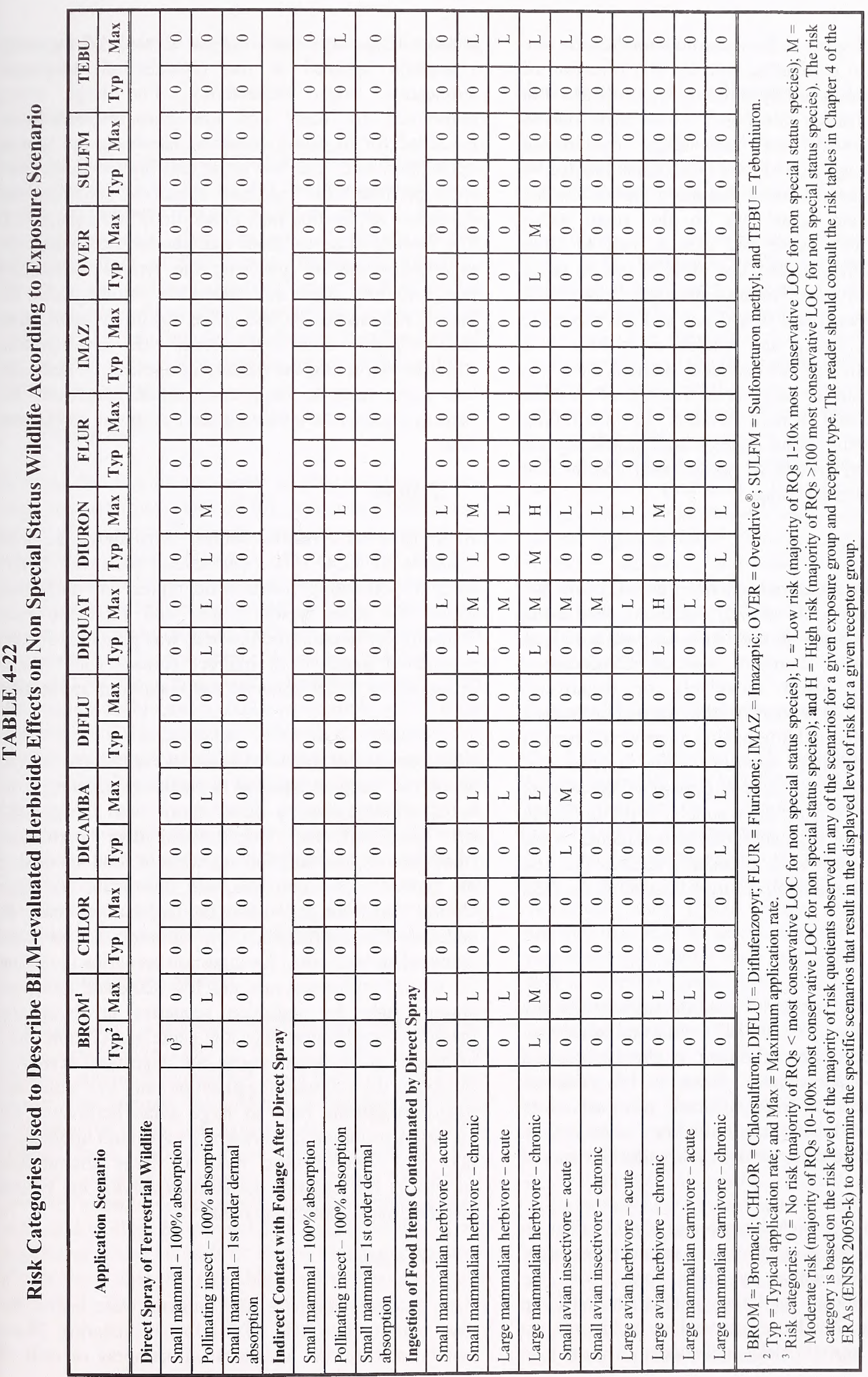


Accidental direct spray at the maximum application rate poses low risk to pollinating insects. The ingestion of food items contaminated by direct spray of dicamba at the typical application rate poses a low acute risk to small avian insectivores and large mammalian carnivores. The ingestion of food items contaminated by direct spray of dicamba at the maximum application rate poses a moderate acute risk to the small avian insectivores, a low acute and chronic risk to large mammalian herbivores, and low chronic risk to small mammalian herbivores. Because dicamba is proposed for use in rangelands and forestlands and has moderate residual activity, insects and wildlife could be at risk from the application of this chemical, particularly if it is sprayed throughout the range area. The use of dicamba in rangeland could benefit wildlife by controlling unpalatable invasive plant species and promoting the establishment and growth of native plant species that may be more suited for forage.

\section{Diflufenzopyr}

Risk quotients for terrestrial wildlife were all below the most conservative LOC of 0.1 , indicating that direct spray of diflufenzopyr is not likely to pose a risk to terrestrial animals. Therefore, use of diflufenzopyr would primarily affect (positively or negatively) wildlife through habitat modification. Its use in forested rangeland and other wildlife habitat areas would benefit wildlife by controlling invasive plant species and promoting the establishment and growth of native plant species that may provide more suitable wildlife habitat and forage. Loss of vegetation due to treatments would impact wildlife short-term, especially species that use knapweeds, thistles, and other target vegetation for food and cover.

\section{Diquat}

Risk quotients for terrestrial wildlife were above the most conservative LOC of 0.1 for several scenarios. Accidental direct spray of diquat at the typical and maximum application rates poses a low risk to pollinating insects. No risks to small mammals were predicted due to direct spray or indirect contact with foliage. Both of these scenarios conservatively assumed $100 \%$ absorption.

Risk assessments predicted acute and chronic risks to nearly all of the receptor types as a result of ingesting food items contaminated by direct spray, with the greatest risk predicted for large mammalian and large avian herbivores. For large mammalian herbivores, no acute and low chronic risks and moderate acute and chronic risks were predicted as a result of ingesting vegetation sprayed at the typical and maximum application rates, respectively. For large avian herbivores, no acute and low chronic risks were predicted for ingestion scenarios involving the typical application rate, and low acute and high chronic risks were predicted for ingestion scenarios involving the maximum application rate. In addition, ERAs predicted: low chronic risks to small mammalian herbivores for ingestion scenarios involving the typical application rate, and low acute and moderate chronic risks for ingestion scenarios involving the maximum application rate; moderate acute and chronic risks for ingestion scenarios involving the maximum application rate; and low acute risks to large mammalian carnivores for ingestion scenarios involving the maximum application rate.

\section{Diuron}

Acute RQs for terrestrial wildlife were above the most conservative LOC of 0.1 for several scenarios. Direct spray of pollinating insects at the typical and maximum application rates poses a low and moderate risk, respectively. In addition, low risk was predicted for the pollinating insect from indirect contact with foliage impacted by direct spray at the maximum application rate.

Risk assessments predicted acute and/or chronic risks to all of the receptor types as a result of ingesting food items contaminated by direct spray, with the greatest risk predicted for large mammalian herbivores (moderate chronic risk for ingestion of food sprayed at the typical application rate, and low acute and high chronic risks for the maximum application rate). In addition, ERAs predicted: low chronic risks to small mammalian herbivores for ingestion scenarios involving the typical application rate, and low acute and moderate chronic risks for ingestion scenarios involving the maximum application rate; low acute and chronic risks to small avian insectivores for ingestion scenarios involving the maximum application rate; low acute and moderate chronic risks to large avian herbivores for ingestion scenarios involving the maximum application rate; and low chronic risks to large mammalian carnivores for ingestion scenarios involving the typical and maximum application rates.

\section{Fluridone}

Risk quotients for terrestrial animals were below the most conservative LOC of 0.1 for all scenarios. These results indicate that accidental direct spray or drift of 
this aquatic herbicide would be unlikely to pose a risk to terrestrial wildlife.

\section{Imazapic}

Risk quotients for terrestrial wildlife were all below the most conservative LOC of 0.1 , indicating that direct spray of imazapic is not likely to pose a risk to terrestrial animals. Therefore, use of imazapic would primarily affect wildlife through habitat modification. Its use in forested rangeland and other wildlife habitat areas could benefit wildlife by controlling invasive plant species and promoting the establishment and growth of native plant species that provide more suitable wildlife habitat and forage.

\section{Overdrive $^{\circledR}$}

Most of the RQs for terrestrial wildlife were below the most conservative LOC of 0.1 , indicating that direct spray of Overdrive ${ }^{\circledR}$ is not likely to pose a risk to terrestrial animals. However, there would be low chronic risk to large mammalian herbivores as a result of consuming plants contaminated by direct spray at the typical application rate and moderate chronic risk at the maximum application rate. Because Overdrive ${ }^{(B)}$ is proposed for use in rangeland and wildlife habitat, large mammalian herbivores could be particularly at risk from application of this herbicide, although it is unlikely that these large animals would do all of their foraging within or immediately adjacent to application areas. The use of Overdrive ${ }^{\circledR}$ would primarily affect (positively or negatively) wildlife through habitat modification. Its use in wildlife habitat areas could benefit most wildlife by controlling invasive plant species and promoting the establishment and growth of native plant species that provide more suitable wildlife habitat and forage.

\section{Sulfometuron Methyl}

Risk quotients for terrestrial wildlife were all below the most conservative LOC of 0.1 , indicating that direct spray of sulfometuron methyl is not likely to pose a risk to terrestrial animals. Because this herbicide is relatively non-selective, it is not likely to be used in wildlife habitat areas, and therefore, should result in few negative or positive impacts on wildlife. Long-term positive impacts could result if sulfometuron methyl was used to clear former wildlife grazing habitat of an aggressive invasive, such as downy brome, and native forage was able to reestablish once this area was cleared.

\section{Tebuthiurom}

Risk quotients for pollinating insects were above the most conservative LOC of 0.1 for direct spray of insects (low risk at the typical and maximum application rates) and indirect contact with foliage after direct spray (low risk at the maximum application rate).

The ingestion of food items contaminated by direct spray at the maximum application rate poses a risk to mammalian herbivores. Low acute risk and chronic risk were predicted for the small and large mammalian herbivores. The strength of this herbicide is its use as a habitat modifier in the BLM shrub reduction program. It is relatively non-selective, but tends to harm grasses that are present. At low rates of application, tebuthiuron is used to thin shrubs, creating a more favorable habitat for shrub-dependent species. Because this application often takes place on land with a low concentration of grass forage, risks to mammalian herbivores associated with its use might be lower than those predicted under the ingestion scenarios, and wildlife forage and habitat could be enhanced by these applications. Birds and mammalian carnivores should not be adversely impacted by direct spray of tebuthiuron under any application scenarios.

\section{Impacts of Forest Service-evaluated Herbicides}

The following information for eight herbicides proposed for use by the BLM is taken from ERAs prepared by the Forest Service to support assessment of the environmental consequences of using these herbicides in Forest Service vegetation management programs. As part of these ERAs, the Forest Service developed worksheets (see USDA Forest Service 2005) that allowed the BLM to assess risks for BLM typical and maximum application rates and LOCs, rather than the Forest Service rates and LOCs. Thus, the risk assessment process for the Forest Service-evaluated herbicides parallels the BLM process as much as possible. However, some Forest Service modeled risk scenarios for terrestrial animals may be different than those used in the BLM ERAs, depending on the specificity of available toxicity data. The assessment of impacts is presented below using the Forest Service upper estimates of hazard quotients to maximize the conservatism of the assessment. In addition, it should be noted that the development of HQs by the Forest Service, as well as the BLM, is already conservative for many reasons (e.g., assumption of $100 \%$ dermal absorption, assumption that $100 \%$ of diet is contaminated, use of most sensitive values for exposure and dose/response assessments). Risks to TEP species 
are specifically analyzed in the Biological Assessment accompanying this document (USDI BLM 2007b).

\section{$2,4-D$}

2,4-D poses a risk to some terrestrial wildlife under direct spray as well as ingestion of contaminated food scenarios (Table 4-23; SERA 1998). Direct spray of 2,4-D at both the typical and maximum application rates poses a moderate risk to insects and small mammals, assuming $100 \%$ absorption of the herbicide. Small mammals face low risk from direct spray if $1^{\text {st }}$ order dermal absorption is assumed. In addition, mammals and large birds would be at risk from the consumption of vegetation contaminated by 2,4-D at the application site: large mammals and large birds would be at moderate acute and chronic risk for ingestion scenarios involving both the typical and maximum application rates (large birds face high acute risk for ingestion scenarios involving the maximum application rate), and small mammals face low acute risk for ingestion scenarios involving the typical and maximum application rates. Long-term consumption of contaminated vegetation would be unlikely if the vegetation were to show signs of damage. In other acute scenarios, small mammals face low risk from consumption of water contaminated by an accidental spill; small mammals face moderate to high risk and small birds face high risk from the consumption of contaminated insects; predatory birds face high risk from the consumption of fish contaminated by a spill; and carnivorous mammals and birds face low risk from the consumption of small mammals contaminated by direct spray of 2,4-D. The risk assessment indicates that insectivores and large herbivores eating large quantities of grass and other vegetation are at risk from routine exposure to 2,4-D, suggesting that 2,4-D should not be applied over large application areas where foragers would only consume contaminated food.

\section{Clopyralid}

According to the Forest Service risk assessnient (SERA 2004 b), clopyralid is not likely to pose a risk to terrestrial animals; however there are several scenarios under which there would be low acute risk to a variety of receptors at the typical and maximum application rates (Table 4-23). For the typical application rate, small mammals are at risk from $100 \%$ absorption of direct spray and consumption of contaminated insects and vegetation. For the maximum application rate, insects are at risk from direct spray, large birds are at risk from the consumption of contaminated vegetation, and small birds face risk from the consumption of contaminated insects. Application of clopyralid at the maximum application rate also poses a low chronic risk to large mammals and large birds consuming on-site contaminated vegetation. The Forest Service asserts that use of clopyralid in Forest Service programs is not likely to result in adverse effects to terrestrial animals; risks identified all fall within the lowest risk category.

\section{Glyphosate}

Glyphosate applications pose low to moderate risk to several terrestrial wildlife receptors under multiple exposure scenarios involving applications at the typical and maximum application rates (Table 4-23; SERA 2003a). Direct spray of a small animal and an insect, both assuming $100 \%$ absorption, poses a low risk at the typical application rate and a moderate risk at the maximum application rate. Consumption of vegetation contaminated by a spill poses a low risk to small mammals for scenarios involving for the maximum application rate only. A large mammal consuming contaminated vegetation would face low acute risk for scenarios involving the typical application rate, moderate acute risk, for scenarios involving the maximum application rate, and low chronic risk for scenarios involving the maximum application rate; a large bird consuming contaminated vegetation would face a low acute and chronic risk. Consumption of contaminated insects would pose a low risk to both small mammals and small birds if the herbicide was applied at the typical application rate. The herbicide would pose a moderate risk if applied at the maximum rate. Acute risks from glyphosate exposure are low at the typical application rate under all scenarios, and there are no chronic risks. Exposure scenarios with the greatest risk are direct spray and acute consumption of contaminated vegetation and insects. Glyphosate is nonselective, suggesting that spot applications in rangeland and wildlife habitat areas would be the most appropriate use of this herbicide. Spot applications would have lower risks associated with consumption of contaminated vegetation and insects than broadcast applications, as fewer non-target areas would be impacted by direct spray or spray drift.

\section{Hexazinome}

Several exposure scenarios involving application of hexazinone would pose a low to moderate risk to wildlife receptors (Table 4-23; SERA 1997). Small mammals would face low risk if directly sprayed at the maximum application rate, assuming $1^{\text {st }}$ order dermal absorption, and low to moderate risk assuming 100\% dermal absorption. Similarly, 100\% absorption of direct 


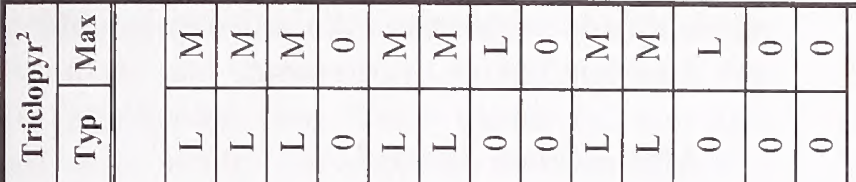

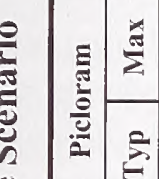

ֻ

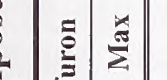

(a)

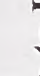

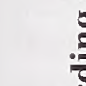

(1)

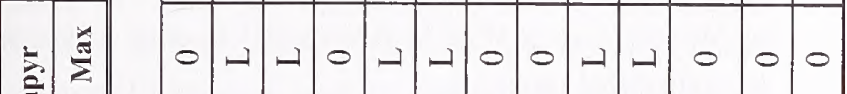

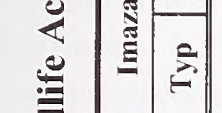

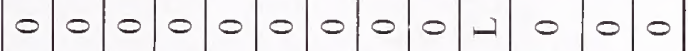

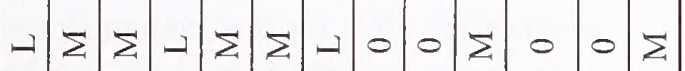

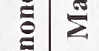

焉

○

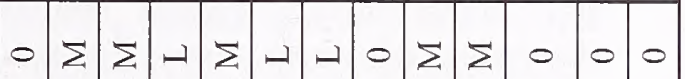

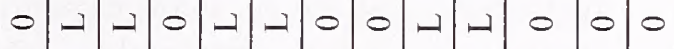

ב

这

○

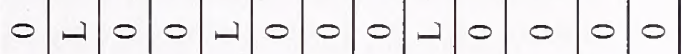

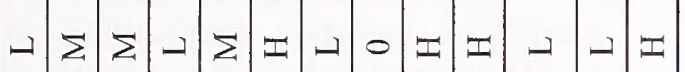

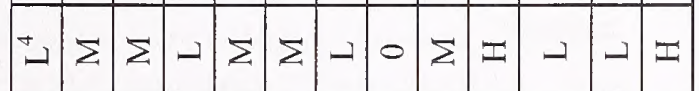

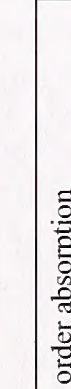

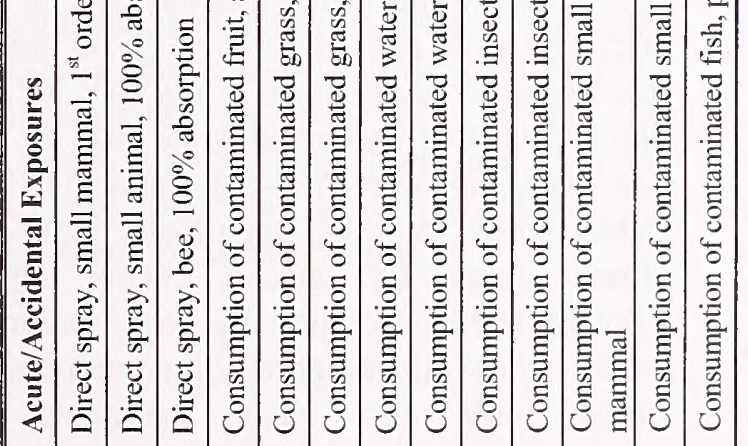

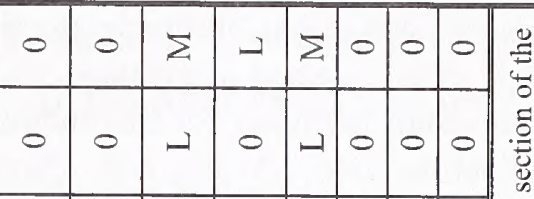

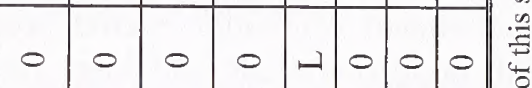

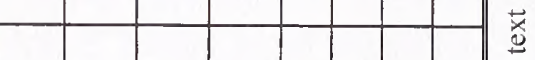

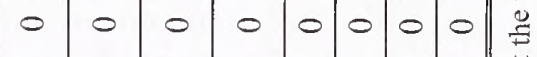

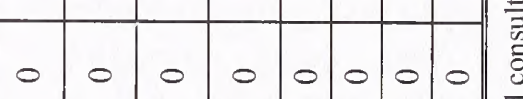

\begin{tabular}{lllllllll}
\hline & 0 & 0 & 0 & 0 & 0 & 0 & 0 \\
\hline
\end{tabular}

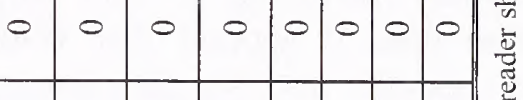

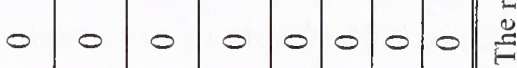

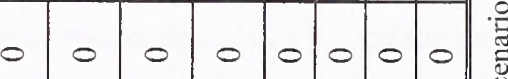

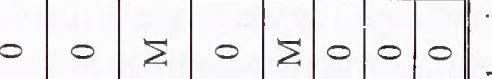

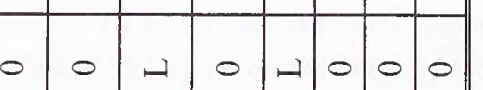

\begin{tabular}{llll|l|l|l|l|l|}
\hline & & & & & & \\
\hline
\end{tabular}

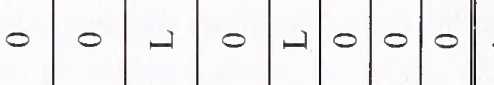

- 0000000

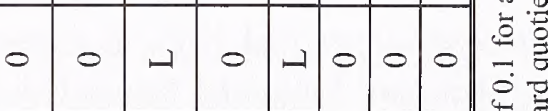

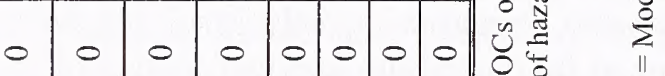

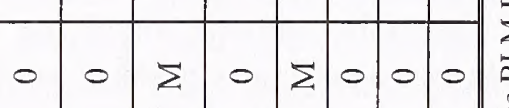

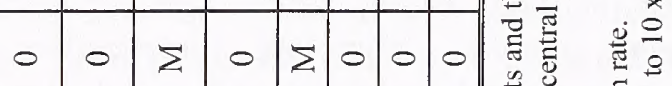

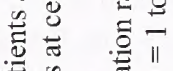

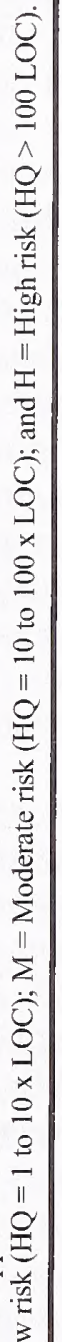


spray by insects would pose a low to moderate risk. Acute consumption of contaminated vegetation would pose a low risk to the small mammal for treatments at the maximum application rate. Acute and chronic consumption of contaminated vegetation would pose a moderate risk to both large mammals and large birds. Acute consumption of contaminated insects would pose a moderate risk to small birds, and acute consumption of contaminated fish would pose a low to moderate risk to predatory birds. Also, acute consumption of contaminated water would pose a low risk to small mammals for scenarios involving a spill at the maximum application rate. It appears that wildlife, especially sensitive species, are at risk from the application of hexazinone; the effects of hexazinone on insects, birds, and soil microarthropods are less certain than the effects on mammals. If food and water sources were not contaminated, risks would be reduced. Contamination of food and water sources could be minimized by utilizing spot applications at the typical application rate. Because hexazinone is semi-selective, is used to control woody species, and is typically only applied in spot applications, risks to wildlife under normal application could be lower than those predicted by the risk assessment.

\section{Imazapyr}

Imazapyr does not pose substantial risks to terrestrial animal species, but there are low risks associated with several exposure scenarios, mostly involving herbicide applications at the maximum application rate (Table 423; SERA 2004d). The only scenario involving the typical application rate that would pose a risk (low risk) to wildlife is that of a small bird consuming contaminated insects. Therefore, application of imazapyr at the typical application rate is not likely to result in adverse effects to terrestrial animals, with the possible exception of small insectivorous bird. For the maximum application rate, however, the following scenarios pose a low risk to wildlife receptors: direct spray of small animals and insects, consumption of contaminated vegetation by large mammals and large birds, and consumption of contaminated insects by small mammals and small birds. The HQs for terrestrial invertebrates are based on a single study using mortality as the endpoint, so results for this receptor are less certain. Because imazapyr is primarily used for the management of saltcedar in riparian zones and is relatively costly to use in the management of upland vegetation, large-scale impacts to wildlife are unlikely, even at the maximum application rate. Wildlife that reside mostly within the riparian zone would be most at risk from application of imazapyr.

\section{Metsulfuron Methyl}

None of the HQs estimated for metsulfuron methyl exposure at the typical application rate indicate risk to any of the receptors (Table 4-23; SERA 2004e). For applications at the maximum application rate, metsulfuron methyl would pose a low risk to small animals via $100 \%$ absorption of direct spray and consumption of contaminated insects, and to large mammals via consumption of contaminated vegetation. Application of metsulfuron methyl at the typical application rate should not result in any adverse effects to terrestrial animals.

\section{Picloram}

Most of the HQs for the evaluated scenarios of picloram exposure were below the LOC for both the typical and maximum application rates (Table 4-23; SERA 2003b). Under three scenarios, low risk was predicted for applications at the typical application rate: $100 \%$ absorption of direct spray by small animals, acute consumption of contaminated vegetation by large mammals, and acute consumption of contaminated insects by small mammals. For the maximum application rate, risk was somewhat elevated for these three scenarios (low to moderate risk), and two additional scenarios posed low risk: $100 \%$ absorption of direct spray by insects and chronic consumption of onsite contaminated vegetation by the large bird. Therefore, picloram applications at the typical rate would potentially have few adverse effects on terrestrial animals.

\section{Triclopyr}

Application of the two evaluated formulations of triclopyr, triclopyr acid and triclopyr butoxyethyl ester (BEE), poses a risk to insects, mammals, and birds under several exposure scenarios (Table 4-23; SERA $2003 \mathrm{c}$ ). Because risks calculated for these two formulas are the same, no differentiation will be made between triclopyr acid and triclopyr BEE in this section. The following scenarios pose a low risk for applications at the typical rate and a moderate risk for applications at the maximum rate: first-order and $100 \%$ absorption of direct spray by small mammals, $100 \%$ absorption of direct spray by insects, acute consumption of contaminated vegetation by large mammals and large birds, acute consumption of contaminated insects by small birds and small mammals, and chronic 
consumption of on-site contaminated vegetation by large mammals and large birds. In addition, for the maximum application rate, there would be low risk associated with acute consumption of contaminated vegetation by small mammals following an accidental spill, acute consumption of contaminated small mammals by carnivorous mammals, and chronic consumption of off-site contaminated vegetation by large mammals. No risk is predicted for small mammals as a result of acute or chronic consumption of contaminated vegetation or water, or for predatory birds as a result of consumption of contaminated fish. In summary, acute or accidental direct spray scenarios would pose a low to moderate risk to terrestrial mammals and insects, consumption of contaminated vegetation would pose a low to moderate risk to large mammals and large birds, and consumption of contaminated insects would pose a low to moderate risk to small birds.

\section{Impacts of Other Herbicides Currently Available for Use}

2,4-DP, asulam, atrazine, fosamine, mefluidide methyl, and simazine were approved for use in the earlier BLM EISs. 2,4-DP could be used in forested rangeland. It has low toxicity to mammals and is practically non-toxic to waterfowl and upland game birds. Asulam is of low toxicity to birds and mammals, and would primarily be used to control brackenfern on forested rangelands (Information Ventures, Inc. 1995a). Atrazine could be used for vegetation treatments in conifer plantations, but would not be used in forestlands or other rangelands. It is slightly toxic to non-toxic in birds, and is slightly to moderately toxic to mammals (Information Ventures, Inc. 1995b; Extension Toxicology Network 1996e). Fosamine is practically nontoxic to insects, birds, and mammals, although some chronic reproductive effects have been noted in mallards (USEPA 1995d). Mefluidide is of low to moderate toxicity to birds and mammals (Information Ventures, Inc. 1995c). Simazine could be used by the BLM on Christmas tree plantations, but would likely not be used on rangeland. Simazine is almost non-toxic to birds and mammals, although sheep and cattle are more sensitive to simazine than other mammals, and a dose as low as $500 \mathrm{mg} / \mathrm{kg}$ can be fatal (Information Ventures, Inc. 1995d). The BLM has not used any of these herbicides, except fosamine ( $<50$ acres annually), since 1997, and does not plan to utilize them in the near future.

\section{Impacts of Herbicide Treatments on Wildlife and Habitat by Ecoregion}

\section{Tundra and Subarctic}

Herbicides have not been used on public lands in Alaska on Arctic tundra or in subarctic forests, and herbicide treatments have not been proposed for these regions. Use of herbicides in these habitats is discouraged because forbs valuable to many tundra and boreal forest wildlife species would be reduced substantially (Braun 1980)

\section{Temperate Desert}

The goal of most treatments in this ecoregion is to restore lands damaged by fires in the Great Basin, and to benefit sage-grouse and other wildlife that use sagebrush communities. In particular, efforts would be focused on improving existing sagebrush stands and replacing invasive annual grasses with native bunchgrasses and forbs (USDA Forest Service and USDI BLM 2000). Although few wildlife vertebrates are endemic to the sagebrush analysis region, the Great Basin provides habitat for about 100 bird, 70 mammal, and 23 amphibian and reptile species (USDI BLM 1999).

At low to mid-elevations, long fire intervals have created climax sagebrush communities that are found on large areas of public land. These communities have diminished perennial herbaceous understory as a result of grazing and other habitat disturbances and competition from sagebrush plants. Where perennial species have been lost, downy brome has replaced these grasses, to the detriment of wildlife habitat (Perryman et al. 2003). As downy brome and other annual grasses have replaced native sagebrush and other shrubs in the region, populations of mule deer, pronghorn, bighorn sheep, Columbian sharp-tailed grouse, sage-grouse, and several species of raptors have declined due to loss of habitat and prey species that depend on shrub habitat (USDI BLM 1999). Vegetation treatments that promote a mixed sagebrushgrass-forb community benefit wildlife. Habitat in these communities is improved by creating openings in dense and crowded sagebrush and rabbitbrush stands, removing invasive species, and promoting production of perennial grasses and forbs (Paige and Ritter 1999, USDI BLM 1999, Sage Grouse Conservation Planning Team 2001). 
Treatments can improve habitat structure, complexity, and layering to the benefit of species that rely on a diversity of plant types and cover to meet their daily needs. Several studies have shown that densities of songbirds and small mammals are greater in mixed communities than in pure sagebrush or grassland stands (USDI BLM 1991a).

Sagebrush rangelands are often treated with herbicides to increase herbaceous plants, with herbicides that remove broad-leaved plants without harming grasses being the most widely used. As noted in the Vegetation section, 2,4-D, glyphosate, picloram, and tebuthiuron are important herbicides for control of sagebrush, rabbitbrush, and other woody species. Olson et al. (1994) used low rates of tebuthiuron to thin big sagebrush stands and enhance wildlife habitat in Wyoming. Glyphosate can be applied to sagebrush in winter months to kill only sagebrush above the snow.

Other studies have shown, however, that nesting and brood-rearing habitat for sage-grouse and other birds can be depleted by spraying. In Wyoming, it can take sagebrush 14 to 17 years to recover from herbicide spraying (see review in Connelly et al. 2000). Past efforts to reduce sagebrush habitat has been implicated as contributing to the decline in sage-grouse breeding populations throughout the West, especially if the treated area was reseeded with crested wheatgrass (Robinson and Bolen 1989; see review in Connelly et al. 2000). Herbicide use may also cause sage-grouse emigration from an area and reduce the suitability of an area for broods and wintering sage-grouse (see review in Connelly et al. 2000). Braun et al. (1977) recommended that sagebrush control not occur within a 2-mile radius of sage-grouse leks, nesting areas, wintering grounds, or breeding grounds. However, Urness (1979) believed that herbicides could be used to prevent shrub invasion onto leks and alter the size and density of sagebrush to more closely approximate nesting requirements. Dahlgren et al. (2006) treated mountain big sagebrush stands with tebuthiuron to reduce canopy cover and increase production of forbs. Sage-grouse adults and their young preferred the treated plots over the untreated plots, although most use of treated plots occurred near the boundary of the treated plots and intact sagebrush areas. The authors suggested that low rates of tebuthiuron be used to ensure that only a portion of the treated sagebrush was killed.

Herbicidal control of sagebrush can reduce populations of some birds, such as Brewer's sparrow and vesper sparrow, and can reduce the production of forbs and seeds that are important to nesting birds and their young for food and cover. Thus, sagebrush treatments must be carefully designed to ensure that large stands of sagebrush are not lost.

Herbicide treatments and fire use may be the only effective ways to control large areas of annual weeds and other invasive vegetation in this ecoregion. For smaller areas, however, mechanical treatments are recommended over herbicides for improving sagegrouse habitat. Mechanical methods often do less damage to the understory and are more effective than herbicides for sagebrush habitat improvement (USDI BLM 1991a).

Response by mammals varies with herbicide treatment. Deer mice seem unaffected, northern pocket gophers and least chipmunks can decrease, American badgers might decrease initially should gophers or ground squirrels be affected negatively, and montane voles usually increase (Cooperrider et al. 1986; Payne and Bryant 1998). Once preferred forbs return to an area, small mammals apparently return to pretreatment levels.

Elk benefit from conversion of sagebrush to bunchgrass-dominated sites. Elk use increased $89 \%$ on chemically treated versus untreated sites in Wyoming (Wilbert 1963, Severson and Medina 1983). Mule deer used sagebrush less in Colorado after it was sprayed with 2,4-D. Loss of forbs associated with herbicide treatments of sagebrush stands can be detrimental to white-tailed deer, as forbs can comprise $60 \%$ or more of the deer's diet (Robinson and Bolen 1989).

Pronghorns rely heavily upon browse diets during fall and winter, but forbs are important in spring and summer. Herbicide treatments that thin dense stands of tall sagebrush and improve forb and grass understories can benefit pronghorns (Urness 1979).

In general, treating large units of sagebrush with herbicides is not recommended for wildlife habitat management. If treatments are done in patches or strips, important refuge areas can be created for amphibians, reptiles, birds, and small mammals (Payne and Bryant 1998); staggering treatments over several years can achieve the same effect. Howard and Wolfe (1976) recommended patterned treatments of small tracts, instead of large tracts, for species such as ferruginous hawks because such treatments improve the prey base. Leaving strips of untreated vegetation between strips of treated vegetation also affords wildlife the opportunity to find food and cover resources while treated stands recover. Spraying areas with over $39 \%$ big sagebrush cover can benefit sage-grouse as long as treatments are 
in small blocks, strips, or patches (Holecheck et al. 1989). Spraying should be conducted before forbs emerge. Little benefit from any habitat modification can be expected unless livestock grazing is closely regulated after treatment (Payne and Bryant 1998).

\section{Subtropical Desert}

Herbicides such as 2,4-D, picloram, tebuthiuron, and dicamba are used to control woody species such as mesquite, creosotebush, and snakeweed in Subtropical Desert habitats. Mesquite has invaded millions of acres of shortgrass and mixed-grass prairies of the Southwest. The invasion of woody species has occurred at the expense of native grassland species, and has reduced the carrying capacity for species that depend upon shortgrass and mixed-grass prairies. In Texas, woody shrubs infest over $80 \%$ of the state's rangelands (Robinson and Bolen 1989). Brush removal may help to conserve water when the foliage of the moisturedemanding brush is removed. However, in some areas, the expanded range of mesquite has increased the distribution and abundance of white-tailed deer, doves, quail, and cottontail (McCormick 1975 cited in USDI BLM 1991a).

Where dense canopies are a problem, treatment with triclopyr and clopyralid might be needed to thin woody vegetation. Stem application of triclopyr is a desirable method of mesquite control because it promotes quick removal of mesquite with minimal damage to native plants and wildlife (Waggoner et al. 2003). In general, no more than $60 \%$ of a mesquite-dominated habitat should be treated, and treatments should be in strips or as a patchwork of openings. Germano (1978 cited in USDI BLM 1991a) observed that jackrabbits, antelope, quail, and lizards favored openings in mesquite stands. Except for northern mockingbirds and golden-fronted woodpeckers, most nongame birds in northern Texas were unaffected by herbicide-treated areas designed to improve habitat for mourning doves and northern bobwhite, as long as stems and dead trees were left standing. Total density of nongame birds increased 54\% on managed versus unmanaged sites; species diversity and richness were similar (Payne and Bryant 1998). Where soil is disturbed in the fall by disking to promote forbs and grasses, herbicides such as diuron and 2,4-D can be cost-effective to enhance production of foods for northern bobwhite and mourning doves.

As long as cover is maintained, white-tailed deer appear to adapt to reduction in browse species associated with herbicide treatments of mesquite. Spraying large blocks of cover habitat adversely affects deer, but treating woodlands in alternating bands can benefit deer (USDI BLM 1991a, Payne and Bryant 1998). Herbicide treatments of upland habitat should be acceptable for most wildlife as long as $20 \%$ of an area is left as old, mature woodland.

Herbicides have also been targeted for plants such as burroweed, creosote bush, American tarwort, tree cholla, yucca, and pricklypear. In creosote bush communities, tebuthiuron treatments were more effective than mechanical treatments in killing these plants, but changes in grass and forb densities were the same whether creosote bush was chemically or mechanically treated (Morton and Melgoza 1991). In Arizona, Smith (1984 cited in USDI BLM 1991a) compared bird use in creosote bush treated with tebuthiuron and found that birds used openings created through treatment for nesting and foraging sites. After 3 years, rodent abundance was $71 \%$ higher on creosote bush areas treated with tebuthiuron than control plots in southeastern Arizona (Standley and Smith 1988).

Cautious and guarded use of herbicides in hot desert communities is recommended. Aside from the semidesert grasslands, herbicides probably have limited value, particularly in the Sonoran and Mojave deserts. Plant control by chemical means usually must be followed by revegetation, which may be unsuccessful due to low and erratic precipitation. In addition, because of the sparse vegetation over much of the desert, removal of vegetation can have substantial impacts on native wildlife that rely on affected plants for food and cover and that cannot readily find new habitat (Payne and Bryant 1998).

\section{Temperate Steppe}

The BLM administers between 10 and 15 million acres of short- and mixed-grass prairie grasslands that support over 130 species of wildlife, including lesser prairie chicken, mountain plovers, and prairie dogs. Over threequarters of treatments in the Temperate Steppe Ecoregion would be focused on annual and perennial grasses and forbs, including downy brome, leafy spurge, and several species of knapweeds and thistles. Much of this work would be done in support of the BLM's Conservation of Prairie Grasslands initiative.

Control of broadleaf plants by selective herbicides, such as 2,4-D, usually increases grass production. 2,4-D is also effective in controlling weedy forbs, such as bull, musk, and Scotch thistle. 2,4-D can be tank mixed with other herbicides, such as glyphosate, dicamba, picloram, and triclopyr to enhance the activity of these herbicides. 
Applications of picloram may damage sensitive grasses as well as broadleaf plants, and can substantially alter the composition of grassland communities and affect wildlife diets (USDI BLM 1991a). For example, Fagerstone et al. (1977) found that the prairie dog diet changed significantly from forbs to grass after their habitat was treated with 2,4-D, which significantly reduced the abundance of forbs on the site. Despite the diet change, the 2,4-D treatment appeared to have little detrimental effect on prairie dogs.

Leafy spurge can be controlled with picloram, dicamba, and glyphosate (Hickman et a1. 1990). Grasshopper sparrow and savannah sparrow densities were lower in areas with high densities of leafy spurge in North Dakota (Scheiman et al. 2003). Because forbs and other broadleaved plants are important to many wildlife species, patchwork treatments of herbicides should be applied when treating large areas of leafy spurge.

Prairie threeawn is an herbaceous invader on degraded, tallgrass prairie range sites; it colonizes bare soil and maintains dominance for many years, and its value to wildlife is minimal. Atrazine effectively controls prairie threeawn (Engle et al. 1990).

Picloram, clopyralid, and a mixture of 2,4-D and clopyralid were used to treat spotted knapweed to enhance elk forage production in Montana (Rice et al. 1997b). Herbicide application increased winter elk forage by $47 \%$ at sites with low to moderate spotted knapweed infestations. However, success would be greatest at sites having a significant bunchgrass component prior to treatment.

Herbicide treatments have also been used to reduce the cover of woody shrubs, such as mesquite and Eastern redcedar, which encroach upon prairie grasslands. While these woody species can benefit some wildlife species (see Wildlife Resources section in Chapter 3), they can also crowd out grassland and forb species, reducing the value of habitat for some species (Engle et al. 1987; Payne and Bryant 1998). Woody shrubs can be controlled where canopy cover reduces the amount of understory vegetation used for food and cover. Picloram and tebuthiuron are effective in controlling woody shrubs.

Herbicides such as 2,4-D have been used in evergreen and deciduous forests at higher elevations to thin sagebrush, snowbrush ceanothus, chokecherry, snowberry, and other shrubs (Vallentine 1989). After treatment, plants often resprout from the crown, producing palatable forage. Whisenant (1987) successfully treated big sagebrush with clopyralid, leaving bitterbrush and serviceberry relatively unharmed. Treating bitterbrush areas with 2,4-D in Idaho resulted in plants that were unharmed or only slightly damaged (Vallentine 1989). Damage to bitterbrush can be reduced if an area targeted for sagebrush control is treated early, before bitterbrush twigs elongate or began to flower (Payne and Bryant 1998). Bitterbrush plants less than 12 inches tall and those that are flowering will be severely damaged or killed by 2,4-D.

\section{Subtropical Steppe Ecoregion}

Over three-quarters of treatments in the Subtropical Steppe Ecoregion would be focused on sagebrush and other evergreen shrublands, while $12 \%$ would focus on pinyon, juniper, and other evergreen woodland species. Healthy pinyon-juniper woodlands, with a full complement of understory grasses, forbs, and shrubs, provide excellent wildlife habitat. However, in many areas, pinyon and juniper have increased in density to the point that understory vegetation is excluded, to the detriment of wildlife (USDA Forest Service and USDI BLM 2000).

Broad-scale herbicide use in pinyon-juniper woodlands has not been popular over the past several decades, especially when used to open up pinyon-juniper stands. The possibility of destroying midstory shrubs that are important food sources is a major disadvantage to herbicide use (Payne and Bryant 1998

Picloram and tebuthiuron are the main herbicides used to treat pinyon-juniper woodlands. Both picloram and tebuthiuron may persist in the soil for several years and may injure understory grasses, shrubs, and forbs. Individual tree treatments with these herbicides are often more effective in controlling trees and less injurious to understory species than broadcast applications. Using picloram on some sites can also result in dominance by annual grasses, such as downy brome or medusahead, if these species become resistant to picloram (USDI BLM 1991a).

Studies of wildlife use of treated pinyon-juniper habitats have shown that mule deer use was greater in a chemically treated plot than on a mechanically treated plot because herbicide treatment resulted in more openings in the woodlands and a greater retention of screening cover (Severson and Medina 1983). If used properly, aerial broadcasts can create numerous, small, irregularly-shaped openings in terrain that is too rough for mechanical operations (Short and McCulloch 1977). 
Herbicides can be used with mechanical treatment to manipulate pinyon and juniper (Evans et al. 1975). Small trees that escape chaining, cabling, or dozing can be treated effectively with picloram to ensure that the opening created is free of trees. Unwanted invaders of mechanically prepared openings, including downy brome, can be controlled with atrazine or glyphosate. Glyphosate can be used to desiccate leaves or needles, rendering them more susceptible to prescribed burning.

Tebuthiuron has been used to control sand shinnery oak to improve habitat for lesser prairie chickens in areas where it forms a dense canopy cover. In a study in Oklahoma, tebuthiuron effectively controlled sand shinnery oak and increased grass production, yet did not reduce the abundance and diversity of forbs required by lesser prairie chickens (Doerr and Guthery 1983).

\section{Mediterranean and Marine Ecoregions}

Approximately 11,000 acres would be treated annually using herbicides in the Marine and Mediterranean ecoregions under the proposed action, primarily using ground-based methods. Over three-quarters of treatments in the Mediterranean and Marine ecoregions would occur in evergreen forestlands. Many of these efforts would be focused on integrated weed management and forest health. The objectives of forest health treatments would be to stem the decline in oldforest habitats primarily due to fire exclusion, to restore more natural fire regimes and reduce hazardous fuels to reduce the potential for catastrophic wildfires, and to restore forests recently burned by wildfires. Fire exclusion has resulted in a gradual shift in stand composition from shade-intolerant tree species such as ponderosa pine, to dense stands of shade-tolerant species such as Douglas-fir and grand fir (Wisdom et al. 2000). High stand densities can make foraging difficult for Lewis' woodpecker, and reduce the vigor of oaks used by western grey squirrels for foraging. The loss of large trees and snags can limit the abundance of nesting and foraging sites for woodpeckers, bats, and other wildlife.

Herbicides are an important tool for improving forest productivity in the Marine Ecoregion, and studies suggest that the range of wood volume gains from effectively managing forest vegetation (primarily using herbicides) is $30 \%$ to $450 \%$ for Pacific Northwest forests (Wagner et al. 2004). Herbicides can be effective in improving forest wildlife habitat by 1) reducing populations of invasive exotic plants, 2) creating snags and downed woody material, 3) maintaining patches of early-successional vegetation within late-successional communities, and 4) maintaining woody and herbaceous plant communities for browsing species (Lautenschlager et al. 1995; Wagner et al. 2004).

Herbicide use in forests has often been perceived by the public as inconsistent with the ecological aspects of forest management. As discussed above, under typical application scenarios, herbicides evaluated by the BLM pose negligible chronic or acute toxicity hazards to wildlife, and most are rapidly eliminated from animal systems once ingested or absorbed (Tatum 2004; Wagner et al. 2004). Response by wildlife to herbicideinduced habitat alteration is highly variable. Blacktailed deer readily browse Douglas-fir seedlings treated with 2,4-D, atrazine, and fosamine, but reduce use of seedlings treated with glyphosate (Bovey 2001). Because herbicides can alter habitat and successional patterns, they may be useful for restoring desirable habitat conditions, especially early-successional plant communities (see review in Guynn et al. 2004).

Due to abundant rainfall along the Pacific Coast, amphibians are common in habitats west of the Cascade Range. As noted above, ERAs did not assess risks to amphibians from herbicide treatments, but several studies have evaluated risks to amphibians from 2,4-D, atrazine, glyphosate, hexazinone, triclopyr, and other pesticides.

Amphibian populations from around the world have apparently declined or experienced range reductions, and some populations have experienced increases in developmental deformities (Kiesecker 2002). Kiesecker (2002) found that trematode infection was required for development of limb deformities in wood frogs, but that deformities were more common at sites adjacent to agricultural runoff where atrazine and other pesticides were used.

A study of herbicides sprayed for pest control in Canada showed that effects to amphibian embryos and larvae from hexazinone, glyphosate, triclopyr, and three other herbicides that are not used by the BLM were similar to those found in freshwater fish when herbicides were applied at typical application rates. High concentrations of hexazinone did not affect embryos and tadpoles, but $2.4 \mathrm{ppm}$ or greater concentrations of triclopyr did lead to death of newly hatched tadpoles (Berrill et al. 1994; Berrill et al. 1997).

Several studies have shown high rates of larval amphibian mortality in areas treated with glyphosate formulations containing POEA (Relyea 2005a). 
Although glyphosate and POEA can be absorbed by soil and broken down by soil microbes, complete breakdown can take weeks and death still occurs in amphibians exposed to glyphosate formulations containing POEA (Giesy et al. 2000). However, Relyea (2005b) found that 2,4-D had no impact on tadpoles and did not lead to a loss of species richness in aquatic communities.

Herbicides can often be more selective than mechanical or fire treatments and just as selective as manual treatments in forestlands (Payne and Bryant 1998). Common herbicides used in forest wildlife management include asulam, atrazine, 2,4-D, glyphosate, simazine, and tebuthiuron; however, the BLM has not used atrazine or asulam on public lands since at least 1997. Spraying herbicides over conifer plantations eliminates competing shrubs and hardwood sprouts, but also reduces the value of these forests to wildlife (Rutske 1969). If treatments are done in patches or strips, important refuge areas can be created for amphibians, reptiles, birds, and small mammals (Payne and Bryant 1998); staggering treatments over several years can achieve the same effect.

Weed management in forestlands would reduce or eliminate weed populations that displace native plants that are generally more desirable to wildlife. Plant species of concern include knapweeds, yellow starthistle, toadflaxes, downy brome, and several species of thistle. Several studies have shown that elk use of forest habitats was substantially lower on sites dominated by knapweeds than on sites dominated by native grasses (Sheley et al. 1999a). Yellow starthistle forms dense stands that provide limited value to wildlife, and it is poisonous to some animals (Sheley et al. 1999b). Knapweeds are effectively controlled by picloram, clopyralid, dicamba, and 2,4-D; these herbicides, along with glyphosate, can also be used to control yellow starthistle. Dalmatian and yellow toadflax displace existing plant communities and associated wildlife, although deer have been observed to browse Dalmatian toadflax, the seeds are eaten by some species of birds and small mammals, and the vegetation can provide some cover for smaller wildlife, toadflaxes are not known to be heavily used by any native species (Lajeunesse 1999). Toadflaxes are often controlled using picloram. Thistle spines make them unpalatable to some wildlife and often create effective barriers to movement (Beck 1999). Several herbicides, including chlorsulfuron, clopyralid, 2,4-D, dicamba, imazapic, metsulfuron methyl, and picloram, are used to control thistles.
Phenoxy herbicides (2,4-D, 2,4-DP) have been used in the California chaparral to stimulate shrub regrowth and increase production of grass and forbs (USDI BLM 1988a). Dense, decadent chaparral provides minimal value to deer and other large mammals, but good food and cover for reptiles, small mammals, and birds, such as mountain quail, thrashers, and wrentits. In one study, species composition, population size, and relative abundance of birds did not change 2 years after herbicide treatment of chaparral (Beaver 1976). Sites of dense chaparral treated as a patchwork mosaic should benefit most edge wildlife.

Glyphosate treatments during fall have been used to improve the success of perennial grass seedings in grasslands dominated by invading annuals in California (Vallentine 1989). Herbicides can also be a valuable tool for improving elk habitat by toppling oaks in areas where dense stands occur. Elk use increased dramatically after Gambel oak was sprayed with herbicides (Kufeld 1977); mule deer response was minimal. Small areas of 12 acres or less should be treated to create habitat diversity and feeding sites. Tebuthiuron and triclopyr are effective for treating almost all oak species. Large trees should be protected for their mast-producing potential because acorns are relished by turkey, bear, deer, elk, and other wildlife species (Payne and Bryant 1998).

\section{Impacts by Alternative}

The following sections detail the expected effects of each of the five alternatives on terrestrial wildlife, and compare these effects to those expected under the other alternatives. These effects may vary depending on the percentage of acres treated using different application methods and different herbicides, as well as the size of treatment events. Earlier in this section, SOPs were described that would reduce some of the impacts described below.

\section{Altermative A - Continue Present Herbicide Use (No Action Alternative)}

Under the No Action Alternative, the BLM would continue its ongoing vegetation treatment programs in 14 western states. Based on the information gathered from BLM field offices in 2002, approximately $3.4 \%$ of acres would be treated specifically to benefit wildlife and their habitats, although all treatments would be likely to provide long-term benefits to wildlife.

Under this alternative, the BLM would be able to use the 20 herbicides previously approved in earlier EIS 
RODs. However, based on the recent pattern of BLM herbicide use, it is likely that approximately three fourths of the area treated would involve the use of only four herbicides: 2,4-D, glyphosate, picloram, and tebuthiuron (Table 2-5). Herbicide use under the No Action Alternative would impact wildlife on approximately 305,000 acres. Public lands in Alaska, Nebraska, and Texas would not be cligible for herbicide treatments under this alternative.

Wildlife impacts (positive and negative) would be similar to those that have occurred in the past 10 years. Negative impacts to wildlife could be lower than under the other herbicide-use alternatives, based on the relative number of acres treated. Impacts would include loss of non-target vegetation used by wildlife, and effects to wildlife health from exposure to herbicides. Aerial applications have the greatest potential to affect wildlife because they typically cover the largest treatment areas (USDI BLM 1991a). The use of glyphosate is of concern in areas with amphibians.

Long-term positive impacts on wildlife communities (i.e., improvements in habitat and ecosystem function) would be much less under this alternative than under the other alternatives. Invasive plant populations would likely continue to expand at the current rate or greater, increasing damage to native plant communities and wildlife habitat and inhibiting ecosystem functions associated with those communities.

In addition, because the new herbicides proposed in this PEIS (diquat, fluridone, imazapic, and Overdrive ${ }^{\circledR}$ ) would not be used, risks to wildlife would be different under this alternative than under the other herbicide treatment alternatives. Imazapic does not present any risks to wildlife in modeled scenarios (similar to chlorsulfuron, dicamba, fluridone, metsulfuron methyl, and sulfometuron methyl), and Overdrive ${ }^{\circledR}$ poses a low to moderate risk to large mammalian herbivores under the chronic ingestion of contaminated vegetation scenario. Diquat is fairly toxic to terrestrial wildlife, particularly under food ingestion scenarios (similar to 2,4-D and diuron). However, diquat is an aquatic herbicide and frequent exposure to terrestrial animals would not be expected. Therefore, the No Action Alternative would prevent the use of a greater repertoire of herbicides that are not injurious to terrestrial animals, possibly increasing per area risks to wildlife if more injurious herbicides were used instead (e.g., 2,4-D, bromacil, diuron, tebuthiuron, triclopyr), as well as decreasing the possibilities of more effective wildlife habitat and native ecosystem improvements.
2,4-DP, asulam, atrazine, fosamine, mefluidide, and simazine were approved for use in the earlier BLM EIS RODs, but the BLM has not used any of these herbicides, except fosamine ( $<50$ acres annually), since 1997, and does not plan to utilize them in the near future. These six herbicides have low toxicity to wildlife, although atrazine could exhibit endocrinedisrupting effects via inhibition of androgen receptors in mammals, amphibians, and potentially reptiles (Rohr et al. 2006; see review in Storrs and Kiesecker 2004). Atrazine appears to increase mortality in amphibians and acts as an endocrine disruptor that chemically castrates and feminizes male amphibians (Hays et al. 2006; Rohr et al. 2006). A review by the USEPA (2003e), however, suggested that information about the effects of atrazine of amphibians was inconclusive. Under this alternative, the BLM would use other herbicides, including bromacil, diuron, sulfometuron methyl, and triclopyr, which are effective in controlling weeds and invasive vegetation, but have less risk to wildlife.

The BLM would not be able to use herbicides in Alaska, Nebraska, and Texas under the No Action Alternative, but would be able to conduct herbicide treatments in these states under the other herbicidetreatment alternatives. No herbicide treatments would occur in Alaska or Nebraska, based on information provided by local field offices during 2002. Approximately 11,000 acres would be treated annually in Texas using herbicides under the other alternatives, which would benefit wildlife in the Subtropical Desert Ecoregion.

\section{Alternative $\mathbb{B}$ - Expand Herbicide Use and Allow for Use of New Herbicides in 17 Western States (Preferred Alternative)}

The Preferred Alternative would result in the treatment of approximately 932,000 acres across the western BLM states. In addition to the 14 previously-approved herbicides, the BLM would be able to use the four new herbicides evaluated in this PEIS. Based on the information provided by local field offices in 2002, approximately $6.8 \%$ of acres ( 6 times as many acres as under the No Action Alternative) would be treated specifically to benefit wildlife and their habitats, although all treatments would be likely to provide longterm benefits to wildlife.

This alternative would result in the most extensive effects to wildlife because it proposes the most acres for treatment ( 3 times the acreagc proposed under the No Action Alternative). The relative degree of positive 
versus negative impacts would depend on the relative amount of each herbicide used; the chance for negative impacts would be higher if diuron and/or diquat and possibly bromacil and 2,4-D were used extensively. If these herbicides were used only in restricted scenarios, as is proposed, positive impacts could outweigh negative impacts. The use of the four new herbicides and the ability to use future herbicides that become registered with the USEPA would allow BLM managers more options in choosing herbicides that best match treatment goals and application conditions, and are less toxic, and may therefore reduce overall per capita risk to wildlife (three of the four new herbicides present little to no risk to wildlife) and increase positive habitat and ecosystem benefits from treatment. In addition, the ability to use future registered herbicides would allow the BLM to employ the most technologically-advanced herbicides, which would likely reduce risk to wildlife and increase management benefits. This alternative would also reduce risk and negative impacts that might be associated with other vegetation management methods (e.g., risk of escaped prescribed fires; see the PER).

Based on current BLM usage, 2,4-D, glyphosate, picloram, and tebuthiuron would comprise about $70 \%$ of herbicides that would be used under this alternative. The risks and benefits of using these and other currently-available herbicides are discussed under the No Action Alternative. Approximately $10 \%$ of all treatment acres would be treated with the new herbicides, and about three-fourths of these acres would be treated using imazapic. Imazapic could be used in all areas except riparian and wetland areas. Imazapic would be used to control downy brome, hoary cress, leafy spurge, perennial pepperweed, and several other invasive species that are known to displace native vegetation and alter wildfire intensity and frequency. Imazapic use would occur in the Great Basin where downy brome has replaced native shrubs after recent catastrophic fires. As noted above, several wildlife species populations have shown sharp declines in the Great Basin, apparently due to loss of sagebrush and other key habitat components.

About $2 \%$ of all treatment acres would be treated using Overdrive $^{\circledR}$. Overdrive ${ }^{\circledR}$ would be used on rangelands; ROW; oil, gas, and mineral sites; and cultural and recreation sites. This herbicide is not effective in downy brome control, but does control oak species to reduce hazardous fuels. It also can be used to control several annual broadleaf species, including burningbush, pigweed, and Russian thistle; several biennial species, including bull, musk, and Scotch thistle, teasel, and diffuse knapweed; and several perennial species including spotted and Russian knapweed and field bindweed. As discussed earlier, these species displace native vegetation, which is more desirable to wildlife, and can lead to conditions that foster wildfires that kill or harm wildlife and destroy habitat.

In addition to being able to use four new herbicides under this alternative, the BLM would be able to use herbicides in Alaska, Nebraska, and Texas. Herbicide use should be avoided in Arctic tundra and subarctic forests. At this time, the BLM does not propose to conduct herbicide treatments in Arctic and subarctic tundra and forest habitats, but could do so in the future should the need arise and the agency deems that treatments were safe for wildlife and their habitats. If used, herbicide weed treatments would likely be targeted for developed areas and ROW. The ability to use herbicides in Nebraska and Texas would allow for more comprehensive weed management programs in these states, which should reduce the negative effects of invasive species on native vegetation and improve wildlife habitat.

Under this alternative, over $70 \%$ of treated acres would be in the Temperate Desert Ecoregion, a much greater proportion than under the No Action or other alternatives. Fifteen percent of treatments would occur in the Temperate Steppe Ecoregion. As with the No Action Alternative, treatments in the Temperate Desert Ecoregion would primarily target sagebrush, rabbitbrush, and other evergreen shrubland species, and annual grass and perennial forb weeds, while those in the Temperate Steppe Ecoregion would focus on control of invasive annual and perennial grasses and forbs. Much of the increase in treatment acreage in this region is associated with the Great Basin Restoration Initiative and related attempts to restore fire-damaged ecosystems and improve habitat for sage-grouse and other sagebrush-dependent species.

\section{Altermative C - No Use of Herbicides}

Under Alternative C, wildlife would not be affected by herbicide use. Primary effects would stem from other vegetation treatment methods (see the accompanying PER). Positive ecosystem and habitat benefits as a result of vegetation management could be reduced under this alternative, as there are certain invasive species for which herbicide use is the only effective method of treatment or for which other methods are impractical due to cost, time, accessibility, or public concerns (e.g., saltcedar in riparian areas). For example, rough terrain 
may prevent treatment by methods requiring terrestrial vehicle and/or foot access, while aerial treatment with herbicides in these areas would be possible. In addition, it is often difficult to eradicate some species, such as shrubs that resprout from rhizomes, by means other than herbicide application (e.g., rabbitbrush, honey mesquite, sand shinnery oak, tree cholla). Similarly, pre-emergent herbicides that persist in the soil are the most effective means of controlling invasive plants with seeds that remain viable for long periods of time.

Under this alternative, in the absence of herbicide treatments, invasive plant populations would likely continue to spread, possibly at increasing rates, and cause further damage to susceptible native plant communities and wildlife habitat, particularly in areas and for species where other treatment methods are not effective or possible (e.g., large tracts of rangeland or grassland dominated by invasive, resprouting shrubs or without enough fine fuels to carry prescribed fires). However, it is uncertain how potential negative impacts from this alternative (mostly indirect) would compare with negative direct and indirect impacts from herbicide use.

\section{Alternative D - No Aerial Applications}

Alternative D would allow the use of the same herbicides in the same areas as under the Preferred Alternative, and would have similar benefits resulting from the increased availability of new and future herbicides. However, this alternative would not allow the use of aerial application methods, thereby dramatically reducing the acreage on which treatments (530,000 acres) would be possible because some large and remote areas cannot be effectively treated by ground application methods.

Because non-aerial treatments would be smaller, fewer wildlife would be exposed to herbicides than under alternatives with aerial treatment options (it would be difficult for most wildlife to avoid spray from aircraft by fleeing). Ground treatments would also be better able to avoid patches of important wildlife habitat or use areas within the larger treatment area than aerial treatments.

This alternative would result in fewer impacts to wildlife due to off-site drift than under the Preferred Alternative. Off-site drift was not specifically modeled for most herbicides (consumption of contaminated vegetation off site was modeled for most of the Forest Service herbicides, with no risk demonstrated for any of these herbicides except triclopyr at the maximum application rate); however, off-site drift impacts to vegetation are somewhat common (see Vegetation section in this chapter), and could alter habitat as well as forage. Conversely, without the option for aerial spraying, the BLM would be unable to treat large areas of vegetation under Alternative D, which could negatively impact wildlife habitat in these areas over the long term.

Under this alternative, long-term negative impacts on wildlife habitat and ecosystems could be greater than any potential short-term negative effects to wildlife that would result from aerial applications under other alternatives. In addition, direct and indirect impacts from other vegetation treatment options could increase if these other treatments were used more extensively to compensate for the loss of acres able to be treated by herbicides (see the PER).

Prescribed fire and mechanical treatments would be substituted for aerial herbicide treatments as much as possible in large areas proposed for treatment. Fire would not be effective in areas with insufficient fuels to carry fire, and could kill or harm wildlife that were unable to flee, as well as substantially alter habitats. Fire could also result in substantial damage to sagebrush stands and enhance the development and spread of downy brome and other annual grasses (USDI BLM 1991a). Mechanical treatments might not be suitable in areas where sprouting species, such as rabbitbrush, might increase after mechanical treatment. This alternative would preclude treatment of large expanses of downy brome and other invasive annual grasses using imazapic and other herbicides.

\section{Alternative $\mathbb{E}$ - No Use of Acetolactate Synthase- inhibiting Active Ingredients}

Approximately 466,000 acres would be treated under Alternative $\mathrm{E}$, which is slightly less than the amount that would be treated under Alternative $D$, and less than half of the amount that would be treated under the Preferred Alternative. In addition to a relatively low impact to wildlife as a result of minimal acreage treated, pertreatment impacts under Alternative $\mathrm{E}$ would be lower than under the other herbicide-use alternatives because of some of the standards detailed by this alternative (e.g., preferential use of spot rather than broadcast applications, preferential treatment of small versus large infestations).

Sulfonylurea herbicides and other ALS-inhibiting herbicides (e.g., chlorsulfuron, imazapic, imazapyr, metsulfuron methyl, sulfometuron methyl) block the 
synthesis of amino acids that are required for protein production and cell growth, thereby resulting in plant death. ALS-inhibiting herbicides would not be used under this alternative because data suggest they have the potential to damage off-site native and crop plant species under certain conditions of environment and application. These herbicides are biologically active at small concentrations, and relatively low application rates are necessary to manage target plants. In 1981, the Environmental Effects Division of the USEPA recommended against registering sulfonylurea herbicides because they persist for long periods of time in the environment and they cannot be detected at low levels. However, in this assessment, the ALS-inhibiting herbicides mostly posed no risk to terrestrial wildlife (chlorsulfuron, imazapic, sulfometuron methyl), except for a few cases of low risk (imazapyr, metsulfuron methyl), suggesting that prohibiting the use of these herbicides would not likely benefit wildlife and could indirectly harm wildlife if more toxic herbicides that are currently available to the BLM were used in their place.

Alternative $\mathrm{E}$ incorporates other management practices that would be likely to have positive impacts on wildlife communities and habitats. Alternative E would limit the use of broadcast applications, which would reduce the possible risks to wildlife associated with off-site drift and consumption of vegetation across large areas. However, these applications would be available for use in appropriate situations (i.e., where no other method was practical and susceptible non-target plant species and aquatic areas were distant from the application area), which would allow some positive ecosystem benefits from larger-scale herbicide applications. In addition, herbicides would not be used in National Riparian Conservation Areas, which would protect wildlife species that frequent the riparian zone and attendant ecosystem functions in these key areas. While per-treatment ecosystem benefits could be greater under Alternative $E$ than under the other herbicide-use alternatives as a result of this ecosystem-based management approach, overall benefits to vegetation and ecosystems across the 17 western states (that cannot be attained by other treatment methods) would be lower under this alternative because of the relatively low treatment acreage and the inability to use certain practices in situations that might require their use (e.g., use of ALS-inhibiting herbicides on highly aggressive weeds).

\section{Mitigation for Herbicide Treatment Impacts}

The following actions would reduce the risks to wildlife associated with herbicide applications:

- Apply dicamba, diuron, glyphosate, hexazinone, tebuthiuron, and triclopyr at the typical application rate to minimize risks to terrestrial wildlife.

- Minimize the size of application areas, where practical, when applying 2,4-D, bromacil, diuron, and Overdrive ${ }^{\circledR}$ to limit impacts to wildlife, particularly through the contamination of food items.

- Where practical, limit glyphosate and hexazinone to spot applications in rangeland and wildlife habitat areas to avoid contamination of wildlife food items.

- Avoid using glyphosate formulations that include $\mathrm{R}-11^{\mathbb{B}}$ in the future, and either avoid using any formulations with POEA, or seek to use the formulation with the lowest amount of POEA available to reduce risks to amphibians.

- Do not aerially apply diquat directly to wetlands or riparian areas.

- Do not apply bromacil and diuron in rangelands, and use appropriate buffer zones (see Vegetation section) to limit contamination of off-site vegetation, which may serve as forage for wildlife.

\section{Special Status Wildlife Species}

\section{Introduction}

As discussed in Chapter 3, public lands in the western U.S. support over 200 species of terrestrial wildlife (including birds, mammals, amphibians, reptiles, mollusks, and arthropods) that have been given a special status based on their rarity or sensitivity. Included are 67 species that are federally listed as threatened or endangered, or are proposed for federal listing. Some of these species have habitat requirements that have been or are being altered or reduced by invasions of nonnative plant species. The Vegetation Treatments on Bureau of Land Management Lands in 17 Western States Programmatic Biological Assessment (USDI BLM 2007b) provides a description of the distribution, life history, and current threats for each federally-listed 
animal species, as well as species proposed for listing. The BA also discusses the risks to federally-listed terrestrial wildlife associated with each of the herbicides proposed for use by the BLM under the different alternatives.

\section{Impacts Assessment Methodology}

The BLM reviewed the literature and findings from ERAs conducted by the BLM and Forest Service to assess the impacts to sensitive wildlife species from the use of herbicides (ENSR 2005b-k; SERA 2005a). The ERA methods are summarized earlier in this section. Methods used by the BLM are presented in detail in the Vegetation Treatments Programmatic EIS Ecological Risk Assessment Protocol (ENSR 2004) and in Appendix C; methods used by the Forest Service can be viewed at http://www.fs.fed.us/r6/invasiveplant-eis/.

As discussed earlier, the USEPA has defined various LOCs for use in assessing risks to different organisms. As far as risks to terrestrial wildlife are concerned, the LOC for acute risks to endangered species is the most conservative. However, there is only one LOC to determine chronic risks. Risk assessments completed by the BLM used the USEPA's chronic risk LOC and the acute high risk when documenting risks to most terrestrial wildlife. Risk assessments used the chronic risk LOC and the acute endangered species LOC when documenting risks to special status terrestrial wildlife.

There are potential risks to special status wildlife species associated with herbicide use. Although the predicted risks for adverse health effects to individual organisms are the same as those predicted for non special status wildlife, the associated population- and species-level effects would be much greater for many sensitive species because of their limited/fragmented distribution and limited population size. Risks to special status wildlife can be minimized by following certain SOPs, which can be implemented at the local level according to specific conditions (see Table 2-8). These SOPs include the following:

- Survey for special status wildlife species before treating an area. Consider effects to these species when designing treatment programs.

- Use drift reduction agents to reduce the risk of drift hazard.

- Select herbicide products carefully to minimize additional impacts from degradates, adjuvants, inert ingredients, and tank mixtures.
- Avoid treating vegetation during time-sensitive periods (e.g., nesting and migration) for species of concern in the area to be treated.

\section{Summary of Herbicide Effects to Special Status Wildlife Species}

Non-native plant species reduce the suitability of some habitats to support special status wildlife species. For some species, particularly butterflies and moths, certain plant species must be present on a site to serve as larval host plants. Other species require, or at the very least prefer, certain plants as food sources. For example, lesser and Mexican long-nosed bats meet most of their dietary needs from agave and cactus (USFWS 1994b, 1995a), and the northern Idaho ground squirrel feeds on native bunchgrasses to fulfill a large portion of its dietary needs (USFWS 2000). Encroachment of nonnative plant species, and displacement of native plant species that serve as important sources of food, reduces the suitability of the habitat for these wildlife species Similarly, the risks to non-target plants associated with herbicide applications amount to indirect risks to these wildlife species through alteration of their habitat.

For some special status wildlife species it is the structure, rather than the species composition of the habitat, that makes it suitable. For example, the western snowy plover nests in areas where vegetation is sparse, the Yuma clapper rail is associated with dense marsh vegetation (USFWS 1997), the southwestern willow flycatcher occurs in riparian areas with dense growths of deciduous shrubs and trees (USFWS 1995b), and kangaroo rats require open, grassland conditions. In some cases, invasive plant species alter the structure of habitats, making them less suitable for supporting sensitive wildlife species (e.g., the encroachment of European beachgrass into western snowy plover habitat, or the exclusion of marsh vegetation by saltcedar and arrowweed in Yuma clapper rail habitat). For these species, use of herbicides to control weed infestations would likely provide a long-term benefit. In other cases, non-native plant species may invade an area without making drastic structural changes, and the suitability of the habitat, though not ideal, is maintained (e.g., thickets of saltcedar and Russian olive providing nesting habitat for the southwestern willow flycatcher, or desert kangaroo rats thriving in annual grasslands dominated by non-native plant species such as red brome). For these species, use of herbicides may result in some improvement of habitat, but the long-term benefits may not outweigh the short-term risks to the species associated with herbicide treatments. 
Some special status wildlife species occupy a wide variety of plant community types, as long as they provide adequate food, cover, and breeding/nesting/denning habitat. These species tend to be larger animals that cover a larger geographic area and eat a wide variety of food items, such as gray wolves, grizzly bears, and bald eagles. Although these species could potentially benefit to some degree from weed control, and are typically at low risk for impacts from exposure to herbicide, they may be impacted through disturbances associated with herbicide treatments (e.g., presence of herbicide applicators, trucks/ATVs, and/or helicopters in their habitat).

The most conservative LOC of 0.1 was used to determine risks to special status terrestrial wildlife species. Terrestrial herbicides with the greatest likelihood of impacting special status wildlife species, via any exposure pathway, include 2,4-D, bromacil, diuron, and hexazinone, for which moderate to high risks to special status terrestrial wildlife were predicted for applications at the typical application rate, under one or more exposure scenario (Table 4-24). Terrestrial herbicides with the least likelihood of impacting special status wildlife species include chlorsulfuron, diflufenzopyr, imazapic, and sulfometuron methyl, for which no risks to special status wildlife were predicted via any exposure pathway.

Although amphibians are considered terrestrial wildlife during their terrestrial phase, they do have an aquatic phase that is not represented by risk assessments for other terrestrial animals. For these species, ERAs assumed that risks to fish (see Fish and Other Aquatic Organisms section of this chapter) represent risks to aquatic amphibians. Aquatic herbicides with the greatest likelihood of impacting special status amphibian species during a normal application to an aquatic habitat are diquat and the more toxic formulation of glyphosate. Normal applications of 2,4-D and imazapyr would not pose a risk to aquatic amphibians. Terrestrial herbicides with the greatest likelihood of impacting special status amphibian species as a result of a spill, drift, accidental direct spray into an aquatic habitat, or surface runoff are bromacil, diuron, and picloram. The following herbicides would pose no risk to aquatic amphibians, according to ERAs: chlorsulfuron, diflufenzopyr, imazapic, Overdrive ${ }^{\circledR}$, and sulfometuron methyl.

Altermative A - Continue Present Herbicide Use (No Action Alternative)

Under this alternative, approximately 305,000 acres of public lands would be treated with herbicides annually.
Based on the acreage that would be treated, it is likely that special status wildlife species would be exposed to herbicides less under this alternative than under the other herbicide-use alternatives. Adverse health effects associated with herbicide exposure should be less extensive as well. Risks to special status species would also be lower, although mitigation would be required to protect these species (as well as key plant food species) from harm under all alternatives, which should minimize differences in risk to special status species among the alternatives.

Out of the four herbicide-use alternatives, control of weed infestations would likely be the least extensive under this alternative, and weed populations would spread at a faster rate. Wildlife species for which native plant communities provide the most suitable habitat would likely fare the worst under this alternative, as far as the quality of their habitat was concerned. For wildlife species that can successfully utilize habitats comprised of non-native plant species, differences among alternatives would be less clear. Although control of weeds and encouragement of native conditions would typically benefit wildlife habitat in general, removal of species that provide key habitat components (such as saltcedar and Russian olive that support nesting southwestern willow flycatchers) could harm some special status species. There are also disturbances associated with herbicide applications that could temporarily impact some special status species. The degree of benefits and impacts to wildlife habitat from treatments would largely depend on where the treatments occurred.

Under this alternative, only those herbicides currently used by the BLM would be used to treat vegetation. The majority of the total acreage would continue to be treated with picloram, tebuthiuron, and 2,4-D. Out of all the herbicides currently used by the BLM, 2,4-D has the highest risk to wildlife, according to ERAs. Although it is likely that the BLM would continue to use 2,4-D extensively because it is inexpensive, alternatives that allow for the use of new herbicides (alternatives B, D, and E) may offer the BLM more options for substituting herbicides that are less toxic to wildlife where special status species occur. Picloram and tebuthiuron pose a low risk to wildlife if applied at the typical rather than the maximum application rate, so continued use of these herbicides would have little impact to special status wildlife species. 


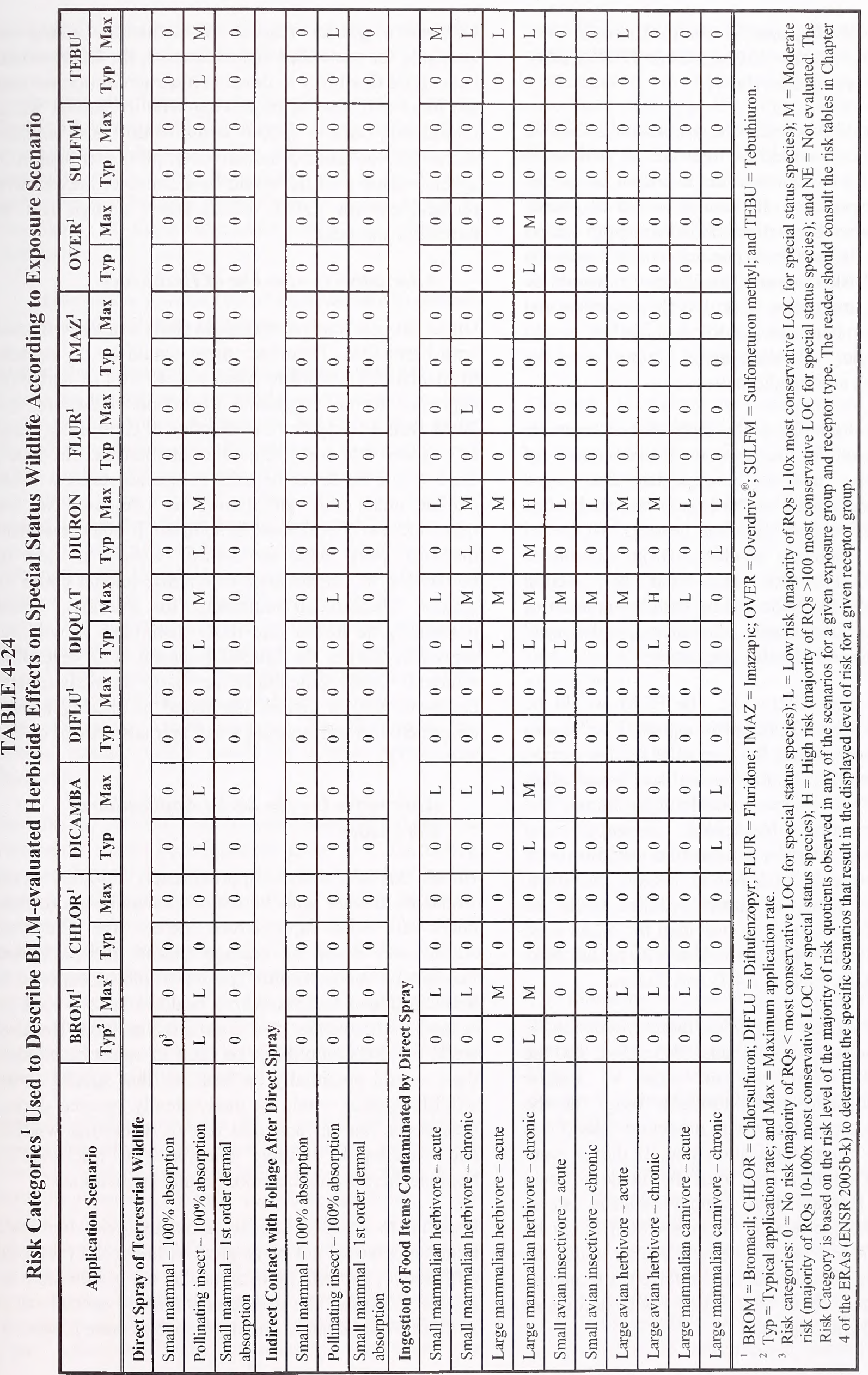




\section{Altermative B - Expand Herbicide Use and Allow for Use of New Herbicides in 17 Western States (Preferred Altermative)}

Under the Preferred Alternative, approximately 932,000 acres of public lands would be treated with herbicides annually. Based on this acreage, the incidence of special status wildlife exposure to herbicides would be greater than under the other alternatives. Adverse health effects associated with herbicide exposure would likely be greater as well. Risks to special status species would be greater, although mitigation to protect these species and their habitats from harm, as identified in the BA, would be required under all alternatives, minimizing the differences in risk among alternatives.

Out of all the alternatives, the Preferred Alternative would likely result in the most extensive control of weed infestations, and it is expected that weed populations would spread at the lowest rate under this alternative. Positive and negative impacts to special status wildlife habitat resulting from herbicide treatments, as discussed under the No Action Alternative, would likely be in line with the amount of acreage treated under each alternative, and would therefore be greatest under this alternative.

Under the Preferred Alternative, the BLM would be able to use 14 of the 20 currently approved herbicides that are currently available for use under the No Action Alternative, as well as four new herbicides and other new herbicides that become available in the future. The two new terrestrial herbicides, imazapic and diflufenzopyr pose no risks to sensitive wildlife under all exposure scenarios analyzed in ERAs. Therefore, risks to special status terrestrial wildlife could be reduced under this alternative, provided the BLM used these herbicides in place of herbicides with higher risks to sensitive wildlife, such as 2,4-D and diuron.

Of the two new aquatic herbicides, diquat poses low to high risks to aquatic amphibians, depending on the application rate. There are no risks to aquatic amphibians associated with fluridone usage at the typical application rate, but low to moderate risks if it is used at the maximum application rate. If diquat were used instead of another less toxic herbicide to treat vegetation in habitats that support special status amphibians, herbicide-related impacts would likely be greater under the Preferred Alternative than under the No Action Alternative. Under the Preferred Alternative, however, less than $1 \%$ of acres treated with herbicides would be treated with diquat.
Because a greater number of herbicides would be available for use under this alternative, the BLM would have more flexibility to develop treatment programs that are more effective at improving wildlife habitat while minimizing risks to special status wildlife species than under the No Action Alternative. Of particular benefit to special status wildlife would be a suitable, inexpensive replacement for 2,4-D, which poses a high risk to terrestrial animals.

\section{Alternative C-No Use of Herbicides}

Under this alternative, no public lands would be treated with herbicides. Therefore, there would be no impacts to special status wildlife species as a result of herbicide exposure during vegetation treatments. However, the BLM would likely be less effective at controlling weed infestations than under the other alternatives. Therefore, there would be fewer benefits to special status wildlife habitat under this alternative, as compared to the herbicide-use alternatives. In addition, if other treatment methods were used to control weeds in lieu of herbicides, the disturbance to wildlife habitat could be greater. Mechanical treatments, for example, would potentially be louder and more disturbing to wildlife, especially during the breeding season, and vegetation removal would potentially be more immediate and complete, with a greater likelihood of altering habitat characteristics and injuring small animals present on the site.

\section{Alternative D - No Aerial Application of Herbicides}

Under this alternative, approximately 530,000 acres would be treated with herbicides annually, more than under all other alternatives except the Preferred Alternative. Based on acreage treated, the likelihood that special status wildlife species would be exposed to herbicides and suffer adverse health effects would be second highest under this alternative as well. Because aerial methods would not be used to apply herbicides, there would potentially be less risk that special status wildlife species would be inadvertently sprayed during treatments, but an increased risk of disturbing wildlife and crushing or hitting animals with trucks/ATVs because there would be more ground applications.

Benefits to wildlife habitat associated with herbicide treatments would not be as great as under the Preferred Alternative, particularly in areas that are inaccessible by ground methods. The degree of impact to special status wildlife would depend on which species were present in 
areas that could not be treated, and whether non-native plant species are a threat to their habitat.

Under this alternative, the herbicides available for use by the BLM would be the same as those discussed for the Preferred Alternative. The benefits associated with flexibility in selecting herbicides, and in using new herbicides that become available in the future, would be the same as those discussed under the Preferred Alternative.

\section{Alternative $E$ - No Use of Acetolactate Symthase- inhibiting Active Ingredients}

Under this alternative, approximately 466,000 acres would be treated with herbicides annually, more than under the No Action Alternative, but fewer than under the other herbicide-use alternatives. Considering only acres treated, special status wildlife species would be less likely to be exposed to herbicides, and therefore would experience fewer herbicide-related impacts than under the other action alternatives (with the exception of Alternative C). Impacts to special status amphibians and riparian species from herbicides would be reduced under this alternative, since herbicide use would be discouraged in areas populated by amphibians, and would not occur in riparian conservation areas. Furthermore, the limit in broadcast applications under this alternative would decrease the likelihood that special status wildlife would be directly sprayed by herbicides.

Benefits to wildlife habitat associated with herbicide treatments would be minimized under this alternative, but would still be greater than those under the No Action Alternative and Alternative C. The increased emphasis on passive restoration under Alternative $\mathrm{E}$ would likely benefit some special status wildlife species by reducing disturbance and preventing the spread of weeds in some areas. With this type of management in place, it is possible that fewer vegetation treatments would be necessary in certain areas, minimizing risks to special status wildlife species.

Under this alternative, the BLM would not be able to use chlorsulfuron, imazapic, imazapyr, metsulfuron methyl, sulfometuron methyl, or any other ALSinhibiting herbicides that are made available in the future. According to the ERAs, there are no risks to special status wildlife associated with exposure to chlorsulfuron, imazapic, or sulfometuron methyl under any exposure pathway, even when applied at the maximum application rate. In addition, there are no risks associated with exposure to imazapyr or metsulfuron methyl when applied at the typical application rate, except in the case of a small bird eating contaminated invertebrates (low risk). The risks associated with applying either of these two chemicals at the maximum application rate are none to low, depending on the exposure pathway. Since these ALSinhibiting herbicides are among the most benign as far as risks to terrestrial animals are concerned, there would be no apparent benefit to special status wildlife from discontinuing their use. Furthermore, there could be increased risks to special status wildlife from exposure to herbicides under this alternative if more toxic herbicides (such as 2,4-D, diuron, or hexazinone) were used in place of ALS inhibitors.

The risks to special status amphibians associated with the use of ALS-inhibiting herbicides are generally none or low, with the exception of an accidental spill exposure of imazapyr. Therefore, increased risks to special status amphibians could occur if the BLM substituted more toxic herbicides (e.g., bromacil, diuron, or glyphosate) in place of ALS inhibitors. However, since use of herbicides would be discouraged in areas populated by amphibians under this alternative, impacts to special status amphibians could still be lower under this alternative than under the other herbicide-use alternatives.

Since the BLM would be able to use new herbicides that are made available in the future under this alternative, there would be more flexibility for creating effective treatment programs that minimize risks to special status wildlife species than under alternatives $\mathrm{A}$ and $\mathrm{C}$. However, the inability to use ALS-inhibiting herbicides would reduce this flexibility below the level offered under alternatives $\mathrm{B}$ and $\mathrm{D}$.

\section{Mitigation for Herbicide Treatment Impacts}

The following mitigation is recommended to reduce the likelihood of impacts to special status terrestrial wildlife species from herbicide applications. This mitigation should be implemented in addition to the SOPs designed to protect wildlife and the general mitigation for wildlife.

- To protect special status wildlife species, implement all conservation measures for terrestrial animals presented in the Vegetation Treatments on Bureau of Land Management Lands in 17 Western States Programmatic Biological Assessment. Apply these measures to sensitive species, as well as listed species (refer to conservation measures for a similar 
size and type of species, of the same trophic guild).

- Avoid using glyphosate formulations that include $\mathrm{R}-11^{\circledR}$ in the future, and either avoid using any formulations with POEA, or seek to use the formulation with the lowest amount of POEA available, to reduce risks to special status amphibians.

\section{Livestock}

\section{Introduction}

Public lands provide an important source of forage for many ranches and help to support the agricultural component of many communities scattered throughout the West. Approximately 165 million acres of public lands are open to livestock grazing, with use levels established by the Secretary of the Interior and administered through the issuance of grazing permits/leases. The majority of the grazing permits issued by the BLM involve grazing by cattle, with fewer and smaller grazing permits for other kinds of livestock, primarily sheep and horses. Many allotments are managed according to an allotment management plan, which outlines how livestock grazing is managed to meet multiple-use, sustained-yield, and other needs and objectives, as determined through LUPs. Even if there is no allotment management plan, grazing is managed to ensure that 1) watersheds are in or are making significant progress towards properly functioning physical condition; 2) ecological processes including the hydrologic cycle, nutrient cycle, and energy flow are maintained; 3) water quality complies with state water quality standards; and 4) habitats are or are making significant progress towards being restored or maintained for proposed, candidate or listed federal threatened and endangered species and other special status species.

\section{Scoping Comments and Other Issues Evaluated in the Assessment}

This section aims to contribute to the understanding of the impacts of herbicides on non-target species, focusing on livestock.. Evaluation of direct impacts of herbicides to livestock will help in the selection of lesstoxic herbicides where feasible, which was a scoping concern identified by numerous respondents.

The alternatives present a variety of herbicide use levels (including no use) for evaluation of relative positive and negative effects on livestock, and one of the alternatives will evaluate the relative impacts of aerial versus ground application on livestock; these were key issues identified in the scoping process. Evaluation of the effects of herbicide use on livestock is in concert with the goal identified by some respondents of improving the management of public lands for multiple use and public benefit.

\section{Standard Operating Procedures}

Herbicide use poses a potential risk to livestock; however, risk can be minimized by following certain SOPs, which can be implemented at the local level according to specific conditions. The following general procedures are designed to reduce potential unintended impacts to livestock from the application of herbicides in the BLM vegetation management program:

- Whenever possible and whenever needed, schedule treatments when livestock are not present in the treatment area. Design treatments to take advantage of normal livestock grazing rest periods, when possible.

- As directed by the herbicide label, remove livestock from treatment areas prior to herbicide application, where applicable.

- Use herbicides of low toxicity to livestock, where feasible.

- Take into account the different types of application equipment and methods, where possible, to reduce the probability of contamination of non-target food and water sources.

- Avoid use of diquat in riparian pasture while pasture is being used by livestock.

- Notify permittees of the project to improve coordination and avoid potential conflicts and safety concerns during implementation of the treatment.

- Notify permittees of livestock grazing or feeding restrictions, if necessary (see below for restrictions associated with each herbicide).

- Notify adjacent landowners prior to treatment.

- Provide alternate forage sites for livestock, if possible. 
These procedures would help minimize impacts to livestock and rangeland on western BLM lands to the extent practical. As a result, long-term benefits to livestock from the control of invasive species would likely outweigh any short-term negative impacts to livestock associated with herbicide use.

\section{Impacts Assessment Methodology}

The BLM reviewed the literature and findings from ERAs conducted by the BLM and Forest Service to assess the impacts to livestock from the use of herbicides (ENSR 2005b-k; SERA 2005a). Risks to livestock were not specifically evaluated in these documents, which focused on risks to plants, fish and wildlife. However, results from the evaluation of terrestrial animal species can be applied to livestock species (i.e., results for large herbivores [154 pound mule deer] are applied to evaluate risks to common grazing animals on BLM lands - cows, sheep, and horses). The ERA methods are summarized in the Wildlife section of this chapter. Methods used by the BLM are presented in detail in the Vegetation Treatments Programmatic EIS Ecological Risk Assessment Protocol (ENSR 2004) and in Appendix C; methods used by the Forest Service can be viewed on the Internet at http://www.fs.fed.us/r6/invasiveplanteis/.

\section{Summary of Herbicide Impacts}

The extent of direct and indirect impacts to livestock would vary by the effectiveness of herbicide treatments in controlling target plants (that are not used as forage) and promoting the growth of native vegetation (that is used as forage), the extent and method of treatment (e.g., aerial vs. ground) and chemical used (e.g., toxic vs. non-toxic, selective vs. non-selective), the physical features of the terrain (e.g., soil type, slope), and the weather conditions (e.g., wind speed) at the time of application. Possible adverse direct effects to individual animals include death, damage to vital organs, change in body weight, decreases in healthy offspring, and increased susceptibility to predation. Possible adverse indirect effects include reductions in forage amount and preferred forage type. The impacts of herbicide use on livestock would depend directly on the sensitivity of each species to the particular herbicides used, the pathway by which the individual animal was exposed to the herbicide, and indirectly on the degree to which a species or individual is positively or negatively affected by changes in rangeland conditions, including forage quality and availability.
Livestock would have a greater chance of being directly adversely impacted by herbicide use if their range extent was partially or completely sprayed because they would have greater exposure to herbicides - either via direct contact with the herbicide upon application or indirect contact via dermal contact with vegetation or ingestion of vegetation. However, livestock could be removed from an area during vegetation treatment, or treatments could be scheduled to occur when livestock were not present, reducing the potential risks. If livestock are removed from the area specifically to facilitate vegetation treatment, the grazing permittee would be adversely affected as a result of the area being unavailable for grazing purposes. The permittee would need to either find alternative pasture somewhere else, or modify ranching operations to account for the unavailable forage, which would result in increased costs and/or a loss of income.

Even though large treatments (e.g., aerial applications on rangelands) would usually occur when livestock are not in the treated pasture, some risk of indirect contact and consumption of contaminated vegetation over a large area would still exist. Some spot treatments could be applied at any time, regardless of the presence of livestock, but in situations where spot treatments are proposed in livestock concentration areas such as riparian areas, treatments may need to be conducted when livestock are not present or temporary fencing may be needed to reduce livestock exposure.

Livestock may experience greater impacts in systems where herbicide transport is more likely, such as areas where herbicides are aerially sprayed adjacent to rangeland, dry areas with high winds, or areas where rainfall is high and soils are porous; however these scenarios have not been modeled. The degree of interception by vegetation, which depends on site and application characteristics, would also affect direct spray impacts. As is evident, the impacts of herbicide use on livestock would be site and application specific, and as such, site assessments would have to be performed, using available impact information, to determine an herbicide-use strategy that would minimize impacts to livestock.

The BLM and Forest Service risk assessments suggested several possible common impacts of herbicides to livestock (ENSR 2005b-k; SERA 2005a). Livestock, which likely consume large amounts of grass, have a relatively greater risk for harm than animals that feed on other herbaceous vegetation or seeds and fruits, because herbicide residue is higher on 
grass than it is on other plants (Fletcher et al. 1994, Pfleeger et al. 1996); this is especially evident when examining risk levels of large mammalian herbivores in the BLM risk assessments. However, harmful doses of herbicide are not likely unless the animal forages exclusively within the treatment area for an entire day, suggesting that smaller treatments may be more appropriate for rangelands in cases where an herbicide has demonstrated risk to herbivores under scenarios involving consumption of contaminated vegetation.

In cases where herbicide treatments reduce the cover of noxious and unpalatable weeds on grazed lands, there would be short- and long-term benefits to livestock from increased quality of forage. In some cases, herbicides are the most effective means of controlling or eradicating invasive plant species. Noxious weed infestations can greatly reduce the land's carrying capacity for domestic livestock, which tend to avoid most-weeds (Olson 1999). Cattle, in particular, preferentially graze native plant species over weeds, which often have low palatability as a result of defenses such as toxins, spines, and/or distasteful compounds. In addition, some noxious weeds (e.g., common tansy, houndstongue, Russian knapweed, and common St. Johnswort) are poisonous to livestock. Although goats and sheep are more likely to consume alien weeds than cattle, they also tend to select native or introduced forage species over weeds (Olsen and Wallander 1998, Olson 1999). The success of weed removal would determine the level of benefit of the treatments over the long term.

Treatments that reduce the risk of future catastrophic wildfire through fuels reduction would also benefit livestock. Weeds that may present a fire hazard in rangelands include downy brome, Russian thistle, burningbush, oak, pinyon, and juniper. Uncontrolled, high intensity wildfires can remove forage from large tracts of rangeland, reducing its suitability for livestock grazing. Some herbicides are approved for use in BLM programs for rangeland as well as fuels management (e.g., glyphosate).

Over the short term, there would be minor impacts to livestock rearing as a result of mandatory restrictions associated with the use of herbicides. Livestock owners would not be able to slaughter (for food) animals that have consumed forage that has been treated by certain herbicides within the time period specified on the herbicide label. In addition, dairy animals would not be allowed to graze on areas treated with certain chemicals for the time period specified on the label.

\section{Impacts of BLM-evaluated Herbicides}

According to BLM risk assessments, herbicide exposure scenarios of direct spray, spill, and indirect contact with foliage after direct spray do not pose a risk to small mammals (large mammals were not modeled, but have a smaller surface area to body weight ratio, so are less likely to be impacted by these scenarios than small mammals; Table 4-25). Several herbicides do pose a risk to large mammalian herbivores under a scenario of ingestion of food items contaminated by direct spray. Risks to livestock associated with each individual herbicide are presented below. See the tables and figures in Section 4 of the ERAs (ENSR 2005b-k) for each herbicide for risk information on applicable ecological receptor groups according to herbicide application method. Also, see Table 4-25 in this section for a summary of the typical degree of risk each of the BLM herbicides pose to possible livestock receptors under different routes of exposure. Large mammalian herbivores were evaluated for a scenario in which they ingest food items contaminated by direct spray of the herbicide. The receptor chosen for the large mammalian herbivore was a 154-pound mule deer. Chlorsulfuron, imazapic, and Overdrive ${ }^{\circledR}$ are the BLM-evaluated herbicides that would be most likely to be used in rangeland situations with grazing livestock. However, it is possible that other herbicides used nearby could impact livestock if they are transported off site.

\section{Bromacil}

Bromacil does not present a risk to small mammals via direct spray or indirect contact with foliage after direct spray (Table 4-25; ENSR 2005b). These scenarios are very conservative because they assume $100 \%$ absorption and because small mammals have a relatively larger surface area for absorption of herbicide. Therefore, it is unlikely that bromacil would affect larger livestock under these scenarios. No acute risk and low chronic risk were predicted for a large mammalian herbivore ingesting vegetation sprayed at the typical application rate, and low acute and moderate chronic risks were predicted for ingestion scenarios at the maximum application rate. Therefore, direct spray of bromacil onto rangeland could pose a risk to livestock consuming sprayed vegetation. The prediction of chronic risk to livestock suggests that caution is needed in applying this herbicide in forage areas, particularly over large areas. However, bromacil is a non-selective herbicide that is not registered for application on rangelands or other livestock grazing areas where some vegetative cover is desired, suggesting that under 


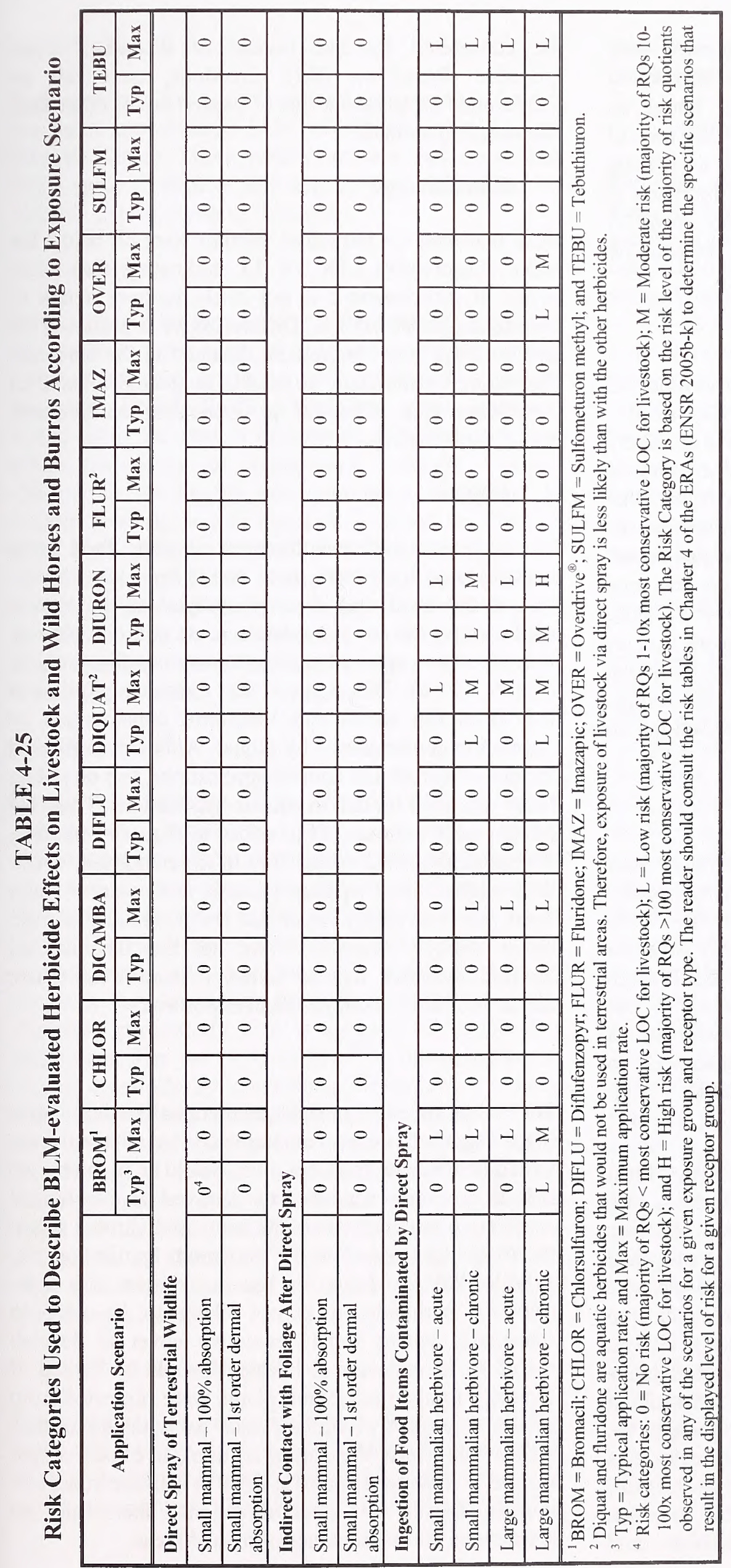


typical use bromacil would not impact livestock. Any risk would come from off-site transport of bromacil to livestock grazing areas - a situation that could be avoided by following SOPs, including the use of appropriate buffer zones to prevent drift to off-site vegetation (see Vegetation section). Use of bromacil in spot applications or over small areas is not likely to impact livestock. Based on label directions, there are no restrictions on livestock use of treated areas.

\section{Chlorsulfuron}

Risk quotients for mammalian receptors for all modeled scenarios were below the conservative LOC of 0.1 , indicating that direct spray of chlorsulfuron is not likely to pose a risk to livestock (ENSR 2005c). Therefore, as chlorsulfuron is likely to be used in rangelands, this herbicide would primarily affect (positively or negatively) livestock through changes in the quality and abundance of forage. If used properly, its use in range and pasture areas could benefit livestock over the long term by controlling unpalatable invasive plant species and promoting the establishment and growth of native plant species that may be more desirable for forage. Based on label directions, there are no restrictions on livestock use of treated areas.

\section{Dicamba}

Overdrive $^{\circledR}$ is a formulation of dicamba and diflufenzopyr; an analysis of risks to livestock for dicamba was conducted during preparation of the Overdrive ${ }^{\circledR}$ ERA. However, an ERA report for dicamba was not done by the BLM as part of this PEIS, although some information on dicamba is included in the Overdrive $^{\circledR}$ ERA. The Forest Service conducted an ERA for dicamba, and the reader is encouraged to review this document (available at: http://www.fs.fed.us/foresthealth/pesticide/risk.shtml).

The ingestion of food items contaminated by direct spray of dicamba at the maximum application rate would pose a low acute and chronic risk to large mammalian herbivores. Because dicamba is proposed for use in rangelands and forestlands and does have moderate residual activity, livestock may be at risk from the application of this chemical, particularly if it is sprayed throughout the range area. The use of dicamba in rangeland could benefit livestock by controlling unpalatable invasive plant species and promoting the establishment and growth of native plant species that may be more suited for forage. However, because chlorsulfuron and imazapic are less risky to livestock and have similar target species, these herbicides could be considered for use instead of dicamba, where possible. Based on label directions, there are no restrictions on livestock use of treated areas, other than for lactating animals.

\section{Diflufenzopyr}

Risk quotients for terrestrial animals were all below the most conservative LOC of 0.1 , indicating that direct spray of diflufenzopyr is not likely to pose a risk to livestock (ENSR 2005d). Diflufenzopyr is proposed for use with the active ingredient dicamba in the herbicide Overdrive $^{\circledR}$, which may be used in rangelands. Based on label directions, there are no restrictions on livestock use of treated areas.

\section{Diquat}

For large mammalian herbivores ingesting food items contaminated by diquat, there would be a low chronic risk if the food was directly sprayed at the typical application rate, and a moderate acute and chronic risk if the food was sprayed at the maximum application rate (ENSR 2005e). This suggests that livestock could be at risk from the short- and long-term consumption of vegetation contaminated by diquat. Although registered for non-cropland and aquatic applications, use on public lands would be limited to aquatic applications. Thus, the likelihood of exposure of livestock to diquat is minimal. Livestock that feed exclusively in riparian areas, where drift might impact riparian grasses, and/or drink water from ponds treated with diquat are potentially at risk. These unlikely scenarios were not directly modeled because livestock will be removed from areas where diquat is used to avoid potential exposure.

\section{Diuron}

For scenarios involving large mammalian herbivores ingesting food items contaminated by diuron, there would be no acute risks but there would be high chronic risk if the food was directly sprayed at the typical application rate, and moderate acute and chronic risk if the food was sprayed at the maximum application rate (ENSR 2005f). However, because diuron is a nonselective herbicide, it is not likely to be used in rangelands where some vegetative cover is desired; therefore, its exposure to livestock would be limited. If typically foraged rangeland plants were protected from off-site transport of diuron, such as with appropriate buffer zones (see Vegetation section), livestock should not be at risk from off-site drift or surface runoff of diuron. Based on label directions, there are no restrictions on livestock use of treated areas. 


\section{Fluridone}

Risk quotients for large terrestrial animals were below the most conservative LOC of 0.1 for all scenarios (ENSR 2005g). These results indicate that accidental direct spray or drift of this aquatic herbicide would be unlikely to pose a risk to livestock.

\section{Imazapic}

Risk quotients for terrestrial animals were all below the most conservative LOC of 0.1 , indicating that direct spray of imazapic would be unlikely to pose a risk to livestock (ENSR 2005h). Therefore, since imazapic would likely be used in rangelands, it would primarily affect (positively or negatively) livestock through changes in the quality and abundance of forage. If applied properly, use of imazapic in range and pasture areas could benefit livestock over the long term by controlling unpalatable invasive plant species and promoting the establishment and growth of native plant species that may be more desirable for forage. Based on label directions, there are no restrictions on livestock use of treated areas.

\section{Overdrive $^{\circledR}$}

Overdrive $^{\circledR}$ poses a low chronic risk to large mammalian herbivores that consume plants contaminated by direct spray at the typical application rate and a moderate risk for ingestion scenarios involving direct spray at the maximum application rate (ENSR 2005i). Because Overdrive ${ }^{\circledR}$ is proposed for use in rangelands and has moderate residual activity, livestock may be at risk from the application of this chemical, particularly if it is sprayed throughout the range area. The use of Overdrive ${ }^{\circledR}$ in rangeland could benefit livestock by controlling unpalatable invasive plant species and promoting the establishment and growth of native plant species that may be more suited for forage. However, because chlorsulfuron and imazapic are less risky to livestock and have similar target species, these herbicides could be considered for use instead of Overdrive ${ }^{\circledR}$, where possible. Based on label directions, there are no restrictions on livestock use of treated areas.

\section{Sulfometuron Methyl}

Risk quotients for terrestrial animals were all below the most conservative LOC of 0.1 , indicating that direct spray of sulfometuron methyl would be unlikely to pose a risk to livestock (ENSR 2005j). This herbicide is relatively non-selective, and is not registered for sites that are grazed. Thus, it should not impact livestock.

\section{Tebuthiuron}

For large mammalian herbivores ingesting food items contaminated by tebuthiuron, there would be a low acute and chronic risk if the food was directly sprayed at the maximum application rate (ENSR 2005k). The strength of this herbicide is its use as a habitat modifier in the BLM shrub reduction program; it is relatively non-selective but does not tend to harm grasses present. Therefore, impacts to livestock would be unlikely with intended use of this herbicide. According to the label for Spike 80DF, which has tebuthiuron as an active ingredient, if a treated area is to be used for haying or grazing, no more than 5 pounds per acre of Spike 80DF should be applied, and the product should not be applied more than once per year.

\section{Impacts of Forest Service-evaluated Herbicides}

The following information for eight herbicides proposed for use by the BLM is taken from ERAs performed by the Forest Service to support assessment of the environmental consequences of using these herbicides in Forest Service vegetation management programs (risk assessment results available at SERA [2005a]). Because the Forest Service completed these ERAs prior to completion of the PEIS, the BLM would use these ERAs to assess the potential ecological impacts of using these herbicides in future BLM vegetation management activities. The BLM previously evaluated and approved these eight herbicides in an earlier EIS-Vegetation Treatment on BLM Lands in Thirteen Western States (USDI BLM 1991a). As part of its risk assessments (see USDA Forest Service 2005), the Forest Service developed worksheets (see SERA 2005b), which allowed the BLM to assess the risks of the herbicides using its own maximum application rates and LOCs (rather than the Forest Service rates and LOCs), and to parallel the BLM risk assessment process as much as possible. However, modeled risk scenarios for terrestrial animals may be different than those used for the BLMevaluated herbicides, depending on the specificity of available toxicity data. The assessment of impacts below is presented using the Forest Service upper estimates of HQs, to maximize the conservatism of the assessment. In addition, it should be noted that the HQs developed by the Forest Service (as well as the BLM) are already conservative for many reasons (e.g., assumption of $100 \%$ dermal absorption, assumption of $100 \%$ of diet contaminated, use of most sensitive values for exposure and dose/response assessments). 2,4-D, 
clopyralid, glyphosate, metsulfuron methyl, and triclopyr are the Forest Service-evaluated herbicides that are most likely to be used in rangeland situations with grazing livestock. However, it is possible that other herbicides used nearby could impact livestock if they were transported off site.

\section{$2,4-D$}

2,4-D does present some risk to livestock under direct spray and ingestion sccnarios (Table 4-26; SERA 1998). Large livestock may face less risk from direct spray than small livestock because they have a smaller surface area to volume ratio over which to absorb the herbicide. Direct spray impacts to livestock can largely be prevented if animals are removed from target areas before spraying 2,4-D. Small mammals, and perhaps smaller livestock, face low risk from the consumption of water contaminated by a spill. In addition, livestock face risk from the consumption of vegetation contaminated by 2,4-D at the application site: large mammals face moderate acute and chronic risk, and small mammals face low acute risk, for both the typical and maximum application rates. Large livestock that primarily consume grasses are particularly susceptible to adverse effects under the vegetation consumption scenarios, although long-term consumption of contaminated vegetation may be unlikely if the vegetation shows signs of damage. The risk assessment suggests that because large livestock eating large quantities of grass and other vegetation are at risk from routine exposure to 2,4-D and because 2,4-D is considered for use in rangeland, this herbicide should not be applied over large application areas where livestock would only consume contaminated food.

According to label directions for one formulation, dairy animals should be kept out of areas treated with 2,4-D for 7 days. Grass for hay should not be harvested for 30 days after treatment. Meat animals should be removed from treated areas 3 days prior to slaughter. Similar restrictions may be in place for other formulations, but users of 2,4-D should consult label directions before applying formulations of this active ingredient.

\section{Clopyralid}

According to the Forest Service risk assessment (SERA 2004b), clopyralid is not likely to pose a risk to terrestrial animals. However, there are a few scenarios involving clopyralid applications under which livestock would be at low risk. For all modeled application rates, small mammals are at low chronic and acute risk from $100 \%$ absorption of direct spray and consumption of contaminated insects, and large mammals face risk low chronic and acute risks from consumption of contaminated vegetation at the typical and maximum application rates. Application of clopyralid at the maximum application rate also poses a low chronic risk to large mammals consuming on-site contaminated vegetation. The most likely livestock risk scenario would be the consumption of contaminated grass across large areas by large livestock, which could be avoided by restricting access of livestock to sprayed areas. In addition, all risks identified fall within the lowest risk category.

According to label directions, there are no restrictions on grazing or hay harvest following application at labeled rates, and livestock should not be transferred from treated grazing areas to sensitive broadleaf crop areas without first allowing for 7 days of grazing on untreated pasture.

\section{Glyphosate}

Livestock face some risk from the use of glyphosate in rangelands. Direct spray of a small animal, assuming $100 \%$ absorption, poses a low risk at the typical application rate and moderate risk at the maximum application rate (SERA 2003a). Smaller livestock, such as sheep and goats, are more likely to experience adverse effects from direct spray than larger livestock, such as cattle and horses, because of their larger surface area-to-body weight ratios. Direct spray impacts can largely be prevented if livestock are removed from the target area before spraying glyphosate. Large mammals consuming contaminated vegetation face low acute risk for scenarios involving the typical application rate, and moderate acute risk for scenarios involving the maximum application rate, and low chronic risk for scenarios involving maximum application rate. Small mammals face low risk from consumption of contaminated vegetation (fruit) sprayed at the maximum application rate. The most likely risk scenario is the consumption of contaminated vegetation (acute exposure), which is particularly risky for cattle because they consume large amounts of grasses, which contain higher herbicide residue levels than other herbaceous vegetation and seeds. Glyphosate is used in rangelands for the management of grasses and broadleaves, including woody species, and it is non-selective, suggesting that spot applications in rangeland would be the most appropriate use of this herbicide. Spot applications would reduce risks associated with 


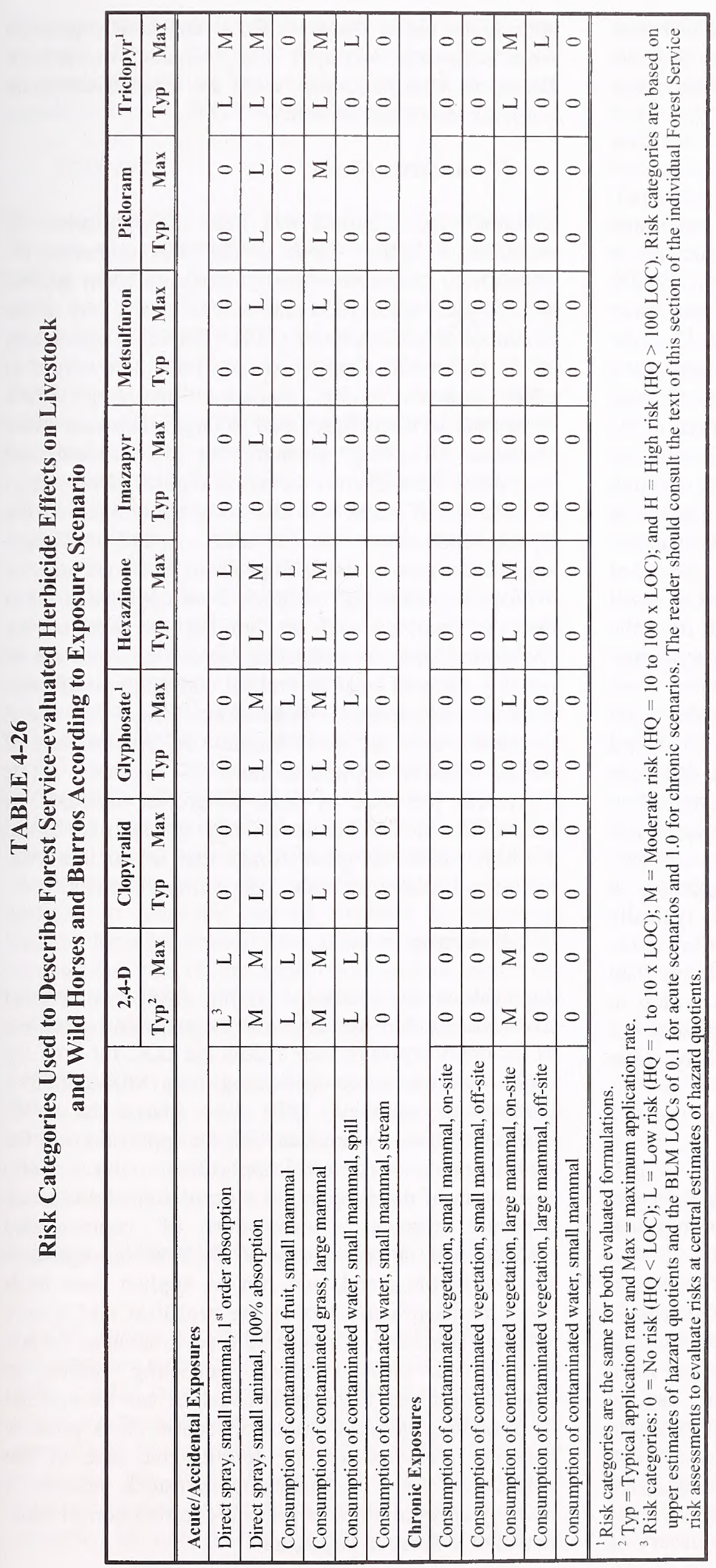


consumption of contaminated vegetation, as fewer nontarget areas would be impacted by direct spray or spray drift. Based on label directions, there are no restrictions on livestock use of treated areas.

\section{Hexazinome}

Applications of hexazinone at the typical and maximum application rates would pose a low to moderate risk to livestock under several exposure scenarios (SERA 1997). Small mammals face low risk from direct spray at the maximum application rate, assuming $1^{\text {st }}$ order dermal absorption, and low to moderate risk assuming $100 \%$ dermal absorption. Acute exposure through consumption of contaminated vegetation sprayed at the maximum application rate poses a low risk to small mammals; and acute and chronic exposure through consumption of contaminated vegetation poses a moderate risk to large mammals. Also, acute exposure through consumption of contaminated water sprayed at the maximum application rate poses a low risk to small mammals. It appears that livestock are at risk from the application of hexazinone, but if food and water sources are not contaminated, risks are reduced, as direct spray can be avoided by removing livestock from the target area prior to treatment. Contamination of food and water sources could be minimized by utilizing spot applications of hexazinone at the typical application rate. Because hexazinone is used for woody species, it is not likely to be applied in rangelands where invasive plants are usually grasses or herbaceous vegetation. In addition, hexazinone is semi-selective, and is typically only applied in spot applications; therefore, risks to livestock under normal application may be lower than those predicted by the risk assessment. According to label directions, livestock should not be grazed, nor forage or hay cut, on treated areas for 60 days after application.

\section{Imazapyr}

Applications of imazapyr at the typical application rate should not pose a risk to livestock, assuming that livestock consume primarily vegetation (SERA 2004d). Applications at the maximum application rate, however, would pose a low risk to livestock under a couple exposure scenarios: direct spray of a small animal and consumption of contaminated vegetation by a large mammal. Imazapyr is not registered for use in rangelands; therefore, it is unlikely that impacts via direct spray or consumption of contaminated vegetation would occur. The chance of adverse effects could be further minimized by removing livestock from areas near application sites prior to spraying and by observing appropriate buffer distances from rangeland vegetation when applying imazapyr (see Vegetation section). Based on label directions, there are no restrictions on livestock use of treated areas.

\section{Metsulfuron Methyl}

Livestock face minimal risk from the application of metsulfuron methyl. None of the HQs estimated for exposure to metsulfuron methyl exposure when applied at the typical application rate indicate risk to any of the terrestrial animal receptors (SERA 2004e). Applications at the maximum application rate pose a low risk to small animals under scenarios involving 100\% absorption of direct spray and to large mammals under scenarios involving consumption of contaminated vegetation. Metsulfuron methyl is registered for use in rangeland, but impacts to livestock are unlikely if the typical application rate is used. If the maximum application rate is used, impacts to livestock can be avoided by removing livestock from application areas prior to spraying and by limiting the size of the application area or restricting access of livestock to recently sprayed areas to prevent consumption of large amounts of sprayed vegetation. Based on label directions, there are no restrictions on livestock use of treated areas for application rates of $1 \frac{2}{3}$ ounces active ingredient per acre or less. If greater amounts of metsulfuron methyl are used, forage grasses may be cut for hay, fodder, or green forage and fed to livestock, including lactating animals, 3 days after treatment.

\section{Picloram}

Application of picloram is not likely to impact livestock. Most of the HQs for the evaluated scenarios of picloram exposure were below the LOC for both the typical and maximum application rates (SERA 2003b). Under two scenarios, HQs were above the LOC, indicating a low to moderate risk for applications at the typical and maximum application rates: $100 \%$ absorption of direct spray by a small animal and acute exposure through consumption of contaminated vegetation by a large mammal. Picloram is registered for use in rangeland, and can be applied over large areas, as its primary targets are broadleaf and woody species. Therefore, it might be used to manage certain broadleaved plants without impacting native or desirable grasses. Impacts to livestock can be avoided by removing animals from application areas prior to spraying picloram and by limiting the size of the application area or restricting livestock access to recently sprayed areas to prevent consumption of large amounts of sprayed vegetation. 
Picloram has a number of restrictions on use in areas grazed by livestock or used for cutting hay. In general, livestock should not be grazed on treated areas, nor should hay be cut, for 2 weeks after treatment.

\section{Triclopyr}

Triclopyr presents some risk to livestock, particularly through the consumption of contaminated vegetation (SERA 2003c). Because risk categories determined using calculated HQs for the two evaluated formulations of triclopyr (triclopyr acid and triclopyr BEE) are the same, no differentiation will be made between these two formulations in this section. The following scenarios pose a low risk for applications at the typical application rate, and moderate risk for applications at the maximum application rate: first-order and 100\% absorption of direct spray by a small mammal, and acute and chronic exposure through consumption of on-site contaminated vegetation by a large mammal. In addition, for applications at the maximum application rate, there would be a low risk associated with exposure through acute consumption of water contaminated by a spill by the small mammal and chronic exposure through consumption of off-site contaminated vegetation by the large mammal. No risk is predicted for small mammals as a result of acute or chronic exposure through consumption of contaminated vegetation or water. Triclopyr can be used in rangelands to selectively manage woody species without impacting native or desirable grasses. It also has low residual activity. Impacts to livestock can be avoided by removing animals from application areas prior to spraying and by limiting the size of the application area or restricting access of livestock to recently sprayed areas to prevent consumption of large amounts of sprayed vegetation.

There are few grazing restrictions for triclopyr, except for lactating dairy cattle. Hay should not be harvested within 14 days of application. Although cattle can graze at any time they would be removed from treated areas at least 3 days prior to slaughter.

\section{Impacts of Other Herbicides Currently Available for Use}

2,4-DP, asulam, atrazine, fosamine, mefluidide methyl, and simazine were approved for use in the earlier BLM EISs. 2,4-DP could be used in forested rangeland, but would not be used in areas where livestock graze. It has low toxicity to mammals. Asulam is of low toxicity to mammals, but livestock should not graze in treated areas or be fed forage from treated areas. It would primarily be used in the control of brackenfern on forested rangelands (Information Ventures, Inc. 1995a). Atrazine could be used for vegetation treatments in conifer plantations, but would not be used in forested or other rangelands where livestock might come in contact with the herbicide. It is slightly to moderately toxic to mammals (Information Ventures, Inc. 1995b; Extension Toxicology Network 1996e). Fosamine does not have a rangeland registration and would not be used where livestock graze. It is practically nontoxic to mammals (USEPA 1995). Mefluidide would not be cost-effective to use on rangelands. It is of low to moderate toxicity to mammals (Information Ventures, Inc. 1995c). Simazine could be used by the BLM on Christmas tree plantations, but would likely not be used where livestock graze. Simazine has low toxicity to most mammals, although sheep and cattle are more sensitive to simazine than other mammals, and a dose as low as $500 \mathrm{mg} / \mathrm{kg}$ can be fatal (Information Ventures, Inc. 1995d). The BLM has not used any of these herbicides, except fosamine ( $<50$ acres annually), since 1997, and does not plan to utilize them in the near future.

\section{Impacts by Alternative}

The following sections discuss the expected effects of each of the five alternatives on livestock, and compare the effects expected under each alternative with those expected under the other alternatives. These effects may vary depending on the percentage of acres treated using different application methods and different herbicides, as well as on the size of treatment events.

\section{Alternative A - Continue Present Herbicide Use (No Action Alternative)}

Under the No Action Alternative, the BLM would continue its ongoing vegetation treatment programs in 14 western states, and would be able to use 20 herbicides previously approved under earlier RODs. Herbicide use under the No Action Alternative could impact livestock over an estimated 305,000 acres. Impacts to livestock (positive and negative) would be similar in nature those that have occurred in the past 10 years. Negative impacts to livestock may be lower than under the other herbicide-use alternatives because fewer total acres would be treated using herbicides. However, long-term positive impacts on livestock communities (i.e., improvements in rangeland forage) could be lower under this alternative, as well. Invasive plant populations would likely continue to expand at the current rate or more quickly, potentially increasing damage to desirable native forage, and the abundance of unpalatable or toxic plants. 
Because the new herbicides proposed in this PEIS (diquat, fluridone, imazapic, and Overdrive ${ }^{\circledR}$ ) would not be used under this alternative, risks to livestock would be different than under the other alternatives. Fluridone and imazapic do not present any risks to livestock in modeled scenarios (similar to chlorsulfuron, metsulfuron methyl, and sulfometuron methyl), and Overdrive $^{\circledR}$ poses low to moderate risk to large livestock under chronic exposure scenarios in which the animal ingests contaminated vegetation over a long time period. Diquat is fairly toxic to livestock, particularly under food ingestion scenarios (similar to 2,4-D and diuron). However, because diquat would be used by the BLM as an aquatic herbicide, frequent exposure to livestock would not be expected. Therefore, the No Action Alternative would prevent the BLM from using a greater repertoire of herbicides that are not injurious to terrestrial animals, possibly resulting in greater per area risks to livestock than under the other alternatives if more injurious herbicides (e.g., 2,4-D, bromacil, diuron, tebuthiuron, triclopyr) were used instead of safer alternatives, as well as decreasing the possibilities of more effective rangeland improvements. Conversely, prohibiting the use of diquat, particularly in rangeland riparian areas, could result in somewhat lower per area risk to livestock than under the other alternatives.

2,4-DP, asulam, atrazine, fosamine, mefluidide, and simazine were approved for use in the earlier BLM EISs, but the BLM has not used any of these herbicides, except fosamine ( $<50$ acres annually) since 1997, and does not plan to utilize them in the near future. None of these herbicides would normally be used in rangeland treatments where livestock might come into contact with the chemical. Instead, the BLM would use other herbicides, including triclopyr, sulfometuron methyl, bromacil, diuron, and Overdrive ${ }^{\circledR}$, which are effective in controlling weeds and invasive vegetation, but have less risk to livestock.

\section{Alternative B - Expand Herbicide Use and Allow for Use of New Herbicides in 17 Western States (Preferred Alternative)}

The Preferred Alternative would result in the treatment of approximately 932,000 acres in 17 western states. In addition to the 14 previously approved herbicides, the BLM would be able to use the four new herbicides evaluated in this PEIS. This alternative would result in the most extensive effects to livestock (both negative and positive) because it proposes the most acres for treatment ( 3 times the acreage that would be treated under the No Action Alternative). The extent of positive and negative impacts to livestock would depend on the relative amount each of the herbicides was used, whether they would be applied in rangeland environments, and the method of application. The chance for negative impacts would be highest if diuron, diquat, bromacil and/or 2,4-D were used extensively. However, diquat would be used by the BLM as an aquatic herbicide, and bromacil and diuron are nonselective herbicides that are not likely to be used extensively in rangelands. If these herbicides were used in restricted scenarios, as proposed, and other herbicides were used effectively to increase the abundance of native forage relative to unpalatable weeds, positive impacts to livestock could outweigh negative impacts. Furthermore, the ability to use the four new herbicides (diquat, fluridone, imazapic, and Overdrive ${ }^{\circledR}$ ) as well as future herbicides that become registered with the USEPA would allow BLM managers more options in choosing herbicides that best match treatment goals and application conditions and are less toxic. As a result, there could be an increase in per capita benefits and a reduction in overall per capita risks to livestock (three of the four new herbicides present little to no risk to livestock), and an increase in habitat and ecosystem benefits from treatment. This alternative would also reduce risks and negative impacts associated with other vegetation management methods (e.g., risk of escaped prescribed fires; see the PER).

\section{Alternative C - No Use of Herbicides}

Under Alternative $\mathrm{C}$, livestock would not be affected by herbicide use. Primary impacts would stem from other vegetation treatment methods (see the PER). Positive benefits to rangelands as a result of vegetation management could be reduced under this alternative, as certain invasive species are only effectively controlled by herbicides, and in some situations other methods are impractical due to cost, time, or public concerns. For example, mechanical and manual methods are impractical over large land areas, which are more effectively treated by broadcast herbicide applications. In addition, it is often difficult to eradicate some species (e.g., rabbitbrush, honey mesquite, sand shinnery oak, tree cholla), by means other than herbicide application. Similarly, pre-emergent herbicides that persist in the soil are the most effective means of controlling invasive plants with seeds that remain viable for long periods of time.

Under this alternative, without the use of herbicides, invasive plant populations would likely continue to spread, possibly at increasing rates. The spread of invasive plant populations would cause further damage to susceptible native plant communities, including 
rangeland communities that provide forage for livestock, particularly in situations where other treatment methods would not be effective or feasible (e.g., large tracts of rangeland or grassland dominated by invasive, resprouting shrubs; or areas without enough fine fuels to carry prescribed fires). The spread of invasive plant populations would likely have deleterious effects on livestock. Rangeland that contains excessive or unpalatable brush cover is less useful for grazing and has reduced carrying capacity for domestic livestock. Similarly, capacity for cattle grazing decreases proportionately with loss of forage caused by weed infestation. Economic returns in terms of improved grazing value typically exceed herbicide treatment costs on lands where herbicides are used to control weeds (Olson 1999). In addition, acres infested by noxious weeds that are toxic to livestock, including common tansy, leafy spurge, Russian knapweed, common St. Johnswort, tansymustard, and yellow starthistle, would increase; in contrast, these species would be targeted by the BLM for herbicide treatments under the other alternatives.

\section{Alternative D - No Aerial Applications}

Alternative D would be the same as the Preferred Alternative as far as herbicides that could be used, and areas that could be treated. Therefore, both alternatives would be equally likely to have both positive and negative effects on livestock and rangeland. The BLM would be able to choose from a suite of currentlyapproved herbicides and herbicides that could be approved under this PEIS, or in the future. However, this alternative would not allow the BLM to apply herbicides aerially. Fewer acres would be treated (535,000 acres) because some large areas, including rangelands, cannot be effectively treated by ground application methods. This alternative would substantially reduce the impacts of off-site drift to livestock, an exposure scenario that is not specifically modeled for most herbicides (consumption of contaminated vegetation off-site was modeled for most of the Forest Service herbicides, with no risk demonstrated to livestock for any of these herbicides, except triclopyr when applied at the maximum application rate). Conversely, without the option to spray herbicides aerially, large areas of rangeland may remain untreated under Alternative $\mathrm{D}$, and which could negatively impact livestock habitat and forage in these areas over the long term.

Under this alternative, long-term negative impacts to rangeland could be greater than any potential short-term negative effects to livestock that would result from aerial applications, particularly given that livestock would be removed from rangeland application areas before aerial spraying. Furthermore, most of the herbicides that are potentially damaging to livestock (e.g., bromacil, diquat, diuron, glyphosate, hexazinone, tebuthiuron) are not likely to be applied aerially in rangelands, and aerial spraying of other damaging herbicides (e.g., 2,4-D, Overdrive ${ }^{\circledR}$ ) could be avoided. In addition, direct and indirect impacts from other vegetation treatment options could increase if these methods were used more extensively to compensate for the reduced number of acres treated by herbicides (see PER).

\section{Alternative $\mathbb{E}$ - No Use of Acetolactate Synthase- inhibiting Active Ingredients}

Approximately 466,000 acres would be treated under Alternative E, which is slightly less than the acreage that would be treated under Alternative D, and less than half of the acreage that would be treated under the Preferred Alternative, but is still an increase from the average annual treatment acreage that has occurred over the past 8 years and would likely occur under the No Action Alternative. Herbicide-related impacts to livestock would be lower under this alternative than under the Preferred Alternative because fewer acres would be treated with herbicides, and additional protective standards would be required during herbicide treatment (e.g., preferential use of spot rather than broadcast applications, preferential treatment of small versus large infestations).

Sulfonylurea herbicides and other ALS-inhibiting herbicides (e.g., chlorsulfuron, imazapic, imazapyr, metsulfuron methyl, sulfometuron methyl) block the synthesis of amino acids that are required for protein production and cell growth, thereby resulting in plant death. ALS-inhibiting herbieides would not be used under this alternative because data suggest they have the potential to damage off-site native and crop plant species under the right conditions of environment and application. These herbicides are biologically active at low concentrations, and are applied at lower application rates than other herbicides to manage target plants. It is uncertain whether use of these herbicides would result in fewer cases of unintended damage to livestock and rangeland due to lower application rates, or more cases due to the high potency of the herbicides and their persistence. In 1981, the Environmental Effects Division of the USEPA recommended against registering sulfonylurea herbicides because they persist for long periods of time in the environment and they cannot be detected at low levels. However, risk 
assessments did not predict risk to livestock for any of the ALS-inhibiting herbicides, when applied at the typical application rate, under any of the modeled scenarios, suggesting that prohibiting the use of these herbicides would not benefit livestock and could indirectly harm livestock if more toxic herbicides were used in their place.

Alternative $\mathrm{E}$ incorporates other management practices that would be likely to have positive impacts on livestock and rangelands. Alternative $\mathrm{E}$ would limit the use of broadcast applications, which would reduce the possible risks to livestock associated with off-site drift and consumption of vegetation across large areas. However these applications would be available for use in appropriate situations (i.e., where no other method is practical, and susccptible non-target plant species and aquatic areas are distant from the application area), which would result in some ecosystem benefits from larger-scale herbicide applications. While per-treatment ecosystem benefits may be greater under Alternative E than under the other herbicide-use alternatives as a result of this ecosystem-based management approach, overall positive vegetation and ecosystem benefits (that cannot be attained by other treatment methods) across the western states would be lower under this alternative because of the relatively small treatment acreages and the inability to use certain practices in situations that might require their use (e.g., usc of ALS-inhibitor herbicides on highly aggressive weeds). For example, imazapic, which has been shown to be effective in treating downy brome and leafy spurge, would be unavailable under this alternative. The BLM would also be unable to use chlorsulfuron and metsulfuron methyl to control yellow starthistle and several species of thistle that are harmful to livestock.

\section{Mitigation for Herbicide Treatment Impacts}

The following actions would greatly reduce the risk of herbicide applications to livestock:

- Apply diuron, glyphosate, hexazinone, tebuthiuron, and triclopyr at the typical, rather than maximum, application rate to minimize risks to livestock.

- Do not apply 2,4-D, bromacil, dicamba, diuron, Overdrive $^{\circledR}$, picloram, or triclopyr across large application areas, where feasible, to limit impacts to livestock, particularly through the contamination of food items.
- Where feasible, limit glyphosate and hexazinone to spot applications in rangeland to avoid contamination of food items.

- Do not aerially apply diquat directly to wetlands or riparian areas.

- Do not apply bromacil or diuron in rangelands, and use appropriate buffer zones (see Vegetation section in this chapter) to limit contamination of off-site rangeland vegetation.

\section{Wild Horses and Burros}

\section{Introduction}

The BLM, in conjunction with the Forest Service, manages wild horses and burros on BLM- and Forest Service-administered lands through the Wild FreeRoaming Horse and Burro Act of 1971. Animals are managed within 201 Wild Horse and Burro herd management areas, with the goal of maintaining the natural ecological balance of public lands as well as the ability to support multiple uses. Public lands inhabited by wild horses or burros are closed to grazing by domestic horses and burros under permit or lease. In FY 2005 , wild horse and burro populations on public lands totaled over 31,760 animals, with nearly half of these animals living in Nevada (Table 3-7). Another 25,000 animals are held in holding pens. The population of wild horses and burros is approximately 4,000 animals above the Appropriate Management Level (AML) of 27,500. The AML is an estimate of the number of wild horses and burros that public lands can support while maintaining a thriving natural ecological balance (USDI BLM 2006c, d).

The proposed herbicide vegetation management activities could affect wild horses and burros through exposure to chemicals that could harm their health, or through changes in vegetation that could positively or negatively alter the carrying capacity of the HMAs. Adverse impacts to wild horses and burros could include direct harm to wild horses and burros and a reduction in the availability or quality of forage in HMAs (decreasing the carrying capacity of the HMAs). Alternately, herbicide vegetation management activities could improve the amount and quality of forage, potentially increasing the carrying capacity of the HMAs. 


\section{Scoping Comments and Other Issues Evaluated in the Assessment}

This section aims to contribute to the understanding of the impacts of herbicides on non-target species, focusing on wild horses and burros. The evaluation of the direct impacts of herbicides to wild horses and burros would help in the selection of less-toxic herbicides where feasible, a scoping concern identified by numerous respondents. The alternatives present a variety of herbicide use levels (including no use) for evaluation of relative positive and negative effect on wild horses and burros, and one of the alternatives will evaluate the relative impacts of aerial versus ground application; these were key issues identified in the scoping process. Evaluation of the effects of herbicide use on wild horses and burros is in concert with the goal identified by some respondents of improving the management of public lands for multiple use and public benefit.

\section{Standard Operating Procedures}

Herbicide use carries a potential risk to wild horses and burros. However, risks can be minimized by following certain SOPs, which can be implemented at the local level according to specific conditions (see Table 2-8). These SOPs include the following:

- Use herbicides of low toxicity to wild horses and burros, where feasible.

- Remove wild horses and burros from identified treatment areas prior to herbicide application, in accordance with label directions for livestock.

- Take into account the different types of application equipment and methods, where possible, to limit the probability of contaminating non-target food and water sources.

These procedures would help to minimize impacts to wild horses and burros and rangeland on western public lands to the extent practical. As a result, long-term benefits to wild horses and burros from the control of invasive species would likely outweigh any short-term negative impacts to these animals associated with herbicide use.

\section{Impacts Assessment Methodology}

The BLM reviewed the literature and findings from ERAs conducted by the BLM and Forest Service to assess the impacts to wild horses and burros from the use of herbicides (ENSR 2005b-k; SERA 2005a). Risks to wild horses and burros were not specifically evaluated in these documents, which focused on risks to plants, fish, and wildlife. However, results from the evaluation of large terrestrial animal herbivores can be applied to wild horses and burros (i.e., results for large herbivores [154 pound mule deer] are used to evaluate risks to common grazing animals on public lands, including wild horses and burros). The ERA methods are summarized in the Wildlife Resources section of this chapter. Methods used by the BLM are presented in detail in the Vegetation Treatments Programmatic EIS Ecological Risk Assessment Protocol (ENSR 2004) and in Appendix C. Methods used by the Forest Service can be viewed on the Internet at http://www.fs.fed.us/r6/invasiveplant-eis/.

\section{Summary of Herbicide Impacts}

The extent of direct and indirect impacts to wild horses and burros would vary by the effectiveness of herbicide treatments in controlling target plants (that are not used as forage) and promoting the growth of native vegetation (that is used as forage); the extent and method of treatment (e.g., aerial vs. ground); the chemical used (e.g., toxic vs. non-toxic, selective vs. non-selective); the physical features of the terrain (e.g., soil type, slope); the weather conditions (e.g., wind speed); and the time of year (e.g., newborn horses and burros would be susceptible during foaling season, with March through June being a critical period) at the time of application. Potential adverse direct effects to individual animals as a result of exposure to herbicides include death, damage to vital organs, change in body weight, decreases in healthy offspring, and increased susceptibility to predation.

Adverse indirect effects could include reductions in forage amount and preferred forage type. Additionally, wild horses and burros may move out of herd management areas and onto lands that are not legally designated for wild horse and burro management. Possible positive effects include improvement in the quality and amount of forage and improvement in general habitat conditions. The impacts of herbicide use on wild horses and burros would depend directly on the sensitivity of each species to the particular herbicides used and the pathway by which the individual animal is 
exposed to the herbicide, and indirectly on the degree to which a species or individual is positively or negatively affected by changes in herd management area conditions.

Wild horses and burros would have a greater chance of exposure to herbicides-either via direct contact with the herbicide upon application or indirect contact via dermal contact with vegetation or ingestion of vegetation-if their range extent was partially or completely sprayed. However, it is unlikely that the entire range of a horse or burro herd would be sprayed, as these animals are wide ranging, and herd management areas are often larger than 10,000 to 100,000 acres (most treatments [77\%] would be less than 1,000 acres).

Wild horses and burros may also experience greater impacts under conditions where herbicide transport is more likely, such as in areas where herbicides are aerially sprayed adjacent to herd management areas, dry areas with high winds, or areas with extensive rainfall and porous soils. However, these scenarios were not modeled.

The BLM and Forest Service risk assessments suggested several possible common impacts of herbicides to wild horses and burros (USDA Forest Service 2005; ENSR 2005b-k; SERA 2005a). Wild horses and burros, which likely consume large quantities of grass, are at relatively greater risk for harm than smaller wildlife or wildlife that feed on other herbaceous vegetation, seeds, or fruits, which have less herbicide residue than grass (Fletcher et al. 1994; Pfleeger et al. 1996). This is especially evident in the sections of the BLM ERAs that examine risk levels of large mammalian herbivores. However, harmful doses of herbicide may be unlikely unless the animal forages exclusively within the treatment area for an entire day, suggesting that smaller treatments may be more appropriate for herd management areas in cases where risk to herbivores from the consumption of contaminated vegetation is predicted by the ERAs.

In cases where herbicide treatments are able to reduce the cover of noxious and unpalatable weeds on grazed lands and replace them with more palatable native plants, there would be benefits to wild horses and burros associated with increased availability and quality of forage. An increase in the amount of forage within a given herd management area could increase the carrying capacity of that area. Many herd management areas are currently overburdened with wild horse and burro populations that exceed the appropriate management level.

Herbicide use, or a combination of herbicide use and another treatment method, may be the most effective means of controlling or eradicating some invasive plant species. Noxious weed infestations can greatly reduce the land's carrying capacity for domestic wild horses and burros, which tend to avoid weeds that have low palatability as a result of defenses such as toxins, spines, and/or distasteful compounds (e.g., thistle [Olson 1999]). In addition, some noxious weeds (e.g., horsetail, wild mustard, poison hemlock, tansy ragwort, yellow starthistle, and common St. Johnswort) are poisonous to horses. Grazing may ultimately be an effective means of managing invasive plants in HMAs. However, if vegetation is overgrazed (e.g., as a result of HMAs supporting horses and wild burros in excess of the AML), another method, such as herbicide treatment, is required to return vegetation to a more desirable composition, followed by grazing within the carrying capacity of the HMA. The success of weed removal would determine the level of benefit of the treatments over the long term.

Treatments that reduce the risk of future catastrophic wildfire through fuels reduction would also benefit wild horses and burros. Weeds of concern that could be found in rangelands include downy brome, medusahead, halogeton, rabbitbrush, diffuse knapweed, Russian thistle, and perennial pepperweed. Uncontrolled, high intensity wildfires can remove forage from large tracts of rangeland, reducing its suitability for wild horse and burro grazing. Some herbicides are approved for use in BLM programs for rangeland as well as fuels management (e.g., glyphosate, imazapic, sulfometuron methyl).

\section{Impacts of BLM-Evaluated Herbicides}

BLM risk assessments indicate that herbicide exposure scenarios of direct spray and spill and indirect contact with foliage after direct spray would pose a risk to small mammals (large mammals were not modeled, but have a smaller surface area-to-body weight ratio, and are less likely to be impacted under these scenarios than small mammals). Several herbicides would pose a risk to large mammalian herbivores under the scenario of ingestion of food items contaminated by direct spray. Specific estimated risks to wild horses and burros from each individual herbicide are presented below. See the tables and figures in Section 4 of the ERAs (ENSR 2005b-k) for each herbicide for risk information on applicable ecological receptor groups according to herbicide 
application method. Also, see Table 4-25 for a summary of the typical degree of risk each of the BLM herbicides poses to wild horse and burro receptors under different routes of exposure. Small mammals were used in direct spray and indirect contact with directly sprayed foliage scenarios. Because small mammals have a relatively larger surface area for absorption of herbicide and because $100 \%$ absorption is assumed, it is unlikely that wild horses and burros would be at more risk than small mammals. Large mammalian herbivores were used in the ingestion of food items contaminated by direct spray scenario. The receptor chosen for the large mammalian herbivore was a 154-pound mule deer. Chlorsulfuron, imazapic, and Overdrive ${ }^{\circledR}$ are the BLM-evaluated herbicides that are most likely to be used in rangeland situations with grazing wild horses and burros; however, it is possible that other herbicides used nearby could impact wild horses and burros if they were transported off site.

\section{Bromacil}

Bromacil does not present a risk to small mammals via direct spray or indirect contact with foliage after direct spray (ENSR 2005b). These scenarios are very conservative because they assume $100 \%$ absorption, and small mammals have a relatively larger surface area for absorption of herbicide than large mammals. Therefore, it is unlikely that bromacil would affect larger wild horses and burros under these scenarios. No acute risk and low chronic risk were predicted for a large mammalian herbivore ingesting vegetation sprayed at the typical application rate, and low acute and moderate chronic risks were predicted for ingestion scenarios at the maximum application rate. Therefore, direct spray of bromacil onto rangeland could pose a risk to wild horses and burros that consume sprayed vegetation. The predicted chronic risk to wild horses and burros suggests that caution is needed in applying this herbicide in HMAs, particularly over large areas. However, because bromacil is a non-selective herbicide and is registered for non-cropland applications, it is not likely to be used in HMAs where vegetative cover is desired, suggesting that under typical use bromacil would not impact wild horses and burros. Any risk would come from off-site transport of bromacil to wild horse and burro grazing areas - a situation that could be avoided by following SOPs, including the use of appropriate buffer zones to prevent drift to off-site vegetation (see Vegetation section of this chapter). Use of bromacil in spot applications or over small areas would be unlikely to impact wild horses and burros.

\section{Chlorsulfuron}

Risk quotients for mammalian receptors for all modeled scenarios were all below the most conservative LOC of 0.1 , indicating that direct spray of chlorsulfuron would not likely pose a risk to wild horses and burros (ENSR 2005c). Therefore, as chlorsulfuron may be used in HMAs, this herbicide would primarily affect (positively or negatively) wild horses and burros through changes in the quality and abundance of forage. If used properly, its use in range and pasture areas could benefit wild horses and burros over the long term by controlling unpalatable invasive plant species and promoting the establishment and growth of native plant species that may be more desirable for forage.

\section{Dicamba}

Overdrive $^{\circledR}$ is a formulation of dicamba and diflufenzopyr; an analysis of risks to horses and burros for dicamba was conducted during preparation of the Overdrive ${ }^{\circledR}$ ERA. However, an ERA report for dicamba was not done by the BLM as part of this PEIS, although some information on dicamba is included in the Overdrive $^{B}$ ERA. The Forest Service conducted an ERA for dicamba, and the reader is encouraged to review this document (available at http://www.fs.fed.us/foresthealth/pesticide/risk.shtml).

The ingestion of food items contaminated by direct spray of dicamba at the maximum application rate poses a low acute and chronic risk to large mammalian herbivores. Because dicamba is proposed for use in rangelands and forestlands and has moderate residual activity, wild horses and burros may be at risk from the application of this chemical, particularly if it is sprayed throughout the range area. The use of dicamba in rangeland could benefit wild horses and burros by controlling unpalatable invasive plant species and promoting the establishment and growth of native plant species that may be more suited for forage. However, because chlorsulfuron and imazapic are less risky to wild horses and burros and have similar target species, these herbicides could be considered for use instead of dicamba, where possible.

\section{Diflufenzopyr}

Risk quotients for terrestrial animals were all below the most conservative LOC of 0.1 , indicating that direct spray of diflufenzopyr would not likely pose a risk to wild horses and burros (ENSR 2005d). Diflufenzopyr is proposed for use with the active ingredient dicamba in 
the herbicide Overdrive ${ }^{(B)}$, which may be used in rangelands.

\section{Diquat}

Ingestion of food items contaminated by direct spray would pose a low chronic risk to large mammalian herbivores if diquat was applied at the typical application rate, and moderate acute and chronic risk if applied at the maximum application rate (ENSR 2005e). This suggests that wild horses and burros could be at risk from the short- and long-term consumption of vegetation contaminated by diquat. However, because diquat is an aquatic herbicide that is not proposed for use in terrestrial areas, the likelihood that wild horses and burros would be exposed to diquat is very minimal. Of most concern would be wild horses and burros that feed exclusively in riparian areas, where drift might impact riparian grasses; however, this unlikely scenario was not modeled.

\section{Diuron}

Ingestion of food items contaminated by direct spray of diquat would pose no acute risk and moderate chronic risk to large mammalian herbivores if diuron was applied at the typical application rate, and low acute risk and high chronic risk if applied at the maximum application rate (ENSR 2005f). However, because diuron is a non-selective herbicide and is registered for non-cropland applications, it is not likely to be used in rangelands where some vegetative cover is desired. Therefore, exposure of wild horses and burros to diuron would be limited. If typically foraged rangeland plants were protected from off-site transport of diuron, such as with appropriate buffer zones (see Vegetation section in this chapter), then wild horses and burros would not likely be at risk from off-site drift or surface runoff of diuron.

\section{Fluridone}

Risk quotients for large terrestrial animals were below the most conservative LOC of 0.1 for all scenarios (ENSR 2005g). These results indicate that accidental direct spray or drift of this aquatic herbicide would not likely pose a risk to wild horses and burros.

\section{Imazapic}

Risk quotients for terrestrial animals were all below the most conservative LOC of 0.1 , indicating that direct spray of imazapic would not likely pose a risk to wild horses and burros (ENSR 2005h). Proper use of imazapic in range and pasture areas could benefit wild horses and burros over the long term by controlling unpalatable invasive plant species and promoting the establishment and growth of native plant species that may be more desirable for forage.

\section{Overdrive ${ }^{\circledR}$}

Overdrive ${ }^{\circledR}$ poses low chronic risk to large mammalian herbivores that consume plants contaminated by direct spray at the typical application rate and a moderate risk for ingestion rates at the maximum application rate (ENSR 2005i). Because Overdrive ${ }^{\circledR}$ is proposed for use in rangelands and has moderate residual activity, wild horses and burros may be at risk from the application of this chemical, particularly if it is sprayed throughout the range area (an unlikely scenario). The use of Overdrive ${ }^{\circledR}$ in rangeland could benefit wild horses and burros by controlling unpalatable invasive plant species and promoting the establishment and growth of native plant species that may be more suited for forage. However, because chlorsulfuron and imazapic are less risky to wild horses and burros and have similar target species, these herbicides could be considered for use instead of Overdrive ${ }^{\circledR}$, where possible.

\section{Sulfometuron Methyl}

Risk quotients for terrestrial animals were all below the most conservative LOC of 0.1 , indicating that direct spray of sulfometuron methyl is not likely to pose a risk to wild horses and burros (ENSR 2005j). Because this herbicide is relatively non-selective, it is not likely to be used in HMAs, and therefore, should result in few negative or positive impacts on wild horses and burros.

\section{Tebuthiuron}

The ingestion of food items contaminated by direct spray of tebuthiuron at the maximum application rate would pose a low acute and chronic risk to large mammalian herbivores (ENSR 2005k). Tebuthiuron is not prominently used in rangeland habitat; the strength of this herbicide is its use as a habitat modifier, including thinning sagebrush to improve sage-grouse habitat. It is relatively non-selective but does not tend to harm grasses that are present. Therefore, impacts to wild horses and burros would be unlikely with intended use of this herbicide.

\section{Impacts of Forest Service-evaluated Herbicides}

The following information for eight herbicides proposed for use by the BLM is taken from ERAs performed by 
the Forest Service to support assessment of the environmental consequences of using these herbicides in Forest Service vegetation management programs (risk assessment results available at USDA Forest Service [2005] and SERA [2005a]). Because the Forest Service completed these ERAs prior to completion of the PEIS, the BLM would use these ERAs to assess the potential ecological impacts of using these herbicides in future BLM vegetation management activities. The BLM previously evaluated and approved these eight herbicides in an earlier EIS-Vegetation Treatment on BLM Lands in Thirteen Western States (USDI BLM 1991a). As part of its risk assessments (see USDA Forest Service 2005), the Forest Service developed worksheets (see SERA 2005b), which allowed the BLM to assess risks of the herbicides using its own maximum application rates and LOCs (rather than the Forest Service rates and LOCs), to parallel the BLM process as much as possible. However, modeled risk scenarios for terrestrial animals may be different than those used for the BLM-evaluated herbicides, depending on the specificity of available toxicity data. The assessment of impacts below is presented using the Forest Service upper estimates of HQs, to maximize the conservatism of the assessment. In addition, it should be noted that the development of HQs by the Forest Service and the BLM is already conservative for many reasons (e.g., assumption of $100 \%$ dermal absorption, assumption of $100 \%$ of diet contaminated, use of most sensitive values for exposure and dose/response assessments). 2,4-D, clopyralid, glyphosate, metsulfuron methyl, and triclopyr are the Forest Service-evaluated herbicides that are most likely to be used in rangeland situations with grazing wild horses and burros. However, it is possible that other herbicides used nearby could impact wild horses and burros if they were transported off site.

\section{2,4-D}

2,4-D could pose a risk to some wild horses and burros as a result of direct spray as well as ingestion of sprayed vegetation (Table 4-26; SERA 1998). Adult wild horses and burros may face less risk from direct spray than young wild horses and burros because they have a smaller surface area to volume ratio over which to absorb the herbicide. Direct spray impacts to wild horses and burros from 2,4-D can largely be prevented if animals are removed from target areas before spraying. In addition, wild horses and burros face risk from the consumption of vegetation contaminated by 2,4-D at the application site; large mammals face moderate acute and chronic risk for ingestion scenarios involving both the typical and maximum application rates, and small mammals face low acute risk for ingestion scenarios involving the typical and maximum application rates. Large wild horses and burros that primarily consume grasses are particularly susceptible to risk under the vegetation consumption scenarios. However, long-term consumption of contaminated vegetation may be unlikely if the vegetation shows signs of damage. The risk assessment suggests that because large wild horses and burros eating large quantities of grass and other vegetation could be at risk from routine exposure to 2,4-D, and because 2,4-D is considered for use in rangeland, this herbicide should not be applied over large application areas where foragers would consume only contaminated food.

\section{Clopyralid}

According to the Forest Service risk assessment (SERA 2004b), clopyralid unlikely to pose a risk to terrestrial animals. However, under a few scenarios there would be a low acute risk to wild horses and burros. Small mammals are at risk from $100 \%$ absorption of direct spray and consumption of contaminated insects, and large wild horses and burros face risk from the consumption of contaminated vegetation. Application of clopyralid at the maximum application rate also poses low chronic risk to large wild horses and burros consuming on-site contaminated vegetation. The most likely risk scenario would be the consumption of contaminated grass across large areas by wild horses and burros, which could likely be avoided by restricting access of these animals to sprayed areas. In addition, all risks identified fall within the lowest risk category.

\section{Glyphosate}

Wild horses and burros would face some risk from the use of glyphosate in rangelands. Direct spray of a small animal, assuming $100 \%$ absorption, would pose a low risk if glyphosate was applied at the typical application rate, and a moderate risk if applied at the maximum application rate (SERA 2003a). Risks to small wild horses and burros from direct spray would likely be greater than risk to large wild horses and burros, because of their larger surface area to body weight ratios. Direct spray impacts from glyphosate can largely be prevented if wild horses and burros arc removed from the target area before spraying glyphosate. For large mammals consuming contaminated vegetation, there would be low acute risk associated with applications at the typical application rate, and moderate acute risk and low chronic risk associated with applications at the maximum application rate. For small mammals there would be low risk associated with 
consumption of contaminated vegetation sprayed at the maximum application rate. The most likely risk scenario is the acute consumption of contaminated vegetation, which is particularly risky for herbivores that consume large amounts of grasses, which contain higher herbicide residue levels than other herbaceous vegetation and seeds. Glyphosate is used in rangelands for the management of grasses and broadleaves, including woody species. It is non-selective, suggesting that spot applications in rangeland would be the most appropriate use of this herbicide, because they would reduce of the likelihood that wild horses and burros would consume contaminated vegetation, since fewer non-target areas would be impacted by direct spray or spray drift.

\section{Herazinone}

At the typical and maximum application rates, several scenarios could potentially pose low to moderate risk to wild horses and burros (SERA 1997). Small mammals directly sprayed by hexazinone at the maximum application rate would face a low risk, assuming $1^{\text {st }}$ order dermal absorption, and low to moderate risk assuming 100\% dermal absorption. Acute exposure through consumption of contaminated vegetation would pose a low risk to small mammals if hexazinone was applied at the maximum application rate; acute and chronic exposure through consumption of contaminated vegetation would pose a moderate risk to large mammals. Also, acute consumption of contaminated water would pose a low risk to small mammals if hexazinone was applied at the maximum application rate. It appears that wild horses and burros would be at risk from adverse effects from hexazinone applications. However, if food and water sources were not contaminated, risks would be minimized, and direct spray could be avoided by removing wild horses and burros from the target area prior to treatment. Contamination of food and water sources could be minimized by utilizing spot applications of hexazinone at the typical application rate. Because hexazinone is used for woody species, it would not likely be applied in rangelands where invasive plants are usually grasses or herbaceous vegetation. In addition, hexazinone is semiselective, and is typically only applied in spot applications; therefore, risks to wild horses and burros under normal applications may be lower than those predicted by the risk assessment.

\section{Imazapyr}

For applications of imazapyr at the typical application rate, ERAs predicted no risks to wild horses and burros under any exposure scenario (SERA 2004d). For applications at the maximum application rate, however, there is a low risk to wild horses and burros under two scenarios: direct spray (small animal) and consumption of contaminated vegetation (large mammal). Imazapyr is not registered for use in rangelands; therefore, it is unlikely that impacts via direct spray or consumption of contaminated vegetation would occur. The likelihood of impacts could be further minimized by removing wild horses and burros from areas near to application sites prior to spraying and by observing appropriate buffer distances from HMA vegetation when applying imazapyr (see Vegetation section in this chapter).

\section{Metsulfuron Methyl}

Wild horses and burros would face minimal risk from the application of metsulfuron methyl. None of the HQs estimated for metsulfuron methyl exposure at the typical application rate indicate risk to any of the terrestrial animal receptors (SERA 2004e). When applied at the maximum application rate, metsulfuron methyl would pose a low risk to small animals via $100 \%$ absorption of direct spray and to large mammals via consumption of contaminated vegetation. Metsulfuron methyl is registered for use in rangeland, but impacts to wild horses and burros would be unlikely if the typical application rate was used. If the maximum application rate was used, impacts to wild horses and burros could be avoided by removing animals from application areas prior to spraying metsulfuron methyl, and by limiting the size of the application area or restricting access of wild horses and burros to recently sprayed areas to prevent consumption of large amounts of sprayed vegetation.

\section{Picloram}

Application of picloram would not likely impact wild horses and burros. Most of the HQs for the evaluated scenarios of picloram exposure were below the LOC for both the typical and maximum application rates (SERA 2003b). Under two scenarios HQs were elevated above the LOC, indicating low to moderate risk at the typical and maximum application rates: $100 \%$ absorption of direct spray by a small animal and acute exposure through consumption of contaminated vegetation by a large mammal. Picloram is registered for use in rangeland, and it could be applied over large areas, as its primary targets are broadleaf and woody species. Therefore, it could be used to manage certain broadleaved plants without impacting native or desirable grasses. Impacts to wild horses and burros could be avoided by removing animals from application 
areas prior to spraying picloram, and by limiting the size of the application area or restricting access of wild horses and burros to recently sprayed areas to prevent consumption of large amounts of sprayed vegetation.

\section{Triclopyr}

Triclopyr presents some risk to wild horses and burros, particularly through the consumption of contaminated vegetation (SERA 2003c). Because risk categories determined using calculated HQs for the two evaluated formulations of triclopyr (triclopyr acid and triclopyr BEE) are the same, no differentiation will be made between these two formulations in this section. The following scenarios pose a low risk for applications at the typical application rate, and a moderate risk for applications at the maximum application rate: $1^{\text {st }}$ order and $100 \%$ absorption of direct spray by a small mammal, and acute and chronic exposure through consumption of on-site contaminated vegetation by a large mammal. In addition, for applications at the maximum application rate, there would be a low risk associated with acute exposure through consumption of water contaminated by a spill by a small mammal, and chronic exposure through consumption of off-site contaminated vegetation by the large mammal. No risk is predicted for small mammals as a result of acute or chronic exposure through consumption of contaminated vegetation or water. Triclopyr can be used in rangelands to selectively manage woody species without impacting native or desirable grasses. It also has low residual activity. Impacts to wild horses and burros could be avoided by removing animals from application areas prior to spraying, and by limiting the size of the application area or restricting access of wild horses and burros to recently sprayed areas to prevent consumption of large amounts of sprayed vegetation. Because large wild horses and burros are susceptible to impacts from long-term consumption of vegetation contaminated by triclopyr, it is important to limit exposure of wild horses and burros to sprayed vegetation until residual activity has tapered off, particularly since sprayed grasses may not show signs of damage.

\section{Impacts by Alternative}

The following sections discuss the expected effects of each of the five alternatives on wild horses and burros, and compare the effects expected under each alternative with those expected under the other alternatives. These effects may vary depending on the acreage treated using different application methods and herbicides, as well as the size of treatment events.

\section{Alternative A - Continue Present Herbicide Use (No Action Alternative)}

Under the No Action Alternative, the BLM would continue its ongoing vegetation treatment programs in 14 western states, and would be able to use 20 herbicides previously approved under earlier RODs. Herbicide use under the No Action Alternative could impact wild horses and burros over an estimated 302,000 acres. The nature of impacts to wild horses and burros (positive and negative) would be similar to those that have occurred in the past 10 years. Negative impacts to wild horses and burros could be lower than under the other herbicide-use alternatives because fewer total acres would be treated using herbicides.

Long-term positive impacts on wild horse and burro communities (i.e., improvements in rangeland forage) could be lower under this alternative than the other herbicide-treatment alternatives. Under the No Action Alternative, invasive plant populations would likely continue to expand at the current rate or more quickly, potentially replacing desirable native forage, and increasing the abundance of unpalatable or toxic plants.

Three-fourths of wild horses and burros are found in Nevada, Utah, and Wyoming (see Table 3-7), and about 82,000 acres of vegetation would be treated in these states using herbicides. Of these acres, over $40 \%$ would occur in evergreen shrublands (primarily sagebrush), $19 \%$ would occur in annual and perennial grasslands (e.g., meadows, grasslands, and prairies), 18\% would occur in perennial forb communities (treatments associated with non-native forbs including knapweed, thistles, and leafy spurge), and $4 \%$ each would occur in evergreen woodlands (primarily pinyon-juniper and pine forest treatments) and in riparian/wetland habitats. The focus of these treatments would be to remove and control invasive vegetation and improve native shrubland and grassland communities, to the benefit of wild horses and burros. Wild horses favor native grasses, including bluebunch wheatgrass, western wheatgrass, Indian ricegrass and blue grasses, and riparian/wetland vegetation, including sedges. Wild burros feed on a variety of plants, including grasses, Mormon tea, paloverde, and plantain. Treatments that improve range habitat should benefit these plant species.

Because the new herbicides proposed in this PEIS (diquat, fluridone, imazapic, and Overdrive ${ }^{\circledR}$ ) would not be used under the No Action Alternative, risks to wild horses and burros would be different than under the other alternatives. Fluridone and imazapic do not 
present any risks to wild horses and burros under modeled scenarios (similar to chlorsulfuron, metsulfuron methyl, and sulfometuron methyl), and Overdrive ${ }^{\circledR}$ poses a low to moderate risk to large wild horses and burros under a chronic exposure scenario in which an animal ingests contaminated vegetation over a long time period. Diquat is fairly toxic to wild horses and burros, particularly under food ingestion scenarios (similar to 2,4-D and diuron). However, diquat is an aquatic herbicide, and frequent exposure to wild horses and burros would not be expected. Under the No Action Alternative, the BLM's repertoire of herbicides that are not injurious to terrestrial animals would be smaller than under the Preferred Alternative. As a result, per area risks to wild horses and burros would potentially be greater if more injurious herbicides (e.g., 2,4-D, bromacil, diuron, tebuthiuron, triclopyr) were used instead of safer herbicides, and the possibilities of more effective rangeland improvements would be reduced. However, prohibiting the use of diquat from use, particularly in rangeland riparian areas, could somewhat decrease per area risk to wild horses and burros.

2,4-DP, asulam, atrazine, fosamine, mefluidide, and simazine were approved for use in the earlier BLM EISs, but the BLM has not used any of these herbicides, except fosamine ( $<50$ acres annually) since 1997, and does not plan to utilize them in the near future. None of these herbicides would normally be used in rangeland treatments where wild horses and burros might come into contact with them. Instead, the BLM would use other herbicides, including triclopyr, sulfometuron methyl, bromacil, diuron, and Overdrive ${ }^{\circledR}$, which are effective in controlling weeds and invasive vegetation, but have less risk to wild horses and burros.

The BLM would not be able to use herbicides in Alaska, Nebraska, and Texas under the No Action Alternative, but would be able to conduct herbicide treatments in these states under the other herbicidetreatment alternatives. No wild horses or burros use lands in these states.

\section{Alternative B - Expand Herbicide Use and Allow for Use of New Herbicides in 17 Western States (Preferred Altermative)}

The Preferred Alternative would result in the treatment of approximately 932,000 acres in 17 western states. In addition to the 14 previously approved herbicides, the BLM would be able to use the four new herbicides evaluated in this PEIS. This alternative would result in the most extensive effects to wild horses and burros (both negative and positive) because it proposes the most acres for treatment ( 3 times the acreage that would be treated under the No Action Alternative). The extent of positive and negative impacts to wild horses and burros would depend on the relative amount each of the herbicides was used, whether they would be applied in rangeland environments, and the method of application. The likelihood of negative impacts would be greatest if diuron, diquat, bromacil and/or 2,4-D were used extensively. However, diquat, an aquatic herbicide, and bromacil and diuron, non-selective herbicides, are not likely to be used extensively in rangelands. If these herbicides were used in restricted scenarios as proposed, and other herbicides were used effectively to increase the abundance of native forage relative to unpalatable weeds, positive impacts to wild horses and burros could outweigh negative impacts.

Because more acres would be treated, benefits to wild horses and burros from improved rangeland and riparian conditions should be much greater under this alternative than under the other alternatives. Over 375,000 acres are proposed for treatment using herbicides in Nevada, Utah, and Wyoming, states with the largest populations of wild horses and burros. The percentage of treatments occurring in different plant community types would be similar to that of the No Action Alternative (43\% of acres treated would occur in evergreen shrublands, $19 \%$ in annual and perennial grasslands, $18 \%$ in perennial forb communities, and $9 \%$ in evergreen woodlands), but 4 times as many acres would be treated in these states under this alternative.

The ability to use the four new herbicides (diquat, fluridone, imazapic, and Overdrive ${ }^{\circledR}$ ) as well as future herbicides that become registered with the USEPA would allow BLM managers more options in choosing the least toxic herbicides that best match treatment goals and application conditions. As a result, there could be an increase in per capita benefits and a reduction in overall per capita risks to wild horses and burros (three of the four new herbicides present little to no risk to wild horses and burros) and an increase in habitat and ecosystem benefits from treatment. This alternative would also reduce risks and negative impacts associated with other vegetation management methods (e.g., risk of escaped prescribed fires; see the PER).

\section{Alternative C - No Use of Herbicides}

Under Alternative C, wild horses and burros would not be affected by herbicide use. Primary impacts would stem from other vegetation treatment methods (see the accompanying PER; USDI BLM 2007a). Positive benefits to rangelands as a result of vegetation 
management could be reduced under this alternative, as certain invasive species are only effectively controlled by herbicides, and in some situations other methods are impractical due to cost, time, or public concerns. For example, mechanical and manual methods are impractical over large land areas, which are more effectively treated by broadcast herbicide applications. In addition, it is often difficult to eradicate some species, such as shrubs that resprout from rhizomes (e.g., sand shinnery oak), by means other than herbicide application. Similarly, pre-emergent herbicides that persist in the soil are the most effective means of controlling invasive plants with seeds that remain viable for long periods of time.

Under this alternative, in the absence of herbicide treatments, invasive plant populations would likely continue to spread, possibly at increasing rates, and replace native vegetation, including rangeland forage for wild horses and burros, particularly where other treatment methods are not effective or possible (e.g., large tracts of rangeland or grassland dominated by invasive species, areas with resprouting shrubs or without enough fine fuels to carry prescribed fires). The spread of invasive weed populations would likely have deleterious effects on wild horses and burros. For example, rangeland within HMAs that contains excessive or unpalatable brush cover is less useful for grazing. However, it is uncertain how potential negative impacts from this alternative (mostly indirect) would compare with negative direct and indirect impacts from herbicide use.

\section{Alternative D - No Aerial Applications}

Alternative D would be the same as the Preferred Alternative as far as herbicides that could be used, and areas that could be treated. Therefore, both alternatives would be equally likely to have both positive and negative effects on wild horses and burros and rangeland. The BLM would be able to choose from a suite of currently-approved herbicides and herbicides that could be approved under this PEIS, or in the future. However, this alternative would not allow the BLM to apply herbicides aerially. Fewer acres would be treated (535,000 acres) because some large areas, including rangelands, cannot be effectively treated by ground application methods. However, acres proposed for aerial treatments comprise only about $20 \%$ of all acres proposed for treatment in the primary wild horse and burro states-Nevada, Utah, and Wyoming. And of these acres, about $65 \%$ of aerial treatments would occur in evergreen shrublands, and 13\% would occur in evergreen woodlands, habitats that provide less value to wild horses and burros than grassland and riparian habitats.

This alternative would substantially reduce the impacts of off-site drift to wild horses and burros, an exposure scenario that was not specifically modeled for most herbicides (consumption of contaminated vegetation off-site was modeled for most of the Forest Service herbicides, with no risks to wild horses and burros predicted for any of these herbicides, except triclopyr at the maximum application rate). Conversely, without the option to spray herbicides aerially, large areas of rangeland may remain untreated under Alternative D, which could negatively impact wild horse and burro habitat and forage in these areas over the long term.

\section{Alternative $\mathbf{E}$ - No Use of Acetolactate Synthase- inhibiting Active Ingredients}

Approximately 466,000 acres would be treated under Alternative $\mathrm{E}$, which is slightly less than the acreage that would be treated under Alternative D, and less than half of the acreage that would be treated under the Preferred Alternative, but is still an increase from the average annual treatment acreage that has occurred over the past 8 years and would likely occur under the No Action Alternative. Herbicide-related impacts to wild horses and burros would be lower under this alternative than under the Preferred Alternative because fewer acres would be treated with herbicides, and additional protective standards would be required during herbicide treatment (e.g., preferential use of spot rather than broadcast applications, preferential treatment of small versus large infestations).

Sulfonylurea herbicides and other ALS-inhibiting herbicides (e.g., chlorsulfuron, imazapic, imazapyr, metsulfuron methyl, sulfometuron methyl) block the synthesis of amino acids that are required for protein production and cell growth, thereby resulting in plant death. ALS-inhibiting herbicides would not be used under this alternative because data suggest they have the potential to damage off-site native and crop plant species under the right conditions of environment and application. These herbicides are biologically active at low concentrations, and are applied at lower application rates than other herbicides to manage target plants. It is uncertain whether use of these herbicides would result in fewer cases of unintended damage to wild horses and burros and rangeland due to lower application rates, or more cases due to the high potency of the herbicides and their persistence. In 1981, the Environmental Effects Division of the USEPA recommended against registering sulfonylurea herbicides because they persist 
for long periods of time in the environment and they cannot be detected at low levels. However, risk assessments did not predict risk to wild horses and burros for any of the ALS-inhibiting herbicides when applied at the typical application rate, under any of the modeled scenarios, suggesting that the elimination of these herbicides would not benefit wild horses and burros and could indirectly harm wild horses and burros if more toxic herbicides were used in their place.

Alternative $\mathrm{E}$ incorporates other management practices that would be likely to have positive impacts on wild horses and burros and rangelands. Alternative E would limit the use of broadcast applications, which would reduce the possible risks to wild horses and burros associated with off-site drift and consumption of vegetation across large areas. However these applications would be available for use in appropriate situations (i.e., where no other method is practical and susceptible non-target plant species and aquatic areas are distant from the application area), which would result in some ecosystem benefits from larger-scale herbicide applications. While per-treatment ecosystem benefits may be greater under Alternative $\mathrm{E}$ than under the other herbicide-use alternatives as a result of this ecosystem-based management approach, overall positive vegetation and ecosystem benefits (that cannot be attained by other treatment methods) across the western states would be lower under this alternative because of the relatively small treatment acreage and the inability to use certain practices in situations that might require their use (e.g., use of ALS-inhibitor herbicides on highly aggressive weeds). For example, imazapic, which has been shown to be effective in treating downy brome and leafy spurge, would be unavailable under this alternative. The BLM would also be unable to use chlorsulfuron and metsulfuron methyl to control yellow starthistle and several species of thistle that are harmful to wild horses and burros.

\section{Mitigation for Herbicide Treatment Impacts}

The following actions would greatly reduce the risks to wild horses and burros from herbicide applications:

- Apply diuron, glyphosate, hexazinone tebuthiuron, and triclopyr at the typical application rate to minimize risks to wild horses and burros.

- Do not apply 2,4-D, bromacil, diuron, Overdrive $^{\circledR}$, picloram, or triclopyr across large application areas, where feasible, to limit impacts to wild horses and burros, particularly through the contamination of food items.

- Apply herbicide label grazing restrictions for livestock to herbicide treatment areas that support populations of wild horses and burros.

- Where practical, limit glyphosate and hexazinone to spot applications in rangeland to avoid contamination of food items.

- Do not aerially apply diquat directly to wetlands and riparian areas.

- Do not apply bromacil and diuron in grazing lands within HMAs, and use appropriate buffer zones (see Vegetation section) to limit contamination of vegetation in off-site foraging areas.

- Do not apply 2,4-D, bromacil, or diuron in HMAs during the peak foaling season (March through June, and especially in May and June), and do not exceed the typical application rate of Overdrive ${ }^{\circledR}$ or hexazinone in HMAs during the peak foaling season.

\section{Paleontological and Cultural Resources}

Invasive plants may have long-term negative impacts on paleontological and cultural resource sites by displacing native vegetation and increasing the potential for soil erosion, potentially leading to the loss of paleontological and cultural resources. In addition to limiting these impacts, removal of invasive vegetation would contribute to the restoration and maintenance of historic and ethnographic cultural landscapes (USDI National Park Service 2003).

Herbicides could harm traditional use plants, or threaten the health of the people gathering, handling, or ingesting recently treated plants, fish, or wildlife that are contaminated with herbicides (BPA 2000). Since roots and other plant materials harvested by Native peoples may be found in close proximity to weed treatment areas, the potential exists for herbicides to drift from treatment areas onto areas used by Native peoples (ENSR 2001). In some cases, vegetation important to Native peoples, including juniper, may be treated in areas where these plants are invasive and crowding out more desirable vegetation. 


\section{Scoping Comments and Other Issues Evaluated in the Assessment}

Some respondents felt that cultural preservation is an important issue, and encouraged addressing the impacts to cultural and archaeological sites. Other respondents suggested that traditional cultural properties should be properly safeguarded, and treatments should be completed in a way that is sensitive to cultural resources. There was concern about the effects of herbicides on basket plants and the people who collect them, in particular Native Americans. Respondents noted that fire generally helps these basket plants, while herbicides are detrimental.

\section{Standard Operating Procedures for Addressing BLM Actions on Paleontological, Cultural, and Subsistence Resources}

Before proceeding with vegetation treatments, the effects of BLM actions on cultural resources would be addressed through compliance with the NHPA, as implemented through a national Programmatic Agreement (Programmatic Agreement among the Bureau of Land Management, the Advisory Council on Historic Preservation, and the National Conference of State Historic Preservation Officers Regarding the Manner in Which BLM Will Meet Its Responsibilities Under the National Historic Preservation Act) and state-specific protocol agreements with SHPOs. Effects on paleontological resources would be addressed as outlined in resource management plans developed under the authority of the FLPMA and site specific NEPA documents developed for vegetation treatments. The BLM's responsibilities under these authorities are addressed as early in the vegetation management project planning process as possible.

The processes for identifying and managing cultural resources are addressed in USDI BLM manuals 8100 (The Foundations for Managing Cultural Resources), 8110 (Identifying and Evaluating Cultural Resources), 8120 (Tribal Consultation under Cultural Resource Authorities), 8130 (Planning for Uses of Cultural Resources), 8140 (Protecting Cultural Resources), and Handbook H-8120-1 (Gnidelines for Conducting Tribal Consultation). Processes for identifying and managing paleontological resources are outlined in Manual 8270 (Paleontological Resource Management). The BLM Cultural Resource Management program is responsible for the study, evaluation, protection, management, stabilization, and inventory of paleontological, historical, and archeological resources. The program also ensures close consultation with Native American tribal and Alaska Native group governments, as required by law, for the maintenance, preservation, and promotion of native cultural heritage and resources, including plant and animal subsistence resources and the use of vegetation for religious and ceremonial purposes. The BLM initiated consultation with Native American tribes and Alaska Native groups to identify their cultural values, religious beliefs, traditional practices, and legal rights that could be affected by BLM actions. Consultation included sending letters to all tribes and groups that could be directly affected by vegetation treatment activities, and requesting information on how the proposed activities could impact Native American and Alaska Native interests, including the use of vegetation and wildlife for subsistence, religious, and ceremonial purposes (see Appendix G).

\section{Paleontological Resources}

The processes for identifying paleontological resources includes consultation with BLM regional paleontologists, paleontology program contacts in BLM field offices, state geological survey agencies, local colleges, universities or museums, or SHPOs (if individual SHPOs deal with fossil resources) as part of the planning process. Procedures would be developed for protecting significant fossil resources as outlined in BLM Handbook 8270-1 (General Procedural Guidance for Paleontological Resource Management). Resource Management Plans may be in place that have classified sensitivity levels for important fossil resources and management prescriptions associated with each sensitivity level. Specific protective measures for paleontological resources would be identified at the local level during project development. In the case of RMPs that lack this classification scheme, projectspecific analysis would be needed to assess whether paleontological resource inventories based on available information should be conducted. If a project area contained documented locations with paleontological resources within the proposed project area, or had geological or geomorphic characteristics likely to contain vertebrate fossils, a field inventory could be required to locate and report previously unrecorded paleontological resources. Site-specific mitigation measures would be developed during the implementation stage of the vegetation treatments, if needed. 


\section{Cultural Resources}

Treatments would follow standard procedures for identifying cultural resources, in compliance with Section 106 of the NHPA, as implemented through the Nationwide Programmatic Agreement and state protocols. The process includes necessary consultations with SHPOs and interested tribes and Tribal Historic Preservation Offices (THPOs), where they are in place, at the state or local level as projects are planned.

As part of the process of preparing for vegetation treatments, cultural resource specialists would identify historic properties eligible for the NRHP. Historic properties may include any prehistoric or historic district, site, building, structure, or object included in, or eligible for inclusion in, the NRHP. Impacts to National Register-eligible cultural resources can be avoided through project redesign or be mitigated through recordation, data recovery, monitoring, or other appropriate measures. If National Register-eligible cultural resources were discovered during vegetation treatments, appropriate actions would be taken to protect these resources or recover data following consultation processes. An important concern regarding the presence of non-cultural resource personnel on the ground during herbicide treatments is the unauthorized collection of artifactual material, especially from National Register-eligible properties. Procedures would be developed, as part of an unanticipated discoveries plan that would include reporting previously unrecorded cultural resources to local BLM professionals.

\section{Subsistence Resources}

Discussions would be held with Native American tribes and Alaska Native groups to determine which plants that could be affected by proposed herbicide treatments have traditional lifeway values, and whether there are specific, traditional collecting areas. Important plants to Native Americans include oak, juniper, pinyon, lodgepole pine, cottonwood, mesquite, amaranth, cattail, and brackenfern. These trees, shrubs, and plants or their fruits and seeds are traditionally used for subsistence, clothing, basketry, shelter, utilitarian items, and possibly medicines by one or more tribes or groups in the western U.S. and Alaska. Since other target species have common names similar to those of some plants used traditionally, such as whorled milkweed or common reeds, the difference in names should be explained to Native Americans and Alaska Natives in those areas where treatments are planned. Treatments of plants that are important for maintaining traditional lifeways may need to be modified or cancelled in certain areas. On the other hand, there could be longterm benefits associated with treatments, such as reduction or elimination of non-native or invasive plant competitors, which would allow proliferation of traditionally used native species.

\section{Herbicide Impacts on Paleontological and Cultural Resources}

\section{Paleontological Resources}

The effect of herbicide treatments on fossil material would vary with respect to: 1) fossil type; 2) minerals; 3 ) degree of fossilization; and 4) whether the fossil is exposed or buried. Although it may be possible for chemicals found in herbicides to impact unique fossil material, herbicide treatments are more likely to affect researchers, students, or other field personnel conducting paleontological research than the paleontological resources. More likely, damage to fossil materials, if present, would result from the use of wheeled equipment used to apply herbicides. The potential for impacts to fossils would depend on the attributes of the fossil material, whether the fossil is buried or exposed, and the method of herbicide application. Methods involving the use of vehicles driving cross-country would potentially crush fossil material exposed on the surface.

\section{Cultural Resources}

While herbicide treatments may affect buried organic cultural resources, they are more likely to have a negative effect on traditional cultural practices of gathering plant foods or materials important to local tribes or groups. The effect of herbicide treatments on cultural resources depends on the method of herbicide application and the herbicide type used. Some chemicals can cause soil acidity to increase, which would result in deterioration of artifacts-even some types of stone from which artifacts are made. Application of chemical treatments can also result in impacts such as altering or obscuring the surfaces of standing wall masonry structures, pictograph or petroglyph panels, and organic materials. While chemicals may affect the surface of exposed artifacts, they can generally be removed without damage if treated soon after exposure. Organic substances used as inactive ingredients in herbicide formulations, such as diesel fuel or kerosene, may contaminate the surface soil and seep into the subsurface portions of a site. These organic substances could interfere with the 
radiocarbon or Carbon 14 (C-14) dating of a site (USDI BLM 1991a).

\section{Subsistence Resources}

Depending on the selected application method for herbicide treatment plans, the BLM might be unable to avoid plants identified by Native American tribes and Alaska Native groups as being important in traditional subsistence, religious, or other cultural practices. Consultation would be undertaken with tribes and groups to locate any areas with plants that are of importance to the tribe and that might be affected by chemical treatments. Certain chemical treatments could also pose a possible health risk, through residues left on plants used as traditional foods or for ceremonial purposes, or as a result of contaminating other food sources or drinking water, as discussed below. A study to assess the exposure of basketweavers to forestry herbicides showed that detectable residues of herbicides were found on $49 \%$ of plant materials used by Native Americans inside treatment areas, but only $3 \%$ of plant materials outside of treatment areas, and that residues continued to be detected for several months (Segawa et al. 1997). However, a study of herbicide uptake by lomatium and bitter root roots in rangeland treated with picloram and sulfometuron methyl showed that no herbicide residues were found in roots at 2, 6, and 45 weeks after treatment (ENSR 2001). Thus, risks would vary depending upon the time of plant use and herbicide treatment, and the portions of the plants that were used.

\section{Herbicide Impacts on Native American Health}

\section{Exposure Characterization}

The potential risks to Native Americans from exposure to herbicides used in BLM programs were evaluated separately from risks to other public receptors (see Human Health and Safety section in this chapter). Native Americans could be exposed to higher levels of herbicides as a result of subsistence and cultural activities such as plant gathering and consumption of fish caught in local streams. Therefore, risk levels determined for Native American receptors reflect unique exposure scenarios as well as typical scenarios for public receptors, but with higher levels of exposure than public receptors.

The BLM risk assessments assume that the Native American receptors (154-pound adult and 33-pound child) are exposed to herbicides via dermal contact with spray, dermal contact with sprayed foliage, ingestion of drinking water from a sprayed pond, ingestion of berries containing spray, dermal contact with water in a sprayed pond, and ingestion of fish from a sprayed pond.

\section{Dermal Contact}

For potential herbicide contact, the risk assessments assume the $50^{\text {th }}$ percentile surface area of the Native American's lower legs, lower arms, and hands are exposed (i.e., $698 \mathrm{in}^{2}$ for adult men and women and 249 in $^{2}$ for children [USEPA 1997]), and that Native American receptors contact foliage for 3 hours per day of subsistence activities (Harper et al. 2002). A dermal transfer coefficient value - to estimate the amount of herbicide transferred from foliage to skin - at the high end of the range was used for harvesting blueberries (i.e., $232 \mathrm{in}^{2} /$ hour for the adult [USEPA 2000b] and 47 $\mathrm{in}^{2}$ /hour for the child based on the child to adult surface area ratio [CalEPA 1996]). The USEPA (2001c) recommends an exposed surface area of 2,790 in for an adult swimmer and 1,023 in ${ }^{2}$ for a child swimmer. Because no specific data were available regarding surface area, these estimates were used to evaluate the Native American child-and-adult in the HHRA. The exposure time for swimming is assumed to be 2.6 hours/day in accordance with Harris and Harper (1997) which results in a swimming exposure frequency of 2.6 hours/day for 70 days/year. Incidental ingestion during swimming was not evaluated for Native Americans, since it is assumed that the pond is also used as a source of drinking water; any incidental ingestion during swimming is therefore included in the drinking water scenario.

\section{Ingestion}

Risk assessments assume that adult Native Americans ingest 1 quart of water per day (Harper et al. 2002) from a sprayed pond, and Native American children consume half the adult rate, or 0.5 quarts/day. The berry ingestion rate was developed from information provided in Harper et al. (2002), which lists an ingestion rate of 0.7 lbs/day for an adult of the Native American Spokane tribe gathering aboveground terrestrial vegetation. Berries are likely to be a small fraction of this 0.7 lbs/day. However, since this rate was not subdivided into additional categories, it was conservatively assumed that the ingestion rate for berries is $0.7 \mathrm{lbs} /$ day for an adult Native American. For a Native American child, the ingestion rate was scaled by body weight (i.e., $0.7 \mathrm{lbs} /$ day x $33 \mathrm{lbs} / 154 \mathrm{lbs}$ ) to $0.15 \mathrm{lbs} /$ day (per CalEPA 1996). The adult fish ingestion rate was assumed to be $2 \mathrm{lbs} /$ day based on a high fish diet scenario discussed in Harper et al. (2002). The high fish 
diet consists primarily of fish, supplemented by big game; aquatic amphibians, crustaceans, and mollusks; small mammals; and upland game birds. This value is much higher than the $95^{\text {th }}$ percentile fish ingestion rate of $0.4 \mathrm{lbs} /$ day recommended in USEPA (1997) for a Native American subsistence population. For Native American children, the ingestion rate was scaled by body weight (i.e., $1.9 \mathrm{lbs} /$ day x $33 \mathrm{lbs} / 154 \mathrm{lbs}$ ) to 0.4 lbs/day (per CalEPA 1996).

The Forest Service risk assessments evaluated risk to Native Americans - in addition to typical risk for public receptors-for the scenarios of acute and chronic consumption of contaminated fish.

\section{Risk Characterization}

Native American adults face the same risks that public receptors face, as well as additional risks associated with exposure to some herbicides as a result of unique subsistence practices or increased time spent in treated areas. There are risks to Native American adults associated with exposure to diquat when it is accidentally spilled or applied at the maximum rate (low risk), and with the consumption of fish contaminated with 2,4-D (high risk) and hexazinone (moderate risk). There are risks to Native American children associated with exposure to diquat when it is applied at the typical rate. There are also risks associated with berry picking in areas sprayed with diquat at the typical rate. Both Native American adults and children residing near the treatment area would face additional risks (i.e., low risk from exposure to diquat when it is applied at the typical or maximum rate, and moderate risk from diquat when accidentally spilled; low risk from exposure to fluridone when it is accidentally spilled). See the Vegetation, Fish and Aquatic Invertebrates, Wildlife, and Human Health and Safety sections in this chapter for more information on the risks of herbicides to Native Americans and the resources they use.

\section{Impacts by Alternative}

The following is a discussion of how risk from herbicides would vary under each herbicide treatment alternative.

\section{Alternative A - Continue Present Herbicide Use (No Action Alternative)}

Of the herbicide treatment alternatives, the fewest acres would be treated under the No Action Alternative; therefore, levels of risk to paleontological and cultural resources, and health risks to Native Americans, Alaska
Natives, and other human receptors would be lower than under the other herbicide treatment alternatives. If more acres were to be treated by other vegetation management methods (e.g., prescribed fire, manual, mechanical, or biological treatments) under the No Action Alternative, then the risks from these methods would also have to be considered (see the associated PER). In addition, the new herbicides proposed in this PEIS (diflufenzopyr+dicamba [Overdrive ${ }^{\circledR}$ ], diquat, fluridone, and imazapic) would not be used. Of these new herbicides, diquat poses a high risk to humans; however, diflufenzopyr, dicamba, and imazapic are all relatively safe to humans, with no potential adverse effects evident from the human health risk characterization, except in cases of unlikely accidental scenarios for dicamba. Of the 20 previously-approved herbicides, only four (clopyralid, imazapyr, metsulfuron methyl, and sulfometuron methyl) have negligible to low risks to humans. Therefore, failure to approve the four new herbicides would limit the options for treatment of vegetation without appreciable risk to humans. Thus, the risk to humans per each herbicide application may be greatest under the No Action Alternative.

Under this alternative, the BLM may be less successful in controlling weeds and poisonous plants that adversely affect humans, especially weeds most effectively controlled by the four newly proposed herbicides, than under the other alternatives. Weeds and other invasive vegetation can displace native species that are desirable to Native Americans, and may provide poorer quality forage and cover for wildlife used by Native American tribes.

Under the No Action Alternative, the BLM would be able to continue to use six herbicides that were approved for use under earlier BLM vegetation treatment RODs: 2,4-DP, asulam, atrazine, fosamine, mefluidide, and simazine. Except for fosamine, which has been used on less than 50 acres annually, these chemicals have not been used by the BLM since 1997 and are not proposed for use under the other herbicide treatment alternatives. It is unlikely that these chemicals would be used under the No Action Alternative.

In 1998, the BLM conducted a literature review to determine whether the earlier vegetation treatment ROD conclusions for asulam, atrazine, mefluidide, and simazine were justifiable based on past and 1998 toxicology and risk assessment procedures. This assessment was based on a literature search and California Vegetation Management Final EIS (California EIS; USDI BLM 1988a) to identify potential 
human health risks. A literature review was not done for 2,4-DP or fosamine, but these herbicides were analyzed in the California EIS (McMullin and Thomas 2000). Based on this analysis, it was determined that systemic risks from using asulam may be greater than projected in the earlier EIS, but that risks to humans from the other three herbicides are similar to, or less than, those identified in earlier EISs. Based on the earlier EISs, literature reviews done for the BLM, and other studies, the risks to humans would be low for asulam, fosamine, and mefluidide, low to moderate for 2,4-DP, and simazine, and moderate to high for atrazine (USEPA 1995d). The BLM uses sulfometuron methyl, bromacil, and diuron in treatment situations where it used atrazine in the past, and triclopyr instead of fosamine. These substitute herbicides have similar, or lower, risks to humans than the herbicides they are replacing.

\section{Alternative B - Expand Herbicide Use and Allow for Use of New Herbicides in 17 Western States (Preferred Alternative)}

Because of the large number of acres treated, this alternative would likely result in the most overall risk to paleontological and cultural resources and human health. The number of acres treated using ground-based application methods would be greater under this alternative and Alternative D than under the other alternatives, increasing the risk of damage to paleontological and cultural resources from equipment. However, human health could benefit from a reduction in the noxious weeds and poisonous plants that adversely affect humans, which would likely occur under this alternative. In addition, this alternative would allow the use of the new herbicides evaluated in the BLM HHRA (ENSR 20051). Of these four herbicides, three appear to be relatively harmless to humans; use of these herbicides would increase the options for appropriately managing vegetation while minimizing the risk to human receptors. It is suggested that diquat be used only in very limited scenarios at the typical application rate and where risk to human receptors is not predicted, such as ground applications from trucks not near residences or berry gathering sites. 2,4-D, glyphosate, picloram, and tebuthiuron would be used for about $70 \%$ of herbicide treatments. There is low risk to human health associated with use of glyphosate, picloram, and tebuthiuron at normal application rates, but risks to human health are low to moderate for 2,4-D.

Although the BLM would be able to treat vegetation in Alaska, Nebraska, and Texas under the Preferred Alternative and Alternatives D and E, it is unlikely that the BLM would use herbicides in Alaska, especially in areas with important Alaska Native resources.

\section{Alternative C - No Use of Herbicides}

Alternative C would eliminate risks to paleontological, cultural, and human health from herbicide applications. However, risks to these resources and human health associated with alternative vegetation management methods would occur (these risks are perhaps greatest for prescribed fire treatments [see PER]). In addition, human health might be adversely affected if populations of noxious weeds and poisonous plants that adversely affect humans were to remain at current levels or increase as a result of ceasing herbicide treatments.

\section{Alternative D - No Aerial Applications}

Human health risks per application area would be lower for Alternative D than for the No Action and Preferred alternatives because herbicides would not be likely to drift as far, potentially affecting fewer humans. For many herbicides, the greatest risks to occupational receptors are associated with aerial applications; these risks would be eliminated under this alternative. Furthermore, this alternative would allow the use of the new herbicides, which pose on average less risk to humans than the currently used herbicides. Overall risks to human health would be lower than under the Preferred Alternative, which would treat about 400,000 more acres and would use aerial spraying (however, the Preferred Alternative could eliminate more noxious and poisonous weeds that adversely affect human health than Alternative D). Overall risks to cultural and paleontological resources from ground-based equipment would be similar to the Preferred Alternative, but risks associated with the herbicides themselves would be less, since fewer acres would be treated with herbicides. Risks under Alternative D would likely be greater than those under Alternative $\mathrm{E}$, as Alternative $\mathrm{E}$ places emphasis on spot applications over broadcast applications, establishes herbicide-free zones to protect culturally significant plant and wildlife resources, and prioritizes treatments that would enhance and preserve culturally significant plants and animals. However, Alternative E would not allow the use of ALS-inhibiting herbicide active ingredients (i.e., chlorsulfuron, imazapic, imazapyr, metsulfuron methyl, and sulfometuron methyl), which exhibit the lowest risks to humans out of the herbicides analyzed by the BLM. In addition, these chemicals are effective in controlling weeds that can displace native plant species and associated wildlife that are of value to Native American tribes. Because 240,000 more acres would be treated 
under Alternative D than under the No Action Alternative, but higher risk aerial applications would not occur and chemicals of lower risk would be used, it is difficult to infer which of these two alternatives would have lower overall risk.

\section{Alternative $\mathbb{E}$ - No Use of Acetolactate Synthase- inhibiting Herbicides}

The five herbicides (chlorsulfuron, imazapic, imazapyr, metsulfuron methyl, and sulfometuron methyl) that would not be used under this alternative are among those that pose the least risk to human health. Even in accidental scenarios, imazapic, imazapyr, metsulfuron methyl, and sulfometuron methyl do not pose a risk to humans, and chlorsulfuron only poses a risk to workers when it is applied in ground broadcast applications at the highest application rate, and poses a risk to the general public if a large amount is accidentally spilled into a very small pond--an unlikely scenario. From a practical perspective, eye and/or skin irritation are likely to be the only effects of mishandling ALS-inhibiting herbicides; these effects can be minimized or avoided by prudent industrial hygiene practices while handling of these compounds. Bromacil, diquat, and diuron, which pose the most severe human health risks, could be used under Alternative E; therefore, risk to humans per area treated is not likely to decrease dramatically as a result of elimination of ALS-inhibiting herbicide active ingredients.

Alternative E places increased emphasis on spot rather than broadcast applications, which would tend to decrease per area risk relative to the No Action and Preferred alternatives, except in the few possible cases where occupational receptors would be at a greater risk from spot applications. In addition, the proposed number of acres treated $(466,000)$ is half that of the Preferred Alternative $(932,000)$, which would translate to lower overall risk. Conversely, more acres would be treated under Alternative $\mathrm{E}$ than under the No Action Alternative $(305,000)$, so overall risk would be greater.

Under all alternatives, the BLM would collaborate with Native American tribes and Alaska Native groups to identify and protect culturally significant plants used for food, basketweaving, fibers, medicine, and ceremonial purposes, and would use minimal impact treatments where culturally significant species are known to occur. In addition, under Alternative E the BLM would establish herbicide-free zones to protect culturally significant plant and wildlife resources, which would reduce the likelihood that Native Americans and Alaska
Natives would consume vegetation with herbicide residues.

\section{Mitigation for Herbicide Treatment Impacts}

In addition to SOPs, there are certain herbicide-specific measures that could be taken to substantially reduce or eliminate human health risk from herbicide use. The following mitigation measures were developed based on the BLM HHRA, the Forest Service HHRAs, and the Final EIS Vegetation Treatment on BLM Lands in Thirteen Western States (1991 13-State EIS; USDI BLM 1991a):

- Do not exceed the typical application rate when applying 2,4-D, bromacil, diquat, diuron, fluridone, hexazinone, tebuthiuron, and triclopyr in known traditional use areas.

- Avoid applying bromacil or tebuthiuron aerially in known traditional use areas.

- Limit diquat applications to areas away from high residential and traditional use areas to reduce risks to Native Americans and Alaska Natives.

\section{Visual Resources}

Visual resources consist of land, water, vegetation, wildlife, and other natural or manmade features visible on public lands. Vast areas of grassland, shrubland, canyonland, and mountain ranges on public lands provide scenic views to recreation visitors, adjacent landowners, and travelers. In addition, roads, rivers, and trails pass through a variety of characteristic landscapes where natural attractions can be seen and where cultural modifications exist. Activities occurring on these lands have the potential to disturb the surface features of the landscape and impact scenic values.

Bureau policy requires that all acres of BLM land be inventoried for scenic values and be assigned a Visual Resource Management (VRM) Class (I-IV) during the land use planning process. These VRM classes are part of the land use plan decisions for a particular office and set the management standards for visual resources that activity level plans must subsequently meet. The acreage of BLM-managed public lands that are categorized as Class I, II, III, or IV is not currently known. 
The proposed vegetation treatments would affect visual resources by changing the scenic quality of the landscape. Herbicide treatments would kill vegetation in the applied area, resulting in visual contrast such as more open, "browned" landscape until new plants were to grow in the area. The degree of change to scenic quality could, in terms of visitor perception, vary relative to a particular area's inherent visual appeal, and distance from human activity, as well as public sensitivity to changes in the landscape character of the area. However, according to the BLM's VRM policy, the extent of visual impact must be evaluated at the project level according to the visual contrast rating process (Handbook 8431-1). This process compares the amount of contrast to the form, line, color, and texture of the characteristic landscape of an area as a result of a surface disturbing activity.

In general, the effects of vegetation treatments on the visual quality of the landscape would be most notable to travelers, sightseers, and residents for the first year to several years following treatment, particularly in impacted areas near major roads or residential areas. Scenic impacts from vegetative treatments are most likely to be associated with projects that 1) reduce the visual rating of the treatment site over the long term, or 2) result in short- or long-term degradation of highsensitivity visual resources.

\section{Scoping Comments and Other Issues Evaluated in the Assessment}

Scoping comments stressed that treatments should improve management of public lands for multiple use and maximum public benefit. The visual quality of the landscape is seen as one component of public benefit, particularly if lands are located in highly visible areas along roads.

\section{Standard Operating Procedures}

There are several SOPs that would help reduce the impact of herbicide treatments on visual resources:

- Minimize the use of broadcast foliar applications in sensitive watersheds to avoid creating large areas of browned vegetation.

- Consider the surrounding land use before assigning aerial spraying as an application method.

- Avoid aerial spraying near agricultural or densely populated areas, where feasible.
- At areas such as visual overlooks, leave sufficient vegetation in place, where possible, to screen views of vegetation treatments.

- Use SOPs that minimize off-site drift and mobility of herbicides (e.g., do not treat when winds exceed $10 \mathrm{mph}$; minimize treatment in areas where herbicide runoff is likely; establish appropriate buffer widths between treatment areas and residences), to contain the visual changes to the intended treatment area.

- If the area is a Class I or II visual resource, ensure that the change to the characteristic landscape is low and does not attract attention (Class I), or if seen, does not attract the attention of the casual viewer (Class II).

- Lessen visual impacts by 1) designing projects to blend in with topographic forms; 2) leaving some low-growing trees or planting some lowgrowing tree seedlings adjacent to the treatment area to screen short-term effects; and 3) revegetating the site following treatment.

- When restoring treated areas, design activities to repeat the form, line, color, and texture of the natural landscape character to meet established VRM objectives.

A more detailed list of SOPs is found in BLM Manual Handbook H-8431-1 (Visual Resource Contrast Rating).

\section{BLM Assessment of Visual Resource Values}

The BLM identifies and evaluates visual resource values through the VRM Inventory system (Handbook H-8410-1; USDI BLM 1986a). The VRM system is a policy used by the BLM to inventory and manage visual resources on public land based on the aforementioned VRM classes describing scenic quality, sensitivity level, and distance zone criteria. Visual resource management objectives are established in resource management plans in conformity with land use allocations (USDI BLM 1984b). These area-specific objectives provide the standards for planning, designing, and evaluating future management projects.

A Contrast Rating System (BLM Manual Handbook H8431-1; Visual Resource Contrast Rating; USDI BLM 1986b) provides a systematic means to evaluate the approved VRM objectives, and to identify mitigation measures to minimize adverse visual impacts. The 
Contrast Rating System is designed to compare the respective features of the existing characteristic landscape with a proposed project and to identify those parts that are not in harmony. These features include the basic design elements of form, line, color, and texture that characterize the landscape and the surrounding environment. Modifications to a landscape that repeat the natural landscape's basic elements are said to be in harmony with their surroundings, while those that differ markedly may be visually displeasing. The information generated is used to determine the amount of visual contrast created and whether the VRM objective for the area would be met, and to develop additional mitigation measures necessary to meet the VRM objective.

\section{Summary of Herbicide Impacts}

The removal of vegetation would affect the visual qualities of treatment sites by creating openings and other vegetation-free areas that provide a noticeable visual contrast to the surrounding areas. In addition, the use of herbicides could create visually distinct areas of discolored vegetation (i.e., areas where herbicides have killed vegetation), which could contrast markedly from surrounding areas of green vegetation. The degree of these effects would depend on the amount of area treated, the appearance of the background vegetation and the vegetation being removed, the type of treatment method used, and the season of treatment.

In general, herbicide treatments would have short-term negative effects and long-term positive effects on visual resources. The greater the area of vegetation treatment, the greater the visual impact is likely to be. The effects of treatments over a large portion of the landscape are more likely to be observed by people than the effects of small-scale treatments. However, since areas receiving large-scale treatments are most likely to be degraded lands of low to moderate scenic quality, the visual impact from treatment would be minimized and there would likely be an improvement in the scenic quality of the land over the long term. Color contrasts caused by vegetation removal would be most apparent in areas dominated by green and/or flowery vegetation and by large plants, such as conifer trees. The visual impacts would be heightened if the herbicides also prevented the manifestation of seasonal changes in vegetation, such as spring flowers and/or fall color. The contrast between a cleared area and the surrounding vegetation would be less in much of the arid west, where low-growing shrubs, and browns, grays, and earth tones dominate the landscape than in areas with greater amounts of rainfall (e.g., the Marine Ecoregion). In addition, the brown colors associated with vegetation treatments would be least noticeable during the late fall and the winter, when they would blend more naturally with surrounding colors, than in the spring and summer, when the green colors of new growth are more likely to be present.

Impacts to visual resources from herbicide treatments would begin to disappear within one to two growing seasons in most landscapes. The regrowth of vegetation on the site would eliminate much of the stark appearance of a cleared area. Impacts would last for the longest amount of time in forests and other areas where large trees and shrubs were removed.

Over the long term, vegetation treatments would likely improve visual resources on public lands. Treatments that aim to rehabilitate degraded ecosystems, if successful, would result in plant communities that are dominated by native species. Native-dominated communities tend to be more visually appealing than plant communities that have been overtaken by weeds (e.g., plant communities supporting a downy brome monoculture) or other undesired species (e.g., grasslands experiencing encroachment by conifer seedlings).

\section{Impacts by Alternative}

\section{Alternative A - Continue Present Herbicide Use (No Action Alternative)}

The No Action Alternative would continue current vegetation and herbicide treatments; therefore, visual impacts would remain the same as at present. These impacts would be less than those under The Preferred Alternative, because only one-third as many acres would be treated using herbicides. The greatest visual impacts would likely be associated with the largest treatment areas. Under the No Action Alternative, projects with the largest treatment acreage (those over 1,500 acres in size; $10 \%$ of all herbicide treatments) would be located in New Mexico (one-third of all largescale treatments) and Idaho/Nevada (one-third of all large-scale treatments). However, assuming that treatments would be effective in reducing or eliminating invasive species populations and promoting conditions that favor the development of native plant communities, the visual quality of degraded landscapes would not improve over the long term to the same extent as under the other treatment alternatives. As compared to the Preferred Alternative, many lands would be left untreated and would continue to be dominated by invasive plants or would be invaded in the future by 
invasive plants. Landscapes containing a large component of invasive species often contrast with surrounding natural landscapes and have a negative visual impact. For example, downy brome often turns brown during summer, while native species usually remain green long into summer or fall.

\section{Alternative B - Expand Herbicide Use and Allow for Use of New Herbicides in 17 Western States (Preferred Alternative)}

The Preferred Alternative would result in the greatest short-term negative impact on visual resources, as it involves treatment of the most acres with herbicides. The most dramatic effects would be seen in states with the most acres treated, such as Idaho, Nevada, and Wyoming, and in project areas where large acreages are treated. Under the Preferred Alternative, projects with the largest treatment acreage (those over 2,000 acres in size; $10 \%$ of all herbicide treatments) would be located in Idaho (one-third of large-scale treatments) and Wyoming (20\% of all large-scale treatments). One third fewer large-scale treatments would occur in New Mexico under this alternative than under the No Action Alternative. However, herbicide treatments in drier states, such as New Mexico, Nevada, and Wyoming, could have reduced visual impact because visual color contrast between natural and "browned" treated areas would be less dramatic (versus wetter states with higher percentages of green vegetation, especially coniferous forests). Over the long term, this alternative could have the greatest positive impact on visual resources, as invasive plants and unwanted vegetation would be removed and visually preferable native vegetation and ecosystems would become reestablished on more acres.

\section{Alternative C - No Use of Herbicides}

Because no herbicide treatments would take place under Alternative $C$, visual resources would not be adversely impacted by herbicide treatments. Conversely, visual resources would not improve over time, and the visual quality of landscapes could become further degraded as invasive plants continued to invade and spread. There are certain kinds of invasive plants that are most effectivcly removed by herbicide treatments (e.g., Russian knapweed, purple loosestrife, Canada and Scotch thistles, yellow star-thistle); it may be difficult to eliminate these species by non-chemical treatment methods. In addition, if prescribed burning were to increase under this alternative in order to maintain control of invasive plants, visual impacts from blackened vegetation and landscapes and short-term smoke would likely be more dramatic than visual impacts from herbicide use.

\section{Alternative D - No Aerial Applications}

Impacts to visual resources under Alternative D would be less than under the Preferred Alternative, and similar to those under the No Action Alternative and Alternative $\mathrm{E}$, based on number of acres treated. In addition, because large-scale treatments are less feasible without aerial spraying, fewer large areas of vegetation are likely to be killed by herbicides, further minimizing the short-term visual impact of herbicide treatments. Over the long term, however, this alternative would leave more large tracts of land untreated than the other treatment alternatives. Therefore, the No Action and Preferred alternatives, and Alternative E, could result in more large land areas of recovering native vegetation and ecosystems, and consequently improved visual quality over time.

\section{Alternative $\mathbb{E}$ - No Use of Acetolactate Synthase- inhibiting Herbicides}

Based on number of acres treated, the visual impacts from herbicide treatments under this alternative would be similar to those under Alternative D. Visual impacts under this alternative would be somewhat moderated as compared to the Preferred Alternative because aerial and boom/broadcast spraying of larger tracts of land would be avoided, thereby reducing visibility of treated lands and sensitivity to treatments. In addition, imazapic, which is proposed for use in treating large expanses of downy brome, would not be used. As fewer large tracts of land with degraded visual quality would be treated, however, fewer large improvements would be made in the visual quality of vegetation and landscapes.

\section{Mitigation for Herbicide Treatment Impacts}

No mitigation measures are proposed for visual resources.

\section{Wilderness and Special Areas}

Because of their special status, wilderness and special areas have strict guidelines for vegetation treatments. These guidelines prohibit activities that degrade the quality, character, and integrity of these protected lands. Vegetation treatments used in wilderness areas follow the guidance contained in 43 CFR 6300 (Wilderness 
Management; Federal Register 2000), and in the Management of Designated Wilderness Areas Handbook H-8560-1 (USDI BLM 1988e), Management of Designated Wilderness Areas Manual 8560 (USDI BLM 1993), Interim Management Policy for Lands under Wilderness Review Handbook H-8550-1 (USDI BLM 1995) and the Wilderness Inventory and Study Procedures Handbook H-6310-1 (USDI BLM 2001a). The guidance states:

- Noxious weeds may be controlled by grubbing or with chemicals when they threaten lands outside wilderness or are spreading within the wilderness, provided the control can be done without serious impacts on wilderness values and treatments are necessary to maintain the natural ecological balances.

- Plant control must be approved for native plants when needed to maintain livestock grazing operations where practiced prior to the designation of wilderness.

- Reseeding may be done by hand or aerial methods to restore natural vegetation.

There are no set restrictions on vegetation treatments in other types of special areas. However, the unique characteristics of these areas would be considered when preparing management plans for treatment activities.

Herbicide treatments can be used to remove noxious weeds, as long as they do not adversely affect wilderness values. The proposed herbicide treatments could affect wilderness and special areas by altering the existing plant species composition and structure, and altering the visual qualities of treated areas.

\section{Scoping Comments and Other Issues Addressed in the Assessment}

Respondents suggested that weeds should be stopped from spreading into wilderness areas by treating them outside of these areas, while others requested that treatments within wilderness areas be undertaken only after the spread of weeds outside of these areas has been effectively halted. Other respondents proposed that unique natural areas, including riparian zones, roadless areas, old growth areas, and areas of highest biological integrity, should be protected and that roadless areas should not be treated.

\section{Standard Operating Procedures}

Actions that reduce the risk of spreading noxious weeds, prevent the establishment of new invaders, and promote public awareness would be encouraged by the BLM in wilderness and special areas.

- Encourage backcountry pack and saddle stock users to feed their livestock only weed-free feed for several days before entering a wilderness area.

- Encourage stock users to tie and/or hold stock in such a way as to minimize soil disturbance and loss of native vegetation.

- Revegetate disturbed sites with native vegetation if there is no reasonable expectation of natural regeneration.

- Provide educational materials at trailheads and other wilderness entry points to educate the public on the need to prevent the spread of weeds.

- Use the "minimum tool" to treat noxious and invasive vegetation, relying primarily on use of ground-based tools, including backpack pumps, hand sprayers, and pumps mounted on pack and saddle stock.

- Use chemicals only when they are the minimum method necessary to control weeds that are spreading within the wilderness or threaten lands outside the wilderness.

- Give preference to those herbicides that have the least impact on non-target species and on the wilderness environment.

- Implement herbicide treatments during periods of low human use, where feasible (USDI BLM 1988e).

- Address wilderness and special areas in management plans.

- Maintain adequate buffers for Wild and Scenic Rivers $(1 / 4 \mathrm{mi}$ on either side of river, $1 / 2 \mathrm{mi}$ in Alaska).

\section{Summary of Herbicide Impacts}

In general, herbicide treatments in wilderness and special areas would have short-term negative effects and long-term positive effects on wilderness and special status area values. In wilderness areas and WSAs, only 
treatments that improve the natural condition of these areas would be allowed. Therefore, long-term effects, if treatments were successful, would be beneficial; noxious weed infestations and risk of future catastrophic wildfires would be reduced in these areas.

The overall effect of herbicides on wilderness and special areas would depend on whether the end condition of the treatment site (considering both longterm benefits and short-term impacts) was an improvement in wilderness characteristics. In many cases (e.g., an eradication of a small population of an incipient pest, a prescribed fire that mimics historical fire), communities in the treatment area would quickly recover, and the overall effect would be positive. In other cases (e.g., treatments that require the creation of access roads to treatment sites, treatments that require repeated access to a site in order to meet a desired objective), the impacts of the treatment to the wilderness character of the site would outweigh the potential long-term benefits.

The short-term effects of vegetation treatments in other special areas would typically be less than those in wilderness areas, as human activities and influences are not necessarily incompatible with their unique qualities. However, all treatments would have the potential to alter these unique qualities, as well as to provide longterm benefits by controlling weeds and reducing fire risks.

The reduction of hazardous fuels and noxious weeds on lands adjacent or near to wilderness and special areas would provide long-term benefits by reducing the likelihood that noxious weeds would spread onto these unique areas, or that a catastrophic wildfire would burn through them, thus degrading their unique qualities. Because there would be fewer restrictions on the intensity of treatments on lands adjacent to wilderness and special areas, preventative treatments in these areas would eliminate or reduce the need for intrusive treatments in wilderness and special areas in the future. The need for emergency fire suppression activities, which can be very damaging, would also be reduced.

Use of herbicides to treat undesirable vegetation could potentially affect the "naturalness" of wilderness areas and WSAs by killing non-target native vegetation through imprecise application and/or drift. The degree of effects would depend on the application method, with spot applications less likely to cause adverse effects than aerial applications. For the most part, vehiclemounted sprayers would not be used to treat vegetation, given the existing restrictions on wilderness areas.
However, vehicles could be used in extreme scenarios, if approved. The long-term effects of herbicide treatments on wilderness and special areas would depend on the success of the treatment in controlling noxious weeds. In most cases, the benefits of eradicating noxious weeds from wilderness and special areas would far outweigh the potential short-term negative effects of using chemical treatments.

The potential effects of chemical treatments on other special areas would depend on numerous site-specific factors, as discussed for the effects of other treatment methods above. Some special areas would support resources that are more sensitive to exposure to herbicides than the resources in other areas. There would also be human health risks involved with using certain types of herbicide application (e.g., aerial application) in special areas that are managed to support wilderness activities.

\section{Impacts by Alternative}

\section{Alternative A - Continue Present Herbicide Use (No Action Alternative)}

Impacts to wilderness and special areas under the No Action Alternative as a result of herbicide treatments would be similar to those that are currently experienced. Wilderness and special areas that are dominated by invasive species are usually less visually appealing and offer fewer wilderness characteristics. Under the No Action Alternative, the BLM would treat only a third of the number of acres treated under the Preferred Alternative. Although BLM field offices did not specifically identify how many acres would be treated in wilderness and special areas when providing information for this PEIS, it is presumed that fewer acres in wilderness and special areas would be treated under the No Action Alternative than under the other herbicide-treatment alternatives. Therefore, fewer positive benefits from herbicide treatments would be generated under this alternative, but there would also be fewer negative impacts on wilderness characteristics, species of concern, and other resources associated with herbicide treatments in wilderness and special areas. In addition, per capita vegetation treatments would not likely be as effective in restoring wilderness and special lands because the No Action Alternative would not allow the use of the four new herbicides evaluated in this PEIS. 


\section{Alternative B - Expand Herbicide Use and Allow for Use of New Herbicides in 17 Western States (Preferred Alternative)}

Because Altcrnative B involves the most treatment acres, it could also have the greatest short-term adverse impact on wilderness and special areas, primarily by resulting in the temporary closure of more lands. Along with these closures, there might be more lost opportunities for collection of plant materials than under other alternatives. Although only a small portion of the acres treated using herbicides would be in wilderness and special areas, more acres in wilderness and special areas would be treated under this alternative than the other alternatives. Thus, this alternative could have the largest positive impact on wilderness and special areas since it would reduce the risk of loss of wilderness values and improve wilderness characteristics over the largest acreage possible. As a result, recreation hours spent at a given site could be greatest under this alternative. Given the larger number of acres that would be treated, it is more likely that the BLM would be able to contain and eradicate noxious weed populations in wilderness and special areas under this alternative.

Under this alternative, four new herbicides would be available for use by the BLM, and herbicide treatments could occur in Alaska, Nebraska, and Texas. Based on the HHRA and ERA, the risks to recreationists and sensitive species from these new herbicides, in many cases, are less than risks associated with currentlyavailable herbicides, such as 2,4-D, hexazinone, and triclopyr. The Alaska BLM does not anticipate using herbicides on public lands, and public lands in Nebraska and Texas are not associated with wilderness or other special areas.

\section{Alternative C - No Use of Herbicides}

Alternative $\mathrm{C}$ would have the benefit of protecting wilderness and special area users, sensitive species, and other resources from accidental exposure to herbicides. However, there are certain plants that could be injurious to humans, which are most easily controlled or eradicated using herbicides (e.g., Russian knapweed, purple loosestrife, Canada and Scotch thistles, yellow star-thistle). Therefore, Alternative $\mathrm{C}$ could negatively impact activities in wilderness and special areas, particularly camping, hiking, and other activities that would present opportunities for easy contact with these noxious weeds. Visitation to these lands could be lower than under the Preferred Alternative, and greater concentrations of visitors could occur in other wilderness and special areas, resulting in greater impact to these areas.

If other treatment methods were used in place of herbicides, these methods could have a greater impact on wilderness and special area values. For example, prescribed burning would be more likely to result in restricted access by recreationists, decreased air quality, more dramatic changes in the visual landscape for a longer period of time, and shorter visit times by recreationists and sightseers. In addition, it is likely that fewer acres would be treated in highly visible areas overall (as a result of the adverse visual and air quality impacts of prescribed burning), meaning that over the long term these areas would remain of a lower ecosystem quality. Fire use would also displace sensitive wildlife and could lead to erosion that impacts fish habitat.

\section{Alternative D - No Aerial Applications}

Aerial spraying would be uncommon in wilderness and special areas under all treatment alternatives. By prohibiting aerial spraying, Alternative D would likely limit the number of acres that could be covered by a single treatment. This limit to acreage could have the benefit of reducing the acreage of lands that are temporarily closed to wilderness use. Furthermore, wilderness and special areas and their values could be disproportionately negatively affected by this alternative if prescribed burning were to increase as a result of fewer larger-scale areas being treated with herbicides. Hunting, camping, backpacking, horseback riding, and other wilderness pursuits would be limited in burned areas, and possibly shifted to other areas.

\section{Altermative $\mathbf{E}$ - No Use of Acetolactate Synthase- inhibiting Active Ingredients}

Several components of Alternative $\mathrm{E}$ pertain to wilderness and special areas (see Appendix I). As discussed in the other resource sections, fewer acres would be treated under this alternative than under the Preferred Alternative and Alternative D. While fewer treated acres would tend to result in fewer negative and positive impacts, an increased emphasis on ecosystembased management techniques under Alternative $\mathrm{E}$ would tend to decrease the short-term negative benefits and possibly increase the long-term positive benefits associated with this alternative. Limits on herbicide use in riparian areas under this alternative would minimize the potential for direct and indirect harm to riparian vegetation, aquatic animals, and water quality. 
Under Alternative $\mathrm{E}$, the following restriction would be implemented: "except for treatment of small infestations without motorized equipment, prescribe treatments within designated wilderness or wilderness study areas only after the spread of invasive species from outside these areas has been effectively halted" (see Appendix I). Under the other treatment alternatives, however, actions could be taken to control invasive species within wilderness and special areas before controlling invasive species populations outside special areas. The BLM policy is to treat infestations where they are found and to prevent their further spread. By not treating an infestation in a wilderness or other special area until the larger invasive species problem outside of the area is addressed, invasive species populations within wilderness and special areas could grow beyond an effectively treatable level.

The five herbicides (chlorsulfuron, imazapic, imazapyr, metsulfuron methyl, and sulfometuron methyl) that would not be used under this alternative are some of the least risky herbicides with respect to human health (see Human Health and Safety section). In addition, the ERAs predicted no risk to fish and terrestrial wildlife from most ALS-inhibiting herbicides (chlorsulfuron, imazapic, sulfometuron methyl), and a low risk in a few scenarios (imazapyr, metsulfuron methyl), suggesting that the elimination of these herbicides would not likely benefit wildlife and could indirectly harm wildlife in wilderness and special areas if more toxic herbicides were used in their place (see Wildlife Resources section). The other herbicides proposed for use by the BLM pose risks to non-target plants that are similar to those associated with these five herbicides; therefore, it is uncertain whether this use restriction would actually reduce risk to non-target plants. Thus, avoidance of ALS-inhibiting herbicides might provide few, if any, benefits to wilderness and special areas and special area users.

\section{Mitigation for Herbicide Treatment Impacts}

Mitigation measures that may apply to wilderness and special area resources are associated with human and ecological health and recreation. Please refer to the Vegetation, Fish and Other Aquatic Resources, Wildlife Resources, Recreation, and Human Health and Safety sections of this chapter.

\section{Recreation}

Approximately $40 \%$ of public lands are within a day's drive of 16 major urban areas in the West (USDI BLM 2005a). Outdoor recreation, nature, adventure, and heritage tourism are the fastest growing segments of the travel and tourism industry Recreational use of public lands consists predominately of camping and picnicking, which represented $43 \%$ of all visitor days in 2005 (USDI BLM 2006d). Other important recreational activities included non-motorized travel, such as hiking, horseback riding, and mountain biking; OHV travel; viewing public land resources and interpretation and education; and hunting. Snow- and ice-based activities, such as cross-country skiing, snowmobiling, and snowshoeing represented less than $1 \%$ of visitor days. The BLM administers many acres of public lands and facilities at least in part for these recreational pursuits. Many of these lands are managed for multiple uses; activities designed for one program or purpose (e.g., vegetation control/enhancement) must be compatible with other programs and purposes.

Less than $1 \%$ of the acreage considered in this PEIS consists of intensively managed, developed recreation areas that tend to have high public visitation. Many of these areas are near major urban areas in California, Arizona, and Utah, and include National Monuments and other National Conservation Areas (see Map 3-12). In these areas, the goals of vegetation treatments include maintaining the appearance of the area and protecting visitors from the adverse effects of contact with noxious weeds and other invasive/unwanted species. Treatments would likely be done using mechanical and manual methods, or with spot treatments using herbicides, and treatment effects on the public would be minimal. However, herbicide treatments would be more likely with increasing distance away from high-use visitor areas. Thus, hikers, hunters, campers, horsemen, livestock owners, and users of plant resources for cultural, social, and economic purposes would be at the greatest risk of coming into contact with herbicide treatment areas.

\section{Scoping Comments and Other Issues Evaluated in the Assessment}

Several respondents remarked that treatments should not be used as an excuse to close OHV trails. Another commentor requested that areas not be treated solely to improve recreational use. If treatments require any travel or access routes to be closed, the impacts on 
recreation and nearby areas that would handle the shift in use should be addressed. The effects of herbicides on recreational users should also be addressed.

\section{Standard Operating Procedures}

There are several SOPs that could help reduce the negative impacts of herbicide treatments on recreation:

- Schedule treatments to avoid peak recreational use times, while taking into account the optimum management period for the targeted species.

- Notify the public of treatment methods, hazards, times, and nearby alternative recreation areas.

- Adhere to entry restrictions identified on the herbicide label for public and worker access.

- Post signs noting exclusion areas and the duration of exclusion, if necessary.

- Use herbicides during periods of low human use, where feasible.

In addition, SOPs identified in the Human Health and Safety, Fish and Aquatic Resources, and Wildlife Resources sections should be implemented to further reduce risks to recreationists and the resources they use.

\section{Summary of Herbicide Impacts}

Vegetation treatments would have short-term negative impacts and long-term positive impacts on recreation. During treatments, there would be some scenic degradation, as well as distractions to users (e.g., noise from machinery). In addition, there would be some human health risks to recreationists associated with exposure to herbicides. These risks are discussed in more detail in the Human Health and Safety section. Finally, some areas would be off-limits to recreation activities as a result of treatments, generally for a few hours or days, but potentially for at least one full growing season or longer depending on the treatment. In most cases, recreationists would be able to find alternative sites offering the same amenities, but a lessened experience could result if concentrated use occurred in these alternative sites.

Site closures would generally last for a short time period following herbicide application, depending on the recommendations on the herbicide label. Usually the recommended exclosure periods would not exceed 24 hours; however, recreational access could be restricted for a season or more to allow vegetation to recover following treatment.

During site closures, signs would be posted stating the chemical used, the date of application, and a contact number for more information, and would remain in place for a period of at least 2 weeks following treatment. Dead brown vegetation could temporarily reduce recreational potential until vegetation recovered, although in most cases any substantial amounts would be removed to avoid hazardous fuels build up. Chemical treatments could also pose some health risks to recreational users, which would be greatest for aerial herbicide applications, and to users engaging in activities such as ingesting berries or fish (see Human Health and Safety section). Chemical treatments would generally result in long-term benefits to recreationists by controlling noxious weeds and other unwanted vegetation and improving plant species diversity. Herbicide use would likely negatively impact sightseeing recreational opportunities, as further discussed in the Visual Resources section.

Developed recreation sites with public facilities would be treated in order to maintain the appearance of the area and to protect visitors from the adverse effects of unwanted vegetation (e.g. thistles, ragweed, and poison ivy). Long-term adverse effects on developed recreational facilities would be unlikely, as treatments are expected to improve the vegetative health and utility of these sites. In some cases, developed recreation sites could be temporarily closed during treatment implementation.

Dispersed recreation in non-developed areas would potentially be affected to a greater degree than recreation in developed sites because most of the 6 million acres of vegetation treatments would occur in these undeveloped, dispersed areas. Recreational activities in these areas are spread out across the landscape, and different types of recreational activities would be affected differently. Impacts to recreation in areas with a greater abundance of recreational opportunities (e.g., Alaska) would not be as significant as impacts to areas with less extensive recreational opportunities. However, over the long term, recreationists in these dispersed recreation areas would likely benefit from a reduction in invasive plants, especially thorny or poisonous noxious weeds, provided by herbicide treatments. In addition, herbicide treatments that reduce the risk of wildfire would reduce the likelihood of recreationists being displaced from favorite hunting, fishing, and camping sites by wildfires. 
During the recent wildfires that swept through the Great Basin, not only were traditional recreation activities affected, but some special events were altered or cancelled. Signs were destroyed, hiking and camping areas burned over, wildlife and game displaced, and the scenery in the Great Basin marred (USDI BLM 1999).

Recreational use of motorized vehicles on public lands is typically limited to designated routes and trails. Trails located in areas of vegetation treatments would be closed during treatments and for a period of time following treatments to allow vegetation to recover. Closures could last for several growing seasons following more intensive treatments involving complete removal of vegetation was completely removed, while less intensive treatments may not require site closures beyond what is recommended for safety on herbicideuse labels.

The effects of herbicide treatments on fish and wildlife could have indirect negative impacts on recreational activities such as fishing, hunting, and wildlife viewing. For example, aerial application of an herbicide over a large area could adversely affect these types of recreation activities by harming or displacing game and non-game fish and wildlife species.

Vegetation treatments could also impact scenic views, particularly large treatments next to roads. The effects of vegetation management on the visual quality of the landscape are discussed further in the Visual Resources section

The impacts of individual herbicides on recreation would differ primarily based on human health risks to recreationists and short-term recreation area closures. The Human Health and Safety section describes the potential risks to different types of recreationists (e.g., hikers, hunters, anglers, swimmers, and plant collectors) associated with exposure to different herbicides. Herbicide-use labels present the minimum period of time that a sprayed site must be closed to humans. The longer a site is closed, the greater the adverse effect to recreationists in terms of lost use days, particularly at sites that experience a higher volume of visitors. Because most mandatory site closure periods are less than 24 hours, it is expected that the impacts would be minimal, particularly if treatments were scheduled during a period of low visitation. On sites experiencing more extensive treatments, however, longer closures could be required to allow vegetation to recover.

Unintended impacts of herbicides on non-target plants and animals could impact recreation activities (e.g., hiking, plant collecting, hunting, and fishing) in off-site areas. The risks to non-target species from use of the evaluated herbicides are discussed in the Vegetation, Fish and Aquatic Resources and Wildlife Resources sections. The longer an herbicide lingers in soil (depending also on its ability to bind to soil [Koskinen et al. 2003]), the more likely it is to contaminate groundwater or run off into water bodies used by recreationists.

Over the long term, herbicide treatments would have a positive effect on recreation on treated lands. Removal of weedy vegetation would return public lands to a more "natural" or "desirable" condition, which hikers and nature enthusiasts would likely value over degraded lands. In addition, the increased aesthetic value of treated sites would benefit most recreational users. In some instances, treated sites could become more desirable as destinations for outdoor activities, making them more popular to recreational users. In addition, fuels reduction treatments would reduce the likelihood of future wildfires on public lands used for recreation. As a result, recreationists would be provided with safer conditions, and there would be less of a chance that a wildfire would burn a large acreage of lands used for recreation. Where wildfires do occur, they are capable of causing damage to recreational resources in large areas and affected sites require long periods of time for recovery. Treatment of sites to restore native vegetation would enhance fish and wildlife habitat, to the benefit of hunters, birdwatchers, and other users of these resources.

\section{Impacts by Alternative}

\section{Alternative A - Continue Present Herbicide Use (No Action Alternative)}

Impacts to recreation areas under the No Action Alternative as a result of herbicide treatments would be similar to those that are currently experienced. Assuming a steady increase in number of recreational users of public lands (although numbers of recreational visitors have held steady or trended slightly downward in recent years), there would be more impact to lands from human activities (e.g., spreading weeds, starting fires), but the same level of treatment. Developed and undeveloped recreation lands that are dominated by invasive species are usually less visually appealing and less attractive to recreationists than areas that support native plant communities. 
Most treatments would occur in New Mexico (32\%), Idaho (19\%), Wyoming (12\%) and Nevada (8\%). Although these states would account for $71 \%$ of treatment acres, they accounted for only $20 \%$ of visitor days during 2005 (USDI BLM 2006d). Thus, the likelihood of visitors to public lands coming into contact with herbicide treatment areas would be minor, as treatments would occur in states with relatively few visitors.

The No Action Alternative would treat only a third of the acreage treated under the Preferred Alternative, and therefore would fall short of the Preferred Alternative in its ability to treat vegetation and generate positive benefits for recreation lands and users, but would also have fewer negative impacts on recreation associated with herbicide treatments. In addition, per capita vegetation treatments would not likely be as effective in restoring recreation lands because the No Action Alternative would not allow the use of the four new herbicides evaluated in this PEIS. Because fewer total acres would be treated under this alternative than under the other herbicide treatment alternatives, this alternative might have fewer long-term recreation benefits than the other treatment alternatives, if a greater amount of treatment acres were to translate to a greater improvement of ecosystem health and scenic quality.

\section{Alternative B - Expand Herbicide Use and Allow for Use of New Herbicides in 17 Western States (Preferred Alternative)}

Because Alternative B involves the largest number of treatment acres, it could also have the largest short-term adverse impact on recreation, primarily by resulting in the temporary closure of more lands. Along with these closures, there might be more lost opportunities for collection of plant materials than under other alternatives. Because of the large number of treatment acres, however, this alternative could have the largest positive impact on recreation, since it would reduce the risk of visitor contact with undesirable plant species and would increase visitor exposure to desirable plants and wildlife over the largest acreage possible. As a result, recreation hours spent at a given site could be greatest under this alternative.

Under the Preferred Alternative, most treatments would occur in Idaho (28\%), Nevada (22\%), Wyoming (16\%), and New Mexico (10\%). Although these states account for $76 \%$ of treatment acres, they accounted for only $20 \%$ of visitor days during 2005 (USDI BLM 2006d). Thus, the likelihood of visitors to public lands coming into contact with herbicide treatment areas would be minor, as treatments would occur in states with relatively few visitors.

Under this alternative, four new herbicides would be available for use by the BLM, and herbicide treatments could occur in Alaska, Nebraska, and Texas. Based on the HHRA, the risks to recreationists from these new herbicides, in many cases, are less than risks associated with currently-available herbicides, such as 2,4-D, hexazinone, and triclopyr. Although the Alaska BLM does not anticipate using herbicides on public lands, treatments in Nebraska and Texas could potentially affect recreational users in those states.

\section{Alternative C - No Use of Herbicides}

Alternative $\mathrm{C}$ would have the positive benefit of protecting recreationists from accidental exposure to herbicides. However, certain plants that can be injurious to humans are most easily controlled or eradicated using herbicides (e.g., Russian knapweed, purple loosestrife, Canada and Scotch thistles, yellow star-thistle). Therefore, Alternative C could negatively impact recreation activities, particularly camping, hiking, and other activities that would present opportunities for easy contact with these noxious weeds. Over 900,000 acres treated under the Preferred Alternative would not be subject to herbicide treatment under this alternative. As a result, these areas could have fewer recreationists because of dominance by undesirable plant species. Visitation to these lands could be lower than under the Preferred Alternative, and higher concentrations of visitors could occur in other areas, resulting in greater impacts elsewhere.

Furthermore, if other treatment methods were used in place of herbicides, these methods could have a greater impact on recreation. For example, prescribed burning could result in restricted access by recreationists, decreased air quality, and more dramatic changes in the visual landscape for a longer period of time. In addition, it is likely that fewer acres would be treated in highly visible areas overall (as a result of the adverse visual and air quality impacts of prescribed burning), meaning that in the long term these areas would remain of a lower ecosystem quality, limiting their attraction to recreationists.

\section{Alternative D - No Aerial Applications}

It is unlikely that aerial spraying would occur in high public use recreational areas under any of the alternatives, but aerial spraying would occur in dispersed use areas under the No Action Alternative, 
Preferred Alternative, and Alternative E. By prohibiting aerial spraying, Alternative D would also likely limit the number of acres that could be covered by a single treatment. This limit could have the benefit of reducing the acreage of lands that are temporarily closed to recreation. Furthermore, dispersed recreation (i.e., recreation in non-developed areas) could be disproportionately negatively affected by this alternative if prescribed burning were to increase as a result of fewer larger-scale areas being treated with herbicides. Hunting, camping, backpacking, horseback riding and other pursuits would be limited in burned areas, and possibly shifted to other areas.

\section{Alternative E - No Use of Acetolactate Synthase- inhibiting Active Ingredients}

Under Alternative E herbicide treatments would result in impacts similar to those under Alternative D, with slightly fewer acres being treated and a reduced, though not eliminated, emphasis on aerial spraying. While fewer treated acres (over Alternative D) would tend to correspond to fewer impacts, an increased emphasis on ecosystem-based and passive management techniques under Alternative E would tend to decrease the shortterm negative effects and possibly increase the longterm positive benefits associated with this alternative. For example, because spot treatments would be favored over broadcast treatments, Alternative E would limit the negative short-term impacts to recreationists from drift of herbicides into off-site areas that have not been temporarily closed to visitors. In addition, limits on herbicide use in riparian areas would minimize the potential for direct and indirect harm to riparian vegetation, aquatic animals, and water quality. As compared to the Preferred Alternative, however, this alternative would treat substantially fewer acres, resulting in fewer long-term improvements to the environmental quality of recreation sites.

The five herbicides (chlorsulfuron, imazapic, imazapyr, metsulfuron methyl, and sulfometuron methyl) that would not be used under this alternative are some of the least risky herbicides with respect to human health (see Human Health and Safety section). In addition, the ALS-inhibiting herbicides either pose no risk to terrestrial wildlife (chlorsulfuron, imazapic, sulfometuron methyl), or low risk (imazapyr, metsulfuron methyl), suggesting that eliminating the use of these herbicides would be unlikely to benefit fish and wildlife and could indirectly harm fish and wildlife if more toxic herbicides were used in their place (see Fish and Other Aquatic Resources and Wildlife Resources sections). Thus, there would likely be few, if any, benefits to anglers and hunters and other recreationists.

\section{Mitigation for Herbicide Treatment Impacts}

Mitigation measures that may apply to recreational resources are associated with human and ecological health. Please refer to the Vegetation, Fish and Other Aquatic Resources, Wildlife Resources, and Human Health and Safety sections of this chapter.

\section{Social and Economic Values}

\section{Introduction}

Herbicide treatments have the potential to affect pcople, communities, and economies in each of the 17 western states that could receive treatments. The susceptibility of these entities to social and economic effects stems from the importance of public lands to the lives of the people and communities in the West, especially in the states with the largest amounts of public land. Public lands commonly provide a major portion of economic sustenance, especially in rural areas, by supporting ranching (grazing leases), mining, active and passive recreation opportunities, and a myriad of other activities that westerners rely on. The dollar value of the social sustenance may not be readily quantifiable, but it, too, is important to the way of life of westerners. "Wide open spaces" are not just a cliché in western songs and novels, they are a tangible part of the experience that attracts and/or retains people who live in western states. The large expanses of federal lands are a significant contributor to the open spaces that define the "sense of place" in many parts of the West. Through support of economies and the social context of the West, federal lands are highly important to the western states. Actions that affect federal lands, such as the application of herbicides, have the potential to affect the economic and social environment of the region.

The extent of potential effects would vary from state to state because of the differing prevalence of federal lands and also because the treatment area in each state would vary, both in acreage and in percentage of land area treated, depending on local issues and needs. The most pervasive effects would likely occur in states with large amounts of public land. During 2002, information was gathered from BLM field offices on the general location of herbicide treatment projects likely to occur under the No Action and Preferred alternatives. Based on this 
information, nearly two-thirds of herbicide treatments proposed under the Preferred Alternative would occur in Idaho, Nevada, and Wyoming, with the largest increases in herbicide use from current levels likely to occur in Nevada.

This EIS is programmatic in nature and very broad in scale. A programmatic analysis at this scale does not permit the completion of a detailed, quantitative social and economic analysis. Therefore, only general effects and expected trends will be addressed here. Concerned individuals should be assured that more detailed, sitespecific analyses would be conducted during the development of actual herbicide treatment projects. Public participation in developing the details of such proposals would be encouraged at appropriate times in those processes.

\section{Scoping Comments and Other Issues Evaluated in the Assessment}

Among the major concerns identified during scoping, were suggestions that economic and ecological costs and benefits to local communities and residents should be examined. Some individuals proposed that the BLM's needs for people and fiscal resources should be addressed, as should costs to state and local governments and private individuals, including secondary costs from such things as loss of recreational use activities. Environmental justice issuesdisproportionate effects on minorities, low-income, and child populations - and Indian Trust issues were raised. Several comments addressed potential economic effects on ranchers from grazing restrictions or changes to forage productivity, while others questioned whether grazing permittees would pay for a portion of the treatment costs. A few respondents questioned whether the BLM would perform the treatment work or contract it out; others proposed contracting to local vendors. Some were concerned about potential economic effects on local fire fighters. Evaluation of the effects of the herbicide use alternatives, both beneficial and detrimental, will address these issues to the greatest degree possible, given the scale of the potentially affected geographic area and the necessarily inexact nature of the alternatives in advance of specific treatment project proposals.

There are numerous stakeholders throughout the western U.S. with differing needs and perspectives, and all of their interests must be taken into consideration when planning the treatment program. On a local level, stakeholders include people in communities located in the vicinity of public lands, such as adjacent landowners, local businesses, and users of public lands (e.g. ranchers and recreationists), as well as the counties and states that benefit from BLM revenues. On a national level, the stakeholders include all taxpayers, whose tax dollars support BLM programs and who have partial "ownership" of federal public lands. Given the wide range in stakeholders whose needs and interests must be considered, many different and often conflicting opinions must be considered. The alternative selected for implementation will be one that balances both national and local interests.

\section{Standard Operating Procedures}

Herbicide use would affect local social and economic resources; some effects would be adverse. Following selected SOPs would reduce some of the adverse effects. The following general procedures are designed to reduce potential adverse impacts to social and economic conditions from the application of herbicides in the BLM vegetation management program:

- Consider surrounding land use before selecting aerial spraying as a method, and avoid aerial spraying near agricultural or densely-populated areas.

- Post treated areas and specify reentry or rest times, if appropriate.

- Notify adjacent landowners prior to treatment.

- Notify grazing permittees of livestock feeding restrictions in treated areas if necessary, as per label instructions.

- Notify the public of the project to improve coordination and avoid potential conflicts and safety concerns during implementation of the treatment.

- Control public access until potential treatment hazards no longer exist, per label instructions.

- Observe restricted entry intervals specified by the herbicide label.

- Notify local emergency personnel of proposed treatments.

- Avoid aerial spraying during periods of adverse weather conditions (imminent snow or rain, fog, or air turbulence).

- During helicopter applications, apply herbicides at an airspeed of 40 to 50 miles per 
hour (mph), and at an elevation of about 30 to 45 feet above ground.

- Comply with herbicide-free buffer zones to ensure that drift will not affect crops or nearby residents/landowners.

- Use spot applications or low-boom broadcast applications where possible to limit the probability of contaminating non-target food and water sources, especially vegetation over areas larger than the treatment area.

- Consult with Native American tribes and Alaska Native groups to locate any areas of vegetation that are of significance to the tribe and that might be affected by herbicide treatments.

- Work with Native American tribes and Alaska Native groups to minimize impacts to these resources.

- To the degree possible within the law, hire local contractors and workers to assist with herbicide application projects.

- To the degree possible within the law, purchase materials and supplies, including chemicals, for herbicide treatment projects through local suppliers.

- To minimize fears based on lack of information, provide public educational information on the need for vegetation treatments and the use of herbicides in an Integrated Pest Management program for projects proposing local use of herbicides.

These procedures would help minimize impacts to people, communities, and human activities in the vicinity of herbicide treatment projects on public lands in the 17 -state study region.

\section{Impact Assessment Assumptions}

The social and economic analyses for the application of herbicides are guided by a number of key assumptions. First and foremost, this is a 17-state PEIS with no sitespecific information on which types of herbicides would be used in any particular area. Consequently, there will be little or no discussion of specific application parameters; any such discussion will be strictly to provide examples. It is expected that communities that are particularly dependent on a single industry are more susceptible to the effects of herbicide use than other communities. In particular, ranching communities and recreation-dependent communities may be more affected than more diversified communities. However, it is not possible to identify particular communities at this scale of analysis. More specific analysis of the effects to communities would be conducted when individual projects were proposed, and the analysis would consider elements cited in this section.

The proposed use of herbicides would only apply to public lands; this PEIS does not attempt to predict possible decisions or actions by other agencies or private individuals. Also, it is not expected that any of the alternatives would significantly affect ongoing, long-term trends such as the increasing demand for outdoor recreation or growth in urban, suburban and rural populations, particularly in states from the Rocky Mountains to the Pacific.

It is assumed that herbicide treatment alternatives would meet, to different degrees, the need for the proposed action (i.e., reduce the risk of wildland fire and improve ecosystem health). Herbicide treatments would reduce the risk of wildland fire by reducing hazardous fuels to reduce the size and severity of wildland fires. In turn, the cost of wildland fire suppression and the loss of life and property would be reduced. Treatments that improve ecosystem health could increase or improve the amount and quality of commercial and casual uses, improve or maintain market and non-market values of existing uses, and reduce the cost of operations on public lands. However, it was not possible to quantify these benefits at this programmatic level of analysis, since there is uncertainty as to when, where, and how treatments would occur.

\section{Summary of Herbicide Impacts}

Social effects of the individual herbicides are, for the most part, impossible to differentiate at the scale addressed by this PEIS. The potential for differing social effects among the chemicals would derive from people's perceptions of different health and safety risks for different chemicals. Data on such perceptions are not available, and, in fact, could differ from one community to another, depending on the level of knowledge about herbicides in the community and possible past experiences with their use (or "misuse," such as accidental spills or damage to non-target plants). The Human Health and Safety section in this chapter discusses health and safety issues related to the proposed herbicides in more detail. There is also some potential for beneficial or adverse effects on the social fabric of communities depending on the success or 
failure of vegetative treatment programs using various chemicals. Successful improvement in the productivity of rangeland, for example, would help sustain a ranching-dependent community, whereas lack of success could put additional pressure on often tight economic margins in ranching, which would tend to encourage out-migration. Successfully reducing hazardous fuels in the WUI could encourage people to remain in, or move to, a community, whereas major fire losses, particularly in smaller communities, could encourage some people to move away. These potential effects are somewhat speculative, but should be examined more closely at the project-specific level.

Economic effects of individual herbicides on communities could be similar to social effects. Changes in range productivity, wildfire risk, and access or attractiveness for recreation activities could potentially affect employment opportunities and income levels in a community, in either a positive or negative fashion. As with social effects, however, the broad scale of this PEIS and the lack of data preclude the ability to accurately predict whether and where such effects would occur, and whether they would be beneficial or adverse.

There would be direct and indirect economic effects from application of herbicides. These effects would vary, depending on the quantities of each herbicide selected for use and the methods of application for each. Table 3-23 illustrates the dramatic differences in costs associated with the various herbicides used in 2005 , which ranged from approximately $\$ 1$ per acre for tebuthiuron to almost $\$ 127$ per acre for bromacil.

In addition to the chemical costs, there would be costs for applying the herbicides. The USDA Forest Service (2005) estimated the average cost per acre for application at $\$ 100$ for ground application and $\$ 25$ for aerial application. The BLM's range of estimated application costs is even broader. For ground applications, the BLM's estimates range from $\$ 50$ to $\$ 300$ per acre for backpack or ATV applications, and $\$ 25$ to $\$ 75$ per acre for boom sprayer applications. Aerial applications are estimated at $\$ 6$ to $\$ 40$ per acre for fixed-wing aircraft and $\$ 25$ to $\$ 200$ per acre for helicopter applications. The differences are largely due to the variation in labor and time required to cover an acre by each application mode. It takes many more man-hours to treat an acre on foot or from a small ATV, for example, than to treat an acre with an aircraft. At best, all of these estimates are crude averages; actual costs would vary widely, dictated by terrain, scale of the treatment project, accessibility of the treatment area, size of the problem vegetation stand being treated, and other factors. None of the specifics of these factors are available for evaluation at the programmatic level, but they would be analyzed in greater detail for specific projects as they were developed.

The source of labor for the applications, included in the application cost, would vary with the project. Aerial application projects would be contracted out in most cases. Ground applications would be done by a combination of contractors and BLM personnel, either full-time or part-time employees. The determination of in-house or contract application would be determined for each project individually, depending on the specific needs of the project and the capabilities of the state or local BLM office.

Purchase of chemicals and contracting of applications would generate dollars to benefit the economy; the location of the benefit would depend on where the chemicals and contractors were obtained. Locally purchased chemicals would generate more local benefit, for example, whereas mass purchase of chemicals from a state or national distributor would likely have little local benefit. Herbicide application would tend to sustain local employment, and, in some cases, provide temporary employment for others.

\section{Impacts by Alternative}

\section{Impacts Common to All Alternatives}

\section{Population and Demography}

None of the five alternatives being analyzed are likely to cause substantive changes to existing patterns and trends in population or demographic conditions in the western states. While there would be some increased employment generated by the increase in BLM acreage treated with herbicides under each of the alternatives, the jobs would generally be short-term, temporary positions or contracted work, which would not be sufficient to encourage measurable in-migration of workers and their families. With few exceptions, perhaps including pilots and certified herbicide applicators, jobs generated by the increased herbicide treatments program would tend to pay moderate wages. Depending on the size and duration of any particular treatment project, there could be small, localized population increases, but it is not possible to ascertain if, or where, such changes would take place at this time. It is unlikely that any such growth would excessively burden the community in which it would occur because 
the growth would be small, even in the context of the rural West.

\section{Environmental Justice}

Executive Order No. 12898, "Federal Action to Address Environmental Justice in Minority Populations and Low-Income Populations" (59 FR 7629), is "intended to promote nondiscrimination in federal programs substantially affecting human health and the environment, and to provide minority communities and low-income communities access to public information on, and an opportunity for participation in, matters relating to human health and the environment." It requires each federal agency to achieve environmental justice as part of its mission by identifying and addressing, as appropriate, disproportionately high and adverse human health or environmental effects, including social and economic effects, of its programs, policies, and activities on minority and low-income populations.

Environmental justice concerns are usually directly associated with impacts on the natural and physical environment, but these impacts are likely to be interrelated with social and economic impacts as well. Native American and Alaska Native access to cultural and religious sites may fall under the umbrella of environmental justice concerns if the sites are on tribal lands or a treaty right has granted access to a specific location.

USEPA guidelines for evaluating potential adverse environmental effects of projects require specific identification of minority populations when either: 1) a minority population exceeds $50 \%$ of the population of the affected area, or 2) a minority population represents a meaningfully greater increment of the affected population than of the population of some other appropriate geographic unit.

Public lands occur predominantly in rural areas. There are large minority populations in rural areas of the West and Alaska, particularly Hispanics and Native Americans. Approximately $63 \%$ of the nation's Hispanic population, $68 \%$ of the nation's American Indian population, and $50 \%$ of the nation's Asian/Pacific Islander population reside in the western U.S., which contains less than $32 \%$ of the nation's total population (Table 3-15). In addition, Hispanics represent a high percentage of the total population of some states, including New Mexico, California, Texas, and Arizona, in particular. Similarly, Alaska, New Mexico, and several other western states have disproportionately high percentages of Native Americans and Alaska Natives. Issues of concern might include the propensity of Native Americans and Alaska Natives to use native plants for cultural and traditional purposes, and the potential for herbicides to damage some of these native plants if projects are not carefully planned and implemented. This combination of factors suggests the possibility that any significant effects associated with herbicide use for vegetation treatments could disproportionately affect these minority populations. It is not possible to determine whether minorities or low income populations would actually be disproportionately affected at this broad scale of analysis, however, because it is not known if treatment areas would coincide with concentrations of minority or low-income populations, or with Native American and Alaska Native use areas. Specific evaluations of environmental justice impacts would be conducted in concert with environmental analyses for site-specific treatment project proposals.

Issues specific to Native Americans, such as subsistence gathering of rangeland products, have been addressed in more detail in the Cultural and Paleontological Resources section, but they must also be addressed in detail with project-specific analyses.

\section{Protection of Children}

Executive Order 13045, Protection of Children from Environmental Health Risks and Safety Risks, instructs federal agencies to identify and assess environmental health risks and safety risks that may disproportionately affect children, and to ensure that their policies, programs, activities, and standards address disproportionate risks to children that result from environmental health or safety risks. Children could have a greater chance of being exposed to health and safety risks associated with vegetation treatments than adults because they typically spend more time outdoors, and because children, especially young children, tend to be more vulnerable to adverse effects from exposure to environmental contaminants. Although children may spend more time outdoors, they are not often on public land without adult supervision because of the remoteness of most public lands. Thus, the increased opportunity for exposure would generally be negligible to minor. If there are potential risks for adverse effects to people who happen to be outside in the vicinity of herbicide treatments, the project could have a disproportionate effect on children. 


\section{Employment and Income}

All of the vegetation treatment alternatives would result in economic benefits to western states and local communities by providing employment and labor income opportunities. The BLM would require the services of local pesticide applicators, pilots, and others, creating jobs and generating income. The benefits are not quantifiable at the scale of this analysis; they would be small in the context of the 17-state region, but could be more significant for some communities, depending on the expertise and availability of personnel in the relevant BLM offices. Local effects cannot be determined at the scale of this PEIS, but details of local economic effects would be determined at the time specific projects were analyzed under NEPA regulations. Regardless of the local economic situation, the nature of treatments indicates employment and related income effects would be short-term in nature and geographically dispersed, benefiting certain communities throughout the 17-state study area. In general, it is expected that communities located in areas with large amounts of public lands, and therefore the most potential treatment acreage, would receive the greatest employment and economic benefits. Idaho, Nevada, Wyoming, and New Mexico are the four states with the largest anticipated treatment acreage under each of the five alternatives, which suggests that communities in these states would also be among the largest beneficiaries of employment and income effects from the proposed herbicide program. Employment and income effects would have the greatest impact on smaller communities, where the increase in jobs and dollars would have a greater influence on the area economy than it would in or near larger towns and cities.

\section{Perceptions and Values}

A range of stakeholder perceptions and values would be influenced by the herbicide treatment alternatives. For example, individuals who have an aversion to chemical use in the environment could find all of the alternatives offensive, except Alternative C. Alternatively, individuals with a much greater concern about wildfires or the effects of invasive species would likely favor the most efficient means of attacking vegetation problems. Some westerners have philosophical issues with government ownership and management of large land areas, but they might be somewhat encouraged by plans to employ private contractors for some of the treatment work and would presumably favor the most efficient means possible to reduce fire risk and improve range productivity. Some individuals place high values on the health and pristine nature of the land and would therefore prefer to see that the least intrusive methods be implemented. All of the alternatives have similar negative and positive responses to these perceptions and values. A few differences are addressed below.

\section{Invasive Species Control Cost Savings}

Estimating the environmental and economic damages caused by invasive vegetation, and the environmental benefits and cost savings from treating invasive vegetation, cannot be quantified at the 17 -state regional scale. However, on a national scale, the costs of treating invasive vegetation can be enormous. For example, purple loosestrife, which occurs in 48 states, costs approximately $\$ 45$ million per year on control (ATTRA 1997). A total of $\$ 100$ million is spent annually in aquatic invasive species control in the U.S. (OTA 1993). In. U.S. agriculture, crop losses due to weeds are estimated at \$24 billion annually, and costs of herbicide treatments are about $\$ 3$ billion annually (Pimentel 1997 , 2005). Forage losses due to weeds total about $\$ 1$ million annually, and ranchers spend about $\$ 5$ billion annually to control invasive vegetation in pastures and rangelands. Total direct and indirect costs of leafy spurge in Montana, South Dakota, and Wyoming is estimated at nearly $\$ 2$ million annually on wildlands and up to $\$ 46$ million annually for grazing lands (Bangsund and Leistritz 1991; Bangsund et al. 1993). Annual losses from knapweed in Montana are estimated at over $\$ 40$ million annually (Hirsch and Leitch 1996). The Research Group (2000) evaluated the impacts of 21 species of weeds and estimated that both existing and potential invasive weeds are costing Oregon about $\$ 100$ million annually.

Studies that have attempted to project the costs and benefits of treating leafy spurge and yellow star-thistle have shown that benefits could total over $\$ 50$ million or more annually if leafy spurge is controlled in the Great Plains region (Bangsund et al. 1997, 1999a). Still, net returns per acre are often negative early in the treatment program, with gains in net return not seen until 10 years or more after treatment, with highest returns from ground spraying rather than aerial spraying programs ((Bangsund et al. 1996, 1999b; Hartmans 1997). Kadrmas et al. (2003) estimated the cost of treating 50 acres of public lands using a single application of herbicides and single attempt at revegetation. The cost of treating 50 acres of weeds was estimated at $\$ 7,500$ at year 0 . However, if the 50 acres were not treated and the weeds continued to spread, weeds would cover an estimated 182 acres by year 18 and it would require 
approximately $\$ 27,000$ to restore to a healthy ecosystem.

\section{Wildland Fire Cost Savings}

All of the herbicide treatment alternatives would commit approximately half of the treatment acreage to hazardous fuels and invasive weed reduction in the WUI. Neither the suppression cost savings, nor the reduction in property losses can be quantified at the 17state regional scale. The potential savings should be addressed further in environmental reviews for specific projects, although they may not be quantifiable even at that scale because of the number of variables contributing to when and where a fire may start and how much damage it may cause. These factors include weather conditions, terrain, human acts of omission, and structure type and density, among others. Further, it may take several years to build a sufficient experience base of data to quantitatively estimate the benefits of vegetative treatment on wildfire suppression costs and damage reduction. The Forest Service and BLM came to similar conclusions when trying to ascertain the effects of vegetation treatment activities on future fire suppression costs in the Interior Columbia Basin (USDA Forest Service and USDI BLM 2000).

Despite the lack of quantifiable data, it is expected that herbicide treatments in non-WUI areas would also reduce hazardous fuels, including invasive weeds, which contribute disproportionately to fire risk. Downy brome provides one example of the potential cost savings from attacking invasive weeds, and the costs of fighting downy brome-fueled fires have been estimated at around $\$ 20$ million per year, and up to $\$ 15$ million annually in southern Idaho alone, including rehabilitation costs (Duncan and Clark 2005). Consequently, it is expected that all of the alternatives would reduce the cost of fire suppression in the backcountry as well as in the WUI.

\section{Economic Activity and Public Revemues Generated from $B L M L$ Lands}

Commercial activities that occur on public lands could be affected by vegetation treatments. Vegetation treatments would not directly affect mineral resources, but could temporarily reduce access to such resources. Vegetation treatments would be unlikely to cause significant reductions in BLM revenues generated from mineral leases. Most of the BLM's mineral lease revenues come from Alaska, Colorado, and Montana (see Table 3-18), yet only about $8 \%$ of the herbicide treatments would occur in these three states under the
Preferred Alternative; herbicide treatments would not be allowed in Alaska under the No Action Alternative. Further, restrictions on access for these activities are likely to be minimal in most places because durable road access is generally required for commercial mineral extraction ventures. Consequently, adverse effects on employment and revenue from mineral production due to herbicide treatments, if any, would likely be very minor.

Historically, nearly all of the BLM's revenues from timber sales came from Oregon. In 2005, timber sales amounted to \$26.4 million and nearly all timber revenues were from Oregon ( $\$ 23.5$ million, Table 3-18), where at most about $8 \%$ of all herbicide treatments are proposed to occur. Treatments would result in long-term improvements in the condition of forest resources and would lead to increases in potential products and revenues generated from public lands over the long term. However, the potential effects are not quantifiable at the scale of this PEIS.

Effects on harvesting other vegetation (non-timber) products would depend on the product and the design of specific herbicide treatment projects. Indiscriminate application of herbicides could damage resources or reduce their value. Alternatively, herbicidal control of undesirable, invasive plants could enhance the habitat for desirable species. Public involvement in project planning and environmental review should be encouraged to minimize adverse effects and maximize benefits.

Herbicide treatments would necessitate some site closures to grazing activities during treatments and for a suitable recovery period afterward, both for effectiveness of the treatment and for safety of the livestock. Treatments that require temporary rest from grazing would result in a reduction in forage for livestock. Although alternative grazing sites may be available, the costs associated with grazing in a different area would likely be higher. The economic effects of temporarily reducing forage production and/or access would vary depending on the size and flexibility of the affected ranching operations. It is not possible to quantify the effects at the 17 -state regional scale. Although forage production could decrease initially following treatment, production would likely increase over the long-term as woody vegetation and weed species were controlled, increasing the suitability of rangeland areas for grazing. Treatments would result in an increased quantity and quality of forage, increased animal production, reduced fire hazard, and a reduced risk of sickness in livestock associated with ingesting 
poisonous plants (see the Livestoek section in this chapter for more information). As for other vegetation products, public involvement in project planning and site-specific environmental review should be encouraged to minimize adverse effects and maximize benefits.

Recreation-based businesses such as outfitters, bait shops, OHV sales and repair shops, fish and hunting shops, and outdoor gear and equipment rental shops are direct beneficiaries of recreational activity. Other services such as gas stations, restaurants, and hotels that are frequented by recreationists also benefit. Temporary closure of a popular recreation site, either to protect public safety during herbicide treatments or to decrease user-related impacts during the site's post-treatment recovery, would result in temporary losses of revenues to surrounding businesses. In most cases, these effects would be short term in nature, lasting only as long as the site closure. In general, most recreational activities would continue, but would shift to other locations (see the Recreation section in this chapter). Depending on the location of the alternate use area, the economic benefits would shift from one community to another. If there were a suitable nearby alternative to the closed site, the effects on surrounding businesses would be minimal; if not, the businesses would be adversely affected for a period of time. It is not possible to quantify the potential effects at the 17-state regional scale, or to identify businesses that would benefit from or be harmed by potential shifts in recreational activities. Over the long term, an improvement in the quality of a site from vegetation treatment could lead to increased recreational usage and a net increase in revenues to surrounding businesses. Reductions in hazardous fuels and the risk of wildfires would benefit the economies of rural communities, which are often dependent on recreational and wilderness values. In some cases, severe wildfires, particularly those occurring during the tourist season, could cause longterm disruption to recreation values, which would adversely affect recreational businesses. To the degree that treatments would reduce the risk of wildland fires, the herbicide treatment alternatives would benefit recreation-related economic activity.

Recreation provides revenues to the BLM through fees and permits. Closure of a popular fee-based recreation site would result in a loss of revenues to the BLM. The severity of any such losses cannot be determined at this scale because no specific fee-based recreation sites have been identified for treatment. Detailed effects would be examined at the site-specific project level.

\section{Expenditures by BLM (Financial Efficiency)}

Herbicide treatments would require a large financial investment by the BLM, which would vary by alternative. These costs represent a substantial input of financial resources into the communities surrounding BLM lands, particularly in areas where BLM landholdings are extensive.

The most cost-effective alternative is the one that produces the greatest benefits for the least amount of financial investment. The cheapest alternative, if it did not substantially improve the health of the land, could require indefinite repeat treatments, thus costing more money over the long term. Unfortunately, it is not possible to determine, on a 17-state regional scale, which broad alternative would be most cost-effective. Benefits to the health of the public lands depend on the specific problem to be addressed in each specific area. These benefits would be evaluated on a site-specific basis as project proposals were developed. Irrespective of the particular alternative selected, the costs associated with restoring or maintaining an ecosystem through vegetation treatments is generally much less than the cost of suppressing wildfires and implementing fire rehabilitation programs (USDI 2001).

An additional consideration regarding BLM expenditures is the distribution of payments to state and local governments (see Table 3-24). None of the herbicide treatments would affect these payments, as they are established by Congress, and none of the alternatives would alter the formula-based payments.

If goods and services were purchased locally, or additional workers were hired locally in support of the herbicide treatment alternatives, state and local governments would benefit through increased tax revenues. The relative public benefits would depend on the taxing structure of the individual states.

\section{Effects on Private Property}

Herbicide treatments could affect private property in the vicinity of public lands, particularly parcels adjacent to treatment areas. Over the short term, there would be minor risks for property damage associated with herbicide treatments because it is possible that some herbicide could drift onto private property, especially during aerial treatments. Under such a scenario, crops could be lost, or, alternatively, rangeland weeds could be killed, resulting in benefits to private property. Losses and gains would likely be minor and short term in nature. 
Over the long term, a reduction in hazardous fuels on public lands would reduce the likelihood of wildfires migrating from public lands to nearby private property and impacting the WUI. Herbicide treatments would also reduce the risks of noxious weeds spreading onto neighboring parcels, including poisonous weeds, which could harm livestock. A reduction in such risks could lead to increased property values over the long term. Any such effects are not quantifiable at this scale of analysis.

\section{Impacts of Individual Alternatives}

The following sections discuss the expected effects of each of the five alternatives on social and economic resources. These effects vary in degree, for the most part, rather than in kind. The differences depend on the percentage of acres treated using different application methods and on the total acreages to be treated. Because very little quantification of effects is possible at the 17state regional scale, the differences are often stated roughly in proportion to the acreages to be treated.

\section{Alternative A - Continue Present Herbicide Use (No Action Alternative)}

Under the No Action Alternative, the BLM would continue its ongoing vegetation treatment programs in 14 western states, and would be able to use 20 herbicides previously approved under earlier RODs. Approximately 305,000 acres would be treated with herbicides annually.

Since future treatment levels would be similar to current levels, there would likely be little change to existing patterns and trends in population or demographic conditions in the western United States. While there would be localized increases in employment generated by the increase in BLM acreage treated with herbicides under this alternative, the jobs would generally be shortterm, temporary positions or contracted work, which would not be sufficient to encourage measurable inmigration of workers and their families.

Most treatments would occur in New Mexico (32\%), Idaho (19\%), Wyoming (12\%) and Nevada (8\%). Except for New Mexico, these states have substantially lower per capita minority and Native American populations than the entire western U.S. (see Table 315 ). In addition, the percentage of the population under 18 in these states is less than or similar to the percentage in the remainder of the West. Thus, disproportionate impacts to minority populations and children from vegetation treatments should not occur under this alternative. Public lands provide lifeway values for Indian tribes, and there is concern among Indian tribes and the public that the BLM vegetation treatments could adversely impact native plants used for cultural and traditional purposes if projects are not carefully planned and implemented. The BLM would consult with Indian tribes before implementing treatments that could impact vegetation of importance to Indian tribes to reduce these potential impacts.

Based on the assumption that the average costs to treat vegetation using ground-based and aerial methods are $\$ 35$ per acre and $\$ 125$ per acre, respectively, and using information on the cost of herbicides in Table 3-23 and assumptions from the BLM on the percentage of acres to be treated using ground- and aerial-based methods for each herbicide, approximately $\$ 30.1$ million would be spent on herbicide applications; $\$ 24$ million would be spent on ground-based applications, and $\$ 6.1$ million would be spent on aerial applications under the No Action Alternative. The cost per acre treated would be approximately $\$ 98.70$ per acre.

These expenditures would provide employment and income benefits. Regardless of the local economic situation, the nature of treatments indicates employment and related income effects would be short-term in nature and geographically dispersed, benefiting certain communities throughout the 17 -state study area. In general, it is expected that communities located in areas where the most acres were treated would receive the greatest employment and economic benefits.

Neither the suppression cost savings nor the reduction in property losses can be quantified at the 17-state regional scale under this alternative. However, benefits would be most likely to occur in ecoregions/states with the greatest number of acres treated (Idaho, Wyoming, Nevada, and New Mexico; Temperate Desert Ecoregion), or where the risk of fire starting by lightning or human causes is greatest (California in 2005; USDA Forest Service 2000b, USDI BLM 2006c).

Commercial activities that occur on public lands could be affected by vegetation treatments. As noted earlier, most treatments would occur in New Mexico, Idaho, Wyoming, and Nevada. Only about $1 \%$ of timber sales occur in these states. Effects on timber sales from vegetation treatments would be greatest in Oregon, where over $95 \%$ of timber sales occur. Based on grazing leases, licenses, and permit fees, over $55 \%$ of these expenditures occur in these states, while $44 \%$ of active animal unit months occur in these states (see Table 3-6; USDI BLM 2006c). Oregon and Utah also have large 
populations of livestock on public lands. Thus, vegetation treatment activities could affect grazing activities and income in these states. Effects on recreation expenditures would likely be modest, as only $27 \%$ of recreation expenditures would occur in these four states. Treatments in California, Oregon, and Utah would be more likely to affect recreation expenditures, as nearly $56 \%$ of annual recreation expenditures occur in these states.

Herbicide treatment effects on private property from drift and accidental applications would be less under this alternative than under the other treatment alternatives. Over the long term, a reduction in hazardous fuels on public lands would reduce the likelihood of wildfires migrating from public lands to nearby private property and impacting the WUI. Herbicide treatments would also reduce the risks of noxious weeds, including poisonous weeds, spreading onto neighboring parcels. These benefits would be less under this alternative than under the other treatment alternatives.

\section{Alternative B - Expand Herbicide Use and Allow for Use of New Herbicides in 17 Western States (Preferred Altermative)}

The Preferred Alternative would result in herbicide treatments on approximately 932,000 acres annually in 17 western states. In addition to the 14 previouslyapproved herbicides, the BLM would be able to use the four new herbicides evaluated in this PEIS.

As future treatment levels would be 3 times that of current levels, there would likely be a minor change in existing patterns and trends in population and demographic conditions in the western states. While there would be localized increases in employment generated by the increase in BLM acreage treated with herbicides under the Preferred Alternative, the jobs would generally be short-term, temporary positions or contracted work, which would not be sufficient to encourage measurable in-migration of workers and their families.

Under the Preferred Alternative, most treatments would occur in Idaho (28\%), Nevada (22\%), Wyoming (16\%), and New Mexico (10\%). Except for New Mexico, these states have substantially lower per capita minority and Native American populations than the entire western U.S. (see Table 3-15). In addition, the percentage of the population under 18 in these states is less than or similar to the percentage in the remainder of the western U.S. Thus, disproportionate impacts to minority populations and children from vegetation treatments should not occur under this alternative. The potential for impacts to plants that provide traditional lifeway values would be greatest under this alternative. Some treatments could occur in Alaska, Nebraska, and Texas under this alternative.

Anticipated adjustments to herbicide usage would not substantively change the expenditure per acre for chemicals, as nearly $90 \%$ of the herbicide usage would simply be a proportional increase in the pattern of active ingredients used in recent years. Of the four new herbicides, imazapic would be the most heavily used; it falls in the lower price range for chemicals. Detailed information is not available on types of herbicides to be used in each of the proposed treatment projects. However, based on information obtained from field offices in 2002, it is assumed that approximately $45 \%$ of the acreage would be treated from the air and $55 \%$ from the ground. Under this scenario, it is expected that existing social and economic trends would continue, with a substantial increase in economic activity generated.

Based on the assumptions given under the No Action Alternative for costs to treat vegetation using herbicides, approximately $\$ 69.6$ million would be spent on groundbased applications, and $\$ 19.5$ million on aerial applications, or $\$ 89.1$ million for all applications under the Preferred Alternative. This figure is about 3 times the amount that would be spent under the No Action Alternative. However, the average cost per acre treated would be $\$ 95.60$ per acre, or $3 \%$ less per acre than under the No Action Alternative.

Considering the scale of the increase in the herbicide treatment program under the Preferred Alternative, it is expected that the economic benefits would likely spread to more local communities than under the other treatment alternatives, and that some individual communities would experience substantial gains. Which communities would be affected, and to what degree, cannot be determined at this time.

Neither the suppression cost savings nor the reduction in property losses can be quantified at the 17-state regional scale under this alternative. However, benefits would be greatest under this alternative because of the acreage treated. As with the other treatment alternatives, benefits would be most likely to occur in those ecoregions/states with the greatest number of acres treated (Idaho, Wyoming, Nevada, and New Mexico; Temperate Desert Ecoregion), or where the risk of fire starting by lightning or human causes is greatest 
(California; USDA Forest Service 2000b, USDI BLM 2006c)

Commercial activities that occur on public lands could be affected by vegetation treatments. As with the other treatment alternatives, effects on commercial activities should be greatest in those states where most acres would be treated (Idaho, Wyoming, Nevada, and New Mexico), where most timber sales occur (Oregon), where most grazing occurs (Wyoming, Montana, Idaho, Utah, and Oregon), and where the greatest recreation expenditures occur (California, Oregon, and Utah).

Herbicide treatment effects on private property from drift and accidental applications would be greatest under this alternative. Some herbicide could drift onto private property, especially during aerial treatments. Under such a scenario, crops could be lost. Alternatively, rangeland weeds could be killed, resulting in benefits to private property. Losses and gains would likely be minor and short term in nature.

Over the long term, a reduction in hazardous fuels on public lands would reduce the likelihood of wildfires migrating from public lands to nearby private property and impacting the WUI. Herbicide treatments would also reduce the risks of noxious weeds, including poisonous weeds, spreading onto neighboring parcels. These benefits would be greatest under this alternative.

\section{Alternative C-No Use of Herbicides}

Under Alternative C, the BLM would not be able to use herbicides to treat vegetation. Positive social benefits could be less than under the other alternatives because wildfire risk reduction in WUI areas would not be as effective and the economic benefits to ranching communities would not be as great as under the other alternatives. It is likely that fire suppression costs and fire damage losses would be greater under Alternative C than under the other alternatives. In addition, benefits to rangelands could be less under this alternative, as certain invasive species are effectively controlled only by herbicides, and in some situations other methods are impractical due to cost, time, or public concerns.

Under this alternative, invasive plant populations would likely continue to spread, possibly at increasing rates, without use of herbicides. Related declines in rangeland capacity, combined with the potential for the spread of invasive plants from public lands to private ranch lands in areas where other treatment methods are not effective or practical, would adversely affect ranching profits and would thus be detrimental to local economies in rural areas of the West.

Generally, non-herbicide vegetation treatment methods tend to be more labor intensive and thus more expensive on a per acre basis in situations where herbicides are preferred, which translates into less effective control of undesirable vegetation. As a result, more workers could be hired in some places under this alternative, although many of the additional jobs would likely be low paying, unskilled labor positions.

\section{Alternative D - No Aerial Applications}

Alternative D would be the same as the Preferred Alternative as far as which herbicides could be used, but the limitation on aerial application would preclude treatments in some areas that would not be suitable for ground application due to access difficulties or the scale of vegetation problems. Because of this limitation, and perhaps also because of the often higher cost of ground application, fewer acres - 530,000 - would be treated under Alternative $\mathrm{D}$ than under the Preferred Alternative. More acres would be treated under Alternative D than under the No Action Alternative. Consequently, the types of social and economic effects of Alternative D would be similar to the effects described for the No Action and Preferred alternatives, but would fall between them in magnitude.

As under the other herbicide treatment alternatives, most treatments would occur in Idaho, Wyoming, Montana, and Nevada. These states have lower per capita minority and Native American populations than the remainder of the western U.S., and the percentage of the population under 18 in these states is less than or similar to the percentage in the remainder of the western U.S. (see Table 3-15). Thus, disproportionate impacts to minority populations and children from vegetation treatments should not occur under this alternative.

Based on the assumptions given under the No Action Alternative for costs to treat vegetation using herbicides, approximately $\$ 76.7$ million would be spent on groundbased applications under Alternative D, or about 14\% less than would be spent under the Preferred Alternative, although $43 \%$ fewer acres would be treated under Alternative D. The average cost per acre treated would be $\$ 144.72$, or nearly $51 \%$ and $47 \%$ more than for treatments under the Preferred and No Action alternatives, respectively.

It is expected that the economic benefits to local communities would be less than under the Preferred 
Alternative, but greater than under the No Action Alternative. Which communities would be affected, and to what degree, cannot be determined at this time.

Herbicide treatment effects on private property from drift and accidental applications would be intermediate between the No Action and Preferred alternatives. Over the long term, a reduction in hazardous fuels on public lands would reduce the likelihood of wildfires migrating from public lands to nearby private property and impacting the WUI. Herbicide treatments would also reduce the risks of noxious weeds, including poisonous weeds, spreading onto neighboring parcels. These benefits would be intermediate to those of the Preferred and No Action alternatives, and similar to Alternative E.

\section{Alternative $E-N o$ Use of Acetolactate Symthase- inhibiting Active Ingredients}

Approximately 466,000 acres would be treated under Alternative E, which is approximately $11 \%$ less than the acreage that would be treated under Alternative D, and about half of the acreage that would be treated under the Preferred Alternative. The acreage treated would be one and one-half times the acreage that would be treated under the No Action Alternative.

Alternative $\mathrm{E}$ would have somewhat more positive social effects than other alternatives in that it would clearly establish protection for Native American and Alaska Native resources. Economically, it could result in prohibitions or restrictions on certain commercial and recreational activities that support and sustain some rural communities. Without more specific information on such restrictions, however, it is not possible to accurately predict how significant the effects would be. In most other respects, the social and economic effects of Alternative $\mathrm{E}$ would be similar to those associated with other alternatives and proportional to the acreage treated.

The profile of selected active ingredients under Alternative $\mathrm{E}$ would be very similar to the profile for the No Action Alternative, and would only notably differ from the Preferred Alternative in that there would be more use of glyphosate and no use of imazapic (Table 2-5). Because these are both lower priced active ingredients, the adjustment would not significantly affect economic activity.

Based on the assumptions given under the No Action Alternative for costs to treat vegetation using herbicides, approximately $\$ 57.7$ million would be spent on groundbased applications, and $\$ 2.3$ million would be spent on aerial applications (assuming that the percentage of acres treated using aerial methods for each herbicide would only be one-third the percentage of acres treated using aerial methods for each herbicide under the Preferred Alternative). Thus, although half as many acres would be treated under this alternative compared to the Preferred Alternative, costs would be reduced by only one-third. The cost per acre treated would be about $\$ 128.75$ under this alternative, or $11 \%$ less than under Alternative D, but $35 \%$ and $30 \%$ greater than the cost per acre treated under the Preferred and No Action alternatives, respectively.

\section{Mitigation for Herbicide Treatment Impacts}

No mitigation measures are proposed for social and economic resources.

\section{Human Health and Safety}

The use of herbicides under a variety of application methods, as proposed in this PEIS, involves potential risk or the perception of risk to workers and members of the public living or engaging in activities in or near herbicide treatment areas. Therefore, as part of the PEIS, an HHRA has been conducted to evaluate potential human health risks that may result from herbicide exposure both during and after treatment of public lands. The HHRA has been conducted to be scientifically defensible, to be consistent with currently available guidance where appropriate, and to meet the needs of the BLM vegetation treatment program.

Risk to two types of human "receptors" was evaluated: occupational receptors and public receptors. Receptors are representative population groups that could have specific exposures to the herbicides. Occupational receptors included those workers that mix, load, and apply herbicides and operate transport vehicles, recognizing that in some cases an occupational receptor may perform multiple tasks, increasing his or her exposure. Public receptors included those members of the public most likely to come into contact with applied herbicides. The public receptors included adult hiker/hunters and anglers, and adult and child berry pickers, swimmers, Native Americans, and residents. Receptors were evaluated assuming both accidental (e.g., direct spray or spill onto skin) and routine exposure scenarios (e.g., ingestion of berries that have been recently sprayed). 


\section{Scoping Comments and Other Issues Evaluated in the Assessment}

A large number of respondents during public scoping were concerned about the risks to human health from herbicide treatments. Respondents suggested that at-risk groups like infants, the elderly, sick people, and people with sensitivities to chemicals be specifically addressed. Numerous respondents urged the BLM to describe all potential toxicological hazards of herbicide chemicals, including their ability to disrupt hormone systems and immune systems. Establishing a goal of using the minimum effective dosage and developing protocols for achieving this was encouraged. There was also concern about the effects of herbicides on basket plants and the people who collect them, in particular Native Americans. Some respondents also feit that the uncertainties regarding the environmental effects of herbicides and inert ingredients should be disclosed. According to some respondents, Oust ${ }^{\circledR}$ (herbicide formulated with sulfometuron methyl) should be considered for evaluation even though it was evaluated previously in the 1991 13-State Vegetation EIS (USDI BLM 1991a). One respondent noted that if there are insufficient toxicological data to be found for a specific herbicide, then that herbicide should not be used.

\section{Standard Operating Procedures}

Standard operating procedures designed to reduce potential unintended impacts to human health from the application of herbicides in the BLM vegetation management program, and considered when evaluating impacts, are listed in Table 2-8. These SOPs include the following:

- Establish a buffer between treatment areas and human residences based on guidance given in the HHRA, with a minimum buffer of $1 / 4$ mile for aerial applications and 100 feet for ground applications, unless a written waiver is granted.

- Use protective equipment as directed by the herbicide label.

- Post treated areas with appropriate signs at common public access areas.

- Observe restricted entry intervals specified by the herbicide label.

- Provide public notification in newspapers or other media where the potential exists for public exposure.
- Have a copy of Material Safety Data Sheets at work sites.

- Notify local emergency personnel of proposed treatments.

- Contain and clean up spills and request help as needed.

- Secure containers during transport.

- Follow label directions for use and storage.

- Dispose of unwanted herbicides promptly and correctly.

The results from the HHRA will help inform BLM field offices about the proper application of herbicides to ensure that impacts to humans are minimized to the extent practical.

\section{Human Health Risk Assessment Methodology}

The BLM conducted an HHRA to evaluate potential risks to humans from exposure to the following six active ingredients, four of which are proposed for use on public lands: dicamba, diflufenzopyr, diquat, fluridone, imazapic, and sulfometuron methyl. The four active ingredients not currently used on public lands are diflufenzopyr, diquat, fluridone, and imazapic. Sulfometuron methyl (Oust ${ }^{\mathbb{B}}$ ) and dicamba were evaluated for risks to humans in earlier EISs and are currently used by the BLM, but were reevaluated for this PEIS. Oust ${ }^{\circledR}$ has been found to impact non-target vegetation when carried on soil to untreated areas; these effects were not evaluated in the earlier vegetation treatment EISs. Dicamba is used in formulation with diflufenzopyr (as Overdrive ${ }^{\circledR}$ ), and was reassessed as part of the evaluation of the formulation. These active ingredients may be formulated into herbicides under a variety of trade names and manufacturers. Therefore, specific trade names and manufacturers are not discussed in this report.

The remaining 18 active ingredients that are available for use by the BLM were evaluated in other HHRAs. The BLM relied on HHRAs prepared in recent years by the Forest Service to evaluate the risks to human health associated with nine active ingredients (2,4-D, chlorsulfuron, clopyralid, glyphosate, hexazinone, imazapyr, metsulfuron methyl, picloram, and triclopyr). For the remaining nine active ingredients (2,4-DP, asulam, atrazine, bromacil, diuron, fosamine, mefluidide, simazine, and tebuthiuron), the BLM relied 
on information provided in earlier BLM vegetation treatment EISs (USDI BLM 1988a, 1989a, 1991a).

As this PEIS relies upon the HHRA results developed by both BLM and Forest Service, the following sections discuss the risk assessment methods used by the BLM in the current assessment, the risk assessment methods used by Forest Service, and the methods used by BLM in the earlier EIS HHRAs. This discussion is followed by a discussion of the uncertainties in the risk assessment process.

\section{BLM Human Health Risk Assessment Methodology}

The BLM HHRA follows the four-step risk assessment model identified by the National Academy of Sciences (NAS 1983). These steps are: 1) hazard identification, 2) dose response assessment, 3) exposure assessment, and 4) risk characterization. The outcome of each of these steps is discussed below. More detailed information on the methodology used to evaluate risks is in Appendix B and in the Vegetation Treatments Programmatic EIS Human Health Risk Assessment Final Report (ENSR 20051).

\section{Hazard Identification}

The hazard identification section provides information on the herbicide active ingredient characteristics and usage, and toxicity profiles. Much of the toxicity information discussed in this section is from USEPA reports, such as the Pesticide Fact Sheets or HHRAs conducted by the USEPA OPP Health Effects Division to evaluate use of the pesticides on specific crops. In addition, a literature search was conducted to ensure that relevant available information was used in these toxicity profiles. The databases searched include the National Library of Medicine's Hazardous Substances Data Bank and Toxline. The USEPA receives many unpublished toxicity data sets that are referenced in USEPA reports using Master Record Identification (MRID) numbers. The HHRA references USEPA reports for the MRID information.

Both acute (short term) and chronic (longer term) toxicity information is discussed for the active ingredient. The USEPA has developed toxicity categories for pesticides based on acute toxicity animal tests conducted in support of registration of the pesticides (USEPA 2003f). Acute toxicity studies are used to determine a number of toxicity endpoints based on short-term exposure to a substance. The toxicity endpoints considered are oral, inhalation, and dermal acute toxicity; eye irritation; skin irritation; and dermal sensitization. An important endpoint in acute testing is the toxicity reference level known as the median lethal dose $\left(\mathrm{LD}_{50}\right)$, which is the dose, usually administered orally, that kills $50 \%$ of the test animals. The lower the $\mathrm{LD}_{50}$ is, the greater the toxicity of the chemical. For the different toxicity endpoints, the USEPA defines four toxicity categories (Lists; I through IV), with higher toxicity categories representing lower herbicide acute toxicity. In longer-term toxicity studies (chronic or subchronic), the endpoints for evaluation are the dose at which no adverse effects were seen (NOAEL), and the lowest observed adverse effect level (LOAEL), which is the lowest level at which adverse effects are seen in chronic studies.

In addition to their active ingredients, most herbicides contain inert ingredients (i.e., those substances included in the formulation that are not the active ingredients) that have various functions such as diluents, binders, dispersants, carriers, stabilizers, neutralizers, antifoamers, and buffers.

The USEPA categorizes inert ingredients into four lists (54 FR 48314):

- List 1 - Inert ingredients of toxicological concern. Any product containing a List 1 ingredient must include the label statement, "this product contains the toxic inert ingredient (name of inert)."

- List 2 - Inerts of unknown toxicity/high priority for testing inerts.

- List 3 - Inerts of unknown toxicity. Inert ingredients on this list have not yet been determined to be of known potential toxicological concern nor have they been determined to be of minimal concern. These substances will continue to be evaluated to determine if they merit reclassification to List 1,2 , or 4 .

- List 4 - Inerts of minimal concern. List 4 is subdivided into List $4 \mathrm{~A}$ (minimal risk inert ingredients) and List 4B (inerts that have sufficient data to substantiate that they can be used safely in pesticide products).

BLM scientists received clearance from the USEPA to review Confidential Business Information (CBI) on inert compounds identified in products containing the six active ingredients evaluated in this risk assessment. The information received listed the inert ingredients, as well as their chemical abstract number, supplier, 
USEPA registration number, percentage of the formulation, and purpose of the formulation. The BLM reviewed one formulation of diflufenzopyr and dicamba; two formulations of diquat; four formulations of fluridone; two formulations of imazapic; and one formulation of sulfometuron methyl. Because it is confidential, this information, including the name of the ingredients, may not be disclosed.

The USEPA has a listing of regulated inert ingredients at http://www.epa.gov/opprd001/inerts/index.html. This listing divides inert ingredients into four lists. The number of inert ingredients found in the six herbicides evaluated in the HHRAs for each category is shown below (seven inerts were not found on the USEPA lists):

List 1 - Inert ingredients of toxicological concern: None.

List 2 - Potentially toxic inert ingredients: None.

List 3 - Inerts of unknown toxicity: 5.

List 4A - Inerts of minimal toxicity: 9.

List 4B - Inerts that have sufficient data to substantiate that they can be used safely in pesticide products: 18 .

Based on this information, the majority of the inerts are of minimal risk. A few are in the category of unknown toxicity.

\section{Dose-Response Assessment}

The purpose of the dose-response assessment is to identify the types of adverse health effects an herbicide may potentially cause and to define the relationship between the dose of an herbicide and the likelihood or magnitude of an adverse effect (response). The doseresponse assessment identifies quantitative doseresponse values that are used in risk calculations to derive risk estimates. The dose-response values used in the HHRA were developed by the USEPA. None of the six herbicides evaluated in the BLM HHRA are designated as potential carcinogens by the USEPA; therefore, this toxicity assessment focuses on noncarcinogenic effects (i.e., potential toxic effects other than cancer). Non-carcinogenic effects are evaluated differently depending on whether the exposure is dietary or non-dietary.
For dietary exposures to non-carcinogenic chemicals, toxicity is represented by a population adjusted dose (PAD), which may be calculated for acute effects or chronic effects. A PAD is an acute or chronic RfD divided by the Food Quality Protection Act (FQPA) Safety Factor, which accounts for cases where infants and children may have extra sensitivity to the pesticide (USEPA 2000c). Reference doses are derived by identifying an NOAEL, which is obtained from the acute or chronic toxicity studies, and dividing the NOAEL by the appropriate uncertainty factors (UFs). Typically, a 10-fold UF is applied to account for variation within the human population (i.e., to account for individuals that may be more sensitive to the effects; intraspecies), and an additional 10-fold factor is applied to account for the differences between humans and animals (interspecies; USEPA 2000c). The FQPA Safety Factor is applied to the PAD in addition to the uncertainty factors used to derive the RfD.

A margin of exposure (MOE) approach is used to evaluate potential non-dietary exposures to herbicides. For evaluating non-cancer effects for non-dietary exposures, toxicity is represented by the NOAEL. The NOAELs are identified for a variety of exposure durations and exposure routes (short-, intermediate-, and long-term exposure durations via oral, dermal, and inhalation exposure routes). The NOAELs representing non-dietary exposures were used to evaluate the occupational receptors and the public receptors for the following scenarios: dermal contact with spray, dermal contact with foliage, dermal contact with water while swimming, and incidental ingestion of water while swimming. The NOAEL divided by the intake (see the Exposure Assessment section below for a description of how intakes are derived) results in the MOE (USEPA 2000c). Unless specified otherwise, the target MOE is 100 , which accounts for uncertainties in the NOAEL. MOEs greater than the target $\mathrm{MOE}$ indicate no significant risk.

\section{Exposure Assessment}

The purpose of the exposure assessment is to predict the magnitude and frequency of potential human exposure to the herbicides under consideration. The BLM takes care to prevent exposures to applied pesticides both through worker training programs and by posting areas that have just been sprayed with information on when reentry into these areas is appropriate. However, to be conservative, the HHRA has evaluated both routine use and accidental exposure scenarios. In addition, exposures were evaluated for two application scenarios: applications using the 
maximum application rate designated by the herbicide label, and applications using a typical application rate that was defined by BLM for this program.

To estimate the potential risk to human health that may be posed by the planned herbicide use, it was first necessary to estimate the potential exposure dose of each herbicide for each receptor via each applicable exposure route. Exposure dose equations combine the estimates of herbicide concentration in the environmental medium of interest, with assumptions (exposure parameters) regarding the type and magnitude of each receptor's potential exposure to provide a numerical estimate of the exposure dose. The exposure dose is defined as the amount of herbicide taken into the receptor, expressed in units of milligrams of herbicide per kilogram of body weight per day (mg/kg-day). The exposure doses were combined with the dose-response values (PADs or NOAELs) to estimate potential risks and hazards for each receptor.

Various guidelines and databases, such as the USEPA's Exposure Factors Handbook (USEPA 1997) and the Framework for Assessing Non-Occupational, NonDietary (Residential) Exposure to Pesticides (USEPA 1998c), were used to develop the exposure parameters. For each exposure scenario, the exposure parameters were used to calculate an exposure factor (EF), which was then used in the risk calculations. The use of the EF combines all the exposure parameters into one value in order to simplify the risk calculations.

Occupational Exposure Scenarios. Both routine-use and accidental exposure scenarios were included in the occupational evaluation. For the routine-use exposure scenario, the exposure assumptions were derived using information from the BLM concerning proposed use of the herbicides, and unit exposure (UE) information from the Pesticide Handlers Exposure Database (PHED), which is a generic database containing empirical dermal and inhalation exposure data for workers mixing, loading, or applying pesticides (USEPA 1998d). To add consistency to the risk assessment process, the USEPA, in conjunction with the PHED task force, has evaluated all data within the system and developed a series of surrogate standard UE values for various exposure scenarios. The majority of the UE values have been taken from these surrogate values. In addition to these values, the USEPA recommended UEs separately for aquatic applications of diquat and fluridone. Generally, UEs are expressed in units of milligrams per pound of active ingredient, and equate the milligrams of active ingredient absorbed by an occupational receptor to the pounds of active ingredient handled in a given day or exposure scenario.

For aerial applications, occupational receptors that may come into routine contact with herbicides include pilots and mixer/loaders. For ground applications by backpack, the occupational receptor is assumed to be an applicator/mixer/loader. For the remaining application methods (horseback, and spot and boom/broadcast methods for ATV, truck mount, and boat applications), applicators, mixer/loaders, and applicator/mixer/loaders were evaluated. In addition, for each occupational receptor, dermal and inhalation exposure pathways were evaluated. For the routine exposures, the exposure dose was calculated using the herbicide application rate and the acres treated per day. Details on how this was done are presented in the Vegetation Treatments Programmatic EIS Human Health Risk Assessment Final Report, found on the CD located in the back of Volume I of the PEIS (ENSR 20051).

Accidental exposures for occupational receptors could occur via spills or direct spray onto a worker. To calculate exposures from direct spills, it is necessary to know the concentration of active ingredient in the formulation that is spilled onto the worker. These concentrations were calculated from the information provided on the herbicide labels. As a worst-case scenario for an accidental exposure, a direct spill event on an occupational receptor was evaluated. This HHRA used the same spill scenario evaluated by the BLM in the Final EIS Vegetation Treatment on BLM Lands in Thirteen Western States (USDI BLM 1991a). The spill scenario assumes that $0.5 \mathrm{~L}(1 / 2$ quart $)$ of the formulation is spilled on a worker receptor. It is assumed that $80 \%$ of the spill lands on clothing and 20\% lands on bare skin. The penetration rate through clothing is assumed to be $30 \%$. While some of the herbicide labels require the use of gloves while handling the herbicide, others do not. Therefore, this scenario assumes that gloves are not worn.

Public Use Exposure Scenarios. The HHRA evaluated the potential risk to public receptors using public lands treated with herbicides. This was done by developing exposure scenarios that combine potential receptors and exposure pathways to identify potential exposures to the herbicide active ingredient addressed in this PEIS. Two types of public use exposure scenarios are addressed:

- Potential exposure by public receptors during routine use of public lands to herbicide active ingredient(s) that may have drifted outside of the area of application. 
- Accidental scenarios where public receptors may prematurcly enter a sprayed area (a reentry scenario), be sprayed directly, or may contact water bodies that have accidentally been sprayed directly or into which an herbicide active ingredient has accidentally been spilled.

Although all of these public scenarios are expected to occur rarely, they are nonetheless used as the basis for evaluating potential public health risks associated with herbicide use in the BLM vegetation treatment program.

Based on consideration of potential public uses of BLM lands, and consistent with the 1991 13-State EIS (USDI BLM 1991a), receptors evaluated in this HHRA include 1) hiker/hunter; 2) berry picker - child and adult; 3) angler; 4) swimmer - child and adult; 5) nearby resident - child and adult; and 6) Native American - child and adult.

Although there are many different exposure scenarios and receptors that could be evaluated, the selected scenarios cover a range of potential exposures that could occur under worst-case conditions on public lands. It is assumed that public receptors could be exposed through one or more of the following exposure pathways: 1) dermal contact with spray, 2) dermal contact with foliage, 3 ) dermal contact with water while swimming, 4) ingestion of drinking water or incidental ingestion of water while swimming, 5) ingestion of berries, and 6) ingestion of fish.

Although all public receptor exposures to herbicides used on pubic lands are considered to be accidental, public receptor exposures were evaluated under two scenarios. Routine-use exposures are assumed to occur when public receptors come into contact with environmental media that have been impacted by spray drift. Accidental exposures are assumed to occur when public receptors come into contact with environmental media that have been subject to direct spray or spills. Each of these scenarios is discussed below.

Public receptors could be exposed to herbicides via offsite drift following routine aerial application. AgDRIFT, a computer model that is a product of the Cooperative Research and Development Agreement between the USEPA's Office of Research and Development and the SDTF (a coalition of pesticide registrants), was utilized in the HHRA to evaluate the off-site deposition of herbicides (SDTF 2002). See Appendix C of the Vegetation Treatments Programmatic EIS Human Health Risk Assessment Final Report (ENSR 20051) for a complete description of AgDRIFT modeling methods.
In addition, public receptors could be exposed to herbicides via surface runoff. The GLEAMS model, a modified version of the Chemical Runoff Erosion Assessment Management System (CREAMS) model that was originally developed to evaluate non-point source pollution from agricultural field-size areas, was used to simulate surface runoff of the three terrestrial herbicides considered in the HHRA. See Appendix D of the Vegetation Treatments Programmatic EIS Human Health Risk Assessment Final Report (ENSR 2005I) for a complete description of GLEAMS modeling methods.

In addition to exposures due to inadvertent spray drift, this HHRA also evaluates potential acute accidental exposures by public receptors to the herbicide active ingredient. Accidental exposure could occur through direct spray and spills. The same types of receptors introduced above are also evaluated for the accidental scenarios. However, because direct spray and spills are localized, exposures to multiple media are not assumed in these scenarios. It is assumed that each of the herbicide active ingredients could be directly sprayed onto humans, foliage, and/or berries, and each of the herbicide active ingredients could be directly sprayed or spilled into a water body. However, for the aquatic herbicide active ingredients (fluridone and diquat), the direct spray into a water body pathway is a reentry scenario.

\section{Risk Characterization}

The purpose of the risk characterization is to provide estimates of the potential risk to human health from exposure to herbicides. The results of the exposure assessment are combined with the results of the doseresponse assessment to derive quantitative estimates of risk. For the noncarcinogenic active ingredients evaluated in this HHRA, risk is described simply by the comparison of the exposure doses to the appropriate dose-response values.

The USEPA risk assessment guidance for pesticides provides different non-cancer methods for evaluating food and non-food exposures (USEPA 2000c). For food exposure, a percent PAD method is used, and for nonfood exposure, a MOE method is used, as described in the Dose-Response Assessment section above.

In assessing risks to humans, it is important to evaluate the cumulative or aggregate risk from all potential exposure pathways for each receptor. For the public receptors, both dietary and non-dietary pathways have been evaluated. To address this, the USEPA's OPP has developed the aggregate risk index (ARI) approach, 
which combines potential risks from various pathways expressed as MOEs (for non-dietary exposures) and \%PADs (for dietary exposures; USEPA 1999d, 2001d). It is important that only exposure pathways encompassing similar exposure durations be combined (i.e., acute exposures cannot be combined with chronic exposures). The ARI is an extension of the MOE concept. As with the MOE, potential risk increases as the ARI decreases. The ARI is compared against a target value of 1 , which is the LOC set by the USEPA. Values $>1$ do not exceed the USEPA's LOC. The ARI method allows for direct comparisons between routes and between chemicals. It considers each route's potency when route-specific NOAELs that may have different UFs are used. ARIs were developed for each of the identified exposure scenarios. Cumulative accidental ARIs were not calculated, as it is assumed that each receptor would be accidentally exposed via only one potential exposure pathway. Details on the ARI method are provided in the Vegetation Treatments Programmatic EIS Human Health Risk Assessment Final Report (ENSR 20051).

\section{Forest Service Human Health Risk Assessment Methodology}

The Forest Service risk assessment methodology was similar to that used by the BLM (see SERA [2001a] for a complete description of the methodology). The steps involved in the Forest Service risk assessments included hazard identification, exposure assessment, dose response assessment, and risk characterization.

Hazard identification involved the review of toxicological data with a focus on the dose-response relationships to determine the effect levels (e.g., NOAEL, LOAEL) and assessment endpoints (e.g., acute toxicity, subchronic or chronic systemic toxic effects, reproductive and teratogenic effects) that are most relevant for the herbicide risk assessments. Carcinogenic endpoints were evaluated for the Forest Service herbicides, as some contain potential carcinogens in their formulations (i.e., hexachlorobenzene in clopyralid and picloram) and 2,4$D$ was still being evaluated by the USEPA for carcinogenicity.

In the exposure assessment phase, the Forest Service developed general and accidental exposure scenarios for workers expected to be handling the herbicides and for the general public who could be inadvertently exposed to herbicides. General exposure for workers included exposure via directed foliar, broadcast ground, and broadcast aerial applications. Accidental exposure scenarios for workers included immersion or contaminated clothing and spills. Exposure scenarios for the public included 1) direct spray, 2) dermal exposure from contaminated vegetation, 3) exposure to contaminated water, 4) acute exposure via spills, 5) consumption of contaminated fish, and 6) consumption of contaminated vegetation.

Dose response assessment described the degree or severity of risk as a function of dose. The Forest Service assessments used RfDs, derived by other government agencies. The RfD is designed to be protective of chronic or lifetime exposure, and it is a very conservative component of the Forest Service risk characterization process because the duration of any plausible and substantial exposures is far less than a lifetime.

The risk characterization process then compared the exposure assessment to the dose response assessment to determine an HQ for a specific exposure scenario. Hazard quotients were calculated by dividing the exposure level determined in the HHRA by the RfD. A higher HQ indicates that the exposure level exceeds the $\mathrm{RfD}$ by a large amount. A quantitative risk assessment for carcinogenicity was conducted for hexachlorobenzene (found in the herbicide formulations of clopyralid and picloram), but not for any of the active ingredients. 2,4-D was still being reviewed as a potential carcinogen at the time of assessment, and therefore no carcinogenicity risk assessment was conducted.

\section{Previous BLM EISs Methodology and Toxicology Literature Review}

Asulam, atrazine, bromacil, diuron, fosamine, mefluidide, simazine, tebuthiuron, and 2,4-DP are herbicides currently available to the BLM for which new HHRAs were not conducted either by the BLM or the Forest Service. Human health risk assessments were conducted for these herbicides by the BLM for earlier vegetation treatment EISs (USDI BLM 1988a, 1989a, 1991a). Since 1997, the BLM has not used asulam, atrazine, mefluidide, simazine, and 2,4-DP, and has used fosamine only sparingly ( $<50$ acres annually). It is unlikely that the BLM would use these herbicides in the future, and they would not be available for use under the action alternatives (alternatives B though $\mathrm{E}$ ).

Literature reviews and evaluations were conducted for the period 1991 to 1998 to assess whether toxicity data for many of these herbicides (asulam, atrazine, bromacil, diuron, mefluidide, simazine, tebuthiuron) 
that were reported since the 1991 13-State EIS would indicate that a new HHRA should be conducted (i.e., if the new toxicity data suggested greater risks to humans; McMullin and Thomas 2000). 2,4-DP, atrazine, bromacil, diuron, simazine, and tebuthiuron did not have recent toxicity data suggesting additional risks to humans; therefore, the human health risks of these herbicides are reported in this chapter using results from the earlier EIS (also see Appendix B for more information on the risks associated with these herbicides). The literature review suggested that revisions may be warranted for asulam (based on a lower RfD) and for mefluidide (based on development of an RfD).

The 1991 13-State EIS HHRA also evaluated occupational and public receptors similar to the current PEIS. Doses to receptors were estimated using assumptions about the characteristics of typical herbicide applications based on realistic as well as worst-case values for these estimates. Doses to receptors resulting from accidental exposures were evaluated. The risk assessment developed MOEs based on a ratio of the estimated herbicide intake to the acceptable concentration represented by the RfD. In addition, cancer slope factors were available for specific herbicides, such as bromacil. For these herbicides, potential cancer risks were also estimated. The cancer slope factor for bromacil was available from the USEPA at the time of the 1991 EIS. However, in the current review, the USEPA did not provide a cancer slope factor (USEPA 1994b); therefore, bromacil is likely not carcinogenic.

Exposure scenarios for the public included 1) dermal exposure through spray drift, 2) dermal contact with vegetation, and 3) consumption of berries, water, fish, and game. It was assumed that occupational receptors could be exposed through inhalation and dermal contact. Occupational receptors included 1) aerial pilots; 2) mixer-loaders; 3) backpack applicators; 4) ground mechanical applicators; and 5) hand applicators.

Routine and worst-case exposures were calculated using variable parameters such as application rate, size of treatment area, and drift conditions. The following accidental scenarios were also analyzed: 1) spills of herbicide concentrate and mix on a person's skin; 2) direct spraying of a worker from a broken hose; 3) direct spraying of a person from aerial application; 4) immediate reentry to a sprayed area; 5) consumption of water from a pond that has been aerially sprayed, or that has received a spill from an airplane or tank mix truck; and 6) consumption of berries that have been directly sprayed.

\section{Uncertainty in the Risk Assessment Process}

The risk assessments conducted by the BLM and Forest Service incorporate various conservative assumptions to compensate for uncertainties in the risk assessment process. Within any of the steps of the human health risk evaluation process, assumptions must be made due to a lack of absolute scientific knowledge. Some of the assumptions are supported by considerable scientific evidence, while others have less support. Every assumption introduces some degree of uncertainty into the risk evaluation process. Regulatory risk evaluation methodology requires that conservative assumptions be made throughout the risk assessment process to ensure that public health is protected. This conservatism, both in estimating exposures and in setting toxicity levels likely led to an exaggeration of the real risks of the vegetation management program to err on the side of protecting human health.

\section{Impacts Common to All Herbicides}

Each of the HHRAs developed risk estimates for occupational and public receptors for a variety of routine and accidental scenarios. The risk estimates for each herbicide, and for herbicides in general, are presented below.

\section{Occupational Receptors}

Herbicide application methods may require the use of heavy machinery, which could involve potential health and safety impacts to people working in the herbicide application programs (occupational receptors). However, the main potential impact associated with the use of herbicides is exposure to the chemicals (including the herbicide active ingredient(s) and other compounds added to the herbicide formula). These chemicals can all be toxic to human workers and exposed members of the public to varying degrees (any chemical poses a health risk at a high enough dose). Most clinical reports of herbicide effects are of skin and eye irritation.

Short-term effects of excessive exposure to herbicides include nausea, dizziness, or reversible abnormalities of the nervous system. In extreme cases of prolonged, repeated, and excessive exposure (resulting from careless and/or negligent work habits), longer-term 
health problems can result, including: organ damage, immune system damage, permanent nervous system damage, production of inheritable mutations, damage to developing offspring, and reduction of reproductive success. It is important to note that the USEPA evaluates and registers herbicides according to a uniform, health-based standard to ensure a "reasonable certainty of no harm" to consumers. The USEPA is responsible for restricting a product's use according to its potential impacts on human health and the environment. Much of that restriction is done through the product label, which states the precautions that must be taken as well as how and where to apply a certain herbicide.

Occupational exposure to herbicides varies with the method of application. The greatest risk occurs when the worker must directly handle and/or mix chemicals. Spot and localized herbicide applications, including the use of backpack sprayers and aerial mixers/loaders, require the most hands-on use of herbicides and, therefore, carry the greatest risk of exposure. Under all application methods, workers can be exposed to herbicides from accidental spills, splashing, leaking equipment, contact with spray, or by entering treated areas. Exposure can occur either through skin or through inhalation. Adherence to operational safety guidelines, use of protective clothing, equipment checks, and personal hygiene can prevent incidents from occurring. The herbicide label and corresponding Material Safety Data Sheet (MSDS) detail these application requirements in addition to safety guidelines.

\section{Public Receptors}

Public receptors can be exposed by being accidentally sprayed, by entering areas soon after treatment (e.g., eating berries or other foods, touching vegetation), drinking contaminated water, or accidentally coming into contact with herbicides that have drifted downwind. Members of the general public, both visitors and residents, are less likely to be repeatedly exposed than vegetation management workers.

Members of the public, both visitors and nearby residents, could potentially be exposed to herbicides from drift or accidental spraying if they were in the area at the time of application. Since aerial and broadcast applications have a higher potential for drift, these application techniques might create a higher potential for public exposure, particularly under certain weather conditions (e.g., high winds).
Laboratory tests on animals have shown that most herbicides are not carcinogenic, even at doses and repeated exposures well above those which could occur accidentally as part of vegetation management activities. Furthermore, herbicides are designed to work on plants, not animals, so that the toxic effects generally do not affect the central nervous system or other vital functions.

Calculated dose-response values and exposure doses were combined to estimate potential risks (in terms of ARIs for BLM HHRA herbicides and in terms of HQs for previously evaluated Forest Service herbicides) from each individual herbicide for each receptor. In addition, the strength of these risks was evaluated by herbicide as well as by receptor, herbicide treatment method (e.g., aerial vs. terrestrial), and herbicide treatment alternative.

\section{Human Health Risks Associated with Herbicides Evaluated in the BLM Human Health Risk Assessment}

The HHRA listed the acute toxicity categories for each herbicide developed by the USEPA, and conducted risk calculations to determine potential risks from routine and accidental exposures for specific receptors. The USEPA has developed toxicity categories for pesticides based on acute toxicity animal tests conducted in support of registration of the pesticides (USEPA 2003g). All six of the herbicides evaluated in the BLM HHRA show slight to very slight acute toxicity to humans as designated by the USEPA in most categories. Based on the USEPA categories, dicamba may result in reversible eye irritation and severe skin irritation. Diquat causes moderate acute dermal effects and reversible eye irritation, and fluridone causes reversible eye irritation. The USEPA has not developed acute toxicity categories for sulfometuron methyl.

None of the six herbicides are designated as potential carcinogens by the USEPA. Therefore, the risk calculations discussed below consider non-cancer risk.

Tables 4-27 and 4-28 present summaries of the level of risk each receptor (occupational and public) would face during the application of a given herbicide, for both maximum and typical application rate scenarios. ARIs are partitioned into no, low, moderate, and high levels of risk for ease of comparison (no risk is identified as an ARI greater than 1, low risk is between 1 and 0.1 , moderate risk is between 0.1 and 0.01 , and high risk is less than 0.01). These designations are strictly for comparison purposes, and do not imply actual risks to people. The Vegetation Treatments Programmatic EIS 
Human Health Risk Assessment Final Report (ENSR 20051) presents more detailed tables of ARIs for each herbicide and receptor.

\section{Dicamba}

For the routine application scenarios at the typical and maximum application rates, dicamba does not present an unacceptable risk to occupational or public receptors. However, dicamba applications do present low risk to occupational receptors during accidental scenarios.

\section{Diflufenzopyr}

For occupational receptors, routine use ARIs were calculated for inhalation exposures under both typical and maximum application rate scenarios. No dermal toxicity values are available for diflufenzopyr, which, based on laboratory data, is not expected to be toxic through the dermal route. Routine use ARIs are greater than 1 under both the typical and maximum application rate scenarios, indicating no exceedance of the USEPA's LOC. Because the accidental occupational scenarios all assume dermal exposure and diflufenzopyr does not have a short-term dermal NOAEL because it is not expected to be toxic through the dermal route, an accidental scenario ARI was not calculated.

For public receptors, routine use scenario ARIs are greater than 1 under both the typical and maximum application rate scenarios for all public receptors, indicating no LOC. Under the accidental scenario, it is assumed that public receptors are exposed directly to maximum herbicide application rates via dermal contact, incidental ingestion of water while swimming, or dietary exposure pathways at the maximum application rate. All accidental scenario ARIs are greater than 1 , indicating no LOC.

These results indicate that exposures to diflufenzopyr are not expected to exceed the USEPA's LOC for occupational or public receptors under the scenarios evaluated.

\section{Diquat}

At the typical application rate, diquat presents a low to moderate risk to some occupational receptors (all aerial, backpack, and horseback applicators), and a low risk to child residents. When diquat is applied at the maximum application rate, there is low to high risk to occupational receptors (except boat applicators) and public receptors (except swimmers). Diquat poses a high risk to occupational receptors and a low to moderate risk to public receptors under all accidental scenarios.

\section{Fluridone}

Fluridone does not pose a risk to occupational or public receptors when applicd at the typical application rate. When fluridone is applied at the maximum application rate, there is low risk to aerial mixer/loaders. For accidental scenarios, fluridone poses a low to high risk to all occupational receptors, and a low risk to child and resident public receptors.

\section{Imazapic}

Imazapic applications do not present risk to any receptors when applied in routine use situations at either the typical or maximum application rate. Accidental scenarios involving dermal contact with direct spray or vegetation or dietary exposure were not calculated because imazapic has not been shown to have acute dietary or dermal effects in hazard analyses conducted by the USEPA (ENSR 20051). Accidental scenarios involving dermal contact with a sprayed water body or a water body into which herbicide is spilled do not result in risk to swimmers.

\section{Sulfometuron Methyl}

Sulfometuron methyl applications do not present risk to any receptors when applied in routine use situations at either the typical or maximum application rate. Accidental scenarios involving dermal contact with direct spray or vegetation or dietary exposure were not calculated because sulfometuron methyl has not been shown to have acute dietary or dermal effects in hazard analyses conducted by the USEPA (ENSR 20051). Accidental scenarios involving dermal contact with a sprayed water body or a water body into which sulfometuron methyl is spilled do not present a risk to swimmers.

\section{Human Health Risks Associated with Herbicides Evaluated in the Forest Service Human Health Risk Assessment}

The BLM used the results of HHRAs prepared by the Forest Service for nine active ingredients (2,4-D, chlorsulfuron, clopyralid, glyphosate, hexazinone, imazapyr, metsulfuron methyl, picloram, and triclopyr [SERA 2005b]). The Forest Service HHRAs presented the risk results as HQs. To create the summary tables presented here, (Tables 4-29 and 4-30), HQs were used to designate a risk level as no, low, moderate or high, 
for ease of comparison (no risk is identified as an HQ greater than 1, low risk is an HQ between 1 and 10 , moderate risk is an HQ between 10 and 100, and high risk is an HQ greater than 100). Tables 4-29 and 4-30 present summaries of the risks to occupational and public receptors, respectively, associated with the Forest Service-evaluated herbicides.

\section{$2,4-1 D$}

Workers involved in ground or aerial application of 2,4D may face low risks based on central estimates of exposure, or low to moderate risks based on upper limits of exposure (SERA 1998). At the typical and maximum application rates, workers involved in directed ground spray, broadcast ground spray, aerial application, and aquatic application face low to moderate risk from 2,4-D exposure. Workers also face low to moderate risk from wearing contaminated gloves for 1 hour, exposure to a spill on the hands for 1 hour (maximum rate only), and exposure to spill on the lower legs for 1 hour. The general public faces low to moderate risk from most modeled scenarios at the typical and maximum application rates. The consumption of contaminated fish presents a moderate risk to the general public, and a high risk to subsistence populations. However, the Forest Service HHRA asserts that (when applied at the typical application rate) there should not be unacceptable risks to the general public associated with exposure to 2,4-D, but that accidental exposures could pose a higher risk. The major concern for members of the general public involves the consumption of contaminated vegetation (fruit) over a period of several months, a scenario that is not likely to occur.

\section{Chlorsulfuron}

For both workers and the general public, most exposures to chlorsulfuron at the typical or maximum application rate would not pose a risk (SERA 2004a). Ground broadcast applications at the maximum application rate would pose a low risk to workers.

From a practical perspective, eye and/or skin irritation are likely to be the only overt effects of mishandling chlorsulfuron. These effects can be minimized or avoided by prudent industrial hygiene practices during the handling of the compound.

\section{Clopyralid}

There are no risks to public or occupational receptors associated with most of the anticipated typical and accidental exposure scenarios for clopyralid evaluated in the Forest Service risk assessment. Irritation and damage to the skin and eyes can result from direct exposure to relatively high levels of clopyralid; this is likely to be the only overt effect as a consequence of mishandling clopyralid (SERA 2004b). Children face low risk from consumption of water contaminated by an accidental spill.

The human health risks of hexachlorobenzene and pentachlorobenzene were also analyzed in the Forest Service HHRA, as technical grade clopyralid may be contaminated with these chemicals. Hexachlorobenzene was evaluated for potential carcinogenicity. Based on the levels of contamination of technical grade clopyralid with hexachlorobenzene and pentachlorobenzene, and the relative potencies of these compounds compared to clopyralid, this contamination is not significant in terms of potential systemic toxic effects. In addition, the contamination of clopyralid with hexachlorobenzene does not appear to present any substantial cancer risk above the Forest Service cancer risk LOC of 1 in 1 million.

\section{Glyphosate}

For both workers and members of the general public, there are no risks associated with nearly all exposures to glyphosate at the typical or maximum application rate (SERA 2003a). The risk assessment calculated no risk for all but one of the tested scenarios, usually at least by a factor of 5. There is low risk to children in the general public associated with accidental exposure to glyphosate consumption of contaminated water after an herbicide spill into a small pond.

\section{Hexazinone}

Over the range of plausible application rates, all worker groups exposed to hexazinone may face risks, with the highest risks predicted for workers using an over-theshoulder broadcast applicator (belly grinder; SERA 1997). Workers exposed to hexazinone via direct and broadcast ground spray and aerial applications at the maximum application rate are at low risk. There would be a low risk associated with accidental exposure to hexazinone mixed for the maximum application rate via contaminated gloves (also low risk at the typical application rate) and via spills on lower legs. The most likely effects include irritation to the eyes, respiratory tract, and skin. Even under the most extreme exposure scenarios, outward toxic effects are not likely to be observed; however, the upper estimates of exposure levels could be associated with subclinical (non- 


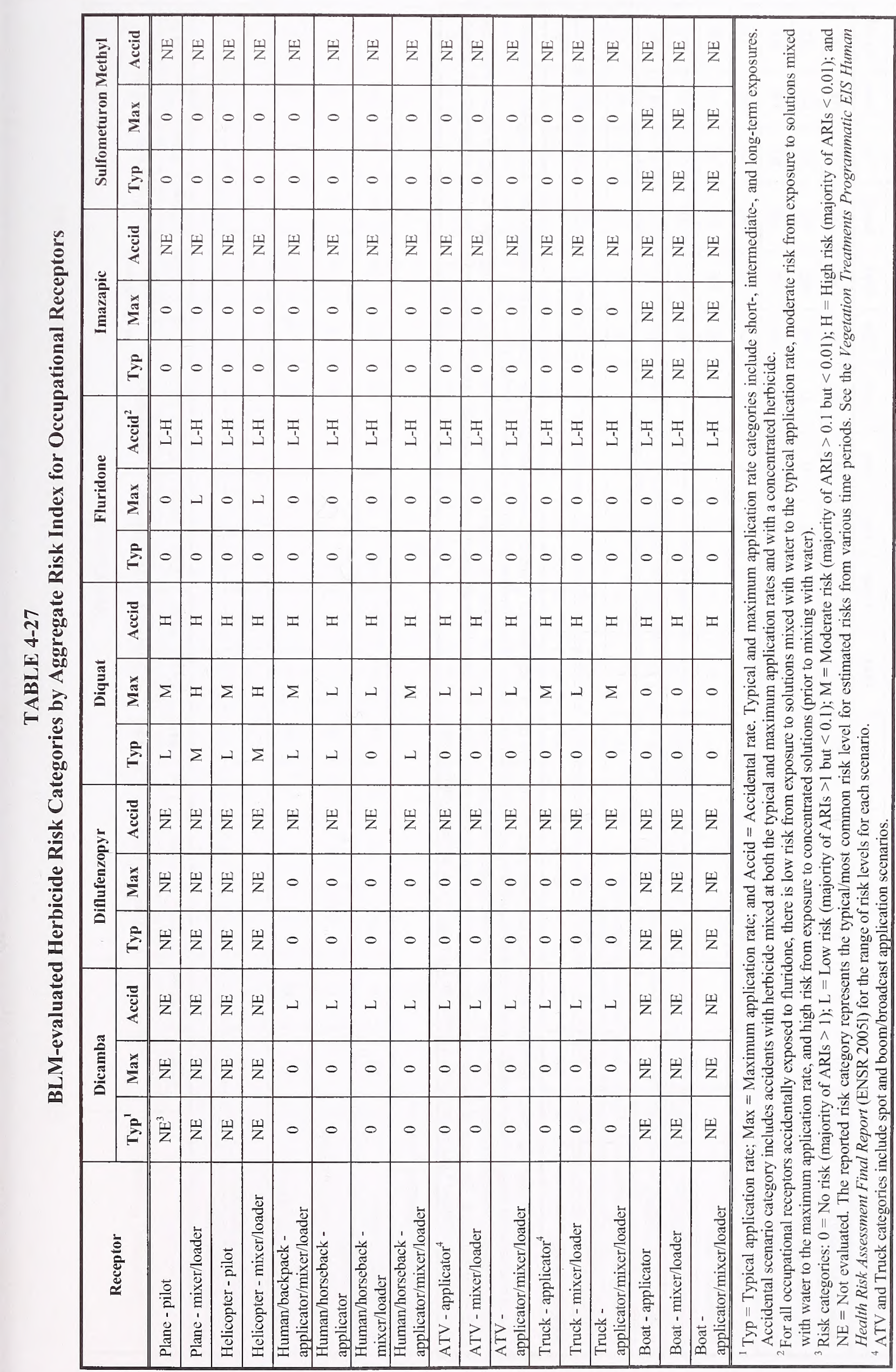




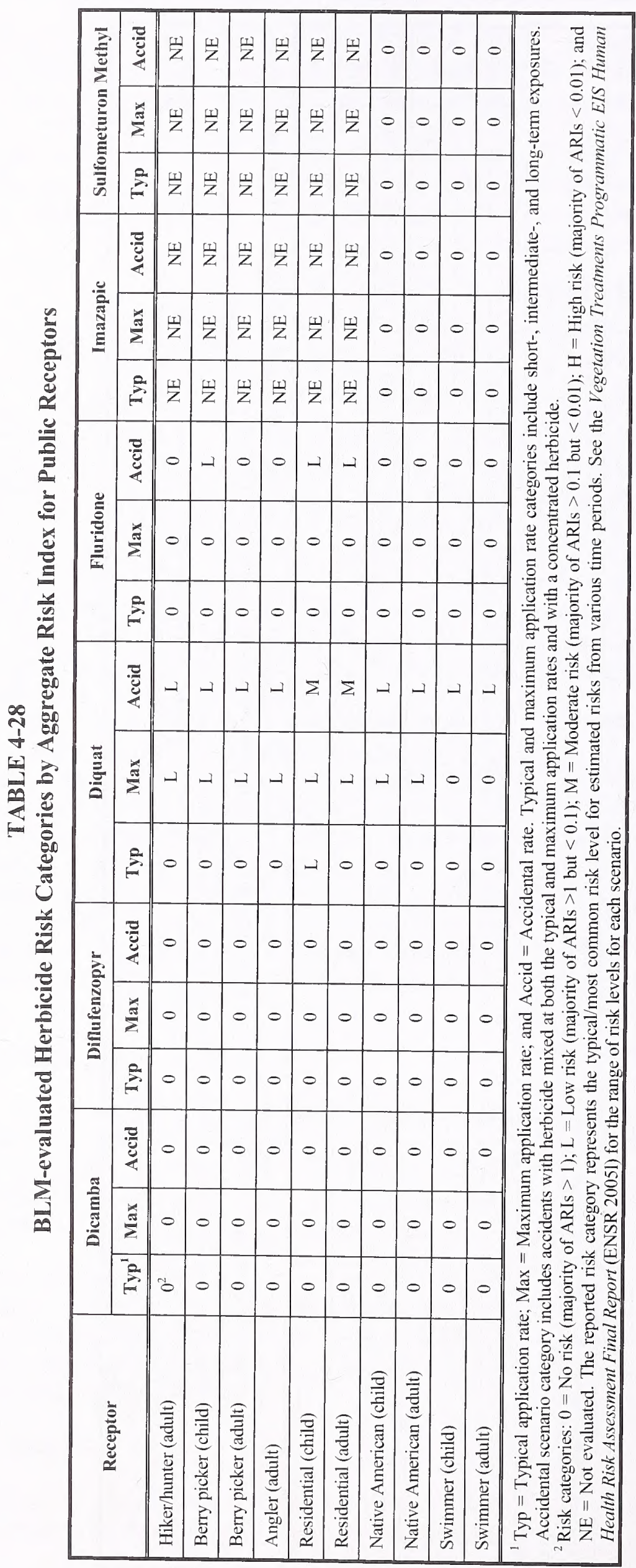




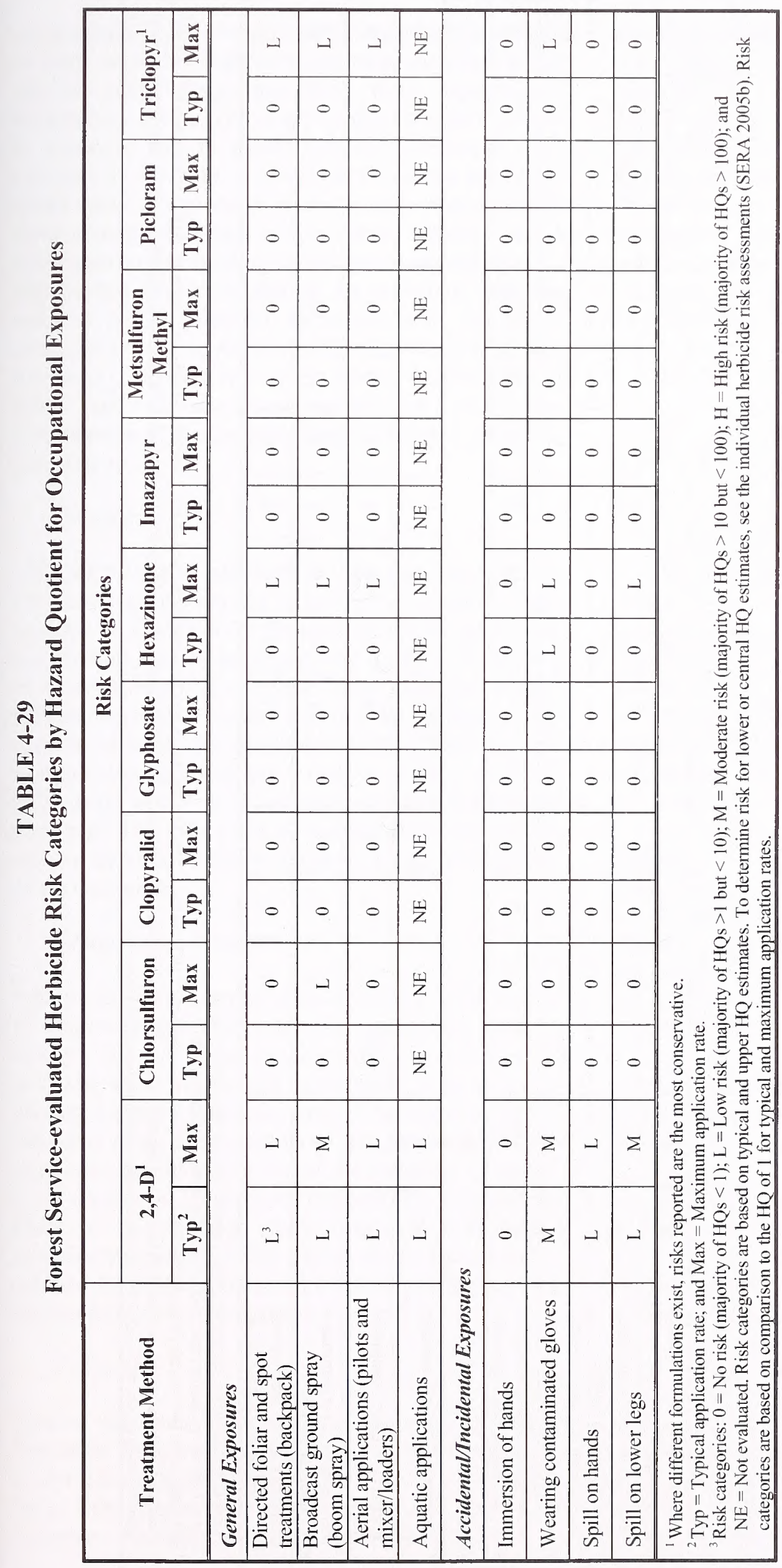




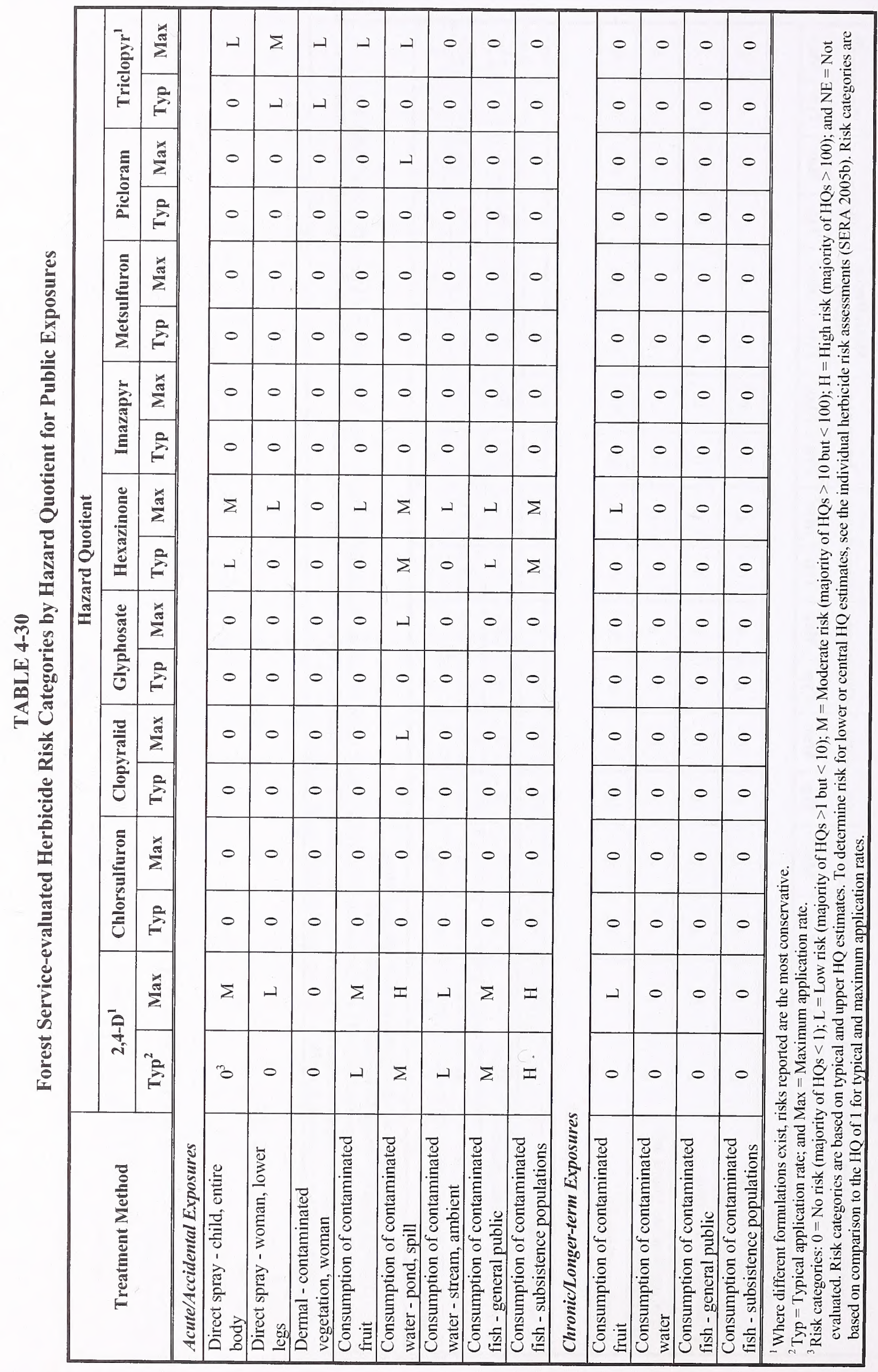


symptomatic) effects and possible reproductive effects. In some accidental exposure scenarios, members of the general public may face risks from exposure to hexazinone. At the typical application rate, there is low to moderate risk to public receptors associated with exposure to hexazinone under the following scenarios: direct spray of the entire body, acute consumption of water contaminated by a spill, and acute consumption of contaminated fish by the general public and subsistence populations. For application at the maximum rate, the risks to public receptors associated with the above scenarios are low to moderate. The following additional scenarios pose a low risk: direct spray of the lower legs, acute and chronic consumption of fruit, and consumption of stream water contaminated by runoff or percolation.

\section{Imazapyr}

Most exposures to imazapyr at either the typical or the maximum application rate do not present a risk to either workers or members of the general public, suggesting that workers and the general public would generally not be at any substantial risk from longer-term exposure to imazapyr even at the upper range of the application rate considered in the risk assessment (SERA 2004d). From a practical perspective, eye irritation is likely to be the only overt effect as a consequence of mishandling imazapyr. This effect can be minimized or avoided by prudent industrial hygiene practices during the handling of the compound.

\section{Metsulfuron Methyl}

Typical exposures to metsulfuron methyl at the typical or maximum application rates do not present a risk to workers or the general public (SERA 2004e). For workers, there is no risk associated with acute or chronic exposure scenarios, even at the upper ranges of estimated dose. For members of the general public, no risks were predicted for any of the exposure scenarios. From a practical perspective, eye and skin irritation are likely to be the only overt effects of mishandling metsulfuron methyl. These effects can be minimized or avoided by prudent industrial hygiene practices during the handling of this compound.

\section{Picloram}

Typical exposures to picloram at either the typical or maximum application rates present few risks to workers or the general public (SERA 2003b). For workers, no risks were predicted even at the upper ranges of exposure. For members of the general public, no risks were predicted except for the consumption of water by a child following an accidental spill of a large amount of picloram into a very small pond, which presents a low risk. From a practical perspective, eye irritation and skin sensitization are likely to be the only overt effects as a consequence of mishandling picloram. Based on the standard assumptions used in this and other Forest Service risk assessments, the contamination of picloram with hexachlorobenzene does not appear to present a substantial cancer risk, even at the upper ranges of plausible exposure.

\section{Triclopyr}

Workers face low risk from directed and broadcast ground spray and aerial applications at the upper ranges of exposures for both evaluated formulations of triclopyr (triclopyr acid and triclopyr BEE), at the maximum application rate (SERA 2003c). At the maximum application rate, workers face low risk from accidental exposure to contaminated gloves ( 1 hour duration). Thus, for workers who may apply triclopyr repeatedly over a period of several weeks or longer, it is important to ensure that work practices involve reasonably protective procedures to avoid the upper extremes of potential exposure. At higher application rates, measures that limit exposure should be developed on a case-by-case basis depending on the application rate and method. There is low to moderate risk to the general public from triclopyr applications under several acute or accidental scenarios: 1) direct spray to the entire body; 2) direct spray to the lower legs; 3) dermal contact with contaminated vegetation; 4) acute consumption of contaminated fruit (maximum application rate only); and 5) aeute consumption of pond water contaminated by a spill.

\section{Human Health Risks Associated with Herbicides Evaluated in Previous BLM EISs and Literature Review}

As discussed earlier, the human health risks of asulam, atrazine, bromacil, diuron, fosamine, mefluidide, simazine, tebuthiuron, and 2,4-DP were evaluated in earlier BLM vegetation treatment EISs. These herbicides were not reevaluated in the BLM HHRA for the current PEIS because a literature review and evaluation showed that most toxicity values for these herbicides reported in more recent studies were not substantially lower (i.e., present more risk) than the values used to assess risks to human health in the 1991 13-State EIS (McMullin and Thomas 2000). Tables 431 and 4-32 present summaries of the risks to occupational and public receptors associated with the 
nine herbicides that were evaluated in the earlier EISs and subsequent literature reviews. The earlier EISs calculate a margin of safety (MOS), which is the NOAEL divided by the exposure dose (and the same as the MOE used in the current HHRA), and cancer risk estimates for potential carcinogens. The EISs included summary tables that identified herbicides and scenarios that pose a high risk, where high risk is identified as an MOS less than 100 , or a cancer risk estimate greater than 1 in 1 million. Therefore, Tables 4-31 and 4-32 also report the high risk herbicides and exposure scenarios, as presented in the earlier EISs.

Another difference between this PEIS HHRA and earlier EIS HHRAs is the toxicity assessment. For the current HHRA, the USEPA either provided toxicity values for the various exposure durations (acute, short term, long term) and exposure routes (oral, dermal), or convened a panel to develop these values for this project. This ensured that the toxicity values used in the current HHRA were consistently derived and have had the benefit of peer review. In the development of these values, the USEPA selected the most sensitive endpoint from the most sensitive species; therefore, the values are protective of all other potential toxic effects (i.e., those that may occur at higher exposure levels). This methodology is standard practice for current HHRA guidance. However, during development of the earlier EISs, there was not much agency-derived information on the herbicides evaluated, nor was the methodology for evaluation as standardized. Thus, the authors evaluated separate toxic endpoints for systemic and reproductive effects for each herbicide, rather than just the most sensitive endpoint. Risks are discussed by toxic endpoint below, rather than in the context of the most sensitive endpoint.

\section{2,4-DP}

\section{According to the 1988 California Vegetation} Management Final EIS (1988 California EIS), backpack and hand applicators are at risk from typical 2,4-D application practices (USDI BLM 1988a). Backpack and hand applicators and ground applicators, mixerloaders, and applicator/mixer-loaders are also at risk for systemic and reproductive effects from maximum exposures. There are risks for systemic, reproductive, and cancer effects to workers and public receptors associated with accidental scenarios of spill to skin and direct spray. Public receptors are at risk for systemic, reproductive, and cancer effects as a result of picking contaminated vegetation, and for systemic and reproductive risks associated with drinking directly sprayed water and eating berries. Nearby residents also face risks for systemic and reproductive effects from treatments on public lands.

\section{Asulam}

According to the 1988 California EIS, asulam applications would pose few risks to workers or the public. Hand applicators would be at risk for systemic and reproductive effects from maximum exposures, while the public would be at risk from systemic, reproductive, and cancer effects from contact with vegetation by picking.

\section{Atrazine}

According to the 1991 13-State EIS, workers and the public would face numerous risks from exposure to atrazine. Workers would be at risk for systemic and/or reproductive effects under nearly all scenarios involving the typical application rate, and would be at risk for systemic, reproductive, and cancer effects under all scenarios involving the maximum application, as well as accidental scenarios. The public would be at risk for systemic and/or reproductive effects under several exposure scenarios involving the maximum application rate. The public would be at risk for systemic, reproductive, and cancer effects under all scenarios involving accidental exposures, except for contact with vegetation by a hiker or from fishing (systemic and reproductive effects only), or by living near a treated area (reproductive effect only).

\section{Bromacil}

According to the 1991 13-State EIS, there would be a risk to workers associated with several exposure scenarios involving typical bromacil application practices. Pilots and aerial mixer-loaders face a risk for systemic, reproductive, and cancer effects from typical and maximum exposures to bromacil. Backpack and hand applicators and ground applicators, mixer-loaders, and applicator/mixer-loaders are also at risk for systemic and reproductive effects from maximum exposures. Risks for systemic, reproductive, and cancer effects to workers and public receptors are associated with accidental scenarios of spill to skin (concentrate and mixture), direct spray (no cancer risk), consumption of fish from a directly sprayed water body (no cancer risk), consumption of directly sprayed berries (no cancer risk), and drinking from water contaminated by a truck spill or a jettison of mixture (no cancer risk). The cancer slope factor for bromacil used in the HHRA was the one available from the USEPA at the time of the 1991 13-State EIS. However, in its most recent review 


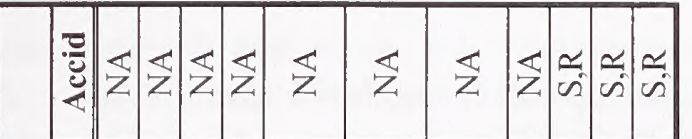

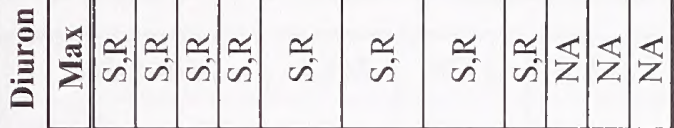

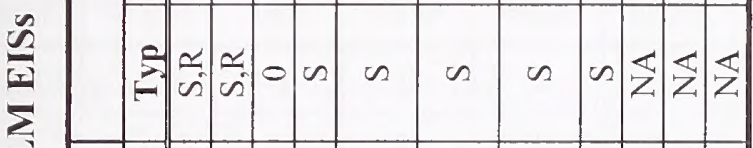

ब̄

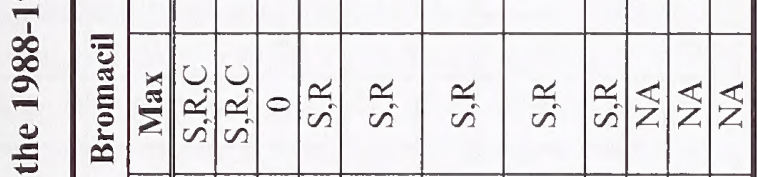

틀

宽

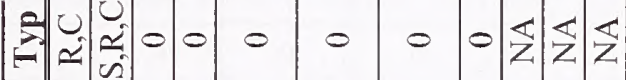

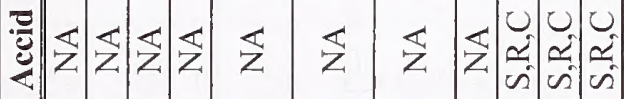

至

F.

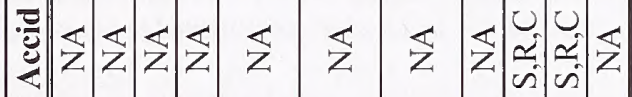

旁畜

:

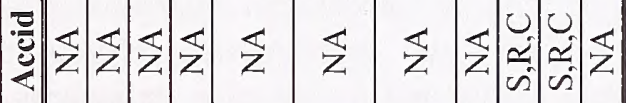

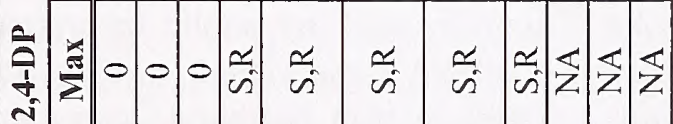

产:

葛

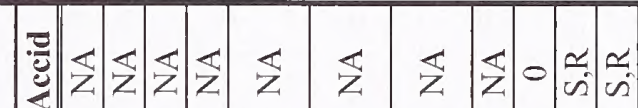

章

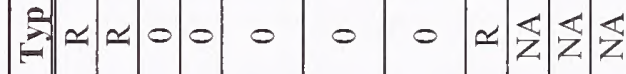

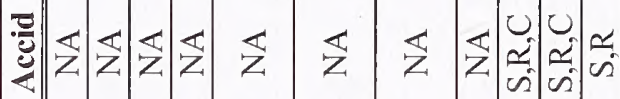
总

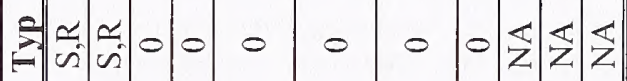

氖突 焉

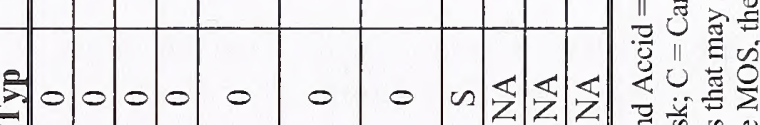
弱商至

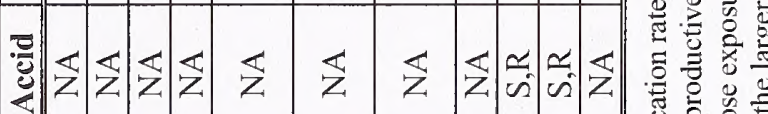
总

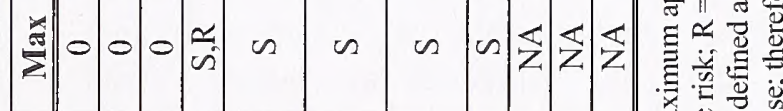

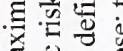

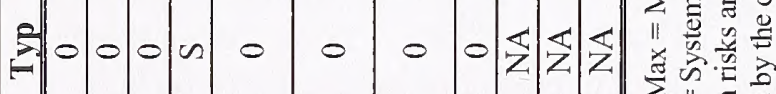

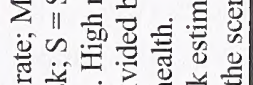

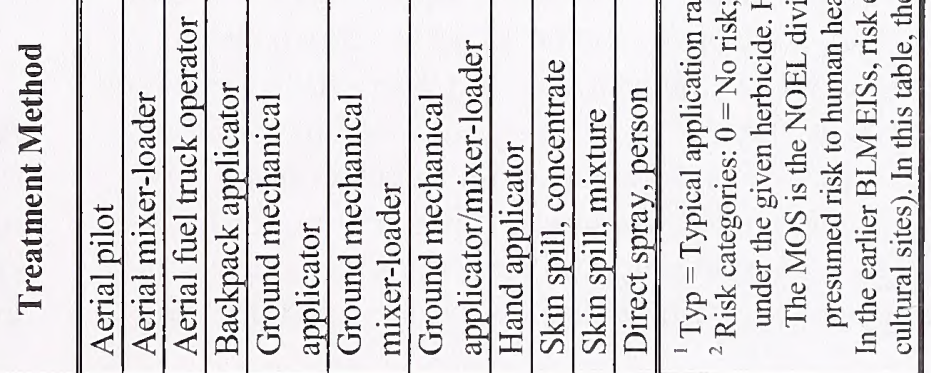


TABLE 4-32

Scenarios Resulting in High Risk to Public Receptors from Herbicides Evaluated in the 1988-1991 BLM EISs

\begin{tabular}{|c|c|c|c|c|c|c|c|c|c|c|c|}
\hline \multirow{2}{*}{ Treatment Method } & \multirow{2}{*}{$\begin{array}{l}2,4 \mathrm{DP}^{1} \\
\text { Accid }^{2} \\
\end{array}$} & \multirow{2}{*}{$\begin{array}{l}\text { ASU } \\
\text { Accid }\end{array}$} & \multicolumn{2}{|c|}{ Atrazine } & \multirow{2}{*}{$\begin{array}{l}\text { BRO } \\
\text { Accid }\end{array}$} & \multirow{2}{*}{$\begin{array}{l}\text { DIUR } \\
\text { Accid }\end{array}$} & \multirow{2}{*}{$\begin{array}{l}\text { FOS } \\
\text { Accid }\end{array}$} & \multirow{2}{*}{$\frac{\text { MEF }}{\text { Accid }}$} & \multicolumn{2}{|c|}{ Simazine } & \multirow{2}{*}{$\frac{\text { TEB }}{\text { Accid }}$} \\
\hline & & & $\operatorname{Max}$ & Accid & & & & & $\operatorname{Max}$ & Accid & \\
\hline Direct spray, person & $\mathrm{S}, \mathrm{R}, \mathrm{C}^{3}$ & 0 & $\mathrm{R}$ & $\mathrm{S}, \mathrm{R}, \mathrm{C}$ & $\mathrm{S}, \mathrm{R}$ & $\mathrm{S}, \mathrm{R}$ & 0 & 0 & 0 & $\mathrm{~S}, \mathrm{R}, \mathrm{C}$ & $\mathrm{S}, \mathrm{R}$ \\
\hline $\begin{array}{l}\text { Drinking directly sprayed } \\
\text { water }\end{array}$ & $\mathrm{S}, \mathrm{R}$ & 0 & $\mathrm{R}$ & $\mathrm{S}, \mathrm{R}, \mathrm{C}$ & 0 & $\mathrm{~S}, \mathrm{R}$ & 0 & 0 & 0 & $\mathrm{~S}, \mathrm{R}, \mathrm{C}$ & $\mathrm{R}$ \\
\hline $\begin{array}{l}\text { Eating fish from directly } \\
\text { sprayed water }\end{array}$ & 0 & 0 & $\mathrm{R}$ & $\mathrm{S}, \mathrm{R}, \mathrm{C}$ & $\mathrm{S}, \mathrm{R}$ & $\mathrm{S}, \mathrm{R}$ & 0 & 0 & 0 & $\mathrm{~S}, \mathrm{R}, \mathrm{C}$ & 0 \\
\hline Immediate reentry, hiker & 0 & 0 & $\mathrm{R}$ & $\mathrm{S}, \mathrm{R}$ & 0 & $\mathrm{~S}$ & $\mathrm{~S}$ & $\mathrm{~S}$ & 0 & 0 & 0 \\
\hline Immediate reentry, picker & $S, R, C$ & $\mathrm{~S}, \mathrm{R}, \mathrm{C}$ & $S, R$ & $\mathrm{~S}, \mathrm{R}, \mathrm{C}$ & $S, R$ & $S, R$ & 0 & 0 & 0 & $\mathrm{~S}, \mathrm{R}, \mathrm{C}$ & $S, R$ \\
\hline $\begin{array}{l}\text { Eating directly sprayed } \\
\text { berries }\end{array}$ & $\mathrm{S}, \mathrm{R}$ & 0 & $\mathrm{~S}, \mathrm{R}$ & $\mathrm{S}, \mathrm{R}, \mathrm{C}$ & $\mathrm{S}, \mathrm{R}$ & $\mathrm{S}, \mathrm{R}$ & 0 & 0 & 0 & $\mathrm{~S}, \mathrm{R}, \mathrm{C}$ & $S, R$ \\
\hline Angler & 0 & 0 & 0 & $\mathrm{~S}, \mathrm{R}$ & 0 & 0 & 0 & 0 & $\mathrm{R}$ & 0 & 0 \\
\hline Nearby resident & $\mathrm{S}, \mathrm{R}$ & 0 & 0 & $\mathrm{R}$ & 0 & 0 & S & 0 & 0 & 0 & 0 \\
\hline $\begin{array}{l}\text { Drinking water } \\
\text { contaminated by a jettison } \\
\text { of mixture }\end{array}$ & NA & NA & 0 & $\mathrm{~S}, \mathrm{R}, \mathrm{C}$ & $S, R$ & $\mathrm{~S}, \mathrm{R}$ & NA & 0 & 0 & $\mathrm{~S}, \mathrm{R}, \mathrm{C}$ & $\mathrm{S}, \mathrm{R}$ \\
\hline $\begin{array}{l}\text { Drinking water } \\
\text { contaminated by a truck } \\
\text { spill }\end{array}$ & NA & NA & 0 & $\mathrm{~S}, \mathrm{R}, \mathrm{C}$ & $S, R$ & $\mathrm{~S}, \mathrm{R}$ & NA & $\mathrm{S}$ & 0 & $\mathrm{~S}, \mathrm{R}, \mathrm{C}$ & $\mathrm{S}, \mathrm{R}$ \\
\hline \multicolumn{12}{|c|}{$\begin{array}{l}12,4 \mathrm{DP}=2,4-\mathrm{DP} ; \mathrm{ASU}=\text { Asulam; } \mathrm{BRO}=\mathrm{Bromacil} ; \mathrm{DIUR}=\mathrm{Diuron} ; \mathrm{FOS}=\text { Fosamine; } \mathrm{MEF}=\text { Mefluidide; and TEB }=\text { Tebuthiuron. } \\
2 \text { Accid = Accidental application; and Max }=\text { Maximum application rate. } \\
{ }^{3} \text { Risk categories: } 0=\text { No risk; } \mathrm{S}=\text { Systemic; } \mathrm{R}=\text { Reproductive; } \mathrm{C}=\text { Cancer; and } \mathrm{NA}=\mathrm{Not} \text { applicable. Marked scenarios are those that result in high } \\
\text { risk under the given herbicide. High risks are defined as those exposures that may result in a margin of safety }(\mathrm{MOS} \text { ) }<100 \text { or a cancer risk greater } \\
\text { than one-in-one million. The MOS is the NOEL divided by the dose; therefore, the larger the MOS, the smaller the estimated human dose compared } \\
\text { to the animal NOEL, and the lower the presumed risk to human health. } \\
\text { In the earlier BLM EISs, risk estimates were presented separately for different land uses (rangeland, public domain forestland, oil and gas sites, ROW, } \\
\text { and recreation and cultural sites). In this table, the scenario is marked if any of these land uses showed a high risk for the specific herbicide. }\end{array}$} \\
\hline
\end{tabular}

of bromacil, the USEPA did not provide a cancer slope factor (USEPA 1994b), therefore bromacil is likely not carcinogenic.

\section{Diuron}

According to the 1991 13-State EIS, there are risks to workers and the general public associated with both routine and accidental exposures to diuron. Aerial application poses a risk to most evaluated public receptors for systemic effects from worst-case exposures (e.g., direct exposure of hikers, berry pickers, anglers, and nearby residents; spray drift to skin; vegetation contact by berry pickers; consumption of contaminated drinking water and fish). Berry pickers also face a risk for systemic effects from worst-case direct exposure and contact with vegetation scenarios. In aerial application scenarios, pilots and mixer-loaders are at risk for systemic and reproductive effects under both typical and worst-case exposures, and fuel-truck operators are at risk for systemic and reproductive effects under worst-case exposures. In addition, backpack and hand applicators and ground applicators, mixer-loaders, and applicator-mixer-loaders are at risk for systemic and reproductive effects for typical (systemic only) and worst-case exposures. There are also risks to workers and the public for systemic and reproductive effects associated with accidental exposures of spill to skin (herbicide concentrate and mixture), direct spray, drinking or eating fish from a directly sprayed water body, or immediate reentry into a sprayed area by a berry picker.

\section{Fosamine}

According to the 1991 13-State EIS, there would be few risks to workers associated with applications of mefluidide. Backpack applicators could experience systemic effects at the typical and maximum rates, and ground applicators and hand applicators could 
experience systemic effects at the maximum rate. Backpack applicators could also experience reproductive effects as a result of applications at the maximum rate.

\section{Mefluidide}

According to the 1991 13-State EIS, there would be few risks to workers associated with applications of mefluidide. Pilots, backpack applicators, and hand applicators could experience systemic effects as a result of application of mefluidide at the maximum rate, and hand applicators could experience systemic effects as a result of applications at the typical rate. Hikers reentering a treated area, or drinking water from a spill at the accidental rate would be at risk for systemic effects.

\section{Simazine}

According to the 1991 13-State EIS, potential effects to workers would be limited to systemic and reproductive effects to pilots and aircraft mixer-loaders, and would be associated with application at the typical and maximum application rates. In addition, a spill to a worker's skin of either a concentrate or mixture of simazine could result in systemic, reproductive, and cancer effects. The public could experience systemic, reproductive, and cancer effects under most accidental scenarios analyzed in the HHRA. However, hikers entering recently treated areas and contacting vegetation, anglers, and nearby residents would not be at risk under accidental exposure scenarios.

\section{Tebuthiuron}

According to the 1991 13-State EIS, tebuthiuron poses health risks to workers under various application scenarios. Typical and worst-case aerial application exposure to tebuthiuron could result in systemic and reproductive effects to pilots and to mixer-loaders (no systemic risk at typical exposures). Fuel-truck operators could experience systemic effects from worst-case exposure to tebuthiuron during aerial application. Backpack applicators face systemic and reproductive risks from worst-case exposures to tebuthiuron. For workers using ground mechanical equipment, there are systemic and reproductive risks to applicators, mixerloaders, and applicator/mixer-loaders associated with worst-case exposures to tebuthiuron. Hand applicators are at risk from typical (reproductive effects) and worstcase (systemic and reproductive effects) exposures. Several accidental scenarios also pose a risk for systemic and reproductive effects to workers and the public: 1) spill of herbicide mixture to skin; 2) direct spray to person; 3) drinking directly sprayed water (reproductive only); 4) immediate reentry of a berry picker into a sprayed area; 5) consumption of directly sprayed berries; and 6) consumption of water contaminated by a jettison of mixture or by a truck spill.

\section{Human Health Risks by Application Method}

\section{Air}

Aerial applications of herbicides generally pose a greater risk due to off-site drift than ground applications, as herbicides applied at greater distances from the ground are able to drift farther from the target application area. Therefore, risks to public receptors recreating or living near an application area would extend out greater distances if the herbicide was applied aerially than if it was applied by a ground application method. The BLM does not apply dicamba and diflufenzopyr by air.

\section{Ground}

Ground applications typically pose a lower risk to offsite receptors than aerial applications because the receptors are less likely to be exposed to spray drift. Similarly, spot rather than boom/broadcast applications are less likely to result in adverse effects to downwind receptors. However, these spot applications could present an increased risk to the occupational receptors charged with applying the herbicide because they are more likely to come into contact with the herbicide (their exposure doses may be higher). In particular, occupational receptors applying diquat by backpack and horseback would be at low to moderate risk for adverse effects from exposure to the herbicide, whereas those applying diquat at the typical application rate by ATV or truck would not be at risk. In contrast, chlorsulfuron does not pose a risk to workers involved with aerial applications, but does pose a risk to workers conducting ground broadcast applications at the highest application rate, and exposure to hexazinone is greatest for workers using an over-the-shoulder broadcast applicator.

\section{Typical Application Rate}

Most of the herbicides do not present a risk to human receptors when applied at the typical application rate. Diquat applications at the typical application rate would pose a low to moderate risk to plane and helicopter pilots and mixer/loaders, backpack applicator/mixer/loaders, horseback applicators and applicator/mixer/loaders, and child residents. 2,4-D, $2,4-$ 
DP, atrazine, bromacil, diuron, hexazinone, simazine, and tebuthiuron also pose a risk to various public and occupational receptors when applied at the typical application rate.

\section{Maximum Application Rate}

At the maximum application rate, more herbicides, in a greater number of exposure scenarios, have the potential to adversely affect human health. Fluridone, chlorsulfuron, clopyralid, glyphosate, picloram and triclopyr do not pose a risk when applied at the typical application rate, but do pose a risk under one or more exposure scenarios when applied at the maximum application rate. Clopyralid, glyphosate and picloram pose a low risk under the accidental scenario involving consumption of water from a small pond that has experienced a recent spill of herbicides mixed for the maximum application rate, which is a very unlikely scenario. In addition, a greater number of exposure scenarios and receptors are at risk for adverse effects from herbicide applications at the maximum application rate. Dicamba, diflufenzopyr, imazapic, imazapyr, metsulfuron methyl, and sulfometuron methyl do not pose a risk to any receptor when applied at the maximum (or typical) application rate.

\section{Accidental Direct Spray and Spill Scemarios}

Accidental direct spray and spill scenarios for many herbicides pose a risk to many receptors (accidental scenarios for diflufenzopyr, imazapic, and sulfometuron methyl were not evaluated because these chemicals are not considered toxic through short-term dermal exposure). These scenarios are unlikely, and can be avoided by following SOPs.

\section{Human Health Risks by Receptor}

\section{Occupational}

2,4-D, 2,4-DP, asulam, atrazine, bromacil, diquat, diuron, fosamine, mefluidide, simazine, and tebuthiuron pose risks to occupational receptors when applied at both typical and maximum application rates. Atrazine and diuron pose a risk to most receptors at the typical application rate. For 2,4-D, atrazine, diquat, bromacil, simazine, and tebuthiuron, receptors working with aerial applications would be at low to moderate risk for adverse effects, even for applications at the typical application rate, and all or most occupational receptors would be at risk when applying these herbicides at maximum application rates. 2,4-D, 2,4-DP, atrazine, and fosamine also pose risks to ground applicators, particularly during applications at the maximum application rate. In addition, there are potential cancer risks to workers who apply atrazine and bromacil aerially. Mixer/loaders working with aerial applications of fluridone are at low risk, and those working with atrazine, bromacil, diuron, simazine, and tebuthiuron are at high risk when applying those herbicides at the typical and maximum application rates.

Ground broadcast applicators are at risk from applying atrazine and diuron at the typical application rate, and 2,4-DP, bromacil, chlorsulfuron, fosamine, and tebuthiuron at the maximum application rate. All occupational receptors are at risk from applying atrazine, hexazinone, tebuthiuron, and triclopyr at the maximum application rate. The rest of the scenarios of potential exposure to herbicides pose risks to occupational receptors were not predicted. Workers involved in the aerial application of herbicides appear to be at greater risk than other occupational receptors; however, the application method that creates the most risk to workers appears to depend on the herbicide, so application methods for each herbicide should be carefully evaluated with respect to potential human health effects.

\section{Public}

In general, there are lower risks to public receptors than occupational receptors. However, within this category, there is higher risk to children than adults. Public receptors do not appear to be at risk from chlorsulfuron, dicamba, diflufenzopyr, imazapic, imazapyr, metsulfuron methyl, or sulfometuron methyl applications (accidental scenarios were not evaluated for imazapic and sulfometuron methyl because these chemicals are not toxic through short-term exposure for specific exposure routes). Diquat application at the typical application rate poses a low risk to child residents. At the maximum application rate, diquat poses a low to moderate risk to all public receptors, except swimmers. Under worst-case exposures, diuron poses a risk to most public receptors. In addition, 2,4-D, 2,4-DP, asulam, atrazine (also at maximum exposure), bromacil, clopyralid, diuron, fluridone, fosamine, glyphosate, hexazinone, mefluidide, picloram, simazine, tebuthiuron, and triclopyr may pose a risk to public receptors under one or more accidental exposure scenarios (e.g., exposure resulting from the spill of an herbicide into a small pond). For most herbicides (except diquat), risk to public receptors can be minimized or avoided by using the typical application rate and following SOPs that greatly reduce the likelihood of accidents. 


\section{Impacts by Alternative}

The following is a qualitative discussion of how risk from herbicide exposure would vary under each herbicide treatment alternative

\section{Alternative A - Continue Present Herbicide Use (No Action Alternative)}

Of the herbicide treatment alternatives (A, B, D, and E), the fewest acres treated would be under the No Action Alternative. Therefore, health risks to occupational and public receptors would be lowest. If the No Action Alternative were to result in more acres being treated by other vegetation management methods (e.g., prescribed fire, manual, biological treatments), then health risks from these methods would also have to be considered (see the PER). In addition, the new herbicides proposed in this EIS (diflufenzopyr+dicamba [Overdrive ${ }^{\circledR}$ ], diquat, fluridone, and imazapic) would not be used. Of these new herbicides, diquat poses a potential risk to humans under various exposure pathways; however, diflufenzopyr, dicamba, fluridone, and imazapic are all relatively safe to humans, with no potential adverse effects predicted by the human health risk characterization, except in cases of unlikely accidental exposures of fluridone. Of the 20 previously-approved herbicides, only nine (asulam, clopyralid, fosamine, glyphosate, imazapyr, mefluidide, metsulfuron methyl, picloram and sulfometuron methyl) pose a similarly negligible to low risk to humans. Therefore, failure to approve the four new herbicides would limit the options for treatment of vegetation without appreciable risk to humans. As a consequence, the No Action Alternative may present greater risk to humans per each herbicide application than the other alternatives. In addition, this alternative may be less successful in controlling weeds and poisonous plants that adversely affect humans, especially weeds most effectively controlled by the four proposed herbicides.

Under the No Action Alternative, the BLM would be able to continue to use six herbicides that were approved for use under earlier BLM vegetation treatment RODs: 2,4-DP, asulam, atrazine, fosamine, mefluidide, and simazine (USDI BLM 1988b, 1991b, 1992a). Except for fosamine, which has been used on less than 50 acres annually, these chemicals have not been used by the BLM since 1997 and are not proposed for use under the other herbicide treatment alternatives.

In 1998, the BLM conducted a literature review to determine if the earlier vegetation treatment ROD conclusions for asulam, atrazine, mefluidide, and simazine were justifiable based on past and 1998 toxicology and risk assessment procedures; a literature review was not performed for 2,4-DP and fosamine, but these herbicides were analyzed in the 1988 California EIS (USDI BLM 1988a, McMullin and Thomas 2000). Based on this analysis, it was determined that systemic risks associated with using asulam may be greater than those projected in the earlier EIS, but that risks to humans from the other three herbicides were similar to, or less than, those identified in earlier EISs.

Based on the earlier EISs, literature reviews done by the BLM, and other studies (USEPA 1995d, 2002), the risks to humans would be low for asulam, fosamine, and mefluidide, low to moderate for 2,4-DP and simazine, and moderate to high for atrazine. The BLM uses sulfometuron methyl, bromacil, and diuron in treatment situations where it used atrazine in the past, and triclopyr instead of fosamine. These substitute herbicides pose similar, or lower, risks to humans than the herbicides they would replace.

\section{Alternative B - Expand Herbicide Use and Allow for Use of New Herbicides in 17 Western States (Preferred Alternative)}

This alternative would likely have the greatest overall risk to human health of the five alternatives considered here because of the large number of acres treated. However, human health could benefit from the reduced occurrence of the noxious weeds and other invasive vegetation that would likely be brought about by this alternative. In addition, this alternative would include the use of the new herbicides evaluated in the BLM HHRA (ENSR 20051). Of these four herbicides, three (all but diquat) appear to be relatively harmless to humans; the use of these herbicides would increase the options for appropriately managing vegetation while minimizing the risk to human receptors. Therefore, the Preferred Alternative could result in more positive impact to humans per application than the No Action Alternative. However, the new herbicide diquat potentially presents greater risk to humans in many application scenarios, and it is suggested that diquat not be used or be used only in very limited scenarios at the typical application rate, where there is risk to human receptors (e.g., possibly ground applications from trucks not near residences or berry gathering sites).

\section{Alternative C - No Use of Herbicides}

Alternative $\mathrm{C}$ would eliminate human health risk associated with herbicide applications. However, risks 
to humans associated with alternative vegetation management methods would likely increase (these risks are perhaps greatest for prescribed fire treatments [see PER]). In addition, human health might be adversely affected if the noxious weeds and poisonous plants that can harm humans increase in occurrence as a result of a cessation of herbicide treatments.

\section{Alternative D - No Aerial Applications}

Human health risks per application area would be lower under Alternative $\mathrm{D}$ than under the other herbicide treatment alternatives because herbicides would not be likely to drift as far, potentially affecting fewer humans. This alternative would allow the use of the new herbicides, which on average present less risk to humans than the currently-used herbicides. Overall risks would be lower than under the Preferred Alternative, which would treat about 400,000 more acres and would use aerial spraying. However, under the Preferred Alternative, the BLM may eliminate more unwanted plants that adversely affect human health than under Alternative D. Overall risks would likely be similar to those under Alternative $\mathbb{E}$, as a similar number of acres would be treated, and Alternative $\mathrm{E}$ places emphasis on spot applications over broadcast applications. However, Alternative E would prohibit the use of ALS-inhibiting herbicide active ingredients (i.e., chlorsulfuron, imazapic, imazapyr, metsulfuron methyl, and sulfometuron methyl), which pose low risks to humans. Because the BLM would treat 240,000 more acres under Alternative $\mathrm{D}$ than under the No Action Alternative, but would not use higher risk aerial applications and would use less risky chemicals, it is difficult to infer which alternative would have a lower overall risk.

\section{Alternative $\mathbf{E}$ - No Use of Acetolactate Synthase- inhibiting Herbicides}

The five ALS-inhibiting herbicides (chlorsulfuron, imazapic, imazapyr, metsulfuron methyl, and sulfometuron methyl) that would not be used under this alternative present some of the lowest risks with respect to human health. Even in accidental exposure scenarios, imazapic, imazapyr, metsulfuron methyl, and sulfometuron methyl do not pose a risk to humans, and chlorsulfuron only poses a risk to workers where applied in ground broadcast applications at the highest application rate. From a practical perspective, eye and/or skin irritation are likely to be the only overt effects of mishandling the ALS-inhibiting herbicides, and these effects can be minimized or avoided by prudent industrial hygiene practices during the handling of these compounds. Bromacil, diquat, diuron, and tebuthiuron, which pose greater human health risks, would not be excluded by Alternative E; therefore, risk per area treated could increase if these herbicides were used in place of ALS-inhibiting herbicides. Alternative $E$ places increased emphasis on spot rather than broadcast applications, which should mean that there would be less per area risk than under the No Action and Preferred alternatives, except in the few possible cases where occupational receptors would be at greater risk from spot applications. In addition, number of acres proposed for treatment $(466,000)$ is half that of the Preferred Alternative $(932,000)$, which would correspond to a lower overall risk. Conversely, more acres would be treated under Alternative $\mathrm{E}$ than under the No Action Alternative $(305,000)$, which corresponds to a greater overall risk. Under Alternative D, the BLM would treat more acres $(540,000)$ than under Alternative E, but would not use aerial spraying, although there would be a minimal amount of aerial spraying under Alternative E (spot applications are preferred over broadcast applications). However, Alternative D would allow the use of the ALS-inhibiting herbicides, which could limit the use of herbicides that may present higher human health risks, and correspond to a greater risk than under Alternative E.

\section{Mitigation}

In addition to following SOPs, there are certain herbicide-specific measures that can be taken to substantially reduce or eliminate human health risk from herbicide use. The following mitigation measures were developed based on the BLM HHRA, the Forest Service HHRAs, and the earlier BLM EIS HHRAs:

- Use the typical application rate, where feasible, when applying 2,4-D, 2,4-DP, atrazine, bromacil, diquat, diuron, fluridone, fosamine, hexazinone, tebuthiuron, and triclopyr, to reduce risk to occupational and public receptors.

- Avoid applying atrazine, bromacil, diuron, or simazine aerially.

- Apply diquat by ATV, truck, or boat to reduce risks to occupational receptors; limit diquat applications to areas away from high residential and subsistence use to reduce risks to public receptors.

- Evaluate diuron applications on a site-by-site basis to avoid risks to humans. There appear 
to be few scenarios where diuron can be applied without risk to occupational receptors.

- Do not apply hexazinone with an over-theshoulder broadcast applicator.

\section{Cumulative Effects Analysis}

The National Environmental Policy Act and its implementing guidelines require an assessment of the proposed project and other projects that have occurred in the past, are occurring in the present, or are likely to occur in the future, which together may have cumulative impacts that go beyond the impacts of the proposed project itself. According to the Act (40 CFR $\$ 1508.7$ and $1508.25[\mathrm{a}][2])$ :

"Cumulative impact is the impact on the environment which results from the incremental impact of the action when added to the other past, present, and reasonably foreseeable future actions regardless of what agency (federal or non-federal) or person undertakes such other actions. Cumulative impacts can result from individually minor but collectively significant actions taking place over a period of time. In addition, to determine the scope of Environmental Impact Statements, agencies shall consider cumulative actions, which when viewed with other proposed actions have cumulatively significant impacts and should therefore be discussed in the same impact statement."

The purpose of this cumulative effects analysis is to determine if the effects of BLM vegetation treatments have the potential to interact or accumulate over time and space, either through repetition or when combined with other effects, and under what circumstances and to what degree they might accumulate.

\section{Structure of the Cumulative Effects Analysis}

For this Programmatic EIS, the analysis of cumulative impacts is a four-step process that follows guidance provided in Considering Cumulative Effects Under the National Environmental Policy Act (CEQ 1997):

- Specify the class of actions for which effects are to be analyzed.

- Designate the appropriate time and space domain in which the relevant actions occur.

- Identify and characterize the set of receptors to be assessed.
- Determine the magnitude of effects on the receptors and whether those effects are accumulating.

\section{Class of Actions to be Analyzed}

This analysis addresses large, regional-scale trends and issues that require integrated management across broad landscapes. It also addresses regional-scale trends and changes in the social and economic needs of people. This analysis does not identify site-specific effects, in part because of the level of specificity in broad-scale management direction, and because site-specific information is not essential for determining broad-scale management direction. As discussed in Chapter 1, Proposed Action and Purpose and Need, site-specific issues would be addressed through NEPA compliance for resource management activities and other land use plans prepared at the state, district, or field office level.

The analysis of cumulative effects assumes that information provided in the PER is incorporated by reference in its entirety into the cumulative effects analysis. The analysis of cumulative effects assumes that SOPs and mitigation measures identified in Chapter 2 would be followed by the BLM under all alternatives to ensure that risks to human health and the environment from herbicide treatment actions were kept to a minimum.

The analysis recognizes that prevention, early detection, and rapid response are the most cost effective methods for weed control. Prevention, early detection, and rapid response strategies that reduce the need for vegetative treatments should lead to a reduction in the number of acres treated using herbicides in the future by reducing or preventing noxious weed establishment. However, once weed populations become established, infestations can increase and expand in size. Weeds colonize highly disturbed ground and invade plant communities that have been degraded, but are also capable of invading intact communities.

As stated in the BLM's Partners Against Weeds: An Action Plan for the Bureau of Land Management [USDI BLM 1996], prevention and public education are the highest priority weed management activities. Priorities are as follows:

- Priority 1: Take actions to prevent or minimize the need for vegetation control when and where feasible, considering the management objectives of the site. 
- Priority 2: Use effective nonchemical methods of vegetation control when and where feasible.

- Priority 3: Use herbicides after considering the effectiveness of all potential methods or in combination with other methods or controls.

Although prevention, early detection, and rapid response are the most cost effective methods of weed control, the analysis also recognizes that public lands must be administered under the principles of multiple use and sustained yield in accordance with the intent of Congress as stated in the FLPMA. Thus, vegetation must be managed to protect and enhance the health of the land while providing a source of food, timber, and fiber for domestic needs (USDI BLM 2000c). Landdisturbing activities are allowed on public lands, but must be conducted in a manner that minimizes ecosystem fragmentation and degradation, and lands should be rehabilitated when necessary to safeguard the long-term diversity and integrity of the land.

All vegetation treatment methods used by the BLM are considered in the analysis. These include herbicide use; manual, mechanical, and biological control methods; and use of fire, as identified in Chapter 2 (Alternatives).

For this PEIS, potential cumulative effects include those that were assessed for all land ownerships, including lands administered by other federal agencies and non-federal lands, particularly effects to air quality and terrestrial and aquatic species.

The analysis and disclosure of cumulative effects alerts decision-makers and the public to the context within which effects are occurring, and to the environmental implications of the interactions of known and likely management activities. During subsequent analyses for site-specific activities, local cumulative effects should be thoroughly considered when designing site-specific alternatives and mitigation measures.

\section{Appropriate Temporal and Spatial Domain}

\section{Temporal Domain}

The analysis period covered by the cumulative effects analysis primarily begins in the 1930s with the passage of the Taylor Grazing Act, and continues through 2057. The ending date is based on the term that treatments would occur under this PEIS (about 10 years) and the time for treated areas to fully realize the results of the treatment in terms of meeting management objectives and desired vegetative conditions (up to 25 years or longer for some treatments). It is also based on the difficulty of predicting advances in technology and the types and amounts of vegetation treatments needed very far into the future. Thus, a reasonable analysis period, and one on which most of the cumulative effects analysis is focused, is 50 years into the future.

\section{Spatial Domain}

As discussed earlier, the BLM has been mandated under a variety of statutes and policy initiatives to increase the number of acres of vegetation treated annually to address the issues of catastrophic fire and invasive species spread and their relationships to habitat improvement and maintenance of healthy landscapes. The BLM estimates that approximately 6 million acres would be treated annually over at least the next 10 years to meet these mandates. Acres to be treated by the BLM and assessed in this PEIS were estimated based on information provided by BLM field offices throughout the western U.S., including Alaska. Treatments could occur on the same acres several times during a single year, or over several years.

In developing acreage estimates for all alternatives, it was assumed that if an acre was treated more than once using the same type of treatment during the same year, it would be counted once. If the acre was treated using two or more different methods during the same year (for example, fire use followed by herbicide treatment), each treatment would count as one acre. Thus, if an acre was treated using fire and herbicides during the same year, two acres would be counted as treated. If an acre was treated using two or more herbicides in a tank mix, it would be counted once.

For some resources and uses, the project area may be where the effect can be felt (known as the "footprint"), but for others, the footprint may extend well beyond that space. For example, air quality effects to humans can extend miles beyond the footprint of the development. For the purposes of this analysis, the spatial domain for past, present, and reasonably foreseeable activities is primarily the 17 western states evaluated in this PEIS. However, this PEIS also considers effects to resources that could occur outside of these states.

The alternatives analyzed in this PEIS identify alternative approaches to herbicide use, including abandonment of their use, as well as limitations on which herbicides may be used or how herbicides may be applied. The effects of vegetation treatments disclosed in the PEIS and PER, combined with subsequent site-specific NEPA analysis, provide a 
comprehensive assessment of cumulative effects of future vegetation treatment activities on public lands. In light of the broad geographic scope and spatial resolution of this PEIS, the cumulative effects analysis cannot and does not address all possible cumulative effects that may result at specific sites on public lands.

For the purposes of this analysis, non-federal lands include lands owned and/or managed by individuals, corporations, American Indian tribes, Alaska Native corporations, states, counties, or other agencies. The BLM does not have the authority to regulate any activities or their timing on lands other than those the BLM administers. However, when an action takes place on public land, it may cause direct, indirect, or cumulative effects on non-federal lands. For example, a wildfire that begins on public land may burn to adjacent private land, or noxious weed infestations that begin on private land may infest adjacent public land. For these examples, treatment activities outlined in the PEIS and PER could benefit adjacent landowners indirectly as a result of better controls on noxious weeds and less severe forest fires.

This PEIS also considers the likely effects on public lands from reasonably foreseeable actions occurring on non-federal land. For example, development of non-federal land may potentially have direct impacts on terrestrial wildlife species that move between federal and non-federal habitats during the year or during their life cycle. The role of management of non-federal lands was considered in the analysis on these species and their associated ecosystems. Localized actions on non-federal lands often affect local environmental conditions on nearby federal land and may also affect federal management decisions.

In preparing the cumulative effects assessment, the BLM considered the magnitude and extent of BLM herbicide treatments in relation to herbicide treatments conducted by other federal and state agencies and private applicators, including treatments on privately-owned croplands and rangelands. The primary sources for this information were the BLM Pesticide Use Reports and the National Pesticide Use Database (Croplife Foundation 2006).

Based on the most recent information available for national pesticide use (2002), approximately 110 million pounds of herbicides were applied on nonfederal lands in the 17 western states evaluated in the PEIS (Table 4-33). Of this amount, approximately $80 \%$ of herbicides by weight were applied in croplands, with the remainder applied in pasturelands and rangelands. In comparison, the BLM applied approximately 115,500 pounds of herbicides in the western U.S. in 2002 (and 147,572 pounds in 2005). Other federal agencies that apply herbicides include the Forest Service $(82,703$ pounds applied during 2004 within 17 western states).

The National Center for Food and Agricultural Policy (2002) reviewed trends in herbicide, fungicide, insecticide, and other pesticide use between 1992 and 2002 based on pounds of active ingredient applied to agricultural rangelands and croplands. During that period, herbicide use declined $5.5 \%$, fungicide use declined $4.6 \%$, insecticide use declined $21.2 \%$, and other pesticide use increased $36.6 \%$ for the 17 western states. Overall pesticide use increased $2 \%$ during 1992 to 2002. Between 1997 and 2005, BLM herbicide use increased $2 \frac{1}{2}$-fold and would increase another 4 -fold (to about 650,000 pounds annually) under the Preferred Alternative. However, under the Preferred Alternative, BLM herbicide use would be only $0.2 \%$ of the total amount of pesticides that was applied to agricultural rangelands and croplands during 2002.

\section{Set of Receptors to be Assessed}

The set of receptors assessed in the cumulative effects analysis are the physical, biological, and human systems discussed in Chapter 3 (Affected Environment).

\section{Magnitude of Effects and Whether Those Effects are Accumulating}

The potential extent of the total cumulative effects (e.g., number of animals and habitat affected), and how long the effects might last (e.g., population recovery time) are estimated to determine the magnitude of effects that could accumulate for each resource. Where possible, the assessment of effects on a resource is based on quantitative analysis (e.g., level of risk to humans from use of an herbicide). However, many effects are difficult to quantify (e.g., animal behaviors; human perceptions) and a qualitative assessment of effects is made.

As suggested by the CEQ (1997) handbook, Considering Cumulative Effects Under the National Environmental Policy Act, this PEIS considers the following basic types of effects that might occur:

- "Additive" - total loss of sensitive resources from more than one incident.

- "Countervailing" - negative effects are compensated for by beneficial effects. 
TABLE 4-33

Herbicide Use in the Western United States for Agricultural Lands and BLM-administered Lands

\begin{tabular}{|l|c|c|}
\hline \multirow{2}{*}{ State } & \multicolumn{2}{|c|}{$\begin{array}{c}\text { Pounds of Herbicides Applied } \\
\text { (2002) }\end{array}$} \\
\cline { 2 - 3 } & $\begin{array}{c}\text { Non-federal- } \\
\text { administered } \\
\text { lands }\end{array}$ & $\begin{array}{c}\text { BLM- } \\
\text { administered } \\
\text { lands }\end{array}$ \\
\hline \hline Arizona & 920,369 & 4,933 \\
\hline California & $12,929,480$ & 2,621 \\
\hline Colorado & $4,565,041$ & 2,108 \\
\hline Idaho & $3,532,008$ & 2,826 \\
\hline Montana & $4,656,964$ & 8,193 \\
\hline Nebraska & $22,614,643$ & 5,379 \\
\hline Nevada & 55,648 & 35,854 \\
\hline $\begin{array}{l}\text { New Mexico, } \\
\text { Oklahoma, } \\
\text { and Texas }\end{array}$ & $25,159,648$ & 11 \\
\hline North Dakota & $14,192,512$ & 11,403 \\
\hline $\begin{array}{l}\text { Oregon and } \\
\text { Washington }\end{array}$ & $7,354,557$ & 279 \\
\hline South Dakota & $15,175,460$ & 18,066 \\
\hline Utah & 690,410 & 115,502 \\
\hline $\begin{array}{l}\text { Wyoming } \\
\text { and Nebraska }\end{array}$ & 704,570 & \\
\hline Total & $109,588,484$ & \\
\hline $\begin{array}{l}\text { Sources: Croplife Foundation }(2006) \text { and BLM Pesticide Use } \\
\text { Reports. }\end{array}$ & & \\
\hline
\end{tabular}

- "Synergistic" - total effect is greater than the sum of the effects taken independently.

The purpose of the analysis of cumulative effects in this PEIS is to determine whether the effects are additive or synergistic or have some other relationship. Additive (or combined) effects on specific resources often are difficult to detect and do not necessarily add up in the strict sense of one plus one equals two. It is much more likely that an additive or combined effect would be greater than one but less than two. A synergistic effect, in theory, is a total effect that is greater than the sum of the additive effects on a resource. To arrive at a synergistic effect in this example (continuing with the numeric analogy), the total cumulative effect would need to end up greater than two. In the highly variable western U.S. environment, where natural variations in population levels can exceed the impacts of human activity, such an effect would need to be much greater than the hypothetical two to be either measurable or noteworthy. A countervailing effect has both negative and beneficial components. For example, herbicide treatments would harm or destroy vegetation used by some species of wildlife (negative effect), but would improve overall ecosystem health and lead to improved watershed conditions and habitat for other wildlife (positive effect).

In the analyses that follows, effects should be considered to be additive in nature, unless otherwise noted. While synergistic impacts have been demonstrated in the laboratory (for certain types of chemical reactions, for example), there is almost no evidence of such impacts occurring when dealing with biological resources. Where synergistic impacts are not specifically accounted for in the analysis section, neither studies nor other information are available to support the identification of such impacts.

Herbicide formulations are a commercial mixture of both active and inert (inactive) ingredients. Inert ingredients are ingredients that are added to the commercial product (formulation) but are not herbicidally active. As part of the ERA, the BLM assessed the general risks to plants and animals from inert ingredients found in herbicide formulations and from adjuvants. The ERAs also addressed potential risks associated with:

- Adjuvants - Chemicals that are added to the herbicide formulation to enhance the toxicity of the active ingredient or to make the active ingredient easier to handle. They include surfactants, materials that improve the emulsifying, dispersing, spreading, wetting, or other surface-modifying properties of liquids.

- Degradates - physical or biological breakdown compounds of a complex compound.

Based on concerns raised by the Services and the public about adjuvants, degradates, and an issue not addressed in the Draft PEIS or BA-the potential for herbicides to be endocrine disrupting chemicals-the BLM prepared an Evaluation of Risks from Degradates, Polyoxyethyleneamine (POEA)) and R-11, and Endocrine Disrupting Chemicals for the Final PEIS (see Appendix D of the Final PEIS) that addressed the following questions:

- Some surfactants may be more toxic to aquatic receptors than the active ingredient in an herbicide. Using polyoxyethyleneamine (POEA) as an example, what are the potential impacts of surfactants in Roundup Original ${ }^{\mathbb{P}}$ and Honcho ${ }^{\circledR}$ applied with glyphosate? 
- The quantitative risk assessments only address the potential impacts of the active ingredients. What about the toxicity of degradates?

- The risk assessments did not identify endocrine disruption as a toxic endpoint. Are any of the herbicides considered to be endocrine disrupting chemicals?

The BLM ERAs also addressed potential risks associated with tank mixtures-the mixture of two or more compatible herbicides in a spray tank in order to apply them simultaneously.

The BLM used mixtures of two or more herbicides to treat approximately $25 \%$ of public lands during 2003 to 2005. The use of tank mixtures, along with the addition of an adjuvant (when stated on the label), may be an efficient use of equipment and personnel; however, knowledge of all products and their interactions is necessary to avoid unintended negative effects. The BLM evaluated tank mixtures to determine whether herbicide interactions can be classified as additive, synergistic, or antagonistic.

The analysis assumes that maintenance of past treatments has occurred, and that the BLM would make an investment in maintaining the condition achieved or the objectives of the project, rather than implementing stand-alone, one-time treatments. The analysis also assumes that the BLM would determine the need for the action based on past monitoring, and that additional monitoring would occur after the project to ascertain if effects are still accumulating or if the treatment has been effective in achieving the resource objective.

\section{Resource Protection Measures Considered in the Cumulative Effects Analysis}

The cumulative impacts assessment assumes that SOPs, monitoring measures, and mitigation developed by the BLM for the alternatives (see Chapter 2 of the PEIS and PER) would be adopted to protect environmental and socioeconomic resources on public lands.

In addition, a number of federal, state, local, and tribal resource management and monitoring programs have been established to protect environmental resources and, in cases where there is existing environmental impairment, to effect restoration. The assessment of cumulative impacts recognizes the existence of these programs and assumes that the mandate under which each program was established will continue. The cumulative effects analysis assumes that these programs effectively avoid or mitigate the environmental impacts that they are designed to address. The programs are discussed in the sections that follow.

\section{Air Quality}

Air quality is regulated under the PSD permitting process. For sources located in state waters and onshore, the PSD program is administered by the state air quality agencies. Although minor sources of air pollutants are not subject to PSD permitting requirements, the analysis of cumulative effects to air quality in this PEIS considers the contribution of both major and minor sources of air pollution in the western U.S., including and Alaska.

\section{Water Quality}

Water quality is regulated and/or monitored through various permitting and regulatory programs administered by the USEPA and state and local regulatory agencies. These programs have been established to protect against the significant degradation of water quality associated with specific human and development activities. In evaluating the cumulative effects to water quality, collective impacts associated with regulated and non-regulated activities and naturally occurring events are considered.

\section{Wetlands}

Wetland impacts are mitigated through SOPs, permits, and approvals issued at the project implementation stages (if needed), and under Section 404 of the Clean Water Act, administered by the USACE, and state certification programs to protect wetlands and ensure no net loss of wetlands, where practical.

\section{Essential Fish Habitat}

The amended Magnuson-Stevens Act requires federal agencies that authorize, fund, or conduct activities that may harm Essential Fish Habitat to work with NMFS to develop measures that minimize damage to EFH. By providing EFH conservation recommendations before an activity begins, NMFS may help prevent habitat damage before it occurs, rather than restoring habitat after the fact, which is less efficient, unpredictable, and often more costly. An analysis of EFH effects is provided as Appendix A in the Vegetation Treatments on Bureau of Land Management Lands in 17 Western States Programmatic Biological Assessment (USDI BLM 2006b). 


\section{Threatened and Endangered Species}

The Endangered Species Act of 1973 and the PEIS scoping process are appropriate vehicles to identify species that are potentially at risk from the incremental cumulative effects of activities that may occur under the PEIS and PER. Effects on listed species identified for the analysis area by NMFS and the USFWS under Section 7 of the ESA are covered by this cumulative analysis. The potential effects on each of the other species identified through scoping have also been reviewed and included, as appropriate.

\section{Environmental Justice}

Executive Order 12898, Federal Actions to Address Environmental Justice in Minority Populations and Low-Income Populations, and an accompanying Presidential memorandum require each federal agency to make the consideration of environmental justice part of its mission. The existing demographics (race and income) and subsistence consumption of plants and animals, and mitigating measures and their effects, are presented.

\section{Consultation and Coordination with Indian Tribal Governments}

Executive Order 13175, Consultation and Coordination with Indian Tribal Governments, requires consultation with tribal governments on "actions that have substantial direct effects on one or more Indian tribes." Representatives of the BLM have met with local tribal governments to discuss subsistence issues pertaining to the PEIS and PER (see Chapter 5, Consultation and Coordination), and have established a dialogue on environmental justice with these communities.

\section{Other Information Considered in Cumulative Effects Analysis}

The assessment of cumulative impacts from vegetation treatment activities also considered the following information and assumptions:

- Mitigation and SOPs identified in PEIS would be more stringent than those required by the USEPA.

- The BLM would comply with existing and future regulations, including FLPMA.

Ground-disturbing activities on public lands are conducted only after any necessary site-specific NEPA analysis has been completed. Such analyses are required to describe the cumulative impacts of the site-specific alternatives on adjacent lands and resources. This process provides opportunities to detect and minimize cumulative environmental effects that cannot be specifically determined at the broad level of this PEIS. Subsequent analyses will help ensure that the incremental and interactive effects on public lands would continue to be considered when implementing treatment actions.

\section{Analysis of Cumulative Effects by Resources}

\section{Air Quality}

Cumulative impacts to air quality could result from the emissions of particulates associated with wildfire, wildland fire use and prescribed fire, as well as particulates, hydrocarbons, and other byproducts of combustion associated with the use of equipment. Indirect impacts from air emissions include impacts to human health and global climate change. These impacts may be regionally additive (e.g., increased concentrations of specific pollutants) or synergistic (e.g., chemical reactions that form ozone). Technology has played an important role in reducing air emissions from engine operation, and an important reason for conducting prescribed burns is to better control smoke emissions and to reduce future smoke emissions associated with wildfire.

\section{Past Effects and Their Accumulation}

The cumulative effects of pollutant-producing activities in the past have led to deterioration in air quality in the western United States. Detailed information about the historic and existing air quality in the area covered by this PEIS is only available for monitoring sites and for criteria pollutants. In the undeveloped regions of public lands, ambient pollutant levels are expected to be low, and probably negligible in remote areas. On public lands on the Alaska North Slope and much of the remaining portions of Alaska, air quality is generally good, except during periods with Arctic haze (USDI BLM $2005 \mathrm{c})$. In general, locations in the treatment area with high ambient pollutant levels are areas that support commercial and industrial land uses (areas with large-scale mining operations, lumber mills, power plants or downwind from power plants, oil and natural gas extraction, etc.) and local population centers (areas with automobile exhaust, residential 
heating, etc).

Despite increases in human population and industrialization, emissions of principal air pollutants in the U.S., after peaking in the 1970s and early 1980s, have generally declined or held steady during the past 2 decades due to more stringent air quality regulations and improvements in pollution control technology (USEPA 2005). Particulate matter is the principal pollutant of concern, from a public health perspective, that is generated by fire. Emissions of particulate matter from all sources have trended lower since the 1970s. However, PM emissions nationwide have shown a close relationship with the number of acres burned annually by wildfire. Since 1990, PM emissions associated with wildfire have ranged from 145,000 tons in 1995 to 1.2 million tons in 2002; the number of acres burned by wildfires in 1995 was onethird the number of acres burned in 2002. The level of PM associated with slash and prescribed burning, however, has trended downward since the 1970s, and in 2001 (165,000 tons) was about half the level of the early 1990s. Based on an estimate of emissions generated by current vegetation treatment activities (primarily from fire and mechanical treatments; see Table 4-4 in PER), BLM treatment activities have accounted for less than $0.5 \%$ of criteria pollutant emissions nationwide.

\section{Future Effects and Their Accumulation}

Under the action alternatives, emissions associated with wildland fire use and prescribed fire and other treatment methods would be greater than those under the No Action Alternative. Still, emissions associated with BLM vegetation treatment activities would comprise less than $1 \%$ of total criteria pollutants generated nationwide. If the BLM were to achieve its goal of treating about 2 million acres annually using fire, annual emissions of PM from prescribed and wildland fire use on public lands would be similar to the total amount of PM emissions currently produced in the U.S. from prescribed fire, but would be only one-sixth the amount of PM produced by wildfires annually in recent years (USEPA 2005).

Although modeling was not done as part of the PER and PEIS to assess cumulative effects from use of fire and other treatment methods, modeling was done as part of a programmatic assessment of vegetation treatments in the Interior Columbia Basin of the Pacific Northwest (USDA Forest Service and USDI BLM 2000). Based on this assessment, the proposed increase in the amount of prescribed burning conducted as a part of forest and rangeland management on Forest Service- and BLMadministered lands over the 100-year planning period would be expected to reduce the amount of wildfire activity within the project area. In addition, the analysis revealed that wildfire impacts on air quality may be significantly greater in magnitude than emissions from prescribed burning. The lower emissions from prescribed fire are attributed to prescribed burning techniques that reduce emissions, as well as smoke management plans implemented by federal, state, and tribal agencies that permit prescribed fires only during meteorological periods favorable to dispersion. If the number of wildfires is reduced over time, air quality impacts from smoke should also be reduced.

Air quality modeling suggested that PM emissions from prescribed burning could cause regional-scale exceedances of the NAAQS based on the cumulative impacts from all sources of air pollution on ambient air. This modeling analysis also assumed that local analysis would be done to assess the possibility of localized exceedances of the NAAQS caused by prescribed burning emissions. Local analysis would also be done for activities conducted by the BLM under this PEIS.

It can be assumed that state smoke management meteorologists would consider the cumulative effects of emissions from other sources (such as road dust and agricultural dust and burning) during the development of daily smoke management instructions, and that state smoke management program managers would consider these sources during development of the smoke management plan submitted for approval (as a component of the state smoke implementation plan) to the USEPA.

The Forest Service modeled several scenarios to predict the long-term effect of treating more acres, and/or targeting treatments in the WUI, on regional air quality and the condition of the land (Hann et al. 2002). The model assumed that in addition to use of fire, mechanical and hand cutting would be important treatment options in the WUI, where air quality and other considerations could limit the use of fire. Based on this analysis, air quality would generally improve as the number of acres treated annually increased, with the most noticeable improvement in air quality associated with treatments targeted at high priority western U.S. WUI landscapes. Thus, the Preferred Alternative, which includes over 4.3 million acres of wildland and prescribed fire use and mechanical treatments, in addition to 1.7 million acres of treatments using other 
methods, would be expected to provide greater improvement in ecosystem function and air quality than is projected under current treatment levels.

The increased use of wildland fire use and prescribed fire proposed by the BLM parallels national trends. The National Wildfire Coordinating Group Fire Use Working Team sanctioned an interdisciplinary and interagency working framework for coordinating development of modeling and data systems to support balancing the increased use of prescribed fire in the context of reducing the local and regional impacts of fires on air quality (Sandberg et al. 1999; USDA Forest Service and USDI BLM 2000). A number of modeling and data system enhancements are currently under development by the Joint Fire Sciences Program of the USDA Forest Service and the USDI. These systems include the modeling of meteorological conditions and smoke dispersion. The Forest Service and BLM also have developed a data system to support prescribed burning and to assist states with emissions tracking under their respective state smoke management plans. The use of more sophisticated models during the implementation of prescribed burning, together with enhanced monitoring of emissions, will help minimize possible impacts from the use of prescribed fire. The inherent limitations of any model used at the programmatic scale highlight the importance of the cooperative development and use of operational smoke management models by the states, with assistance from the BLM, Forest Service, and the USEPA.

Most emissions on public lands in Alaska are associated with wildfire and wildland fire use, and oil and gas exploration and development on the North Slope in the National Petroleum Reserve - Alaska (USDI BLM 2005c). Long term, fire emissions would likely remain near current levels. Emissions on the North Slope are expected to decrease as a result of an overall downward trend in oil production; therefore, any possible contribution from local sources to air quality and Arctic haze would be reduced. Greater reliance on technologies that reduce the need for permanent roads and pads, and reduce the size of facility footprints, would also result in lower levels of PM emissions. Arctic haze has the potential to increase as Asian economies grow. Until air pollution concentrations in Asia and Europe begin to decline, Arctic haze is likely to persist or get worse.

\section{Contribution of Alternatives to Cumulative Effects}

As discussed under Air Quality in Chapter 4 of the PER, the majority of emissions would be associated with wildland fire use, and prescribed fire, and to a lesser extent, with mechanical treatments. Manual and biological control methods and herbicide treatments would contribute only small amounts of pollutants to the air. These emissions would accumulate and the amount of emissions released into the environment would be related to the number of acres treated and the type of treatment. Exceedances of NAAQS, however, should not occur under any alternative, and under all alternatives vegetation treatments would account for less than $1 \%$ of pollutants generated nationwide.

As discussed in Chapter 2 under Determination of Treatment Acreages, approximately 645,000 acres would be treated using wildland fire use and prescribed fire and 582,000 acres would be treated using mechanical methods under Alternative A (No Action Alternative). Approximately 2,107,000 acres would be treated using fire and 2,232,000 acres would be treated using mechanical methods under the Preferred Alternative. Under alternatives C, D, and E, approximately $1,055,000$ acres would be treated using fire, 1,986,000 acres would be treated using mechanical methods, 396,000 acres would be treated using manual methods, and 597,000 acres would be treated using biological control.

The Annual Emissions Inventory for BLM Vegetation Treatment Methods (ENSR 2005; included on the CD that accompanies the Final PEIS) found that annual emissions associated with prescribed fire and mechanical treatments for Alternative A were about $40 \%$ and $25 \%$ of those predicted to occur under the Preferred Alternative. Annual emissions for fire and mechanical treatment methods under Alternatives C, D, and $\mathrm{E}$ would be about $50 \%$ and $10 \%$ less, respectively, than those under the Preferred Alternative. Higher levels of fire treatments associated with the Preferred Alternative would increase smoke emissions and regional haze, although some of these impacts could be reduced by following proper smoke management procedures identified earlier in this chapter.

Although air emissions associated with vegetation treatments would be less under Alternatives A, C, D, and $\mathrm{E}$ than under the Preferred Alternative, gains in long-term air quality improvement are projected to be greater under the Preferred Alternative than under other alternatives, since more acres with hazardous fuels, 
dense forest cover, and invasive vegetation that contribute to wildfire would be treated under the Preferred Alternative than other alternatives.

The cumulative effects of all projects affecting the North Slope of Alaska in the past generally have caused little deterioration in air quality, which remains better than what is required by national standards. The amount of air pollutants generated should remain near current levels, and approximately 50\% lower than emission levels in the late 1980s (USDI BLM 2005c). Improvements in air pollution control technology would also help to reduce emissions from current levels.

\section{Soil Resources}

\section{Past Effects and Their Accumulation}

Cumulative impacts to soils on public lands and throughout the western U.S. have occurred from human-caused disturbance factors, including natural resource extraction, grazing, road construction, timber harvesting, OHV and other recreation use, agriculture, and development, as well as natural disturbances. More recently, large-scale, uncharacteristic wildfires have increased the number of landscapes with declining soil productivity by causing a reduction in effective vegetative ground cover and a loss of root strength, which has resulted in increased soil erosion rates (USDA Forest Service and USDI BLM 2000). Soils in the western U.S. are generally stable in wilderness areas, but in other locations soils are at varying levels of decreasing productivity depending on soil types and intensity of management. Determining the exact soil conditions in any given area is difficult because of the lack of inventory and monitoring data. In general, greater declines in soil productivity are directly associated with greater loss of soil through erosion and displacement, loss of soil organic matter, changes in vegetation composition, removal of whole trees and branches, and increases in bulk density from compaction.

Soil productivity may currently be higher in areas where fire has been suppressed and where organic matter and vegetation have not been removed. However, the unnaturally high amounts of vegetation and large woody material put these areas at risk for uncharacteristic fire intensity and severity, which can lead to decreased soil productivity because of high rates of erosion, loss of organic matter, woody material, and nutrient reservoirs.
In Alaska, non-oil and gas activities associated with villages, towns, and military sites have disturbed soils on public lands. Since the 1970s, oil and gas exploration and development have been the dominant soildisturbing activities associated with public, other federal, state, tribal, and private lands on the North Slope. On the North Slope, direct impacts to soil and soil productivity persist on over 12,000 acres (USDI BLM 2005c). Another 18,000 acres of indirect impacts have occurred, some of which persist today.

\section{Future Effects and Their Accumulation}

As discussed earlier in this chapter, vegetation treatments could occur on 6 million acres. Loss of vegetation and soil disturbance associated with use of treatment equipment could cause some short-term loss of soil functions, process, and productivity on nearly all treated land. However, it is assumed that watershedlevel restoration treatments designed and implemented by the BLM and other federal agencies with large landholdings in the West would achieve long-term effects similar to those occurring under historical disturbance regimes (USDA Forest Service and USDI BLM 2000). The disturbance effects resulting from restoration activities are predicted to have less impact and be less severe than fire effects and erosion caused by past fire exclusion and traditional management activities. Monitoring and evaluation, integrated with adaptive management and sustainable use practices, would result in adjustments to treatment design and implementation and restoration actions in order to reduce soil disturbance to levels similar to historic conditions.

Studies in forested and rangeland environments have suggested that landscapes that contain native plant communities in natural mosaic patterns and have relatively uninterrupted natural disturbance regimes provide favorable conditions for soil functions and processes that contribute to long-term sustainability of soil productivity (Munn et al. 1978, Cannon and Nielsen 1984, and Hole and Nielsen 1970 cited in USDA Forest Service and USDI BLM 2000). In addition, a reduction in the spread of exotic and invasive vegetation is expected to help maintain soil productivity and function. Forests and rangelands with conditions outside the historical range of vegetation variability are most vulnerable to accelerated nutrient loss from management activities or wildfire.

In recent years, a number of policies, programs, and initiatives have been proposed to restore soil productivity and improve the health of ecosystems by 
the BLM and other federal, state, and local land management entities to meet nationwide and regionwide conservation goals. These include the National Fire Plan, Healthy Forests Restoration Initiative, this PEIS, the Interior Columbia Basin Ecosystem Management Project, the Great Basin Restoration and Conservation of Prairie Grasslands initiatives, the sage-grouse conservation program, and the program to treat invasive vegetation on Forest Service lands in the Pacific Northwest (USDA Forest Service and USDI BLM 2000, USDA Forest Service 2005, USDI BLM 2006c). The success of these policies and programs to restore healthy ecosystems will depend in part on future funding levels, and on our understanding of soil processes and our ability to develop and implement vegetation management projects that are effective and lead to long-term improvement in soil and other ecosystem resources. Much of the focus of these efforts is on reducing hazardous fuels and wildfire activity in the West. In addition, conservation programs and best management practices to reduce soil loss in agricultural areas have been developed and implemented during the past several decades. Although gains in soil productivity have been slow, improvement has been observed.

Changes in disturbance regimes, such as changes resulting from fire suppression, introduction of nonnative plant species, timber management practices, human populations and related activity, minerals extraction, and livestock grazing over the past 100 years, have caused a departure from the historical ranges of vegetation composition and structure and landscape mosaic patterns. Still, in a study of the Interior Columbia Basin, soil disturbance on approximately $92 \%$ of federally-administered lands was rated as none to low. Nationwide, the estimated average annual loss of soil due to erosion associated with rainfall and wind on non-federal lands has decreased by about a third from levels in the early 1980s; similar trends have been seen in the western states (National Resources Conservation Service 2000). These data suggest a need for improvement in soil productivity and rangeland conditions throughout the West, but also suggest that long-term improvement in soil productivity in the West can occur under careful stewardship of lands.

\section{Contribution of Alternatives to Cumulative Effects}

Based on the number of acres treated, short-term impacts to soil function and productivity would be greatest under the Preferred Alternative (approximately 6 million acres for all treatments), and least under the
No Action Alternative (1.9 million acres). The number of acres treated under Alternatives D and E (about 4.5 million acres each) would be similar, and short- and long-term effects under these two alternatives would be similar, while the effects under Alternative C ( 4 million acres) would be intermediate between those under these alternatives and the Preferred Alternative. Treatments would occur on about $2 \%$ of public lands annually under the Preferred Alternative.

During FY 2005, the BLM applied approximately 0.9 pounds of herbicide per acre treated. Based on this ratio, the BLM would apply about 840,000 pounds of herbicides annually under the Preferred Alternative, about half this much under Alternatives D and E, and about a third as much under Alternative A. Although the BLM would contribute only about $0.1 \%$ of the amount of pesticides applied annually in the western U.S., these herbicides would accumulate in the soil at a greater rate than presently occurs. Most herbicides that would be applied by the BLM have a soil half-life of 60 days or less, although the soil half-life for diquat is about 1,000 days.

Alternative E places greater emphasis on passive restoration than the other alternatives. Poorly planned or managed livestock grazing, forestry practices, minerals development, and OHV use are just some of the activities that can lead to loss of soil productivity and cause soil erosion. The BLM would also use passive restoration to improve soil conditions, but would have to balance soil protection and improvement with the multiple use requirements under FLPMA. As discussed in Chapter 2, Vegetation Treatment Programs, Policies, and Methods, passive restoration would be considered first when developing restoration management plans, and would be used to the extent possible within the constraints of FLPMA.

Short-term effects to soils could accumulate under all alternatives, but if treatments were successful, a countervailing effect of long-term improvement in soil function and productivity should more than offset shortterm soil losses. Largest improvements are expected for the Preferred Alternative and Alternatives D and E.

\section{Water Resources and Quality}

Watersheds are natural divisions of the landscape and the basic functioning units of hydrologic systems. The BLM conducts monitoring of watersheds on public lands and bases the success of its treatments on the condition of watersheds and their subbasins (USDI BLM 2006c). Stream flow regimes and water quality 
can be affected by modifications to watershed processes occurring as a result of both natural disturbances and land management activities. Water quality and quantity, which are key components of wetland and riparian habitat, can also have substantial influence over the health of fish and other aquatic organisms. They are components over which the BLM has some degree of influence on public lands (USDA Forest Service and USDI BLM 2000).

Section 303(d) of the Clean Water Act requires that water bodies violating state water quality standards and failing to protect beneficial uses be identified and placed on a 303(d) list. The delisting of 303(d) listed streams is a priority of the BLM. Nonpoint source pollution, which is the largest source of water quality problems on public lands, comes from diffuse or scattered sources rather than from an outlet, such as a pipe, that constitutes a point source. Sediment is a nonpoint source of pollution that results from activities such as grazing and timber harvest, and from erosion associated with wildfires and the spread of noxious weeds. Erosion and delivery of eroded soil to streams is the primary nonpoint source pollution problem of concern to the BLM.

\section{Past Effects and Their Accumulation}

Problems associated with water quality in the western U.S. were first recognized in the $19^{\text {th }}$ century when mining in California was polluting the water so greatly that crops could not be grown. Exploration and development of oil resources later contributed to water quality concerns, especially in California, Oklahoma, and Texas. New sources of pollution arose in the $20^{\text {th }}$ century, including pollutants associated with agriculture (e.g., fertilizers, pesticides, and animals wastes), industry, and other human activities (e.g., sewage, household cleaning products, pollutants associated with automobiles). In 1999, the USEPA released its first ever national index on the quality of the nation's watersheds. The USEPA also conducted an assessment of general groundwater quality (based on concentration of TDS). Based on these assessments, $21 \%$ of the watersheds have serious problems. In watersheds in the West, water quality is poor to moderate over many areas (based on concentration of TDS for groundwater), primarily in areas associated with agricultural activities. Thus, actions that further deteriorate water quality or watershed health must be carefully evaluated before being implemented on public lands (Wright 2002).

Minor cumulative effects to water resources have occurred on public lands in Alaska. Cumulative effects to water resources from oil and gas exploration, gold placer mining, and other development have included: 1) disturbance of stream banks and beds or lake shorelines; 2) melting of permafrost (thermokarst erosion); 3) temporary blockages of natural channels and floodways during construction of roads and pipelines that have resulted in the disruption of drainage patterns; 4) increased erosion and sedimentation in rivers and lakes; 5) removal of water from lakes for ice roads and pads; 6) spills; 7) removal of gravel from riverine pools and lakes; and 8) extensive erosion of off-road trails (USDI BLM 2005c).

The Clean Water Act of 1972 was intended to solve many of the nation's water pollution problems, but has had only modest success. In 1972, a third of the nation's rivers were safe for fishing and swimming. That number improved to more than $50 \%$ in the $1980 \mathrm{~s}$, but began to fall in the 1990s. The primary cause for deteriorating conditions in the 1990s was agricultural and municipal wastes rather than industrial wastes. (The standard for classifying deteriorating conditions has also changed over that time.) An estimated 14.1 million Americans drink water that contains agricultural pesticides in amounts that would exceed the acceptable concentrations for food products (Wright 2002).

Past land management activities on private and public lands in the western U.S. have contributed to deterioration in water quality. The spread of invasive plant species is one factor that degrades hydrologic function. In addition, buildup of hazardous fuels can lead to wildfires that adversely impact water resources and quality. Changes in hydrologic function have occurred as a result of changes in flow regimes due to dams, diversions, and surface water and groundwater withdrawal; and as a result of changes in channel geometry due to sedimentation and erosion, channelization, and installation of roads and railroads. Large amounts of wetland and riparian habitat, which function to cleanse water and recharge groundwater aquifers, have been lost in the West due to agriculture and urbanization. Over 109 million pounds of pesticides are applied annually in the western U.S.; these chemicals affect water quality.

During the early years of the BLM, most resource conservation and management was focused on upland sites. An increased emphasis on wetland and riparian habitat protection began in the 1960s with the passage of the Water Resources Research Act and Water Resource Planning Act (1965), which allowed the BLM to increase watershed research and planning. Much of the early work consisted of identifying lands in the critical stages of erosion (Muhn and Stewart 1988). In 
the 1970s, FLPMA was passed (1976) and the BLM began preparing land use plans to better manage natural resources.

\section{Future Effects and Their Accumulation}

Despite spending nearly $\$ 1$ trillion to improve water quality since the enactment of the 1972 Clean Water Act, the United States has no adequate database for water quality. Water quality monitoring is done by state and federal agencies, local governments, tribes, and others, among which there is wide variance in the extent and types of monitoring (Hayward 2005). Additionally, the nature of the resource presents challenges because the effects of both natural and man-made contaminants vary greatly according to specific water conditions. Researchers must account for water source, velocity, volume, depth, $\mathrm{pH}$, photosynthetic activity, seasonal variations, and even time of day to accurately measure water quality. Thus, predicting the extent and magnitude of future effects to water resources and quality is difficult.

In its 2001 Annual Performance Plan (USDI BLM 2000e), the BLM eommitted to 1) implementing water quality improvement prescriptions on public lands in $20 \%$ of watersheds within priority sub-basins that do not meet state/tribal water quality standards; 2) achieving proper functioning condition or an upward trend in wetland/riparian areas in $80 \%$ of priority watersheds by cooperating with the Forest Service and other land management agencies to restore degraded wetland and riparian areas; and 3) achieving an upward trend in the condition of uplands within $50 \%$ of priority watersheds by reducing the spread of weeds and reintroducing fire into specific landscapes. Generally, high priority watersheds are those that have impaired water bodies.

According to an Office of Management and Budget Program Assessment Rating Tool, in 2005 the BLM had met or was making measurable progress toward meeting its goals. The OMB assessment noted that the BLM was challenged by the need to meet multiple land use objectives, such as allowing oil and gas development that may conflict with restoration objectives (Office of Management and Budget 2005).

Based on information provided by field offices, the BLM would treat about 300,000 acres to improve watershed, and another 30,000 acres to improve wetland and riparian area functions and values. These types of treatments are not proposed for Alaska. Efforts to restore natural disturbance regimes, reduce the potential for large-scale wildland fire, and manage and control noxious weeds and other invasive vegetation would help to reduce erosion and sedimentation and restore native plant communities. In addition, the ability of the BLM and other resource-protection entities to use new herbicides, such as fluridone and imazapic, to control weeds would benefit public lands with minimal risk to drinking water, human health, and fish and wildlife.

Gravel mining, construction of roads, permanent drill pads, and water use from lakes during the winter months would be the major contributors to water resource impacts in Arctic Alaska. Impacts from activities such as gold mines in placer gravels, deteriorated $\mathrm{OHV}$ trails, and fires and fire control are the major contributors in the rest of the state. Because of the abundance of water resources in Alaska, the overall cumulative impact to water resources on public lands in Alaska would probably be small in magnitude, and most effects would be local in nature.

\section{Contribution of Alternatives to Cumulative Effects}

Based on the number of acres treated, short-term adverse impacts and long-term improvements to hydrologic function and water quality would be greatest under the Preferred Alternative (approximately 6 million acres for all treatments), and least under the No Action Alternative (1.9 million acres). The number of acres treated under Alternatives D and E (about 4.5 million acres each) would be similar, and short- and long-term effects under these two alternatives would be similar, while the effects under Alternative C (4 million acres) would be intermediate between those under these alternatives and the Preferred Alternative. In addition, approximately twice as many acres would be treated using prescribed and wildland fire under the Preferred Alternative (2.2 million acres) than under alternatives C, $\mathrm{D}$, and $\mathrm{E}$ (1.06 million acres), and three times as many as compared to the No Action Alternative $(645,000$ acres). It is anticipated that use of fire and herbicides would have the greatest short-term impact on water quality and quantity and watershed conditions. Adverse effects to water quality from wildfire and spread invasive species would accumulate in the West, but if BLM and other public and private vegetation treatment efforts were successful, a countervailing effect of longterm improvement in water resources and quality should help than slow losses. Improvements in water resources and quality should be greatest for the Preferred Alternative and Alternatives D and E. 
Based on recent herbicide use, the BLM would apply about 652,000 pounds of herbicides annually under the Preferred Alternative, about half this much under Alternatives D and $\mathrm{E}$, and about a third as much under Alternative A. This would amount to about $0.6 \%$ of the amount of pesticides applied annually in the western U.S. based on the Preferred Alternative. An increase in use of herbicides, regardless of source, would contribute to loss of water quality both on and off public lands, as these herbicides have the potential to move off site in surface water or groundwater. The movement of herbicides off public lands could contaminate public drinking water sources and water sources used by fish and wildlife. However, the use of newer herbicides by the BLM that pose fewer risks to humans and fish and wildlife, and strict adherence to buffer guidelines given in the PEIS, PER, ERAs, and HHRA during treatments to protect water resources, should mitigate for some of the loss in water quality. Alternative E places greater emphasis on passive restoration than the other alternatives. Passive restoration is often an important first step in improving watershed health because the anthropogenic activities that are causing degradation or preventing recovery are reduced or eliminated. Livestock grazing and OHV use are often cited as factors that lead to loss of wetland and riparian habitat function and watershed degradation. By prohibiting livestock from entering wetland and riparian areas, and placing limits on OHV activity, improvement in watershed function can be expected (Kauffman et al. 1997). Improvements in the management of these activities can also reduce potential impacts to wetland and riparian areas, and the BLM would have to balance watershed protection with the multiple use requirements under FLPMA. As discussed in Chapter 2, Vegetation Treatment Programs, Policies, and Methods, passive restoration would be considered first when developing restoration management plans, and would be used to the extent possible within the constraints of FLPMA.

Regardless of the alternative chosen, there would be an accumulation of loss of water resources and quality under all alternatives, but the rate of loss would be expected to slow from historic levels over the long term.

\section{Wetland and Riparian Areas}

Under natural conditions, wetland and riparian plant communities have a high degree of structural and species diversity, reflecting past disturbances from floods, fire, and fish and wildlife use (Gregory et al. 1991). Since European settlement, many wetland and riparian areas have been drained or altered and their functions and values lost or reduced. The Clean Water
Act (1972) and Executive Order 11990, Protection of Wetlands and Floodplains (1977), identified the importance of wetland and riparian areas and directed federal and state agencies to focus more attention on the health of these areas. As a result of legislative and policy guidance, the BLM and other land management entities have spent considerable effort and money to restore wetland and riparian functions and values during the past several decades.

\section{Past Effects and Their Accumulation}

Cumulative impacts to wetland and riparian areas on public lands and throughout the western U.S. have occurred from human-caused disturbance factors, including natural resource extraction, recreation, dams and diversions, road construction, agriculture, urbanization, and fire exclusion. An estimated 53\% of wetlands present at the time of colonization in the lower 48 states have been lost in the U.S., but less than $0.1 \%$ have been lost in Alaska. The USFWS estimates that about 117,000 acres of wetlands were lost annually between 1985 and 1995 (Wright 2002), while the USEPA has estimated wetland losses on non-federal rural lands at approximately 70,000 to 90,000 acres annually (Washington State Department of Ecology 2005).

Today, the BLM's annual budget for wetland and riparian management is nearly $\$ 22$ million (USDI BLM 2006b). Program priorities include identifying priority watersheds on which to focus restoration efforts, with special emphasis on watersheds that contain habitat for sage-grouse. The BLM spent an additional \$13 million in FY04 assessing the condition of watersheds and conducting restoration efforts in areas that are less than properly functioning (USDI BLM 2006c).

Even with these efforts, $25 \%$ of wetlands surveyed on public lands in the lower 48 states are not functioning properly or are functioning at risk (USDI BLM 2006c), while $50 \%$ of riparian areas are non-functional, or are functioning at risk. The poorest functioning riparian areas are found in the southwest and Montana, while most riparian areas in Alaska, Colorado, and Utah function properly. High sediment and turbidity levels and high temperatures are the primary reasons for listing wetlands and riparian areas as not functioning properly (USDA Forest Service and USDI BLM 2000; USDI BLM 2006b). In addition to water quality and flow concerns, many wetlands and streams have lost the capability to support salmonids and other aquatic organisms. 
The spread of invasive plant species is one factor that degrades wetland and riparian function. In addition, hazardous fuels buildup can lead to catastrophic wildfires that adversely impact wetland and stream habitat. Within riparian woodlands, the abundance of mid-size trees has increased while the abundance of trees in other size categories has decreased, primarily due to fire exclusion, increasing the risk of wildfire and reducing the value of these habitats to fish and wildlife. Within riparian shrublands, there has been extensive conversion to riparian herblands and increases in exotic grasses and forbs, primarily because of processes and activities associated with excessive livestock grazing. This conversion has made these shrublands more susceptible to fire and reduced their value to fish and wildlife (USDA Forest Service and USDI BLM 2000).

\section{Future Effects and Their Accumulation}

The rate of loss of wetland and riparian habitat in the West has slowed, and on public lands there has been some improvement in the functional quality of these areas. For example, the percentage of wetland and riparian areas in the lower 48 states that lack the characteristics necessary for high function has decreased by about 10\% since 1996 (USDI BLM 1997, USDI BLM 2006d). Vegetation treatment programs proposed by the BLM and Forest Service, and similar efforts by other agencies, private landowners, and private entities (e.g., Ducks Unlimited, The Nature Conservancy) to protect and preserve wetland and riparian habitat, should restore wetland and riparian habitat and health over the long term. In the Interior Columbia Basin, proposed treatment efforts could improve aquatic habitat capacity by $50 \%$ over 100 years (USDA Forest Service and USDI BLM 2000).

Efforts to restore natural disturbance regimes, reduce the potential for large-scale wildland fire, and control noxious weeds and other invasive vegetation should help to reduce erosion and sedimentation and restore native plant communities. In addition, the ability of the BLM and other resource-protection entities to use new herbicides, such as fluridone, to control aquatic weeds would benefit lakes and ponds and the aquatic organisms that use these habitats. In Alaska, early detection and control of weeds would be effective in protecting wetland and riparian habitat, as the state does not yet face a severe weed problem as in the lower 48 states (Hebert 2001).

\section{Contribution of Alternatives to Cumulative Effects}

Based on the number of acres treated, short-term adverse impacts and long-term improvements to wetland and riparian area function and productivity would be greatest under the Preferred Alternative, and least under the No Action Alternative. The number of acres treated, and short- and long-term impacts, under alternatives $\mathrm{D}$ and $\mathrm{E}$ would be similar, while Alternative $\mathrm{C}$ would be intermediate between these alternatives and the Preferred Alternative. Treatments would occur on about 10,000 and 2,300 acres of wetland and riparian habitat annually under the Preferred Alternative under the No Action Alternative, respectively. Short-term effects could accumulate, but if treatments were successful, a countervailing effect of long-term improvement in wetland and riparian area function and productivity should more than offset short-term losses.

Herbicide treatments would not be allowed under Alternative C. Therefore, control of some aquatic weeds, including giant salvinia, water-thyme, and Eurasian watermilfoil could be difficult, as mechanical and other treatment methods would be less effective. Under alternatives $C$ and $D$, it could be difficult for the BLM to adequately treat weed infestations in remote areas and large weed infestations to benefit aquatic organisms. Thus, the risk of loss of aquatic habitat and habitat function in more remote areas could be greater under these alternatives than under the Preferred Alternative.

Alternative $\mathrm{E}$ places greater emphasis on passive restoration than the other alternatives. Passive restoration is often a critical first step in successful riparian or wetland area restoration because the anthropogenic activities that are causing degradation or preventing recovery are reduced or eliminated. Livestock grazing is often cited as a factor that causes loss of wetland and riparian habitat function; by prohibiting livestock from entering these areas, improvement in habitat function can be expected (Kauffman et al. 1997). However, the BLM must balance wetland and riparian habitat protection with the multiple use requirements under FLPMA. Therefore, the BLM modifies the timing and duration of grazing to reduce potential impacts, rather than implementing total exclusion, whenever possible. As discussed in Chapter 2, Vegetation Treatment Programs, Policies, and Methods, passive restoration would be considered first when developing restoration management plans, and would be used to the extent possible within the constraints of FLPMA. 
Regardless of the alternative chosen, there would be an accumulation of loss of wetland and riparian functions and values under all alternatives over the short term, but the rate of loss would be expected to slow from historic levels, over the long term, if the BLM was successful in improving wetland and riparian habitat functions and values.

\section{Vegetation}

Historically, ecosystems on public lands were comprised of a mosaic of vegetation types adapted to natural disturbances, including climate, fire, flood, and geological events. They were dynamic and resilient, tending to return to some developmental pathway when disturbed or changed. However, ecosystems have biological or physical limits that, if exceeded as a result of natural or human causes, can lead to deterioration in ecosystem health. If these limits are exceeded for extended periods of time, the characteristics of the ecosystem can change, often substantially, to the detriment of the ecosystem.

\section{Past Effects and Their Accumulation}

North America has been occupied by Native peoples for at least 12,000 years (USDI BLM 2005c). Contrary to the beliefs of European emigrants arriving in the western U.S. in the $18^{\text {th }}$ century, western lands at that time were not pristine wilderness but ecological systems in which humans were an active component. American Indians used fire as a tool to manage vegetation. As Euroamericans moved west, they reshaped ecosystems to meet their needs. They cleared forests for agriculture and grazed livestock, fragmenting landscapes and changing plant and animal species composition. As people settled areas, they built homes and other structures, and began suppressing fires to protect their property. The resultant fire exclusion promoted aging forests and shrublands, insect and disease outbreaks, an overaccumulation of fuel, and a consequent increase in fire severity and intensity. The disruption of natural fire cycles in fire-adapted ecosystems became the dominant agent of change that initiated an increased wildland fire risk (Hann et al. 2002).

Most rangelands have experienced significant changes in fire regimes during the past 150 years. Removal of the use of fire by native Americans would have significantly changed fire regimes for many rangelands. Some rangelands have experienced reductions in herbaceous cover and increased dominance of woody species, resulting in a lengthening of the fire return interval. Other rangelands have shorter fire return intervals, primarily as a result of wildland fire disturbances that created conditions favorable for exotic species' invasions.

Previously, wildland fire had maintained grasslands by rejuvenating decadent grasses and killing young woody species that might have seeded between fire occurrences. Although woody species would have increased based on reductions in the frequency of fires alone, other factors also contributed to these changes. During the late 19th and early 20th centuries, decreases in grass cover caused by overgrazing by livestock provided open sites that promoted more rapid establishment of woody species. As woody species increased, they competed for soil nutrients and moisture, which inhibited recovery and production of herbaceous cover. Because combustible vegetation became patchier, fire frequency continued to decrease on these sites.

Later in the 20th century, organized fire suppression further contributed to the invasion of grasslands by woody species and the increased density of woodlands and shrublands. Some rangeland sites lost much of their herbaceous ground cover. On some sites, this loss of ground cover resulted in increased wind and water erosion. Erosion further reduced herbaceous cover, perpetuating the cycle of degradation. During the 20th century, many of these rangelands also provided suitable sites for non-native species establishment. Invasive herbaceous non-native species affect rangeland fire regimes much differently than invasive woody species. Many non-native annual plant species dry out earlier than native perennials, prompting a longer annual flammable period. The longer flammable season, coupled with denser ground cover typical of these nonnative species, triggers much more frequent fire. In many cases, each time a fire occurs, additional opportunities for the establishment of non-native species are created. The result is a cycle of ecosystem degradation and costly, unwanted wildland fires.

Fire exclusion and historical logging practices altered forest structure, species composition, and associated fire regimes, particularly in forest types with high frequency fire regimes. Fire suppression efforts began influencing forest structure and composition more than 100 years ago. In the absence of fire, understory trees became much denser in dry forest types. In these areas, understories shifted to species that were more shadetolerant and less resistant to fire and drought cycles. As these forests aged, resistance further declined and they becamc increasingly susceptible to insect and disease outbreaks. As a result, wildland fires in these degraded 
forests burned more severely and became more difficult to control.

Natural reseeding and well-intentioned, aggressive planting programs also helped create dense stands of smaller trees and brush where forests of large trees had once existed. Although mechanical thinning and slash treatment programs were planned for many of these plantations, funding for these activities did not keep pace with the need to reduce stand density.

Today, forest structure on significant portions of federal lands has shifted to a dominance of these small, more closely spaced trees. As these stands age, they become susceptible to, and provide fuel for, intense wildland fire (USDA Forest Service and USDI BLM 2000).

In some forests and woodlands, logging, grazing, and unnaturally severe fires have also contributed to increases in non-native plants, insects, and pathogens. The invasion of non-native plants has caused various impacts to ecosystems, including displacement and endangerment of native species, reduced site productivity, and degraded water quality.

Since the 1970s, the interior West's population has increased more rapidly than the country at large. As human populations continue to grow in the WUI, even more people and their property will be at risk from unwanted wildland fires. The vegetation in many of these interface areas, where wildland fire now poses the greatest threat to human lives and values, evolved with fire.

Actions taken by the BLM and other land management agencies to restore watersheds and ecosystem health by treating invasive vegetation and reducing hazardous fuels can reverse the trend of increasing risk of unwanted wildland fire and deteriorating land health. For example, in 1986, the BLM reported that only $34 \%$ of public land was in excellent or good condition (Forest Service 1989). Today, approximately $42 \%$ of public land is considered to be in excellent or good condition (USDI BLM 2006c).

\section{Future Effects and Their Accumulation}

Treatments that remove hazardous fuels from public lands would be expected to benefit the health of plant communities in which natural fire cycles have been altered. Treatments that restore and maintain fireadapted ecosystems, through the appropriate use of mechanical thinning, fire, and other vegetation treatment methods, would decrease the effects of wildfire on plant communities and improve ecosystem resilience and sustainability. Treatments should also reduce the incidence and severity of wildfires across the western U.S. (USDA Forest Service and USDI BLM 2000). Treatments that control populations of nonnative species on public lands would be expected to benefit native plant communities by reducing the importance of non-native species and aiding in the reestablishment of native species.

Over half the treatments would occur in the Temperate Desert Ecoregion. Much of this ecoregion is comprised of grasslands and shrublands that have altered fire regimes, have suffered catastrophic fires during the past decade, and are dominated by downy brome and other invasive species. Recovery to pre-fire conditions could take decades to centuries. Treatments would improve the mix of habitats so that vegetation would be more resilient to disturbance and sustainable over the long term. Treatments would reduce the encroachment and density of woody species in shrublands and/or herblands. Treatments would slow the spread of weeds and increase the number of acres dominated by bunchgrasses and other important forage species for wildlife and livestock. As a result, plant communities that have declined substantially in geographic extent from historical to current periods (e.g., big sagebrush and bunchgrasses) would increase. Treatments would not be implemented in shrublands and other communities with the potential to become dominated by downy brome. In situations where loss of native understory has occurred, such as in pinyon-juniper woodlands, and prescribed fire is desired to remove woody vegetation after mechanical treatments, analysis should show that reseeding and possibly application of a selective herbicide can be effective to restore desired native species.

Given the current rate of urbanization and degradation of privately-owned lands and the limited funding available to restore public and other publicly-owned lands, the extent of weeds and other exotic and undesirable plants would continue to increase, but the rate of expansion would slow (USDA Forest Service and USDI BLM 2000). Based on modeling done for development of the cohesive strategy and assuming vegetation treatment funding would remain near current levels, the cumulative number of acres of site degradation within 15 years from severe wildland fires and invasive plants would triple from current levels. However, even in that short time frame, risk to watersheds would only increase by one-fifth under the proposed program (assuming equal weighting of 
treatments in the WUI and non-WUI), and would remain static if more emphasis was given to restoring natural fire regimes and healthy ecosystems in the nonWUI $(67 \%$ of treatments in non-WUI; Hann et al. 2002). Modeling done for treatments of BLM- and Forest Service-administered lands in the Interior Columbia Basin, which encompasses much of the Pacific Northwest, showed that over a 100-year analysis period, there would be a decrease in vegetation types that are most susceptible to fire, insect, and disease risks, and an increase in vegetation that is more resilient to these risks if treatments similar to those proposed in this PEIS were implemented (USDA Forest Service and USDI BLM 1996).

\section{Contribution of Treatment Alternatives to Cumulative Effects}

Based on the number of acres treated, short-term adverse impacts and long-term improvements to vegetation would be greatest under the Preferred Alternative, and least under the No Action Alternative. The total number of acres treated, and the effects to vegetation would be similar under Alternatives $\mathrm{D}$ and $\mathrm{E}$. Effects to vegetation under Alternative $\mathrm{C}$ would be intermediate between these alternatives and the Preferred Alternative.

It is anticipated that the use of wildland and prescribed fire and herbicides, and mechanical methods, would have the greatest short term impacts on vegetation, and that impacts would be somewhat in proportion to acres treated. Approximately three times as many acres would be treated annually using herbicides under the Preferred Alternative than under the No Action Alternative, and about twice as many acres would be treated using herbicides under the Preferred Alternative than under alternatives D and E. No acres would be treated using herbicides under Alternative C. In addition, approximately twice as many acres would be treated using prescribed and wildland fire under the Preferred Alternative (2.2 million acres) than under alternatives $\mathrm{C}$, $\mathrm{D}$, and $\mathrm{E}$ (1.06 million acres), and three times as many as compared to the No Action Alternative $(645,000$ acres). Acres treated using mechanical methods would be similar among alternatives B, C, D, and E (about 2 million acres annually), and greater than for the No Action Alternative (about 582,000 acres annually).

Alternative $\mathrm{E}$ places greater emphasis on passive restoration than the other alternatives. Passive restoration is often considered a critical first step in successful restoration of degraded areas, since anthropogenic activities that are causing degradation or preventing recovery are halted. As discussed at the beginning of the cumulative effects section, passive restoration would be considered under all alternatives when developing restoration management plans, and would be used to the extent possible within the constraints of FLPMA. However, alternatives A through D would likely take a more aggressive approach to vegetation management than Alternative $\mathrm{E}$.

All alternatives include both passive and active management. Recovery of vegetation through passive management is expected to take longer than under active management, where treatments such as seeding with native species, establishing intermediate vegetation to control erosion, and use of pre-emergent herbicides to prevent weed establishment would be expected to promote faster recovery.

The use of ever greater amounts of herbicides and their repeated use may result in weed populations that develop a resistance to a particular herbicide over time. This risk would be greatest under the Preferred Alternative and least under Alternatives $\mathrm{C}$ and $\mathrm{A}$. Herbicide resistant plants are present in a population in extremely small numbers. The repeated use of one herbicide allows these few plants to survive and reproduce. The number of resistant plants then increases in the population until the herbicide no longer effectively controls the weed. To reduce this risk, the BLM would 1) rotate herbicides, 2) apply these herbicides with the understanding that they can lead to weed resistance if used yearly for several consecutive years, 3) use mechanical and biological management options to eliminate weed escapes that may represent the resistant population, 4) use passive methods of weed control to reduce or eliminate factors leading to the spread of weeds, and 5) keep accurate records of herbicide application.

Regardless of the alternative chosen, there would be a cumulative loss of native vegetation function. Over the long term, treatments should restore native vegetation and natural fire regimes and benefit ecosystem health and slow the loss of native vegetation function. The rate of loss under each alternative would be somewhat in proportion to the number of acres treated under each alternative and the ability of the BLM to implement passive restoration techniques to slow the spread of weeds.

\section{Fish and Other Aquatic Organisms}

Fish, the dominant aquatic vertebrate in the analysis area, constitute a key component of aquatic systems on 
public lands. Fish are a critical resource to humans and as such have influenced the development, status, and success of social and economic systems in Alaska and the western U.S. Aquatic organisms such as insects and other aquatic invertebrates provide food for fish. The health of fish and other aquatic organisms is often indicative of the health of the watershed. Fish and other aquatic organisms are often more sensitive than humans and wildlife to herbicides and other chemicals in their environment, and thus can be an indicator of the concentrations of these pollutants in aquatic bodies.

The BLM administers lands directly affecting almost 155,000 miles of fish-bearing streams and 4 million acres of reservoirs and natural lakes (USDI BLM 2006c). These habitats range from isolated desert springs of the Southwest to large interior rivers and their numerous tributaries throughout the Pacific Northwest and Alaska. Today, the rapid expansion of invasive species and buildup of hazardous fuels across public lands are threats to ecosystem health and one of the greatest challenges in ecosystem management.

\section{Past Effects and Their Accumulation}

Cumulative impacts to fish and other aquatic organisms and the lakes, ponds, wetlands, and riparian areas that provide habitat for aquatic organisms on public lands and throughout the western U.S. have occurred from human-caused disturbance factors, including natural resource extraction, recreation, fire exclusion, construction of roads, dams, and hydropower facilities, agriculture, and urbanization. In addition to natural disturbances, use of wetland and riparian areas by livestock and wild horses and burros has degraded habitat values. Water withdrawal from ditches and diversions have impacted fish habitat on public and other lands. Overfishing has been blamed for the declines in some fish populations (USDA Forest Service and USDI BLM 2000). The introduction of non-native game fish has also impacted some native fish populations.

The condition of much of the remaining habitat has become degraded since that time. BLM surveys show that about $25 \%$ of wetlands and $50 \%$ of riparian habitat on public lands outside of Alaska lack characteristics necessary for "proper" functioning condition (USDI BLM 2006c). A proper functioning wetland or riparian area has the necessary physical and structural components to dissipate stream energy associated with high water flows, as well as conditions that support a diverse and healthy population of fish and other aquatic organisms.
The spread of invasive plant species is one factor that degrades habitat for aquatic organisms. In addition, hazardous fuels can lead to large-scale wildfires that can adversely impact wetland and stream habitat. Within riparian woodlands, the abundance of mid-size trees has increased while the abundance of trees in other size categories has decreased, primarily due to fire exclusion, increasing the risk of wildfire and reducing the value of these areas to aquatic organisms. Within riparian shrublands, there has been extensive conversion to areas dominated by exotic grasses and forbs, primarily because of processes and activities associated with excessive livestock grazing pressure. This conversion has made these areas more susceptible to fire and reduced their value to aquatic organisms (USDA Forest Service and USDI BLM 2000).

Activities in Alaska, including oil and gas development and subsistence and recreational fishing, have impacted fish and other aquatic organisms on public lands. These effects have accumulated, but do not appear to have adversely affected fish populations to a great extent. The permitting process and the regulatory environment for protecting fish have improved over time and are generally effective. Proper construction and placement of bridges and culverts have greatly reduced effects but have not eliminated them. Little is known about the effects of water withdrawals from lakes on fish. Some fish have been harmed or killed during water extraction, but these numbers have been small and have not accumulated (USDI BLM 2005c).

As discussed under Wetland and Riparian Areas, during the early years of the BLM, most resource conservation and management was focused on upland sites. An increased emphasis on wetland and riparian habitat protection began in the 1960s. In the 1970s, FLPMA was passed (1976) and the BLM began preparing land use plans to better manage natural resources on public lands. Land use plans set goals and objectives for natural resource management and identify priority watersheds on which to focus restoration efforts, with special emphasis on watersheds that contain habitat for sage-grouse. In addition, the BLM is assessing the condition of wetland and riparian areas, and conducting restoration efforts in areas that are less than proper functioning. The BLM has restored about 160,000 acres of wetlands, and about 1,000 miles of stream habitat.

Past control efforts by the BLM, other federal and state agencies, private landowners, and businesses (particularly the agricultural industry) have resulted in the application of thousands of tons of herbicides and other pesticides to the environment. As discussed 
earlier, some of these herbicides break down relatively quickly in the environment or are not harmful to aquatic organisms at typical application rates. However, some herbicides are harmful to aquatic organisms, and may persist in the environment for many months.

\section{Future Effects and Their Accumulation}

The rate of loss of wetland and riparian areas has slowed with the passage of federal, state, and local regulations that strive to protect wetland and riparian habitat. There has been some improvement in the functional quality of wetland and riparian areas on public lands, a trend that is likely to continue. For example, the percentage of wetland and riparian areas that lack the characteristics necessary for high function has decreased by about 10\% since 1996 (USDI BLM 1997, USDI BLM 2006d). As a result, the loss of riparian and wetland functions and values over portions of the West should slow in the future.

Efforts to restore natural disturbance regimes, reduce the potential for large-scale wildland fire, and manage and control noxious weeds and other invasive vegetation would help to reduce erosion and sedimentation and restore native plant communities. Restoration of native vegetation should improve riparian habitat and moderate stream temperatures and water flows. In addition, the ability of the BLM and other natural resource management agencies to use aquatic herbicides to control aquatic weeds would benefit lakes and ponds and the aquatic organisms that use these habitats.

Modeling done for the Interior Columbia Basin assessment predicted that vegetation treatments proposed by the BLM and Forest Service would improve the habitat capacity for fish and other aquatic organisms, including threatened and endangered salmon, but that fish populations might be slow to respond to improved habitat conditions. Fish inhabit streams found on and off public lands, and streams cross multiple jurisdictions, including private land, along their entire course. In many cases the condition of the stream habitat off of public lands and on private or other jurisdiction lands is unknown and could be of lower quality. A portion of most fish populations is harvested each year. Competition with non-native fish may limit the ability of native species to access or fully utilize available habitat. Perhaps most importantly, dams and other diversions found in the Columbia River, Colorado River, and most other major rivers in the West also limit access to upriver habitats and alter occupied habitats for certain anadromous fish and other species.
Thus, restoration of native vegetation and natural ecosystems may be most immediately beneficial to resident fish rather than migratory fish that may travel off of public lands to meet part of thcir life requisites (USDA Forest Service and USDI BLM 2000).

Most water-related impacts to fish resources on public lands in Alaska would be associated with oil and gas development, mining, and other development. Development would include an increased number of ice roads and new pipelines, spills of hazardous materials, and habitat disturbance. Potential impacts to fish would be related to water withdrawal and direct habitat loss or indirect disturbance associated with construction of facilities.

\section{Contribution of Altermatives to Cumulative Effects}

Based on the number of acres treated, short-term adverse impacts and long-term improvements to the health and productivity of aquatic organisms would be greatest under the Preferred Alternative, and least under the No Action Alternative. The number of acres treated under alternatives D and $\mathrm{E}$ and their associated shortand long-term effects would be similar, while Alternative $\mathrm{C}$ would be intermediate between these alternatives and the Preferred Alternative. Treatments would occur on about 10,000 acres of wetland and riparian habitat annually under the Preferred Alternative, but aquatic organisms would also benefit from upland treatments located near aquatic habitats.

Because herbicide treatments would not be allowed under Alternative $\mathrm{C}$, control of some aquatic weeds, including giant salvinia, water-thyme, and Eurasian watermilfoil, could be difficult, as mechanical and other non-herbicide treatment methods are less effective. Under Alternative B, the BLM's ability to use four new chemicals (fluridone and diquat for aquatic applications, and imazapic and Overdrive ${ }^{\circledR}$ for terrestrial applications), and new herbicides as they become available, would provide new capabilities to the BLM for controlling problematic invasive species and would provide benefits to aquatic resources and habitats if invasive species were controlled or eliminated. Under alternatives $\mathrm{C}$ and $\mathrm{D}$, it could be difficult for the BLM to adequately treat remote areas or large weed infestations to benefit aquatic organisms. Thus, the risk of loss of aquatic habitat and habitat function in more remote areas could be greater under alternatives $\mathrm{C}$ and $\mathrm{D}$ than under the other alternatives. 
Alternative $\mathrm{E}$ places greater emphasis on passive restoration than the other alternatives. Passive restoration of aquatic habitats would likely entail mitigation and management of terrestrial-based activities, which could directly or indirectly affect habitat quality. As discussed in Chapter 2, Vegetation Treatment Programs, Policies, and Methods, passive restoration would be considered when developing restoration management plans, and would be used to the extent possible within the constraints of FLPMA.

Under Alternative E, the BLM would not be able to use ALS-inhibiting active ingredients (i.e., chlorsulfuron, imazapic, imazapyr, metsulfuron methyl, and sulfometuron methyl).

Of the herbicides that would be unavailable to the BLM under this alternative, imazapyr is the only one that could be used in riparian and aquatic habitats, where it has been shown to be very effective against saltcedar. Imazapyr poses little risk to fish and aquatic organisms when used at typical application rates. Without imazapyr, the BLM would likely treat larger stands of saltcedar using prescribed fire followed by a foliar application of triclopyr, and smaller stands by cutting the stem and applying triclopyr.

Chlorsulfuron, imazapic, and sulfometuron methyl do not pose risks to fish or aquatic invertebrates. Metsulfuron methyl poses a low risk to aquatic invertebrates in streams under an accidental direct spray scenario involving the maximum application rate (an unlikely scenario). Therefore, disallowing use of these four herbicides would be unlikely to benefit fish and aquatic organisms if they are replaced with herbicides that are more harmful to fish and other aquatic organisms.

Short-term effects could accumulate, but if treatments were successful, a countervailing effect of long-term improvement in habitat for aquatic organisms would offset habitat losses. Regardless of the alternative chosen, loss of aquatic habitat and values would accumulate under all alternatives, but the rate of loss would be expected to slow from historic levels over the long term..

\section{Wildlife Resources}

Public lands sustain an abundance and diversity of wildlife and wildlife habitat. Wildlife is found in areas where basic needs - -food, shelter, water, reproduction, and movement-are met (Anderson 2001). In general, the greater the diversity of habitats in an area the more species of wildlife that area can support. Some species, however, have special behaviors and physical traits that allow them to successfully compete with other animals in only one or a few habitats, limiting their distribution.

As discussed in Chapter 3, several structural features make some habitats better for wildlife than others. These features include: 1) structure, 2) vertical layers, 3) horizontal zones, 4) edge, and 5) and special features. The more of these features that are present in a habitat, the more niches there are in which animals can live (Cooperrider et al. 1986).

Historically, landscapes provided a continuous mosaic of vegetation types adapted to climatic and natural disturbance regimes. Plant communities were dynamic and resilient, tending to return to some developmental (successional) pathway after a disturbance. Although structural complexity varied depending on the characteristics of the dominant vegetation (e.g., forestlands tend to be more structurally complex than grasslands), even structurally "simple" habitats provided numerous niches for wildlife to exploit. For example, grasslands may provide only one or two strata, or levels, of vegetation for wildlife to use, but still contain a diversity of wildlife species (Payne and Bryant 1998).

At the ecoregion level, habitats showed little change over decades or even hundreds or thousands of years. However, at the landscape level $(1,000$ to 100,000 s of acres; Paige and Ritter 1999) and stand level (1 to 1,000 s of acres), vegetation and habitats were in constant flux, changing and adapting to natural perturbations in the environment. Disturbances consisting of infrequent, high-intensity events (such as drought, flood, and major fire) interspersed with frequent, low intensity events (wildlife grazing, low intensity burns, disease) constantly shaped and modified the environment. As a result, habitat types varied over time and space and resulted in different species groups being dominant at different times depending on the characteristics of the habitat.

\section{Past Effects and Their Accumulation}

North America has been occupied by Native peoples for at least 12,000 years. As humans settled the West, they altered succession and introduced disturbance processes to which many native plants and animals were not evolved. The following sections examine direct and indirect human-related effects on wildlife habitat loss, modification, and fragmentation, and on wildlife health. These effects have resulted in death and harm to 
wildlife that has accumulated since the arrival of man in North America.

Habitat Loss. Approximately $21 \%$ of land in the western states (excluding Alaska) has been converted to intensive uses-urbanization, agriculture, and pastureland - that provide fewer benefits for wildlife than undisturbed habitats or habitats subjected to less intensive uses (Wright 2002). Although wildlife find food and shelter in highly modified habitats, these habitats generally provide fewer habitat values and are less structurally complex than the habitats they replace. Therefore, they support fewer wildlife species and numbers.

Conversion of lands to more intensive uses has caused injury and mortality to wildlife, primarily less mobile species that live near the ground surface, and species that depend on special habitat lost during conversion. Large numbers of wildlife have been displaced, and many of these animals have died because they were unable to find food, shelter, or other life requisites, or were unable to successfully compete with species found in their new environs. As urbanization and development has intensified in the West during the past several decades, it has not been uncommon to see coyote, bear, deer, and other wildlife in urbanized settings. Some of these animals prey upon dogs, cats, and other domestic animals, or upon vegetation used for landscaping, and must be captured, removed, and in some case euthanized, to reduce this problem. Loss of habitat is also an important factor contributing to the increase in the number of species listed as threatened or endangered in recent years (see BA prepared for this PEIS; USDI BLM 2007b).

Some lands that have been developed for agricultural, urban, and industrial uses were once some of the most productive lands in terms of resource values and wildlife habitat. Once converted to these uses, the habitat values they provided were impacted, often significantly, and most wildlife populations they supported decreased. Wetland and riparian areas in the West are good examples of productive habitats that have been lost or modified as a result of development. Even where wetlands and riparian areas still exist, they have often been converted to other uses. For example, much of the remaining wetland habitat in central and northern California has been converted to agricultural uses (e.g., rice production). Although these areas provide habitat for waterfowl and other wildlife, their food, cover, and other habitat values are usually less than they were before the conversion.
Industrial activities, such as mining, can substantially modify or eliminate habitat within and near the development footprint. Dams and water diversions have been constructed on most major rivers in the West. Where streams and rivers that once supported a productive riparian ecosystem have been dammed, the riparian ecosystems have been inundated by large lakes or reservoirs that provide some habitat for wildlife, but are generally not as productive as they once were.

Not all species are harmed by conversion of land to more intensive uses. Numerous species are adapted to urbanized environments. Even native species that can readily adapt to change, or find their needs met by the modified habitat, may thrive. For example, deer, elk, geese, and some songbirds have benefited by the conversion of lands to urban, agricultural, and recreational uses. These species find food and water at bird feeders, in intensively managed pasturelands, at golf courses and other parks, and in cornfields and other croplands. In some cases, species that use developed habitats may benefit from reduced predation pressure, as their predators are unable to adapt to the new surroundings.

Habitat Modification. Most of the remaining $79 \%$ of lands that have not been converted to more intensive land uses (which would include most of the lands managed by the BLM) have still undergone some modification that has reduced their value to wildlife. An analysis of habitat condition in the Interior Columbia Basin showed a general downward trend in habitat value from historical conditions for nearly all habitat types evaluated in the study (USDA Forest Service and USDI BLM 2000). This study also showed that species that rely upon older forests, sagebrush, and grassland habitats have been most affected by loss and modification of habitat in the region; similar losses of these habitat types have been seen throughout the western U.S. (Payne and Bryant 1998, Paige and Ritter 1999, Smith 2000). Factors that have modified habitat in the West include grazing by domestic livestock and wild horses and burros, timber management, fire suppression, and invasion by weeds and other unwanted vegetation.

Grazing. Excessive grazing pressure has modified wildlife habitat over many areas in the West. Wetland and riparian areas, in particular, have suffered from heavy domestic livestock and wild horse and burro grazing pressure (USDA Forest Service and USDI BLM 2000). Livestock grazing can remove or trample vegetation used by wildlife for food and cover. Domestic livestock removed much of the native grass in 
the Great Basin by the early $20^{\text {th }}$ century, and today, less than $1 \%$ of the sagebrush steppe in the region remains untouched by livestock (Paige and Ritter 1999). Livestock selectively choose grasses and forbs because of their palatability and avoid browsing on sagebrush, which can have a toxic effect on the microorganisms in their rumen (Young 1994). Grasses and forbs also provide food and cover for sage-grouse and other sagebrush-dependent species. In areas with sparse vegetative cover, such as the Subtropical Desert Ecoregion, livestock can remove much of the available forage.

Timber Management. Since the 1800s, millions of acres of timber have been harvested in the West. Historically, preferred timber species were often the more valuable shade-intolerant species such as ponderosa pine, western white pine, and western larch, and the larger trees. Many stands were harvested using even-aged harvest techniques, such as clearcutting, which promoted conversion of forests to shade-intolerant trees that usually had single-storied canopies and lacked vertical structure (Payne and Bryant 1998). Species that depend upon late seral forest habitat or a mosaic of forest types, such as spotted owl, white headed woodpecker, white-breasted nuthatch, and western grey squirrel, declined in numbers. Deer and elk thrived in intensively managed forests, as dense even-aged stands provided good hiding cover (although poor snow intercept-thermal cover), and were often in close proximity to recently-harvested clearcuts that provided grasses, forbs, and shrubs for forage. The checkerboard system of clearcutting also increased edge (a place where two habitat types meet, such as a forestland and shrubland), to the benefit of edge species, including most game species, but to the detriment of forestinterior species (Payne and Bryant 1998).

Fire Exclusion. During the past 100 years, fires have become less frequent and more intense in the western U.S. (Agee 1993; Lyon et al. 2000a). Exceptions to this general trend have occurred in grassland and shrubland habitats that have been invaded by exotic annual grasses, where fire frequency has increased beyond natural fire cycles. Intense wildfires likely harm or kill more wildlife than less intense fires, and are more likely to destroy large areas of habitat, potentially eliminating "islands" of habitat that may provide the only remaining refuge for some species (Lyon et al. 2000b).

Lack of frequent non-lethal burns has resulted in an increase in stand density, an increase in shade tolerant species, and an encroachment of invasive species and trees into grasslands. In forests, nearly uniform stands of dense, mid-seral trees limit the amount of light that can reach the understory, preventing growth of understory shrubs, grasses, and forbs (Payne and Bryant 1998). These changes have not only resulted in habitat loss for species that require open old-growth stands and early seral stages, but have also led to conditions that could result in large, severe fires in the future. Fire suppression has benefited some species, such as northern spotted owl in parts of its range, but has made them more susceptible to harm by a large fire (Thomas et al. 1990).

Dense stands of mid-seral trees are often lacking in special habitat features that are found in more mature forests. For example, early- and mid-seral forests are less able to capture snow in their branches than more mature trees. Where large trees capture snowfall in their branches during winter, rather than letting it accumulate on the ground, shrubs and other types of forage are more readily available to deer and other browsers, and animals are able to travel through the snow without difficulty.

Changes in rangeland habitat, either from fire suppression that has allowed shrubs and trees to invade grasslands, or from high fire frequency that has encouraged the growth of non-native annual weeds, has impacted rangeland species such as sage-grouse, Brewer's sparrow, and sage sparrow (Paige and Ritter 1999). Encroaching shrubs and trees crowd out grasses and forbs used by wildlife, while annual weeds provide little forage value or habitat structure for wildlife. Declines in big game winter range, density of nesting raptors, and non-game bird abundance have also been observed in areas dominated by downy brome (USDA Forest Service and USDI BLM 2000).

Invasive Species. Euroamerican settlement facilitated the invasion and spread of invasive plants. Weeds and other invasive species are able to colonize disturbed (downy brome) and relatively intact (spotted knapweed, yellow starthistle, and leafy spurge) sites, reproduce and grow quickly, and outcompete native species for water and nutrients. Construction of roads and ROWs has facilitated the spread of weeds. Noxious weeds and other exotic plants harm wildlife by reducing the amount of high quality forage and habitat complexity in an area so that it is unable to support an abundance and diversity of wildlife (Payne and Bryant 1998). Invasive species can also increase sedimentation and surface water runoff to the detriment of amphibians and other aquatic species whose habitats may be impacted. Pinyon-juniper woodlands have encroached into grasslands over much of the West, to the detriment of 
edge species and ground-nesting and foraging species. However, the expansion of these species has also benefited wildlife, as pinyon-juniper woodlands provide forage for wintering deer, and in some areas, support more bird species than forest and sagebrush communities (Payne and Bryant 1998).

Habitat Fragmentation. From historical to current periods, there has been an increase in fragmentation of larger habitats into smaller "islands" of habitat and a loss of connectivity within and between blocks of habitat, especially in lower elevation forests, shrublands, and riparian areas (USDA Forest Service and USDI BLM 2000). All of the factors discussed above have contributed to the fragmentation of habitats in the West.

In general, the smaller the habitat island, the fewer the species it can support, since larger areas support a greater diversity of vegetation types and microhabitats. Larger areas are also able to support uncommon species that live at low population densities. In addition, small islands, on average, support small populations, which are more likely than large populations to go extinct (Hunter 1990). This risk of extinction is a concern for several special status species that are restricted to small islands of habitat. A catastrophic wildfire or other major habitat-disturbing event could make the habitat unsuitable for some special status species, leading to their extinction. For example, pygmy rabbits in Washington State are restricted to a few small areas of sagebrush habitat in central Washington surrounded primarily by agricultural land. A major fire event or disease would likely eliminate the population (McAllister 1995).

Fragmentation isolates sedentary and less mobile animal populations, or populations with restricted habitat requirements, and reduces their ability to disperse across the landscape, potentially leading to long-term loss of genetic exchange. Even where habitats are contiguous, human disturbance (e.g., roads, noise) and development can discourage wildlife from moving between adjacent areas, effectively fragmenting habitat. Fencing for livestock can also inhibit the free movement of some wildlife species.

Public land settlement policies have, in part, contributed to the fragmentation of habitats across the West. Public lands in many states outside of Nevada are often scattered and have taken on checkerboard, jigsaw, and patchwork patterns as a result of public land policies pursued by the country prior to the BLM's founding in 1946. As a result, blocks of public land are often isolated and surround by agricultural or other lands. From a wildlife perspective, these blocks act as islands, and some species may be unwilling or unable to travel between blocks of public land or other suitable habitat (Muhn and Stewart 1988). In contrast, there are also large tracts of contiguous public lands in the West that provide habitat connectivity for many species, including sage-grouse, deer, elk, and numerous migratory bird species.

Wildlife Health. Human-related activities are responsible for the death and injury of wildlife each year. Hunting removes large numbers of animals each year. Approximately 409,000 hunters used public lands in FY 2005 (USDI BLM 2006d). Hunting did not adversely affect populations of most species, but overharvest of other species, including American bison, pronghorn antelope, and wild turkey, nearly led to their demise.

Thousands of animals are killed each year by automobiles and other vehicles, and from flying into powerlines and other elevated structures associated with ROW, wind-power generating facilities, transmission towers, and other structures. Wildland and prescribed fires kill or harm animals, with animals that have limited mobility and live above the ground being most vulnerable (Lyon et al. 2000b). Disturbance associated with public recreation, including public-use facilities and OHV use, has displaced wildlife or impacted their activity patterns and habitat use, and likely led to some deaths or reduced animal health.

The use of pesticides, especially organochlorine pesticides such as DDT, has caused death, sickness, and poor reproduction in birds and other wildlife, especially prior to the 1980s when the public was largely unaware of these issues. Diseases that spread from domestic animals to wildlife (e.g., rabies) can also contribute to the loss or harm of wildlife.

In recent years, several studies have focused on the effects of herbicides and other pesticides on amphibian survival, development, and growth. A study of herbicides sprayed for pest control in Canada showed that effects to amphibian embryos and larvae from hexazinone, glyphosate, triclopyr, and three other herbicides that are not used by the BLM, were similar to those found in freshwater fish when herbicides were applied at typical application rates; high concentrations of hexazinone did not affect embryos and tadpoles, but concentrations of triclopyr $2.4 \mathrm{ppm}$ or greater led to death of newly hatched tadpoles (Berrill et al. 1994; Berrill et al. 1997). 
Herbicides can often be more selective than mechanical or fire treatments and just as selective as manual treatments in forestlands (Payne and Bryant 1998). Common herbicides used in forest wildlife management include asulam, atrazine, 2,4-D, glyphosate, simazine, and tebuthiuron; however, the BLM has not used atrazine or asulam on public lands since at least 1997. Spraying herbicides over conifer plantations eliminates competing shrubs and hardwood sprouts, but also reduces the value of these forests to wildlife (Rutske 1969). If treatments are done in patches or strips, important refuge areas can be created for amphibians, reptiles, birds, and small mammals (Payne and Bryant 1998); staggering treatments over several years can achieve the same effect.

\section{Future Effects and Their Accumulation}

The objective of future management will be to restore native vegetation in fire-adapted ecosystems to benefit wildlife and their habitats. Treatments that reduce hazardous fuels on public lands, control the spread of non-native plant species, and restore natural fire regimes would benefit most wildlife. Species that have adapted to, or have exploited, habitats that have developed as a result of fire suppression and weed spread may decline in numbers. However, modeling conducted during development of the cohesive strategy, and for the Interior Columbia Basin assessment, suggests that it will take decades to centuries for treatments to result in major habitat changes (USDA Forest Service and USDI BLM 2000; Hann et al. 2002).

Habitat Loss. Vegetation treatments will do little to slow the loss of habitat in the West. Population growth in the West will likely continue to exceed that of the rest of the country, placing new demands on undeveloped land to meet human-related needs, including urbanization, agriculture, and recreation. As a result, more wildlife will be lost or displaced as lands are converted to uses that do not support historic species or numbers of wildlife, and it is likely that many displaced animals will perish. It is also possible that loss of habitat could lead to the extirpation of species, although the provisions of the ESA should minimize this risk. Most habitat loss would occur on privately-owned lands, although public lands will continue to be developed for mining, oil and gas, recreation, roads and other uses as authorized under FLPMA.

Habitat Modification. The basic premise of the vegetation treatment program is to manage ecosystems to maintain viable populations of native and desirable non-native plant and animal species. This goal would be accomplished by using fire and other treatments to reduce hazardous fuels and the risk of catastrophic fire, to reduce or eliminate weeds and other invasive plants, and to promote conditions that favor the restoration and development of native vegetation. While treatments would not stem the loss and modification of vegetation and wildlife habitat that occurs on private lands, they would improve ecosystem health on public lands and improve habitat for wildlife that historically used treatment areas.

Over half the treatments would occur in the Temperate Desert Ecoregion. Much of this ecoregion is comprised of grasslands and shrublands that have altered fire regimes, have suffered large-scale fires during the past decade, and are dominated by downy brome and other invasive species. Treatments are also targeted at evergreen woodlands, primarily to slow the encroachment of pinyon, juniper and other woodland species into grassland habitats.

There is currently greater awareness than there was historically, on the part of the BLM and other federal land management agencies, and the public, about the effects of livestock, wild horses and burros, timber management practices, mining, fluid minerals, and other land disturbing activities, on wildlife habitat. Better management of human-related disturbance factors through application of site-specific mitigation, SOPs, reclamation and rehabilitation, and monitoring, will continue to benefit wildlife habitat.

Habitat Fragmentation. Factors that contribute to habitat fragmentation on and off public lands will continue, increasing the likelihood of local extinctions of wildlife and loss of species diversity; these risks are greatest on privately-owned lands. Vegetation management that creates a mosaic of native vegetation within larger continuous areas of similar habitat would be beneficial to "interior" and wide-ranging species. Efforts to restore native vegetation in disturbed areas would help to link islands of habitat, as would forest treatments focused on thinning, rather than clearcutting, timber. Closing and revegetating little-used or abandoned roads and removing or modifying fencing and other barriers would encourage the movement of wildlife among habitats and facilitate genetic exchange among populations. Treatments that reduce the risk of catastrophic fire and the spread of weeds would result in more continuous stands of similar vegetation and a reduced likelihood that islands of good habitat would be surrounded by less desirable habitat (e.g., a patch of native riparian sagebrush surrounded by a continuous stand of downy brome). 
In addition, efforts by the BLM and Forest Service to consolidate landholdings through land tenure adjustments, such as land exchanges with other federal agencies and private landowners to create larger blocks of common ownership, would help to reduce habitat fragmentation and improve management of federal and private lands.

Wildlife Health. Hunting and other disturbance factors that have impacted wildlife in the past are likely to continue. However, current management of game populations and enforcement of hunting laws has reduced the risk of major declines in the numbers of game species from historic levels. Development and implementation of land use and project-level plans that consider the effects of OHVs and other disturbance factors, road closures, screening of facilities, and other SOPs to minimize disturbances would benefit wildlife.

Although the amount of herbicides used by the BLM and Forest Service to treat vegetation would increase in response to proposed treatment programs, the risks to wildlife should remain near current levels, or decline, as both agencies move towards used of less toxic chemicals to treat vegetation. In particular, the BLM and other federal agencies would ensure that herbicide formulations that have been shown to be harmful to amphibians and other wildlife, such as atrazine and glyphosate formulations containing POEA and R-11, are not used or are used minimally and only in areas where benefits of use greatly outweigh risks to wildlife. Atrazine appears to increase mortality in amphibians and acts as an endocrine disruptor that chemically castrates and feminizes male amphibians (Hays et al. 2006; Rohr et al. 2006). Atrazine, which would be available for use only under Alternative $\mathrm{A}$, has not been used by the BLM for over 7 years and there are no plans to use this herbicide in the future.

The use of atrazine, glyphosate formulations containing POEA and R-11, triclopyr, and other herbicides that are harmful to amphibians and other wildlife, would continue be used on private lands and could cause the decline in numbers of amphibians and other wildlife in areas where they are used. Fifty-one thousand tons of glyphosate, thirty-eight thousand tons of atrazine, and six hundred sixty-eight tons of triclopyr were applied to non-federal agricultural lands and rangelands during 2002. Use of triclopyr has increased 11-fold, and glyphosate 6-fold, since 1992 on these lands.

\section{Contribution of Treatment Alternatives to Cumulative Effects}

Based on the number of acres treated, short-term adverse impacts and long-term improvements to wildlife and habitat would be greatest under the Preferred Alternative, and least under the No Action Alternative. The number of acres treated, and the effects to wildlife and habitat would be similar under alternatives D and E. Effects to wildlife and habitat under Alternative $\mathrm{C}$ would be intermediate between these alternatives and the Preferred Alternative.

It is anticipated that the use of wildland fire use and prescribed fire and herbicides, and mechanical methods, would have the greatest short term impacts on wildlife and their habitat, and that impacts would be somewhat in proportion to acres treated. Approximately three times as many acres would be treated annually using herbicides under the Preferred Alternative than under the No Action Alternative, and about twice as many acres would be treated using herbicides under the Preferred Alternative than under alternatives D and E. No acres would be treated using herbicides under Alternative C. In addition, approximately twice as many acres would be treated using prescribed and wildland fire under the Preferred Alternative than under alternatives $\mathrm{C}, \mathrm{D}$, and $\mathrm{E}$, and three times as many as compared to the No Action Alternative. Acres treated using mechanical methods would be similar among alternatives $\mathrm{B}, \mathrm{C}, \mathrm{D}$, and $\mathrm{E}$ (about 2 million acres annually), and greater than for the No Action Alternative (about 582,000 acres annually).

Short-term effects from treatments and other human causes would accumulate, but a countervailing effect of long-term improvement in the ecosystem health and wildlife habitat with success and maintenance of treatments, would offset short-term losses.

Alternative $\mathrm{E}$ places greater emphasis on passive restoration than the other alternatives. Passive restoration is often considered a critical first step in successful restoration of degraded areas, since anthropogenic activities that are causing degradation or preventing recovery are halted. As discussed at the beginning of the cumulative effects section, passive restoration would be considered under all alternatives when developing restoration management plans, and would be used to the extent possible within the constraints of FLPMA. However, alternatives A through $\mathrm{D}$ would likely take a more aggressive approach to vegetation management than Alternative $\mathrm{E}$. 
All alternatives include both passive and active management. Recovery of vegetation through passive management is expected to take longer than under active management, where treatments such as seeding with native species, establishing intermediate vegetation to control erosion, and use of pre-emergent herbicides to prevent weed establishment would be expected to promote faster recovery.

The risks to wildlife from use of herbicides could be less under Alternative $\mathrm{E}$ than under the other herbicide use alternatives because ALS-inhibiting herbicides would not be used under Alternative E. ALS-inhibiting herbicides are effective at very low doses and could drift onto wildlife and harm them. However, in this assessment, the ALS-inhibiting herbicides mostly posed no risk to terrestrial wildlife (chlorsulfuron, imazapic, sulfometuron methyl), except for a few cases of low risk (imazapyr, metsulfuron methyl), suggesting that prohibiting the use of these herbicides would not likely benefit wildlife and could indirectly harm wildlife if more toxic herbicides that are currently available to the BLM were used in their place.

The risk of herbicide drift affecting wildlife and their habitats would be less under alternatives D and E than under the other herbicide treatment alternatives, as aerial treatments are prohibited under Alternative $\mathrm{D}$, and discouraged under Alternative E.

Over the long term, treatments should restore native vegetation and natural fire regimes and benefit ecosystem health and wildlife and their habitats. Regardless of the alternative chosen, however, there would be a cumulative loss of native vegetation and healthy ecosystem function that would continue into the future.

\section{Livestock}

Approximately 165 million acres of public lands are open to livestock grazing, with use levels established by the Secretary of the Interior and administered through the issuance of grazing permits/leases. The majority of the grazing permits issued by the BLM involve grazing by cattle, with fewer and smaller grazing permits for other kinds of livestock, which would include primarily sheep and horses. Livestock grazing leases and fees contribute $\$ 12$ to $\$ 15$ million annually to the U.S. Treasury, and ranching is an important economic and social component of many rural communities (USDI BLM 2006c). There are over 12.7 million active animal unit months that could be authorized for use on public lands. The ability of public lands to support healthy populations of domestic livestock is important to the livelihood of livestock producers.

\section{Past Effects and Their Accumulation}

Loss of native vegetation and deterioration in ecosystem health on public land due to changes in fire regimes, as well as an increase in lands dominated by noxious weeds and other invasive vegetation, has contributed to reductions in the ability of public lands to support livestock grazing. Livestock grazing itself is a factor contributing to some of these changes. However, increases in other human-caused factors such as mineral extraction and recreation have also affected vegetation communities or resulted in conflicts that reduce the ability of public lands to support livestock grazing. Where human activities and wildland fire have disturbed the land, weeds and other unwanted species have taken over and in some cases dominated landscapes (USDA Forest Service and USDI BLM 2000). It is estimated that downy brome alone covers over 11 million acres in the West, and that leafy spurge covers 3 million acres (Lajeuness et al. 1998). Weed species are often of little nutritional value to livestock, and some weed species are toxic to livestock.

\section{Future Effects and Their Accumulation}

The focus of management in the future is on restoring ecosystem processes and maintaining livestock populations in balance with the health of rangelands. Many of these treatments will require rest from livestock grazing and will therefore result in temporary reductions in livestock grazing. In the long term, treatments that remove hazardous fuels from public lands would be expected to benefit the health of plant communities in which natural fire cycles have been altered. Treatments that restore and maintain fireadapted ecosystems through the appropriate use of mechanical thinning, fire, and other vegetation treatment methods would decrease the effects of wildfire on communities and improve ecosystem resilience and sustainability. Treatments should also reduce the incidence and severity of wildfires across the western U.S. to the benefit of livestock (USDA Forest Service and USDI BLM 2000).

Vegetation treatments would provide a better mix of habitats so that vegetation would be more resilient to disturbance and sustainable in the long term. Treatments would reduce the encroachment and density of woody species in shrublands and/or undesirable herbaceous species in rangelands. Treatments would slow the spread of weeds and increase the number of acres 
dominated by bunchgrasses and other important forage for livestock. Although the number of acres impacted by weeds and other exotic and undesirable plants would continue to increase, the rate of increase should slow (USDA Forest Service and USDI BLM 2000).

In addition, the BLM will continue efforts to bring livestock populations in balance with the condition of rangelands. Where feasible, the BLM will incorporate the use of livestock as part of the overall weed management program, and improvements will be made to the grazing management program and grazing regulations (see Proposed Revisions to Grazing Regulations for the Public Lands Final EIS; USDI BLM 2004). Although these efforts should benefit the livestock industry, it is projected that there will be a slow, but steady loss in availability of public lands for livestock grazing (USDA Forest Service 1989, USDA Forest Service and USDI BLM 2000).

\section{Contribution of Treatment Alternatives to Cumulative Effects}

Based on the number of acres treated, short-term impacts and long-term improvements to domestic livestock would be greatest under the Preferred Alternative, and least under the No Action Alternative. The number of acres treated, and the effects to these animals, would be similar under alternatives D and E. Effects to livestock under Alternative $\mathrm{C}$ would be intermediate between these alternatives and the Preferred Alternative. Short-term effects from treatments and other human causes would accumulate, but if treatments were successful, a countervailing effect of long-term improvement in the ecosystem health and range conditions.

Alternative E places greater emphasis on passive restoration through the elimination or reduction of uses on public lands than the other alternatives. Livestock grazing is often cited as a factor contributing to loss of resource function and degradation of rangeland quality. By reducing the number of livestock entering degraded areas, improvement in ecosystem health can be expected (Kauffman et al. 1997). Thus, fewer livestock may be able to graze on public lands under this alternative than under the other alternatives.

The risks to non-target vegetation from use of herbicides could be less under Alternative $\mathrm{E}$ than under the other herbicide use alternatives because ALSinhibiting herbicides would not be used. ALS-inhibiting herbicides are effective at very low doses and could drift onto non-target vegetation, where a potential impact could occur, depending on the species composition of the non-target site and the ALSinhibiting herbicide selected. However, risk assessments did not predict risk to livestock for any of the ALSinhibiting herbicides when applied at the typical application rate under any of the modeled scenarios, suggesting that prohibiting the use of these herbicides would not benefit livestock and could indirectly harm livestock if more toxic herbicides were used in their place.

The risk that herbicide drift would affect livestock would be less under alternatives D and $\mathrm{E}$ than under the other herbicide treatment alternatives, as aerial treatments are prohibited under Alternative D, and discouraged under Alternative E. Regardless of the alternative chosen, there would be a cumulative loss of rangeland forage for livestock.

\section{Wild Horses and Burros}

The Wild Free-Roaming Horses and Burros Act of 1971 provides protection for all wild horses and burros on federal lands and provides guidance for their management as a wildland species. At the time the Act was passed, approximately 17,000 wild horses occupied federal lands designated for their protection. By 1980, the number of wild horses had increased to between 65,000 and 80,000 (USDI BLM 2005d). As a result of this increase, impacts to vegetation, water, and soil from wild horses and burros increased, especially in heavily used areas. Loss of native vegetation, especially grasses and some shrubs, due to wildfires and invasive plants further reduced available forage and increased competition among wild horses and burros, livestock, and wildlife for dwindling resources. The loss of native vegetation and degradation of ecosystems has impacted wild horses and burros and has likely reduced herd productivity in some herd management areas. At the same time, wild horses and burros have adversely impacted vegetation, although efforts to reduce herd populations in recent years have reduced these effects (USDI BLM 2001c).

\section{Past Effects and Their Accumulation}

The wild horses that roam the West are feral descendants of domestic stock that were brought to North America by European colonists. No native wild horses existed in North America at that time, even though horses evolved in North America, and spread to Eurasia about 2.5 to 3 million years ago. The last remaining native horses persisted in North America until about 8,000 to 10,000 years ago, when they 
became extinct. Climate change, change in vegetation, and perhaps overexploitation by Native Americans may have contributed to the horse's demise in North America (USDI BLM 2005d).

The Spaniards reintroduced horses and burros into North America during the $1500 \mathrm{~s}$. By the $1800 \mathrm{~s}$, more than 2 million wild horses roamed western North America. Population growth resulted from successful reproduction in the wild, and from escape or abandonment of domestic horses brought to the frontier by trappers, settlers, miners, and other immigrants. Wild burro herds also increased as individuals escaped from shepherds and miners. At the same time, the available open range began to shrink as livestock, fences, farms, ranches, and roads proliferated. Wild horses were shot to reduce competition with livestock, or rounded up and sold for use as draft animals, military mounts, and food. Burros were less persecuted because they tended to graze lands that were too barren and dry for livestock to use (USDI BLM 2001c, 2005f).

The Taylor Grazing Act of 1934 authorized the formation of the Grazing Service (a precursor to the BLM) and empowered the Service to responsibly manage grazing pressure on federal rangelands. This step accelerated the capture and removal of wild horses and burros, which were primarily used as pet food. Lucrative European markets for horsemeat emerged, as did domestic markets for use of horsemeat in pet and chicken feed. By the 1950s, the number of wild horses dropped to less than 20,000 . In addition, professional horse-catchers often used brutal methods to capture and transport wild horses for sale to slaughterhouses. Public concern developed over the falling population and inhumane treatment of animals (USDI BLM 2005d).

In response to concerns over the plight of wild horses and burros, the Wild Horse Annie Act was passed in 1959 that prohibited hunting or harassment of wild horses on public lands using motorized vehicles or aircraft, although enforcement was difficult. In the Wild Free-Roaming Horses and Burros Act of 1971, Congress stated that free-roaming horses and burros were living symbols of the historic and pioneer spirit of the West; that they contributed to the diversity of life forms within the Nation and enriched the lives of the American people; and that these horses and burros were fast disappearing from the American scene. Congress mandated that wild free-roaming horses and burros be protected from capture, branding, harassment, and death (USDI BLM 2005d). Responsibility for management fell upon the BLM and Forest Service.
Under protection, herds thrived and increased to over 65,000 by 1980 . Unlike wildlife, which are hunted, and livestock, which are managed under a permit system, there were no controls on wild horse and burro populations. In absence of control, populations increase by 15 to $20 \%$ annually.

The BLM strives to manage wild horses and burros as wildland species, not as livestock. Typically, the BLM does not feed or water the animals, but does intervene during extreme drought, fire, or freezing weather, and may relocate animals or remove them from the range during extreme conditions. For example, more than 3,500 animals were removed from public lands in 2000 due to extreme drought conditions and placed in longterm holding facilities (USDI BLM 2001c).

Wild horses and burros are managed in herd management areas, where the BLM tries to balance the number of animals with the available resources needed by the animals for survival. Land managers consider the number of animals, rangeland health, and other desired rangeland uses in developing an appropriate management level. Wild horse advocates express concern about keeping numbers too low to maintain genetic diversity. Many sportsmen and ranchers want the number of wild horses and burros reduced because they compete with wildlife and livestock for food (USDI BLM 2001c).

Urbanization has reduced the amount of private land near public land that is available to wild horses and burros. Paved highways, traffic, cross-fencing, and livestock gates impede herd movements and have reduced the amount of land available for wild horses and burros. Loss of native vegetation and deterioration in ecosystem health on public land during the past 100 years due to changes in fire regimes, increases in lands dominated by weeds and other noxious vegetation, and other human-caused factors, have increased competition for dwindling plant resources by these animals and further contributed to the loss and degradation of native plants. Livestock and wild horses and burros often congregate in areas with high quality forage or water, including wetland and riparian areas. As some native habitats are impacted, they provide new areas for invasive weeds, perpetuating the downward trend in land health. Although wild horses and burros occur in 10 states, most animals are found in Nevada $(46 \%)$ or Wyoming (13\%), in the Temperate Desert Ecoregion (see Table 3-7). Rangeland conditions in many areas where wild horses and burros are found are degraded. To reduce damage to rangeland ecosystems, the BLM began to reduce wild horse and burro numbers 
beginning in the 1980s. By 1996, there were about 40,000 wild horses and burros on public lands. In FY 2005 , wild horse and burro populations on public lands totaled over 31,760 animals, with nearly half of these animals living in Nevada (Table 3-7). Another 25,000 animals are held in holding pens. The population of wild horses and burros is approximately 4,000 animals above the Appropriate Management Level (AML) of 27,500. The AML is an estimate of the number of wild horses (USDI BLM 2006c, d).

\section{Future Effects and Their Accumulation}

The focus of management in the future will be on restoring native ecosystem processes and keeping wild horse and burro populations in balance with the health of rangelands. Treatments that remove hazardous fuels from public lands would be expected to benefit the health of plant communities in which natural fire cycles have been altered. Treatments that restore and maintain fire-adapted ecosystems, through the appropriate use of mechanical thinning, fire, and other vegetation treatment methods would decrease the effects of wildfire on communities and improve ecosystem resilience and sustainability. Treatments should also reduce the incidence and severity of wildfires across the western U.S. to the benefit of wild horses and burros (USDA Forest Service and USDI BLM 2000).

Treatments would improve the mix of habitats so that vegetation would be more resilient to disturbance and sustainable over the long term. Treatments would reduce the encroachment and density of woody species in shrublands and/or herblands. Treatments would slow the spread of weeds and increase the number of acres dominated by bunchgrasses, Indian ricegrass, western wheatgrass, and other important forage species of wild horses and burros. As a result, plant communities that have declined substantially in geographic extent from historical to current periods (e.g., big sagebrush and bunchgrasses) would increase. Although the number of acres impacted by weeds and other exotic and undesirable plants would continue to increase, the rate of increase should slow (USDA Forest Service and USDI BLM 2000, USDI BLM 2001c).

The BLM will continue management efforts to keep wild horse and burro populations at appropriate management levels in balance with the condition of rangelands. This will require continued removal and adoption of animals, and continuing efforts to develop a fertility control agent for these animals. Nearly 209,000 animals have been adopted since 1971 (USDI BLM 2006d). The number of animals found in the Temperate
Desert. However, populations on public lands need to be reduced from about 31,000 to 27,500 animals to bring populations in balance with their habitat. As a result, effects to wild horses and burros from habitat degradation will continue to accumulate because fewer animals can be supported by degraded ecosystems than by healthy ecosystems (USDI BLM 2001c, 2005f).

\section{Contribution of Treatment Alternatives to Cumulative Effects}

Based on the number of acres treated, short-term adverse impacts and long-term improvements to the wild horses and burros would be greatest under the Preferred Alternative, and least under the No Action Alternative. The number of acres treated, and the effects to these animals would be similar under alternatives D and E. Effects to wild horses and burros under Alternative $\mathrm{C}$ would be intermediate between these alternatives and the Preferred Alternative. Short-term effects from treatments and other human causes would accumulate. A countervailing effect of long-term improvement in ecosystem health and the ability of public lands to support wild horses and burros would offset short-term losses through successful treatments meeting desired objectives.

Alternative E places greater emphasis on passive restoration than the other alternatives. Passive restoration is often considered a critical first step in successful restoration of degraded areas, since anthropogenic activities that are causing degradation or preventing recovery are halted. Foraging by wild horses and burros is often cited as a factor contributing to loss of resource function and degradation of rangeland quality. By maintaining the number of wild horses and burros on public lands at levels in balance with rangeland productivity, improvement in habitat function would be expected (Kauffman et al. 1997).

The risks to non-target vegetation from use of herbicides could be less under Alternative E than under the other herbicide use alternatives because ALSinhibiting herbicides would not be used. ALS-inhibiting herbicides are effective at very low doses and could drift onto non-target vegetation and degrade the forage quality of the impacted area. However, as with livestock, risk assessments did not predict risk to wild horses and burros for any of the ALS-inhibiting herbicides, when applied at the typical application rate, under any of the modeled scenarios, suggesting that prohibiting the use of these herbicides would not benefit livestock and could indirectly harm these animals if more toxic herbicides were used in their place. 
The risk of drift affecting wild horse and burro health would be less under alternatives $\mathrm{D}$ and $\mathrm{E}$ than under the other herbicide treatment alternatives, as aerial treatments are prohibited under Alternative D, and discouraged under Alternative E. Regardless of the alternative chosen, there would be a cumulative loss of rangeland habitat for wild horses and burros.

\section{Paleontological and Cultural Resources}

\section{Paleontological Resources}

Paleontological resources (plant and animal fossils) are nonrenewable. Since paleontological material is buried, the location of plant and animal fossils is predictable only to a limited degree, and most fossil localities remain unknown, making assessment of cumulative impacts difficult. In many settings, paleontological resources are well protected by nature, in that they are so deeply buried and completely encased in sediments or rock that virtually nothing can impact them aside from excavation. In other instances, they are located on or near the ground surface and are very susceptible to impacts.

Once paleontological resources are impacted or displaced from their natural context, the damage is irreparable and cumulative. Paleontological resources are found over much of the West. Except perhaps for mechanical treatments and fire use, vegetation treatment methods do not present a substantial threat to paleontological resources.

Past Effects and Their Accumulation. Most paleontological material is typically buried considerably deeper than archaeological material and is therefore not regularly encountered by chance. However, some fossiliferous formations, particularly in the arid West, crop out at or near the surface and may have surface expressions or eroded material as "float." Natural and human activities that cause ground disturbance have likely impacted near-surface paleontological resources throughout the West. Paleontological research and excavation, necessary for the recovery of scientific data, have contributed to the displacement of paleontological resources. Past exploration and development of the West led to legal and illegal collecting and inadvertent damage, especially prior to the 1970 s when there was less concern for protecting these resources. As awareness for the importance of these resources has increased, and as state and federal regulations have been put in place that require surveys for and prohibit the removal of paleontological resources, the cumulative loss of paleontological resources has slowed.
Future Effects and Their Accumulation. Most paleontological material is exposed as a result of natural erosion. Typically, erosion occurs as a result of the action of flowing water, but it also can occur as a result of wind, seasonal freezing and thawing, ground subsidence, and the movement of soil down slopes. Natural erosion, and its impact on paleontological resources, is difficult to assess because in most cases it is regarded as discovery rather than a negative impact to the resource. Some of the most important paleontological resources are associated with river bank cuts and drainages.

An estimated 305,000 to 932,000 acres could be disturbed by herbicide treatments during the next 10 to 15 years under the herbicide treatment alternatives. Of this area, about half would be treated using grounddisturbing equipment, and only a small portion would involve substantial ground disturbance that could impact paleontological resources. An additional 1.7 to 5.1 million acres could be impacted by other vegetation treatment methods, including 4.3 million acres by wildland fire use or prescribed fire and grounddisturbing equipment. These treatment methods pose the greatest risks to paleontological resources, either through direct harm to resources, or indirectly as a result of soil erosion and other soil disturbances that could result from treatments (see PER). In addition, population growth and development in the West have resulted in land impacts that disturb soil. These actions have the potential to add to the cumulative loss of paleontological resources. Site reclamation would not reduce this loss, as paleontological resources would have already been lost during site disturbance and development.

New innovations in technology that reduce the amount of surface disturbance associated with development on public and private lands, and enforcement of regulations that require the assessment and protection of paleontological resources before ground-disturbing activities can occur, would contribute to the future protection of paleontological resources and slow their cumulative loss. Assessments to identify and protect paleontological resources in proposed treatment areas should minimize or avoid the loss of these resources. In addition, vegetation treatments that restore natural fire regimes and native plant communities, and improve ecosystem health, would lead to conditions that would slow soil erosion and reduce risk of fire, slowing the loss of paleontological resources.

Contribution of Alternatives to Cumulative Effects. The potential for cumulative impacts to paleontological 
resources from vegetation treatments would be least under the No Action Alternative and greatest under the Preferred Alternative, based on the number of acres that would be impacted by ground-disturbing activities. Other treatment alternatives would be intermediate between these two. Most equipment would disturb only the upper few inches of soil, and in many cases, would be confined to existing disturbed areas such as roadways, trails, and other ROWs. All treatment methods could cause indirect loss of paleontological resources as a result of erosion and soil disturbance, but these effects would be minimal. Potential effects would be further reduced because the BLM has surveyed, or would conduct surveys in the future, for paleontological resources to lessen the chance they would be impacted by treatment activities. Thus, there would be a negligible cumulative loss of paleontological material on public lands due to vegetation treatment methods under all alternatives.

\section{Cultural Resources and Traditional Lifeway Values}

Cultural resources, including archaeological and historic sites and materials, as well as traditional cultural properties, have a very limited ability to absorb cumulative impacts. Cultural resources, which are nonrenewable resources, risk being destroyed by erosion, construction, excavation, data collection, and looting; removal of artifacts from their surrounding contexts; movement of the material such that it loses context; or removal or re-deposition of artifacts and their surrounding context to another location. Cultural properties, including camps, cabins, hunting and fishing sites, graves, and areas of particular religious or traditional importance, lose their integrity and thus their potential eligibility for the National Register of Historic Places when they become degraded as a result of natural or human disturbance processes, or when the people who value these places can no longer access them, thus losing their cultural connection to the site over time.

Past Effects and Their Accumulation. Prior to European settlement, Native American and Alaska Native tools, pottery, artwork, religious artifacts, and other cultural resources were subject only to the effects of the natural environment, such as the forming, deforming, and destroying of resources and sites, and the effects of human activity, such as Native people reusing found objects and materials. Later, as Europeans settled in North America, settlers collected, harmed, or destroyed cultural resources and sites and displaced Native peoples. Under the influence of inspired leaders, however, traditional Native cultures have survived
(Garbarino and Sasso 1994, Zimmerman and Molyneaux 1996).

As settlement continued in the West, more lands were developed and additional cultural resources were destroyed, taken, or lost. On public lands in the western U.S., grazing, timber removal, and mineral extraction were activities that likely caused the greatest loss of cultural materials due to land disturbance, especially prior to the $1960 \mathrm{~s}$, when the National Historic Preservation Act (1966) and NEPA (1969) were passed.

Historically, Alaska Natives were geographically widespread and technologically capable people who lived in dispersed, small communities based on family and social connections (USDI BLM 2005c). Life in the northern subarctic revolved around the caribou, or reindeer, while the Inuit and Aleut hunted waterfowl and marine mammals including whales, and fish. Alaska Natives had intermittent contact with Russian, American, British, and Norwegian traders, explorers, missionaries, and government representatives in the early $1800 \mathrm{~s}$. This contact intensified when commercial whaling north of the Bering Strait began in the 1850s. Activities that have had the greatest effect on cultural resources in Alaska, particularly in public lands along the Arctic Coast, are most likely linked to both oil development and military activity, given that public lands on the Arctic North Slope were designated as a Naval Petroleum Reserve in 1920. Alaska also was a theatre of war during World War II, and remnants of military bases and other Cold War-related facilities remain today and are considered historic resources.

The inadvertent loss of cultural materials was slowed by the passage of the National Historic Preservation Act and NEPA, which mandated the identification of cultural resources potentially affected by developments and mitigation for potential impacts. In addition, these developments resulted in the discovery of many previously undocumented cultural resources. The Archaeological Resources Protection Act of 1979 added additional protections for cultural resources on public or Native-owned lands. In addition, the Native American Graves Protection and Repatriation Act of 1990 provided protection for Native human remains, sacred objects, and associated funerary objects on federal and Native-owned lands.

Future Effects and Their Accumuiation. Cultural resources are distributed unevenly across the western states and Alaska. Areas with high probabilities of prehistoric and historic use are generally predictable, but specific subsurface cultural resources are often 
unknown until some sort of disturbance occurs, making it difficult to assess the cumulative impacts to cultural resources. The more surface and subsurface disturbance that occurs, the larger the area affected and the greater the possibility that cultural resources will be impacted. Because of their surface or near-surface stratigraphic contexts, cultural resources are not well protected by soil and vegetation, and are vulnerable to any surfaceor subsurface-disturbing activity.

The buildup of hazardous fuels and spread of noxious weeds and other invasive vegetation have increased the risk of wildfire and displacement of plants and animals that are important to Native peoples for their traditional lifeway values. Although fire is being reintroduced to undeveloped areas in the West that were historically burned by Native peoples to maintain early successional plant species and improve habitat for game species, natural disturbance regimes have not been restored over much of the West. Encroachment by non-native species into natural ecosystems continues, to the detriment of many native species of importance to Native peoples.

Resource extraction, livestock grazing, motorized recreation, and other land disturbing activities would increase the potential for impacts to cultural resources. However, federal regulations and management policies that require the identification of cultural resources and mitigation of impacts prior to most ground-disturbing activities, including those associated with vegetation treatments are likely to remain in effect. An increase in the number of acres treated to restore native vegetation and natural fire regimes, and to promote ecosystem health could have short-term impacts on access to traditional resources by Native peoples. For example, herbicide use, wildland fire use, or prescribed fire could prohibit use of traditional areas by Native peoples until areas are safe to enter and resources are suitable for use.

Contribution of Alternatives to Cumulative Effects. As with paleontological resources, the potential for cumulative impacts to cultural resources from the use of herbicides and other treatment methods would be least under the No Action Alternative and greatest under the Preferred Alternative, based on the number of acres that would be impacted by ground-disturbing activities. Other treatment alternatives would be intermediate between these two. It is anticipated that the use of wildland and prescribed fire and mechanical methods would have the greatest short term impacts on wildlife and their habitat, and that impacts would be somewhat in proportion to acres treated. Approximately twice as many acres would be treated using prescribed and wildland fire under the Preferred Alternative than under alternatives $\mathrm{C}, \mathrm{D}$, and $\mathrm{E}$, and three times as many as compared to the No Action Alternative. Acres treated using mechanical methods would be similar among alternatives $\mathrm{B}, \mathrm{C}, \mathrm{D}$, and $\mathrm{E}$, and greater than for the No Action Alternative.

Most ground-based equipment would disturb only the upper few inches of soil, and in many cases, would be confined to existing disturbed areas such as roadways, trails, and ROWs. Cultural resources on the surface should be discovered during pretreatment surveys. All treatment methods could cause indirect loss of cultural resources as a result of erosion and soil disturbance, but these effects should be minimal. Potential effects would be further reduced because the BLM has inventoried, or would conduct inventories for, cultural resources in treatment areas to lessen the chance that they would be impacted by BLM vegetation treatment activities. Thus, there should be a negligible cumulative loss of cultural resources on public lands due to herbicide and other vegetation treatment methods under all alternatives.

Based on the number of acres treated using herbicide and non-herbicide treatment methods, short-term impacts to plants that are important to Native peoples, as well as habitats used by fish and wildlife that are important to Native peoples, would be greatest under the Preferred Alternative and least under the No Action Alternative. However, as the long-term objective of treatments is to restore native plant communities and habitats, including those of traditional importance to Native peoples, the greatest benefits should accrue under the Preferred Alternative. In addition, since the herbicides proposed for use by the BLM are less harmful to non-target vegetation, fish and wildlife, and humans than most currently-available herbicides used by the BLM, and any future herbicides used by the BLM would also likely have low risk. The Preferred Alternative and Alternative D should have fewer cumulative impacts than the other herbicide-use alternatives.

As long as surveys and inventories were completed prior to vegetation treatments in areas that are likely to have cultural resources and lifeway values, the effects on those resources would be minimized. The accidental discovery or damage to sites, presently known or unknown, would affect those sites to some extent, but would also require measures to recover or record the remaining material, adding that information to the archaeological record.

The National Historic Preservation Act requires federal agencies to take into account the effects of a proposed 
action on properties included in, or eligible for, the National Register of Historic Places (also known as historic properties) before approving or funding the action. The Act also requires federal agencies to completc a cultural resources survey prior to federal actions and ground-disturbing activities that occur on federal lands, and in some cases to survey private lands if there is a clear link between the land and the activities on federal lands. Surveys on private lands are most applicable to cooperative projects involving federal agencies and private landowners to reduce hazardous fuels or invasive species on commingled land jurisdictions. These surveys ensure that the protection of cultural resources goes beyond just the federal component. The BLM's guidelines and policies require that all effects to identified historic properties and other cultural resources identified during surveys be mitigated to the satisfaction of the land manager and the State Historic Preservation Officer. Standard operating procedures and agency guidance, as identified in manuals and handbooks (see Table 2-8 of the PEIS and Table 2-5 of the PER), would reduce the likelihood of impacts to cultural resources.

\section{Visual Resources}

Humans have had a profound effect on landscapes across the western U.S. and Alaska. While much of Alaska is still primarily a natural landscape with scenic qualities that have not been changed substantially by humans, changes to the landscape in the lower 48 states have been substantial (USDA Forest Service and USDI BLM 1997; USDI BLM 2005c). Much of this change reflects past land management goals that focused on resource allocation, as commodity production took precedence over custodial protection of land. Since the 1970s, however, concern for ecosystem conditions has gained importance and is reflected by a greater effort on the part of federal, state, tribal, and other land stewards to restore ecosystems to near historic conditions. The objective of these efforts is to provide continued, predictable flows of resources, including visual resources, which contribute to both traditional and current human demands and values (USDA Forest Service and USDI BLM 1997).

\section{Past Effects and Their Accumulation}

Scenic quality, a measure of the visual appeal of the land, is rated based on landform, vegetation, water, color, adjacent scenery, scarcity, and cultural modifications. Sensitivity levels, which are measures of public concern for scenic quality, consider the types of users of the area, the amount of use, public interest in the area, adjacent land uses, and whether the area is classified as a special area. As landscapes are modified by human factors, impacts to scenic quality occur, and visual effects may accumulate on a particular landscape, based on levels of activity and degree of modification. For example, an area of high mining interest may display landscapes modified in form and color due to waste dumps, open pits, and other facilities. Efforts to mitigate these effects by designing waste dumps to mimic landforms and rehabilitating with vegetation cover often reduce these effects concurrently and over time to a point where the modifications may be substantially unnoticeable in the long term. Contrary to some common perceptions, lands in the western U.S. were not pristine wilderness prior to settlement by nonIndian emigrants, but ecological systems in which humans were an active component. American Indians used fire as a tool to manage vegetation to provide better forage for game animals, to encourage growth of plants used for food, and in ceremonial events (USDA Forest Service and USDI BLM 1997).

As European settlers moved into the West, impacts to the natural landscape accelerated. With population growth came an increase in extraction of minerals and other resources, agriculture, road construction, urbanization, and similar types of development that have the potential to adversely impact the visual qualities of the landscape. In addition, timber harvesting, livestock grazing, the introduction of exotic species, and the exclusion of fire have resulted in substantial changes to the landscape, succession and disturbance regimes, and associated vegetation composition, structure, and pattern.

The systematic exclusion of fire from western ecosystems began in the early $1900 \mathrm{~s}$, with the intent of reducing threats to lives, property, and timber from fire. The result over time was a change from seral, fireadapted species to more fire-susceptible species that often formed dense, unhealthy stands subject to largescale fires and disease outbreaks. Trees that are dead or dying as a result of insect infestations, and areas that have been browned and blackened by wildland fire, have become common visual characteristics of western landscapes during the last several decades. Where human activities and wildland fire have disturbed the land, weeds and other unwanted invasive species have taken over and dominated landscapes (USDA Forest Service and USDI BLM 1997). It is estimated that downy brome alone covers over 11 million acres in the West, and that leafy spurge covers 3 million acres (Lajeuness et al. 1998). In addition, some invasive 
species have spread into pristine areas independently of human activities or wildland fire because they compete well and are adaptable. Regardless of whether these species are present because of anthropogenic or natural processes, they may provide a seasonal visual contrast to native vegetation, particularly downy brome, which turns brown and dries during summer and fall when most native plant species are still green.

\section{Future Effects and Their Accumulation}

The proposed vegetation treatments would affect visual resources by changing the scenic quality of the landscape. Vegetation treatments would kill or harm vegetation in the applied area, resulting in a more open, browned or blackened landscape until new plants were to grow in the area. Treatment areas would vary in terms of their visual appeal prior to treatment and their distance from human activity, as well as in terms of the resulting public sensitivity to the pre- and posttreatment visual character of the area. The effects of vegetation treatments on the visual quality of the landscape would be most notable to travelers, sightseers, and residents for the first year to several years following treatment, particularly in treated areas located near major roads or residential areas.

The BLM's treatment program would focus on nearterm vegetation management to improve the likelihood of moving toward or maintaining ecosystem processes that function properly over the long term (50 to 100 years or more from now) and require less treatment in the future to maintain. Through long-term passive management to reduce disturbance factors (e.g., limitations on OHVs, reduction in grazing activity), and active management of forestlands and rangelands (e.g., use of fire, weed removal), landscapes that have been degraded in the past will gradually return to a mosaic of plant community types that are more diverse and visually appealing.

The BLM will continue to pursue initiatives and planning efforts to preserve and protect intact landscapes and restore degraded lands. In addition to the initiatives listed above, the BLM, through land use planning, provides support to the National Landscape Conservation System, Congressionally-designated National Conservation Areas and Monuments, and wilderness and special areas, including Areas of Critical Environmental Concern, by identifying appropriate goals, objectives, and management actions, with public input, to preserve and conserve special public land values.
Other federal, state, tribal, and local agencies, and private conservation groups have also increased their commitment to improving land health and therefore the visual characteristics of lands in the western U.S., including Alaska. Their ability to improve land health will depend on future funding and competing demands on land resources. Given the population growth in the western U.S., and the need to provide food and other resource commodities, visual impacts to lands in the western U.S. will continue to accumulate over the long term. At the same time, continual implementation of Congressional and administrative policies that aim to conserve and enhance resources will provide some countervailing effect to these long term changes.

\section{Contribution of Treatment Alternatives to Cumulative Effects}

Based on the number of acres treated, short-term adverse impacts and long-term improvements to the visual qualities of public lands would be greatest under the Preferred Alternative, and least under the No Action Alternative. The number of acres treated, and the effects to visual resources, would be similar under Alternatives D and E. Effects to visual resources under Alternative C would be intermediate between these alternatives and the Preferred Alternative. Short-term effects from treatments and other human causes would accumulate, but would be offset in the long term through the countervailing effect of treatment success and improvement in the health and visual characteristics of the land.

The risks to non-target vegetation from use of herbicides could be less under Alternative $E$ than under the other herbicide use alternatives because ALSinhibiting herbicides would not be used. Because ALSinhibiting herbicides are effective at very low doses, any drift onto non-target vegetation could temporarily and locally degrade the visual qualities of the affected area.

Regardless of the alternative chosen, there would be a cumulative loss of visual resources. Longer term, these resources should improve, and the cumulative loss should slow.

\section{Wildermess and Other Special Areas}

The toughest challenge faced by the BLM and other federal wilderness land stewards is to keep wilderness wild, and (as stated in the Wilderness Act of 1964) "affected primarily by the forces of nature, with the imprint of man's work substantially unnoticeable" (Hendee and Dawson 2002). The invasion of wilderness 
ecosystems by noxious weeds and other non-native plant species is of great risk to wilderness. Some species have been introduced to wilderness areas by pack stock, livestock that have been specifically brought into these areas, or wild horses and burros, which may travel in and out of wilderness areas. Native migratory wildlife, particularly birds, can be vectors for spreading nonnative seeds in their droppings or on their fur as they migrate through wilderness. Hikers may also bring in weed seeds on their clothing,

\section{Past Effects and Their Accumulation}

There are numerous threats to wilderness and special areas. These threats include: 1) exotic and non-native species; 2) wildland fire suppression; 3) loss of water and deterioration in water quality; 4) fragmentation and isolation of wilderness as ecological islands; 5) loss of threatened and endangered species; 6) deterioration in air quality; 7) motorized and mechanical equipment trespass and use; 8) increasing commercial and public recreation use; 9) adjacent land uses; and 10) urbanization and encroachment. Wilderness and special areas comprise about $4 \%$ of lands in the U.S. As wilderness and special areas often represent the last remaining pieces of many ecosystems, wild conditions, and natural landscapes that have either disappeared or been altered, these threats could have a profound effect on the values of wilderness and special area values now and in the future (Hendee and Dawson 2002). Loss of wilderness values associated with these threats has accumulated in the past and will continue to do so into the future.

Vegetation treatments primarily would address threats 1 through 6. Non-native species are a direct threat to wilderness. Noxious weeds often outcompete native species and spread rapidly, altering native ecosystems to the detriment of wilderness. Secondary impacts can then result from vegetation management, such as use of mechanical methods and wildland and prescribed fire. Although treatments are usually implemented with the intent of restoring native conditions, sometimes management actions cause other perturbations to the ecosystem.

Fire prevention and suppression alter the natural fire frequency of fire dependant ecosystems, leading to changes in ecosystem function and structure. As discussed in Vegetation, fire suppression has led to an accumulation of fuel loads, as well as forest stands dominated by dense concentrations of shade-tolerant trees, that contribute to larger and more intense wildfires. The use of fire and other treatment methods to reduce hazardous fuels and the risk of wildfire should improve ecosystem function on public lands. However, benefits to wilderness and special areas may be minimal because treatments are primarily targeted toward the WUI and priority watersheds, rather than toward wilderness and special areas. In addition, the public is often not receptive to the wildland fire use approach and use of fire and other treatments (especially mechanical) in these areas because they disturb the sense of solitude and wilderness.

Water resources in wilderness and special areas are threatened. In some cases, water storage facilities in wilderness and special areas that were built before passage of the Wilderness Act continue to be used today. The quality of water in some wilderness streams may be affected by runoff from grazed areas and other pollutant sources within and outside of wilderness and special areas.

Because of their small size $(42 \%$ of all wilderness areas in the U.S. are 10,000 to 50,000 acres, and the average size of wilderness areas administered by the BLM is 42,000 acres), most wilderness areas are ecological "islands" that are vulnerable to outside influences. A large fire or infestation of weeds can substantially alter the characteristics of wilderness. Without connectivity to other wilderness areas, it is often impossible for lowmobility species, species with narrow habitat requirements, or species with large home ranges to find enough habitat within the wilderness to survive, or to survive a major fire or other threat to survival.

Polluted air is a threat to wilderness and special areas because of its physical and biological impacts and its accompanying reduced visibility. The wilderness experience can be greatly diminished for visitors to wilderness areas near urban sources of air pollution. Treatments involving the use of fire in wilderness areas would contribute to these impacts.

The remaining threats listed can affect wilderness when they weaken the natural conditions, processes, and variability that were historically part of a wilderness or special area. Most of these threats will increase over time, and their impacts to wilderness resources and values will accumulate.

\section{Future Effects and Their Accumulation}

The goal of wilderness fire management would be to restore fire to its natural role in the wilderness ecosystem. Although benefits would accrue from fire management-reduced hazardous fuels, improved 
wildlife habitat, and a mosaic of vegetation types-the intent of management would be to restore naturalness. In larger wildernesses, land managers also aim to perpetuate landscapes and landscape processes. However, there are limits to fire management. As mentioned earlier, fires can impact regional air quality, escape from within the wilderness and harm people and property, and alter habitat to the detriment of threatened and endangered species. Mechanical and manual treatments can disturb solitude, while chemical treatments can affect plant, animal, and human health and impact the wildness of an area.

In wilderness and special areas, where noxious weeds and other invasive species are limited to small areas, it may be possible to control weed infestations with minimal tools. Introducing and establishing native plants is also necessary to successfully manage weed infestations and restore desirable plant communities (Jacobs et al. 1999). The degree of benefit would depend on the success of these treatments over both the short and long term. Successful management would also require knowledge of the source of weeds and implementation of controls to minimize future spread of weeds onto wilderness and special areas.

Increasing recreational use of wilderness and special areas, which is projected to occur in the $21^{\text {st }}$ century, will put greater pressure on wilderness ecosystems, resources, and values, especially in areas located near major population centers. The BLM, Forest Service, and other federal land management agencies with wilderness protection responsibilities work closely to protect and enhance wilderness values. However, disturbances outside of wilderness boundaries, including urbanization and agriculture, could further isolate some wilderness areas. Approximately $86 \%$ of wilderness acres administered by the BLM are achieving wilderness character as specified by statute, and about $73 \%$ of wilderness study areas are meeting their heritage resource objectives (USDI BLM 2006c). Although impacts to wilderness areas from altered fire regimes and spread of weeds should slow as treatments restore ecosystems and historic fire regimes, loss of wilderness values may be inevitable from other threats identified above, which are outside the agency's control and would continue to accumulate over the long term.

\section{Comtribution of Alternatives to Cumulative Effects}

Based on the number of acres treated, short-term adverse impacts and long-term improvements to wilderness and special areas should be greatest under the Preferred Alternative, and least under the No Action Alternative. The number of acres treated, and the effects to wilderness and special areas, would be similar under Alternatives D and E. Effects to these resources under Alternative $\mathrm{C}$ would be intermediate between these alternatives and the Preferred Alternative. Short-term effects from treatments and other human causes would accumulate. However, a countervailing effect of longterm improvement in the function of wilderness and special areas from successful treatments would offset short-term losses.

Several components of Alternative $E$ pertain to wilderness and special areas (see Appendix I of the PEIS). As discussed in the other resource sections, fewer acres would be treated under this alternative than under the other treatment alternatives.

Under Alternative E, except for treatment of small infestations without motorized equipment, treatments would be prescribed within designated wilderness or wilderness study areas only after the spread of invasive species from outside these areas was effectively halted. Under the other treatment alternatives, however, actions could be taken to control invasive species within wilderness and special areas before controlling invasive species populations outside special areas. The BLM policy is to treat infestations where they are found and to prevent their further spread. By not treating an infestation in a wilderness or other special area until the larger invasive species problem outside of the area is addressed, invasive species populations within wilderness and special areas could grow beyond an effectively treatable level.

The five herbicides (chlorsulfuron, imazapic, imazapyr, metsulfuron methyl, and sulfometuron methyl) that would not be approved under this alternative are some of the least risky herbicides with respect to human health (see Human Health and Safety section). In addition, the ERAs predicted no risk to fish and terrestrial wildlife from most of these herbicides (chlorsulfuron, imazapic, sulfometuron methyl), and a few cases of low risk (imazapyr, metsulfuron methyl), suggesting that the elimination of these herbicides would not likely benefit wildlife and could indirectly harm wildlife in wilderness and special areas if more toxic herbicides were used in their place (see Wildlife Resources section). The other herbicides proposed for use by the BLM pose risks to non-target species that are similar to the risks associated with these five herbicides; therefore, it is uncertain whether this use restriction would actually reduce risk to non-target plants and animals. Thus, avoidance of ALS-inhibiting herbicides 
might provide few, if any, benefits to wilderness and special areas and special area users.

Regardless of the alternative chosen, there would be a cumulative loss of wilderness values and other special area values. Over the long term, these values should improve, and cumulative loss should be slowed.

\section{Recreation}

The BLM's long-term goal for recreation is to provide opportunities to the public for environmentally responsible recreation. Public lands host over 68 million visitors annually. Over 4,000 communities with a combined population of 23 million people are located within 25 miles of public lands. Although much of the focus of the recreation program is on providing visitor services, the BLM's most daunting challenge is to manage travel on public lands. Technological advances in modes of transportation, coupled with the explosive growth of this activity, have created a management challenge to meet these needs while protecting land resources (USDI BLM 2005a). As identified during scoping, the public recognizes the potential for travel access routes to spread weeds and for off-road travel activities to degrade land, leading to conditions that favor the establishment and spread of unwanted vegetation.

Cumulative effects to recreational resources would result from past and future activities that have long-term effects on solitude, naturalness, or primitive/unconfined recreation. Short-term or transient loss of an area's naturalness and solitude from such impacts as temporary roads and noise from equipment would not be cumulative. Therefore, their contribution to the cumulative impacts would be "momentary."

\section{Past Effects and Their Accumulation}

Although the BLM showed interest in recreational activities on public lands in the 1940s and 1950s, it was not until 1961 that the BLM developed a recreation management handbook, and not until 1963 that the agency began an inventory to identify recreation sites and facilities (Muhn and Stewart 1988). Between 1963 and 1968 , the number of recreational visits to public lands more than tripled, and over the next decade visits nearly doubled to about 50 million visitors annually.

With population growth in the western U.S. came an increase in extraction of mineral and other resources, agriculture, road construction, urbanization, and similar types of development, which have altered western landscapes and reduced the amount of land available for recreation. Timber harvesting and livestock grazing, the introduction of exotic species, and the exclusion of fire have also resulted in substantial changes to the landscape, succession and disturbance regimes, and associated vegetation composition, structure, and pattern that have impacted the quality of the recreation experience (USDA Forest Service and USDI BLM 1997). The effects of OHV use on soil and vegetation were first brought to public attention in the late 1960s in the California deserts, and eventually led to the development of a management program for OHV use on public lands and establishment of the Imperial Sand Dunes National Recreation Lands (Muhn and Stewart 1988). OHV and other travel-related activities continue to present challenges for land managers.

Wildfires and the spread of weeds have led to the cumulative loss of recreational resources, although these losses are not irreversible. Wildfires are capable of causing substantial damage to large areas of recreational resources and require long periods of time for recovery. During the recent wildfires that swept through the Great Basin, not only were traditional recreation activities affected, but some special events were altered or cancelled. Signs were destroyed, hiking and camping areas burned over, wildlife and game displaced, and the scenery in the Great Basin marred (USDI BLM 1999). Noxious weeds and other invasive vegetation adversely impact the scenic and recreational qualities of public lands. They displace native vegetation to the detriment of fish and wildlife sought by wildlife viewers, hunters, and fishermen. Given the increase in the number and magnitude of wildfires during the past decade, and a weed population that grows by 1,000 acres a day on public lands, losses of recreational opportunities continue to accumulate (USDI BLM 2006c).

In recent years, several initiatives have been introduced to provide additional recreation opportunities, including the National Landscape Conservation System, Great Basin Restoration Initiative, Sage-grouse Habitat Conservation Strategy, and the Prairie Grasslands Conservation Initiative. All of these initiatives are designed to bring improved management to critical natural systems under the BLM's jurisdiction and to address conservation at the landscape level. Continued implementation of these initiatives will lead to improved recreational opportunities on public lands.

\section{Future Effects and Their Accumulation}

As urbanization of the West continues and the American public's desire to recreate increases, public 
land recreation areas will experience greater usage. Although the satisfaction rating of visitors to public lands is presently $94 \%$, increased usage will inevitably increase the expectations of the public regarding the quality of their recreation experience (USDI BLM 2006c). The trend towards greater limits on public access to privately-held forestlands and hunting and fishing lands, as a result of concerns by landowners over public safety, litigation, vandalism, and damage to natural resources and commodity products (e.g., timber) produced on these lands, will put additional pressure on public lands to meet the recreational needs of Americans.

Vegetation treatments would have short-term cumulative effects. There would be some scenic degradation, as well as distractions to users (e.g., noise from machinery) from treatments. In addition, there would be some human health risks to recreationists associated with exposure to herbicides or smoke from fire. Some areas would be off-limits to recreation activities as a result of treatments, for periods ranging from a few hours to days, or even one full growing season or longer, depending on the treatment. In most cases, recreationists would be able to find alternative sites offering the same amenities or experiences, although a lessened experience could result from more concentrated use in these alternative sites. The effects of herbicide treatments and fire use on fish and wildlife could have indirect negative impacts on recreational activities such as fishing, hunting, and wildlife viewing. For example, aerial application of an herbicide over a large area could adversely affect these types of recreation activities by harming or displacing fish and wildlife species. Vegetation treatments could also impact scenic views, particularly those located next to roads. The effects of vegetation management on the visual quality of the landscape are discussed further under Visual Resources.

The BLM's treatment program would focus on nearterm vegetation management to improve the likelihood of moving toward or maintaining properly functioning ecosystems in the long term (50 to 100 years or more from now). Through passive management to reduce disturbance factors (e.g., closure of roads, reduction in grazing activity), and active management of forestlands and rangelands (e.g., through use of fire, weed removal), the BLM hopes to restore a mosaic of plant community types that are more diverse and visually appealing than those in lands that are not functioning properly. Vegetation treatments that reduce hazardous fuels, restore natural fire regimes, and control weeds and other invasive vegetation would slow the loss of recreational opportunities and the reduction in quality of the recreation experience. In addition, treatments that reduce the risk of wildfire would reduce the likelihood of recreationists being displaced from their favorite hunting, fishing, and camping sites by wildfires. Treatments in public use facilities (e.g., campgrounds, visitor centers) could have short-term impacts, but would enhance the visitor experience and ensure continued high-satisfaction ratings from visitors over the long term.

\section{Contribution of Alternatives to Cumulative Effects}

Based on the number of acres treated, short-term adverse impacts and long-term improvements to recreation resources on public lands would be greatest under the Preferred Alternative, and least under the No Action Alternative. However, based on visitor use days, the number of visitors to public lands in states where the majority of treatments would take place, as a percentage of all visitors to public lands, is small in relation to the number of acres treated in those states (USDI BLM 2006d), suggesting that effects to recreationists could be less than expected based on treatment acreage.

Alternative $\mathrm{E}$ places greater emphasis on passive restoration than the other alternatives. Passive restoration is often a critical first step in successful restoration of degraded areas, since it entails halting anthropogenic activities that are causing degradation or preventing recovery. OHVs are often cited as a factor contributing to loss of resource function and degradation of scenic quality. By controlling OHV use, improvement in recreational values can be expected (Kauffman et al. 1997). However, the BLM would have to balance resource protection with the multiple use requirements under FLPMA. As discussed in Chapter 2 of the PEIS, Vegetation Treatment Planning and Management, passive restoration would be considered when developing restoration management plans, and would be used to the extent possible within the constraints of FLPMA.

Regardless of the alternative chosen, there would be an accumulation of loss of recreation resources. Longer term, these resources should benefit from the proposed treatments and cumulative losses should slow.

\section{Social and Economic Values}

The western U.S., including Alaska, is more sparsely populated than the rest of the U.S., containing about 
$32 \%$ of the total U.S. population, but comprising approximately $65 \%$ of the total land area. However, population growth between 1990 and 2000 averaged over $16 \%$, which was slightly higher than the national average. Many of the western states exceeded the national average, with growth rates of $20 \%$ or higher during this time period.

The western U.S. contains a large percentage of the nation's minority populations, including over $60 \%$ of the nation's Hispanics and American Indians, and over $50 \%$ of the nation's Asian/Pacific Islanders. In particular, Arizona, California, New Mexico, and Texas contain large Hispanic populations, which comprise from $25 \%$ to over $40 \%$ of the total population in each of these states. Over $15 \%$ of Alaska's population is comprised of Alaska Natives. Federal agencies must be cognizant of the needs of these peoples when formulating management decisions. Executive Order 12898, Environmental Justice, requires that federal agencies address the potential for their actions to have disproportionate effects on minority populations and/or low-income populations.

Population growth can stimulate economic growth and provide economic diversification. However, development in support of the growing population is encroaching on previously undeveloped areas near public lands. Growth also increases demands on public lands for timber, minerals, livestock grazing, and other commodities, and for recreation and roads. Because public lands and open space are an important component of the western landscape, they are valued by westerners, who expect the BLM to manage public lands to ensure their protection and enhancement. These conflicting demands can make it challenging for BLM land managers to meet the multiple need requirements under FLPMA, while still preserving the natural characteristics of the landscape.

Agency social and economic policy has long emphasized the goal of supporting rural and tribal communities by promoting the continued production of goods and services from public lands for those communities deemed dependent upon timber harvest and proccssing, mineral extraction, and livestock forage. In addition, the BLM promotes the use of services provided by communities in support of BLM management activities (e.g., firefighting and herbicide applications; USDA Forest Service and USDI BLM 2000, USDI BLM 2006c).

\section{Past Effects and Their Accumulation}

Population. Population growth rates in much of the West exceed those of the rest of the country. Nevada, Arizona, Idaho, and Utah have been among the fastest growing states in the U.S. in recent years; between 1970 and 2000, Nevada's population grew 309\%, while the population of the rest of the country grew only $38 \%$. This growth has placed increasing demands on public lands and other open spaces for recreation, and for providing the natural resources needed to support growth in this region and in the world.

Population growth has been highest in the WUI. Increasing migration to rural areas with a high quality of life is expected to continue as our country moves toward a more service-based economy (USDA Forest Service and USDI BLM 2000). Growth in the WUI, however, has increased the risk of wildfire to people and property, and has impacted fish and wildlife habitat use and movements among public lands, rural areas, and the WUI.

Environmental Justice. The western U.S. contains a large percentage of the nation's minority populations. These populations use public lands, and Native Americans and Alaska Natives depend on public lands for food and other traditional lifeway values. Many individuals in the forestry, mining, oil and gas, and service sectors also derive work from public lands. Native American, Alaska Native, and Hispanic populations increased at 2 to 4 times the rate of growth of the population as a whole during the past decade, suggesting that ever greater numbers of minorities use public lands for pleasure and work and have the potential to be affected by vegetation treatments and other activities.

Employment and Income. Over 23\% of the nation's employment opportunities, amounting to over 40 million jobs, are located in the western U.S. (Table 317). Employment in the trade and services industries accounts for over half of the total jobs. Industries related to natural resources, such as agriculture and mining, are important sources of employment and represent nearly one third of the nation's agricultural services, forestry, and fishing jobs. Recreation and tourism associated with public lands provide many jobs in the services sector. For example, an estimated $\$ 1.3$ billion was spent by hunters and anglers on hunting and fishing supplies while using public lands, and $\$ 1.7$ billion was spent by wildlife viewers using public lands during FY 2005 (USDI BLM 2006d). Changing federal land uses have affected the number and types of jobs associated with 
public and other federal lands. For example, jobs associated with the timber industry have declined in recent years as the amount of timber harvested on federal lands has declined, while recreation employment has increased. In addition, some industries, including timber harvesting, wood products manufacturing, and mining, have become more mechanized, reducing employment opportunities over time. Still, sales of timber, wood products, and non-wood forest products from public lands totaled approximately $\$ 36$ billion, and leasable minerals generated $\$ 38.9$ million, in FY 2005 (USDI BLM 2006c, d).

Vegetation treatments have likely had minimal impact on employment and income in the West. However, increased federal budgets for wildland fire suppression and restoration of natural fire regimes have increased employment and income in communities that have supported these efforts. For example, $\$ 201$ million was spent on hazardous fuels reduction treatments and \$25 million was spent by the BLM on Emergency Fire Stabilization and Rehabilitation Projects during FY 2005 (USDI BLM 2006b, c)

Perceptions and Values. Survey research shows differences in the opinions of residents of small, rural towns and residents of larger urban areas. Residents of urban areas tend to be more concerned about environmental protection, be less sympathetic to local economic impacts, and have greater trust in the federal government and environmental organizations than do residents of rural areas (Harris and Associated 1995 cited in USDA Forest Service and USDI BLM 2000). Rural residents want less government intrusion into their lives, and believe that current government policies tend to favor the environment too much over jobs. Rural residents seek a balance between the environment and jobs, enjoying the open spaces and clean air and water that public and other federal lands provide, while still wanting jobs so that they and their children will be able to remain in the community. In recent decades, federal land management policies have discouraged employment in some sectors (e.g., forestry), while promoting employment in others (e.g., oil and gas and other mineral exploration and development). However, some of the values that rural westerners associate with public lands, including clean air and native vegetation, have been lost or degraded by the increase in the number and severity of wildfires and the spread of noxious weeds and other invasive vegetation.

Revenues. Mineral leases, recreation and grazing fees, and sale of timber are important sources of revenue for the federal government, although the contribution of each to the U.S. Treasury fluctuates in response to the national and global economy and national and local policies. For example, the amount of revenue collected from mineral leases and permits and recreation fees in FY 2005 was about 4 times that collected in 1996, which reflected national energy policies, higher energy prices, and increases in the recreating population. In contrast, in 2005 timber sale revenues were 4 times less, and grazing fee collections were about $15 \%$ less, than in 1996 (USDI BLM 2006c). Timber sale reductions reflect policies that have discouraged timber harvesting on federal lands in response to concerns over the loss of forest wildlife, including the spotted owl, and forest habitat, including mature and old-growth forests. Livestock use reductions reflect continuing resource damage and implementation of protections for federally-listed plant and animal species (USDA Forest Service and USDI BLM 2000).

Expenditures. The BLM makes payments to counties to compensate them for the non-taxable status of federal lands in their jurisdiction. Generally, there is a per acre payment associated with the county population, (payments in lieu of taxes, or PILT) and an additional revenue-sharing payment based on revenues received from the sale of timber, grazing fees, recreation fees, special use permits, and other uses. There is concern in counties over the potential loss of revenue if changes in federal land uses cause a decline in timber harvest or other resource revenue. However, since 1996, payments have doubled, with the largest gains seen in states with an active mining and oil and gas industry (e.g., Alaska and Nevada).

Effects on Private Property. The value of rural property has increased in recent years as the population has increased and more people are able to move to rural areas or buy second homes for recreation, retirement, or as investment property. In some areas, however, it is likely that recent wildfires have depressed home values, either because of the future risk of fire, or because of land degradation associated with recent fires.

\section{Future Effects and Their Accumulation}

Population. None of the proposed treatment methods being analyzed is likely to cause substantive changes to existing patterns and trends in population or demographic conditions in the western states. In particular, it is unlikely that vegetation treatments would either exacerbate or counteract the trend toward outmigration from small rural communities. Effects of growth upon the landscape would continue to accumulate. 
Environmental Justice. As Hispanic, Native American, and Alaska Native populations grow, the likelihood of these groups using public lands is likely to increase. With increasing levels of treatment, the possibility increases that any significant effects associated with vegetation treatments would disproportionately affect these minority populations. However, there are no data to suggest that there is any relationship between treatment areas and areas of low income or minority population, because treatment areas are widely scattered across the landscape. The BLM is proposing to use new herbicides that are less harmful than many currently-available herbicides, and would likely use even safer herbicides in the future. This could reduce health risks to minority groups and to the general public on a per-acre basis.

Employment and Income. Based on an assessment done for the BLM and Forest Service for the Interior Columbia Basin, recreation and tourism associated with public lands are expected to show little change during the next decade (USDA Forest Service and USDI BLM 2000). If fuel prices remain high, fewer people may travel to public lands for recreation. Jobs associated with the timber industry could increase as more timber is harvested to restore natural fire regimes and reduce the risk of wildfire. Employment in mining and oil and gas industries would reflect the global economy. However, since many of the available and potential oil and gas and mineral resources in the U.S. are located on public lands, and since the need for these resources is likely to continue to grow, these industries will continue to be important employers in the West.

Vegetation treatments will have a minimal impact on employment and income in the West. However, increased federal budgets for vegetation treatment activities discussed in this PEIS, and wildland fire suppression and restoration of natural fire regimes, would increase employment and income in communities that provide support to these efforts.

Perceptions and Values. The treatment alternatives would be associated with a range of stakeholder perceptions and values. For example, individuals who have an aversion to chemical use in the environment could find all of the alternatives undesirable. Alternatively, individuals with a much greater concern about wildfires or the effects of invasive species would likely favor the most efficient means of attacking vegetation problems that could lead to catastrophic fires. As the number of acres treated could increase 3-fold from current levels, it is likely that both groups would be affected by treatments. Some westerners have philosophical issues with government ownership and management of large land areas, but they might be somewhat encouraged by plans to employ private contractors for some of the treatment work and would presumably favor the most efficient means possible to reduce fire risk to protect and maintain range productivity.

Revenues. Certain commercial activities that occur on public lands could be adversely affected by vegetation treatments over the short term, such as OHV tours or guide and outfitter operations. Vegetation treatments would not directly affect mineral resources and would be unlikely to cause significant reductions in BLM revenues generated from mineral leases. Vegetation treatments to reduce fire risk in forested areas would serve to protect commercially valuable timber from loss through catastrophic fire (USDA Forest Service and USDI BLM 2000).

Vegetation treatments could necessitate closures of some sites to grazing activities during treatments and for a suitable recovery period afterward, usually two growing seasons, both for effectiveness of the treatment and, for some methods, for safety of the livestock. Treatments that require temporary rest from grazing would force livestock operators to find alternative forage sources on private or other lands, which could lead to increased costs for the same amount of revenue. Livestock grazing on lands administered by the BLM and Forest Service in the Interior Columbia Basin is projected to decline about $1 \%$ annually to ensure protection of rangeland habitats and special status species. It is likely that alternative sources of forage will become scarcer as population growth leads to greater use of private pasturelands for crop production and urban uses.

Recreation-based businesses such as outfitters, bait shops, OHV sales and repair shops, fish and hunting shops, and outdoor gear and equipment rental shops are direct beneficiaries of recreation use of public lands. Other services such as gas stations, restaurants, and hotels that are frequented by recreationists also benefit. Temporary closures of recreation areas due to treatments would reduce revenues from these sources. As discussed above, recreation activity on public lands is expected to remain near current levels over the next decade.

Expenditures. Vegetation treatments would require a large commitment of financial resources by the BLM, which would vary by treatment method, location, terrain and other factors. Using guidance from the Healthy 
Forests Initiative, the National Fire Plan, and the 10Year Comprehensive Strategy Implementation Plan, the USDA and USDI are proposing to spend $\$ 770$ million during FY 2007 for wildland fire management. Of this, nearly $\$ 200$ million would be spent on hazardous fuels treatments and \$24 million on land rehabilitation (USDI BLM 2006b). In addition, funding to conduct additional vegetation treatments would come from other program budgets within both agencies for program-specific treatments. These benefits would accumulate in the communities where the funds were spent. Over $\$ 984$ million was spent by the federal government to control wildland fire during 2005, and based on modeling done for the cohesive strategy, even greater sums may be needed in the future to manage wildfire risk (Hann et al. 2002; USDI BLM 2006c).

A major component of vegetation treatments, as proposed under the National Fire Plan and 10-Year Comprehensive Strategy Implementation Plan, is to promote community assistance. In FY 2004, assistance with fuel hazard treatments, risk assessment plans, and other wildfire preparedness was given to over 14,000 communities by the USDA and USDI. The agencies also initiated approximately $\$ 140$ million in contractual actions.

Effects on Private Property. Vegetation treatments could affect private property in the vicinity of public lands, particularly parcels adjacent to treatment areas. Over the short term, there would be minor risks for property damage associated with treatments because it is possible that some treatment effects would extend beyond BLM boundaries onto private property. Long term, treatments that reduce the risk of loss of property to wildfire and improve the scenic and recreational values of public lands should increase property values near public lands.

\section{Contribution of Treatment Alternatives to Cumulative Effects}

The costs of prescribed fire range from $\$ 50$ per acre to $\$ 1,300$ per acre depending on the location of the burn, but the cost in most circumstances would be about $\$ 290$ per acre in the WUI, and $\$ 105$ per acre outside the WUI based on average treatment costs during 2002 to 2005 (USDI BLM 2006c). The range of costs for mechanical treatments is also quite broad: from $\$ 100$ to $\$ 600$ per acre. Estimated costs for manual treatments range from $\$ 70$ to $\$ 700$ per acre. Costs for biological treatment vary depending on the type of organism employed. Use of domestic animals - cattle, sheep or goats-is quite inexpensive, in the range of $\$ 12$ to $\$ 15$ per acre. Use of biological control agents such as insects, nematodes, mites or other pathogens is more costly, ranging from $\$ 80$ to $\$ 150$ per acre for ground applications and $\$ 150$ to $\$ 300$ per acre for aerial applications. As itemized in the PEIS, the overall average cost per acre would be approximately $\$ 96$ per acre for treatment involving both ground-based and aerial applications.

Based on the number of acres treated as discussed under treatment acreages in Chapter 2 of the PEIS, estimated annual treatment costs would be greatest under the Preferred Alternative ( $\$ 1.4$ billion) and lowest under Alternative A (\$420 million). Treatment costs for the other three alternatives are estimated at $\$ 1.1$ billion annually. Short-term adverse impacts in terms of costs and long-term improvements in terms of resource benefits would be greatest under the Preferred Alternative, and least under the No Action Alternative. The other three alternatives would be intermediate between these two. However, the contribution of treatment actions to the economy of the western U.S. would be minor.

\section{Human Health and Safety}

When addressing cumulative impacts to human health and safety, the impacts to individuals conducting vegetation treatments, as well as the effects of these treatments (or lack of treatment) on the welfare of the public must be considered. In addition, it must also be acknowledged that vegetation treatments to improve ecosystem resilience and promote the welfare of the public are a cooperative effort among federal, tribal, state, and county land-management agencies, as well as other local and private cooperators. The bulk of the responsibility, however, falls upon the BLM and Forest Service because of the large amounts of public land they administer in the WUI. Finally, it must be taken into consideration that it will take many years before measurable results are achieved.

\section{Past Effects and Their Accumulation}

Risks to public health in areas in close proximity to public lands include risks from occupational injury and death, from exposure to industrial pollutants, including pesticides and herbicides, from cancer, and from wildfire.

Occupational Risks. In 2005, more than 29 million nonfatal injuries were reported in the United States (CDC 2007a). Some chronic injuries are directly linked to the nature of the work performed. For example, vibration syndrome affects a large proportion of 
workers using chippers, grinders, chainsaws, jackhammers, or other handheld power tools, causing blanching and reduced sensitivity in the fingers. Noiseinduced hearing loss may also affect production workers who are exposed to noise levels of 80 decibels or more on a daily basis. Still, since 1992, the nationwide nonfatal injury rate has declined by about $34 \%$ (CDC 2007a).

The occupational fatality rate in 2005 was approximately 4.0 fatalities per 100,000 employed. The fatality rate for the agriculture, forestry, fishing, and hunting sector was the highest, at 32.5 fatal industries per 100,000 workers. The mining sector had the second highest rate, at 25.6 fatalities per 100,000 employed. The largest number of fatal work injuries resulted from construction-related incidents, which accounted for $21 \%$ of workplace fatalities in 2005 (U.S. Department of Labor Bureau of Labor Statistics 2007). In 1994, the occupational fatality rate was 5.3 per 100,000 employed. During the past decade, the trend in the fatality rate has steadily declined (Centers for Disease Control and Prevention 2005). Deindustrialization and greater emphasis on safety in the workplace are factors often cited as accounting for the downward trend in occupation injury risk in the U.S. (Loomis et al. 2003).

Only minor injuries have occurred to workers involved in vegetation treatment activities on public lands during the past decade. As discussed under Human Health and Safety in the PER, there are minor risks to workers from treating vegetation, primarily associated with the operation of heavy equipment and power tools, and the use of fire and herbicides. Workers would follow SOPs to minimize the risk of injury when treating vegetation, including using protective equipment, and using herbicides with low health risks.

Cancer Risks. Based on the data shown in Table 3-25, cancer accounted for between $13 \%$ and $33 \%$ of all deaths in the treatment states in 2002-2003. Nationwide, cancer accounts for approximately $23 \%$ of all fatalities (National Center for Health Statistics 2007b). In the western U.S., cancer mortality rates are generally highest in counties in western and southern Nevada and northern California, and lowest in counties in Utah, central Colorado, and northern New Mexico (Devesa et al. 1999). Cancer rates increased during most of the $20^{\text {th }}$ century, but began to decline in the 1990s for the leading causes of cancer (Wingo et al. 2005). Improved detection and treatment, along with healthier lifestyles, are believed to account for the declining rates.
Several herbicides used by the BLM could cause cancer in workers and the public based on exposure scenarios evaluated in HHRAs done for earlier EISs. These include 2,4-DP, asulam, atrazine, bromacil, and simazine (see Tables 4-31 and 4-32). With the exception of atrazine, cancer risks were only predicted for accidental exposure scenarios. In the case of atrazine, cancer risks were predicted for maximum and accidental exposure scenarios (USDI BLM 1991a). Except for bromacil, these chemicals have not been used by the BLM since at least 1997, and bromacil is used on less than $1 \%$ of the total acreage treated using herbicides.

Exposure to Pollutants. Exposure to industrial pollutants and toxic chemicals, including those produced by industries operating on public lands (e.g., mining, oil and gas), is a public health concern. The Toxics Release Inventory (TRI) is the principal source of data for analyzing the amount of toxic chemicals used in American industry. Although data on recent trends in toxic emissions are confusing due to differing data reporting requirements, the overall trend in toxic emissions since 1988 is downward, a sign of the increasing efficiency and dematerialization of our economy (Hayward 2005).

Air pollutants have the potential to impact the health of people using or living near public lands. The USEPA has identified criteria pollutants that affect air quality and human health (see Air Quality in Chapter 3). Despite increases in human population and industrialization, emissions of principal air pollutants in the U.S., after peaking in the 1970s and early 1980s, have generally declined or held steady during the past 2 decades due to more stringent air quality regulations and improvements in pollution control technology (USEPA 2005).

Particulate matter is the principal pollutant of concern, from a public health perspective, for activities occurring on public lands. Nationwide, emissions of particulate matter from all sources have trended downward since the 1970s. However, PM emissions have shown a close relationship with the number of acres burned annually by wildfire. Since 1990, PM emissions associated with wildfire have ranged from 145,000 tons in 1995 to 1.2 million tons in 2002; the number of acres burned by wildfires in 1995 was onethird the number of acres burned in 2002. The level of PM associated with slash and prescribed burning, however, has trended downward since the $1970 \mathrm{~s}$, and in 2001 (165,000 tons) was about half the level of the early 1990s. Based on an estimate of emissions generated by current vegctation treatment activities 
(primarily fire and mechanical treatments; see Table 4-4 in PER), BLM treatment activities have accounted for less than $0.5 \%$ of criteria pollutant emissions nationwide.

Herbicides contain chemical compounds that are harmful to human health. Most of the herbicides used by the BLM do not pose a risk to human receptors when applied at the typical application rate. At the maximum application rate, however, more herbicides, in a greater number of exposure scenarios, have the potential to adversely affect human health. Aerial applications of herbicides pose a greater risk to the public due to offsite drift than ground applications, as herbicides applied at greater distances from the ground are able to drift farther from the target application area. Spot applications would be less likely to pose a risk to downwind receptors than boom/broadcast applications. However, spot applications would be more likely to pose a risk to workers charged with applying the herbicide through dermal contact.

In recent years there has been concern regarding the potential for herbicides used by the BLM or other federal, state, or private applicators to contain compounds that are endocrine disruptors. According to the World Health Organization (2002), endocrine disrupters have been defined as exogenous substances that alter function(s) of the endocrine system and consequently cause adverse health effects in an intact organism or its progeny, or in (sub)populations. Endocrine disrupters interfere with the functioning of the endocrine system in at least three possible ways:

- By mimicking the action of a naturallyproduced hormone, such as estrogen or testosterone, and thereby setting off similar chemical reactions in the body;

- by blocking the receptors in cells receiving the hormones (hormone receptors), thereby preventing the action of normal hormones; or

- by affecting the synthesis, transport, metabolism and excretion of hormones, thus altering the concentrations of natural hormones.

During the toxicity review for the HHRAs, no endocrine disrupting effects were noted. The toxicity review consisted of a literature search and a review of USEPA registration data. In order to further evaluate whether any of the BLM herbicides have endocrine disruption effects, the BLM conducted a search of endocrine disrupter databases, including sources from the U.S., the European Union, and Japan. The databases included official government lists and lists published by concerned citizen groups, such as the Pesticide Action Network. The results of this search are presented in Table D-5 in Appendix D. With the exception of 2,4-D and diuron, none of the BLM herbicides were included among those associated with endocrine disrupting effects. As shown in the table, diuron and 2,4-D are listed by the European Commission Directorate-General for the Environment (2000) as Category 2 chemicals, meaning that there is evidence of the potential for the listed chemical to cause endocrine disruption. Diuron only appeared on a single list, so there is some uncertainty within the scientific community about this chemical's status as an endocrine disruptor.

Several other lists include $2,4-\mathrm{D}$ as a potential or probably endocrine disrupting chemical. However, the Endocrine Disruptor Knowledge Base supported by the U.S. Food and Drug Administration's National Center for Toxicological Research indicates that there are no reports in the scientific peer-reviewed literature of 2,4-D acting as an estrogen receptor binder.

The USEPA Health Effects Division (HED) HHRA that was used in the RED, and a correction to the HED HHRA provided by the 2,4-D Industry Task Force, were reviewed. The HED HHRA and Task Force correction provided additional detail regarding the studies used to test for potential endocrine effects. In general, the studies cited as showing evidence of endocrine disruption effects were conducted using extremely high doses of 2,4-D, where often renal saturation or other systemic effects were noted. The findings of these studies, therefore, do not indicate that 2,4-D has selective toxicity to the endocrine system.

In the health risk assessment conducted to support the reregistration of 2,4-D (USEPA 2004c), the USEPA concluded that there is not sufficient evidence that 2,4$\mathrm{D}$ is an endocrine disrupting chemical. The USEPA did not conduct the health risk assessment using endocrine disruption endpoints. Since the current studies that showed evidence of endocrine effects were tested using doses above renal saturation, the USEPA recommended formal testing of 2,4-D for endocrine endpoints. However, there is no standard protocol for determination of endocrine effects of chemicals.

The lack of a standardized and broadly accepted set of protocols for identifying and quantifying potential endocrine effects has very important implications. The absence of such a test has contributed to the development of several, potentially conflicting, 
summaries of potential endocrine disruptors. As importantly, in the absence of an agreed upon process to quantify dose-response relationships, quantitative risk assessments are difficult and highly uncertain.

Nationwide, the annual amount of herbicide use has declined from an estimated 620 million pounds of active ingredient in 1982 to 553 million pounds in 2001, although the amount of herbicide use has remained relatively steady since the late $1980 \mathrm{~s}$. The amount of other pesticides used has also declined by about $15 \%$ during the same period (Donaldson et al. 2004).

Vegetation treatment activities by the BLM, Forest Service, and other agencies, for agricultural and other uses, have contributed to the release of harmful materials into the environment. As discussed above, prescribed fire use has steadily increased during the past decade and has contributed to PM emissions. Heavy equipment, transport vehicles, and power tools have also contributed minor amounts of PM and other pollutants into the atmosphere. Herbicide use by the BLM, Forest Service, agricultural operations, and others has steadily increased, but these users have emphasized the use of less toxic herbicides that have shorter halflives and do not bioaccumulate. Users have also kept application rates as low as possible, to minimize the amount of toxic material released into the environment while still meeting treatment goals. In addition, these users have increased passive treatments and nonherbicide treatments, such as biological control, to minimize the use of herbicides in vegetation control.

Risks from Wildfire. Wildfires cause loss of life and property. According to the National Interagency Fire Center (2005), 12 people died from wildland fire accidents in 2005. During 1999 to 2005, 149 individuals died from wildland fire accidents, including agency personnel, contractors, volunteers, and private individuals. The largest number of fatalities was associated with use of a vehicle or ground-based mechanical equipment $(23.8 \%)$, heart attacks $(22.7 \%)$, use of aircraft $(22.3 \%)$, or burnovers $(20.2 \%)$. During 2005 , wildland fires resulted in the loss of 240 primary structures, many on or near BLM- or Forest Serviceadministered lands (USDI BLM 2006c).

Growth in the western U.S. has exceeded that of the rest of the country, and while the region remains more rural than the rest of the country, over 23 million people now live within 25 miles of public lands (USD1 BLM 2006c). As wildfires have become more severe, the associated risks to life and property within the WUI have increased. Because of concern about this risk, the
Department of the lnterior stepped up efforts to reduce hazardous fuels in the WUI from 164,000 acres in 1991 to over 506,168 acres in FY 2005. Despite these efforts, over $\$ 91$ million was spent by the BLM in 2005 on fire control, much of it in the WUI (USDI BLM 2006c).

\section{Future Effects and Their Accumulation}

Occupational Risks. It is projected that incidence of occupational injury and death will continue to decline as our nation moves to a more service-oriented economy. Occupations with higher risk of injury and death will continue to be associated with rural areas and public lands; risks in these areas will likely be greater than in more urbanized areas. However, continued improvement in equipment and emphasis on workplace safety should help to reduce risks of occupational injury and death in the West.

Out of the various treatment activities, mechanical treatments and herbicide use pose the greatest risk to worker health. The number of acres treated using herbicides and mechanical methods will increase 3-fold under the Preferred Alternative. Thus, risks of injury associated with equipment could also increase 3 -fold, and permanent injuries and loss of life could accumulate. It is likely that risk to workers from application of and exposure to herbicides would not be as great as at present, since the BLM would place the greatest emphasis on use of herbicides that have low risk to humans. For example, three of the four herbicides proposed for use by the BLM would pose essentially no risk to humans under exposure scenarios modeled in the HHRA.

Cancer Risks. Cancer rates have declined for over a decade, and are likely to continue to do so with improvements in lifestyle and our ability to recognize and treat the underlying causes. Cancer risks for workers conducting fire and herbicide treatments on public lands could increase because more acres would be treated by these methods. However, risks to workers would be lessened by improvement in equipment and treatment technologies and use of newer herbicides, including those proposed for use in this PEIS, that pose no known cancer risk.

Exposure to Pollutants. The trend in pollutant emissions is expected to continue to decrease nationwide. For example, the USEPA projects that emissions from automobiles will decline by more than $80 \%$ over the next 25 years as Americans shift to more fuel efficient and less polluting vehicles and use fuels that have been developed to reduce emissions. Industrial 
pollution is also expected to decline as our economy becomes more service-based (Hayward 2005).

The proposed increase in use of fire by the BLM, Forest Service, and other federal and state land management agencies to restore natural fire regimes and reduce hazardous fuels could increase the amount of smoke, and therefore the incidence of health effects associated with PM and other harmful constituents of smoke in the West. The Forest Service modeled several scenarios to predict the long-term effect of treating more acres and/or targeting treatments in the WUI on regional air quality and the condition of the land (USDA Forest Service and USDI BLM 2000). The model assumed that in the WUI, where air quality and other considerations could limit the use of fire, mechanical and hand cutting would be important treatment options, in addition to use of fire. According to the model, air quality would generally improve as the number of acres treated annually increased, and improvement in air quality would be most noticeable for treatments targeted at high priority western U.S. WUI landscapes. Thus, the proposed action, which includes over 4.3 million acres of fire use and mechanical treatments, in addition to 1.7 million acres of treatments using other methods, would be expected to provide greater improvement in ecosystem function and air quality than is projected under current treatment methods (see Air Quality).

Risks to the public and workers on or near public lands from exposure to herbicides could increase as a result of the increase in herbicide use. To reduce this risk, the BLM would primarily use herbicides that have low risk to humans, including new herbicides proposed for use as part of this PEIS, and would continue to identify and make available to field offices herbicides that have lower risk to workers than currently-available herbicides.

Risks from Wildfire. In response to the threats of wildfire and invasive vegetation and noxious weeds, the President and Congress have directed the USDI and BLM, through implementation of the National Fire Plan (USDI and USDA Forest Service 2001), and the Healthy Forests Restoration Act of 2003, to take more aggressive actions to reduce catastrophic wildfire risk on public lands. The intent of these actions is to protect life and property, and to manage vegetation in a manner that provides for long-term economic sustainability of local communities, improved habitat and vegetation conditions for fish and wildlife, and other public land uses.
Treatment activities to reduce fire risk include timber harvest, thinning, prescribed fire, fuel reduction activities, greenstrips, brush reduction, and effective suppression efforts. While prescribed fire is not without risk, it is generally safer to burn under the controlled conditions of prescribed fire than to chance a wildfire when fuels are extremely dry and weather conditions are unfavorable.

The proposed treatment program would restore natural fire regimes and encourage the growth of native vegetation that is more resilient to wildfire, reducing the risk of wildland fire. If plant community structure, species composition, and disturbance regimes return to near historical ranges, then disturbances should have effects that are similar to historical effects, which would be less severe, and result in less fire danger, than at present. Because of the limitations on the types and amounts of treatments that can occur in the WUI, it may be more difficult to restore natural fire regimes on lands in the WUI than on non-WUI lands, but over the long term, benefits to the WUI should accrue and the loss of life and property associated with wildfire should slow or begin to decrease (USDA Forest Service and USDI BLM 2000; USDI BLM 2006c).

An assessment of risks to people and property from varying levels and types of treatments was done for the cohesive strategy. Assuming funding levels remained static and two-thirds of treatments were targeted for the WUI, risks to people and property would remain near current levels after 15 years (Hann et al. 2002). If more funding was provided, it would be possible to substantially reduce the risk that life and property would be lost.

\section{Contribution of Treatment Alternatives to Cumulative Effects}

As discussed above, short-term risks to human health are related to the types of treatments and methods used, and the number of acres treated. Based on number of acres treated, the greatest risk to human health would occur under the Preferred Alternative, and the least risk would occur under the No Action Alternative. The other alternatives would likely be intermediate between these two.

Risks associated with fire use and mechanical, manual, and biological control treatments would be similar for the four action alternatives, which differ primarily in the types of herbicides available for use and number of acres treated. Risks associated with herbicide use could be less under alternatives $C, D$ and $E$ than under the 
Preferred Alternative, because fewer acres would be treated and aerial spraying would be prohibited (Alternatives $\mathrm{C}$ and $\mathrm{D}$ ) or discouraged (Alternative $\mathrm{E}$ ). The risk of off-site drift would be less under these alternatives, with no risk under Alternative C. Alternative $\mathrm{E}$ would prohibit use of ALS-inhibiting herbicides, some of which have less risk to humans than herbicides that would be allowed under this alternative. About one-third as many acres would be treated using herbicides under the No Action Alternative, compared to the other alternatives. However, the BLM would be able to use several herbicides (2,4-DP, asulam, atrazine, fosamine, mefluidide, and simazine) under the No Action Alternative that pose high risks to human health, but that would not be available for use under the other herbicide treatment alternatives.

Alternative E places greater emphasis on passive restoration than the other alternatives and would result in fewer risks or injuries to workers due to less emphasis on the use of mechanical, herbicide or fire treatments. Alternative E also focuses more hazardous fuels treatments in the WUI, and encourages practices to reduce vegetation near homes and to develop a defensible space in the WUI to reduce risks to people and property from wildfires.

Regardless of the alternative chosen, there could be an accumulation of injury or loss of human life from treatments, and there would be a cumulative loss of property from wildfires. Over the long term, restoration of natural fire regimes and improvement in ecosystem health should reduce risk to human health from activities originating on public lands and affecting public land users or those living near public lands.

\section{Unavoidable Adverse Effects}

This section summarizes the unavoidable adverse effects that would occur under the actions considered in the PEIS and PER. Unavoidable adverse effects would primarily be associated with the use of herbicides and fire.

\section{Air Quality}

An increase in emissions of air pollutants would occur as a result of all the action alternatives. However, air quality standards would not be exceeded under any of the alternatives (see Air Quality Modeling for BLM Vegetation Treatment Methods [ENSR 2005m] and Annual Emissions Inventory for BLM Vegetation Treatment Methods [ENSR 2005a] that are found on the
CD that accompanies the PEIS and on the BLM website at hitp://www.blm.gov).

\section{Soil Resources}

Regardless of the method used to remove vegetation, vegetation treatments would potentially result in adverse short-term impacts through increased erosion and reduced water infiltration, leading to loss of soil and reduced soil productivity. The degree of these effects would vary by region, depending on climate, landform, hydrology, soil, vegetation, and land use. In many western U.S. regions, the combination of hydrologic characteristics, steep topography, and slow vegetative growth make soil erosion a serious concern (Kennard and Fowler 2005).

Vegetation treatments could disturb biological soil crusts, potentially reducing soil quality and ecosystem productivity. The extent of impacts to biological soil crusts would be dependent on the intensity and kind of disturbance and the amount of area covered. The duration of the effects would vary, but recovery of biological soil crusts typically takes much longer than the recovery of vascular vegetation.

\section{Water Resources and Quality}

An increase in soil erosion and surface water runoff could result from vegetation removal, which could lead to stream bank erosion and sedimentation (Ott 2000). Rates of runoff would be influenced by precipitation rates, soil types, and proximity to the treated area. All vegetation removal activities could disturb the soil and reduce the amount of vegetation binding to soil, potentially causing erosion and increased sedimentation. The removal of vegetation would decrease the amount of rainfall captured by plants, detritus, and soil, potentially leading to increased stormwater flows, runoff velocity, and sedimentation. Herbicides have the potential to directly impact surface water quality or leach through the soil and impact groundwater quality.

\section{Wetland and Riparian Areas}

An increase in soil erosion and surface water runoff could result from vegetation removal, and could lead to streambank erosion and sedimentation in wetlands and riparian areas (Ott 2000). Rate of runoff would be influenced by precipitation rate, soil type, and proximity to the treated area. All vegetation removal activities could disturb the soil and reduce the amount of vegetation binding to soil, potentially causing erosion and increased sedimentation of wetlands and riparian 
areas. Sediments can impact plants within wetland and riparian areas by reducing the amount of sunlight reaching plants and slowing or stopping plant growth.

The removal of vegetation would decrease the amount of rainfall captured by plants, detritus, and soil, potentially leading to increased stormwater flows and runoff velocity in both ecosystems. Increased stormwater runoff can scour wetlands, modify their morphology, and affect the distribution and abundance of aquatic organisms within the area. Decomposition of treated non-target aquatic vegetation could result in oxygen depletion. Siltation of wetlands could reduce water quality and the amount of oxygen available to aquatic organisms. In addition, siltation could reduce the acreage of wetland and riparian habitat.

\section{Vegetation}

The proposed vegetation treatments would cause unavoidable short-term disturbances to plant communities by killing both target and non-target plants. The extent of disturbances would vary by the extent and type of treatment. In many cases, the treatments would return all or a portion of the treated area to an early successional stage by freeing up resources such as light and nutrients for early successional species, such as annual grasses and forbs.

\section{Fish and Other Aquatic Organisms}

Removal or alteration of terrestrial vegetation, either through treatment activities or natural occurrences such as catastrophic fire, could result in an increase in soil erosion and surface water runoff, potentially leading to streambank erosion and sedimentation in aquatic habitats (Ott 2000). Sediments can harm spawning habitat, make foraging more difficult for aquatic organisms, and harm breathing organs of aquatic animals. The effects of catastrophic fire in watersheds would be ameliorated through timely emergency stabilization activities that are usually implemented within the same season as the fire, and are designed to minimize erosion and siltation.

\section{Wildlife Resources}

The proposed vegetation treatments could kill or harm wildlife, and cause unavoidable short-term adverse impacts to wildlife habitat and behavior. The extent of these disturbances would vary by the extent and type of treatment. In general, greatest risks would be associated with the wildland fire use, prescribed fire, and herbicide treatments. If treatments were successful, species using sites prior to treatment could be displaced by species better adapted to the restored sites.

Many species that use wetlands have evolved lifehistory strategies that depend upon stable conditions (i.e., stable water quality and quantity). For example, vegetation removal resulting in increased water flows to wetlands during the spring could flood the breeding sites of aquatic organisms that breed or lay eggs in moist soil, harming or killing eggs or juveniles.

\section{Livestock}

The proposed vegetation treatments could temporarily affect non-target vegetation that might provide forage, shelter, or other life requisites for livestock. Livestock could also be adversely impacted by herbicide treatments. Livestock, which consume large quantities of grass, are at greater risk for harm than smaller wildlife or wildlife that feed on other herbaceous vegetation, seeds, or fruits, because herbicide residue is higher on grass than it is on these other plants (Fletcher et al. 1994; Pfleeger et al. 1996; see Appendix C). These potential impacts are usually mitigated because livestock can be removed from areas scheduled for treatment.

\section{Wild Horses and Burros}

The proposed vegetation treatments could adversely affect wild horse and burro populations by killing or harming non-target vegetation that might provide forage, shelter, or other life requisites for wild horses and burros. Wild horses and burros could also be impacted by herbicide treatments. Because these animals likely consume large quantities of grass, they are at greater risk for harm than smaller wildlife or wildlife that feed on other herbaceous vegetation, seeds, or fruits. However, harmful doses of herbicide would be unlikely unless an animal were to forage exclusively within the treatment area for an entire day. Therefore, smaller treatments may be most appropriate in herd management areas in certain cases involving use of an herbicide with a demonstrated risk to herbivores from the consumption of contaminated vegetation. In some cases, treatment areas can be designed to exclude use by wild horse and burros to reduce the likelihood of adverse impacts to these animals. 


\section{Paleontological and Cultural Resources}

\section{Paleontological Resources}

The loss of paleontological resources has the potential to be adverse, especially if it results in the loss of scientifically important fossils. However, if surveys and inventories were conducted in areas where grounddisturbing activities were proposed to occur, and treatments avoided paleontological resource sites, the incidence of impacts would be greatly reduced, and any impacts that did occur would be minimal. Use of SOPS would reduce the likelihood of impacts to paleontological resources.

\section{Cultural Resources and Traditional Lifeway Values}

Cultural resources are nonrenewable, so any effects to these resources would have some importance. Because the exact locations of all potential cultural resources sites are unknown, their disturbance cannot be entirely avoided. There are cultural resources on public lands that may relate to the entire span of human occupation, including locales used by the first humans to enter the Western Hemisphere. Historic and prehistoric sites representing varied ages, cultures, and functions, may be located anywhere within the treatment area. Because soil forms slowly in the Arctic, cultural resources that are thousands of years old may be near the surface at Arctic sites. If surveys and inventories for cultural resources were conducted in areas where vegetation treatments were proposed to occur before the work began, effects to cultural resources in these areas could be reduced or avoided. Timely intervention following the discovery of cultural resources would effectively mitigate many effects, either through site avoidance or data recovery. Archaeological excavation to recover scientific data under the terms of an appropriate data recovery plan could result in the partial or total destruction of the site, although the recovered data would effectively mitigate for this destruction.

In many areas of the West, noxious weeds and other invasive vegetation grow together with more desirable vegetation used for traditional lifeway values such as food or basketweaving. Vegetation treatments in these areas could harm desirable plants, discourage or prohibit Native peoples from using these areas, or in the case of herbicides, potentially harm Native peoples harvesting plant materials in treated areas.

\section{Visual Resources}

The proposed vegetation treatments would not result in unavoidable adverse effects to visual resources over the long term. Over the short term, vegetation treatments would kill or harm vegetation in the applied area, resulting in a more open, browned or blackened landscape until new plants were to grow in the area. While these effects are unavoidable, they are considered short-term impacts, as the vegetation would recover and lead to improved natural conditions. Treatment areas would vary in terms of their visual appeal prior to treatment and their distance from human activity, as well as in terms of the resulting public sensitivity to the pre- and post-treatment visual character of the area. The effects of vegetation treatments on the visual quality of the landscape would be most noticeable to travelers, sightseers, and residents for the first year to several years following treatment, particularly near major roads or residential areas.

\section{Wilderness and Special Areas}

The effects of fire on wilderness and special areas would depend on a number of factors, such as the vegetation on the site, the condition of the site, the weather, fuel and soil moisture conditions under which the fire occurred, and the particular unique quality of the site that requires special management. In general, sites with special qualities that could be destroyed by fire would be the most likely to experience significant adverse effects from fire treatments.

Use of mechanical treatment methods would adversely affect wilderness areas and wilderness study areas because vehicles and heavy equipment are incompatible with the "unspoiled" nature of wilderness. For this reason, mechanical treatments would only be allowed on a very limited number of sites where no other method was feasible (e.g., tamarisk removal) and in the few areas where mechanical treatments have occurred in the past and repeat treatments are required.

Use of herbicides to treat undesirable vegetation could potentially affect the condition of wilderness areas and wilderness study areas by killing non-target native vegetation through imprecise application and/or drift. Since label directions, SOPs, and any additional wilderness restrictions would be followed during application of herbicides, there is little impact expected from drift due to imprecise application or other accidental scenarios. The degree of effects would depend on the application method, with spot 
applications less likely to cause adverse effects than aerial applications.

\section{Recreation}

There would be some scenic degradation, as well as distractions to public land users (e.g., noise from machinery) from treatments. In addition, there would be some human health risks to recreationists associated with exposure to herbicides (if use were allowed) or smoke from fire. These risks are discussed in more detail under Human Health and Safety. Finally, some areas would be off-limits to recreation activities as a result of treatments, from periods ranging from a few hours to days, or even one full growing season or longer, depending on the treatment. In most cases, recreationists would be able to find alternative sites offering the same amenities, although a lessened experience could result from more concentrated use in these areas.

The effects of herbicide treatments and fire use on fish and wildlife could have indirect negative impacts on recreational activities such as fishing, hunting, and wildlife viewing. For example, aerial application of an herbicide over a large area could adversely affect these activities by harming or displacing wildlife.

\section{Social and Economic Values}

Short-term closures or restrictions on public lands for certain vegetation treatments, such as implementation of herbicide use re-entry restrictions to protect public health or to restrict access by grazing animals until seeding efforts are established (up to two growing seasons) are unavoidable. It is expected that communities that are particularly dependent on a single industry would be most susceptible to adverse effects to employment or income due to vegetation treatment projects. In particular, ranching communities and recreation-dependent communities may be more affected than communities with diversified industries.

Limits on grazing activity on public lands could put additional pressure on often tight economic margins in ranching. Closures of treatment areas for extended periods of time could temporarily affect some recreational uses and commercial activities.

\section{Human Health and Safety}

All treatment methods have the potential to injure or kill workers or the public. The health and safety of workers could be at risk from exposure to herbicides; from working on uneven ground, broken terrain, and in dense vegetation; from use of hand and power tools; from inhalation of smoke; from exposure to falling debris; and from other accidental situations. Although workers would follow SOPs to reduce risks, not all risks could be avoided.

Members of the public could be at risk from flying debris if they were near an area where manual or mechanical equipment was used. Risks could be avoided if a safe zone was established around work areas and the public did not enter this area. However, spray drift of herbicide, particulate matter, and other harmful materials associated with herbicide and fire treatments could harm the public outside of treatment areas. Smoke risks would be minimized or avoided by following fire management plans and conducting burns during periods when meteorological conditions were favorable to reduce smoke impacts to the public. Herbicide drift would be minimized by using proper application equipment, using drift reduction agents, and spraying during periods with little or no wind.

\section{Relationship between the Local Short- term Uses and Maintenance and Enhancement of Long-term Productivity}

This section discusses the short-term effects of vegetation treatment activities, versus the maintenance and enhancement of potential long-term productivity of public land environmental and social resources.

Short term refers to the total duration of vegetation treatment activities considered in the PEIS and PER (about 10 to 15 years), whereas long term refers to an indefinite period of time. The specific impacts vary in kind, intensity, and duration according to the activities occurring at any given time. Initial activities, such as herbicide and mechanical treatments and fire use, result in short-term, localized impacts. However, the overarching goal of the proposed vegetation treatments program is to restore natural fire regimes, vegetation, and ecosystems, which should benefit all resources over the long term.

\section{Air Quality}

Vegetation treatments would cause short-term degradation of air quality, with most degradation associated with fire use. As discussed earlier, much of the focus of treatments is on restoring natural fire regimes and reducing the incidence and severity of 
wildfires. In general, wildfire impacts on air quality would likely be significantly greater than emissions from prescribed burning (USDA Forest Service and USDI BLM 2000), since techniques to minimize emissions would be implemented during prescribed burns and smoke management plans would permit prescribed fires only during meteorological periods favorable to dispersion. Thus, the proposed vegetation treatments should reduce smoke emissions associated with public lands over the long term.

In addition, state smoke management meteorologists would consider the cumulative effects of emissions from other sources (such as road dust, other federal vegetation management activities, and agricultural dust and burning) during the development of daily smoke management instructions. State smoke management program managers would also consider these sources during development of smoke management plans submitted for approval (as a component of the state smoke implementation plan) to the USEPA (USDA Forest Service and USDI BLM 2000).

\section{Soil Resources}

Although treatments would have short-term effects on soil condition and productivity, it is predicted that the soil disturbance associated with restoration activities would have less impact and be less severe than soil erosion caused by wildfire and encroachment by invasive species and noxious weeds. Furthermore, monitoring and evaluation, integrated with an adaptive management approach, would allow the BLM to adjust treatments to reduce soil disturbance to levels similar to historical conditions.

Studies in forested and rangeland environments indicate that forest and range landscapes that resemble conditions within historical ranges of variability provide favorable conditions for soil functions and processes that contribute to long-term sustainability of soil productivity (Munn et al. 1978, Cannon and Nielsen 1984, and Hole and Nielsen 1970 cited in USDA Forest Service and USDI BLM 2000).

Restoration activities that move forests and rangelands toward historical ranges of variability would provide favorable conditions for soil functions and processes, and contribute to long-term soil productivity levels at the broad scale (USDA Forest Service and USDI BLM 2000)

\section{Water Resources and Quality}

The BLM proposes a 3-fold increase in overall treatment acreage, and over a 4-fold increase in the number of acres treated in wetland and riparian habitats. Treatment of vegetation would cause a short-term increase in soil erosion and surface water runoff. Successful control of invasive plants, however, would lead to improved conditions in watersheds over the long term, with the greatest improvement likely to occur in degraded watersheds. The eventual growth of desirable vegetation in treated areas would moderate water temperatures, buffer the input of sediment and herbicides from runoff, and promote streambank stability. Ongoing efforts by the BLM to enhance vegetation would also help to increase the acreage of watersheds that are functioning properly. Improvement of watersheds and water resources and quality would benefit salmonids and other species of concern that depend upon these habitats for their survival (USDA Forest Service and USDI BLM 2000).

Vegetation treatments that reduce hazardous fuels would benefit ecosystems by reducing the chances of a large, uncontrolled wildfire, which could result in the destruction of a large amount of high quality habitat potentially leading to erosion, especially if followed by heavy rainfall. Hazardous fuels reduction would also decrease the likelihood that wildfire suppression activities would occur in or near aquatic habitats.

The BLM's ability to use four new chemicals (fluridone and diquat for aquatic applications, and imazapic and Overdrive $^{(}$for terrestrial applications), and new herbicides as they become available, would provide new capabilities for controlling problematic invasive species that would be less likely to contaminate water than treatments with many of the currently available herbicides.

\section{Wetland and Riparian Areas}

Removal of vegetation could cause a short-term increase in soil erosion and surface water runoff and could impact wetland and riparian areas. Successful control of invasive plants in wetlands and riparian areas, however, would lead to improved conditions in these habitats over the long term. The eventual growth of desirable vegetation in treated areas would moderate water temperatures, buffer the input of sediment and herbicides from runoff, and promote bank stability in riparian areas. Ongoing efforts by the BLM to enhance wetland and riparian vegetation would also help to increase the miles of streams and acres of wetlands that 
are classified by the BLM as "Proper Functioning." Improvement of riparian and wetland habitat would also benefit salmonids and other species of concern that depend upon these habitats for their survival (USDA Forest Service and USDI BLM 2000).

Control of aquatic and riparian vegetation can improve habitat quality for fish and wildlife, improve hydrologic function, and reduce soil erosion. Non-native species, such as purple loosestrife, form extensive monotypic stands that displace native vegetation used by wetland animal species for food and cover (Bossard et al. 2000). Water-thyme is an aquatic species that forms large mats that fill the water column and can severely restrict water flow, leading to a decrease in water quality and habitat for fish and wildlife. Eurasian watermilfoil, a species of aquatic plant that has spread widely over the western U.S., alters the physical and chemical characteristics of lakes and streams. Much of the BLM's vegetation control efforts in wetland and riparian areas would focus on these species.

\section{Vegetation}

All treatments would have short-term adverse impacts to target vegetation, and in some cases non-target vegetation. Treatments that remove or control invasive vegetation could provide immediate benefits to nontarget species, however, such as increased access to water and nutrients and enhanced vigor from reduced competition with invasive species.

Treatments that remove hazardous fuels from public lands would be expected to benefit the long-term health of plant communities in which natural fire cycles have been altered. The suppression of fire results in the buildup of dead plant materials (e.g., litter and dead woody materials), and often increases the density of flammable living fuels on a site. Treatments that restore and maintain fire-adapted ecosystems, through the appropriate use of mechanical thinning, wildland fire use or prescribed fire, and other vegetation treatment methods, would decrease the effects of future wildfires on plant communities and improve ecosystem resilience and sustainability. Over the long term, treatments should also reduce the incidence and severity of wildfires across the western U.S.

Treatments that control populations of non-native species on public lands would be expected to benefit native plant communities over the long term by aiding in the reestablishment of native species. The degree of benefit would depend on the success of these treatments over both the short and long term. Some treatments are very successful at removing weeds over the short term, but are not successful at promoting the establishment of native species in their place. In such cases, seeding and planting of native plant species would be beneficial.

Although modeling was not done as part of the PEIS and PER to determine the long-term effects of vegetation treatments, modeling done for similar treatments proposed by the BLM and Forest Service in the Interior Columbia Basin showed that improvements in land condition would be slow. However, treatments would improve the mix of habitats so that vegetation would be more resilient to disturbance and sustainable in the long term. Plant communities that have declined substantially in geographic extent from historical to current periods (e.g., big sagebrush and bunchgrasses) would increase. Although the extent of weeds and other exotic and undesirable plants would continue to increase, the rate of expansion would be slower (USDA Forest Service and USDI BLM 2000).

\section{Fish and Other Aquatic Organisms}

Control of aquatic and riparian vegetation can improve habitat quality for fish and wildlife, improve hydrologic function, and reduce soil erosion. Vegetation treatments that reduce hazardous fuels would benefit aquatic organisms by reducing the chances of a large, uncontrolled wildfire, which could result in the destruction of a large amount of high quality wetland and riparian habitat, especially if followed by heavy rainfall. Hazardous fuels reduction would also decrease the likelihood that wildfire suppression activities would occur in or near aquatic habitats. Treatments that restore natural fire regimes and native vegetation near streams should ensure a steady supply of large woody debris that would provide habitat for aquatic organisms in the future.

\section{Wildlife Resources}

All treatments would have short-term adverse impacts to wildlife and their habitats, as discussed above. Treatments that improve habitat would provide longterm benefits to wildlife. Treatments that remove hazardous fuels from public lands and reduce the risk of large, intense wildfire would reduce the potential for future death and injury of wildlife and lead to improved habitat. Treatments that control populations of nonnative species on public lands would be expected to benefit most wildlife over the long term by aiding in the reestablishment of native vegetation and restoring wildlife habitat to near historical conditions. 
Although modeling was not done as part of the PEIS and PER to determine the long-term effects of vegetation treatments, modeling done for similar treatments proposed by the BLM and Forest Service in the Interior Columbia Basin showed that improvements in habitat would be slow, perhaps not occurring for decades.

\section{Livestock}

The proposed vegetation treatments would affect the availability and palatability of vegetation over the short term. These impacts would begin to disappear within one to two growing seasons after treatment.

All treatments that successfully reduce the cover of noxious weeds and restore native vegetation on grazed lands would benefit livestock by increasing the number of acres available for grazing and the quality of forage. In addition, treatments would remove some noxious weeds (e.g., tansy ragwort, houndstongue, Russian knapweed, and common St. Johnswort) that are harmful to livestock. The success of weed removal and restoration of native habitats would determine the level of benefit of the treatments over the long term.

Treatments that reduce the risk of future catastrophic wildfire through fuels reduction would also benefit livestock. Uncontrolled, high intensity wildfires can remove forage from large tracts of rangeland, reducing its suitability for livestock in the short term. Treatments that restore and maintain fire-adapted ecosystems, through the appropriate use of mechanical thinning, fire, and other vegetation treatment methods would decrease the effects of wildfire on rangeland plant communities and improve ecosystem resilience and sustainability.

\section{Wild Horses and Burros}

The proposed vegetation treatments would affect the availability and palatability of vegetation over the short term. These impacts would begin to disappear within one to two growing seasons after treatment.

All treatments that successfully reduce the cover of noxious weeds and restore native vegetation on grazed lands would benefit wild horses and burros by increasing the number of acres available for foraging and the quality of forage. In addition, treatments would remove some noxious weeds (e.g., tansy ragwort, houndstongue, Russian knapweed, and common St. Johnswort) that are poisonous to wild horses and burros. The success of weed removal and restoration of native habitats would determine the level of benefit of the treatments over the long term.

Treatments that reduce the risk of future catastrophic wildfire through fuels reduction would also benefit wild horses and burros. Uncontrolled, high intensity wildfires can remove forage from large tracts of rangeland, reducing its suitability for wild horses and burros. Treatments that restore and maintain fire-adapted ecosystems, through the appropriate use of mechanical thinning, fire, and other vegetation treatment methods would decrease the effects of wildfire on rangeland plant communities and improve ecosystem resilience and sustainability.

\section{Paleontological and Cultural Resources}

\section{Paleontological Resources}

Because paleontological resources are nonrenewable, there is no difference between short-term and long-term impacts. The resource cannot recover from some types of adverse impacts. Once disturbed, the materials and information of paleontological deposits may be permanently compromised. Any destruction of paleontological sites, especially those determined to have particular scientific value, would represent longterm losses. Furthermore, once paleontological deposits were disturbed and exposed, natural erosion could accelerate the destruction of fossils, and exposed fossils would be vulnerable to unauthorized collecting and digging. Any discoveries of paleontological resources as a result of surveys required prior to treatment would enhance long-term knowledge of the area and these resources.

\section{Cultural Resources and Traditional Lifeway Values}

Any destruction of cultural resource sites would represent long-term losses. Archaeological excavation to recover scientific data under the terms of an appropriate data recovery plan could result in the partial or total destruction of the site, although the recovered data would effectively mitigate for this destruction. Any investigations of cultural resources made during inventories or investigations required prior to vegetation treatments would enhance knowledge of the history and early inhabitants of the region and serve to effectively mitigate further potential effects of activities in the area.

Vegetation treatments could have short-term impacts on vegetation used for traditional lifeway values, especially if herbicide drift were to impact non-target vegetation, 
or treatments were to affect both target and non-target vegetation, as would occur during certain herbicide treatments (such as with non-selective herbicides) and fire use. In addition, fire use and herbicide treatments could displace Native peoples from traditional use areas until it was safe to reenter, or desirable vegetation was reestablishing. However, long-term restoration of native plant communities and natural ecosystem processes to the benefit of traditional lifeway resources should compensate for the short-term losses in use.

\section{Visual Resources}

The proposed vegetation treatments would affect visual resources by changing the scenic quality of the landscape. Over the short-term, impacts to visual resources from all treatment methods would begin to disappear within one to two growing seasons. The regrowth of vegetation on the site would eliminate much of the stark appearance of cleared areas, and the site would develop a more natural appearance. Impacts would last for the longest amount of time in forests and other areas where large trees and shrubs were removed.

Over the long term, vegetation treatments would likely improve visual resources on public lands. Treatments that aim to rehabilitate degraded ecosystems, if successful, would result in plant communities dominated by native species (see Vegetation section for more information). Native-dominated communities tend to be more visually appealing and productive than areas that have been overtaken by weeds (e.g., areas supporting a downy brome monoculture), or that have been invaded by woody species (e.g., grasslands experiencing encroachment by conifer seedlings).

\section{Wilderness and Special Areas}

Impacts to wilderness and sensitive area resources would begin to disappear within one to two growing seasons after treatment, regardless of the treatment method. The regrowth of vegetation on the site would eliminate much of the stark appearance of cleared areas, and the site would develop a more natural appearance. The longest lasting impacts would occur in forests and other areas where large trees and shrubs were removed. Benefits to plants and animals in terms of ecosystem function and improved forage and cover would occur as the treated area recovered.

Over the long term, vegetation treatments would likely improve resources on wilderness and special areas. Treatments that aim to rehabilitate degraded ecosystems would result in plant communities that are dominated by native species (see Vegetation section for more information). Native-dominated communities often provide better habitat for fish and wildlife, including species of concern.

\section{Recreation}

There would be some scenic degradation, as well as distractions to users (e.g., noise from machinery), from treatments. In addition, there would be some human health risks to recreationists associated with exposure to herbicides (if use were allowed) or smoke from fire. Finally, some areas would be off-limits to recreation activities as a result of treatments. These effects would be localized and short term.

Developed recreation sites with public facilities would be treated in order to maintain the appearance of the area and to protect visitors from the adverse effects of unwanted vegetation (e.g. thistles, ragweed, and poison ivy). Some mechanical activities, such as mowing in visitor use areas or along ROWs, would provide an immediate benefit in terms of improved appearance of vegetation. Long-term adverse effects on developed recreational facilities would be unlikely, as treatments are expected to improve native vegetation and the utility of these sites. In some cases, developed recreation sites could be temporarily closed during treatments.

Treatments that restore native vegetation and natural fire regimes and other ecosystem processes would be beneficial to recreationists. Treatments would improve the aesthetic and visual qualities of recreation areas for hikers, bikers, horseback riders, and other public land users; reduce the risk of recreationists coming into contact with noxious weeds and poisonous plants; increase the abundance and quality of plants harvested from public lands; and improve habitat for fish and wildlife sought by fishermen and hunters. These benefits would be long term and improve the productivity of land resources and their ability to provide recreational values.

\section{Social and Economic Values}

Vegetation treatments would adversely affect use of treated areas over the short term. Any restrictions on the use of treated lands could cause social and economic hardship to affected parties. However, individuals and industries involved in the restoration of native ecosystems on public lands would benefit.

Over the long term, most users of public lands, and those with interests near public lands, would likely 
benefit. An important goal of treatments is to restore ecosystem health so that public lands can provide sustainable and predictable products and services. In addition, treatments would reduce risks to communities associated with large-scale wildfire, improve ecosystem health to the benefit of recreationists and other public land users, and emphasize employment- and incomeproducing management activities near those communities most in need of economic support and stimulus. The enhancement in long-term productivity of public lands to provide for social and economic needs would reflect not only the success or failure of treatments, but also the influence of outside forces (e.g., economy, lifestyle changes, climate) over which the BLM and other federal agencies have no control (USDA Forest Service and USDI BLM 2000).

\section{Human Health and Safety}

The proposed vegetation treatments could harm the health of workers and the public over the short term. Adverse reactions to smoke and herbicides could cause minor to severe discomfort to sensitive individuals, but most symptoms would go away in a few hours. If serious injury or death resulted from treatments, the effects to the health of the affected individual would be long term, or in the case of death, permanent.

All treatments that successfully reduce the cover of noxious weeds and restore native vegetation would help to restore natural fire regimes and improve ecosystem health. If treatments were successful, long-term improvement in fire regimes and ecosystem health would reduce the risk of wildfire and slow the spread of poisonous and other noxious weeds that are harmful or annoying to humans. As native vegetation was restored, it could be possible to reduce the number of acres treated with herbicides. Even if this were not possible, the ability to use several new herbicides evaluated in this PEIS, and new herbicides that may become available in the future that are effective and less harmful to humans than currently-available herbicides, should reduce the risk to humans from herbicides on a per acre basis.

\section{Irreversible and Irretrievable Commitment of Resources}

This section identifies irreversible and irretrievable commitments of resources that would occur from vegetation treatments. Irreversible and irretrievable commitments of resources refer to impacts or losses to resources that cannot be reversed or recovered.
Examples are the extinction of a species or the permanent conversion of a vegetated wetland to open water. In the first case, the loss is pcrmanent and not reversible under current genetic technology. In the second case, it is possible the open water could be drained, so while the initial loss of the vegetated wetland is irretrievable, the action could be reversible.

\section{Air Quality}

Air quality would be affected by all treatment methods, with fire use contributing the most to degradation of air quality. These effects would occur only during the period of the treatment activity and there would be no irreversible or irretrievable cffects on air quality.

\section{Soil Resources}

Disturbance activities associated with current and proposed treatments could result in soil erosion and loss of soil and soil productivity. This loss of soil and soil productivity would be irretrievable in the disturbance area, although the soil could be available for use at some other location. However, a benefit of increasing the amount of acres treated would be to slow the loss of soil and soil productivity due to invasive vegetation and wildfire and to restore soil structure and function on degraded sites as part of a larger goal to restore native ecosystem processes. As a result of these actions, soil productivity in disturbed areas should reestablish over time.

\section{Water Resources and Quality}

An accidental herbicide spill or uncontrolled prescribed fire could cause damage to water bodies lasting for several months. The ability to use water resources in the affected area could be lost for an unknown period of time. However, these impacts could be reversed if restoration treatments were successful and herbicides naturally degraded. Other treatments should not result in irreversible or irretrievable commitments of water resources.

\section{Wetland and Riparian Areas}

There would be no irreversible or irretrievable commitment of wetland or riparian resources. Although there would be short-term impacts to these resources from vegetation treatments, these impacts would not be irretrievable and would be reversed if restoration treatments were successful. In Alaska, it is possible that changes in the melting permafrost due to fire use could 
cause subsidence that could last a long time and possibly be permanent.

\section{Vegetation}

Native vegetation and plant productivity that was lost as a result of treatments would be irretrievable only until vegetation was reestablished, usually within several growing seasons.

\section{Fish and Other Aquatic Organisms}

Several of the herbicides currently used, or proposed for use, by the BLM would have a moderate to high risk of causing adverse health effects to fish and other aquatic organisms under maximum application and accidental spill scenarios, and could potentially result in illness or death. Loss of control over a prescribed fire could also harm aquatic habitat and cause mortality or injury to aquatic organisms. Treatments would likely result in short-term habitat degradation and some reduction in populations of fish and other aquatic organisms. These effects, however, would be reversible, as habitats would improve and aquatic organism populations would likely increase as a result.

\section{Wildlife Resources}

Native wildlife and habitat productivity that was lost as a result of treatments would be irretrievable until native plant communities were reestablished, usually within several growing seasons. Treatments that improve rangeland and forestland ecosystem health, including plant productivity, would translate into benefits for wildlife, except for those species that have adapted to or thrive in areas where vegetation has changed from historic conditions.

\section{Livestock}

Short-term loss in vegetation function and quality from treatments would have a short-term impact on livestock productivity. Although some livestock could be displaced from public lands, forage could be found elsewhere, although possibly at a higher cost. As rangelands improved, their ability to support livestock use levels at or near current levels should also improve. Herbicide treatments have the potential to cause injury or death to livestock. Although this impact would represent an irreversible loss of the individual animal, the impacts to the livestock operation and industry would be reversible.

\section{Wild Horses and Burros}

Short-term loss in vegetation function and quality as a result of treatments would have a short-term impact on wild horse and burro productivity. Wild horses and burros could be removed from rangelands to reduce their impacts to rangeland health and to speed up the process of rangeland restoration. These animals would be placed into adoption and would provide value to their owners. As rangelands improved, their ability to support populations of wild horses and burros near current levels would also improve.

Herbicide treatments have the potential to cause injury or death to wild horse and burros. Although this impact would represent an irreversible loss of the individual animal, the impacts to the wild horse and burro populations would be reversible.

\section{Paleontological and Cultural Resources}

\section{Paleontological Resources}

Because paleontological resources are nonrenewable, any impacts would render the resource disturbance irreversible and the integrity of the resource irretrievable.

\section{Cultural Resources and Traditional Lifeway Values}

Cultural resources are nonrenewable, so any impacts would be irreversible, and the integrity of the affected resource would be irretrievable. If near-surface cultural resources were encountered, as during disking or chaining, such resources could be damaged or destroyed. The loss of such cultural resource information would be irreversible and irretrievable. Archaeological excavation to recover scientific data under terms of an appropriate data recovery plan could result in the partial or total destruction of the site, although the recovered data would effectively mitigate for this destruction. Any investigations of cultural resources made during inventories or investigations required prior to vegetation treatments would enhance knowledge of the history and early inhabitants of the region and serve to effectively mitigate further potential effects of activities in the area. Overall, such finds could help fill gaps in our knowledge of the history and early inhabitants of the area.

Vegetation treatment activities would impact plants and animals of traditional importance to Native peoples. However, these effects should be short-term and 
reversible, as native plant communities would recover and habitat for fish and game species would improve.

\section{Visual Resources}

There would be no irreversible or irretrievable commitment of visual resources. Although there would be short-term impacts to visual resources from vegetation treatments, loss of visual resources would not be irretrievable and could be reversed if restoration treatments were successful.

\section{Wilderness and Special Areas}

There would be no irreversible or irretrievable commitment of resources. Although there would be short-term impacts to wilderness and special area resources from vegetation treatments, these impacts would not be irretrievable and could be reversed if restoration treatments were successful.

\section{Recreation}

There would be no irreversible or irretrievable commitment of recreation resources. Although there would be short-term impacts to recreation resources from vegetation treatments, these impacts would not be irretrievable and could be reversed if restoration treatments were successful.

\section{Social and Economic Values}

Vegetation treatments would involve a substantial commitment by the BLM in terms of labor and financial resources. An estimated $\$ 1.1$ billion would be needed to treat 6 million acres annually using the treatment and acreage assumptions outlined in Chapter 2. Several thousand jobs would be created to support treatment and restoration activities. Once the financial resources were used, they could not be retrieved. Treatments that result in the closure of recreation or grazing areas could have an irretrievable impact on the income of those involved in these industries.

\section{Human Health and Safety}

Serious injury or death to humans caused by vegetation treatments could be irreversible and irretrievable. However, risk of death or serious injury is very unlikely, based on incidence of injury (very low) and death (none) associated with BLM vegetation treatments during the past decade. It is likely that humans would experience minor discomfort from fire and herbicide treatments, but these effects would be short term and reversible.

\section{Energy Requirements and Conservation Potential}

Herbicide formulations may contain petroleum products, and all herbicide treatment methods require the use of energy, to operate equipment to treat vegetation and to transport workers to and from the job site. Wildland fire use and prescribed fire would likely require the least amount of energy per acre treated, followed by biological control, manual, herbicide, and mechanical treatment methods. For herbicide treatments, less energy would be used to conduct aerial treatments than ground treatments for each acre treated. Because the Preferred Alternative treats the most acres using herbicides, it would use the most energy. The amount of energy used to treat vegetation using fire, mechanical, manual, and biological control methods would be similar among the action alternatives. The fewest acres treated, and the least amount of energy used would occur under the No Action Alternative.

\section{Natural or Depletable Resource Requirements and Conservation}

Herbicide formulations may contain natural or depletable resources as constituents of the herbicide products or as carriers. It is anticipated that the use of natural and depletable resources-would be minimal, with greatest use under the Preferred Alternative, and least amount of use under the No Action Alternative, with other alternatives intermediate between these two. All herbicide treatment methods require the use of energy, as described above. 

CHAPTER 5

\section{CONSULTATION AND COORDINATION}





\section{TABLE OF CONTENTS}

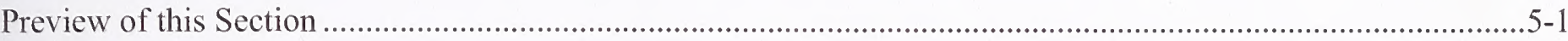

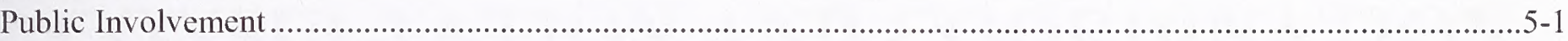

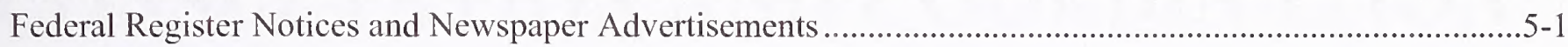

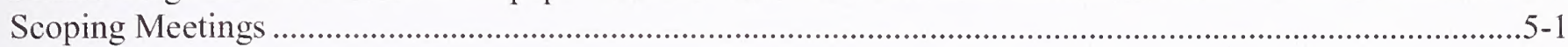

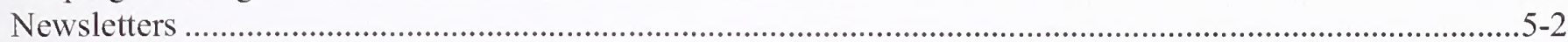

Public Review and Comment on the Draft Programmatic EIS and ER, and Biological Assessment..............5-2

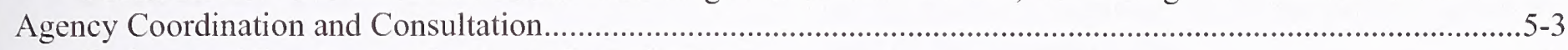

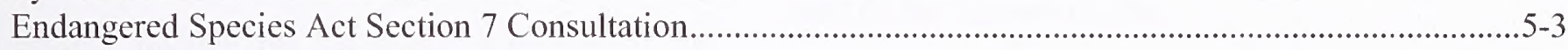

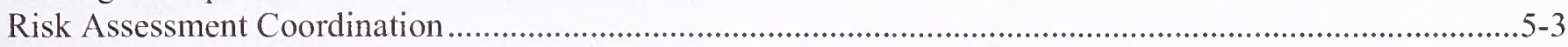

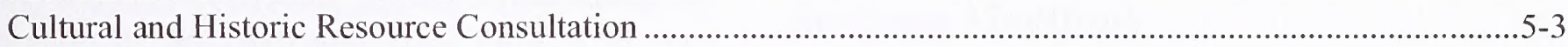

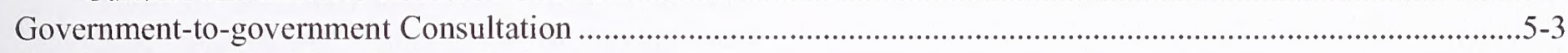

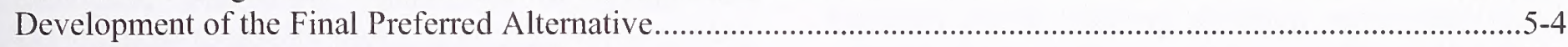

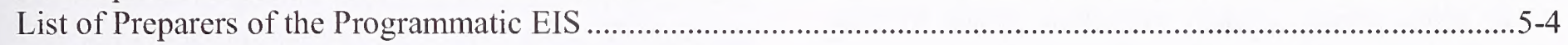

\section{List of Tables}

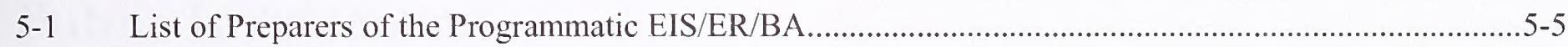





\section{CHAPTER 5}

\section{CONSULTATION AND COORDINATION}

\section{Preview of this Section}

This section summarizes the public involvement and scoping and public comment process conducted for the preparation of the Draft and Final PEIS, PER, and Biological Assessment. Summaries of agency and Government-to-government consultation are provided. The individual preparers, with their areas of expertise and/or responsibility, are also listed.

\section{Public Involvement}

\section{Federal Register Notices and Newspaper Advertisements}

The BLM published a Federal Register Notice of Intent to Plan (Notice) on October 12, 2001 (Federal Register, Volume 66, Number 198, Pages 5214852149). The BLM also released a press release concurrent with the Notice. The Notice asked the public to help the BLM identify issues and resources relevant to vegetation treatment activities on lands administered by the BLM in 17 western states, including Alaska. The Notice stated that public comments on the proposal would be accepted from October 12 through November 11, 2001. A second Federal Register Notice was published on January 2, 2002 , notifying the public of the location of public scoping meetings, and extending the public comment period until March 29, 2002 (Federal Register, Volume 67, Number 1, Pages 101-102). A third Federal Register Notice was published on January 22, 2002 , notifying the public of changes to the meeting schedule (Federal Register, Volume 67, Number 14, Pages 2901-2903).

All affected states issued public notices of the scoping period, which were placed in newspapers in or near locations where public meetings were held. In addition, information on the location of scoping meetings was provided by electronic mail in early December 2001, and again in early January 2002, to all members of the public that had placed their names on the electronic mailing list for the project before the date of the announcements.

\section{Scoping Meetings}

Eighteen public scoping meetings were held in 12 western states, including Alaska, during early 2002. Meeting locations were: Salt Lake City, Utah (January 8); Rock Springs, Wyoming (January 10); Socorro, New Mexico (January 14); Phoenix, Arizona (January 16); St. George, Utah (January 22); Grand Junction, Colorado (January 24); Miles City, Montana (January 29); Worland, Wyoming (January 31); Alturas, California (February 5); Helena, Montana (February 11); Boise, Idaho (February 13); Twin Falls, Idaho (February 14); Reno, Nevada (February 19); Elko, Nevada (February 21); Bakersfield, California (February 26); Spokane, Washington (February 28); Portland, Oregon (March 4); and Anchorage, Alaska (March 6). In addition, a meeting was held in Washington, D.C. (March 12). The scoping meetings were conducted in an open-house style. Informational displays were provided at the meeting, and handouts describing the project, the NEPA process, and issues and alternatives were given to the public. A formal presentation provided the public with additional information on program goals and objectives. This presentation was followed by a question and answer session.

The BLM received 1,034 requests to be placed on the project mailing list from individuals, organizations, and government agencies, and 381 written comment letters or facsimiles on the proposal. In addition, the public provided comments on the project at the public scoping meetings; over 2,800 catalogued individual comments (written and oral) were given during public scoping. In many cases, multiple respondents submitted the same comment. A Scoping Comment Summary Report for the Vegetation Treatments Programmatic EIS (ENSR 2002) was prepared that summarized the issues and alternatives identified 
during scoping. This document was made available to the public in July 2002.

\section{Newsletters}

The BLM prepared three newsletters during preparation of the Draft PEIS. These newsletters were made available to those individuals that provided their names and addresses to the BLM during scoping, and to BLM state offices and local field offices for distribution to visitors.

The first newsletter was issued in July 2002 and discussed the outcome of the scoping meetings, development of the initial project alternatives, coordination with affected tribes and fish and wildlife agencies, and treatment acreage determinations.

A second newsletter was issued in January 2003. It summarized activities on the risk assessments and development of the alternatives. It discussed the process the BLM was undertaking to determine future vegetation treatment acres. Other studies being conducted in support of the PEIS and PER, including preparation of a Biological Assessment and a cultural resource and Native American resource use report, were also discussed in the newsletter.

A third newsletter was issued in March 2005. This newsletter discussed the Draft PEIS/PER schedule, and noted that the PEIS will now focus on herbicide treatments, while a PER will be prepared to discuss other treatment methods. The newsletter also provided information of the alternatives that were evaluated in the Draft PEIS.

In July 2005, the BLM sent out a business reply mail request to those on the mailing list to let the BLM know if they would like to remain on the mailing list and if they would like to receive a printed and/or CD copy of the Draft PEIS, PER, and BA.

In April 2007, the BLM sent out a business reply mail request to those on the mailing list to let the BLM know if they would like to remain on the mailing list and if they would like to receive a printed and/or CD copy of the Final PEIS, PER, and BA.

\section{Public Review and Comment on the Draft Programmatic EIS and ER, and Biological Assessment}

The Notice of Availability (NOA) of the Draft Vegetation Treatments using Herbicides on Bureau of Land Management Lands in 17 Western States Programmatic Environmental Impact Statement was published in the Federal Register on November 10, 2005 (Federal Register, Volume 70, Number 217, Pages 68474-68475). The public comment period was originally scheduled from November 10, 2005, through January 9, 2006, however, a notice extending the public comment period through February 10, 2006, was published in the Federal Register on January 20, 2006. Public notices announcing the comment period were placed in newspapers with circulation in or near locations where public meetings were held. The BLM issued a press release on November 10, 2006, notifying the public that the Draft PEIS and PER were available for public review, and the schedule for public comment hearings. Information on the Draft PEIS and PER was also posted on the interactive website (http://www.blm.gov). The public was able to access the website to download a copy of the Draft PEIS, PER, Biological Assessment, and supporting documents.

Public hearings were held in Portland, Oregon on November 28; Sacramento, California on November 29; Salt Lake City, Utah on November 30; Albuquerque, New Mexico on December 1; Grand Junction, Colorado on December 5; Boise, Idaho on December 6; Billings, Montana on December 7; Cheyenne, Wyoming on December 8; and Las Vegas, Nevada, and Washington, D.C. on December 13, 2006 , for the BLM to provide an overview of the alternatives and to take public comments. Nearly 3,000 comments were received on the Draft PEIS, PER, and Biological Assessment. These included letters, electronic mail, and facsimiles, and comments provided at public hearings in Boise and Sacramento (no public testimony was given at the other public hearings). A summary of the comments received and specific comments and responses are presented in Volume III of this Final PEIS. All comments are reproduced on the $\mathrm{CD}$ located in the back pocket of Volume I. 


\section{Agency Coordination and Consultation}

\section{Endangered Species Act Section 7 Consultation}

The BLM initiated informal consultation with the USFWS and NMFS (Services) in November 2001. The BLM met with the Services on November 16, 2001, to discuss the ESA Section 7 consultation process and to identify key contacts within the agencies. A preliminary draft consultation agreement was submitted to the Services in June 2002. The BLM and Services met in Denver, Colorado, on November 6-7, 2002, to discuss the risk assessment protocols and Biological Assessment. The BLM met with the Services on February 28, 2003, to further discuss issues related to the development of the risk assessments and preparation of the Biological Assessment. A revised draft consultation agreement was submitted to the Services in April 2004 (see Appendix G).

The BLM prepared a formal initiation package that included: 1) a description of the program, species proposed for listing, listed species and their critical habitats that may be affected by the program; and 2) a Biological Assessment that evaluated the likely impacts to listed species and critical habitats from the proposed action and SOPs to minimize impacts to listed species. In addition, the BLM coordinated with the NMFS on Essential Fish Habitat as required under the Magnuson-Stevens Fishery Management Act. This package was submitted to the Services concurrently with release of the Draft PEIS.

After receipt and review of the initiation package, the BLM and Services held several meetings to discuss the package and to respond to information requests from the Services. Meetings were held in Washington, D.C., on January 18 and Silver Springs, Maryland, on November 14, 2006. A conference call was held with the Services on February 27, 2006.

Consultation with the Services pursuant to the ESA and Magnuson-Stevens Fishery Management Act is ongoing and will be completed by the time of signing of the Record of Decision.

\section{Risk Assessment Coordination}

The BLM convened a group of scientists from the USEPA, USFWS, NMFS, BLM, and its contractor, ENSR Corporation, to work cooperatively to develop protocols for conducting HHRAs and ERAs that would meet agency guidelines and scientific and public scrutiny. Weekly conference calls were held among the participants beginning in May 2002, and continuing through November 2002. A meeting was held in Boise on Scptember 12-13, 2002, and in Denver, Colorado, on November 5-6, 2002, to discuss the risk assessment protocols. Conference calls were held intermittently from November 2002 through July 2003 to resolve remaining issues related to the protocols. Conference calls were also held among agency participants during preparation of the risk assessments. The final HHRA and ERA protocols were finalized and submitted to the Services and USEPA in August 2003.

\section{Cultural and Historic Resource Consultation}

The BLM consulted with State Historic Preservation Officers as part of Section 106 consultation under the National Historic Preservation Act to determine how proposed industrial activities could impact cultural resources listed on or eligible for inclusion in the National Register of Historic Places. Formal consultations with State Historic Preservation Officers and Indian Tribes also may be required during implementation of individual projects. Consultations with State Historic Preservation Officers are ongoing and will be completed by the time of the signing of the Record of Decision.

\section{Government-to-government Consultation}

Federally-recognized tribes have a unique legal and political relationship with the government of the United States, as defined by the U.S. Constitution, treaties, statutes, court decisions, and executive orders. These definitive authorities also serve as the basis for the federal government's obligation to acknowledge the status of federally-recognized tribes.

The BLM consults with federally-recognized tribes, consistent with the Presidential Executive 
Memorandum dated April 29, 1994, on Governmentto-Government Relations with Native American Tribal Governments; and Executive Order 13175 dated November 6, 2000, on Consultation and Coordination with Indian Tribal Governments. The BLM formally consults with federally-recognized tribes before making decisions or undertaking activities that will have a substantial, direct effect on federallyrecognized tribes, or their assets, rights, services, or programs. To this end, formal Government-togovernment consultation with federally-recognized traditional governments was initiated by written correspondence in July 2002 (see Appendix G).

The letter sent to all of the tribal governments described the proposed action. The tribes were provided with information on the project and were asked to provide the BLM with any concerns they might have about any of the proposed vegetation treatments and their impacts on subsistence, religious, and ceremonial purposes and traditional cultural properties.

The BLM invited the tribes to call if they had questions or wanted to set up individual meetings with the BLM. The letter also invited the tribal councils to attend the scoping meeting scheduled for their community.

The BLM prepared an Alaska National Interest Land Conservation Act (ANILCA) Section 810 analysis of subsistence impacts to evaluate the potential impacts to subsistence pursuits in Alaska. This analysis is found in Appendix $\mathrm{H}$ of the Final PEIS.

\section{Development of the Final Preferred Alternative}

After completion of the public hearings and closure of the public comment period, the core planning team, resource staff, and management met to review the comments and alternative proposals and to develop the BLM's final Preferred Alternative. No alternative proposals were received from the public, although the BLM did receive numerous comments in support of all four of the proposed actions (alternatives B, C, D, and E).

The BLM took these comments into consideration when reviewing the alternatives developed for the Final PEIS. Based on these comments, the BLM developed a final Preferred Alternative for the Final PEIS. This alternative is similar to the draft Preferred Alternative in terms of numbers and types of acres that would be treated using herbicides, but does include new SOPs and mitigation measures to reduce the risks associated with the use of herbicides.

\section{List of Preparers of the Programmatic EIS}

The following specialists (and company/agency and area of specialty) that participated in the development of the PEIS are listed below (Table 5-1). Agencies included the BLM, USEPA, USFWS, and NMFS. Subcontractors that provided assistance to the BLM during preparation of the PEIS/PER included ENSR Corporation; Historical Research Associates (HRA); Planera, Inc. (Planera); and Paleo Consultants. 
TABLE 5-1

List of Preparers of the Programmatic EIS/ER/BA

\begin{tabular}{|c|c|c|c|}
\hline Contributor & Areas of Specialty & $\begin{array}{c}\text { Years of } \\
\text { Experience }\end{array}$ & Highest Degree/Education \\
\hline \multicolumn{4}{|c|}{ Bureau of Land Management } \\
\hline Scott Abdon & $\begin{array}{l}\text { Recreation and Visitor Services } \\
\text { Management }\end{array}$ & 37 & $\begin{array}{l}\text { B.S., Forest and Recreation } \\
\text { Management }\end{array}$ \\
\hline Fran Ackley & Wild Horses and Burros & 22 & $\begin{array}{l}\text { B.S., Range and Forest } \\
\text { Management }\end{array}$ \\
\hline Brian Amme & $\begin{array}{l}\text { Project Manager and Co-Team Lead, } \\
\text { NEPA }\end{array}$ & 24 & B.A., Cultural Anthropology \\
\hline Scott Archer & Air Resources & 29 & $\begin{array}{l}\text { B.S., Chemistry and Environmental } \\
\text { Science }\end{array}$ \\
\hline Dianna Brink & $\begin{array}{l}\text { Range Management and Weed } \\
\text { Management }\end{array}$ & 24 & $\begin{array}{l}\text { B.S., Forestry and Range } \\
\text { Management }\end{array}$ \\
\hline Miles Brown & $\begin{array}{l}\text { Rangeland Management, Invasive } \\
\text { Species, and Natural Resource Planning }\end{array}$ & 26 & B.S., Rangeland Management \\
\hline Lisa Bryant & Soils and Invasive Species & 17 & M.S., Soil Science \\
\hline Wendy Bullock & $\begin{array}{l}\text { Spatial Data Analysis and Geographic } \\
\text { Information System }\end{array}$ & 28 & B.S., Civil Engineering \\
\hline Thomas Burke & $\begin{array}{l}\text { Archaeology and Cultural Resources } \\
\text { Management }\end{array}$ & 32 & Ph.D., Anthropology \\
\hline Tim Burton & $\begin{array}{l}\text { Fisheries Biology, Hydrology, and } \\
\text { Aquatic Ecology }\end{array}$ & 30 & M.S., Watershed Science \\
\hline Bill Carey & $\begin{array}{l}\text { Hydrology, Water Quality, and } \\
\text { Sediment Transport }\end{array}$ & 31 & M.S., Geophysics \\
\hline Christina Caswell & Economics & 14 & $\begin{array}{l}\text { B.B.A., Marketing, Economics, anc } \\
\text { International Business }\end{array}$ \\
\hline Erik Christiansen & Fire and Fuels Management & 28 & $\begin{array}{l}\text { M.S., Forest Protection, } \\
\text { Silviculture, and Forestry }\end{array}$ \\
\hline Jerry Cordova & $\begin{array}{l}\text { Native American and Alaska Native } \\
\text { Issues and Tribal Liaison Coordinator }\end{array}$ & 33 & $\begin{array}{l}\text { B.S., Political Science and Native } \\
\text { American Studies }\end{array}$ \\
\hline Brad Cownover & $\begin{array}{l}\text { Visual Resource Management and } \\
\text { Landscape Architecture }\end{array}$ & 11 & B.S., Landscape Architecture \\
\hline Bruce Crespin & $\begin{array}{l}\text { Paleontology; Cultural and Historic } \\
\text { Resources; Native American and Alaska } \\
\text { Native Resource Issues }\end{array}$ & 30 & B.A., Anthropology \\
\hline Cliff Faning & Soil & 33 & B.S., Soil Science \\
\hline Scott Feldhausen & $\begin{array}{l}\text { Fish and Fish Habitat, and Threatened, } \\
\text { Endangered, and Sensitive Species } \\
\text { Consultation }\end{array}$ & 18 & B.S., Fisheries \\
\hline Karl Ford & $\begin{array}{l}\text { Human Health, Ecological Risk } \\
\text { Assessment, and Toxicology }\end{array}$ & 33 & Ph.D., Toxicology \\
\hline Mark Goldbach & Recreation Resource Management & 29 & $\begin{array}{l}\text { B.S., Recreation Resource } \\
\text { Management }\end{array}$ \\
\hline Carl Gossard & $\begin{array}{l}\text { Fire Management and Smoke } \\
\text { Management }\end{array}$ & 27 & $\begin{array}{l}\text { B.S., Natural Resource } \\
\text { Management }\end{array}$ \\
\hline Jeannette Griese & Forestry & 17 & B.S., Resource Management \\
\hline Ruth Gronquist & $\begin{array}{l}\text { Noxious Weeds and Invasive Species, } \\
\text { Alaska State Weed Coordinator, and } \\
\text { Wildlife Biology }\end{array}$ & 24 & B.S., Biology \\
\hline Bill Grossi & Wildlife Habitat and Species of Concern & 28 & B.S., Wildlife Science \\
\hline
\end{tabular}


TABLE 5-1 (Cont.)

List of Preparers of the Programmatic EIS/ER/BA

\begin{tabular}{|c|c|c|c|}
\hline Contributor & Areas of Specialty & $\begin{array}{c}\text { Years of } \\
\text { Experience }\end{array}$ & Highest Degree/Education \\
\hline Theresa Hanley & Cultural Resources and Planning & 16 & M.A., Anthropology \\
\hline Dave Harmon & Wilderness and Forestry & 31 & M.S., Forest Management \\
\hline Doug Havlina & Fire Ecology & 20 & M.S., Fire Ecology \\
\hline Rob Hellie & $\begin{array}{l}\text { National Landscape Conservation } \\
\text { System }\end{array}$ & 33 & B.S., Outdoor Recreation \\
\hline Ken Henke & Natural Resources & 14 & B.S., Wildlife Biology \\
\hline Patricia Hester & Paleontology & 21 & M.S., Geology \\
\hline Barbara Hill & $\begin{array}{l}\text { Wildlife Resources and Threatened, } \\
\text { Endangered, and Sensitive Species }\end{array}$ & 28 & M.S., Wildlife Biology \\
\hline Steve Hodapp & Threatened and Endangered Species & 20 & B.S., Wildlife Management \\
\hline Karen Holmstrom & GIS & 15 & B.S., Anthropology \\
\hline Mike "Sherm" Karl & $\begin{array}{l}\text { Plant Ecology and Livestock Grazing } \\
\text { Management }\end{array}$ & 25 & Ph.D., Rangeland Ecology \\
\hline Lee Koss & Hydrology and Riparian Restoration & 36 & $\begin{array}{l}\text { B.S., Water Resource Management, } \\
\text { Civil and Engineering, and Biology }\end{array}$ \\
\hline Vonnie Larvie & $\begin{array}{l}\text { Attorney, Division of Land and Water, } \\
\text { Office of the Solicitor }\end{array}$ & 12 & J.D., Law \\
\hline Richard Lee & Herbicide Use and Management & 22 & Ph.D., Weed Science \\
\hline Bonnie Lippitt & Recreation, Interpretation, and Tourism & 23 & B.S., Recreation Administration \\
\hline Steve Lydick & Threatened and Endangered Species & 14 & B.S., Biology \\
\hline Mary Lynch & Wildland Fire Management & 25 & B.A., Psychology \\
\hline Elroy Masters & $\begin{array}{l}\text { Recreation, Fish and Wildlife } \\
\text { Management, and Land Use Planning }\end{array}$ & 15 & B.A., Biology \\
\hline Rosemary Mazaika & $\begin{array}{l}\text { Water Resources, Wetlands, and } \\
\text { Riparian Areas }\end{array}$ & 17 & $\begin{array}{l}\text { M.S., Wildlife Ecology and } \\
\text { Management } \\
\text { M.A., Public Policy and } \\
\text { Administration }\end{array}$ \\
\hline Linda Mazzu & $\begin{array}{l}\text { Fire Management, Plant Ecology, } \\
\text { Invasive Plant Management, and Botany }\end{array}$ & 24 & $\begin{array}{l}\text { M.S., Natural Resources } \\
\text { Management }\end{array}$ \\
\hline Carolyn McClellan & Cultural Anthropology & 12 & M.A., Cultural Anthropology \\
\hline Erin McConnell & $\begin{array}{l}\text { Weed Management, Plant Science, and } \\
\text { Recreation }\end{array}$ & 13 & B.S., Forestry and Recreation \\
\hline Henry McNeel & Integrated Weed Management & 47 & M.S., Plant Science \\
\hline Ted Milesnick & Wildland Fire Management & 36 & B.S., Rangeland Management \\
\hline Melanie Miller & Fire Ecology and Plant Ecology & 32 & M.S., Forestry \\
\hline Joseph Moreau & Fish Resources & 25 & $\begin{array}{l}\text { M.S., Natural Resources and Fish } \\
\text { Biology }\end{array}$ \\
\hline Dan Muller & $\begin{array}{l}\text { Natural Resource and Watershed } \\
\text { Management }\end{array}$ & 29 & B.S., Watershed Science \\
\hline Bill Murphy & Hazardous Materials & 20 & B.A., Physical Geography \\
\hline Robert Ohrn & Forestry & 31 & B.S., Forestry \\
\hline Peggy Olwell & $\begin{array}{l}\text { Endangered Species and Plant } \\
\text { Conservation }\end{array}$ & 25 & M.S., Biology \\
\hline Jim Perry & $\begin{array}{l}\text { Mineral Development and Reclamation, } \\
\text { Forestry, NEPA Planning, Lands and } \\
\text { Realty, and Noxious Weeds }\end{array}$ & 29 & $\begin{array}{l}\text { B.S., Environmental and Resource } \\
\text { Management }\end{array}$ \\
\hline Doug Powell & $\begin{array}{l}\text { Rangeland Management and Livestock } \\
\text { Grazing }\end{array}$ & 26 & B.S., Natural Resources \\
\hline
\end{tabular}


TABLE 5-1 (Cont.)

List of Preparers of the Programmatic EIS/ER/BA

\begin{tabular}{|c|c|c|c|}
\hline Contributor & Areas of Specialty & $\begin{array}{c}\text { Years of } \\
\text { Experience }\end{array}$ & Highest Degree/Education \\
\hline Gina Ramos & $\begin{array}{l}\text { Co-Project Manager and Weed } \\
\text { Management, Invasive Species, } \\
\text { Pesticide Use, Range Management, and } \\
\text { Economics }\end{array}$ & 25 & $\begin{array}{l}\text { B.S., Range Science } \\
\text { M.B.A., Business Administration }\end{array}$ \\
\hline Roger Rosentreter & $\begin{array}{l}\text { Botany, Plant Ecology, Weed Control, } \\
\text { and Plant Species of Concern }\end{array}$ & 28 & Ph.D., Botany \\
\hline Paul Schlobohm & Smoke Management and Fire & 21 & $\begin{array}{l}\text { M.S., Environmental and Natural } \\
\text { Resource Science }\end{array}$ \\
\hline John Simons & $\begin{array}{l}\text { Rangeland Resource Management and } \\
\text { Invasive Species Management }\end{array}$ & 30 & $\begin{array}{l}\text { B.S., Range Ecology and Soil } \\
\text { Science }\end{array}$ \\
\hline Peg Sorensen & Land Use Planning and NEPA & 23 & M.A., Recreation and Planning \\
\hline Carol Spurrier & $\begin{array}{l}\text { Native Plant Communities and Species } \\
\text { of Concern }\end{array}$ & 27 & M.S., Biology \\
\hline Jeanne Standley & $\begin{array}{l}\text { ANILCA } \S 810 \text { Consultation and } \\
\text { Vegetation Specialist }\end{array}$ & 15 & B.S., Rangeland Resources \\
\hline Karl Stein & $\begin{array}{l}\text { Threatened and Endangered Species, } \\
\text { USFWS and NMFS Consultation, and } \\
\text { Fisheries Biology }\end{array}$ & 26 & B.S., Fisheries \\
\hline John Styduhar & Realty and Rights-of-ways & 36 & B.S., Forest Science \\
\hline Paul Summers & $\begin{array}{l}\text { Groundwater Hydrology and Water } \\
\text { Resources }\end{array}$ & 37 & B.S., Geology and Water Resources \\
\hline Rob Sweeten & Visual Resource Management & 14 & $\begin{array}{l}\text { B.L., Landscape Architecture and } \\
\text { Environmental Planning }\end{array}$ \\
\hline Peter Teensma & $\begin{array}{l}\text { Fire Ecology, Fire Management, and Air } \\
\text { Quality Management }\end{array}$ & 28 & Ph.D., Geography \\
\hline Rick Tholen & $\begin{array}{l}\text { Forestry, Forest Health, and Landscape } \\
\text { Ecology }\end{array}$ & 29 & M.S., Forest Management \\
\hline Joan Trent & $\begin{array}{l}\text { Social Environment and Social Impact } \\
\text { Assessment }\end{array}$ & 28 & $\begin{array}{l}\text { M.S., Environmental Science and } \\
\text { Social Science }\end{array}$ \\
\hline Duane Wilson & Rangeland Management & 30 & $\begin{array}{l}\text { B.S., Biology and Range } \\
\text { Management }\end{array}$ \\
\hline Sharon Wilson & Public Relations & 44 & B.A., Journalism \\
\hline Kate Winthrop & $\begin{array}{l}\text { Native American and Alaska Native } \\
\text { Issues; Paleontology; Cultural and } \\
\text { Historic Resources }\end{array}$ & 28 & Ph.D., Anthropology \\
\hline Margaret Wolf & Outdoor Recreation & 29 & M.S., Public Administration \\
\hline William Ypsilantis & Soils & 29 & M.S., Forest Soils \\
\hline \multicolumn{4}{|c|}{ Environmental Protection Agency } \\
\hline Sid Abel & Environmental Chemistry and Modeling & 31 & M.S., Science \\
\hline Tom Bailey & $\begin{array}{l}\text { Fishery Biology and Aquatic } \\
\text { Toxicology }\end{array}$ & 27 & Ph.D., Zoology \\
\hline Angel Chiri & $\begin{array}{l}\text { Entomology and Integrated Pest } \\
\text { Management }\end{array}$ & 26 & Ph.D., Entomology \\
\hline Pat Cimino & $\begin{array}{l}\text { Pesticide Regulation, Plant Pathology, } \\
\text { and Weed Science }\end{array}$ & 30 & M.S., Plant Pathology \\
\hline Roxolana Dashuba & $\begin{array}{l}\text { Air Quality Modeling and } \\
\text { Environmental Fate }\end{array}$ & 5 & M.S., Chemistry \\
\hline
\end{tabular}


TABLE 5-1 (Cont.)

List of Preparers of the Programmatic EIS/ER/BA

\begin{tabular}{|c|c|c|c|}
\hline Contributor & Areas of Specialty & $\begin{array}{c}\text { Years of } \\
\text { Experience }\end{array}$ & Highest Degree/Education \\
\hline Mike Davy & $\begin{array}{l}\text { Phytotoxicity and Ecological Risk } \\
\text { Assessment }\end{array}$ & 30 & B.S., Agronomy \\
\hline Michelle Embry & $\begin{array}{l}\text { Ecotoxicology and Molecular } \\
\text { Toxicology }\end{array}$ & 8 & Ph.D., Toxicology \\
\hline William Erickson & $\begin{array}{l}\text { Wildlife Biologist and Ecological Risk } \\
\text { Assessment }\end{array}$ & 31 & Ph.D., Ecology \\
\hline Jeff Evans & Toxicology and Pesticide Exposure & 31 & B.S., Agronomy \\
\hline Brian Kiernan & Forest and Plant Ecology & 8 & M.S., Plant Ecology \\
\hline Arty Williams & $\begin{array}{l}\text { Endangered Species Act Implementation } \\
\text { and Pesticide Registrations }\end{array}$ & 27 & B.S., Wildlife Biology \\
\hline \multicolumn{4}{|c|}{ U.S. Fish and Wildlife Service } \\
\hline Maria Boroja & $\begin{array}{l}\text { Forest Management, Environmental } \\
\text { Contaminants, and Fish and Wildlife } \\
\text { Biology }\end{array}$ & 17 & B.S., Wildlife Management \\
\hline Michael Horton & Endangered Species Coordinator & 16 & M.S., Wildlife Management \\
\hline Jim Serfis & $\begin{array}{l}\text { Endangered Species and Environmental } \\
\text { Assessments }\end{array}$ & 22 & M.S., Environmental Studies \\
\hline Ken Seeley & $\begin{array}{l}\text { Ecological Risk Assessment and } \\
\text { Environmental Toxicology }\end{array}$ & 16 & Ph.D., Marine Science \\
\hline \multicolumn{4}{|c|}{ National Oceanic and Atmospheric Administration National Marine Fisheries Service } \\
\hline Rachel Friedman & $\begin{array}{l}\text { Endangered Species, Pesticide } \\
\text { Ecosystem Effects, Contaminated } \\
\text { Sediments, and Water Biotic Effects } \\
\end{array}$ & 26 & M.S., Forest Ecology \\
\hline Kelly Foster & $\begin{array}{l}\text { Endangered Species Act Section } 7 \\
\text { Consultation and Marine Biology }\end{array}$ & 15 & M.S., Biological Oceanography \\
\hline \multicolumn{4}{|c|}{ ENSR Corporation } \\
\hline Jon Alstad & Rangeland Management & 27 & M.S., Range Science \\
\hline $\begin{array}{l}\text { Kimberly } \\
\text { Anderson }\end{array}$ & Botany, Species of Concern, and Editor & 8 & M.S., Botany \\
\hline Christine Archer & Ecological Risk Assessment & 10 & B.S., Zoology \\
\hline Robert Berry & Hydrogeologist and Water Quality & 30 & Ph.D., Geology and Geochemistry \\
\hline Lisa Bradley & Human Health Risk Assessment & 23 & Ph.D., Toxicology \\
\hline Amanda Canning & Fish and Other Aquatic Organisms & 5 & B.S., Environmental Science \\
\hline Ishrat Chaudhuri & Human Health Risk Assessment & 22 & Ph.D., Toxicology \\
\hline Tyler Creech & Terrestrial Ecology & 2 & B.S., Environmental Science \\
\hline Rollin Daggett & Fish and Other Aquatic Organisms & 31 & $\begin{array}{l}\text { M.S., Freshwater and Marine } \\
\text { Biology }\end{array}$ \\
\hline Gail Dethloff & Ecological Risk Assessment & 12 & Ph.D., Toxicology \\
\hline Doree DuFresne & Ecological Risk Assessment & 10 & B.S., Biology and Microbiology \\
\hline Kristie Dunkin & Soil, Wetlands, and Water Resources & 17 & Ph.D., Soil Science \\
\hline Steve Ellsworth & Wildlife and Wetland Ecology & 23 & M.S., Wildlife Management \\
\hline Ara Erickson & Forest Ecology & 4 & M.S., Forest Ecology \\
\hline Cameron Fisher & $\begin{array}{l}\text { Fish, Other Aquatic Organisms, and } \\
\text { Geographic Information System } \\
\end{array}$ & 11 & $\begin{array}{l}\text { M.S., Marine Science and Fisheries } \\
\text { Ecology }\end{array}$ \\
\hline Barry Flaming & $\begin{array}{l}\text { Soil Resources and Geographic } \\
\text { Information System } \\
\end{array}$ & 4 & M.S., Forest Ecology \\
\hline Lucy Fraiser & Human Health Risk Assessment & 18 & Ph.D., Toxicology \\
\hline
\end{tabular}


TABLE 5-1 (Cont.)

List of Preparers of the Programmatic EIS/ER/BA

\begin{tabular}{|c|c|c|c|}
\hline Contributor & Areas of Specialty & $\begin{array}{c}\text { Years of } \\
\text { Experience }\end{array}$ & Highest Degree/Education \\
\hline Marcus Garcia & Human Health Risk Assessment & 13 & B.S., Toxicology \\
\hline Robert Gensemer & $\begin{array}{l}\text { Aquatic Toxicology and Ecological Risk } \\
\text { Assessment }\end{array}$ & 22 & Ph.D., Biology \\
\hline Mark Gerath & Ecological Risk Assessment & 21 & M.S., Environmental Engineering \\
\hline Melisa Holman & Rangeland and Invasive Species & 5 & $\begin{array}{l}\text { M.S., Forest and Rangeland } \\
\text { Ecology }\end{array}$ \\
\hline Alissa Long & Wetland and Aquatic Resources & 8 & $\begin{array}{l}\text { B.S., Ecology, Evolution, and } \\
\text { Conservation Biology }\end{array}$ \\
\hline Amanda MacNutt & Air Quality & 5 & B.S., Meteorology \\
\hline Ken Mongar & Graphics & 17 & A.T.A., Tele-data Communications \\
\hline Rami Naddy & Ecological Risk Assessment & 17 & Ph.D., Environmental Toxicology \\
\hline Kathleen Nolan & Human Health Risk Assessment & 16 & M.S., Public Health \\
\hline Robert Paine & Air Quality & 31 & M.S., Meteorology \\
\hline Merlyn Paulson & Visual Resources & 30 & $\begin{array}{l}\text { M.L.S., Landscape Architecture, } \\
\text { Geographic Information System }\end{array}$ \\
\hline Stuart Paulus & $\begin{array}{l}\text { Project Manager, NEPA Specialist, and } \\
\text { Wildlife Ecology }\end{array}$ & 26 & Ph.D., Wildlife Ecology \\
\hline David Pillard & Ecological Risk Assessment & 25 & Ph.D., Ecology \\
\hline Devan Richardson & Wild Horses and Burros, Livestock & 6 & M.S., Range Management \\
\hline Vanessa Stevens & Plant and Soil Sciences & 6 & M.S., Plant and Soil Science \\
\hline Kelly Vosnakis & Human Health Risk & 11 & $\begin{array}{l}\text { M.S., Civil and Environmental } \\
\text { Engineering and Environmental } \\
\text { Health }\end{array}$ \\
\hline Frank Vertucci & Ecological Risk Assessment & 27 & $\begin{array}{l}\text { Ph.D., Ecology and Evolutionary } \\
\text { Biology }\end{array}$ \\
\hline Kristin Durocher & Ecological Risk Assessment & 11 & $\begin{array}{l}\text { M.S., Natural Resources and } \\
\text { Terrestrial Ecology }\end{array}$ \\
\hline Janet Wolf & Public Relations & 17 & B.A., Biological Sciences \\
\hline Melinda Woodard & Aquatic Ecology & 10 & M.S., Environmental Science \\
\hline \multicolumn{4}{|c|}{ Historical Research Associates } \\
\hline Thomas Becker & Anthropology & 10 & M.A., Anthropology \\
\hline Trent DeBoer & Archaeology and Anthropology & 13 & M.A., History \\
\hline Ann Emmons & History & 15 & M.A., History \\
\hline T. Weber Grieser & Archaeology & 33 & M.A., Anthropology \\
\hline Gail Thompson & Archaeology and Anthropology & 34 & Ph.D., Anthropology \\
\hline \multicolumn{4}{|c|}{ Paleo Consultants } \\
\hline Rebecca Hanna & Paleontology & 18 & M.S., Earth Science \\
\hline \multicolumn{4}{|c|}{ Planera } \\
\hline Berhard Strom & $\begin{array}{l}\text { Socioeconomic and Visual Resource } \\
\text { Assessment }\end{array}$ & 35 & M.C.R.P., Regional Planning \\
\hline
\end{tabular}



CHAPTER 6 REFERENCES 



\section{CHAPTER 6}

\section{REFERENCES}

Adams, L., W. Collins, B. Dale, and K. Joly. 2000. Assessing Wildlife Fire Impacts on Winter Habitat Use and Distribution of Caribou within Alaska's Boreal Forest Ecosystem. U.S. Geological Survey and Alaska Department of Fish and Game. Juneau, Alaska.

Adovasio, J.M. 1986. Prehistoric Basketry. Pages 194-205 in Great Basin (W.L. d'Azevedo, ed.). Handbook of North American Indians, Volume 11 (W.C. Sturtevant, general ed.). Smithsonian Institution. Washington, D.C.

Agee, J. 1993. Fire Ecology of Pacific Northwest Forests. Island Press. Washington, D.C.

Aikens, M.C. 1983. The Far West. Pages 203-241 in Ancient North Americans (J.D. Jennings, ed.). W.H. Freeman and Company. New York, New York.

, and D.B. Madsen. 1986. Prehistory of the Eastern Area. Pages 149-160 in Great Basin (W.L. d'Azevedo, ed.). Handbook of North American Indians, Volume 11 (W.C. Sturtevant, general ed.). Smithsonian Institution. Washington, D.C.

Alameda County Agriculture Advisory Committee. 2005. Alameda Oak Woodlands Management Plan and Background for the General Plan and S.B. 1334 Implementation. Alameda County, California. Available at: http://www.acred.org/agriculture/ACOakPlanDec0 5.pdf.

Allen, E.B., and N.E. West. 1993. Nontarget Effects of the Herbicide Tebuthiuron on Mycorrhizal Fungi in Sagebrush Semidesert. Mycorrhiza 3:7578.

Allen, M.F. 1991. Ecology of Mycorrhizae. Cambridge University Press. Cambridge, United Kingdom.

Alley, W.M., T.E. Reilly, and O.L. Franke. 1999. Sustainability of Ground-water Resources. U.S.
Geological Survey Circular 1186. Available at: http://water.usgs.gov/pubs/circ/circ1186/index.html

Aly, O. M., and S. D. Faust. 1964. Studies on the Fate of 2,4-D and Ester Derivatives in Natural Surface Waters. Agricultural Food Chemistry 12:541-546.

American Cyanamid. 1986. Arsenal Herbicide: Technical Report. American Cyanamid Agricultural Division. Madison, New Jersey.

American Cyanamid Company. 2000. Plateau Herbicide, for Weed Control, Native Grass Establishment and Turf Growth Suppression on Roadsides and Other Noncrop Areas. PE-47015. Parsnippany, New Jersey.

Ames, K.M., D.E. Dumond, J.R. Galm, and R. Minor. 1998. Prehistory of the Southern Plateau. Pages 73-80 in Plateau (D.E. Walker, Jr., ed.). Handbook of North American Indians, Volume 12 (W.C. Sturtevant, general ed.). Smithsonian Institution. Washington, D.C.

, and H.D.G. Maschner. 1999. Peoples of the Northwest Coast: Their Archeology and Prehistory. Thames and Hudson Ltd. London, England.

Andersen, S.M., P.B. Hertz, T. Holst, R. Bossi, and C.S. Jacobsen. 2001. Mineralisation Studies of C14-labelled Metsulfuron-methyl, Tribenuronmethyl, Chlorsulfuron and Thifensulfuron-methyl in One Danish Soil and Groundwater Sediment Profile. Chemosphere 45:775-782.

Anderson, D.C., K.T. Harper, and S.R. Rushforth. 1982. Recovery of Cryptogamic Soil Crusts from Grazing on Utah Winter Ranges. Journal of Range Management 35:355-359. 
Anderson, D.D. 1984. Prehistory of North Alaska. Pages 80-93 in Arctic (D. Damas, ed.). Handbook of North American Indians, Volume 5 (W.C. Sturtevant, general ed.). Smithsonian Institution. Washington, D.C.

Anderson, L. 2001. Terrestrial Wildlife and Habitat. Chapter 7 in Fire Effects Guide. National Wildfire Coordinating Group, National Interagency Fire Center. Boise, Idaho. Available at: http://fire.r9.fws.gov/ifcc/monitor/EFGuide/index. $\underline{\text { htm. }}$.

Anderson, R. 1988. Montane Hardwood-conifer. Pages 70-71 in A Guide to Wildlife Habitats of California (K.E. Mayer and W.F. Laudenslayer, Jr., eds.). California Department of Forestry and Fire Protection. Sacramento, California.

Anderson, W.P. 1983. Weed Science: Principles. 2nd Edition. West Group. Eagan, Minnesota.

Andreev, V. N. 1954. The Growth of Forage Lichens and the Methods for Their Regulation. Geobotanika 9:11-74.

Aquatic Ecosystem Restoration Foundation. 2004. Aquatic Plant Management: Best Management Practices Handbook in Support of Fish and Wildlife Habitat. Volume 3M CMC 2-13-4. Aquatic Ecosystem Restoration Foundation. Lansing, Michigan.

Asher, J.E., and S.A. Dewey. 2005. Estimated Annual Rates of Weed Spread on Western Federal Wildlands. Draft White Paper. Federal Interagency Committee for Management of Noxious and Exotic Weeds (FICMNEW). Washington, D.C.

ATTRA. 1997. Purple Loosestrife: Public Enemy No. 1 on Federal Lands. ATTRA Interior Helper Internet. Washington, D.C. Available at: http://ceris.purdue.edu/napis/pests/pls/factspls.txt.

Austin, A.P., G.E. Harris, and W.P. Lucey. 1991. Impact of an Organophosphate Herbicide (Glyphosate) on Periphyton Communities Developed in Experimental Streams. Bulletin of Environmental Contamination and Toxicology 41:29-35.
Back, G.N., B.L. Perryman, and J.K. McAdoo. 2002. Application of Sage Grouse Guidelines to Sage Grouse Habitats in Nevada. Paper Presented at the Restoration and Management of Sagebrush/grass Communities Workshop. Elko, Nevada.

Badejo, M.A., and T.A. Adejuyigbe. 1994. Influence of Hexazinone on Soil Microarthropods in Nigeria. Fresenius Environmental Bulletin 3:263268.

Bailey, R.G. 1997. Map: Ecoregions of North America (Revised). (Scale: 1:15,000,000). U.S. Department of Agriculture Forest Service in Cooperation with the Nature Conservancy and the U.S. Geological Survey. Washington, D.C.

. 2002. Ecoregions. Pages $235-245$ in The Physical Geography of North America (A.R. Orme, ed.). Oxford University Press. Oxford, England.

Bangsund, D. A., and F.L. Leistritz. 1991. Economic Impacts of Leafy Spurge in Wildlands in Montana, South Dakota, and Wyoming. North Dakota State University, Agricultural Economics - Station. Agricultural Report No. 275. Fargo, North Dakota.

, J.F. Baltezore, J.A. Leitch, and F.L. Leistritz.. 1993. Economic Impacts of Leafy Spurge in Wildlands in Montana, South Dakota, and Wyoming. North Dakota State University, Agricultural Economics Station. Agricultural Report No. 304. Fargo, North Dakota.

J.A. Leitch, and F.L. Leistritz. 1996. Economic Analysis of Herbicide Control of Leafy Spurge in Rangeland. North Dakota State University Agricultural Experimental Station. Agricultural Economics Report No. 342. Fargo, North Dakota.

, F.L. Leistritz, and J.A. Leitch. 1997. Predicted Future Economic Impacts of Biological Control of Leafy Spurge in the Upper Midwest. North Dakota State University Agricultural Experimental Station. Agricultural Economics Report No. 382. Fargo, North Dakota. 
1999a. Assessing

Economic Impacts of Biological Control of Weeds: the Case of Leafy Spurge in Northern Great Plains of the United States. Journal of Environmental Management 56:35-53.

, D.J. Nudell, R.S. Sell, and F.L. Leistritz. 1999b. Economic Analysis of Controlling Leafy Spurge with Sheep. North Dakota State University Agricultural Experimental Station. Economics Report No. 431. Fargo, North Dakota.

Barbash, J. E., G. P. Thelin, D. W. Kolpin, and R. J. Gilliom. 1999. Distribution of Major Herbicides in Ground Water of the United States. Water-resources Investigations Report 98-4245.

Barker, C., K. Drottar, and H. Krueger. 1998. Toxicity of AC263,222 During the Early Lifestages of the Flathead Minnow (Pimephales promelas): Lab Project Number 2CO 98-134; 95498-134; 130A-120. Unpublished Study by Wildlife International, Ltd. OPPTS 850.1440. MRID No. 44728202.

Barrows, D.P. 1900. The Ethnobotany of the Cahuilla Indians of Southern California. Ph.D. Dissertation, University of Chicago. Chicago, Illinois.

BASF. 2004. Plateau Herbicide Label. Research Triangle Park, North Carolina.

Basso, K.H. 1983. Western Apache. Pages 462-488 in Southwest (A. Ortiz, ed.). Handbook of North American Indians, Volume 10 (W.C. Sturtevant, general ed.). Smithsonian Institution. Washington, D.C.

Battaglin, W.A., E.T. Furlong, M.R. Burkhardt, and C.J. Peter. 2000. Occurrence of Sulfonylurea, Sulfonamide, Imidazolinone, and Other Herbicides in Rivers, Reservoirs and Ground Water in the Midwestern United States, 1998. Science of the Total Environment 248:123133.

一 $\longrightarrow$ and 2001. Concentration of Selected Sulfonylurea, Sulfonamide, and Imidazolinone Herbicides, Other Pesticides, and Nutrients in 71 Streams, 5 Reservoir Outflows, and 25 Wells in the Midwestern United States, 1998. Water-resources
Investigations Report 00-4225. USGS. Denver, Colorado.

, E.M. Thurman, S.J. Kalkhoff, and S.D. Porter. 2003. Herbicides and Transformation Products in Surface Waters of the Midwestern United States. Journal of the American Water Resources Association 39:743-756.

Bean, L.J., and K.S. Sabel. 1972. Cahuilla Indian Knowledge and Usage of Plants. Malki Museum Press. Banning, California.

Beaver, D.L. 1976. Avian Populations in Herbicide Treated Brush Fields. Auk 93:543-553.

Beck, K.G. 1999. Biennial Thistles. Pages 145-165 in Biology and Management of Noxious Rangeland Weeds (R.L. Sheley and J.K. Petroff, eds.). Oregon State University Press. Corvallis, Oregon.

Behnke, R.J. 1992. Native Trout of Western North America. American Fisheries Society Monograph Number 6. Washington, D.C.

Belnap, J. 1994. Potential Role of Cryptobiotic Soil Crust in Semiarid Rangelands. Pages 179-185 in Proceedings-Ecology and Management of Annual Rangelands. (S.B. Monsen and S.G. Kitchen, eds.). General Technical Report INTGTR-313. U.S. Department of Agriculture Forest Service, Intermountain Research Station. Ogden, Utah.

. 1995. Surface Disturbances: Their Role in Accelerating Desertification. Environmental Monitoring and Assessment 37:39-57.

2005. Personal Communication with $\mathrm{K}$. Dunkin, ENSR, on Effects of Herbicides on Biological Soil Crusts. U.S. Biological Resources Division, Canyonlands Research Station. Moab, Utah.

, and J.S. Gardner. 1993. Soil Microstructure of the Colorado Plateau: The Role of the Cyanobacterium Microcoleus vaginatus. Great Basin Naturalist 53:40-47.

, and D.A. Gillette. 1998. Vulnerability of Desert Soil Surfaces to Wind Erosion: Impacts of Soil Texture and Disturbance. Journal of Arid Environments 39:133-142. 
, and S. L. Phillips. 2001. Soil Biota in an Ungrazed Grassland: Response to Annual Grass (Bromus tectorum) Invasion. Ecological Applications 11:1261-1275.

, R. Rosentreter, S. Leonard, J.H. Kaltenecker, J. Williams, and D. Eldridge. 2001. Biological Soil Crusts: Ecology and Management. U.S. Department of the Interior, Bureau of Land Management, National Science and Technology Center. Report Technical Reference 1730-2. Denver, Colorado.

Bender, G.L. (ed.). 1982. Reference Handbook on the Deserts of North America. Greenwood Press. Westport, Connecticut.

Bendix, J. 2002. Pre-european Fire in California Chaparral in Fire, Native Peoples, and the Natural Landscape (T.R. Vale, ed.). Island Press. Washington, D.C.

Beran, D.D., R.E. Gaussoin, and R.A. Masters. 1999. Native Wildflower Establishment with Imidazolinone Herbicides. Hortscience 34(2):283286.

Berrill, M., S. Bertram, L. McGillivray, M. Kolohon, and B. Pauli. 1994. Effects of Low Concentrations of Forest-use Pesticides on Frog Embryos and Tadpoles. Environmental Toxicology and Chemistry 13:657-664.

, and B. Pauli. 1997. Effects of Pesticides on Amphibian Embryos and Larvae. Pages 233-245 in Amphibians in Decline: Canadian Studies of a Global Problem (D.M. Greed, ed.). Society for the Study of Amphibians and Reptiles.

Bevans, H.E., M.S. Lico, and S.J. Lawrence. 1998. Water Quality in the Las Vegas Valley Area and the Carson and Truckee River Basins, Nevada and California, 1992-96. U.S. Geological Survey Circular $1170 . \quad$ Available at: http://pubs.usgs.gov/circ/circ1170/.

Biological Resources Research Center. 2001. Threatened and Endangered Animals of the Great Basin. University of Nevada. Reno, Nevada.

Blumler, M.A. 1992. Some Myths About California Grasslands and Grazers. Fremontia 20:22-27.
Bodine, J.J. 1979. Taos Pueblo. Pages 255-267 in Southwest (A. Ortiz, ed.). Handbook of North American Indians, Volume 9 (W.C. Sturtevant, general ed.). Smithsonian Institution. Washington, D.C.

Boertje, R.R., and C.L. Garner. 1998. Factors Limiting the Fortymile Caribou Herd. Federal Aid Final Report Study 3.38. Alaska Department of Fish and Game. Fairbanks, Alaska.

Bogan, M.A., C.D. Allen, E.H. Muldavin, S.P. Platania, J.N. Stuart, G.H. Farley, P. Mehlhop, and J. Belnap. 2003. Southwest in Status and Trends of the Nation's Biological Resources. Available at: http://biology.usgs.gov/s+t/SNT/index.htm.

Bohn, C.C., and J.C. Buckhouse. 1985. Coliforms as an Indicator of Water Quality in Wildland Streams. Journal of Soil and Water Conservation 40:95-97.

Bolen, E.G. 1998. Ecology of North America. John Wiley and Sons, Inc. New York, New York.

Bonneville Power Administration (BPA). 2000. Transmission System Vegetation Management Program Final Environmental Impact Statement. Portland, Oregon.

Boreson, K. 1998. Rock Art. Pages 611-619 in Plateau (D.E. Walker, ed.). Handbook of North American Indians, Volume 12 (W.C. Sturtevant, general ed.). Smithsonian Institution. Washington, D.C.

Borjesson, E., L. Torstensson, and J. Stenstrom. 2004. The Fate of Imazapyr in a Swedish Railway Embankment. Pest Management Science 60:544549.

Bossard, C.C., J.M. Randal, and M.C. Hoshovsky (eds.). 2000. Invasive Plants of California's Wildlands. University of California Press. Berkeley, California.

Boucard, T.K., R.D. Bardgett, K.C. Jones, and K.T. Semple. 2005. Influence of Plants on the Chemical Extractability and Biodegradability of 2,4-dichlorophenol in Soil. Environmental Pollution 133:53-62. 
Boutin, C., N. Elmegaard, and C. Kjaer. 2004. Toxicity Testing of Fifteen Non-crop Plant Species with Six Herbicides in a Greenhouse Experiment: Implications for Risk Assessment. Ecotoxicology 13(4):349-369.

Bovey, R.W. 2001. Woody Plants and Woody Plant Management. Marcel Dekker, Inc. New York, New York.

Brabets, T.P., B. Wang, and R.H. Meade. 2000. Environmental and Hydrologic Overview of the Yukon River Basin, Alaska and Canada. U.S. Geological Survey Water-resources Investigations Report 99-4204. Washington, D.C.

Brady, N.C., and R.R. Weil. 1999. The Nature and Properties of Soils $\left(12^{\text {th }}\right.$ Edition). Prentice-Hall, Inc. Upper Saddle River, New Jersey.

, and R.R. Weil. 2002. The Nature and Properties of Soils (13 ${ }^{\text {th }}$ Edition). Prentice-Hall, Inc. Upper Saddle River, New Jersey.

Braun, C.E. 1980. Alpine Bird Communities in Western North America: Implications for Management and Research. Pages 280-291 in Workshop Proceedings: Management of Western Forests and Grasslands for Nongame Birds (R.M. DeGraaf and N.G. Tilghman, eds.). U.S. Department of Agriculture Forest Service General Technical Report INT-86.

T. Britt, and R.O. Wallestad. 1977. Guidelines for the Maintenance of Sage Grouse Habitats. Wildlife Society Bulletin 5:99-106.

British Crop Protection Council and The Royal Society of Chemistry. 1994. The Pesticide Manual - Incorporating the Agrochemicals Handbook. $10^{\text {th }}$ Edition. British Crop Protection Council and Royal Society of Chemistry. Surrey and Cambridge, United Kingdom.

Brown, D.E. (ed.). 1982. Desert Plants. Volume 4 of Biotic Communities of the American Southwest United States and Mexico. University of Arizona, for the Boyce Thompson Southwestern Arboretum. Tucson, Arizona.

Brown, D.N., and L. Irwin. 2001. Ponca, Pages 416431 in Plains (R.J. DeMallie, ed.). Handbook of North American Indians, Volume 13 (W.C.
Sturtevant, general ed.). Smithsonian Institution. Washington, D.C.

Buffington, L.C., and C.H. Herbel. 1965. Vegetation Changes on a Semidesert Grassland Range from 1858 to 1963. Ecological Monographs 35:139164.

Bussan, A.J., and W.E. Dyer. 1999. Herbicides and Rangeland. Pages 116-132 in Biology and Management of Noxious Rangeland Weeds (R.L. Sheley and J.K. Petroff, eds.). Oregon State University Press. Corvallis, Oregon.

Busse, M.D., G.O. Fiddler, and A.W. Ratcliff. 2004. Ectomycorrhizal Formation in Herbicide-treated Soils of Differing Clay and Organic Matter Content. Water Air and Soil Pollution 152:23-34.

Butler, B.R. 1986. Prehistory of the Snake and Salmon River Area. Pages 127-134 in Great Basin (W.L. d'Azevedo, ed.). Handbook of North American Indians, Volume 11 (W. C. Sturtevant, general ed.). Smithsonian Institution. Washington, D.C.

Butler, V.L., and R.F. Schalk. 1986. Holocene Salmonid Resources of the Upper Columbia. Institute for Environmental Studies, Office of Public Archaeology, University of Washington. Seattle, Washington.

Calabrese, E.J., and M.W. Dorsey. 1984. Healthy Living in an Unhealthy World. Simon and Schuster. New York, New York.

California Environmental Protection Agency (CallPA). 1996. Memorandum from T. Formoli (California Environmental Protection Agency, Department of Pesticide Regulation, Worker Health and Safety Branch) to M. Mason (California Environmental Protection Agency, Department of Pesticide Regulation, Pesticide Regulation Branch).

Callaway, D., J. Janetski, and O.C. Stewart. 1986. Ute. Pages 336-367 in Great Basin (W.L. d'Azevedo, ed.). Handbook of North American Indians, Volume 11 (W.C. Sturtevant, general ed.). Smithsonian Institution. Washington, D.C. 
Campbell, S.E. 1979. Soil Stabilization by a Prokaryotic Desert Crust: Implications for Precambrian Land Biota. Origins of Life 9:335348.

Cannon, M.E., and G.A. Nielsen. 1984. Estimating Production of Range Vegetation from Easily Measured Soil Characteristics. Journal of the Soil Science Society of America 48:1393-1397.

Carlson, C.A., and E.M. Carlson. 1982. Review of Selected Literature on the Upper Colorado River System and its Fishes. Pages 1-8 in Fishes of the Upper Colorado River System: Present and Future (W.H. Miller, H.M. Tyus, and C.A. Carlson, eds.). Western Division, American Fisheries Society.

Cassell, M. 1998. The Rio Grande. The Green Line Volume 9, Number 4. Colorado Riparian Association. Available at: http://www.coloradoriparian.org/GreenLine/V094/RioGrande.html.

Centers for Disease Control (CDC). 2005. Worker Health Chartbook 2004. Chapter 1. National Institute for Occupation Safety and Health. Hyattsville, Maryland. Available at: http://www2a.cdc.gov/niosh-Chartbook/ch1/chl3.asp.

. 2007a. Injury and Violence. Department of Health and Human Services. Hyattsville, Maryland. Available at: http://www.cdc.gov/node.do/id/0900f3ec8000e53 $\underline{9}$.

2007b. Health Data for All Ages. Department of Health and Human Services. Hyattsville, Maryland. Available at: http://209.217.72.34/HDAA/ReportFolders/report Folders.aspx.

Chamberlain, J., R. Bush, and A.L. Hammett. 1998. Non-timber Forest Products - The Other Forest Products. Forest Products Journal 48:10-19.

Chatters, J.C. 1998. Environment. Pages 29-48 in Plateau (D. Walker, ed.). Handbook of North American Indians, Volume 12 (W.C. Sturtevant, general ed.). Smithsonian Institution. Washington, D.C.
, and D.L. Pokotylo. 1998. Prehistory: Introduction. Pages 73-80 in Plateau (D.E. Walker, Jr., ed.). Handbook of North American Indians, Volume 12 (W.C. Sturtevant, general ed.) Smithsonian Institution. Washington, D.C.

Chaudhry, G.R., and L. Cortez. 1988. Degradation of Bromacil by a Pseudomonas Species. Applied and Environmental Microbiology 54:2203-2207.

Chiou, C.T., and D.E. Kile. 2000. Contaminant Sorption by Soil and Bed Sediment. Is There a Difference? Fact Sheet-087-00. U.S. Department of the Interior U.S. Geological Survey. Washington, D.C.

Clark, G.M., T.R. Maret, M.G. Rupert, M.A. Maupin, W.H. Low, and D.S. Ott. 1998. Water Quality in the Upper Snake River Basin, Idaho and Wyoming, 1992-95. U.S. Geological Survey Circular $1160 . \quad$ Available at: http://pubs.usgs.gov/circ/circ1160.

Clarke, S.E., and S.A. Bryce (eds.). 1997. Hierarchical Subdivisions of the Columbia Plateau and Blue Mountains Ecoregions, Oregon and Washington. General Technical Report PNWGTR-395. U.S. Department of Agriculture Forest Service, Pacific Northwest Research Station. Portland, Oregon.

Clelow, C.W., Jr. 1978. Prehistoric Rock Art. Pages 619-625 in California (R.F. Heizer, ed.). Handbook of North American Indians, Volume 8 (W.C. Sturtevant, general ed.). Smithsonian Institution. Washington, D.C.

Coffin, P., and W. Cowan. 1995. Lahontan Cutthroat Trout (Oncorhynchus clarki henshawi) Recovery Plan. U.S. Fish and Wildlife Service, Region 1. Portland, Oregon.

Cole, E.D., W.C. McComb, M. Newton, C.J. Chambers, and J.P. Leeming. 1997. Response of Amphibians to Clearcutting, Burning, and Glyphosate Application in the Oregon Coast Range. Journal of Wildlife Management 61:656664. 
Cole, G.A. 1981. Habitats of North American Desert Fishes. Pages 477-492 in Fishes in North American Deserts (R.J. Naiman and D.L. Soltz, eds.). Wiley-Interscience Publication. New York, New York.

Colorado Natural Areas Program. 2000. Creating an Integrated Weed Management Plan: A Handbook for Owners and Managers of Lands with Natural Values. Colorado Natural Areas Program, Colorado State Parks, Colorado Department of Natural Resources, and Division of Plant Industry, Colorado Department of Agriculture. Denver, Colorado.

Conetah, F.A. 1982. Uintah-Ouray Tribe in A History of the Northern Ute People (K.L. MacKay and F.A. O’Neil, eds.). Salt Lake City, Utah.

Cooperative Extension Service, USDA Forest Service, USDA Natural Resource Conservation Service Grazing Land Technology Institute, and USDI BLM. 1999. Sampling Vegetation Attributes Interagency Technical Reference. BLM Technical Reference 1734-4. Washington, D.C. Available

at: http://www.blm.gov/nstc/library/pdf/samplveg.pdf

Cooperrider, A.Y., R.J. Boyd, and H.R. Stuart (eds.). 1986. Inventory and Monitoring of Wildlife Habitats. U.S. Bureau of Reclamation. Washington, D.C.

Croes, D. 2007. Recent Investigations at Sauvie Island Wet Site, Portland, Oregon. A Symposium at the $60^{\text {th }}$ Annual Northwest Anthropological Conference. Pullman, Washington.

Cronquist, A., A.H. Holmgren, N.H. Holmgren, and J.L. Reveall. 1972. Intermountain Flora. Vascular Plants of the Intermountain West, U.S.A, Volume 1. Hafner Publishing Company, Inc. New York, New York.

Dahlgren, D.K., R. Chi, and T.A. Messmer. 2006. Greater Sage-grouse Response to Sagebrush Management in Utah. Wildlife Society Bulletin 34:975-985.

D'Antonio, C.M., T.L. Dudley, and M. Mack. 1999. Disturbance and Biological Invasions: Direct Effects and Feedbacks. Pages 413-452 in Ecosystems of the World: Ecosystems of
Disturbed Ground (L. R. Walker, ed.). Elsevier. Amsterdam, The Netherlands.

Deacon, J.E., and C.D. Williams. 1991. Ash Meadows and the Legacy of the Devils Hole Pupfish. Pages 69-87 in Battle Against Extinction: Native Fish Management in the American West (W.L Minckley and J.E. Deacon, eds.). University of Arizona Press. Tucson, Arizona.

DeByle, N.V., and R.P. Winokur. 1985. Aspen: Ecology and Management in the Western United States. U.S. Department of Agriculture Forest Service General Technical Report RM-119. Rocky Mountain Research Station. Fort Collins, Colorado.

Dennehy, K.F., D.W. Litke, C.M. Tate, S.L. Qi, P.B. McMahon, B.W. Bruce, R.A. Kimbrough, and J.S. Heiny. 1998. Water Quality in the South Platte River Basin, Colorado, Nebraska, and Wyoming, 1992-95. U.S. Geological Survey Circular $1167 . \quad$ Available at: http://pubs.usgs.gov/circ/circ1167/.

Devesa, S.S., D.G. Grauman, W.J. Blot, G. Pennello, R.N. Hoover, and J.F. Franmeni, Jr. 1999. Atlas of Cancer Mortality in the United States, 1950-1994. National Institutes of Health Publication No. 99-4564. U.S. Government Printing Office. Washington D.C. Available at: http://www3.cancer.gov/atlasplus/.

Dexter, A.G. 1993. Herbicide Spray Drift. North Dakota State University Extension Service Fact Sheet A-657 (revised). Available at: http://www.ext.nodak.edu/extpubs/plantsci/weeds/ a657w.htm.

Diaz, G., C. Carrillo, and M. Honrubia. 2003. Differential Responses of Ectomycorrhizal Fungi to Pesticides in Pure Culture. Cryptogamie Mycologie 24:199-211.

Dixon, E.J. 1999. Bones, Boats, and Bison: Archaeology and the First Colonization of Western North America. University of New Mexico Press. Albuquerque, New Mexico.

Doerr, T.B., and F.S. Guthery. 1983. Effects of Tebuthiuron on Lesser Prairie-chicken Habitat and Foods. Journal of Wildlife Management 47:11381142. 
Domagalski, J.L., D.L. Knifong, P.D. Dileanis, L.R. Brown, J.T. May, V. Connor, and C.N. Alpers. 2000. Water Quality in the Sacramento River Basin, California, 1994-98. U.S. Geological Survey Circular 1215. Available at: http://pubs.usgs.gov/circ/circ1215/.

Donaldson, D., T. Kiely, and A. Grube. 2004. 20002001 Pesticide Industry Sales and Usage. U.S. Environmental Protection Agency Pesticide's Program. Washington, D.C. Available at: http://www.epa.gov/oppbead1/pestsales/.

Dorn, P.B., J.H. Rodgers, S.T. Dubey, W.B. Gillespie, and R.E. Lizotte. 1997. An Assessment of the Ecological Effects of a C9-11 Linear Alcohol Ethoxylate Surfactant in Stream Mesocosm. Ecotoxicology 6:275-292.

Douglas, M. E., and P. C. Marsh. 1996. Population Estimates/Population Movements of Gila cypha, An Endangered Cyprinid Fish in the Grand Canyon Region of Arizona. Copeia 1996:15-28.

, P.C. Marsh, and W.L. Minckley. 1994. Indigenous Fishes of Western North America and the Hypothesis of Competitive Displacement: Meda fulgida (Cryprinidae). Copeia 1994:9-19.

Dow AgroSciences. 1998. Clopyralid: A North American Technical Profile. Dow AgroSciences LLC. Indianapolis, Indiana.

Drake, J.A., H.A. Mooney, F. Di Castri, R.H. Groves, E.J. Kruger, M. Rejmanek, and $M$. Williamson. 1989. Biological Invasions: A Global Perspective. John Wiley and Sons. Chichester, England.

Driver, H.E., and W.C. Massey. 1957. Comparative Studies of North American Indians. Transactions of the American Philosophical Society 47(2). Philadelphia, Pennsylvania.

Dubrovsky, N.M., C.R. Kratzer, L.R. Brown, J.M. Gronberg, and K.R. Burow. 1998. Water Quality in the San Joaquin-Tulare Basins, California, 1992-95. U.S. Geological Survey Circular 1159. Available at: http://pubs.usgs.gov/circ/circ1159/.
Duffy, W.G., C.R. Berry, and K.D. Keenlyne. 1996. Biology of the Pallid Sturgeon with an Annotated Bibliography Through 1994. South Dakota Cooperative Research Unit Technical Bulletin Number 5. South Dakota State University. Brookings, South Dakota.

Dumond, D.E. 1987. The Eskimos and Aleuts. Thames and Hudson, Ltd. London, United Kingdom.

Duncan, C.L., and J.K. Clark (eds.). 2005. Invasive Plants of Range and Wildlands and Their Environmental, Economic, and Social Impacts. Weed Science Society of America. Lawrence, Kansas.

Dunham, J. 1998. Bringing Back the Lahontan Cutthroat Trout: Restoring Habitat for Fish and People. Trout Magazine (Spring), Trout Unlimited.

Egan, H.R. 1917. Pioneering the West, 1846-1878: Major Howard Egan's Diary. Howard R. Egan Estate. Richmond, Utah.

Eijsackers, H., and J. Van Der Drift. 1976. Effects on the Soil Fauna. Pages 149-174 In Herbicides Physiology, Biochemistry, and Ecology. Academic Press. London, United Kingdom.

Eldridge, D.J. 1996. Distribution and Floristics of Terricolous Lichens in Soil Crusts in Arid and Semi-arid New South Wales, Australia. Australian Journal of Botany 44:581-599.

, and R.S.B. Greene. 1994. Microbiotic Soil Crusts: A Review of Their Roles in Soil and Ecological Processes in the Rangelands of Australia. Australian Journal of Soil Research 32: 389-415.

Eli Lilly and Company. 2003. Sonar Guide to Aquatic Habitat Management: User's Guide.

Elston, R.G. 1986. Prehistory of the Western Area. Pages 135-148 in Great Basin (W.L. d'Azevedo, ed.). Handbook of North American Indians, Volume 11. (W.C. Sturtevant, general ed.). Smithsonian Institution. Washington, D.C. 
Energy Information Administration. 2005. Annual Energy Review 2005. Report No. DOE/EIA-0384. Chapter 5. Petroleum. Available at: http://www.eia.doe.gov/emeu/aer/pdf/pages/sec5.p df.

Engle, D.M., J.F. Stritzke, and P.L. Claypool. 1987. Herbage Standing Crop Around Eastern Redcedar Trees. Journal of Range Management 40:237-239.

, T.G. Bidwell, J. F. Stritzke, and D. Rollins. 1990. Atrazine and Burning in Tallgrass Prairie Infested with Prairie Threeawn. Journal of Range Management 43:424-427.

English Nature. 2003. The Herbicide Handbook: Guidance on the Use of Herbicides on Nature Conservation Sites. Nature Contract No. EIT 31 04-003. Wetherby, West Yorkshire, United Kingdom.

ENSR. 2001. The Effects of Herbicides on Plants Used for Subsistence by Native Americans on Yakima Training Center, Washington. Prepared for the Department of the Army, Fort Lewis, Washington. Redmond, Washington.

2002. Scoping Comment Summary Report for the Vegetation Treatments Programmatic Environmental Impact Statement. Prepared for the U.S. Department of the Interior Bureau of Land Management, Nevada State Office, Reno, Nevada. Redmond, Washington.

2004. Vegetation Treatments Programmatic EIS Ecological Risk Assessment Protocol. Prepared for the U.S. Department of the Interior Bureau of Land Management, Nevada State Office, Reno, Nevada. Westford, Massachusetts.

- 2005a. Annual Emissions Inventory for BLM Treatment Alternatives. Prepared for the U.S. Department of the Interior Bureau of Land Management, Nevada State Office, Reno, Nevada. Westford, Massachusetts.

2005b. Vegetation Treatments Programmatic EIS - Bromacil Ecological Risk Assessment Final Report. Prepared for the U.S. Department of the Interior Bureau of Land Management, Nevada State Office, Reno, Nevada. Westford, Massachusetts. 2005c. Vegetation Treatments Programmatic EIS - Chlorsulfuron Ecological Risk Assessment Final Report. Prepared for the U.S. Department of the Interior Bureau of Land Management, Nevada State Office, Reno, Nevada. Westford, Massachusetts.

2005d. Vegetation Treatments Programmatic EIS - Diflufenzopyr Ecological Risk Assessment Final Report. Prepared for the U.S. Department of the Interior Bureau of Land Management, Nevada State Office, Reno, Nevada. Westford, Massachusetts.

2005e. Vegetation Treatments Programmatic EIS - Diquat Ecological Risk Assessment Final Report. Prepared for the U.S. Department of the Interior Bureau of Land Management, Nevada State Office, Reno, Nevada. Westford, Massachusetts.

2005f. Vegetation Treatments Programmatic EIS - Diuron Ecological Risk Assessment Final Report. Prepared for the U.S. Department of the Interior Bureau of Land Management, Nevada State Office, Reno, Nevada. Westford, Massachusetts.

2005g. Vegetation Treatments Programmatic EIS - Fluridone Ecological Risk Assessment Final Report. Prepared for the U.S. Department of the Interior Bureau of Land Management, Nevada State Office, Reno, Nevada. Westford, Massachusetts.

2005h. Vegetation Treatments Programmatic EIS - Imazapic Ecological Risk Assessment Final Report. Prepared for the U.S. Department of the Interior Bureau of Land Management, Nevada State Office, Reno, Nevada. Westford, Massachusetts.

2005i. Vegetation Treatments Programmatic EIS - Overdrive $\left.{ }^{(}\right)$Ecological Risk Assessment Final Report. Prepared for the U.S. Department of the Interior Bureau of Land Management, Nevada State Office, Reno, Nevada. Westford, Massachusetts. 
2005j. Vegetation Treatments Programmatic EIS - Sulfometuron Methyl Ecological Risk Assessment Final Report. Prepared for the U.S. Department of the Interior Bureau of Land Management, Nevada State Office, Reno, Nevada. Westford, Massachusetts.

2005k. Vegetation Treatments Programmatic EIS - Tebuthiuron Ecological Risk Assessment Final Report. Prepared for the U.S. Department of the Interior Bureau of Land Management, Nevada State Office, Reno, Nevada. Westford, Massachusetts.

2005l. Vegetation Treatments Programmatic EIS Human Health Risk Assessment Final Report. Prepared for the U.S. Department of the Interior Bureau of Land Management, Nevada State Office, Reno, Nevada. Westford, Massachusetts.

. 2005m. Air Quality Modeling for BLM Vegetation Treatment Methods. Prepared for the U.S. Department of the Interior Bureau of Land Management, Nevada State Office, Reno, Nevada. Westford, Massachusetts.

Environmental Laboratory. 1987. Corps of Engineers Wetland Delineation Manual. Technical Report Y-87-1, U.S. Army Engineers Waterways Experimental Station. Vicksburg, Mississippi.

Eschholz, W.E., F.A. Servello, B. Griffith, K.S. Raymond, and W.B. Krohn. 1996. Winter Use of Glyphosate-treated Clearcuts by Moose in Maine. Journal of Wildlife Management 60(4):764-769.

Estok, D., B. Freedman, and D. Boyle. 1989. Effects of the Herbicides 2,4-D, Glyphosate, Hexazinone, and Triclopyr on the Growth of Three Species of Ectomycorrhizal Fungi. Bulletin of Environmental Contamination and Toxicology 42:835-839.

European Commission Directorate-General for the Environment. 2000. Towards the Establishment of a Priority List of Substances for Further Evaluation of Their Role in Endocrine Disruption. Brussels, Belgium.

Evans, R.A., R.E. Eckert, and J.A. Young. 1975. The Role of Herbicides in Management of Pinyonjuniper Woodlands. Pages 83-89 in The Pinyon- juniper Ecosystem: A Symposium (G.F. Gifford and F.E. Busby, eds.). Utah State University. Logan, Utah.

Evans, R.D., and J.R. Ehleringer. 1993. A Break in the Nitrogen Cycle in Aridlands? Evidence from ${ }^{15} \mathrm{~N}$ isotope of Soils. Oecologia 94:314-317.

Extension Toxicology Network (Extoxnet). 1993. Pesticide Information Profiles. A Pesticide Information Project of Cooperative Extension Offices of Cornell University, Oregon State University, the University of Idaho, the University of California at Davis, and the Institute for Environmental Toxicology, Michigan State University. Available at: http://extoxnet.orst.edu/.

1996a. Glyphosate. Pesticide Information Profiles. Extension Toxicology Network. Available at: http://extoxnet.orst.edu/pips/glyphosa.htm.

- 1996b. Metsulfuron Methyl. Pesticide Information Profiles. Extension Toxicology Network. Available at: http://extoxnet.orst.edu/pips/metsulfu.htm.

- 1996c. Picloram. Pesticide Information Profile. Extension Toxicology Network. Available at: http://extoxnet.orst.edu/pips/picloram.htm.

- 1996d. Sulfometuron Methyl. Pesticide Information Profiles. Extension Toxicology Network. Available at: http://extoxnet.orst.edu/pips/sulfomet.htm.

- 1996e. Atrazine. Pesticide Information Profiles. Extension Toxicology Network. Available at: http://extoxnet.orst.edu/pips/atrazine.htm.

Fagerston, K.A., H.P. Tietjen, and K. LaVoie. 1977. Effect of Range Treatment with 2,4-D on Prairie Dog Diet. Journal of Range Management 30:5760 .

Fanning, D.S., and C.B. Fanning. 1989. Soil: Morphology, Genesis, and Classification. John Wiley and Sons. New York, New York. 
Federal Geographic Data Committee. 1997. Vegetation Classification Standard. FGDC-STD005. Vegetation Subcommittee, Secretariat, U.S. Geological Survey, Reston, Virginia. Available at: http://biology.usgs.gov/fgdc.veg/.

Federal Register. 1994. Endangered and Threatened Wildlife and Plants; Final Rule to List the Rio Grande Silvery Minnow as an Endangered Species. Department of the Interior, Fish and Wildlife Service, Volume 59, Number 138. Washington, D.C.

2000. Wilderness Management. Department of the Interior Bureau of Land Management 43 CFR Parts 6300 and 8560. Final Rule. Washington, D.C.

. 2002. Volume 67, Number 1, Page 102. Wednesday, January 2, 2002.

Feldmeth, C.R. 1981. The Evolution of Thermal Tolerance in Desert Pupfish (Genus Cyprinodon). Pages 357-384 in Fishes in North American Deserts (R.J. Naiman and D.L. Soltz, eds.). WileyInterscience Publication. New York, New York.

Feng, J.C., D.G. Thompson, and P. E. Reynolds. 1990. Fate of Glyphosate in a Canadian Forest Watershed: 1. Aquatic Residues and Off-target Deposit Assessment. Journal of Agricultural Food Chemistry 38:1110-1118.

Field, J.A., R.L. Reed, T.E. Sawyer, S.M. Griffith, and P.J. Wigington, Jr. 2003. Diuron Occurrence and Distribution in Soil and Surface and Ground Water Associated with Grass Seed Production. Journal of Environmental Quality 32:171-179.

Fire Regime Condition Class. 2004. Interagency Handbook Reference Conditions. Available at: http://www.frcc.gov/docs/PNVG/West/JUST1 De scription.pdf.

Fletcher, J.S., J.E. Nellessen, and T.G. Pfleeger。 1994. Literature Review and Evaluation of the EPA Food-chain (Kenaga) Nomogram, and Instrument for Estimating Pesticide Residue on Plants. Environmental Toxicology and Chemistry 13(9):1383-1391.
, T.G. Pfleeger, H.C. Ratsch, and R. Hays. 1996. Potential Impact of Low Levels of Chlorsulfuron and Other Herbicides on Growth and Yield of Nontarget Plants. Environmental Toxicology and Chemistry 15:1189-1196.

Folmar, L.C., H.O. Sanders, and A.M. Jullin. 1979. Toxicity of the Herbicide Glyphosate and Several of Its Formulations to Fish and Aquatic Invertebrates. Archives of Environmental Contamination and Toxicology 8:269-278.

Forest Ecosystem Management Assessment Team. 1993. Forest Ecosystem Management: An Ecological, Economic, and Social Assessment. U.S. Department of the Interior, U.S. Department of Agriculture, U.S. Department of Commerce, and U.S. Environmental Protection Agency. Washington, D.C.

Forsyth, D.J., P.A. Martin, and G.G. Shaw. 1997. Effects of Herbicides on Two Submerged Aquatic Macrophytes, Potamogeton pectinatus L. and Myriophyllum sibiricum Komarov, in a Prairie Wetland. Environmental Pollution 95:259-268.

Foster, R.K., and R.B. McKercher. 1973. Laboratory Incubation Studies of Chlorophenoxyacetic Acids in Chernozemic Soils. Soil Biology and Biochemistry 5:333-337.

Fowler, C.S. 1986. Subsistence. Pages 64-97 in Great Basin (W.L. d'Azevedo, ed.). Handbook of North American Indians, Volume 11 (W.C. Sturtevant, general ed.). Smithsonian Institution. Washington, D.C.

Fowler, E. 2005. The Deer of DeSoto National Wildlife Refuge. Nebraskaland Magazine. Nebraska Game and Parks Commission. Available at:

http://www.ngpc.state.ne.us/nebland/articles/hunti ng/desoto.asp.

Franklin, J.F. 1988. Pacific Northwest Forests. Pages 103-130 in North American Terrestrial Vegetation (M.G. Barbour and W.D. Billings, eds.). Cambridge University Press. New York, New York. 
Frison, G.C. 2001. Hunting and Gathering Tradition: Northwestern and Central Plains. Pages 131-145 in Plains (R.J. Demailie, ed.). Handbook of North American Indians, Volume 13 (W.C. Sturtevant, general ed.). Smithsonian Institution. Washington, D.C.

Fuerst, E.P., T.M. Sterling, M.A. Norman, T.S. Prather, G.P. Irzyk, Y. Wu, N.K. Lownds, and R.H. Callihan. 1996. Physiological Characterization of Picloram Resistance in Yellow Starthistle. Pesticide Biochemistry and Physiology 56:149-161.

Gadkari, D. 1988. Effect of Some Photosynthetic Inhibiting Herbicides on Growth and Nitrogenase Activity of a New Isolate of Cyanobacteria Nostoc G3. Journal of Basic Microbiology 28:419-426.

Garbarino, M.S., and R.F. Sasso. 1994. Native American Heritage. Waveland Press, Inc. Prospect Heights, Illinois.

Garrison, G.A., A.J. Bjugstad, D.A. Duncan, M.E. Lewis, and D.R. Smith. 1977. Vegetation and Environmental Features of Forest and Range Ecosystems. Agriculture Handbook No. 475. U.S. Department of Agriculture Forest Service. Washington, D.C.

Gautier D.L., G.L. Dolton, and E.D. Attanasi. 1998. 1995 National Oil and Gas Assessment and Onshore Federal Lands. U.S. Geological Survey Open-file Report 95-75-N. Denver, Colorado.

Gay, D.L., D.M. Engle, E.R. Allen, and J.F. Stritzke. 1997. Nitrogen and Biomass Dynamics Following Brush Control in the Cross Timbers. Journal of Range Management 50:55-61.

Gebhardt, K., S. Leonard, G. Staidl, and D. Prichard. 1990. Riparian Area Management: Riparian and Wetland Classification and Review. USDI, BLM /YA/PT-91/002+1737. Denver, Colorado.

George, M.R. 1996. Creating Awareness of Clean Water Issues Among Private Landowners. Pages 96-100 in Sustaining Rangeland Ecosystems (W.D. Edge and S.L. Olson-Edge, eds.). Oregon State University Extension Service, Special Report 953. Corvallis, Oregon.
Germano, D.J. 1978. Response of Selected Wildlife to Mesquite Removal in Desert Grassland. M.S. Thesis, University of Arizona. Tucson, Arizona.

Giacomazzi, S., and N. Cochet. 2004. Environmental Impact of Diuron Transformation: A Review. Chemosphere 56:1021-1032.

Giesy, J.P., S. Dobson, and K.R. Solomon. 2000. Ecotoxicological Risk Assessment for Roundup ${ }^{\circledR}$ Herbicide. Review of Contamination and Toxicology 167:35-120.

Gilbraith, D.M., M.J. Schwalbach, and C.R. Berry. 1998. Preliminary Report on the Status of the Pallid Sturgeon, Scaphirhychus albus, a Candidate Endangered Species. Cooperative Fish and Wildlife Research Unit, South Dakota State University. Brookings, South Dakota.

Gimsing, A.L., O.K. Borggaard, and M. Bang. 2004. Influence of Soil Composition on Adsorption of Glyphosate and Phosphate by Contrasting Danish Surface Soils. European Journal of Soil Science 55:183-191.

Glenn-Lewin, D.C. 1977. Species Diversity in North American Temperate Forests. Vegetation 33:153162.

Goldsborough, L.G., and D.J. Brown. 1993. Dissipation of Glyphosate and Aminomethylphosphonic Acid in Water and Sediments of Boreal Forest Ponds. Environmental Toxicology and Chemistry 12:1139-1147.

Grand Canyon Visibility Transport Commission (GCVTC). 1996. Report of the Grand Canyon Visibility Transport Commission to the United States Environmental Protection Agency. June 1996. Available at: http://www.westgov.org/wga/publicat/epafin.htm.

Grant, N., E. Prusinkiewicz, and R. Makowski. 1990. Effect of Selected Pesticides on Survival of Colletotrichum gloeosporioides f. sp. malvae, a Bioherbicide for Round-leaved Mallow (Malva pusilla). Weed Technology 4:701-715.

Gregory, S.V., F.J. Swanson, W.A. McKee, and K.W. Cummins. 1991. An Ecosystem Perspective of Riparian Zones. Bioscience 41:540-551. 
Griffith, J.S., and T.R. Tiersch. 1989. Ecology of Fishes in Redfield Canyon, Arizona, with Emphasis on Gila robusta intermedia. Southwestern Naturalist 34:131-164.

Groves, R. 2006. Are Some Weeds Sleeping? Some Concepts and Reasons. Euphytica 148:111-120.

Gruell, G.E. 1983. Fire and Vegetative Trends in the Northern Rockies: Interpretations from 1871-1982 Photographs. General Technical Report INT-158. U.S. Department of Agriculture Forest Service Intermountain Research Station. Ogden, Utah.

Gunnerson, J.H. 2001. Plains Village Tradition: Western Periphery. Pages 234-244 in Plains (R.J. DeMallie, ed.). Handbook of North American Indians, Volume 13 (W.C. Sturtevant, general ed.). Smithsonian Institution. Washington, D.C.

Guynn, D.C., Jr., S.T. Guynn, T.B. Wigley, and D.A. Miler. 2004. Herbicides and Forest Biodiversity-What Do We Know and Where Do We Go From Here? Wildlife Society Bulletin 32:1085-1092.

Halter, M. 1980. 2,4-D in the Aquatic Environment. Section II in Literature Reviews of Four Selected Herbicides: 2,4-D, Dichlobenil, Diquat \& Endothall (R. Shearer and M. Halter, eds.).

Hamilton, J.G. 1997. Changing Perceptions of Preeuropean Grasslands in California. Madrono 44:311-333.

Han, J.C. 1979. Stability of [C14] Fosamine Ammonium in Water and Soils. Journal of Agricultural Food Chemistry 27:564-571.

Hance, R. J. 1976. Adsorption of Glyphosate by Soils. Pesticide Science 7:363-366.

Hann, W.J., M. Beighley, P. Teensma, T. Sexton, and M. Hilbruner. 2002. A Cohesive Strategy for Protecting People and Sustaining Natural Resources: Predicting Outcomes for Program Options. Presented at Fire, Fuel Treatments, and Ecological Restoration Conference. Fort Collins, Colorado. Available at: http://www.frcc.gov/AssocPubs.html.
Harper, B.L., B. Flett, S. Harris, C. Abeyta, and F. Kirschner. 2002. The Spokane Tribe's Multipathway Subsistence Exposure Scenario and Screening Level RME. Risk Analysis 22(3):513526.

Harper K., and J. Belnap. 2001. The Influence of Biological Soil Crusts on Mineral Uptake by Associated Vascular Plants. Journal of Arid Environments 47(3):347-357.

Harris, S.G., and B.L. Harper. 1997. A Native American Exposure Scenario. Risk Analysis 17(6):789-795.

Harrison, I., R.U. Leader, J.J.W Higgo, and G.M. Williams. 1998. A Study of the Degradation of Phenoxy Acid Herbicides at Different Sites in a Limestone Aquifer. Chemosphere. 36:1211-1232.

Hartmans, M.A., H. Zhang, and E.L. Michalson. 1997. Costs of Yellow Starthistle Management. University of Idaho Agricultural Experimental Station. Bulletin 793. Moscow, Idaho.

Hassan, S., F. Bigler, and H. Bogenschutz. 1994. Results of the Sixth Joint Pesticide Testing Programme of the IOBC/WPRS-Working Group "Pesticides and Beneficial Organisms." Entomophaga 39:107-119.

Hayes, T.B., A.A. Stuart, M. Mendoza, A. Collins, N. Noreiga, A. Vonk, G. Johnston, R. Liu, and D. Kpodzo. 2006. Characterization of Atrazineinduced Gonadal Malformations in African Clawed Frogs (Xenopus laevis) and Comparisons with Effects of an Androgen Antagonist (Cyproterone Acetate) and Exogenous Estrogen (17B-Estradiol): Support for the Demasculinization/Feminization Hypothesis. Environmental Health Perspectives 114:134-141.

Hayward, S.F. 2005. Index of Leading Environmental Indicators. Pacific Research Institute. San Francisco, California.

Hebert, M. 2001. Strategic Plan for Noxious and Invasive Plants Management in Alaska. University of Alaska. Fairbanks, Alaska. 
Hein, L. 2002. Checklist for the Potential Costs of Land Degradation and the Benefits of Mitigation Measures. Prepared for The International Centre for Environmental Assessment Foundation for Sustainable Development and The International Centre for Integrative Studies. Available at: http://www.icis.unimaas.nl/medaction/downs/Deli verable 12.pdf.

Hendee, J.C., and C.P. Dawson. 2002. Wilderness Management Stewardship and Protection of Resources and Values. Third Edition. Fulcrum Publishing. Golden, Colorado.

Hershler, R., and D.W. Sada. 1987. Springsnails (Gastropoda: Hydrobiidae) of Ash Meadows, Amargosa Basin, California-Nevada. Proceedings of the Biological Society of Washington 100:776843.

, and W.L. Pratt. 1990. A New Pyrgulopsis (Gastropoda: Hydrobiidae) from Southeastern California, With a Model for Historical Development of the Death Valley Hydrographic System. Proceedings of the Biological Society of Washington 103:279-299.

Hesse, L.W., J.C. Schmulbach, J.M. Carr, K.D. Keenlyne, D.G. Unkenholz, J.S. Robinson, and G.E. Mestl. 1989. Missouri River Resources in Relation to Past, Present, and Future Stresses. Pages 352-371 in Proceedings of the International Large River Symposium (D.P. Dodge, ed.). Canadian Special Publications in Fisheries and Aquatic Science 106. Department of Fisheries and Oceans, Ottawa. Ontario, Canada

Hickman, M.V., C.G. Messersmith, and R.G. Lynn. 1990. Picloram Release from Leafy Spurge Roots. Journal of Range Management 43:442-445.

Higgins, S.I, D.M. Richardson, and R.M. Cowling. 1996. Modeling Invasive Plant Spread: The Role of Plant-Environment Interactions and Model Structure. Ecology 77(7):2043-2054.

Hirsch, S.A. and J.A. Leitch. 1996. The Impact of Knapweed on Montana's Economy. North Dakota State University Agricultural Experimental Station. Agricultural Economics Report No 355. Fargo, North Dakota.
Hobbs, R.J., and S.E. Humphries. 1995. An Integrated Approach to the Ecology and Management of Plant Invasions. Conservation Biology 9(4):761-770.

Hofman, V., and E. Solseng. 2001. Reducing Spray Drift. North Dakota State University Extension Service, Agricultural and Biosystems Engineering. Fargo, North Dakota.

Hole, F.D., and G.A. Nielsen. 1970. Some Processes of Soil Genesis under Prairie. Pages 28-34 in Symposium on Prairie and Prairie Restoration. Special Publication No. 3. Knox College Field Station. Galesburg, Illinois.

Holecheck, J.L., R.D. Pieper, and C.H. Herbel. 1989. Range Maintenance Principles and Practices. Prentice-Hall. Englewood Cliffs, New Jersey.

, and - 1995. Range

Management: Principles and Practices. Second Edition. Prentice Hall. Englewood Cliffs, New Jersey.

Howard, P. (ed). 1991. Handbook of Physical Properties of Organic Chemicals. CRC Lewis Publishers. Boca Raton, Florida.

Howard, R.P., and M.L. Wolfe. 1976. Range Improvement Practices and Ferruginous Hawks. Journal of Range Management 29:33-37.

Hudson, B., J. Augsburger, M. Hillis, and P. Boehne. 2000. Draft Biological Assessment for the Interior Columbia River Basin Ecosystem Management Project Final Environmental Impact Statement. U.S. Department of the Interior Bureau of Land Management and U.S. Department of Agriculture Forest Service. Washington, D.C.

Hunn, E.S. 1990. Nch'i-Wana: The Big River. University of Washington Press. Seattle, Washington.

and D.H. French. 1998. Western Columbia River Sahaptins. Pages 378-394 in Plateau (D.E. Walker, Jr., ed.). Handbook of the North American Indian, Volume 12 (W.C. Sturtevant, general ed.). Smithsonian Institution. Washington, D.C. 
Hunter, M.L., Jr. 1990. Wildlife, Forests, and Forestry. Principles of Managing Forests for Biological Diversity. Regents/Prentice Hall. Englewood Cliffs, New Jersey.

Information Ventures, Inc. 1995a. Asulam. Prepared for the U.S. Department of Agriculture Forest Service. Philadelphia, Pennsylvania.

1995b. Atrazine. Prepared for the U.S. Department of Agriculture Forest Service. Philadelphia, Pennsylvania. Available at: http://infoventures.com/ehlth/pesticide/atrazine.ht $\underline{\mathrm{ml}}$.

.1995c. Mefluidide. Prepared for the U.S. Department of Agriculture Forest Service. Philadelphia, Pennsylvania. Available at: http://www.fluoridealert.org/pesticides/mefluidide .fact.shcet.usda.html.

- 1995d. Simazine. Prepared for the U.S. Department of Agriculture Forest Service. Philadelphia, Pennsylvania. Available at: http://infoventures.com/ehlth/pesticide/simazine.ht $\underline{\mathrm{ml}}$.

Irwin-Williams, C. 1979. Post-Pleistocene Archeology, 7000-2000 B.C. Pages 22-30 in Southwest (A. Ortiz, ed.). Handbook of North American Indians, Volume 9 (W.C. Sturtevant, general ed.). Smithsonian Institution. Washington, D.C.

Ismail, B., and L. Wong. 1994. Effects of Herbicides on Cellulolytic Activity in Peat Soil. Microbios 78:117-123.

, and B.A. Azlizan. 2002. Persistence and Bioactivity of Metsulfuron-methyl in Three Soils. Journal Of Environmental Science and Health Part B-Pesticides Food Contaminants and Agricultural Wastes 37:345-353.

, K. Yapp, and O. Omar. 1998. Effects of Metsulfuron-methyl on Amylase, Urease, and Protease Activities in Two Soils. Australian Journal of Soil Research 36:449-456.

Jacobs, J.S., M.F. Carpinelli, and R.L. Sheley. 1999. Revegetating Noxious Weed-infested Rangeland. Page 133-141 in Biology and Management of Noxious Rangeland Weeds (R.L. Sheley and J.K.
Petroff, eds.). Oregon State University Press. Corvallis, Oregon.

James, T.K., P.T. Holland, A. Rahman, and Y.R. Lu. 1999. Degradation of the Sulfonylurea Herbicides Chlorsulfuron and Triasulfuron in a High-organic-matter Volcanic Soil. Weed Research 39:137-147.

Janetski, J.C. 1991. The Ute of Utah Lake. University of Utah Anthropological Papers Number 116. Salt Lake City, Utah.

Jenny, H. 1980. The Soil Resource: Origins and Behavior. Ecological Studies, Volume 37. Springer-Verlag. New York, New York.

Jensen, M., I. Goodman, K. Brewer, T. Frost, G. Ford, and J. Nesser. 1997. Biophysical Environments of the Basin. Pages 99-320 in An Assessment of Ecosystem Components in the Interior Columbia Basin and Portions of the Klamath and Great Basins (T.M. Quigley and S.J. Arbelbide, tech. eds.). General Technical Report PNW-GTR-405. U.S. Department of Agriculture Forest Service, Pacific Northwest Research Station. Portland, Oregon.

Johnsen, T. N., Jr. 1980. Picloram in Water and Soil from a Semiarid Pinyon-juniper Watershed. Journal of Environmental Quality 9:601-605.

Johnson, W.G., T.L. Lavy, and E.E. Gbur. 1995. Persistence of Triclopyr and 2,4-D in Flooded and Non-flooded Soils. Journal of Environmental Quality 24:493-497.

Joly, K.B., W. Dalle, W.B. Collins, and L.G. Adams. 2002. Evaluating the Impacts of Wildland Fires on Caribou in Interior Alaska. Arctic Research of the United States 16:63-67.

Jones, K.B. 1986. Deserts. Pages 123-145 in Inventory and Monitoring of Wildlife Habitat (A.Y. Cooperrider, R.J. Boyd, and H.R. Stuart, eds.). U.S. Department of the Interior Bureau of Land Management Service Center. Denver, Colorado.

Jorgensen, J. 1980. Western Indians: Comparative Environments, Languages, and Cultures of 172 Western American Indian Tribes. W.H. Freeman and Company. San Francisco, California. 
Joseph, T.W., J.A. Sinning, R.J. Behnke, and P.B. Holden. 1977. An Evaluation of the Status, Life History, and Habitat Requirements of Endangered and Threatened Fishes of the Upper Colorado River System (FWS/OBS-77/62). U.S. Fish and Wildlife Service. Fort Collins, Colorado.

Kadrmas, T., W.S. Johnson, M. Eiswerth, and M. Coca. 2003. The Estimated Costs of Treating Invasive Weeds in Elko County, Nevada. University of Nevada Cooperative Extension. Reno, Nevada. Available at: http://www.unce.unr.edu/publications/FS03/FS03 41.pdf.

Kaeding, L.R., B.D. Burdick, P.A., Schrader, and W.R. Noonan. 1986. Recent Capture of a Bonytail (Gila elegans) and Observations on this Nearly Extinct Cyprinid from the Colorado River. Copeia 1986:1021-1023.

Karthikeyan, R., L.C. Davis, L.E. Erickson, K. AlKhatib, P.A. Kulakow, P.L. Barnes, S.L. Hutchinson, and A.A. Nurzhanova. 2003. Studies on Responses of Non-target Plants to Pesticides: A Review. Hazardous Substance Research Center, Kansas State University. Manhattan, Kansas.

Kauffman, J.B., R.L. Beschta, N. Otting, and D. Lytjen. 1997. An Ecological Perspective on Riparian and Stream Restoration in the Western United States. Fisheries 22:12-24.

Kehoe, A.B. 1992. North American Indians: A Comprehensive Account $\left(2^{\text {nd }}\right.$ Edition). Prentice Hall. Englewood, New Jersey.

Kelly, I.T. 1964. Southern Paiute Ethnography. Glen Canyon Series 21, University of Utah Anthropological Paper 69. Salt Lake City, Utah.

1976. Southern Paiute Ethnography. Pages 11-223 in Paiute Indians II (D.A. Horr, ed.). Garland Publishing Inc. New York, New York.

, and C.S. Fowler. 1986. Southern Paiute. Pages 368-397 in Great Basin (W.L. d'Azevedo, ed.). Handbook of North American Indians, Volume 11 (W.C. Sturtevant, general ed.). Smithsonian Institution. Washington, D.C.
Kelsey, R.G., and D.J. Bedunah. 1989. Ecological Significance of Alleopathy for Centaurea Species in the Northwestern United States. Knapweed Symposium Proceedings, Land and Soil Science Department and Extension Service. Montana State University Bulletin 45:10-31.

Kennard, D., and C. Fowler. 2005. Encyclopedia of Southern Fire Science. Forest Encyclopedia Network. Available at: http://fire.forestencyclopedia.net/.

Kennard, E.A. 1979. Hopi Economy and Subsistence. Pages 554-563 in Southwest (A. Ortiz, ed.). Handbook of North American Indians, Volume 9 (W.C. Sturtevant, general ed.). Smithsonian Institution. Washington, D.C.

Kennedy, D., and R.T. Bouchard. 1998. Northern Okanogan, Lakes, and Colville. Pages 238-252 in Plateau (D.E. Walker, Jr., ed.). Handbook of the North American Indian, Volume 12 (W.C. Sturtevant, general ed.). Smithsonian Institution. Washington, D.C.

Khera, S., and P.S. Mariella. 1983. Yavapai. Pages 38-54 in Southwest (A. Ortiz, ed.). Handbook of North American Indians, Volume 10 (W.C. Sturtevant, general ed.). Smithsonian Institution. Washington, D.C.

Kie, J.G. 1988. Annual Grasslands. Pages 120-121 in A Guide to Wildlife Habitats of California (K.E. Mayer and W.F. Laudenslayer, eds.). California Department of Forestry and Fire Protection. Sacramento, California.

Kiesecker, J.M. 2002. Synergism between Trematode Infection and Pesticide Exposure: A Link to Amphibian Limb Deformities in Nature? Proceedings of the National Academy of Sciences of the United States of America 99:9900-9904.

Kirby, D.R., R.G. Lym, J.J. Sterling, and C.H. Sieg. 2003. Observation: Leafy Spurge Control in Western Prairie Fringed Orchid Habitat. Journal of Range Management 56(5):466-473.

Kirkpatrick, C., C.J. Conway, and P.B. Jones. 2006. Distribution and Relative Abundance of Forest Birds in Relation to Burn Severity in Southeastern Arizona. Journal of Wildlife Management 70:1005-1012. 
Kleijn, D., and G.I.J. Snoeijing. 1997. Field Boundary Vegetation and the Effects of Agrochemical Drift: Botanical Change Caused by Low Levels of Herbicide and Fertilizer. Journal of Applied Ecology 34:1413-1425.

Kookana, R. S., and L. A. G. Aylmore. 1993. Retention and Release of Diquat and Paraquat Herbicides in Soils. Australian Journal Of Soil Research 31:97-109.

Koskinen, W.C., J.C. Anhalt, O. Sakaliene, P.J. Rice, T.B. Moorman, and E.L. Arthur. 2003. Sorption-desorption "Aged" Sulfonylaminocarbonyltriazolinone Herbicide Metabolites in Soil. Journal of Agricultural and Food Chemistry 51:3604-3608.

Koterba, M. T., W. S. L. Banks, and R. J. Shedlock. 1993. Pesticides in Shallow Groundwater in the Delmarva Peninsula. Journal of Environmental Quality. 22:500-518.

Kreamer, G. 1996. Early Life-stage Toxicity of DPXT6376-141 (Metsulfuron-methyl) to Rainbow Trout (Oncorhynchus mykiss). Lab Project Number HLR 182-96 10352:182-196. Unpublished Study Prepared by DuPont Haskell Lab for Toxicity and Industrial Medicine. MRID Number 44122801.

Kroeber, A.L. 1976. Handbook of the Indians of California. Dover Publications, New York. Originally Published in 1925 as Bureau of Ethnology Bulletin 78. Smithsonian Institution. Washington, D.C.

Krueger, J.P., R.G. Butz, and D.J. Cork. 1991. Aerobic and Anaerobic Soil Metabolism of Dicamba. Journal of Agricultural and Food Chemistry 39:995-999.

Krzyszowska, A., R. Allen, and G. Vance. 1994. Assessment of the Fate of Two Herbicides in a Wyoming Rangeland Soil: Column Studies. Journal of Environmental Quality 23:1051-1058.

Kuchler, A.W. 1964. Potential Natural Vegetation of the Conterminous United States, American Geographical Society, Special Publication No. 36. New York, New York.
Kufeld, R.C. 1977. Improving Gambel Oak Ranges for Elk and Mule Deer by Spraying with 2,4,5-TP. Journal of Range Management 30:53-57.

Kuhlmann, B., B. Kaczmarczyk, and U. Schottler. 1995. Behavior of Phenoxyacetic Acids During Underground Passage with Different Redox Zones. International Journal Of Environmental Analytical Chemistry 58:199-205.

Lacey, J.R., C.B. Marlow, and J.R. Lane. 1989. Influence of Spotted Knapweed (Centaurea macuolosa) on Surface Runoff and Sediment Yield. Weed Technology 3:627-631.

Lajeunesse, S. 1999. Dalmatian and Yellow Toadflax. Pages 202-216 in Biology and Management of Noxious Rangeland Weeds (R.L. Sheley and J.K. Petrolff, eds.). Oregon State University Press Corvallis, Oregon.

Lantis, M. 1984. Aleut. Pages 161-184 in Arctic (D. Damas, ed.). Handbook of North American Indians, Volume 5 (W.C. Sturtevant, general ed.). Smithsonian Institution. Washington, D.C.

LaPrade, J.C. 1992. Fate of Pesticides in Soil and Water. Alabama Cooperative Extension System, Community Resource Development, Auburn University Document Number ANR-737. Auburn, Alabama. Available at: http://www.aces.edu/department/crd/publications/ ANR-737.html.

Larsen, L., and J. Aamand. 2001. Degradation of Herbicides in Two Sandy Aquifers under Different Redox Conditions. Chemosphere 44:231-236.

Larson, S.J., P.D. Capel, and M.S. Majewski. 1997. Pesticides in Surface Water: Distribution, Trends, and Governing Factors. Series 3: Pesticides in the Hydrologic System. Ann Arbor Press. Chelsea, Michigan.

Laudenslayer, W.F., Jr., and J.R. Boggs. 1988. Desert Scrub. Pages 114-115 in A Guide to Wildlife Habitats of California (K.E. Mayer and W.F. Laudenslayer, Jr., eds.). California Department of Forestry and Fire Protection. Sacramento, California. 
Lautenschlager, R.A., T.P. Sullivan, and R.G. Wagner. 1995. Using Herbicides for Wildlife Management in Northern Ecosystems. Pages 152154 in Proceedings for Second International Conference on Forest Vegetation Management (R.E. Gaskin and J.A. Zabkiewicz, eds.). New Zealand Forest Research Institute, Bulletin No. 192. Rotorua, New Zealand.

Lelong, B., C. Lavoie, Y. Jodoin, and F. Belzille 2007. Expansion Pathways of the Exotic Common Reed (I): a Historical and Genetic Analysis. Diversity and Distributions (Online Early articles). doi:10.1111/j.1472-4642.2007.00351.

Lent, P.C. 1986. Tundra. Pages 149-167 in Inventory and Monitoring of Wildlife Habitat (A.Y. Cooperrider, R.J. Boyd, and H.R. Stuart, eds.). U.S. Department of the Interior Bureau of Land Management Service Center. Denver, Colorado.

Leopold, A. 1924. Grass, Brush, Timber, and Fire in Southern Arizona. Journal of Forestry 22:1-10.

Levings, G.W., D.F. Healy, S.F. Richey, and L.F. Carter. 1998. Water Quality in the Rio Grande Valley, Colorado, New Mexico, and Texas, 199295. U.S. Geological Survey Circular 1162. Available at: http://pubs.usgs.gov/circ/circ1162/.

Levy, R. 1978. Eastern Miwok. Pages 398-413 in California (R.F. Heizer, ed.). Handbook of the North American Indians, Volume 8 (W.C. Sturtevant, general ed.). Smithsonian Institution. Washington, D.C.

Lewis, H.T. 1973. Patterns of Indian Burning in California: Ecology and Ethnohistory. Ballena Press Anthropological Papers 1:1-101. Ramona, California.

Lewis, M.A. 1991. Chronic and Sublethal Toxicities of Surfactants to Aquatic Animals: a Review and Risk Assessment. Water Research WATRAG 25:101-113.

Liljeblad, S., and C.S. Fowler. 1986. Owens Valley Paiute. Pages 412-434 in Great Basin (W.L. d'Azevedo, ed.). Handbook of North American Indians, Volume 11 (W.C. Sturtevant, general ed.). Smithsonian Institution. Washington, D.C.
Loeb, E.M. 1926. Pomo Folkways. University of California Publications in American Archaeology and Ethnology 19(2):149-405. Berkeley, California.

Loomis, D., D.B. Richardson, J.F. Bena, and A.J. Bailer. 2004. Deindustrialization and the Longterm Decline in Fatal Occupation Injuries. Occupational and Environmental Medicine 61:616-621. Available at: http://oem.bmj.com/cgi/content/full/61/7/616.

Lyman, R.L. 1991. Prehistory of the Oregon Coast: The Effects of Excavation Strategies and Assemblage Size on Archeological Inquiry. Academic Press. San Diego, California.

Lyman, W., W. Reehl, and D. Rosenblatt. 1990. Handbook of Chemical Estimation Methods. American Chemical Society. Washington, D.C.

Lyon, L.J., J.K. Brown, M.H. Huff, and J.K. Smith. 2000a. Introduction. Pages 1-8 in Wildland Fire in Ecosystems (J.K. Smith, ed.). USDA Forest Service Rocky Mountain Research Station General Technical Report RMRS-GTR-42, Volume 1. Fort Collins, Colorado.

, E.S. Telfer, and D.S. Schreiner. 2000b. Direct Effects of Fire and Animal Responses. Pages 17-23 in Wildland Fire in Ecosystems (J.K. Smith, ed.). USDA Forest Service Rocky Mountain Research Station General Technical Report RMRS-GTR-42, Volume 1. Fort Collins, Colorado.

Mack, R.N., D. Simberloff, W.M. Lonsdale, H. Evans, M. Clout, and F.A. Bazzazz. 2000. Biotic Invasions: Causes, Epidemiology, Global Consequences, and Control. Ecological Applications 10(3):689-710.

MacKay, D., S. Wan-Ying, and M. Kuo-ching. 1997. Handbook of Environmental Fate and Exposure Data for Organic Chemicals. Volume III. Pesticides. Lewis Publishers. Chelsea, Michigan.

MacMahon, J.A. 1988. Warm Deserts. Pages 231-264 in North American Terrestrial Vegetation (M.G. Barbour and W.D. Billings, eds.). Cambridge University Press. New York, New York. 
Maddux, H.R., L.A. Fitzpatrick, and W.R. Noonan. 1993. Colorado River Endangered Fishes Critical Habitat, Draft Biological Document. U.S. Fish and Wildlife Services. Salt Lake City, Utah.

Mahler, R.L., H.W. Homan, and G.P. Carpenter. 1998. Pesticides and Their Movement in Soil and Water. Quality Water for Idaho Current Information Series No. 865. University of Idaho College of Agriculture Cooperative Extension System Agricultural Experiment Station. Moscow, Idaho.

Maikawa, E., and K.A. Kershaw. 1976. Studies on Lichen-dominated Systems. XIX. The Postfire Recovery Sequence of Black Spruce-lichen Woodland in the Abitau Lake Region, N.W.T. Canadian Journal of Botany 54:2679-2687.

Malik, J., G. Barry, and G. Kishore. 1989. A Minireview of the Herbicide Glyphosate. BioFactors $2: 17-25$

Malik, M., and D. Drennan. 1990. Bioavailability and Dissipation of Fluridone under Controlled Conditions. Journal of Environmental Science and Health B25:447-472.

Mallipudi, N.M., S.J. Stout, A.R. daCunha, and A. Lee. 1991. Photolysis of Imazapyr (Ac 243997) Herbicide in Aqueous Media. Journal of Agricultural Food Chemistry 39:412-417.

Mangels, G. 1991. Behavior of the Imidazolinone Herbicides in the Aquatic Environment. In The Imidazolinone Herbicides (D. L. Shaner and S. L. O'Connor, eds.). CRC Press. Boca Raton, Florida.

Markle, D.M., and R.G. Lym. 2001. Leafy Spurge (Euphorbia esula) Control and Herbage Production with Imazapic. Weed Technology 15(3):474-480.

Martens, D.A., and J.M. Bremner. 1993. Influence of Herbicides on Transformations of Urea Nitrogen in Soil. Journal Of Environmental Science And Health Part B-pesticides Food Contaminants And Agricultural Wastes 28:377395.

Masters, R.A., D.B. Beran, and R.E. Gaussoin. 2001. Restoring Tallgrass Prairie Species Mixtures on Leafy Spurge-infested Rangeland. Journal of Range Management 54(4):362-369.

Maxwell, J.A. 1978. America's Fascinating Indian Heritage. Reader's Digest Association, Inc. New York, New York.

Mayack, D.T., P.B. Bush, D.G. Neary, and J.E. Douglass. 1982. Impact of Hexazinone on Invertebrates after Application to Forested Watersheds. Archives of Environmental Contamination and Toxicology 11:209-217.

Mayes, M. 1990. Dow Chemical USA Phase 3 Summary of MRID 00151958. The Acute and Chronic Toxicity of Triclopyr [(3,5,6-Trichloro-2Pyridiny)loxy) Acetic Acid] Triethylamine Salt Solution to the Fathead Minnow (Pimephales promelas). Project ID: ES-582. Dow Chemical. Colorado.

D.C. Dill, K.M. Bodner, and C.G. Mendoza. 1984. Triclopyr Triethylamine Salt Toxicity to Life Stages of the Fathead Minnow Pimpephales promelas. Bulletin of Environmental Contamination and Toxicology 33(3):339-347.

Mayeux, H. S., Jr., C. W. Richardson, R. W. Bovey, E. Burnett, M. G. Merkle, and R. E. Meyer. 1984. Dissipation of Picloram in Storm Runoff. Journal of Environmental Quality 13:44-49.

McAllister, K.R. 1995. Washington State Recovery Plan for the Pygmy Rabbit. Washington Department of Fish and Wildlife. Olympia, Washington.

McCartney, A.P. 1984. Prehistory of the Aleutian Region. Pages 119-135 in Arctic (D. Damas, ed.). Handbook of North American Indians, Volume 5 (W.C. Sturtevant, general ed.). Smithsonian Institution. Washington, D.C.

McClellan, C., and G. Deniston. 1981. Environment and Culture in the Cordillera. Pages 372-386 in Sub-arctic (J. Helm, ed.). Handbook of North American Indians, Volume 6 (W.C. Sturtevant, general ed.). Smithsonian Institution. Washington, D.C.

McCormick, D.P. 1975. Effect of Mesquite Control on Small Game Populations. M.S. Thesis, University of Arizona. Tucson, Arizona. 
McDonald, P.M. 1988. Montane Hardwood. Pages 72-73 in A Guide to Wildlife Habitats of California (K.E. Mayer and W.F. Laudenslayer, eds.). California Department of Forestry and Fire Protection. Sacramento, California.

McGuire, T.R. 1983. Walapai. Pages 25-37 in Southwest (A. Ortiz, ed.). Handbook of North American Indians, Volume 10 (W.C. Sturtevant, general ed.). Smithsonian Institution. Washington, D.C.

McMullin, C., and R. Thomas. 2000. Phase II Herbicide Analysis - Environmental Impact Statement. Prepared for the U.S. Department of the Interior Bureau of Land Management by Intercet Ltd. McLean, Virginia.

McNabb, K. 1997. Environmental Safety of Forestry Herbicides. Alabama Cooperative Extension System ANR-846. Available at: hitp://www.aces.edu/pubs/docs/A/ANR-0846/.

Meehan, W.R. (ed.). 1991. Influences of Forest and Rangeland Management on Salmonid Fishes and their Habitats. American Fisheries Society Special Publication 19. Bethesda, Maryland.

, and T.C. Bjornn. 1991. Salmonid Distribution and Life Histories. American Fisheries Society Special Publication 19:47-82. Bethesda, Maryland.

Mehringer, P.J., Jr. 1986. Prehistoric Environments. Pages 31-50 in Great Basin (W.L. d'Azevedo, ed.). Handbook of North American Indians, Volume 11 (W.C. Sturtevant, general ed.). Smithsonian Institution. Washington, D.C.

Metting, F.B. 1990. Soil Algae. Pages 355-368 in The Rhizosphere (J. M. Lynch, ed.). Wiley Interscience. London, England.

Michael, J.L. 2000. Pesticides. Pages 139-149 in Drinking Water from Forests and Grasslands: A Synthesis of the Scientific Literature (G.E. Dissmeyer, ed.). General Technical Report SRS039. U.S. Department of Agriculture Forest Service, Southern Research Station. Asheville, North Carolina.

, D. G. Neary, and M. J. M. Wells. 1989. Picloram Movement in Soil Solution and
Streamflow from a Coastal Plain Forest. Journal of Environmental Quality 18:89-95.

, E. C. Webber, D. R. Bayne, J. B. Fischer, H. L. Gibbs, and W. C. Seesock. 1999. Hexazinone Dissipation in Forest Ecosystems and Impacts on Aquatic Communities. Canadian Journal of Forest Research 29:1170-1181.

Miller, J. 1998. Middle Columbia River Salishans. Pages 253-270 in Plateau (D.E. Walker, Jr., ed.). Handbook of the North American Indians, Volume 12 (W.C. Sturtevant, general ed.). Smithsonian Institution. Washington, D.C.

Miller, J.H., R.S. Boyd, and M.B. Edwards. 1999. Floristic Diversity, Stand Structure, and Composition 11 years after Herbicide Site Preparation. Canadian Journal of Forest Research 29:1073-1083.

Miller, J.J., B.D. Hill, C. Chang, and C.W. Lindwall. 1995. Residue Detections in Soil and Shallow Groundwater after Long-term Herbicide Applications in Southern Alberta. Canadian Journal of Soil Science 75:349-356.

Miller, K.V., and J.H. Miller. 2004. Forestry Herbicide Influences on Biodiversity and Wildlife Habitat in Southern Forests. Wildlife Society Bulletin 32(4):1049-1060.

Miller, R.F., and J.A. Rose. 1999. Fire History and Western Juniper Encroachment in Sagebrush Steppe. Journal of Range Management 52(6):550559.

Miller, W.H., H.M. Tyus, and C.A. Carlson (eds). 1982. Fishes of the Upper Colorado River System: Present and Future. American Fisheries Society, Western Division. Bethesda, Maryland.

Mills, M.J. 1994. Harvest, Catch, and Participation in Alaska Sport Fisheries during 1993. Alaska Department of Fish and Game Fishery Data Series 94-28. Anchorage, Alaska.

Minckley, W.L. 1973. Fishes of Arizona. Arizona Game and Fish Department. Phoenix, Arizona. 
, and J.E. Deacon (eds). 1991. Battle against Extinction: Native Fish Management in the American West. University of Arizona Press. Tucson, Arizona.

Minino, A.M., E. Arias, K.D. Kochanek, S.L. Murphy, and B.L. Smith. 2002. Deaths: Final Data for 2000. National Vital Statistics Reports Volume 50, Number 15. September 16, 2002. Centers for Disease Control, Division of Vital Statistics. Washington, D.C.

Moapa Memories. 2002. Available at: http://www.xeri.com/Moapa/moapa-afidavits.htm.

Montana Department of Environmental Quality. 2002. Montana Modeling Guideline for Air Quality Permits. Available at: http://www.deq.state.mt.us/AirQuality/AQinfo.asp

Montgomery, J.H., editor. 1997. Illustrated Handbook of Physical-chemical Properties and Environmental Fate for Organic Chemicals. Volume V, Pesticide Chemicals. Lewis Publishers. Boca Raton, Florida.

Moratto, M.J. 1984. California Archaeology. Academic Press, Inc. Orlando, Florida.

Morton, H.L., and A. Melgoza 1991. Vegetation Changes Following Brush Control in Creosotebush Communities. Journal of Range Management 44:133-139.

Mostafa, F.I.Y., and C.S. Helling. 2003. Isolation and 16s DNA Characterization of Soil Microorganisms from Tropical Soils Capable of Utilizing the Herbicides Hexazinone and Tebuthiuron. Journal of Environmental Science and Health Part B-pesticides Food Contaminants and Agricultural Wastes 38:783-797.

Moyle, P.B. 1976. Inland Fishes of California. University of California Press. Berkeley, California.

Mueggler, W.F., and W.L. Stewart. 1980. Grassland and Shrubland Habitat Types of Western Montana. General Technical Report INT-66. U.S. Department of Agriculture Forest Service Intermountain Research Station. Ogden, Utah.
Mueller-Warrant, G., and S.M. Griffith. 2005. High Yield Grass Seed Production and Water Quality Handbook. Oregon Seed Council. Salem, Oregon. Available at: http://forages.oregonstate.edu/organizations/seed/o sc/brochures/water-quality/index.html.

Muhn, J., and H.R. Stewart. 1988. Opportunity and Challenge: The Story of the BLM. USDI BLM. U.S. Government Printing Office. Washington, D.C.

Muir, D.C.G.L., N.P. Grift, A.P. Blouw, and W.L. Lockhart. 1980. Persistence of Fluridone in Small Ponds. Journal of Environmental Quality 9(1):151-156.

Muller, R. 1980. Fish Toxicity and Surface Tension of Non-Ionic Surfactants: Investigations of Antifoam Agents. Journal of Fish Biology 16:585-589.

Munn, L.C., G.A. Nielsen, and W.F. Mueggler. 1978. Relationships of Soils to Mountain and Foothill Range Habitat Types and Production in Western Montana. Journal of the Soil Science Society of America 42:135-139.

Murphy, R.F., and Y. Murphy. 1986. Northern Shoshone and Bannock. Pages 284-307 in Great Basin (W.L. d'Azevedo, ed.). Handbook of North American Indians, Volume 11 (W.C. Sturtevant, general ed.). Smithsonian Institution. Washington, D.C.

Naiman, R.J. 1981. An Ecosystem Overview: Desert Fishes and Their Habitats. Pages 493-531 in Fishes in North American Deserts (R.J. Naiman and D.L. Soltz, eds.). Wiley-Interscience Publication. New York, New York.

Nash, L. 1993. Water Quality and Health. Pages 25-39 in Water in Crisis: A Guide to the World's Fresh Water Resources (P.H. Gleick, ed.). Oxford University Press. New York, New York.

National Academy of Sciences (NAS). 1968. Principles of Plant and Animal Pest Control, Volume 2: Weed Control. Washington, D.C.

- 1983. Risk Assessment in the Federal Government: Managing the Process. National Academy Press. Washington, D.C. 
National Center for Health Statistics (NCHS). 2007. Vital Statistics. U.S. Department of Health and Human Services, Centers for Disease Control and Prevention. Hyattsville, Maryland. Available at: http://www.cdc.gov/nchs/.

National Institute for Occupational Safety and Health (NIOSH). 1997. NIOSH Facts. Workrelated Musculoskeletal Disorders. Available at: http://www.cdc.gov/niosh/muskdsfs.html.

- 2001. Traumatic Occupational Injuries. Available at: http://www.cdc.gov/niosh/injury/.

- 2002. Occupational Cancer. Available at: http://www.cdc.gov/niosh/occancer.html.

National Interagency Fire Center. 2005. Wildland Fire Statistics. Boise, Idaho. Available at: http://www.nifc.gov/stats/wildlandfirestats.html.

National Invasive Species Council. 2001. Management Plan for Meeting the Invasive Species Challenge. Washington, D.C.

National Library of Medicine. 2002. Hazardous Substances Data Bank. A Toxicology Data file on the National Library of Medicines Toxicology Data Network (TOXNET). Available at: http://toxnet.nlm.nih.gov.

- 2003. Database Prepared by the U.S. National Library of Medicine, Office of Health and Human Services, National Institute of Health. Available at: http://toxnet.nlm.nih.gov/cgibin/sis/htmlgen?hsdbb.htm.

National Network of Forest Practitioners. 2005. Nontimber Forest Products (NTFP) Fact Sheet. Available at: http://www.nnfp.org.

National Wildlife Federation and Natural Resources Defense Councill. 2001. Conservation Management of America's Public Lands: An Assessment and Recommendations for Progress 25 Years after FLPMA. National Wildlife Federation. Washington, D.C.

Natural Resources Conservation Service. 2000. National Resources Inventory Summary Report. Tables 10 and 11. Washington, D.C. Available at: http://www.nrcs.usda.gov/technical/NRI/1997/ summary report/.
NatureServe Explorer. 2001. An Online Encyclopedia of Life. Version 1.6. Arlington, Virginia. Available http://www.natureserve.org/explorer.

Neary, D.G., and J.L. Michael. 1996. Herbicides. Protecting Long-term Sustainability and Water Quality in Forest Ecosystems. New Zealand Journal of Forestry Science 26:241-264.

, J.W. Taylor Jr., and P.B. Bush. 1984. Fate of Hexazinone in Forest Watersheds. U.S. Department of Agriculture Forest Service. Forest Pest Management Technology Update. Washington D.C.

, P.B. Bush, and J.E. Douglass. 1983. Offsite Movement of Hexazinone in Stormflow and Baseflow from Forest Watersheds. Weed Science 31:543-551.

, and J. L. Michael. 1993. Fate, Dissipation and Environmental-effects of Pesticides in Southern Forests - A Review of a Decade of Research Progress. Environmental Toxicology and Chemistry 12:411-428.

Nelson, C.M. 1990. Prehistory of the Puget Sound Region. Pages 481-484 in Northwest Coast (W. Suttles, ed.). Handbook of North American Indians, Volume 7 (W.C. Sturtevant, general ed.). Smithsonian Institution. Washington, D.C.

Newmaster, S.G., F.W. Bell, and D.H. Vitt. 1999. The Effects of Glyphosate and Triclopyr on Common Bryophytes in Northwestern Ontario. Canadian Journal of Forest Research 29:11011011.

Newton, M., F. Roberts, A. Allen, B. Kelpsas, D. White, and P. Boyd. 1990. Deposition and Dissipation of Three Herbicides in Foliage, Litter, and Soil of Brushfields of Southwest Oregon. Journal of Agricultural Food Chemistry 38:574583.

Nomura, N.S., and H.W. Hilton. 1977. The Adsorption and Degradation of Glyphosate in Five Hawaiian Sugarcane Soils. Weed Research 17:113-121.

Norris, K.S. 1953. The Ecology of the Desert Iguana, Dipsosaurus dorsalis. Ecology 34:265-287. 
Norris, L.A., H.W. Lorz, and S.V. Gregory. 1991. Forest Chemicals. American Fisheries Society Special Publication 19:207-296. Bethesda, Maryland.

Norton, J.B., T.A. Monaco, J.M. Norton, D.A. Johnson, and T.A. Jones. 2004. Cheatgrass Invasion Alters Soil Morphology and Organic Matter Dynamics in Big Sagebrush-Steppe Rangelands. In Seed and Soil Dynamics in Shrubland Ecosystems: Proceedings; 2002, August 12-16 (A. L. Hild, N. L. Shaw, S. E. Meyer, D. T. Booth, and E. D. McArthur, eds.). U.S. Department of Agriculture Forest Service, Rocky Mountain Research Station. Laramie, Wyoming.

Obrigawitch, T.T., G. Cook, and J. Wetherington. 1998. Assessment of Effects on Non-target Plants from Sulfonylurea Herbicides Using Field Approaches. Pesticide Science 52:199-217.

Office of Management and Budget (OMB). 2005. Program Assessment Rating Tool Direct Federal Programs. Washington, D.C. Available at: http://www.whitehousc.gov/omb/budget/fy2006/p ma/interior.pdf.

Office of Technology Assessment (OTA). 1993. Harmful Non-indigenous Species in the United States. United States Congress. Washington, D.C.

Oh, K.H., and O.H. Tuovinen. 1991. Bacterial Degradation of Phenoxy Herbicide Mixtures 2,4-D and Mcpp. Bulletin of Environmental Contamination and Toxicology 47:222-229.

Olson, B.E. 1999. Grazing and Weeds. Pages 85-97 in Biology and Management of Noxious Rangeland Weeds (R.L. Sheley and J.K. Petroff, eds.). Oregon State University Press. Corvallis, Oregon.

, and R.T. Wallander. 1997. Biomass and Carbohydrates of Spotted Knapweed and Idaho Fescue After Repeated Grazing. Journal of Range Management 50:409-412.

Olson, R., J. Hansen, T. Whitson, and K. Johnson. 1994. Tebuthiuron to Enhance Rangeland Diversity. Rangelands 16:197-201.

Opler, M.E. 1983. Mescarlero Apache. Pages 419-439 in Southwest (A. Ortiz, ed.). Handbook of North
American Indians, Volume 10 (W.C. Sturtevant, general ed.). Smithsonian Institution. Washington, D.C.

Ott, R. 2000. Factors Affecting Stream Bank and River Bank Stability, with an Emphasis on Vegetation Influences. Prepared for the Region III Forest Practices Riparian Management Committee. Tanana Chiefs Conference, Inc. Forestry Program. Fairbanks, Alaska.

Page, L.M., and B.M. Burr. 1991. The Peterson Field Guide Series: A Field Guide to Freshwater Fishes. Houghton Mifflin Publishers. Boston, Massachusetts.

Paige, C., and S.A. Ritter. 1999. Birds in a Sagebrush Sea: Managing Sagebrush Habitats for Bird Communities. Partners in Flight Western Working Group. Boise, Idaho.

Patterson, R.L. 1952. The Sage Grouse in Wyoming. Sage Books. Denver, Colorado.

Paulim, K.M., J.J. Cook, and S.R. Dewey. 1999. Pinyon-juniper Woodlands as Sources of Avian Diversity. Pages 240-243 in Proceedings: Ecology and Management of Pinyon-juniper Communities within the Interior West. U.S. Department of Agriculture Forest Service Proceedings RMPRSP-9. Rocky Mountain Research Station. Ogden, Utah.

Paveglio, F.L. 1996. Use of Rodeo and X-77 Spreader to Control Smooth Cordgrass (Spartina alterniflora) in a Southwestern Washington Estuary: Environmental Fate. Environmental Toxicology and Chemistry 15:961-968.

, and K.M. Kilbride. 2000. Response of Vegetation to Control of Reed Canarygrass in Seasonally Managed Wetlands of Southwestern Washington. Wildlife Society Bulletin 28:730740 .

Pavel, E.W., A.R. Lopez, D.F. Berry, E.P. Smith, R.B. Reneau, and S. Mostaghimi. 1999. Anaerobie Degradation of Dicamba and Metribuzin in Riparian Wetland Soils. Water Research 33:87-94. 
Payne, N.F., and F. Copes. 1986. Wildlife and Fisheries Habitat Improvement Handbook. U.S. Department of Agriculture Forest Service. U. S. Government Printing Office. Washington, D.C.

, and F.C. Bryant. 1998. Wildlife Habitat Management of Forestlands, Rangelands, and Farmlands. Krieger Publishing Company. Malabar, Florida.

Pekar, S. 2002. Susceptibility of the Spider Theridion impressum to 17 Pesticides. Anzeiger fuer Schaedlingskunde 75:51-55.

Perryman, B.L., R.E. Wilson, and W.I. Morrill. 2003. Eastern Nevada Landscape Coalition Position. Rangelands 25:30-34.

Perschbaucher, P., G.M. Ludwig, and R. Edzigie. 2004. Effects of Propanil, Diuron, and Atrazine Drift on Sunshine Bass Pond Plankton and Water Quality. University of Arkansas-Pine Bluff Aquaculture Field Day.

Pesticide Mamagement Education Program. 2001. 2,4-DP (dichlorprop) Herbicide Profile 9/88. Cornell University. Ithaca, New York. Available at: http://pmep.cce.cornell.edu.

Peterjohn, W.T., and W.H. Schlesinger. 1990. Nitrogen Loss from Deserts in the Southwestern United States. Biogeochemistry 10:67-79.

Peterson, E. 2006. Invasive Annual Grasses in Nevada. Natural Heritage Program. Carson City, Nevada.

Peterson, H., C. Boutin, P. Martin, K. Freemark, N. Ruecker, and M. Moody. 1994. Aquatic Phytotoxicity of 23 Pesticides Applied at Expected Environmental Concentrations. Aquatic Toxicology 28:275-292.

Petit, V., R. Cabridenc, R.P.J. Swannell, and R.S. Sokhi. 1995. Review of Strategies for Modeling the Environmental Fate of Pesticides Discharged into Riverine Systems. Environment International 21(2):167-176.

Pfleeger, T.G., K.D. Getsinger, and K.B. Woodburn. 2003. A Review of the Aquatic Environmental Fate of Triclopyr and Its Major
Metabolites. Journal of Aquatic Plant Management 41:69-75.

, J.G. Skogerboe, K.D. Getsinger, D.R. Foster, B.A. Houtman, J.F. Fairchild, and L.W. Anderson. 2001. The Aquatic Fate of Triclopyr in Whole-pond Treatments. Pest Management Science 57:764-775.

Pfleeger, T.G., A. Fong, R. Hayes, H. Ratsch, and C. Wickliff. 1996. Field Evaluation of the EPA (Kenaga) Nomogram, a Method for Estimating Wildlife Exposure to Pesticide Residues on Plants. Environmental Toxicology and Chemistry 15(4):535-543.

Pianka, E.R. 1966. Convexity, Desert Lizards, and Spatial Heterogeneity. Ecology 47:1055-1059.

Pimentel, D. 1997. Techniques for Reducing Pesticides: Environmental and Economic Benefits. John Wiley and Sons. New York, New York.

, R. Zuniga, and D. Morrison. 2005. Update on the Environmental and Economic Costs Associated with Alien-invasive Species in the United States. Ecological Economics 52:273-288.

Pitelka. F.A. 1979. An Avi-faunal Review for the Barrow Region and North Slope of Arctic Alaska. Arctic and Alpine Research 6:161-184.

Platania, S.P. 2003. Perils Facing the Gila Trout in the Status and Trends of the Nation's Biological Resources. Available at: http://biology.usgs.gov/s+t/SNT/index.htm.

, and K.R. Bestgen. 1988. An Interim Report on the Fishes of the Lower San Juan River, New Mexico, 1987. New Mexico Department of Game and Fish. Santa Fe, New Mexico.

Plog, F. 1979. Prehistory: Western Anasazi. Pages 108-130 in Southwest (A. Ortiz, ed.). Handbook of North American Indians, Volume 9 (W.C. Sturtevant, general ed.). Smithsonian Institution. Washington, D.C.

Poff, N.L., J.D. Allan, M.B. Bain, J.R. Karr, K.L. Prestegarrd, B.D. Richter, R.E. Sparks, and J.C. Stromberg. 1997. The Natural Flow Regime: A Paradigm for River Conservation and Restoration. BioScience 47:769-784. 
Prichard, D., F. Berg, S. Leonard, W. Hagenbuck, M. Manning, R. Krapf, C. Noble, R. Leinard, and J. Staats. 2003. Riparian Area Management: A User Guide to Assessing Proper Functioning Condition and the Supporting Science for Lentic Areas. TR 1737-16, U.S. Department of the Interior Bureau of Land Management, BLM/RS/ST-99/001+1737+REV03. Denver, Colorado.

Purdue Pesticide Programs. 2001. Pesticide Impact Assessment Program. Purdue University Pesticide Program. Document Number PPP-35., Purdue Cooperative Extension Service, West Lafayette, Indiana. Available http://www.btny.purdue.edu/PPP/.

Que Hee, S.S., and R.G. Sutherland. 1981. The Phenoxyalkanoic Herbicides, Volume I: Chemistry, Analysis, and Environmental Pollution. CRC Press, Inc. Boca Raton, Florida.

Rahman, A., T.K. James, and P. Sanders. 1993. Leaching and Movement of Imazapyr in Different Soil Types. Proceedings of the Forty Sixth New Zealand Plant Protection Conference. Christchurch, New Zealand 1:115-119.

Rees, N.E., P.C. Quimby Jr., G.L. Piper, E.M. Coombs, C.E. Turner, N.R. Spencer, and L.V. Knutson (eds.). 1996. The Biological Control of Weeds in the West. Western Society of Weed Science. Bozeman, Montana.

Reinert, K.H. 1989. Environmental Behavior of Aquatic Herbicides in Sediments in Reactions and Movements of Organic Chemicals in Soils. Soil Science Society of American and American Society of Agronomy. Madison, Wisconsin.

Rejmanek, M., D.M. Richardson, and P. Pysek. 2005. Plant Invasions and Invisibility of Plant Communities in Vegetation Ecology (E. van der Maarel, ed.). Blackwell Publishing, Malden, Massachusetts.

Relyea, R.A. 2005a. The Impact of Insecticides and Herbicides on the Biodiversity and Productivity of Aquatic Communities. Ecological Applications 15:618-627. Available at: 2005b. The Lethal Impact of Roundup on Aquatic and Terrestrial Amphibians. Ecological Applications 15:1118-1124.

Retzinger, E.J., Jr., and C. Mallory-Smith. 1997. Classification of Herbicides by Site of Action for Weed Resistance Management Strategies. Weed Technology 11:384-393.

Rice, P.M., J.C. Toney, and D.J. Bedunah. 1997a. Plant Community Diversity and Growth Form Responses to Herbicide Applications for Control of Centaurea maculosa. Journal of Applied Ecology 34:1397-1412.

and C.E. Carlson. 1997b. Elk Winter Forage Enhancement by Herbicide Control of Spotted Knapweed. Wildlife Society Bulletin 25:627-633.

Rinne, J.N. 1995. The Effects of Introduced Fishes on Native Fishes: Arizona, Southwestern United States. Pages 149-159 in Protection of Aquatic Biodiversity, Proceedings of the World Fisheries Congress, Theme 3. Science Publishers, Inc. Lebanon, New Hampshire.

2003. Native and Introduced Fishes: Their Status, Threat, and Conservation. Pages 194-213 in Ecology, Hydrology, and Management of Riparian Areas in the Southwestern United States (P.F. Ffolliott, M.B. Baker, L.F. Debano, and D.G. Neary, eds.). Lewis Publishers. Boca Raton, Florida.

, and W.L. Minckley. 1991. Native Fishes of Arid Lands: A Dwindling Resources of the Desert Southwest. General Technical Report RM206. U.S. Department of Agriculture Forest Service, Rocky Mountain Forest and Range Experiment Station. Fort Collins, Colorado.

, and J.A. Stefferud. 1997. Factors Contributing to Collapse Yet Maintenance of a Native Fish Community in the Desert Southwest (USA). In Developing and Sustaining World Fisheries Resources: The State of Science and Management (D.A. Hancock, D.C. Smith, A. Grant, and J.P. Beaumer, eds.). Second World Fish Congress. Brisbane, Australia. 
Robinson, W.L., and E.G. Bolen. 1989. Wildlife Ecology and Management. MacMillan Publishing Company. New York, New York.

Robson, S.G., and E.R. Banta. 1995. Ground Water Atlas of the United States: Arizona, Colorado, New Mexico, Utah. HA 730-C. Available at: http://capp.water.usgs.gov/gwa/.

Rohr, J.R., T. Sager, T.M. Sesterhenn, and B.D. Palmer. 2006. Exposure, Postexposure, and Density-mediated Effects of Atrazine on Amphibians: Breaking Down Net Effects into Their Parts. Environmental Health Perspectives 114:46-50. Available at: http://www.pubmedcentral.nih.gov/articlerender.fc gi? artid=1332655.

Roshon, R.D., J.H. McCann, D.G. Thompson, and G.R. Stephenson. 1999. Effects of Seven Forestry Management Herbicides on Myriophyllum sibiricum, as Compared with Other Nontarget Aquatic Organisms. Canadian Journal of Forest Research 29:1158-1169.

Ross, R.E. 1998. Prehistory of the Oregon Coast. Pages 554-559 in Northwest Coast (W. Suttles, ed.). Handbook of North American Indians, Volume 7 (W.C. Sturtevant, general ed.). Smithsonian Institution. Washington, D.C.

Rotenberry, J.T., and J.A. Wiens. 1980. Habitat Structure, Patchiness, and Avian Communities in North American Steppe Vegetation: A Multivariate Analysis. Ecology 61:1228-1250.

Rovesti, L., and K.V. Deseo. 1990. Compatibility of Chemical Pesticides with the Entomopathogenic Nematodes: Steinernema carpocapsae Weiser and Steinernema feltiae Filipjev (Nematoda: Steinernematidae). Nematologica 36:237-245.

Rowe, J.S., J.L. Bergsteinsson, G.A. Padbury, and R. Hermesh. 1974. Fire Studies in the Mackenzie Valley. Indian and Northern Affairs Publication No. QS-1567-000-EE-A1. Arctic Land Use Research Program, Northern Economic Development Branch, Department of Indian Affairs and Northern Development. Ottawa, Canada.

Rueppel, M.L., B.B. Brightwell, J. Schaefer, and J.T. Marvel. 1977. Metabolism and Degradation of Glyphosate in Soil and Water. Journal of Agricultural and Food Chemistry 25:517-528.

Rutske, L.H. 1969. A Minnesota Guide to Forest Fame Habitat Improvement. Minnesota Department of Conservation Technical Bulletin 10.

Sage Grouse Conservation Planning Team. 2001. Nevada Sage Grouse Conservation Strategy. Office of the Governor. Carson City, Nevada.

Sandberg, D.V., C.C. Hardy, R.D. Ottmar, J.A.K. Snell, A.L. Acheson, J.L. Peterson, P. Seamon, P. Lahm, and D. Wade. 1999. National Strategic Plan: Modeling and Data Systems for Wildland Fire and Air Quality. USDA Forest Service Pacific Northwest Research Station. Portland, Oregon.

Sandmann, E., M.A. Loos, and L.P. v. Dyk. 1988. The Microbial Degradation of 2,4Dichlorophenoxyacetic Acid in Soil. Reviews in Environmental Contamination and Toxicology 101.

Sarmah, A.K., and J. Sabadie. 2002. Hydrolysis of Sulfonylurea Herbicides in Soils and Aqueous Solutions: A Review. Journal Of Agricultural and Food Chemistry 50:6253-6265.

, R.S. Kookana, and A.M. Alston. 1998. Fate and Behaviour of Triasulfuron, Metsulfuronmethyl, and Chlorsulfuron in the Australian Soil Environment: A Review. Australian Journal of Agricultural Research 49:775-790.

and

1999.

Degradation of Chlorsulfuron and Triasulfuron in Alkaline Soils under Laboratory Conditions. Weed Research 39:83-94.

Satterlund, D.R., and P.W. Adams. 1992. Wildland Watershed Management ( $2^{\text {nd }}$ edition). John Wiley and Sons, Inc. New York, New York.

Scarnecchia, D., S. Everett, T. Welker, and F. Ryckman. 2002. Missouri River Fishes: Big Changes in the Big Muddy. North Dakota Outdoors (March). 
Schaafsma, P. 1980. Indian Rock Art of the Southwest. School of American Research, Southwest Indian Art Series. Santa Fe, New Mexico.

Schaefer, J.A., and W.O. Pruitt, Jr. 1991. Fire and Woodland Caribou in Southeastern Manitoba. Wildlife Monographs No. 116.

Scheiman, D.M., E.K. Bollinger, and D.H. Johnson. 2003. Effects of Leafy Spurge Infestation on Grassland Birds. Journal of Wildlife Management 67:115-121.

Schmidt, K.M., J.P. Menakis, C.C. Hardy, W.J. Hann, and D.L. Bunnell. 2002. Development of Coarse-scale Spatial Data for Wildland Fire and Fuel Management. General Technical Report RMRS-GTR-87. U.S. Department of Agriculture Forest Service Rocky Mountain Research Station. Fort Collins, Colorado.

Schroeder, A.H. 1979. Pueblos Abandoned in Historic times. Pages 236-254 in Southwest (A. Ortiz, ed.). Handbook of North American Indians, Volume 9 (W.C. Sturtevant, general ed.). Smithsonian Institution. Washington, D.C.

Schuster, H.H. 1998. Yakima and Neighboring Groups. Pages 308-335 in Great Basin (W.L. d'Azevedo, ed.). Handbook of North American Indians, Volume 11 (W.C. Sturtevant, general ed.). Smithsonian Institution. Washington, D.C.

Schwartz, D.W. 1983. Havasupai. Pages 13-24 in Southwest (A. Ortiz, ed.). Handbook of North American Indians, Volume 10 (W.C. Sturtevant, general ed.). Smithsonian Institution. Washington, D.C.

Scifres, C.J., R.R. Hahn, J. Diaz-Colon, and M.G. Merkle. 1971. Picloram Persistence in Semiarid Rangeland Soils and Water. Weed Science 19:381-384.

Scurlock, D. 1998. From the Rio to the Sierra: An Environmental History of the Middle Rio Grande Basin. General Technical Report RMRS-GTR-5. U.S. Department of Agriculture Forest Service, Rocky Mountain Research Station. Fort Collins, Colorado.
Seaber, P.R., F.P. Kapinos, and G.L. Knapp. 1987. Hydrologic Unit Maps. U.S. Geological Survey Water-supply Paper 2294. Available at: http://water.usgs.gov/GIS/huc.html.

Segawa, R., A. Bradlye, P. Lee, D. Tran, J. White, J. Hsu, and K. Goh. 1997. Residues of Forestry Herbicides in Plants of Interest to Native Americans: Phase One - Development of Methodologies and Pilot Sampling. Environmental Hazards Program, California Environmental Protection Program. Sacramento, California.

Severson, K.E., and A.L. Medina. 1983. Deer and Elk Habitat Management in the Southwest. Journal of Range Management Monograph 2.

Shaw, L.J., and R.G. Burns. 1998. Biodegradation of 2,4-D in a Noncontaminated Grassland Soil Profile. Journal of Environmental Quality 27:1464-1471.

Sheley, R.L., J.S. Jacobs, and M.L. Carpinelli. 1999a. Spotted Knapweed. Pages 350-361 in Biology and Management of Noxious Rangeland Weeds (R.L. Sheley and J.K. Petrolff, eds.). Oregon State University Press. Corvallis, Oregon.

, L.L. Larson, and J.S. Jacobs. 1999b. Yellow Starthistle. Pages 408-416 in Biology and Management of Noxious Rangeland Weeds (R.L. Sheley and J.K. Petrolff, eds.). Oregon State University Press, Corvallis.

Shelton, D.R., S. Khader, J.S. Karns, and B.M. Pogell. 1996. Metabolism of Twelve Herbicides by Streptomyces. Biodegradation 7:129-136.

Shimkin, D.B. 1986. Eastern Shoshone. Pages 308335 in Great Basin (W.L. d'Azevedo, ed.). Handbook of North American Indians, Volume 11 (W.C. Sturtevant, ed.). Smithsonian Institution. Washington, D.C.

Shinn S.L., and D.C. Thill. 2002. The Response of Yellow Starthistle (Centaurea solstitialis), Annual Grasses, and Smooth Brome (Bromus inermis) to Imazapic and Picloram. Weed Technology 16(2):366-370. 
Short, H.L., and C.Y. McCulloch. 1977. Managing Pinyon-juniper Ranges for Wildlife. General Technical Report RM-47. U.S. Department of Agriculture Forest Service Rocky Mountain Forest and Range Experiment Station. Fort Collins, Colorado.

Sieg, C.H. 1991. Rocky Mountain Juniper Woodlands: Year-round Avian Habitat. Research Paper RM296. U.S. Department of Agriculture Forest Service Rocky Mountain Forest and Range Experiment Station. Fort Collins, Colorado.

Simberloff, D. 1996. Impacts of Introduced Species in the United States. Consequences - the Nature and Implications of Environmental Change 2(2):13-22.

Sims, P.L. 1988. Grasslands. Pages 265-286 in North American Terrestrial Vegetation (M.G. Barbour and W.D. Billings, eds.). Cambridge University Press. New York, New York.

Simsiman, G.V., and G. Chesters. 1976. Persistence of Diquat in Aquatic Environment. Water Research 10:105-112.

Skogerboe, J.G. 2003. Invasion of Eurasian Watermilfoil in Lakes of the Western Upper Peninsula, Michigan. Waterways Experiment Station U. S. Army Engineer Research and Development Center. Vicksburg, Mississippi.

Smith, A.E. 1976. The Hydrolysis of Herbicidal Phenoxyalkanoic Esters of Phenoxyalkanoic Acids in Saskatchewan Soils. Weed Research 16:19-22.

, and A.J. Aubin. 1994. Loss of Enhanced Biodegradation of 2,4-D and MCPA in a Field Soil Following Cessation of Repeated Herbicide Applications. Bulletin of Environmental Contaminant Toxicology 53.

Smith, B.H. 1984. Avian Habitat Selection in a Mixed Creosotebush-grassland Community. M.S. Thesis, University of Arizona. Tucson, Arizona.

Smith, J.K. 2000. Wildland Fire in Ecosystems: Effects of Fire on Fauna. General Technical Report RMRS-GTR-42 Volume 1. USDA Forest Service Rocky Mountain Research Station. Fort Collins, Colorado.
Soil Quality Institute. 2001. Soil Quality Introduction, Prepared by the Soil Quality Institute, National Soil Survey Center, Natural Resource Conservation Service, U.S. Department of Agriculture, and the National Tilth Laboratory, ARS, U.S. Department of Agriculture. Available at:

http://soils.usda.gov/sqi/concepts/concepts.html.

Spahr, N.E., L.E. Apodaca, J.R. Deacon, J.B. Bails, N.J. Bauch, C.M. Smith, and N. Driver. 2000. Water Quality in the Upper Colorado River Basin, Colorado, 1996-98. U.S. Geological Survey Circular $1214 . \quad$ Available at: http://water.usgs.gov/pubs/circ1214.

Spence, B.C., G.A. Lomnicky, R.M. Hughes, and R.P. Novitzki. 1996. An Ecosystem Approach to Salmonid Conservation, TR-4501-96-6057. Management Technology. Portland, Oregon.

Sprankle, P., W.F. Meggitt, and D. Penner. 1975. Rapid Inactivation of Glyphosate in the Soil. Weed Science 23:224-228.

Spray Drift Task Force (SDTF). 2002. A User's Guide for AgDRIFT ${ }^{\circledR}$ 2.0.05: A Tiered Approach for the Assessment of Spray Drift of Pesticides. Regulatory Version. C.D.I. Report No. 01-02. Macon, Missouri.

Spurlock, F., K. Burow, and N. Dubrovsky. 2000. Chlorofluorocarbon Dating of Herbicidecontaining Well Waters in Fresno and Tulare Counties, California. Journal of Environmental Quality 29:474-483.

Standley, W.G., and N.S. Smith. 1988. Effects of Treating Creosotebush with Tebuthiuron on Rodents. Pages 422-424 in Symposium on the Management of Amphibians, Reptiles and Small Mammals in North America. Flagstaff, Arizona.

Starnes, W.C. 1995. Colorado River Basin Fishes in Our Living Resources: A Report to the Nation on the Distribution, Abundance, and Health of U.S. Plants, Animals, and Ecosystems (E.T. LaRoe, G.S. Farris, C.E. Puckett, P.D. Doran, and M.J. Mac, eds.). U.S. Department of the Interior National Biological Service. Washington, D.C.

Steward, J.H. 1939. Changes in Shoshonean Indian Culture. Scientific Monthly 49:524-537. 
1997. Basin-Plateau Aboriginal Sociopolitical Groups. Reprint. University of Utah Press, Salt Lake City. Originally Printed in 1938, Smithsonian Institution Bureau of American Ethnology Bulletin 120, United States Government Printing Office. Washington, D.C.

Storrs, S.I., and J.M. Kiesecker. 2004. Survivorship Patterns of Larval Amphibians Exposed to Low Concentrations of Atrazine. Environmental Health Perspectives. Volume 112. Available at: http://www.ehponline.org/members/2004/6821/68 21.html.

Strek, H.J. 1998a. Fate of Chlorsulfuron in the Environment. 1. Laboratory Evaluations. Pesticide Science 53:29-51.

- 1998b. Fate of Chlorsulfuron in the Environment. 2. Field Evaluations. Pesticide Science 53:52-70.

Sturtevant, W.C. (ed.). 1978-2001. Handbook of North American Indians. Smithsonian Institution. Washington, D.C.

Sullivan, T.P., C. Nowotny, and R.A. Lautenschlager. 1998. Silvicultural Use of Herbicide in Sub-boreal Spruce Forest: Implications for Small Mammal Population Dynamics. Journal of Wildlife Management 62(4):1196-1206.

Suttles, W. 1990. Environment. Pages 16-29 in Northwest Coast (W. Suttles, ed.). Handbook of North American Indians, Volume 7 (W.C. Sturtevant, general ed.). Smithsonian Institution. Washington, D.C.

Suzuki, T., K. Yaguchi, S. Suzuki, and T. Suga. 2001. In Vitro Pesticide Degradation in Turfgrass Soil Incubated under Open and Sealed Conditions. Journal of Environmental Quality 30:18-23.

Swetnam, T. 1990. Fire History and Climate in the Southwest United States. Pages 6-17 in Proceedings of Symposium: Effects of Fire Management of Southwestern Natural Resources. General Technical Report RM-191. U.S. Department of Agriculture Forest Service Rocky Mountain Forest and Range Experiment Station. Fort Collins, Colorado.
Syracuse Environmental Research Associates, Inc. (SERA). 1997. Selected Commercial Formulations of Hexazinone - Human Health and Ecological Risk Assessment Final Draft. SERA TR 95-21-04-01b. March 4, 1997.

- 1998. 2,4 Dichlorophenoxyacetic Acid Formulations - Human Health and Ecological Risk Assessment Final Report. SERA TR 95-2109-01d. Prepared for the U.S. Department of Agriculture Forest Service. Arlington, Virginia. Fayetteville, New York.

- 1999. Clopyralid (Transline) - Human Health and Ecological Risk Assessment Final Report. SERA TR 99-21-11/12-01c. Prepared for the U.S. Department of Agriculture Forest Service, Arlington, Virginia. Fayetteville, New York.

2001a. Preparation of Environmental Documentation and Risk Assessments, SERA MD 2001-01a, Draft Dated July 2001. Syracuse Environmental Research Associates, Inc. Fayetteville, New York.

. 2001b. Imazapic [Plateau and Plateau DG] - Human Health and Ecological Risk Assessment Final Report. SERA TR00-21-28-01e. Prepared for the U.S. Department of Agriculture Forest Service, Arlington, Virginia. Fayetteville, New York.

- 2003a. Glyphosate - Human Health and Ecological Risk Assessment Final Report. SERA TR 02-43-09-04a. Prepared for the U.S Department of Agriculture Forest Service, Arlington, Virginia. Fayetteville, New York.

. 2003b. Picloram - Revised Human Health and Ecological Risk Assessment Final Report. SERA TR 03-43-16-01b. Prepared for the U.S. Department of Agriculture Forest Service, Arlington, Virginia. Fayetteville, New York.

.2003c. Triclopyr - Revised Human Health and Ecological Risk Assessment Final Report. SERA TR 02-43-13-03b. Prepared for the U.S. Department of Agriculture Forest Service, Arlington, Virginia. Fayetteville, New York. 
.2004a. Chlorsulfuron - Human Health and Ecological Risk Assessment Final Report. SERA TR 04-43-18-01c. Prepared for the U.S. Department of Agriculture Forest Service, Arlington, Virginia. Fayetteville, New York.

- 2004b. Clopyralid (Transline) - Human Health and Ecological Risk Assessment Final Report. SERA TR 04 43-17-03c. Prepared for the U.S. Department of Agriculture Forest Service, Arlington, Virginia. Fayetteville, New York.

2004c. Imazapic Plateau and Plateau Dg Human Health and Ecological Risk Assessment Final Report. SERA TR 04-43-17-04b. Prepared for the U.S. Department of Agriculture Forest Service, Arlington, Virginia. Fayetteville, New York.

- 2004d. Imazapyr - Human Health and Ecological Risk Assessment Final Report. SERA TR 04-43-17-05b. Prepared for the U.S. Department of Agriculture Forest Service, Arlington, Virginia. Fayetteville, New York.

- 2004e. Metsulfuron methyl - Human Health and Ecological Risk Assessment Peer Review Draft. SERA TR 04-43-17-01b. Prepared for the U.S. Department of Agriculture Forest Service, Arlington, Virginia. Fayetteville, New York

2005a. Herbicide Risk Assessment Locator: Herbicides and Surfactants Analyzed in the Invasive Plants EIS. Prepared for U.S. Department of Agriculture Forest Service, Arlington, Virginia. Fayetteville. New York. Available at: http://www.fs.fed.us/r6/invasiveplant-eis/RiskAssessments/Herbicides-Analyzed-InvPlantEIS.htm.

- 2005b. Risk Assessment Worksheets. Prepared for the U.S. Department of Agriculture Forest Service by Syracuse Environmental Research Associates, Inc., Fayetteville, New York.

Szaro, R.C. 1995. Biodiversity of Forest Ecosystems of Western North America. International Union of Forest Research Organizations. Tenth Congress "Caring for the Forest: Research in a Changing World" August 6-12, 1995. Tampere, Finland.
IUFRO-95 Papers and Abstracts. Available at: http://www.metla.fi/iufro/iufro95abs/rsp7.htm.

Tatum, V.L. 2004. Toxicity, Transport, and Fate of Forest Herbicides. Wildlife Society Bulletin 32:1042-1048.

The Research Group. 2000. Economic Analysis of Containment Programs, Damages, and Production Losses from Noxious Weeds in Oregon. Report Prepared for the Oregon Department of Agriculture Plant Division, Noxious Weed Control Program. Corvallis, Oregon. Available at: http://www.oregon.gov/ODA/PLANT/docs/pdf/w eed body a.pdf.

Thomas, D.H., L.S.A. Pendleton, and S.C. Cappannari. 1986. Western Shoshone. Pages 262-283 in Great Basin (W.L. d'Azevedo, ed.). Handbook of North American Indians, Volume 11 (W.C. Sturtevant, general ed.). Smithsonian Institution. Washington, D.C.

Thomas, J.W. 1997. California's Oak Woodlands: Where We Have Been, Where We Are, Where We Need to Go. General Technical Report PSW-160. U.S. Department of Agriculture Forest Service, Pacific Southwest Research Station. Albany, California.

, E.D. Forsman, J.B. Lint, E. Meslow, B.R. Noon, and J. Verner. 1990. A Conservation Strategy for the Northern Spotted Owl. Report to the Interagency Scientific Community to Address the Conservation of the Northern Spotted Owl. U.S. Government Printing Office. Washington, D.C.

Thompson, D.G., L.M. Macdonald, and B. Staznik. 1992. Persistence of Hexazinone and Metsulfuronmethyl in a Mixed-wood/Boreal Forest Lake. Journal of Agricultural and Food Chemistry 40:1444-1449.

D.P. Kreutzweiser, S.S. Capell, D.R. Thomas, B. Staznik, and T. Viinikka. 1995. Fate and Effects, of Triclopyr Ester in a First-order Forest Stream. Environmental Toxicology and Chemistry 14:1307-1317. 
Tiller, V.E. 1983. Jicarilla Apache. Pages 440-461 in Southwest (A. Ortiz, ed.). Handbook of North American Indians, Volume 10 (W.C. Sturtevant, general ed.). Smithsonian Institution. Washington, D.C.

Tixier, C., M. Sancelme, S. Ait-Aissa, P. Widehem, F. Bonnemoy, A. Cuer, N. Truffaut, and $\mathbf{H}$. Veschambre. 2002. Biotransformation of Phenylurea Herbicides by a Soil Bacterial Strain, Arthrobacter Sp. N2: Structure, Ecotoxicity and Fate of Diuron Metabolite with Soil Fungi. Chemosphere 46:519-526.

Tomlin, C. (ed.). 1994. The Agrochemicals Desk Reference. 2nd Edition. Lewis Publishers. Boca Raton, Florida.

Tranel, P.J., and T.R. Wright. 2002. Resistance of Weeds to ALS-inhibiting Herbicides: What Have We Learned? Weed Science 50(6):700-712.

Tu, C.M. 1994. Effects of Herbicides and Fumigants on Microbial Activities in Soil. Bulletin of Environmental Contaminant Toxicology 53:12-17.

Tu, M., C. Hurd, and J.M. Randall. 2001. Weed Control Methods Handbook: Tools and Techniques for Use in Natural Areas. Wildland Invasive Species Program. The Nature Conservancy. Available at: http://ncweeds.ucdavis. edu/handbook.html.

Turmer, S.A. 1987. Post-application Movement of Sulfometuron Methyl from Treated Rights of Way Areas Via Wind Erosion. Proceedings Fourth Symposium on Environmental Concerns in Rights of Way Management. October 25-28, 1987. Indianapolis, Indiana.

University of Missouri Extension. 1997. Pesticides and the Environment. Columbia, Missouri. Available at: http://muextension.missouri.edu/explore/agguides/ pests/g07520.htm.

Urness, P.J. 1979. Wildlife Habitat Manipulation in Sagebrush Ecosystems. Pages 164-178 in The Sagebrush Ecosystem: A Symposium. Utah State University. Logan, Utah.

U.S. Congress Office of Techmology and Assessment (OTA). 1993. Harmful Non-Indigenous Species in the United States. OTA-F-565. U.S. Government Printing Office. Washington, D.C.

U.S. Department of Agriculture (USDA). 1995. Pesticide Properties Database. U.S. Department of Agriculture Agricultural Research Service.

U.S. Department of Agriculture Forest Service (USDA Forest Service). 1989. An Analysis of the Range Forage Situation in the United States: 1989-2040. Available at: http://www.fs.fed.us/pl/rpa/rge89.htm.

- 1999. Dicamba Herbicide Information Profile. Pacific Northwest Region. Available at: http://www.fs.fed.us/r6/nr/fid/pubsweb/dicamba 9 9.pdf.

- 2000a. Picloram Herbicide Information Profile. Pacific Northwest Region. Report Available at: http://www.fs.fed.us/r6/nr/fid/pubsweb/piclo.pdf.

- 2000b. Protecting People and Sustaining Resources in Fire-adapted Ecosystems-A Cohesive Strategy.

2005. Preventing and Managing Invasive Plants, Final Environmental Impact Statement. U.S. Department of Agriculture Forest Service Pacific Northwest Region. Available at: http://www.fs.fed.us/r6/invasiveplant-eis/.

, and U.S. Department of the Interior. 2000. Managing the Impacts of Wildfires on Communities and the Environment. A Report to the President in Response to the Wildfires of 2000. September $8,2000$. http://www.fireplan.gov/reports/8-20-en.pdf.

U.S. Department of Agriculture Forest Service and U.S. Department of the Interior Bureau of Land Management. 1997. Upper Columbia River Basin Draft Environmental Impact Statement Interior Columbia Basin Ecosystem Management Project. BLM-ID-PT-96-021. Washington, D.C.

, and . 2000. Interior Columbia Basin Supplemental Draft Environmental Impact Statement. Boise, Idaho. 
, and

. 2004. The Healthy Forests Initiative and Healthy Forests Restoration Act Interim Field Guide.

\section{U.S. Department of Agriculture Natural Resources} Conservation Service. 1996. Soil Quality Indicators: Organic Matter. Soil Quality Information Sheet Series. Natural Resources Conservation Service National Soil Survey Center in Cooperation with the Natural Resources Conservation Service Soil Quality Institute, and the Agricultural Research Services National Soil Tilth Lab. Available Online with Updates at: http://soils.usda.gov/sqi/sqiinfo.html.

- 2000. Geospatial Data of Soil Orders. Available at the NRCS Soil Data Mart, http://soildatamart.nres.usda.gov/.

U.S. Department of Commerce (USDOC) Bureau of the Census. 2004. Washington, D.C. Available at: http://www.census.gov/.

U.S. Department of the Interior (USDI). 2001. Integrating Fire and Natural Resource Management - A Cohesive Strategy for Protecting People by Restoring Land Health. Draft Report. Washington, D.C.

. 2004. Interagency Burned Area Emergency Stabilization and Rehabilitation Manual 620 Wildland Fire Management. Washington, D.C. Available at: http://elips.doi.gov/app DM/act getfiles.cfm?reln $\underline{\mathrm{um}+3610}$.

\section{U.S. Department of the Interior Bureau of Land} Management (USDI BLM). 1980. Control of Salinity from Point Sources Yielding Groundwater Discharge and from Diffuse Surface Runoff in the Upper Colorado River Basin. BLM Service Center. Denver, Colorado.

- 1984a. Grazing Management. Manual Handbook Number H-4120-1. Washington, D.C.

- 1984b. Visual Resource Management. Manual Handbook Number 8400-1. Washington, D.C.

- 1984c. Visual Resource Management. Manual 8400. Washington, D.C.
- 1985. Northwest Area Noxious Weed Control Program Final Environmental Impact Statement. BLM Oregon State Office. Portland, Oregon.

- 1986a. Visual Resources Inventory. Handbook H- 8410-1. Washington, D.C.

- 1986b. Visual Resources Inventory. Manual Handbook H-8431-1. Washington, D.C.

- 1987a. Supplemental Record of Decision Northwest Area Noxious Weed Control Program. Washington, D.C.

- 1987b. Supplement to the Northwest Area Noxious Weed Control Program Final Environmental Impact Statement. BLM Oregon State Office. Portland, Oregon.

1988a. California Vegetation Management Final Environmental Impact Statement. BLM California State Office. Sacramento, California.

- 1988b. Record of Decision, California Vegetation Management. BLM California State Office. Sacramento, California.

-1988c. National Environmental Policy Act Handbook. BLM Handbook H-1790-1. Washington, D.C.

- 1988d. Chemical Pest Control. BLM Handbook H-9011-1. Washington, D.C.

- 1988e. Management of Designated Wilderness Areas. BLM Manual Handbook H8560-1. Washington, D.C.

1989. Western Oregon - Management of Competing Vegetation Final Environmental Impact Statement. Washington, D.C.

- 1991a. Final Environmental Impact Statement Vegetation Treatment on BLM Lands in Thirteen Western States. BLM Wyoming State Office. Casper, Wyoming.

- 1991b. Record of Decision for Final Environmental Impact Statement Vegetation Treatment on BLM Lands in Thirteen Western States. BLM Wyoming State Office. Casper, Wyoming. 
1991c. Forest Management (Public Domain). Manual Number 5000-1. Washington, D.C.

- 1992a. Western Oregon Programmanagement of Competing Vegetation. Final Record of Decision. Portland, Oregon.

- 1992b. Integrated Weed Management. BLM Manual Section 9015. Washington, D.C.

- 1993. Management of Designated Wilderness Areas. Manual Number 8560. Washington, D.C.

- 1995. Interim Management Policy for Lands Under Wilderness Review. BLM Manual Handbook H-8550-1. Washington D.C.

1996. Partners Against Weeds: An Action Plan for the Bureau of Land Management. Washington, D.C.

1997. Public Land Statistics. Washington, D.C. Available at: http://www.blm.gov/.

. 1998. Pulling Together: National Strategy for Invasive Plant Management. Washington, D.C. Available at: http://www.blm.gov/weeds/PullingTogether/Pullin gTogether.htm.

- 1999. Out of Ashes, An Opportunity. National Office of Fire and Aviation. Boise, Idaho.

- 2000a. Strategic Plan FY 2000-2005. Washington, D.C.

. 2000b. Public Rewards from Public Lands 2000 - Great Basin Restoration. Washington, D.C.

2000c. Public Rewards from Public Lands 2000 - Alaska. Washington, D.C.

.2000d. The Great Basin: Healing the Land. Washington, D.C.

2000e. Annual Performance Plan 2001 and Annual Performance Report 1999. Washington, D.C.

2000f. Science Strategy. Washington, D.C.
. 2000g. Land Use Planning Handbook H1601-1. Washington, D.C.

- 2001a. Geospatial Data of BLMAdministered Lands. National Science and Technology Center. Denver, Colorado.

- 2001b. Dawn of an American Legend. Prepared for Science and Children Magazine. National Science Teachers Association. Available at:

http://www.blm.gov/education/00 resourees/articl es/wild bunch/wildbunch1.html.

. 2002a. Budget Justifications and Annual Performance Plan FY 2003, Annual Performance Report. Washington, D.C.

- 2002b. Geospatial Data of Alaska Vegetation Coverage from the Earth Cover Mapping Project. Anchorage, Alaska.

.2002c. A Legacy of Land Treatments. Final Report of the 2002 Legacy Program. National Science and Technology Center. Denver, Colorado. Available at: http://www.blm.gov/nstc/legacy.html.

- 2003. Geospatial Data of Vegetation Subclasses. Adapted from 1990-2000 data from the National Land Cover Data Mapping Program, USGS Land Cover, and the Gap Analysis Program.

2004a. Public Land Statistics Fiscal Year 2004. Washington, D.C.

- 2004b. Manual 620 Wildland Fire Management. Washington, D.C.

- 2004c. Map of the National Landscape Conservation System. Available at: http://www.blm.gov/nlcs/maps.htm.

- 2005a. The United States Department of the Interior Bureau of Land Management Budget Justifications and Performance Information Fiscal Year 2006, and Annual Performance Report Fiscal Year 2005. Washington, D.C.

.2005b. Injury Breakout. All Injuries Report Breakout by Cause. Washington, D.C. 
2005c. Northeast National Petroleum Reserve-Alaska Final Amended Integrated Activity Plan/Environmental Impact Statement. Document BLM/AK/PL-05/006+1610+930. Anchorage, Alaska.

. 2005d. Strategic Research Plan Wild Horse and Burro Management. Wild Horse and Burro Program. Washington, D.C. Available at: http://www.wildhorseandburro.blm.gov.

- 2006a. Draft Burned Area Emergency Stabilization and Rehabilitation Handbook. BLM Manual H-1742-1. Washington, D.C.

. 2006b. A Common Vision: A Strategy for Integrated Vegetation Management in the Bureau of Land Management. BLM Instructional Memorandum 2006-213. Washington, D.C.

. 2006c. The United States Department of the Interior Bureau of Land Management Budget Justifications and Performance Information Fiscal Year 2007, and Annual Performance Report Fiscal Year 2006. Washington, D.C.

2006d. Public Land Statistics Fiscal Year 2005. Washington, D.C.

. 2006e. BLM Forest Lands Report - 2006: Status and Condition. BLM/ST/ST-07/001+5000. Denver, Colorado.

- 2006f. 2006 Cultural Resource Annual Report. Washington, D.C. Available at: http://www.blm.gov/heritage/data 06CRM.html.

2007a. Final Vegetation Treatments on Bureau of Land Management Lands in 17 Western States Programmatic Environmental Report. Reno, Nevada.

- 2007b. Final Programmatic Biological Assessment for Vegetation Treatments on Bureau of Land Management Lands in 17 Western States. Reno, Nevada.

- 2007c. Wildland Fire Management Information Fire Reporting. National Interagency Fire Center. Available at: http://www.nifc.blm.gov/nsdu/fire reporting/.
U.S. Department of the Interior, and U.S. Department of Agriculture. 2001a. Managing the Impacts of Wildland Fires on Communities and the Environment. The National Fire Plan. Available at: http://www. fireplan.gov.

, and 2006a. A Collaborative Approach for Reducing Wildland Fire Risks to Communities and the Environment 10-Year Comprehensive Strategy Implementation Plan. December 2006. http://www. fireplan.gov.

, and .2006b. Protecting People and Sustaining Resources in Fire Adapted Ecosystems: A Cohesive Strategy. February 2006. Available

http://www.healthyforests.gov/CFTS 03-0306.pdf.

, and .2006c. Draft Interagency Burned Area Emergency Response Guidebook. February 2006. Available at: http://fire.r9.fws.gov/ifcc/esr/Policy/es $\% 20$ handbo ok\%202-7-06.pdf.

, and

2006d. Interagency Burned Area Rehabilitation Guidebook. February 2006. Energy. 2003. Scientific Inventory of Onshore Federal Lands' Oil and Gas Resources and Reserves and the Extent and Nature of Restrictions or Impediments to the Development: The Paradox/San Juan, Uinta/Piceance, Greater Green River, and Powder River Basins, and the Montana Thrust Belt. Washington, D.C.

, and U.S. Department of Agriculture Forest Service. 1994. Rangeland Reform '94. Final Environmental Impact Statement. U.S. Department of Interior. Washington, D.C.

U.S. Department of the Interior National Park Service. 1998-2006. Geospatial Data of Class I National Park Service Parks, FWS Refuges, Forest Service Wilderness Areas, and American Indian Lands. Adapted from National Park Service AirWeb. Available at http://www2.nature.nps.gov/air/maps/ClassILoc.cf $\underline{\text { m. }}$ 
2003. Invasive Exotic Plant Management Plan and Environmental Assessment. Rocky Mountain National Park, Colorado.

U.S. Department of Labor Bureau of Labor Statistics. 2004. Census of Fatal Occupational Injuries, 2003 Summary. Washington, D.C. Available at: http://stats.bls.gov/news.release/cfoi.nro.htm.

- 2007. Census of Fatal Occupational Injuries, 2005 (preliminary data). Summary. Washington, D.C. Available at: http://stats.bls.gov/iif/oshwc/cfoi/cfch0004.pdf.

U.S. Environmental Protection Agency (USEPA). 1986. Pesticide Fact Sheet - Fluridone. Fact Sheet 81. Office of Pesticide Programs. Washington, D.C.

- 1992. Pesticide Environmental Fate Oneliner Summaries: Sulfometuron Methyl. USEPA. Washington, D.C.

1994a. Tebuthiuron Reregistration Eligibility Decision (RED). Special Review and Reregistration Division, Office of Pesticide Programs. Washington D.C.

. 1994b. HED Doc. No. 013110. Bromacil. PC Code: 012301. 11/16/94.

- 1995a. Compilation of Air Pollution Emission Factors, AP-42, Fifth Edition, Volume II: Mobile Sources, Appendix H Highway Mobile Source Emission Factor Tables. Supplemented through November 2000. Available at: http://www.epa.gov/otaq/ap42.htm.

. 1995b. Re-registration Eligibility Decision (RED) Asulam. Prevention, Pesticides, and Toxic Substances. EPA 738-R-95-024. Washington, D.C.

. 1995c. Re-registration Eligibility Decision (RED) Diquat Dibromide. Prevention, Pesticides, and Toxic Substances. EPA 738-R-95-016. Washington, D.C.

1995d. Re-registration Eligibility Decision (RED) Fosamine Ammonium. Prevention, Pesticides, and Toxic Substances. EPA 738-F-95005. Washington, D.C.
- 1996. Pesticide Tolerance for Cadre. Final Rule Published in the Federal Register. 40 CFR Part 180.490. Docket number: PP 4F4390/R2215. March 20, 1996.

- 1997. Exposure Factors Handbook, Volumes I, II, and III. EPA/600/P-95/002Fa, b, and c. Office of Research and Development, Washington, D.C.

- 1998a. Guidelines for Ecological Risk Assessment. EPA/630/R-95/002F. Washington, D.C.

- 1998b. Freedom of Information Act Request. Cited in: Aerial Herbicide Spraying: Poisoning the Maine (and New Hampshire) Woods. Available at: http://www.forestecologynetwork.org/tmwfall99 05.html.

- 1998c. Framework for Assessing Nonoccupational, Non-dietary (Residential) Exposure to Pesticides. Office of Pesticide Programs. Washington, D.C.

- 1998d. Pesticide Handlers Exposure Database Version 1.1, Surrogate Exposure Table. August 1998.

- 1999a. Regional Haze Regulations: Final Rule. 40 CFR Part 51. Federal Register, Volume 64, Number 126, July 1, 1999. Washington, D.C. Available at:

http://www.epa.gov/ttn/oarpg/t1/fr_notices/rhfedre g.pdf.

1999b. Overall Watershed Characterization-National Maps. September 1999 Index of Watershed Indicators (IWI) Release. Washington, D.C.

.1999c. Pesticide Fact Sheet: Diflufenzopyr United States Environmental Protection Agency. Office of Prevention, Pesticides and Toxic Substances. Washington, D.C.

-1999d. Guidance for Performing Aggregate Exposure and Risk Assessments. Office of Pesticide Programs, Environmental Protection Agency. October 29, 1999. 
. 2000a. Water Quality Conditions in the United States: A Profile from the 1998 National Water Quality Inventory Report to Congress. EPA-841-F-00-006. Office of Water (4503F). Washington, DC.

- 2000b. Science Advisory Council For Exposure. Policy Number 3.1: Agricultural Transfer Coefficients. Office of Pesticide Programs, Health Effects Division. Washington, D.C.

.2000c. The Role of Use-related Information in Pesticide Risk Assessment and Risk Management. Office of Pesticide Programs, USEPA. August 21, 2000. Available at: http: Ilwww.epa.gov/oppbead1/use-related.pdf.

. 2001a. Environmental Risk Assessment for the Reregistration of Diuron. Environmental Fate and Effects Division. Washington, D.C.

. 2001b. Notice of Availability of National Management Measures to Protect and Restore Wetlands and Riparian Areas for the Abatement of Nonpoint Source Pollution. EPA 841-B-01-001. Washington, D.C.

- 2001c. Risk Assessment Guidance for Superfund. Volume 1: Human Health Evaluation Manual. Part E. Supplemental Guidance for Dermal Risk Assessment. Interim. Review Draft for Public Comment. EPA/540/R/99/005. OSWER 9285.7-02EP. Washington, D.C.

- 2001d. General Principles for Performing Aggregate Exposure and Risk Assessments. November 28, 2001.

2002. Revised Human Health Risk Assessment - Atrazine. Health Effects Division, Reregistration Branch 3, Office of Pesticide Programs. Washington, D.C. Available at: http://www.epa.gov/oppstrd1/reregistration/atrazin e/hed redchap 16apr02.PDF.

- 2003a. Compilation of Air Pollution Emission Factors, AP-42, Fifth Edition, Volume I, Chapter 13 Miscellaneous Sources 13.2.2 Unpaved Roads. Available at: http://www.epa.gov/ttn/chief/ap42/ch13/final/c13s 0202.pdf.
- 2003b. Atrazine Interim Re-registration Eligibility Decision (IRED). Case Number 0062. Washington, D.C.

. 2003c. Reregistration Eligibility Decision (RED) for Diuron. United States Environmental Protection Agency. Office of Prevention, Pesticides and Toxic Substances. Washington D.C.

. 2003d. Laws and Regulations, Clean Water Act. Washington, D.C. Available at: http://www.epa.gov/rcgion5/water/cwa.htm.

2003e. White Paper on Potential Development Effects of Atrazine on Amphibians. Office of Prevention, Pesticides, and Toxic Substances Office of Pesticide Programs Environmental Fate and Effects Division. Washington, D.C. Available at: http://www.epa.gov/scipoly/sap/2003/june/finaljun e2002tclconfreport.pdf\#search='atrazine $\% 20 \mathrm{and} \%$ 20amphibians.

- 2003f. 40 Code of Federal Regulations. Section 156.62. Available at: http://www.epa.gov/pesticides/health/tox categori es.html.

2004a. Prevention of Significant Deterioration (PSD) Basic Information. Available at: http://www.epa.gov/nsr/psd.html. Updated June 30, 2004.

. 2004b. 2,4-D. HED's Human Health Risk Assessment for the Reregistration Eligibility Decision (RED). PC Code 030001; DP Barcode D287199. Office of Prevention, Pesticides, and Toxic Substances, Health Effects Division. Washington, D.C.

.2005a. National Emissions Inventory (NEI) Air Pollutant Emissions Trends Data. Technology Transfer Network Clearinghouse for Inventories and Emissions Factors. Available at: http://www.epa.gov/ttn/chief/trends/index.html.

. 2005b. Reregistration Eligibility Decision for 2,4-D. Office of Prevention, Pesticides and Toxic Substances. EPA 738-R-05-002. Washington, D.C. 
2006. Application of Pesticides to Waters of the United States in Compliance with FIFRA: Final Rule. Office of Water and Office of Prevention, Pesticides, and Toxic Substances. Available at: http://www.epa.gov/npdes/regulations/pest final $\mathrm{r}$ ule.pdf.

U.S. Environmental Protection Agency Office of Pesticide Programs (OPP). 1993. Re-registration Eligibility Decision (RED) for Glyphosate. EPA 738-R-93-014. Available at: http://www.epa.gov/oppsrrd1/REDs/factsheets/01 78fact.pdf.

U.S. Fish and Wildlife Service (USFWS). 1985. Endangered and Threatened Wildlife and Plants; Determination of Threatened Status for Hutton Tui Chub and Foskett Speckled Dace. Federal Register 50:12302-12306.

- 1990. Determination of Endangered Status for the Pallid Sturgeon. Federal Register, 55(173). Washington D.C.

- 1994a. Desert Tortoise (Mojave Population) Recovery Plan. Portland, Oregon.

1994b. Mexican Long-nosed Bat (Leptonycteris nivalis) Recovery Plan. Albuquerque, New Mexico.

- 1995a. Lesser Long-nosed Bat Recovery Plan. Albuquerque, New Mexico.

1995b. Final Rule Determining Endangered Status for the Southwestern Willow Flycatcher. Federal Register 60(38): 10693-10715.

1997. Endangered and Threatened Wildlife and Plants; Determination of Endangered Status for Three Wetland Species Found in Southern Arizona and Northern Sonora, Mexico. Federal Register 62(3):665-689.

2000. Determination of Threatened Status for the Northern Idaho Ground Squirrel. Federal Register 65(66):17779-17786.

U.S. Geological Survey (USGS). 1994a. Geologic Spatial Data of Hydrologic Units of the United States. Adapted from the Hydrologic Unit Maps
Published by the USGS Office of Water Data Coordination. Reston, Virginia.

- 1994b. Geologic Spatial Data of Alaska Hydrologic Units. Unpublished material available at

http://agdc.usgs.gov/data/projects/anwr/anwr.html.

- 1994-1999. Geologic Spatial Data of General Groundwater Quality. Adapted from the Groundwater Atlas of the United States. Available at: http://capp.water.usgs.gov/gwa/gwa.html.

-1996. Geologic Spatial Data of Oil and Gas Resources of the United States. Adapted from the 1995 U.S. National Oil and Gas Assessment. Central Region Energy Team. Denver, Colorado.

. 2000. Groundwater Atlas of the United States. HA 730-B-HA 730-N. Reston, Virginia. Available at: http://capp.water.usgs.gov/gwa/gwa.html.

. 2002a. Hydrologic regions data. Available at: http://water.usgs.gov/GIS/huc.html.

. 2002b. National Water Information System (NWIS) Database. Available at: http://waterdata.usgs.gov/nwis/.

.2002c. National Water Quality Assessment (NAWQA) Program. Available at: http://water.usgs.gov/nawga/.

- 2002d. Geospatial Data of Alaska Vegetation/Land Cover, Earth Resources Observation and Science Data Center. Sioux Falls, South Dakota.

. 2003. An Introduction to Biological Soil Crusts. Prepared by Canyonlands Research Station, Southwest Biological Science Center. Moab, Utah. Available at: http://www.soilcrust.org/crust101.htm.

- 2004. Southwest Biological Research Center, Canyonlands Research Station. Moab, Utah. Website Available at: http://www.soilcrust.org/crust101.htm. 
- 2006. The National Map LANDFIRE:

LANDFIRE Rapid Assessment Fire Regimes Layer. Available at: http://gisdata.usgs.net/website/landfire/.

Valdez, R.A., and G.H. Clemmer. 1982. Life History and Prospects for Recovery of the Humpback and Bonytail Chub. Pages 109-119 in Fishes of the Upper Colorado River System, Present and Future: Proceedings of a Symposium Presented at the Annual Meeting of the American Fisheries Society in Albuquerque, New Mexico, September 18, 1981 (W.H. Miller, H.M. Tyus, and C.A. Carlson, eds.). Western Division of the American Fisheries Society. Bethesda, Maryland.

Vallentine, J.F. 1989. Range Development and Improvement. $3^{\text {rd }}$ Edition. Brigham Young University Press. Provo, Utah.

Vehik, S.C. 2001. Hunting and Gathering Tradition: Southern Plains. Pages 146-158 in Plains (R.J. Demailie, ed.). Handbook of North American Indians, Volume 13 (W.C. Sturtevant, general ed.). Smithsonian Institution. Washington, D.C.

Vienneau, D.M., C.A. Sullivan, S.K. House, and G.W. Stratton. 2004. Effects of the Herbicide Hexazinone on Nutrient Cycling in a Low-pH Blueberry Soil. Environmental Toxicology 19:115-122.

Viereck, L.A. 1973. Wildfire in the Taiga of Alaska. Quaternary Research 3(3):465-495.

Voget, F.W. 2001. Crow. Pages 695-717 in Plains (R.J. DeMallie, ed.). Handbook of North American Indians, Volume 13 (W.C. Sturtevant, general ed.). Smithsonian Institution. Washington, D.C.

Vogue, P.A., E.A. Kerle, and J.J. Jenkins. 1994. Oregon State University Extension Pesticide Properties Database. Corvallis, Oregon. Available at: http://npic.orst.edu/ppdmove.htm.

Voos, G., and P. Groffman. 1997a. Dissipation of 2,4-D and Dicamba in a Heterogeneous Landscape. Applied Soil Ecology. Agriculture, Ecosystems and Environment 5:181-187.

, and 1997b. Relationships between Microbial Biomass and Dissipation of
2,4-D and Dicamba in Soil. Biology and Fertility of Soils 24:106-110.

Waggoner, J.A., S.L. Dowhower, W.R. Teague, and J.F. Cadenhead. 2003. Herbicide Use and Labor for Hand Applied Control of Mesquite. Rangelands 25:19-23.

Wagner, R.G., M. Newton, E.C. Cole, J.H. Miller, and B.D. Shiver. 2004. The Role of Herbicides for Enhancing Forest Productivity and Conserving Land for Biodiversity in North America. Wildlife Society Bulletin 32:1028-1042.

Wallace, W.J. 1978. Post-Pleistocene Archeology, 9000 to 2000 B.C. Pages 25-37 in California (R.F. Heizer, ed.). Handbook of North American Indians, Volume 8. (W.C. Sturtevant, general ed.). Smithsonian Institution. Washington, D.C.

Wallestad, R.O., J.G. Peterson, and R.L. Eng. 1975. Foods of Adult Sage Grouse in Central Montana. Journal of Wildlife Management 39:628-630.

Walleyes Unlimited. 2002. Available at: http://www.walleyesunlimited.com/.

Wan, M.T., R.G. Watts, and D.J. Moul. 1988. Evaluation of the Acute Toxicity of Juvenile Pacific Salmonids of Hexazinone and its Formulated Products: Pronone 10G; Velpar L; and Their Carriers. Bulletin of Environmental Contamination and Toxicology 41:609-616.

, and

1990. Acute

Toxicity to Juvenile Pacific Salmonids and Rainbow Trout of Butoxyethyl Esters of 2,4-D, 2,4-DP and Their Formulated Product: Weedone $\mathrm{CB}$ and its Carrier. Bulletin Environmental Contamination and Toxicology 45(4):604-11.

Wang; Y.S., J.H. Yen, Y.N. Hsieh, and Y.L. Chen. 1994. Dissipation of 2,4-D, Glyphosate, and Paraquat in River Water. Water Air and Soil Pollution 72:1-7.

Warren, C.N., and R.H. Crabtree. 1986. Prehistory of the Southwestern Area. Pages 183-193 in Great Basin (W.L. d'Azevedo, ed.). Handbook of North American Indians, Volume 11 (W.C. Sturtevant, general ed.). Smithsonian Institution. Washington, D.C. 
Washington Department of Ecology. 2002. Eurasian Watermilfoil Infested Lake Control Strategies. Eradication - Whole Lake Fluridone Treatment (Aquatic Herbicide). Available at: http:/www.ecy.wa.gov/programs/wq/plants/mana gement/fluridone strategies.html.

2004. Aquatic Plant Management: Aquatic Herbicides. Available at: http://www.ecy.wa.gov/programs/wq/plants/mana gement/aqua028.html.

2005. Wetlands in Washington State. Volume I - A Synthesis of the Science. Chapter 7. Olympia, Washington.

Washington Department of Health. 2000. Fluridone (Sonar) Fact Sheet. Environmental Health Programs. Office of Environmental Health and Safety. Available at: http://www.doh.wa.gov/ehp/factsheets.htm.

Water Science and Technology Board and Board on Environmental Studies and Toxicology. 2002. Riparian Areas: Functions and Strategies for Management. National Academy Press. Washington, D.C. Available at: http://books.nap.edu/books/0309082951/html/1.ht $\underline{\mathrm{ml}}$.

Weber, J., P. Shea, and S. Weed. 1986. Fluridone Retention and Release in Soils. Soil Science Society of America Journal 50:582-588.

Wedel, W.R. 1961. Prehistoric Man on the Great Plains. University of Oklahoma Press. Norman, Oklahoma.

. 1983. The Prehistoric Plains. Pages 203241 in Ancient North Americans (J.D. Jennings, ed.). W.H. Freeman and Company. New York, New York.

, and G.C. Frison. 2001. Environment and Subsistence. Pages 44-60 in Plains (R.J. DeMallie, ed.). Handbook of North America Indians, Volume 13 (W.C. Sturtevant, general ed.). Smithsonian Institution. Washington, D.C.

Wentz, D.A., B.A. Bonn, K.D. Carpenter, S.R. Hinkle, M.L. Janet, F.A. Rinella, M.A. Uhrich, I.R. Waite, A. Laenen, and K.E. Bencala. 1998. Water Quality in the Willamette Basin, Oregon,
1991-95. U.S. Geological Survey Circular 1161. Available at: http://pubs.usgs.gov/circ/circ1161/.

West, N.E., and N. Van Pelt. 1987. Successional Patterns in Pinyon-juniper Woodlands. Pages 4352 in Proceedings Pinyon-juniper Conference. General Technical Report INT-215. U.S. Department of Agriculture Forest Service Intermountain Research Station. Ogden, Utah.

Whisenant, S.G. 1987. Selective Control of Mountain Big Sagebrush (Artemesia tridentata spp. vaseyana) with Clopyralid. Weed Science 35:120123.

Whitcomb, C.E. 1999. An Introduction to ALSinhibiting Herbicides. Toxicology and Industrial Health 15(1-2):231-239.

White R.G., and R.G. Bramblett. 1993. The Yellowstone River: Its Fish and Fisheries. Pages 396-414 in Proceedings of the Symposium on Restoration Planning for the Rivers of the Mississippi River Ecosystem (L.W. Hesse, C.B. Stalnaker, N.G. Benson, and J.R. Zuboy, eds.). Biological Report 19. U.S. Department of the Interior National Biological Survey. Washington, D.C.

Whitson, T.D. (ed.) 2001. Weeds of the West. The Western Society of Weed Science. Jackson, Wyoming.

Whittaker, R.H. 1975. Communities and Ecosystems. MacMillian Publishing Co. New York, New York.

Whittier, T.R., R.M. Hughes, and D.P. Larsen. 1988. Correspondence between Ecoregions and Spatial Patterns in Stream Ecosystems in Oregon. Canadian Journal of Fisheries and Aquatic Sciences 45:1264-1278.

Widehem, P., S. Ait-Aissa, C. Tixier, M. Sancelme, H. Veschambre, and N. Truffaut. 2002. Isolation, Characterization and Diuron Transformation Capacities of a Bacterial Strain Arthrobacter Sp. N2. Chemosphere 46:527-534. 
Wiens, J.A., and M.I. Dyer. 1975. Rangeland Avifaunas: Their Composition, Energetics, and Role in the Ecosystem. Pages 146-182 in Proceedings of the Symposium on Management of Forests and Range Habitats for Nongame Birds (D.R. Smith, ed.). General Technical Report WO1. U.S. Department of Agriculture Forest Service. Washington, D.C.

Wilbert, D.E. 1963. Some Effects of Chemical Sagebrush Control on Elk Distribution. Journal of Range Management 16:74-78.

Wild, A. 1993. Soils and the Environment. First edition. Cambridge University Press. Cambridge, Massachusetts.

Williamson, A.K., M.D. Munn, S.J. Ryker, R.J. Wagner, J.C. Ebbert, and A.M. Vanderpool. 1998. Water Quality in the Central Columbia Plateau, Washington and Idaho, 1992-95. U.S. Geological Survey Circular 1144. Available at: http://pubs.usgs.gov/circ/circ1144/.

Willis, M.J., and R.F. Miller. 1999. Importance of Western Juniper Communities to Small Mammals. Pages 210-214 in Proceedings: Ecology and Management of Pinyon-juniper Communities within the Interior West. Forest Service Proceedings RMRS-P-9. U.S. Department of Agriculture Forest Service Rocky Mountain Research Station. Ogden, Utah.

Wingo, P.A., C.J. Cardinez, S.H. Landis, R.T. Greenlee, L.A. Ries, R.N. Anderson, and M.J. Thun. 2005. Long-term Trends in Cancer Mortality in the United States, 1930-1998. Available at: http://www.ncbi.nlm.nih.gov/.

Wisdom, M.J., R. S. Holthausen, B. C. Wales, C.D. Hargi, V. A, Saab, D.C. Lee, W.J. Hann, T.D. Rich, M.M. Rowland, W.J. Murphy, and M.R. Eames. 2000. Source Habitats for Terrestrial Vertebrates of Focus in the Interior Columbia Basin: Broad-scale Trends and Management Implication. Volume 2 - Group Level Results. U.S. Department of Agriculture Forest Service and USDI BLM General Technical Report PNWGTR-485. Portland, Oregon.

Witherspoon, G. 1983. Navajo Social Organization. Pages 524-535 in Southwest (A. Ortiz, ed.). Handbook of North American Indians, Volume 10
(W.C. Sturtevant, general ed.). Smithsonian Institution. Washington, D.C.

Wong, D.C.L., P.B. Dorn, and E.Y. Chai. 1997. Acute Toxicity and Structure-Activity Relationships of Nine Alcohol Ethoxylate Surfactants to Fathead Minnow and Daphnia magna. Environmental Toxicology and Chemistry 16: 1970-1976.

Wong, P.K. 2000. Effects of 2,4-D, Glyphosate, and Paraquat on Growth, Photosynthesis and Chlorophyll-a Synthesis of Scenedesmus quadricauda, Berb 614. Chemosphere 41:177182.

Wood, J.A., and D.H.J. Anthony. 1997. Herbicide Contamination of Prairie Springs at Ultratrace Levels of Detection. Journal of Environmental Quality 26:1308-1318.

Wood, W.R., and L. Irwin. 2001. Mandan. Pages 349-364 in Plains (R.J. DeMallie, ed.). Handbook of North American Indians, Volume 13 (W.C. Sturtevant, general ed.). Smithsonian Institution. Washington, D.C.

Woodburn, K.B., D.D. Fontaine, E.L. Bjerke, and G.J. Kallos. 1989. Photolysis of Picloram in Dilute Aqueous Solution. Environmental Toxicology and Chemistry 8:769-775.

Woodbury, R.B. 1979. Prehistory: Introduction. Pages 22-30 in Southwest (A. Ortiz, ed.). Handbook of North American Indians, Volume 9 (W.C. Sturtevant, general ed.). Smithsonian Institution. Washington, D.C.

, and E.B.W. Zubrow. 1979. Agricultural Beginnings, 2000 B.C. - A.D. 500. Pages 43-61 in Southwest (A. Ortiz, ed.). Handbook of North American Indians, Volume 9 (W.C. Sturtevant, general ed.). Smithsonian Institution. Washington, D.C.

World Wildlife Fund. 2002. Endangered Spaces, the Global 200. Washington, D.C. Available at: http://www.worldwildlife.org/global200/spaces.cf $\underline{\text { m? }}$ sectionid $=25 \&$ newspaperid $=20$.

Wright, J.W. (ed.). 2002. 2003 Almanac: The Almanac of Rccord. New York Times. New York, New York. 
Wullschleger, J. 2000. River Management and the Upper Colorado River Recovery Implementation Program. Available at: http://www2.nature.nps.gov/YearinReview/yir200 0/pages/04 resource risks/04_01_wullschleger.ht $\underline{\mathrm{ml}}$.

Young, J.A. 1994. Changes in Plant Communities in the Great Basin Induced by Domestic Livestock Grazing. Pages 113-123 in Natural History of the Colorado Plateau and Great Basin (K.T. Harper, L.L. St. Clair, K.H. Thorne, and W.M. Hess, eds.). University Press of Colorado. Niwot, Colorado.

Young, M.K. 1994. Movement and Characteristics of Stream-borne Coarse Woody Debris in Adjacent Burned and Undisturbed Watersheds in Wyoming. Canadian Journal of Forest Research 24:19331938.

Youtie, B., J. Ponzetti, and D. Salzer. 1999. Fire and Herbicides for Exotic Annual Grass Control: Effects on Native Plants and Microbiotic Soil Organisms. Pages 590-591 in Proceedings of People and Rangelands: Building the Future; Proceedings of the VI International Rangeland Congress (D. J. Eldridge, and D. Freudenberger, eds.). VI International Rangeland Congress. Townsville, Queensland, Australia.
Zanardini, E., A. Arnoldi, G. Boschin, A. D'Agostina, M. Negri, and C. Sorlimi. 2002. Degradation Pathways of Chlorsulfuron and Metsulfuron-methyl by a Pseudomonas fluorescens Strain. Annals of Microbiology 52:25-37.

Zaranyika, M.F., and M.G. Nydandoro. 1993. Degradation of Glyphosate in the Aquatic Environment: An Enzymatic Kinetic Model That Takes into Account Microbial Degradation of Both Free and Colloidal (or Sediment) Particle Adsorbed Glyphosate. Journal of Agricultural Food Chemistry 41:838-842.

Zigmond, M.L. 1986. Kwaiisu. Pages 398-411 in Great Basin (W.L. d'Azevedo, ed.). Handbook of North American Indians, Volume 11 (W.C. Sturtevant, general ed.). Smithsonian Institution. Washington, D.C.

Zimmerman, L.J., and B.L. Molyneaux. 1996. Native North America. University of Oklahoma Press. Norman, Oklahoma.

Zoltai, S.C. 1974. Structure of Subarctic Forests on Hummocky Permafrost Terrain in Northwestern Canada. Canadian Journal of Forest Research 5(1):1-9. 

CHAPTER 7

GLOSSARY 



\section{CHAPTER 7}

\section{GLOSSARY}

A

Absorption: The process by which a chemical or other substance is able to pass through body membranes and enter an organism.

Active ingredient (a.i.): The chemical or biological component that kills or controls the target pest.

Acute adverse effect level: The level at which a substance can cause adverse effects within a short time of dosing or exposure.

Acute effect: An adverse effect on any living organism in which symptoms develop rapidly and often subside after the exposure stops.

Acute toxicity: The quality or potential of a substance to cause injury or illness shortly after exposure to a relatively large dose.

Adaptive management: A system of management practices based on clearly identified outcomes, monitoring to determine if management actions are meeting outcomes, and if not, facilitating management changes that will best ensure that outcomes are met or reevaluated.

Additive: A substance added to another in relatively small amounts to impart or improve desirable properties or suppress undesirable properties.

Additive effect: A situation in which combined effects of exposure to two chemicals simultaneously is equal to the sum of the effect of exposure to each chemical given alone.

Adjuvant: A chemical that is added to the pesticide formulation to enhance the toxicity of the active ingredient or to make the active ingredient easier to handle.

Adsorption: 1) The adhesion of substances to the surface of solids or liquids. 2) The attraction of ions of compounds to the surface of solids or liquids.
Adverse impact: An impact that causes harm or a negative result.

Aerobic biodegradation: The breakdown of organic contaminants by microorganisms when oxygen is present.

Air pollutant: Any substance in the air that could, if in high enough concentration, harm humans, animals, vegetation, or material. Air pollutants may include almost any natural or artificial matter capable of being airborne in the form of solid particles, liquid droplets, gases, or a combination of these.

Air quality: The composition of air with respect to quantities of pollution therein; used most frequently in connection with "standards" of maximum acceptable pollutant concentrations.

Alien Species: Per Executive Order 13112, alien species means, with respect to a particular ecosystem, any species, including its seed, eggs, spores, or other biological material capable of propagating that species, that is not native to that ecosystem.

Allotment (grazing): Area designated for the use of a certain number and kind of livestock for a prescribed period of time.

Alluvium: General term for clay, silt, sand, or gravel deposited in the bed of a stream during relatively recent geologic time as a result of stream action.

Alternative: In an EIS, one of a number of possible options for responding to the purpose and need for action.

Ambient air: Any unconfined portion of the atmosphere; open air and surrounding air. Often used interchangeably with "outdoor air."

Anadromous: A term used to describe fish that mature in the sea and swim up freshwater rivers and streams to spawn. Salmon, steelhead, and sea-run cutthroat trout are examples. 
Anaerobic biodegradation: The breakdown of organic contaminants by microorganisms when oxygen is not present.

Animal Unit (AU): A standardized unit of measurement for range livestock that is equivalent to one cow, one horse, five sheep, five goats, or four reindeer, all over 6 months of age.

Animal Unit Month (AUM): The amount of feed or forage required by one animal unit grazing on a pasture for 1 month.

Annual (plant): A plant whose life cycle is completed in 1 year or season.

Antifoamer: A type of adjuvant added to a commercial pesticide that prevents the formation of foam.

Aquatic: Growing, living in, frequenting, or taking place in water; used to indicate habitat, vegetation, or wildlife in freshwater.

Aquifer: Rock or rock formations (often sand, gravel, sandstone, or limestone) that contain or carry groundwater and act as water reservoirs.

Area of Critical Environmental Concern (ACEC): An area within public lands that requires special management attention to protect and prevent irreparable damage to important historic, cultural, or scenic values; fish and wildlife resources; other natural systems or processes; or to protect life or provide safety from natural hazards.

Arid: A term applied to regions or climates where lack of moisture severely limits growth and production of vegetation. The limits of precipitation vary considerably according to temperature conditions.

Attainment area: A geographic area that is in compliance with the National Ambient Air Quality Standards. An area considered to have air quality as good as or better than the National Ambient Air Quality Standards as defined in the Clean Air Act.

\section{B}

Binder: A material used to bind together two or more other materials in mixtures.

Bioaccumulation: The process of a plant or animal selectively taking in or storing a persistent substance. Over time, a higher concentration of the substance is found in the organism than in the organism's environment.

Biodegradability: Susceptibility of a substance to decomposition by microorganisms; specifically, the rate at which compounds may be chemically broken down by bacteria and/or natural environmental factors.

Biodiversity: The variety of life and its processes, including all life forms from one-celled organisms to complex organisms such as insects, plants, birds, reptiles, fish, other animals; and the processes, pathways, and cycles that link such organisms into natural communities.

Biological Assessment (BA): A document prepared by or under the direetion of a federal agency. A BA addresses federally-listed and species proposed for listing and designated and proposed critical habitat that may be present in the action area, and evaluates the potential effects of the action on such species and habitat.

Biological crust: Thin crust of living organisms on or just below the soil surface; composed of lichens, mosses, algae, fungi, cyanobacteria, and bacteria.

Boom (herbicide spray): A tubular metal device that conducts an herbicide mixture from a tank to a series of spray nozzles. It may be mounted beneath a helicopter or a fixed-wing aircraft, or behind a tractor or all-terrain vehicle.

Brackish: Saline water whose salt concentration is between that of freshwater and seawater (ranging from 0.5 to 30 parts per thousand).

Broadcast application: An application of an herbicide that uniformly covers an entire area.

Broad scale: A large, regional area, such as a river basin; typically a multi-state area.

Buffer: A solution or liquid whose chemical makeup is such that it minimizes changes in $\mathrm{pH}$ when acids or bases are added to it.

Buffer strip/zone: A strip of vegetation that is left or managed to reduce the impact that a treatment or action on one area might have on another area. 
Bunchgrass: A grass having the characteristic growth habit of forming a bunch; lacking stolons or rhizomes.

\section{C}

California Puff (CALPUFF): CALPUFF is an advanced non-steady-state meteorological and air quality modeling system adopted by the U.S. Environmental Protection Agency as the preferred model for assessing long range transport of pollutants and their impacts involving complex meteorological conditions.

Carbon-14 dating: The use of the naturally occurring isotope of carbon-14 in radiometric dating to determine the age of organic materials.

Carcinogen: A chemical capable of inducing cancer.

Carnivore: An animal that feeds on other animals, especially the flesh-eating mammals.

Carrier: A non-pesticidal substance added to a commercial pesticide formulation to make it easier to handle or apply.

Carrying capacity: The maximum population of a particular species that a particular region can support without hindering future generations' ability to maintain the same population.

Chaining: Vegetation removal that is accomplished by hooking a large anchor chain between two bulldozers; as the bulldozers move through the vegetation, the vegetation is knocked to the ground. Chaining kills a large percentage of the vegetation, and is often followed a year or two later by burning and/or seeding.

Chemical degradation: The breakdown of a chemical substance into simpler components through chemical reactions.

Chronic adverse effect level: The level at which a substance can cause adverse effects in which symptoms recur frequently or develop slowly over a long period of time.

Chronic exposure: Exposures that extend over the average lifetime or for a significant fraction of the lifetime of the individual. Chronic exposure studies are used to evaluate the carcinogenic potential of chemicals and other long-term health effects.

Class I area: Under the 1977 Clean Air Act amendments, all international parks, parks larger than 6,000 acres, and national wilderness areas larger than 5,000 acres that existed on August 7, 1977. This class provides the most protection to pristine lands by severely limiting the amount of additional air pollution that can be added to these areas.

Climate: The composite or generally prevailing weather conditions of a region throughout the year, averaged over a series of years.

Coarse woody debris: Pieces of woody material derived from tree limbs, boles, and roots in various stages of decay, generally having a diameter of at least 3 inches and a length greater than 3 feet.

Code of Federal Regulations (CFR): A codification of the general and permanent rules published in the Federal Register by the executive departments and agencies of the federal government.

Consultation: Exchange of information and interactive discussion; when the "C" in consultation is capitalized it refers to consultation mandated by statute or regulation that has prescribed parties, procedures, and timelines (e.g. Consultation under National Environmental Policy Act or Section 7 of the Endangered Species Act).

Council on Environmental Quality (CEQ): An advisory council to the President of the United States established by the National Environmental Policy Act of 1969. It reviews federal programs for their effect on the environment, conducts environmental studies, and advises the President on environmental matters.

Countervailing: A type of cumulative impact where negative effects are compensated for by beneficial effects.

Cover: 1) Trees, shrubs, rocks, or other landscape features that allow an animal to partly or fully conceal itself. 2) The area of ground covered by plants of one or more species, usually expressed as a percent of the ground surface. 
Criteria: Data and information that are used to examine or establish the relative degrees of desirability of alternatives or the degree to which a course of action meets an intended objective.

Criteria pollutants: Air pollutants designated by the U.S. Environmental Protection Agency as potentially harmful and for which ambient air quality standards have been set to protect the public health and welfare. The criteria pollutants are carbon monoxide, sulfur dioxide, particulate matter, nitrogen dioxide, ozone, hydrocarbons, and lead.

Critical habitat: 1) Specific areas within the habitat a species occupies at the time it is listed under the Endangered Species Act that have physical or biological features (a) that are essential to the conservation of the species and (b) that may require special management considerations or protection; and 2) specific areas outside the habitat a species occupies at the time it is listed that the Secretary of the Interior determines are essential for species conservation.

Cultural resources: Nonrenewable evidence of human occupation or activity as seen in any area, site, building, structure, artifact, ruin, object, work of art, architecture, or natural feature, which was important in human history at the national, state, or local level.

Cumulative effects: Impacts on the environment that result from the incremental impact of an action when added to other past, present, and reasonably foreseeable future actions. Cumulative effects can result from individually minor, but collectively significant, actions taking place over a period of time.

D

Degradation: Physical or biological breakdown of a complex compound into simpler compounds.

Density: The number of individuals per a given unit area.

Diluent: An inert diluting agent added to a commercial pesticide formulation that decreases the viscosity of the formula.

Dilution: The act of mixing or thinning, and therefore decreasing a certain strength or concentration.
Direct effects: Impacts on the environment that are caused by the action and occur at the same time and place.

Dispersant: A type of inert ingredient added to an herbicide formulation that reduces the cohesive attraction between like particles.

Dispersion: The act of distributing or separating into lower concentrations or less dense units.

Disturbance: Refers to events that alter the structure, composition, or function of terrestrial or aquatic habitats. Natural disturbances include, among others, drought, floods, wind, fires, wildlife grazing, and insects and pathogens. Human-caused disturbances include actions such as timber harvest, livestock grazing, roads, and the introduction of exotic species.

Dominant: A group of plants that by their collective size, mass, or number exerts a primary influence onto other ecosystem components.

Dose: The amount of chemical administered or received by an organism, generally at a given point in time.

Dose-response: Changes in toxicological responses of an individual (such as alterations in severity of symptoms) or populations (such as alterations in incidence) that are related to changes in the dose of any given substance.

Draft Environmental Impact Statement (DEIS): The draft statement of the environmental effects of a major federal action which is required under Section 102 of the National Environmental Policy Act, and released to the public and other agencies for comment and review.

Drift: That part of a sprayed chemical that is moved by wind off a target site.

Ecosystem: Includes all the organisms of an area, their environment, and the linkages or interactions among all of them; all parts of an ecosystem are interrelated. The fundamental unit in ecology, containing both organisms and abiotic environments, each influencing the properties of the other and both necessary for the maintenance of life. 
Ecosystem-based management: The use of an ecological approach to achieve multiple-use management of public lands by blending the needs of people and environmental values in such a way that public lands represent diverse, healthy, productive, and sustainable ecosystems.

Ecotone: A boundary or zone of transition between adjacent communities or environments, such as the boundary between a forest and a meadow. Species present in an ecotone are intermixed subsets of the adjacent communities.

Edge effect: The influence of two communities on populations in their adjoining boundary zone or ecotone, affecting the composition and density of the populations in these bordering areas.

Effect: Environmental change resulting from a proposed action. Direct effects are caused by the action and occur at the same time and place, while indirect effects are caused by the action but are later in time or further removed in distance, although still reasonably foreseeable. Indirect effects may include growth-inducing effects and other effects related to induced changes in the pattern of land use, population density, or growth rate, and related effects on air and water and other natural systems, including ecosystems. Effect and impact are synonymous as used in this document.

Endangered species: Plant or animal species that are in danger of extinction throughout all or a significant part of their range.

Endemic species: Plants or animals that occur naturally in a certain region and whose distribution is relatively limited to a particular locality.

Environment: 1) The physical conditions that exist within an area (e.g., the area that will be affected by a proposed project), including land, air, water, minerals, flora, fauna, ambient noise, and objects of historical or aesthetic significance. 2) The sum of all external conditions that affect an organism or community to influence its development or existence.

Environmental Assessment (EA): A concise public document, for which a federal agency is responsible, that serves to: 1) briefly provide sufficient evidence and analysis for determining whether to prepare an environmental impact statement or a finding of no significant impact; 2) aid an agency's compliance with the National Environmental Policy Act when no environmental impact statement is necessary; and 3) facilitate preparation of an environmental impact statement when one is necessary.

Environmental Impact Statement (EIS): A required report for all federal actions that will lead to significant effects on the quality of the human environment. The report must be systematic and interdisciplinary, integrating the natural and social sciences as well as the design arts in planning and decision-making. The report must identify 1) the environmental impacts of the proposed action, 2) any adverse environmental effects which cannot be avoided should the proposal be implemented, 3) alternatives to the proposed action, 4) the relationship between short-term uses of human environment and the maintenance and enhancement of long-term productivity, and 5) any irreversible and irretrievable commitments of resources which would be involved in the proposed action should it be implemented.

Epidemiology study: A study of human population or human populations. In toxicology, a study which examines the relationship of exposures to one or more potentially toxic agent to adverse health effects in human populations.

Eradication: Removal of all traces of a population or elimination of a population to the point where individuals are no longer detectable.

Erosion: The wearing away of the land surface by running water, wind, ice, gravity, or other geological activities; can be accelerated or intensified by human activities that reduce the stability of slopes or soils. 
Essential Fish Habitat ( $\mathrm{EFH})$ : As defined by Congress in the interim final rule (62FR 66551): "those waters and substrate necessary to fish for spawning, breeding, feeding, or growth to maturity." For the purpose of interpreting the definition of $\mathrm{EFH}$ habitat, "waters" include aquatic areas and their associated physical, chemical, and biological properties; "substrate" includes sediment underlying the waters; "necessary" refers to the habitat required to support a sustainable fishery and the managed species contribution to a healthy ecosystem; and "spawning, breeding, feeding, or growth to maturity" covers all habitat types utilized by a species throughout its life cycle.

Exotic species: Includes species introduced into an area that may have adapted to the area and compete with resident native (indigenous) species.

F

${ }^{\circ} \mathrm{F}$ : Degrees Fahrenheit.

Fate: The course of an applied herbicide in an ecosystem or biological system, including metabolism, microbial degradation, leaching, and photodecomposition.

Fauna: The vertebrate and invertebrate animals of the area or region.

Feasible: Capable of being accomplished in a successful manner within a reasonable period of time, taking into account economic, environmental, legal, social, and technological factors.

Final Environmental Impact Statement (Final EIS): A revision of the Draft Environmental Impact Statement based on public and agency comments on the draft.

Fire dependent: An ecosystem evolving under periodic perturbations by fire and that consequently depends on periodic fires for normal ecosystem function.

Fire intolerant: Species of plants that do not grow well with or die from the effects of too much fire.

Fire return interval: The average time between fires in a given area.

Fire tolerant: Species of plants that can withstand a certain frequency and intensity of fire.
Fire use: The combination of prescribed fire and wildland fire use for resource benefit to meet resource objectives.

First order dermal absorption: Absorption of a material (herbicide) that occurs over 24 hours, taking into consideration the potential for some herbicide to not be absorbed.

Fisheries habitat: Streams, lakes, and reservoirs that support fish populations.

Fishery: The act, process, occupation, or season of taking an aquatic species.

Food Quality Protection Act (FQPA) safety factor: The Food Quality Protection Act safety factor is applied to pesticides that exhibit threshold effects to "take into account potential pre- and post-natal toxicity and completeness of the data with respect to exposure and toxicity to infants and children." The Act requires 1) an explicit determination that exposure tolerances are safe for children; 2) an additional safety factor of up to 10 -fold, if necessary, be used to account for uncertainty in data relative to children (this is in addition to the current 100 -fold safety factor which is already used to account for the use of animals, versus humans, in laboratory testing, and the variability in potential adult response to pesticide exposure); and 3) an analysis of exposure risks to children that takes into account the special sensitivity and exposure of children to pesticides.

Forage: Vegetation eaten by animals, especially grazing and browsing animals.

Forbs: Broad-leafed plants; includes plants that commonly are called weeds or wildflowers.

Forestland: Land where the potential natural plant community contains $10 \%$ or more tree canopy cover.

Formulation: The commercial mixture of both active and inactive (inert) ingredients

Fossilization: The process of fossilizing a plant or animal that existed in some earlier age; the process of being turned to stone.

Fragmentation (habitat): The breaking-up of a habitat or cover type into smaller, disconnected parcels. 
Fuel (fire): Dry, dead parts of trees, shrubs, and other vegetation that can burn readily.

\section{G}

Gavage: Introduction of material in the stomach by a tube.

Groundwater: Subsurface water that is in the zone of saturation. The top surface of the groundwater is the "water table." Source of water for wells, seeps, and springs.

$\mathrm{H}$

Habitat: The natural environment of a plant or animal, including all biotic, climatic, and soil conditions, or other environmental influences affecting living conditions. The place where an organism lives.

Half life: The amount of time required for half of a compound to degrade.

Hazardous fuels: Includes living and dead and decaying vegetation that form a special threat of ignition and resistance to control.

Hazard quotient (HQ): The ratio of the estimated level of exposure to a substance from a specific substance from a specific pesticide application to the reference dose (RfD) for that substance, or to some other index of acceptable exposure or toxicity. A HQ less than or equal to 1 is presumed to indicate an acceptably low level of risk for that specific application.

Herbaceous: Non-woody plants that include grasses, grass-like plants, and forbs.

Herbicide: A chemical pesticide used to control, suppress, or kill vegetation, or severely interrupt normal growth processes.

Herbicide resistance: Naturally-occurring heritable characteristics that allow individual weeds to survive and reproduce, producing a population, over time, in which the majority of the plants of the weed species have the resistant characteristics.
Herd Management Areas (HMAs): Areas established for wild and free-roaming horses and burros through the land use planning process. The Wild Free-roaming Horse and Burro Act of 1971 requires that wild free-roaming horses and burros be considered for management where they were found at the time Congress passed the Act. The BLM initially identified 264 areas of use as herd management areas.

Home range: The area around an animal's established home that is visited during the animal's normal activities.

Hydrologic cycle (water cycle): The ecological cycle that moves water from the air by precipitation to the earth and returns it to the atmosphere; includes evaporation, run-off, infiltration, percolation, storage, and transpiration.

Hydrologic unit code (HUC): A hierarchical coding system developed by the U.S. Geological Survey to identify geographic boundaries of watersheds of various sizes.

Hydrolysis: Decomposition or alteration of a chemical substance by water.

Impermeable: Cannot be penetrated.

Indigenous: Living or occurring naturally in an area; native, endemic people, flora, or fauna.

Indirect effects: Impacts that are caused by an action, but are later in time or farther removed in distance, although still reasonably foreseeable.

Inert ingredient(s): Those ingredients that are added to the commercial product (formulation) and are not herbicidally active.

Infiltration: The movement of water through soil pores and spaces.

Insectivore: An organism that feeds mainly on insects.

Herbivore: An animal that feeds on plants. 
Integrated pest management (IPM): A long-standing, science-based, decision-making process that identifies and reduces risks from pests and pest management related strategies. It coordinates the use of pest biology, environmental information, and available technology to prevent unacceptable levels of pest damage by the most economical means, while posing the least possible risk to people, property, resources, and the environment. IPM provides an effective strategy for managing pests in all arenas from developed agricultural, residential, and public areas to wild lands. IPM serves as an umbrella to provide an effective, all encompassing, low-risk approach to protect resources and people from pests. BLM Departmental Manual 517 (Pesticides) defines integrated pest management as "a sustainable approach to managing pests by combining biological, cultural, physical, and chemical tools in a way that minimizes economic, health, and environmental risks."

Intermittent stream: A stream that flows only a certain times of the year when it receives water from other streams or from surface sources such as melting snow.

Invasive plants: Plants that 1) are not part of (if exotic), or are a minor component of (if native), the original plant community or communities; 2) have the potential to become a dominant or codominant species on the site if their future establishment and growth is not actively controlled by management interventions; or 3) are classified as exotic or noxious plants under state or federal law. Species that become dominant for only one to several years (e.g. short-term response to drought or wildfire) are not invasive plants.

Invasive species: Per Executive Order 13112, an invasive species means an alien species whose introduction does or is likely to cause economic or environmental harm or harm to human health.

Invertebrate: Small animals that lack a backbone or spinal column. Spiders, insects, and worms are examples of invertebrates.

Irretrievable commitment: A term that applies to losses of production or commitment of renewable natural resources. For example, while an area is used as a ski area, some or all of the timber production there is "irretrievably" lost. If the ski area closes, timber production could resume; therefore, the loss of timber production during the time the area is devoted to skiing is irretrievable, but not irreversible, because it is possible for timber production to resume if the area is no longer used as a ski area.

Irreversible commitment: A term that applies to nonrenewable resources, such as minerals and archaeological sites. Losses of these resources cannot be reversed. Irreversible effects can also refer to the effects of actions on resources that can be renewed only after a very long period of time, such as the loss of soil productivity.

Issue: A matter of controversy, dispute, or general concern over resource management activities or land uses.

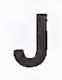

$\mathrm{K}$

$\mathbf{K}_{\mathbf{o c}}$ : Organic carbon-water partition coefficient.

$\mathbf{L}$

Land management: The intentional process of planning, organizing, programming, coordinating, directing, and controlling land use actions.

Landscape: All the natural features such as grasslands, hills, forest, and water, which distinguish one part of the earth's surface from another part; usually that portion of land that the eye can comprehend in a single view, including all of its natural characteristics.

Land use allocation: The assignment of a management emphasis to particular land areas with the purpose of achieving the goals and objectives of some specified use(s) (e.g., campgrounds, wilderness, logging, and mining).

Large woody debris: Pieces of wood that are of a large enough size to affect stream channel morphology.

$\mathrm{LC}_{50}$ (median lethal concentration): A calculated concentration of a chemical in air or water to which exposure for a specific length of time is expected to cause death in $50 \%$ of a defined experimental animal population. 
LD $_{50}$ (median lethal dose): The dose of a chemical calculated to cause death in $50 \%$ of a defined experimental animal population over a specified observation period. The observation period is typically 14 days.

Leaching: Usually refers to the movement of chemicals through the soil by water; may also refer to the movement of herbicides out of leaves, stems, or roots into the air or soil.

Level of concern (LOC): The concentration in media or some other estimate of exposure above which there may be effects.

Lichens: Organisms made up of specific algae and fungi, forming identifiable crusts on soil, rocks, tree, bark, and other surfaces. Lichens are primary producers in ecosystems. They contribute living material and nutrients, enrich the soil and increase soil moisture-holding capacity, and serve as food sources for certain animals. Lichens are slow growing and sensitive to chemical and physical disturbances.

Lifeways: The manner and means by which a group of people lives; their way of life. Components include language(s), subsistence strategies, religion, economic structure, physical mannerisms, and shared attitudes.

Litter: The uppermost layer of organic debris on the soil surface, which is essentially the freshly fallen or slightly decomposed vegetation material such as stems, leaves, twigs, and fruits.

Long term: Generally refers to a period longer than 10 years.

Lowest observed adverse effect level (LOAEL): The lowest dose of a chemical in a study, or group of studies, that produces statistically or biologically significant increases in frequency or severity of adverse effects between the exposed and control populations.

Lymph: A clear water fluid containing white blood cells. Lymph circulates throughout the lymphatic system, removing bacteria and certain proteins from body tissue. It also is responsible for transporting fat from the small intestine and supplying mature lymphocytes to the blood.
Lymphatic: Pertaining to lymph, a lymph vessel, or a lymph node.

M

Macrophytes: Terrestrial or aquatic plants that are large enough to be seen without the aid of a microscope.

Material safety data sheet (MSDS): A compilation of information required under the Occupational Safety and Health Administration Communication Standard on the identity of hazardous chemicals, health and physical hazards, exposure limits, and precautions.

Memorandum of Understanding (MOU): Documents an agreement reached among agencies.

Microbial degradation: The breakdown of a chemical substance into simpler components by bacteria or other microorganisms.

Microbiotic crust: See biological crust.

Minimize: Apply best available technology, management practices, and scientific knowledge to reduce the magnitude, extent, and/or duration of impacts.

Minimum tool rule: Apply only the minimum-impact policy, device, force, regulation, instrument, or practice to bring about a desired result.

Mitigation: Steps taken to: 1) avoid an impact altogether by not taking a certain action or parts of an action; 2) minimize an impact by limiting the degree or magnitude of the action and its implementation; 3) rectify an impact by repairing, rehabilitating, or restoring the affected environment; 4) reduce or eliminate an impact over time by preserving and maintaining operations during the life of the action; and, 5) compensate for an impact by replacing or providing substitute resources or environments (40 CFR Part 1508.20).

Mitigation measures: Means taken to avoid, compensate for, rectify, or reduce the potential adverse impact of an action.

Monitoring: The orderly collection, analysis, and interpretation of resource data to evaluate progress toward meeting management objectives. 
Multiple uses: A combination of balanced and diverse resource uses that takes into account the long-term needs of future generations for renewable and nonrenewable resources. These may include recreation, range, timber, minerals, watershed, wildlife, and fish, along with natural scenic, scientific, and historical values.

\section{N}

National Ambient Air Quality Standards (NAAQS): Standards set by the U.S. Environmental Protection Agency for the maximum levels of pollutants that can exist in the outdoor air without unacceptable effects on human health or the public welfare.

National Back Country Byways: A program developed by the BLM to complement the National Scenic Byway program. The BLM's Byways show enthusiasts the best the West has to offer-from waterfalls to geology sculpted by volcanoes, glaciers, and rivers. Back Country Byways vary from narrow, graded roads, passable only during a few months of the year, to two-lane paved highways providing year-round access.

National Conservation Areas: Areas designated by Congress so that present and future generations of Americans can benefit from the conservation, protection, enhancement, use, and management of these areas by enjoying their natural, recreational, cultural, wildlife, aquatic, archeological, paleontological, historical, educational, and/or scientific resources and values.

National Environmental Policy Act (NEPA): An act of Congress passed in 1969, declaring a national policy to encourage productive and enjoyable harmony between people and the environment, to promote efforts that will prevent or eliminate damage to the environment and the biosphere and stimulate the health and welfare of people, and to enrich the understanding of the ecological systems and natural resources important to the nation, among other purposes.

National Historic Trails: Trails established to identify and protect historic routes; they follow as closely as possible the original trails or routes of travel of national historic significance.

National Landscape Conservation System (NLCS):

A single system that encompasses some of the
BLM's premier land designations. By putting these lands into an organized system, the BLM hopes to increase public awareness of these areas' scientific cultural, educational, ecological, and other values.

National Monument: An area designated to protect objects of scientific and historic interest by public proclamation of the President under the Antiquities Act of 1906, or by the Congress for historic landmarks, historic and prehistoric structures, or other objects of historic or scientific interest situated upon the public lands; designation also provides for the management of these features and values.

National Recreation Area: An area designated by Congress to assure the conservation and protection of natural, scenic, historic, pastoral, and fish and wildlife values and to provide for the enhancement of recreational values.

National Recreation Trails: Trails established administratively by the Secretary of the Interior to provide for a variety of outdoor recreation uses in or reasonably close to urban areas. They often serve as connecting links between the National Historic Trails and National Scenic Trails.

National Scenic Areas: Refers to the one national scenic area managed by the BLM: The Santa Rosa Mountains National Scenic Area in California, which encompasses approximately 101,000 acres. This area was designated by the Secretary of the Interior in 1990 to provide for the conservation, protection, and enhancement of scenic, recreation, and pastoral values.

National Scenic Trails: Trails established by an Act of Congress that are intended to provide for maximum outdoor recreation potential and for the conservation and enjoyment of nationally significant scenic, historical, natural, and cultural qualities of the areas through which these trails pass. National Scenic Trails may be located to represent desert, marsh, grassland, mountain, canyon, river, forest, and other areas, as well as land forms that exhibit significant characteristics of the physiographic regions of the nation. 
National Wild and Scenic Rivers: Rivers designated in the National Wild and Scenic Rivers System that are classified in one of three categories, depending on the extent of development and accessibility along each section. In addition to being free flowing, these rivers and their immediate environments must possess at least one outstandingly remarkable value: scenic, recreational, geologic, fish and wildlife, historical, cultural, or other similar values.

Native species: Species that historically occurred or currently occur in a particular ecosystem and were not introduced.

Natural community: An assemblage of organisms indigenous to an area that is characterized by distinct combinations of species occupying a common ecological zone and interacting with one another.

Natural resources: Water, soil, plants and animals, nutrients, and other resources produced by the earth's natural processes.

Neurotoxicity: Materials that affect nerve cells and may produce muscular, emotional, or behavioral abnormalities, impaired or abnormal motion, and other physiologic changes.

Neutralizer: A type of inert ingredient added to an herbicide that modifies the effect of, or counteracts the properties of, something within the herbicide or spray solution.

No action alternative: The most likely condition to exist in the future if current management direction were to continue unchanged.

No observed adverse effect level (NOAEL): The exposure level at which there are no statistically or biological significant differences in the frequency or severity of any adverse effect in the exposed or control populations.

No observed effect level (NOEL): Exposure level at which there are no statistically or biological significant differences in the frequency or severity of any effect in the exposed or control populations.

Non-selective herbicide: An herbicide that is generally toxic to plants without regard to species.
Non-target: Any plant, animal, or organism that a method of application is not aimed at, but may accidentally be injured by the application.

Noxious weed: A plant species designated by federal or state law as generally possessing one or more of the following characteristics: aggressive and difficult to manage; parasitic; a carrier or host of serious insects or disease; or non-native, new, or not common to the United States.

Nutrient cycle: Ecological processes in which nutrients and elements such as carbon, phosphorous, nitrogen, and others, circulate among animals, plants, soils, and air.

\section{0}

Objective: A concise, time-specific statement of measurable planned results that respond to preestablished goals. An objective forms the basis for further planning to define the precise steps to be taken and the resources to be used to achieve identified goals.

Omnivore: An animal that eats a combination of meat and vegetation.

Oregon and Calliformia lands: Public lands in Western Oregon that were granted to the Oregon Central Railroad companies (later the Oregon and California Railroad Company) to aid in the construction of railroads, but that were later forfeited and returned to the federal government by revestment of title.

Overgrazing: Continued heavy grazing which exceeds the recovery capacity of the plant community and creates a deteriorated rangeland.

Overstory: The upper canopy layer.

Paleontological resources: A work of nature consisting of or containing evidence of extinct multicellular beings and includes those works or classes of works of nature designated by the regulations as paleontological resources.

Palleontology: A science dealing with the life of past geological periods as known from fossil remains. 
Particulate matter (PM): A complex mixture consisting of varying combinations of dry solid fragments, solid cores with liquid coatings, and small droplets of liquid. These tiny particles vary greatly in shape, size and chemical composition, and can be made up of many different materials such as metals, soot, soil, and dust.

Particulates: Solid particles or liquid droplets suspended or carried in the air.

Pathogen: An agent such as a fungus, virus, or bacterium that causes disease.

Payments in lieu of taxes: Payments made to counties by the BLM to mitigate for losses to counties because public lands cannot be taxed.

Per capita income: Total income divided by the total population.

Perennial: A plant that lives for 2 or more years.

Permit: A revocable authorization to use public land for a specified purpose to for up to 3 years.

Persistence: Refers to the length of time a compound, once introduced into the environment, stays there.

Pest Infestation: 1) The occurrence of one or more pest species in an area or location where their numbers and impact are currently or potentially at intolerable levels. 2) A sudden increase in destructiveness or population numbers of a pest species in a given area.

Petroglyph: An image recorded on stone, usually by prehistoric peoples, by means of carving, pecking, or otherwise incised on natural rock surfaces.

Pictograph: A symbol that represents an object or a concept by illustration.

pH: A measure of how acidic or alkaline (basic) a solution is on a scale of 0 to 14 with 0 being very acidic, 14 being very alkaline, and 7 being neutral. The abbreviation stands for the potential of hydrogen.

Photodegradation: The photochemical transformation of a molecule into lower molecular weight fragments, usually in an oxidation process. This term is widely used in the destruction (oxidation) of pollutants by ultraviolet-based processes.

Photolysis: Chemical decomposition induced by light or other radiant energy.

Phytotoxicity: The ability of a material such as a pesticide or fertilizer to cause injury to plants.

Piscivore: Animal that feeds on fish.

Plant community: A vegetation complex, unique in its combination of plants, which occurs in particular locations under particular influences. A plant community is a reflection of integrated environmental influences on the site, such as soils, temperature, elevation, solar radiation, slope aspect, and precipitation.

Playas: Flat land surfaces underlain by fine sediment or evaporate minerals deposited from a shallow lake on the floor of a topographic depression.

$\mathbf{P M}_{2.5}$ : Fine particulates that measure 2.5 microns in diameter or less.

$\mathbf{P M}_{10}$ : Particulate matter that measures 10 microns in diameter or less.

Population adjusted dose: The acute or chronic reference dose (RfD) divided by the Food Quality Protection Act safety factor.

Porosity: The ratio of the volume of void space in a material (e.g., sedimentary rock or sediments) to the volume of its mass.

Predator: An organism that captures and feeds on parts or all of a living organism of another species.

Preferred alternative: The alternative identified in an EIS that has been selected by the agency as the most acceptable resolution to the problems identified in the purpose and need.

Prescribed fire: A management ignited wildland fire that burns under specified conditions and in predetermined area, and that produces the fire behavior and fire characteristics required to attain fire treatment and resource management objectives. 
Prescribed fire projects: Includes the BLM's efforts to utilize fire as a critical natural process to maintain and restore ecosystems, rangeland, and forestlands, and to reduce the hazardous buildup of fuels that may threaten healthy lands and public safety.

Prescribed grazing: The careful application of grazing or browsing prescriptions (i.e., specified grazing intensities, seasons, frequencies, livestock species, and degrees of selectivity) to achieve natural resource objectives. Livestock production is a secondary objective when using prescribed grazing as a natural resource management tool.

Prevention of Significant Deterioration (PSD): A U.S. Environmental Protection Agency program in which state and/or federal permits are required in order to restrict emissions from new or modified sources in places where air quality already meets or exceeds primary and secondary ambient air quality standards.

Productivity: The innate capacity of an environment to support plant and animal life over time. Plant productivity is the rate of plant production within a given period of time. Soil productivity is the capacity of a soil to produce plant growth, due to the soil's chemical, physical, and biological properties.

Programmatic EIS: An area-wide EIS that provides an overview when a large-scale plan is being prepared for the management of federally-administered lands on a regional or multi-regional basis.

Proper functioning condition: Riparian and wetland areas achieve proper functioning condition when adequate vegetation, landform, or large woody debris is present to dissipate stream energy associated with high water flows. This reduces erosion and improves water quality; filters sediment, captures bedload, and aids in floodplain development; improves floodwater retention and groundwater recharge; develops root masses that stabilize streambacks against cutting; develops diverse ponding and channel characteristics to provide habitat and water depth, duration, and temperature necessary for fish production, avian breeding habitat, and other uses; and supports greater biodiversity.

Proposed action: A proposal by a federal agency to authorize, recommend, or implement an action.
Public domain lands: One category of public lands that have never left federal ownership; also, lands in federal ownership that were obtained by the government in exchange for public domain lands or for timber on public domain lands.

Public lands: Any land and interest in land owned by the United States that are administered by the Secretary of the Interior through the BLM, without regard to how the United States acquired ownership, except for 1) lands located on the Outer Continental Shelf, and 2) lands held for the benefit of Indians, Aleuts, and Eskimos. Includes public domain and acquired lands.

Public scoping: A process whereby the public is given the opportunity to provide oral or written comments about the influence of a project on an individual, the community, and/or the environment.

Q

Qualitative: Traits or characteristics that relate to quality and cannot be readily measured with numbers.

Quantitative: Traits or characteristics that can be measured with numbers.

$\mathbf{R}$

Rangeland: Land on which the native vegetation is predominantly grasses, grass-like plants, forbs, or shrubs; not forests.

Raptor: Bird of prey; includes eagles, hawks, falcons, and owls.

Receptor: An ecological entity exposed to a stressor.

Record of Decision (ROD): A document separate from, but associated with, an EIS, which states the decision, identifies alternatives (specifying which were environmentally preferable), and states whether all practicable means to avoid environmental harm from the alternative have been adopted, and if not, why not.

Recovery plan: Identifies, justifies, and schedules the research and management actions necessary to reverse the decline of a species and ensure its longterm survival. 
Reference dose (RfD): An estimate (with uncertainty spanning perhaps an order of magnitude) of a daily oral exposure to the human population (including sensitive subgroups) that is likely to not result in an appreciable risk of deleterious effects during a lifetime. It is derived from the no-observedadverse-effect-level, the lowest-observed-adverseeffect-level, or a benchmark dose. Uncertainty factors are generally applied when developing the reference dose to reflect the limitations of the data used.

Registered herbicide: All herbicides sold or distributed in the United States must be registered by the U.S. Environmental Protection Agency, based on scientific studies, showing that they can be used without posing unreasonable risks to people or the environment.

Research Natural Areas: Special management areas designated either by Congress or by a public or private agency to preserve and protect typical or unusual ecological communities, associations, phenomena, characteristics, or natural features or processes for scientific and educational purposes. They are established and managed to protect ecological processes, conserve biological diversity, and provide opportunities for observation for research and education.

Resident fish: Fish that spend their entire life in freshwater (e.g., bull trout).

Residue: The quantity of an herbicide or its metabolites remaining in or on soil, water, plants, animals, or surfaces.

Resillience: 1) The ability of a system to respond to disturbances. Resiliency is one of the properties that enable the system to persist in many different states or successional stages. 2) In human communities, refers to the ability of a community to respond to externally induced changes such as larger economic forces.

Resource Management Plan (RMP): Comprehensive land management planning document prepared by and for the BLM's administered properties under requirements of the Federal Land Policy and Management Act. Bureau of Land Management lands in Alaska were exempted from this requirement.
Restoration: Actions taken to modify an ecosystem to achieve desired, healthy, and functioning conditions and processes.

Revegetation: Establishing or re-establishing desirable plants on areas where desirable plants are absent or of inadequate density, by management alone (natural revegetation) or by seeding or transplanting (artificial revegetation).

Rights-of-way (ROW): A permit or an easement that authorizes the use of lands for certain specified purposes, such as the construction of forest access roads or a gas pipeline.

Riparian: Occurring adjacent to streams and rivers and directly influenced by water. A riparian community is characterized by certain types of vegetation, soils, hydrology, and fauna and requires free or unbound water or conditions more moist than that normally found in the area.

Risk: The likelihood that a given exposure to an item or substance that presents a certain hazard will produce illness or injury.

Risk assessment: The process of gathering data and making assumptions to estimate short- and longterm harmful effects on human health or the environment from particular products or activities.

Runoff: That part of precipitation, as well as any other flow contributions, that appears in surface streams, either perennial or intermittent.

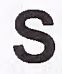

Salmonids: Fishes of the family Salmonidae, including salmon, trout, chars, whitefish, ciscoes, and grayling.

Scoping: The process by which significant issues relating to a proposal are identified for environmental analysis. Scoping includes eliciting public comment on the proposal, evaluating concerns, and developing alternatives for consideration.

Section 3: Lands administered under Section 3 of the Taylor Grazing Act. This section of the law provided for the lease of grazing district lands to landowners and homesteaders in or adjacent to the reserves first and issuance of 1 to 10 year leases. 
Section 15: Lands administered under Section 15 of the Taylor Grazing Act. Under Section 15, public lands outside of grazing districts could be leased to ranchers with contiguous property.

Sediments: Unweathered geologic materials generally laid down by or within waterbodies; the rocks, sand, mud, silt, and clay at the bottom and along the edge of lakes, streams, and oceans.

Sedimentation: The process of forming or depositing sediment; letting solids settle out of wastewater by gravity during treatment.

Selective herbicide: A chemical designed to affect only certain types of plants, leaving other plants unharmed.

Semi-arid: Moderately dry; region or climate where moisture is normally greater than under arid conditions, but still limits the production of vegetation.

Sensitive species: 1) Plant or animal species susceptible or vulnerable to aetivity impacts or habitat alterations. 2) Species that have appeared in the Federal Register as proposed for classification or are under consideration for official listing as endangered or threatened species.

Short-term impacts: Impacts occurring during project construction and operation, and normally ceasing upon project closure and reclamation. For each resource the definition of short-term may vary.

Significant: The description of an impact that exceeds a certain threshold level. Requires consideration of both context and intensity. The significance of an action must be analyzed in several contexts, such as society as a whole, and the affected region, interests, and locality. Intensity refers to the severity of impacts, which should weighted along with the likelihood of its occurrence.

Snag: A standing dead tree, usually larger than 5 feet tall and 6 inches in diameter at breast height.

Sociocultural: Of, relating to, or involving a combination of social and cultural factors.

Socioeconomic: Pertaining to, or signifying the combination or interaction of social and economic factors.
Soil compaction: The compression of the soil profile from surface pressure, resulting in reduced air space, lower water holding capacity, and decreased plant root penetrability.

Soil horizon: A layer of soil material approximately parallel to the land surface that differs from adjacent genetically related layers in physical, chemical, and biological properties.

Southern Nevada Public Land Management Act: Act that provides for the disposal of public land within a specific area in the Las Vegas Vallcy and creates a special account into which $85 \%$ of the revenue generated by land sales or exchanges in the Las Vegas Valley is deposited. The remaining 15\% goes to state and local governments.

Special status species: Refers to federally-listed threatened, endangered, proposed, or candidate species, and species managed as sensitive species by the BLM.

Spot treatment: An application of an herbicide to a small selected area as opposed to broadcast application.

Stabilizer: A type of inert ingredient added to a commercial pesticide that makes the mixture more stable.

Stand: A group of trees in a specific area that is sufficiently alike in composition, age, arrangement, and condition so as to be distinguishable from the forest in adjoining areas.

Standard Operating Procedures (SOPs): Procedures that would be followed by the BLM to ensure those risks to human health and the environment from treatment actions were kept to a minimum.

Step-down: Refers to the process of applying broadscale science findings and land use decisions to site-specific areas using a hierarchical approach of understanding current resource conditions, risks, and opportunities.

Stressor: Any event or situation that precipitates a change. 
Subalpine: A terrestrial community that generally is found in harsher environments than the montane terrestrial community. Subalpine communities are generally colder than montane and support a unique clustering of wildlife species.

Subchronic: The effects observed from doses that are of intermediate duration, usually 90 days.

Subsistence: Customary and traditional uses of wild renewable resources (plants and animals) for food, shelter, fuel, clothing, tools, etc.

Succession: A change in structure and composition of plant and animal communities over time. This change does not always occur in a predictable and orderly manner. Change can be a response to random or chaotically occurring disturbances.

Surfactant: A material that improves the emulsifying, dispersing, spreading, wetting, or other surfacemodifying properties of liquids.

Surrogate: A substitute or stand-in.

Synergistic: A type of cumulative impact where total effect is greater than the sum of the effects taken independently.

T

Tank mixture: The mixture of two or more compatible herbicides in a spray tank in order to apply them simultaneously.

Target species: Plant species of competing vegetation that is controlled in favor of desired species.

Teratogenic: Causing structural defects that affect the development of an organism; causing birth defects.

Terrestrial: Of or relating to the earth, soil, or land; inhabiting the earth or land.

Threatened species: A plant or animal species likely to become an endangered species throughout all or a significant portion of its range within the foreseeable future.

Threshold: A dose or exposure below which there is no apparent or measurable adverse effect.
Tier: In an EIS, refers to incorporating by reference the analyses in an EIS or similar document of a broader scope. For example, BLM field offices could prepare environmental assessments for local projects that tier to this PEIS.

Total suspended particles (TSP): A method of monitoring airborne particulate matter by total weight.

Toxicity: A characteristic of a substance that makes it poisonous.

Toxicokinetics: The process of the uptake of potentially toxic substances by the body, the biotransformation they undergo, the distribution of the substances and their metabolites in the tissues, and the elimination of the substances and their metabolites from the body.

Transpiration: Water loss from plants during photosynthesis.

Tribe: Term used to designate any Indian tribe, band, nation, or other organized group or community (including any Alaska Native village or regional or village corporation as defined in or established pursuant to the Alaska Native Claims Settlement Act) which is recognized as eligible for the special programs and services provided by the U.S. to Indians because of their status as Indians.

\section{U}

Understory: Plants that grow beneath the canopy of other plants. Usually refers to grasses, forbs, and low shrubs under a tree or shrub canopy.

Undesirable plants: Species classified as undesirable, noxious, harmful, exotic, injurious, or poisonous under state or federal law, but not including species listed as endangered by the Endangered Species Act, or species indigenous to the planning area.

Upland: The portion of the landscape above the valley floor or stream. 
Vascular plants: Plants that have specialized tissues which conduct nutrients, water, and sugars along with other specialized parts such as roots, stems, and reproductive structures. Vascular plants include flowering plants, ferns, shrubs, grasses, and trees.

Vertebrate: An animal with a backbone. Fishes, amphibians, reptiles, birds, and mammals are vertebrates.

Visual resources: The visible physical features of a landscape.

Volatilization: The conversion of a solid or liquid into a gas or vapor.

W

Water quality: The interaction between various parameters that determines the usability or nonusability of water for on-site and downstream uses. Major parameters that affect water quality include: temperature, turbidity, suspended sediment, conductivity, dissolved oxygen, $\mathrm{pH}$, specific ions, discharge, and fecal coliform.

Watershed: The region draining into a river, river system, or body of water.

Weed: A plant considered undesirable and that interferes with management objectives for a given area at a given point in time.

Wetlands: Those areas that are inundated or saturated by surface water or groundwater at a frequency and duration sufficient to support, and that under normal circumstance do support, a prevalence of vegetation typically adapted for life in saturated soil conditions. Wetlands include habitats such as swamps, marshes, and bogs.

Wilderness: Land designated by Congress as a component of the National Wilderness Preservation System. For an area to be considered for Wilderness designation it must be roadless and possess the characteristics required by Section 2(c) of the Wilderness Act of 1964. These characteristics are: 1) naturalness - lands that are natural and primarily affected by the forces of nature; 2) roadless and having at least 5,000 acres of contiguous public lands; and 3) outstanding opportunities for solitude or primitive and unconfined types of recreation. In addition, areas may contain "supplemental values," consisting of ecological, geological, or other features of scientific, educational, scenic, or historical importance.

Wildfire: Unplanned human or naturally caused fires in wildlands.

Wildland fires: Occur on wildlands, regardless of ignition source, damages, or benefits, and include wildfire and prescribed fire.

Wildland fire use for resource benefit: A fire ignited by lightening but allowed to burn within specified conditions of fuels, weather, and topography, to achieve specific objectives.

Wildland Urban Interface (WUI): An area where structures and other human development intermingle with undeveloped wildlands or vegetative fuels.

Woodland: A forest in which the trees are often small, characteristically short-bolded relative to their crown depth, and forming only an open canopy with the intervening area being occupied by lower vegetation, commonly grass.

\section{$\mathrm{X}$}

Xeric: Very dry region or climate; tolerating or adapted to dry conditions.

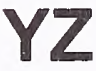



CHAPTER 8

INDEX 



\section{CHAPTER 8}

\section{INDEX}

\section{Air Quality}

Description: $3-3$

Effects: $4-5$

Scoping Comments and Other Issues Evaluated in the Assessment: 4-5

Methodology for Assessing Impacts to Air Quality: 4-6

Standard Operating Procedures: 4-8

Impacts by Alternative: 4-9

Mitigation: 4-13

Cumulative Effects: 4-202

Unavoidable Effects: 4-243

Short and Long Term Effects: 4-246

Irreversible Effects: 4-251

\section{Alternatives}

Chapter 2 of the EIS is devoted to describing the

alternatives

Chapter 4 is devoted to analyzing the effects of the No Action Alternative and alternatives $B, C, D$, and $E$

Development of Alternatives: 1-13

Description of the Alternatives: 2-14

Alternative A: 2-14

Alternative B: $2-17$

Alternative C: 2-19

Alternative D: 2-19

Alternative E: 2-20

Alternatives Considered but Not Further Analyzed: 222

Summary of Impacts by Alternatives: 2-40

See also Air Quality; Soil Resources; Water Resources and Quality; Wetland and Riparian Areas; Fish and Other Aquatic Organisms; Wildlife Resources;

Livestock; Wild Horses and Burros; Paleontological and Cultural Resources; Visual Resources; Wilderness and Special Areas; Recreation; Social and Economic Values; and Human Health and Safety

\section{American Indian and Alaska Native Cultural Resources \\ Alaska National Interest Conservation Lands (ANILCA) Section 810 Analysis of Subsistence Impacts: Appendix G See Paleontological and Cultural Resources}

\author{
Anadromous Fish \\ See Fish and Other Aquatic Organisms
}

\section{Biological Crust}

See Soil Resources

\section{Climate}

Description: 3-2

\section{Consultation and Coordination}

Chapter 5 of the EIS is devoted to consultation and coordination

Description: 1-9

Coordination and Education: 2-39

\section{Cumulative Effects}

Structure of the Cumulative Analysis: 4-197

Resource Protection Measures Considered in the

Cumulative Impacts Analysis: 4-201

Other Information Considered: 4-202

Cumulative Effects by Resources: 4-202

Unavoidable Adverse Effects: 4-243

Short and Long Term Effects: 4-246

Irreversible Effects: 4-251

\section{Decisions to be Made}

Decisions to be Made by Decisionmaker: 1-5

\section{Demographic}

See Social and Economic Values

\section{Economic Environment}

See Social and Economic Values

\section{Effects}

Comparison of Alternatives: $2-40$

How the Effects of the Alternatives Were Estimated: 4-1

Chapter 4 is devoted to analyzing the effects of the No Action Alternative and alternatives $B, C, D$, and $E$

\section{Environment}

Chapter 3 of the EIS is devoted to a description of the environment 


\section{Environment (cont.)}

Chapter 4 of the EIS is devoted to analysis of effects on the environment

\section{European Settlement Resources}

See Paleontological and Cultural Resources

\section{Expenditures by the BLM}

See Social and Economic Values

Fish and Other Aquatic Organisms

Description: 3-31

Special Status Species: 3-36

Effects: $4-76$

Scoping Comments and Other Issues Evaluated in the Assessment: 4-77

Standard Operating Procedures: 4-77

Impacts by Treatment: $4-80$

Impacts by Alternative: $4-89$

Special Status Fish and Other Aquatic Organisms: 4-92

Cumulative Effects: 4-213

Unavoidable Effects: 4-244

Short and Long Term Effects: 4-248

Irreversible Effects: 4-252

\section{Fire}

Vegetation Condition and Fire Regimes: 3-28

See Wildland Fire

\section{Forest and Woodland Management}

Description: 2-3

\section{Herbicides}

Herbicide Active Ingredients Evaluated under the

Proposed Alternatives: 2-9

Herbicide Modes of Action and Treatment Methods:

2-13

Herbicide Treatment Standard Operating Procedures:

$2-22$

\section{Human Health and Safety}

Description: 3-71

Effects: 4-174

Scoping Comments and Other Issues Evaluated in the Assessment: 4-175

Standard Operating Procedures: 4-175

Assessment of Human Health Risks for Each

Herbicide: 4-175

Impacts by Alternative: 4-195

Mitigation: 4-196

Cumulative Effects: 4-238

\section{Human Health and Safety (cont.)}

Effects (cont.)

Unavoidable Effects: 4-246

Short and Long Term Effects: 4-251

Irreversible Effects: 4-253

\section{Impacts}

See Alternatives and Cumulative Effects

\section{Important Plant Uses and Species Used by} American Indians and Alaska Natives

See Paleontological and Cultural Resources

\section{Issues and Concerns}

Issues and Concerns: 1-12

Issues Not Addressed: 1-13

\section{Land Uses and Ecoregions}

Description: $3-1$

Effects: $4-5$

\section{Livestock}

Description: 3-44

Effects: $4-124$

Scoping Comments and Other Issues Evaluated in the Assessment: 4-124

Standard Operating Procedures: 4-124

Summary of Herbicide Impacts: 4-125

Impacts by Alternative: 4-133

Mitigation: 4-136

Cumulative Effects: 4-222

Unavoidable Effects: 4-244

Short and Long Term Effects: 4-249

Irreversible Effects: 4-252

\section{Mitigation}

Description: 2-40

See also Air Quality; Soil Resources; Water Resources and Quality; Wetland and Riparian Areas; Fish and Other Aquatic Organisms; Wildlife Resources;

Livestock; Wild Horses and Burros; Paleontological and Cultural Resources; Visual Resources; Wilderness and Special Areas; Recreation; Social and Economic Values; and Human Health and Safety

\section{Native Peoples}

See Social and Economic Values; Paleontological and Cultural Resources; Cumulative Effects; Scoping

\section{Non-timber Forest Products}

Description: $3-30$ 
Noxious Weeds and Other Invasive Species

Description: 3-26

\section{Paleontological and Cultural Resources}

Special Precautions: 2-29

Description: 3-45

Effects: 4-146

Scoping Comments and Other Issues Evaluated the in Assessment: 4-147

Standard Operating Procedures for Addressing

BLM Actions on Paleontological, Cultural, and

Subsistence Resources: 4-147

Herbicide Impacts on Paleontological and Cultural

Resources: 4-148

Herbicide Impacts on Native American Health: 4149

Impacts by Alternative: 4-150

Mitigation: 4-152

Cumulative Effects: 4-226

Unavoidable Effects: 4-245

Short and Long Term Effects: 4-249

Irreversible Effects: 4-252

\section{Public Involvement}

Public Scoping Meetings: 1-12

Public Involvement: 5-1

\section{Purpose and Need for the Proposed Action}

Proposed Action: 1-3

Purpose and Need: 1-4

\section{Rangeland Management}

Description: 2-3

\section{Recreation}

Description: 3-60

Effects: 4-159

Scoping Comments and Other Issues Evaluated in the Assessment: 4-160

Standard Operating Procedures: 4-160

Impacts by Treatment: $4-160$

Impacts by Alternative: $4-161$

Mitigation: 4-163

Cumulative Effects: 4-233

Unavoidable Effects: 4-246

Short and Long Term Effects: 4-250

Irreversible Effects: 4-253

Revenues Generated by BLM Lands

See Social and Economic Values
Rights-of-way

Description: 3-62

Risk from Cancer, Disease, Injuries, or Using Herbicides and Wildfire Control on Public Lands See Human Health and Safety

\section{Scoping}

Scope of Analysis: 1-5

Public Involvement, Scoping, and Issues: 1-12, 5-1

Smoke Management Policies and Regullations

See Air Quality

\section{Social and Economic Values}

Description: 3-63

Effects: 4-163

Scoping Comments and Other Issues Evaluated in the Assessment: 4-164

Standard Operating Procedures: 4-164

Impacts by Alternative: 4-166

Mitigation: 4-174

Cumulative Effects: $4-234$

Unavoidable Effects: 4-246

Short and Long Term Effects: 4-250

Irreversible Effects: 4-253

\section{Soil Compaction}

See Soil Resources

\section{Soill Erosion}

See Soil Resources

\section{Soill Resources}

Description: 3-7

Effects: 4-13

Scoping Comments and Other Issues Evaluated in the Assessment: 4-13

Factors that Influence the Fate, Transport, and

Persistence of Herbicides in Soil: 4-14

Impacts by Treatment: 4-15

Impacts by Alternative: $4-21$

Mitigation: 4-24

Cumulative Effects: 4-205

Unavoidable Effects: 4-243

Short and Long Term Effects: 4-247

Irreversible Effects: 4-251

Speciall Precautions: 2-28

Riparian Management

Description: 2-4, 3-18 


\section{Special Status Species}

Special Precautions: 2-28

See Fish and Other Aquatic Resources

See Vegetation

See Wildlife Resources

\section{Species}

Common and Scientific Names of Species:

Appendix A

Special Status Species List: Appendix J

\section{Statues, Regulations, and Policies}

Laws, Policies, and Regulations that Influence

Vegetation Treatments: 1-6

\section{Stipulations and Required Operating Procedures}

Herbicide Treatment Standard Operating Procedures:

\section{2-22}

Monitoring: 2-35

See also Air Quality; Soil Resources; Water Resources and Quality; Wetland and Riparian Areas; Fish and Other Aquatic Organisms; Wildlife Resources; Livestock; Wild Horses and Burros; Paleontological and Cultural Resources; Visual Resources; Wilderness and Special Areas; Recreation; Social and Economic Values; and Human Health and Safety

\section{Threatened and Endangered Species}

Consultation: Chapter 5

List of Special Status Species: Appendix J

Topography, Geology, Minerals, Oil, and Gas

Description: 3-6

\section{Vegetation}

Planning and Management: 2-5

Treatment Acreages: 2-31

Monitoring: 2-35

Description: 3-19

Special Status Species: 3-31

Effects: 4-44

Scoping Comments and Other Issues Evaluated in the Assessment: 4-44

Standard Operating Procedures: 4-44

Impacts by Treatments: $4-47$

Impacts by Alternative: 4-64

Mitigation: 4-71

Special Status Plant Species: 4-71

Cumulative Effects: 4-211

Unavoidable Effects: 4-244

Short and Long Term Effects: 4-248

Irreversible Effects: 4-252

\section{Vegetation Condition and Fire Regimes}

Description: $3-28$

\section{Visual Resources \\ Description: $3-58$ \\ Effects: 4-152}

Scoping Comments and Other Issues Evaluated in the Assessment: 4-153

Standard Operating Procedures: 4-153

Impacts by Treatment: 4-154

Impacts by Alternative: 4-154

Mitigation: 4-154

Cumulative Effects: 4-229

Unavoidable Effects: 4-245

Short and Long Term Effects: 4-250

Irreversible Effects: 4-253

\section{Water Resources and Quality}

Water Resources Description: 3-11

Water Quality Description: 3-15

Effects: 4-24

Scoping Comments and Other Issues Evaluated in the Assessment: 4-22

Standard Operating Procedures: 4-24

Impacts by Treatment: 4-24

Impacts by Alternative: 4-34

Mitigation: 4-36

Cumulative Effects: 4-206

Unavoidable Effects: 4-243

Short and Long Term Effects: 4-247

Irreversible Effects: 4-251

\section{Wetlands and Riparian Areas}

Description: 3-18

Effects: 4-36

Scoping Comments and Other Issues Evaluated in the Assessment: 4-37

Factors that Influence the Fate, Transport, and

Persistence of Herbicides in Wetlands and Riparian Areas: 4-37

Summary of Herbicide Impacts: 4-37

Impacts by Alternative: 4-41

Mitigation: 4-44

Cumulative Effects: 4-209

Unavoidable Effects: 4-243

Short and Long Term Effects: 4-247

Irreversible Effects: 4-251 


\section{Wild Horses and Burros}

Description: 3-45

Effects: $4-136$

Scoping Comments and Other Issues Evaluated in the Assessment: 4-137

Standard Operating Procedures: 4-137

Summary of Herbicide Impacts: 4-137

Impacts by Alternative: 4-143

Mitigation: 4-146

Cumulative Effects: 4-223

Unavoidable Effects: 4-244

Short and Long Term Effects: 4-249

Irreversible Effects: 4-252

\section{Wilderness and Special Areas}

Special Precautions: 2-29

Description: $3-58$

Effects: $4-155$

Scoping Comments and Other Issues Addressed in the Assessment: 4-156

Standard Operating Procedures: 4-156

Impacts by Treatment: 4-156

Impacts by Alternative: 4-157

Mitigation: 4-159

Cumulative Effects: $4-230$

Unavoidable Effects: 4-245

Short and Long Term Effects: 4-250

Irreversible Effects: 4-253

See also Recreation Resources

See also Visual Resources

\section{Wildland Fire}

Wildland Fire Management: 2-2

\section{Wild life and Fisheries Management}

Description: 2-4

\section{Wildlife Resources}

Description: 3-36

Special Status Species: 3-44

Effects: 4-96

Scoping Comments and Other Issues Evaluated in the Assessment: 4-98

Standard Operating Procedures: 4-98

Summary of Herbicide Impacts: 4-101

Impacts of Herbicide Treatments on Wildlife and

Habitat by Ecoregion: 4-109

Impacts by Alternative: 4-114

Mitigation: 4-118

Special Status Wildlife Species: 4-118

Cumulative Effects: 4-216

Unavoidable Effects: 4-244

Short and Long Term Effects: 4-248

Irreversible Effects: 4-252 



\section{ACRONYMS, ABBREVIATIONS, AND SYMBOLS}

$\begin{array}{ll}\text { ACEC } & \text { Area of Critical Environmental Concern } \\ \text { a.e./ac } & \text { Acid equivalent per acre } \\ \text { a.j. } & \text { Active ingredient } \\ \text { a.i./ac } & \text { Active ingredient per acre } \\ \text { a.i./ha } & \text { Active ingredient per hectare } \\ \text { a.i./L } & \text { Active ingredient per Liter } \\ \text { AGL } & \text { Above ground level } \\ \text { ALS } & \text { Acetolactate synthase } \\ \text { AML } & \text { Appropriate management level } \\ \text { AMP } & \text { Allotment management plan }\end{array}$

AN1LCA Alaska National Interest Lands Conservation Act

APD Application for permit to drill

AR1 Aggregate risk index

ATV All-terrain vehicle

AUM Animal use months

BA Biological assessment

BAR Burned area rehabilitation

BO Biological opinion

BEE Butoxyethyl ester

BLM Bureau of Land Management

BMP Best management practice

BP Before the present

BPA Bonneville Power Administration

BW Body weight

CALPUFF California Puff

CDC Centers for Disease Control and Prevention

CEQ Council on Environmental Quality

CERCLA Comprehensive Environmental Response. Compensation and Liability Act

CFR Code of Federal Regulations

cm Centimeter

CO Carbon monoxide

COA Conditions of approval

CREAMS Chemical Runoff Erosion Assessment Management System

CWMA Cooperative weed management area

CWPP Community wildfire protection plan

DCPMU 3-(3,4-dichlorophenyl)-1-methyl-urea

EA Environmental assessment

$\mathbf{E C}_{50} \quad$ Median exposure concentration

EEC Estimated exposure concentration

EF Exposure factor

EFR Emergency fire rehabilitation

E1S Environmental impact statement

EO Executive order

ERA Ecological risk assessment
ERMA Extensive recreation management area

ESA Endangered Species Act

ES Emergency stabilization

FIFRA Federal Insecticide, Fungicide, and Rodenticide Act

FLPMA Federal Land Policy and Management Act

FORVIS Forest Vegetation Information System

FQPA Food Quality Protection Act

FR Federal Register

FRCC Fire regime condition class

ft Foot/feet

FTE Full time equivalent

FY Fiscal year

gal Gallon(s)

gal/day Gallons per day

GBRI Great Basin Restoration Initiative

GCVTC Grand Canyon Visibility and Transport Commission

GLEAMS Groundwater Loading Effects of Agricultural Management Systems

HFRA Healthy Forests Restoration Act

HHRA Human health risk assessment

HMA Herd management area

HQ Hazard quotient

In/yr Inches per year

IWM Integrated weed management

kg Kilogram(s)

km Kilometer(s)

$\mathrm{km}^{2} \quad$ Square kilometer(s)

$\mathbf{K}_{\mathrm{oc}} \quad$ Organic carbon-water partition coefficient

L Liter

LANDFIRE Landscape Fire and Resource Management Planning Tools Project

Ib(s) Pound(s)

$\mathrm{LC}_{50} \quad$ Lethal concentration at which half of the organisms die

LD $_{50} \quad$ Lethal dose at which half of the organisms die

L.MR Land management regulation

LOAEL Lowest observed adverse effect level

LOC Level of concern

LUP Land use plan

m Meter(s)

$\mathrm{m}^{2} \quad$ Square meter(s)

Mcf Thousand cubic feet (of gas)

Meq/L Milliequivalents per liter

MFP Management framework plan 



\begin{tabular}{|c|c|c|c|}
\hline $\begin{array}{l}\mathrm{mg} \\
\mathrm{mg} / \mathrm{kg}\end{array}$ & $\begin{array}{l}\text { Miltigram(s) } \\
\text { Milligrams per kilogram }\end{array}$ & $\mathbf{P M}_{2.5}$ & $\begin{array}{l}\text { Fine particulate matter less than } 25 \text { microns } \\
\text { in- diameter }\end{array}$ \\
\hline $\mathrm{mg} / \mathrm{kg}$-day & $\begin{array}{l}\text { Milligrams of herbicide per kilogram of body weight per } \\
\text { day }\end{array}$ & $\mathbf{P M}_{10}$ & $\begin{array}{l}\text { Particulate matter less than } 10 \text { microns in } \\
\text { diameter }\end{array}$ \\
\hline $\mathrm{mg} / \mathrm{L}$ & Milligrams per Liter & POEA & Polyoxyethyleneamine \\
\hline $\mathrm{mi}$ & Mile(s) & ppb & Parts per billion \\
\hline $\mathrm{mi}^{2}$ & Square mile(s) & ppm & Parts per million \\
\hline MOE & Margin of exposure & ppt & Parts per thousand \\
\hline MOS & Margin of safety & PSD & Prevention of significant deterioration \\
\hline MOU & Memorandum of understanding & PUP & Pesticide use proposal \\
\hline $\mathrm{mph}$ & Miles per hour & RCRA & Resource Conservation and Recovery Act \\
\hline MRID & Master Record Identification & & of 1976 \\
\hline MSDS & Material safety data sheets & RfD & Reference dose \\
\hline NA & Not applicable or not available & RMP & Resource management plan \\
\hline NAAQS & National Ambient Air Quality Standard & RNEA & Restore Native Ecosystems Alternative \\
\hline NAS & National Academy of Sciences & ROD & Record of decision \\
\hline NAWQA & National Water Quality Assessment & ROW & Rights-of-way \\
\hline NCHS & National Center for Heatth Statistics & $\mathrm{RQ}$ & Risk quotient \\
\hline NCIPC & National Center for Injury Prevention and Control & SDTF & Spray Drift Task Force \\
\hline NE & Not evaluated & SERA & Syracuse Environmental Research \\
\hline NEPA & National Environmental Policy Act & & Associates, Inc. \\
\hline NHPA & National Historic Preservation Act & SHPO & State Historic Preservation Officer \\
\hline NIOSH & National Institute for Occupational Safety and Health & SIP & State implementation plan \\
\hline NLCS & National Landscape Conservation System & SRMA & Special recreation management area \\
\hline NMFS & National Oceanic and Atmospheric Administration & SRP & Special recreation permit \\
\hline & National Marine Fisheries Service & $\mathrm{SO}_{2}$ & Sulfur dioxide \\
\hline $\mathrm{NO}_{2}$ & Nitrogen dioxide & SOCATS & Southern Oregon Citizens Against Toxic \\
\hline NOA & Notice of availability & & Sprays \\
\hline NOAA & National Oceanic and Atmospheric Administration & SOP & Standard operating procedure \\
\hline NOAEL & No observable adverse effect level & TDS & Total dissolved solids \\
\hline NOEC & No observable effect concentration & TEA & Triethylamine salt \\
\hline NOEL & No observable effect level & TEP & Threatened, endangered, and proposed \\
\hline NO1 & Notice of intent & TES & Threatened, endangered, and sensitive \\
\hline NPDES & National Pollutant Discharge Elimination System & THPO & Tribal Historic Preservation Office \\
\hline NPMP & Native Plant Materials Program & TSP & Total suspended particles \\
\hline NRHP & National Register of Historic Places & TSS & Total suspended solids \\
\hline NWCG & National Wildfire Coordinating Group & TIP & Tribal implementation plan \\
\hline NWIS & National Water Information System & TPY & Tons per year \\
\hline $\mathbf{O}_{3}$ & Ozone & TRV & Toxicity reference value \\
\hline O\&C & Oregon and California & UE & Unit exposure \\
\hline ОНА & Office of History and Archaeology & $\mathbf{U F}$ & Uncertainty factor \\
\hline OHV & Off-highway vehicle & USC & United States Code \\
\hline OPP & Office of Pesticide Programs & USACE & U.S. Army Corps of Engineers \\
\hline PAD & Population adjusted dose & USDA & U.S. Department of Agriculture \\
\hline $\mathrm{Pb}$ & Lead & USDI & U.S. Department of tnterior \\
\hline PEIS & Programmatic environmental impact statement & USEPA & U.S. Environmental Protection Agency \\
\hline PER & Programmatic environmental report & USFWS & U.S. Fish and Wildlife Service \\
\hline PHED & Pesticide Handlers Exposure Database & USGS & U.S. Geological Survey \\
\hline PM & Particulate matter & VOC & Volatile organic compounds \\
\hline
\end{tabular}



VRM Visual resource management

WRAP Western Regional Air Partnership

WSA Wilderness study area

WSR Wild and scenic river

WSRA Wild and Scenic Rivers Act

WUI Wildland urban interface

yd $\quad$ Yard(s)

$\mathbf{y d}^{3} \quad$ Cubic yard(s)

$\geq \quad$ Greater than or equal to

$\leq \quad$ Less than or equal to

$>\quad$ Greater than/more than

$<\quad$ Less than

$\mu \mathrm{g} / \mathrm{kg} \quad$ Micrograms per kilogram

$\mu \mathrm{g} / \mathrm{m}^{3} \quad$ Micrograms per cubic meter

$\mu \mathrm{g} / \mathrm{L} \quad$ Micrograms per Liter

${ }^{\circ} \mathbf{F} \quad$ Degrees Fahrenheit

2,4-D 2,4 dichlorophenoxyacetic acid

2,4-DP Dichlorprop

3,4-DCA 3,4-dichloraniline 



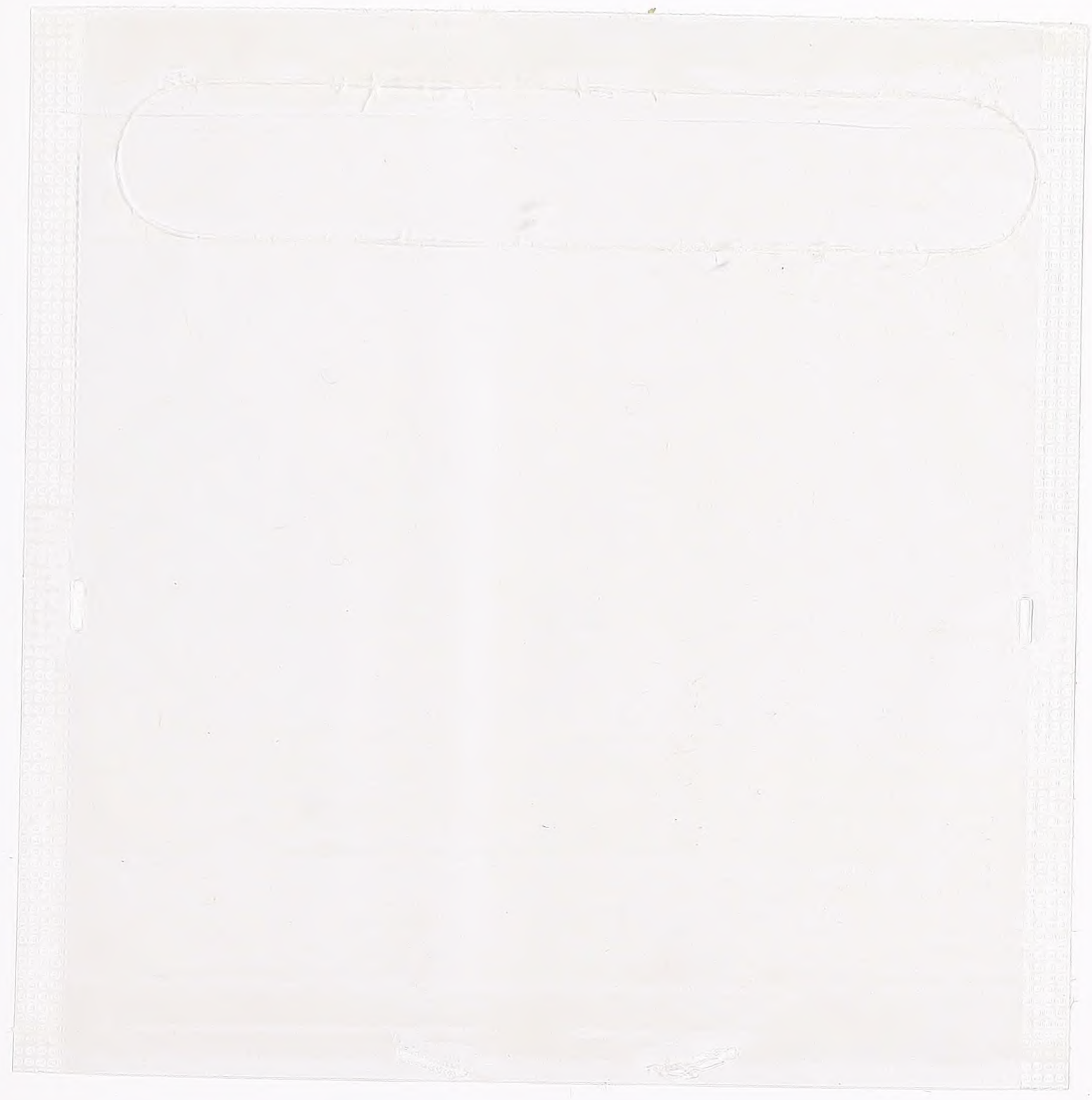




\title{
Bureau of Land Management \\ Vegetation EIS \\ P.O. Box 12000 \\ Reno, NV 89520-0006 \\ Tel: 775-861-6645
}

Web site address: www.b/m.gov

\author{
Bureau of Land Management \\ Rangeland, Soils, Water, and Air Group \\ DOI/BLM WO-220, 201LS \\ 1849 C Street, NW \\ Washington, DC 20240
}

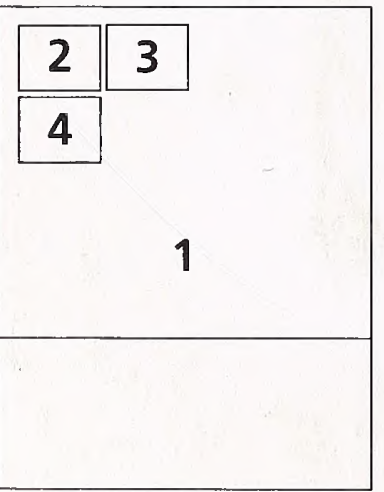

Cover Photos and Photo Credits

1. Arrowleaf balsamroot (Balsamorhiza sagittata) in bloom near Elko, Nevada (courtesy of Stan White, Bureau of Land Management Volunteer)

2. Helicopter spraying (courtesy of Keith Duncan, New Mexico State University Cooperative Extension Service)

3. All-terrain vehicle spraying (courtesy of L. D. Walker, Bureau of Land Management)

4. Herbicide spraying using a llama (courtesy of Cindy Lair, Colorado State Department of Agriculture)

Covers, spines, and CD labels layout and design provided by the BLM National Science and Technology Center. 